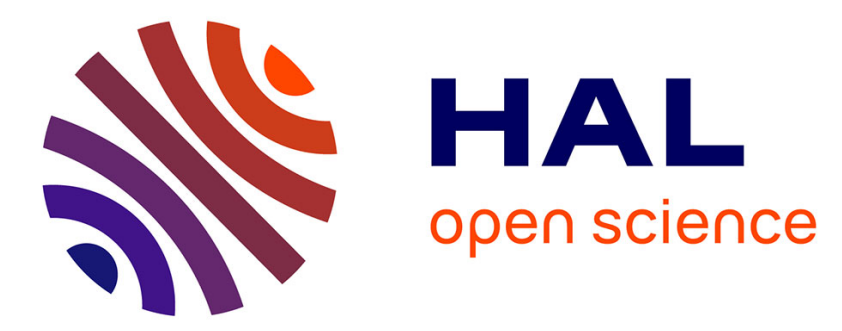

\title{
Deep-Sea Trenches of the Pacific Ocean: a Comparative Analysis of the Submarine Geomorphology Using Data Modeling by GMT, Python and R
}

Polina Lemenkova

\section{- To cite this version: \\ Polina Lemenkova. Deep-Sea Trenches of the Pacific Ocean: a Comparative Analysis of the Sub- marine Geomorphology Using Data Modeling by GMT, Python and R. 2021, pp.431. 10.5281/zen- odo.4892142 . hal-03245754}

\section{HAL Id: hal-03245754 \\ https://hal.science/hal-03245754}

Submitted on 2 Jun 2021

HAL is a multi-disciplinary open access archive for the deposit and dissemination of scientific research documents, whether they are published or not. The documents may come from teaching and research institutions in France or abroad, or from public or private research centers.
L'archive ouverte pluridisciplinaire HAL, est destinée au dépôt et à la diffusion de documents scientifiques de niveau recherche, publiés ou non, émanant des établissements d'enseignement et de recherche français ou étrangers, des laboratoires publics ou privés.

\section{(c)(1)}

Distributed under a Creative Commons Attribution| 4.0 International License 
Deep-Sea Trenches of the Pacific Ocean:

a Comparative Analysis of the Submarine Geomorphology Using Data Modeling by GMT, Python and R

Polina Lemenkova

June 2, 2021 


\section{Disclaimer}

I do certify that the content of this thesis is my own, original work, written by me personally. All maps and cartographic visualization have been plotted by me personally in GMT and QGIS. All graphical illustrations have been plotted by me personally in Python, Octave, $\mathrm{LT}_{\mathrm{E}} \mathrm{X}$ and R. Literature sources are cited where referenced.

June 2, 2021 


\section{Contents}

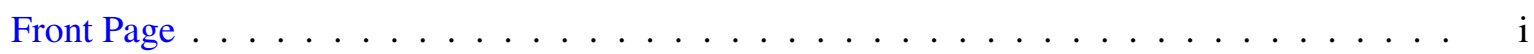

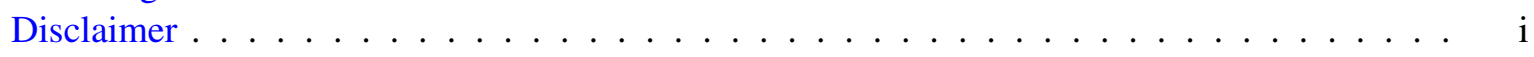

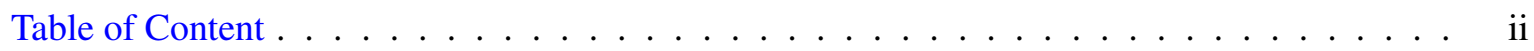

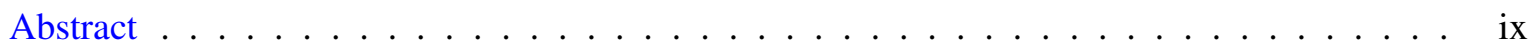

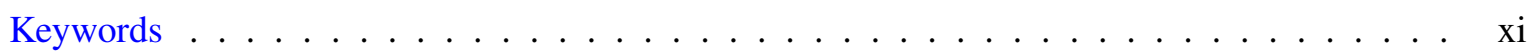

Lists

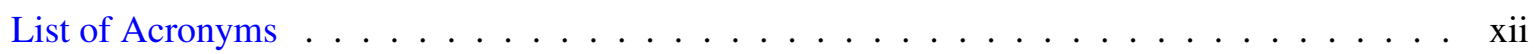

List of Equations $\ldots \ldots \ldots \ldots \ldots \ldots \ldots \ldots \ldots \ldots$

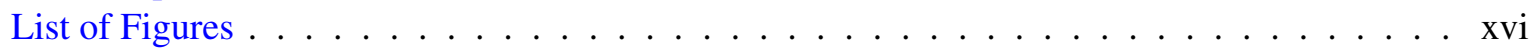

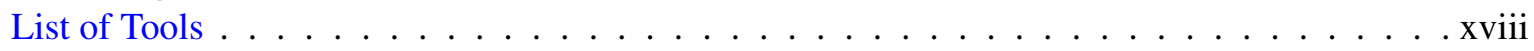

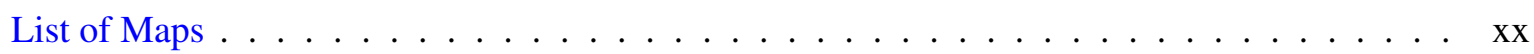

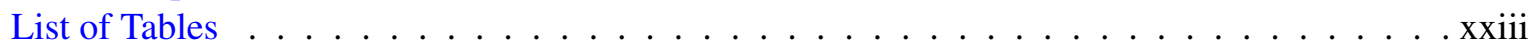

Document Outline 1

1 Introduction 2

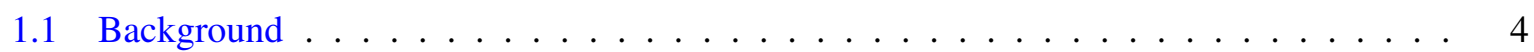

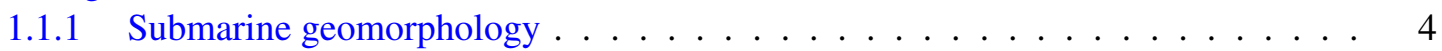

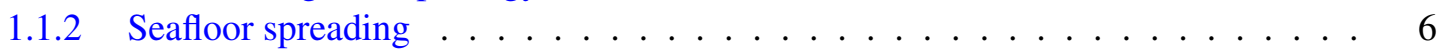

1.1.3 Historical milestones . . . . . . . . . . . . . . . . . 6

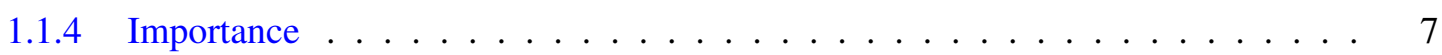

1.2 Research problem . . . . . . . . . . . . . . . . . . 8

1.3 Research gap identification . . . . . . . . . . . . . . . . . . . . . 9

1.4 Research objective . . . . . . . . . . . . . . . . . . . . . . 10

1.4.1 General objective . . . . . . . . . . . . . . . . . . . . . 10

1.4.2 Specific objectives . . . . . . . . . . . . . . . . . . 10

1.5 Research questions . . . . . . . . . . . . . . . . . . . 10

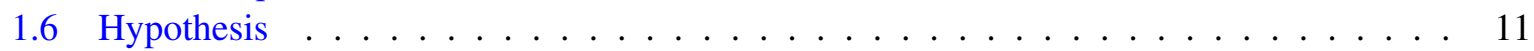

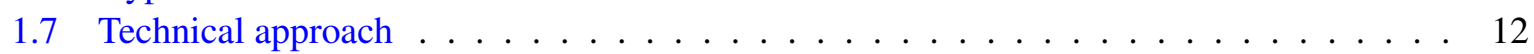

2 Trenches of the Pacific Ocean 13

2.1 Kuril-Kamchatka Trench . . . . . . . . . . . . . . . . . . . . . . . . 13 
2.2 Aleutian Trench . . . . . . . . . . . . . . . . . . . . . . 18

2.3 Middle America Trench . . . . . . . . . . . . . . . . . . . . . . . . . . . . . 21

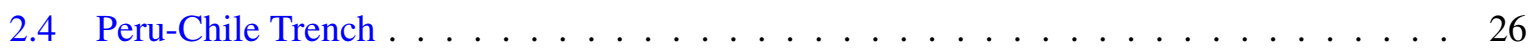

2.5 Kermadec Trench . . . . . . . . . . . . . . . . . . . . . . . . 30

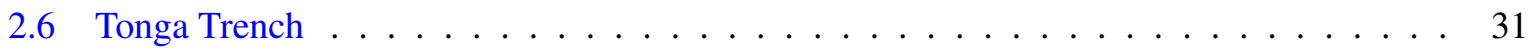

2.7 Vanuatu (New Hebrides) Trench . . . . . . . . . . . . . . . . . . . . 32

2.8 Vityaz Trench . . . . . . . . . . . . . . . . . . . . . 33

2.9 New Britain (Bougainville) Trench . . . . . . . . . . . . . . . . . . 35

2.10 San Cristobal Trench . . . . . . . . . . . . . . . . . . . . . . 37

2.11 Philippine Trench . . . . . . . . . . . . . . . . . . . . . . . . . . . . . . . 39

2.12 Manila Trench . . . . . . . . . . . . . . . . . . . . . . . . 45

2.13 Ryukyu Trench . . . . . . . . . . . . . . . . . . . . . . . . . 48

2.14 Palau Trench . . . . . . . . . . . . . . . . . . . . . . 53

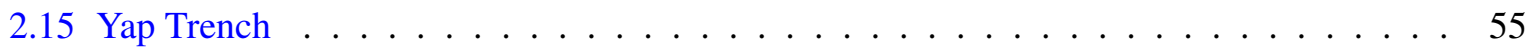

2.16 Mariana Trench . . . . . . . . . . . . . . . . . . . . 57

2.17 Izu-Bonin Trench . . . . . . . . . . . . . . . . . . . . . . . . . . . 64

2.18 Japan Trench . . . . . . . . . . . . . . . . . . . . . . . . . . . 67

2.19 Puysegur Trench . . . . . . . . . . . . . . . . . . . . 72

2.20 Hikurangi Trench . . . . . . . . . . . . . . . . . . . . . 75

3 Methodology $\quad 78$

$3.1 \quad$ Data . . . . . . . . . . . . . . . . . . . . . . 78

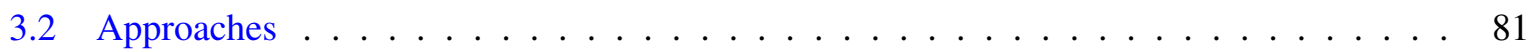

3.3 Generic Mapping Tools (GMT) . . . . . . . . . . . . . . . . . . . . . 83

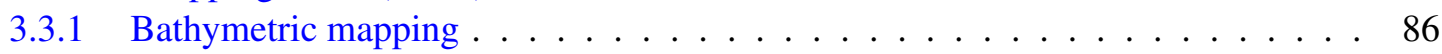

3.3 .2 Seismic mapping . . . . . . . . . . . . . . . . . 88

3.3 .3 Velocity mapping . . . . . . . . . . . . . . . . . . . . . 92

3.3 .4 Histogram equalization . . . . . . . . . . . . . . . . . . . . . . . . . 94

3.3.5 Geological mapping . . . . . . . . . . . . . . . . . . . . . . . . . . . . 97

3.3 .6 Geoid modelling . . . . . . . . . . . . . . . . . . . . . . 98

3.3 .7 3D mesh grid modelling . . . . . . . . . . . . . . . . . . . . . . 99

3.3 .8 Gravity modelling . . . . . . . . . . . . . . . . . . . 101

3.3.9 Automatic digitizing of the cross-section transecting profiles . . . . . . . . . . 103

3.3.10 Modelling 2D statistical histograms . . . . . . . . . . . . . . . . . . 105

3.3.11 Modelling 3D statistical histograms . . . . . . . . . . . . . . 106

3.3.12 Modelling statistical trends of the profiles gradient . . . . . . . . . . . . . 106

3.3.13 Surface modelling . . . . . . . . . . . . . . . . . . . . . . . . 108

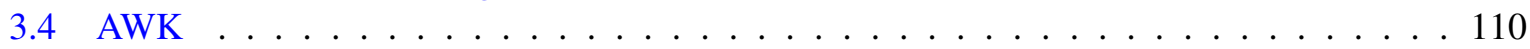

3.4.1 Advantages of AWK . . . . . . . . . . . . . . . . . . . . 110

3.4 .2 Data pre-processing . . . . . . . . . . . . . . . . . . . 111

3.4 .3 Table reshaping . . . . . . . . . . . . . . . . . . . . 111

3.5 Octave/MATLAB . . . . . . . . . . . . . . . . . . . . . . . 114

3.5.1 Advantages of Octave . . . . . . . . . . . . . . . . . . . . . . 114

3.5 .2 Data processing . . . . . . . . . . . . . . . . . . 115

3.5 .3 Data analysis . . . . . . . . . . . . . . . . . . 115

3.6 Quantum GIS . . . . . . . . . . . . . . . . . . . . . . . . 117

3.7 Statistical Algorithms . . . . . . . . . . . . . . . . . . . . . . . . 119

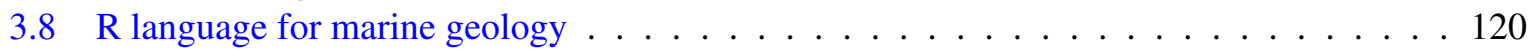


3.8.1 Analysis of bathymetric data distribution . . . . . . . . . . . . . . 120

3.8.1.1 Box plots . . . . . . . . . . . . . . . . . . . 120

3.8.1.2 Histograms . . . . . . . . . . . . . . . . . . 121

3.8.1.3 Violin plots . . . . . . . . . . . . . . . . . 121

3.8.1.4 Notched boxplots . . . . . . . . . . . . . . . . . . . 122

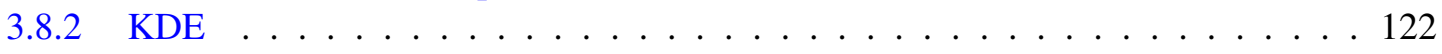

3.8 .3 Regression analysis . . . . . . . . . . . . . . . . . . . . 123

3.8.4 Comparative geospatial analysis by tectonic plates . . . . . . . . . . . . 126

3.8.5 Ridgeline, categorywise and circular plots . . . . . . . . . . . . . . . . 127

3.8.6 Dumbbell charts for data pairwise comparison by tectonic plates . . . . . . . . . 128

3.8.7 Ranking dot plots by data grouping . . . . . . . . . . . . . . . . . . . . . 129

3.8.8 Ternary diagrams, radar and pairwise double- $\mathrm{Y}$ axis charts . . . . . . . . . . . 129

3.8.9 Ranking data for variation of the geomorphic steepness . . . . . . . . . . . . . 130

3.8.10 Compositional charts of the determinants variations . . . . . . . . . . . . . . 131

3.8.11 Mosaic, silhouette and association plots . . . . . . . . . . . . . . . 131

3.8.12 Clustering ( $k$-means method), correlation ellipses and data partition . . . . . . 133

3.8.13 Hexagonal plots and data partition . . . . . . . . . . . . . . . . . . . . . 134

3.8.14 Correlation analysis of impact factors . . . . . . . . . . . . . . . 135

3.8.14.1 Pearson correlation . . . . . . . . . . . . . . . . 135

3.8.14.2 Spearman rank correlation coefficient $\rho \ldots \ldots \ldots \ldots . \ldots 136$

3.8.14.3 Kendall $\tau$ coefficient . . . . . . . . . . . . . . . . . . . . . 137

3.8.15 Calculation of the normalized steepness angle of the Mariana Trench . . . . . 137

3.8.16 Principal Component Analysis (PCA) . . . . . . . . . . . . . . 138

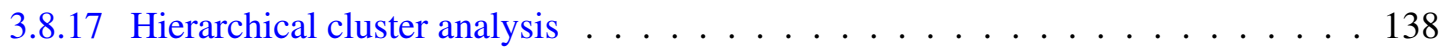

3.8 .18 Scatterplot Matrices . . . . . . . . . . . . . . . . . . . . . 140

3.8.19 Exploratory Factor Analysis (EFA) ～. . . . . . . . . . . . . . . . . . . . . 142

3.8.20 Analysis of Variance (ANOVA) to assess hypothesis testing . . . . . . . . . . 145

3.8.21 Euler-Venn Diagram . . . . . . . . . . . . . . . . . . . . . 147

3.8 .22 Word cloud . . . . . . . . . . . . . . . . . . . . . . . . . 147

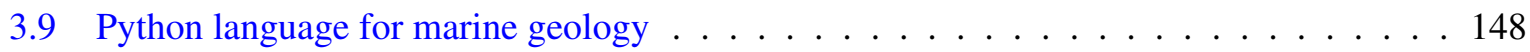

3.9.1 Advantages of Python . . . . . . . . . . . . . . . . . . . . . 148

3.9 .2 Installing Python libraries . . . . . . . . . . . . . . . . 150

3.9 .3 Data preprocessing . . . . . . . . . . . . . . . . . 150

3.9.4 Pandas: a Python library for creating DataFrames . . . . . . . . . . . . . . . 151

3.9.5 Python libraries: Matplotlib, NumPy, SciPy, Seaborn, StatsModels, Bokeh . . 152

3.9.6 Data Analysis . . . . . . . . . . . . . . . . . . . . . . . . . . 154

3.9.6.1 Letter-value plots . . . . . . . . . . . . . . . . . 154

3.9 .6 .2 Violin plots . . . . . . . . . . . . . . . . 155

3.9.6.3 Hierarchically-clustered heatmaps . . . . . . . . . . . . . . 156

3.9.6.4 Histograms plotted by Python . . . . . . . . . . . . . . . . 156

3.9.6.5 Strip plots by Python . . . . . . . . . . . . . . . . 157

3.9.6.6 Euler-Venn diagrams by Python . . . . . . . . . . . . . . . . 157

3.9.6.7 Regression Analysis . . . . . . . . . . . . . . . . . . . . . . 158

3.9.6.8 Cluster heatmap and hexagonal data distribution and Kernel Density estimation . . . . . . . . . . . . . . . . 160

3.9.6.9 Correlograms by Python . . . . . . . . . . . . . . . . . . 160

3.9.6.10 Data distribution . . . . . . . . . . . . . . . . . 162 
3.9.6.11 Probability of the depths distribution by Kernel Density Estimation (KDE) plots . . . . . . . . . . . . . . . . 162

3.9.6.12 Data sorting and grouping . . . . . . . . . . . . . . 163

3.9.6.13 Hierarchical dendrogram and clustermap . . . . . . . . . . . . . . 164

3.9.6.14 Principal Component Analysis (PCA) . . . . . . . . . . . . . . . 165

3.9.6.15 3D scatterplot matrices for fata correlation . . . . . . . . . . 166

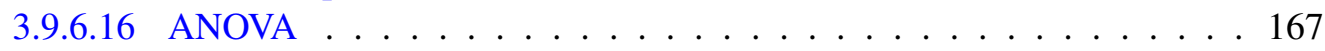

3.9.6.17 Flowchart network . . . . . . . . . . . . . . . . . 168

3.9.6.18 Visualizing bathymetric pattern by stacked area charts . . . . . . . 168

3.9.6.19 Stacked bar plots . . . . . . . . . . . . . . . . . . . . . . . 169

3.9.6.20 Radar charts for analysis of depth distribution . . . . . . . . . . 170

3.9.6.21 Stacked bar charts for analysis of sediment thickness . . . . . . . . . 170

3.9.6.22 Pie charts for circular visualization of the bathymetry vs tectonic plates 171

3.9.6.23 Design matrix and model fit summary by Ordinary Least Squares . . . 171

3.9.6.24 Quantile statistics (QQ) . . . . . . . . . . . . . . . . 172

3.9.6.25 Weighted Least Squares . . . . . . . . . . . . . . . . . . . . . 174

3.9.6.26 Isotonic regression . . . . . . . . . . . . . . . . . . . . 175

3.9.6.27 Dynamic regression model: SARIMA . . . . . . . . . . . . 176

$3.10 \mathrm{LT}$ EXfor processing bathymetric data . . . . . . . . . . . . . . . 177

4 Results 178

4.1 Classification of the submarine geomorphology . . . . . . . . . . . . . . . . 179

4.2 Kuril-Kamchatka Trench . . . . . . . . . . . . . . . . . . . . . . . . 186

4.3 Aleutian Trench . . . . . . . . . . . . . . . . . . . . . . . . . . . 191

4.4 Middle America Trench . . . . . . . . . . . . . . . . . . . . . . . . . . . . . . . . . . 194

4.5 Peru-Chile Trench . . . . . . . . . . . . . . . . . . . . . . . . . . 196

4.6 Kermadec Trench . . . . . . . . . . . . . . . . . . . . . . . . . . . . . . 198

4.7 Tonga Trench . . . . . . . . . . . . . . . . . . . . . . . . . . . . . . . . . . . 199

4.8 Vanuatu (New Hebrides) Trench . . . . . . . . . . . . . . . . . . . . . 200

4.9 Vityaz Trench . . . . . . . . . . . . . . . . . . . . . . . . . . . 201

4.10 New Britain (Bougainville) Trench . . . . . . . . . . . . . . . . . . 203

4.11 San Cristobal Trench . . . . . . . . . . . . . . . . . . . . . . . 204

4.12 Philippine Trench . . . . . . . . . . . . . . . . . . . . . . . . . . 207

4.13 Manila Trench . . . . . . . . . . . . . . . . . . . . . . . 213

4.14 Ryukyu Trench . . . . . . . . . . . . . . . . . . . . . . . . 216

4.15 Palau Trench . . . . . . . . . . . . . . . . . . . . . . . . . . . 219

4.16 Yap Trench . . . . . . . . . . . . . . . . . . . . . . . 221

4.17 Mariana Trench . . . . . . . . . . . . . . . . . . . . . . . . . 224

4.18 Izu-Bonin Trench . . . . . . . . . . . . . . . . . . . . . . . . . . . 231

4.19 Japan Trench . . . . . . . . . . . . . . . . . . . . . . . . . . . 234

4.20 Puysegur Trench . . . . . . . . . . . . . . . . . . . . . 237

4.21 Hikurangi Trench . . . . . . . . . . . . . . . . . . . . . . . . . 239

5 Discussion $\quad \mathbf{2 4 2}$

5.1 Novelty . . . . . . . . . . . . . . . . . . . . . . . . . . . . 242

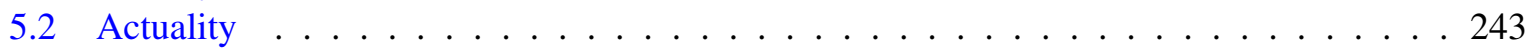

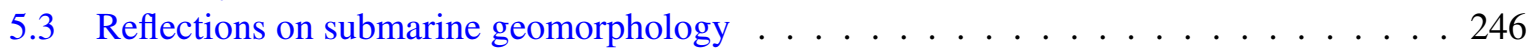

5.4 Perspectives of the IT tools for geology . . . . . . . . . . . . . . . . . 247 
6 Conclusion

6.1 Global Summary . . . . . . . . . . . . . . . . . . . . . . . 250

6.2 Recommendations . . . . . . . . . . . . . . . . . . . . . . . . 252

6.3 Outlook and future developments . . . . . . . . . . . . . . . 253

Author's Publications $\quad 254$

A Programming codes ii

A.1 Octave/Matlab language $\ldots \ldots \ldots \ldots \ldots \ldots \ldots$ ii

A.1.1 Octave/Matlab script for cartographic visualization of the bathymetric profiles . . ii

A.2 $\mathrm{T}_{\mathrm{E} X} \mathrm{Xmacro}$ language $\ldots \ldots \ldots \ldots \ldots \ldots \ldots \ldots \ldots$ iii

A.2.1 $\mathrm{LAT}_{\mathrm{E}} \mathrm{Xcode}$ to plot bathymetric profiles . . . . . . . . . . . . . . . iii

A.3 AWK language . . . . . . . . . . . . . . . . . . . . . iv

A.3.1 AWK shell script for table reshaping . . . . . . . . . . . . . iv

A.4 GMT shell/bash scripts . . . . . . . . . . . . . . . . . . . . v

A.4.1 GMT script for bathymetric mapping, ETOPO1 (here: KKT) . . . . . . . . . v v

A.4.2 GMT script for 3D mesh grid modelling, DEM based (here: AT) . . . . . . . . vi vi

A.4.3 GMT script for bathymetry contour mapping (here: KKT) . . . . . . . . . . vii

A.4.4 GMT script for geoid modelling (here: KKT) . . . . . . . . . . . . . . viii

A.4.5 GMT script for geological World map . . . . . . . . . . . . . . ix

A.4.6 GMT script for regional geological map (here: MAT) . . . . . . . . . . . . $\mathrm{x}$

A.4.7 GMT script for free-air gravity modelling (here: KKT) . . . . . . . . . . . . xiii

A.4.8 GMT script for generating and plotting stacked cross-sectioning bathymetric profiles (here: MAT). Profiles info: $400 \mathrm{~km}$ long, spaced $20 \mathrm{~km}$, sampled every $2 \mathrm{~km}$ xiv

A.4.9 GMT script for topographic surface modelling from the xyz ASCII data (here:

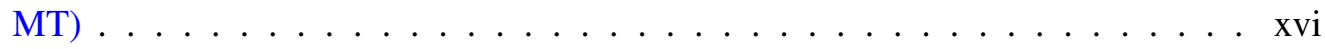

A.4.10 GMT script for gridding xyz data by Nearest Neighbor algorithm (here: KKT) . xvii

A.4.11 GMT script for regression trend1d mixed models (here: AT) . . . . . . . . . . xviii

A.4.12 GMT script for 2D bar histogram and rose diagram (here: MAT) . . . . . . . . xx

A.4.13 GMT script for 3D bar histogram plot (here: KKT) . . . . . . . . . . . . . xxi

A.5 Python language scripts . . . . . . . . . . . . . . . . . . xxii

A.5.1 Python code for statistical data analysis by violin plots . . . . . . . . . . xxii

A.5.2 Python code for clustermap: bathymetric data distribution by profiles . . . . . . xxii

A.5.3 Python code for histograms: distribution of the observation samples . . . . . . xxiii

A.5.4 Letter-value plots for the Mariana Trench bathymetry . . . . . . . . . . . . xxiv

A.5.5 Python code for the strip plots (here: Philippine Trench) . . . . . . . . . xxv

A.5.6 Python code for the correlogram matrices by Seaborn library . . . . . . . . . . . xxvi

A.5.7 Python code for the regression analysis . . . . . . . . . . . . xxvii

A.5.8 Python code for Letter-value plots for the Mariana Trench bathymetry . . . . . . xxvii

A.5.9 Python code for joint Hexagonal and KDE plots . . . . . . . . . . . . . . xxviii

A.5.10 Python code for the correlogram plot (here: Pearson's method) . . . . . . . . x xxviii

A.5.11 Python code for a box-and-whisker plot for the Mariana Trench bathymetry . . . xxix

A.5.12 Python code for sorting data in stem plots: analysis of the angle steepness . . . . xxx

A.5.13 Python code for plotting dendrograms . . . . . . . . . . . . . . . . xxxi

A.5.14 Python code for 3D scatter plots: correlation of the factors (sediment thickness,

slope steepness, bathymetry) . . . . . . . . . . . . . . . . xxxi

A.5.15 Python code for ANOVA . . . . . . . . . . . . . . . . xxxiii

A.5.16 Python code for KDE, example for the subplot $(\mathrm{F}) \ldots \ldots$. . . . . . . xxxiii

A.5.17 Python code for stacked area charts on the bathymetry . . . . . . . . . . xxxv 
A.5.18 Python code for the facetted plot of the radar charts . . . . . . . . . . . xxxvi

A.5.19 Python code for the distribution of the bathymetric data by stacked bar plots . . xxxvii

A.5.20 Python code for analysis of the distribution of sediment thickness, stacked bar

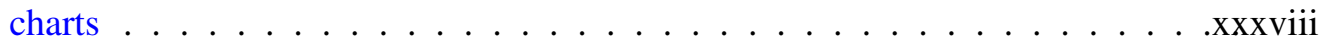

A.5.21 Python code for pie charts visualizing bathymetry vs tectonic plates . . . . . . xxxix

A.5.22 Python code for QQ plots visualizing descriptive statistics for the bathymetry . xxxix

A.5.23 Python code for WLS calculations . . . . . . . . . . . . . . . . . . xl

A.5.24 Python code for quantile (QQ) regression . . . . . . . . . . . . . . . . xlii

A.5.25 Python code for SARIMA model . . . . . . . . . . . . . . . . . xliii

A.5.26 Python code for Euler-Venn diagrams . . . . . . . . . . . . . . xliv

A.6 R language scripts . . . . . . . . . . . . . . . . . . . . . . xlvi

A.6.1 R code to create histograms using (ggplot) library . . . . . . . . . . . . . xlvi

A.6.2 R code to generate boxplots 'whiskerplots' using default boxplot function . . . . xlvii

A.6.3 R code for notched boxplot using (ggboxplot) . . . . . . . . . . . . . . .xlviii

A.6.4 R code to generate Quantile-Quantile (QQ) quantile statistics for facetted wrapped

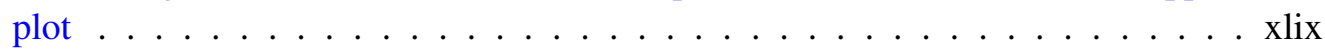

A.6.5 R code for regression analysis for the bathymetric profiles . . . . . . . . 1

A.6.6 R code for cluster analysis, dendrograms . . . . . . . . . . . . . . li

A.6.7 R code for correlogram by (ggplot) library . . . . . . . . . . . . . . . lii

A.6.8 R code for Principal Component Analysis (PCA) . . . . . . . . . . . . . liii

A.6.9 R code for k-means clustering . . . . . . . . . . . . . . . . liv

A.6.10 R code for Pairwise Standard Scatter Plots of k-means Cluster Correlation (comparing 4 tectonic plates) . . . . . . . . . . . . . . . $1 v$

A.6.11 R code for 'lollipop' charts and diverging bars by (ggplot) library . . . . . . . . lvii

A.6.12 R code for Dumbbell chart by (ggalt) and (ggplot2) libraries . . . . . . . . . . lix

A.6.13 R code for categorywise bar charts . . . . . . . . . . . . . . . Ix

A.6.14 R code for dot plot with encircling by (ggalt) library . . . . . . . . . . . lxi

A.6.15 $\mathrm{R}$ code for double-Y axis using (LatticeExtra) library to perform comparative analysis of categories . . . . . . . . . . . . . . . 1xiii

A.6.16 R code for circular barplot by library tidyverse . . . . . . . . . . . . . 1xiv

A.6.17 R code for multiple strip plots divided groups, by LatticeExtra library . . . . . . 1xvi

A.6.18 R code for multiple panels by groups (tectonic plates, depths, slope angles) . . . lxvii

A.6.19 R code for density curves: data distribution . . . . . . . . . . . . . . . Ixvii

A.6.20 $\mathrm{R}$ code to generate brackets for the specific regions along the Mariana Trench using library (pBrackets) . . . . . . . . . . . . . . . . . . . . . . . . . . . . . . . . . .

A.6.21 R code for radar chart using (fmsb) library . . . . . . . . . . . . . . . Ixx

A.6.22 R code for highlighted group in lollipop chart by libraries (ggsignif) and (tidyverse) lxx

A.6.23 R code for Euler-Venn Diagram (logical correlation of objects) using (venn) librarylxxii

A.6.24 $\mathrm{R}$ code for animation using (gganimate), (gapminder) and (ggplot2) libraries: regression analysis plots for 25 bathymetric profiles . . . . . . . . . . . lxxiii

A.6.25 R code for 'violin' plots using (violinmplot) library: statistical analysis of bathymetric data distribution . . . . . . . . . . . . . . . . . . . . . . . . . . . . . . . . . .

A.6.26 R code for Exploratory Factor Analysis (EFA) using (FactoMiner), (factoextra) and (psych) libraries . . . . . . . . . . . . . . . . . . . lxxv

A.6.27 $\mathrm{R}$ code for hexagonal plot by library(hexbin): bathymetric data distribution, Mar-

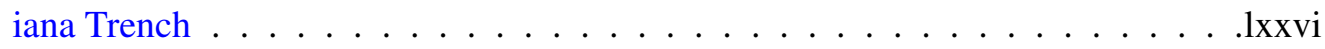

A.6.28 R code for ANOVA for Mariana Trench . . . . . . . . . . . . . . . Ixxvii

A.6.29 R code for Ternary Diagram by (ggtern) library . . . . . . . . . . . . . . Ixxviii 
A.6.30 R code for silhouette plot by (cluster) library . . . . . . . . . . . . lxxx

A.6.31 R code for mosaic and association plots . . . . . . . . . . . . . . 1xxx

A.6.32 R code plot correlation ellipses using library(ellipse) . . . . . . . . . . . . lxxxi

A.6.33 R code for level plot using (ggplot2) library: sediment thickness . . . . . . . . . lxxxi

A.6.34 R code for hierarchical edge funding by (ggraph), (igraph), (tidyverse), (RColor-

Brewer) libraries: Mariana Trench project . . . . . . . . . . . . . . 1xxxii

A.6.35 R code for ridgeline plots by (ggridges) and (ggplot2) libraries . . . . . . . . lxxxiii

A.6.36 R code for word could by libraries (wordcloud), (tm), (RXKCD): Mariana Trench

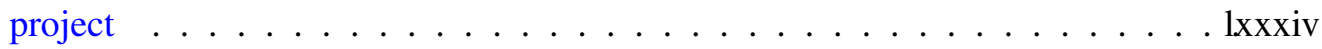

A.6.37 R code for 'waffle' plot by library (ggplot2): bathymetric data distribution . . . lxxxiv

A.6.38 R code for 'waffle' plot by library (waffle): bathymetric data distribution . . . Ixxxv

A.6.39 R code for treemap by library (treemap) . . . . . . . . . . . . . . lxxxuvi

A.6.40 R code for network by (igraph) library: Mariana Trench project . . . . . . . . lxxxvi

A.6.41 $\mathrm{R}$ code for scatterplot matrices by (GGally) library to assess data distribution,

Mariana Trench . . . . . . . . . . . . . . . . . . . . . . . . . . . . . . . . . .

A.6.42 $\mathrm{R}$ code for diagonal scatterplot matrices by (car) library $\ldots \ldots \ldots$. . . . lxxxix

G Indices $\quad$ xc

G.1 Index of Places . . . . . . . . . . . . . . . . . . . xci

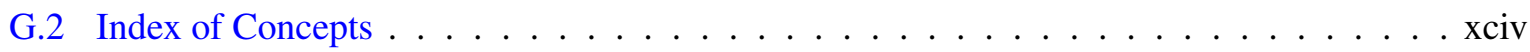

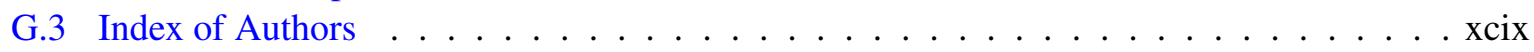

$\begin{array}{lcc}\text { Bibliography } & \text { cxii }\end{array}$ 


\section{Abstract}

Geomorphological landforms of the oceanic trenches, their formation and variation of the geometric shapes is a question of special importance to the scientific community in marine geology. The actuality of this question has significantly increased since the beginning of the rapid development of the IT tools and methods of the advanced data analysis, yet its understanding remains patchy. Since the majority of the oceanic trenches are located along the margins of the Pacific Ocean, it plays a central role for their analysis and understanding their formation oceanic trenches.

Specific geological conditions, presence of the tectonic subduction zones, vast territory of the Pacific Ocean with complex circulation system, extension of the 'Ring of Fire', a seismically active belt of the earthquakes and volcanic, make the trenches of the Pacific Ocean highly sensitive to the factors affecting their formation which cause variations in their geomorphic shape forms. In this context, the most representative indicators of the variations in the deep-sea trenches are geological and tectonic factors, such as dynamics of lithosphere crust affecting speed and intensity of plates subduction, magnitude and frequency of the submarine volcanoes causing active sedimentation.

Nowadays, studying marine geological phenomena and complex processes by programming and scripting has been a powerful method. Rapid development of the advanced methods of data analysis presented such effective tools as GMT, Octave/MATLAB, R and Python. It is particularly efficient when applied to the massive amounts of marine geological data. Big data processing by advanced scripting is a crucial approach, as algorithms of libraries give access to the accurate and rapid data analysis [373]. Specific information about distant and hard-to-reach deep-sea trenches can be gained for precise visualization and analysis of their submarine geomorphology from local to regional and global scales.

However, despite all the efforts, there is a lack of uniformity in studying deep-sea trenches, a shortage of systematic mapping of the Pacific trenches and a lack of understanding of the geomorphological variation between the trench profiles in different parts of the ocean: southern and northern, eastern and western, and their response to the geological and tectonic local settings in the places of formation.

Therefore, this dissertation develops a systematic approach to monitoring and comparative analysis of the geomorphological shape forms of the deep-sea trenches formed under specific geological and tectonic conditions along the margins of the Pacific Ocean. The study area encompasses Pacific Ocean, and more specifically, includes 20 selected target trenches: Aleutian, Mariana, Philippine, Kuril-Kamchatka, Middle America, Peru-Chile, Palau, Japan, Kermadec, Tonga, Izu-Bonin, New Britain, San Cristobal, Manila, Yap, New Hebrides, Puysegur, Hikurangi, Vityaz and Ryukyu. These are the major trenches of the Pacific Ocean and, therefore, the most representative for the geomorphological modelling.

This dissertation identifies tectonic plates formation, slab subduction, historical geological development, earthquakes and submarine volcanoes as the primary types of impact factors affecting trenches formation. Secondary factors include ocean currents, sedimentation and biota contributing to the sedimentation. Seafloor geomorphology in hadal trenches is strongly affected by a variety of factors that necessarily affect the shape of their landforms. Using data modelling, the shapes of the profiles transecting the trenches in an orthogonal direction were compared and analyzed in order to highlight the differences and variations in their geomorphology. 
The objective of this PhD study is to perform a geomorphological classification of the shape forms of the trenches through ordering them into groups base don the common characteristics of the trenches' landforms in plan and attaching labels to these groups. Following geomorphological profile shape types have been identifies and trenches are classified into seven types: U-formed (in plan), V-formed (in plan), asymmetric, crescent-formed, sinuous-formed, elongated, cascade-formed. For each type (U, V, asymmetric and so on) characteristic steepness sub-types are identified: strong, very strong, extreme, steep, very steep. Valley slopes are classified as follows: very high, high, moderate, low, based on the curvature degree. Size and valley slope classes are analyzed in the context of physical environment and tectonic and geological development of the area of trench formation.

Technical aim of this $\mathrm{PhD}$ study was to experiment with and extend current methods of geospatial modelling for geomorphological classification of the submarine landforms of the trenches. Using methods of the advanced data analysis is crucial for the precise and reliable data processing, since understanding seafloor landforms can only be based on the computer-based data modelling due to their unreachable location. The selection of the methodology, tools and algorithms is explained by research objectives and goals. The specifics of the marine geology consists in the high requirements towards data processing. Datasets were processed, computed and analyzed in semi-automatic regime by Machine Learning (ML) approaches, using advanced algorithms of data analysis and effective visualization through application of the advanced programming tools and Generic Mapping Tools (GMT) scripting toolsets.

This dissertation presents an automated workflow enabling large-scale profile cross-sectioning aimed at transect geomorphological mapping, quantitative comparative analysis and classification of the 20 trenches of the Pacific Ocean. The methodology of the GMT includes algorithms of sequential scripting for the cartographic visualization and mapping, automatic digitizing of the cross-section transect profiles, and geomorphic modelling of the trenches. In total 50 modules of GMT scripting toolset were trained on extensive datasets collected from 20 trenches across the whole region of the Pacific Ocean. Using high-resolution bathymetric datasets (General Bathymetric Chart of the Oceans (GEBCO), ETOPO1 and Shuttle Radar Topographic Mission (SRTM)), sample transects of the trenches were modeled, analyzed and compared. Variations in shape forms, steepness and curvature were analyzed by computed models for each trench. The tables were converted from QGIS plugins to Python libraries and R packages, and from GMT to Octave via AWK languages.

The results revealed variation in the shape and steepness of the submarine geomorphology in 20 trenches of the Pacific Ocean. A strong correlation between the geomorphic profile shapes with geological factors and level of tectonic activities (earthquakes, volcanism, speed of tectonic plate subduction) and the scale of trench steepness, curvature and shape unevenness is confirmed and analyzed. Geomorphological structure of the trenches and dynamics of the tectonic plates subduction are analyzed and assessed at each trench regionally (north, south, west and east Pacific).

The novelty of the study consists in presented systematic classification and comparative modelling of the geomorphic profiles of the deep-sea trenches by means of the sequential usage of the advanced scripting toolsets. Technical innovativeness consists in a combination of GIS, GMT, Python, AWK, R and

The actuality of this dissertation lies in its strongly multi-disciplinary nature demonstrating a combination of the following approaches: 1) systematic multi-source geospatial data analysis; 2) statistical data modelling and processing by libraries of the Python and R, AWK and Octave/Matlab; 3) geological literature analysis; 4) cartographic mapping and modelling by GMT shell scripts and visualization in QGIS. The dissertation contributes to the studies on

Technical scripts used for advanced statistical analysis are presented in full in the Appendix A for future replication and reproducible analysis in other trenches of the World Ocean.

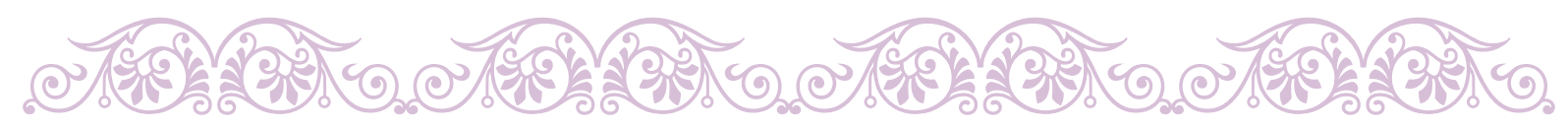




\section{Keywords}

Keywords: Pacific Ocean; geomorphology; bathymetry; Aleutian Trench; Mariana Trench; Philippine Trench; Kuril-Kamchatka Trench; Middle America Trench; Peru-Chile Trench; Palau Trench; Japan Trench; Kermadec Trench; Tonga Trench; Izu-Bonin Trench; New Britain Trench; San Cristobal Trench; Manila Trench; Yap Trench; New Hebrides Trench; Puysegur Trench; Hikurangi Trench; Vityaz Trench; Ryukyu Trench; New Zealand; Central America; R; Python; Matplotlib; NumPy; SciPy; Pandas; Seaborn; geomorphic modelling, cartography, visualization, data analysis, programming language; statistics; spatial analysis; statistical analysis; cluster analysis; factor analysis; marine geology; geomorphology; bathymetry; algorithm; oceanography; GMT; GIS; QGIS, geoinformatics; GEBCO; ETOPO1; geodata; dataset; 


\section{Lists}

\section{List of Acronyms ${ }^{1}$}

AI Artificial Intelligence $\ldots \ldots \ldots \ldots \ldots \ldots$

AOI Area of Interest . . . . . . . . . . . . . . . . . . . . . . 104

ASL Above Sea Level . . . . . . . . . . . . . . . . . . . . . . . 188

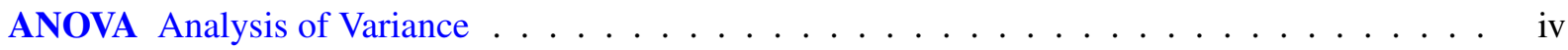

ASCII American Standard Code for Information Interchange . . . . . . . . . . . . . . . 78

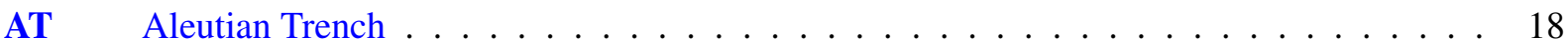

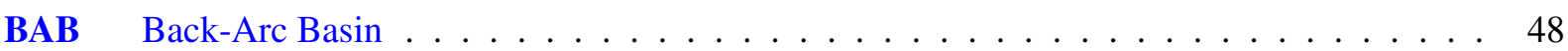

bash Bourne Again SHell . . . . . . . . . . . . . . . . . . . . . . . 104

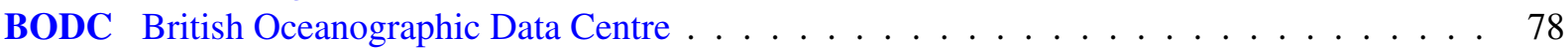

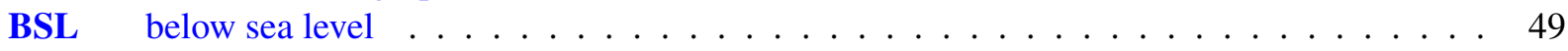

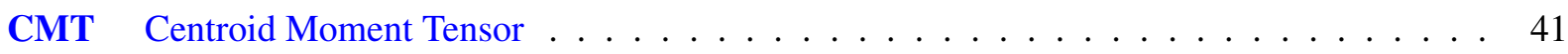

CTAN The Comprehensive TEX Archive Network . . . . . . . . . . . . . . . . . . 177

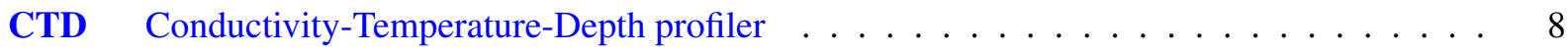

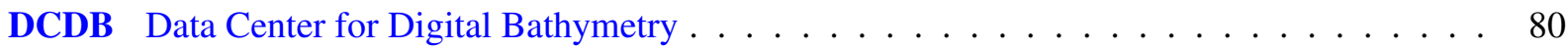

DEM Digital Elevation Model . . . . . . . . . . . . . . . . . . . . . . . 37

EPSG European Petroleum Survey Group . . . . . . . . . . . . . . . . . . . . . . 117

GDAL Geospatial Data Abstraction Library . . . . . . . . . . . . . . . . . . . . . 83

GEBCO General Bathymetric Chart of the Oceans . . . . . . . . . . . . . . . . . x

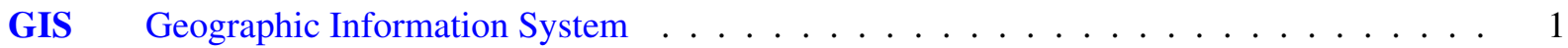

GLM Generalized Linear Models . . . . . . . . . . . . . . . . . . . . . . 125

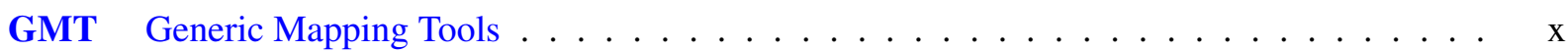

GNU GNU's Not Unix . . . . . . . . . . . . . . . . . . . . . . . . . . . 114

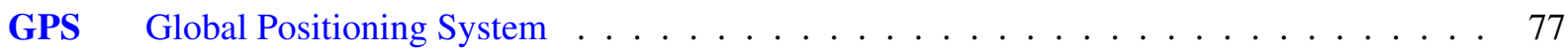

GRASS GIS Geographic Resources Analysis Support System . . . . . . . . . . . . . . . . . . . 12

GSFC Goddard Space Flight Center . . . . . . . . . . . . . . . . . . . . . . . . . 99

GSHHGD Global Self-consistent, Hierarchical, High-resolution Geography Database . . . . . 78

GUI Graphical User Interface . . . . . . . . . . . . . . . . . . . . . . . . . 83

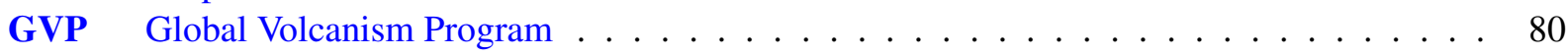

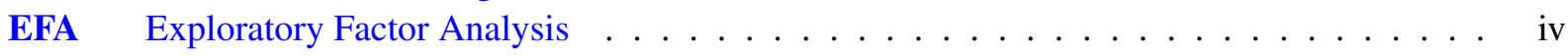

EGM96 Earth Gravitational Model of $1996 \ldots \ldots \ldots \ldots$

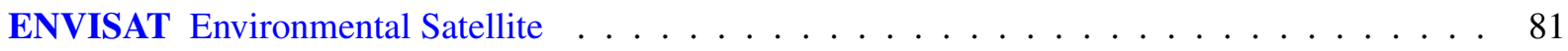

ESRI Environmental Systems Research Institute . . . . . . . . . . . . . . . . . . . 81

ETOPO1 1 Arc-Minute Global Relief Model of Earth's topography . . . . . . . . . . . . . . . 3

ETOPO5 5 Arc-Minute Global Relief Model of Earth's topography . . . . . . . . . . . . . . . . 80

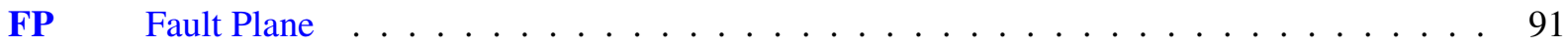

\footnotetext{
${ }^{1}$ The page is given where the glossary is first entered and defined
} 
HCA Hierarchical Cluster Analysis . . . . . . . . . . . . . . . . . . . . . . . . 164

HSD Honest Significant Differences . . . . . . . . . . . . . . . . . . . . 145

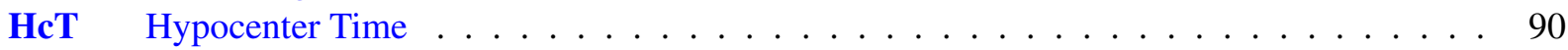

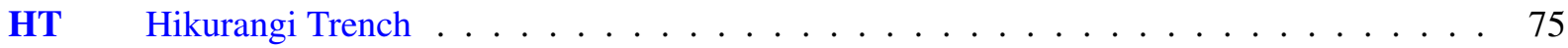

IBM Izu-Bonin Mariana $\operatorname{arc} \ldots \ldots \ldots \ldots \ldots \ldots \ldots$

IBT Izu-Bonin Trench . . . . . . . . . . . . . . . . . . . . . . . . . 64

IDLE Integrated Development and Learning Environment . . . . . . . . . . . . . . . 150

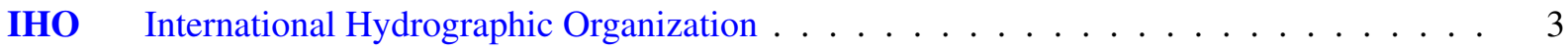

IRIS Incorporated Research Institutions for Seismology . . . . . . . . . . . . . . . . . 5

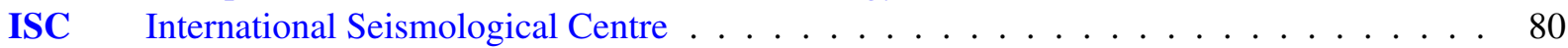

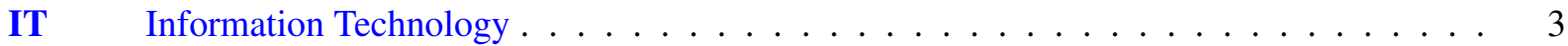

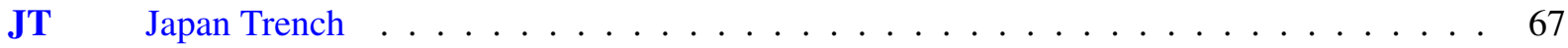

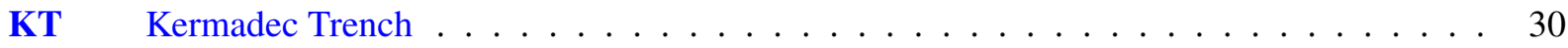

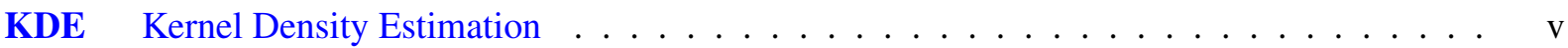

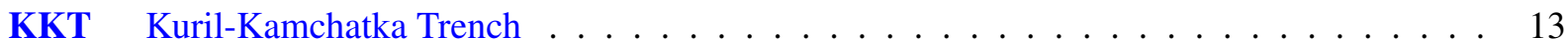

KMZ Keyhole Markup language Zipped . . . . . . . . . . . . . . . . . . . . . . . 90

kwargs Keyword arguments . . . . . . . . . . . . . . . . . . . . . . . . 93

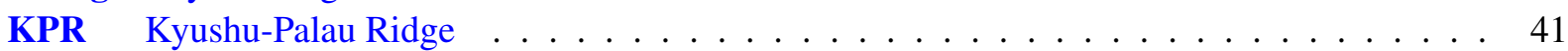

LIPs $\quad$ Large Igneous Provinces . . . . . . . . . . . . . . . . . . . . . . . . . 97

LOESS Locally Estimated Scatterplot Smoothing . . . . . . . . . . . . . . . . . . . . 119

OLS Ordinary Least Square . . . . . . . . . . . . . . . . . . . . . 153

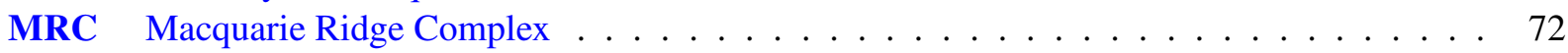

MAT Middle America Trench . . . . . . . . . . . . . . . . . . . . . 21

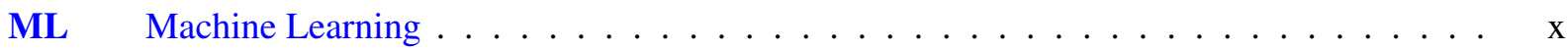

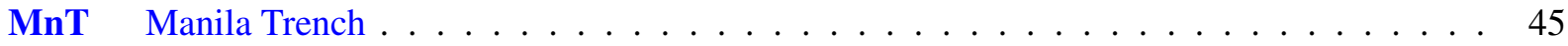

MORB Mid-Ocean Ridge Basalts . . . . . . . . . . . . . . . . . . . . . . . . . . . 60

MORVEL Mid-Ocean Ridge VELocity . . . . . . . . . . . . . . . . . . . . . . . . . . 92

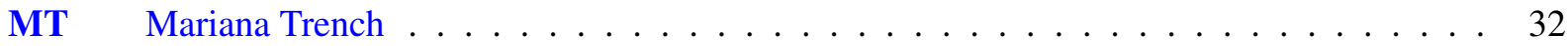

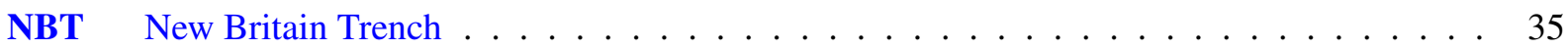

NGA National Geospatial Intelligence Agency . . . . . . . . . . . . . . . . . . . 80

NGDC National Geophysical Data Center . . . . . . . . . . . . . . . . . . . . . . . . . 80

NetCDF Network Common Data Form . . . . . . . . . . . . . . . . . . . . . . . . 101

NumPy Numerical Python . . . . . . . . . . . . . . . . . . . . . . . 8

NASA National Aeronautics and Space Administration . . . . . . . . . . . . . . . . 78

NIMA National Imagery and Mapping Agency . . . . . . . . . . . . . . . . . . . . . . . 99

NOAA National Oceanic and Atmospheric Administration . . . . . . . . . . . 78

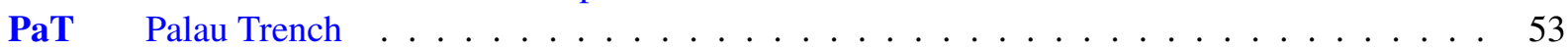

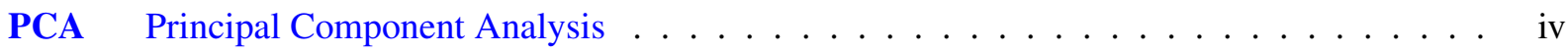

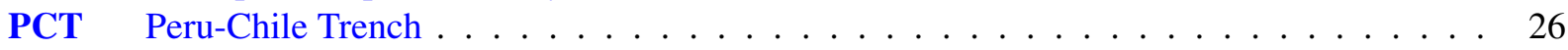

POSIX Portable Operating System Interface . . . . . . . . . . . . . . . . . . 150

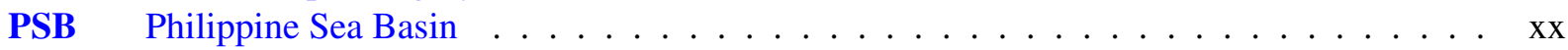

PSP Philippine Sea Plate . . . . . . . . . . . . . . . . . . . . . . 39

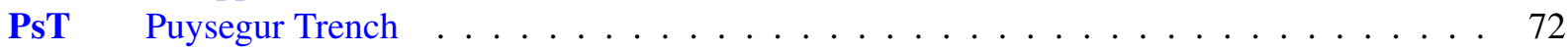

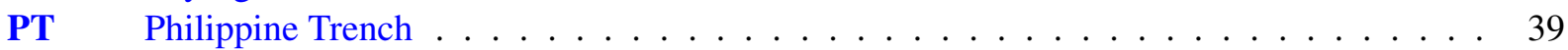

PVEL Pacific VELocity . . . . . . . . . . . . . . . . . . . . . . . . . 92

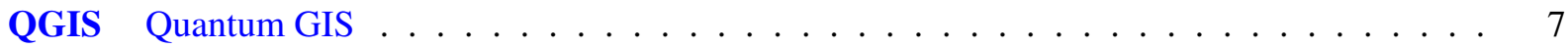

QQ Quantile-Quantile ......................... vii

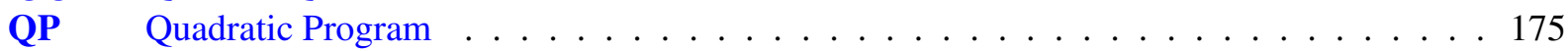




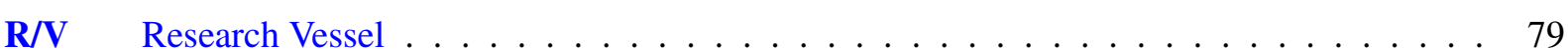

ROV Remotely Operated underwater Vehicle . . . . . . . . . . . . . . . . . . 81

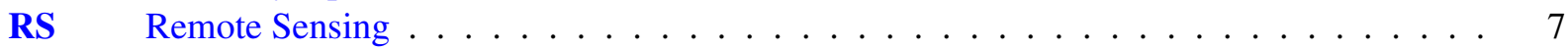

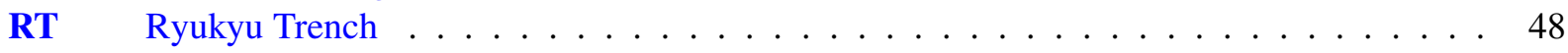

SARIMA State Autoregressive Moving Average . . . . . . . . . . . . . . . 176

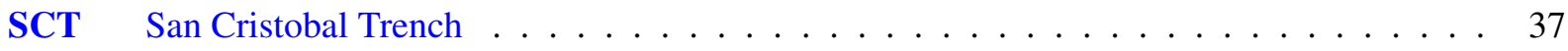

SIO Scripps Institution of Oceanography . . . . . . . . . . . . . . . . . 79

SRTM Shuttle Radar Topographic Mission . . . . . . . . . . . . . . . . . . . .

SSH Sea Surface Height . . . . . . . . . . . . . . . . . . . . . . . . 203

SSL Secure Sockets Layer . . . . . . . . . . . . . . . . . . . . . . . . . 153

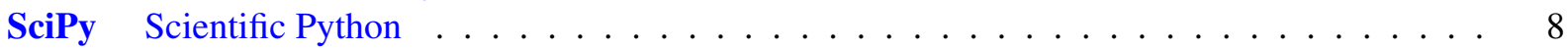

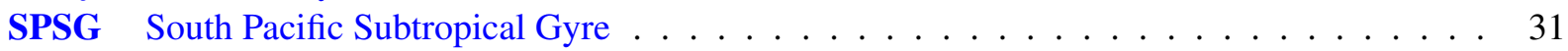

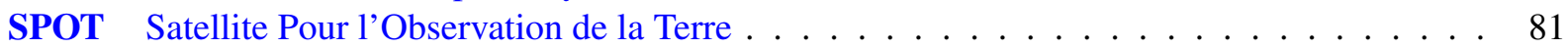

SPSS Statistical Package for the Social Sciences . . . . . . . . . . . . . . . . . . 105

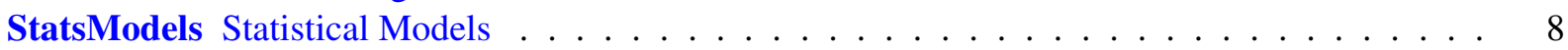

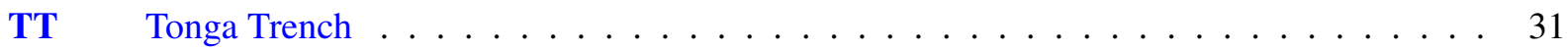

UPGMA Unweighted Pair Group Method with Arithmetic Mean . . . . . . . . . . . . . . . 161

USGS United States Geological Survey . . . . . . . . . . . . . . . . . . . . . . . . . 24

UTM Universal Transverse Mercator coordinate system . . . . . . . . . . . . . . . . . 117

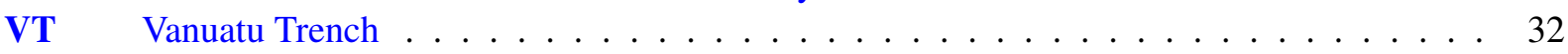

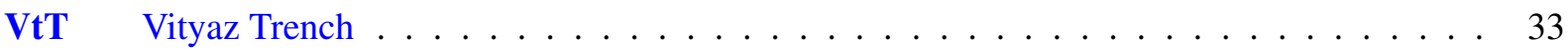

WPGMA Weighted Pair Group Method with Arithmetic Mean . . . . . . . . . . . . . . 164

WGS84 World Geodetic System of $1984 \ldots \ldots$. . . . . . . . . . . . . . . . . . . . 90

WLS Weighted Least Squares . . . . . . . . . . . . . . . . . . . . . . 125

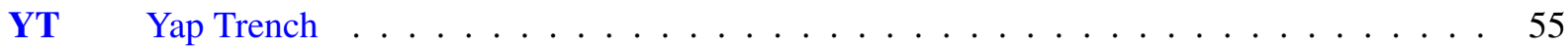




\section{List of Equations}

3.1 Surface wave magnitude $(\mathrm{Ms}) \ldots \ldots \ldots \ldots \ldots \ldots$

3.2 Body wave magnitude $(\mathrm{mb}) \ldots \ldots \ldots \ldots \ldots$

3.3 GMT regression analysis formula $(1) \ldots \ldots \ldots \ldots \ldots \ldots$

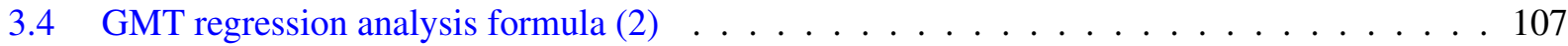

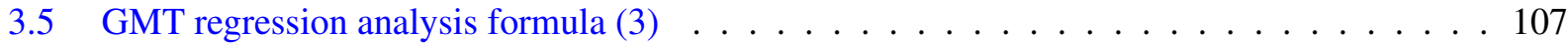

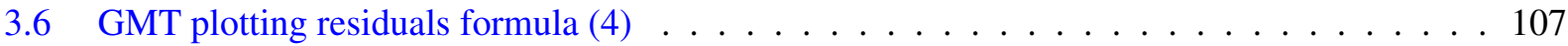

3.7 Linear regression analysis formula . . . . . . . . . . . . . . . . . . . . 125

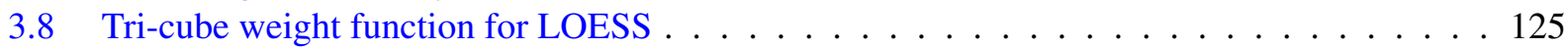

3.9 Savitzky-Golay smoothing filter for LOESS algorithm . . . . . . . . . . . . . . . 125

$3.10 G$-test of maximum likelihood statistical significance . . . . . . . . . . . . . . . 132

3.11 Euclidean distance metric . . . . . . . . . . . . . . . . . . . . . . . . 132

$3.12 k$-means Clustering equation . . . . . . . . . . . . . . . . . . . . . 134

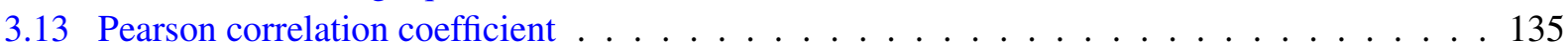

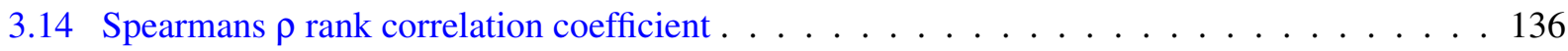

3.15 Kendall $\tau$ correlation coefficient . . . . . . . . . . . . . . . . . . . . 137

3.16 Smooth bootstrapping of dataset in hierarchical cluster analysis . . . . . . . . . . . 139

3.17 Covariance matrix equality . . . . . . . . . . . . . . . . . . 140

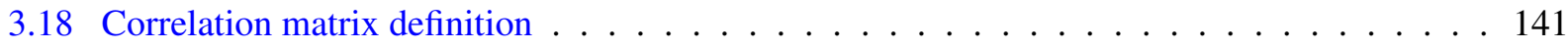

3.19 Covariance 2D matrix mapping . . . . . . . . . . . . . . . . . 142

3.20 Definition of factor analysis for random variables . . . . . . . . . . . . . . . . 143

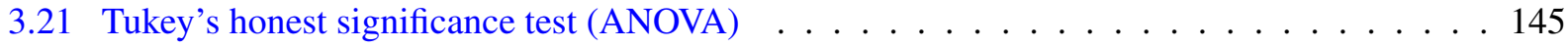

3.22 Levene's test (ANOVA) to assess the equality of variances . . . . . . . . . . . . . 145

3.23 Welch unequal variances t-test (ANOVA) . . . . . . . . . . . . . . . . 145

3.24 Shapiro-Wilk test of normality (ANOVA) . . . . . . . . . . . . . . . . . . 146

3.25 Kruskal-Wallis rank sum test (ANOVA) . . . . . . . . . . . . . . . . . . . . . 146

3.26 Mathematical definition for statistical histogram . . . . . . . . . . . . . . 156

3.27 Regression model . . . . . . . . . . . . . . . . . . . . . . . . . 158

3.28 Hierarchical clustering method (simple agglomerative approach) . . . . . . . . . . . . 161

3.29 Covariance matrix formula . . . . . . . . . . . . . . . . . . . . . 161

3.30 Kernel density estimator of the the probability density function . . . . . . . . . . . . . 162

3.31 Hierarchical dendrogram and clustermap algorithm WPGMA . . . . . . . . . . . . 164

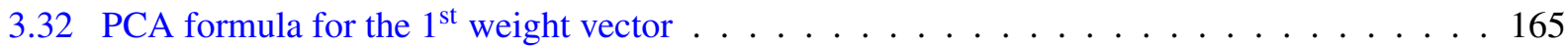

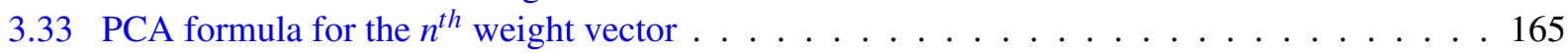

3.34 ANOVA definitional equation of sample variance . . . . . . . . . . . . . . 167

3.35 Computing Ordinary Least Square (OLS) … . . . . . . . . . . . . . . 171

3.36 QQ statistics calculation . . . . . . . . . . . . . . . . . . . . 172

3.37 Gauss-Newton algorithm for non-linear least squares problem . . . . . . . . . . . . . 175

3.38 Isotonic regression function of quadratic program . . . . . . . . . . . . . . 175

3.39 Simply ordered case for isotonic regression . . . . . . . . . . . . . . 175

3.40 Dynamic regression model (SARIMA) definition $\ldots \ldots \ldots \ldots \ldots$ 


\section{List of Figures}

3.3.1 Kuril-Kamchatka Trench: 2D histograms and rose diagrams of depths [409] . . . . . . 105

3.3.2 Kuril-Kamchatka Trench and Sea of Okhotsk: 3D histograms: depths distribution [409] 106

3.3.3 Middle America Trench: trend regression models for the cross-section profiles . . . . . 107

3.5.1 Kuril-Kamchatka Trench: Octave graph based on AWK-reshaped table, north [410] . . . 114

3.5.2 Kuril-Kamchatka Trench: Octave graph based on AWK-reshaped table, south [410] . . 115

3.8.1 Mariana Trench: boxplots on data distribution by profiles. R code: A.6.2 . . . . . . 121

3.8.2 Mariana Trench: violin plots on depth distribution by profiles. R code: A.6.25 . . . . 122

3.8.3 Mariana Trench: notched plots on depth distribution by profiles. R code: A.6.3 . . . . 122

3.8.4 Mariana Trench: KDE for the 25 bathymetric profiles, R code: A.6.19 . . . . . . . . . 123

3.8.5 Example of the regression analysis: Mariana Trench, selected profiles . . . . . . . . 123

3.8.6 Philippine Trench: Regression analysis of 25 profiles. Plotting: R code A.6.5 . . . . . 124

3.8.7 Four tectonic plates, trench slope angle in the deepest point . . . . . . . . . . . 126

3.8 .8 Multiple panel by groups: tectonic plates, depth by profiles . . . . . . . . . . . . . . . 127

3.8 .9 Mariana Trench: Ridgeline plots . . . . . . . . . . . . . . . . . . . . . . 128

3.8.10 Mariana Trench: ranking dot plots by data grouping, by R code: A.6.12 . . . . . . . 128

3.8.11 Mariana Trench: ranking dot plots by data grouping, by R code: A.6.14 . . . . . . . . 129

3.8.12 Pairwise double-Y axis charts showing correlation between factors . . . . . . . . . 130

3.8.13 Mariana Trench: ranking data for steepness variation, R code: A.6.22 . . . . . . . . . 130

3.8.14Mariana Trench: compositional chart of the geometry of the profiles, R . . . . . . . 131

3.8.15 Mosaic and silhouette plots for the Mariana Trench . . . . . . . . . . . . . . . . 132

3.8.16 Association plots for the Mariana Trench . . . . . . . . . . . . . . . . . 133

3.8.17 Mariana Trench: classification of the k-means clustering by plates, R code A.6.9 . . . 134

3.8.18 Mariana Trench: hexagonal data distribution, by $\mathrm{R}\{$ hexbin $\}$ library . . . . . . . . . 135

3.8.19Mariana Trench: Pearson and Spearman correlation matrices, by R code A.6.41 . . . . . 136

3.8.20 Mariana Trench: normalized steepness of the slope angles by profiles, R . . . . . . . 138

3.8.21 Mariana Trench: hierarchical dendrogram tree of the profiles, by R code: A.6.6 . . . . . 139

(a) Unsorted dendrogram . . . . . . . . . . . . . . . . . . . . . . 139

(b) Sorted dendrogram . . . . . . . . . . . . . . . . . . . . . . . 139

3.8.22 Mariana Trench: hierarchical clustering, R code: A.6.6 . . . . . . . . . . . . . . . 140

(a) Bootstrap resampling . . . . . . . . . . . . . . . . . . . . 140

(b) Bootstrap probability . . . . . . . . . . . . . . . . . . . . 140

3.8.23 Mariana Trench: scatterplot matrix of the correlation between variables. R. . . . . . . . 141

3.8.24 Mariana Trench: Factor Analysis, R code A.6.26 . . . . . . . . . . . . . . . . . . 143

(a) EFA correlation matrix . . . . . . . . . . . . . . . . . . . . 143

(b) iCLUST analysis . . . . . . . . . . . . . . . . . . 143

3.8.25 Mariana Trench: fragment of factor analysis, by R code A.6.26 . . . . . . . . . . . . 144

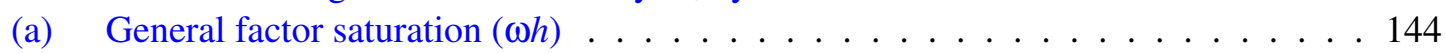

(b) General factor saturation through omega coefficient: 3 factors $\omega \ldots \ldots$. . . . . . 144 
3.8.26 Mariana Trench: ANOVA hypothesis testing, by R code: A.6.28 . . . . . . . . . . . . 146

3.8.27 Mariana Trench: Euler-Venn diagram, R code A.6.23 . . . . . . . . . . . . . . . . . 147

(a) Variables: tectonic plates . . . . . . . . . . . . . . . . . . . . . . 147

(b) Variables: geomorphology . . . . . . . . . . . . . . . . . . . . . 147

3.9.1 Mariana Trench: KDE of the bathymetric profiles, Python (Matplotlib and Seaborn) [428]148

3.9.2 Python-based word cloud (libraries: Wordcloud, Matplotlib) . . . . . . . . . . . . . . . 149

3.9.3 Mariana Trench: letter-value plot for data distribution by profiles, Python . . . . . . . 154

3.9.4 Mariana Trench: violin plots on depth ranges, Python, by code A.5.1 [415] . . . . . . 155

3.9.5 Mariana Trench: heatmap for the bathymetric data distribution by profiles. Python . . . 156

3.9.6 Mariana Trench: histograms of data distribution by tectonic plates. Python. Source: [421] 157

3.9.7 Mariana Trench: Euler-Venn diagrams, Python [415] . . . . . . . . . . . . . . 158

3.9.8 Mariana Trench: area chart and facet grid of the profiles, Python (Seaborn) . . . . . . 159

3.9.9 Mariana Trench: facet grid of the regression analysis of the profiles, Python . . . . . . . 159

3.9.10 Mariana Trench: hexagonal and KDE plots by profiles. Python code A.5.9 . . . . . 160

3.9.11 Mariana Trench: correlation matrices for bivariate analysis, Python . . . . . . . . . . 161

(a) Pearson's correlation (parametric approach) . . . . . . . . . . . . . . . . . 161

(b) Kendal rank correlation (non-parametric approach) . . . . . . . . . . . . . 161

3.9.12 Mariana Trench: box-and-whisker plot for data distribution by 25 profiles. [419] . . . . 162

3.9.13 Philippine Trench: KDE of the bathymetric profiles, Python (Matplotlib and Seaborn) . 163

3.9.14 Mariana Trench: stem plot of the slope gradient steepness by 25 profiles. . . . . . . . 163

3.9.15 Mariana Trench: hierarchical cluster dendrogram of the profiles. Python . . . . . . . . . 164

3.9.16 Mariana Trench: PCA of the sediment thickness by 25 bathymetric profiles, 3D view. . 165

3.9.17 Mariana Trench: 3D scatterplot of the relationships between environmental factors . . . 166

3.9.18 Mariana Trench: one-way ANOVA box plots . . . . . . . . . . . . . . . 167

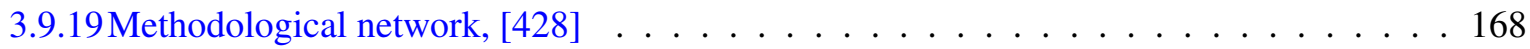

3.9.20 Mariana Trench: bathymetric patters visualized by stacked area charts. . . . . . . . . . 169

3.9.21 Mariana Trench: stacked bar plots on depths variations by profiles, Python. . . . . . . . 169

3.9.22 Mariana Trench: radar charts of the variation in bathymetric data . . . . . . . . . 170

3.9.23 Mariana Trench: stacked bar charts showing geological factors. Python. . . . . . . . . 170

3.9.24 Mariana Trench: pie charts of the bathymetric data distribution by tectonic plates. Python. 171

3.9.25 Plotted QQ statistics for the data distribution . . . . . . . . . . . . . . . 172

3.9.26Quantile regression plotted for sediment thickness $(\mathrm{m})$ versus geologic parameters . . . 173

3.9.27 Weighted Least Squares plotted for data distribution. . . . . . . . . . . . . . . . . . . . 174

3.9.28 Mariana Trench: isotonic regression for variables, Python [415] . . . . . . . . . . 175

3.10.1 Mariana Trench: selected bathymetric profiles. Plotting: $\mathrm{LT}_{\mathrm{E}} \mathrm{X}$. . . . . . . . . . . . . . 177

3.10.2 Mariana Trench: 3D-view of the 25 bathymetric profiles. Plotting: $\mathrm{LT}_{\mathrm{E}} \mathrm{X} \ldots \ldots$. . . . 177

4.2.1 Kuril-Kamchatka Trench: median stacked profiles . . . . . . . . . . . . . . . 186

4.3.1 Aleutian Trench: modeled trend curves of the relief of the mean cross-section profile. [370] . . . . . . . . . . . . . . . . . . . . . . . 192

4.3.2 Aleutian Trench: histogram chart on bathymetric data distribution by profiles. [370] . . 193

4.4.1 Middle America Trench: histograms of the samples distribution by cross-section profiles, [413] . . . . . . . . . . . . . . . . . . . . . . . . . . . 195

4.5.1 Peru-Chile Trench: profiles in Chilean (A) and Peruvian (B) parts [411] . . . . . . . 196

4.5.2 Peru-Chile Trench: histograms for the Peruvian and Chilean segments [411] . . . . . 197

4.6.1 Kermadec and Tonga trenches: geomorphological modelling. Source: [420] . . . . . . 198

4.7.1 Kermadec and Tonga trenches: models of slope gradient trends by profiles. Source: [420] 199

4.7.2 Kermadec and Tonga trenches: histograms of the bathymetric data distribution. [420] . 199 
4.10.1 New Britain and San Cristobal trenches: graph model of the cross-section profiles . . 203

4.11.1 San Cristobal Trench: modeled trends of the slopes gradient by profiles . . . . . . . . . 204

4.11.2 New Britain and San Cristobal trenches: histograms for bathymetric samples . . . . . . 206

4.12.1 Philippine Trench: faceted plot of the profiles. Plotting: QGIS . . . . . . . . . . . . . 208

4.12.2 Philippine Trench: strip plots by tectonic plates and geology, Python code A.5.5 [414] . 209

4.12.3 Philippine Trench: samples distribution by tectonic plates. Plotting: Python, and R [414] 210

4.12.4 Philippine Trench: correlation matrix of variables (Spearman method), Plotting: R [414] 211

4.12.5 Philippine Trench: ranking geomorphology of the cross-section profiles. Plotting: R [414]212

4.13.1 Manila Trench: transect of the digitized cross-section profilesh . . . . . . . . . . . 213

4.13.2 Manila Trench: histograms of the bathymetry . . . . . . . . . . . . . . . . 215

4.14.1 Ryukyu Trench: models of the slope gradient trends for the profile curves . . . . . . . 217

4.14.2 Ryukyu Trench: histograms of frequency of the depth distribution . . . . . . . . . . . 218

4.15.1 Yap and Palau trenches: geomorphological modelling of the profiles [412] . . . . . . 219

4.15.2 Yap and Palau trenches: statistical histograms on bathymetry [412] . . . . . . . . . 220

4.16.1 Yap trench: trend model of the slope gradient direction [412] . . . . . . . . . . . . . 221

4.17.1 Histograms on depths frequency: Mariana and Philippine trenches . . . . . . . . . . . 225

4.17.2 Mariana Trench: graph of the 25 bathymetric profiles, QGIS [415] . . . . . . . . . . . 226

4.17.3 Mariana Trench. Data distribution analysis: maximal depths by profiles, Python [415] . 227

4.17.4 Mariana Trench. Correlation, k-means Clustering and Data Grouping, R [422] . . . . . 228

4.17.5 Results of the $k$-means clustering of the Mariana Trench with different $k$-values, $\mathrm{R}$ [422] 229

4.19.1 Japan Trench: modeling geomorphic cross-section profiles . . . . . . . . . . . . . . . 234

4.19.2 Japan Trench: statistical analysis of the data distribution (histograms) . . . . . . . . 236

4.20.1 Comparative analysis on data distribution by Hikurangi, Puysegur and Hjort trenches . . 238

4.21.1 Geomorphic cross-sections by Hikurangi, Puysegur and Hjort trenches . . . . . . . . . 240

\section{List of Tools}

\section{Software and utilities used in the current work:} Main Tools:

- Generic Mapping Tools: used for cartographic mapping, modelling, automatic digitizing and spatial analysis.

- R: Programming language used for statistical analysis.

- Python: Programming language used for for statistical analysis.

- Quantum GIS: GIS used for mapping, digitizing, spatial analysis and cartographic visualization.

- AWK: Programming language used for tables reformating and reshaping.

- GNU Octave: Programming language used for statistical analysis.

\section{Auxiliary Tools:}

- ${ }^{\mathrm{AT}} \mathrm{T} \mathrm{E}$ X: used for document typesetting and formatting

- BibLTTEX: used for for management of bibliography and reference database

- Gretl: Gnu Regression, Econometrics and Time-series Library used for statistical analysis 
- SPSS: statistical software used for statistical analysis

- GIMP: graphics software used for auxiliary drawing 


\section{List of Maps}

1.0.1 Pacific Ocean: bathymetric map of the seafloor . . . . . . . . . . . . . . . . 2

1.1.1 Pacific Ocean: geologic map of main structures, GMT . . . . . . . . . . . . . 4

1.1.2 Pacific Ocean: tectonic structures and main lineaments on the seafloor, GMT. [376] . . . 6

2.1.1 Kuril-Kamchatka Trench and the Sea of Okhotsk: bathymetric map [418] . . . . . . . . 13

2.1.2 Kuril-Kamchatka Trench. Miscellaneous projections in GMT, [418] . . . . . . . . . . . 14

(a) Mercator oblique projection . . . . . . . . . . . . . . . . . . 14

(b) Conic projection . . . . . . . . . . . . . . . . . . 14

2.1.3 Kuril-Kamchatka Trench: 3D-topographic mesh map. Source: [418] . . . . . . . . . . . 15

2.1 .4 Kuril-Kamchatka Trench [418] . . . . . . . . . . . . . . . . . . . . . . . . . . . . . . . 16

(a) Geoid model with clipped land area . . . . . . . . . . . . . . . . 16

(b) Marine free-air gravity anomaly . . . . . . . . . . . . . . . . 16

2.1 .5 Kuril-Kamchatka Trench $[418] \ldots \ldots \ldots$

(a) Topographic map, GMT . . . . . . . . . . . . . . . . . . . . 16

(b) Gravity surface model, GMT . . . . . . . . . . . . . . . . . . . 16

2.2.1 Aleutian Trench: bathymetric map based on ETOPO1 grid, [370] . . . . . . . . . . . 18

2.2.2 Aleutian Trench: contour bathymetric map, [370] . . . . . . . . . . . . . . . . . . . . 19

2.2.3 Aleutian Trench and Aleutian Islands: geoid model map, [370] . . . . . . . . . . . . 19

2.2.4 Aleutian Trench and Aleutian Islands: 3D mesh grid model, [370] . . . . . . . . . . . 20

2.3.1 Middle America Trench: bathymetric map, ETOPO1 grid, [413] . . . . . . . . . . . . . 21

2.3.2 Middle America Trench: topographic contour map, [413] . . . . . . . . . . . . . . . . 21

2.3.3 Middle America Trench: map of geological settings . . . . . . . . . . . . . . . . . 22

2.3.4 Middle America Trench: vertical gravity model map, [413] . . . . . . . . . . . . . . 23

2.3.5 Middle America Trench: topographic surface map modeled by ASCII data, [413] . . . . 24

2.4.1 Peru-Chile Trench: bathymetric map, ETOPO1 [411] . . . . . . . . . . . . . . . 26

2.4.2 Peru-Chile Trench: geological map $[411] \ldots \ldots \ldots \ldots$

2.4.3 Peru-Chile Trench: geoid regional model $[411] \ldots \ldots \ldots \ldots \ldots \ldots$

2.4.4 Peru-Chile Trench: map of gravity surface model $[411] \ldots \ldots \ldots \ldots \ldots$

2.5.1 Tonga and Kermadec trenches: bathymetric map, ETOPO1 . . . . . . . . . . . . . . 30

2.6.1 Kermadec and Tonga trenches: transect segments; geologic and tectonic settings. . . . . 31

2.7.1 Vanuatu and Vityaz trenches: topographic map . . . . . . . . . . . . . . . . . 32

2.8 .1 Vanuatu and Vityaz trenches: geologic map . . . . . . . . . . . . . . . 33

2.9.1 New Britain and San Cristobal trenches: topographic map . . . . . . . . . . . . . . 35

2.10.1 New Britain and San Cristobal trenches: geoid model map . . . . . . . . . . . . . . 37

2.10.2 New Britain and San Cristobal trenches: geological and tectonic map . . . . . . . . . 38

2.10.3 New Britain and San Cristobal trenches: gravimetry model map . . . . . . . . . . . 38

2.11.1 Philippine Sea Basin: GEBCO based bathymetric map . . . . . . . . . . . . . . . . 39

2.11.2Philippine Sea Basin: Geologic map. . . . . . . . . . . . . . . . . . . . . 40

2.11.3 Geoid model of the Philippine Sea Basin (PSB) . . . . . . . . . . . . . . . . . . . 41 
2.11 .4 Gravity model of the PSB $\ldots \ldots \ldots \ldots \ldots \ldots$. . . . . . . . . . . . 42

2.11.53D relief model: Philippine Trench (south segment) . . . . . . . . . . . . . . . . 43

2.12.1 Manila Trench: bathymetric map, SRTM $15 \mathrm{sec}$ grid . . . . . . . . . . . . . . 45

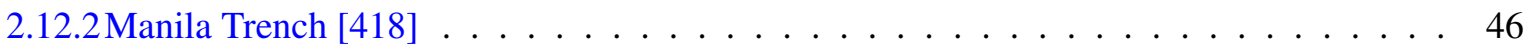

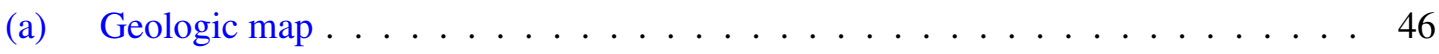

(b) Geoid model . . . . . . . . . . . . . . . . . . . . 46

2.12.3 Manila Trench: marine free-air gravity map . . . . . . . . . . . . . . . . 46

2.12.4 Manila Trench: 3D mesh map of the geomorphology . . . . . . . . . . . . . . . 47

2.13.1 Ryukyu Trench and Arc, East China Sea and Philippine Sea: bathymetric map . . . . . 48

2.13.2 Ryukyu Trench: geologic map, ETOPO1 . . . . . . . . . . . . . . . . . . . . . . 49

2.13.3 Ryukyu Trench: geoid map . . . . . . . . . . . . . . . . . . 50

2.13.4Ryukyu Trench: gravimetry map . . . . . . . . . . . . . . . . . . 51

2.13.5 Ryukyu Trench: 3D mesh geomorphological modelling . . . . . . . . . . . . 52

2.14.1 Yap and Palau trenches: geological map [412] . . . . . . . . . . . . . . . . . 53

2.14.2 Yap and Palau trenches: geophysical gravity map [412] . . . . . . . . . . . . . . . 54

2.15.1 Yap and Palau trenches: topographic map [412] . . . . . . . . . . . . . . . . 55

2.15.2 Yap and Palau trenches: geoid model $[412] \ldots \ldots \ldots \ldots$. . . . . . . . . 56

2.16.1 Mariana Trench: bathymetric map . . . . . . . . . . . . . . . . . . . 57

2.16.23D relief model: Mariana Trench, south segment . . . . . . . . . . . . . . . . . 59

2.16.3 Earthquakes event map at PSB area: prime hypocentres and magnitude values . . . . . . 62

2.17.1 Izu-Bonin Trench: bathymetric map . . . . . . . . . . . . . . . . . . . . . 64

2.17.2 Izu-Bonin Trench: geologic map . . . . . . . . . . . . . . . . . . . . . 65

2.17.3 Izu-Bonin Trench . . . . . . . . . . . . . . . . . . . . . 66

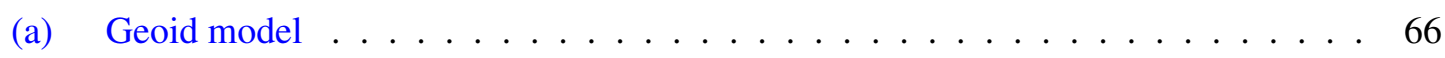

(b) Free-air marine gravity model . . . . . . . . . . . . . . . . 66

2.18.1 Japan Trench: topographic map . . . . . . . . . . . . . . . . . . . . 67

2.18.2 Japan Trench: geological map . . . . . . . . . . . . . . . . . . . . . . . 68

2.18.3 Japan Trench: geoid model map . . . . . . . . . . . . . . . . . . . . . . . . 69

2.18.4 Japan Trench: gravity model map . . . . . . . . . . . . . . . . . . 70

2.18.5 Japan Trench: 3D mesh model map of geomorphology . . . . . . . . . . . . . . 71

2.19.1 Hikurangi, Puysegur and Hjort trenches, New Zealand: GEBCO based topographic map 72

2.19.2 Hikurangi, Puysegur and Hjort trenches, New Zealand: geoid model . . . . . . . . . . . 73

2.20.1 Hikurangi Trench, New Zealand: tectonic and geological settings . . . . . . . . . . . 75

2.20.2 Hikurangi, Puysegur and Hjort trenches, New Zealand: Marine free-air gravity anomaly 76

3.1.1 Comparison of the resolution in datasets: GEBCO, SRTM, ETOPO1 and ETOPO5 . . . 79

3.3.1 North Pacific Ocean: contour map in the Orthographic azimuthal projection, GMT . . . 84

3.3.2 Landmask of the shorelines (land vs water areas), GMT _ . . . . . . . . . . . 85

3.3.3 Grid contour modelling by Nearest neighbor algorithm, KKT GMT . . . . . . . . . 87

3.3.4 Grid contour modelling by XYZ2grd algorithm, GMT . . . . . . . . . . . . . . 87

3.3.5 Seismic map of the focal mechanisms: PSB margins . . . . . . . . . . . . . . 88

3.3 .6 Velocity ellipses at PSB margins . . . . . . . . . . . . . . . . . . . . 92

3.3.7 Histogram equalization on the topography grids, ETOPO1 . . . . . . . . . . . . . . . 94

3.3.8 Histogram equalization on the topography grids, GEBCO . . . . . . . . . . . . . . 96

3.3.9 Kuril-Kamchatka Trench: map of geologic settings, [409] . . . . . . . . . . . . . . . . 97

3.3.10 Middle America Trench: geoid model . . . . . . . . . . . . . . . . . . . . . 98

3.3.11 Mariana Trench: color geoid image with grey-shaded topography of the clipped areas, GMT . . . . . . . . . . . . . . . . . . . . . . 99 
3.3.12 Middle America Trench: 3D topographic mesh model map . . . . . . . . . . . . . . . 100

3.3.13 Middle America Trench: gravity model map . . . . . . . . . . . . . . . . . . . . 102

3.3.14 Izu-Bonin Trench: Digitizing cross-section profiles . . . . . . . . . . . . . . 103

3.3.15 Middle America Trench: gravity surface map modeled by ASCII data . . . . . . . . . 108

3.3.16 Aleutian Trench: surface modelling from the ASCII xyz data. [370] . . . . . . . . . . . 109

3.3.17 Aleutian Trench and Aleutian Islands: gravimetry map. [370] . . . . . . . . . . . . 109

3.6.1 Mariana Trench: map of the profiles and fragment of the coordinates . . . . . . . 117

3.6.2 Philippine Trench: map and digitized cross-section profiles. QGIS . . . . . . . . . . 118

4.2.1 Kuril-Kamchatka Trench: enlarged view of the profiles . . . . . . . . . . . . . . . 187

4.3.1 Aleutian Trench: digitized cross-section profiles. [370] . . . . . . . . . . . . . . . . 191

4.3.2 Aleutian Trench: topographic surface modelling from the ASCII xyz data. [370] . . . . 193

4.4.1 Middle America Trench: cross-section profiles on the selected segment, [413] . . . . . 194

4.5.1 Peru-Chile Trench: digitized profiles of Peruvian and Chilean segments [411] . . . . . . 197

4.8.1 Vanuatu and Vityaz trenches: cross-section profiles map . . . . . . . . . . . . . . . 200

4.8.2 Vanuatu and Vityaz trenches: histograms of the cross-section profiles . . . . . . . . 200

4.9.1 Vanuatu and Vityaz trenches: digitizing cross-section profiles . . . . . . . . . . . . . 201

4.9 .2 Vanuatu and Vityaz trenches: 3D models . . . . . . . . . . . . . . . . . 202

4.11.1 New Britain and San Cristobal trenches: segments of the digitized profiles . . . . . . 205

4.12.1 Cross-section transect profiles: Philippine Trench . . . . . . . . . . . . . . . . . 207

4.13.1 Manila Trench: two segments of the digitized cross-section profiles . . . . . . . . . . 214

4.14.1 Ryukyu trench: cross-section profiles of the southern and northern segments . . . . 216

4.16.1 Yap and Palau trenches: digitized cross-section profiles [412] . . . . . . . . . . . . 222

4.16.2 Yap and Palau trenches: 3D mesh modelling [412] . . . . . . . . . . . . . . . 223

4.17.1 Cross-section transect profiles of the Mariana Trench . . . . . . . . . . . . . . . . . . 224

4.18.1 Izu-Bonin Trench: modeled graph of the cross-section profiles in two segments . . . . . 231

4.18.2 Izu-Bonin Trench: 3D mesh model map . . . . . . . . . . . . . . . . . . . 232

4.18.3 Izu-Bonin Trench: statistical histograms of the depth frequency . . . . . . . . . . . 233

4.19.1 Japan Trench: map of the cross-sectional profiles along two segments . . . . . . . . . 235

4.20.1 Puysegur and Hjort trenches, Macquarie Island Arc: Digitizing cross-section profiles . . 237

4.21.1 Hikurangi Trench, North Island, New Zealand: Digitizing cross-section profiles . . . . . 239 


\section{List of Tables}

1.1.1 Summary of the statistics on the 20 deep-sea trenches of the Pacific Ocean $\ldots \ldots \ldots$

3.1.1 Data sources, types and precision . . . . . . . . . . . . . . . 80

3.2.1 Software and tools used in dissertation . . . . . . . . . . . . . . . . . . 81

3.3.1 Earthquake events for $1976 / 1977 \ldots \ldots \ldots$

3.3.2 Magnitude and Moment Tensor . . . . . . . . . . . . . . . . . . . . . . . . . . 91

3.4.1 GMT-derived table for the Cross profile \#1 . . . . . . . . . . . . . . . 110

3.4.2 AWK-based reshaped table (fragment): location and depths (m) for the first 10 profiles . 112

3.7.1 Types of the statistical analysis used by Python and R libraries . . . . . . . . . . . . . 119

3.8.1 Algorithms of the descriptive statistical analysis . . . . . . . . . . . . . . . . . . 120

3.8.2 Statistical algorithm of clustering, R code: A.6.9 . . . . . . . . . . . . . 133

3.9.1 Advantages of Python language for geo data analysis and processing . . . . . . . . . 149

4.1.1 Mariana Trench: variations in gradient steepness of the right flank . . . . . . . . . 181

4.1.2 Mariana Trench: variations in gradient steepness of the left flank . . . . . . . . . . . . 181 


\section{Document Outline}

The content of dissertation: 104 maps, 101 Figures, 13 Tables, 40 listed equations, 937 cited references, in total 436 pages. The structure consists of 10 main chapters:

- Chapter 1: Introduction summarizing the scope, goal and aim of the research. Background section presents research focus and object (20 hadal trenches). Existing works are reviewed and discussed, research gap identified, problem formulated. Research objective gives the direction of the study divided by general objective (geospatial analysis) and specific objective (technical approaches). Research questions and hypothesis underline the introductory chapter. Abbreviations are introduced in the List of Acronyms.

- Chapter 2: Study Area (trenches of the Pacific Ocean). It gives a review of each of the 20 trenches of the Pacific Ocean presenting study area, geographic and geological settings, depicts geomorphic features of the trenches based on the existing research.

- Chapter 3: Methodology and Data. It describes used data, workflow of the GMT, R, Python, AWK and Matlab scripting algorithms. The functionality of the applied tools is discussed, graphical output presented as graphs, diagrams and charts. Mathematical algorithms used in statistical data modelling and Geographic Information System (GIS) are presented and listed in the List of Equations. Tables summarizing statistical approaches and methods are presented in the List of Tables. Graphs and Maps are listed in the List of Figures and List of Maps. Full programming codes are provided in the Appendix A. Advanced solutions of GMT toolset enabling high quality mapping by various cartographic techniques are discussed and described.

- Chapter 4: Results of the work: classification and comparison of the geomorphology of the 20 hadal trenches used by GMT, R and Python statistical methods. The results are presented as a series of the thematic maps of geological and geophysical visualization of the 20 trenches of the Pacific Ocean and their geomorphic modelling.

- Chapter 5: Discussion obtained in this research and discusses findings in geostatistical analysis by $\mathrm{R}$ and Python. Besides, this chapter provides a detailed interpretation of the results suggesting impact factors affecting trench formation.

- Chapter 6: Conclusion on the undertaken research. It concerns the effects of the impact factors that influence geomorphic structure of the ocean trenches. In a global summary, it reflects the perspectives of the geostatistical analysis in marine geology, using GMT and programming languages in marine geology. The dissertation ends by providing recommendations for further studies and discussing perspectives and further outlook for similar research. 


\section{Chapter 1}

\section{Introduction}

7 HE focus of this dissertation is oceanic trenches, the deepest areas of the Earth. Specifically, study object are 20 deep-sea trenches located along the margins of the Pacific Ocean (Fig. 1.0.1), Tab.

1.1.1. Worldwide, deep-sea ocean trenches are mostly formed in the locations of the subduction zones of plate, along which lithospheric tectonic plates subduct one under another. Geomorphological shape of the deep-sea trenches is highly variable (V-shaped, U-shaped, elongated to upside-down-ridgelike, circular-like, arcuate, symmetric of irregular: left- or right-sided), which is often related to the prevailing tectonic plate movements, geologic regime and substrate.

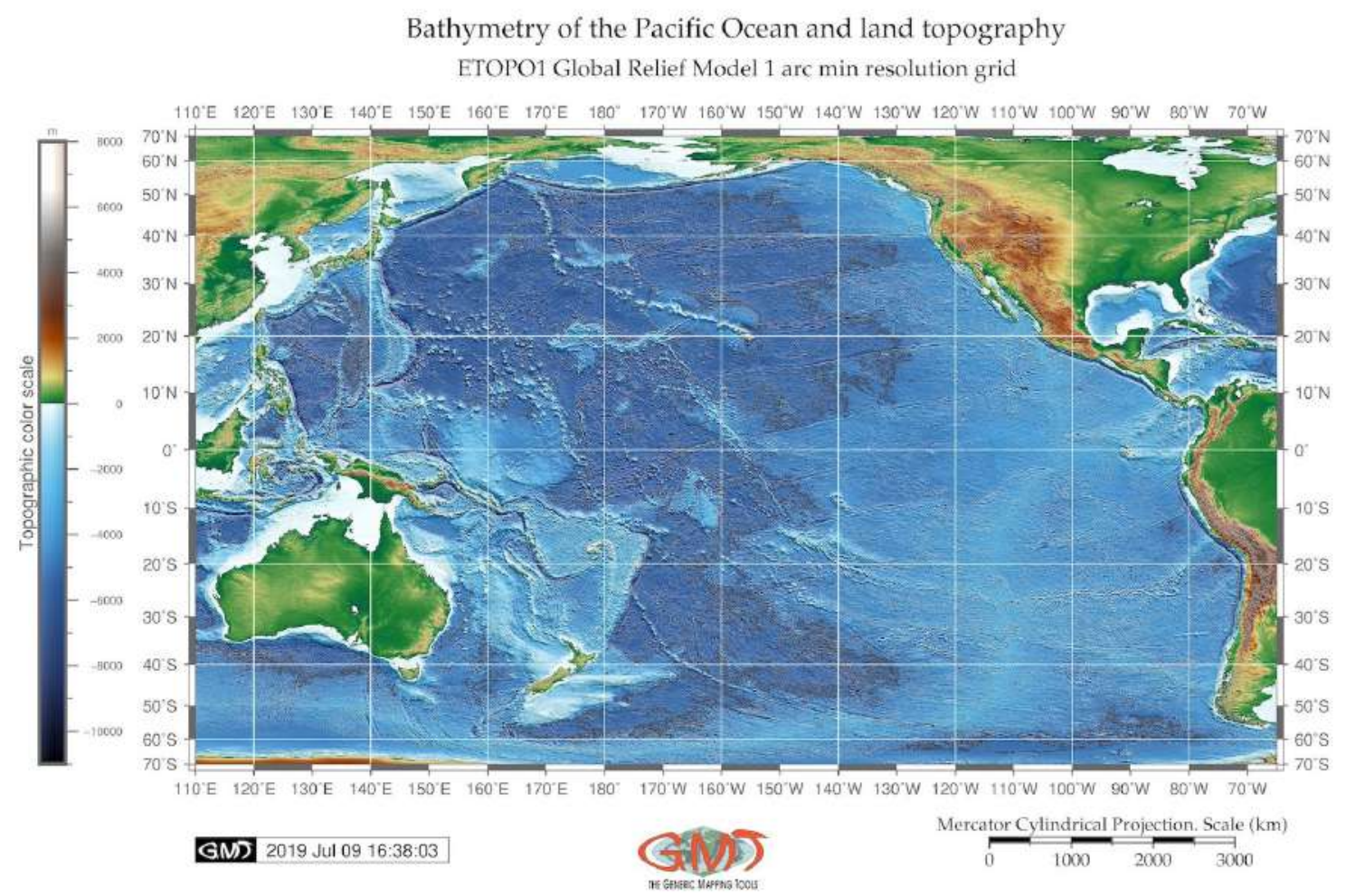

Map 1.0.1: Pacific Ocean: bathymetric map of the seafloor

Due to the specific geological conditions, oceanic trenches have unique structure and features formed as a result of the complex process. Morphologically presented as long, narrow, steep-sided depressions in the ocean bottom, trenches typically occur in the maximum oceanic depths, ca 7,300 up to $>11,000$ 
$\mathrm{m}$. There is a range of the factors influencing trench structure and formation: bathymetry, geography, geology and tectonics with complex interconnections among these determinants. The is focused upon comparative analysis of variability in geomorphological structure, classification of the cross-section profiles and formation of the 20 deep-sea trenches. The work continues investigations of the geology of the Pacific Ocean and highlights interplay between geomorphic, geological, tectonic and volcanic factors affecting submarine landform formation.

Remote location and complex bathymetry necessarily arises a need for the ML GIS approaches to visualize, model and map seafloor at such depths, to visualize and compare the geomorphology of the trenches and to assist in the development of the effective cartographic methods, technical tools and accurate datasets for submarine mapping contributing to our better understanding of the seafloor. This dissertation focuses on the comparative analysis of the submarine geomorphology of the trenches located in the Pacific Ocean by means of data processing, visualization mapping and modeling through GMT shell scripting, $\mathrm{R}$ and Python languages.

According to the International Hydrographic Organization (IHO) classification, trenches are 'long narrow, characteristically very deep and asymmetrical depressions of the sea floor, with relatively steep sides' [272]. The innovativeness of the work consists in the multi-disciplinary approach combining GIS analysis and statistical methods of $\mathrm{R}$ which contributes towards studies of ocean trenches, aimed at geospatial analysis of big data. Modelling patterns of the correlation between the geomorphic and geological features of the seafloor of the trenches is critical for proper ocean modelling.

Mapping deep-sea trenches has always been constrained both by their remote location and by a lack of high-quality bathymetric datasets on the seafloor. However, converging Earth observation advances (e.g. GEBCO, 1 Arc-Minute Global Relief Model of Earth's topography (ETOPO1) datasets) and Information Technology (IT) technologies enable accurate mapping and modelling of the least reachable objects of the seabed over wide areas of the seafloor in hadal trenches. Utilization of the statistical approaches for comparative analysis of the trenches geomorphology enables to compare variations between their shape form and highlight different submarine landforms.

Rapidly developing IT methods has revolutionized seafloor mapping, enabling to collect contextual information for visualization of the bathymetry and thereby established the knowledge base for marine geo-science. Current dissertation contributes towards advancing of the marine geo-science through report detailing of the mapping of oceanic trenches.

In this framework, following key questions were addressed: which depths of the seafloor are the most repetitive for each of the trenches and how can knowledge on geological and tectonic settings be used to explain variations in their geomorphology. Large study area and limited datasets available to perform the study determined that these questions had to be answered through mapping and characterization of the cross-section modelling performed via GMT, QGIS, Python and R.

The geomorphology of the oceanic trenches has been mapped and visualized insufficiently detailed comparing to the terrestrial areas the Earth, due to the complex submarine relief and the technical difficulties of seafloor observations. However, rapid development of new cartographic techniques, advanced methods of data modelling and visualization contributed to the progress in mapping and interpretation of the submarine geomorphology. Deep-sea trenches are mostly present a V- or U-shape in their crosssection profiles, yet can be more complex in form: trough-form, asymmetric, oblique, displaying riverinelike geometric system in a plain 2D (Fig. 4.12.1 and Fig. 4.17.1), oblique or 3D view (Fig. 2.11.5 and Fig. 2.16.2). Generally, trench geomorphology vary in slope steepness, curvature and depths. 


\subsection{Background}

\subsubsection{Submarine geomorphology}

Ceanic trenches present a complex system with highly interconnected factors: geology (sediment thickness and tectonics including tectonic plates), bathymetry (coordinates, slope angle, depth values in the observation points) [400]. There are various geodynamic processes that influence tectonic rift dynamics and structure as well as and rifted margin geomorphology. Currently, the interest towards the geodynamics, the drivers and consequences of these processes was implemented as a key target goals of the oceanographic research in China [117]; [118]. Knowing and proper understanding of the driving factors affecting the ocean ecosystems gives an understanding of the possible dynamics, accumulation and location of the target ocean resources that are crucial for the economic development.

Geomorphological evolution of the oceanic trenches in the Pacific Ocean is largely controlled by a variety of factors including geological settings, tectonic plate movements [180], [202], [432], geophysical processes [580], [221], [666], submarine volcanism [589], [433], inducing intensity of sedimentation [400] and marine biological factors contributing to the sediment supply. Earlier studies on oceanic trenches highlighted relationship between the geomorphic patterns of the deep-sea channels, submarine fans and their topography related to the mid-ocean ridge tectonics, volcanism and dynamics, for instance of the Philippine back arc [542]; [90]; [181]; [221]; [220], as well as earthquakes and gravitation [498].

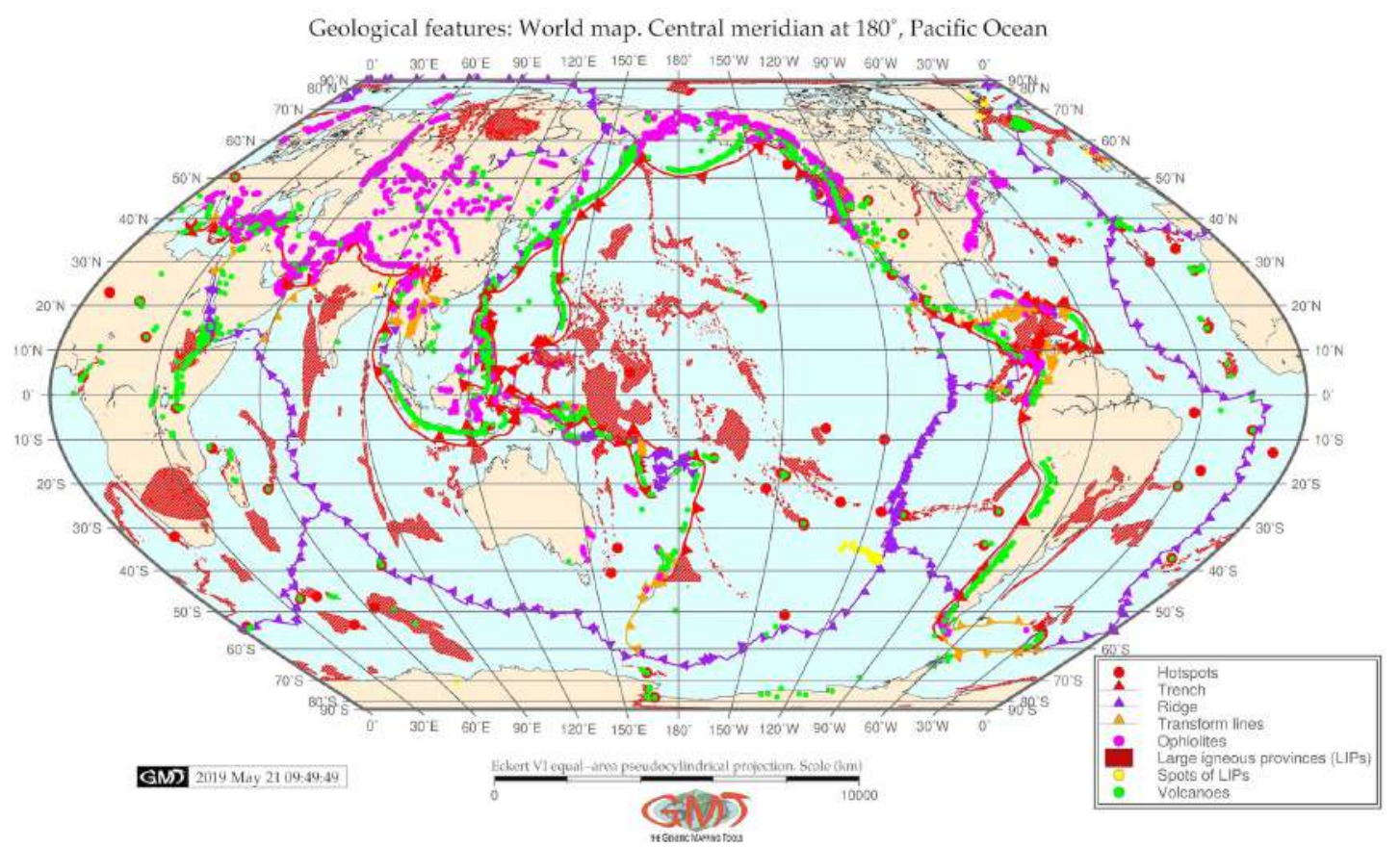

Map 1.1.1: Pacific Ocean: geologic map of main structures, GMT

The seafloor of the trench presents a background for all geological, oceanological and geochemical processes that are necessarily reflected in its shape. Understanding bathymetry of the ocean is crucial for the marina geological research. As noted by [132], the distribution of elevations on the Earth or hypsography is highly uneven. The majority of depths is occupied by deep basins (4-6.5 km) covered with abyssal plains and hills, while seafloor with ranges $2-4 \mathrm{~km}$ depth mostly consists of oceanic ridges and in total cover about $30 \%$ of the total ocean seafloor. Finally, the shallow areas and continental margins with $2 \mathrm{~km}$ depth and shallower cover only the least amount of area: $15 \%$ of the seafloor [508]. 
Finally, valley, seamounts, and submarine canyons are only the minor features of the seafloor. Given the importance of the deep-sea areas, study of trenches geomorphology with regards to the bathymetry is clear.

Table 1.1.1: Summary of the statistics on the 20 deep-sea trenches of the Pacific Ocean

\begin{tabular}{|c|c|c|c|c|}
\hline $\mathrm{No}$ & Name & Max. depth (m) & Length $(\mathrm{km})$ & Width $(\mathrm{km})$ \\
\hline 1 & Aleutian & 8,109 & 3,400 & 59 \\
\hline 2 & Mariana & 11,022 & 2,550 & 59 \\
\hline 3 & Philippine & 10,540 & 1,320 & 65 \\
\hline 4 & Kuril-Kamchatka & 10,542 & 2,900 & 59 \\
\hline 5 & Middle America & 6,669 & 2,750 & 34 \\
\hline 6 & Peru-Chile & 8,065 & 5,900 & 64 \\
\hline 7 & Palau & 8,080 & 700 & 47 \\
\hline 8 & Japan & 8,513 & 800 & 59 \\
\hline 9 & Kermadec & 10,047 & 1,200 & 88 \\
\hline 10 & Tonga & 10,882 & 1,375 & 78 \\
\hline 11 & Izu-Bonin & 9,810 & 2,800 & 82 \\
\hline 12 & New Britain & 9,140 & 335 & 70 \\
\hline 13 & San Cristobal & 9,020 & 742 & 64 \\
\hline 14 & Manila & 5,400 & 648 & 76 \\
\hline 15 & Yap & 8,946 & 500 & 45 \\
\hline 16 & New Hebrides & 7,600 & 1,200 & 34 \\
\hline 17 & Puysegur & 6,300 & 835 & 65 \\
\hline 18 & Hikurangi & 3,750 & 342 & 95 \\
\hline 19 & Vityaz & 6,000 & 413 & 47 \\
\hline 20 & Ryukyu & 7,790 & 2,250 & 38 \\
\hline
\end{tabular}

This dissertation aims at geomorphological modelling, systematic mapping, spatial analysis and classification of the 20 oceanic trenches of the Pacific Ocean (Tab. 1.1.1). There are many attempts undertaken to understand, to what extent and how do the geophysical movements in the subduction zones affect the trench geomorphology, deformation and migration, [136]; [169]; [203]; [257]; [490]. General concepts and understanding of the functioning and current problems in research directions of the deep-sea trenches were implied in the current thesis.

The actuality of the studies of the ocean seafloor cannot be underestimated. Recent progress in modelling and predicting earthquakes and tsunamis in Pacific ocean are base don the data analysis applied for submarine regions [335]. For example, using global datasets of broadband and long-period seismograms, recorded as a time series ranging 2006-2014 from Incorporated Research Institutions for Seismology (IRIS), a clear descendance in the morphology of the Pacific Plate was detected, which becomes flatten at the base of the upper mantle [137]. Moreover, application of the geodynamics data related to the tsunami, its possible reasons and consequencs, are presented recently reporting that the shallowest reaches of plate boundary subductions host substantial slips that generate large and destructive tsunamis [273]. Attempts towards studies of the ocean geomorphology, dynamics and intercorrelation between 
various factors affecting its functioning are given by various research, [531]; [535]; [521]; [516].

\subsubsection{Seafloor spreading}

S eafloor spreading creates an axial rift and corrugated hills. Spreading ridges are formed by nearby faults where subduction of the cooled tectonic plate into the mantle causes creation of the deep ocean trenches usually accompanied by earthquakes. Subduction of the cooled plate into the mantle causes creation of the deep ocean trenches and here major earthquakes and tsunamis originate.

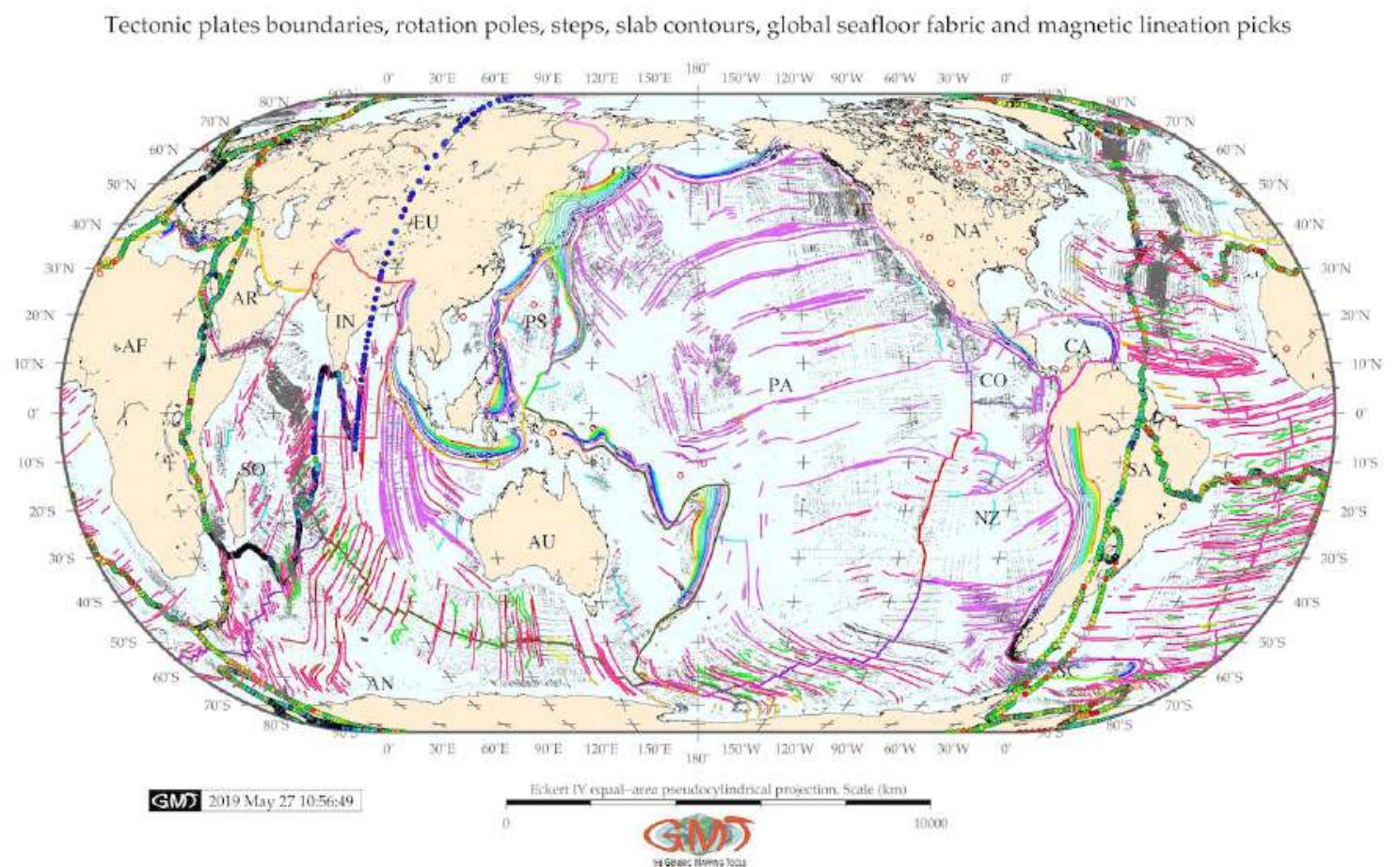

Map 1.1.2: Pacific Ocean: tectonic structures and main lineaments on the seafloor, GMT. [376]

There are 20 deep-sea trenches of the Pacific Ocean (Tab. 1.1.1), including major and minor ones. The classification of the tectonic plate boundaries according to their cross-correlation with the kinematical and geometrical properties of the plate boundaries should reflect their geodynamics. Previous works discussed a problem of the slab movement around the trench [180]; [183]; [239]. Bathymetric patterns of the seafloor of the Pacific Ocean (1.0.1) show more complex and deep structure in its western part. The geologic structure of the Pacific Ocean has a complex character (Fig. 1.1.1), [376]. Global seafloor fabric, magnetic lineation picks, slab contours and tectonic plates boundaries are presented on Fig. 1.1.2.

\subsubsection{Historical milestones}

The history of the studies of ocean geomorphology is being constantly developing throughout the $20^{\text {th }}$

century until now. The chronology of the landmark research include, for instance: [121]; [233]; [673]; [235]; [3]; [314]; [205]; [42]. Understanding a variety of landforms in submarine geomorphology is a very complex task that ideally include a combination of the multi-disciplinary approaches: spatial data visualization, geostatistical analysis, geological modelling, etc.

The question of the formation and structure of the ocean trenches has long attracted science [543]; [551]. A variety of research has been done in various aspects of the trenches: bathymetric measurements, 
to assess the volumes of mineral resources in the abyss, analysis of the pelagic and biotic communities, predicting earthquakes location and frequencies. Nowadays, sound statistical methods are elaborated as important additions for traditional GIS methods of geospatial analysis of the deep ocean trenches.

$20^{\text {th }}$ century is notable for systematic ocean exploration using Remote Sensing (RS) methods, Quantum GIS (QGIS) tools for data processing and a variety of the ML tools for data post-processing and statistical analysis. Many attempt of seafloor mapping and monitoring exist so far [84]; [271]; [354]; [574] and the advances in marine seafloor mapping are constantly developing. Mapping submarine geomorphic features and understanding factors of their variability centers several important components in the development of marine geology. $1^{\text {st }}$, support spatial marine observations and management; $2^{\text {nd }}$, supporting environmental monitoring of the oceans; $3^{\text {rd }}$, generating knowledge of the Earths shape; $4^{\text {th }}$, economic monitoring and evaluation of the natural resources in the deep ocean that has a strategic aim of planning.

Rapid recent development of the IT technologies in $21^{\text {st }}$ century enabled to analyze geological and oceanological stream data in large quantities which facilitates the studies of the marine geomorphology. In $21^{\text {st }}$ century, the advantages of the application of modern IT technologies for marine geology include, above all, the possibility to apply programming languages for data analysis. A multi-disciplinary approach includes GIS geospatial analysis, algorithms of the data analysis provided by the scripting libraries of high-level programming languages, such as Python and R.

In the last 2 decades along with recent progress of the programming and ML, many research presented applications of Python and R. By testing functionality of packages, algorithms and methods, these works challenged data science and brought about a new field of study in geosciences. However, examples of the geological studies on ocean trenches mostly focus on slab subduction and tectonic plate movements [219]; [58]; [304]; [221]; [61]; [256]; [163], yet insufficient use of the programming applications, and mostly apply GIS methods [164]; [509]. Therefore, in marine geology domain, despite obvious importance of the linkage between GIS and programming languages, enough case studies are not yet available. Current thesis contributes to fill in this gap.

\subsubsection{Importance}

$\mathcal{A}$

dvanced data computing and processing by a combined approach of the advanced scripting tools for data analysis (GMT, Python, R, Matlab, AWK) in marine geology is a promising dynamically developing extension of the existing traditional GIS. Shell scripting and programming languages enable to deal with massive amounts of the geological data. Batch processing of big geological datasets is possible through applying ML methods from the IT domains. Number of use cases in processing big data sets in the marine geology is increasing since they are produced in a machine-generated stream at cruise as output of sampling series massive as data arrays and captured streams of video and imagery.

The advantage of the numerical computing by programming languages lies in its effectiveness for the marine geology, specifically, its effectiveness and functionality when processing with big datasets. The ML tools are highly effective for processing arrays and tables containing data of thousands of samples. Correlation between various parts of the submarine geomorphology is very complex. For example, there are proven correlations between geographic locations of the trenches, shapes, geophysical settings and submarine geomorphology [539]; [650]; [297]; [304]; [305].

The value of the big data in marine geology is indisputable nowadays since larger datasets increase reliability and precision. However, the question is not about the need for the massive data processing and their storage but in how to manipulate effectively with big structured datasets, which ML algorithms and methods to apply for stream data processing in marine geology. Effective answer to these questions is given by programming algorithms that enable to process data arrays by complex approaches. As demonstrated in this dissertation, graph-based analysis of the geological data models by GMT, Python, $\mathrm{R}$ and Matlab with table reshaping by AWK enable to process data as a stream through shell scripting. 


\subsection{Research problem}

The problem of proper understanding of the deep-sea areas in the ocean seafloor lies in its unreach-

able location. As noted by [290], there is a need to evaluate and proper understanding seafloor geomorphology for marine resource management. However, current knowledge on ocean functioning is relatively scarce. At the same time, modeling ocean seafloor is critical for the precise bathymetric mapping. The majority of the methods of ocean modelling have overlooked the Python programming approach for statistical analysis where large data sets are being processed by a set of the embedded mathematical algorithms.

Various papers reported problems of deep ocean slab dynamics, tectonics, [577]; [240], deep ecosystems functionings and development [634]; [586]; [111]; [103]; [635]. Many attempts have been made so far to study correlation between factors involved in trench formation. However, there are certain limitations in these studies caused by the study object: submarine trenches are the least reachable land form on the Earth that require application of advanced numerical modelling.

Besides, submarine erosion occurring within the main channel of the trench and adjusting slope areas, plays important role in sculpting geomorphology of the trenches. Due to their physical inaccessibility, oceanic trenches are distinct from other objects on the Earth. Various studies are reported on the geologic variations of the trench involving uneven distribution of various geomorphic phenomena across the seafloor [544]; [208]. Amongst these, the question of how the trench shape varies and what are the factors affecting its geomorphology is the most challenging in view of the importance of the deep segments for the whole ocean environment. The distribution of elevations on the Earth or hypsography is highly uneven. The majority of the depths is occupied by deep basins $(4-6.5 \mathrm{~km})$ while relatively few areas are covered by shallow zones. At the same time, a considerable pool of resources is hidden by the ocean depths which explains the actuality of the ocean research for the national economies.

Limitations in marine geological studies are imposed by the high cost of the marine expeditions. Using available open source geodata sets removed this problem by the use of low-cost geospatial data and their processing in GIS and open source programming language R and Python. Similarly, Python based statistical set of statistical libraries, such as Numerical Python (NumPy), Scientific Python (SciPy), Statistical Models (StatsModels), and Matplotlib present effective low-cost and easily available method for the marine oceanological data processing and modelling. Multiple approaches and GIS methods have been used so far to model ocean seafloor, the most unreachable part of the Earth. These include: RSecho sounding [688], Conductivity-Temperature-Depth profiler (CTD) technique [704], acoustic methods, continual profiling with single-beam systems and bottom coverage capability, multi-beam swathmapping systems, computer based modeling.

Regional studies of the marine geology of the trenches across the Pacific Ocean, [46]; [67], modelling and predictions made upon analysis of the geophysical settings of various trench, produced by these investigators were instrumental in understanding current issues of the marine geological studies. The concepts of these reports on seafloor spreading, tectonic slab subduction, continental drift, and plate tectonics in the Pacific Ocean were analyzed in the current research.

Understanding deep connections between various factors of the ocean trenches gives a key to proper modelling of the location of the mineral resources and prognosis of the dynamic processes, e.g. earthquakes. Studies of such complex objects require numerical approach. Solutions proposed by the advanced data processing proved to be effective tool for the analysis of the data sets in marine geology. For instance, linking raster datasets and geologic data on tectonic spreading lineaments with seafloor processes eventually shaping present bathymetric forms, it is possible to interpolate geomorphology patterns to the large scale to provide a framework in which a detailed seafloor mapping can be performed. Therefore, the importance of the precision in numerical computing for marine geology cannot be underestimated. 


\subsection{Research gap identification}

This dissertation aimed to fill the gap in classification and systematic mapping of the deep-se trenches

of the Pacific Ocean. Technically, the gap consists in lack of multi-disciplinary research combining programming and Earth sciences research by demonstrating the advantages of the programming languages (e.g. Python, R, AWK) in marine geology. This work introduces application of such advanced data analysis applied to studies of the submarine geomorphology. Novelty of this approach consists in highlighting functionality of the high-level languages, Python and R, and applicability of the ML algorithms in marine geology, doing a step apart from the use of traditional GIS.

Methodologically, this dissertation contributed to fill in the gap in the fields by connecting ML analysis in marine geological data analysis with geomorphological analysis, gradient modelling and classification. Technical application of GMT, Python and R was performed to identify key algorithms assisting in geomorphological analysis. It advanced methodological testing of combination of several programming languages with GMT in marine geology with a case study of 20 trenches of the Pacific Ocean. Algorithms applied for the marine geological data set enabled to gain insights into the seafloor geomorphology. Statistical methods and advanced ML graph-based data analysis has a broad applicability to similar research aimed at modelling landform variations.

Practical purpose of this dissertation is to test statistical libraries of Python and $\mathrm{R}$ for geospatial data analysis, modeling and visualization and GMT shell scripting for geomorphological modelling. Effective and precise plotting demonstrates indisputable advantages of the ML in geology. Application of the programming significantly increases precision, speed and effectiveness of the data analysis. Accurate cartographic visualization of the datasets is crucial for proper classification, highlighting correlations and detecting dependancies such as geology, bathymetry, oceanography, tectonics. Precise mapping by means of GMT is strongly recommended for further application in marine geological studies, especially for analysis of geomorphology of the oceanic trenches.

Rapid development of methods in geospatial data processing recently grown in marine geology. However, use of high-level programming languages still require special focus and attention as lacking comprehensive introduction of the ML algorithms. Current state of research in geology includes methods supported mainly by GIS. While some work fragmentary include Python scripts as plugins embedded in GIS, relatively few works use programming in full [680]. On the other hand, supporting GIS methods by computer modelling contributes significantly towards understanding of the ocean trenches.

Hence, this dissertation has both scientific and practical implications for understanding spatiotemporal rates of the interplay between various factors affecting submarine structure of the trenches of the Pacific Ocean. Geomorphic modelling and comparative assessment of the bathymetry between major deep-sea trenches of the Pacific Ocean based on the automatic cross-section transecting and analysis of their geological, geophysical and tectonic settings, enables to highlight differences between their local structure and to visualize how their morphology vary in different segments.

The relationship between submarine geomorphology, bathymetry and tectonic settings of the trenches can be derived by comparing geomorphic features (e.g. slope steepness) and geological conditions (sedimentation) [400]. Variations in structure of the submarine geomorphology have origin in the palaeologic geological time caused by the variety of impact factors [671]. To evaluate relationships between factors affecting morphology of the trench, methods of the advanced modelling and statistical analysis can be applied [302]; [702]. Examples of the studies on correlation between various factors influencing ocean functioning are presented [547]; [666]; [205]. They aim to analyze the interconnections between geology, sedimentation and ocean landforms using available methods. 


\subsection{Research objective}

\subsubsection{General objective}

- To analyze variations in geomorphological shape of the submarine geomorphology in 20 deep-sea trenches of the Pacific Ocean.

- To perform classification of the geomorphological types of the 20 deep-sea trenches based on their geometric properties, distinctness and similarities

The thesis aims at the analysis of the variation of the geomorphology of the 20 trenches of the Pacific Ocean in their various segments based on the applied statistical analysis supported by GMT, Octave, Python and R libraries.

\subsubsection{Specific objectives}

- To visualize and map local geological properties of the 20 deep-sea trenches based on the available datasets

- To visualize and map geophysical properties (marine free-air gravity and geoid model) of the 20 deep-sea trenches based on the available datasets

- To use methods of the advanced programming algorithms (Python and R) in order to receive models of the correlation between geological factors and trench geomorphology

- To apply GMT modules to systematically model cross-section identical profiles for 20 trenches for geomorphological comparative monitoring of their geometry

- To perform statistical analysis of the bathymetry for the 20 respective trenches, along the margins of the Pacific Ocean.

Combined application of the advanced tools of data analysis (Python, R, GMT, Octave, AWK) for the data analysis and modelling reveals a significant unevenness in the geomorphology in trenches along the margins of the Pacific Ocean, and a correlation between the geological factors affecting its structure.

\subsection{Research questions}

This study answers three questions aimed to describe and characterize variations and perform classification in the geomorphic types of the 20 tenches located along the margins of the Pacific Ocean, using advanced methods of data analysis (GMT, R, Python, AWK). To systematically record the cross-section profiles of the trenches and assess their geological, tectonic, geographic, oceanological and bathymetric settings, a combination of the statistical methods, GIS and programming were applied [417]. Hence, the research questions of this dissertation are as follows:

- Are deep-sea trenches distinct in geomorphology with varying in-situ geological and geographic conditions along the margins of the Pacific Ocean?

- What are the factors affect the geomorphology of the trenches and which of them are the most influencing ones?

- What classification of the geomorphic shape forms in plan (orthogonal) view can be suggested for the trenches of the Pacific Ocean? 


\subsection{Hypothesis}

$\mathcal{F}$ or research question 1 the Hypothesis Ho claims: geomorphic types of the deep-sea trenches are not distinct from each other and independent with varying geographic location along the margins of the Pacific Ocean, which means Ho1: $\mu 1=\mu 2=\mu 3=\ldots=\mu n$. The alternative Hypothesis Ha claims the opposite statement: geomorphic types of the deep-sea trenches are distinct from each other and vary according to their geographic location (NSWE) along the margins of the Pacific Ocean, Ha1: $\mu 1 \neq \mu 2 \neq \mu 3 \neq \ldots \neq \mu$.

For research question 2 the Hypothesis Ho claims: geophysical, geological, bathymetric and geodetic information extracted from the attribute features of the GIS layers may explain interplay between the geomorphic variations of the selected hadal trenches located in the Pacific Ocean, which contains all aspects of interconnections of mentioned above geospatial factors, which means Ho2: $\mu 1=\mu 2=\mu 3=$ $\ldots=\mu n$. The alternative Hypothesis Ha claims the opposite statement: information on geophysical and geological settings of the trenches cannot be used for the comparative mapping and analysis of the geomorphology of the trenches, because they do not provide enough thematic information and correlation to discriminate types of the submarine landforms, $\mathrm{Ha} 2: \mu 1 \neq \mu 2 \neq \mu 3 \neq \ldots \neq \mu n$.

For research question 3 the classification of the trenches has been performed based on the comparative analysis of the similarities and distinctiveness between the geometric shape forms and steepness by profiles. Central hypothesis of this research is: factor variables of geological origin or geospatial factors (i.e., geodetic location of the segments of the trench and tectonic properties of the underlying plates) explain variations of the geomorphology of the deep-sea trench. Hence, the hypothesis considered in the research objective where a set of the geological settings was explored by a GIS dataset.

A statistical testing by $\mathrm{R}$ and Python has been used used to compare between various factors and geomorphic responses of the trenches, whether they are geomorphologically distinct and at least one pair of factors (slope steepness, geographic location, depths, tectonic plates, closeness of the submarine volcanoes, slope aspect) is statistically different and affecting trench geomorphology. One sample data set covers environmental factors of the trenches (i.e., geology, tectonics, geodetic features (descriptive statistical data on depths across the profiles), geospatial locations, sediment thickness [400] and active volcanism in the nearby area. Second sample data set is aimed to prove the hypothesis and perform comparative analysis on geomorphic and geological domains.

Variations of the factors affecting trench geomorphology is assumed to be normal as well as the equality of the statistical variances. The hypothesis testing was carried out using the ANOVA statistical test. The ANOVA test was performed by R library $\{\mathrm{car}\}$. Thus, the key hypotheses of the research will be tested to prove whether the results of the research are accurate, reasonable and correct. The results have been interpreted on homogeneity of variance by means of one - way ANOVA tests. Since the p-value is $<$ the significance level 0.05 , there are significant differences between the groups of tectonic factors affecting trench formation. Tukey multiple pairwise comparisons test enabled to perform multiple pairwisecomparison between the means of groups and shown $95 \%$ familywise confidence level of the results.

In contrast to the traditional existing approaches, the hypothesis of this dissertation presents improvements on the marine geological data processing and interpretation methods by applying advanced methods of data analysis and visualization: a combination of GMT cartographic scripting toolset and programming languages Python, R, Octave and AWK. Developed methodology enabled to model submarine geomorphology, allowed assessment of variations between their shape, and estimation of factors affecting trench formation by complex interplay of the geospatial factors. 


\subsection{Technical approach}

$\mathcal{M}$

ain technical tools of this research is open source GIS toolsets and programming languages: R, Python,

Octave, AWK. Choosing right statistical methods for the seafloor modelling is a crucial step in planning research. Available data may vary depending on current research scope, be it structure of the sedimentary cover of the ocean trench, geometric features of the deep horizons (angle steepness), waves velocity characteristics as reflected by rock density, submarine earthquakes, deep ocean currents. Methodological approach require careful reflection of the data set and goal of the statistical analysis.

Marine geology data processed by the $\mathrm{R}$ and Python libraries present data models on the topography of the ocean floor and environmental variables. Such data available online as free GIS layers in vector and raster formats were used in current research. Ocean research methodology is based on application of various GIS with specific tools for geospatial rater of vector data processing. Both commercial ArcGIS and open-source Geographic Resources Analysis Support System (GRASS GIS) or QGIS are suited for the seafloor study, processing attribute data of the biological and geological resources of the hadal trenches, geophysical fields and tectonic plates [393]. The diversity of the scientific tasks and need to study various aspects of the trench structure recorded as objects in the machine system, led to the creation of the specialized geological and geophysical methods, GIS and different equipment and tools.

Although use of traditional GIS is generally recommended, programming presents more powerful tool for geospatial data processing, sometimes overlooked. Open source tools of Python, R, AWK and Octave were used extensively to set up the processing scripts enabling rapid and reproducible analysis. Python and R, are highly suitable for the statistical analysis in geosciences, as having powerful statistical and math libraries, highly effective for scientific computing and used in current research.

The proposed approach of the combined data analysis by GMT, QGIS, R and Python for geospatial and statistical analysis enabled accurate and efficient computation and modelling of the large datasets in marine geology. Challenge in the assessment of the geological big datasets (several thousand of sampels) concerns the difficulty in manual identifying a correct algorithms in the computations and analysis of data distribution. The necessity to apply a precise ML algorithms recently increased in geographic sciences with respect to the importance of choosing effective method for data visualization and computation. The solutions to these problems are provided by Python's Pandas data frames: optimizing data structure, selecting correct parts from the data frame (columns, rows in data arrays), plotting.

In its geospatial part, this dissertation presents a GMT based automated workflow enabling large-scale profile cross-sectioning aimed at transect mapping in 20 trenches. It starts with cartographic mapping using high-resolution datasets (GEBCO, SRTM_15) and ends with automated cross-sectioning aimed at comparative analysis and classification of the geomorphic shape forms of the trenches. In total 50 modules of GMT scripting toolset were trained on extensive datasets collected from 20 trenches across the whole region of the Pacific Ocean.

This dissertation presents a computer-based approach by advanced data modelling. Classic approaches of the GIS mapping and other tools of geoinformatics [179], [133], RS, navigation charts and data modelling by cross-sections, [657]), statistical modelling by R and packages, e.g. dplyr, ggplot2, PMCMR, car [616]. Of these, GMT shell scripting and statistical modelling of the oceanological data sets by R and Python languages are the most cost-effective tools for studies on submarine geomorphology.

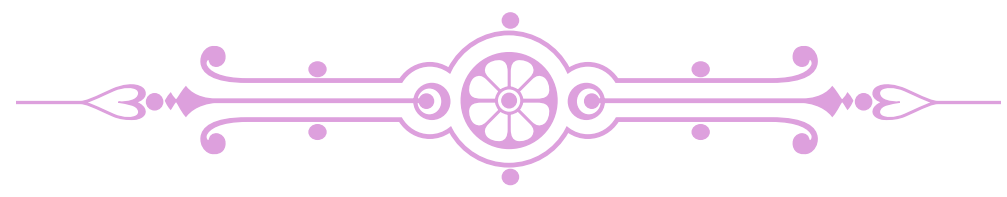




\section{Chapter 2}

\section{Trenches of the Pacific Ocean}

\subsection{Kuril-Kamchatka Trench}

Kuril-Kamchatka Trench (KKT) is an oceanic trench with depths more than $5000 \mathrm{~m}$, located on the border of the Sea of Okhotsk located in the Far East, north-west Pacific Ocean (Fig. 2.1.1).

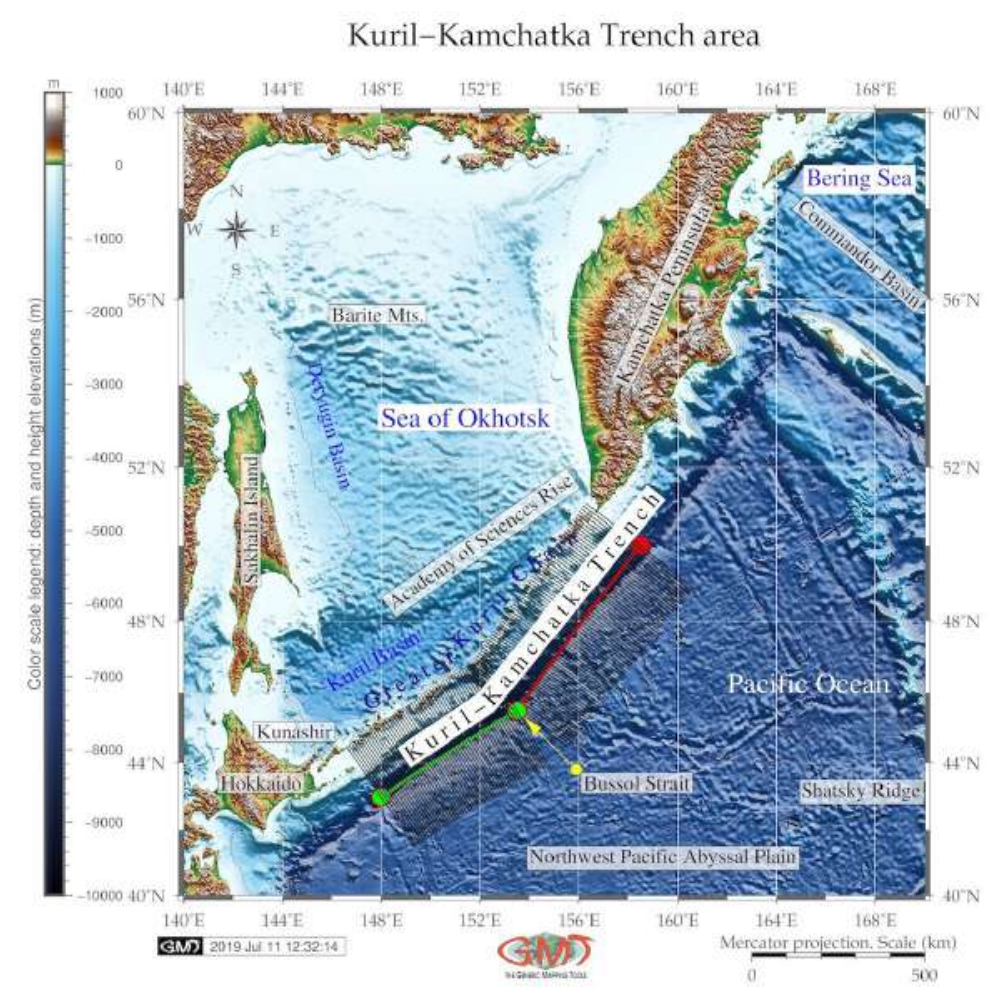

Map 2.1.1: Kuril-Kamchatka Trench and the Sea of Okhotsk: bathymetric map [418]

Geographically, the KKT continues south-eastwards from the coast of the Kamchatka Peninsula, in parallel to the Kuril Island chain, and meets Hokkaido Island. Geologically, the KKT presents a boundary of the large subduction zone of the Pacific tectonic plate under the Okhotsk tectonic plate [58], which causes irregularity in its bathymetric shapes and geomorphic structure. The submarine geomorphology of the seafloor underlying the KKT is formed as a result of the complex interplay between the geological substrate, water column and a range of the geophysical processes and phenomena [398]. As a result, 
the variations in the distribution of the geomorphic landforms in the trench were caused by a continuous effect of various factors through the whole history of the trench formation.

The Sea of Okhotsk is a semi-enclosed sea, connected in terms of bathymetry with the Pacific Ocean through the Bussol and Krusenstern straits [527]. The Sea of Okhotsk is not isolated, has maximal depths of $3374 \mathrm{~m}$. It has deep-sea straits to the NW Pacific Ocean, the deepest of which are the Bussol with depths reaching 2300m [71], (Map 2.1.1). The Sea of Okhotsk is connected with with the Pacific Ocean hydrologically through the Bussol Strait. The upper water masses of the KKT region are strongly influenced by the currents in opposite directions: the Oyashio coming from the Arctic southwards into the Pacific Ocean and the Kuroshio coming from the South China and flowing in northeast direction [45].

KKT is characterized by a geometrically long narrow, elongate, deep and asymmetrical depression of the seafloor with steep slopes. Together with Aleutian Trench, it presents contiguous complex covering area of $254,740 \mathrm{~km}^{2}$ [225]. The KKT is distributed along Kuril island arcs and Eurasian continent masses, developed in the association with an island-arc system where Pacific tectonic plate subducts below the North American and Okhotsk plates. The Okhotsk plate represents a region of active grabens lying southwards of a chain of small sedimentary basins in the Cherskii Mountains [656]. The geomorphic and topographic patterns of the land area of Kamchatka Peninsula are influenced by the climate and glaciological effects (glacier cirques) [33]. The KKT is divided by the Bussol Strait into southern and northern parts. Because geologic factors differ in northern and southern parts of the trench, it affects its geomorphology.

Southern part of the Greater Kuril Chain includes the large Kunashir, Iturup, and Urup islands constituting the islands-arc-trench system. This part is confined to the northwestern Pacific subduction zone [315]. The topographic and geomorphic features of the trench in its northern part are different from those located further southwards near the group of the seamounts.

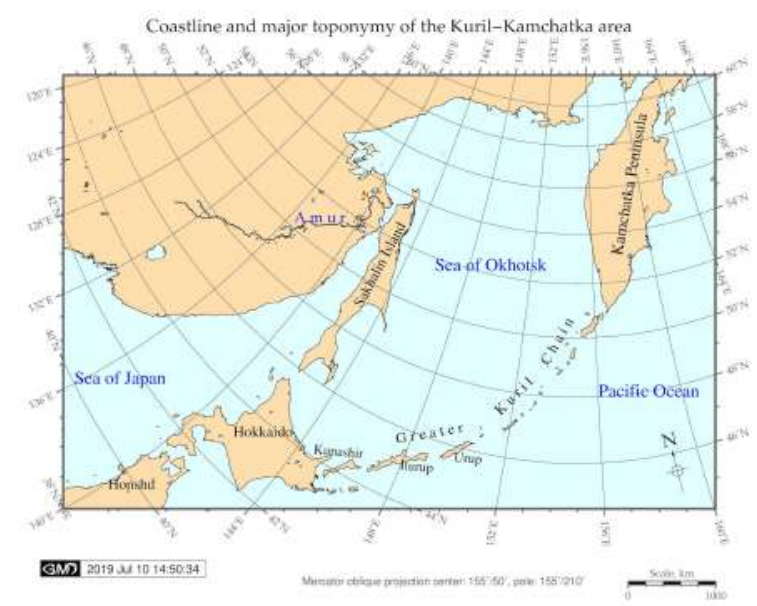

(a) Mercator oblique projection

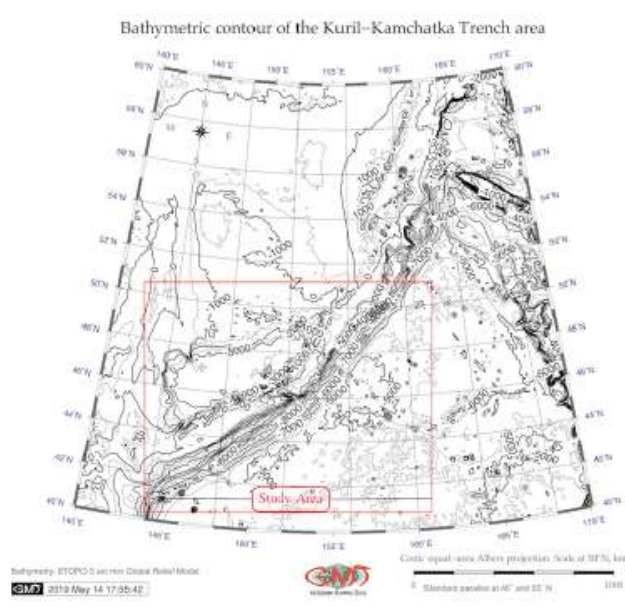

(b) Conic projection

Map 2.1.2: Kuril-Kamchatka Trench. Miscellaneous projections in GMT, [418]

Specific distinction of the KKT is its division into two parts: northern and southern segments separated by the Bussol Strait [398]. The geological settings of the study area is characterized by high seismicity, repeated earthquakes, and tectonic instability caused by plate subduction. Geological factors differ in northern and southern parts of the trench, which naturally affects its geomorphology. The comparisons on the northern and southern parts of the KKT seafloor are not assessed within the published literature. Therefore, the novelty of this study is a contribution towards the regional analysis of the geospatial variation of the trench geomorphology in its southern and northern parts. The formation 
of the hadal trench is affected by the impacts of local geological and geophysical settings varying along the trench.

The tectonic properties of the KKT mutually affect both land and submarine geomorphology. Thus, as noted by [597], the location of the KKT at the meeting place of active Kuril-Kamchatka and Aleutian arcs causes the coastline of the Kamchatka Peninsula to be affected by strong tectonic activities. Fracture zones have variable influence on the uplift of the Kamchatka Peninsula. Geomorphic consequence include raise of the multi-level, highly uplifted marine terraces displaced along the active tectonic faults. Furthermore, the tectonic movements cause the uplift of the coastal sediments [597].

KKT belongs to the Chilean tectonic subduction type, which has a gentle subduction dip advancing at a speed of ca. $2 \mathrm{~cm}$ yr-1 and inter-seismic elastic shortening of 1-2 mm yr-1 [128]. Strong lateral velocity in the shallower mantle wedge accounts for both the compressional subduction tectonics and back arc compression in the KKT. This results in the seismic-velocity anomalies in the mantle under the KKT, as shown on the tomographic images by [761]. Despite the age of the Pacific Plate, there is no sharp variation of the age on the seafloor along the KKT [617], and the old Pacific Plate is rejuvenated at the north of the KKT around the Meiji Guyot seamount.

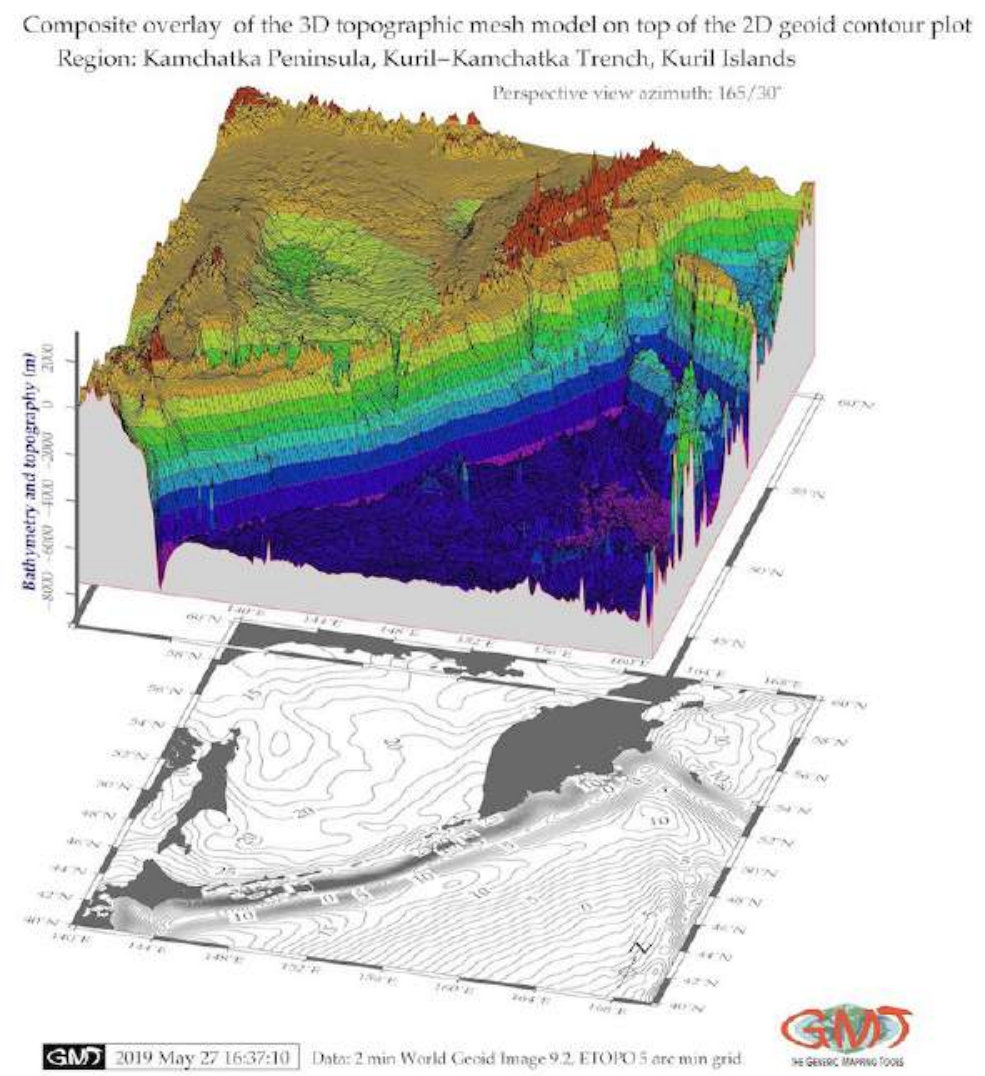

Map 2.1.3: Kuril-Kamchatka Trench: 3D-topographic mesh map. Source: [418]

The Kuril-Kamchatka subduction zone, a part of the circum-Pacific 'Ring of Fire', forms northern part of the Kuril-Kamchatka volcanic arc in the North-West Pacific Ocean [602]; [206], [398]. The subduction rate of the Pacific plate beneath the Eurasian Plate is ca. $79 \mathrm{~mm}$ yr-1 [129]; [57] or 8-9 m per century along the KKT [568]. This causes high seismic and volcanic activities, making this region one of the most tectonically active, seismic regions of the world. More specifically, one of the most active volcanic arcs in the world is located on the eastern coast of Kamchatka [203]; [600]. A number of studies analyzed earthquakes across the region of the southern Sea of Okhotsk in in the adjusting Kamchatka 
Peninsula. Nowadays, there are 29 active, and ca. 300 extinct volcanoes located on the Kamchatka Peninsula near the KKT [689].

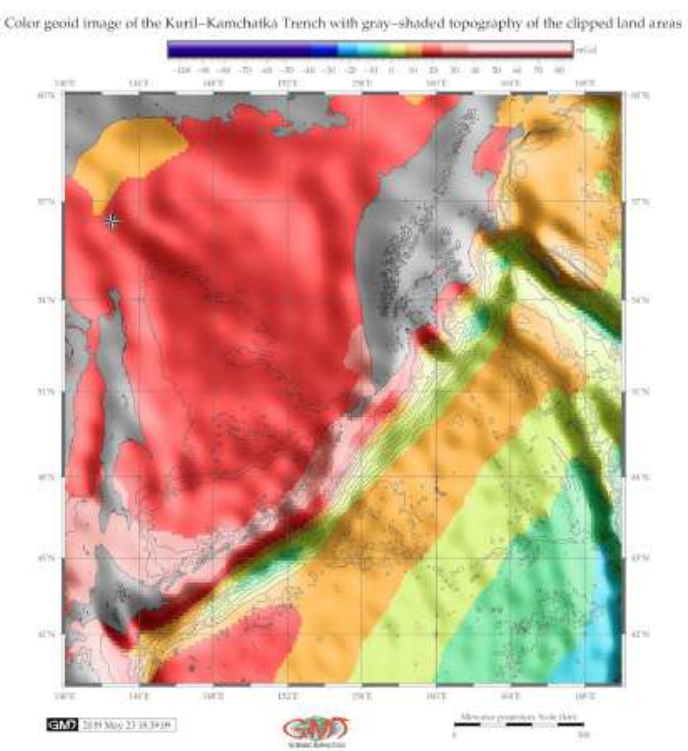

(a) Geoid model with clipped land area

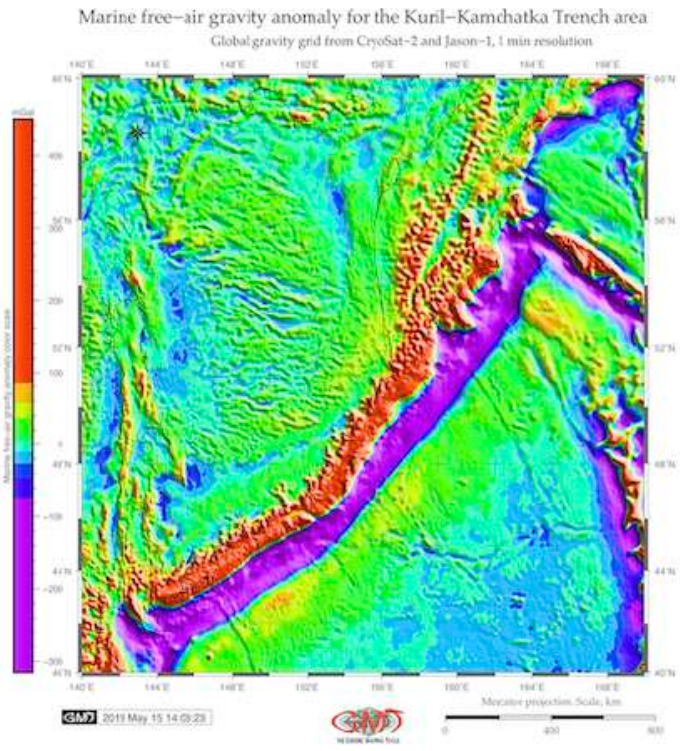

(b) Marine free-air gravity anomaly

Map 2.1.4: Kuril-Kamchatka Trench [418]

Southern part of the KKT differ, as proved by recent findings [315] where it is demonstrated on the example of South Kuril that intense fluid thermal fluxes in the continental lithosphere cause of the formation of magma chambers and the development of volcanism and multi-metal ores. Over 700 earthquakes with hypo-centers $>50 \mathrm{~km}$ are recorded in the KKT focal zone [41] Individual earthquakes show large variations in seismic slip and distribution of foreshocks and aftershocks that shows spatial heterogeneity in the stress level and geological settings along the tectonic plate boundary [642].

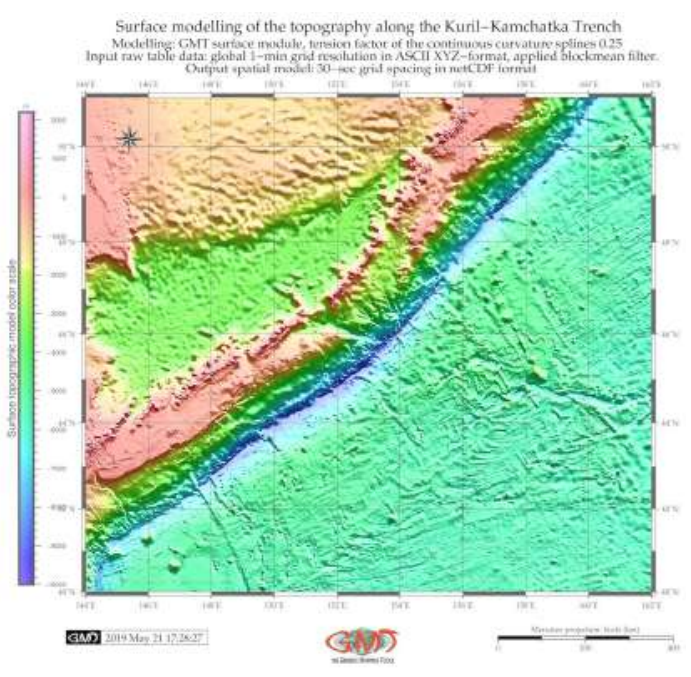

(a) Topographic map, GMT

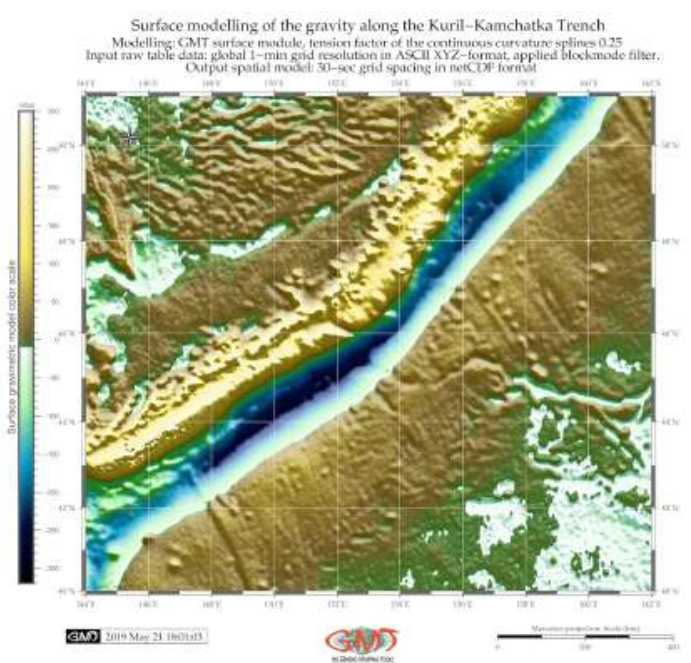

(b) Gravity surface model, GMT

Map 2.1.5: Kuril-Kamchatka Trench [418] 
Northern part of the KKT located northwards from the Bussol Strait presents a geographically complicated region with smaller islands than in other parts of the Kuril volcanic arc [525], Map 3.3.9. This area is notable for the abnormally high heat flow in the ocean floor. Reduced thermal thickness of the Pacific Plate upon its subduction into the northern KKT indicates underlying mantle plume and point out that thermal thickness of the underlying plate is lesser than expected comparing to the normal oceanic plate of such age [683]; [667]; [682]; [681].

Historically, the KKT subduction zone experienced a variety of large tsunamis along the trench [773]. Reports on the seismisity of the KKT are provided by numerous studies [307]; [204]; [643]. Maximal depth of the seismicity along the KKT changes gradually from ca. $600 \mathrm{~km}$ to ca. $300 \mathrm{~km}$ with latitude increasing in a central part from ca. $50^{\circ} \mathrm{N}$ to ca. $54^{\circ} \mathrm{N}$ [203], and then decreasing sharply to a depth of $100 \mathrm{~km}$ northwards. The rate occurrence of the tsunami on the Shikotan Island, the southern end of the Kuril Island Chain, is one per $250 \mathrm{yr}$.

The most active section of the KKT subduction zone is the southern Kuril Islands and Hokkaido sections with nine $\mathrm{Mw}$ 7.5-8.5 earthquakes [525]. Larger earthquakes estimated as Mw 9.0 occur only every ca. $500 \mathrm{yr}$ on Iturup Island [275]. Such seismic situation in the KKT makes this area in the northwest Pacific coast a tsunami-prone region [216]. The focal mechanism of the strongest earthquakes $(M>5)$ in the southern part of the KKT affects the orientation of the trench in this part through the main fracture zones with respect to the direction and type of the geomorphic displacements. The formation of the KKT is affected by the impacts of local geological, geophysical and oceanological settings that resulted from the complex process of the tectonic plates movements and subduction. At the same time, there are local variations in northern and southern parts of the seafloor that influence the shape of the slopes. In the subduction zone of the Pacific Plate, these cross-sections of the tilted trench illustrate crustal processes of the subduction and deposition of deep-sea sediments into the trench in its both segments. The sediment dispersal system of the trench forms two distinct types: the first one is a trenchparallel and a second one is a trench-crossing system. The geological parameters visualized on the Map 3.3.9 show fracture lines that predominantly have south-eastern direction showing perpendicular stretching towards the trench general direction.

The geomorphology of the KKT includes main submarine landforms related to the sedimentation processes, volcanic activities, tectonics, geologic formation history and regional oceanographic processes. The most important of them are as follows:

- system of connected submarine canyons and channels;

- gullies, and deep-sea fans located on the slopes;

- turbidity currents;

- drifts, moats and abyssal channels driven by the ocean circulations;

- rotational deep-seated landslides triggered by the instability of the trench slopes and mass-transportation connected to the geologic underlying rocks structure;

- craters associated with deep-sea fluid-flow processes.

The formation of a variety of landforms including terraces and slopes of the trench reflects the complex action of a range of factors. These include tectonic, sedimentary, oceanographic, biochemical processes and hydrodynamic phenomena. As a result, morphological character of the seabed in both southern and northern part is depending on the local and regional factors. The Greater Kuril Chain forms a natural barrier dividing the Sea of Okhotsk basin from the Pacific Ocean by the chain of islands and adjacent KKT, and separated into 2 parts by the Bussol Strait. The lateral slopes of the KKT are formed by the cumulative effects of the geologic, seismic and sedimentary factors at the subducting tectonic plate boundaries. 


\subsection{Aleutian Trench}

The Aleutian Trench (AT) is located in the North Pacific Ocean (Map 2.2.2) along the and Aleutian Islands (Fig. 2.2.1) in the area of tectonic plate subduction [144].

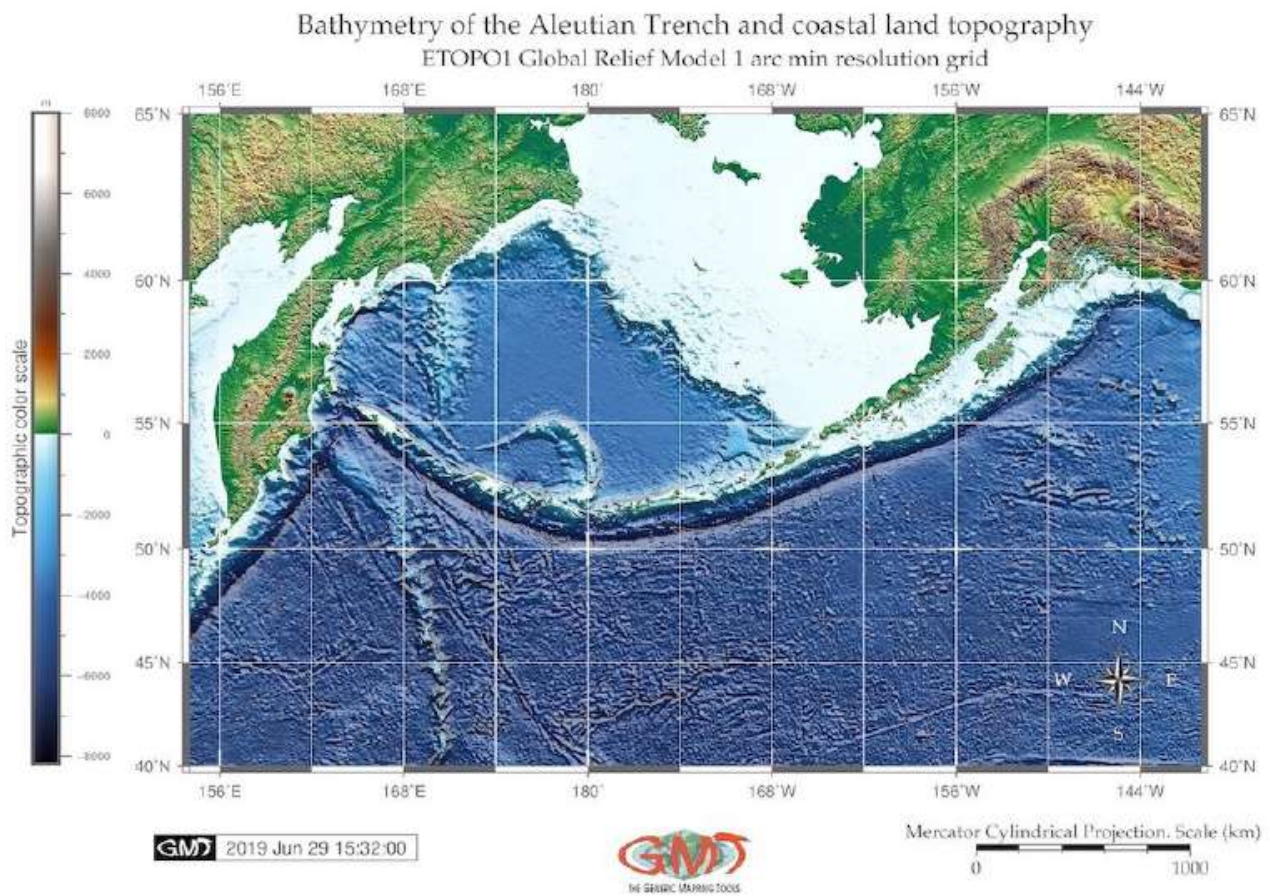

Map 2.2.1: Aleutian Trench: bathymetric map based on ETOPO1 grid, [370]

Geologically, the Aleutian Islands arc is classified as an accreting margin with most of the arc having a well-developed frontal prism formed in the Plio-Pleistocene. Central Aleutian volcanic front migrated northwards 30-60 km since the formation of the arc massif completed in the Late Eocene. AT has weak coupling between the surface tectonic plate and subducting slabs [761]. The seismicity of the Aleutian regions causes tsunami that affect far located regions [644] of which the 1946 was by far the most severe [23]. Further studies on the seismicity, earthquake sources and effects distribution in the region of the Aleutian Islands is developed in various studies [153], [156]. The tectonics of the Aleutian-Komandorsky chain that is proved [184] to be colliding with Kamchatka at the Kamchatka Peninsula.

Structural evolution of the Kamchatka-Aleutian triple junction area in the Mesozoic and Tertiary was affected by the subduction in Kronotskiy subduction zone and collision of the Kronotskiy arc against North-East Eurasia margin [8]. The Aleutian tectonics is deeply connected with Kuril-Kamchatka since the Aleutian transform fault separated the Kronotskiy terrane block from the Pacific plate [174]. Relevant studies [173], [249] develop further investigations on the crustal structure transition form oceanic to continental arc in the Aleutian Islands region. The geological composition of the andesite substrate in the AT results as melts from subducted Pacific ocean crust [313]. More details on the geological and biological uniqueness of the Aleutian islands area are provided in relevant research [614]. An interesting example of the existing cartographic work as contour bathymetric map dated 1945 can be found by [561].

Processes of the deep-sea terrigenous sedimentation are formed by the transfer of the erosion materials from the adjacent land. The main processes include transportation, deposition and re-deposition of the sedimentation materials. The origin of the deep ocean sedimentation is diverse. In general, apart from the sediments from the rivers, the terrigenous material goes to the oceans through iceberg melting and glacial deposits transferred to the seafloor, as well as dusty material moved by the aeolian processes. 
Topographic contour map of the Aleutian Islands and Aleutian Trench area

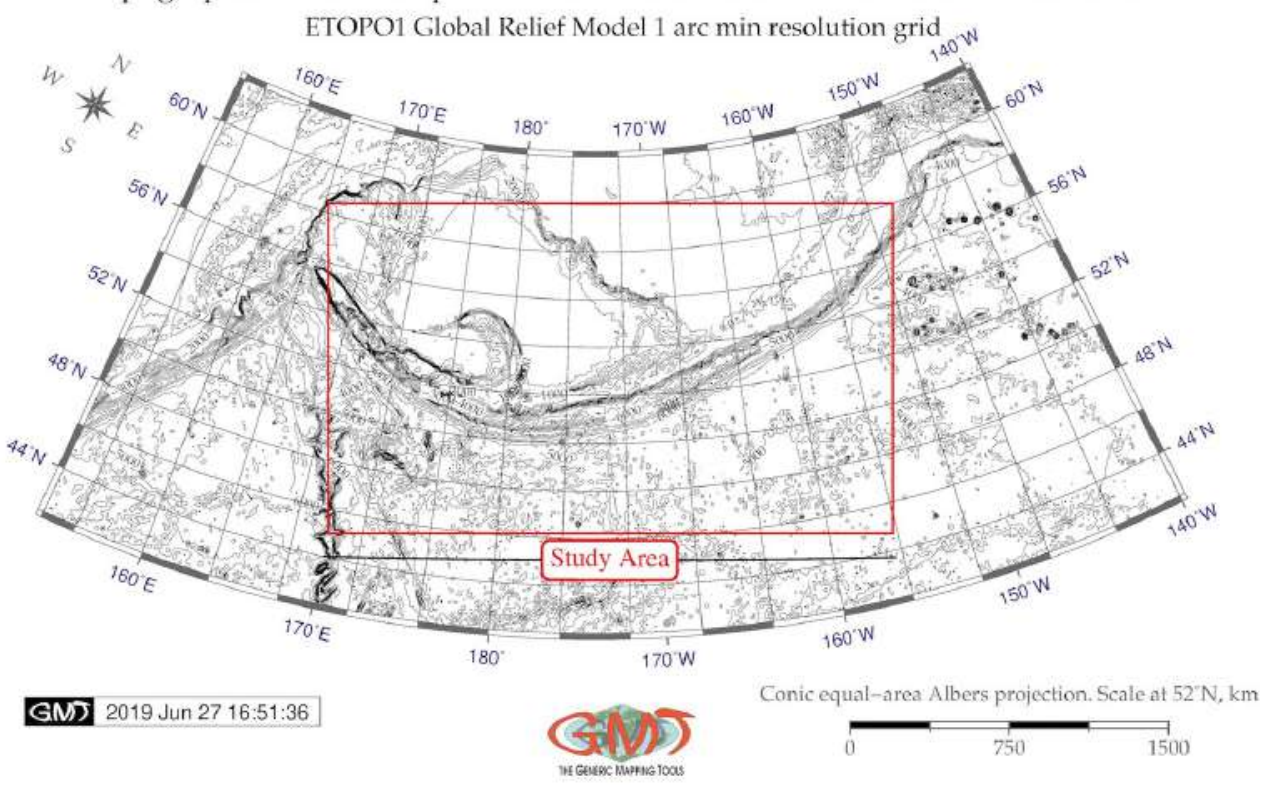

Map 2.2.2: Aleutian Trench: contour bathymetric map, [370]

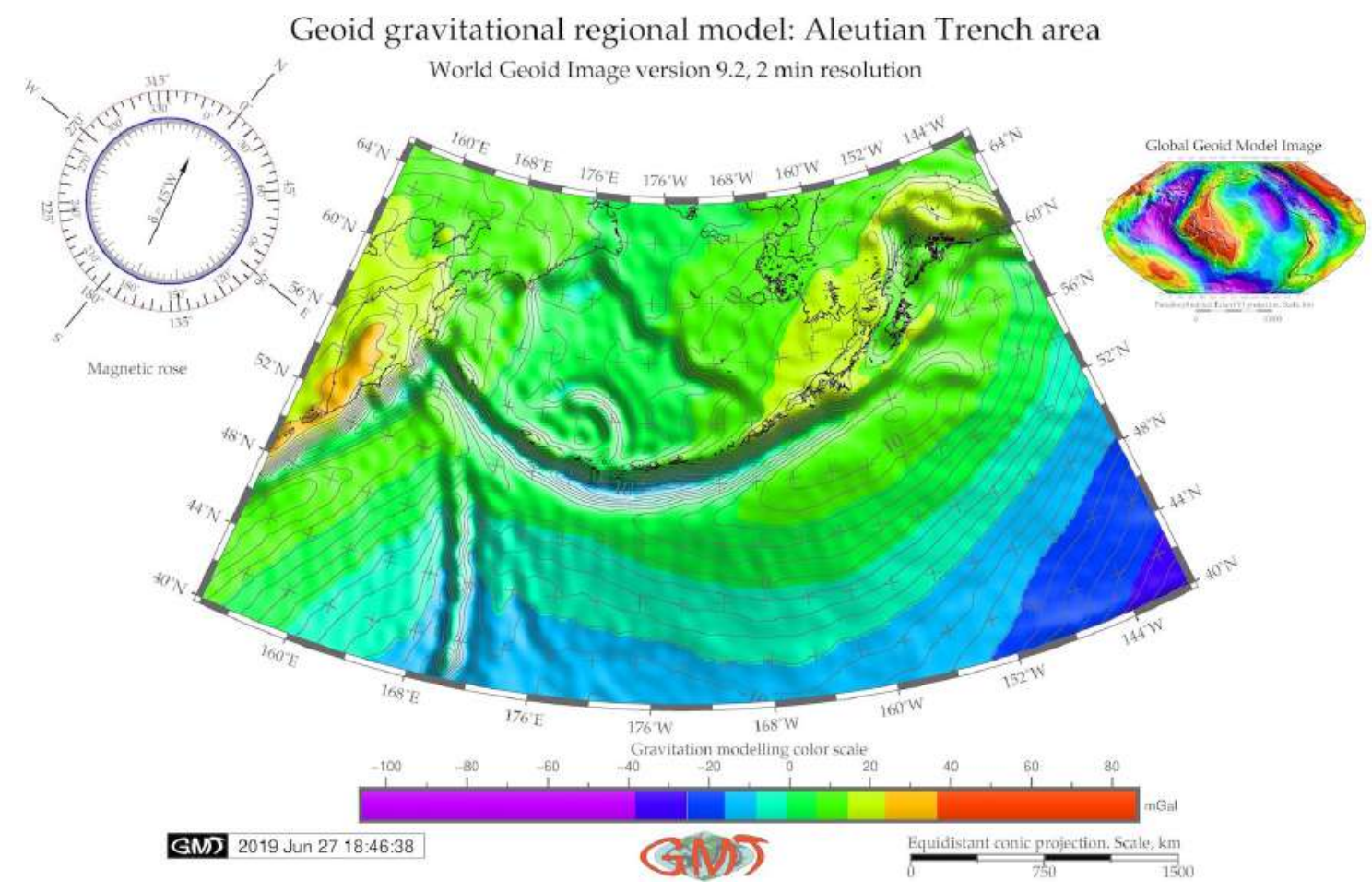

Map 2.2.3: Aleutian Trench and Aleutian Islands: geoid model map, [370]

Normally, the sediments transferred by rivers are deposited within the shelf sublittoral areas, and rarely reach deeper regions of the continental slope and, even less the abyssal basins. However, sediments deposited on the shelf may move to the deeper parts of the ocean including hadal trenches, due to further move from the shelf edge downwards, avalanche sedimentation, i.e. gravitational flows, which are caused 
by the gravity. Deep currents flow through the trench ventilating its bottom water flowing through the West Pacific trenches originates from the Southern Ocean and Antarctic and flows northward [734].

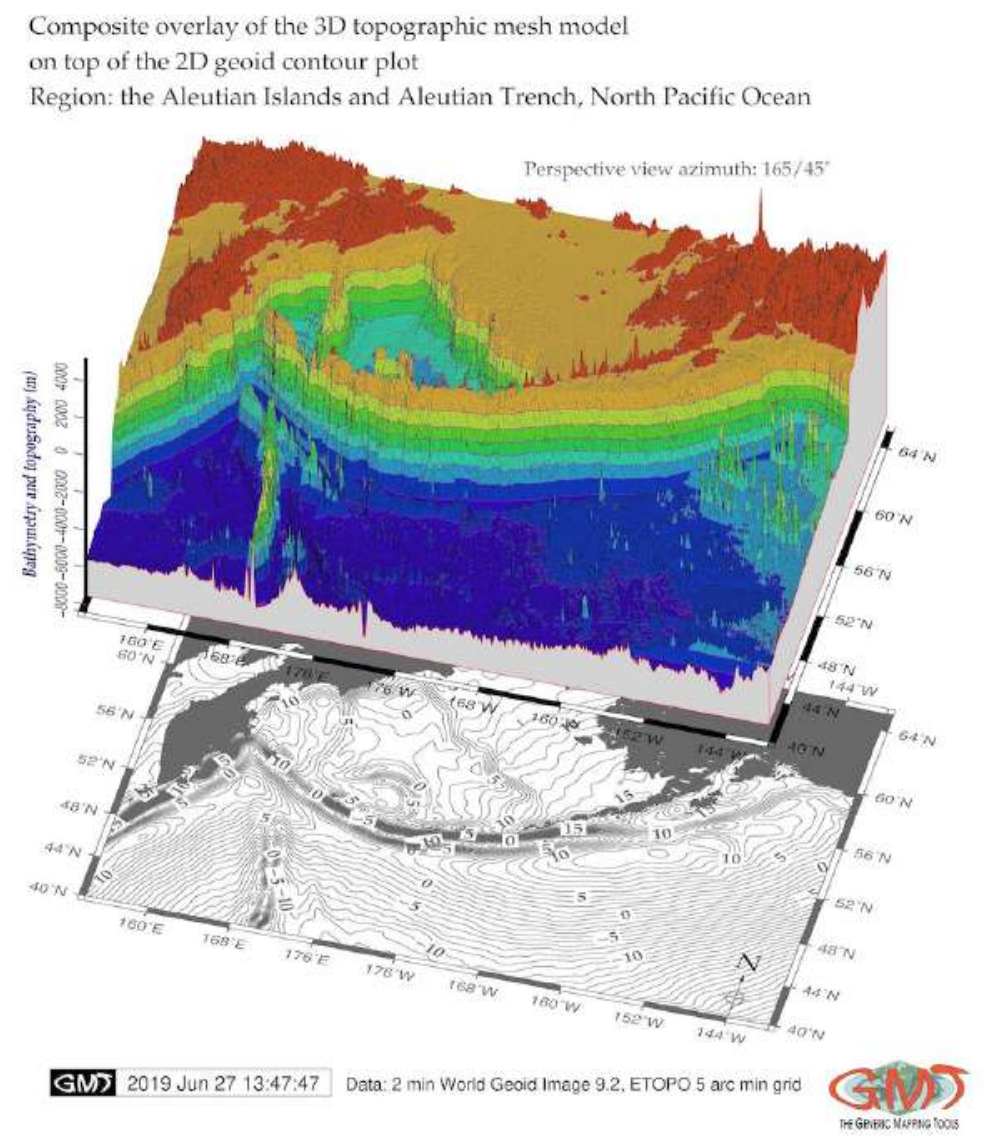

Map 2.2.4: Aleutian Trench and Aleutian Islands: 3D mesh grid model, [370]

Sediments cover is less than $10 \mathrm{~m}$ thick and is composed of soft, bedded clay with sand-size ash fragments. This clayey sediment covers a very gentle terrace $500 \mathrm{~m}$ wide [119]. The turbidity currents causing deposition of turbidites are being generated on the outer shelf and upper continental slope, due to the precipitation and transport via the submarine canyons to the axial part of the trench. The speed of such sedimentation in the bottoms of trenches closely depends on the volumes of the incoming sediments ranging from 300 to $3000 \mathrm{~mm} /$ thousand years [281]. As a result of such sedimentation, over one kilometer of sediments have accumulated in the southern AT and Peru-Chile Trench over the last several hundred thousand years [370]. 


\subsection{Middle America Trench}

Middle America Trench (MAT) is located along the eastern margin of the Pacific Ocean, Map 2.3.1. Tested segment is focused on the Guatemala Trench, a southern part of MAT, located on the Cocos Plate between the Tehuantepec Ridge and stretching until Cocos Ridge, between the coordinates: $96^{\circ} \mathrm{W}-82^{\circ}$ $\mathrm{W}, 7^{\circ} \mathrm{N}-17^{\circ} \mathrm{N}$ (Map 2.3.1), off Middle America (Map 2.3.3), [413].

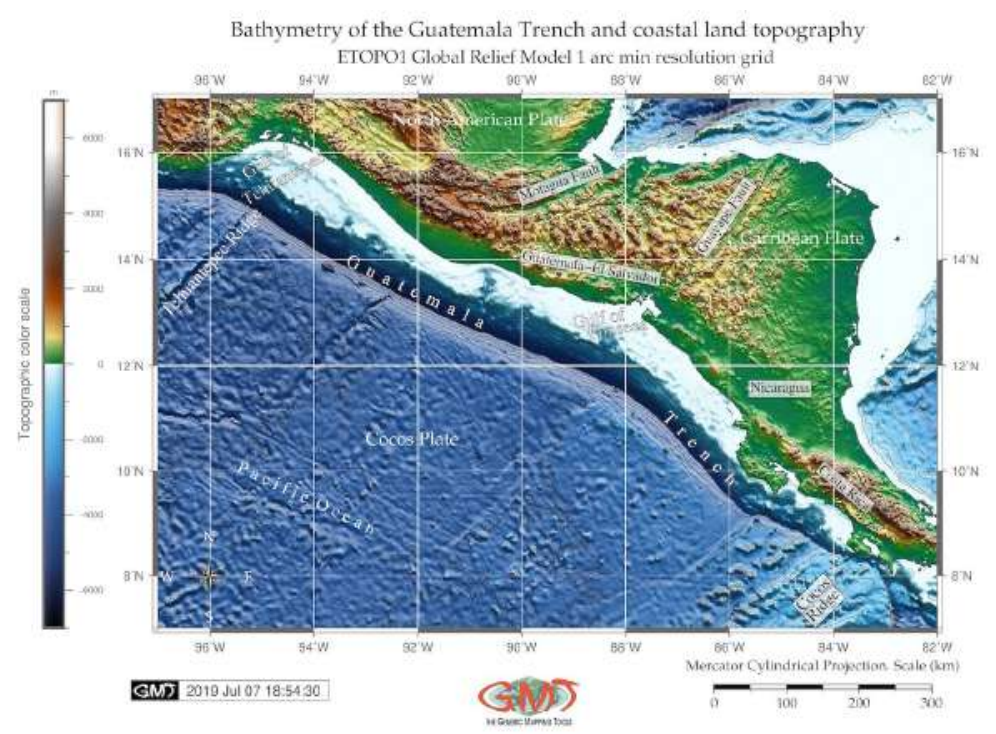

Map 2.3.1: Middle America Trench: bathymetric map, ETOPO1 grid, [413]

The MAT is located in the place of the subduction of Cocos Plate, a young oceanic tectonic plate, beneath the Pacific Ocean off the coast of the Central America continent.

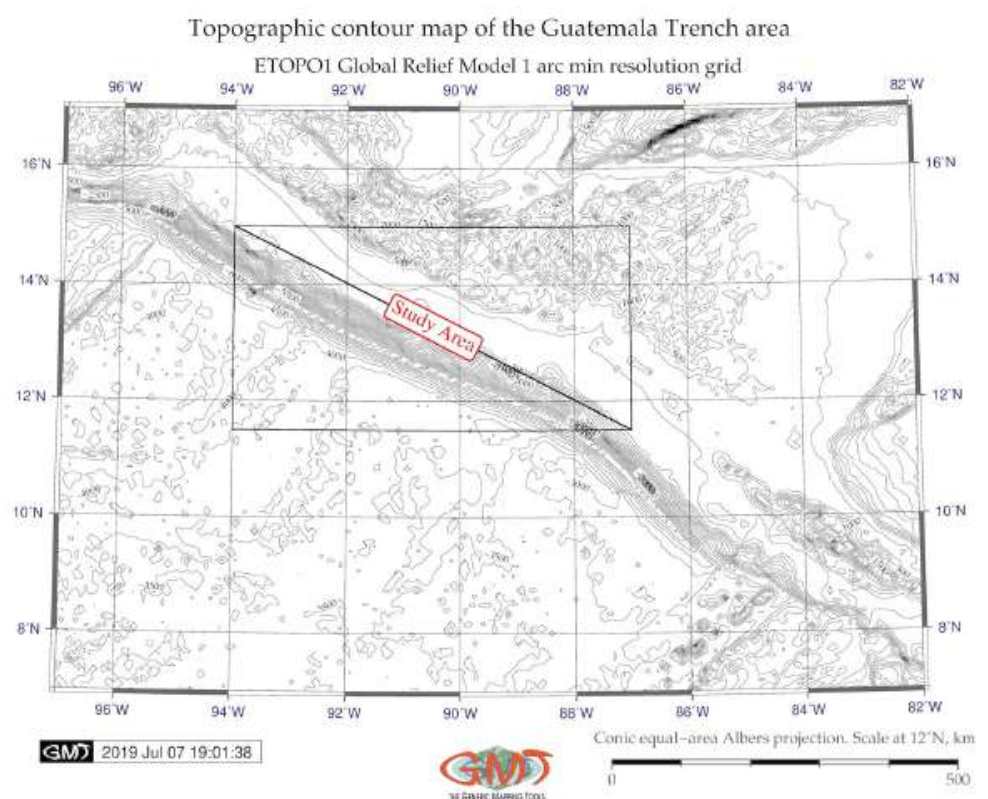

Map 2.3.2: Middle America Trench: topographic contour map, [413]

The Cocos Plate was created as a results of the break of Farallon Plate into two pieces that initiated 
two tectonic plates: Nazca Plate and Cocos Plate. In turn, the Cocos Plate is bounded by the North American Plate to the northeast, the Caribbean Plate on the south, the Pacific Plate on the west and by the Nazca Plate to the south. The MAT is unique among other Pacific trenches, since its nature is complex and varies in its different parts.

The neotectonics of the MAT consists of two distinct parts with varying features of the oceanic plate and geology in northern and southern parts. The division between the both parts goes by the Tehuantepec Ridge, a linear undersea ridge located off the west coast of Mexico in the Pacific Ocean, a remnant of an old fracture zone formed as a fracture zone and transform fault along the East Pacific Rise that reoriented the fracture zone as a result of a change in the motion of the Pacific Plate [719].

Northern part of the MAT, located off Mexico, is sometimes referred to as Acapulco Trench. It is a minor hadal trench, a part of the East Pacific Rise that stretches from from Jalisco to Tehuantepec Ridge. The Acapulco region, was initiated by a large slip motion giving to the Honduras Platform an offset of ca. $800 \mathrm{~km}$ and cutting the Mexican structure off. In its northern part, the MAT goes along the continent of North America along Mexico up to the Middle America Transverse Zone. Because MAT runs very obliquely, it is not related to the neotectonic features of Mexico, [413].

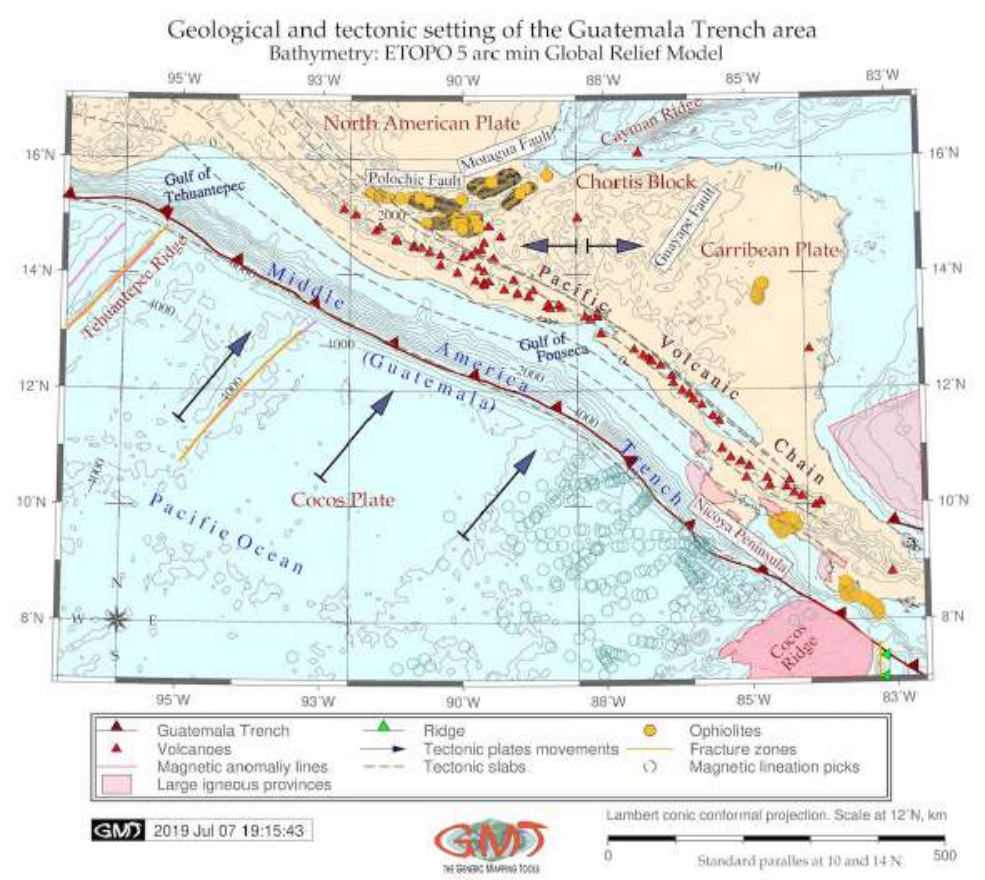

Map 2.3.3: Middle America Trench: map of geological settings

The MAT borders the end of the North American continent up to the Middle America Transverse Zone. Tectonically, the southern end of the North American continent is a special place due to the changed direction of the plates compression: during the Late Cretaceous to the Paleocene, north-south compression between the North and South Americas was predominant, therefore the Caribbean thrust system was dominating, [413]. However, the situation changed since the Pliocene and the dominant movement now became a west-east strike slip [20]. The MAT is a hadal trench trending northwest, which marks the Caribbean-Cocos plate boundary in the east Pacific Ocean [218].

Southern part is MAT, located off Middle America. The minor study area where the transects of the cross-sectional profiles are located is bordered by the square with coordinates: $94^{\circ} \mathrm{W}-87^{\circ} \mathrm{W}, 11,5^{\circ} \mathrm{N}-15^{\circ}$ $\mathrm{N}$ (Map 2.3.2). Southern part of the MAT is resulted from a subduction zone related to the Franciscan subduction zone of North America where the Isthmus of Panama supports a huge Tertiary volcanic 
cover. Here MAT originated from an ancient subduction zone involving Mesozoic oceanic sediments and crust [20]. The Cocos Ridge serves as a border for the start of the wide continental margin characteristic of the MAT [558], [413]. The Upper Jurassic-Cretaceous-Tertiary oceanic sediments occur in the slope of the GuatemalaTrench, a southern part of the MAT, as well as in the Nicoya Complex of Costa Rica. Deformation across a convergent tectonic plate boundary of MAT correlate with gravity-driven and subduction-driven tectonic processes.

Geochemistry of the sediments of the MAT is presented by the olivine-plagioclase phyric basalts, the only igneous rocks is the study area, and plagioclase phyric high-alumina basalts. Basalts with thickness layer of $7 \mathrm{~m}$ covered by $150 \mathrm{~m}$ of sedimentary layers were detected on the Cocos Plate section of MAT.

The petrographic features of MAT basalts are typical for the basalts of the ocean floor: subaphyric, with plagioclase phenocrysts dominant over olivine phenocrysts, composed of abundant plagioclase microlites, olivine, clinopyroxene and rare spinel microcrysts, partly devitrified brown glass. [300]. However, white some of the basalts are similar to the oceanic tholeiites, others have a composition transitional to island-arc tholeiitic basalts. As described by [135], this may indicate presence of magmatism in the zones of convergence of the oceanic and continental or island-arc crust. Petrochemical setting of the MAT basalts show compositions typical for the oceanic tholeiites and transitional to island-arc tholeiites with advanced differentiation of high-alumina varieties in both types of rocks. Namely, such transitionaltype basalts differ from rocks of the oceanic and island-arc basalts by values of $\mathrm{TiO}_{2}$ concentration and the $\mathrm{K}_{2} \mathrm{O} / \mathrm{K}_{2} \mathrm{O} / \mathrm{Na}_{2} \mathrm{O}$ ratio, [413].

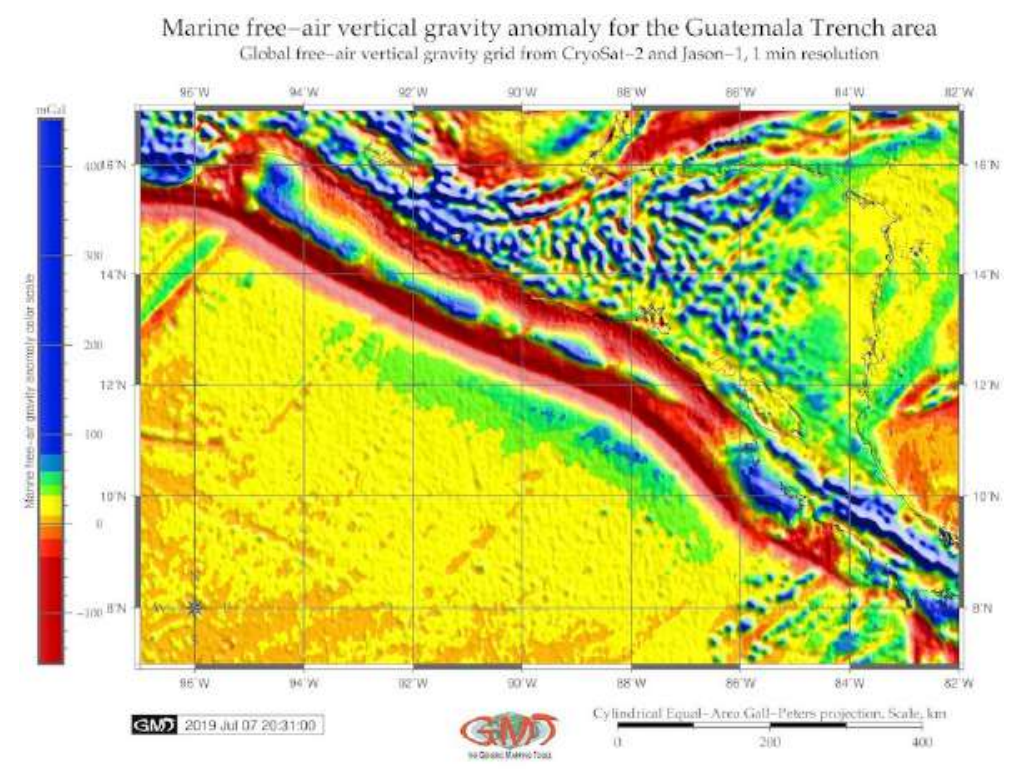

Map 2.3.4: Middle America Trench: vertical gravity model map, [413]

Among other deep-sea trenches, chemically similar to MAT tholeiitic basalts are detected in the transects of Philippine and Yap trenches. Young age of some basalts from the oceanward slopes of the MAT may indicate evidences of the local magmatism caused by the zone of convergence of oceanic and continental crust located nearby. This explain the eruption of the transitional basalts as oceanic and island-arc tholeiites in theMAT. Secondary minerals of the basalts of MAT in studied transects include smectite and chlorite, as well as talc, calcite, phillipsite, mica, and mixed-layer chlorite-montmorillonite also fill veins in the basalts of the trench [346].

The MAT runs parallel to the ancient structures that can be explained by the processes of paleosubduction. On the contrary, the Acapulco Trench, which is a northern part of the MAT, intersects geologic structures of the southern Mexico. The differences in the south and northern parts of the MAT are notable 
on the land- and oceanward sides. Thus, the impact of the Tehuantepec and Cocos ridges differ on the seaward side, but very weak on the landward side of the MAT. Thus, on the oceanward side, both ridges restrict the MAT off the Middle America continental shelf, but on the continental side, the Tehuantepec Ridge produces only a slight offset in the geological structures, whereas the Cocos Ridge raises them as a whole [20]. A system of major, active transform faults 'Motagua-Polochic system' consists of the Motagua Fault and Polochic Fault (Map 2.3.3, north), [413].

The Motagua Fault runs across the Middle America, continuing offshore until it merges with the MAT near the Acapulco forming part of the tectonic boundary between the North American Plate and the Caribbean Plate. The Polochic fault lies north and continues Motagua Fault in parallel, sharing motion between the North American and Caribbean Plates [523]. The Motagua Fault caused several major earthquakes, including the $7.5 \mathrm{Mw}$ Middle America 1976 earthquake. The geologic structure of the MAT includes Paleozoic crystalline basement rocks, Mesozoic intrusive igneous rocks and sedimentary rocks spanning the Cretaceous to the Pleistocene. The subduction of the Cocos Plate in the Paleogene caused eruption of the volcanoes, which resulted in active melting and formation of magma. The volcanoes are mainly located along the Pacific Volcanic Chain (Map 1.1.1) that runs in parallel to the MAT.

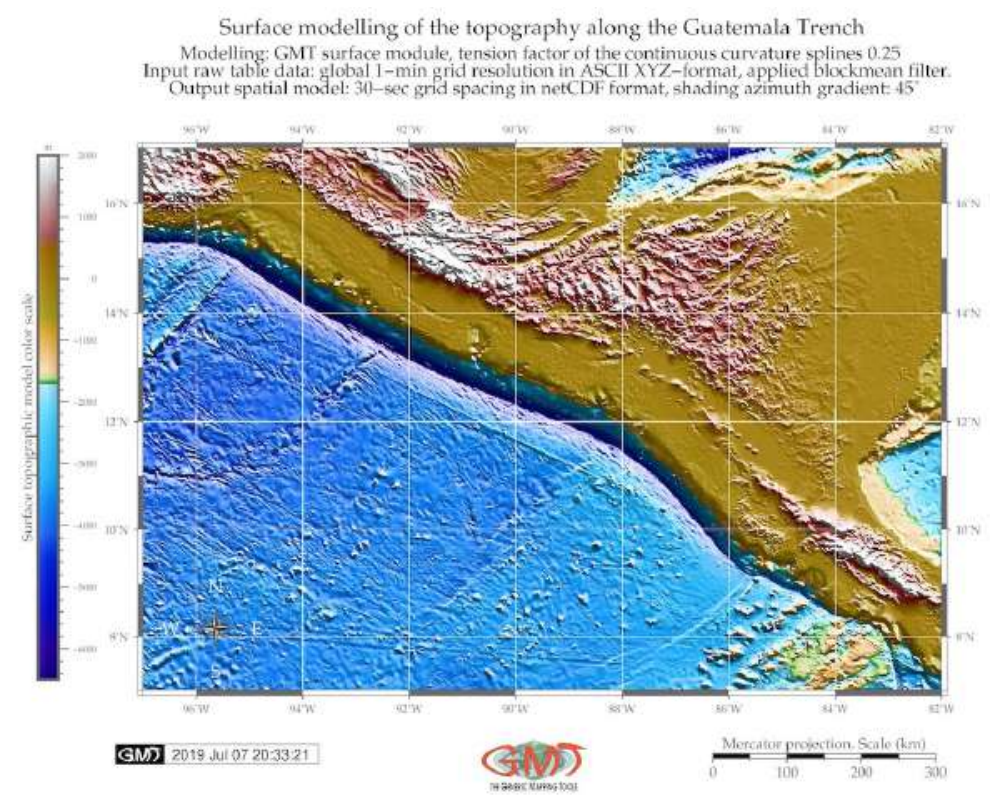

Map 2.3.5: Middle America Trench: topographic surface map modeled by ASCII data, [413]

Northern part of the study area is distanced by the location of Chortis Block, a group unit of the rocks originated as continental crust in Nicaragua. The Nicoya Peninsula (south-east on Map 2.3.3) is formed by a volcanic-sedimentary series determined by radiolarian assemblages as Upper Jurassic and Cretaceous [663]. The distribution of the ophiolites and other geologic features is presented on Map 2.3.3, [185]. The schematic map of the geological setting of the study area is visualized on Map 2.3.3 by available data from the GMT and United States Geological Survey (USGS) sources: bathymetry, tectonic plates movement directions, distribution of volcanoes, ophiolites, ridges and tectonic slabs in the MAT area.

Marine biological analysis of the samples taken from the MAT [677] shows calcareous benthic, planktonic foraminifers, and calcareous nannoplankton recovered within sediment cores along the trench axis that show relatively high faunal diversity. Their presence at great depth indicates rapid sediment transport and burial. The abundance of the biogenic silica throughout the sediment section indicated that continental slope of MAT had high biological productivity environment. The conglomerates of the trench indicate 
rapid sedimentation of the deposits accumulated in a trench slope that proved a relatively quiet environment of sediment deposition [112]. The samples from the MAT revealed areas composed of hemipelagic muds containing substantial biogenic components that proves a high degree of bioturbation: the samples consist of diatoms, radiolarians, sponge spicules, calcareous nannoplankton, and foraminifers of lower to middle bathyal benthic species [678].

The 'Glomar Challenger' expedition sampling shown that selected spots on MAT predominantly consist of dark olive gray biogenic muds. The terrigenous component of the sediments is dominant and consists of clay minerals and minor contributions of volcanic glass. Biogenous contribution is secondary and consists of ca. 50\% diatoms and nannofossils and biogenic debris (foraminifers and sponge spicules), [413].

Brief sedimentation history of the MAT area was summarized by [345]: the sedimentation on the continental slope was supplied by a smectite- and plagioclase-rich terrigenous land source area during the Late Cretaceous. In middle Miocene a volcanic source existed in MAT area, as proved by the volcanic glasses followed by the persisted volcaniclastic constituents. Major sediment types of MAT include turbidites, hemipelagic sediments, chalk, basalt and slope sediments [638], [413]. Sedimentation processes on the MAT began in the early Miocene with an increased accumulation of the metalliferous foraminifernannofossil ooze above the basalt basement. The basal chalk, a source of Fe and Mn, presents a typical mid-oceanic metalliferous sediment type, located near the spreading center of MAT. Sedimentation time gap at MAT in the middle Miocene to Early Pliocene refers to a radiolarian-bearing pelagic clay and weak supply of terrigenous sediment at this period, which in turn may indicate remote location of the site from the land masses. The Cocos Plate moved away from its spreading center toward the subduction zone in the MAT during this period.

During Pleistocene, the hemipelagic sedimentation was substituted for the turbidite accumulation that reached present location on the trench seafloor. Sites located at the juncture of the Middle America slope and the MAT seafloor contain biogenic debris, including wood fragments. The sequence of the Quaternary trench-filling turbidites is either faulted or deposited against a fault scarp in lower Miocene chalk on the detected sites of the MAT [674], [114].

Lithologic variation and differing compaction states at the MAT show [162] that sediments on the continental slope have identical compaction as sediments in the trench, yet their compaction curve is intermediate between pelagic clays and diatom ooze. The sediments in the MAT have intermediate compaction level between the pelagic clays and terrigenous sediments, which is caused by the mix of pelagic sediments with terrestrially derived turbidites. Another particular feature of the MAT consists in partly consolidated lower Miocene to Quaternary hemipelagic muds that contain vertical-subvertical veins, $<2$ $\mathrm{mm}$ thick, spaced from one to several millimeters apart. Apart from the MAT, such morphologically analogous structures were obtained from the inner slope of the Japan Trench [396], [393].

Ocean crust of the Cocos Plate subducting beneath the landward slope of the MAT has a linear horst and graben topography of hundreds $m$ relief. This passive assimilation of oceanic material occurs without disturbing topography shape. The subduction of the horst and graben in the MAT area is largely passive and locally active. Mid-slope area has rugged topography covered by thick slope deposits, while lower slope is smooth except local brakes by benches. Upper and middle slope areas are correlated with strong magnetic anomalies. Rough midslope topography may reflect erosion following the Paleocene uplift and local subsidence in the early Miocene. Slope deposits covered the MAT landward slope, correlate with the increased arc volcanism indicated by ash layers [260]. A thick sequence of the terrigenous sediments was discovered seaward of the MAT [678]. More detailed insight to the origins of the geomorphology of the MAT and factors affecting formation of its landforms, have been studied in relevant papers [676], [10], [675], [22], [9]. 


\subsection{Peru-Chile Trench}

The Peru-Chile Trench (PCT), alternatively called Atacama Trench [187], is the longest hadal trench of the Pacific Ocean (Map 2.4.1). It stretches on $5,900 \mathrm{~km}$ from Ecuador to Chile $6^{\circ} 00^{\prime} \mathrm{N}, 81^{\circ} 50^{\prime} \mathrm{W}$ to $39^{\circ} 00^{\prime} \mathrm{S}, 75^{\circ} 00^{\prime} \mathrm{W}$ [172], Map 2.4.1.

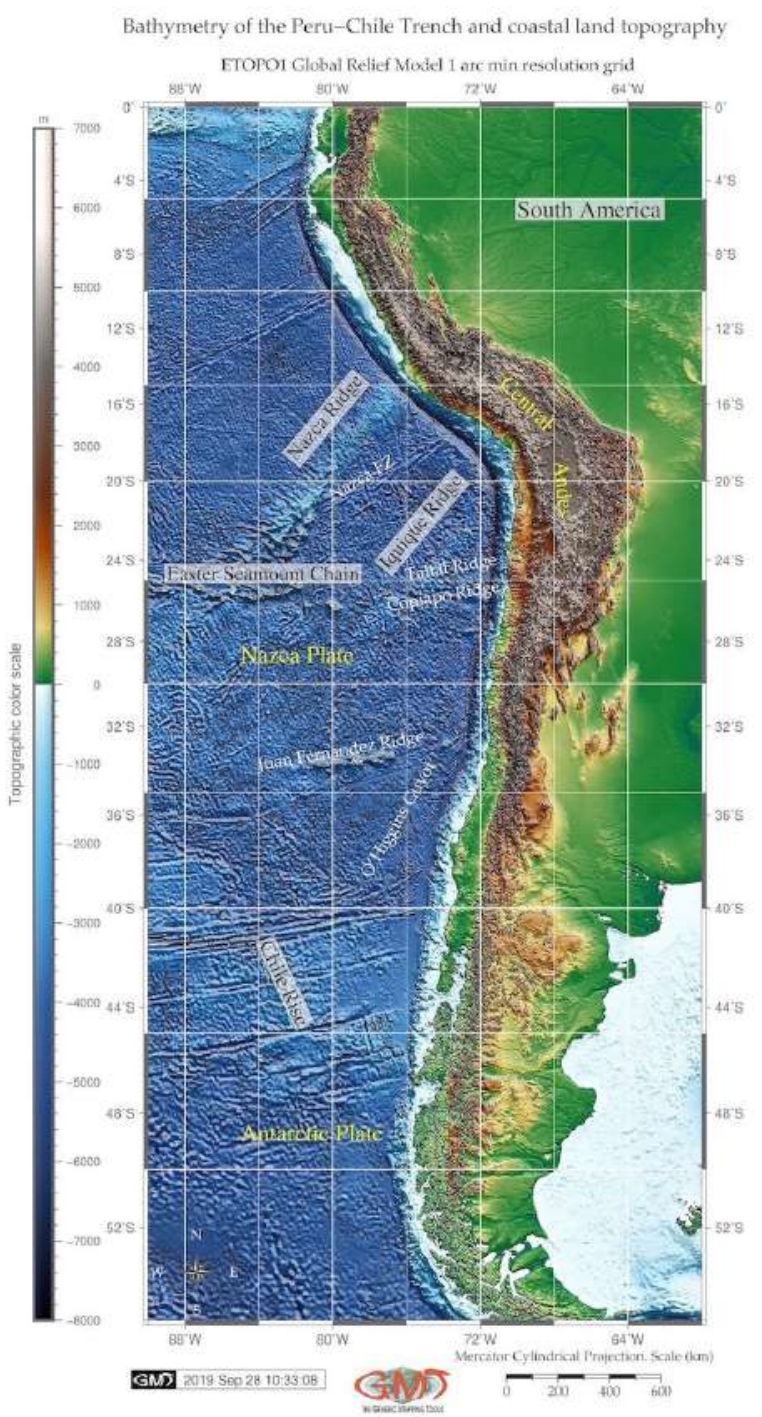

Map 2.4.1: Peru-Chile Trench: bathymetric map, ETOPO1 [411]

In its total length, the trench covers an area of ca. 590,000 km2 [14]. The PCT is shallower comparing to other trenches of the Pacific Ocean (64 $\mathrm{km}$ width). Reaching maximal depth of $8,065 \mathrm{~m}$, it is deepest trench of the South Pacific Ocean. The PCT is formed by the subduction of the Nazca and
Antarctic plates beneath the South American Plate. As followed by its name and location, PCT can be logically divided into two parts: Peruvian and Chilean one. The Chilean part is longer than Peruvian, stretching in a NS direction along 4,300 km, from $-18^{\circ} \mathrm{S}$ to $-56^{\circ} \mathrm{S}$.

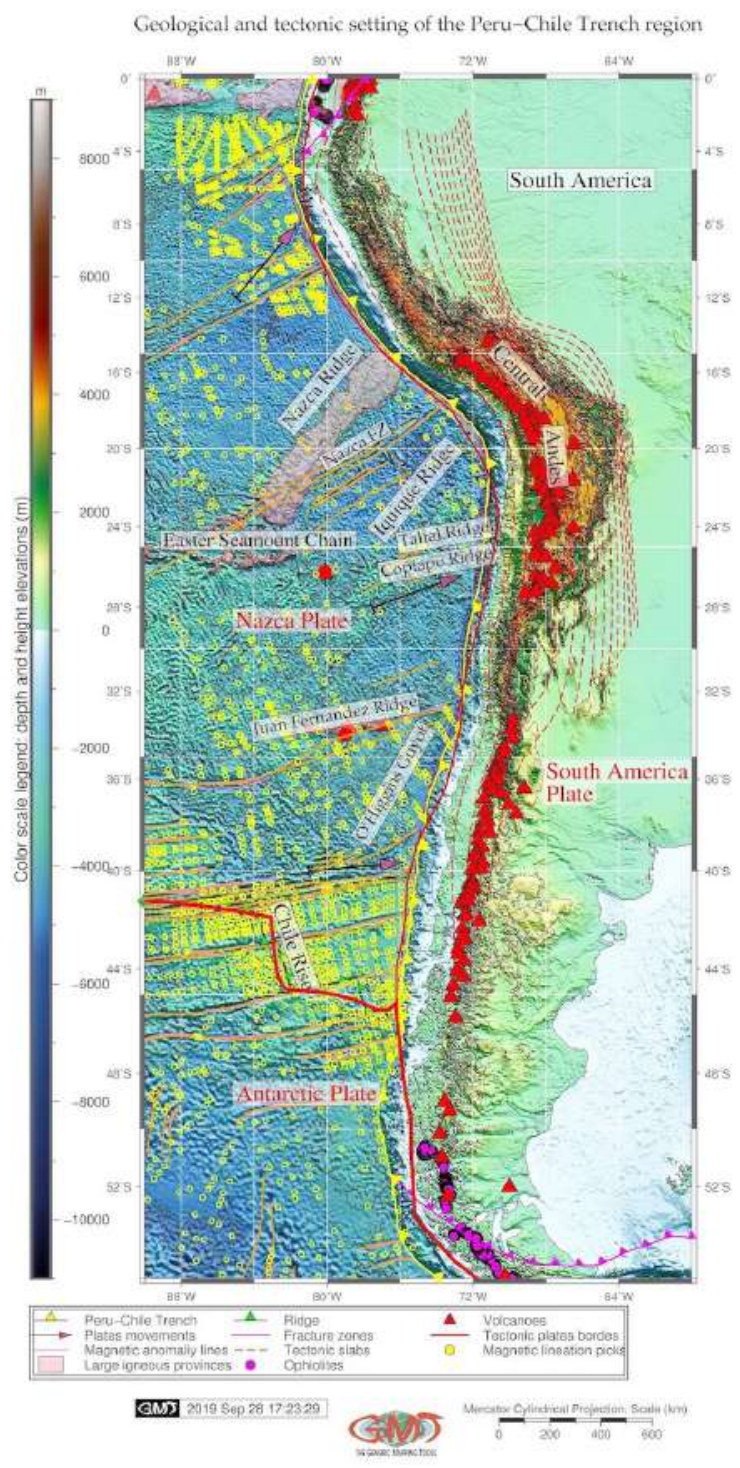

Map 2.4.2: Peru-Chile Trench: geological map [411]

Due to the specific geologic, geotectonic, geomorphic and climatic characteristics, the region of the PCT is exposed to a wide variety of hazardous processes such as earthquakes, local tsunamis, generated between the PCT and Chilean coasts, volcan- 
ism and continent-specific geological hazards, e.g. floods, landslides and mass movements, as briefly discussed below.

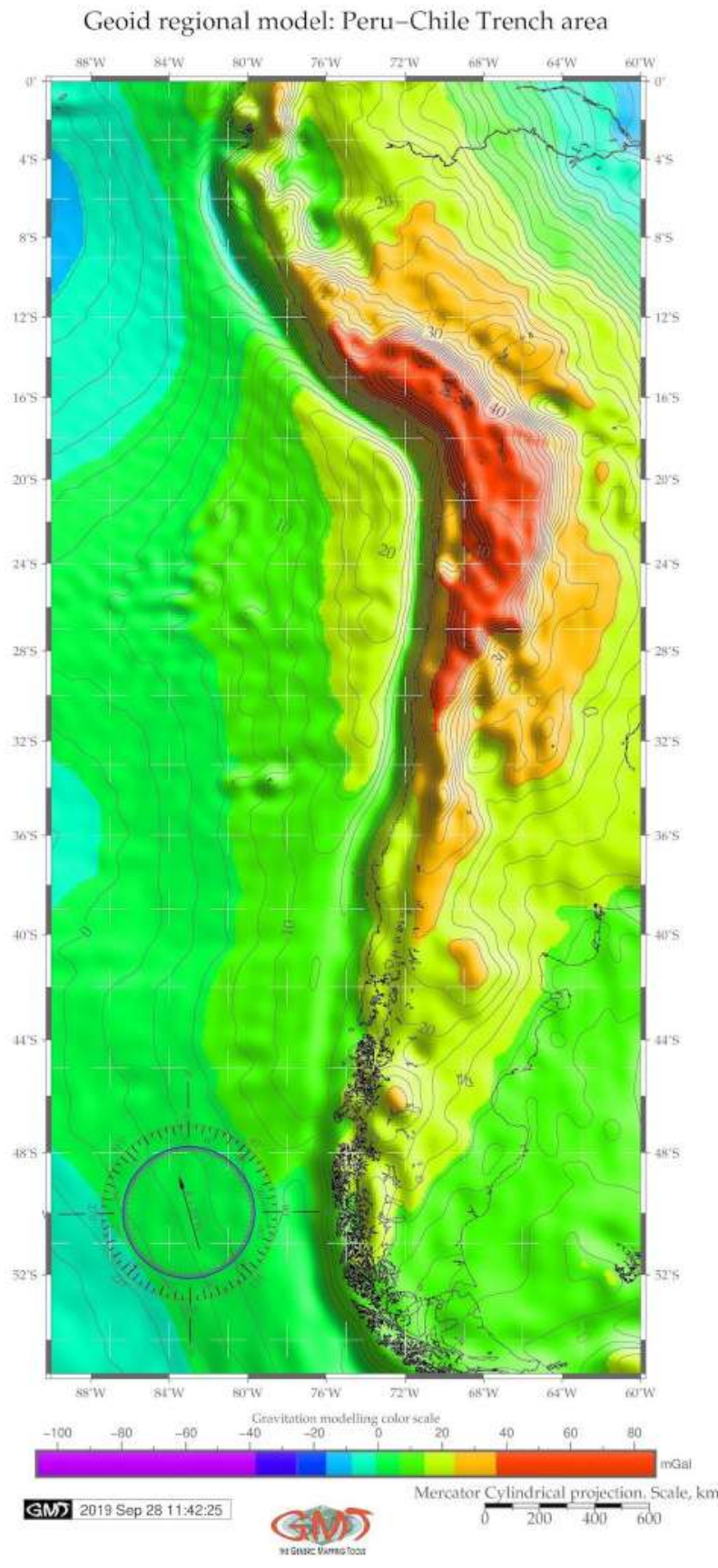

Map 2.4.3: Peru-Chile Trench: geoid regional model [411]

Volcanism intensity in the study area can be illustrated by recent documented tsunamigenic giant earthquakes: Valdivia earthquake, the largest ever recorded $(\mathrm{Mw}=9.5), 1960$ and the Maule earthquake $(\mathrm{Mw}=8.8), 2010$ [104].
Bathymetry of the PCT has following distinguished features. The continental margin of Southern Chile between $36^{\circ} \mathrm{S}$ and $39^{\circ} \mathrm{S}$ has intermediate shelf of width $20-30 \mathrm{~km}$ [728]. Here the gradient of the continental slope is inclined at $2.5^{\circ}-4.0^{\circ}$ with frequent irregularities: plateaus, slope basins and escarpments as steep as $10^{\circ}$. South Chilean slope is dissected by four major and some minor meandering submarine canyons (Biobío, Imperial, Tolten and Calle-Calle) connected to the large rivers flowing off the continent.

The Biobío Canyon ends in submarine fans where it enter the trench [711]. Slightly sinuous axial channel is observed in the Chilean Trench, with a width of a 7-10 km and depth ca. 150 $m$ [728]. It originates from the Chacao Canyon at $41^{\circ} \mathrm{S}$ and connected to the exits of the largest submarine canyon systems of the continental margin (Calle-Calle, Tolten, Biobío and San Antonio Canyons).

Nazca Plate forms oceanward boundary of the PCT, elevating ca. 100-400 m comparing to the trench and showing parallel geological lineaments. Nazca Plate has chains of 2-km-high seamounts aligned almost parallel to the complex subduction of the Valdivia and Mocha Fracture Zones [109], Map 2.4.2. More details on the complexity of the processes in the oceanic fracture zones, affected by high degree of hydration in the crust and upper mantle is discussed by [105]. Geophysical setting of the study area in the Peru-Chile area are shown on Map 2.4.4.

The PCT is formed by the subduction of the Oligocene oceanic crust of the Nazca Plate and Antarctic tectonic plates beneath the South American Plate at the PCT. The convergence rate of the Nazca Plate is $6.76 .9 \mathrm{~cm} / \mathrm{a}$ at an angle of ac. $80^{\circ}$ [192]. The tectonic setting of the trench is complex, formed by a set of the processes of tectonic plates subduction, sediments accretion and their implications on the PCT. The Mocha crustal block, configured by the PCT, Mocha and Valdivia fracture zones, lies on the Nazca Plate between ca. $37.5^{\circ}$ and $40^{\circ} \mathrm{S}$. It separates two segments Maule segment to the north and Chiloé segment to the south [104].

Subduction processes in a historical context of the evolution of the Nazca and Antarctic tectonic 
plates and their formation along the western margin of South America has been thoroughly described (e.g., [653]; [530]; [664]; [81]; [662]; [72]; [659]. Central Andes is a typical example of the convergent continental margin where the forearc, an important element directly reflects the interaction between the subducting and overriding plates [536]. The dynamic interaction between the active Chile Ridge and the continental margin determines the Taitao Triple Junction $\left(46^{\circ}-47^{\circ} \mathrm{S}\right)$.

North of the triple junction, Nazca Plate is subducted beneath the South American Plate in an ENE direction at a rate of $8.4 \mathrm{~cm} /$ year. To the south, the Antarctic Plate subducts along the E direction at only $2.4 \mathrm{~cm} /$ year [88]. The Nazca Plate adjacent the PCT is placed at the eastern boundary of the East Pacific Rise, which is the fastest-spreading ocean ridge on Earth. The Nazca Plate is bordered by two microplates: Easter microplate and the Juan Fernandez microplate. In turn, these include three major seamount chains: the Easter Seamount Chain, the Nazca Ridge, and the Carnegie Ridge [46]. The huge earthquake of 1960 resulted because of the subduction of the Mocha fracture zone which caused stress concentration and rupture of the Nazca Plate[100]; [727].

Main geomorphological structural units in Chile from west to east are Coastal Cordillera, Central Depression or Central valleys, and Andean Cordillera. The distinguished submarine geomorphological features of the PCT area include submarine ridges: Juan Fernández Ridge, Copiapó Ridge, Taltal Ridge, Nazca Ridge, and Iquique Ridge. The Iquique Ridge is composed of several seamounts (b1.5 km high) surrounded by a broad region of shallow seafloor, swelling up to 250 $\mathrm{km}$ wide in some areas and $>500 \mathrm{~m}$ in elevation. The submarine Taltal Ridge intersects the PCT at $25^{\circ} \mathrm{S}$ offshore [108]. Other geomorphic features are O'Higgins Guyot and Eastern seamount chain (Map 2.4.2). The place of bending of the PCT on two parts (Peru and Chile, respectively) is the Arica bend (Map 2.4.2).

The geomorphology of the subducted slab in the PCT region changes from flat to the steep one along its path beneath the Andes. The region where the Juan Fernandez Ridge is subducting beneath the continental margin $\left(27^{\circ}-33^{\circ} \mathrm{S}\right)$ correlates with a flat-slab subduction zone [88]. On the contrary, in north- and southwards direction from this area, the Wadati-Benioff zone, i.e. a zone of seismicity corresponding to the down-going tectonic slab in a subduction zone [605], is steeper.

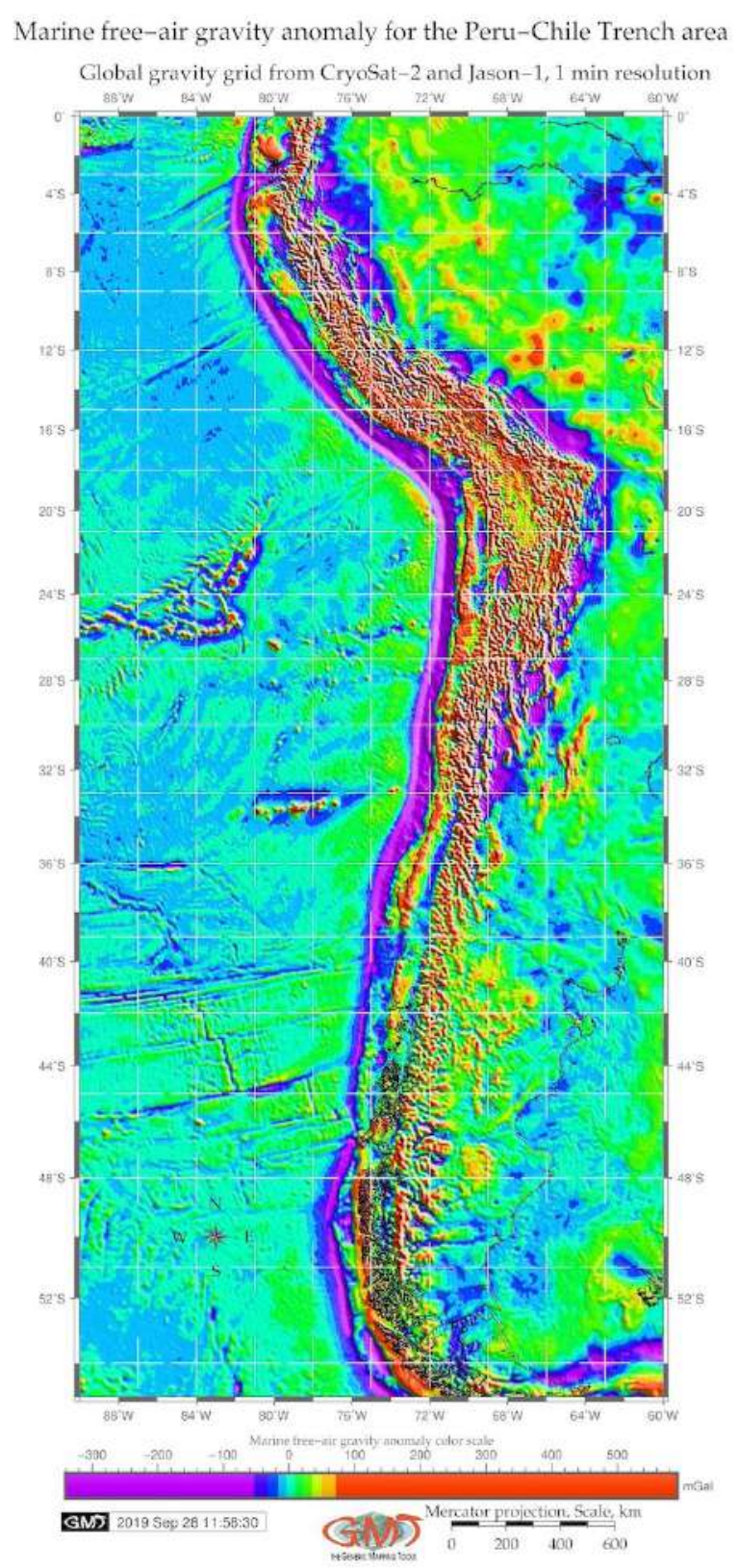

Map 2.4.4: Peru-Chile Trench: map of gravity surface model [411]

The flat-slab subduction zone is located northwards of the Taitao Triple Junction, or Chile Tripe Junction [43] where geomorphological feature of the Chilean Andes is characterized by the 
transverse river valleys that separates the Coastal Cordillera from the Andean Cordillera $\left(27^{\circ}-33^{\circ} \mathrm{S}\right)$. Southwards $33^{\circ} \mathrm{S}$, the geologic and geomorphic features in the Peru-Chine Trench region change due to the dip change of the subduction zone [88]. [536] report existence of $>60$ individual large-scale landslides located within the hyper-arid coastal Cordillera of the Atacama Desert, Northern Chile adjacent to the PCT. The system of such giant landslides, developed as a combination of rock avalanches and multiple rotational failures, is located along the coastline within a distance of ca. $650 \mathrm{~km}$ and contributes to the sedimentation of the PCT. Other sources of sediments can include earthquakes, e.g. sediment thickness in the PCT area in the region of 1960 earthquake ranged from ca. 300 to $700 \mathrm{~m}$, thus having significantly increased sedimentation [604].

Over 50\% of the world's deep-sea trenches are classified as sediment starved or partly sediment filled [193]. Northern part of the PCT, that is Peruvian segment, is classified as 'sediment starved', while southern part (Chilean segment) is 'partly sediment filled', as illustrated by [192]. As a response of sediment loading at the trench, the downward deflection of the trench plays a crucial role in determining its inlet sediments capacity (the amount of the subducted sediments). Weak and hot oceanic plates show more downward deflection at the trench due to sediment loading comparing to the old oceanic plates [107]. Thus, weak oceanic plate involves a larger space for sediment subduction.

From the environmental aspect of view, the Peru-Chile is considered as eutrophic, that is having high biological productivity and organic matter on the seafloor of the trench [348]. [187] illustrates the uniqueness of the biodiversity within the PCT system as follows: high concentrations of the nutritionally-rich organic matter also at 7800-m depth, high nematode densities (>6000 ind. $10 \mathrm{~cm}-$ 2). The geomorphology of the trench is crucial for the deep-sea biology. Geographic location and geomorphic structure of the trench have affects on its biomass. Trenches located closer to the continents receive more inputs of the organic matter from the adjacent shelves. This creates more food supplies for the continental slope with steep angles and less food for the slopes with low gradients.

The availability of the nutrients largely relies on the flux of the depositing organic-rich matter [720]. The content of the geological $\mathrm{CO}_{2}$ burial rates varies in the seafloor, with the increase in the Pacific basin [85]. Two distinctly different domains of the seafloor exist, on which carbon burial takes place: surfaces located by the fringes of the continents and the constantly submerged surfaces of continental slopes and the deep sea. The mixture of the geochemical components located at various depths of the continental slope and trench implies that sediments from upper to lower slope incorporate into a single bed [728]. Examples of the geochemical complex circulation, system of deposition and transport include [655]; [757]; [364].

Specifically for the PCT, larger downward deflection of the plate is found along the Chiloé segment than along the Maule segment [109]. Hence, according to the sedimentation conditions, the PCT can be divided into two main provinces: the main sediment-free province extending $8^{\circ}-32^{\circ} \mathrm{S}$ and the sedimentary province extending $33^{\circ}-57^{\circ} \mathrm{S}$ [231]. The margin off Isla de Chiloé is characterized by a largely sedimented segment of the PCT. This is caused by the extension of turbidite deposits seaward reaching $250 \mathrm{~km}$ from the trench axis [106]. The region close to the Taitao Triple Junction is nearly devoid of sediments and has rapid narrowing of the forearc region [43]. 


\subsection{Kermadec Trench}

Kermadec Trench (KT) is located in southwest Pacific Ocean, eastwards from Australia. It is located $120 \mathrm{~km}$ off the New Zealand with axis continuing from ca. $26^{\circ}-36^{\circ} \mathrm{S}$. It is the $5^{\text {th }}$ deepest trench in the world with a maximum depth of $10,177 \mathrm{~m}$ [285] $\mathrm{m}$ and a length of $1500 \mathrm{~km}$ [288], Map 2.5.1.

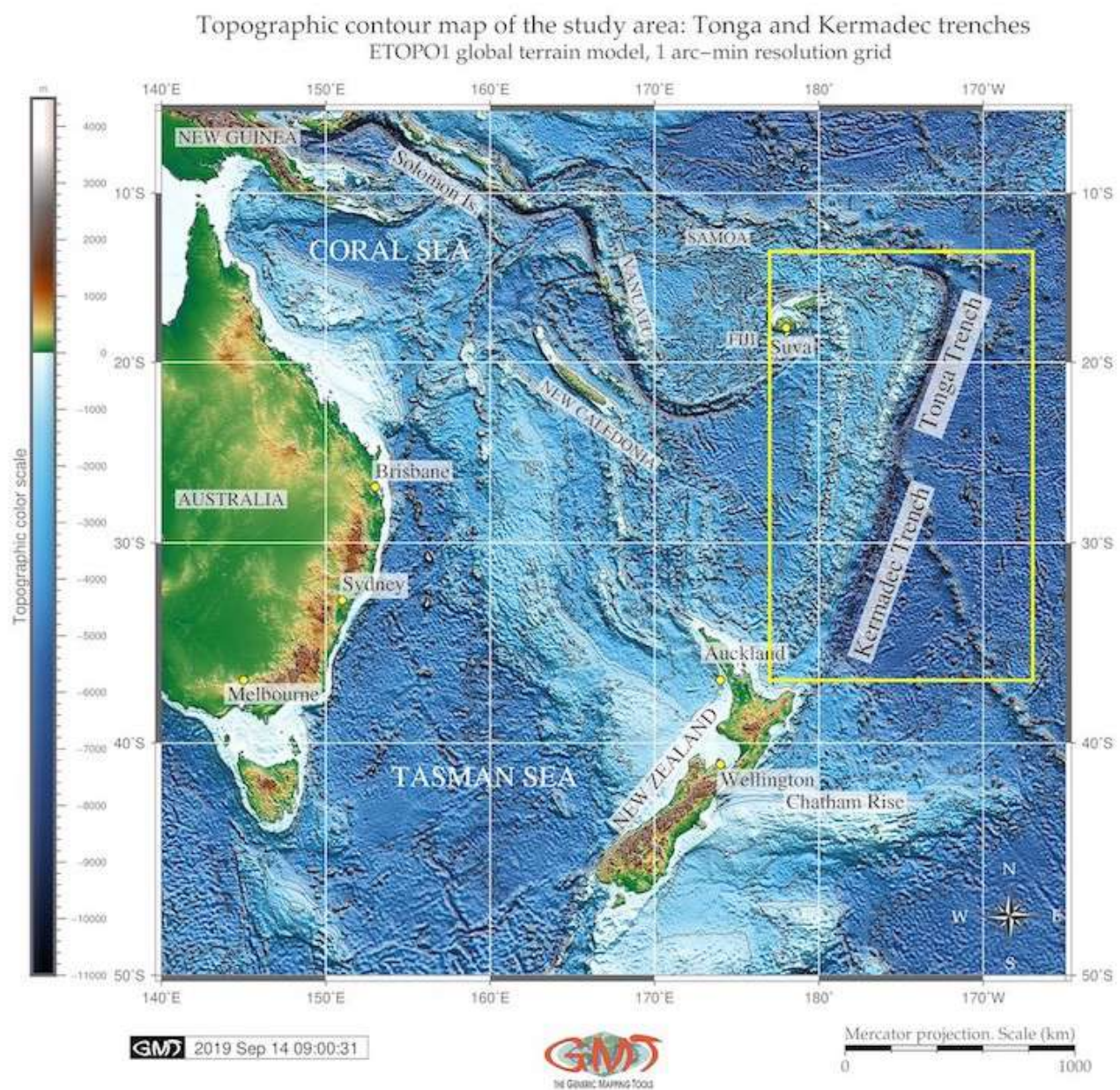

Map 2.5.1: Tonga and Kermadec trenches: bathymetric map, ETOPO1

Southward continuation of the KT is Hikurangi Trough located eastwards off the North Island of New Zealand lying between the southern end of the Cook Strait and the Chatham Rise. A convergence at maximal rate ca. $249 \mathrm{~mm} / \mathrm{yr}$ along the Tonga-Kermadec island arc system makes it one of the most seismically active subduction zones in the world [54].

Detailed description of the environmental, geological and tectonic settings of the KT is in [685]; [12]; [615]; [684]. The majority of research on KT focus on the biota communities of the deep-sea ecosystems [358], [360], [576] or tectonic plates in the Pacific Ocean [146], [706]. Example of the morphological heterogeneity affected by the geographic isolation of the KT gives a case study of New Hebrides and KT, SW Pacific Ocean [347]. The effects of the geographical proximity and geological ages of the KT, bottom current patterns and bathymetry on the patterns of the biogenetic structure are explained by geographical isolation and demographic independency of the marine species which preserve species endemism [626]. 


\subsection{Tonga Trench}

Tonga Trench (TT) is located in southwest Pacific Ocean, eastwards from Australia northwards from the KT. The study area is focused on two hadal trenches located in south-west Pacific Ocean northwards from Australia and New Zealand: KT and Tonga. Their brief geographic description can be characterized as follows.
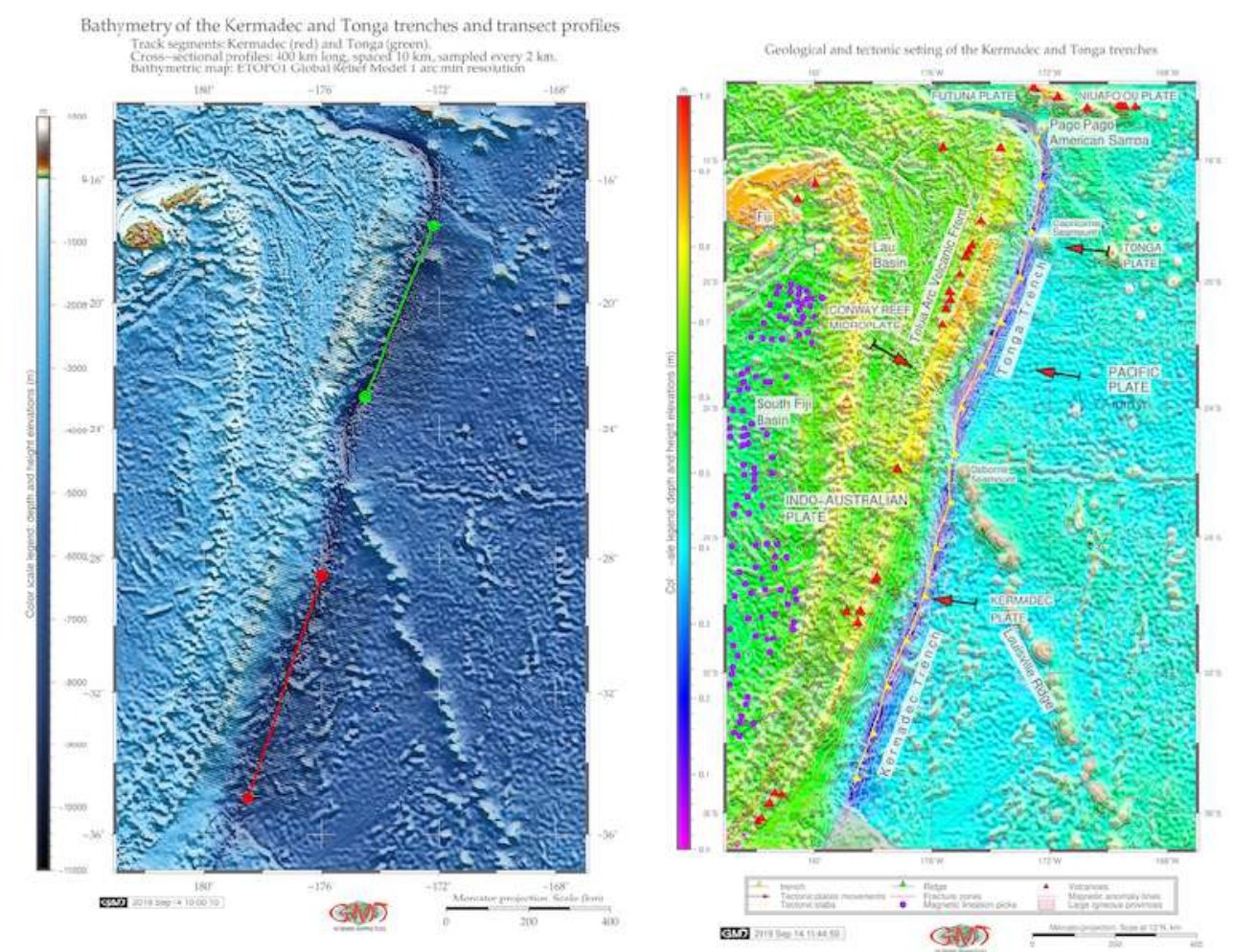

Map 2.6.1: Kermadec and Tonga trenches: transect segments; geologic and tectonic settings.

Its closeness to the Antarctic makes it to be one of the coldest trenches in the world [47]. KT runs parallel to the Kermadec Ridge (southern part of the Tonga-Kermadec Ridge) with geomorphology of Vshape formed by tectonic subduction of the Pacific Plate under the Indo-Australian Plate extending from approximately $26^{\circ}-36^{\circ} \mathrm{S}$ near the northeastern tip of New Zealand's North Island [359]. The specific conditions of the tectonic setting in the study area is the subduction of the Pacific Plate at a rapid rate beneath the Indo-Australian Plate along the Tonga-Kermadec Trench [86], Map 2.6.1, right.

Similar to KT, TT belongs to the South Pacific Subtropical Gyre (SPSG) biogeochemical province and has the same primary productivity rate of $87 \mathrm{~g} \mathrm{C} \mathrm{m-2} \mathrm{y-1} \mathrm{[751].} \mathrm{TT} \mathrm{is} \mathrm{adjacent,} \mathrm{continuing} \mathrm{KT}$ northwards with axis stretching from ca. $15^{\circ}-26^{\circ} \mathrm{S}$. Located in close proximity to the KT, it is separated by a sill located on the Tonga Platform [747] and by the Louisville Seamount Chain [289] (Map 2.6.1, right). With maximum depths of $10,882 \mathrm{~m}$, TT is the $2^{\text {nd }}$ deepest trench in the world [60]. Both trench axes have roughly $30^{\circ}$ slight from the longitude line. Due to the complex interaction of various factors (ocean currents, closeness to the Antarctica) the deep Pacific Ocean seafloor underlying the trenches is notable for variable surface productivity [505]. Further studies on TT, its environment and communities can be found in relevant literature [706]; [161]; [237]. 


\subsection{Vanuatu (New Hebrides) Trench}

The Vanuatu Trench (VT) (alternative former spelling: New Hebrides Trench) is located in Fiji Basin, East Australia [388].

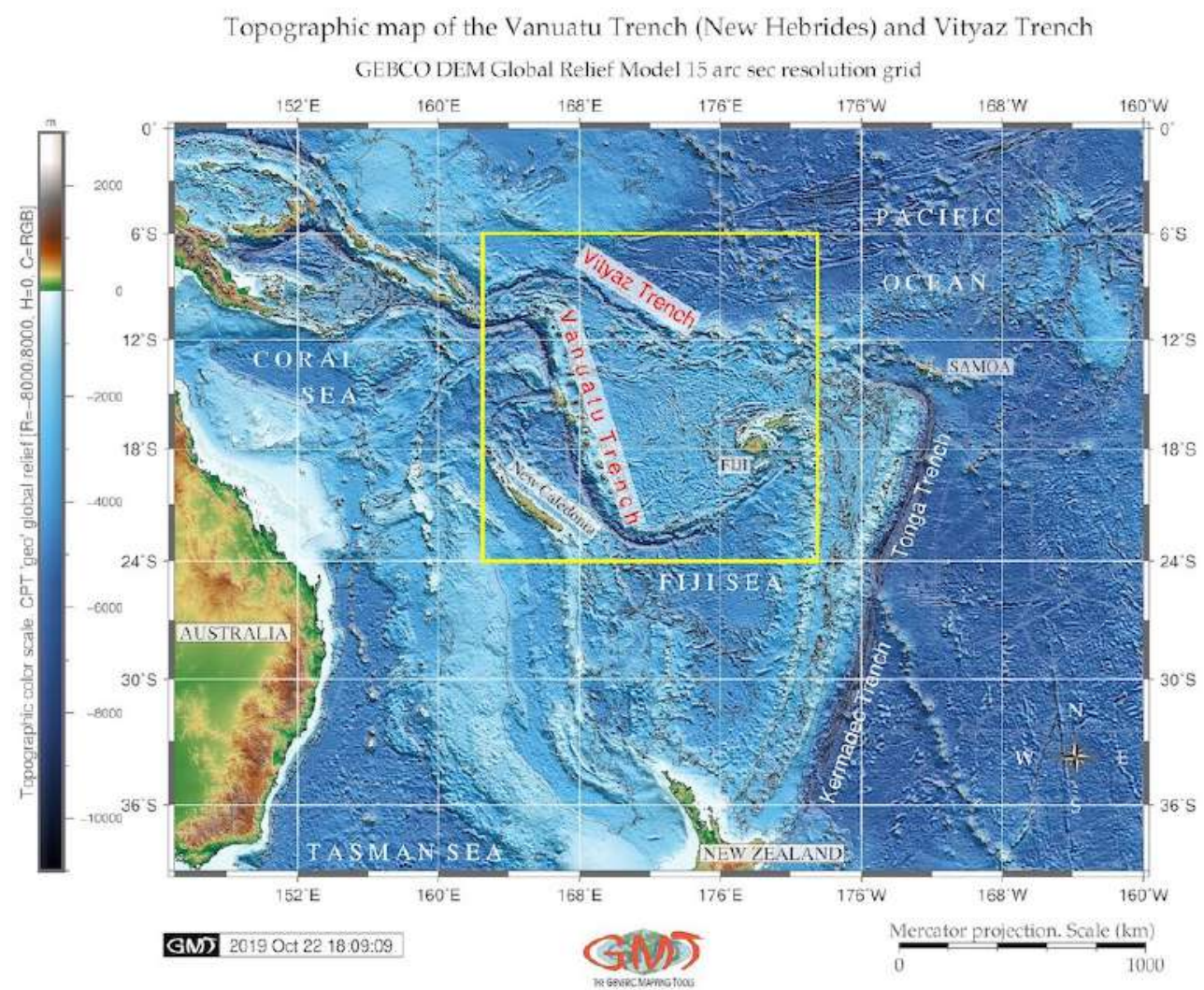

Map 2.7.1: Vanuatu and Vityaz trenches: topographic map

The region is notable for complex geophysical settings which resulted in the formation of the trenches, high seismicity, geodynamic complexity and seismic instability. Vanuatu (New Hebrides) trench-arc system divides the New Hebrides back-arc troughs and the active North Fiji marginal basin. The Vanuatu arc stretches ca. $1200 \mathrm{~km}$ in the SW Pacific Ocean located in the area with coordinates $10^{\circ}-23^{\circ} \mathrm{S}, 160^{\circ}$ $180^{\circ} \mathrm{E}$ (Fig. 2.7.1). Narrow VT is bordered by the Vanuatu volcanic archipelago (New Hebrides), which is a submersed part of an oceanic island arc that extends between $12^{\circ} \mathrm{S}$ and $25^{\circ} \mathrm{S}$, between the Torres to Hunter Islands [294], $1000 \mathrm{~km}$ to the northwest of the KT. Geomorphology of the VT is reported [234] to have masses of rubble, talus slopes and fragmented outcrops [407].

VT is a shallower trench of ca. $7156 \mathrm{~m}$. Relative to other neighbour trenches (KT, Mariana Trench (MT)), it is warmest, and underlies intermediate bio-productivity [505]. VT has developed in a situation of complex tectonic settings. More specifically, it is located in a double convergent boundary between the Australian and Pacific tectonic plates [36]. The tectonic development of the VT has two distinct subduction stages [294]: 1) subduction of the Pacific Plate under the Indian-Australian plate westward direction; 2) subduction of the Indo-Australian plate beneath the North Fiji back-arc basin at the margin of the Pacific Plate, north-eastwards direction. Therefore, the convergence is marked by two opposite subduction zones, defined by the VT to the west and the TT to the east, resulting in an asymmetric opening of the North Fiji back-arc basin [21]. 


\subsection{Vityaz Trench}

Vityaz Trench (VtT) is located in the North Fiji Basin, East Australia [388]. It belongs to the New Hebrides trench-arc system, caused by the Indo-Australian subducting tectonic plate and a subduction of the d'Entrecasteaux ridge [91]. This area is notable for the double convergent complex boundary where Pacific Plate subducts under the Indian-Australian plate westwards, and Indo-Australian plate beneath the North Fiji back-arc basin northeastwards [388].

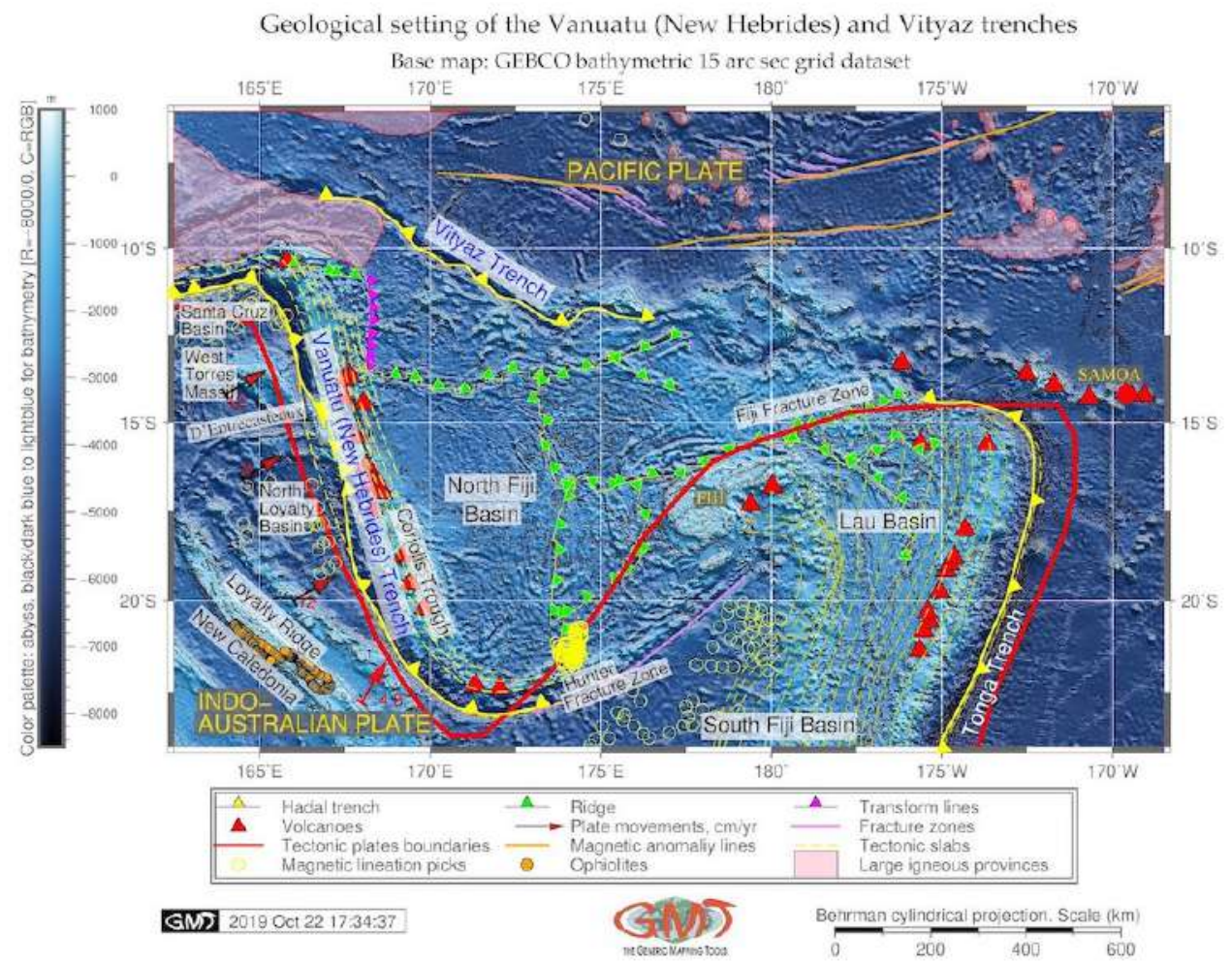

Map 2.8.1: Vanuatu and Vityaz trenches: geologic map

Previous surveys on bathymetry, magnetism, seismicity and focal mechanism in the region between the southern New Hebrides Arc and North Fiji Basin enlighten the geodynamic complexity and instability of the area [526], [388]. An active volcano Mt. Yasur is located in Tanna Island of the Vanuatu arc [692]. Discussions on the geologic setting of the VT exist in literature [555]; [691]; [721]; [519]; [68]; [598], where particular attention is paid to geochemistry, mineralogy, magmatism, volcanology, seismicity and tectonics of the region [407]. The New Hebrides island arc consists of numerous volcanoes that frequently form islands situated in a tectonically complex arc-backarc system [44], [79], Fig. 2.8.1.

Three flat, mainly covered by forests, islands of Maré, Lifou and Ouvéa may illustrate tectonic deformation at various distances from the VT. Loyalty Islands serve as tension cracks resulting from the elastic bulging of the Australian plate before its subduction at the VT [62]. The New Hebrides archipelago is a complex reversed-arc system that divided into four major volcanic provinces [83]:

1. Western Belt is an Early Miocene extinct volcanic arc in the frontal arc;

2. Eastern Belt formed in the Middle Miocene, a calc-alkaline arc volcanism;

3. Marginal Province submerged in the Early Pleistocene is shown by volcanic activity; 
4. Central Chain is a present volcanic line continues Marginal Province volcanism;

The anomalous morphology of the central New Hebrides arc is caused by the subduction of the DEntrecasteaux aseismic ridge which enters the central part of the VT. Besides, there is a deformation distributed over numerous spreading ridges in Lau and North Fiji back-arc basins. Geometry of Lau and North Fiji back-arc basins and segmentation of the New Hebrides arc are significantly influenced by the subduction of aseismic ridges: Louisville, D'Entrecasteaux and Loyalty [594], [388] (Fig. 2.8.1). The basaltic rocks from the central and southern islands of the New Hebrides (Aneityum, Tanna, Erromango, Efate, Emae, Tongoa and Epi), have geochemical features typical of island arc volcanics. The basalts from Futuna Island display characteristics typical of calc-alkaline rocks [147].

Conversion of the two tectonic plates at the ocean margins causes sinks or subduction of the oceanic plates. The mechanism of faulting in the subducting plates at the trench is well described [777]; [776]. The terrestrial crust appearing at the top of this new layer is formed either by new masses of the terrestrial crust caused by the arc volcanism, or because of the piled up sediment deposits coming from the subducting lower tectonic plate [262]. Therefore, ocean margins with high seismicity, repeated earthquakes and volcanism indicate areas of the collision and movements of the ocean plates and active sedimentation, where trenches are located. Such and other geodynamic processes of the deep subduction take place of the Pacific Plate underneath cause extensional events and volcanism [779]. Specific changes in the geochemical content of the underlying seafloor has also beed detected.

Factors affecting plate subduction include hydrothermal factors [763], buoyancy forces, rheology of mantle minerals, stabilities of hydrous minerals, partial melting, mechanisms and rates of melt migration, kinetics of phase transformations, mechanisms of deep earthquakes, geochemical recycling, and the processes of continental collision that result from the subduction [545]. One fundamental problem concerns the depth to which subducted lithosphere penetrates into the mantle because this is related to the scale of mantle convection and the Earths evolution.

Finally, active sedimentation on the bottom of the seafloor leads to the accumulated amount at rifted margins which contributes to the formation of the VtT. Sediments outflowing further to the ocean provide important geological bodies and resources. Natural hazards taking place in the ocean, strongly correlate with submarine earthquakes and volcanic eruptions during active rifting [74]. Moreover, there is a certain correlation between the high oceanic features and thickness of the subduction channels and earthquake rupture segments [108]. VtT result from the complex geodynamic processes that continuously shape the surface of the trench' seafloor [64], [407]. Nowadays, the its seafloor demonstrates footprints of the many continuous steps of the seafloor evolution.

Tectonic plates act as giant radiators of the heat cooling, thickening, and gradually subsiding by progressing from ridge to trench. For example, it explains the appearance of the double seismic zone beneath the Mariana island arc [647]. In such a way, tectonic plates form the large-scale pattern of the system of ridges and deep ocean basins. The deformation of the upper plates together with surface migration of the ocean trenches of the Pacific Ocean are the prevailing observables of the dynamics of the inter parts of the plates [546]. 


\subsection{New Britain (Bougainville) Trench}

The New Britain Trench (NBT) (a.k.a. Bougainville Trench) is located eastwards off Papua New Guinea as northern borders of the Solomon Sea, Pacific Ocean (Map 2.9.1) [383]. The region is one of the world's most active subduction zones at the triple junction of the Pacific Plate, Indo-Australian Plate and Solomon Sea Plate. The Woodlark Basin subducts beneath the Solomon Islands arc region, forming a double-sided subduction zone [760]. As the region is situated in the complex zone of the convergence at the tectonic plates boundary, it is trapped between the converging Ontong Java Plateau and Australia. Geologically, the area belongs to one of the most prospective for intrusion-related mineral deposits [250], [383].

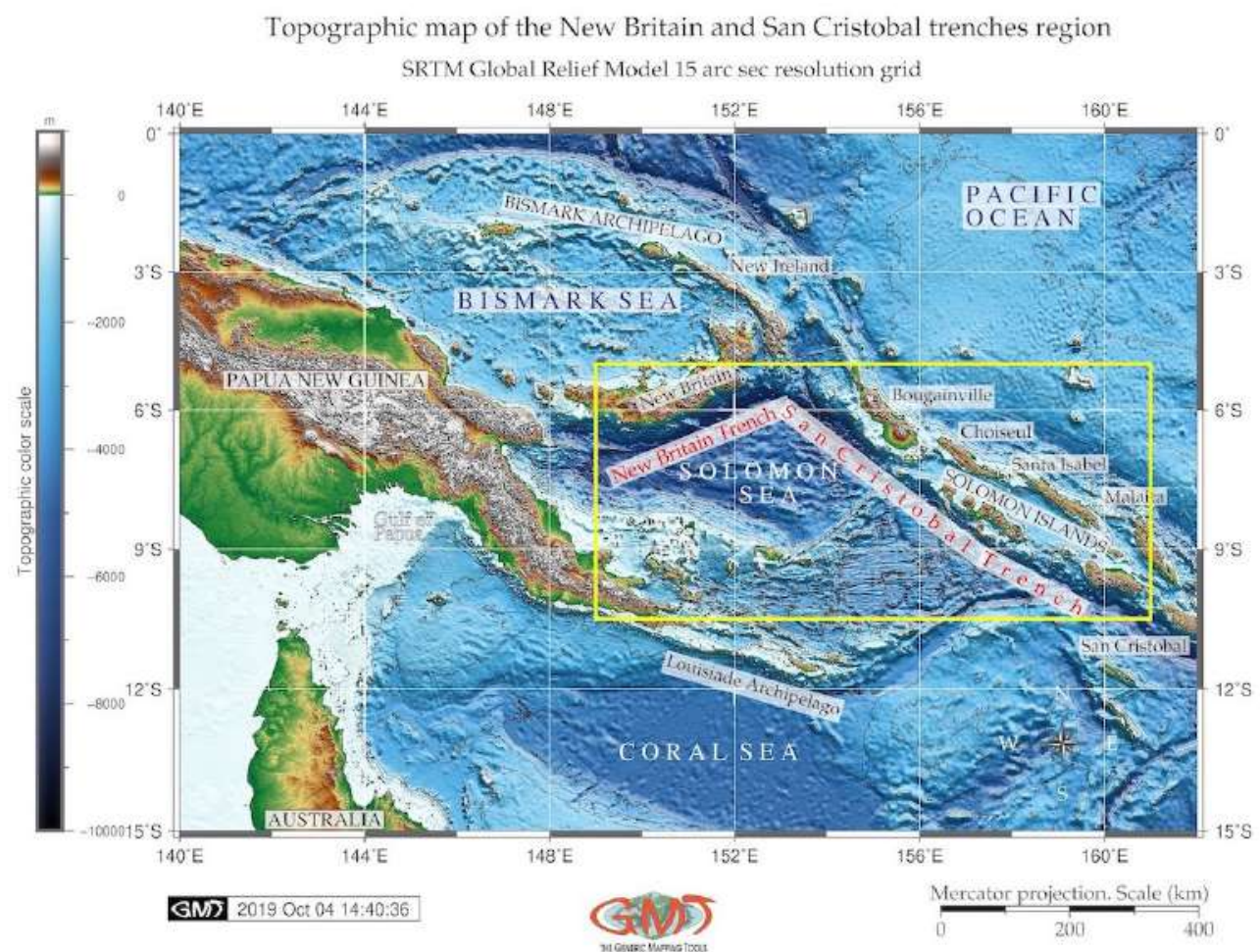

Map 2.9.1: New Britain and San Cristobal trenches: topographic map

NBT is defined by the $6,000 \mathrm{~m}$ isoline. It is a narrow, $50-75 \mathrm{~km}$ wide trench extending northeasterly from the eastern end of the Huon Gulf along the south coast of New Britain [529]. Its name is derived from the homonymous New Britain Island from the New Britain arc (Map 2.9.1) [383]. Its western extension are the north-dipping Ramu-Markham Fault zone and the West Bismarck arc [1]. Northern part is characterized by the Bismark Sea back-arc basin (Fig. 2.10.2) where active rifting and seafloor spreading take place. The Bismark Sea back-arc basin comprises the South and North Bismarck microplates separated by the Bismarck Sea fault [708]. The islands of eastern Papua New Guinea and the Solomon islands are island arc terranes, surrounding NBT, formed adjacent to the boundary between the Australia and Pacific plates [25].

The subduction along the NBT is crucial for the tectonic development in Papua New Guinea because comparing to other Pacific trenches, it differs in its seismic structure [502]. Thus, it indicates a steeply dipping $\left(>80^{\circ}\right)$ structure to upper mantle depths $(630 \mathrm{~km})$, unlike other Pacific trenches where dips range between $45^{\circ}-60^{\circ}$. Active volcanic arc along the north coast of New Britain Island (Fig. 2.10.2, red triangles) correlates with the subduction curve along the NBT [383]. More discussion on NBT tectonics 

and structure exist in existing papers [737]; [110]. 


\subsection{San Cristobal Trench}

San Cristobal Trench (SCT) stretches in SE direction from the junction from the New Britain along the group of Solomon Islands: Bougainville, Choiseul, Santa Isabel, Malaita until it reaches San Cristobal Island from which it derived the name. The Woodlark Basin is adjacent to the SCT to the southwest and to the south of the Solomon Islands arc region (Fig. 2.10.2) [383]. It is a young (ca. $5 \mathrm{Ma}$ ) oceanic basin that subducts beneath the NBT [760]. The eastern part of the Solomon Plate bordering the SCT, enters the front of the Pacific Plate. As a consequence, it results of significant earthquakes along the Solomon Plate [756].

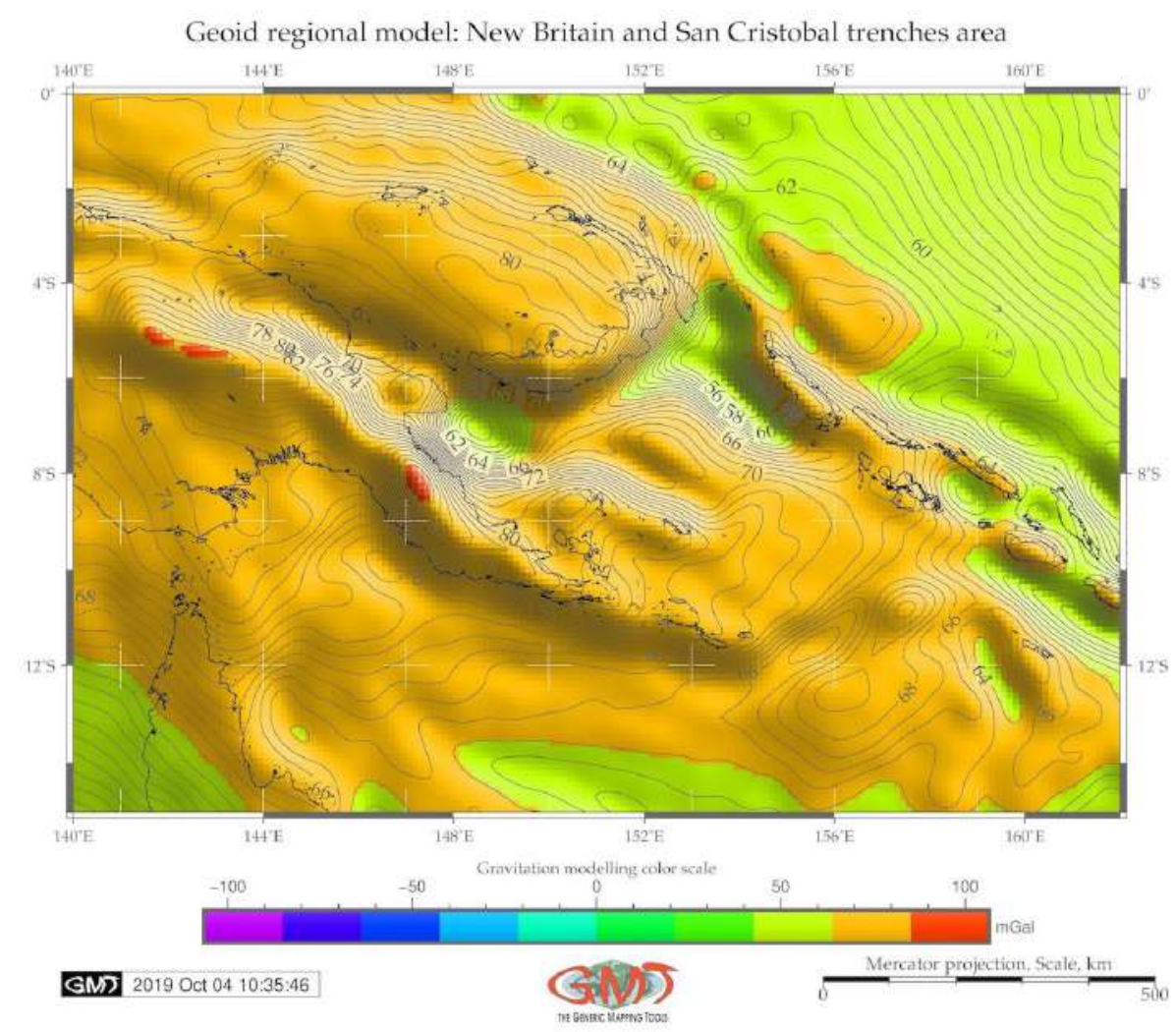

Map 2.10.1: New Britain and San Cristobal trenches: geoid model map

The environment of the hadal trench presents a complex system with highly interconnected factors affecting geomorphological structure, formation and development of the trench: slabs and tectonics plates, bathymetry, geographic location, geologic structure of the underlying basement and sediment thickness [433]. Further detailed explanation on structure and these factors can be found in existing literature [124]; [171]; [716]; [298]; [503]; [625]; [252] describing bathymetry, geomorphology, sedimentation, submarine canyons and terraces of the NBT. However, these work are mainly restricted to the western part of the Solomon Sea and are based on the existing data at that time. Current study proposes a comparative analysis of the NBT with its contiguous SCT. Moreover, this study is supported by modern datasets (SRTM $15 \mathrm{sec}$ Digital Elevation Model (DEM), gravity and geoid grids) using fine cartographic toolset GMT. 


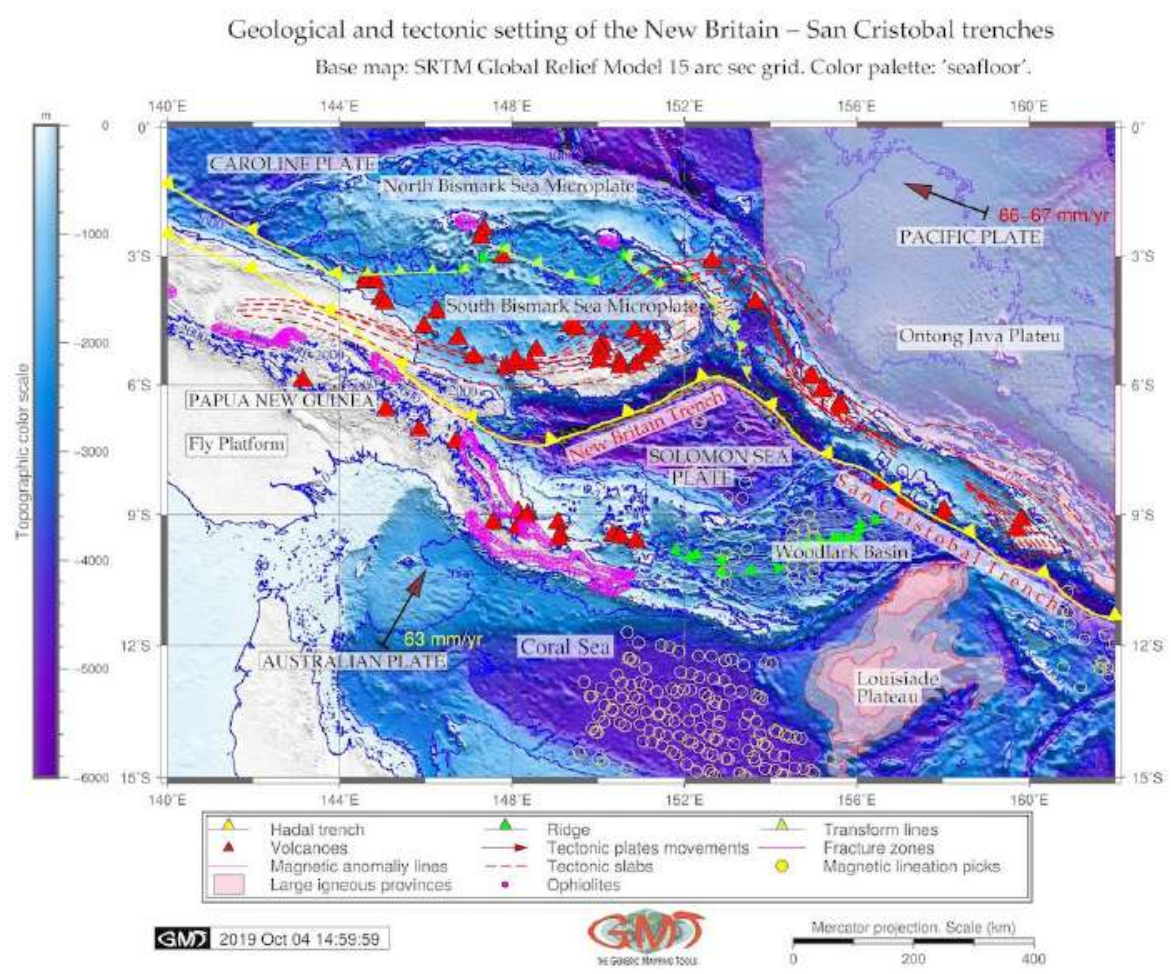

Map 2.10.2: New Britain and San Cristobal trenches: geological and tectonic map

Marine free-air gravity anomaly: New Britain and San Cristobal trenches area Global gravity grid from CryoSat-2 and Jason-1, 1 min resolution

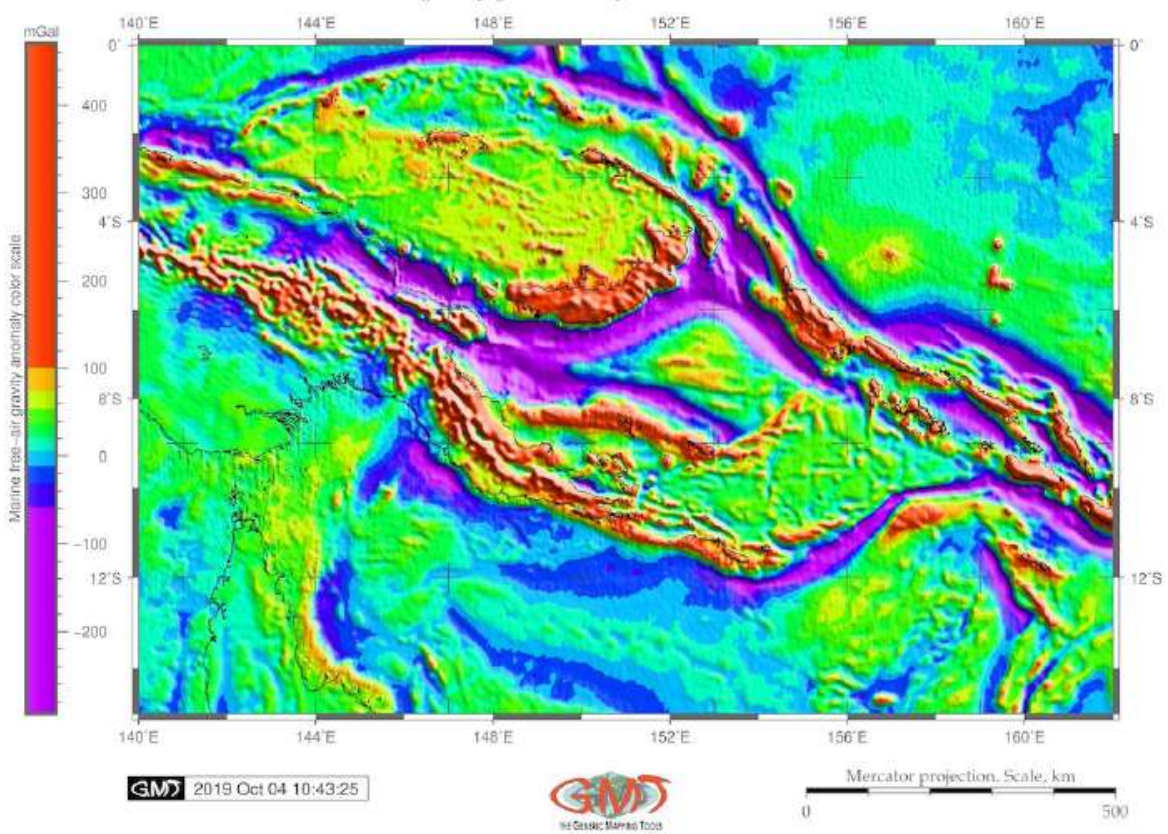

Map 2.10.3: New Britain and San Cristobal trenches: gravimetry model map 


\subsection{Philippine Trench}

Philippine Trench (PT) is located in the axe of the collision of the Philippine Sea Plate (PSP) and Sunda Plate, west Pacific Ocean.

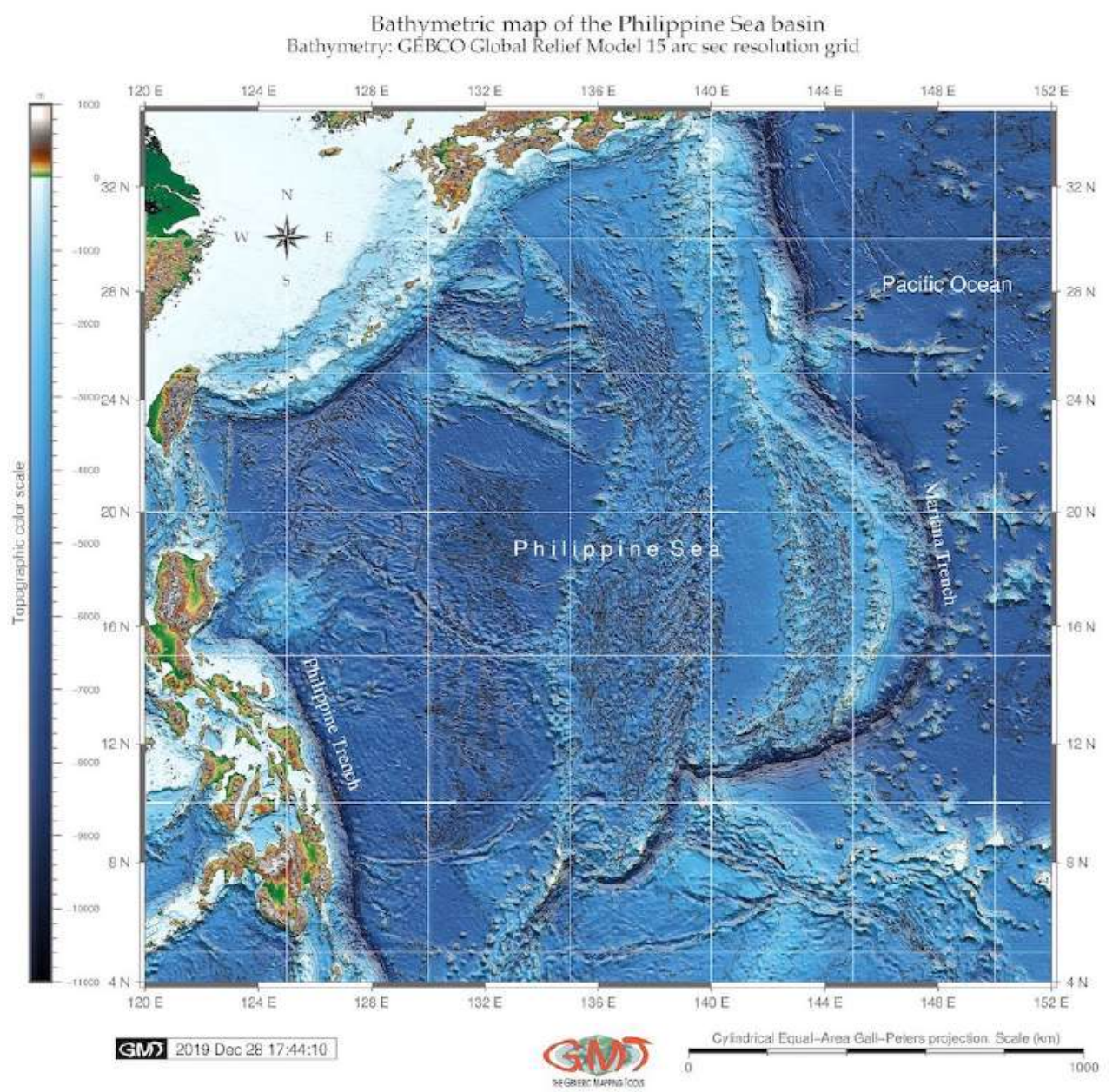

Map 2.11.1: Philippine Sea Basin: GEBCO based bathymetric map

PSB is marked by the complex interaction of three lithospheric plates: Eurasian, Australian and the PSP, which includes collision, subduction and accretion. Old, heavy and large $\left(103,300,000 \mathrm{~km}^{2}\right)$ Pacific plate plays the major role comparing to the Australian Plate $\left(47,000,000 \mathrm{~km}^{2}\right)$ and the PSP 5,500,000 $\mathrm{km}^{2}$ [7]. The morphology of the Pacific plate has a low dip angle at shallow depths. The PSP, a large and tectonically complex region of the western Pacific located between the Pacific, Eurasian and Australian plates, is the worlds largest marginal basin plate [664]. The PSP has two back-arc basins formed in Oligocene to Miocene period: Parece Vela and Shikoku Basins (Fig. 2.11.2).

Slab dynamics is one of the important driving forces for the trench formation affecting the mechanisms of its migration (retreat or advance). It is therefore crucial to characterize the origin of the subducting slab morphology in the deep mantle identifying the features of subduction zones, which are among the fundamental issues of solid Earth [761]. Effects of slab mineralogy and phase chemistry on the subduction dynamics (buoyancy, stress field) kinematics (rate of subduction and plate motion), elasticity (deformation and seismic wave speed), thermometry (effects of latent heat, isobaric superheating) and seismicity (adiabatic shear instabilities) are discussed previously [56]. 


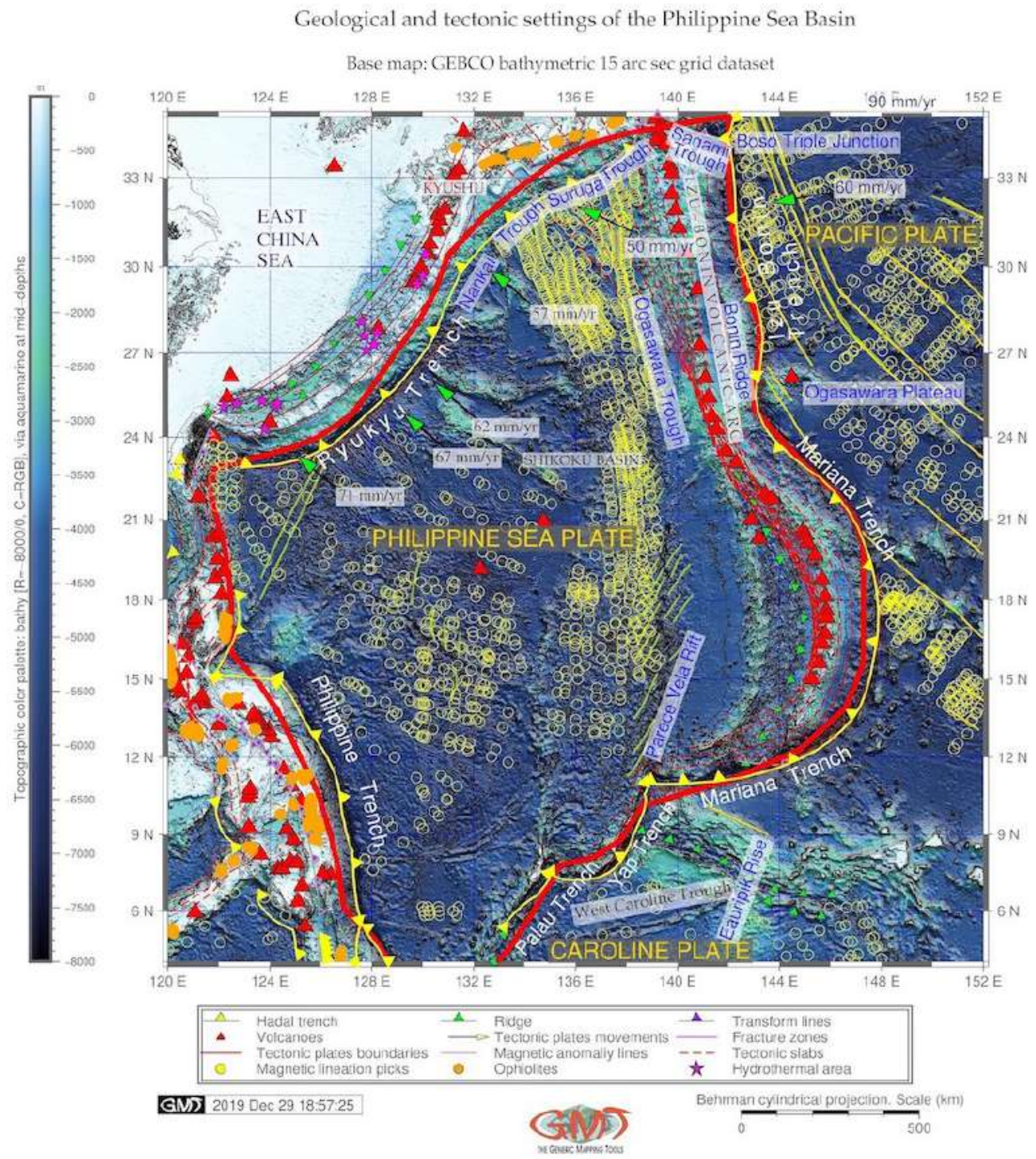

Map 2.11.2: Philippine Sea Basin: Geologic map.

The geologic map shown on Fig. 2.11.2 indicates boundaries between the lithospheric plates (solid red lines). Yellow fronts denote trench axes. Tectonic slab contours are depicted by the red dashed lines. Green arrows and relevant numbers indicate the convergence rates ( $\mathrm{mm} / \mathrm{year}$ ) along the trenches. Magenta triangles denote hydrothermal areas mostly located along the trench. The morphology and development of the subducted slabs are complex [97], on either mantle flow or convective layering at 660 $\mathrm{km}$ depth. Slabs can deflect horizontally in the upper mantle transition zone beneath some convergent margins whereas penetration to lower mantle depths occur beneath other island arc segments. As a result, different styles of the subduction across the upper mantle transition zone affect trench formation and are reflected in its geomorphology.

Double seismic zone beneath the Mariana Island arc is explained [647] by the following conceptual scheme of the processes of the global plate tectonics. Subduction of the cooled plate into the mantle causes formation of the deep ocean trenches where, as a consequence, earthquakes and tsunamis originate. Active volcanism and seismic situation around Mariana arc show recorded events at the cross-sections of the earthquake transects. Subducting lithospheric plates act as giant radiators of the heat cooling, thickening, and progressively subsiding from ridge to trench. As a result, spreading seafloor, affected by 
moving plates, creates an axial rift, corrugated hills, and ridges, formed by the nearby faults.

Plate subduction along the Izu-Bonin Mariana arc (IBM) trench caused trench roll-back, arc rupture and back-arc rifting of two interconnected back-arc basins: Parece Vela and Shikoku Basins. The Kyushu-Palau Ridge (KPR), a remnant arc of the active IBM system results from the spreading of the Shikoku Basin (Fig. 2.11.2). It plays a key role in the subduction process of the west Philippine Sea Plate: the subduction zone here is characterized by the KPR subducting beneath the Kyushu Arc (Fig. 2.11.2) [82]. A set of various geo dynamic processes including subduction-interface rheology, phase-transition buoyancy, slab stagnation, rollback of mantle and ridge-push effects, cause significant trench motion of the IBM detected as advance by global plate-motion observations [101].

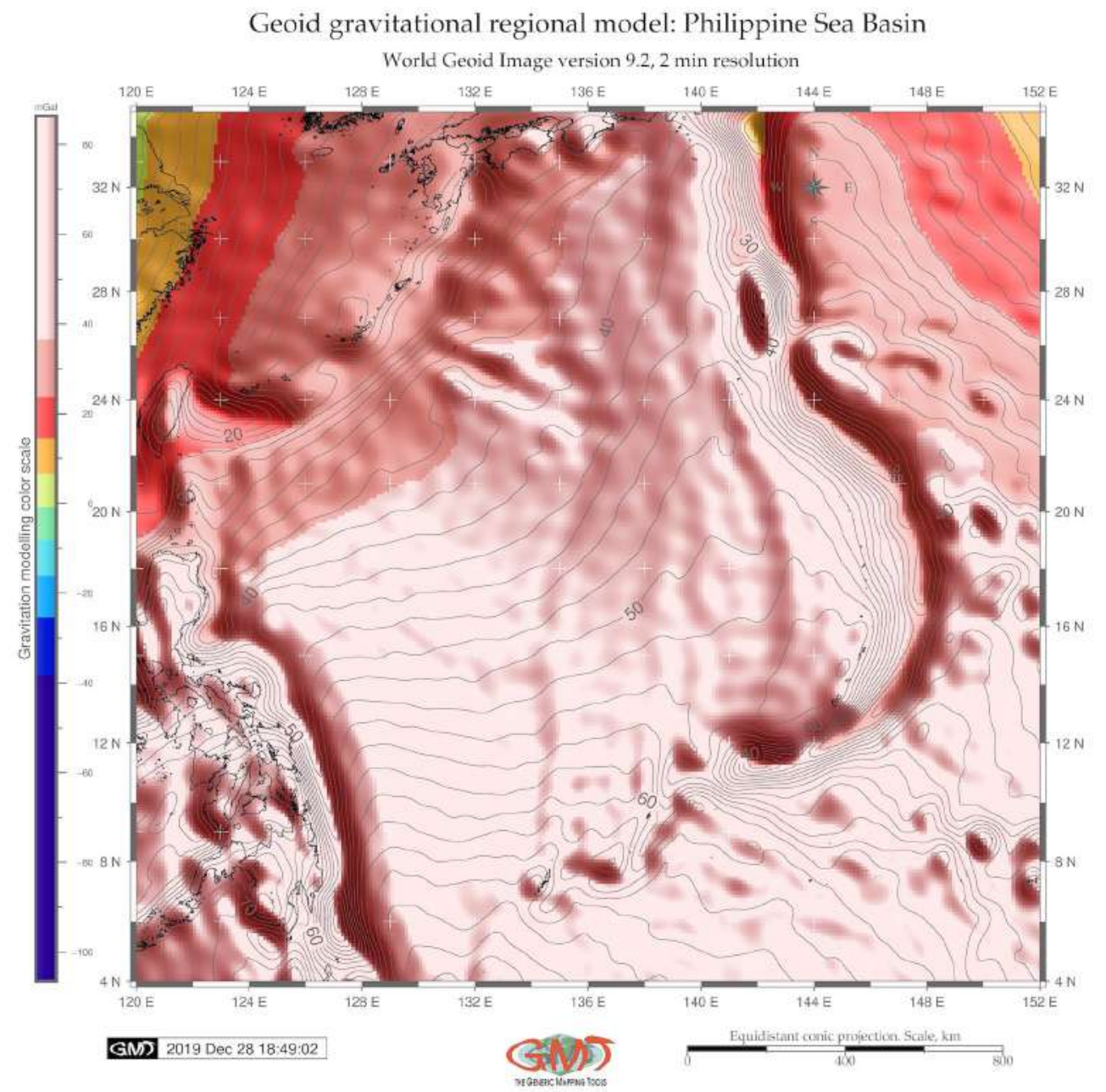

Map 2.11.3: Geoid model of the PSB

Seismic phenomena is the PSB (Fig. 3.3.5) can be explained as the result of tectonic processes at the edges of the lithospheric plates that spread apart at the ocean ridges along the large strike-slip faults and converge at the hot and weak volcanic island arcs of IBM and the Philippines. Seismicity map (Fig. 3.3.5) in the PSB area shows that most earthquakes are confined to the marginal areas presenting a narrow, continuous belts around large stable areas of the PSP. The activity differs by divergence and convergence zones being moderate in the zones of plate divergence and including deep shocks at shallow depths in the zones of plate convergence. Seismic data on focal mechanisms are presented at Centroid Moment Tensor (CMT) catalogue which gives a relative direction of tectonic plates motion throughout active 
belts. Focal mechanisms point at relative motions of the lithosphere plates determined from magnetic and topographic data associated with the zones of plate divergence.

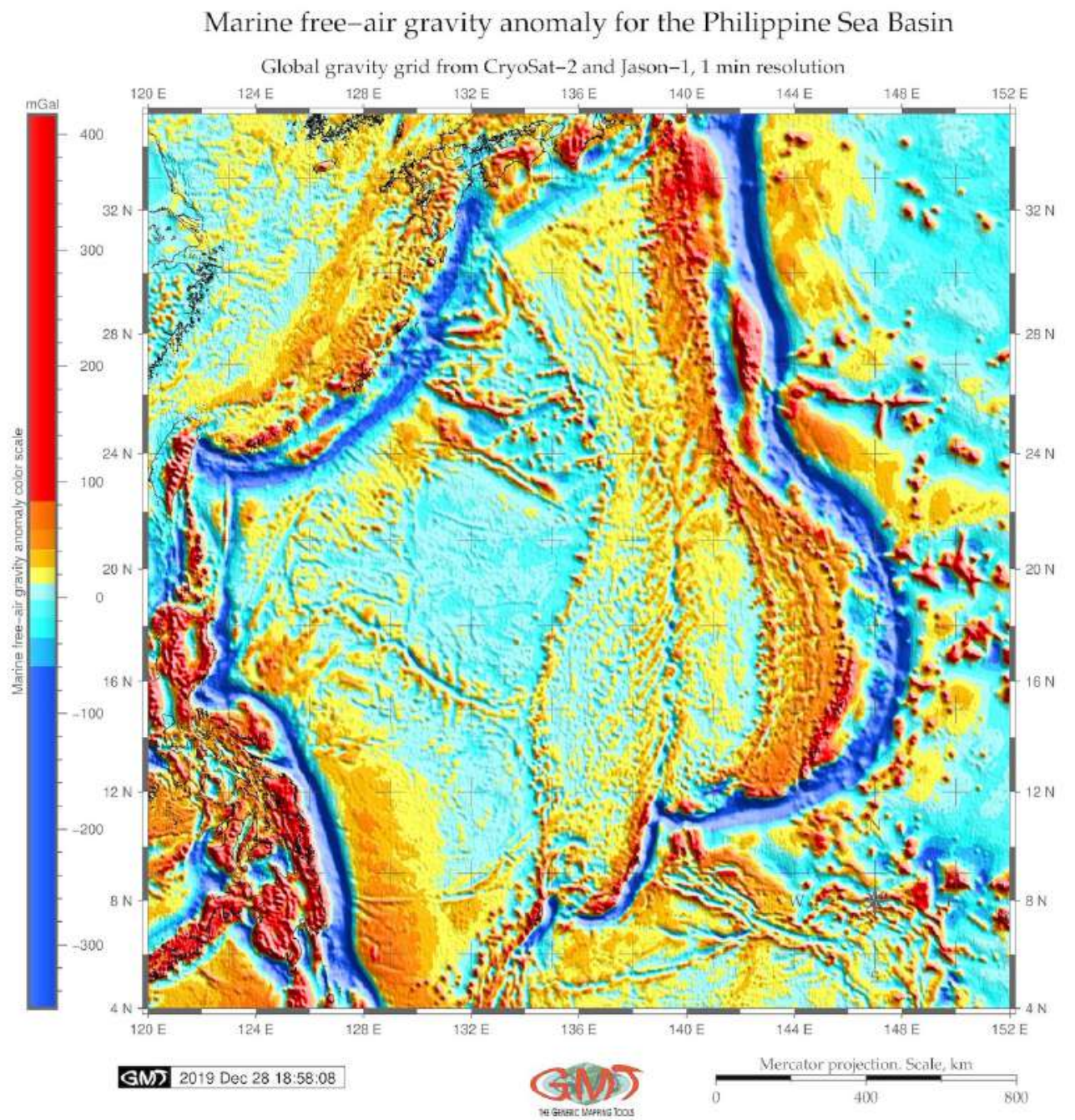

Map 2.11.4: Gravity model of the PSB

A phenomena of the deep-sea trench includes its migration that depends primarily on the age at the trench [165], [217]: located on the place of the subduction plate boundary at a given time, the trench may change its location over time as a result of the complex processes of the global plate tectonics. As proved by [350], trench migration and hence, geomorphic fluctuations, depends on the lower plate parameters and controlled by the subducting plate velocity $V_{s u b}$. From the more recent publications on PT dynamics it has been noted [761] that fluctuations in the trench dynamics affect slab morphology and character. Another particular feature of the PT regions is tectonic plate tearing in the northwestern corner of the subducting PSP discussed in detailed by [497].

[766] keep track of the lateral fluctuations in the upper mantle structure of the PSB, which is later more detailed studied by [767] with a more close focus on the geophysics across the Philippine Sea. In some previous case studies [542]; [524]; [570], using available methods of the oceanographic mapping existing at that time, the geomorphic patterns of the deep-sea channels, submarine fans and their topography were analyzed with regards to the deep-water sedimentation [134], mid-ocean ridge tectonics and volcanism, dynamics of the Philippine back arc [90]; [181]; [220], eaqthquakes and gravitation [499]. 
There are proven relationships between the geomorphic structure of the submarine landforms and sedimentation in the selected parts of the Ocean [138]. Other factors include oceanology as underwater currents [197], geology [225], tectonics [226], earthquakes in the Western PSP [496], accumulation of the sedimentation that goes into the hadal trenches through the canyon-channel systems [113].

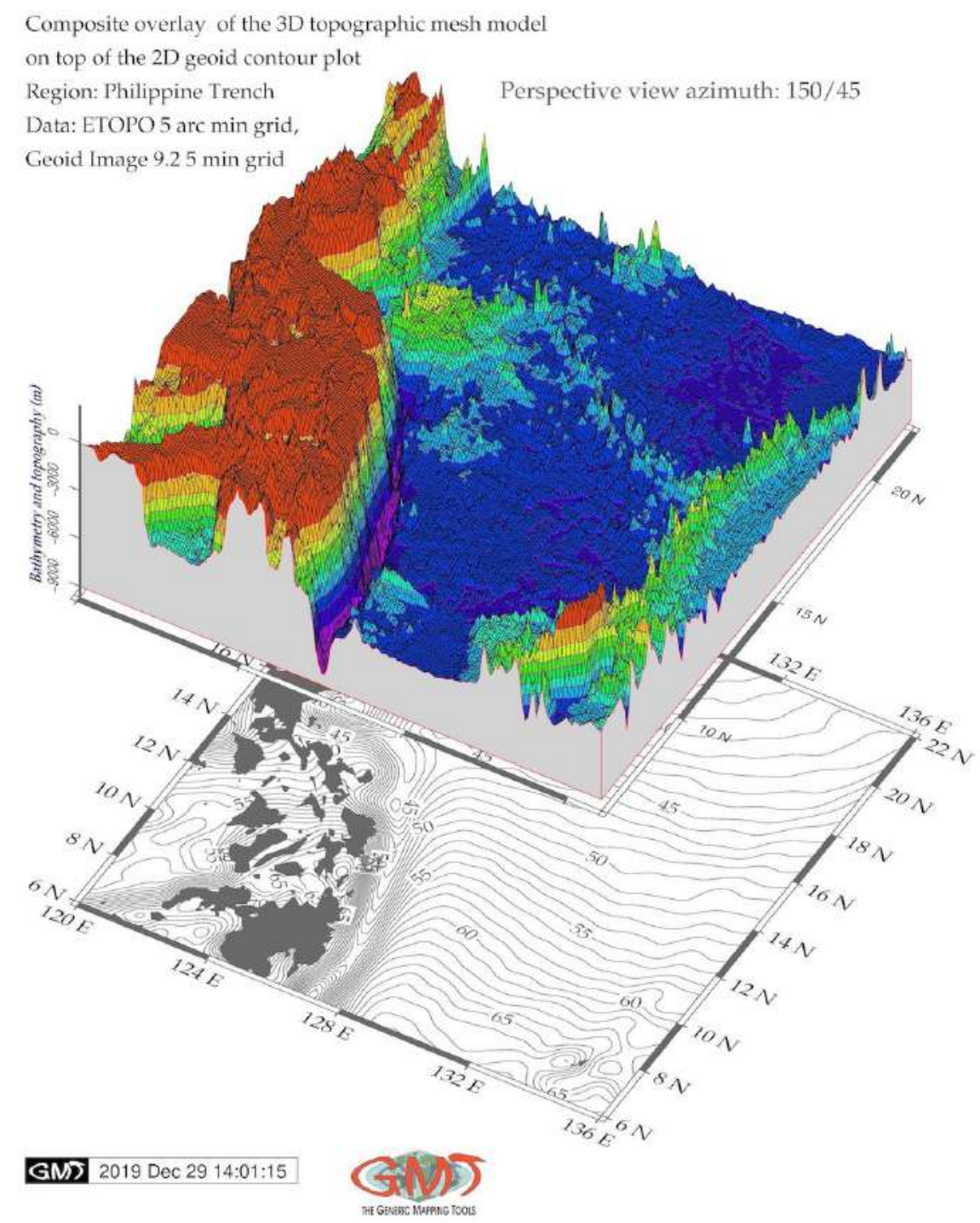

Map 2.11.5: 3D relief model: Philippine Trench (south segment)

PT is located along the eastern edge of the Philippine archipelago, which is a deformed orogenic belt resulting from the collision of oceanic and continental blocks [310]. Here, the PSP subducts under the Philippine archipelago $\left(4^{\circ}-15^{\circ} \mathrm{N}\right)$, which is a part of a convergence zone between the Eurasian plate (Sunda block) and the PSP [596]. Subducting PSP cause a high-velocity anomaly in the KPR area. The PSP tears and forms a slab window corresponding to the KPR subduction [82]. Tearing of the tectonic plate in the northwestern corner of the subducting PSP is further discussed by [497]. The PSB is a complicated region, notable for complex bathymetry and tectonic plate shape [753], consisting of many different patchworks of the seafloor ages [101].

Because of the location in the Philippine and Sunda tectonic slabs collision, the Philippine Fault is proven to have motion in its dynamics [245]; [765]; [758]; [646]; [311]; [282]. The northwestward mo- 
tion of the Philippine Sea Plate is partially absorbed by the subduction of first, the PT moving westwards, second, the East Luzon Trough located in the north-east, and third, by the Philippine Fault. Along with geologic factors, tectonic instability of the Philippine Sea Trench necessarily causes variations in the structure of its geomorphology, which is studied in this paper.

PT has been studied with respect to the geophysical processes and geological settings at selected sample points margins. This interest is in part due to correlation that exist between tectonic plate movements and historical evolution of the geological processes [242]; [671]; [611]; [130]; [89]. There is also evidence of deep-sea species existing on the seafloor of the PT which provides a habitat to a certain examples of the hadal crustaceans shrimps such as amphipods [238]. PT supports geomorphic evidence of the tectonic deformation resulting from the westward PSP subduction along the trench, as reconstructed by [611] who detected a raised marine platforms and terraces along the $80-\mathrm{km}$-long coastline of the Philippine coasts.

Heterogeneous nature of its submarine geomorphology resulting in depths and steepness variations at the local level (ca $1200 \mathrm{~km}$ ) is caused by crustal deformation along the Philippine Fault, Luzon originated from Eocene [771], [701]. Specifically, the fault reveals left-lateral slip of the Philippine archipelago from the northwest corner of Luzon to the southeast end of Mindanao. Therefore, it is often challenging to distinguish the multiple spatial variables of the tectonic and geological factors with those of depth distribution and gradients in deep-sea trenches.

Simulated tectonic evolution of the southern Japan [228] shown that it was caused by the subduction of the Pacific and PSP and the collision of the IBM arc: geomorphological and geological data on plate movements suggest that subsidence affected the entire PSB after which the area of subsidence narrowed until the basin's uplift. [167] identified the geodynamic processes in the crust and mantle of the Philippines archipelago which induce geographic differences in azimuthal tomographic anisotropy between the central and southern Philippines. Recorded earthquake events at the 11 cross-sections of the earthquake transects visualized at three groups of depths: 0-60, 60-350 and $>350 \mathrm{~km}$, demonstrating active volcanism and seismicity around the Philippine archipelago and trench.

Further reading on tectonics and geologic settings of the PT can be found in relevant papers, e.g. with more detailed discussions on spatial variation in seismic earthquake data [52]; shape form of the subducting slabs [35]; tectonics of the Parece Vela Basin [583]; subduction system of the PSP [251]; questions of fault topography patterns and quaternary faulting along the Philippine Fault zone, Central Luzon [245]; highlighted accreted terranes in the northern part of the Philippine archipelago [310]. Recent surveys revealed the presence of peridotites, gabbros, and massive and pillowed flows of the Mesozoic ophiolite belt. Major, trace and rare earth elements of the volcanic rocks show subduction-related influences on formation of the island arc [214]. Mixed sedimentary consolidated rocks were formed by the submarine erosion from the abyssal plain area located near the PT and transported to the trench, as well as submarine canyons followed by water currents [425].

Some more studies of the PSP have investigated its geophysical settings with a special focus on magnetism and reconstruction models highlighting its complex tectonic history, origin and motion development, seismicity and earthquakes [221]; [220]; [765], [408]. Other efforts have been focussed on interpreting the geophysical and tectonic settings of the PSP. Thus, [766] discussed lateral fluctuations in the upper mantle structure of the PSB, studied more detailed by [767] with a close focus on the geophysics across the PSB. 


\subsection{Manila Trench}

Manila Trench (MnT) is located in South China Sea, west Pacific Ocean, west of the islands of Luzon and Mindoro in the Philippines (Map 2.12.1), [404].

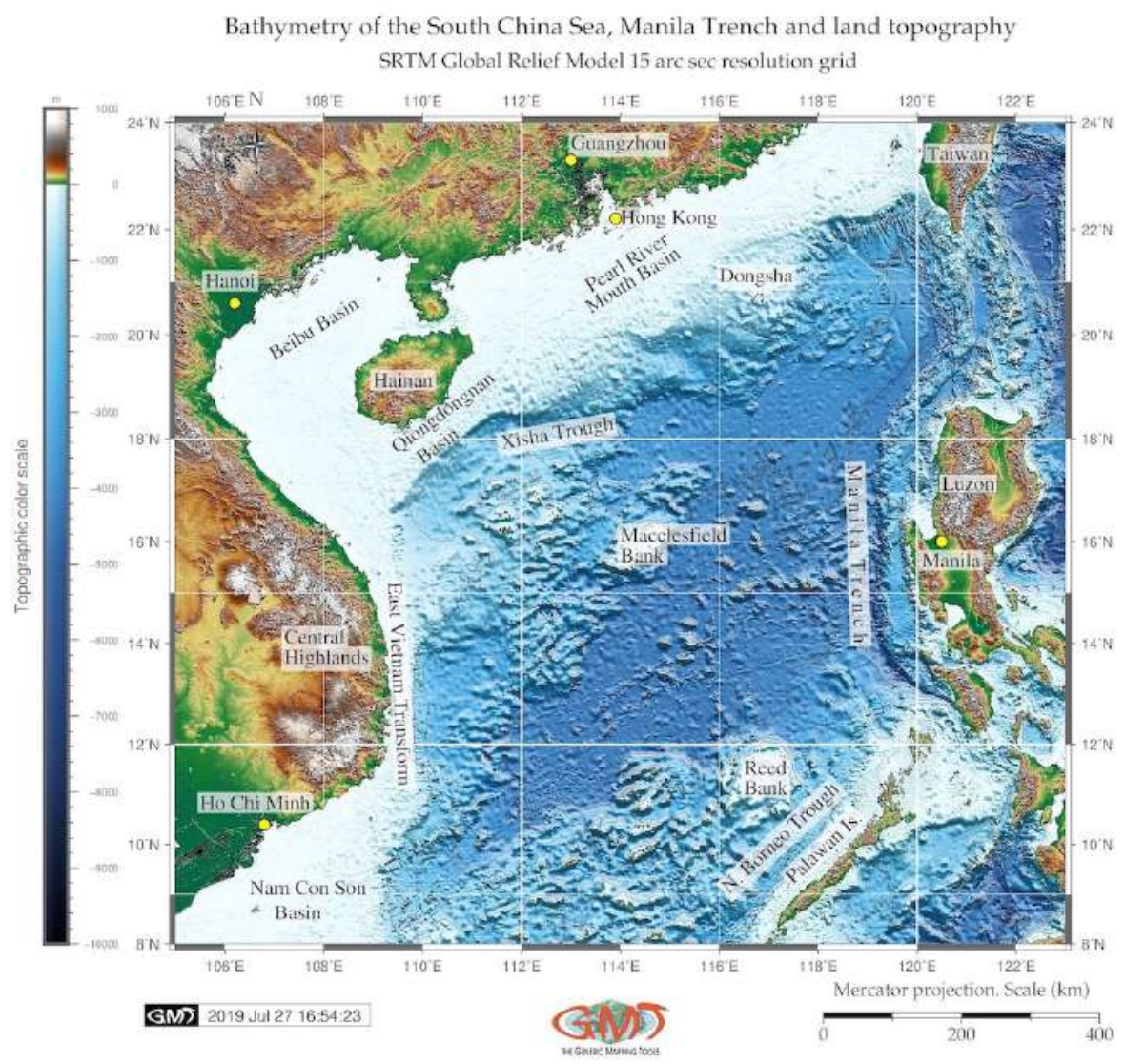

Map 2.12.1: Manila Trench: bathymetric map, SRTM $15 \mathrm{sec}$ grid

The area of the MnT is located in the Manila subduction zone at the Philippine Sea plate boundary where it moves in the northwest direction toward the Eurasian plate with a high convergence rate [514], [406]. The MnT with its maximal depth of the trench about 5,400 $\mathrm{m}$ [511] and stretching in almost vertical North-South direction is created by the subduction of the Eurasian Plate (through its part Sunda Plate) under the Philippine Sea Plate. Specific geological structure of the MnT causes potential repetitive earthquakes and seismicity [749].

Another frequent hazard caused by the subducting slab of the Eurasian plate beneath the MnT (Map 2.12.2, left) is destructive tsunamis causing catastrophic damages in the source area and along the coastlines of the Luzon Island. The hypocenters of the tsunami of the MnT are located at the depths $<100 \mathrm{~km}$ [641]. The tsunami hazard from the MnT source has been assessed in more details in several research papers [571], [35], [690]. The zone of the Eurasian Plate subduction explains the belt of volcanoes in the MnT area (Map 2.12.2, left), on the west side of the Philippine island of Luzon. The area between the northernmost Manila subduction zone and southern Taiwan is considered a transition from subduction to initial collision and a weakly coupled nature for the northern part of the MnT [96], [406].

The geological complexity of the MnT is also expressed by the connection with the PT where a horizontal mantle flow exists between the MnT and the PT. It is caused by the collision between the Palawan block and the Philippine Mobile Belt, and movement off the South China Sea slab [167], [406], 
[404]. Various factors cause the formation of the MnT. Being a hadal trench, it presents a special area of the ocean seafloor with distinct geomorphological structures characterized by the notable depths and steep gradient angles, located in the zones of the continental margin tectonic plates bending.

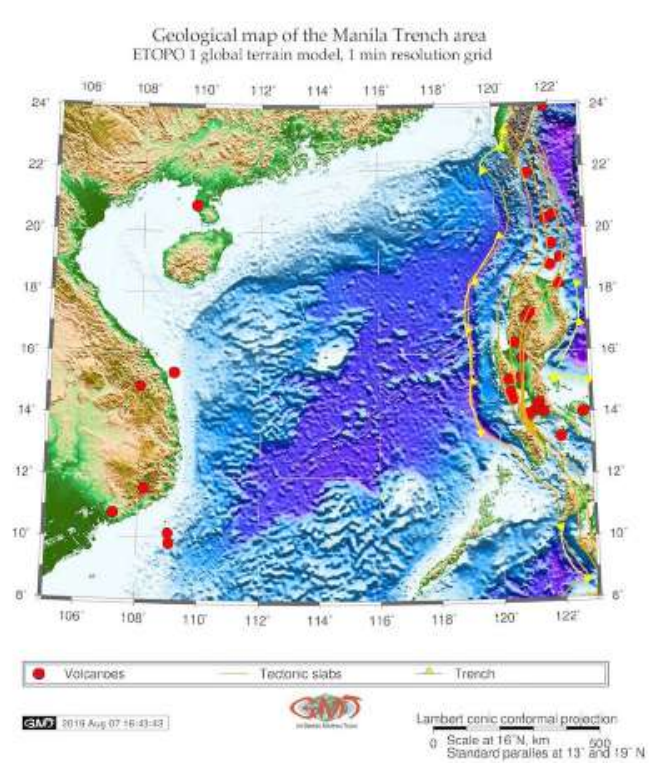

(a) Geologic map

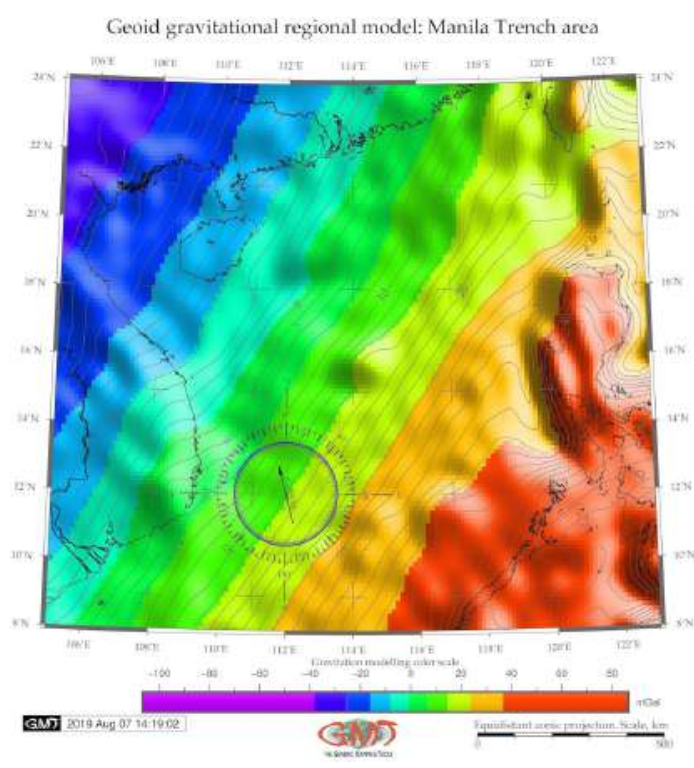

(b) Geoid model

Map 2.12.2: Manila Trench [418]

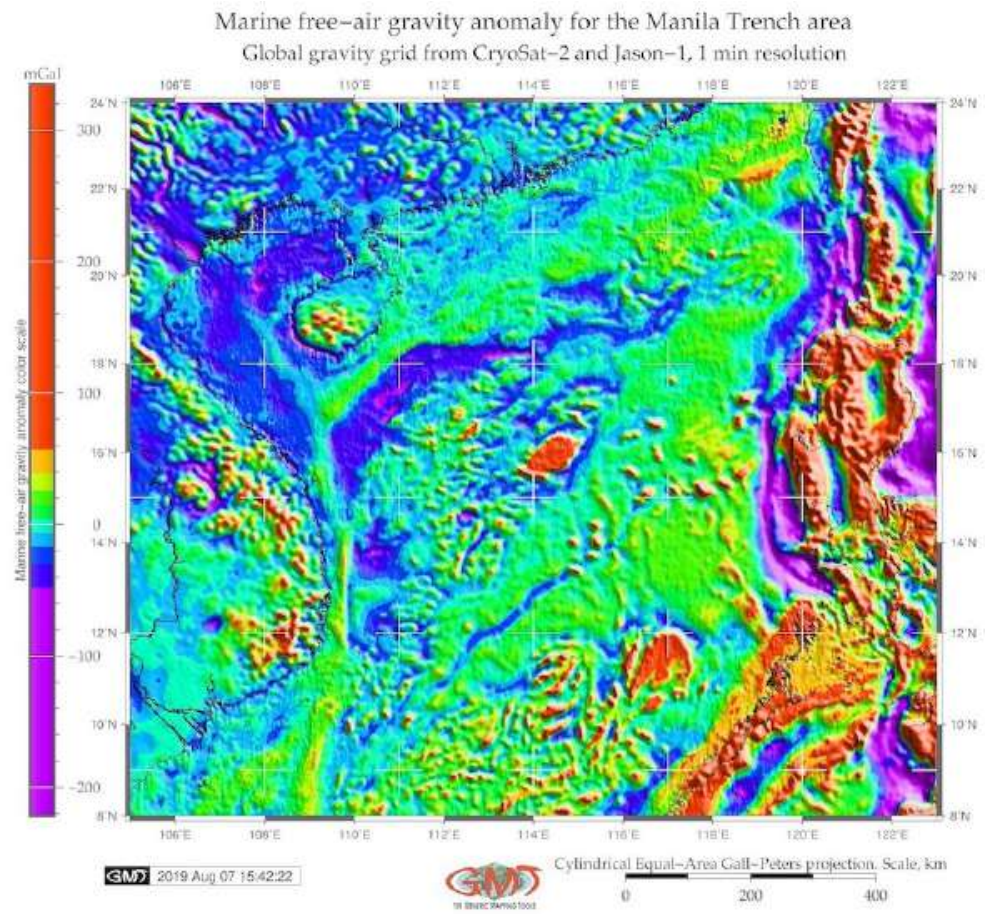

Map 2.12.3: Manila Trench: marine free-air gravity map

The convergence between the two plates forming the MnT is roughly northwestward [406]. There 
is a high-velocity zone present in the crust and upper mantle beneath the Luzon Arc where the MnT is stretching [140]. All these factors briefly mentioned to illustrate the tectonic settings of the study area indicate high seismicity and special tectonic zone where the MnT has been formed. The seafloor of the hadal trench presents a complex structure combined of of various landforms: mid-ocean ridges, transform faults, ocean plains complicated by chains of seamounts, minor ridges, trenches and plateaus.

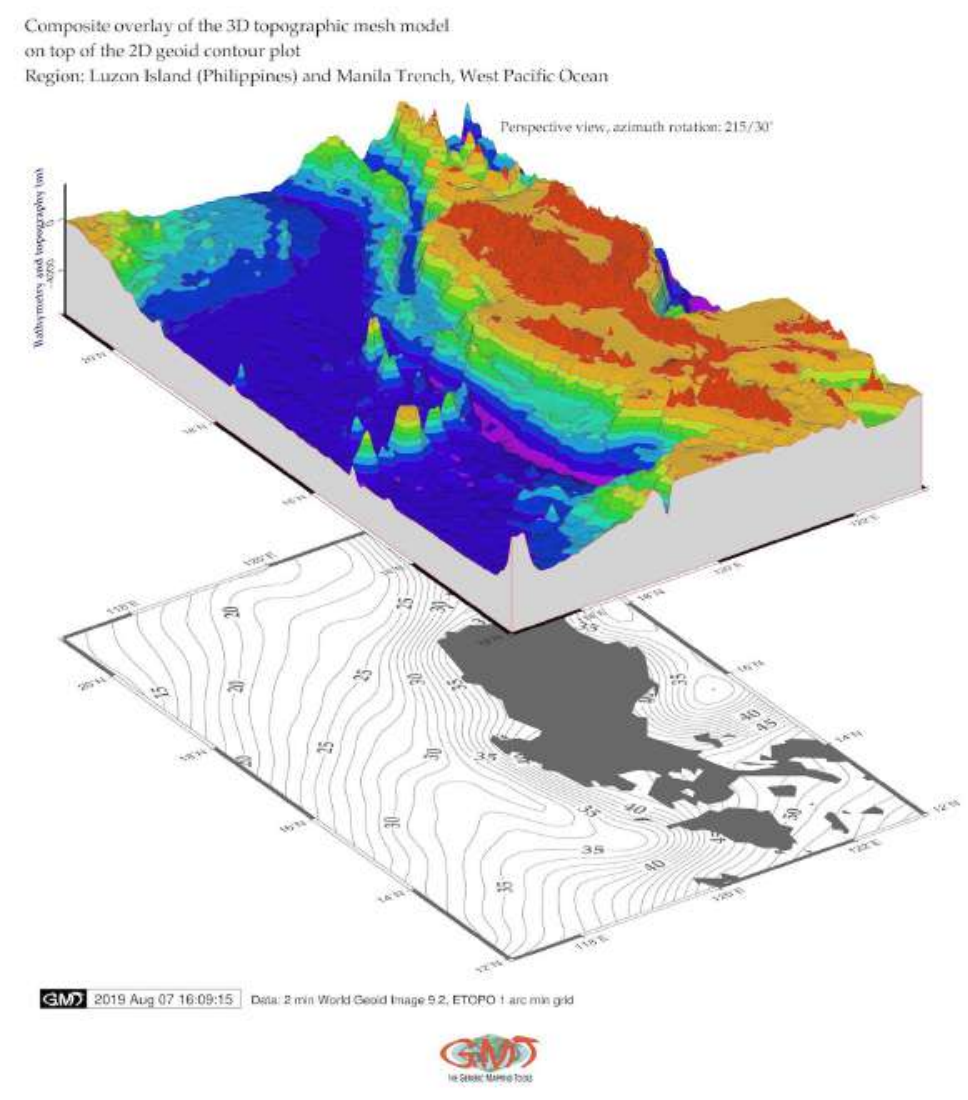

Map 2.12.4: Manila Trench: 3D mesh map of the geomorphology

Factors influencing geomorphic development, structure and bathymetric patterns of the trench are diverse. To mention some of them: geological, hydro-chemical, geothermal, climatic, tectonic and bathymetric determinants. The steepness of the Manila geomorphology varies: the dip angles along the MnT increasing gradually southwards from ca. $25^{\circ}$ at the latitudes between $18^{\circ}$ and $21^{\circ} \mathrm{N}, 32^{\circ}$ at the latitude $17^{\circ} \mathrm{N}$, and nearly vertical at the latitude $14^{\circ} \mathrm{N}$ [93]. The tectonic front of the MnT continuing northward into the frontal thrust faults in the western Taiwan shows active plate boundary between the Eurasian and Philippine Sea plates in the Luzon-Taiwan region [768].

The structure of the northern MnT has been studied in various papers focused on the problems of crustal structure and deformation in the north of the MnT [493], [232], [340]. Among other findings, the increasing dip angle of the MnT from north to south has been discovered. The MnT loses its sharp bathymetric pattern in the early collision zone and gradually becomes a less well-defined deformation front [491]. However, the comparative analysis of its southern and northern parts is still missing. Therefore, current paper contributes to better understanding of the MnT by comparative analysis of its geomorphology in the northern and southern segments. 


\subsection{Ryukyu Trench}

The Ryukyu Trench (RT) is a $1400 \mathrm{~km}$ long hadal oceanic trench, stretching along the southeastern edge of the Ryukyu island arc, between the Philippine Sea, Taiwan Island and Kyushu Island, southern Japan, Pacific Ocean [13] (Map 2.13.1) [392]. The trench was formed as a result of the subduction of the oceanic crust of the Philippine Sea Plate beneath the continental crust of the Eurasian Plate [142]. The aim of the research is to analyze differences in the geomorphology and bathymetry of the northern and southern parts of the trench using GMT [743].

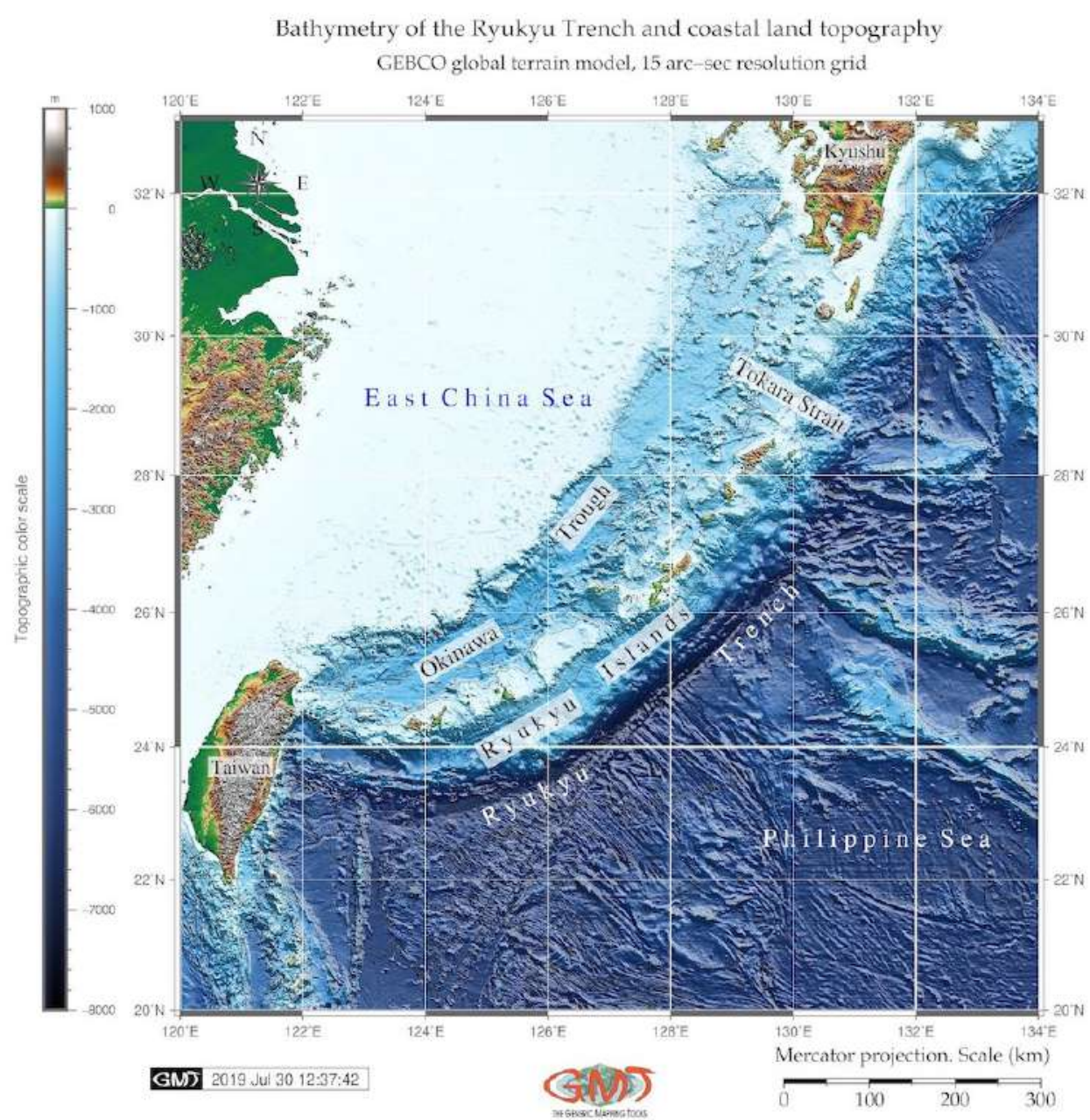

Map 2.13.1: Ryukyu Trench and Arc, East China Sea and Philippine Sea: bathymetric map

The bathymetric pattern of the RT varies in its northern and southern parts which reflects the correlation between the geomorphic shape of the hadal trench, steepness of its gradient slope angles and tectonic settings in the area. Thus, in the northern part of the trench, the subduction of the Philippine Sea Plate is notable for shallow depths and steepness, reaching only ca. $11^{\circ}$. On the contrary, the angle becomes steeper, reaching $70^{\circ}$ below ca. $70 \mathrm{~km}$. The region located to north-west of the Ryukyu volcanic island arc is a Back-Arc Basin (BAB), a depression of the Okinawa Trough (Map 2.13.2) [392].

The subduction of the Philippine Sea tectonic plate causes eruption of the approximate 34 volcanoes (Map 2.13.2) and earthquakes producing tsunami. In contrast, the slab dip in the central and southern parts of the RT is more gentle, reaching $40-50^{\circ}$ at $70 \mathrm{~km}$ depth [333], [517], [392]. There are three groups 
of islands on the forearc basement stretching over the Ryukyu arc [322]. The Kerama Fault, about 250 $\mathrm{km}$ wide (Map 2.13.2), separates the southern from the central group of islands.

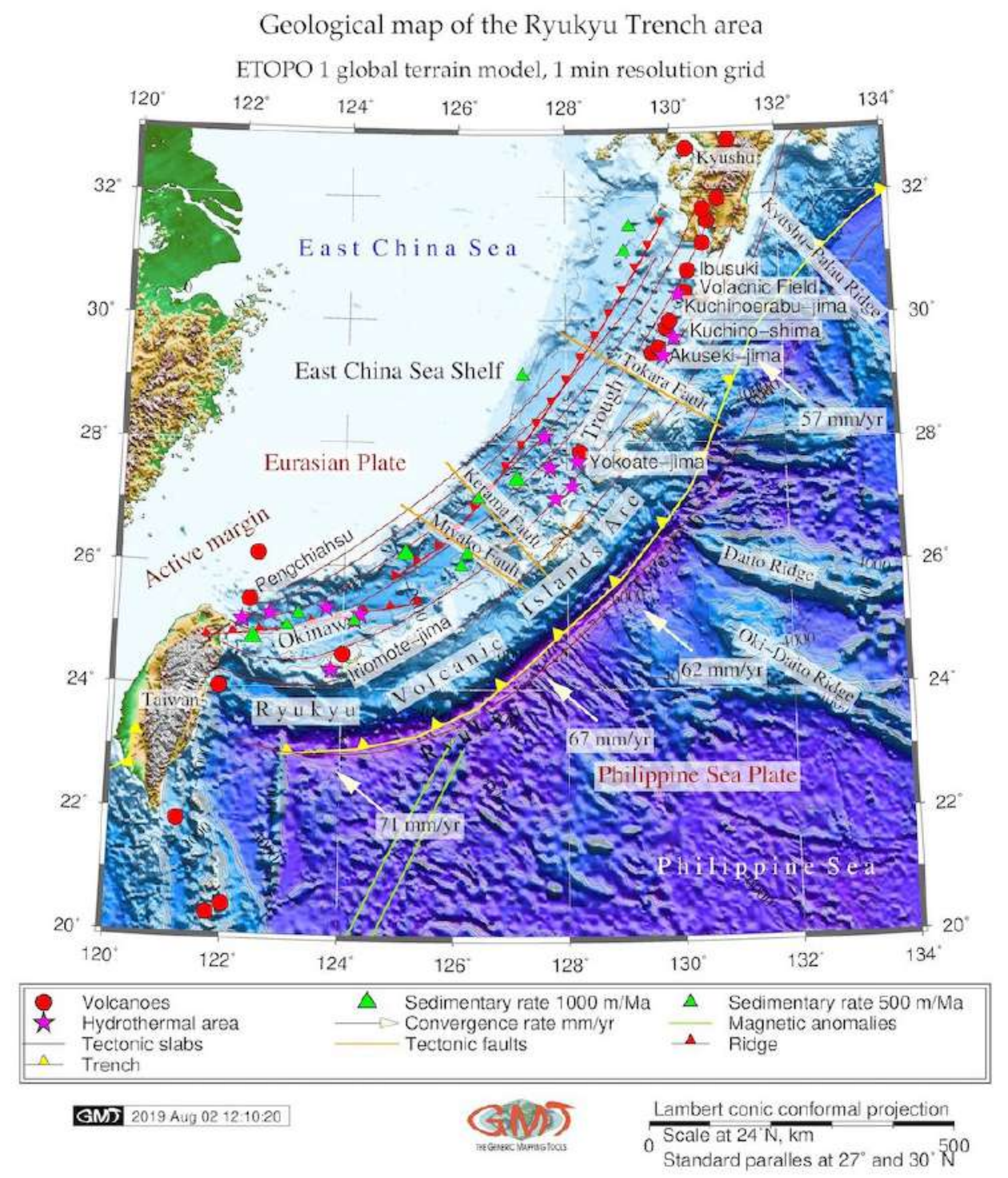

Map 2.13.2: Ryukyu Trench: geologic map, ETOPO1

The RT reaches depths of $7000 \mathrm{~m}$ below sea level (BSL) and the forearc slope between the forearc island chain and the trench is between 130 to $160 \mathrm{~km}$ wide. The northern group has Yaku-shima and Tanega-shima and a $200 \mathrm{~km}$ long Tokara Channel gap between the island groups [582]. The tectonics of the hadal trench reflects evolutional processes of the building seamounts and the structure of the Earths crust. Therefore, it causes variations in the lithological patters, geological conditions of the rocks formation, stratigraphy and sedimentary settings of the ocean seafloor formation during Jurassic, Mesozoic and Cretaceous. Double subduction system of the RT reflects the complex trench motions as an expression of the interaction between the subducting plates and the underlying mantle of the RT. The Pacific plates subducts beneath the Philippine Sea Plate, which is in turn subducting beneath the Eurasian Plate along the RT [166], [392].

Geomorphology of the ocean seafloor results from the complex geodynamic processes. These demon- 
strate traces of the continuous evolution and shape seabed surface as a system of the mid-ocean ridges, transform faults, vast ocean plains complicated by chains groups, ridges and plateaus as well as minor forms such as terraces, seamounts and hills, 3D Map 2.13.5. Various factors affect the trench geomorphology and in turn, are reflected in its complex structure and functionality of the submarine environment. To mention some of them: effects of the magmatism [317], seismicity [217], volcanism and hydrothermal system [549], [550].

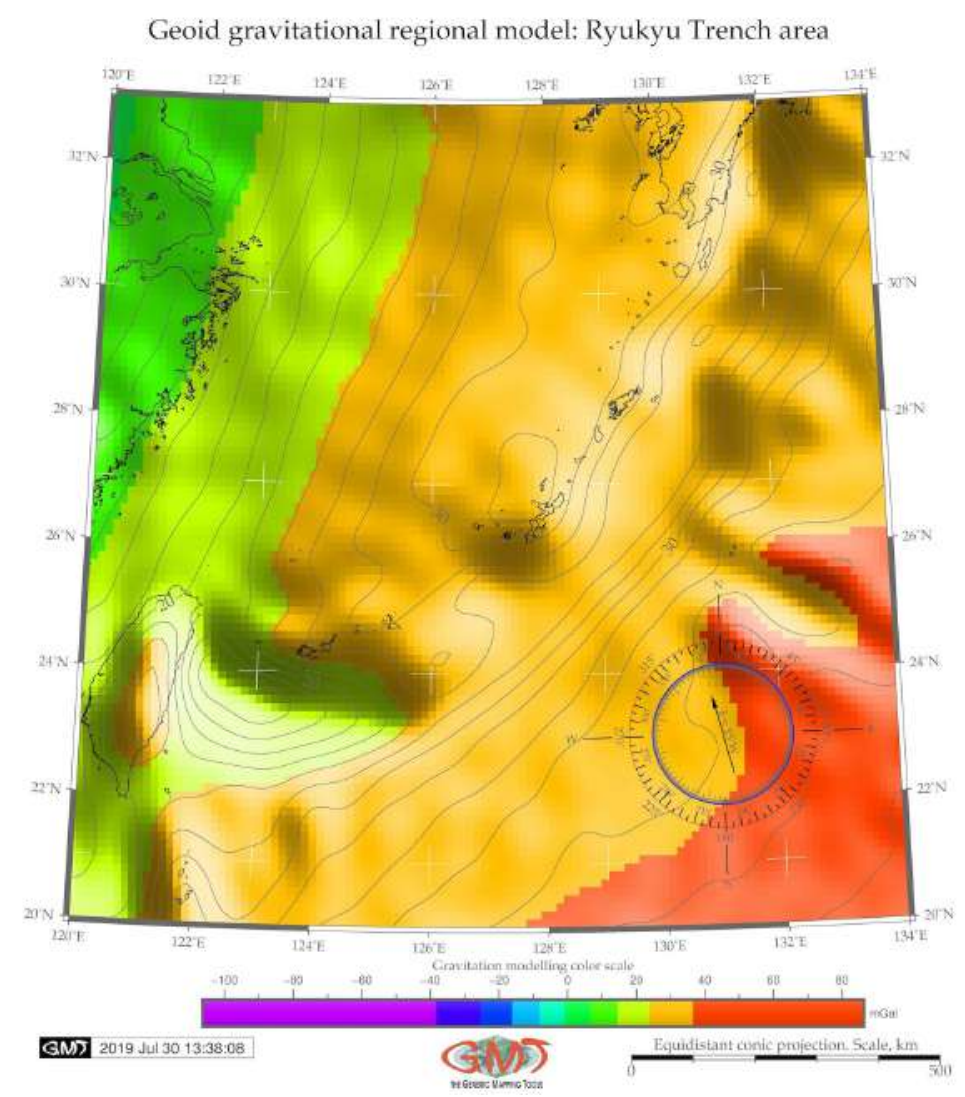

Map 2.13.3: Ryukyu Trench: geoid map

Another example is the effect of the thickness of the subduction channels and earthquake rupture segments on the geomorphology of the oceanic landforms. Thus, the spatial differences of the RT geomorphology is reflected in its sediment composition that change systematically from lighter off northern Ryukyu arc to heavier along the central part of the Ryukyu arc. This is explained by the dominance of the terrigenous and pelagic sedimentation off of the northern and central Ryukyu arc, respectively [679], [392].

RT presents a structural trap in the continental margins of the Pacific Ocean since the sediments are carried by the ocean currents passing through the system of trenches on the west of the Pacific [392]. The sediment types of the RT include among others mud diapirs, hemipelagic sediments, mud-supported breccia, fossil planktonic foraminifera, calcareous nannofossils [723]. The content of the planktonic foraminifera varies according to the seasonal warming of surface waters and vertical mix as a result of the NW monsoon [750]. 


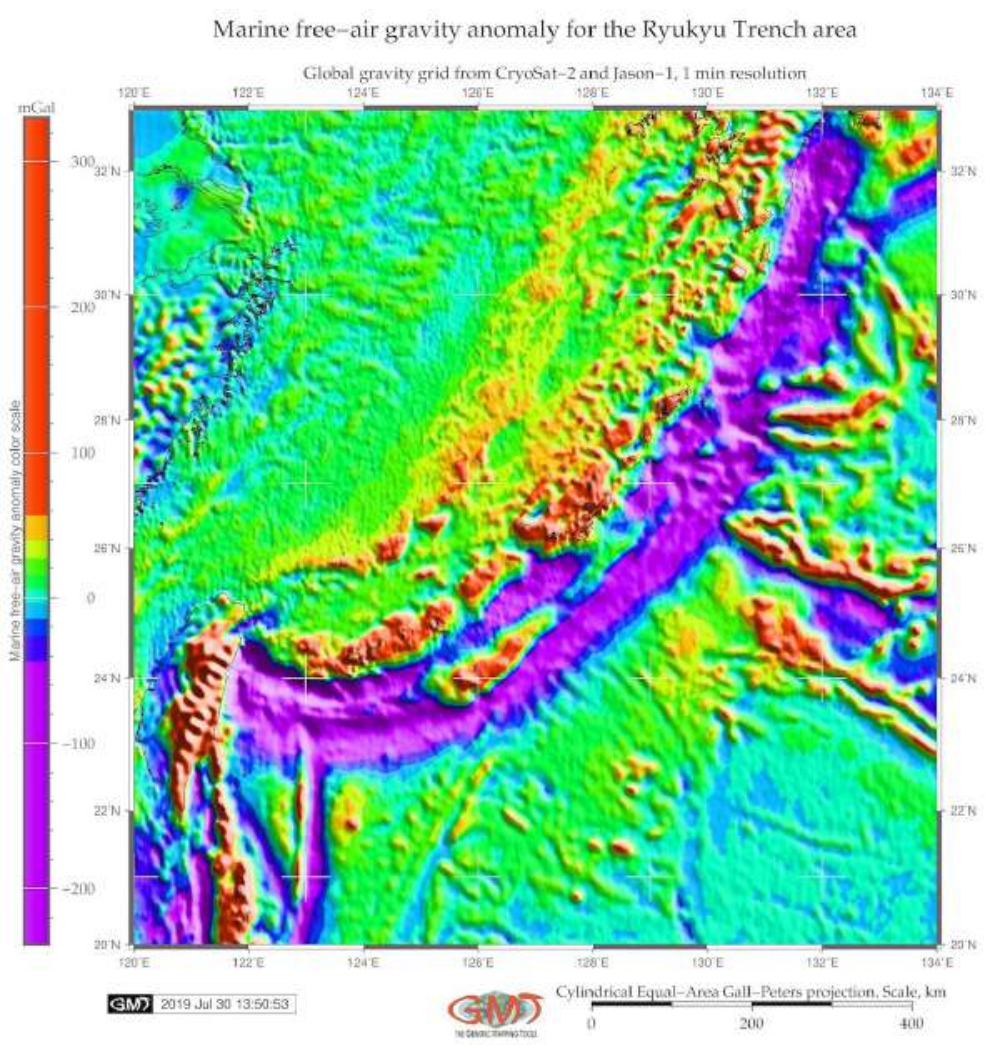

Map 2.13.4: Ryukyu Trench: gravimetry map

Seismic investigations of the RT area show that the sedimentary thickness is ca. $2-3 \mathrm{~km}$ on the oceanic plate, oceanic crust thickness is $5-6 \mathrm{~km}$. The upper mantle material underlying the oceanic plate has low seismic velocities, explained by the geochemical processes of the mantle peridotites [330]. Submarine margins of the continents can be divided into two types: the passive and active ones, depending on the features of the geomorphology and geology. The active margin in the Ryukyu area is located off northern Taiwan in the southern Ryukyu forearc (Map 2.13.2), [392]. A mega-splay fault system associated with great earthquakes in the south of the Ryukyu region is described by [254]. Indeed, the southwestern Ryukyu system is characterized by the edge regime that is heavily influenced by the juxtaposing continental lithosphere [344].

Although the seafloor of the RT is separated vertically from the euphotic zone, is serves as a depositional center for the organic carbon accumulation. This is caused by the geomorphological factors: steep slopes enable lateral transport from the adjacent continental margins [284]. Studies on the spatial biodiversity of the RT show [320] low values at shallow depths, but increased with water depth reaching maximum between the trench floors and abyssal plains. This proves that bathymetric patterns of the deep-sea biomass of the RT spatially differ in various regions of the trench. 


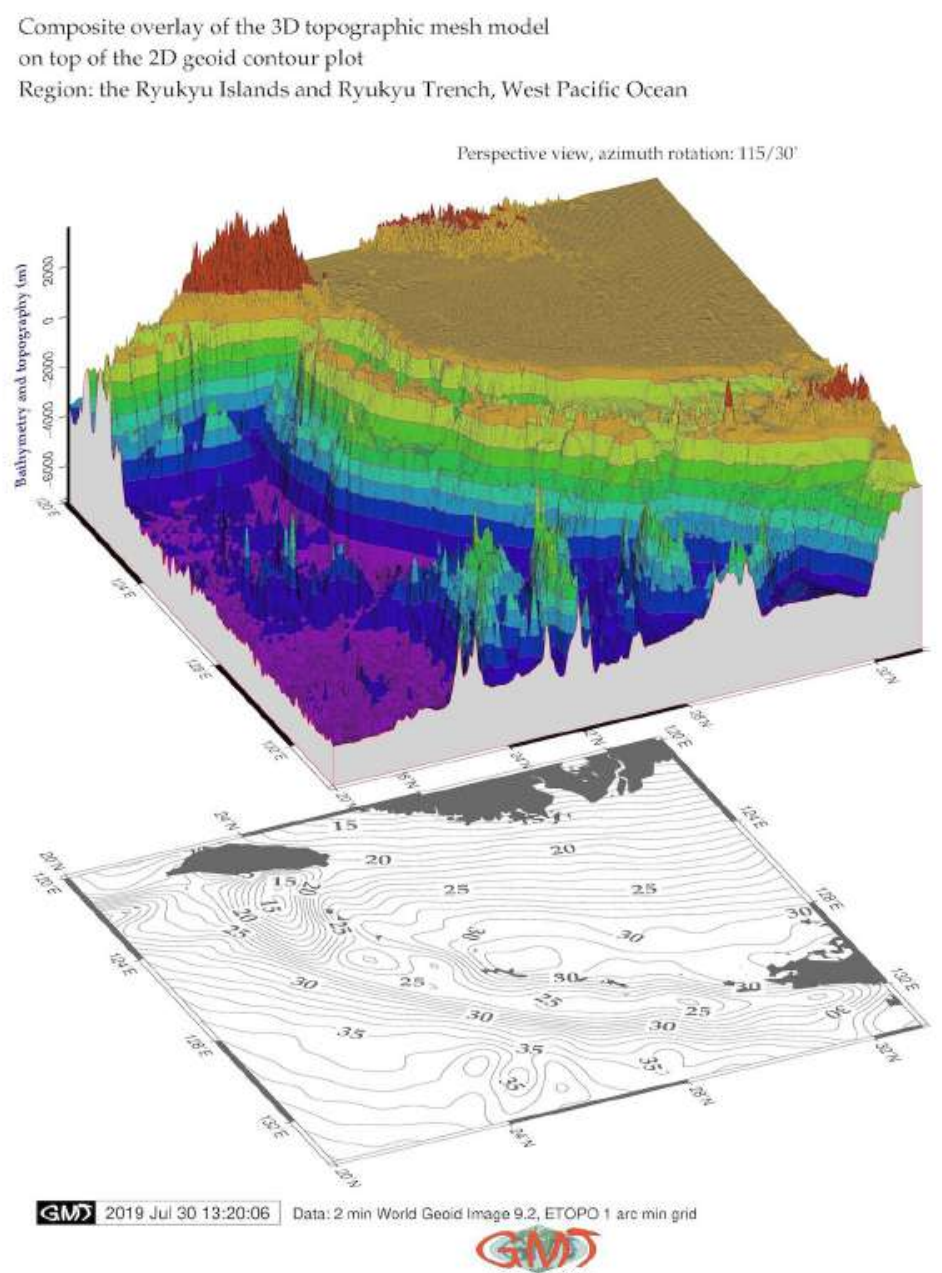

Map 2.13.5: Ryukyu Trench: 3D mesh geomorphological modelling

Such discrepancies reflect differences in the environmental conditions, e.g. primary productivity. level. This is also supported by the discoveries of the migration patterns in the RT area where reefs and geomorphic landforms serves as a land bridge for the migration of terrestrial organisms from Okinawajima to Miyako-jima [16]. 


\subsection{Palau Trench}

The Palau Trench (PaT) is located in the Philippine Sea, northwards from the Papua-New Guinea and eastwards from the Philippines, west Pacific Ocean (Map. 2.15.1).The geological settings of the PaT area is shown on Map 2.14.1. PaT with the greatest depth at $8,080 \mathrm{~m}$ (situated in its southern part) has a straight shape of the geometric form, stretching from south-west to north-east (Map map:YPT1 and Map map:YPT6), located within a square $133^{\circ}-136^{\circ} \mathrm{E}$ and $6^{\circ}-8^{\circ} \mathrm{N}$, east from the Yap Islands.

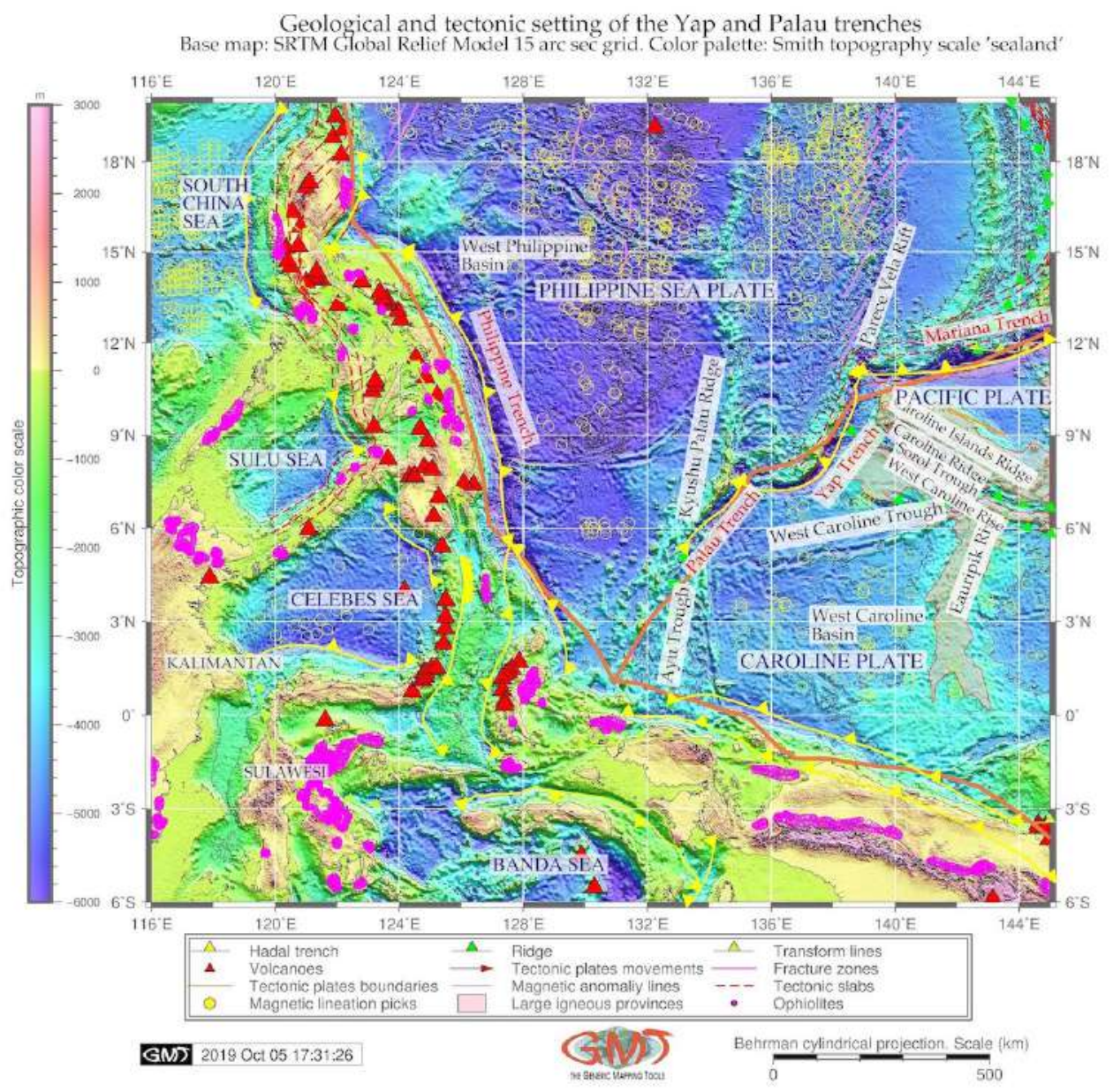

Map 2.14.1: Yap and Palau trenches: geological map [412]

One of the most unique characteristics of the PaT is its short distance $(35 \mathrm{~km})$ between the trench axis and the coast of the Palau Islands westwards [332]. The geology of the PaT includes sequences of serpentinized peridotite, basalt and limestone on its landward slope and a huge block of coral-reef limestones at depths 4,900 $\mathrm{m}$ to 6,500 $\mathrm{m}$ [332]. PaT is connected with the Kyushu-Palau Ridge in the north and Ayu Trough in the south. Yap and PaT are distinguished from the flat-bottomed Ayu Trough by their more similar to $\mathrm{V}$ shape in the cross section.

The Islands of Palau located westwards to the PaT are composed of volcanic rocks capped by coral reef limestone. This indicates that the Palau islands were located along the volcanic front earlier [332]. The tectonic situation of Yap and PaT is on the PSP. The PSP is the tectonic plate completely surrounded by convergent boundaries of the tectonic plates [758]. The tectonic settings of Yap and PaT presents a complex region of convergence among three tectonic plates: the PSP, the Pacific and the Caroline plates. 
Hence, Yap and PaT belong to the subduction zones surrounding PSP along its eastern boundary.

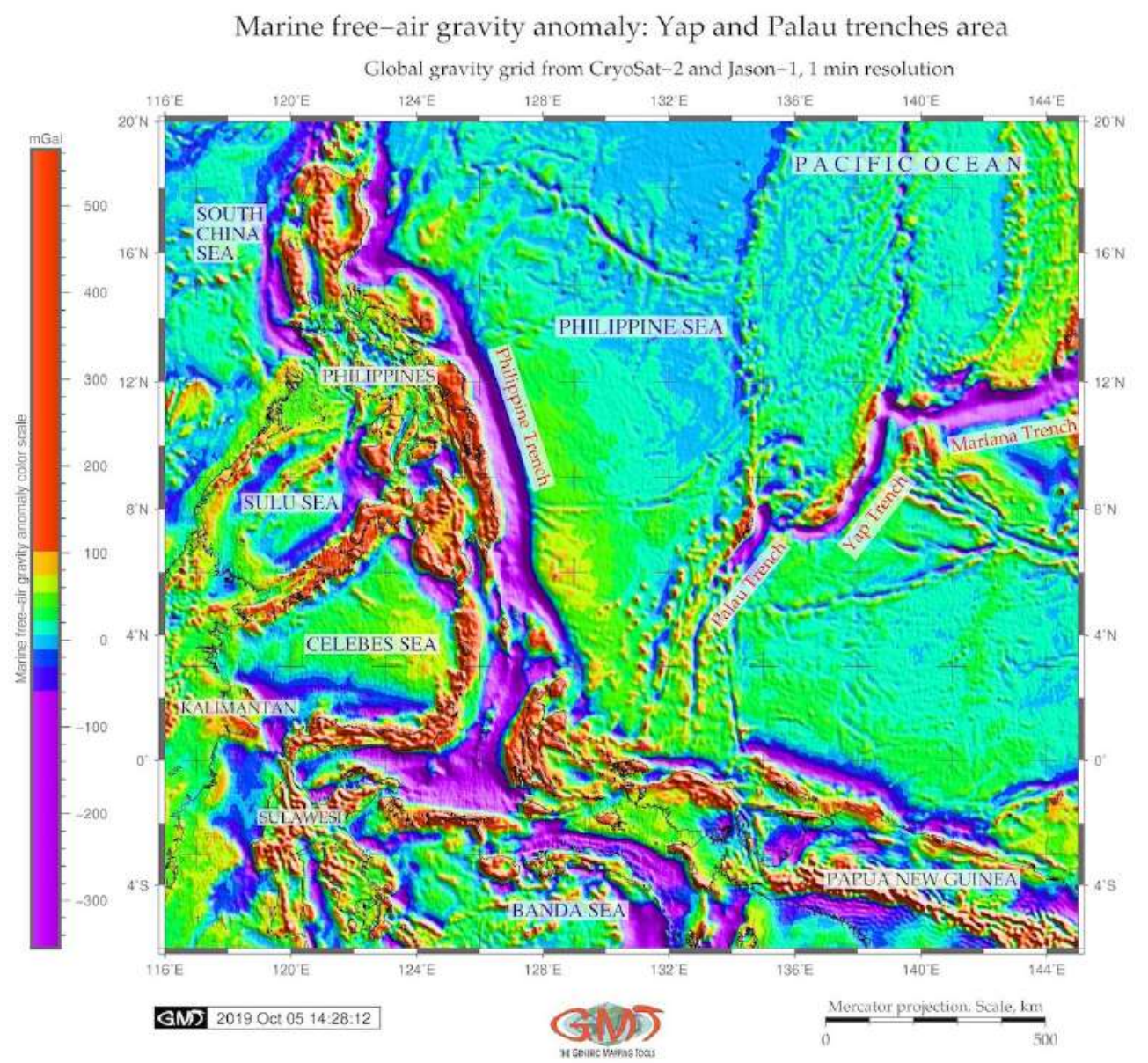

Map 2.14.2: Yap and Palau trenches: geophysical gravity map [412]

Increasing developments of the ocean resource exploration caused concerns on ocean areas and PaT geomorphology, formed as a result of complex set of processes [401]. The data analysis revealed deep interconnections between its submarine geomorphology and impact factors: geology and bathymetry. The structure of the submarine geomorphology of the PaT is a complex interplay of these processes. Various factors affect its geomorphic structure, geometry of shape, formation and development. The most important include the following: sediments, tectonics and stratigraphy, bathymetry, geographic location, slope aspect degree; geologic structure of the underlying basement, ocean streams determining local geomorphological conditions that depend on the sediment deposition processes.

Main morphostructure elements of the seafloor of the PaT are the outskirts of the continents, tectonic plates and ocean bedrock. The structure of the trench and the nature of its geomorphic shape are therefore greatly complicated by the multiple secondary tectonic disturbances: system of faults, displacements of grabens, horsts and lateral geologic shifts. The interconnection of these complex processes is also illustrated by recent findings [240] that demonstrates correlation between the back-arc deformation and upper continental tectonic plate velocity. 


\subsection{Yap Trench}

Yap Trench (YT) is located in the Philippine Sea, northwards from the Papua New Guinea, eastwards from the Philippines, west Pacific Ocean (Map. 2.15.1). YT with the greatest depth at 8,292 $\mathrm{m}$ is ca. 700 $\mathrm{km}$ long and $50 \mathrm{~km}$ wide [654]. It stretches from the trench axis to Yap islands arc with a characteristic ' J' form [362]. It is morphologically divided into the northern and southern segments with the the boundary between the two segments at $8^{\circ} 26^{\prime} \mathrm{N}[182]$.

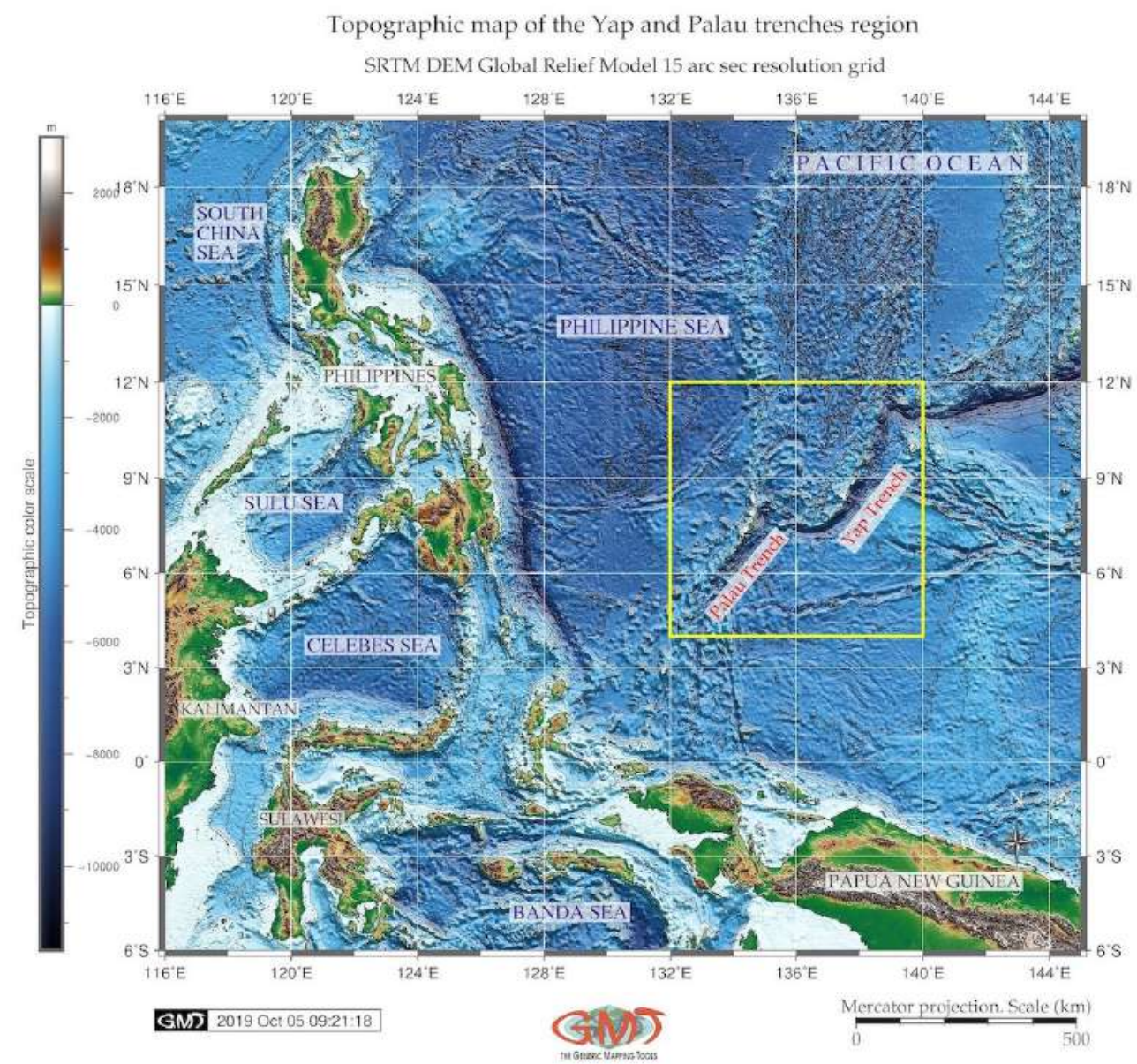

Map 2.15.1: Yap and Palau trenches: topographic map [412]

The Yap-Palau subduction zone lies southwards off the Mariana arc-trench system. The Caroline Plate subducts here northwestwards beneath the Philippine Sea Plate. The most prominent geological structures in the Caroline Plate are Caroline Ridge (Map 2.14.1), a buoyant oceanic plateau, and Sorol Trough, spreading in the middle of the ridge [139].

YT and PaT are formed in the place of the PSP subduction and oceanic lithosphere sinking to the mantle. As sinking PSP moves deeper into the mantle, the fluids are released from the mantle rock. This cause melting of the overlying mantle. New magma (molten rock) rises to the surface and erupts violently forming volcanoes and arcs of islands along the convergent tectonic plate boundary. Therefore, earthquakes are common in the subduction zone of the PSP (Map 2.15.1, red triangles). 


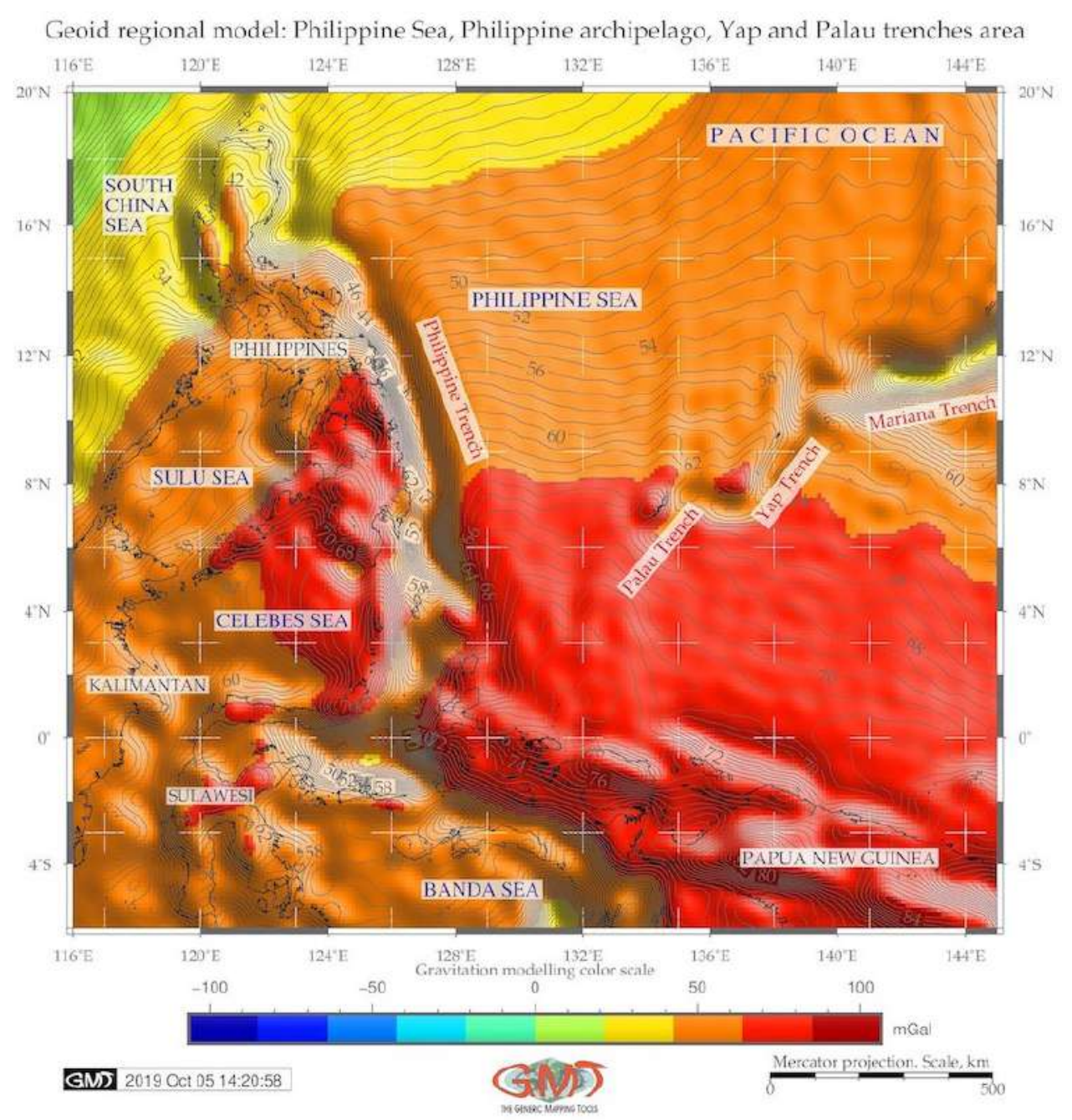

Map 2.15.2: Yap and Palau trenches: geoid model [412]

YT and PaT form a typical trench-arc-basin system which includes deep trench, island arcs, and backarc basin, a Parece Vela Basin, located in the eastern side of the Philippine Sea Plate (Map. 2.14.1). Such complex tectonic structure of the region is reflected in notable heterogeneity of the crustal and upper mantle velocity structures beneath the Philippine Sea Plate [578]. Necessarily, it affects the submarine seafloor topography and its geomorphic shape. Environment of the YT and PaT (biochemical and ecological setting) are described in relevant papers [757]; [751]; [512].

Syntheses of the tectonic and magmatic evolution of the region of the Philippine Sea, YT and PaT can be found in further works [39], [599], [672], [581], [717]. Water mass properties and deep currents in the northern YT were observed and discussed recently [512]. 


\subsection{Mariana Trench}

Geographic Location $\quad$ MT is the deepest part of the World Ocean with a maximal depth of 10,984 \pm $25 \mathrm{~m}(95 \%)$ at $11.329903^{\circ} \mathrm{N} / 142.199305^{\circ} \mathrm{E}$ at the Challenger Deep [188]. As the deepest place on the Earth, it is constantly deserving attention of the scientific world [89]; [119]; [166]; [180]; [709]; [712]. The arc of the MT can be fitted into a square with coordinates $140^{\circ} \mathrm{E}-148^{\circ} \mathrm{E}, 11^{\circ} \mathrm{N}-25^{\circ} \mathrm{N}$ (Fig. 2.16.1). Geographic location of the edge of the MT along the coasts of the continents or island arcs is explained by the subduction of tectonic plates at the boundaries of their collision: Mariana, Pacific, Philippine, Caroline tectonic plates [278].

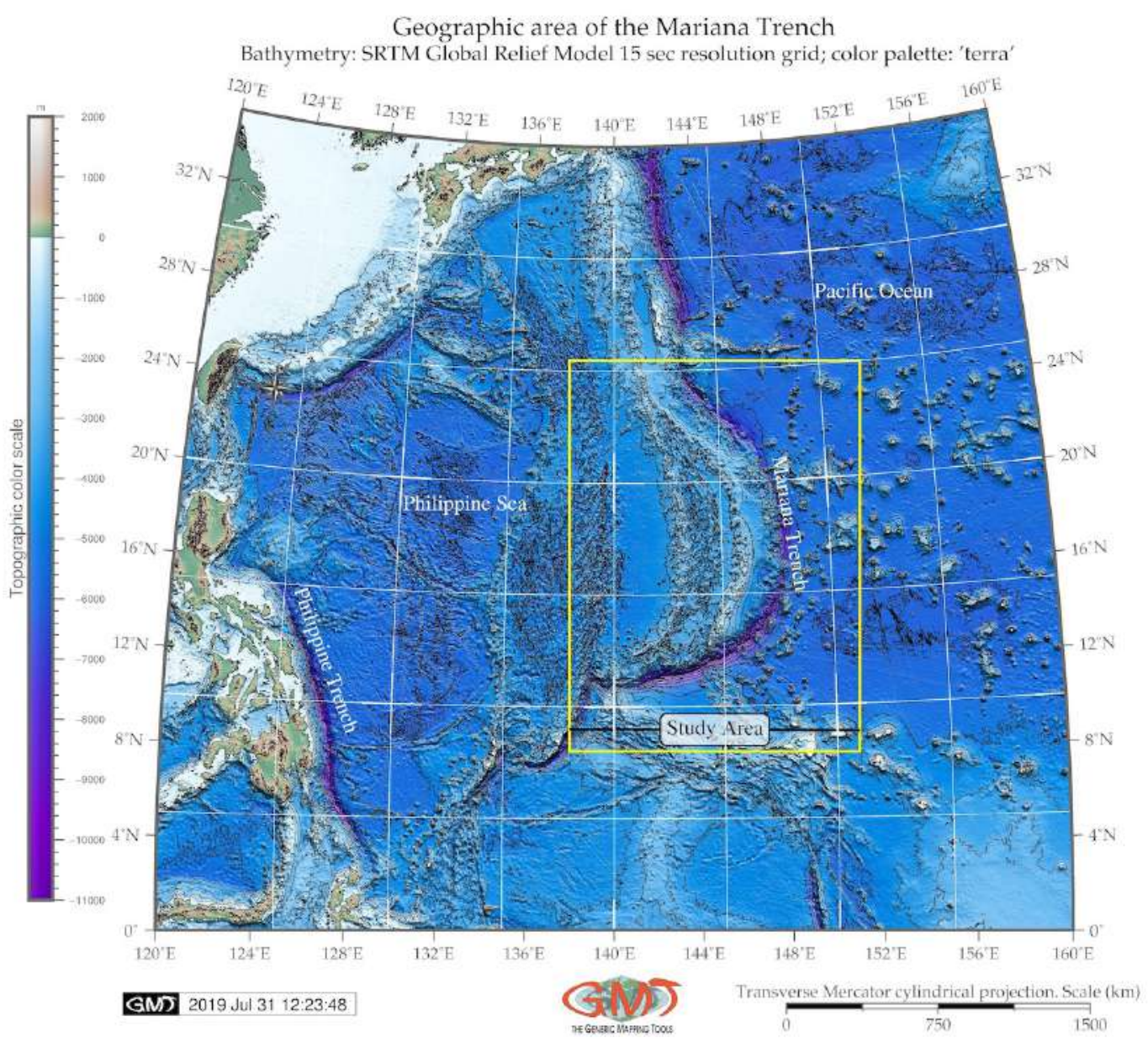

Map 2.16.1: Mariana Trench: bathymetric map

MT is one of the 37 known deep-water trenches of the World Ocean, 28 of which located in the margin areas of the tectonic plates of the Pacific Ocean [607], and the rest is as follows: 5 are located in the Atlantic Ocean [63] and 5 in Indian Ocean [215]. With a total length of about 2,550 km, MT creates a complex of the deeply interrelated factors and processes of tectonic plates. MT is a strongly elongated, arched in plan and lesser rectilinear, narrow topographic depression of the seafloor, crescent-like in its geometric plain shape. It is located in the west Pacific Ocean, $200 \mathrm{~km}$ to the east of the Mariana Islands, eastwards of the Philippine Islands and China, Fig. 2.16.1. Its transverse profile is asymmetric: the slope is higher on the side of the Mariana island arc, dissected by the deep underwater canyons.

Seafloor bathymetry varies seaward of the trench axis: the Challenger Deep area, southwest of Guam, is associated with the deepest relief sounding of $10,984 \pm 25 \mathrm{~m}(95 \%)$ at $11.329903^{\circ} \mathrm{N} / 142.199305^{\circ} \mathrm{E}$, 
and axial vertical loading [188]. The Challenger Deep is up to $2 \mathrm{~km}$ deeper than the average depth along the axis of the MT [178]. MT has complex geomorphic structure and unevenness in profiles stretching $\mathrm{SW}$ where its geomorphological structure varies. The geomorphology is subjected to various phenomena that affect its shape. These include bathymetry (depths), tectonics plates, geology (sedimentation) and geometry (slope steepness). Stretching for hundreds kilometers, MT is formed as a result of the subduction of the Pacific Plate beneath the PSP. The subduction boundaries have a classified 'Mariana type' where the coupling between the two plates is either weak or non existent [724]. Westward slope of the MT presents a barren trench wall with no uplift, while eastern part is the border along which western edge of the Pacific Plate is subducting beneath the smaller Mariana Plate. As a result, the geomorphic feature of the MT is its very steep slopes and depths of 3-5 km width of the bottoms rarely exceeding 5 $\mathrm{km}$ in breadth [567].

MT has complicated steps of various shapes and sizes, caused by active tectonic and processes of sedimentation. The steepness of its geomorphic depth averages in $4-5^{\circ}$, but its individual parts can be limited to steeper slopes as subjects to the gravitational flow system of the submarine canyons and valleys[312] [574]; [226]. Complex distribution of the various geomorphic material on the adjacent abyssal plains of the ocean contributes to the formation of the geomorphic features of the particular region of the MT. The main area of the seafloor of the trench has prevailing depths of $>3000 \mathrm{~m}$, a seabed being the most ancient parts of the ocean floor formed in the late Jurassic. To date, research on MT and IBM arc has focused on aspects of the tectonic processes of plate subduction [166], faulting and deformation [777], [778], geometry of the lithospheric gradient dips [61], plate motion, geologic structure and depths of slabs [243]. [39], petrogenetic studies on geochemic traces of volcanic rocks from the MT pointed at its tectono-magmatic evolution.

Bathymetry Recent bathymetric and topographic analyses [544] indicate that thin lithosphere in the IBM region $(20 \mathrm{~km})$ might have been intensely deformed during tectonic evolution of the region. It may explain notable variation in microstructure of samples taken from the ground on the MT, which range from coarse granular and intensely elongated texture to fine porphyroclastic and fine-grained equigranular textures. Submarine relief of the MT is marked by complicated steps of various shapes and sizes, caused by active tectonic and processes of sedimentation. NW Pacific Ocean is specially characteristic for the vast areas of the bottom of the basins occupied by depressions $>6000 \mathrm{~m}$. The structure of the MT has following general pattern: a major total area is being occupied by the abyssal depths (3-6 km), while the extreme depths $>6 \mathrm{~km}$, are smaller in comparison to the previous areas [724]. The abyssal make up relatively small part of the total area of the MT, while the $2^{\text {nd }}$ ones cover about $2 / 3$ of the whole.

Depths $>6000 \mathrm{~m}$ are confined mainly to the deepest part of the trench located in its SW part, although individual depressions to depths of 6-7 km, rarely up to $7.5 \mathrm{~km}$, occur in the central part of the basins along the trench [557]. Typical depths of the Mariana seafloor are 4000-5000 m where mid-ocean ridges and deep-sea basins are formed by numerous seamounts and deep-sea depressions are located. There are differences in the velocity of the longitudinal seismic waves in the geological layers of the MT structure: water and sedimentary layer have speed of $3.5-6.2 \mathrm{~km} / \mathrm{s}$, basalt layer has speed of $6.5-7.0 \mathrm{~km} / \mathrm{s}$. The layer of gabbro and banded gabbro are located beneath. The boundary of the crust-mantle is made by a sharp increase in the velocities from 7 to $8 \mathrm{~km} / \mathrm{s}$ (the boundary of the Mohorovičić (Moho)). Upper mantle is the region with velocities of $8.0-8.2 \mathrm{~km} / \mathrm{s}$ [189]. Analogues of the oceanic crust on the ground are ophiolites. The average thickness of the crust of this type under the platforms is ca. $40 \mathrm{~km} \mathrm{[215].} \mathrm{The}$ regions with bark continental type in the ocean are fragments of continental mass formed as a result of the formation of the modern ocean floor causing migration and slow movement of the trench [265]. MT has a a distinctive morphological feature of the convergent plate boundaries, along which lithospheric plates move towards each other, located about $200 \mathrm{~km}$ parallel to a volcanic island arc [308]. 

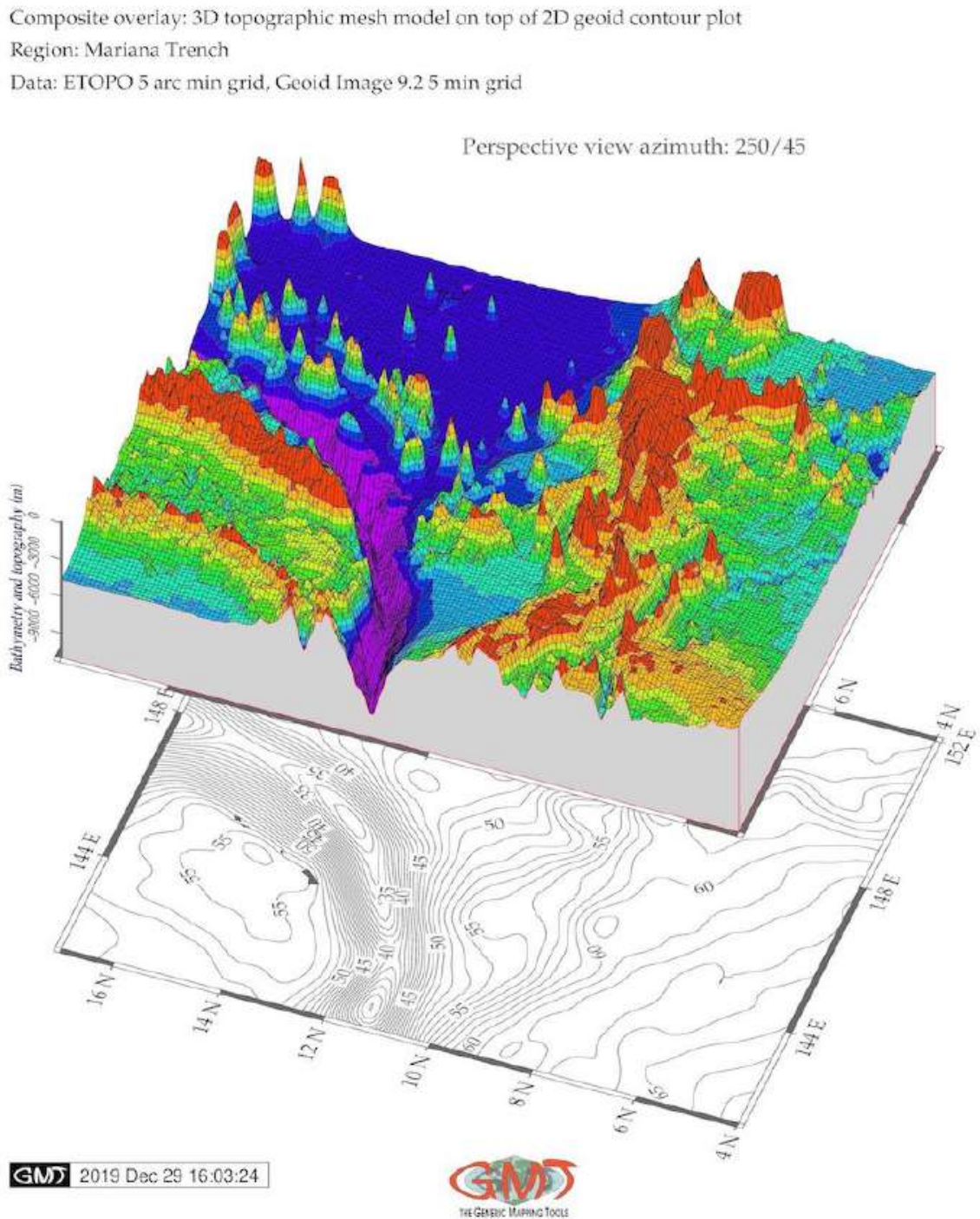

Map 2.16.2: 3D relief model: Mariana Trench, south segment

The formation of the trench is caused by the complex interconnection of various factors [188]. A trench marks the position at which the subducting slab descends beneath another lithospheric slab [130]. General form of the bathymetry of the MT is inclined toward the margin plate being connected with the ocean basic zone. It has high and steep island or continental slopes and more low and gentle slopes from the south-eastern side. The trench has a distinctive morphological feature of the convergent Pacific plate boundaries, along which lithospheric plates move towards each other. Various narrow steps are often found on the slopes of the trench. On the longitudinal profiles of the bottom of the MT there are many deepwater detected transverse steps and thresholds connected by movements of the Earth's crust along transverse faults [777]. These thresholds can play important role in the evolution of the deep water trough. For example, they control the intensity of its filling by sediment precipitation. In this process very important are the streams of the precipitation moving along the bottom from the part of the trough which is closer to the continent [703]. At the bottom of the trough there is a transverse threshold, which can present kind of a dam, in front of which there is accumulation of a thick layer of sediment precipitation. 
Geologic development Geologic development of the MT took place in several phases shaped by the influence of various factors: geologic conditions, volcanic submarine areas, hydrological settings of the currents and sedimentation. Seafloor bathymetry of the trench varies significantly in seaward axis. The Caroline Ridge is located off the trench axis at a distance of ca. $250 \mathrm{~km}$. A prominent trenchparallel belt of seamounts with trench-perpendicular width of ca. $250 \mathrm{~km}$, is located $<1350 \mathrm{~km}$. Another prominent group of wide seamounts intersects the trench at distance of 1600-2000 km [774]. The effects of the volcanism on the biological communities [321] proved correlation between earthquakes and the assemblage structures. Because rapid sedimentation is induced by turbidity currents, the organic matter content increased in the topmost layers which indicate that disturbances to the deep-sea sediments affects vertical distribution structure of meiofauna in the trench.

The seabed structure of the MT is composed in the following way from top to bottom: a sedimentary cover, a basalt of the leitic composition, a complex of parallel dykes of diabases, an isotropic gabbro, a banded gabbro-ultrabasic complex lying on the mantle ultrabasites [77]. The trench advances toward the upper plate corresponding to the subduction of very old, Mesozoic, oceanic lithosphere. Mariana Arc lavas are enriched in Molybdenum (Mo) and have $\delta^{98 / 95}$ Mo >Mid-Ocean Ridge Basalts (MORB). This implicates the addition of a Mo-rich fluid with $\delta^{98 / 95} \mathrm{Mo} \sim+0.05 \%$ to $+0.05 \%$ to the mantle wedge beneath most islands [175]. Thin Quaternary clayey sediments overlie a $400 \mathrm{~m}$ thick alternating sequence of the Early Cretaceous quartz-trachyte pillow lava and Early to Late Cretaceous radiolarian cherts in the oceanward slope of the MT [244]. MT belongs to the one of the deepest $45 \%$ of the oceans depth range, and its unique topography disrupts the continental shelf-slope-rise to abyssal plain continuum, resulting in an array of deep isolated habitats. The often abrupt and distinct topography is likely to further promote speciation through high hydrostatic pressure, remoteness from surface derived food sources and geographic isolation [159].

Lithology Lithological structure and sediment thickness are among other factors affecting MT formation. Relatively few other trenches, comparing to MT, also formed on the boundaries of the tectonic plates, but usually at a greater distance from the continents in the rift zones. Therefore, sedimentation processes within MT are deeply impacted by the location near the rift zones that are mainly associated with the formation of the underwater mountain ranges and spreading. Their expansion in the sides of the neighboring lithospheric plates is a result of the rise towards MT. The outflow to the surface of the ocean floor of the substance of the upper layer of the Earth's mantle. As a result of the unevenness of this process, the transversed faults are formed that have excellent conditions for sedimentation accumulation. According to available geophysical data [145], the oceanic crust of the tectonic plates surrounding MT is composed by a number of layers. Therefore, the impact of the sediment subduction on the trench dynamics is relatively high [253].

MT is the largest structural trap located in the continental margins of the Pacific Ocean: the sediments are being carrying by the ocean waves in a clockwise direction, passing through the trenches on the west of the Pacific (i.e. Kermadec Trench and the TT through the Samoan Passage) flowing northwest across the equator to the MT. Its geomorphic conditions create ideal conditions for the sedimentation intercepting almost all clastic material originating from the adjacent land. Accumulation of the terrigenous sedimentation on the MT seafloor depends on various factors: climatic and hydrodynamic local settings, tectonics, seafloor bathymetry, geomorphiology, type and size of particles. Large areas of active sedimentation can be distinguished where speed and volumes are very high, as well as local areas of active sedimentation, or on the contrary, dominating erosion areas. Sedimentation occur in various sediment traps, with some areas noted by areal sedimentation. The processes of the sedimentation within the MT are highly uneven. 
Geomorphic structure MT has a complicated geomorphic structure with various types of the continental tectonic plate boundaries producing a unique type of its seafloor bathymetry. The seafloor of the trench is a background, on which all the processes are reflected [131]. Main morphostructure elements of the seafloor are the outskirts of the continents and of the ocean bedrock. The structure of the trench and the nature of its relief are greatly complicated by the multiple secondary tectonic disturbances, i.e. by the occurrence of faults and displacements on of graben, horsts and lateral geologic shifts [507].

Among other trenches, MT is distinct for its edge type associated with the marginal tectonic plate subduction processes [69]. It is formed in the process of plates subduction. Its submarine terrain has a complex structure, the scale of which sharply exceeds the dimensions forms of the Earth's surface on the margin continents. These include the system of the mid-ocean ridges, crossing transform faults, deep-sea ridges, vast ocean plains complicated by chains and mountain groups and plateaus [293]. The width of the continental shelf of the margin plates connecting to the MT occupies varies from a few tens to thousands $\mathrm{km}$ with average bottom slope $17-25^{\circ}$ [606].

Areas with seamounts at the trench axis are marked by gentle trench geomorphology, smaller axial vertical loading, and bulgy topography at the outer-rise. Mariana Arc and West Mariana Ridge border the trench on the west side. The Caroline Ridge and a group of Caroline Islands are located southwards off the trench axis at distance of about 0-250 km. A prominent trench-parallel belt of seamounts with trenchperpendicular width of about $250 \mathrm{~km}$, is located at around $1350 \mathrm{~km}$ BSL. Another notable group of wide seamounts, intersects the trench at a distance of 1600-2000 km BSL [774]. Morphological structure of the of the MT has following pattern: a majority of the seafloor is occupied by the abyssal depths (3-6 $\mathrm{km})$ followed by the extreme depths $(>6 \mathrm{~km})$. Depths of $>6 \mathrm{~km}$ are restricted mostly to the deepest part of the trench located in the south-western part of the trench (area of Challenger Deep), although depressions of 6-7.5 km BSL, occasionally occur in the central part of the trench crescent [557]. Typical depths of the MT seafloor are 4-5 km [422], [424].

Seafloor of the MT is composed by the oceanic crust forming rift zones of the mid-ocean ridges with a capacity of 5-10 km [557]. MT is complicated and constituent of the interrelated factors forming its tectonic structure. Deformations of the trench respond to the coupling between the upper and lower plates: coupling relating to the continental slab age-buoyancy [642]. Back-arc deformation roughly correlate with upper continental tectonic plate velocity [240]. Trench migration rates are chiefly controlled by lower continental tectonic plate velocity [350], which depends on the tectonic slab age buoyancy [92]. Main ridge axes of the MT represent a place where the upwelling magma encounters cold seawater in the location of tectonic plates. Hydrothermal cooling of magma at the ridge axes causes recycling of the entire volume of the water in the trench column. In this way it provides nutrients for biological communities in the abyssal zone of trench [353], [522], [269]. Examples of interconnection of the system are illustrated by biological communities [186], [348].

Geomorphic structure of the MT is complicated by the longitudinal ridges, steps, large landslide, bodies and ledges. Transverse profile of the MT is strongly asymmetric: slopes are higher on the side of the island arc, dissected by deep underwater canyons with narrow steps. MT has complicated steps of various shapes and sizes, caused by active tectonic and sediment processes. Continental slopes are high, reaching up to several thousand $\mathrm{m}$ and inclining to $3-6^{\circ}$ (in the SW part up to $30-40^{\circ}$ ), upper boundary of which coincides with the edges of the shelf (depths 150-200 m). Slopes of the passive margins are strongly complicated by the terraces, ledges, marginal plateaus and canyons. Slopes of the margins are steeper, reaching can 5-7 km in height. Seafloor geomorphology with very steep escarpment of the narrow MT does not play a crucial role for ocean water mixing [223]. Interplay between topography and turbulence of the ocean waves includes impacts of the inertial and meridionally directed tidal inertiogravity waves, responsible for turbulence and variation of water masses mix according to the depth stratification. At the base of the continental slope of passive margins formed by the adjacent tectonic plates, continental foot forms accumulative body. In turn, it is formed by merged cones of the removal 
and plumes of the suspension flows and submarine landslides with abyssal sedimentation.

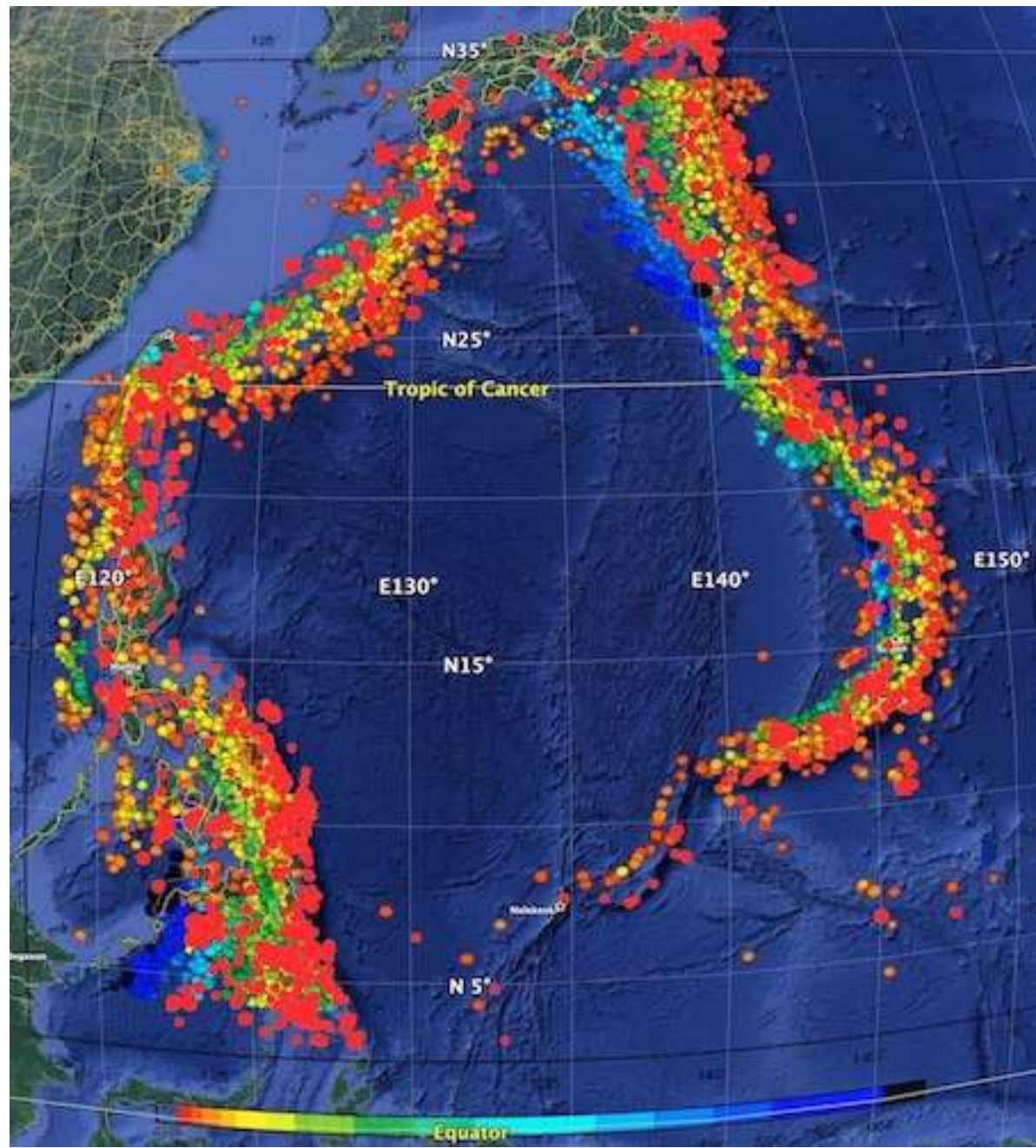

Map 2.16.3: Earthquakes event map at PSB area: prime hypocentres and magnitude values

Submarine margins of continents, or transition zones, depend on the features of the relief and geology. Accordingly, they are divided into 2 types: the passive and active ones. The $1^{\text {st }}$ ones include the shelf, that is mainland bank, the slope and the mainland foot. Having complicated relief structure with marginal seas, island arcs and deep-sea gutters, MT belongs to the active type of trench. Due to the geodynamic reasons, MT motion, migration and upper plate deformation can be described as the result of the response to the mantle flow and imbalance between the forces exerted by lower and upper continental plates at the plate interface.

Cracks MT is notable for well-developed systems of cracks in the structure. Cracks of the MT are abundantly developed at the edge, in the middle and upper parts of the terrace [240]. The formation of these cracks is caused by gravitational instability: horizontal extension is due to the trench-ward increase of the dip angle of the seafloor surface. Besides, it cause slope instability due to gravity pull. The cracks on the surface of the seafloor on the oceanward slopes of the MT are attributed to tensile rock failure. Cracks are elongated nearly parallel to the strike of the cliffs, some are aligned, branching or merging have no vertical nor lateral displacement. This can be explained by open tension fractures. Surface edges of the MT cracks are sharp, indicating young origin with a noticeable pressure ridge caused by mud 
overflow during closure of cracks. Cracks are formed at topographically specific areas, at the horizontally stretched surface of the down-going plates under tensional stress, on the horizontal or very gentle slopes above steep cliffs. Cracks are caused by a combination of gravitational slope instability at the edges of the slope or top of the ridge [280] and additional inertia during earthquake shaking [129], [658].

Submarine earthquakes Deep earthquakes are important factors causing system of cracks of the MT. Transformation faulting is the mechanism for deep earthquakes [319]. Experimental observations [209], [75], [318] indicate a shear instability that develops during the incipient transformation of metastable olivine to wadsleyite or ringwoodite. Horizontal tensional stress during the earthquake shaking triggers development of the system of cracks in the MT, as stress difference under static conditions is caused by the slope inclination. The majority of the cracks within the MT are open tensile failures and are situated in areas of very gentle slope or horizontal parts of the seabed, in most cases near the edges of steep cliffs which delimit the terraces. There is no lateral nor vertical dislocations on both sides of the cracks, so they are open fractures.

Igneous volcanic areas $\mathrm{MT}$ is important integral feature of the active continental margins that naturally includes deep plate subduction. Subduction of slabs of oceanic lithosphere into the deep mantle involves a wide range of the geophysical and geochemical processes and is of major importance for the physical and chemical evolution of the Earth [546]. Thus, it is noticed [277] that the continuity of the slab across gaps in the Wadati-Benioff seismic zone between deep earthquake clusters and shallow seismicity and they argue that only the deep earthquakes beneath the north Fiji basin and the deep events beneath New Zealand may occur as detached events with no mechanical connection to the surface [388]. Using the observation and triggering mechanism of high-frequency oceanic T-waves, [28], it has been argued [213], [243] for the mechanical continuity of most slabs across the deep seismicity gap.

Recent studies revealed [165] that MT advance toward the upper plate corresponding to the subduction of very old, Mesozoic oceanic lithosphere. The Mariana Arc lavas are relatively enriched in Molybdenum (Mo) and have $\delta^{98 / 95}$ Mo significantly greater than MORB (apart from the samples from the island of Agrigan). This implicates the addition of a Mo-rich fluid with $\delta^{98 / 95}$ Mo ca. $-0.05 \%$ to $+0.05 \%$ to the mantle wedge beneath most islands [175]. Recently updated analyses of global plate motions indicate that significant trench advance is also rare on Earth, being largely restricted to the Marianas-Izu-Bonin arc [101]. The effects of trench migration on the descent of subducted slabs are discussed by [211]. The global plate tectonics movements shaping the seafloor bathymetry can be described as follows.

The seafloor spreading fabric in the MT is obscured by the absence of magnetic anomaly lineations. Elongated topographic structures accompanied by plate bending exist in the oceanward slope of the Challenger Deep [774]. The Japanese Lineation set is a Mesozoic magnetic anomaly lineation, it exists in the East Mariana Basin, east of the MT [566], which means that the subducting plate along the southern part of the MT is a part of the Pacific plate formed in the Mesozoic.

Other remarkable topographic feature of the MT includes a set of many elongated ridges and escarpments accompanied by the plate bending on the outer slopes with two existing distinct strikes for these structures. The elongated structures have two strikes: $\mathrm{N} 85^{\circ} \mathrm{E}$ and the same as the trench axis; $\mathrm{N} 70^{\circ} \mathrm{E}$. Most bending-related structures except those near the trench axis, were formed by the reactivation of the seafloor spreading fabric. The presence of cracks is another distinguished geological feature of the MT [580]. MT has many open prominent cracks on its surface, up to a few meters deep and a few hundred meters long on the diatomaceous clayey sediment surfaces of its oceanward slopes. The shape of the cross-section is Y-shaped. More precisely, the bottom is a very narrow $(1-3 \mathrm{~km})$, yet in some places wide (several tens of kilometers) flattened. 


\subsection{Izu-Bonin Trench}

The Izu-Bonin Trench (IBT), also known as Izu-Ogasawara Trench is a hadal trench located in west Pacific Ocean and lies south of Japan (Map 2.17.3), [405].

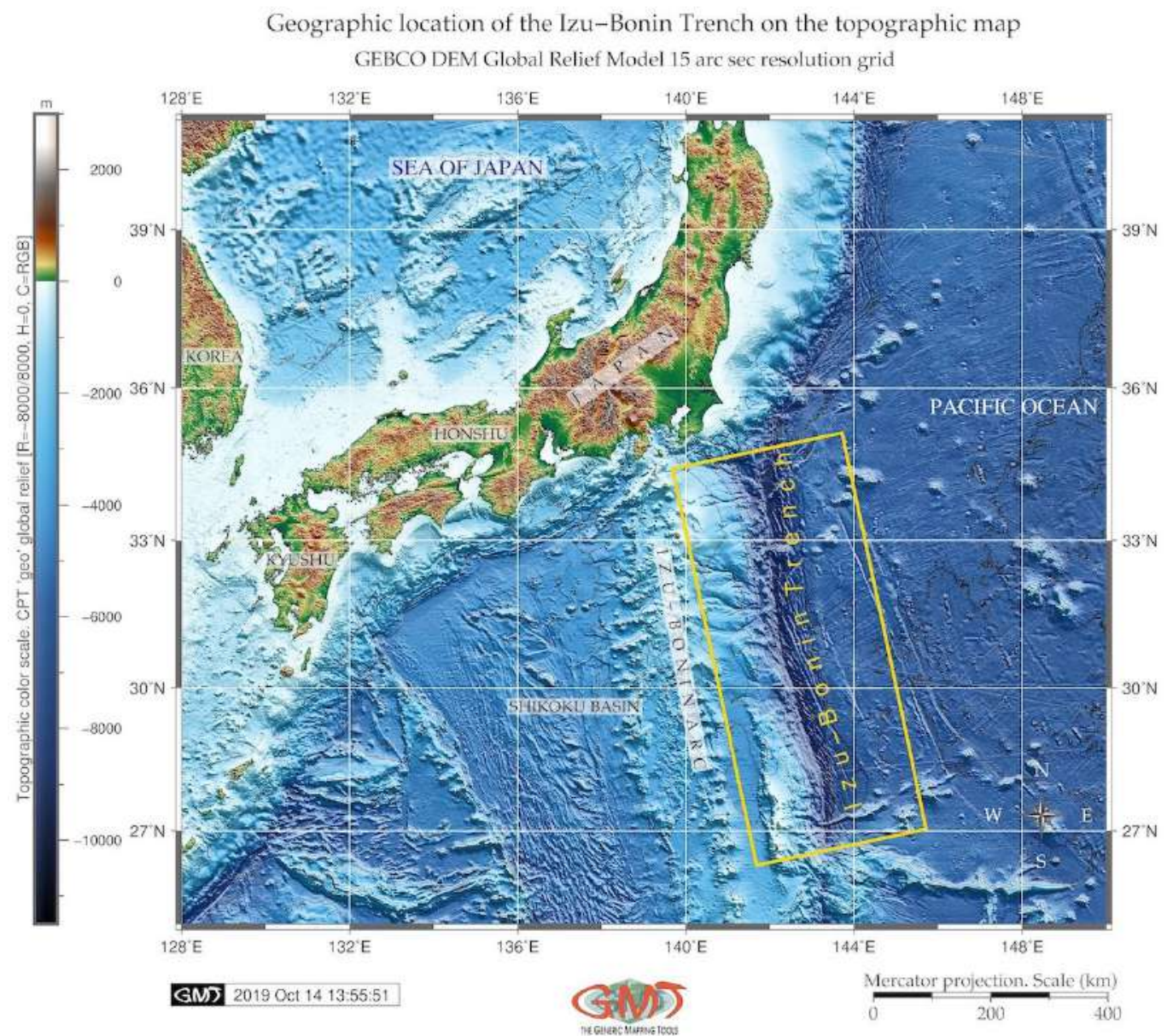

Map 2.17.1: Izu-Bonin Trench: bathymetric map

Longitudinally, it extends from near Tokyo, Japan to Guam [30]. In its structure, the trench continues the Japan Trench. The IBT is formed in the area of active tectonic subduction of the Cretaceous (135 Ma) Pacific Plate beneath the Philippine Sea Plate [652], [405]. As a consequence of this subduction the following structured are formed: a volcanic arc of the Izu and Bonin Islands on the Izu-Bonin-Mariana Arc system and the Shikoku Basin as a backarc basin (Map 2.17.2). The IBT is boarded on the east by the Ogasawara Plateau [573], [405].

In its historical development, the Izu Bonin arc has two major periods of arc formation that differ in duration, composition, and volcanology. The first lasted $\sim 5$ to 6 million years and produced voluminous boninitic-tholeiitic magmas. The second post- $42 \mathrm{Ma}$ Izu Bonin arc formation period produced a classical volcanic arc with stratocones [30]. The formation of the Shikoku backarc basin took place in the early Miocene, ca. 30-15 Ma [707]. A new period of along-strike arc rifting began about 2.5 Ma ago [279]. The historical development of the oceanic trench is mirrored in its seabed structure, which is is well structured, including valious layers: a sedimentary cover, a basalt of the leitic composition, a complex of parallel dykes of diabases, gabbro and gabbro-ultrabasic complex lying on the mantle ultrabasites. 


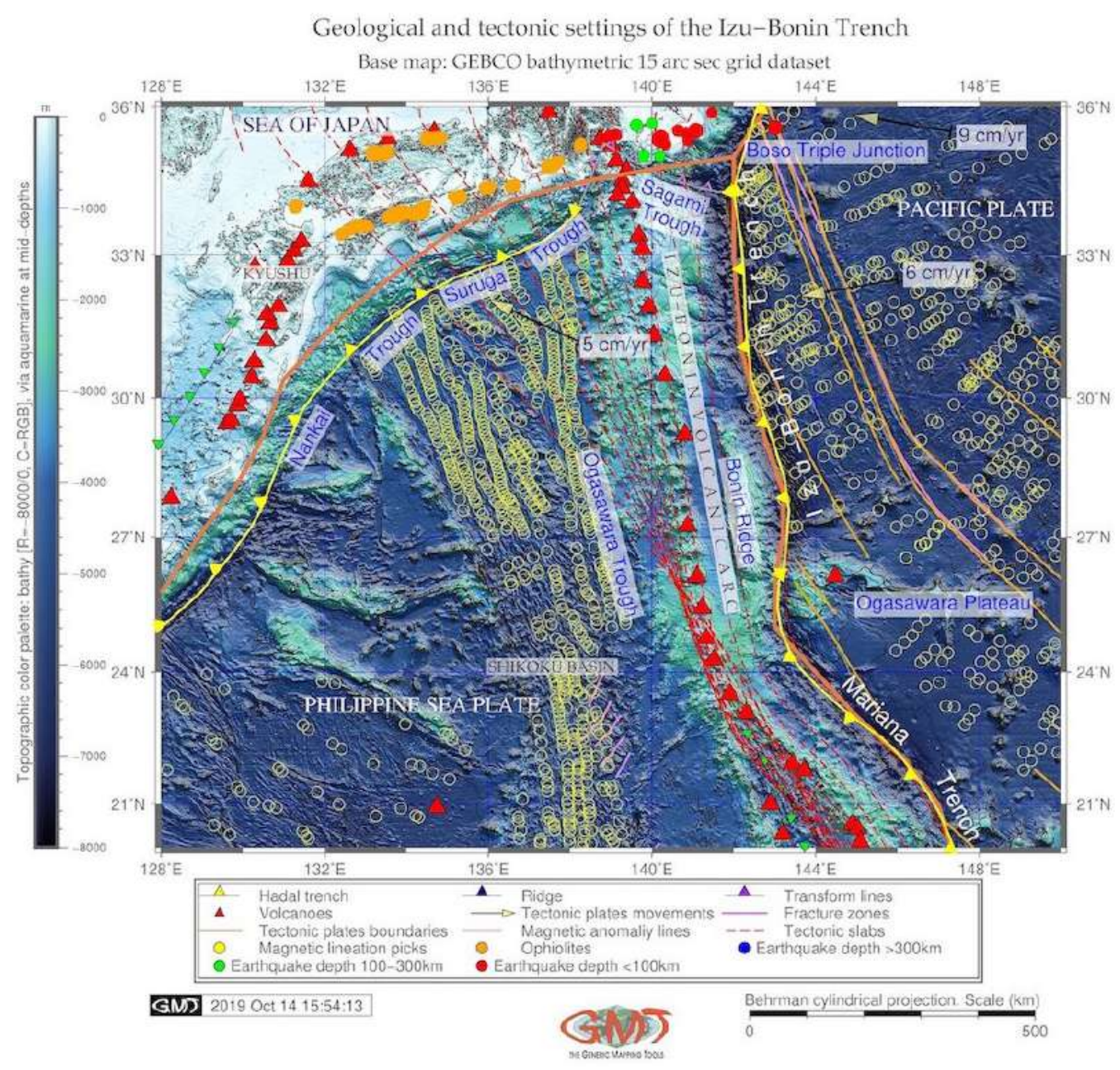

Map 2.17.2: Izu-Bonin Trench: geologic map

The trench extends to nearly $10 \mathrm{~km}$ depth. The $200 \mathrm{~km}$ wide forearc region includes inner trench slope with a basal terrace and seamounts, outer arc connected with the Bonin Islands and a thick forearc sedimentary basin east of the active arc volcanoes. The backarc region encompasses active rift basins and cross-chains of submarine arc volcanoes extending into the Shikoku Basin [127]. Northern end of the Izu-Bonin arc is a juvenile oceanic arc colliding with the Honshu arc, a mature island arc since Middle Miocene Saito and Tani, 2017).

A chain of serpentine seamounts is exposed at the forearc slope 40-50 km west of the IBT axis. Seismically, few large earthquakes ( $>$ M7.0) [306] are detected at depths $<100 \mathrm{~km}$ (red circles on Map 2.17.2) and many large earthquakes at depths 100-300 km (green circles on Map 2.17.2). The Boso triple junction located on the north of the Izu-Bonin Collision Zone (Map 2.17.2) is the northern end of the arc colliding with the Honshu Island arc as a consequence of the northwestward migration of the Philippine Sea Plate [579], [405].

The IBT is boarded by the Philippine Sea tectonic plate in the west. The Philippine Sea is a geologically complicated region notable for complex bathymetry and plate shape [753] and a complex patchwork of seafloor ages. The bounding subduction zones of the the Philippine Sea Plate exhibit significant NS variation in slab morphology [101]. As a results of the interplay of these factors, the trench is consisting of the Izu (north) and the Bonin (south) separated roughly by the Ogasawara Plateau. Thus, seafloor ageing affects advancing trench through the subduction of progressively older and stiffer lithospheric 
material [165], which was further discussed by [281] who pointed on asymmetric spreading caused by ridge migration in the Izu-Bonin region in view of age difference between the oldest forearc basalt and the crust of the Amami Sankaku Basin.

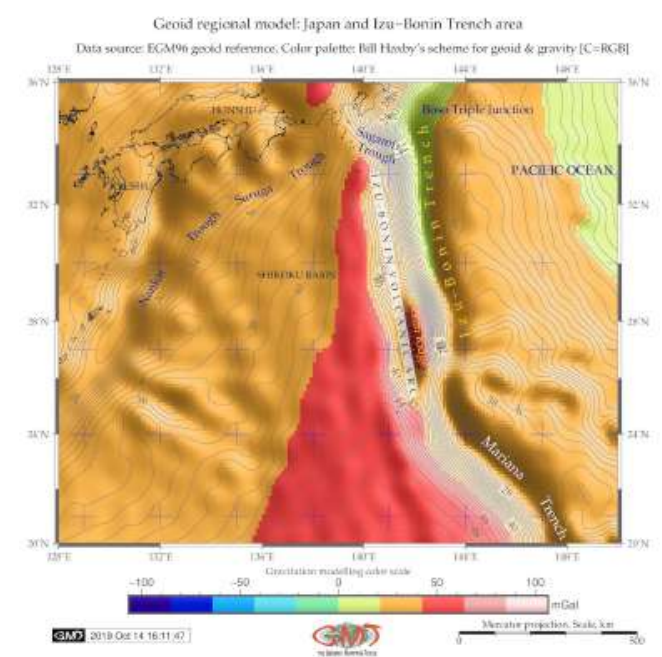

(a) Geoid model

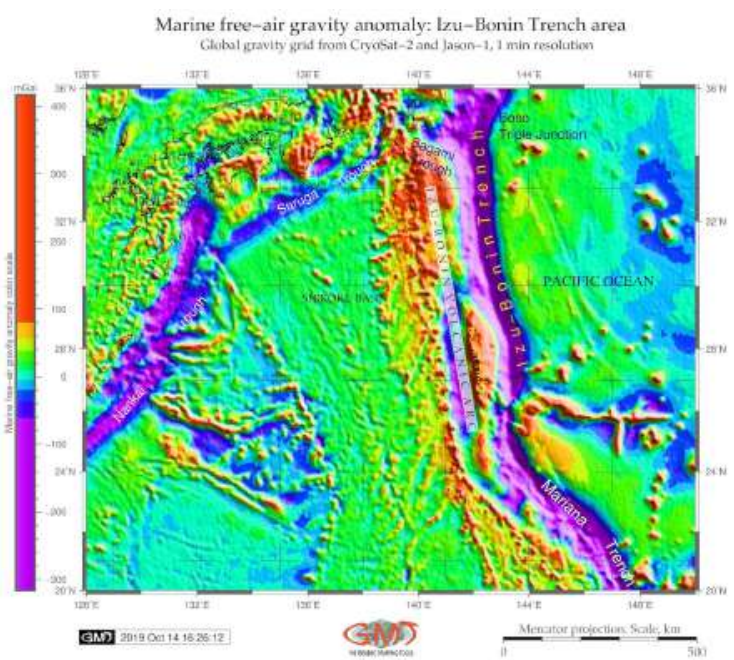

(b) Free-air marine gravity model

Map 2.17.3: Izu-Bonin Trench

More detailed description of the Izu-Bonin tectonics, geophysical, petrological and geochemical settings, volcanism and seismic characteristics, analysis and interpretation of geomorphological, geological, and thermochronological data, are reported in relevant publications [270]; [18]; [670]; [587]; [228]; [202]. Hence, the region of the Izu-Bonin-Mariana Arc is now one of the best and intensively studied oceanic arcs. However, lesser attention is given to the submarine geomorphology of the IBT as a deep-sea geomorphic structure. Referring the lack of such research, current study aims at visualizing the trench by mapping and modelling its geomorphic form using cartographic approach of the GMT.

Morphologic development of the IBT took place in several phases shaped by the impact of various factors: geologic conditions, volcanic submarine areas, and inner ocean currents and sedimentation. Factors affecting formation, geomorphic development and bathymetric patterns of the trench are diverse. The most important ones include tectonic development, geological, hydro-chemical, biological, geothermal, climatic, tectonic, bathymetric and geomorphological determinants, deep ocean currents that bring sediments to the trench bottom and contributing towards accumulation of the sediment thickness. Impact of lithosphere is illustrated by a constant exchange of matter and energy between the submarine volcanoes located nearby [266]. The hydrosphere influence on the MT is reflected by deep ocean currents bringing sediments to the trench bottom and contributing towards accumulation of the sediment thickness [253]. The trench is located in the collision of the tectonic plates. It has a distinctive morphological feature of the convergent Pacific Plate boundaries, along which lithospheric plates move towards each other. Not all seismic zones in subducted slabs of the IBT are continuous and that some deep events seem to occur isolated from those at shallower depths. 


\subsection{Japan Trench}

The Japan Trench (JT) is located in western part of the Pacific Ocean, eastwards off Japan (Map 2.18.1) [396]. The geologic and tectonic settings in the region of the JT are strongly influenced by the subduction of the Pacific Plate beneath northeastern Japan and North American Plate along the JT (Map 2.18.2), which is well described in the previous works [261], [393]. The region of the JT is a convergent zone associated with many earthquakes [762]. It belongs to the circum-Pacific seismic belt (a.k.a. 'Ring of Fire') where large earthquakes originate within the areas of sedimentation on upper forearc slopes [17], [396], [393].

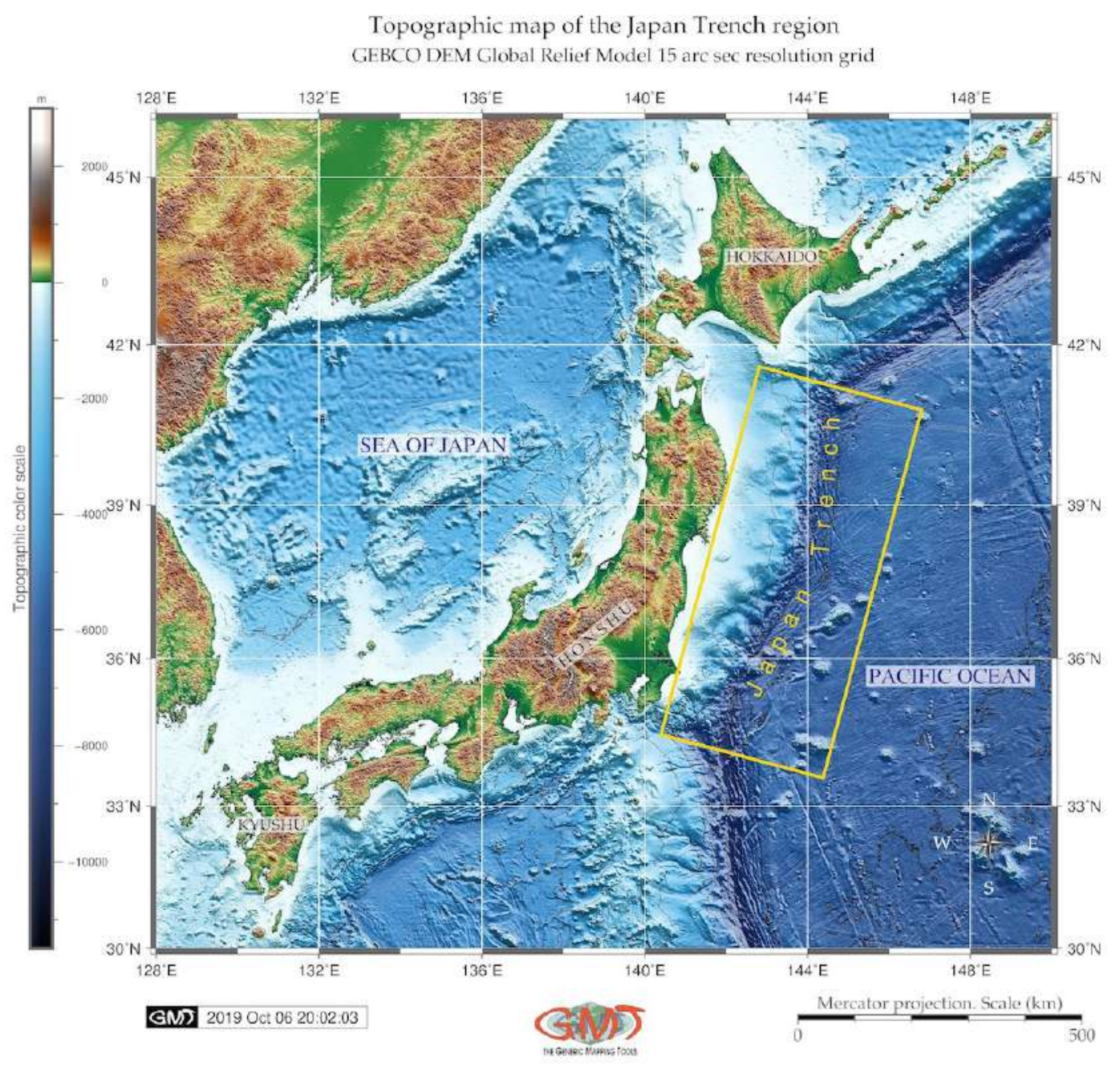

Map 2.18.1: Japan Trench: topographic map

The structure of the trench presents a typical arc-trench system [520]. In terms of tectonic geomorphology, the arc-trench system is a type of the mobile belts with bathymetric and topographic relief formed under the impact of tectonic plates subduction, active volcanism, repetitive earthquakes and orogenesis. The geological complexity of the JT results in the high seismicity of the area, which is well studied in various works [565], [259]; [500]; [67], [393]. The geology of Japan trench-arc system consists of Jurassic to Neogene accretionary prisms and Neogene to Quaternary sedimentary and volcanic rocks caused by volcanism during the opening of the Sea of Japan in the middle Miocene [730], [396]. 


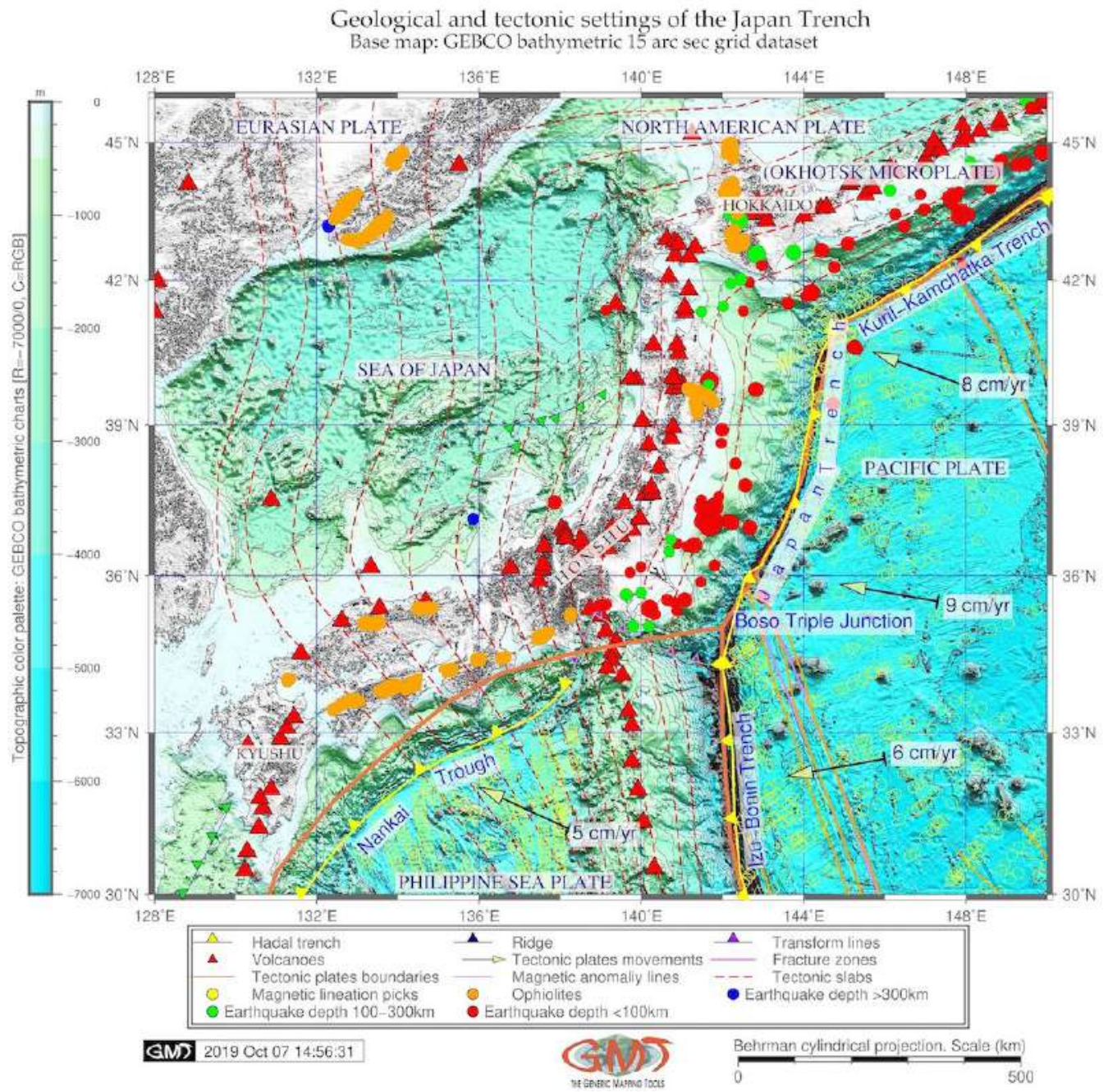

Map 2.18.2: Japan Trench: geological map

The Cretaceous-Paleogene granitic rocks are exposed in several regions, especially on the fore-arc side. High seismicity of the region can be illustrated by several large interplate earthquakes that have affected the Tohoku region along the JT during the last century [752]. Because JT is located on the tectonic plates subduction zone, the earthquakes here belong to the largest and most destructive earthquakes in the world [292]. Many open cracks on the diatomaceous clayey sediment surfaces of oceanward slopes of the northern JT were detected by [580]. The surface of the seabed outside the cracks (i.e. normal seabed) appears to be coated by ferroman-ganese oxides [283], and is overlain by fine pelagic mud, containing dominantly diatoms, silicoflagelates, radiolarians and sponge spicules, together with a considerable amount of detrital quartz and ash fragments.

Northern and southern parts of the JT demonstrate variations in their geologic features with heterogeneously distributed seismicity around the JT. Most of the large earthquakes with magnitudes $>7$ occurred in the northern forearc region of the trench. For example, the Tohoku-Oki earthquake of 2011, is the largest earthquake that took place in forearc region of the Northeast Japan subduction zone, west off the JT [356]; [274], through the shallow part of the subduction zone to the seafloor surface. It triggered a devastating tsunami with massive damages along the northeast coast of Honshu, Japan [292]. 


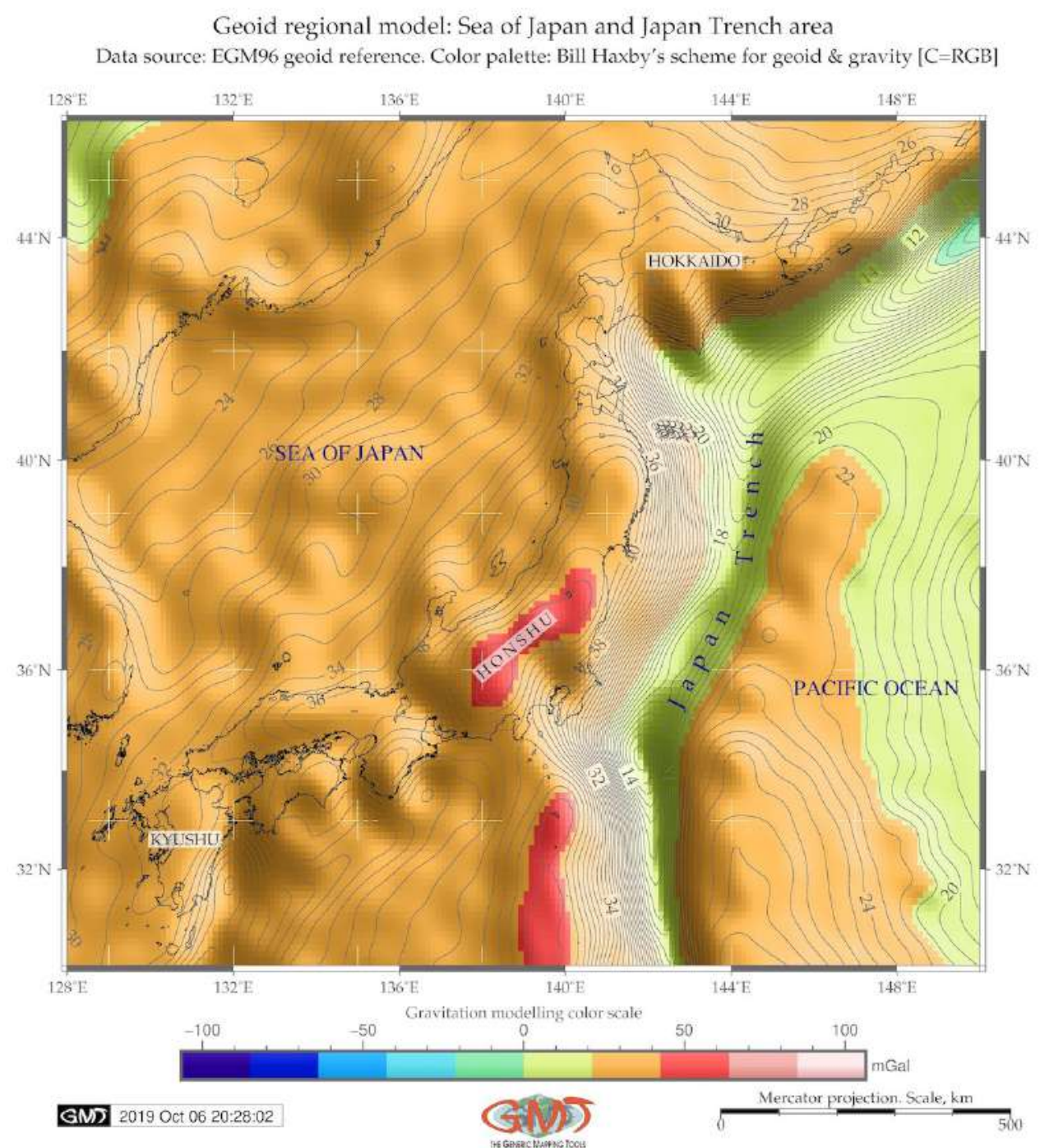

Map 2.18.3: Japan Trench: geoid model map

Southern part of the trench is seismically more 'quiet': no large earthquakes were recorded during recent centuries [552], except for the 1938 Shioya-oki earthquake. The subduction zone characterizes northern part of the trench [718]. In a $60 \mathrm{~km}$ buffer gap off the trench axis, a decollement structure with soft sediments is located. The zone of this structure between two tectonic plates decouples shear stresses, which in turn, forms an aseismic zone. Comparing two devastating earthquakes: the 1968 Tokachi-Oki and the 1994 Sanriku-Haruka-Oki, two distinct heterogeneities along the plate boundary at $40^{\circ} 10^{\prime} \mathrm{N}$, located exactly at the southern boundary of the two earthquakes were detected [230]. This well illustrates the direct affect of the plate tectonics triggering earthquake events that naturally lead to significant deformations in the geomorphic landforms. It further explains the coincidence of the focal regions and the structure with slower velocities in the lower crust.

The subduction of the seamount chain penetrating to the Pacific Plate possibly take place. It can further create irregular geomorphic landforms. When these seamounts subduct deep, they collapse due to the mechanical affects from the free water released by a collapsing seamount. In turn, it may rise into the island-arc mantle and the lower crust. This brief illustration of the deep correlation of the tectonic and geological processes that result in actual land forms and geomorphological patterns. Seismic 
investigations of the JT axis shown [66] variations in the frictional resistance along a décollement on the structural development of the frontal wedges near the subduction zones.

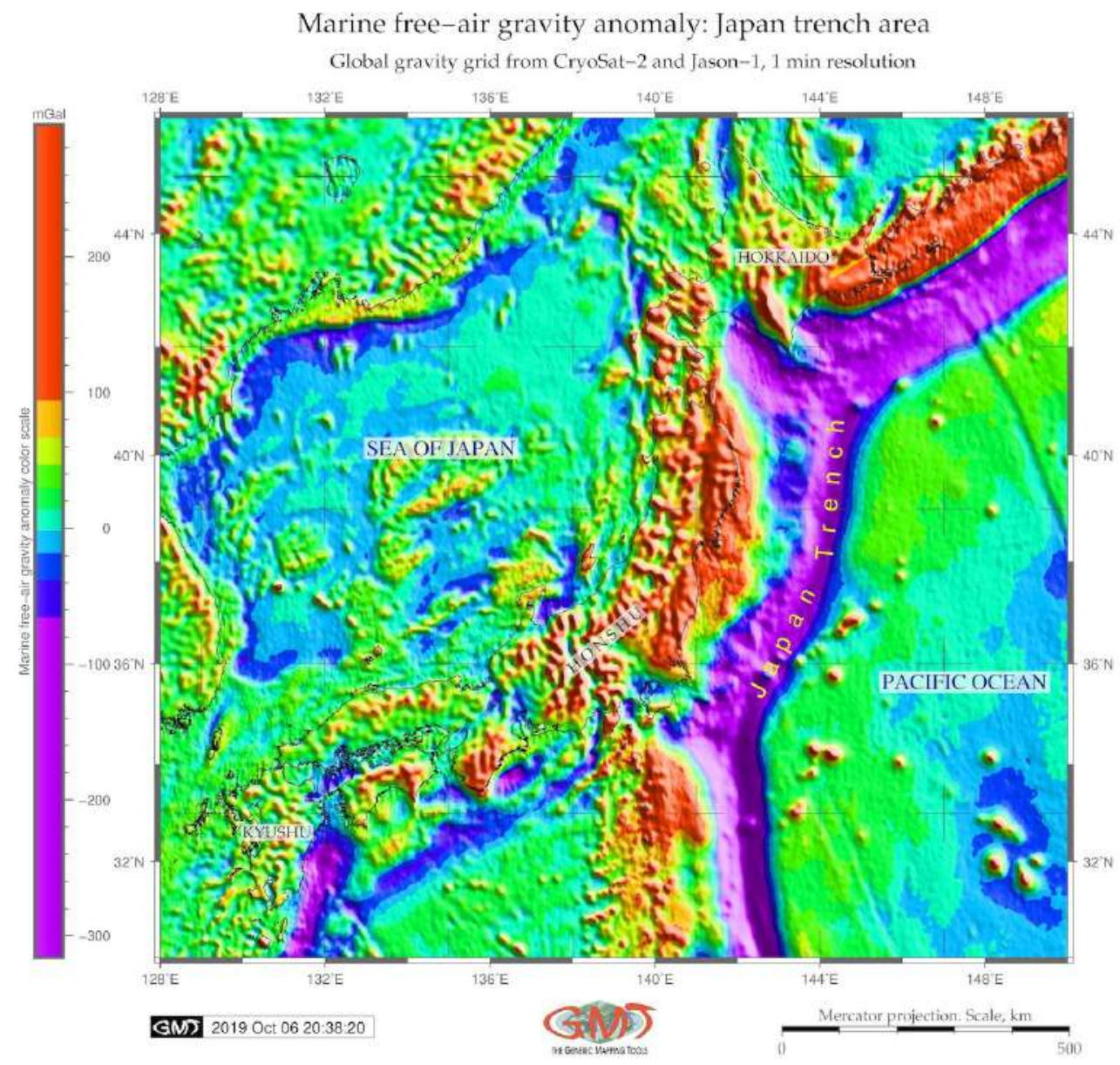

Map 2.18.4: Japan Trench: gravity model map

The observed slope sediments between the inner and outer wedge may have accumulated during the growth of supercritical wedge. Seismic surveys indicate [334] that shallow areas at the Tohoku earthquake experienced significant deformation. During this event multiple faults slipped above and below the pelagic clay layer [610].

The geophysical features of the JT area were discussed [500]: comparison of the JT Nankai subduction zone for the distribution of the stress state [396], [393]. Based on the correlations between strength and temperature, the deep seismicity is likely to result from plastic instabilities, with the distribution of earthquakes being related to strength distribution and therefore slab mineralogy. A complex rheological structure for subducting slabs has been proposed by Karato, Riedel, and Yuen [308], due to the effects of grain size reduction during phase transformations. Based on their model, rapidly subducting and therefore relatively cold slabs should be weaker than slowly subducting warm slabs. Not all seismic zones in subducted slabs are continuous and that some deep events seem to occur isolated from those at shallower depths [277]. 
Composite overlay of the 3D topographic mesh model on top of the 2D geoid contour plot
Region: Japan trench
Perspective view azimuth: $165 / 45^{\circ}$

Data: ETOPO 5 arc min grid, World Geoid Image 9.25 min grid

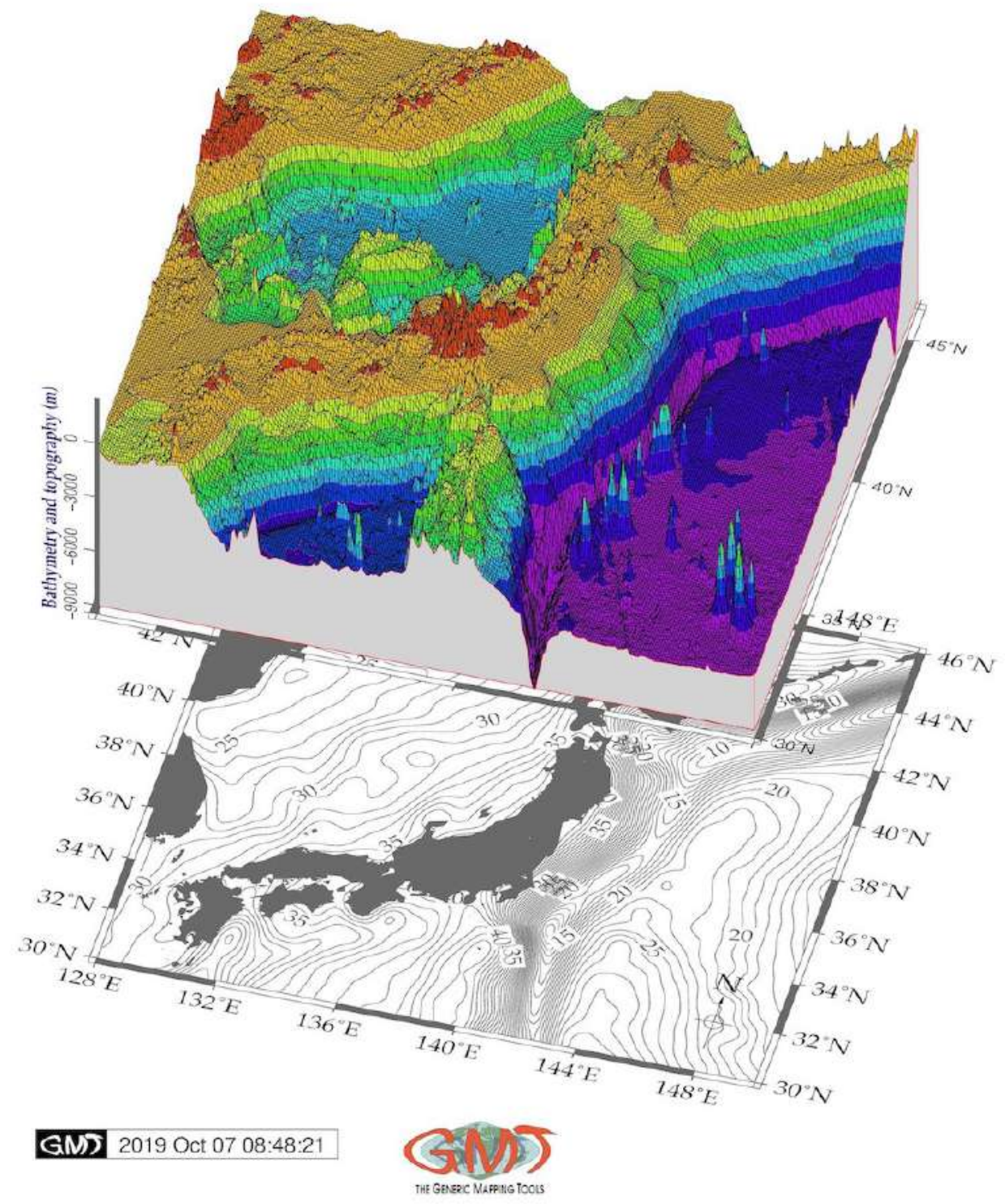

Map 2.18.5: Japan Trench: 3D mesh model map of geomorphology

Structure, magnetism, and dynamics of subduction zones, the continuation of the low wave speed, high attenuation (low Q), and seismically anisotropic wedge are normally near $400 \mathrm{~km}$ depth beneath some back arcs. This may be explained by the persistence of hydrous phases to that depth and that magnetic systems are not limited to near-surface regions of the mantle. The correlation also exist between the dehydration of the slab, rupture nucleation and crustal earthquake triggering. 


\subsection{Puysegur Trench}

Puysegur Trench (PsT) has ca. $800 \mathrm{~km}$ in length, stretching from the most southern tip of the South Island to the Macquarie Triple Junction [387].

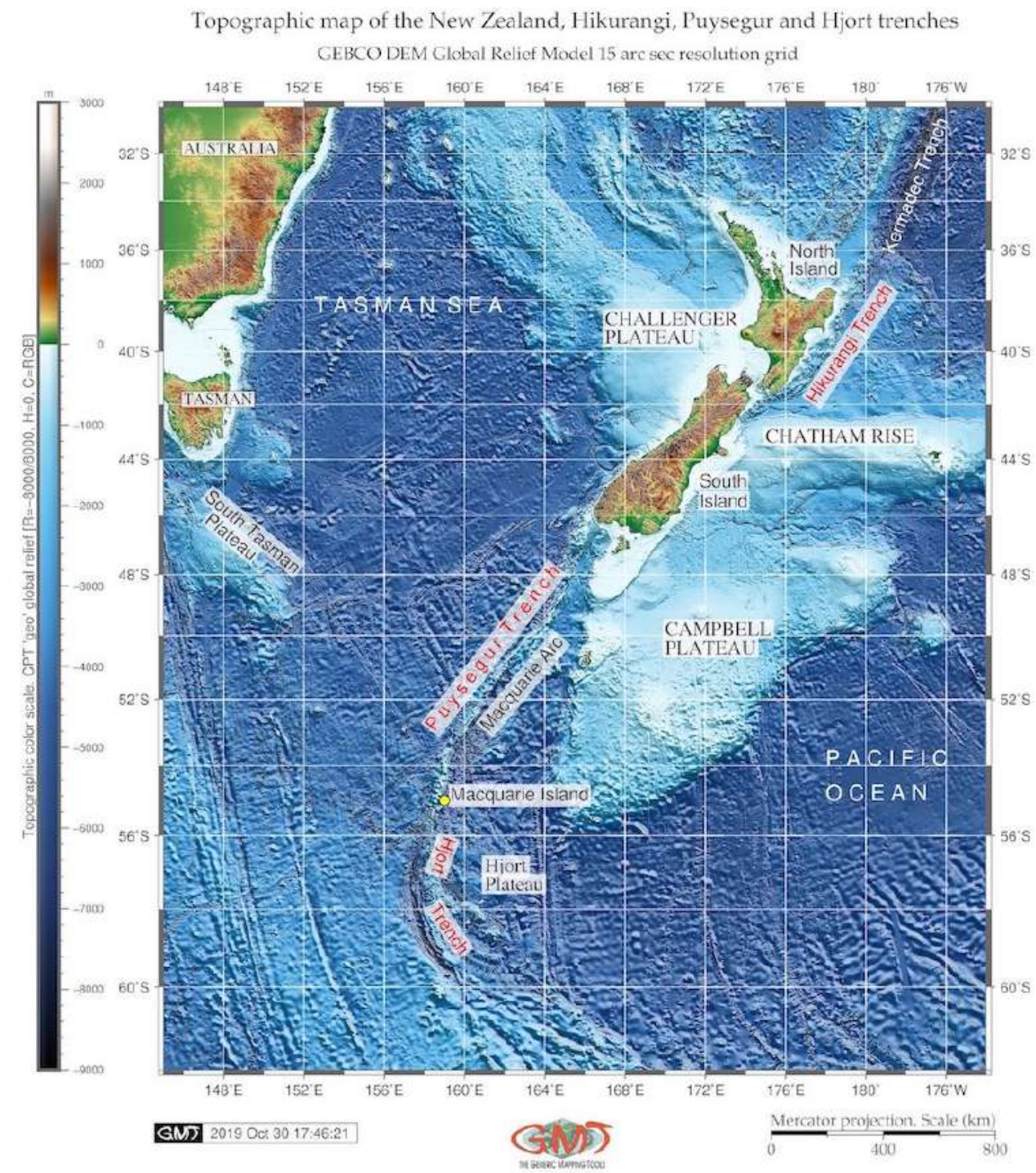

Map 2.19.1: Hikurangi, Puysegur and Hjort trenches, New Zealand: GEBCO based topographic map

The Macquarie Fault Zone is associated with the Alpine Fault, which is the right-lateral transform fault boundary separating the PsT and the northern KT [37], [387]. The Macquarie Ridge Complex (MRC) is a dominantly translational structure accommodating right-lateral motion between the Australian and Pacific Plates and PsT, where Australian lithosphere subducts beneath the southwest corner of New Zealand on the Pacific Plate. The plate boundary south of New Zealand is located along the MRC which is crucial for understanding the tectonic structure of the region. Comparing to the Hikurangi, PsT and Hjort are younger (started at $168 \mathrm{Ma}$ ) and less developed [700], [387]. The Indo-Australian Plate subducts beneath the Puysegur Bank and the Fiordland Massif forming PsT.

Hjort Trench continues PsT southwards from the Macquarie Island (Fig. 2.19.1) [387]. It presents a linear topographic depression south of Macquarie Island in the southwest Pacific Ocean (Fig. 2.20.1). 
Hjort Trench lies in an area of transpression where plate boundary transitions from a transform boundary to a convergent one. Hence, this region shows how a transform boundary with a vertical (near-vertical) transform fault becomes an area of under-thrusting [540]. The deepest point of Hjort Trench is ca. 6.3 $\mathrm{km}$ b.s.l. Eastwards, the Hjort Ridge follows the general curve of the Hjort Trench, separating it from the Hjort Plateau, [387].

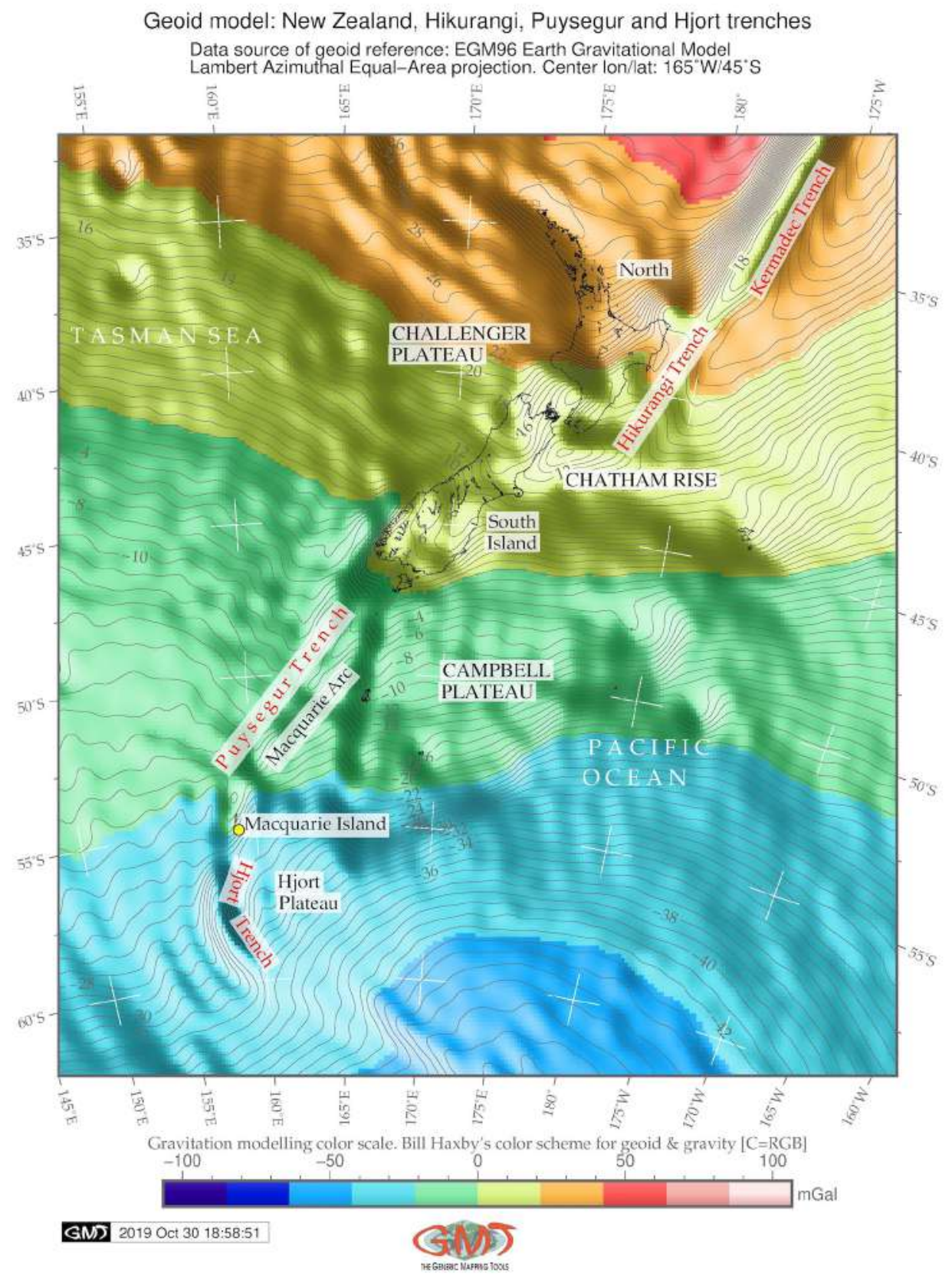

Map 2.19.2: Hikurangi, Puysegur and Hjort trenches, New Zealand: geoid model

Unique tectonic setting of the region consist in the connection of two subduction zones in the north (Hikurangi margin) and in the south (Puysegur margin), connected by an oblique continental collision along the Alpine Fault located in the South Island of New Zealand. This cause variations in the submarine geomorphic structure of the trenches which is also referred as 'subduction scissor' [608]. The 
Puysegur/Hjort subduction is highly oblique (dextral) and directed southwards. The Hikurangi subduction is directed northwestwards. Hence, the South Island is caught in between by the 'subduction scissor'. In the absence of available high-resolution information and detailed mapping on the seabed geomorphology of the Hikurangi, Puysegur and Hjort trenches, a GMT approach to map their seafloor on a local scale were undertaken. Since seafloor of the deep-sea trench represents an integrated response to a complex range of factors, such as oceanographic, geological and tectonic conditions which eventually define the present shape of the seabed landforms, an integrated approach was used to visualize, model and map three trenches on the New Zealand margin [387].

Hjort Trench is characterized by an oblique subduction zone geoid anomaly. Large 1924 earthquake occurred in the northern Hjort Trench which suggest a thrust focal mechanism and active subduction of young oceanic lithosphere beneath older oceanic lithosphere [87]. Frequent seismic events, most less than $20 \mathrm{~km}$ deep, characterize the transpression along this plate boundary [515]. The southern segment of the Alpine Fault on the South Island continues into the Tasman Sea Basin and finishes at the PsT (Fig. 2.20.1). The oceanic Indo-Australian Plate subducts eastwards through the PsT under the Pacific Plate [387].

Geologic events during the tectonic historical records of this region, such as Eocene-Oligocene rifting as well as Miocene-Quaternary strike-slip, crustal thinning in the Solander Basin, development of the oblique subduction zone in the PsT, are studied by processing seafloor relief data and interpretation of the seismic and bathymetric cross-section profiles acquired over the PsT area [541]; [351]; [352]. Effects of slab mineralogy and phase chemistry on the subduction dynamics (buoyancy, stress field), kinematics (rate of subduction and plate motion), elasticity (deformation and seismic wave speed), thermometry (effects of latent heat, isobaric superheating) and seismicity (due to adiabatic shear instabilities) are well discussed [56]. The morphology and development of the subducted slabs are more complex than modeled [97], on either whole mantle flow or convective layering at $660 \mathrm{~km}$ depth. Apparently, slabs can deflect horizontally in the upper mantle transition zone beneath some convergent margins whereas penetration to lower mantle depths can occur beneath other island arc segments. Different styles of the subduction across the upper mantle transition zone and trench formation.

Various physical and chemical processes interact during tectonic plates subduction, and the complexity of the system necessitates an interdisciplinary approach involving seismology, mineral physics, geochemistry, petrology, structural geology, rock mechanics, and geodynamic modeling. For example, phase transformation kinetics determine buoyancy, rates of subduction and, therefore, thermal structure, with the latter feeding back to affect the kinetics.

Rheology and large scale slab dynamics is affected by mineral transformations and their kinetics. The rheology of mantle minerals, though having considerable importance in controlling the subduction process, is exceedingly difficult to study experimentally, due to the experimental limitations, since rheology at pressures of the transition zone and lower mantle [309]. An increase of intrinsic density or viscosity with depth as well as phase transitions with a negative Clapeyron slope can all inhibit or delay deep subduction, tectonic conditions and relative motion of the tectonic plates at Earths surface play important role. The effects of subduction of crustal rocks during continental collision consists in following subduction to depths $>90 \mathrm{~km}$. Slices of continental crust exhumed back to the surface very rapidly, thus ensuring the survival of the high-pressure minerals. 


\subsection{Hikurangi Trench}

The Hikurangi Trench (HT) (sometimes also referred as trough) is located on the Hikurangi margin, $500 \mathrm{~km}$ long $480 \mathrm{~km}$ wide [572], northeast from the North Island [387].

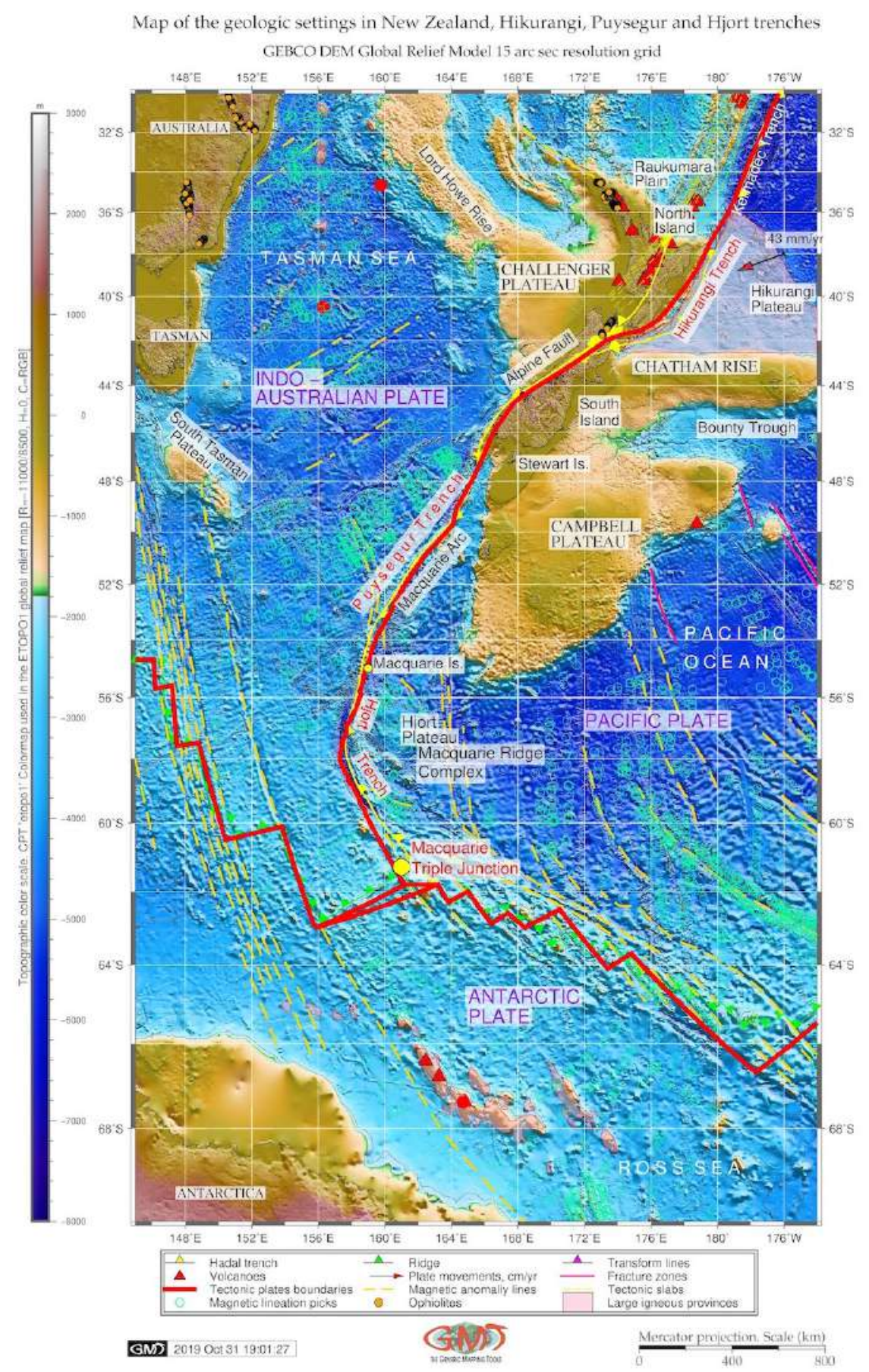

Map 2.20.1: Hikurangi Trench, New Zealand: tectonic and geological settings

The Pacific Plate subducts beneath the Indo-Australian Plate at the HT; Indo-Australian Plate subducts beneath the Pacific Plate at the Puysegur and Hjort trenches, Fig. 2.20.1. Two subduction margins are 
joined by the dextral transform Alpine Fault west off New Zealand. The area selected for the dataset lies in southern Pacific Ocean and encompasses region off New Zealand coast (Fig. 2.19.1) [387].

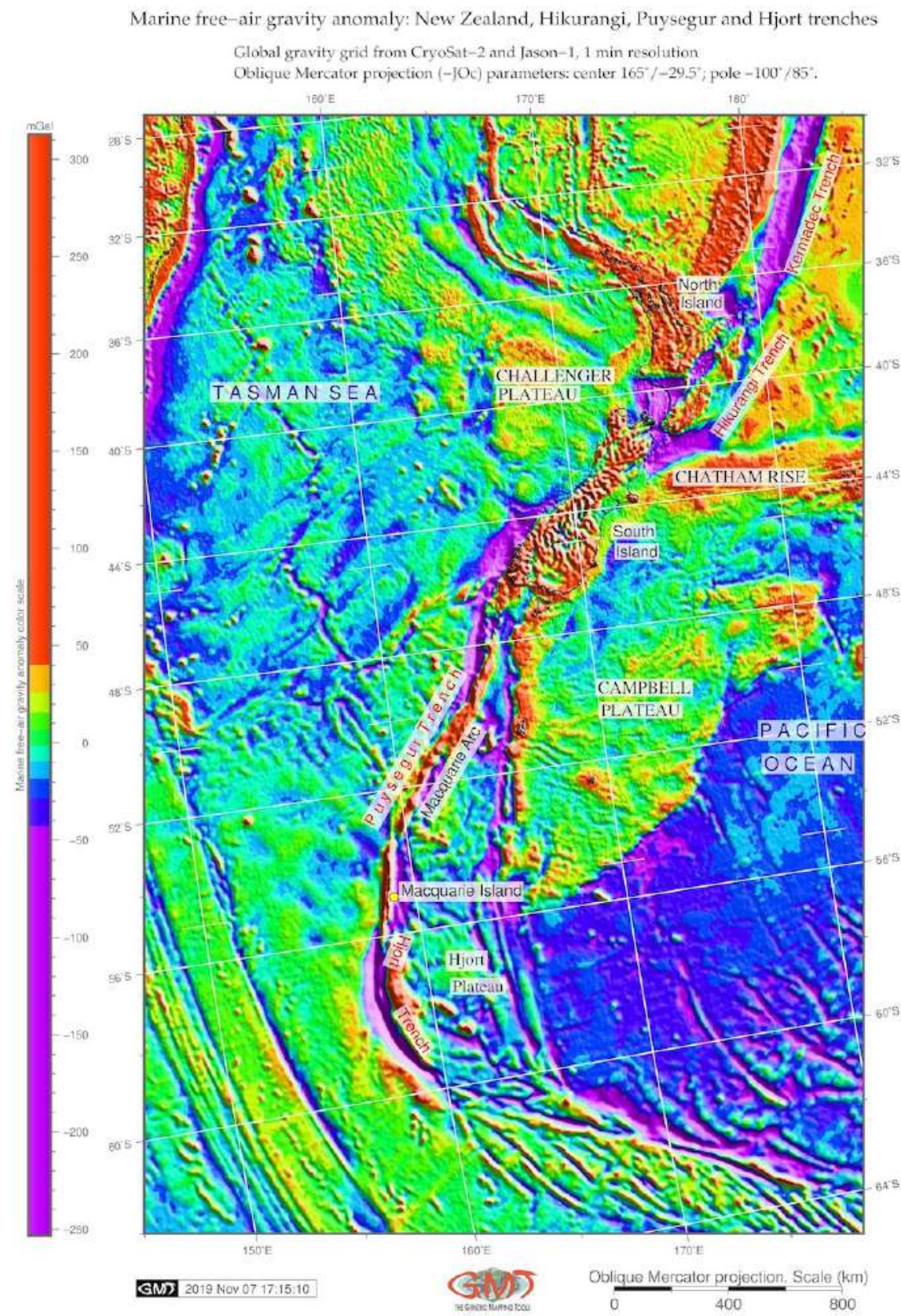

Map 2.20.2: Hikurangi, Puysegur and Hjort trenches, New Zealand: Marine free-air gravity anomaly

This area is characterized by a geologically complex history and current situation with oblique subduction zone and subduction scissors. Such complex bathymetry exhibits considerable geomorphological variability among the Hikurangi, Puysegur and Hjort trenches: there are differences caused by seamounts and seafloor obstructing natural curvatures of the trenches. The toponymy of the HT vary in the existing literature due to its specific geomorphology: in some works it is referred as 'trench', e.g. [102]; [619]; [620]; [621], in other works - as 'trough, e.g. [31]; [210]; [295]; [296].

The tectonic location of the Hikurangi is at the southern end of the $1000 \mathrm{~km}$ long Tonga-Kermadec- 
Hikurangi subduction systems, where Pacific Plate subducts obliquely southwards beneath the IndoAustralian Plate [32] and Indo-Australian Plate has a strike-slip motion at $4 \mathrm{~cm} / \mathrm{yr}$, Fig. 2.19 .1 [387]. Comparing to the KT reaching up to $9000 \mathrm{~m}$, HT is shallow (ca. $3000 \mathrm{~m}$ ).

Pacific Plate dips at HT at a gentle angle of about $3^{\circ}$ for at least $100 \mathrm{~km}$ beneath the trench and then further steepens beneath the North Island [29]. The Alpine Fault stretches sub-parallel to the western edge of the HT (Fig. 2.19.1). The speed of subduction on the Hikurangi Margin varies with a general trend of increase northwards: $34 \mathrm{~mm} / \mathrm{yr}$ in the south (westward off Bounty Trough), $38 \mathrm{~mm} / \mathrm{yr}$ in its central part (North Island) and $47 \mathrm{~mm} / \mathrm{yr}$ in the north (North Island) according to [620]. The Hikurangi north-west dipping subduction zone is old (started ca. $20 \mathrm{Ma}$ ). The subducted slab has a well defined WadatiBenioff zone and steepens from shallow angles near the surface to near-vertical at depths $>100$ $\mathrm{km}[26]$.

The geophysical and geological settings of the Hikurangi margin vary along the trench from south to north [731]. Thus, interseismic coupling is strong and deep in the south, then gradually shallows northwards and becomes shallow and weak in the north. Southern region is characterized by accretionary wedge and tectonic contraction in the forearc. Northern region is characterized by frontal subduction erosion, numerous seamounts, and a slightly extensional upper plate.

Kinematics of the Hikurangi margin studied by Global Positioning System (GPS) measurements of the horizontal velocity fields [572] shown changes in faulting along the margin and clockwise tectonic block rotations caused by collision of the Hikurangi Plateau and Chatham Rise with HT and subduction of oceanic crust northeast of the North Island [387].

The Hikurangi Plateau initially formed a part and now separated from the largest oceanic plateau on Earth, the Ontong Java Plateau, located in the southwestern Pacific Ocean [569]. The Hikurangi Margin and continental shelf of the North Island of the New Zealand is well studied through various geologic investigations, more specifically: bathymetric, hydro-acoustic investigations [31], active tectonics. Palaeogeographic reconstruction of the region of Hikurangi introduced by [296] with respect to the evolution of its current topography/bathymetry was done using advanced methods of the thermochronology.

Slab dynamics is one of the most important drivers for the trench formation, dynamics and migration. Many factors affect speed and direction of the trench migration. These include plate-mantle coupling, slab interactions with the mantle transition, plate geometry, kinematics, strain rate, temperature, fluid pressure, deformation mechanisms, as well as mantle rheology [166]. Understanding mechanisms of trench migration (retreat or advance) is crucial to characterizing the driving forces of Earths tectonics plates, the origins of subducting slab morphologies in the deep mantle, and identifying the characteristics of subduction zones systems, which are among the fundamental issues of solid Earth science [761].

Further findings in exploration geology in the HT with a special focus on methane seepage and gas hydrates in the underlying sediments are relatively well studied (e.g. [210]; [732]; [323]; [591]; [337]; [338]; [534]); studies on past (Holocene) subduction earthquakes, coseismic coastal deformation and tsunami [102]; [50] which later on largely affected submarine geomorphology of the Hikurangi margin forming submerged terraces [49]. 


\section{Chapter 3}

\section{Methodology}

Current dissertation contributed towards the development of the advanced approaches of data analysis demonstrating the combined use of GMT, Python, AWK, R and Octave/Matlab. IT approaches in Earth sciences are effective method. Statistical data analysis was implemented by ML algorithms. Seamless integration of the multi-dimensional data by $\mathrm{R}$ and Python statistical packages enabled to perform marine geodata analysis and proper selection of the optimal algorithms to process the data features. The fully provided codes written on the programming language make this research easily repeatable and accessible for other scientists. The adoption of the open source programming rapidly replacing the commercial technologies, Python and $\mathrm{R}$ will soon become popular among the marine geologists. This research contributes towards the development of the technical implementation of the ML algorithms for effective processing of the geodata.

\subsection{Data}

$\mathrm{D}$

ATA used in the dissertation for modelling and visualization include raster and vector types. Data are listed in details in Table 3.1.1. High-quality geospatial data sets are crucial for the geospatial data analysis in a big research project. The importance of the quality of the input data is explained by the fact that it affects the final results: high-precision data always results in the reliability of the output. Therefore, the selection, assessment and integration of relevant data was initial step of the cartographic project. Selecting correct data significantly improves the quality of the results, and the interpretation of the trench geomorphology. The more it is actual for the bathymetric and geomorphic mapping where precision is the key factor for the research output [686], [744], [401].

Raster data include bathymetric and topographic grids. Based on an analysis of the ETOPO1 maps for the 20 trenches, suitable segments were selected for plotting sample data on the cross-section profiles. The geoid and gravity grids were visualized based on the CryoSat-2, Jason-1 raster grids. Usage of such data as GEBCO (supported by British Oceanographic Data Centre (BODC)), ETOPO1 (from National Oceanic and Atmospheric Administration (NOAA), [11]), SRTM (supported by National Aeronautics and Space Administration (NASA)), CryoSat-2 and Jason-1 raster grids enables to perform advanced spatial analysis that were demonstrated further in relevant sub-sections. Data analysis and processing grids were performed using GMT,

Vector data include global layers of coastlines, continents and shorelines embedded in the GMT and downloaded high-resolution American Standard Code for Information Interchange (ASCII) xyz topographic and gravity data sets from open source repositories (USGS). Coastal borders on all maps were based on the Global Self-consistent, Hierarchical, High-resolution Geography Database (GSHHGD) to visualize thematic geologic maps for the area of the trenches. High-resolution geo data collection was performed from the web-site USGS and available embedded GIS layers of GMT [740], [741], [687]. A 
subset of regional geological settings was collected from the unified catalog of the Scripps Institution of Oceanography (SIO). Geologic lineaments, ridges, volcanic spots, seafloor fabric, lines of tectonic plates boudaries, rate of movements and fracture zones were mapped through the batch use of several GMT modules and converted to image files by GMT 'psconvert' module. Topographic descriptions of the submarine features were referenced to the existing IHO database of names.

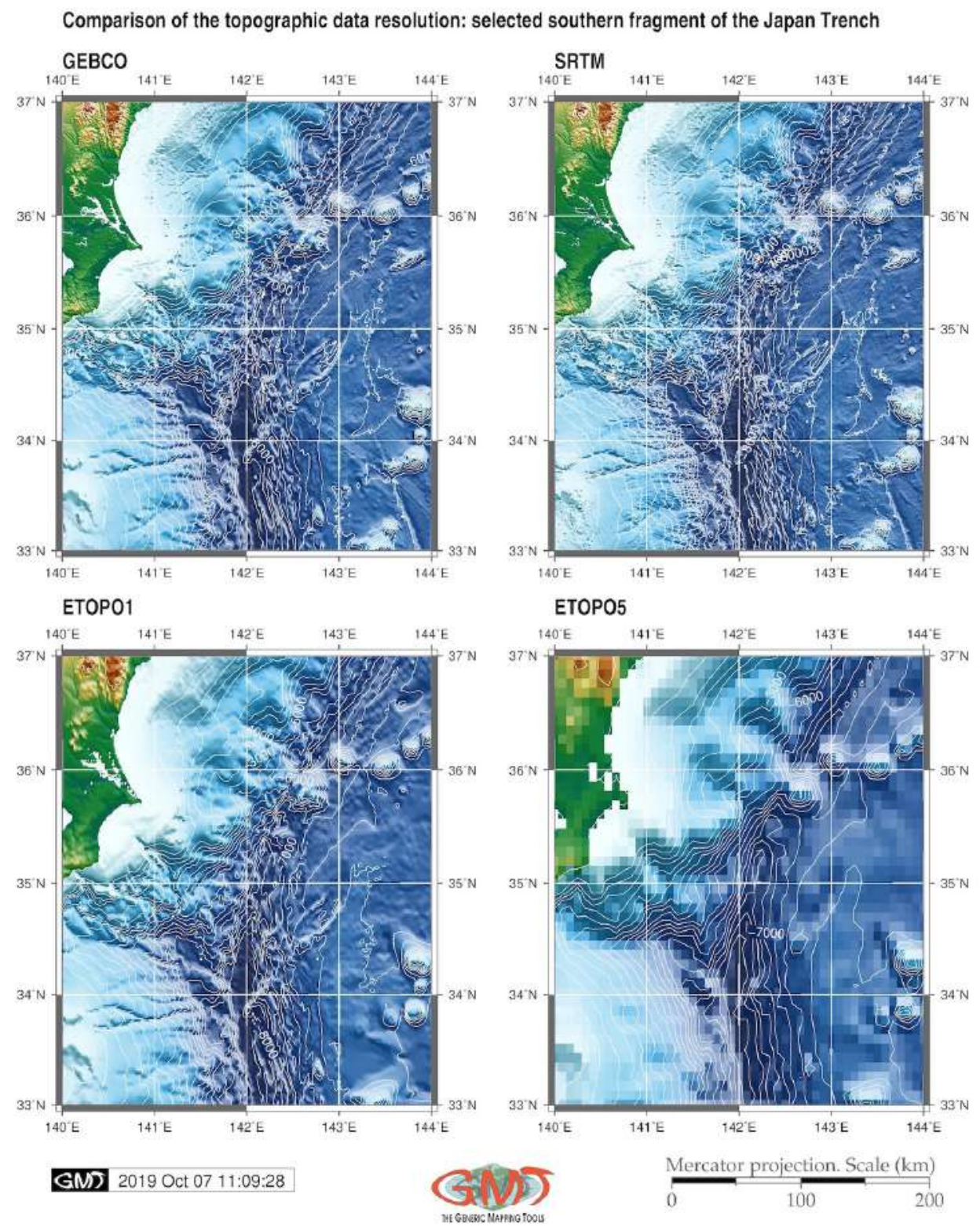

Map 3.1.1: Comparison of the resolution in datasets: GEBCO, SRTM, ETOPO1 and ETOPO5

Other data used in current dissertation included high-resolution bathymetric dataset GEBCO [191]; [553]). The GEBCO project aimed at high precision mapping of the ocean seafloor originated as early as origins at the beginning of the $20^{\text {th }}$ century and since then up to now have been developed by several oceanographic organizations [537]; [735].

Regular updates of the GEBCO dataset grid, Research Vessel (R/V) based bathymetric observation and hydrographic meetings [170] maintain both the accuracy of GEBCO grids [705] and the actuality of 
names of the submarine objects [693]. There are other data sets commonly used in the geographic studies (SRTM, ETOPO1, 5 Arc-Minute Global Relief Model of Earth's topography (ETOPO5)). However, GEBCO resolution of the 15 seconds grids gives a reliable accuracy comparing to the other raster data (Fig. 3.1.1). Using GEBCO grid was done by GMT scripting toolset using existing methodologies and technical documentation available both on GEBCO [343] and GMT [743].

Table 3.1.1: Data sources, types and precision

\begin{tabular}{|c|c|c|c|}
\hline $\mathrm{No}$ & Data & Origine & Type and Source \\
\hline 1 & ETOPO1, ETOPO5 & NOAA & $\begin{array}{l}1 \text { arc-min global relief } \\
\text { model raster grid [11] }\end{array}$ \\
\hline 21 & Global CMT Catalog & Harvard CMT & {$[154],[149]$} \\
\hline 3 & $\begin{array}{l}\text { Earth Gravitational Model of } \\
1996 \text { (EGM96) }\end{array}$ & $\begin{array}{l}\text { National Geospatial Intelligence } \\
\text { Agency (NGA) }\end{array}$ & $\begin{array}{l}\text { described by [651]; } \\
{[648]}\end{array}$ \\
\hline 4 & GSHHGD & GMT embedded dataset & {$[740]$} \\
\hline 5 & GEBCO & $\begin{array}{l}\text { BODC, IHO Data Center for } \\
\text { Digital Bathymetry (DCDB) }\end{array}$ & $\begin{array}{lcl}\text { 15-sec } & \text { DEM } & \text { raster } \\
\text { grid }[537], & {[553],} \\
{[207]} & & \end{array}$ \\
\hline 6 & SRTM & NASA & $\begin{array}{l}\text { 15-sec DEM raster } \\
\text { grid }\end{array}$ \\
\hline 7 & DEM & $\begin{array}{l}\text { National Geophysical Data Cen- } \\
\text { ter (NGDC) }\end{array}$ & NOAA \\
\hline 81 & Toponimic Gazettier & $\mathrm{IHO}$ & {$[271],[272]$} \\
\hline 9 & $\begin{array}{lll}\text { Global } & \text { Volcanism } & \text { Pro- } \\
\text { gram }(\mathrm{GVP}) & \text { database }\end{array}$ & $\begin{array}{l}\text { compiled by Smithsonian Insti- } \\
\text { tution }\end{array}$ & U.S. \\
\hline 10 & $\begin{array}{l}\text { International Seismological Cen- } \\
\text { tre (ISC) database }\end{array}$ & $\begin{array}{l}\text { catalogue of the seismicity and } \\
\text { earthquakes }\end{array}$ & [276]; [157]; [745] \\
\hline 11 & Google Earth Pro & Keyhole, Inc. & U. S. \\
\hline 12 & Geologic datasets & $\begin{array}{l}\text { tectonic plate boundaries, slabs, } \\
\text { lineaments, trenches, ophiolites, } \\
\text { volcanoes }\end{array}$ & $\mathrm{SIO}$ \\
\hline
\end{tabular}

High precision data resources and grids were selected and chosen from the variety of the available datasets, as a ground basis of this research as summarized in the Tab. 3.1.1. General bathymetric maps were based on a cartographic visualizing of the ETOPO1 raster grid [11], enlarged visualization by SRTM [168] and GEBCO, both 15 seconds resolution. High-quality bathymetric ETOPO1 and and ETOPO5 data were used and compared to perform mapping and geomorphological modelling (Fig. 3.1.1). 


\subsection{Approaches}

$\mathrm{G}$

ENERAL methodological scheme of the presented research is summarized in Tab. 3.2.1. Traditional methods of the marine geological modelling include using GIS based processing of the RS images, such as for instance aerial photos, Satellite Pour l'Observation de la Terre (SPOT)3, SPOT4 and Environmental Satellite (ENVISAT) data, or producing digital maps based on the data capture in the field [62]. The methodology of the research in submarine geomorphology is traditionally being supported by the GIS software, mainly in geological modeling. Geomorpholoigal studies of the hydrological effects often use GIS modeling and digital terrain analysis for geospatial analysis [48].

Table 3.2.1: Software and tools used in dissertation

\begin{tabular}{r|lll} 
No & Tools & Methods & Approach \\
\hline \hline 1 & GMT & Cartography & $\begin{array}{l}\text { GIS mapping, modelling. Profiles automatic digitizing by } \\
\text { modules. Comparative geospatial analysis. Classification }\end{array}$ \\
\hline 2 & QGIS & Cartography & GIS mapping. Profiles manual digitizing by plugins \\
\hline 3 & AWK & Data conversion & Table reshaping \\
\hline 4 & R & Statistical libraries & Modelling, statistical analysis, graph plotting \\
\hline 5 & Python & Statistical libraries & Modelling, statistical analysis, graph plotting \\
\hline 6 & Octave & Visualization & Modelling, statistical analysis, graph plotting \\
\hline 7 & BibIATEX & Bibliography & Literature review \\
\hline 8 & LTEX & Compiling & Typesetting \\
\hline \hline
\end{tabular}

Riverine morphological analysis [51] uses methodology base don experimental fieldwork, setup of network development combined with spatial data analysis by GIS. Other examples include application of aerial imagery of the analysis of the river deltas discharge time series, and land cover and morphological planimetric changes by methods of combined GIS based overlay of the topographic maps, air photographs, and satellite images [19], [395].

Recent methodological example of the Environmental Systems Research Institute (ESRI) ArcGIS application [40] shown riverine geomorphology covering large spatial extents by assessment of their structure, functioning and geomorphology using free datasets, GEarthView plugin for QGIS and algorithms of the RS data processing. ArcGIS based research is presented by [532] focused an a regional scale analysis of changes in channel width and pattern. SAGA GIS are suited for environmental analysis and remote sensing data processing [395], [384], [390]. The assessment of the magnitude and direction of changes caused by flood management in the low land rivers is presented by [258]. By cross-section profiles plotting large datasets of the multi-source data were analyzed: sedimentary cores, hydrographic surveys and historic map to visualize degrees of the involved engineering activities and infrastructure resulting in channel and floodplain modification that affect fluvial processes.

Combined methods of field surveys, seismic profiles echo sounding and classification of the Landsat TM imagery is a core approach [268]. The approach towards submarine canyon mapping is presented as a Remotely Operated underwater Vehicle (ROV)-based habitat mapping program using GEBCO map cartography [267]. The proposed methodology of modeling hydro-morphological degradation [328] is based on various environmental parameters of particular ecological importance (longitudinal and transverse banks, flow diversity, depth and width variance, substrate type and diversity). An application of the Matlab ProcessV3 for hydrological modeling was presented by [357]. Effective approach of the assessment of status and trends in marine fisheries and ecosystems considering marine geomorphology as proxy for marine habitats is proposed by [241].

On the contrary with given above examples, current dissertation makes an accent on using high-level 
programming languages and scripting approach for processing large data frames imported from GIS. 


\subsection{Generic Mapping Tools (GMT)}

$\mathrm{M}$

AIN toolset used in this research is GMT with modules functionality described in relevant documentation and software release announcement [743]. Comparing to the traditional GIS software, the advantages of the GMT consist in its high efficiency for the scripting based cartographic workflow rather than Graphical User Interface (GUI) as well as open source availability. General scheme of the methodology in GMT included following steps:

- Bathymetric mapping based on the extracted ETOPO1 grid by GMT modules 'grdcut' and 'grdimage';

- mapping, visualizing and analysis of the thematic data sets: marine gravity and geoid,

- topographic and gravimetric surface modelling: based on the xyz ASCII data;

- cartographic data processing by 'psbasemap', 'psxy', 'grdcontour' for contour plotting;

- 3D-mesh modelling;

- automatically digitized set of the orthogonal cross-stacked profiles by 'grdtrack' module along the selected segment of the trench with track $400 \mathrm{~km}$ long, spaced $20 \mathrm{~km}$, sampled $2 \mathrm{~km}$ along;

- visualizing mean, median values and plotting trends for the profiles by 'trend1d' module;

- descriptive statistical analysis through the visualized histograms.

The use of the GMT was presented as mapping in some works, e.g. [255]. Examples of other advanced tools for geological data analysis include, e.g., PHASER diffractometer, direct observations received from the R/V cruises, observations from DEM [195]. The mapping in the presented dissertation is based on the available data sets and those embedded in the GMT [688].

GMT scripting toolset was selected as a geospatial tool for raster grids processing, mapping and automated digitizing of the geomorphological profiles. The GMT was initially developed by P. Wessel and P. Smith [743], maintained and improved to finally become a powerful open source scripting toolset for the geospatial analysis and cartographic visualization.

In contrast with classic GIS, GMT is completely based on the UNIX-based shell scripting approach with command-line usage without graphical GUI interface. Thus, it is not a classical GIS. Using the full powerful functionality of the GMT requires writing a script with numerous arguments for the fine-tuning and setting up of every cartographic element: projections, labels, north direction, major and minor grids, titles, color palettes, legends, vector elements, annotations, map elements (coastlines, directional roses, scale bars) etc.

Hence, the functionality of the GMT approach consists in its scripting when individual features for the cartographic objects can be defined in each line of the GMT code. Each small code line presents a reference to a specific GMT module. Combined together as a sequential script, the codes are used for mapping. As demonstrated further in the presented codes (see Appendix for the GMT scripts), a great advantage of the GMT is a high cartographic functionality of the toolset enabling to fully adjust and refine aesthetics of the cartographic elements: fonts, lines width and type, layout, a large variety of the visualization, plotting, modelling, advanced cartographic modules (mapping projections, modelling, grid raster data processing), color scales etc. [741].

However, the high cost of the steep learning curve of the GMT as well as its non-visual command line based operation pays off by its powerful functionality and excellent visualization. The GMT is compatible with Unix commands (cut, rm, echo) and Geospatial Data Abstraction Library (GDAL) raster 
processing [393], it operates both with raster and vector data, produces high-quality maps and figures, has embedded functions for descriptive statistical analysis (histograms). All this makes it one of the most preferred data visualization and mapping toolsets by the cartographers.

North Pacific Ocean (Orthographic azimuthal projection)

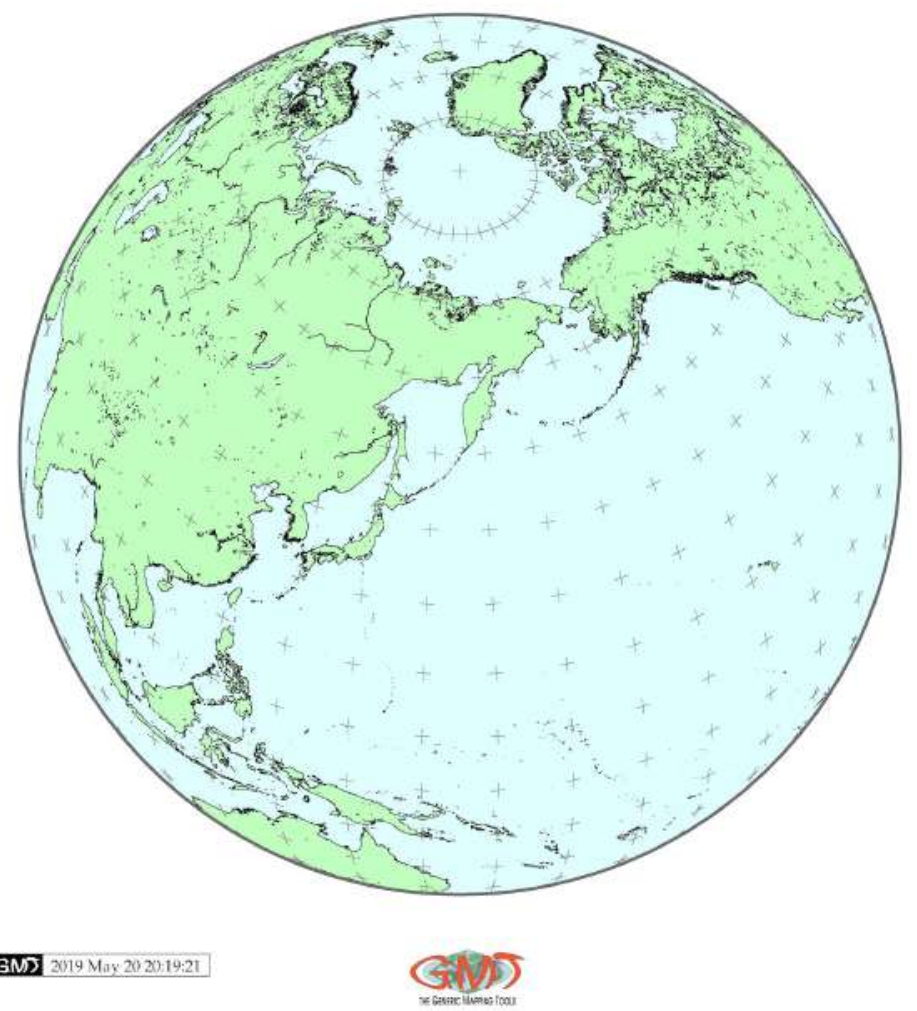

Map 3.3.1: North Pacific Ocean: contour map in the Orthographic azimuthal projection, GMT

As the utility of the seafloor-mapping technology, a GMT scripting was demonstrated with a case study for comparative analysis of the 20 trenches. Because the GMT is a scripting toolset consisting of modules, several main modules were used for preparing maps. The auxiliary GMT modules were used for mapping and cartographic visualizations. Methods of data visualization through GMT modules include cross-section profiles, topographic modelling, thematic geologic mapping, modelling geoid and gravity fields. A number of GMT techniques and modules (e.g. grdhisteq, pscoast, pshistogram, pstext, gmtset, gmtdefaults, grdcut, makecpt, grdimage, psscale, grdcontour, psbasemap, nearneighbor for KKT, Figure and gmtlogo, psconvert) were used to visualize, model and map seafloor characteristics, as well as texture and shape of the cross-section profiles. A 'gmtinfo'module was used to get information about data tables from the raster grids. Auxiliary GMT modules were used for technical data processing, for example, 'gmtwhich' to find the full paths to the files given on the command line, a 'gmt.conf' module was used to define configuration of the GMT parameters. Interpretation of the topographic profiles, geological sampling, gravity modelling and statistical analysis was also made by means of the GMT scripting toolset. A combination of GMT modules was applied for modelling, analysis, comparison and visualization of the variations in the geomorphology of the trenches.

ML approach of GMT was used for semi-automatic plotting, visualization, modelling, mapping and interpretation of the three hadal trenches located in southern Pacific Ocean. Sequential use of GMT modules enabled to gain further insights into their geomorphic shape, and to compare accuracy of the data grid interpretation approaches based on the scripting concept aimed to visualize cross-section transects. 
Indeed, GMT cross-section stacking methodology as performed in this research proved to be a successful means of visualizing and plotting geomorphological models applied for the submarine bathymetry by effectively minimizing the hand-made cartographic routine. Indeed, using GMT enables to automatically digitize profiles, then to perform statistical analysis by plotting histograms and model trends for the general shape of the profiles using mathematical models of the lines approximation.

Several GMT modules were tested and applied for the cartographic visualization of the marine freeair gravity, geoid, bathymetric mapping, geomorphic modelling and statistical data analysis. Existing semi-automated methods of cartographic digitizing (e.g. Autotrace based) [661], [442] or sequential use of the specialized software for bathymetric mapping, Hydrosweep DS-2 [470], CARIS HIPS [443], GMT for mapping using CARIS HIPS data by grids and coastlines was driven largely by the developed algorithms of the ML. Application of the Artificial Intelligence (AI) in the cartographic routine, significantly minimizes the handmade routine and subjectivity. On the contrary, it increases the overall precision of the data processing and accuracy of visualization. The GMT proposes more advanced solutions in the automatization of the cross-sections through the ML based digitizing that results in a series of the profile transects across the 20 trenches of the Pacific Ocean.

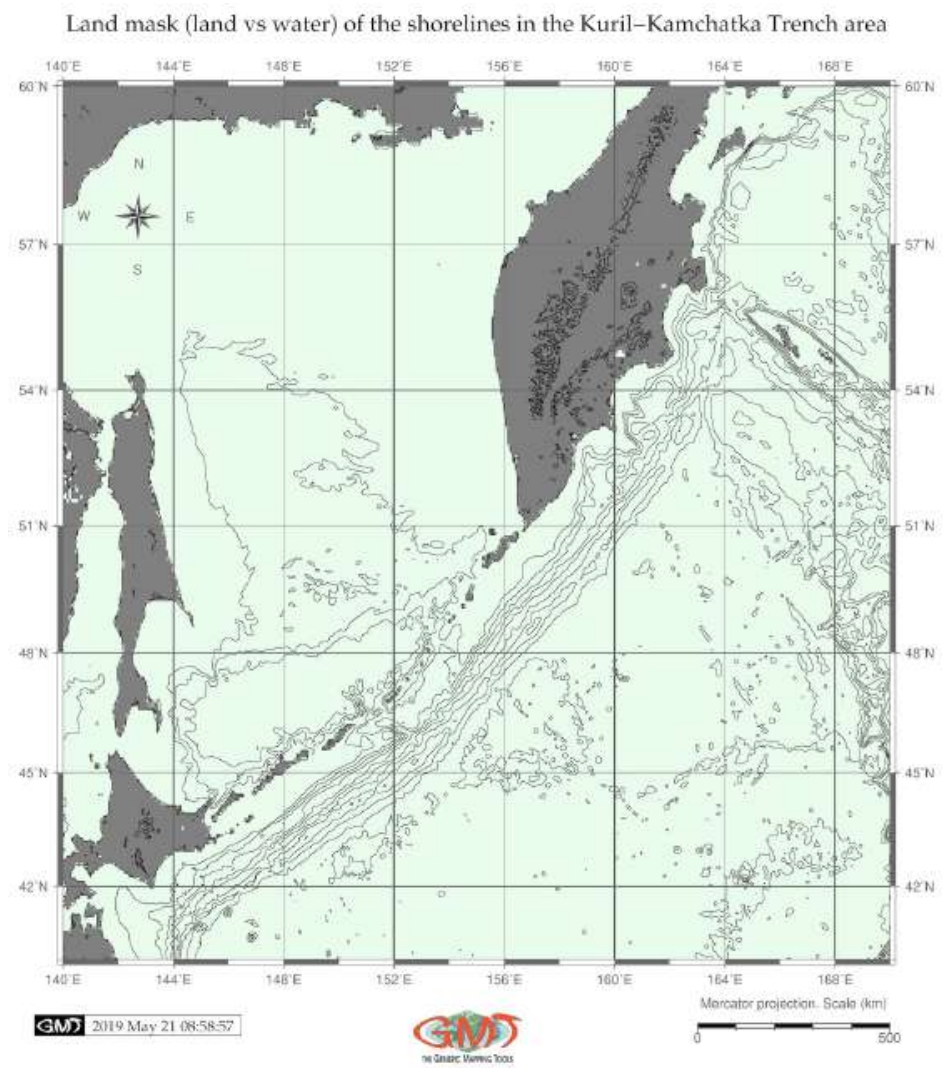

Map 3.3.2: Landmask of the shorelines (land vs water areas), GMT

Applying GMT techniques to mapping trenches enabled to model profiles and visualize geologic settings. Each trench was distinguished by specific geomorphic shape of the submarine landform, geologic substrate, complexity of the tectonic settings and historical development of the lithospheric plates movements in this area. Bathymetry data were modeled by GMT cross-section profiling for the trenches and compared. Maximal depths in the trench segments derived from digitized GEBCO and ETOPO1 grids were used for comparative analysis and visualized at histograms. 


\subsubsection{Bathymetric mapping}

$\mathrm{M}$

APPING oceanic trench geomorphology data from the bathymetric maps should be based on the high resolution data to highlight isolines enabling to interpret steepness and gradient which requires certain cartographic interpretation. High-resolution bathymetric data is important for mapping trench shape in a cross-section and to identify clearly its geomorphology. Pixel size at a course resolution bathymetric maps (e.g. ETOPO5) may reduce accuracy, therefore, ETOPO1 and GEBCO dataset grids were chosen for bathymetric mapping.

The ETOPO1 global relief model was modeled using grdimage module of GMT. Examples of trenches are presented in corresponding section (Map 2.2.1), KKT (Fig. 2.1.1). The psbasemap, grdcontour GMT modules were used to map base map elements (e.g. contours of the land, geoid and bathymetry, net grids and titles) on the bathymetric maps. Each module consists of the small code line. Combined together as a script, they were used to produce and visualize maps. For example, the GMT modules grdimage was main module used to map the bathymetric grid of the RT (Map 2.13.1) using GMT code:

gmt grdimage GEBCO_2019.nc -Cmyocean.cpt -R120/134/20/33 - JM6i -P -I+a15+ne0.75 -Xc -K > $\$ p s$

For example, in case of Tonga-Kermadec region, the -R command was used to cut off part of the image was by the given coordinates: -R140/195/-50/-5 from the whole grid in WESN way. As can be noticed, the southern hemisphere has negative coordinates.

The color palette was made using 'makecpt' module from the available 'geo' palette adjusted according to the data range (for example, the Tonga-Kermadec area had topography from -11000 to 4500. The cartographic projection, for the bathymetric map was selected as traditional Mercator, which was set up using the following command: '-JM6i' means Mercator projection, with 6 inches width of the map; '-P' means portrait orientation; '- $\mathrm{K}$ ' means continue of the script (not finalized). The legend on the left part of the bathymetric maps was added using 'psscale' module by following code snippet (here example is given for the Kermadec region, Map 2.5.1):

gmt psscale -Dg131/-50+w14.8c/0.4c+v+o0.3/0i+ml Rtkt_relief.nc $-\mathrm{J}-$ Cmyocean.cpt -FONT_LABEL=8p,Helvetica,dimgray $-F O N T \_A N N O T \_P R I M A R Y=5 p$,Helvetica,dimgray -Baf+1"Topographic color scale" -I0.2 -By+lm -O -K » \$ps

For the case of Middle America Trench, the general bathymetric map (Fig. 2.3.1) was visualized using a sequence of GMT modules: 'grdcut' module for cutting area from the global grid earth_relief_01m.grd by selecting coordinates -R263/278/7/17, following by 'grdimage' module for visualizing the grid itself. Several auxiliary modules were then used both for cartographic purposes (color scale, scale bar, directional rose, grid ticks and lines) and for the map embellishment (GMT logo) using available techniques [688]. The shoreline vector layers were driven from the existing GMT data sets [740]: tectonics, bathymetry, geomorphology and geology.

The GMT modules psconvert, psscale were used for visualizing scale bar on the maps, GMT module logo to add GMT logo below the maps, pstext GMT module was used for adding annotations on the maps, psxy module - for plotting geologic lineaments and sample points. The bathymetric data are presented as plan and oblique shaded-relief grids to highlight the major and distinct seafloor landforms of the MAT (Fig. 2.3.1) which was mapped using the script provided in full in Appendix A.4.1.

Cartographic functionality of the GMT is assessed by technical visualization of the produced maps, models and graphs as well as tested variety of map projections. In this study, following various cartographic projections were used for plotting maps: Mercator (Fig. 2.19.1, 2.20.1, 3.3.7, 3.3.8, 4.21.1, 4.20.1), Mollweide pseudo-cylindrical homolographic equal-area, Eckert IV equal-area pseudo-cylindrical, Lambert Azimuthal Equal-Area (Fig. 2.19.2), Oblique Mercator (Fig. 2.20.2 by GMT, Orthographic azimuthal projection (Fig. 3.3.2), Polyconic projection, Cylindrical Equal-Area Gall-Peters, Transverse Mercator cylindrical , Fig. 2.16.1. Conic equal-area Albers projection for map with digitized lines of the 
profiles (on Fig. 7. Location of the cross-sectioning 25 profiles in [419]) is plotted by GMT.

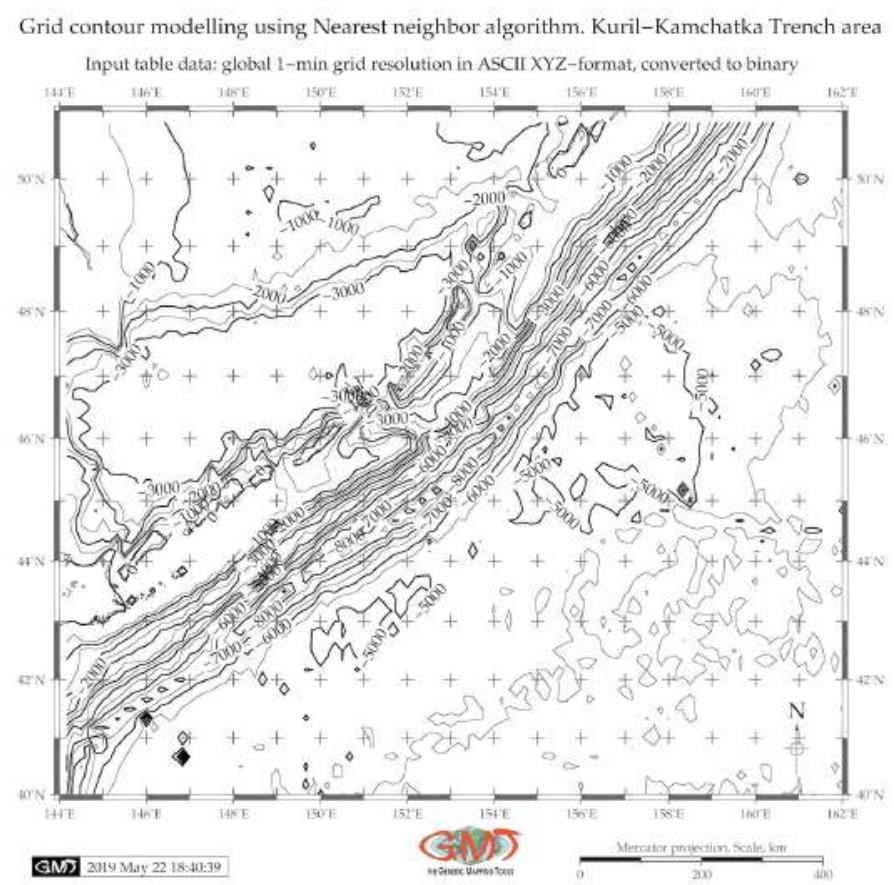

Map 3.3.3: Grid contour modelling by Nearest neighbor algorithm, KKT GMT

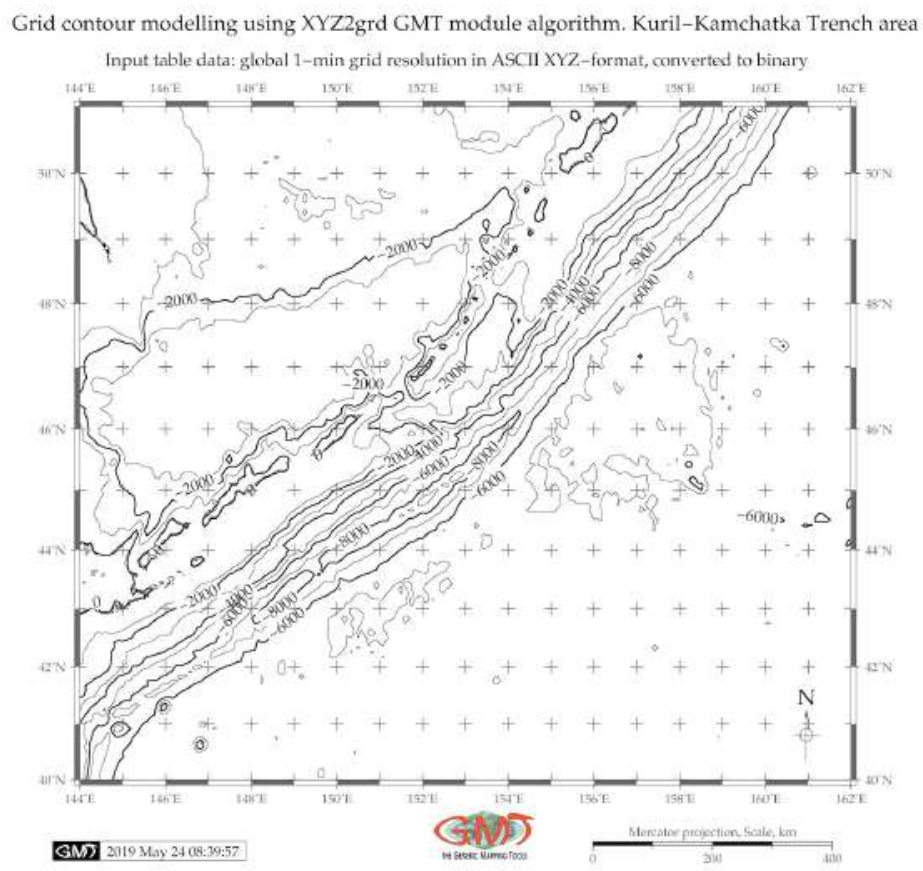

Map 3.3.4: Grid contour modelling by XYZ2grd algorithm, GMT 


\subsubsection{Seismic mapping}

$\mathrm{F}$

IOCAL mechanisms (Fig. 3.3.5) were drawn using 'psmeca' GMT module that reads dataset values from ASCII file and generates a PostScript code plotting focal mechanisms. Centroid moment tensor solutions are shown for shallow depth earthquakes of $M w<10$ along the PSB margins from 1976 to 2010. Earthquakes along the tectonic plate subduction zone are shown by GMT using data from Global CMT Project.

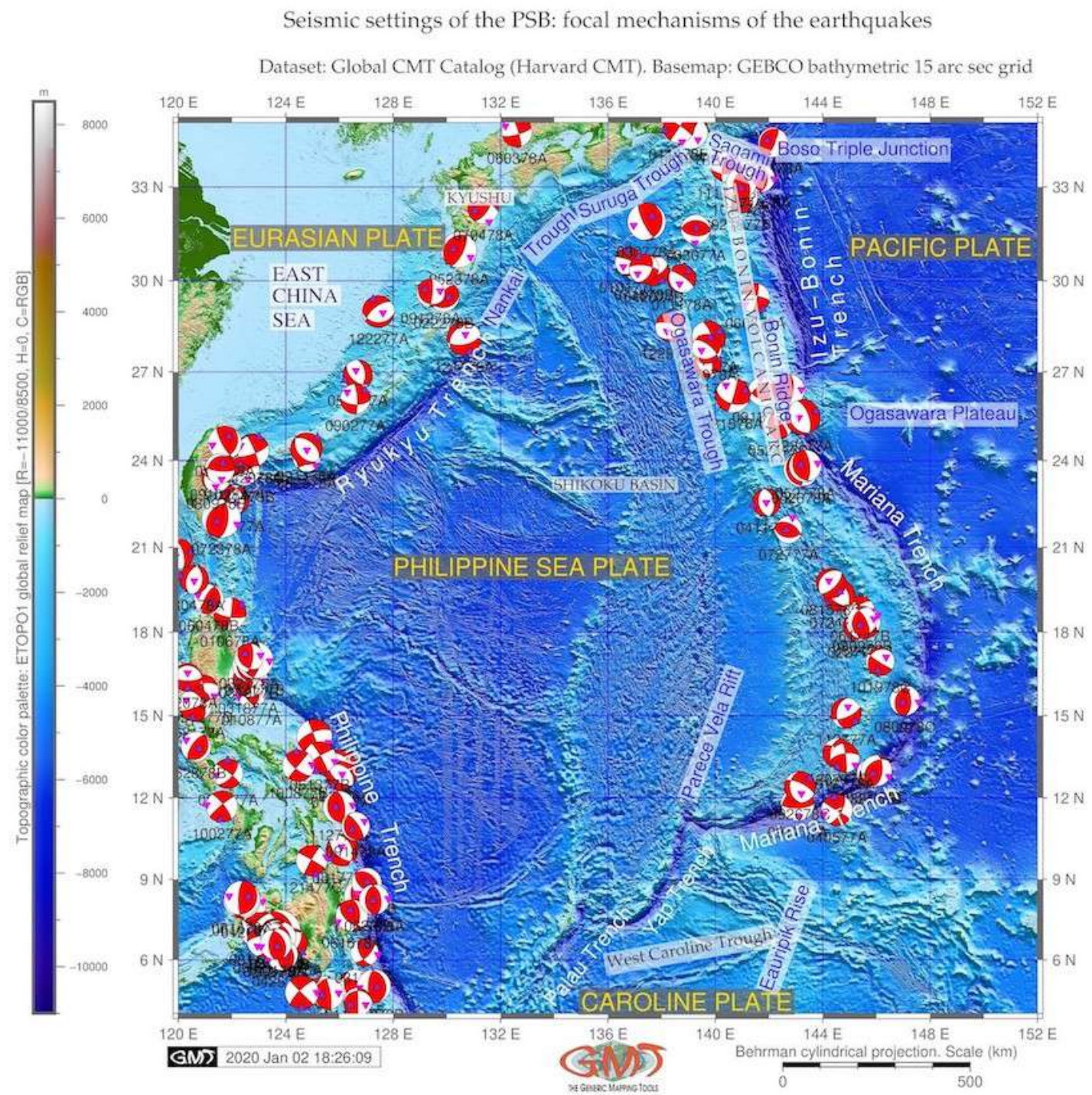

Map 3.3.5: Seismic map of the focal mechanisms: PSB margins

Focal mechanisms depict a commonly accepted theory of the focal depths of the earthquake, showing a depth from the surface to the earthquake's origin (hypocenter). Given dataset contains significant amount of shallow earthquakes of the PSB with focal depths of several tens kilometers (mostly $<50$ ), intermediate earthquakes with focal depths from 70 to 200 kilometers, and also a few earthquakes of PSB with deep focus reaching depths $>500$ kilometers, Table 3.3.1. The foci of the most PSB earthquakes are concentrated in the crust and upper mantle, that is, originate in shallow parts of the Earth's interior.

The original dataset of the focal mechanism solutions are from the was taken from the Global CMT Catalog, formerly known as the Harvard CMT catalog [155]. Technical parameters are set up as follow- 
ing:

- Moment magnitude $(M w)<10$;

- Surface wave magnitude $(M s):<10)$;

- Body wave magnitude $(M b):<10$;

- Data time span: 1976-2010.

While magnitude is a widely understood concept, describing the energy of the earthquake release on a logarithmic scale, some technical details are presented in Table 3.3.1 and Table 3.3.2 used for mapping velocity (Fig. 3.3.6), assigning and interpreting magnitudes. Introduced in the 1930's, the Richter Scale is the best known scale for measuring the magnitude of earthquakes [559]. L-waves (Surface waves) magnitude, creating the strongest disturbance within the upper layers of the Earth, is computed by the following algebraic Formula 3.3.2:

$$
M S=\log _{1} 0(A / T)+1.66 \log _{1} 0(D)+3.30
$$

where $\mathrm{T}$ is the measured wave period and $\mathrm{D}$ is the distance in radians.

On the contrary, earthquakes occurring deep in the Earth do not generate large surface waves. Therefore, a body wave magnitude $(\mathrm{Mb})$ is scaled based on the seismic waves penetrating through the Earth's interior (body) [559]. Body wave magnitude ( $\mathrm{mb}$ ) is measured based on the maximum amplitude $A$ by a Formula 3.3.2:

$$
M b=\log _{1} 0(A / T)+Q(D, h)
$$

where $\mathrm{T}$ is the measured wave period and Q is an empirical function of focal depth $h$ and epicentral distance $D$ [559].

Moment magnitude (MW) relies on an underlying robust physical and mathematical development through converting seismic moment using a formula calibrated to agree with MS over much of its range. Others parameters are taken as default ones.

Data are collected in both GMT 'psvelomeca' and GMT 'psmeca' input formats and tested. Final solution was for GMT 'psmeca' (the reason is for the GMT version 5.4.5 compatibility). The focal mechanisms are derived from a solution of the earthquakes' moment tensor, which is estimated by an analysis of the observed seismic wave forms.

Technically, the seismic moment tensor (Harvard CMT, with zero trace) was plotted (Fig. 3.3.5) by 'psmeca' module using the following GMT code snippet:

gmt psmeca -R CMT.txt -J -Sd0.5/8/u -Gred -L0.1p -Fa/5p/it -Fepurple -Fgmagenta -Ft -W0.1p -Fz -Ewhite $-\mathrm{O}-\mathrm{K}>>$ \$ps

The scale (0.5) was adjusted to the scaling of the 'beach ball' radius, which is proportional to the magnitude. Here the '-Sd0.5/8/u' implies the scale, label size and annotation placement below the 'beach ball'. Filling of the extensive quadrants was defined by -E parameter; -L parameter defines drawing the 'beach ball' outline of $0.1 \mathrm{pt}$. Shaded compressional quadrants of the focal mechanism 'beach ball' are colored by -Gred function. The -Fa/5p/it option was used to plot size, P_axis_symbol and $\mathrm{T}$ _axis_symbol, to compute and plot $\mathrm{P}$ and $\mathrm{T}$ axes with symbols (selected inverse triangle (i) and triangle (t)).

Focal mechanisms (Fig. 3.3.5) visualized as commonly accepted in geophysical mapping 'beachballs' show a representation of the lower half of the focal sphere as viewed from above the focus at the earthquake epicenter and respective zones of compression and dilatation. Based on the recorded dataset of 
Table 3.3.1: Earthquake events for 1976/1977

\begin{tabular}{|c|c|c|c|c|c|c|c|}
\hline Location code & Date & Centroid Time & Lat $\left({ }^{\circ} \mathrm{N}\right)$ & Lon $\left({ }^{\circ} \mathrm{E}\right)$ & Depth & $\mathrm{HD}^{*}$ & $\mathrm{CHT}^{* *}$ \\
\hline 021576A PHILIPPINE ISL & $1976 / 2 / 15$ & 1:54:30.3 GMT & 13.12 & 126.02 & 15.6 & 4.2 & 7.2 \\
\hline 060776A LUZON PHILIPPINE ISL & $1976 / 6 / 7$ & 7:36:0.3 GMT & 14.23 & 125.07 & 24.4 & 4.8 & 4.9 \\
\hline 081676B LEYTE & $1976 / 8 / 16$ & 16:11:58.7 GMT & 7.07 & 123.75 & 33.0 & 21.7 & 51.4 \\
\hline 081776A LEYTE PHILIPPINE ISL & $1976 / 8 / 17$ & 1:11:16.5 GMT & 10.08 & 126.10 & 47.3 & 2.6 & 6.3 \\
\hline 081776B MINDANAO & $1976 / 8 / 17$ & $4: 19: 39.8$ GMT & 7.14 & 123.01 & 15.0 & 8.7 & 12.5 \\
\hline 092976A MINDANAO & $1976 / 9 / 29$ & $21: 2: 31.5$ GMT & 6.61 & 124.24 & 15.0 & 1.8 & -1.2 \\
\hline 110776B MINDANAO & $1976 / 11 / 7$ & 17: 9:13.7 GMT & 8.35 & 126.86 & 42.1 & 6.2 & 7.6 \\
\hline 112276A MINDANAO & $1976 / 11 / 22$ & $4: 22: 20.7$ GMT & 7.03 & 123.58 & 60.0 & 3.0 & -4.6 \\
\hline 121476A RYUKYU ISLANDS & $1976 / 12 / 14$ & 16: 6:49.2 GMT & 28.12 & 130.64 & 15.0 & 3.8 & 4.8 \\
\hline 010177C SOUTH OF HONSHU JAPAN & $1977 / 1 / 1$ & 11:33:45.9 GMT & 30.62 & 136.80 & 476.5 & 1.8 & 4.3 \\
\hline 010777B TAIWAN REGION & $1977 / 1 / 7$ & 19:36:48.6 GMT & 20.78 & 120.01 & 10.0 & 2.5 & 1.7 \\
\hline 010877A LUZON PHILIPPINE IS. & $1977 / 1 / 8$ & $6: 41: 10.9$ GMT & 15.77 & 122.73 & 13.3 & 1.6 & 6.8 \\
\hline 011577A PHILIPPINE ISL & $1977 / 1 / 15$ & 10:49: 8.8 GMT & 12.80 & 126.06 & 32.9 & 2.2 & 3.0 \\
\hline 011777A BONIN ISL REGION & $1977 / 1 / 17$ & $6: 23: 40.7$ GMT & 26.40 & 142.74 & 13.9 & 3.4 & 4.6 \\
\hline 011977B MINDANAO & $1977 / 1 / 19$ & 13:54: $9.8 \mathrm{GMT}$ & 5.01 & 126.56 & 50.1 & 4.8 & 5.3 \\
\hline 012077A MINDANAO, PHILIPPINE & $1977 / 1 / 20$ & 20:51:17.2 GMT & 8.00 & 122.70 & 41.8 & 2.3 & 2.3 \\
\hline 022777A MARIANA ISLANDS & $1977 / 2 / 27$ & 18:34:15.0 GMT & 18.21 & 145.30 & 592.6 & 2.1 & 6.5 \\
\hline 022877B MINDANAO, PHILIPPINE IS & $1977 / 2 / 28$ & 1:50:38.7 GMT & 8.87 & 127.01 & 55.8 & 2.3 & 6.8 \\
\hline 030277B MINDANAO, PHILIPPINE IS & $1977 / 3 / 2$ & 9:53:26.4 GMT & 6.62 & 123.53 & 33.4 & 6.0 & 3.2 \\
\hline
\end{tabular}

*Half duration; **Centroid Hypocenter Time (HcT)

the P-waves, compressional longitudinal waves, a graphical model shows red areas of the 'beachballs' as upward moving, i.e. compressional motion, while white areas- a downward, dilatational motion. Determining geological information, such as rupture of the Earth's surface, it depicts two nodal planes, fault and auxiliary ones. For instance, auxiliary plane intersects the line of fault plane between the circle and its center of the 'beachball' with the general rule that the closer the intersection is to the center, the more dominant is the strike slip. Increase of the the curvature of the crossing hemispheres denotes shallower dip. The strike of a nodal plane is measured in degrees around the circle from north to the line of the nodal plane. Based on existing classification [559], various focal plane solutions are shown:

1. normal fault striking north, dipping $\mathrm{E} / \mathrm{W}$ at ca. $45^{\circ}$

2. oblique fault, right or left lateral and reverse slip

3. oblique fault, reverse slip dominant, with some right/left lateral

4. oblique fault, strike slip dominant, attitude ca. $\mathrm{N}^{\circ} 40 \mathrm{~W} / 70^{\circ} \mathrm{W}$ (right/left lateral), or $\mathrm{N} 35^{\circ} \mathrm{E} / 70^{\circ} \mathrm{E}$ (left/right lateral).

Earthquakes event map at PSB area (Fig. 2.16.3) shows prime hypocentres and magnitude values by color and size of the circles, respectively. The map was plotted on the basis of the ISC-EHB Bulletin, overlaid on the Google Earth map as a file in Keyhole Markup language Zipped (KMZ), which is a file extension for a placemark file used by Google Earth Pro. The geographic coordinates include x,y,z components in decimal degrees defined by the World Geodetic System of 1984 (WGS84). The overlay is visualized on Fig. 2.16.3. The explanation of the map is as follows. Circle size shows magnitude values. Circle color shows hypocenter depths, $\mathrm{km}$ (from red: 0 to dark blue/black: $>600$ ).

A multi-source dataset applied for seismic mapping includes a compilation of GEBCO, ETOPO1, ETOPO5, CMT, EGM96, GVP and GSHHGD sources. Combined studies of seismic and tectonic settings (focal mechanism, velocity, geological lineaments), volcanic activity and general topography of the 
ocean seafloor are essential for understanding complicated bathymetry and geomorphic patterns of the trenches in the PSB. A multi-source GIS data analyze on the southern side of the PSB and discussion of the current situation and historical evolution of the geology of this area was performed and presented.

Table 3.3.2: Magnitude and Moment Tensor

\begin{tabular}{|c|c|c|c|c|c|c|c|}
\hline Location code & Moment Tensor & $\mathrm{Mw}^{*}$ & $\mathrm{Mb}^{* *}$ & $\mathrm{Ms} * * *$ & $\mathrm{SM}^{* * * *}$ & $F P_{1} * * * * *$ & $F P_{2} * * * * * *$ \\
\hline 021576A Philippine Isl & $\begin{array}{c}\text { Expo=25 }-5.1403 .270 \\
1.860-1.5600 .510-4.690\end{array}$ & 6.5 & 6.1 & 6.1 & $6.47 e+25$ & $322 / 39 /-73$ & $121 / 53 /-104$ \\
\hline 060776A Luzon & $\begin{array}{c}\text { Ехро=25 }-0.9305 .570 \\
-4.630-1.8102 .820-5.740\end{array}$ & 6.5 & 6.1 & 6.4 & $8.35 \mathrm{e}+25$ & $249 / 67 / 180$ & $339 / 90 / 23$ \\
\hline 081676B Mindanao & $\begin{array}{c}\text { Expo=27 } 9.3300 .240 \\
-9.5701 .450-3.3404 .330\end{array}$ & 8.0 & 6.4 & 7.9 & $1.09 \mathrm{e}+28$ & $341 / 35 / 92$ & $158 / 55 /-89$ \\
\hline 081776A Leyte Philippines & $\begin{array}{c}\text { Expo }=25-1.2500 .390 \\
0.860-0.5000 .070-0.570\end{array}$ & 6.0 & 6.0 & 5.7 & $1.34 \mathrm{e}+25$ & $340 / 39 / 67$ & $131 / 55 /-108$ \\
\hline 081776B Mindanao & $\begin{array}{c}\text { Ехро=26 }-1.2205 .310 \\
-4.100-1.9201 .3302 .110\end{array}$ & 7.1 & 6.2 & 6.8 & $5.71 \mathrm{e}+26$ & $214 / 64 /-172$ & $120 / 83 /-26$ \\
\hline 081776B Mindanao & $\begin{array}{c}\text { Еxpo=24 }-4.6202 .220 \\
2.400-0.530-1.8101 .870\end{array}$ & 5.7 & 6.0 & 5.4 & $4.78 \mathrm{e}+24$ & $232 / 35 /-76$ & $34 / 56 /-100$ \\
\hline 110776B Mindanao & $\begin{array}{c}\text { Expo=26 } 1.5400 .230 \\
-1.7700 .9900 .610-0.170\end{array}$ & 6.8 & 6.0 & 6.8 & $2.03 \mathrm{e}+26$ & $162 / 39 / 49$ & $30 / 62 / 118$ \\
\hline 112276A Mindanao & $\begin{array}{c}\text { Expo=23 } 2.0304 .260 \\
-6.2901 .7802 .0200 .220\end{array}$ & 5.1 & 6.0 & 0.0 & $6.07 e+23$ & $136 / 59 / 14$ & $38 / 78 / 148$ \\
\hline 121476A Ryukyu Isl & $\begin{array}{c}\text { Expo=25 }-4.1602 .940 \\
1.230-2.4900 .3301 .350\end{array}$ & 6.4 & 6.3 & 6.2 & $4.62 \mathrm{e}+25$ & $230 / 33 /-114$ & $78 / 61 /-75$ \\
\hline 010177C Honshu Japan & $\begin{array}{c}\text { Expo=24 }-0.3240 .799 \\
-0.4751 .014-0.3560 .401\end{array}$ & 5.4 & 5.2 & 0.0 & $1.34 \mathrm{e}+24$ & $33 / 32 /-163$ & $289 / 81 /-59$ \\
\hline 010777B Taiwan Region & $\begin{array}{c}\text { Expo=24 }-3.009-0.044 \\
3.0541 .185-2.128-0.023\end{array}$ & 5.7 & 5.7 & 5.1 & $3.88 \mathrm{e}+24$ & $194 / 29 /-62$ & $343 / 65 /-105$ \\
\hline 010877A Luzon Philippines & $\begin{array}{c}\text { Expo=23 } 6.3642 .443 \\
-8.8071 .626-1.1762 .219\end{array}$ & 5.2 & 5.3 & 0.0 & $8.16 \mathrm{e}+23$ & $8 / 43 / 118$ & $152 / 53 / 67$ \\
\hline 011577A Philippine Isl Reg & $\begin{array}{c}\text { Ехро=24 }-1.8421 .248 \\
0.594-0.7370 .570-1.652\end{array}$ & 5.5 & 5.6 & 4.6 & $2.41 \mathrm{e}+24$ & $311 / 34 /-88$ & $128 / 56 /-91$ \\
\hline 011777A Bonin Isl Reg & $\begin{array}{c}\text { Еxpo=24 } 4.8130 .539 \\
-5.3520 .7574 .5210 .467\end{array}$ & 5.8 & 5.6 & 5.6 & $6.87 e+24$ & $164 / 25 / 71$ & $5 / 66 / 99$ \\
\hline 011977B Mindanao & $\begin{array}{c}\text { Expo }=251.646-0.866 \\
-0.781-0.990 \quad 0.267 \quad 1.834\end{array}$ & 6.2 & 5.8 & 5.9 & $2.45 \mathrm{e}+25$ & $161 / 40 / 130$ & $293 / 61 / 62$ \\
\hline 012077A Mindanao & $\begin{array}{c}\text { Еxpo=24 } 0.0441 .453 \\
-1.4960 .5170 .9471 .691\end{array}$ & 5.5 & 5.4 & 4.9 & $2.49 \mathrm{e}+24$ & $111 / 65 / 3$ & $20 / 87 / 155$ \\
\hline 022777A Mariana Islands & $\begin{array}{c}\text { Еxpo=24 - } 1.502-0.378 \\
1.880-0.671-0.473-0.742\end{array}$ & 5.5 & 5.0 & 0.0 & $2.04 \mathrm{e}+24$ & $136 / 48 /-132$ & $10 / 56 /-53$ \\
\hline 022877B Mindanao & $\begin{array}{c}\text { Expo }=242.750-1.458 \\
-1.2920 .444-0.2740 .678\end{array}$ & 5.5 & 5.7 & 0.0 & $2.46 \mathrm{e}+24$ & $313 / 39 / 92$ & $130 / 51 / 88$ \\
\hline 030277B Mindanao & $\begin{array}{c}\text { Expo=25 } 3.195-3.570 \\
0.3750 .728-1.5262 .261\end{array}$ & 6.4 & 6.1 & 6.1 & $4.34 \mathrm{e}+25$ & $271 / 41 / 53$ & $135 / 58 / 117$ \\
\hline
\end{tabular}

*Moment magnitude $(\mathrm{Mw})$; ** Body wave magnitude $(\mathrm{Mb}) ; * * *$ Surface wave magnitude (Ms); ****SM: Scalar Moment; *****Fault Plane (FP); ******strike/dip/slip. 


\subsubsection{Velocity mapping}

$\mathrm{V}$

ELOCITY ellipses with 95\% confidence in rotated convention (red) and in (N,E) convention (green), on a PSB region were plotted using 'psvelo' module of GMT, Fig. 3.3.6. Theoretical background of the best-fitting angular velocities and Mid-Ocean Ridge VELocity (MORVEL) is presented by [128] who described and modeled geologically current motions of 25 tectonic plates using geologically determined and geodetically constrained subsets of the global circuit. The datasets include Pacific VELocity (PVEL)

Velocity ellipses in $(\mathrm{N}, \mathrm{E})$ and rotated conventions. Rotational wedges: PSB margins

Dataset: Global CMT Catalog (Harvard CMT). Contourmap: GEBCO 15 arc sec grid, isobaths: 2,000 m.

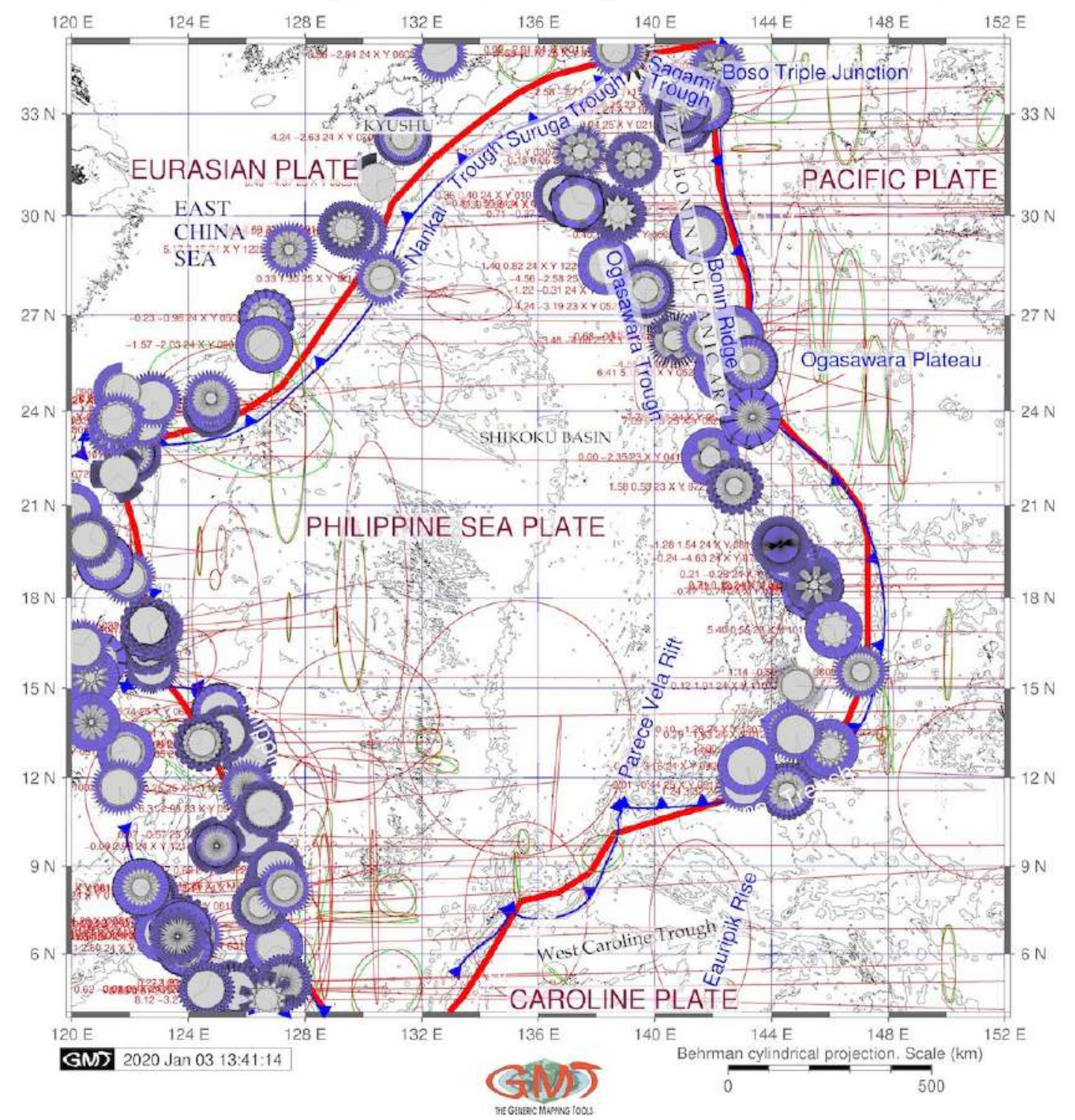

Map 3.3.6: Velocity ellipses at PSB margins

Velocity ellipses at PSB margins from 1976 to 2010 in (N, E) convention (green) and rotated convention (red). Rotational wedges (purple 'gear wheels'): by 'psvelo' module of GMT. Data: Global CMT Project. Contour: GEBCO grid. Technical visualization of the velocity map (Fig. 3.3.6) was performed 
using following GMT code snippet:

- Velocity ellipses in (N,E) convention: 'gmt psvelo CMT.txt -R -J -W0.3p,green -L -Ggreen Se0.1/0.95/5 -A0.2p -O -K >> \$ps'. Here, the Vscale gives the scaling of the velocity in inches; the CMT.txt is the dataset; parameters $-\mathrm{R}$ and $-\mathrm{J}$ indicate the region (in this case coordinates: R120/152/4/35)

- Velocity ellipses in rotated convention: 'gmt psvelo CMT.txt -R -J -W0.3p,red -Sr0.1/0.95/5 Ggreen -A0.2p -O -K >> \$ps'. Here the 'Sr0.1/0.95/5' is the main Keyword arguments (kwargs) showing the Vscale (0.1 inch), Confidence (0.95) and Fontsize (5pt).

- Rotational wedges: 'gmt psvelo CMT.txt -R -J -W0.05p -L -Sw0.5/1.e7 -D2 -Gslateblue2 -Elightgray $-\mathrm{A} 0.2 \mathrm{p}-\mathrm{O}-\mathrm{K}>>$ \$ps'. Here, the '-Sw0.5/1.e7' indicates Rotational wedges with kwargs as Wedge_scale and Wedge_mag. The '-D2' parameter enables to rescale the uncertainties of velocities by sigma_scale (in this case 2 scale was set up).

The respective red and green circles with confidence ellipses are PVEL dataset estimates, which use a plate circuit to estimate subduction across the plate subduction zones in the west Pacific. According to [129], relative to the PSP, the Pacific Plate rotates conter-clockwise around a pole near the southern end of the plate boundary. The best-fitting angular velocity indicates rapid decrease of the convergence rates southward, from $49 \pm 0.7 \mathrm{mmyr}^{-1}(1 \sigma)$ at the northern end of the IBT to $9 \pm 0.8 \mathrm{mmyr}^{-1}$ of orthogonal subduction along the southern YT, south off MT [128].

The PSP-Pacific plate velocities are estimated to fit the interval $1 m m y r^{1}$ and $2^{\circ}$ along the lithospheric plate boundary [668], which reflects the overlap in the GPS stations used to estimate the motions of the two plates. The existence of the Caroline plate was first proposed by [738] who estimated its motions from a synthesis of marine seismic, bathymetric, and seismologic observations from its boundaries with the Pacific and Philippine plates. Located in the western equatorial Pacific immediately south of the PSP (Fig. 2.11.2), it remains the poorly understood and enigmatic with uncertainties about the style and rate of its present deformation caused by scarcity of reliable kinematic data. 


\subsubsection{Histogram equalization}

7 HE smoothness of the grids intensities for GEBCO and ETOPO1 was improved by passing the output of 'grdgradient' to 'grdhisteq' with a case example of the Hikurangi, Puysegur and Hjort trenches [387].

New Zealand region, Hikurangi, Puysegur and Hjort trenches:

Histogram equalization on topography grid

ETOPO1 DEM Global Relief Model 1 arc min resolution
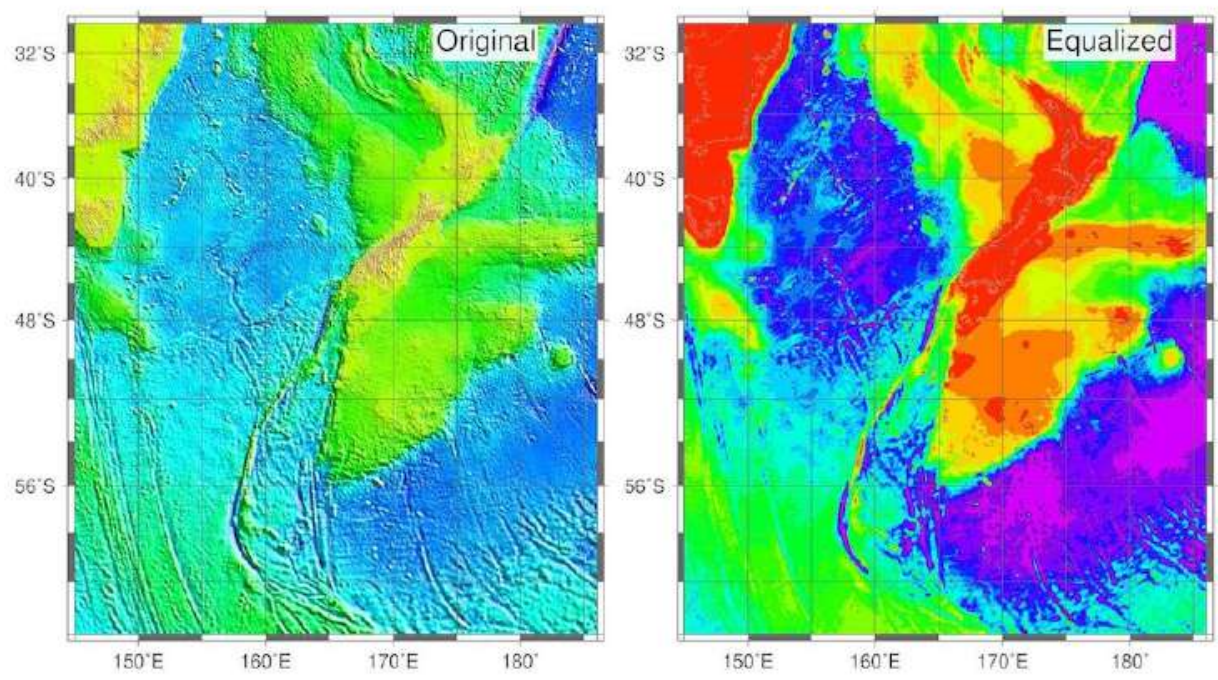

Nan

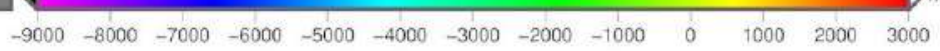
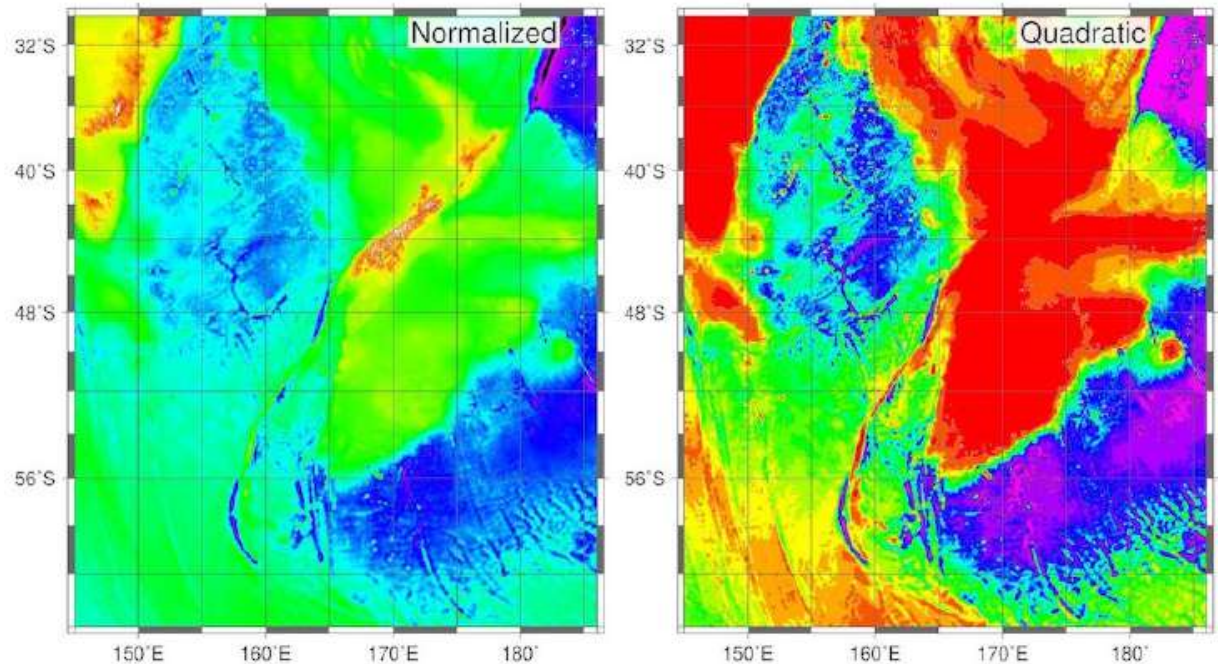

$\operatorname{NaN} \square$

$-3$
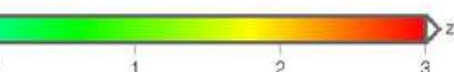

$$
\text { Nan } \square
$$

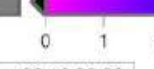

GMD 2019 Nov 06 16:08:38

Map 3.3.7: Histogram equalization on the topography grids, ETOPO1 
The histogram equalization was performed by key GMT module 'grdhisteq' to enhance visualization of the various ranges of the comparison of two grids (ETOPO1 and GEBCO) depending on their frequency distribution (Fig. 3.3.7 and Fig. 3.3.8). Four subplots were generated to find values dividing grid files into equal area patches. The grdhisteq module performs a histogram equalization of raster images. Using 'grdhisteq', the ASCII data values dividing the range of the initial raster data into cells segments was written to an output file. A -C16 argument defines 16 cells. The resulting raster grid has an equal area in the images. Using 'makecpt' GMT module this output was then colored according to the actual bathymetric values by following code: gmt makecpt -Crainbow -T- 9000/3000 > t.cpt. The explanations for the subplot with four maps (Fig. 3.3.7 for ETOPO1 and Fig. 3.3.8 for GEBCO) is as follows:

1. Top left: The original map (top left) visualizes initial raster (artificial cpt rainbow) to highlight changes in elevation;

2. Top right: equalized raster grid;

3. Low left: normalized raster grid derived using $-\mathrm{N}$ argument that stands for Gaussian output, used to to receive data with smooth Gaussian distribution. The default standard normal scores was used for grid normalization.

\section{Low right: quadratic equalization}

The subplot on the low right of the presented Figures 3.3.7 and 3.3.8 shows quadratic equalization plotted using following snippet: gmt grdhisteq hpt_relief.nc-Gout.nc -Q. Here, the -Q argument is output selecting quadratic histogram equalization, unlike the default linear one. The -T-9000/3000 argument means range of the topographic elevations. The image was then visualized using 'grdimage' module by code snippet:

\$gmt grdimage hpt_relief.nc

-I+a45+nt1 -Ct.cpt -JM3i -Y6i -K -P -Bpxg5f5a10 -Bpyg4f2a8 -Bsxg5 -Bsyg4 -BWSne > \$ps

In this code, the -Ct.cpt argument passes cpt created in the previous step for visualization; the '-JM3i' arguments explains the Mercator projection with 3 inches width; '- Y6i' argument plots the map with 6 inches distance from the previous one by $\mathrm{Y}$ axis; '- $\mathrm{K}$ ' argument refers to the continuation of the code. The annotation was added using Unix 'echo' prog: echo 172 - 33Original'|gmtpstext - Rhpt_relief.nc$J-F+j B L+f 12 p-T-G w h i t e @ 10-D j 0.1 i-O-K>>\$ p s$.

The 'grdhisteq' GMT module enables to write a raster grid with statistics based on cumulative distribution function. That means, after applying the 'grdhisteq' module, the output raster file has relative elevations in the same locations as the input file (that is, $\mathrm{x}, \mathrm{y}$ ). However, the values are modified to reflect their place in cumulative distribution with reference to the initial input file. This illustrates the principle of the equalization of the topographic grids by GMT module 'grdhisteq', as visualized on Fig. 3.3.7 for ETOPO1 and Fig. 3.3.8 for GEBCO, respectively. The difference in grids intensities for GEBCO and ETOPO1 raster grids can be clearly seen on the subplot 4 on quadratic equalization. The grid was smoothed prior to use by applying 'blockmean' module of the GMT: it interpolated the original values in the table by smoothing algorithm. Two other modules were tested as well: 'blockmedian' and 'blockmode' as pre-processors before running surface to avoid aliasing in a grid.

The effect of using different histogram equalization algorithms was examined using subplots for data on GEBCO and ETOPO1 covering study area for three trenches (Fig. 3.3.7 and Fig. 3.3.8). Equalization compression for bathymetry grids were tested as comparison for four grids: original, equalized, normalized, quadratic algorithms. The results for this step are demonstrated in Fig. 3.3.7 and Fig. 3.3.8 showing a visual summary of a grid equalization by different GMT algorithms. Consistent cpt across all raster dataset grids where applied for better comparison. Differences can be seen between the values calculated at quadratic equalization at ETOPO1 and GEBCO. From the analysis of histogram equalization 
algorithms it is notable that there are variations in the grids values obtained depending on the method: equalized, normalized, quadratic algorithms. This in itself means that the topic is worthy of further elaboration. Through the demonstrated examples (Fig. 3.3.7 and Fig. 3.3.8) the effects of using different algorithms varying with raster dataset grids equalization can be notable.

Histogram equalization on topography grid

GEBCO DEM Global Relief Model 15 arc sec resolution

New Zealand region, Hikurangi, Puysegur and Hjort trenches
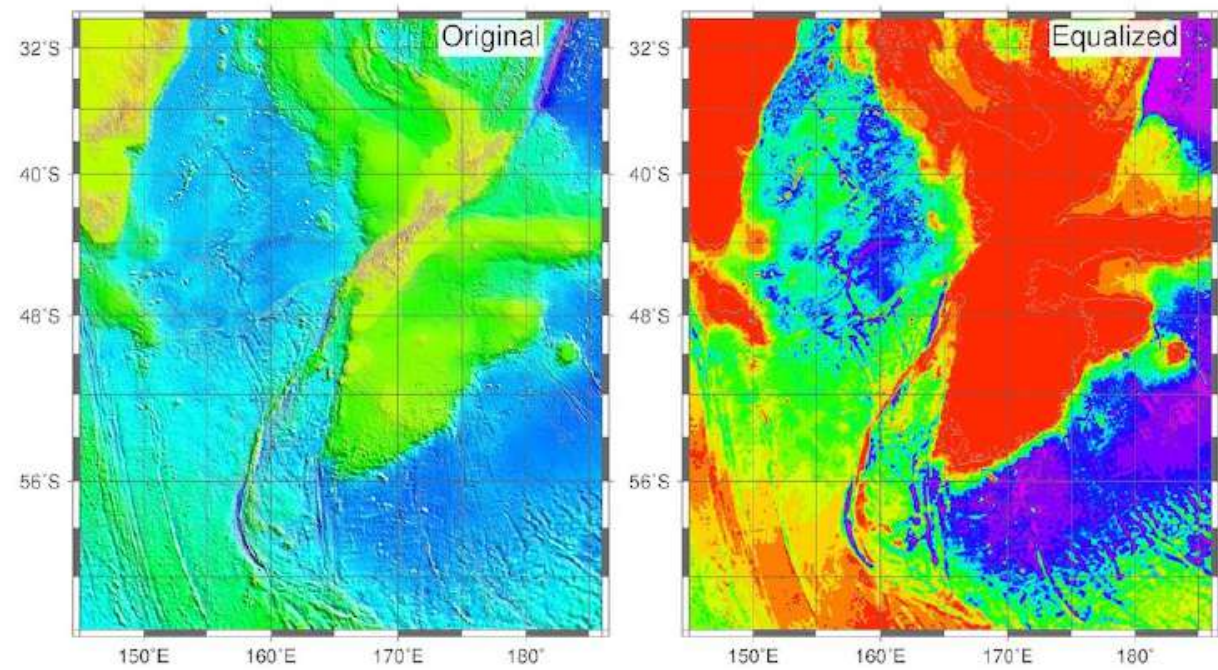

NaN

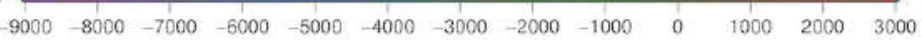

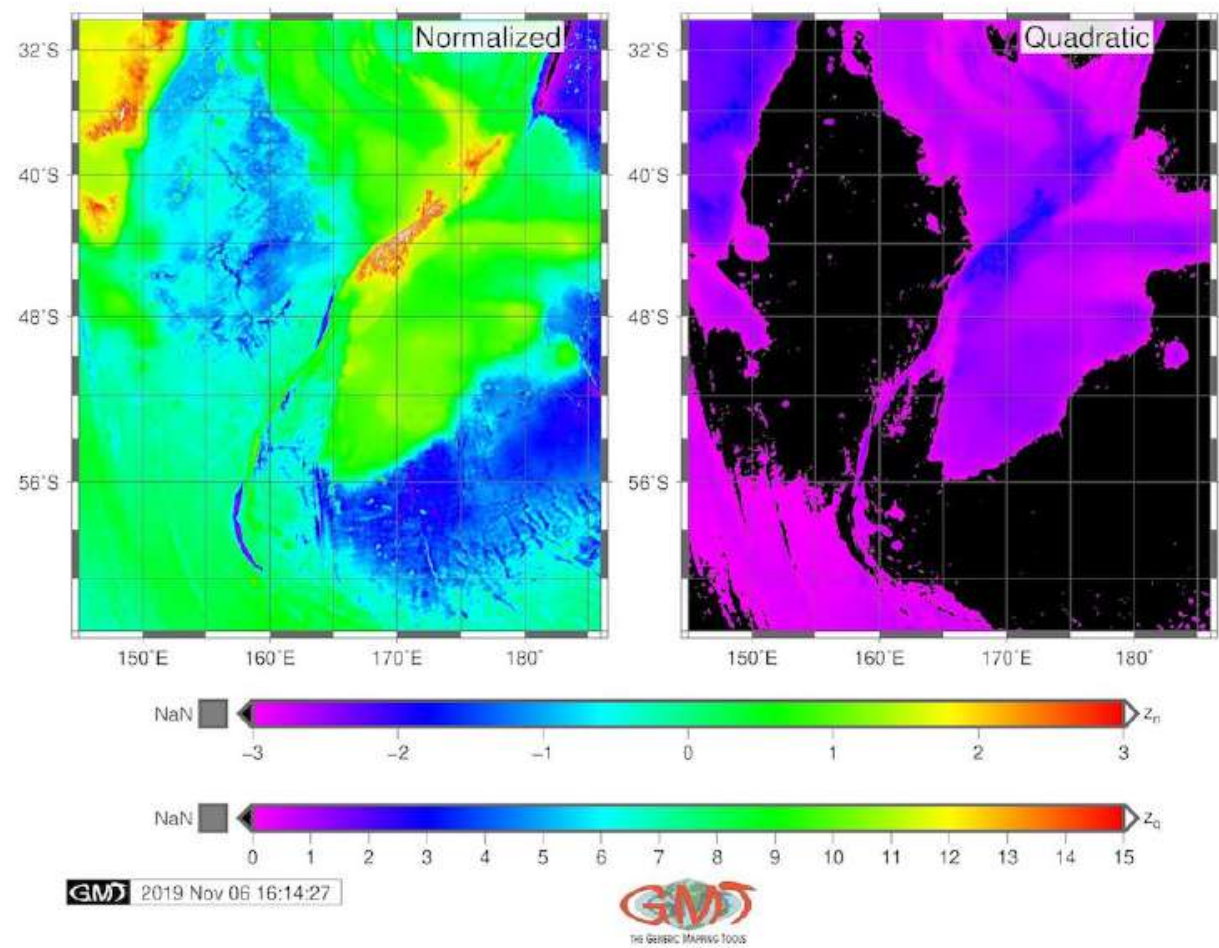

Map 3.3.8: Histogram equalization on the topography grids, GEBCO 


\subsubsection{Geological mapping}

$\mathrm{G}$

EOLOGICAL mapping (example of the KKT shown on Map 3.3.9) is based on the use of the sequence of the GMT modules, the most important of which are the following. Example of the geological mapping of the hadal trench using QGIS with a case study of the MT, the deepest trench on the Earth includes application of $\mathrm{R}$ programming and various statistical approaches towards data modelling. The scope of the research is more focused on the geological assessment than statistical analysis. Therefore, the special attention was paid to mapping geological lineaments, faults, trench extent, location of the Large Igneous Provinces (LIPs), volcanic spots and earthquakes in the KKT (Map 3.3.9). Various depth of the earthquakes are presented in different colors, as well as fracture zones, ophiolites, magnetic anomalies and extension of the tectonic slabs (Map 3.3.9).

\section{Geological settings in the Kuril-Kamchatka area}

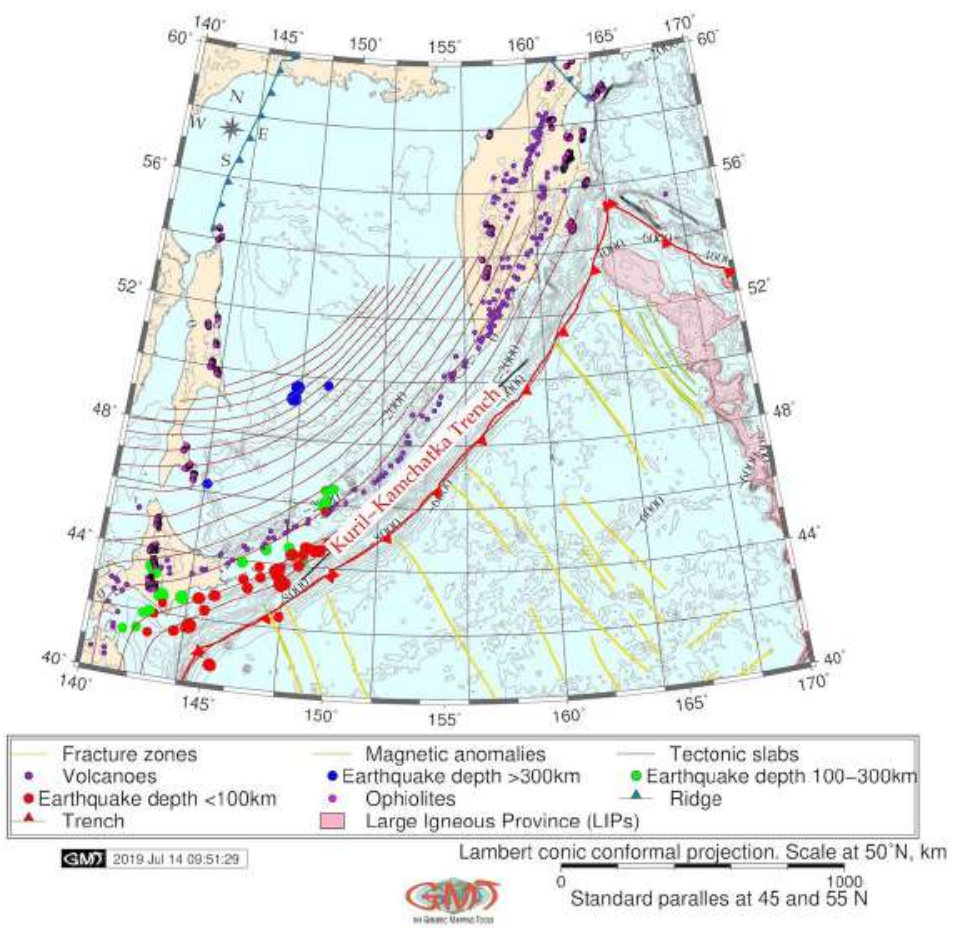

Map 3.3.9: Kuril-Kamchatka Trench: map of geologic settings, [409]

The geological layers (lines and points) were added on the thematic geological maps. Plotting of the vector elements on the map is done by '-W' command, e.g. '-Wthinnest,red'. Each code is saved to the initially created file using "ps command. The $1^{\text {st }}$ mention of this command goes with single bracket, e.g. '> \$ps'. Then all the elements added to the map overlay the same. In this sense, there is certain similarity with GIS layers and a sequence of codes in the GMT script. The initial files with extension gmt (e.g. ridge.gmt) are tables with attribute data (coordinates and values) in native GMT format. Example of the geological mappings for the Kermadec-Tonga region is on Map 2.6.1, right, KKT (Map 3.3.9). GMT module psxy was used for adding annotations on the maps, plotting geologic lineaments and sample points. The psbasemap and grdcontour GMT modules were used to map base map elements: bathymetry contours, net grids, titles and subtitles. The full GMT codes for geological mapping are presented in Appendix, for contour mapping A.4.3, regional mapping A.4.6 and global geologic map A.4.5. 


\subsubsection{Geoid modelling}

7 HE geoid model is a complex function that depends on various geophysical phenomena, such as permanent Earth tide, postglacial land uplift, sea level changes, polar drift and other parameters [151], [76], [236]. The geoid model was analyzed to determine the oceanographic properties of the study area: a mathematical shape that of the ocean surface on the Earth with the sole impact of the gravity and rotation, with absent other influence (e.g. winds and tides). A modeled geoid presents a smooth yet irregular surface with visualized shape resulted from the uneven distribution of the mass on the Earth's surface.

The sequence of GMT modules (gmtset, grd2cpt, grdimage, pscoast, grdcontour, psbasemap, psscale, psimage, logo, pstext, psconvert) was used to map the geoid model for the trench by GMT code areas for plotting contours of the terrestrial and water areas, geoid and bathymetry, net grids and basic cartographic elements such as titles, scales, annotations. Each GMT module consists of the set of code lines, which, combined together as a script produce and visualize maps.

The geoid modelling of the RT (Map 2.13.3) was done using following code: gmt grdimage geoid.egm96.grd -I+a45+nt1 -R120/134/20/33 - JD127/24/27/30/6i -Cgeoid.cpt -P -K > \$ps Example of modelling geoid of MAT area is on Map 3.3.10. The additional cartographic elements were added using GMT basemap module: grid, title, coastline and GMT pscoast module. The full script is presented in Appendix A.4.4.

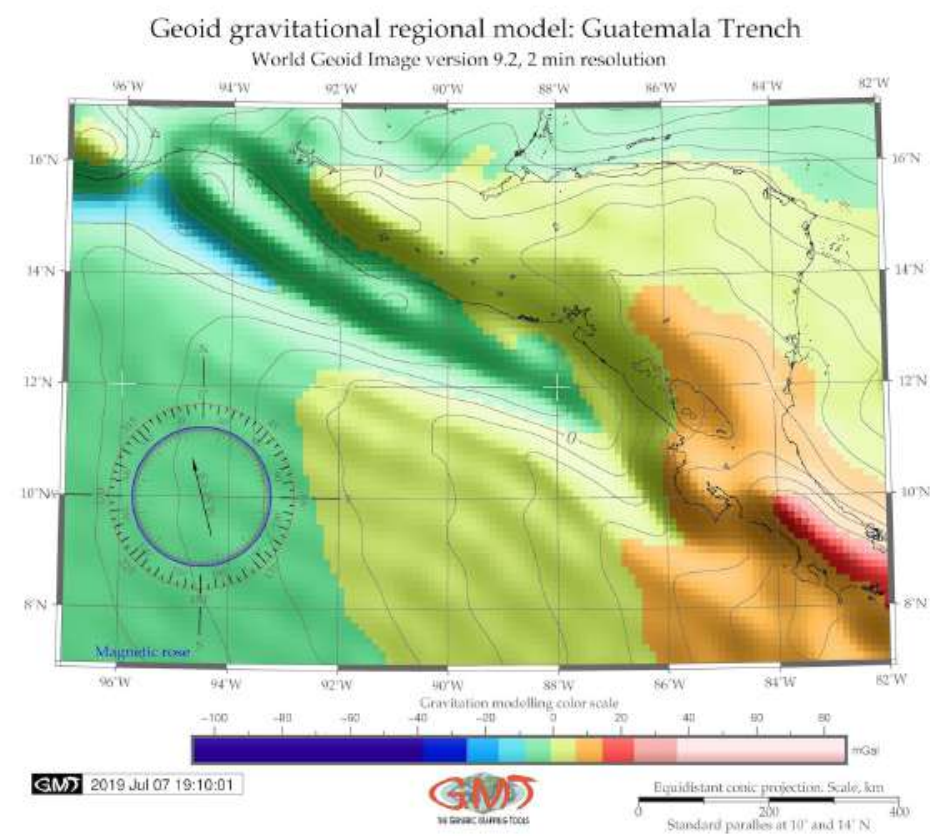

Map 3.3.10: Middle America Trench: geoid model

There are various existing gravity and geoid concepts that originate from differing numerical applications and approaches in processing of the permanent Earths tide [152]. Modelling geoid and gravity was plotted using sequence of several GMT modules (to be more specific: img2grd, grd2cpt, grdimage, pscoast, makecpt, grdcontour and psbasemap) based on the existing methodology [420], [418]. The data are global marine gravity model from CryoSat-2, Jason-1, free-air gravity grids, Scripps Institution of Oceanography [649]: grav/grav_27.1.img and grav/curv_27.1.img via topex.ucsd.edu.

The geoid data grids used for current study and retrieved from the website geoid data grids are based on the EGM96 with $n=m=360$ and WGS 84 reference system [528]: geoid.egm96.grd. The EGM96 has reference ellipsoid the same as WGS 84, but higher spatial resolution and more accurate geoid. The 
model is based on the fully-normalized, unitless spherical harmonic coefficients. The data are made public by National Imagery and Mapping Agency (NIMA), the NASA Goddard Space Flight Center (GSFC), and the Ohio State University.

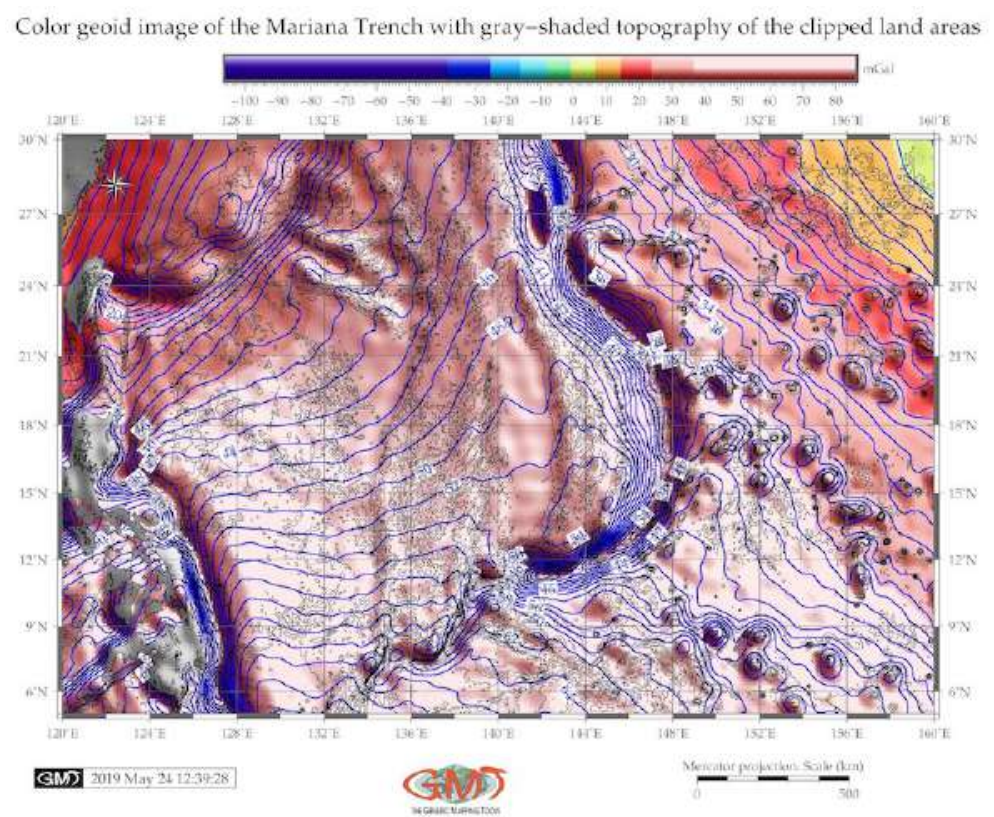

Map 3.3.11: Mariana Trench: color geoid image with grey-shaded topography of the clipped areas, GMT

The EGM96 geopotential model is a spherical harmonic model of the Earths gravitational potential complete to degree and order 360 (Lemoine et al., 1998). The EGM96 contains fully-normalized, unitless spherical harmonic coefficients and their standard deviations for a gravitational model from $2^{\circ}$, to $360^{\circ}$. These coefficients are consistent with scaling values of gravitational models [613]. The data are based on the surface gravity data covering various regions of the globe including southern hemisphere.

\subsubsection{D mesh grid modelling}

7 HE 3D mesh gridding aimed to visualize and highlight the topographic and bathymetric landforms and patterns of the region of the trenches, through dividing the input grid model into smaller shapes formed after discretization of the geometric model of the area. 
Composite overlay of the 3D topographic mesh model

on top of the 2D geoid contour plot

Region: Guatemala Trench Perspective view azimuth: 165/30
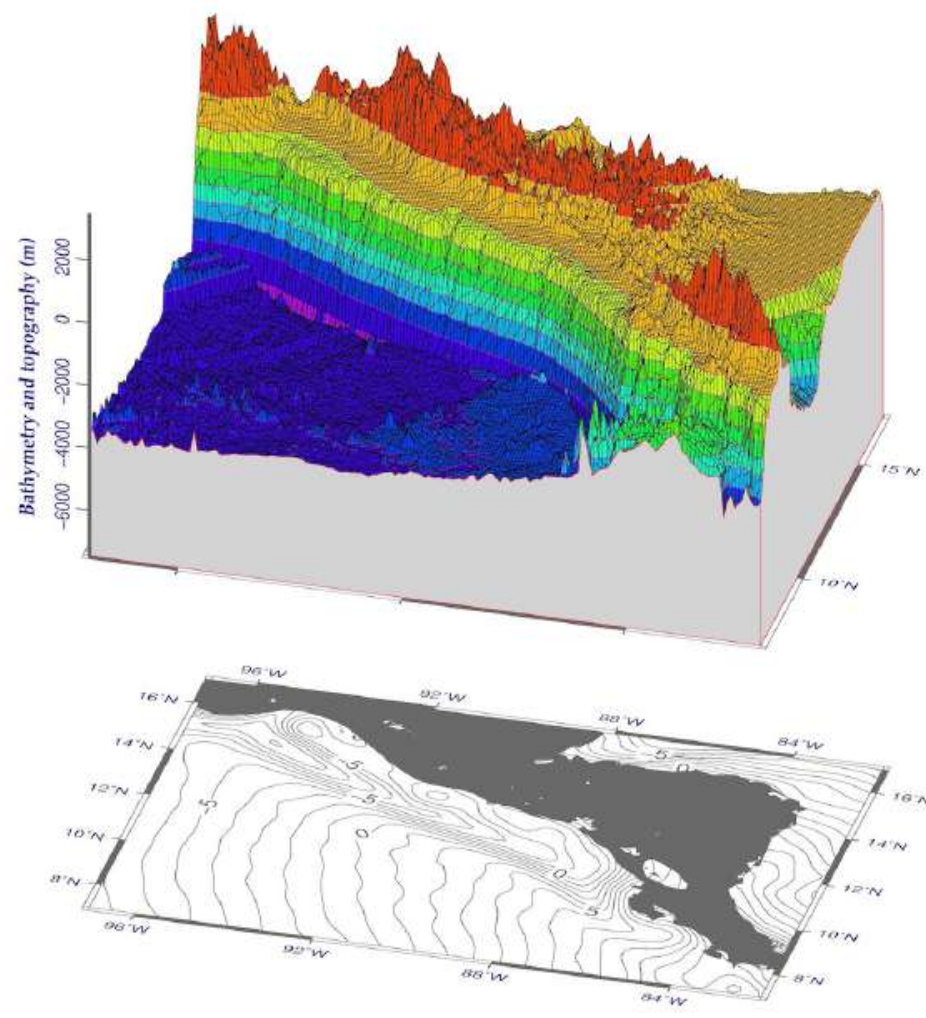

GMग 2019 Jul 07 19:07:47 Data: 2 min World Geoid Image 9.2, ETOPO 5 arc min grid

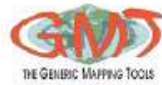

Map 3.3.12: Middle America Trench: 3D topographic mesh model map

Hence, the purpose of the 3D-mesh gridding (example for the MT: Map 3.3.12) was to create an overlay that highlights the geomorphic surface of each of the trenches and adjusting continental steep slope. Therefore, unlike in case of bathymetric mapping (Fig. 2.3.1) where the data were taken as (ETOPO1, lower resolution grid was used (ETOPO5). This was done to avoid small-scale irregularities possible in case of the high-resolution data which tend to visually overload the derived topographic attributes, making 3D mesh overlay visually complex. This allowed a smoother visualization of the 3D-mesh polygons by removing unnecessary details in 3D plotting using GMT code.

The 3D modelling consists in the following steps. the data were initially extracted from the ETOPO5 grid using the following (snippet for the Vanuatu) [407]: gmt grdcut earth_relief_05m.grd -R160/170/25/-10 -Gvv3d_relief.nc. The ETOPO5 was selected to plot the 3D with aim to reduce the grid size and hence to save computer memory space. The next step of the 3D modelling is a calculation of the regular 3D grid mesh using GMT parameters of the 'grdview' module. The dimension of the grid was chosen in a way which ensures that every point of the trench axis is located within the grid boundaries. For example, the coordinates for Vityaz were selected as $163^{\circ} 173^{\circ}-15^{\circ} 0^{\circ}$ and for Vanuatu [407]: $160^{\circ} 170^{\circ}-25^{\circ}-10^{\circ}$. Visualization parameters of the 3D models can be summarized as follows. Grid extent was in 160/45 azimuthal direction rotation with the grid ranges from $160^{\circ}$ to $173^{\circ}$ for both grids, in latitudinal direction 
from $-25^{\circ}$ to $0^{\circ}$, and in vertical direction from $-9,000 \mathrm{~km}$ depths up to $1000 \mathrm{~km}$. On ' $\mathrm{Z}$ ' argument the grid was extended by $4 \mathrm{~cm}$ as a visual distance between the 3D and basemap 2D, to enable interpreted them better. The $2 \mathrm{D}$ mesh was divided into small simple polygons with curved contour lines and color palette highlighting the topography. The 3D map was then overlaid with 2D geoid.

The background geoid contour (a plane grayscale map below the map, Map 3.3.12) was plotted using GMT module 'grdcontour'. The geoid field data of the 2D map were taken from the ETOPO1 dataset are given by following code (here: Vanuatu) [407]: gmtgrdcontourearth_relief_01m.grd -JM6.0c$R 160 / 170 /-25 /-10-p 160 / 45-C 500-G d 6 c-W$ thinnest, dimgray $-Y 5.5 c-P-K>\$ p s$. In order to ensure that grids are visually depict geomorphic shapes of the surfaces, the '-Qsm' argument was selected to specify 's' for the surface plot, and 'm' to have mesh lines drawn on top of surface. For the vertical component, an option '-N-9000+glightgray' was selected to draw a plane at the $-9,000 \mathrm{~m}$ level of bathymetry. Final 3D model of the two subplots is shown on Fig. 4.9.2. The contour lines are given by every one with annotations at every five (-C1 -A5). The rotation of the 3D mesh grid was chosen at the angle most corresponding to the visualization of the trenches, after several trials at different angles, depending on the oblique rotation and depth by GMT code. A plane was drawn at $-7500 \mathrm{~m} s$ z-level with dimgray color provided via the $+\mathrm{g}$ modifier to highlight the frontal facade between the 3D plane and the data perimeter and -Wf0.1p,red setting used for the pen outline.

After the data were compared and optimal resolution selected, the rotation azimuth was set as $\mathrm{p} 165 / 30^{\circ}$ with an overlay distance from the geoid contour at $4,5 \mathrm{~cm}$. As a result of the combination of several GMT modules, 3D mesh model of the trenches (example of the Aleutian: Fig. 2.2.4) was computed and visualized. They show the 3D model rotated in $165 / 45^{\circ}$ overlapping the contour map of the geoid. Several GMT modules were used, e.g. 'pscoast' module used for mapping coastal lines and contour, 'psscale' module was used for mapping color legend strip showing visual colors, 'pstext' module was used to add textual explanations on the map. The Network Common Data Form (NetCDF) grid format [618] was processed as a grid file. The cartographic routine include adding elements on the map: plotting ticks, selecting lines for grids, adding directional rose and legend, selecting proper projection. Topographic data were collected rom the ETOPO5 covering seafloor bathymetry and coastal topography of the area of each trench. The modelling was performed using GMT module 'grdview' followed by a sequence of the GMT modules: grdcut, grd2cpt, grdcontour, pscoast, grdview, logo, psconvert. Additionally, some UNIX progs (rm, echo) were used. The output 3D model is presented at (Map 3.3.12). The full GMT code is available in Appendix, A.4.2.

\subsubsection{Gravity modelling}

$\mathrm{G}$

RAVITY model is used to support geophysical investigations, geological prognosis as well as geological resources management. Here the GMT script is presented for modelling gravity from $m$ the 'grdimage' GMT module, and 'img2grd' module was used for the data conversion. The combination between the GMT modules and cartographic features enables to properly visualize thematic map by the GMT tools. The essential GMT elements include selecting map projections, fonts, map layout, grid, adding elements on the map. Gravity data showing free-air gravity anomalies covering study area including terrestrial and marine regions, were taken from the data sets based on the 1 arcminute resolution CryoSat-2 and Jason-1 satellite-derived raster grids described in detailed in relevant studies [651], [648], [687], [649], for the trenches and surrounding regions. Gravity data revealed ground information for the geologic and geophysical settings of the study area, as free-air gravity anomalies reflect subsurface density variations [141]. The gravity map was plotted using GMT following code (here example for the RT):

gmt grdimage gravRT.grd -I+a45+nt1 -R105/123/8/24 -JY114/12/6.5i - CgravRT.cpt -P -K > \$ps. 


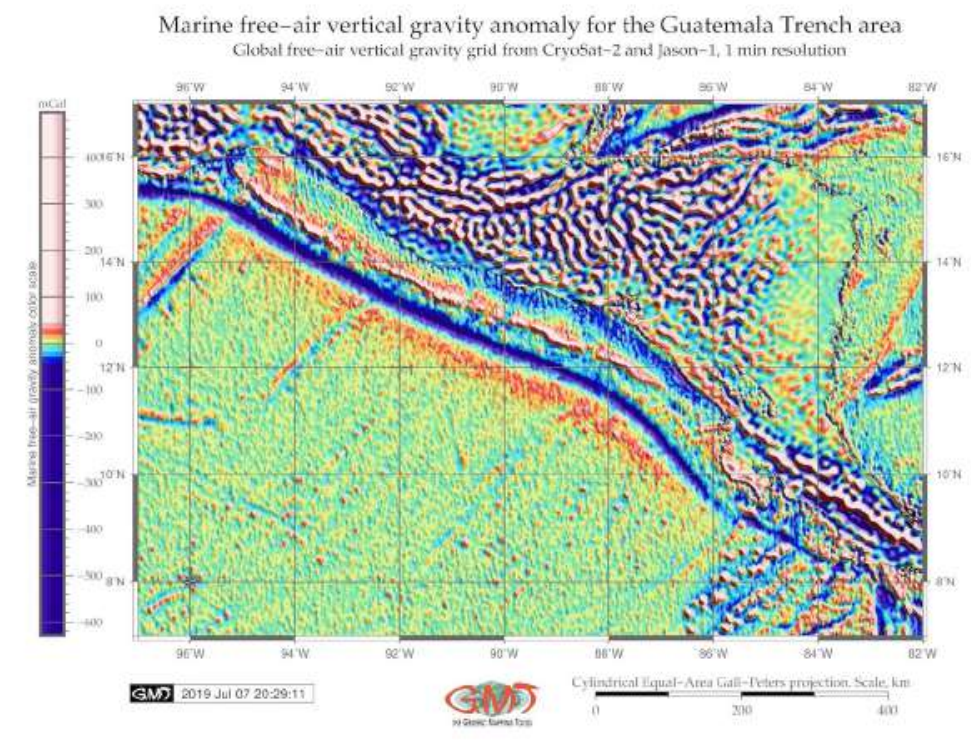

Map 3.3.13: Middle America Trench: gravity model map

Here the -R function shows the selected region, the JY114/12/6.5i stands for the cylindrical equalarea Gall-Peters projection and 6,5 inches the overall dimensions of the map; -I+a45+nt1 shows the illumination parameters and -CgravRT.cpt selects the color palette created on the previous step.

Chosen color palette (gravRT.cpt) shows the transition from lower (red) values (loser than $20 \mathrm{mGal}$ ) to higher values (bright blue) gravity values (over $90 \mathrm{mGal}$ ). The gravity modelling (example: Fig. 3.3.17) was performed using the following script. The example of the RT is on Map 2.13.4, MAT: Map 3.3.13 and Map 2.3.4. The full GMT code of modelling gravity is available in Appendix, A.4.7.

Gravity and bathymetric data were examined to obtain a visualization and better understanding of the seafloor fabric and structures within the PSB. The EGM96 gravity grid was visualized based on the with the satellite altimetry data [688] producing gravity map of the PSB (Fig. 2.11.4). The subset of the img file was extracted through the following GMT shell script (example for the Kuril-Kamchatka Trench): Appendix, A.4.7, (Vertical gravity for Kuril-Kamchatka Trench). 


\subsubsection{Automatic digitizing of the cross-section transecting profiles}

$\mathrm{C}$

ROSS-SECTION profiling is a common technique used in geosciences to receive a sample of the selected segment in the study area and analyze variability of the studied elements along the track. Examples of the cross-section area presented: DEM cross-profile [772]. Semi-automated methods have been explored in cartography, driven largely by the advantages of using machine-learning algorithms in cartographic routine, thus minimising handmade routine, subjectivity in processes of the digitizing and vectorizing of the bathymetric data.

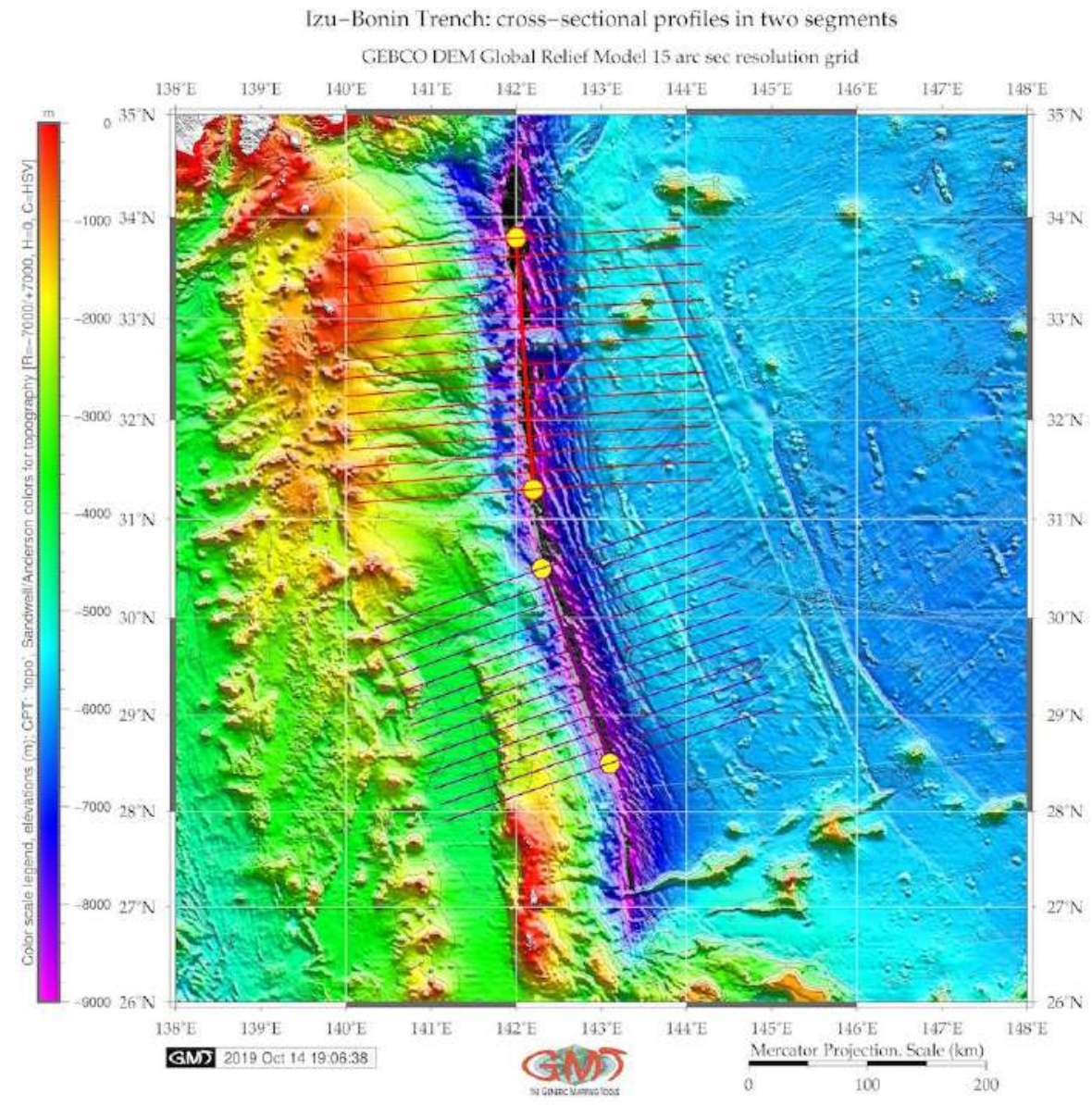

Map 3.3.14: Izu-Bonin Trench: Digitizing cross-section profiles

Example of such works is presented by [661]. The GMT proposes more advanced solution in the automatization of the cross-sections through ML based digitizing that results in a series of the profile transects across the trench [739]. Two methods were tested in visualizing the profile by GMT arguments: median '-Sm' and the mean '-Sa'. Of these two, median was selected as the best one representing the empirical nature of the trench's shape. Although mean method shows fine interpolation accuracy, median is more favorable, since visual representation of the trench lies within a reasonable reflection of the submarine geomorphology.

The geomorphological modelling consisted in plotting sets of the cross-section orthogonal profiles in perpendicular direction to the main trench axis, and then comparing their parameters for each of the 20 trenches. Plotting cross-sectional profiles, or transects along the selected segment of the study area is a common technique in geological investigations. Examples of the geological cross-section profiles plot- 
ting and data analysis can be seen in [639], [556]. In this study, the orthogonal cross-section bathymetric profiles were drawn automatically using presented GMT script across the trenches. Because the scope of the current work is rather large (20 trenches of the Pacific Ocean), the automatization of the process was crucial point in the methodology and a key decision for selecting GMT.

To analyze the geomorphology of the trenches, the method developed by [741] was adapted in this study where the original focus was set on the modelling terrains, since the oceanic trenches have a similar geomorphic setting with reverse general shape form. In this method, the observed elevations, Z, along the cross-section transects is read into a table, using GMT 'grdtrack' module along the selected segment of the trench with track $400 \mathrm{~km}$ long, spaced $20 \mathrm{~km}$ and samples taken $2 \mathrm{~km}$ along the corresponding line [420]; [418]. These recorded bathymetric measurements are then read into the input table from which a graph was plotted denoting the profile shapes (example for the Philippine and MT: Fig. 4.12.1 and Fig. 4.17.1).

The profiles have length of $400 \mathrm{~km}$, that is from -200 to $+200 \mathrm{~km}$ from the trench axis, spaced 20 $\mathrm{km}$, sampled every $2 \mathrm{~km}$ to achieve evenness of the sampling for the trenches. The depths values were calculated by each profile, and their mean and median values were modeled thereafter. Mean values are notable for smoothing the splines rather as a mathematical functions which lesser reflects the geographic phenomena of the objects. The uncertainties of the actual geomorphology are expected to exceed the theoretical interpolation of the actual geomorphology represented on the graphs. Hence the shape of the trenches is highlighted as median using -Sm argument, example is visualized by red line on Fig. 4.21.1.

The combination of several GMT modules was used for mapping geomorphological profiles, as shown in GMT. Plotting and stacking of the profiles was done using using 'grdtrack' module of GMT by statistical mean, through the following main lines of the code based on the 'tkt_relief.nc' raster in NetCDF format. Minor GMT modules used for plotting cartographic elements included 'psxy', 'gmtlogo', 'psconvert', as well as Unix 'echo' utility. For example, with a case of the Philippine Trench, the target area for the was selected off Mindanao Island, the $2^{\text {nd }}$ largest island in the Philippines, situated in the southern part of the archipelago. The Area of Interest (AOI) square is $126.62^{\circ} \mathrm{E} 10.7^{\circ} \mathrm{N} 127.27^{\circ} \mathrm{E} 8.0^{\circ} \mathrm{N}$. The AOI for the MT is located in the southwestern part of the crescent (Fig. 2.11.1) and is bounded on the east by the Guam Island and on the south by the YT (Fig. 2.11.2) encircled by the target square of $141.2^{\circ} \mathrm{E}$ $11.0^{\circ} \mathrm{E} 143.8^{\circ} \mathrm{E} 11.65^{\circ} \mathrm{N}$, capturing the Challenger Basin.

A sequence of the GMT codes was used for plotting transects as follows (example for Puysegur). A 'cat' Unix 'cat' utility was used to plot target coordinates. The line of transect with start and end points was plotted using 'psxy' module. Generating cross-track profiles $400 \mathrm{~km}$ long, spaced $20 \mathrm{~km}$, sampled every $2 \mathrm{~km}$ and saving them in a table (here: tableP.txt) was done using GMT code (Appendix A.4.8). Other examples of modelling and digitizing a series of the cross-section profiles along the two trenches: Hikurangi and Puysegur is presented on Fig. 2.19.2, performed using GMT and to plot the graphs using retrieved tables (Fig. 2.20.2) [387]. Example is presented on Fig. 2.6.1, left. The trench segment and end points were plotted and profiles written into table with modelling done at the next step.

The annotations were added using Unix utility 'echo'. The advantage of the GMT for the automated profiles digitizing lies in the increased precision and speed of the plotting and highlighted submarine geomorphic features of the trench. For the case of MAT (Map 4.4.1), the cross-section profiles were taken through the key sea floor features at coordinates $268.4^{\circ} \mathrm{W} 13.0^{\circ} \mathrm{N} 271.9^{\circ} \mathrm{W} 11.6^{\circ} \mathrm{N}$ to show the variety of the steepness angles. Full GMT Bourne Again SHell (bash) code and characterization of the module options and elements in comments including UNIX progs (echo, rm, cat) are provided in Appendix, A.4.8. 


\subsubsection{Modelling 2D statistical histograms}

S

TATISTICAL data modelling in geology is an important tool for the data analysis [125], [116]. The statistical techniques of the data analysis are widely used in geospatial studies, applied and described in previous works: [563]; [98]; [645]; [633]. Proper data interpretation always include testing several algorithms, selecting appropriate approaches and statistical packages [299]. This thesis applied the histogram techniques showing data distribution (depths), along the profiles. Unlike traditional statistical data analysis that utilizes standard tools for this purpose, such as R and Python [55]; [196], MATLAB/Octave, Statistical Package for the Social Sciences (SPSS) IBM Statistics [645], [425], Gretl [426], this research demonstrated the possibility to perform statistics directly from the cartographic GMT toolset using embedded statistical modules.
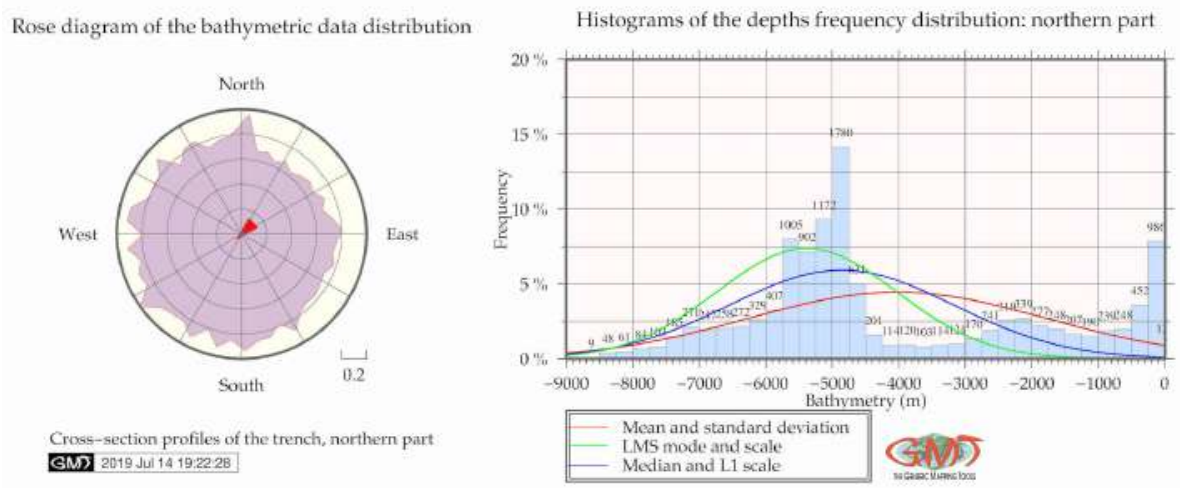

Rose diagram of the bathymetric data distribution

Histograms of the depths frequency distribution: southern part
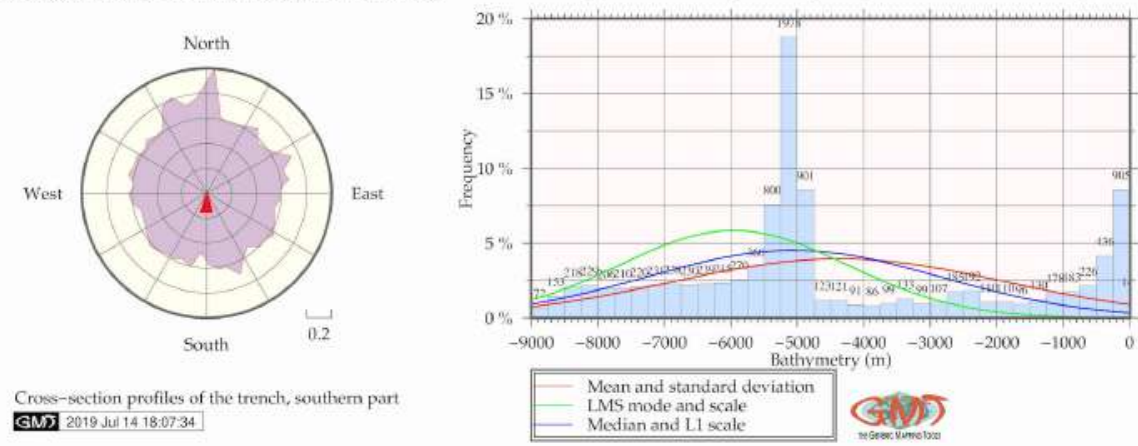

GM] 2019 Jul $1418: 0734$

LMS mode and scale
Median and L1 scalc

Figure 3.3.1: Kuril-Kamchatka Trench: 2D histograms and rose diagrams of depths [409]

Plotting statistical 2D histograms and rose diagrams was done using GMT code by 'pshistogram' and 'psrose' modules, respectively (KKT: Fig. 3.3.1). It shows statistical 2D histograms and rose diagrams for comparative analysis of depths distribution in the southern and northern part of the KKT. Rose diagram shows the aspect of the slopes. Modelling digitized cross-section profiles was followed by a comparison of the two sets either in southern and northern segments of one trench, or comparison of the two neighboring trenches. The statistical modelling and digitizing cross-section profiles were done using GMT modules pshistogram; and 'grdtrack'. The statistics by histograms was performed using a sequence of the GMT modules: gmtset, psrose, pshistogram, pslegend, logo and psconvert. The histogram plotting demonstrated the frequency of the data distribution against bathymetric variables. The full GMT code of modelling 2D statistical histograms and rose diagrams is presented in in Appendix, A.4.12. 


\subsubsection{Modelling 3D statistical histograms}

XAMPLE of the 3D modelling of the histograms is presented on Fig. 3.3.2 (here: the KKT). The full GMT code of modelling 3D statistical histograms is presented in Appendix, A.4.13.

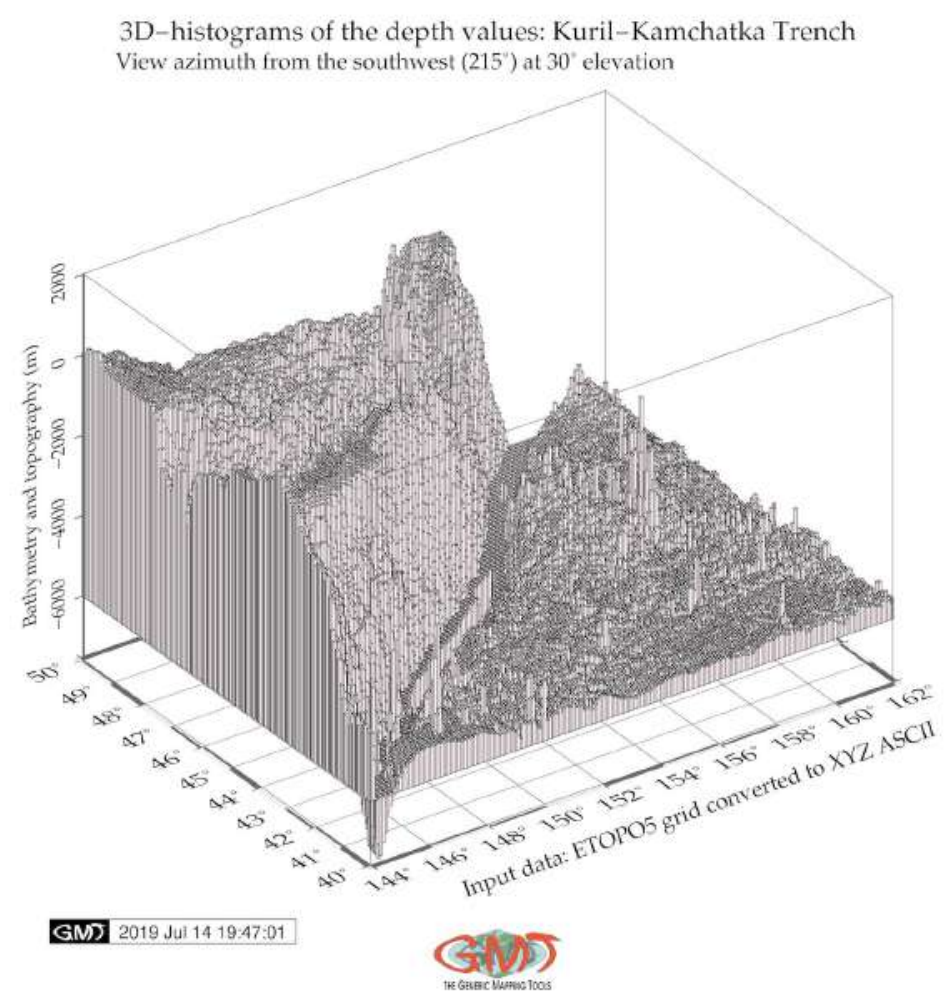

Figure 3.3.2: Kuril-Kamchatka Trench and Sea of Okhotsk: 3D histograms: depths distribution [409]

\subsubsection{Modelling statistical trends of the profiles gradient}

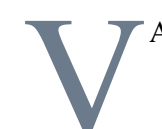

ARIOUS approaches in modelling trends are presented to show the variety of the mathematical algorithms embedded in the GMT tool set. The trend curves were modeled using trend1d module by the following code: gmt trend1d -Fxm stackRTn.txt -Np1 > model.txt Using generated table the statistical data processing were performed: modeling trend regression for the cross-section profiles (Fig. 3.3.3), computing trends for the profiles and plotting two types of the statistical histograms, that is rose diagram and standard box histogram (Fig. 4.4.1). A sequence of the codes was applied to model of the mathematical approximation of the slope gradient trends by profiles (example is visualized on Fig. 4.7.1). For example, the basic LS line shown on the Fig. 4.7.1, E (lower left) was plotted using following methodology combining GMT and Unix utilities. Four types fo the mathematical models were used to analyze the curvature of the profiles, GMT regression analysis Formula 3.3.12:

$$
m_{2} t=a+b * t
$$

GMT regression analysis Formula 3.3.12:

$$
m_{3} t=a+b * t+c * t^{2}
$$



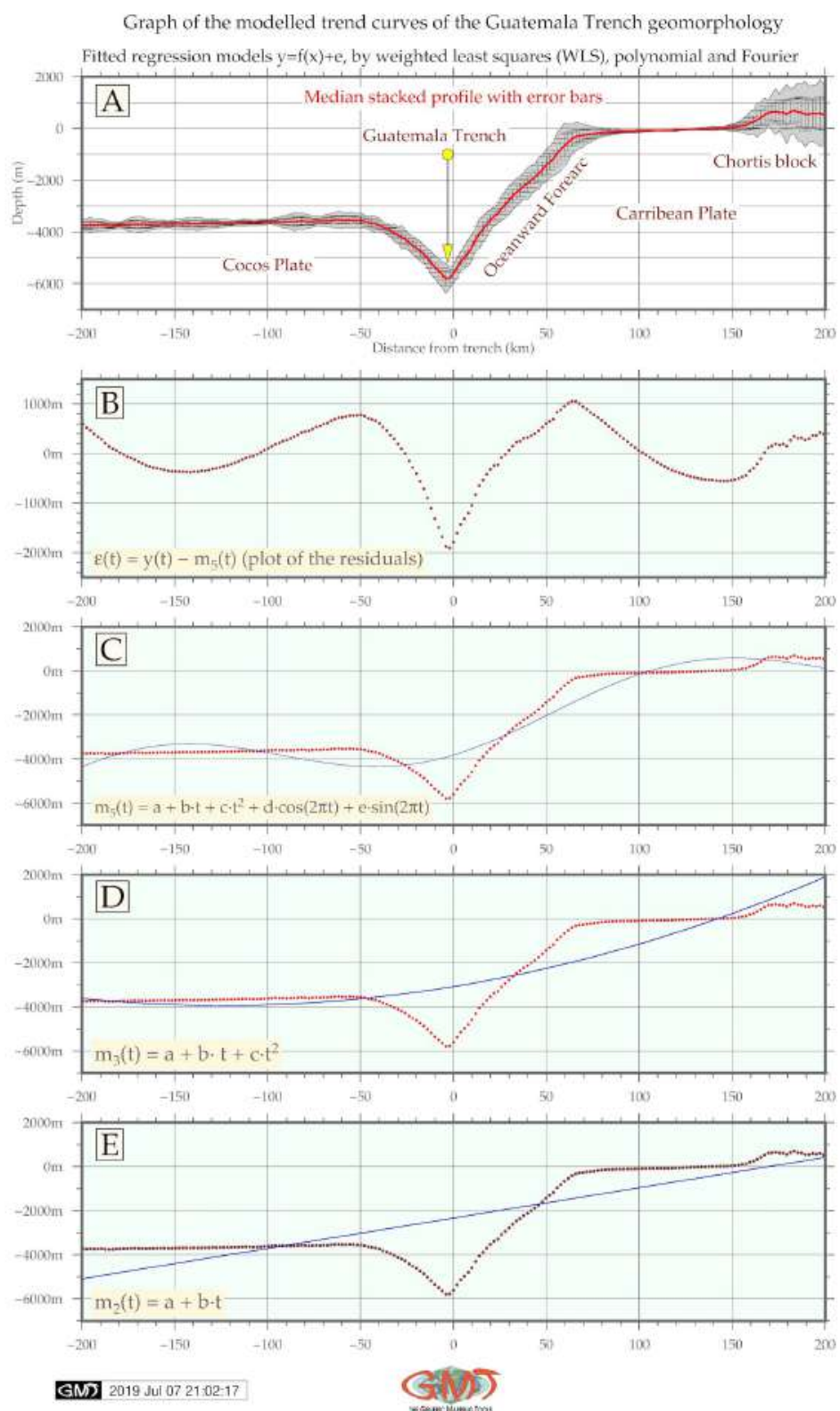

Figure 3.3.3: Middle America Trench: trend regression models for the cross-section profiles

GMT regression analysis Formula 3.3.12:

$$
m_{5} t=a+b * t+c * t^{2}+d * \cos 2 \pi * t+e * \sin 2 * \pi * t
$$

GMT regression analysis Formula 3.3.12:

$$
\varepsilon(t)=y(t)-m_{5} t
$$


Example of the resulting graph of the trend regression models for the MAT was plotted on Fig. 3.3.3. The GMT scripts used for the cartographic visualization and modelling of the statistical trends are based on GMT codes provided in Appendix, A.4.11.

\subsubsection{Surface modelling}

7 HE dataset of this research was augmented by free ASCII data on gravity and topography as xyz table, collected from the available source in a table format: USGS. The data range was set to the following coordinates square (here with a systems of $0-360 ; 0-90$ rotation): Lon $263^{\circ} / 278^{\circ}$; Lat $7^{\circ} / 17^{\circ}$. According to the gravity data inspection (gmt info grav_MAT.xyz), the range for the data is as follows: total number of points $=554115$; minimal value is $-157.1 \mathrm{mGal}$ at point with coordinates $263.0083^{\circ} 7.0076^{\circ}$; maximal value is $452.4 \mathrm{mGal}$ at coordinate $278.0083^{\circ} \mathrm{W} / 17.0032^{\circ} \mathrm{N}$. Based on this, the color palette was adjusted accordingly to the data range: gmt makecpt-Ccyclic.cpt -V -T160/455 > surface.cpt where -T-160/455 shows the $\mathrm{min} / \mathrm{max}$ data. Thereafter, before modelling surface, the data were interpolated for the correction for the source data by generated 1 by 1 minute block for the mean values from the raw ASCII xyg table. Afterwards the data were processed by 'gmt surface grav_MAT_BM.xyg -R263/278/7/17 -T0.25 -I30s -GSurface_MAT.nc -Vv' command, which modeled the surface from the xyz data. Both topographic surface modelling (Fig. 2.3.5) and gravity surface mapping (Fig. 3.3.15) are based on the modelling numerical ASCII data in xyz format to the NetCDF format [618].

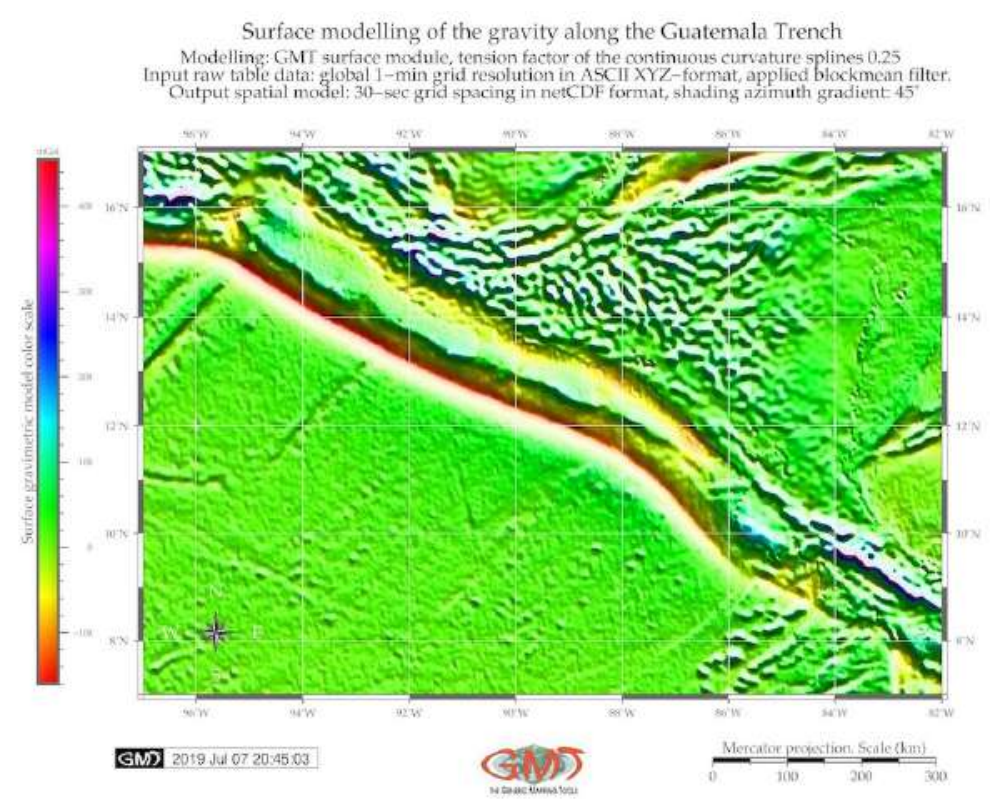

Map 3.3.15: Middle America Trench: gravity surface map modeled by ASCII data

Gradient illumination was added to intensify the surface with azimuth $45^{\circ}$ using gmt 'grdgradient' module with shading azimuth gradient $45^{\circ}$. It highlighted topographic pits, furrows and submarine landforms on the seafloor of the MAT. The data were coded by the cyclic color palette (cyclic.cpt) with the resulting image: Fig. 3.3.15. Raster image output was made by GMT code 'gmt grdimage Surface_MAT.nc -Csurface.cpt -R263/278/7/17 -JM6i -P -ISurface_MAT.int -Xc -K > ps'. Additional cartographic elements (ticks, legend, scale bar, grid ticks, directional rose, etc) were added by GMT modules. The $1 \mathrm{~m}$ bathymetry and xyz grids were interpolated to $30-\mathrm{sec} \mathrm{m}$ resolution and grids derived from bathymetry and gravity were visualized. Gravity contours (mGal) were derived with tension factor 
of the curvature splines at 0,25 . Final data were exported as a 30 -sec resolution grid spacing in NetCDF grid. Full GMT code for surface modelling (codes for gravity surface: codes for topographic surface of the xyz ASCII data is available in A.4.9 and A.4.10.

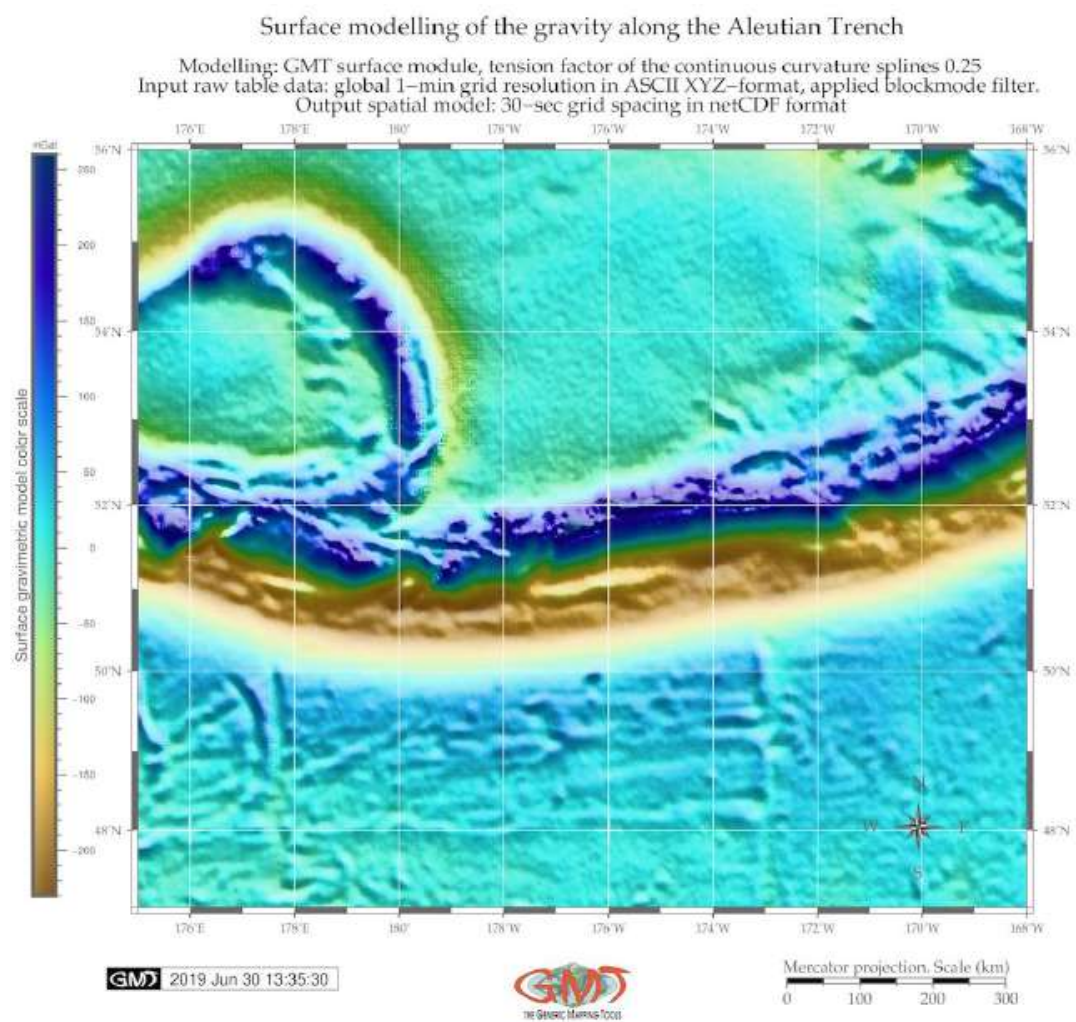

Map 3.3.16: Aleutian Trench: surface modelling from the ASCII xyz data. [370]

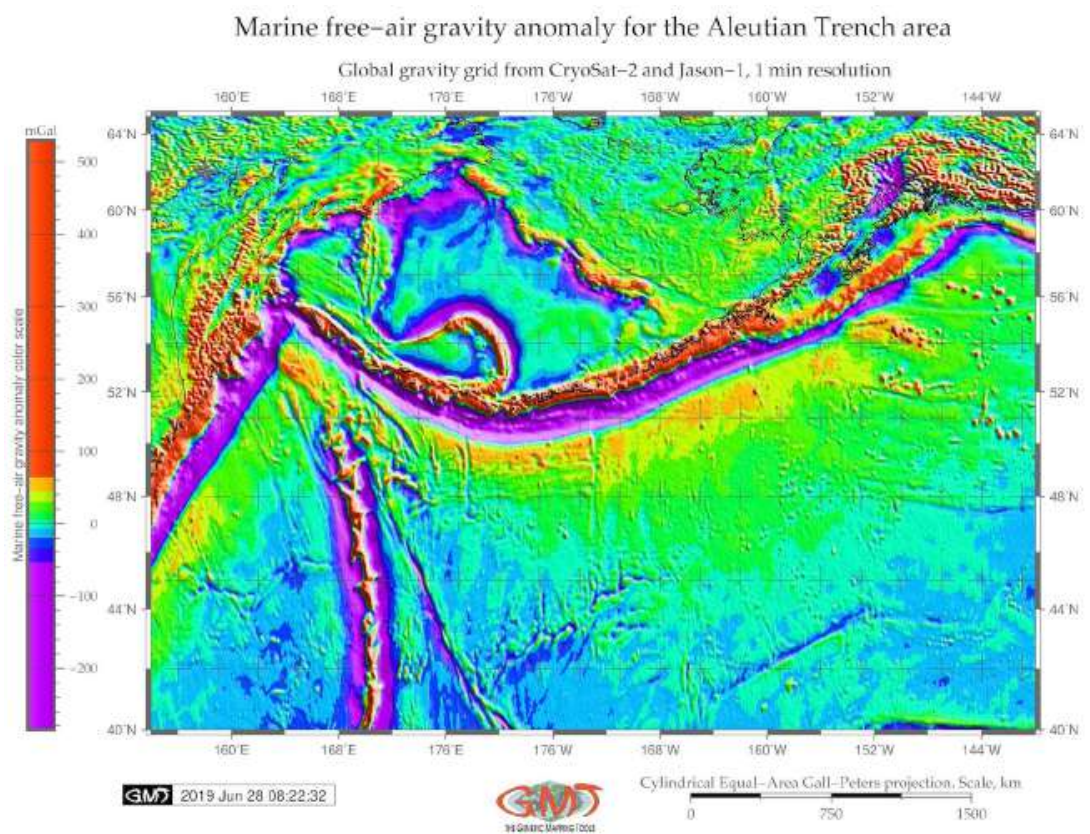

Map 3.3.17: Aleutian Trench and Aleutian Islands: gravimetry map. [370] 


\subsection{AWK}

\subsubsection{Advantages of AWK}

AWK, a domain-specific programming language designed for the text processing, was used in this dissertation for table reshaping. The AWK programming language was created at Bell Labs in the 1970s [6] and its name is derived from the surnames of its authors: Alfred Aho, Peter Weinberger, and Brian Kernighan. The GNU implementation of AWK is called GAWK. The available documentation and information on AWK was used extensively in this research [697], [5], [494]. AWK language is highly suitable for sorting multi-field records in a table due to its specially designed syntax and embedded algorithms. Other possibilities include managing small databases, generate reports based on tables, validating data, producing indexes, performing document-preparation tasks, extracting pieces of data for further processing, sorting data [627].

AWK is a data-driven scripting language and a powerful tool for data extraction integrated with commands of Unix operating system and can be run from the console. It consists of a set of codes-actions that can be taken against to operate with streams of table data [630]. AWK enables to extract or transform text, produce formatted records [628]. It uses string datatype, associative arrays indexed by key strings, and regular expressions [629]. Based on this, AWK was selected as a powerful advanced tool for the processing of tables.

Table 3.4.1: GMT-derived table for the Cross profile \#1

\begin{tabular}{r|lllll} 
No & Coordinates, lon & Coordinates, lat & Location, $m$ & Azimuth, grad & Depth, $m$ \\
\hline \hline 1 & 149.353224965 & 41.5059926426 & -200.065204481 & 326.61376193 & -5388.91250029 \\
\hline 2 & 149.34000552 & 41.5210101811 & -198.064782729 & 326.61376193 & -5386.2095364 \\
\hline 3 & 149.326779938 & 41.5360262051 & -196.064356317 & 326.605000128 & -5378.97817425 \\
\hline 4 & 149.313548214 & 41.5510407131 & -194.063925248 & 326.596231663 & -5363.02735362 \\
\hline 5 & 149.300310343 & 41.5660537036 & -192.063489519 & 326.587456531 & -5336.36810313 \\
\hline 6 & 149.287066319 & 41.5810651752 & -190.063049132 & 326.578674725 & -5300.09852962 \\
\hline 7 & 149.273816136 & 41.5960751262 & -188.062604087 & 326.569886241 & -5249.45260443 \\
\hline 8 & 149.260559789 & 41.6110835552 & -186.062154384 & 326.561091074 & -5188.08489127 \\
\hline \hline 9 & 149.247297273 & 41.6260904606 & -184.061700023 & 326.552289219 & -5116.35098797 \\
\hline \hline 10 & 149.234028582 & 41.6410958411 & -182.061241004 & 326.54348067 & -5051.39489267 \\
\hline \hline 11 & 149.22075371 & 41.6560996949 & -180.060777327 & 326.534665422 & -5070.64221477 \\
\hline \hline 12 & 149.207472652 & 41.6711020207 & -178.060308993 & 326.525843469 & -5345.61405245 \\
\hline \hline 13 & 149.194185402 & 41.6861028169 & -176.059836002 & 326.517014808 & -5504.76112339 \\
\hline \hline
\end{tabular}

Sequential use of the AWK programming language has been integrated with GMT for geospatial data analysis with a case study of the KKT. Practical technical aim is to analyze and compare bathymetry in the southern and northern part of the trench using digitized cross-section profiles. The initial mapping and geospatial analysis was performed in GMT. The GMT was used for mapping based on ETOPO1 grid and automatic digitizing of the profiles crossing the trench perpendicularly.

The processed geodata were received in a numerical form as a complex multi-field table for each segment. These tables were generated by the GMT in its native format and could not be directly processed by MATLAB/Octave. Therefore, tables were exported to AWK. The table was restructured, sorted and 
reshaped by the AWK script. Tab 3.4.1 illustrates Initial table derived from the GMT for the Profile \#1, KKT. The geometric model of each profile in Tab. 3.4.1 is as follows: the trench valley corresponds to the zero value of the segment, that is the origin of the plot. Left and right parts of the segments stretch to the 200 and $-200 \mathrm{~m}$, correspondingly as shown on X axis. The direction of each profile is NW-SE, that is from the Sea of Okhotsk and Greater Kuril Chain directed to the Pacific Ocean.

The conceptual idea of the use of AWK consists in a chain of data processes by GMT, reshaped by AWK and further converted to Octave. Technical experiment aimed at the analysis of the geomorphic differences of the KKT located in the north-west Pacific Ocean (Fig. 2.1.1) through the analysis of its cross sectioning profiles. For this purpose, the profiles were automatically digitized by the GMT and then the data were converted to the AWK where the tables were reshaped. Further processing and plotting of tables was done in Octave. The geographic aim is to visualize the difference in the northern and southern parts of the trench separated by the Bussol Strait (Fig. 2.1.1).

The use of AWK was to enabled table reshaping for regional geomorphological variations in the trench in its southern and norther parts [410]. The table generated directly by GMT was not readable by Octave, therefore reshaping in AWK was applied. The experimental batch sequence of the data processing through three different tools is advantageous, because they were used sequentially for each step of the data analysis where they suit best: GMT for mapping, geospatial data analysis and generating series of profiles, AWK for reshaping complex tables, and Octave for plotting graphs of the selected profiles. The explanation of the methodology is as follows.

\subsubsection{Data pre-processing}

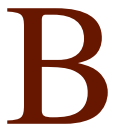

ATHYMETRIC mapping, modelling, geospatial analysis and plotting profiles by GMT modules using codes provided in Appendix. Map was visualized (Fig. 2.1.1) using ETOPO1 raster grid. Profiles were generated using GMT code. The enlarged view of the profiles is shown on Map 4.2.1 where numbering starts from $\mathrm{S}$ to $\mathrm{N}$ for both segments. Stacked profiles with a median as a red line and error bars are shown on Fig. 4.2.1. The profiles contained coordinates and depths in each point across the profile (by $2 \mathrm{~km}$ ). 62 profiles were plotted for northern and 52 profiles for the southern parts of the trench.

These data were stored as two tables in GMT format. The fragment of the initial table is shown on Tab. 3.4.1. The geological conditions associated with the studied geomorphology were analyzed using available literature on the geology of KKT. The geospatial data visualization methods included the following steps: selecting cartographic projections, choosing fonts and cartographic layout, ticks, scale bar, legend, annotations, color palettes, etc. Because the table produced by the GMT automatically during digitizing process (Tab. 3.4.1) was not compatible with GNU Octave and could not be used directly for plotting, the AWK table reshaping was then performed in the $2^{\text {nd }}$ step.

\subsubsection{Table reshaping}

$\mathrm{T}$

HE second step consisted in reshaping the tables generated automatically by GMT in previous step. These tables were reshaped using AWK programming provided in Appendix. Only necessary columns and rows were selected from the initial tables using AWK script. As a result, two tables were reshaped into the new ones, as shown on Tab. 3.4.2 (fragment) where each column contained depth values by the profiles which could be processed by Octave. Tab 3.4.2 illustrates AWK-reshaped new table containing location and depths $(\mathrm{m})$ for the first 15 rows.

The AWK part of the research followed the GMT aimed at table processing. The .csv table was run directly as a file following by a set of the temporary files (tempfiles) created to store the selected columns from the initial tables as part of a script pipeline. The AWK script (see Appendix) was used for reshaping 
initial table (Tab. 3.4.1) that was received directly from the GMT as a result of the automatically digitized profiles.

Table 3.4.2: AWK-based reshaped table (fragment): location and depths (m) for the first 10 profiles

\begin{tabular}{lllllllllll}
\hline \hline location & profile1 & profile2 & profile3 & profile4 & profile5 & profile6 & profile7 & profile8 & profile9 & profile10 \\
\hline \hline$-200,07$ & $-5388,91$ & $-5066,99$ & $-5096,23$ & -5007 & $-5095,57$ & $-5089,61$ & $-5111,86$ & $-5105,17$ & $-5230,93$ & $-5387,38$ \\
\hline \hline$-198,06$ & $-5386,21$ & $-5056,08$ & $-5087,92$ & $-4990,77$ & $-5111,1$ & $-5113,8$ & $-5126,26$ & $-5116,11$ & $-5242,93$ & $-5395,11$ \\
\hline \hline$-196,06$ & $-5378,98$ & $-5056,92$ & $-5076,23$ & $-4991,77$ & $-5127,27$ & $-5143,67$ & $-5136,49$ & $-5127,79$ & $-5263,13$ & $-5400,87$ \\
\hline \hline$-194,06$ & $-5363,03$ & $-5068,51$ & $-5063,31$ & $-4998,02$ & -5125 & $-5174,22$ & $-5137,67$ & $-5145,92$ & $-5286,53$ & $-5405,93$ \\
\hline$-192,06$ & $-5336,37$ & $-5084,85$ & $-5052,82$ & $-5000,48$ & $-5102,27$ & $-5197,73$ & $-5131,9$ & -5174 & $-5300,04$ & $-5412,8$ \\
\hline$-190,06$ & $-5300,1$ & $-5099,18$ & $-5047,83$ & $-5001,55$ & $-5077,16$ & $-5207,11$ & $-5117,67$ & $-5204,43$ & $-5304,92$ & $-5417,57$ \\
\hline$-188,06$ & $-5249,45$ & $-5109,15$ & $-5047,52$ & $-5005,99$ & $-5057,1$ & $-5203,18$ & $-5092,88$ & $-5222,58$ & $-5303,37$ & $-5410,98$ \\
\hline \hline$-186,06$ & $-5188,08$ & $-5114,52$ & $-5049,58$ & $-5008,41$ & $-5041,25$ & $-5189,31$ & $-5067,21$ & $-5232,12$ & $-5295,12$ & $-5394,34$ \\
\hline \hline$-184,06$ & $-5116,35$ & $-5117,15$ & $-5039,51$ & $-5017,05$ & $-5031,61$ & $-5169,68$ & $-5049,59$ & $-5232,31$ & $-5281,9$ & $-5380,4$ \\
\hline$-182,06$ & $-5051,39$ & $-5123,59$ & $-5024,97$ & $-5029,04$ & $-5029,31$ & $-5146,61$ & $-5043,71$ & $-5220,18$ & $-5265,19$ & -5367 \\
\hline$-180,06$ & $-5070,64$ & $-5133,68$ & $-5020,5$ & $-5038,68$ & $-5034,43$ & $-5125,47$ & $-5044,13$ & $-5190,62$ & $-5245,44$ & $-5364,2$ \\
\hline \hline$-178,06$ & $-5345,61$ & $-5147,98$ & $-5028,46$ & $-5045,35$ & $-5040,97$ & $-5109,78$ & $-5043,65$ & $-5147,64$ & $-5224,38$ & $-5350,02$ \\
\hline \hline$-176,06$ & $-5504,76$ & $-5156,31$ & $-5042,72$ & $-5048,1$ & $-5047,01$ & -5102 & $-5033,99$ & $-5108,91$ & $-5201,76$ & $-5320,17$ \\
\hline \hline$-174,06$ & $-5511,42$ & $-5150,97$ & $-5057,82$ & $-5048,89$ & $-5051,76$ & $-5108,89$ & $-5018,05$ & $-5082,59$ & $-5179,36$ & $-5282,81$ \\
\hline \hline$-172,06$ & $-5475,67$ & $-5137,74$ & $-5073,48$ & $-5057,95$ & $-5052,26$ & $-5132,15$ & $-4991,71$ & $-5070,96$ & $-5155,37$ & $-5246,77$ \\
\hline \hline
\end{tabular}

This table was then reshaped by AWK into the second table (Tab. 3.4.2) that now had structured view with columns containing only necessary data: depths (m) and profile length (from -200 to $200 \mathrm{~m}$, according to the stretch). The main task of the reshaping was to select necessary data from the initial huge table that contained 12726 rows 5 columns. Therefore, during this procedure the unnecessary rows were removed, and only necessary columns were picked. The AWK research steps were done consequentially as explained below stepwise.

Initially, the working directory was set up to store all the files (both temporary and main ones) in this folder (cd/Users/pauline/Documents/Octave) which was then controlled by pwd check. Then the input file (table2.csv) was read in into AWK environment in units (records) processed by the embedded syntax rules of the AWK one record at a time line by line [143]. Each record was automatically split into peaces, that is fields of the table making it more convenient for AWK to work on the parts of a table [631].

1. At the first step the series of the temporary files was created where all the preliminary results were stored using Unix: mktemp utility. Several kinds of tasks occurred repeatedly when working with table file received from the GMT: extracting one by one columns from the initial file and then storing them as separate files. Therefore, certain lines were extracted from the table and the rest was discarded at this step.

2. The initial GMT tables for two segments of the profiles contained 62 and 52 profiles for northern and southern parts, respectively. Therefore, at this step only two necessary columns were selected using AWK predefined variable FS (field separator) as space. That means, in both input and output data (output field separator as OFS) the items were separated by single spaces.

3. Now only profile 1 was selected and save as a separate table with $\mathrm{X}$ and $\mathrm{Y}$ (location and depths). 
4. Only Y column (field 5) was taken from the initial table. This column contained depths for all profiles, for example for the northern segment these are 12726 rows.

5. The profile I was selected consequentially from the Y column. This is done using command printing section of file between two regular expressions (regex). Patterns in awk control the execution of rules when its pattern matches the current input record. This tables now contained information for the depths in all points along the profile nr. 7. Then the same procedure was repeated for all other profiles. The regular expression that matches the text of the table ('/-L0-07/,/-L0-08/') is put between the slash lines, like this: /regular expression/. Consequently, this pattern was repeated for the northern segment for the profiles of i number: 1, 7, 14, 21, 28, 35, 42, 49, 56, 62. The output data are stored as tables.

6. At this step the single Y column of the profile i was added to the table. Then, the output was saved to table. Making these modifications in the table was done using patterns (see AWK script), but leaving the rest of the table file alone. The same procedure was repeated for the southern segment using the same regular expression as a template.

7. Now the header and tail were deleted from the output table using the AWK expression that prints only lines which do not match regex.

8. The auxiliary files were removed by the rm.

9. The number of lines was counted for initial table. In this case initial table had 12726 lines.

10. Finally, the number of lines was counted for the output table. In this case the final table had only 201 lines (against previous 12726).

As can be noticed, the presented AWK script consists of expressions that are the basic building blocks of AWK patterns and actions. An expression performed in each step of the script evaluates to a value that was printed and consequentially passed to the next expression at the following step in the script. For the case of the temporary files (Step-5), a series of expressions assigned a new value to the table variables using an assignment operator. AWK expressions extensively used in the script served as a pattern for the selected geomorphological profiles along the whole length of the trench, thus facilitating the repeatability of the research steps.

Final output table was reshaped in view, that is columns became rows. Azimuth and absolute coordinates were deleted from the table. As a result, the output table contained 201 rows and 11 columns and initial long table has been reshaped. The new structure of the table is as follows: column 1 contains cross-section line $400 \mathrm{~km}$ long (-200:200 km). Columns 2-11 contains depths for the cross-section profiles. Unix programs and utilities used additionally included: mktemp for creating a series of temporary files and $\mathrm{rm}$ for removing preliminary temporary files. The final table was then processed in GNU Octave language for the visualization of the cross-section profiles. 


\subsection{Octave/MATLAB}

\subsubsection{Advantages of Octave}

GNU Octave is an open source high-level interactive language, designed for numerical computations by J. B. Rawlings and J. G. Ekerdt. It is compatible with Matlab and is suitable for a variety of scientific tasks: linear and nonlinear equations, numerical linear algebra, statistical analysis, numerical experiments [150]. A significant well-known advantage of the Octave consists in its compatibility with Matlab: although there are some minor differences in their syntax, GNU's Not Unix (GNU) Octave is known as a free open-source analogue of the commercial licensed Matlab which is widely used in both academia and industry by thousands researchers and engineers worldwide.

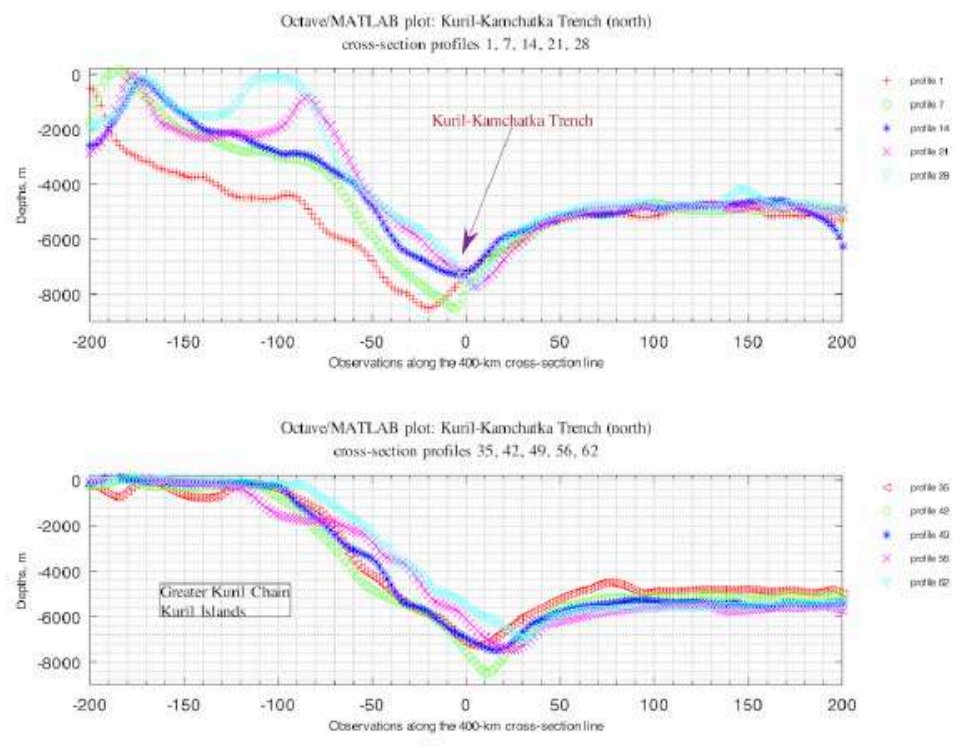

Figure 3.5.1: Kuril-Kamchatka Trench: Octave graph based on AWK-reshaped table, north [410]

Therefore, Octave scripts may be converted to the Matlab environment using the syntax and power of Matlab. Technically, as Matlab, GNU Octave has various built-in functions, operates with arrays, vectors, strings, booleans, scalars and matrices, enables plotting of the high-quality graphics, performs mathematical computations, operates with variables and different data types, as demonstrated further in this paper (Appendix: GNU Octave codes). The Octave was used in this work for plotting several geomorphological profiles.

The experimental novelty of using Octave is integration of this typically statistical tool with geospatial mapping in GMT via AWK. Combined together for the geospatial data analysis, these tools enabled to model submarine geomorphology of the KKT. Therefore, the main goal is to develop technical methodology for the batch processing of the geospatial data by the smooth stepwise GMT-AWK-Octave workflow chain. This technical workflow also supported geomorphic studies helping to visualize and better understand structure of the trench. Usually, similar research is maintained in the GIS, but applying advanced data processing scripting tools facilitates research through the automatization. Automatically digitized transect profiles are precise, finely plotted and statistically correct comparing to the hand-made vector drawing using GIS (e.g. ArcGIS, MapInfo, or QGIS). 


\subsubsection{Data processing}

$\mathrm{B}$

ECAUSE the total amount of the KKT profiles overstepped 100 (62 and 52 for the northern and southern trench segments), only selected profiles were visualized. For this purpose, the modified tables were converted to GNU Octave language for visualizing and plotting selected profiles, as further described in this section. Finally, the geomorphology was analyzed and two segments compared.
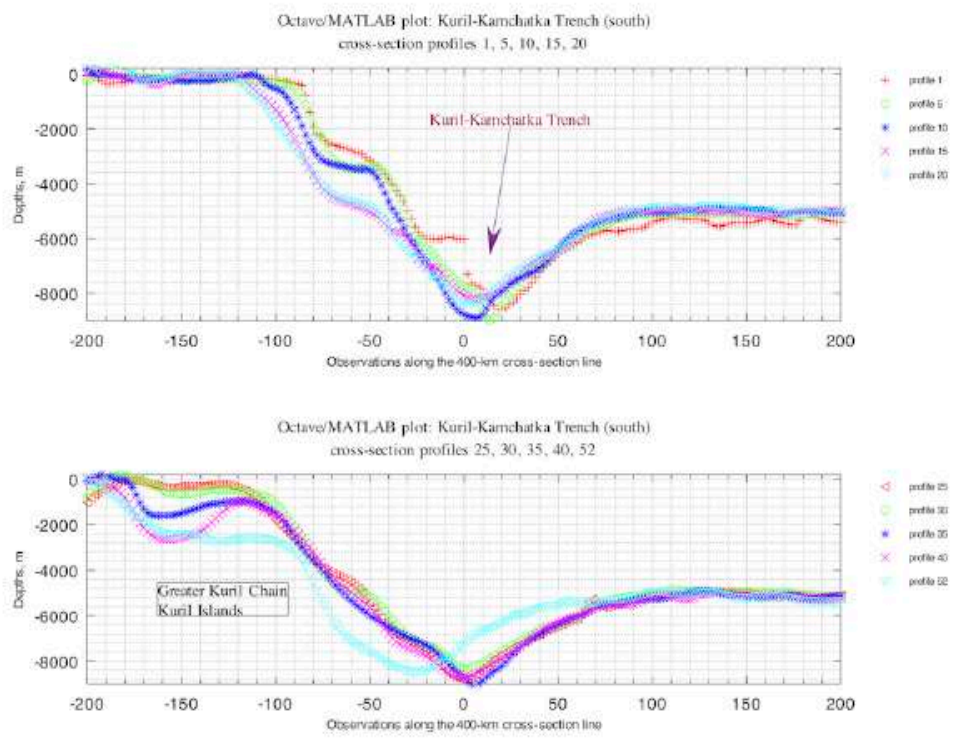

Figure 3.5.2: Kuril-Kamchatka Trench: Octave graph based on AWK-reshaped table, south [410]

Plotting graphs of the selected profiles by the GNU Octave was based on the code provided in Appendix. After the table was converted to the necessary format through AWK manipulations, it was then processed by the GNU Octave scripting and two graphs showing northern and southern segments of the trench were plotted (Fig. 3.5.1 and Fig. 3.5.2) by Octave scripts. The GNU Octave scripting was used for visualizing and plotting graph and geomorphological analysis for the selected profiles.

Trench segments were visualized on graphs (Fig. 3.5.1 and Fig. 3.5.2) plotted based on the tables reshaped by AWK in the previous step. The profiles were selected taking into account qualitative and quantitative assessment of data. Quantitative comparability consists in the repeatability of the sampling intervals: every $7^{\text {th }}$ profile in the $\mathrm{N}$ segment and every $5^{\text {th }}$ profile in the $\mathrm{S}$ segment until profile 40 and profile 52. Qualitative selection was based on the analysis of the bathymetric shapes: similar profiles were removed to avoid repeatability and only varying profiles were compared.

Visualization of the selected graphs of the geomorphology was done by plotting using available technical documentation [518]. Fig. 3.5.1 and Fig. 3.5.2 show selected graphs of the profiles made on basis of the table reshaped by AWK and visualized in GNU Octave using script of m-file, example of $\mathrm{N}$ segment. S segment was repeated using the same script template in corresponding table and necessary minor amendments (numbers of profiles, depths for the $\mathrm{S}$ segment).

\subsubsection{Data analysis}

ING Octave, a comparative analysis of the geomorphology in selected profiles crossing the KKT was performed visualizing the V shape of the KKT which can be notice in a series of the cross-section profiles (Fig. 4 and 5). The Octave graphs (Fig. 4 and Fig. 5) highlighted 
geomorphic patterns in northern and southern parts of the trench visualizing variations in depths and geomorphic shapes. Southern part of the trench proved to have deeper bathymetric ranges and steeper trench gradient slope which is caused by the intensive seismicity and volcanic activities in this particular area of the trench.

The series of the SW-NE-aligned orthogonal bathymetric profiles (Fig. 2) show gradual changes in the geomorphology of the KKT along the islands from the Greater Kuril Chain northwards from the Bussol Strait: Simushir, Ketoi, Ushishir, Rasshua, Matua, until it finally approaches the north-eastern end of the Sea of Okhotsk and Bering Sea. GMT/AWK/Octave sequential data processing, automatic digitizing of the orthogonal profiles and graphical plotting based on various algorithms of the data analysis have been tested as an experimental design of this research, aimed to visualize two morphological patterns along the southern and northern segment flanks of the KKT.

Trench migration rates are also mainly controlled by the lower continental tectonic plate velocity [350], which in turn depends on the tectonic slab age buoyancy [92]. More detailed study on the tectonic impact goes beyond the scope and size of this manuscript which aims at development of the technical methodology of the batch geodata processing by GMT, AWK and Octave as a chain methodological workflow. As a suggestion for further studies on this phenomena, a comparative analysis of the subduction speed of the tectonic plates in northern and southern parts of the trench could be performed in a separate research based on the availability of the precise geophysical and seismic data.

Combination of various data analysis tools, such as GMT scripting toolset, AWK and Octave programming languages for sorting and reshaping data, plotting graphs and mapping enabled to create geospatial analysis of the selected specific areas of the Pacific Ocean: the KKT. Successful application of the programming languages and advanced statistical tools towards geospatial data analysis has been demonstrated in various papers: Python [770], [424], Fortran language [4], [94], R language [633], [434], [429], [422]. However, only few examples were given so far specifically for AWK language and its application is traditionally limited by the IT domains [603], [726]. Current work contributes to filling the gap in the need for using such effective language as AWK [492] in the geological and Earth sciences and absence of the practical examples and full codes that are always useful besides technical manuals.

Understanding complex interrelation and spatial variation of the geological and geophysical factors affecting the KKT is crucial to analysis of its geomorphic patterns. Various factors contribute to the trench geomorphology and shape: motion of the Pacific plate subduction to the adjacent small Okhotsk plate, seismicity and location of the earthquakes. Special geophysical settings, geological parameters and special sedimentation processes induced by active volcanism and seismicity in the region are among the crucial factors affecting trench geomorphology. Geological settings of the Kamchatka region in general are notable for the mountains chains in the adjacent land, recorded active seismicity and magmatism, steep gradients of the mountains Hokkaido and Sakhalin islands, and Kamchatka Peninsula, as well as frequent earthquakes and erodible lithology. Necessarily, these factors contribute towards the active sedimentation processes which in turn affect geomorphology of the trench. Large amounts of the sediments are being transported to the Sea of Okhotsk and then driven in SE direction from the Hokkaido and NW from the Kamchatka Peninsula to the neighboring KKT. 


\subsection{Quantum GIS}

$\mathrm{Q}$

GIS part of this project was performed in version 3.6.1 Noosa. Submarine geomorphology was studied through the spatial and statistical analysis of the cross-section profiles digitized across the trenches. QGIS data processing included various aspects of the data processing: data search from the web resources, data storage in QGIS platform, digitizing and geospatial processing using GIS plugins, geospatial analysis, data capture and export to the csv tables, transfer data sets to R and Python libraries, statistical processing, modelling and visualizing graphical plots.
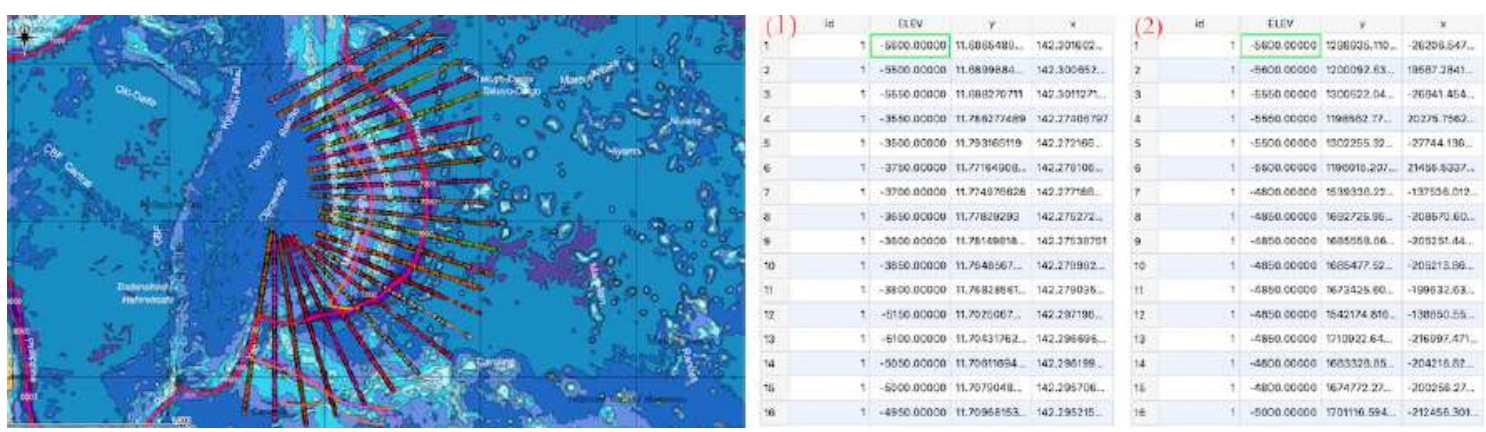

Map 3.6.1: Mariana Trench: map of the profiles and fragment of the coordinates

The QGIS plugins splits several complex tasks into smaller and more manageable components: reading coordinates, crossing profile lines. The GIS digitizing workflow are illustrated on the Fig. 3.6.2. The fragment of the map and coordinates are shown on Fig. 3.6.1: map of the digitized profiles (left) and coordinates for the selected profile (Nr. 21), Table (right): (1) fragment in geographic coordinate system European Petroleum Survey Group (EPSG) Geodetic Parameter Dataset: EPSG 4326 WGS84. (2), right: fragment in Cartesian coordinate system, re-projected The QGIS methodology includes following steps:

- Geospatial data were collected as thematic layers and uploaded to GIS project including their attributes and coordinate system parameters: bathymetry, geology, topography, tectonics, sediment thickness, slope angle, aspect class, igneous volcanic zones, ophiolites, etc.

- A QGIS project has been projected into the Universal Transverse Mercator coordinate system (UTM) cartesian coordinate system (square N-55).

- 25 cross-section bathymetric profiles were drawn manually across the trench by 'Add Line Feature / Digitizing Toolbar'. Each profile has a length of $1000 \mathrm{~km}$ and a distance between each 2 is 100 $\mathrm{km}$. The profiles geometry was digitized along the trenches, attributes (profiles names, coordinates) entered (Fig. 3.6.1)

- The line has been copied and re-entered for the next 24 profiles.

- Numbering of the profiles goes consequently from the north to the south, from 1 to 25 .

- Intersections between the lines and bathymetry was done by 'Vector / Analysis Tools / Lines Intersection'. This resulted in the array of the points along each profile. Each point has depth value and a reference number.

- Each profile contained 518 observation sample points, XY coordinates, elevation depth data and thematic geological data (e.g. thickness of the sediment layer) stored in an attribute table. The total data intakes consisted in pool of 12.590 points. 
- 'Lat Lon Tools' plugin adding projected coordinated was installed to activate QGIS option of adding XY values to the Spreadsheet.

- Lat/lon coordinates were added to the attribute table of each intersection line by Lat Lon Tools plugin. This plugin was selected as external map support, point digitizing tool to capture and zoom to profiles coordinates. Attribute tables contained data in various segments.

- The coordinates were added to attribute tables of each corresponding profile using plugin function Lat Lon Tools / Conversion / Point layer to fields. The initial 25 layer's latitude, longitude (Y, X) were added and copied into the text fields in the new layers.

- The topography of the 25 cross-section profiles (Fig. 4.12.1) was plotted using ProfileFromPoints plugin of QGIS. The topography data were plotted along a centerline of the cross-section profiles by elevation $\mathrm{Z}$ (depth). The resulting profiles are shown on Fig. 3.6.2.

- The attribute information has been derived from each profile and stored in a table containing coordinates, depths and thematic information.

- The tables were exported from QGIS (Export / Save Features As) into csv format for each of the 25 profiles, respectively. The csv data were read into $\mathrm{R}$ and Python for statistical analysis using Pandas and NumPy libraries.

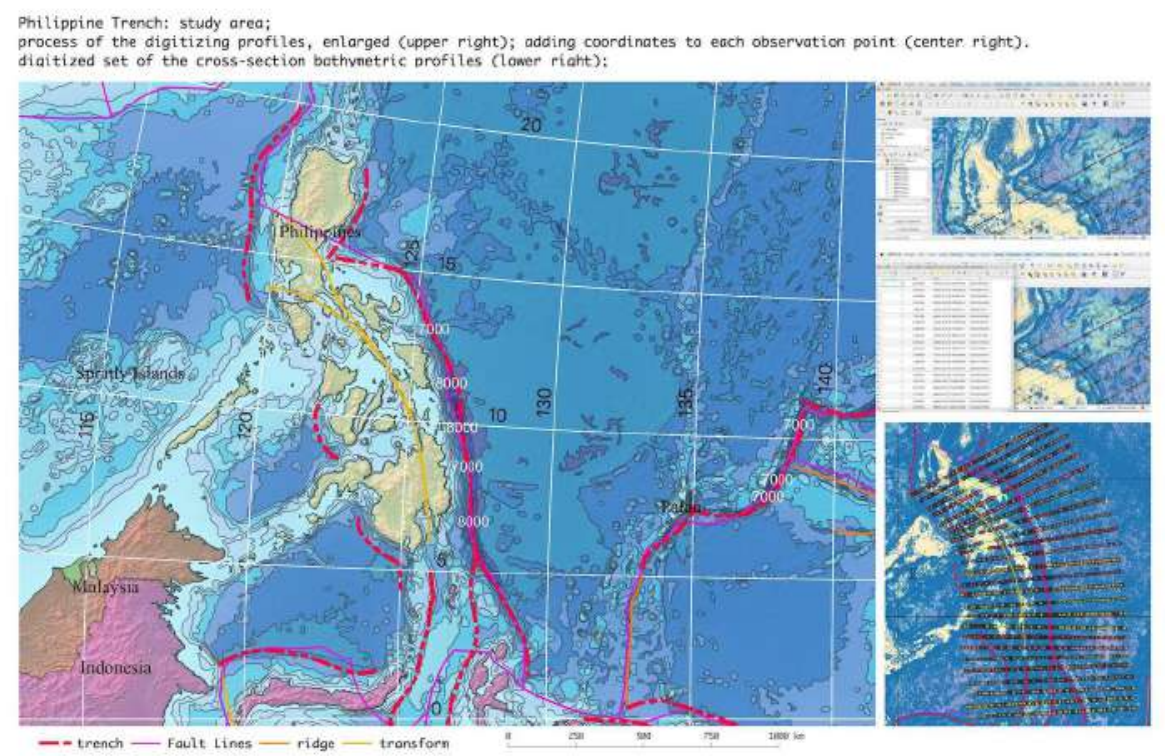

Map 3.6.2: Philippine Trench: map and digitized cross-section profiles. QGIS

Cross-sectionig transects (Fig. 4.12.1) were digitized in QGIS and their coordinates and attribute values collected as a csv table. A GIS methodology consists in a stepwise illustration of the creating a series of 25 bathymetric profiles, Mariana Trench by digitizing routing of the profiles. Using queries of the QGIS, the data on geology of the underlying surface was retrieved: local geomorphic conditions, variation in the lithology and sedimentation transport processes. Geology and tectonics as attributes were used to analyze their effects on variations in trench geomorphology. Prior to statistical analyses, the bathymetry of the cross-sections on the joint facetted plot was visually inspected (Fig. 4.12.1). 


\subsection{Statistical Algorithms}

HE methodology of the current research includes a range of the mathematical algorithms designed for statistical analysis [609]. The functionality of these methods has been tested using statistical libraries of the scripting languages R, Python, Octave and GMT. The statistical methods includes various types summarized in a Table 3.7.1. Various statistical methods were developed for application at geospatial research [733]; [585]; [632]. Existing powerful technologies provided by R, Python and Matlab/Octave enable to perform precise computations and statistical analysis of the geodata and to create data frames.

Table 3.7.1: Types of the statistical analysis used by Python and R libraries

\begin{tabular}{|c|c|c|}
\hline \multicolumn{2}{|c|}{\begin{tabular}{l|l} 
No & Type
\end{tabular}} & \multirow{2}{*}{$\begin{array}{l}\text { Example } \\
\text { Clustering (k-means method), hierarchical clustering, dendrogram } \\
\text { trees, clustermaps with marginal dendrograms }\end{array}$} \\
\hline 1 & $\begin{array}{l}\text { Data grouping \& parti- } \\
\text { tion }\end{array}$ & \\
\hline 2 & Correlation analysis & $\begin{array}{l}\text { Covariance scatterplot matrices; Correlation ellipses; Pearson, Spear- } \\
\text { man, Kendall correlograms, 3D correlation plots }\end{array}$ \\
\hline \multirow[t]{2}{*}{3} & Regression analysis & $\begin{array}{l}\text { Linear regression; Locally Estimated Scatterplot Smoothing } \\
\text { (LOESS) }\end{array}$ \\
\hline & Data distribution & $\begin{array}{l}\text { Boxplots; QQ, Violin/Letter-value plots; KDE for analysis of the } \\
\text { probability of data distribution }\end{array}$ \\
\hline 5 & Exploratory analysis & Ranking dot plots with areas; PCA; EFA; ANOVA \\
\hline 6 & Quantitative variables & $\begin{array}{l}\text { Pairwise double Y-axis plots; Ridgeline plots, Dumbbell charts, Di- } \\
\text { verging bars }\end{array}$ \\
\hline 7 & Data sorting & Circular Bar plots, Stemplots; Radar charts \\
\hline$\varepsilon$ & Set theory & Euler-Venn diagrams; Conceptual analysis Mindmaps, Word clouds \\
\hline s & Compositional charts & Categorywise bar charts; 'Waffle' charts \\
\hline 10 & Descriptive statistics & $\begin{array}{l}\text { Histograms, Heatmaps; line plots, circular pie charts, area charts, } \\
\text { strip plots, hexagonal plots, facet grids, stacked area charts for data } \\
\text { range across trench segments; stacked bar plots for data distribution } \\
\text { by tectonic plates; stacked bar charts; }\end{array}$ \\
\hline 11 & Qualitative variables & Mosaic plots; Silhouette plots; Hierarchical edge plots \\
\hline
\end{tabular}

The ML and data mining for the marine geological research is nowadays one of the most important technical approaches. Using programming based ML algorithms ensure the precision, effectiveness and objectiveness of the big data set processing, which is always the case for marine geological research. This enables to process big data dividing them into compatible data sets for statistical analysis. Thus, one can select attribute tables specifically for magmatism of the nearby areas to analyze the possibilities of the earthquakes, or to focus on the bathymetric properties and distribution of various depth values across the selected profiles. Statistical analysis of the geospatial data by histograms, KDE Plots, boxplots, regression analysis and other statistical methods has been presented by Python. Tab. 3.8.1 illustrates a summary of the approaches of the statistical analysis used in current dissertation. 


\subsection{R language for marine geology}

$\mathrm{R}$ programming language is especially attractive to the geologists for the scientific computing due to its logical and straightforward syntax and multi-functional standard libraries [380]. Using R statistical libraries, the unevenness of various factors affecting trench geomorphic structure has been studied. These include such factors as sediment thickness, slope steepness, angle aspect, depth at the basement and magmatism of the nearby areas. Methods includes following major R libraries: \{ggplot 2$\}$ for regression analysis, Kernel density curves, compositional charts; \{ggalt $\}$ for Dumbbell charts for data comparison by tectonic plates, ranking dot plots for correlation analysis; $\{\mathrm{vcd}\}$ for mosaic plots, silhouette plots for compositional similarities among the bathymetric profiles, association plots; $\{$ car $\}$ for ANOVA.

Table 3.8.1: Algorithms of the descriptive statistical analysis

\begin{tabular}{r|lll} 
No & Type & Method & Method \\
\hline \hline 1 & Variables Relationship & Ternary diagrams & Link \\
\hline 2 & Advanced methods & ANOVA Hypothesis testing & SARIMA \\
\hline 3 & Dataset dimension & EFA & PCA \\
\hline 4 & Advanced methods & Association plots & Level plots, Hexagonal binning \\
\hline \hline
\end{tabular}

Methodological scheme of the statistical analysis of the bathymetric profiles includes four general steps of the statistical analysis of the submarine geomorphology. The geospatial analysis aims to extract a more regular impact factors of the geologic morphology development, whereas cluster analysis and correlation matrices extracts groups and classes from a total cloud of observation points. Statistical analysis performed by means of R scripting [65] is composed of separate written codes and algorithm for data processing. $\mathrm{R}$ codes presented below call for various statistical formulae and algorithms used by the ML for data processing.

\subsubsection{Analysis of bathymetric data distribution}

The data distribution for the bathymetric profiles has been computed using various existing methods of the statistical analysis [702] of R, e.g.: plotting historgrams using standard libraries or \{ggpubr\} library for plotting common legend, QQ facetted wrap script for cowplot with labels, 3D scatterplot, hierarchical network by \{igraph\} library, animated approach to run animated sequence for 25 bathymetric profiles showing regression analysis, Mariana Trench, hierarchical network of the environmental factors affecting trench by libraries \{ggraph and \{igraph\}. Methodological approach of the assessment of data distribution may change depending on the structure and size of the data frame. However, the most essential statistical analysis in analysis of the marine geological data start by question of data distribution. Computing and plotting Kernel distribution curves, boxplots, regression lines (probability of bathymetric data across profiles), quantile statistics, empirical distribution density function and other methods can be distinguished as the most useful for data processing.

\subsubsection{Box plots}

The boxplot of depths distribution show summary statistics: range and quartiles of the observation points across the cross-section profiles. A boxplot (Fig. 3.8.1) graphically displays frequencies of the bathymetric observations data set of the 25 profiles of MT. It plots frequency, or count, on the depth on yaxis (vertical) and measured variable (number of profile) on the $\mathrm{x}$-axis. The boxplot was generated by the default R library (stat) graphically representing five most important descriptive values for a bathymetric data set: A.6.2. These values include the following bathymetric values: minimum value, the $1^{\text {st }}$ quartile 
(0.25), the median, the $3^{\text {rd }}$ quartile (0.75), and the maximum value (absolute depth). When graphing this five-number summary, only horizontal axis displays values, while vertical line is placed above each of the summary numbers showing depth values. A box is drawn around the middle three lines $\left(1^{\text {st }}\right.$ quartile, median, and $3^{\text {rd }}$ quartile) and 2 lines are drawn from the boxs edges to the 2 endpoints (minimum and maximum depths values) using R code: A.6.2

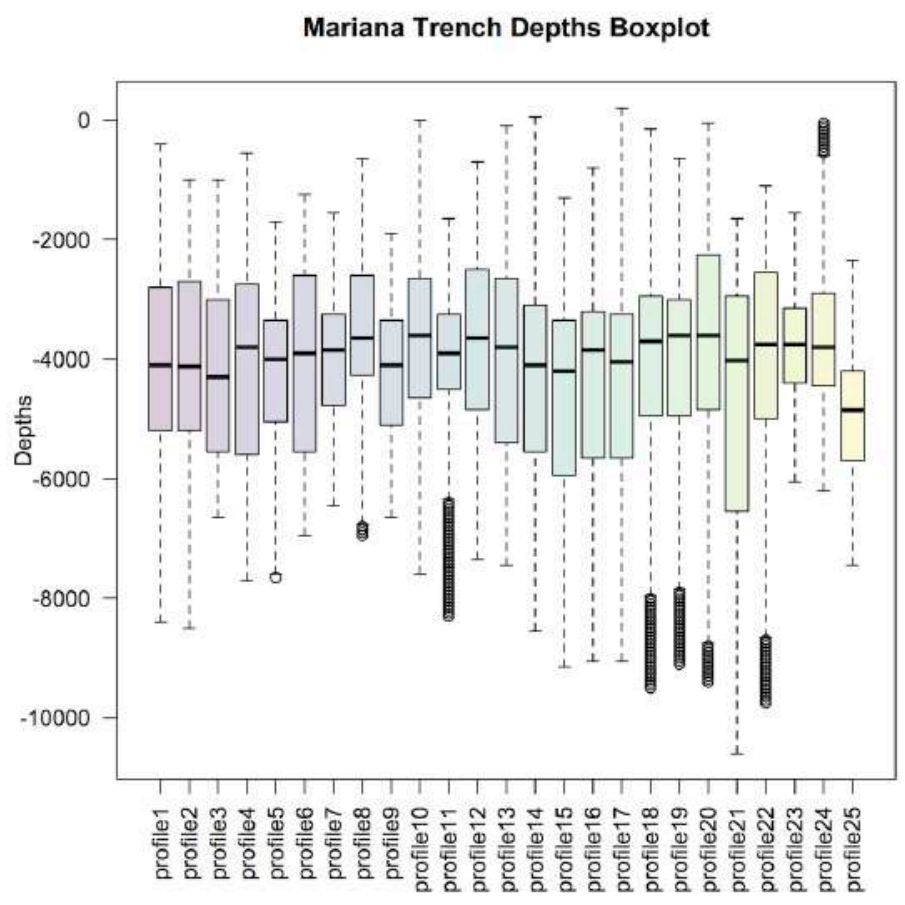

Figure 3.8.1: Mariana Trench: boxplots on data distribution by profiles. R code: A.6.2

\subsubsection{Histograms}

The histogram plots (Fig. 4) [422] show normal distribution of the depth observation data by the cross-section profiles, their outliers, skewness, median, mean, average, maximal, minimal and quartile distribution values. For each of 25 bathymetric profile various colors are taken for the following statistical data of depth values along the profile: black curves stands for normal distribution, blue curves for density distribution. Vertical dashed lines: purple median values, green mean values. The histograms was drawn by $\mathrm{R}$ library \{ggplot 2$\}$. On the $1^{\text {st }}$ step a single histogram for each of 25 profiles was created. The full $\mathrm{R}$ script to create one histogram is as follows (here: for the profile Nr. 1, further applied for every one from 25 profiles by changing the name of the file from 01 to 02 , and so on to 25). Using this script further 25 profiles were created, consequently, p01, p02, .. p25. The combination of histograms of the 25 profiles on one layout was done using following R script: A.6.1. The histograms illustrate the frequency of the score occurrences in a continuous data set of the bathymetric depths that were divided into classes showing variation in the samples of the depths, assumptions of the underlying statistical distribution of observation points values.

\subsubsection{Violin plots}

The violin plots (Fig. A.6.25) show Kernel probability density distribution of the bathymetric observations, as multimodal distributions with multiple peaks. The \{violinplot $\}$ package was installed and 
activated prior to the current work. Kernel density distribution plot as shown on the Fig. 3.8.2 was created using library \{violinmplot $\}$ of $\mathrm{R}$ in a combined plot, which includes calculated quantiles for 0.25 and 0.75 of the data pool.

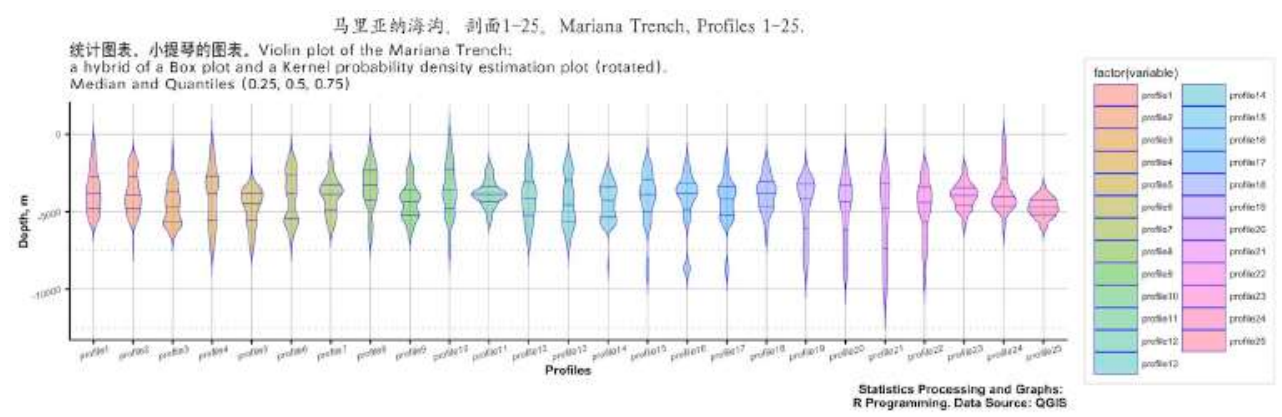

Figure 3.8.2: Mariana Trench: violin plots on depth distribution by profiles. R code: A.6.25

\subsubsection{Notched boxplots}

Another way of representing boxplots is 'notched boxplots'. These were computed and visualized in $\mathrm{R}$ using code A.6.3 aimed to show depths distribution with majority of the data from -3000 to $-5000 \mathrm{~m}$ and outliers (the deepest points) show that from profile 1 to 16 general depth increase with the deepest values at profiles 10 and 11. The notched boxplot on Fig. 3.8.3 shows the shallowest parts of the trench located on profiles 24 and 25 where MT crosses YT, near Yap Island in west Pacific Ocean, [422].

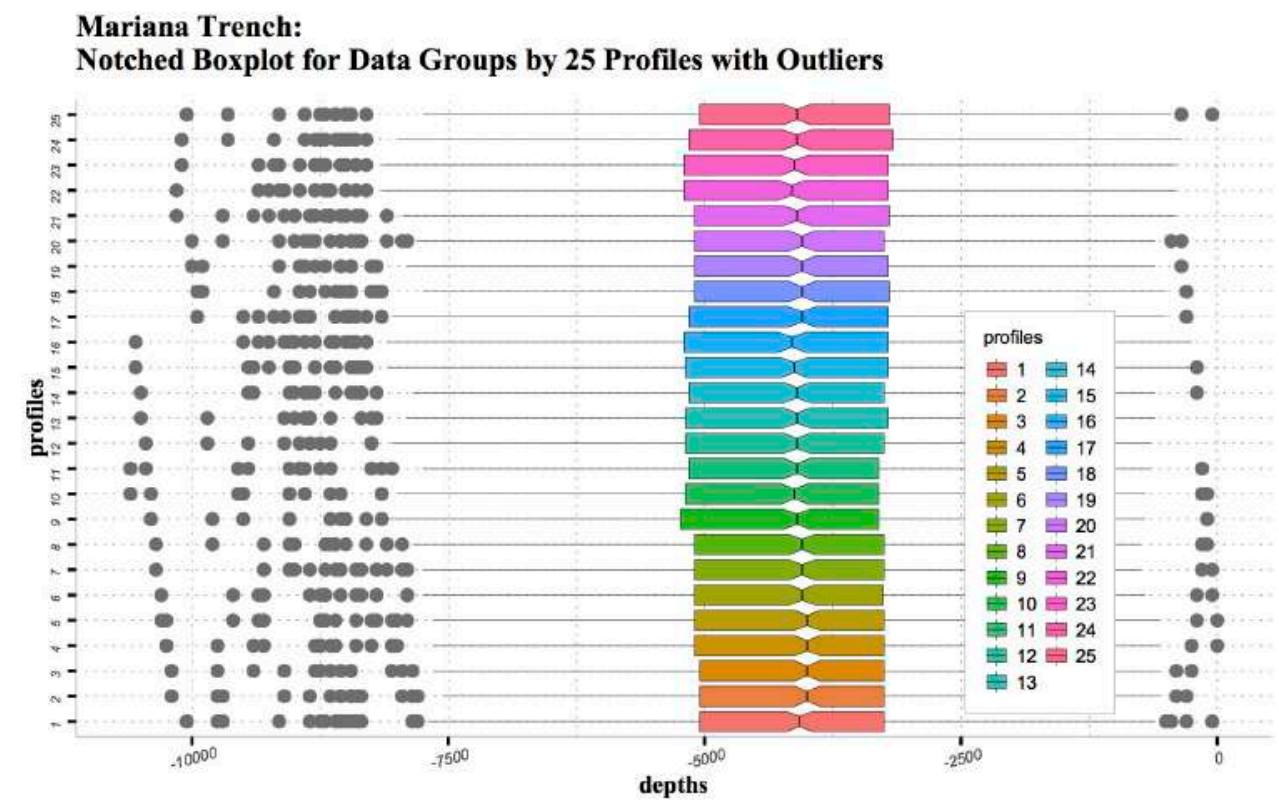

Figure 3.8.3: Mariana Trench: notched plots on depth distribution by profiles. R code: A.6.3

\subsubsection{KDE}

The KDE is a non-parametric way to estimate the probability density function of a random variable of the samples. The KDE was performed by smoothing data points across the sample points in the profiles 1:25 of the trench. The KDE can be endowed with properties such as smoothness or continuity of the 
bathymetric data by using a suitable kernel. Technically, besides \{violinplot) library, a KDE function can be implemented in R through density, $\{$ bkde $\}$ function in the $\{$ KernSmooth $\}$ library, and through $\{k d e\}$ function in the $\{k s\}$ library: Fig. 3.8.4. To use $\{k d e . R\}$ function, it is not required to install special packages. The KDE shows the majority of the depths of the trench between 3000 and $6000 \mathrm{~m}$. The graph was made as a combined plot (Fig. 3.8.4) enabling to compare overlapping and max aptitude of the density curves for the profiles and depth distribution by tectonic plates.
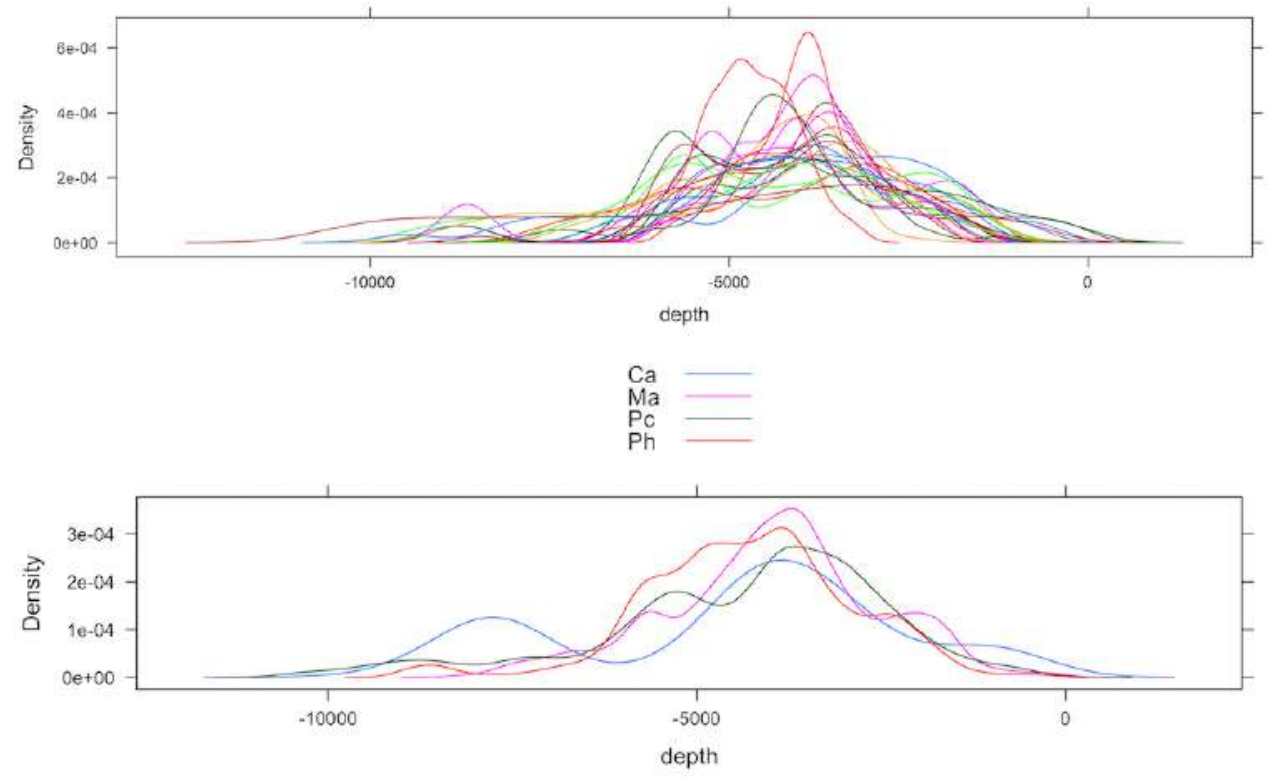

Figure 3.8.4: Mariana Trench: KDE for the 25 bathymetric profiles, R code: A.6.19

\subsubsection{Regression analysis}

Regression analysis was done to estimate the relationships between variables using existing methods [301]. The principle of the regression analysis is based on the analysis of the probability of the data values according to their actual distribution.

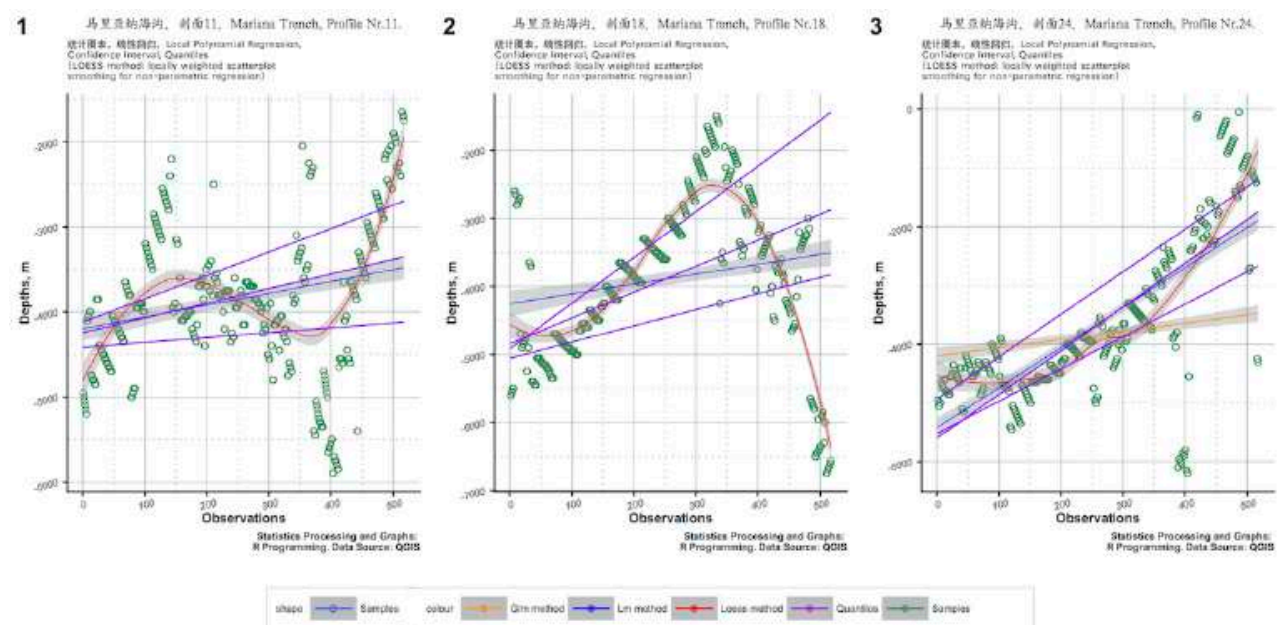

Figure 3.8.5: Example of the regression analysis: Mariana Trench, selected profiles 
A regression analysis represents outlying depths by each profile, as shown on Fig. 3.8.5, code (3 profiles) or 1 profile and facetted plot of 25 profiles.

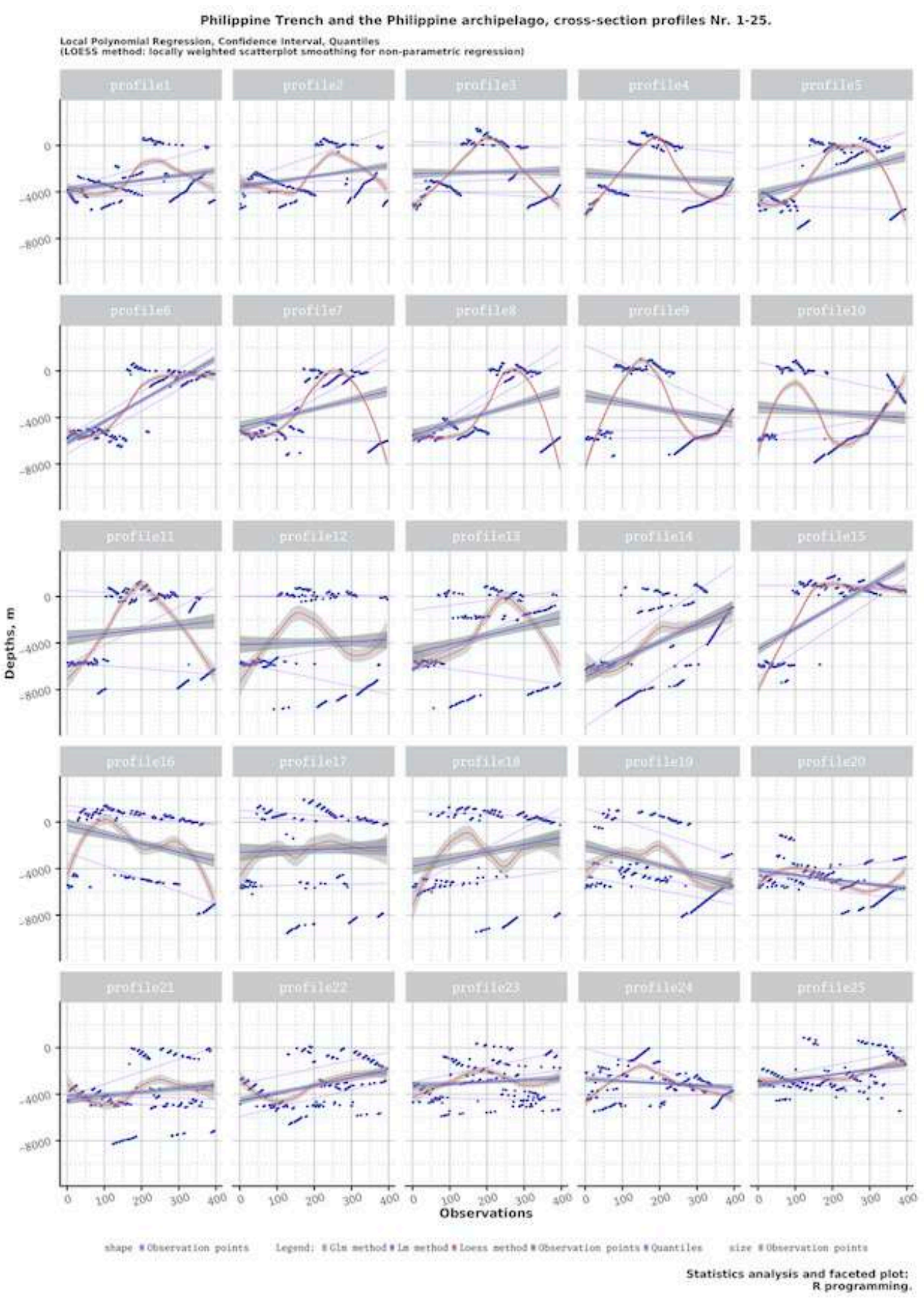

Figure 3.8.6: Philippine Trench: Regression analysis of 25 profiles. Plotting: R code A.6.5

For the assessment of the variation in the geomorphology of the trench, it is of significant advantage to visualize the data set using regression analysis (Fig.3.8.6). Regression analysis determines the range, general trend in data distribution and scale of the changes in the observed bathymetry by analyzing changes in the values of the elevation and (Fig. 3.8.6). The following $\mathrm{R}$ codes were used for the four 
methods of the regression analysis visualized on Fig. 3.8.6: A.6.5. Advantages of plotting a facetted graph consists in visualizing a stream of the data at one look. The algorithms and approaches for the regression analysis use existing methods [80]; [247]; [125] and embedded in \{ggplot\} R library.This methodology utilizes the relation between two or more quantitative depth variables so that one variable can be predicted from another. Thus, one can estimate the probability that the depth values will be located in this or that interval of values profile by profile according to the machine-based algorithm of the probability of their distribution.

Regression analysis and facetted plot wrapping for 25 bathymetric profiles were executed by R library \{ggplot2\}. Using non-parametric regression analysis the conditional expectation of the dependent variable (that is depth values) was estimated given the independent variables. The confidence interval for each of 25 profiles was done by 4 methods, visualized by the facetted plot wrapping for the series data comparison. The regression analysis reveals how typical value of the criterion variable changes are, when any of the independent variables change, while other independent variables are fixed. The Formula 3.8.3 describing regression equation describing the relationship between two variables used in this research is as follows:

$$
Y=a+b X+e(1)
$$

The literature refers [301] to three major applications of the regression analysis including general loess method ('glm), loess method ('lm') and LOESS, all of which were tested in this research. A smooth curve through a set of data points obtained with LOESS statistical technique is called a LOESS curve, Fig. 3.8.6 and 3.8.5. LOESS data smoothing is based on the mathematical assumption that a function can be approximated in a neighborhood by a low-order polynomial and simple models can be fit to data easily. LOESS uses the tri-cube weight function computed by Formula 3.8.3:

$$
w(x)=\left(a-|d|^{3}\right)^{3}
$$

The subsets of data used for each Weighted Least Squares (WLS) fit in LOESS are determined by a nearest neighbors algorithm using Savitzky-Golay filter, applied to a dataset for smoothing the data 3.8.3

$$
Y_{j}=\sum_{i=\frac{1-m}{2}}^{\frac{m-1}{2}} C_{i} y_{j+i}, \frac{m-1}{2} \leq j \leq n-\frac{m-1}{2}
$$

Where dataset includes $\mathrm{n} x_{j}, y_{j}$ points $(\mathrm{j}=1, \ldots, \mathrm{n})$, where $\mathrm{x}$ is an independent variable and $y_{j}$ is an observed value, treated with a set of $m$ convolution coefficients, $C_{i}$.

Hence, the quantiles were drawn by calling (geom-quantile) function of R 3.8.5. The Generalized Linear Models (GLM) method was used to give a symbolic description of the linear predictor of depth variability within each bathymetric profile, and a description of the error distribution in a range of the depth observation points. Example of statistical quantile-quantile (QQ) plot for the 25 cross-sectioning profiles is given on Fig. 3 in [426]. Quantiles graphically depict groups of the depth values through their distribution mode, according to the methods of the descriptive statistics.

The spacings between the different parts of the box indicate the degree of the dispersion, i.e. spread, skewness in the bathymetric data, and show outliers. The data outside the upper and lower quartiles are the outliers that are plotted as individual points. The outliers are the non-usual values of the depths indicating specific features of the geomorphology with extra deep values. The histograms show probability of the density distribution of the bathymetric observation by the profiles, i.e. how likely is that the data will belong to this or that part of the group values within certain depth range. 


\subsubsection{Comparative geospatial analysis by tectonic plates}

Mariana Trench is located in the collision of four tectonic plates: Mariana, Philippine Sea, Pacific and Caroline. Therefore, a comparative analysis of multidimensional data was performed to analyze inter-relationships between the geographic location of the specific parts of the trench and factors that may impact changes in the geomorphic systems. Using existing methodology [73], various dependences between the impact factors were tested: Fig. 7 in [422].

First, the distribution of various environmental factors affecting the morphology of the trench were analyzed: slope angle, sediment thickness, depth and closeness of the igneous volcanic zones to the selected bathymetric profiles.

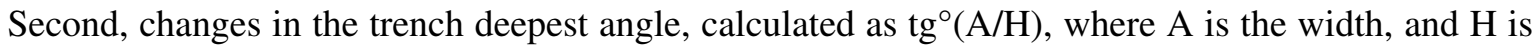
the maximal depth of the profile, were calculated for each of the 25 bathymetric profiles and compared, respectively.

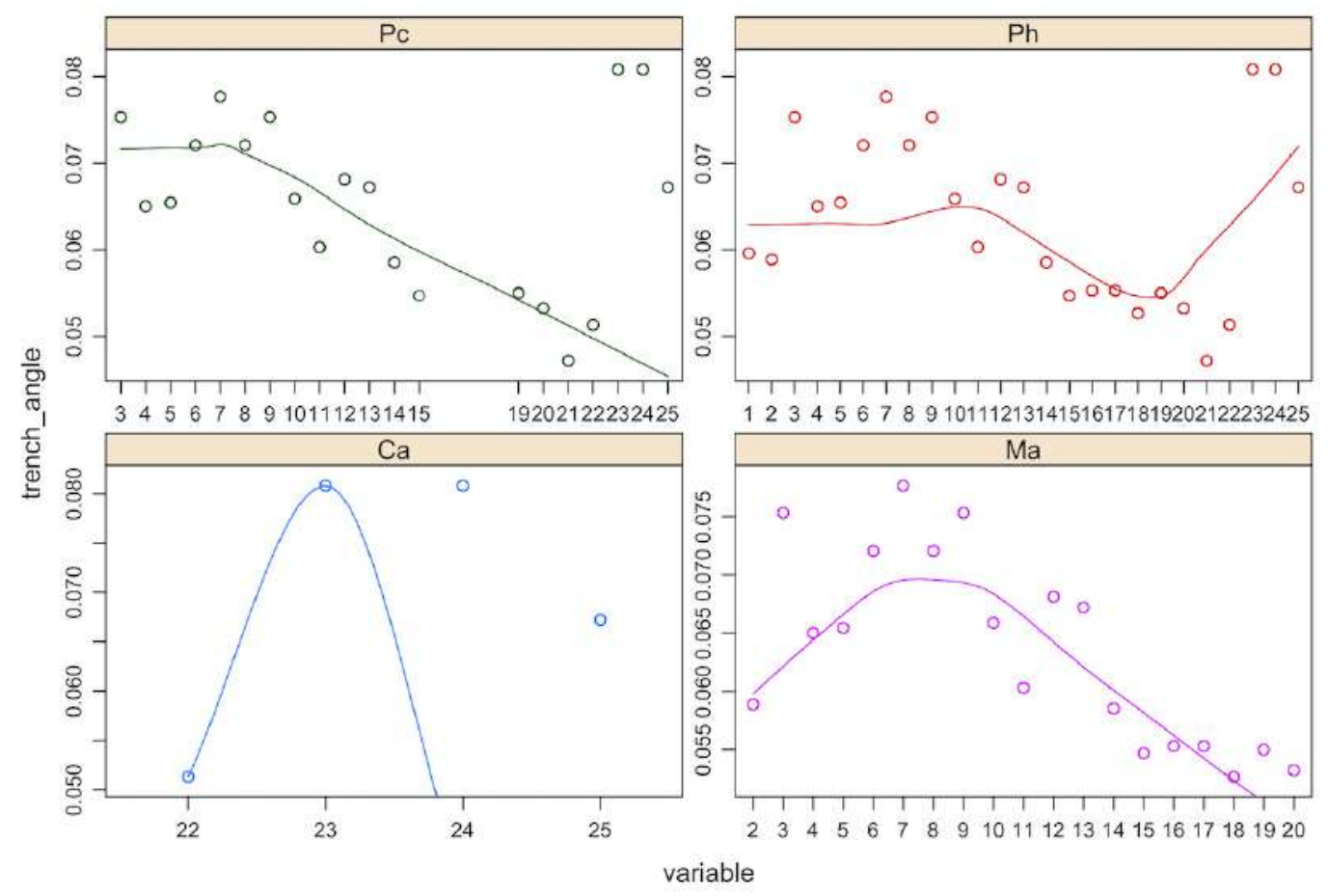

Figure 3.8.7: Four tectonic plates, trench slope angle in the deepest point

Third, the depth distribution by four tectonics plates was visualized using multiple scatter function of R. A pairwise correlation of the environmental factors was performed by the scripting approach of $\mathrm{R}$, which is convenient not only for looping over parts of the geomorphic model of the Mariana Trench, but also for pairwise iterating over bathymetric and geomorphic variables for the comparative analysis. Called functions 'geom-smooth', 'geom-point' and 'geom-quantile' were used to draw smoothed conditional means and to perform regression analysis. The multiple panel strip plots were generated in a combined plot using \{LatticeExtra2\} package of $\mathrm{R}$ by strip plot function.

The distribution of the slope angle, sediment thickness, depth and closeness of the igneous volcanic zones towards Mariana Trench, by four tectonic plates is shown on Fig. 7 in [422]. It shows distribution of slope angle, sediment thickness, depth and igneous volcanic zones, by four tectonic plates. The $\mathrm{R}$ code used: A.6.17 (for several strip plots on one layout) (single strip plot with multiple parameters). The multiple panel by groups analyzing four tectonic plates, trench slope angle in the deepest point, depth 
scope (min-max) by profiles using overlapping points, are computed and visualized in $\mathrm{R}$ code: A.6.18, scatterplot with overlapping points and brackets using library \{pBrackets $\}$ A.6.20.

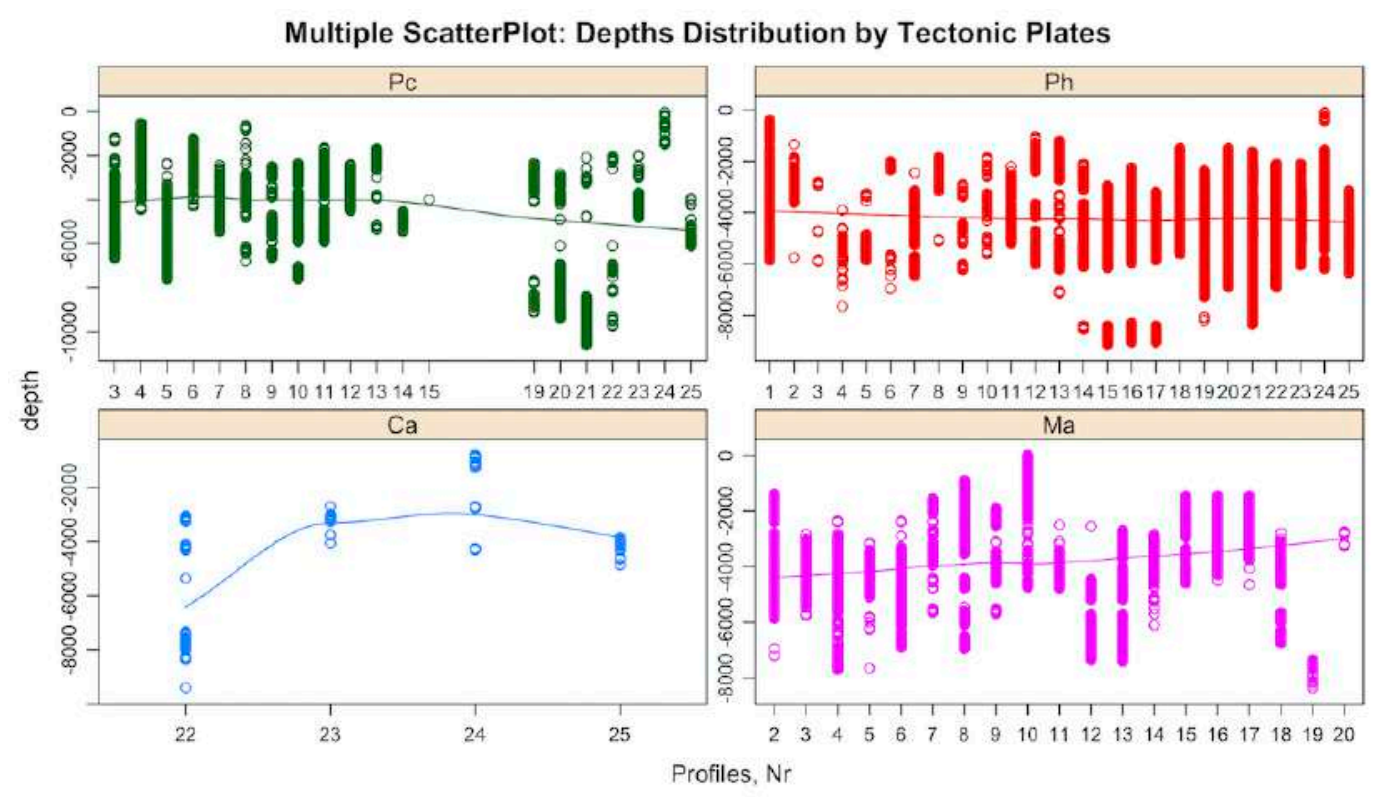

Figure 3.8.8: Multiple panel by groups: tectonic plates, depth by profiles

Variation of the slope angle in the deepest point and depths by 25 bathymetric profiles of the Mariana Trench according to four tectonic plates that is crosses is illustrated on Fig. 3.8.7 and Fig. 3.8.8 (overlapping points approach), [422]. The graphs show variation of the slope angle in the deepest point and depths by bathymetric profiles of the Mariana Trench for four tectonic plates: Mariana, Caroline, Pacific and Philippine, respectively.

\subsubsection{Ridgeline, categorywise and circular plots}

The ridge plots (R: A.6.35 combine information about statistical data on 25 bathymetric profiles: arithmetic density distribution, mean and standard deviation along the profiles in a facetted way, (Fig. 3.8.9. They have lines extending horizontally from the boxes indicating variability of the depths distribution across all the profiles. The code was written in \{ggridges $\}$ and \{ggplot2\} R libraries A.6.35. To create categorywise plot, first, the table was read into R: Second, the tables columns were merged calling \{merge $\}$ function from library(data.table) by environmental variables: depth, tectonics, slope angles. Third, the new data frame (DFDT) was created. Forth, a plot function was called by the code using data frame created in previous step: A.6.13 and a graph was visualized (Fig. 12 in [422], left.

To better understand the behavior of the spatial distribution in elevations in a stream view, a ridge line technics of the landforms data visualization was applied by R [609]. From the graph showing ridge lines (Fig. 3.8.9) one can see comparative visualization of the density distribution of depths by profiles. Ridgeline profiling provides insight into the statistical distribution of the depth and elevation ranges of the trench and archipelago. From these profiles (Fig. 3.8.9), it is possible to comparatively analyze and observe distribution of an elevation values varied for 25 cross-section profiles. The elevation curves illustrate ranges across the profiles transversal to the main channel of the trench (Fig. 3.8.9).

A \{tidyverse\}, another $\mathrm{R}$ package, was used to visualize a circular plot showing the comparative analysis of the bathymetric ranged by the sediment thickness. The algorithms and syntax of $\mathrm{R}$ coding was applied from the available manuals [609]; [329]. The circular bar plot shows distribution of depths 
by tectonic plates (Fig. 12 in [422] right, and the distribution of the sediment thickness (\%) according to the slope steepness by profiles. To create circular barplot divided by groups, following code was used: R: A.6.16.
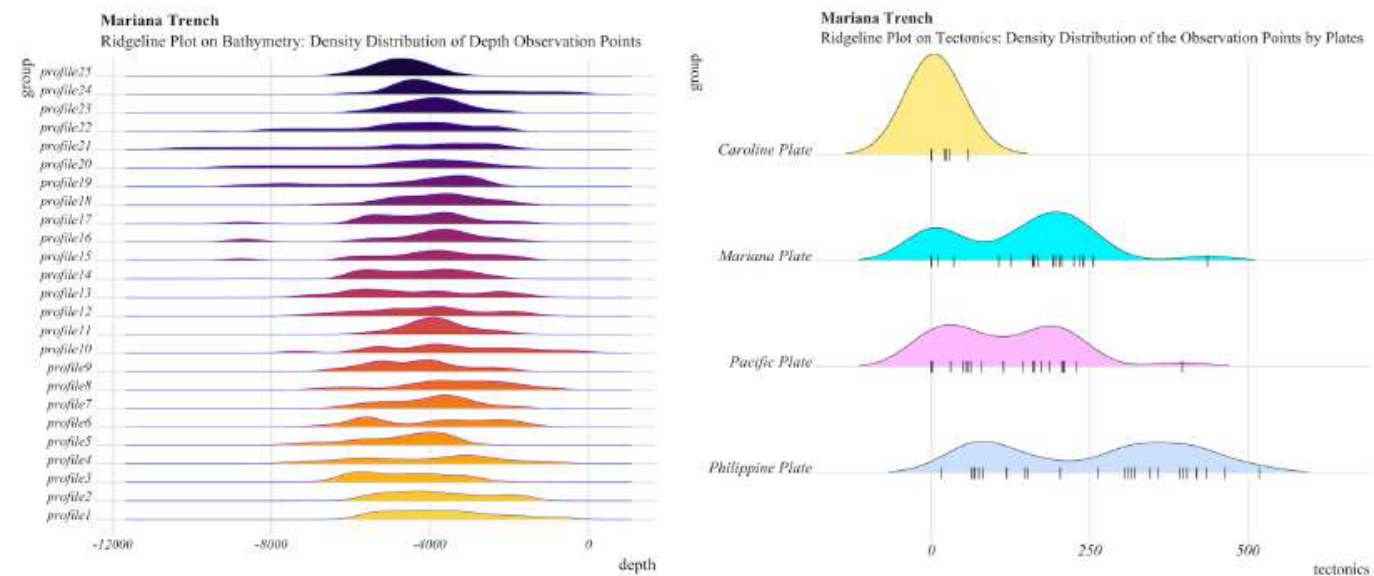

Figure 3.8.9: Mariana Trench: Ridgeline plots

\subsubsection{Dumbbell charts for data pairwise comparison by tectonic plates}

Since Mariana Trench is located in the collision of four tectonic plates, the comparative testing of the values distribution by the tectonic plates has been completed through the Dumbbell chart plotting.

1 马里亚的海沟, 剖面1-25。Dumbbell Chart Mariana Trench, Profiles Nr.1-25.

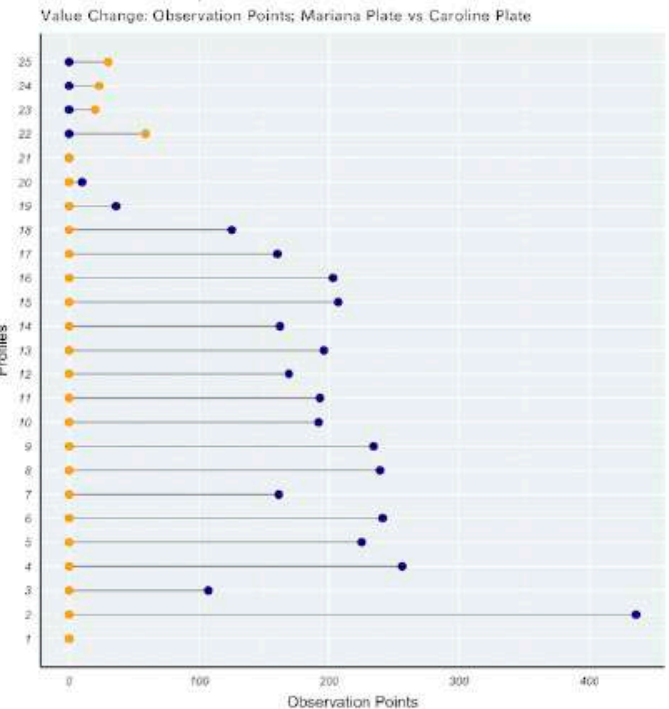

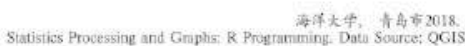

2 马里亚纳海沟。剖面1-25, Dumbbell Char Mariana Trench, Profiles Nr.1-25.

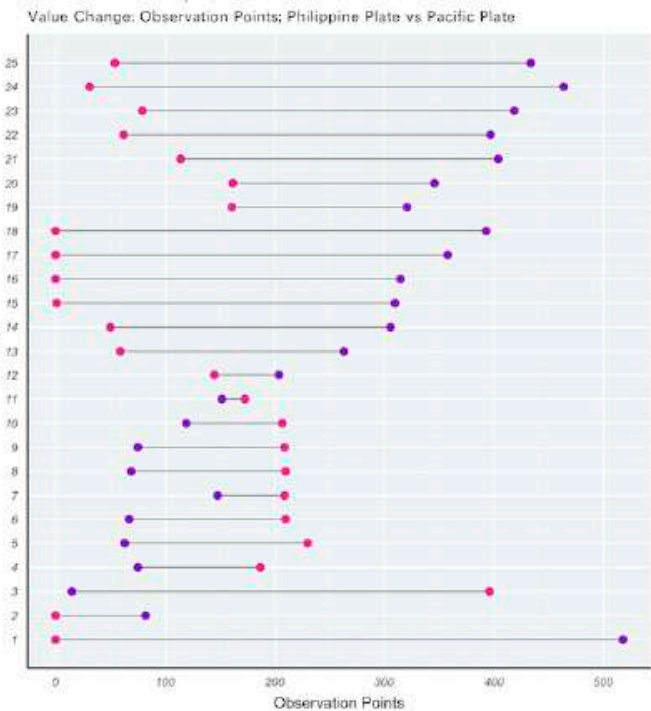

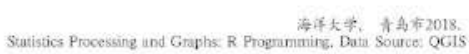

Figure 3.8.10: Mariana Trench: ranking dot plots by data grouping, by R code: A.6.12

Dumbbell chart is a visualization aimed to give an insight of how the margin tectonic plates constitute to the Mariana Trench pairwise. It is one of the new statistical methods that initially was widely used in biosciences, yet can be applied to spatial analyses when it is necessary to take pairwise comparison of the data distribution from any thematic layer. Plotting was carried out by calling R libraries \{ggplot 2$\}$ and 
\{ggalt\} by code: A.6.12. Dumbbell chart demonstrates pairwise distribution of the bathymetric points constituting the continental plates, to show the composition of the sedimentary coverage by four tectonic plates, Fig. 3.8.10 [429].

\subsubsection{Ranking dot plots by data grouping}

Pairwise correlation was visualized by ranking dot plots, an effective tool to perform data grouping by variables (tectonic plates). Plotting distribution of the sample points by igneous volcanic areas aimed at visualizing areas affected by magmatism. Large igneous volcanic areas contribute towards localization of possible earthquake zones. As can be seen (Fig. 3.8.11), the volcanic areas increase along the Mariana Trench SW. Alike to the volcanic areas, variation of the steepness slope was performed by ranking dot plot: profiles with the steepest angles across the trench are located in the NE with a slight decrease towards the $\mathrm{SW}$. The $\operatorname{tg}^{\circ}$ of the profiles were calculated by a standardized formula: a relation of the max depth by the profiles divided by the width of each corresponding profile.
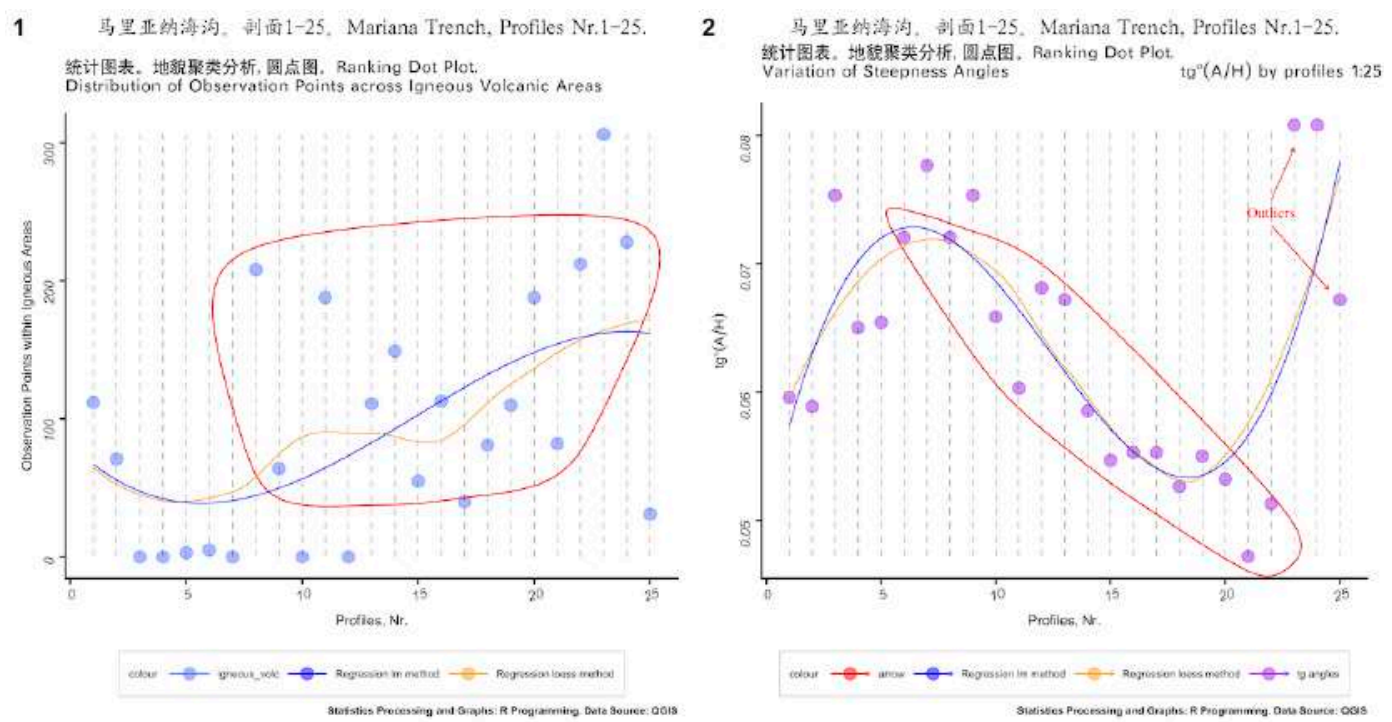

Figure 3.8.11: Mariana Trench: ranking dot plots by data grouping, by R code: A.6.14

Crucial points (Fig. 3.8.11) were selected using library \{ggalt $\}$ by calling following R code: A.6.14. The distribution of the steepness values across the trench were shaped by the components of the igneous volcanic areas near the profiles, as seen from the Fig. 3.8.11: profiles \# 20, 22, 24, 8 and 11 with notable amount of igneous volcanic observation points (over 180) correlate with steepness angle.

\subsubsection{Ternary diagrams, radar and pairwise double-Y axis charts}

Ternary diagrams and radar charts show the triple correlation of several factors across tectonic plates: slope morphology classes, tectonics, igneous volcanic areas, aspect degree, slope angle, sediment thickness [416]. The programming R code for the ternary diagrams is R: A.6.29. Radar chart was plotted by $\{\mathrm{fmsb}\}$ library: A.6.21 (plotting radar chart for depth distribution within bathymetric profiles, Mariana Trench (modelling distribution of the profiles across the trench).

The pairwise double-Y axis was enables to analyze the effect of the $b i$-factor correlation between the slope angle and other variables (Fig. 3.8.12). The following script runs the model in each case, calculates the $\mathrm{X}$-Y dependences and places both graph on one plot, which his very convenient for comparative studies. The following is a code for the double-Y axis with correlations "Slope angle", "Sediment thickness" 
by library $\{$ LatticeExtra $\}$ in $R$ in consecutive steps: A.6.15. At the end of each run, the final results are copied to the p1, p2 and p3 plot, and afterwards combined three graphs on one plot, [422].
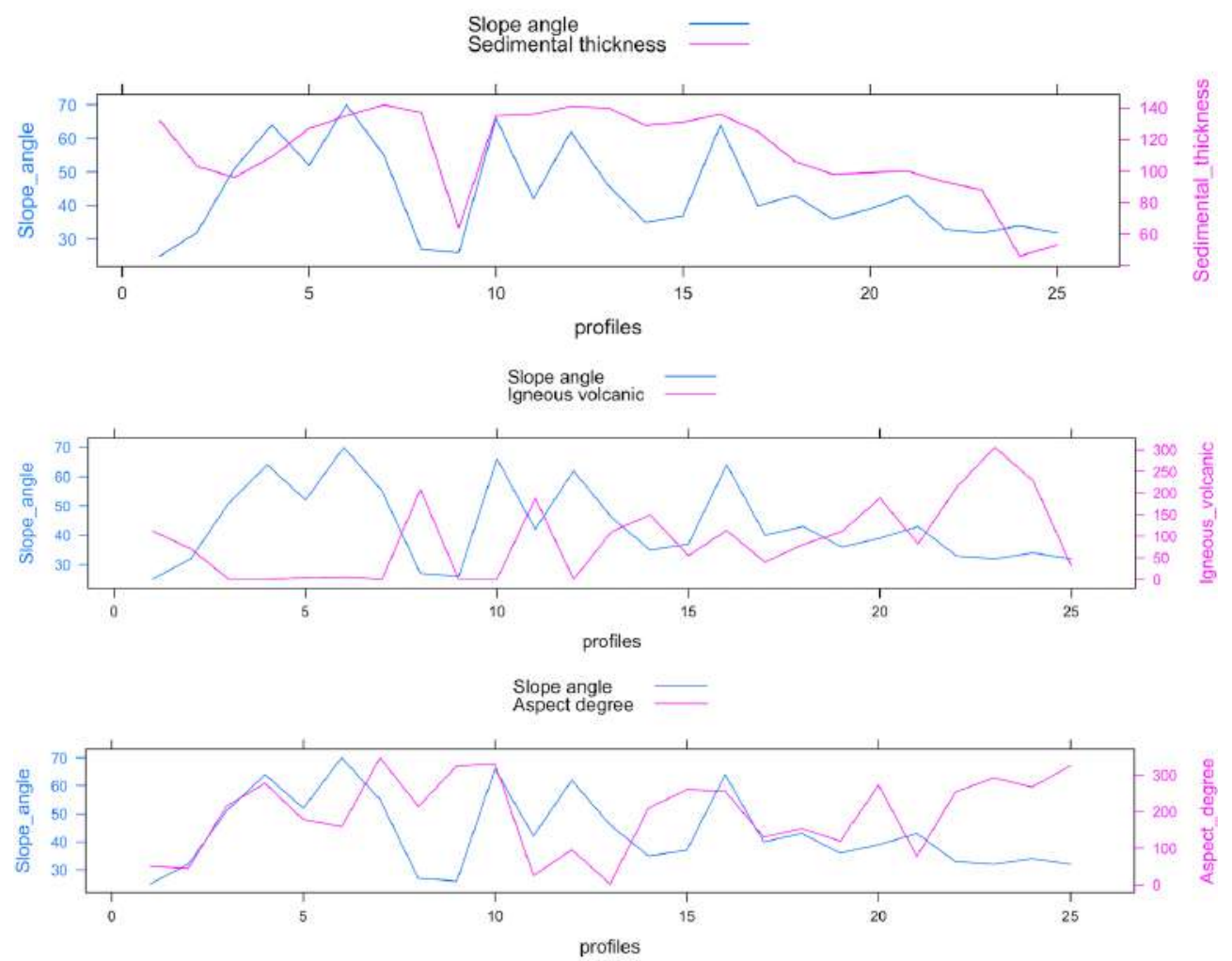

Figure 3.8.12: Pairwise double- $Y$ axis charts showing correlation between factors

\subsubsection{Ranking data for variation of the geomorphic steepness}

Geomorphic variation distinguishes a certain segment of the profile of the trench from neighbor areas.

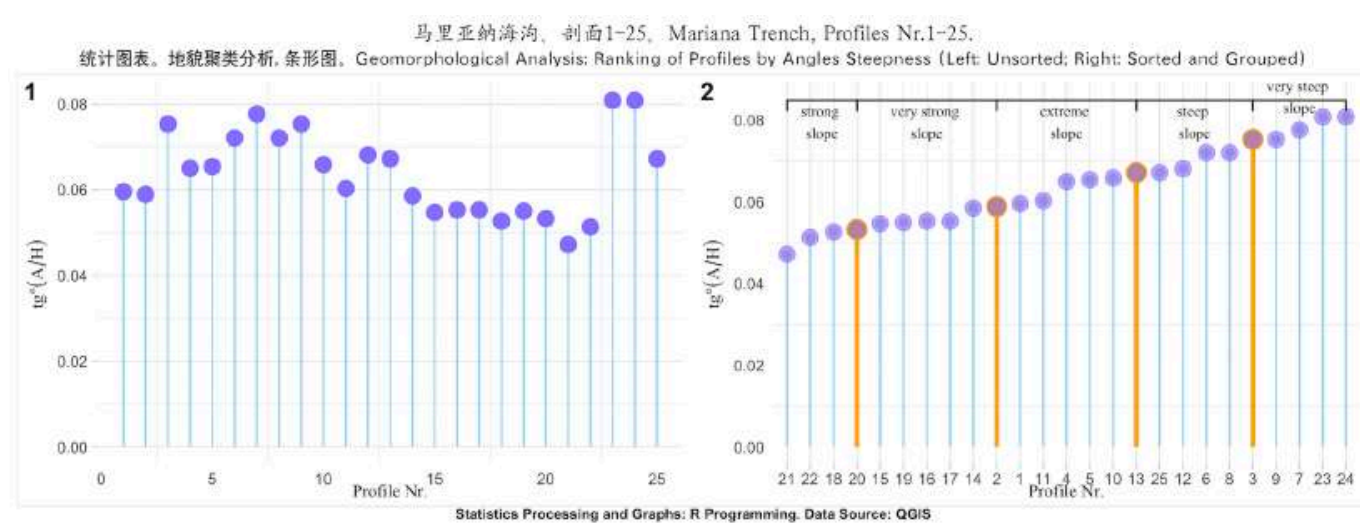

Figure 3.8.13: Mariana Trench: ranking data for steepness variation, R code: A.6.22

Variation in geomorphology changes in shape that varies from one segment to another depending on the tectonic properties and geospatial location. Correlation between the geomorphic shape with geologic settings and geographic location revealed that the submarine geomorphology of the Mariana Trench 
is influenced by the geospatial settings of the underlying tectonic plates that affect its shape and cause variation of the steepness across the trench segments. The variation of the shape form is strongly affected by the geospatial location of the trench crescent.

Variations in the presented bathymetric profiles shows (Fig. 3.8.13) trench varying in shape across its crescent: five divided regions varying in steepness degree, ranging from the strong slope, very strong slope, extreme slope and very steep slope. The unsorted spatial series of the profiles (Fig. 3.8.13, left) only shows the consequent distribution of the slopes, so we cannot judge their variations, but only general range. Upon sorting and ranking profiles (Fig. 3.8.13, right), the segments with similar geomorphic slope steepness are ranked and grouped. Ranking data was based on the geomorphic steepness using R libraries and existing mathematical algorithms [609]. The methodology for plotting Fig. 3.8.13 consists in the application of the R code A.6.22.

\subsubsection{Compositional charts of the determinants variations}

The constitution of the system composition has been visualized by the categorical plotting. One of the methods enabling categorical plotting is presented by compositional charts, sometimes referred to as waffle charts.
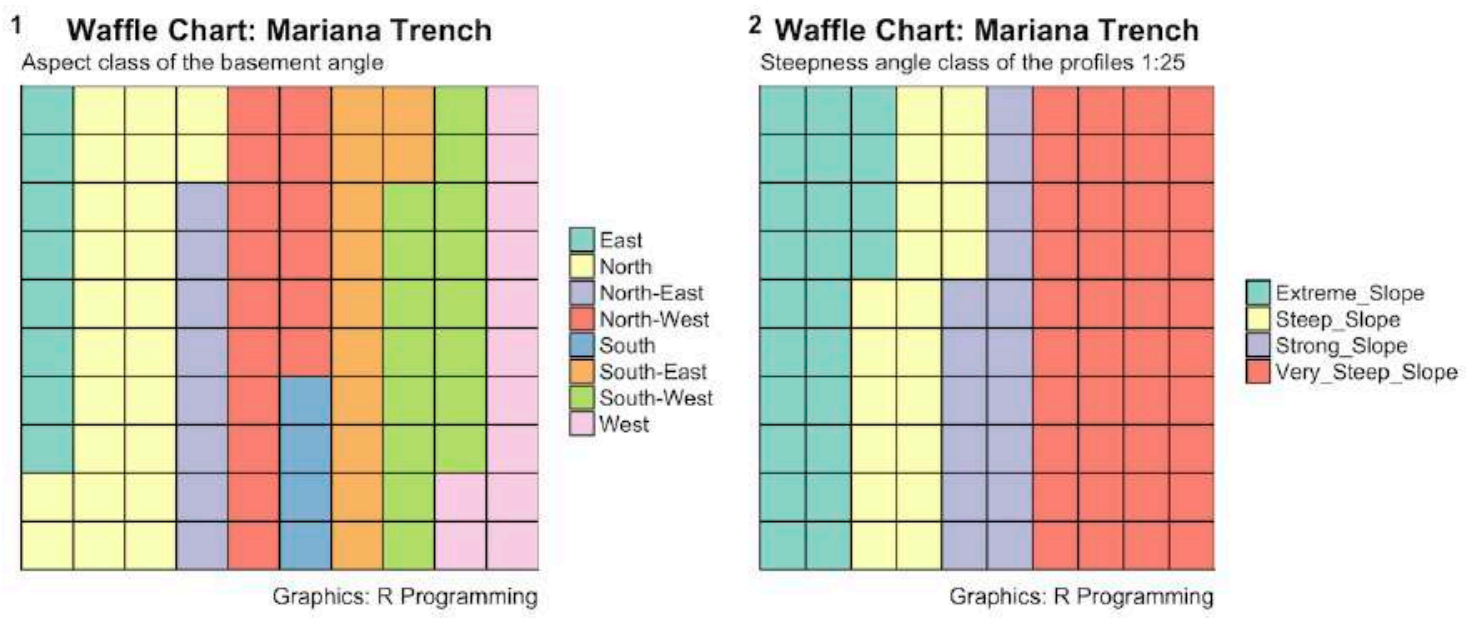

Figure 3.8.14: Mariana Trench: compositional chart of the geometry of the profiles, $R$

The principal approach of this method is to demonstrate the division of the whole system by parts in percentage. Several $\mathrm{R}$ libraries were used to perform technically compositional plotting, of which the \{ggplot2\} was selected as the most effective (A.6.37) comparing to the \{waffle\} library (A.6.38): it enables to control the appearance of the plot by adjusting details (colors, font size, types, facetted plotting). The compositional chart is aimed to compare distribution of the data across the area, and composition of the aspect class and slope angle for the trench. As can be seen (Fig. 3.8.14), the category very steep slope is the dominant among all other geomorphological types of the slope degree of the Mariana Trench. Likewise, N and SW aspect of the slope direction are best describing the geometry of the northern and southern part of the trench, respectively.

\subsubsection{Mosaic, silhouette and association plots}

Mosaic chart aims at categorial comparison of the geomorphological features of the trench by four tectonic plates (Fig. 3.8.15). Visualizing mosaic plot is a statistical method that involves a subdivision of a rectangular tiles into the areas that represent the conditional relative frequency for a cell in the contingency table. The algorithms and approaches used in mosaic plotting vary slightly. Upon examination 
of possible packages, the R library $\{\mathrm{vcd}\}$ was selected for this research (R code: A.6.31. Using $\{\mathrm{vcd}\}$ library, each tile is colored to show the deviation from the expected frequency, that is residuals, from a Pearson X2 or likelihood ratio $G$-test showing maximum likelihood statistical significance by Formula 3.8.11:

$$
G=2 \sum_{i} O_{i} * \ln \left(\frac{O_{i}}{E_{i}}\right)
$$

The algorithm set includes execution of the $\mathrm{R}$ code. The convenience of the mosaic plot for the geomorphological analysis of the ocean trenches consists in its visual representation of the association between the environmental variables. Thus, it gives an overview of the data structure and enables to recognize relationships between the different environmental variables. Conversely, boxes across categories constituting Pacific and Mariana plates have similar areas. The area of the tiles, the bin size, includes the identification of the sampling data, giving the proportional value to the number of observations within that category.
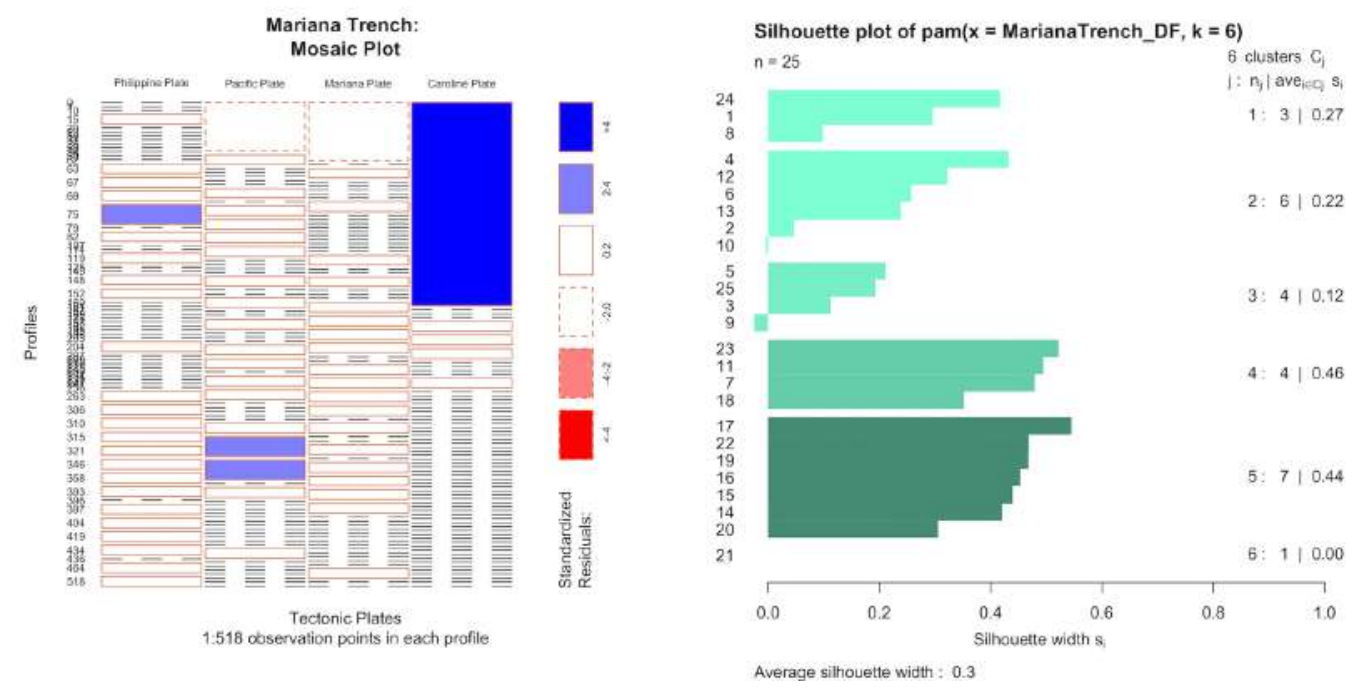

Figure 3.8.15: Mosaic and silhouette plots for the Mariana Trench

The interpretation and validation of consistency within clusters of geomorphologic and geological variables have beet tested using silhouette plotting (Fig. 3.8.15). This technique provides a succinct graphical representation of the suitability and fitness of each from 518 observation points across 25 bathymetric profiles within the clusters. The silhouette value measured similarity of the points derived from the thematic layers (sediment thickness, slope steepness) to the cluster by cohesion and comparison them with other clusters, and separating them from the distinct points. Lower sediment thickness area lie within one class while a class of areas with high level of sediment level fits to another.

The silhouette was calculated with Euclidean distance metric by calling library \{cluster\} using following R code: A.6.30. The Euclidean distance metric is computed by Formula 3.8.11:

$$
\|a-b\|_{2}=\sqrt{\sum_{i}\left(a_{i}-b_{i}\right)^{2}}
$$

The $\mathrm{R}$ script plots the silhouettes, returns the values in the $\mathrm{n}$-by- 1 vectors. A deviations from the independence of rows and columns containing bathymetric data and environmental variables is presented in a two-dimensional contingency table of the Cohen-Friendly association plots (Fig. 3.8.16). Extended asso- 
Table 3.8.2: Statistical algorithm of clustering, R code: A.6.9

\begin{tabular}{r|l} 
No & Step \\
\hline \hline 1 & Computed hierarchical clustering and cutting the tree in the k-clusters \\
\hline 2 & Computed pairwise standard scatter plot of k-means cluster correlation \\
\hline 3 & Computed pairwise standard scatter plot of k-means cluster correlation \\
\hline 4 & Computed centers (2 to 7 were tested, in total 6 centers) of each cluster \\
\hline 5 & Created groups of the correlation matrix tested by distributions on the plates \\
\hline \hline
\end{tabular}

ciation plot in $\mathrm{R}$ reveals relationships between the variables by the assoc() function in the $\{\mathrm{vcd}\}$ package. In this case, it is tectonic plates and geomorphological values (bathymetric depths, slope steepness).
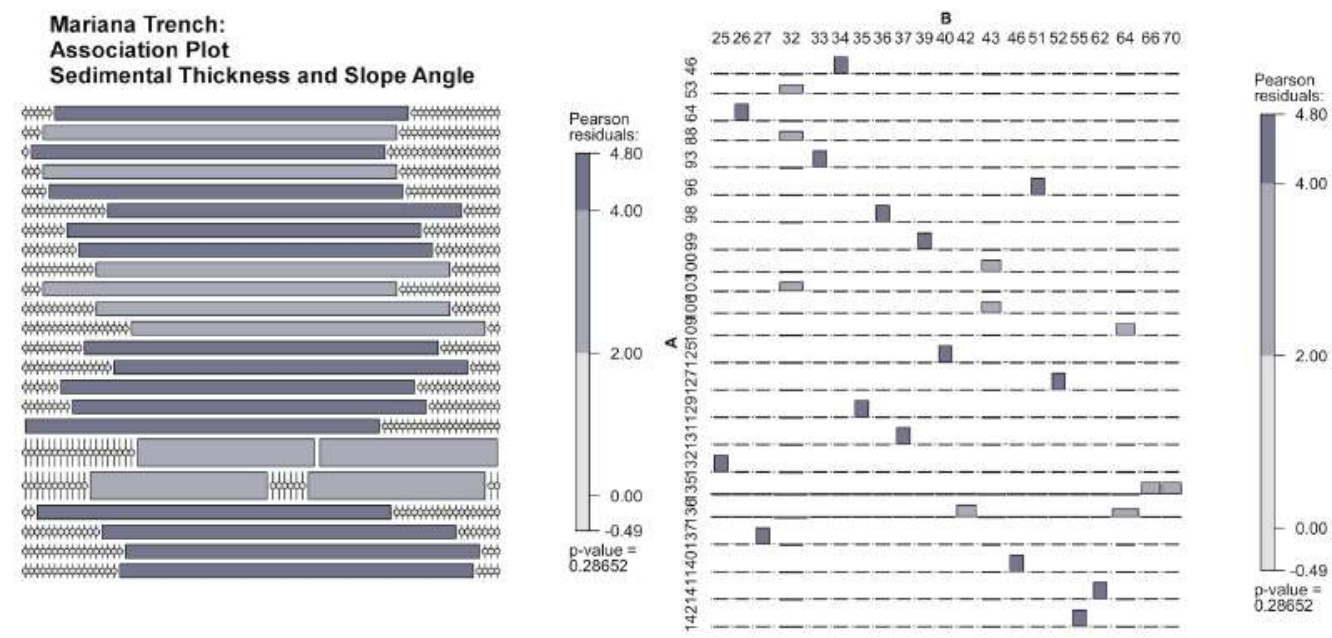

Figure 3.8.16: Association plots for the Mariana Trench

Pearson's residuals on the association plot report test for the statistical goodness of fit: it enables to assess the model fit at each of samples for each profile for the generalized linear models within the context of the chi- square, as shown further in [429]. It has been computed as a raw residual divided by the square root of the variance function. Technically, association plot method includes R code: A.6.31.

\subsubsection{Clustering ( $k$-means method), correlation ellipses and data partition}

Finding correlations among the geomorphic factors that impact the morphological formation of the profiles was done by cluster analysis and correlation ellipses. The $k$-means clustering is a machine learning technique for classification performs data partition into set up number of clusters [488], [444]. $\mathrm{K}$-means clustering was done by R library \{factoextra\} using codes for (pairwise cluster analysis) and cluster analysis.

The goal of the $k$-means clustering was to perform partition of the dataset of the observations across the trench into clusters, in which each depth observation belongs to the cluster with the nearest mean, serving as a prototype of the cluster. Clustering is sensitive to the initial random selection of the cluster centers. Therefore, several clusters were tested starting from 2 to 7 . This function provides a solution using a hybrid approach by combining the hierarchical clustering and the $k$-means methods. The workflow procedure include following steps: Tab. 3.8.2. 
The $k$-means of the clustering of the trench profiles was computed and visualized in R by code A.6.9, Fig. 14, the $k$-means clustering with different $k$-values is shown on Fig. 15, [422]. The $k$-means cluster analysis has been performed using set of cluster centers as the initial cluster centers. The algorithm worked iteratively to assign each profile to one of the groups (2 to 7) based on the morphometric features of the trench across these profiles that were clustered based on their geomorphic feature similarity. The results of the $k$-means clustering are shown on the Fig. 3.8.17, further details are given in [423]. The pairwise standard scatter plot of $k$-means cluster correlation distributed by four tectonic plates is shown on Fig. 3.8.17.

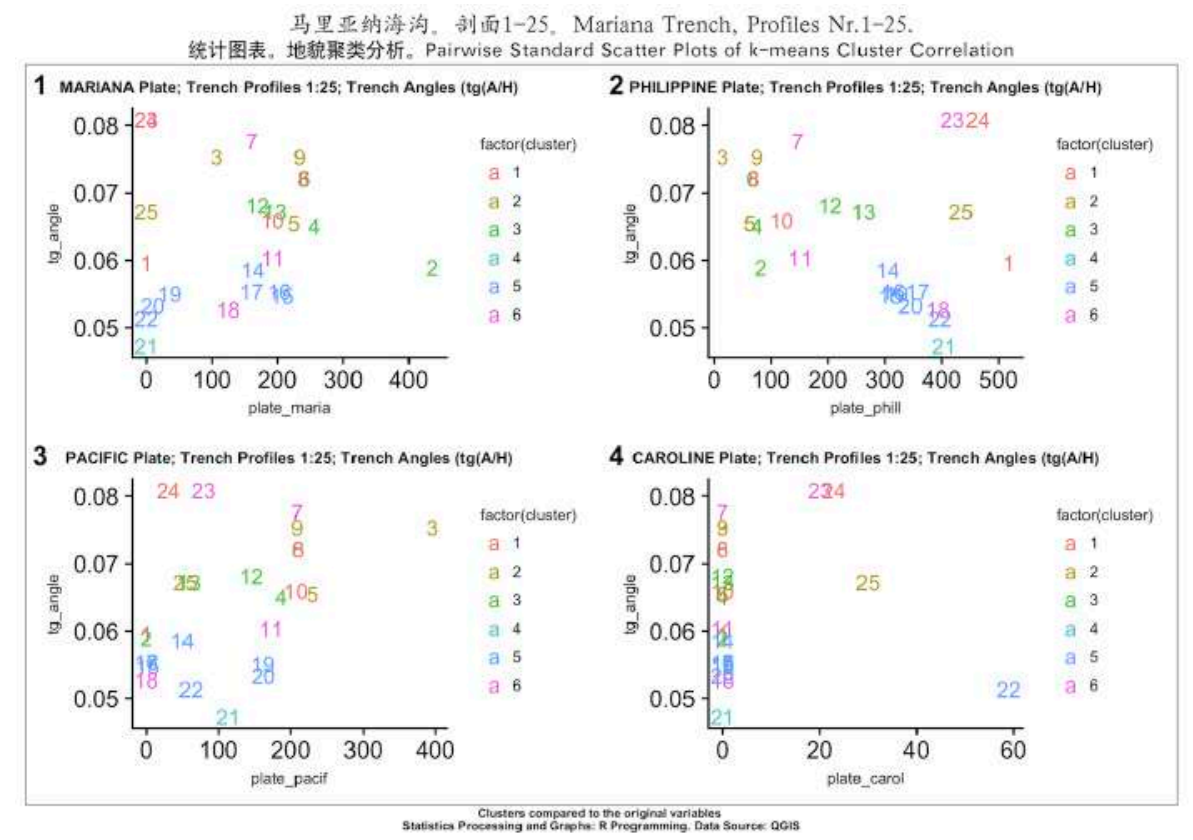

Figure 3.8.17: Mariana Trench: classification of the k-means clustering by plates, R code A.6.9

The $k$-means cluster analysis was done using following R code: A.6.9. The mathematical background is as follows. $k$-means clustering aims to partition the $\mathrm{n}$ observations into $k(\leq n)$ sets $S=\{S 1, S 2, \ldots, S k\}$ so as to minimize the within-cluster sum of squares (WCSS) by the Formula 3.8.12:

$$
\arg _{s} \min \sum_{i=1}^{k} \sum_{x \in S_{i}}\left\|x-\mu_{i}\right\|^{2}=\arg _{s} \min \sum_{i=1}^{k}\left|S_{i}\right| \operatorname{Var} S_{i}
$$

Where $\mu_{i}$ is the mean of points in $S_{i}$. The advantages of the $k$-means clustering applied for Mariana Trench consists in the algorithm nature: rather than defining groups before looking at the data, clustering enabled to find and analyze the groups in the profiles that have formed organically. As the structure of the tectonics and trench geomorphic properties are rather complex, clustering facilitated data partition and grouping. The correlogram ellipses were generated to visualize correlation between the factors affecting the morphology of the trench [422]. The methodological approach includes calling \{ellipse\} library and executing following script: A.6.32.

\subsubsection{Hexagonal plots and data partition}

Plotting hexagonal plot was performed using R library \{hexbin\}. This plot shows how bathymetric data are distributed by the profiles in terms of frequency: how often the values are being repeated by 
profiles. Hexbin plots serve as a useful alternative to scatter plots, as the data are are dense. Therefore, plotting each point individually in this case is not effective: the data would be indistinguishable on the graph. Hence, the \{hexbin\} library was used to plot the range of the depths values within Mariana Trench using the R code: A.6.27. Studies revealed that major depth observation points of the Mariana Trench are located in between the -3000 and -5000 meters (Fig. 3.8.18), as also discussed by [212]. The significant point is that sediment thickness changes notably both within the trench by profiles (1:25) and between four adjacent tectonic plates: Philippine Sea, Pacific, Mariana and Caroline. Data grouping and partition was performed by dividing angles across the trench on to classes (Fig. 19 left [422]). The level plot heatmap (Fig. 19 right [422]) shows classes of the sediment thickness by Mariana Trench and modelling correlation between sediment thickness, slope angle and bathymetry, was built by R code: A.6.33.

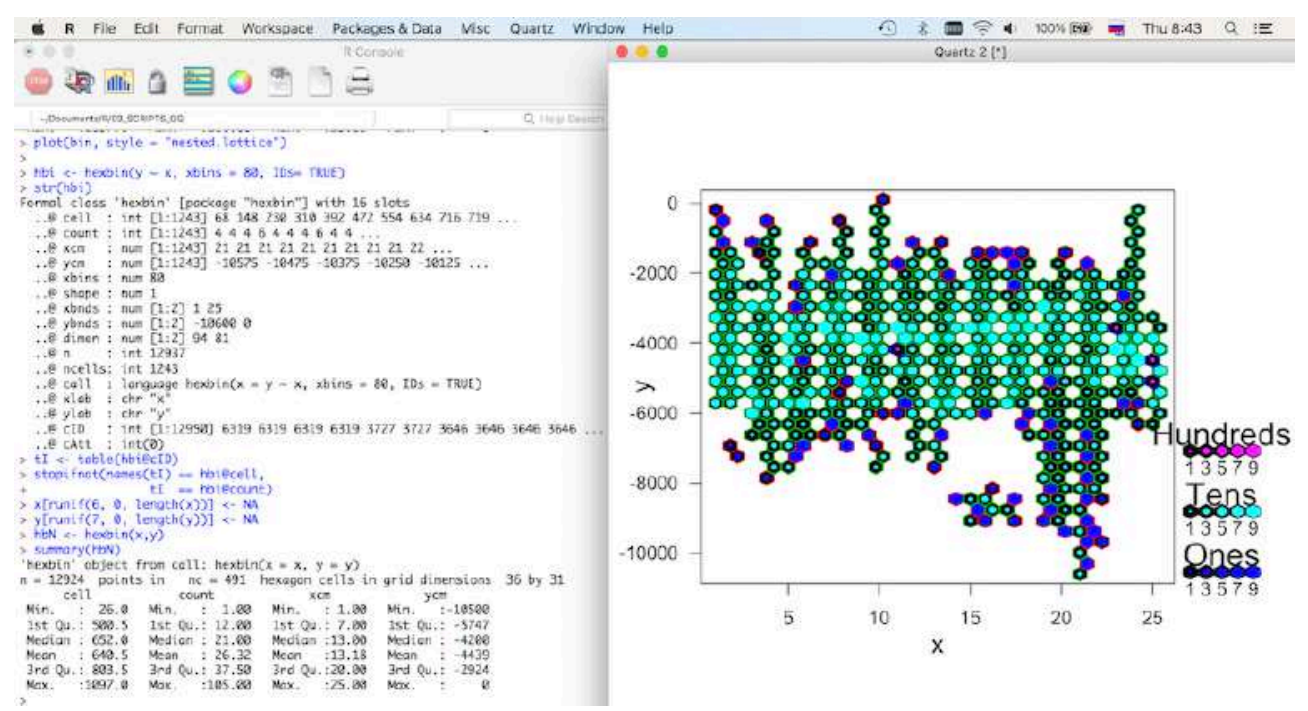

Figure 3.8.18: Mariana Trench: hexagonal data distribution, by $\mathrm{R}$ \{hexbin $\}$ library.

\subsubsection{Correlation analysis of impact factors}

Correlation coefficient is a numerical measure of direction and strength of the linear correlation between variables, i.e. how strong a relationship is between geomorphological, bathymetric and geological factors is across four different tectonic plates. Three methods of computing correlation analysis were tested: Pearson correlation, Spearman correlation, Kendall correlation [434]. Additionally, numerical correlogram, correlation and cross-correlations matrices were generated to analyze environmental impact factors for the trench. The correlogram matrices are computed and visualized by $\mathrm{R}$ scripting libraries.

\subsubsection{Pearson correlation}

Developed by Karl Pearson from a related idea of Francis Galton in the 1880s, a Pearson product moment correlation coefficient, a. k. a. the bivariate correlation, is a measure of the linear correlation between two variables by Formula 3.8.14.1:

$$
r=\frac{\sum(x-m x)(y-m y)}{\sqrt{\sum(x-m x) 2 \sum(y-n)}}
$$

In this case, the environmental variables and geomorphological factors were tested by Pearson correlation: sediment thickness, slope angle and class, aspect degree, hill shade in values, location of igneous 
volcanic zones across the abyssal valley, tectonics by 4 plates, bathymetric values, that is $\mathrm{max} / \mathrm{min}$ depths, median, means for each profile, tan angle ${ }^{\circ}$. Pearson correlation has a value between +1 and -1 , where 1 is a total positive linear correlation, 0 is no linear correlation, and -1 is total negative linear correlation. It is presented on Fig.3.8.19, computed and visualized by R script: A.6.41.

1

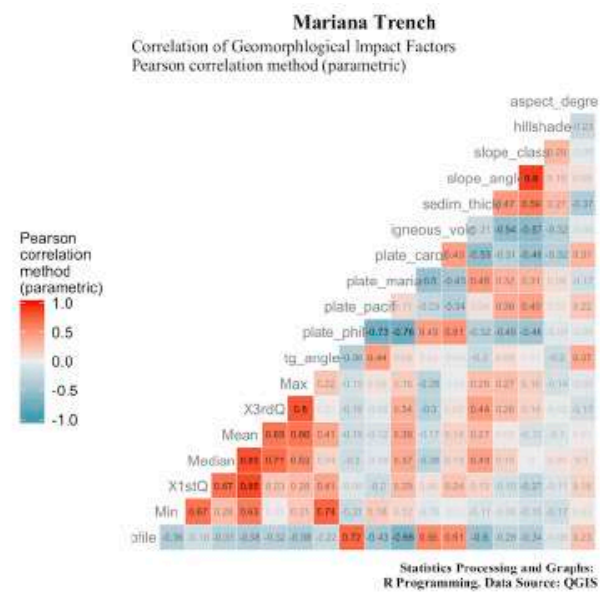

2

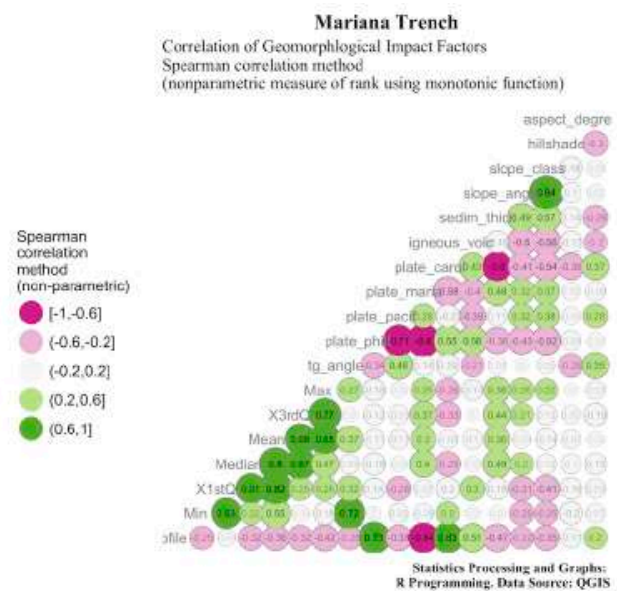

Figure 3.8.19: Mariana Trench: Pearson and Spearman correlation matrices, by R code A.6.41

\subsubsection{Spearman rank correlation coefficient $\rho$}

The environmental variables were tested by Spearman rank correlation coefficient $\rho$ : sediment thickness, slope angle and class, aspect degree, hill shade in values, location of igneous volcanic zones across the abyssal valley, tectonics by four plates, bathymetric values, max/min depths, median, means for each profile, tan angle ${ }^{\circ}$. Named after Charles Spearman, a Spearman non-parametric $\rho$ coefficient is handling ties between the variables less properly comparing to the previously computed Pearson coefficient (Fig.3.8.19). The Spearman's $\rho$ was computed on sets of paired rankings between the factors. On Fig.3.8.19 the more correlated variables are represented by the colors of green. The size of the circle also depends on the correlation value. Spearmans rank correlation coefficient is denoted by $\rho$ or $r_{s}$. It is given by the following formula [563]:

$$
r_{s}=1-\frac{6 \sum\left(d_{i}^{2}\right)}{n\left(n^{2}-1\right)}
$$

where

$d_{i}=\operatorname{rg}\left(X_{i}\right)-\operatorname{rg}\left(X_{y}\right)$ is the difference between the 2 ranks of each observation, $\mathrm{n}$ is the number of observations.

Here $d_{i}$ represents the difference in the ranks given to the values of the variable for each data item received and processed from the csv table via library \{data.table\}. The formula of Spearmans rank correlation coefficient $\rho$ is applied for case with no tied ranks. Technically, $\mathrm{R}$ script for Pearson correlation was changed for case of Spearman's $\rho$ by following code: A.6.41. On Fig.3.8.19 the measure of rank correlation, that is a statistical dependence between the rankings of two variables has been computed using \{GGalt\} library by R code: A.6.41. Spearman correlation shows (Fig.3.8.19) the relationship between every pair of two variables described as a monotonic function and comparing following factors: tectonics, geology, geographic, bathymetric and magmatism. Spearman's correlation assesses monotonic relationships, whether linear or not, between the available factors. If there are no repeated data values, a 
perfect Spearman correlation of +1 or 1 occurs when each of variables is a perfect monotone function of the other.

\subsubsection{Kendall $\tau$ coefficient}

Similar to Spearman, Kendall $\tau$ coefficient to measure rank correlation, invented by M. Kendall, is a non-parametric test for statistical dependence between environmental ordinal (or rank-transformed) variables. Kendall rank correlation distance is defined as follows:

$$
\tau=\frac{2}{n(n-1)} \sum \operatorname{sgn}\left(x_{i}-x_{j}\right) \operatorname{sgn}\left(y_{i}-y_{j}\right)
$$

Kendall rank correlation $\tau$ coefficient is statistically used to measure ordinal association between two measured quantities: geological factors in this case. Based on non-parametric hypothesis $\tau$ coefficient test for statistical dependence, it was computed by R code A.6.41. It measures rank correlation: the similarity of the orderings of the data when ranked by each of the quantities. Unlike Spearman's, Kendall can handle ties. There are three Kendall $\tau$ statistics: $\tau$-a, $\tau$-b, and $\tau$-c, of which $\tau$-b is specifically adapted to handle ties.

By $\tau$-b statistics, each pair of members of the environmental variables (tectonics, geological factors, geographic location, magmatism, sediment thickness) was tested against igneous volcanic spots. It has the same ordinal value by a divisor term. The latter represents geometric mean between the number of environmental factor pairs that are not tied on factor 1 and the number not tied on 2. Visualized Kendall $\tau$-correlation (Fig. 7) for geomorphological factors of the trench and numerical scatterplot matrix are computed by R code: A.6.41, [433], libraries $\{$ Matrix $\}$, \{mclust $\}$, \{correlplot $\}$. Numerical scatterplot matrix of correlation between the factors and cross-correlation matrix of the depths in profiles of the trench (Fig. 9, [433]) are plotted by R code: A.6.7 and visualized by library \{ggimage .

\subsubsection{Calculation of the normalized steepness angle of the Mariana Trench}

The normalized steepness was computed as a steepness of dominance hierarchies of the slope angle (Fig.3.8.20). 


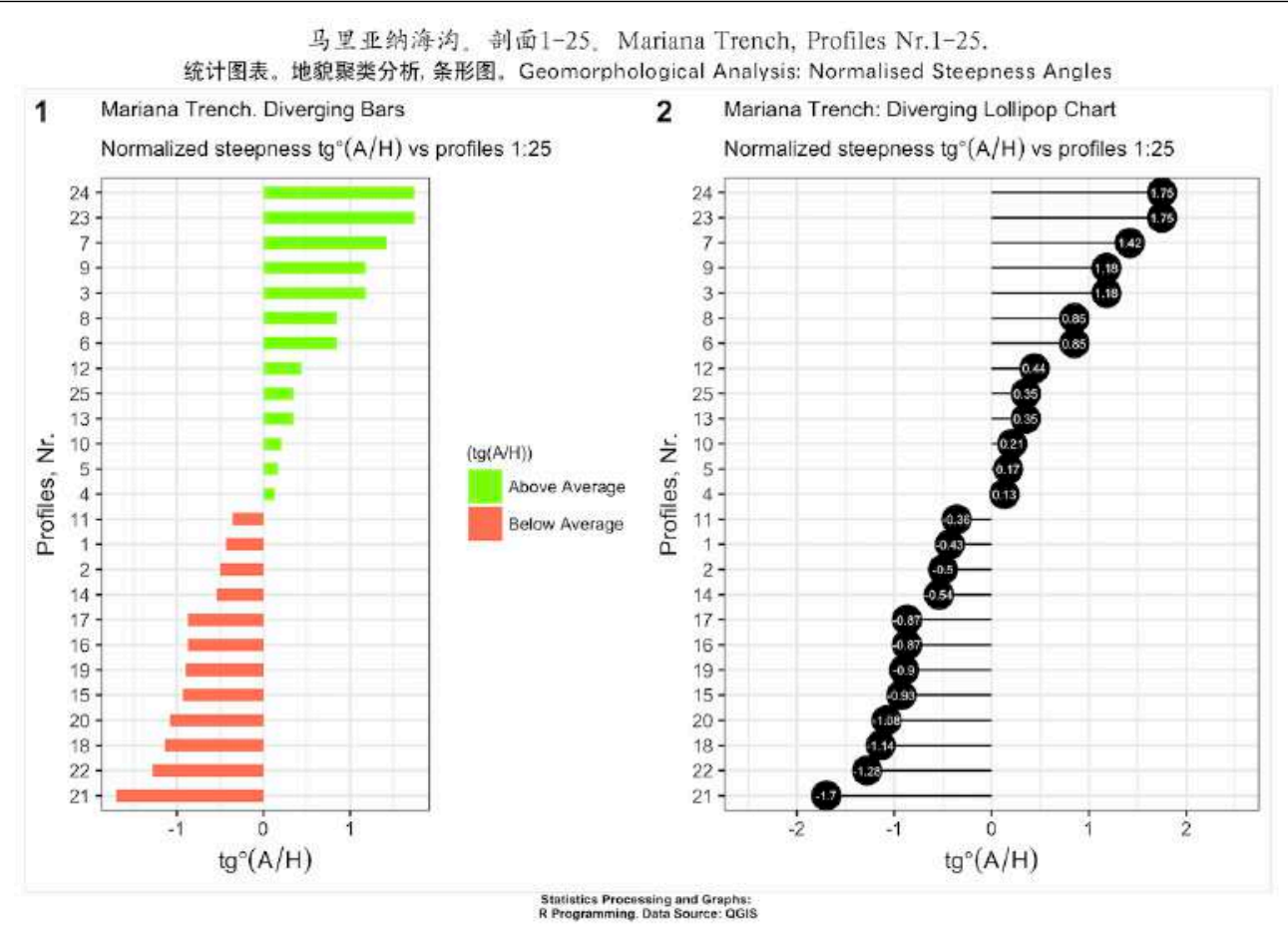

Figure 3.8.20: Mariana Trench: normalized steepness of the slope angles by profiles, $R$

Steepness is defined as the absolute slope of the straight line fitted to the normalized scores. The normalized scores were obtained on the basis of dominance indices corrected for chance or by means of the proportions of wins. Given an observed data set, it computed hierarchy's steepness and estimated statistical significance by means of a randomization test for the steepness of the trench (here: example of the normalized steepness angles by the bathymetric profiles, Mariana Trench, single-colored (here: plotting 'lollipop charts' and diverging bars of the Mariana Trench bathymetry).

\subsubsection{PCA}

The PCA (Fig. 10, [433]) performed using R code A.6.8 enabled to visualize eigenvectors as showing major direction and vector length for the principal components affecting categorical values. Through the PCA a statistical procedure using an orthogonal transformation to convert a set of bathymetric depth observations of possibly correlated variables, was performed. Thus, the direction of the eigenvectors shows depths, highly influenced by its geomorphic settings: location by 25 profiles and similarities between the profiles.

\subsubsection{Hierarchical cluster analysis}

In this dissertation, the main method of the determining clusters of the environmental variables affecting trench formation is the algorithm provided by cluster analysis for recognition of the data patterns, executed by \{dendextend\} R library, code A.6.6, [402]. R enabled to perform stepwise cluster analysis, data partition, sorting and grouping. Comparative analysis of the multi-dimensional data enabled to analyze inter-relationships between the factors impacting changes in the morphology and dynamics of the trench system. The most efficient method was computing hierarchical dendrogram clustering with p-values called by R libraries \{dendextend\}, \{gridExtra\}, \{magrittr\}, \{methods\} and \{gridGraphics [402]. Used hierarchical clustering method is default $\{$ hclust $\}$. 
The results of the algorithm are visualized as a plotted dendrogram. Working flowchart include following steps: creating unsorted and sorted dendrograms (Fig. 3.8.21), cross-comparison of the both, hierarchical clustering using $p$-values, and dendrogram by clustering using bootstrap probability method (Fig. 3.8.22). Bootstrapping is based on using a scheme that creates new data sets through reweighting and resampling the initial dataset. Given a set of $\mathrm{N}$ data points, the weighting assigned to data point $\mathrm{i}$ in a new data set $D^{J}$ is $w_{i}^{J}=x_{i}^{J} x_{i-1}^{J}$, where $x^{J}$ is a low-to-high ordered list of $\mathrm{N}-1$ uniformly distributed random numbers on $[0,1]$ preceded by 0 and succeeded by 1 . Using this approach, a small amount of normally distributed random noise is added onto each resampled data. This is equivalent to sampling from a KDE of the data by Formula 3.8.17:

$$
\hat{f}_{h}(x)=\frac{1}{n g} \sum_{i=1}^{n} K\left(\frac{x-X_{i}}{h}\right)
$$

where $h$ is the smoothing parameter, $\mathrm{K}$ is a symmetric $\mathrm{KDE}$ function with unit variance, $\hat{f}_{h}(x)$ is a standard kernel estimator. This sampling process was repeated in a loop several times until the data were sorted and grouped (Fig. 3.8.22).

The initial step included created unsorted dendrogram. Several adjustments were applied thereafter: changed and colored labels based on real profiles groups category, colored branches based on the procedure of cutting dendrogram tree into the clusters. Then dendrogram was sorted using ML algorithm. After the reflection of the unsorted dendrogram on the sorted according to the data distribution by sample values, the model proceeded to the comparison of the two dendrograms (Fig. 4, [434]). Compared dendrograms formed cluster kernels. Further processing was completed on the machine by an embedded mathematical algorithm of $\mathrm{R}$ that filter out less significant profiles and compares them to the kernel ones. The data are stored to make final step: clustering using bootstrap probability. Thus, there are 4 modifications of the initial model consisted of cross-section bathymetric profiles of the trench.

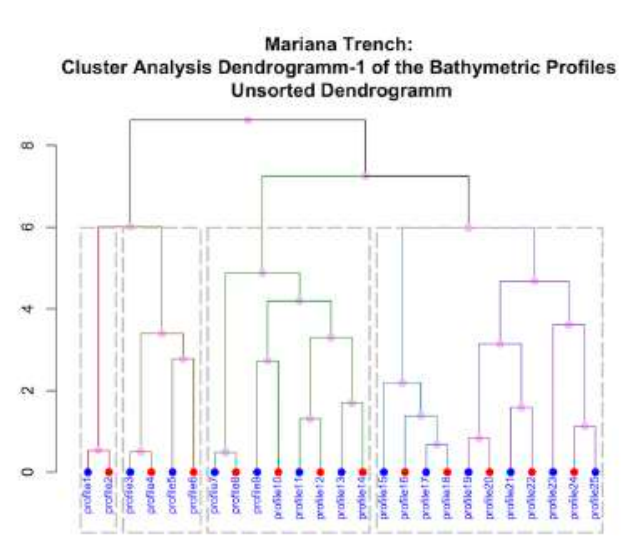

(a) Unsorted dendrogram

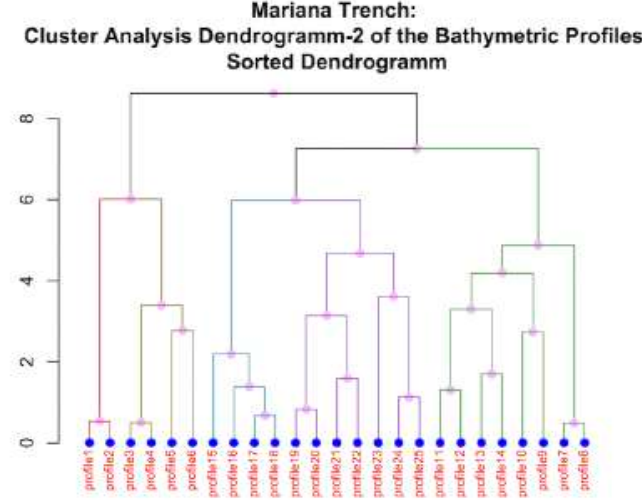

(b) Sorted dendrogram

Figure 3.8.21: Mariana Trench: hierarchical dendrogram tree of the profiles, by R code: A.6.6

Hierarchical dendrogram clustering method was selected due to its flexibility: this type of the ML is used specially for unlabelled data, i.e. without defined categories or groups, aimed to understand data possible allocation into groups. As the structure of the tectonics and trench geomorphic properties are rather complex, the dendrogram clustering facilitated data partition though defining the resulting groups, with similar morphology, distance to the volcanic areas, slope angles and sediment thickness. Used $\mathrm{R}$ script for cluster analysis: A.6.6. 


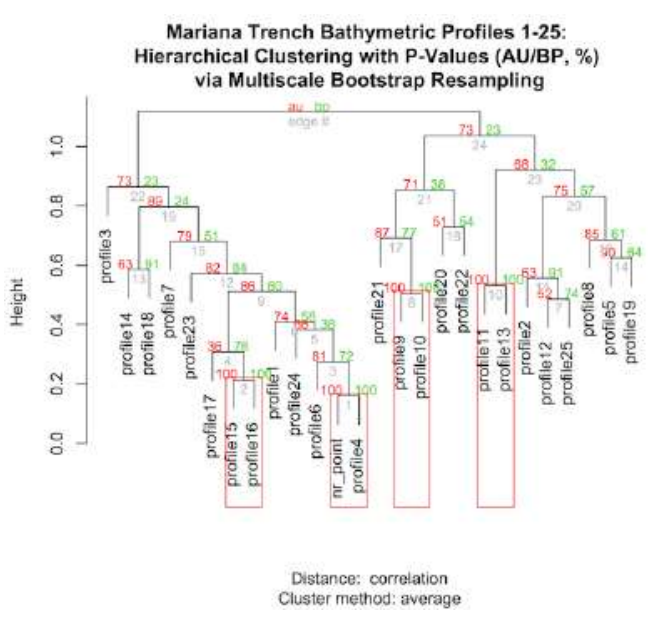

(a) Bootstrap resampling

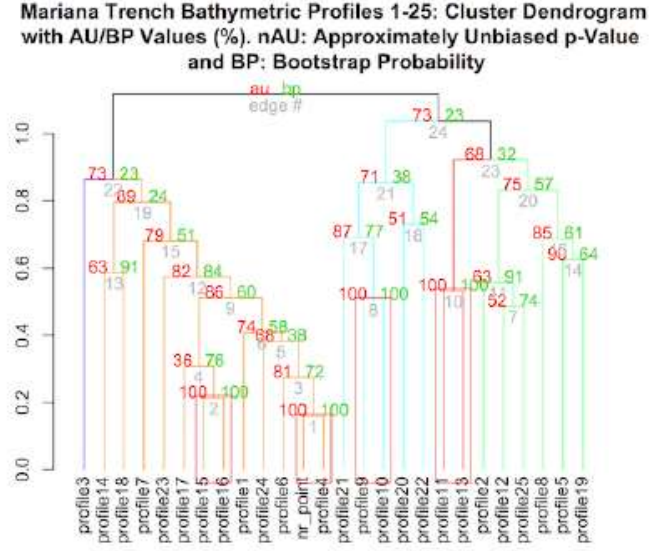

(b) Bootstrap probability

Figure 3.8.22: Mariana Trench: hierarchical clustering, R code: A.6.6

To summarize methodology of clustering, the advantages consist in usability of $\mathrm{R}$ libraries and algorithms at one time to understand the best option for the data set. The approach is dendrogram by the \{dendextend \} library aimed at data partition according to the geospatial properties [402]. A table in (.csv) format was read as data frame into $\mathrm{R}$, and a script was called based on mathematical algorithm of data processing. It calculated variables (geology, bathymetry, geomorphology, sedimentation and tectonics), and divided the dataset into clusters according to their similarity. Once the data are analyzed by the ML, the visualization of the groups and data partition were performed.

\subsubsection{Scatterplot Matrices}

Scatterplot (covariance) matrix is an advantageous approach for the analysis of the big datasets containing multi-source data. Covariance matrix is a square matrix giving the covariance between each pair of elements in a dataset. It illustrates determinant for linear correlation between multiple variables, are efficient way to highlight the environmental variables that might have similar correlations to the geomorphic structure of the trench. Mathematical definition of the covariance matrices is given in Formula 3.9.6.9:

$$
\left.K_{X X}=\operatorname{cov}[X, X]=E\left[X-\mu_{x}\right)\left(X-\mu_{X}\right)^{T}\right]=E\left[X X^{t}\right]-\mu_{x} \mu_{x}^{T}
$$

The matrix is used to solve the problem of selection of the crucial impact factors affecting the hadal formation. The application is supported by purely practical algorithms of data partition that is, inspection of the possible determinants. The data with multiple variables congregating a geo-system are particular suitable to be used for the scatterplot matrix. The matrices correlation for tectonic plates were executed by $\{$ Ggally $\},\{$ data.table $\}$ and $\{$ ggplot 2$\}$ libraries. 


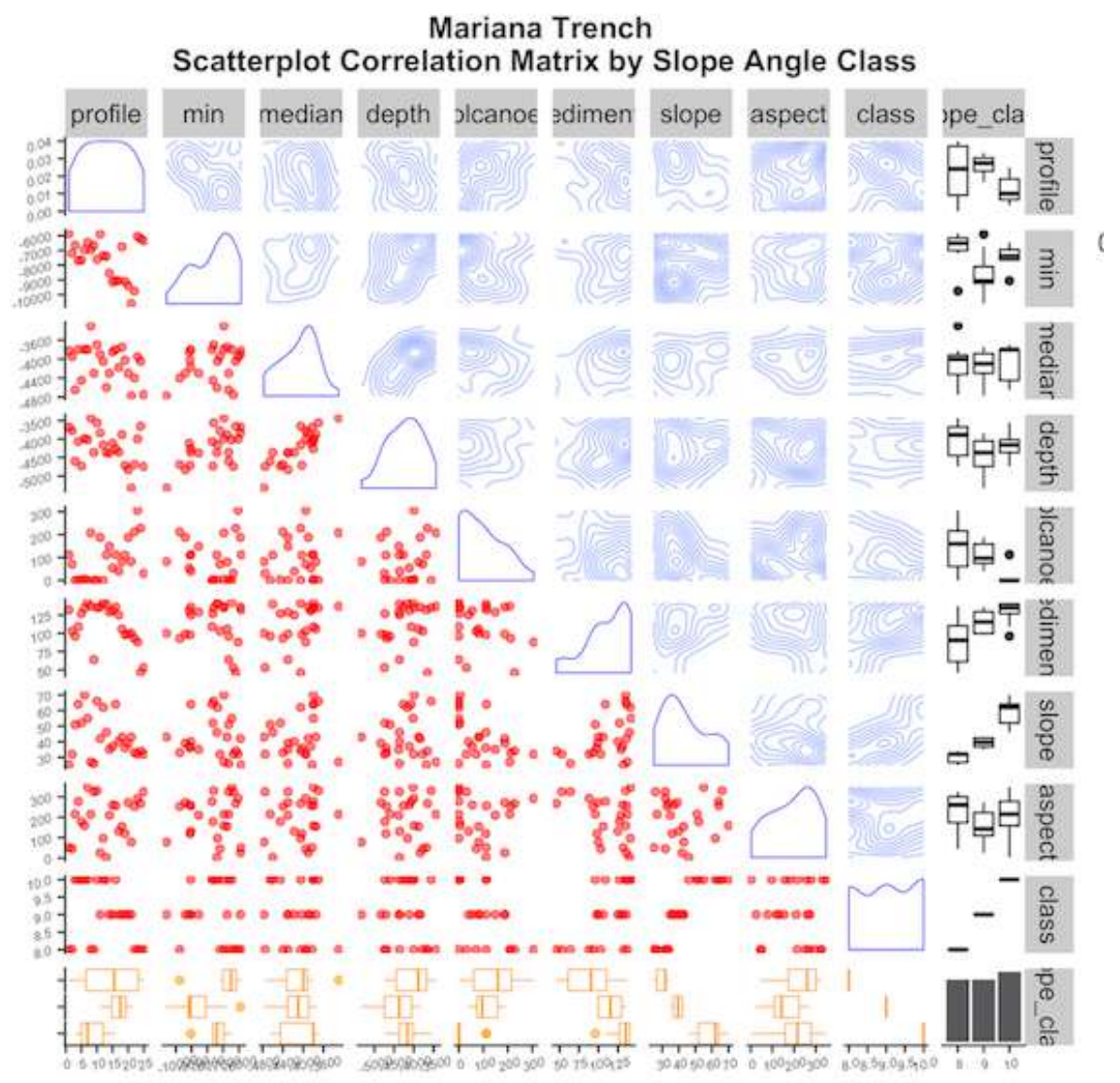

Figure 3.8.23: Mariana Trench: scatterplot matrix of the correlation between variables. R.

The matrix of Pearson correlation coefficients between each of the random variables in a given dataset, closely related to the covariance matrix is defined by Formula 3.8.18:

$$
\operatorname{corr}(X)=\left(\operatorname{diag}\left(K_{X X}\right)\right)^{-\frac{1}{2}} K_{X X}\left(\operatorname{diag}\left(K_{X X}\right)\right)^{-\frac{1}{2}}
$$

where $\operatorname{diag}\left(K_{X X}\right)$ is the diagonal matrix $X_{i}$ of the variances (diagonal elements) of $K_{X X}$ for $i=1, \ldots, n$. The $\mathrm{R}$ script, based on this mathematical definition, was used to assess correlation between factors affecting trench geomorphology: A.6.41. The bathymetric determinant of the 4 distinct groups of the cross section profiles cause certain variability in the sediment thickness of the basement, slope angle steepness degree, angle aspect, depth at the basement and statistical values (means, median and absolute minimum). A magmatism of the nearby area is notable among other factors. The closeness of the igneous volcanic areas contribute towards earthquake frequency across tectonic plates. The results demonstrated that cross-section profiles of the trench can be divided into clusters according to their properties, e.g. bathymetry, geographic location (latitude and longitude), geological (width of the sediment thickness), magmatism (large igneous polygon areas) and tectonic (location of the tectonic plates nearby).

The algorithms consist of taking variables to show correlation of their values with others across the range of the dataset. Scatterplot matrix shows similarity at the diagonal view, with increasing dissimilarity as the differences in the geologic and tectonic values increase. It analyzes correlation between the factors. Correlation function shows similarities between the characteristics of the tectonic plates. When depth increases (Fig. 1, [430], right center), correlation with sediment thickness increases to a maximum. 
As sample points change their position from plates, correlation increases to a maximum, because geologic settings vary accordingly. A notable peak in the correlation between the magmatism of the igneous volcanic areas and slope ${ }^{\circ}$ indicates the dependancies between the geomorphology and tectonics.

In a resulting covariance mapping the values of the $\operatorname{cov}(\mathrm{X}, \mathrm{Y})$ or pcov $(X, Y \mid I)$ matrix are plotted as a 2-dimensional map (Fig. 3.8.23) by following Formula 3.8.18:

$$
\left[X_{1}, X_{2}, \ldots, X_{n}\right]=\left[\begin{array}{cccc}
X_{1}\left(t_{1}\right) & X_{2}\left(t_{1}\right) & \ldots & X_{n}\left(t_{1}\right) \\
X_{1}\left(t_{2}\right) & X_{2}\left(t_{2}\right) & \ldots & X_{n}\left(t_{2}\right) \\
\vdots & \vdots & \ddots & \vdots \\
X_{1}\left(t_{m}\right) & X_{2}\left(t_{m}\right) & \ldots & X_{n}\left(t_{m}\right)
\end{array}\right]
$$

The method of the scatterplot matrix shows appropriate visualization for the large dataset overstepping thousands of the observation points. Scatterplot matrix displays values for typical variables for a dataset: depths, aspect, slope ${ }^{\circ}$ of the transects, sediment thickness, volcanic areas, topographic settings (max/min/mean depths, by profiles). The diagonal view of the scatterplot matrix gives an inside in to the relationships between these factors. Based on the scatterplot matrix it can be roughly determined that there is a linear correlation between several geological variables: sediment thickness have correlations to the slope angle degree and a depth values.

Scatterplot matrix enables to visualize several approaches (Fig. 3.8.23): scatter plots, boxplots with residuals, margin plots and surface plots, R code A.6.41. The effects of factors that increase sedimentation (location on tectonic plates, steepness) may hidden other environmental triggers underlying sedimentation responses. This is also induced by the biomass accumulation in the deep layers of the trench. Changes in patterns of the deep currents and intensity affected by submarine volcanism may cause increase sedimentation. This proves a feedback mechanism between the marine geological and biological factors. The submarine sedimentation in the oceanic trenches spatially correlate to the geological and tectonic factors and to the deformation features that induce submarine volcanism and closeness of the igneous volcanic areas. In such cases, sedimentation response rapidly.

The results indicate (Fig. 3.8.23) that sediment sources at the Mariana Trench are connected with trench tectonics. The relationships and links between the sediment thickness, slope angle steepness and profiles depth of the trench are shown on (Fig. 3.9.11. The sediment thickness gives a response towards the steepness and the depth. The rate of the submarine sediment accumulation is critical due to the preconditioning by these factors. It is also sensitive to the triggering factors: ocean deep currents contributing to the sedimentation and topographic variability observed in the cross-section profiles. $\mathrm{R}$ proved to be an effective tool for modelling scatterplot matrices that show distribution of the factors affecting geomorphic properties of the oceanic trench by distinct unevenness of the factors [609].

\subsubsection{EFA}

Factor analysis and PCA are based on R script: A.6.26 using dataset [431]. The fa() function from $\mathrm{R}$ was used (A.6.26), with the following primary arguments: $r$ : the correlation matrix; Nfactors: number of factors to be extracted; rotate: one of several matrix rotation methods, such as varimax or oblimin. $\mathrm{R}$ libraries for scripting simulations were used to model principal factors affecting the trench morphology. Mathematical definition of the statistical model is as follows.

There is a given set of $p$ observable random variables, $x_{1}, \ldots, x_{p}$ with means $\mu_{1}, \ldots, \mu_{p}$, unknown constants $l_{i j}$ and $\kappa$ unobserved random variables $F_{j}$ (common factors, as they influence all the observed random variables), where $i \in 1, \ldots, p$ and $j \in 1, \ldots, k$ where $k<p$. Then the definition can be described by Formula 3.8.19:

$$
x_{i}-\mu_{i}=l_{i 1} F_{1}+\cdots+l_{i k} F_{k}+\varepsilon_{i}
$$


Here, the $\varepsilon_{i}$ are unobserved stochastic error terms with zero mean and finite variance, which may not be the same for all i. The schematic process of factor analysis includes grid generation, model setup, execution and analysis of the results with visualized correlation matrix showing the most important impacts factors according to their values. The results of the correlation matrix are shown on Fig. 4, [432]. The standardized loadings based upon correlation matrix of factor analysis of the trench (Fig. 5 [432]) show impact values for each factor.

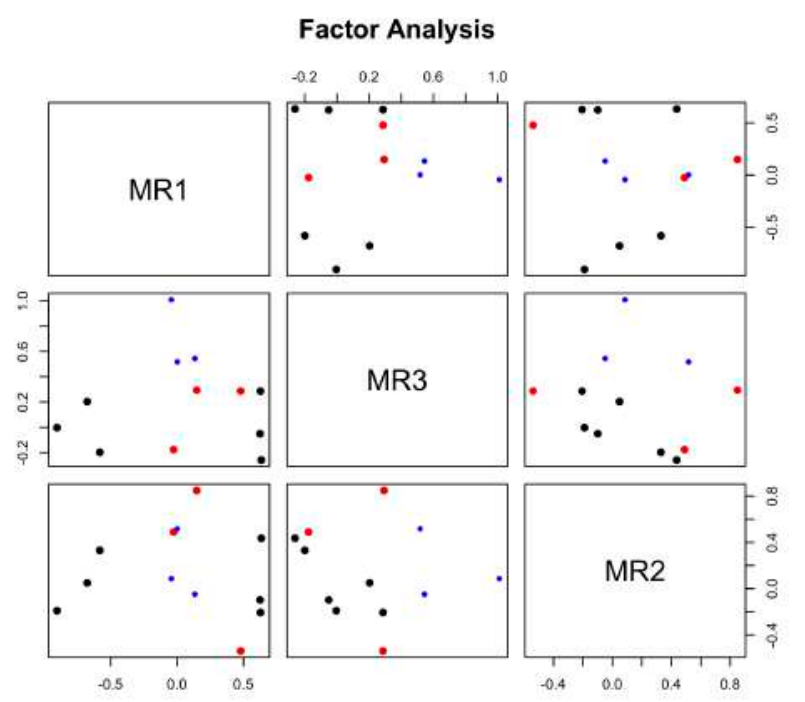

(a) EFA correlation matrix

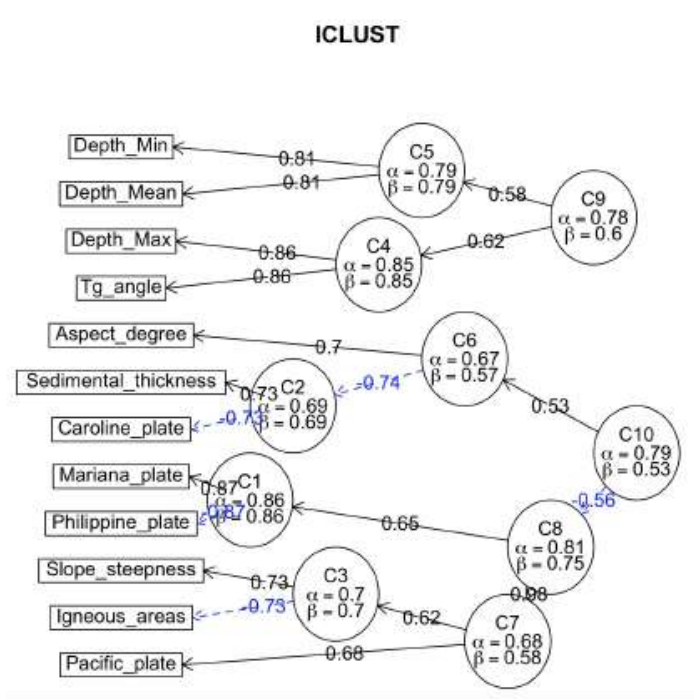

(b) iCLUST analysis

Figure 3.8.24: Mariana Trench: Factor Analysis, R code A.6.26

A \{FactoMiner\} library was used for cluster analysis iCLUST (Fig. 3.8.24). The goal is the same as for the factor or components analysis, but methodologically, it reduces the complexity of the data and attempts to identify homogeneous sub-groups. Here, EFA aims to extract more regular impact factors of the geologic morphological development, whereas cluster analysis and hierarchical dendrogram extract the groups and classes in a total cloud of the bathymetric observation points. Factor analysis results in illustrating cross-influences of the most notable factors: geological, geomorphological, tectonic, geographic and environmental parameters. This enabled to quantitatively analyze correlation between the actual shape of the trench and its impact factors (Fig. 6 [432]). Fm: one of several factoring methods, such as pa (principal axis) or ml (maximum likelihood), as shown on the code: A.6.26.

The $\omega$ testing was done to find out two alternative estimates of the reliability that take into account hierarchical structure of the inventory data $\omega$ (Fig. 3.8.25). It shows general factor saturation in a simple way ( $\omega$ h) (left) and through 3 factors $\omega$ coefficient (right). These were called using omega function for factor analysis, R code A.6.26. The computed coefficient omega (hierarchical) ( $\omega \mathrm{h}$ ) is an estimate of the general factor saturation of the performed test. Various factoring methods were tested to better describe data factors. Nevertheless, fa() function provided the best results used for common factoring (Fig. 7 [432]). The oblique rotation (rotate $=$ oblimin) was used, which recognizes that there is some correlation between geomorphological factors affecting trench formation. 


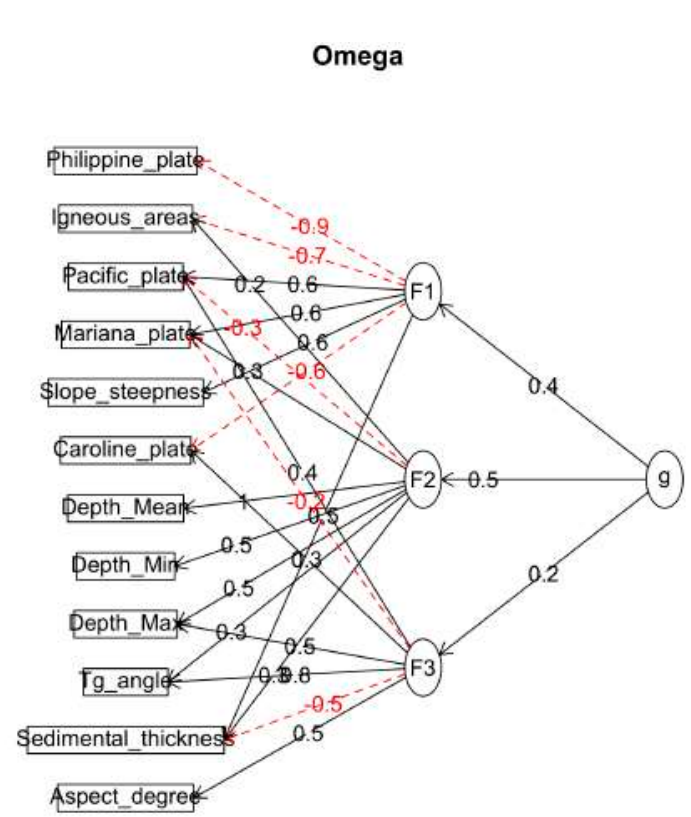

(a) General factor saturation $(\omega h)$

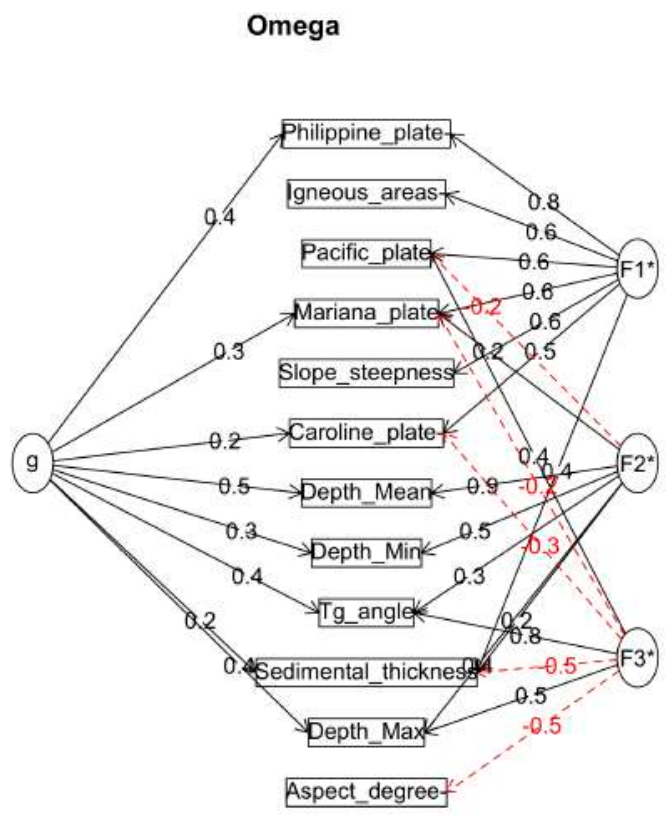

(b) General factor saturation through omega coefficient: 3 factors $\omega$

Figure 3.8.25: Mariana Trench: fragment of factor analysis, by R code A.6.26

The principal axis factoring ( $\mathrm{fm}=$ "pa") was used, as the identifying the underlying constructs in the data was not necessary in this case. The EFA matrix is shown on Fig. 3.8.24, left. Once all cross-section profiles are inspected, the assessment of the bathymetric sample points and other parameters (depth, sediment thickness) were met by factor analysis correlation matrix: Fig. 3.8.24. Factor loadings (Fig. 5 in [432]) enable to assess the results of the factor solutions. Thus, one can see that sediment thickness (factor solution $=0.65$ ), slope angle steepness (factor solution $=0.61$ ), and Mariana Plate location (factor solution $=0.74$ ) have high factor loadings $>0.5$ around 0.7 on the first factor (PA1).

Therefore, these factors are the most influencing and representative for the trench morphology. The sediment thickness is mostly impacted by the slope steepness. 2 geophysical indicators were particularly tested in the comparative analysis. It was found that slope degree and amplitude has important impact on the sediment thickness, while aspect degree has lesser effect. The second column (PA2) reveals (Fig. 5 [432]) that calculated $\operatorname{tg}^{\circ}$ slope angle has a factor solution $=0.98$ (extremely high), following by depth distribution (factor solution $=0.76$ ). General factor saturation $(\omega \mathrm{h})$ and 3 factors $\omega$ coefficient are shown on Fig. 3.8.25.

The location of the Caroline and Philippine Plates do not affect that much trench with negative factor solutions (-0.79 and -0.70 , respectively), by lower loading on PA2 (factor solutions $=0.25$ and 0.12 ) and a slight loading on factor PA1. This suggests that statistics is less related to the concept of Caroline and Philippine Plates than Mariana Plate and its geomorphic settings, e.g. $\operatorname{tg}^{\circ}$ slope angle steepness, sediment thickness. On the resulting table (Fig. 5, [432]) one can see that each factor accounted for around $20 \%(0.26 \%$ and $0.18 \%)$ of the variance in responses leads to a factor solution accounted for $100 \%$ of the total variance (Cumulative proportion PA2: 1.00) in the trench morphology. Finally, these factors are correlated in-between at 0.15 and recall that this choice of the oblique rotation allowed for the recognition of this relationship. The hypothesis testing was sufficient, with following factors having the highest score: $\operatorname{tg}^{\circ}$ slope angle, sediment thickness, Mariana Plate location. 


\subsubsection{ANOVA to assess hypothesis testing}

The results have been interpreted on the homogeneity of variance by means of the one-way ANOVA series of tests (Fig. 3.8.26). Several ANOVA test methods were executed. The brief description of their advantages and particularities is given below. The Tukey Honest Significant Differences (HSD) multiple pairwise-comparisons was applied to the ANOVA results. The Formula 3.8.20: for Tukey's test is as follows:

$$
q_{s}=\frac{Y_{A}-Y_{B}}{S E}
$$

where $Y_{A}$ is the larger of the two means being compared, $Y_{B}$ is the smaller of the two means being compared, and SE is the standard error of the sum of the means. Since ANOVA test is significant, the Tukey HSD test was computed by R code: A.6.28. TukeyHSD() takes the fitted ANOVA as an argument. This test enabled to perform multiple pairwise-comparison between the means of groups. The library \{multcomp\} was used to perform a Pairewise t-test and to calculate pairwise comparisons between the group levels with the corrections for the multiple testing using $\mathrm{R}$ function pairewise.t.test().

The Levene's test was used to analyse the homogeneity of variances at the next step of ANOVA testing by calling function leveneTest() in the car package: A.6.28. This is an inferential statistic used to assess the equality of variances for a variable calculated for two or more groups by Formula 3.8.20:

$$
W=\frac{N-k}{k-1} * \frac{\sum_{i=1}^{k} N_{i}\left(Z_{i}-Z . .\right)^{2}}{\sum_{i=1}^{k} \sum_{j=1}^{N_{i}}\left(Z_{i j}-Z_{i}\right)^{2}}
$$

Where $\mathrm{k}$ is the number of different groups to which the sampled cases belong; $N_{i}$ is the number of cases in the $\mathrm{i}$ group; $\mathrm{N}$ is the total number of cases in all groups; $Z_{i j}$ is received from the value of the measured variable for the $j$ case from the $i$ group.

Comparing to the Pairewise t-test, the advantages of the Levene's test is its lesser sensitiveness towards the departures from the normal distribution. Afterwards, the Welch t-test was executed in parallel to the oneway.test() in experimental mode defined by the following Formula 3.8.20:

$$
t=\frac{\hat{X}_{1}-\hat{X}_{2}}{\sqrt{\frac{s_{1}^{2}}{N_{1}}+\frac{s_{2}^{2}}{N_{2}}}}
$$

The Welch-test does not require that assumption have been implemented in the function oneway.test() which make is more suitable comparing to the last one. 

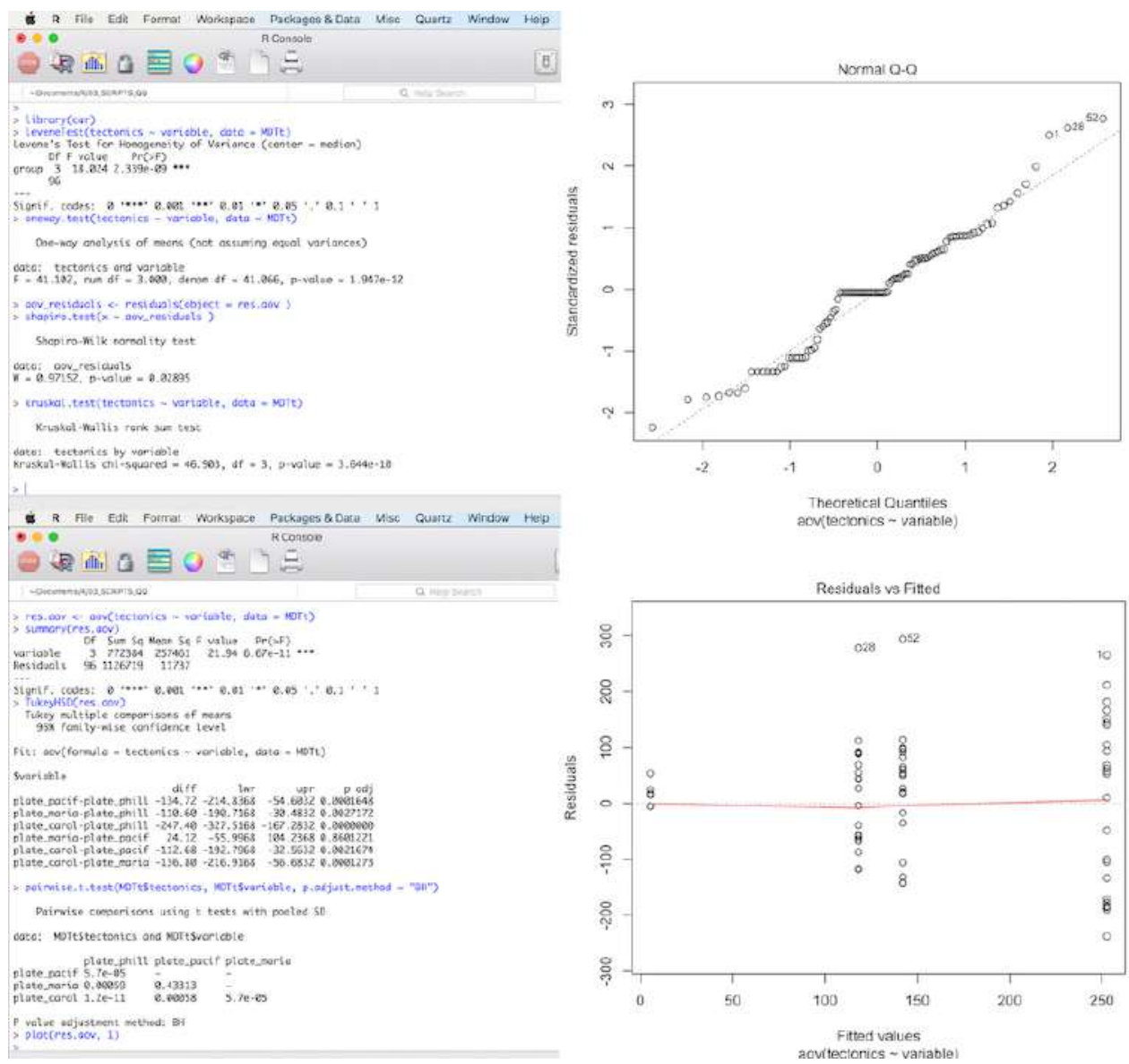

Figure 3.8.26: Mariana Trench: ANOVA hypothesis testing, by R code: A.6.28

The Shapiro test was alternatively used to analyze variance of the residuals to assess a test of normality (Fig. 3.8.26) by Formula 3.8.20:

$$
W=\frac{\left(\sum_{i=1}^{n} a_{i} x_{i}\right)^{2}}{\sum_{i=1}^{n}\left(x_{i}-\hat{x}\right)^{2}}
$$

Finally, a non-parametric Kruskal-Wallis rank sum test was applied to finish with a series of ANOVA testing. The test statistic is given by Formula 3.8.20:

$$
H=(N-1) \frac{\sum_{i=1}^{g} n_{i}(\bar{r}-\bar{r})^{2}}{\sum_{i=1}^{g} \sum_{j=1}^{n_{i}}\left(\overline{r_{i j}}-\bar{r}\right)^{2}}
$$

where: $n_{i}$ is the number of observations in group $\mathrm{i} ; r_{i, j}$ is the rank (among all observations) of observation $\mathrm{j}$ from group $\mathrm{i} ; \mathrm{N}$ is the total number of observations across all groups; $\bar{r}_{i}$ is the average rank of all observations in group; $\bar{r}$ is the average of all the $r_{i, j}$. The result have been interpreted on homogeneity of variance by means of one-way ANOVA tests. Since the p-value (Fig. 3.8.26) is less than the significance level 0.05 , one can conclude that there are significant differences between the groups highlighted with "*" in the model summary, that is four tectonic plates. The Tukey multiple pairwise-comparisons test enabled to perform multiple pairwise-comparison between the means of groups and demonstrated $95 \%$ family-wise confidence level of the results. The plotted homogeneity of variances of the results are shown in Fig. 3.8.26. 


\subsubsection{Euler-Venn Diagram}

Logical visualization of the results as Euler-Venn diagram (Fig. 3.8.27) was plotted as illustration of correlations between the impact factors affecting trench geomorphology. The Euler-Venn diagram shows 4 and 6 factors (Fig. 3.8.27), plotted to visualize possible crossings between the variables and the most notable parameters using \{venn\} R library by script: A.6.23

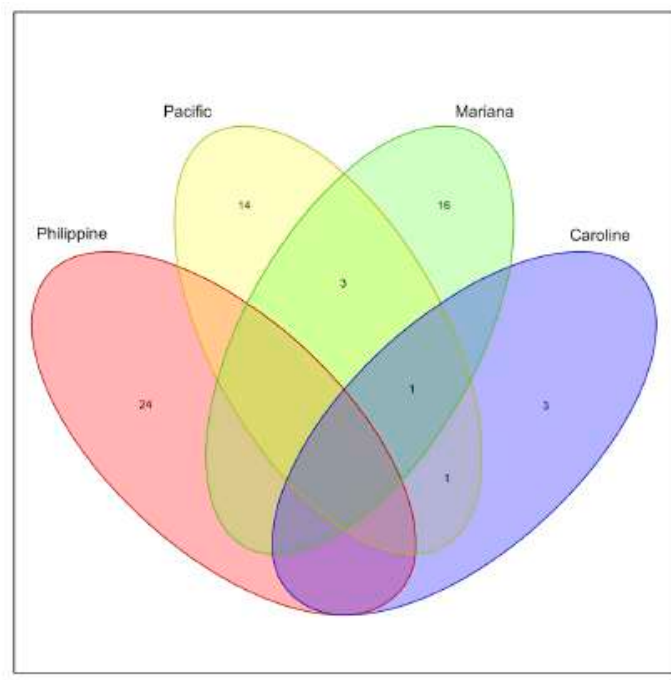

(a) Variables: tectonic plates

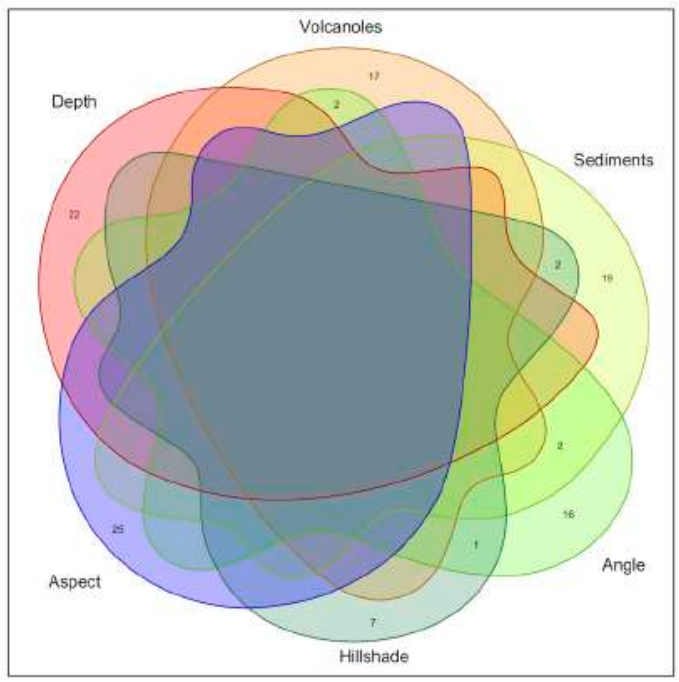

(b) Variables: geomorphology

Figure 3.8.27: Mariana Trench: Euler-Venn diagram, R code A.6.23

The Euler-Venn diagrams enable to analyze logical factors crossing and categories affecting morphology. It shows possible logical relationships between entries of a datasets: tectonic plates, sediment thickness; geometry of the trench (slope ${ }^{\circ}$, aspect class, hill shade group class derived as quantitative values from GIS); morphology; volcanism and depths. The area of the shape is proportional to the number of elements it contains, which is useful for explaining complex hierarchies and overlapping definitions as the case of factors affecting trench morphology (Fig. 3.8.27). Mariana plate crosses all other plates, yet the most correlation has with Pacific Plate. Comparing crossings between categories: sediment thickness and slope angle, igneous zones and trench slope ${ }^{\circ}$. Upon analysis of possible combinations, intersections and similarities between categories, one can see the relationship between the factors (Fig. 3.8.27).

\subsubsection{Word cloud}

The integrated use of GIS, statistical methods by R scripting applied for geological data processing aimed at a multi-disciplinary approach to study spatial distribution of the impact factors affecting trench geomorphology schematically presented on Fig. 22 [422] by R code A.6.34. The interpretation and classification of the spatial data were used to estimate factors of the trench geomorphology. Cumulated flowchart of methods, approaches and data was done by \{wordcloud\} library by R code A.6.36. 


\subsection{Python language for marine geology}

\subsubsection{Advantages of Python}

Python, an object-oriented, high-level programming language of general purpose applied for marine geological data analysis and data processing still remains a relatively novel approach. Usually applied in IT domain applications, such as computer data analysis or data science, Python initially released in 1991 by [640] can effectively be used in the marine geology as demonstrated in this section. Among other languages, Python has become increasingly popular [495], [533] both in industry and academia. There are various significant advantages of the Python that make it a stand-alone language among the others. The advantages of Python can be summarized in a concise way in a Tab. 3.9.1 as following answer to the main question of this subsection:
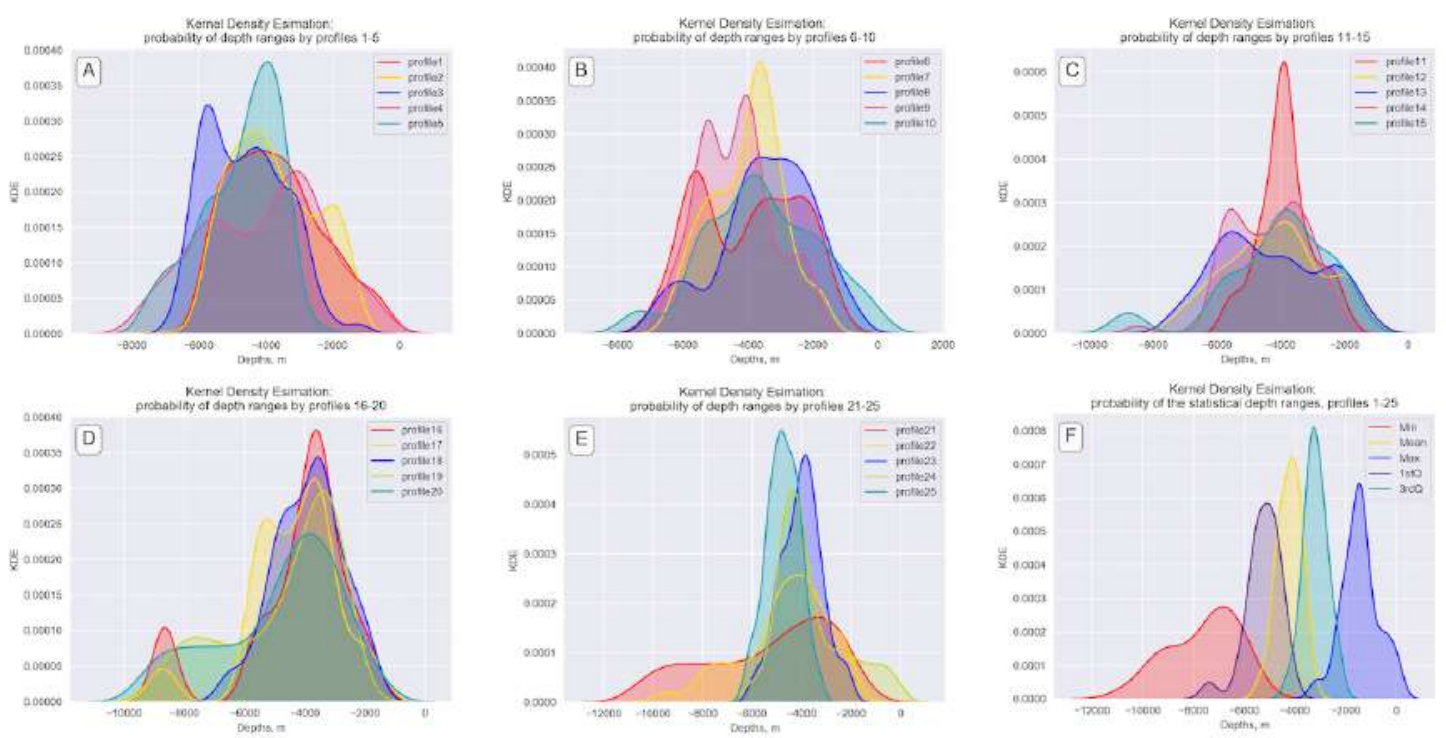

Figure 3.9.1: Mariana Trench: KDE of the bathymetric profiles, Python (Matplotlib and Seaborn) [428]

The polymorphism embedded to the Python syntax enables to seamless overload standard operators to adjust their behavior in the context of the current task. Since Python is a very-high-level and constantly evolving language, it has flexible arrays. Another feature of Python is its of the inheritance that scripts lets create subclasses containing qualities of their upper-level classes. GIS plugins do not able to perform a Python-level data analysis with the same effectiveness and visualization, e.g. such Python libraries as NumPy, SciPy, Matplotlib [399].

The syntax of the Pythons codes include operating with both immutable objects (such as strings and tuples) and mutable sequences of mixed types of items (such as lists). Besides, the division of the code into a visible interface and run makes the coding intuitive and fast. Moreover, the important feature of the Python consists in its object-oriented approach: encapsulating the long lists of the arguments and passing them into the objects makes the implementation of the code effective and not overloading the computer memory which is freed shortly after the last reference to it has been removed [399]. Pythons ability to read-in, manipulate, and write data to and from .csv files is a key feature enabling effective data analysis. Finally, syntax coding in Python can be formatted in readable and very structured style due to the long history of the language development.

In view of these advantages, Python was selected as a refined tool due to its powerful functionality and effective coding solutions. Hence, this dissertation introduces a broad application of the Python for data modelling based on the application of its embedded mathematical algorithms and statistical libraries: 
Table 3.9.1: Advantages of Python language for geo data analysis and processing

\begin{tabular}{r|lll} 
No & What ? & How ? & Where ? (Libraries) \\
\hline \hline 1 & Beauty of graphs & Color palettes, lines and design solution & Seaborn, Matplotlib, Bokeh \\
\hline 2 & Precision of data analysis & processing arrays, data frames & Pandas, NumPy, SciPy \\
\hline 3 & Elegance of coding & IDLE, Jupyter Notebook & All libraries \\
\hline \hline
\end{tabular}

Matplotlib, NumPy, SciPy, StatsModels [399]. The effectiveness of the data computing and visualization by Python is the key factor for applying its functionality in this dissertation. Some approaches of the scientific visualization and methods of the data analytics discussed previously by [115] were considered in this research.

Python provides an appropriate base for the geospatial analysis of the factors that affect the geomorphology of the trenches in their distinct parts. Python-based part of the research implemented the proposed statistical approach using SciPy, NumPy and Pandas libraries of Python and embedded algorithms. Applied methods of Python defines the variability in local geomorphological structure of the oceanic trenches. Spatial correlation between variables (sediment thickness, gradient degree of the cross-section profiles, geospatial location of the segments of the trench) were detected. Processing large data sets with variable numeric values: geomorphic, geologic and tectonic and geometric values (degree of slope steepness of profiles) were processed by Python and its libraries for statistical analysis and graphical plotting. The perspectives of Python application lies in its repeatability by existing codes. Proposed methodology can guide similar research on the analysis of the geologic variables in the trenches, in context of marine geologic analysis.

Python codes demonstrated in this dissertation are provided in full for repeatability of the methods in similar case studies (as summarized on Fig. 3.9.2). There are many approaches to analyze big data sets in marine science, and many of them are based on the use of GIS in various contexts: e.g. marine biology, bathymetric mapping, navigation, marine geology for exploration, etc. The novelty of using Python lies in the attempt to perform a multidisciplinary approach that combine programming with marine geological analysis. Most of the current GIS tools do not include the power functionality of Python for the statistical analysis of the large data sets in full and this dissertation contributes to the methodological development of the technical tools in marine geology.

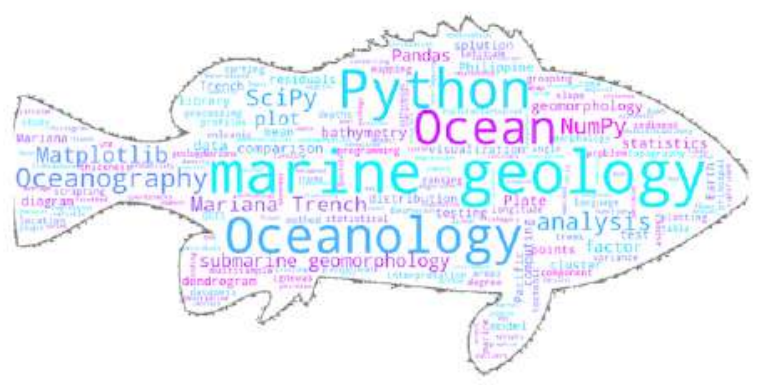

Figure 3.9.2: Python-based word cloud (libraries: Wordcloud, Matplotlib)

In view of the multidisciplinarity of the Python algorithms, methods and codes demonstrated with a case study of the given data frame can effectively be applied in other aspects of the geological data, including data taken from the R/V observations. 


\subsubsection{Installing Python libraries}

The statistical analysis and programming algorithms were widely applied from the existing descriptions of the mathematical methods and computing approaches, [633]; [725]; [222]; [224]; [341]. Data processing was performed in Integrated Development and Learning Environment (IDLE), a Python editor and interpreter. Processing tables was done using multi-module NumPy fundamental library for fast computing and effective operating with arrays and matrices [575].

Current research uses the most recent version of Python: 3.7.2. installed via pip. The installation of the Python libraries and dependancies has been implemented via command line in bash terminal (bash is a Portable Operating System Interface (POSIX)-compliant shell). Because this process is not trivial, a brief explanation of the crucial installation steps is provided below. Upon installing the core packages of Python, the settings were adjusted. The package installer for Python pip version 19.0.3 was installed to ensure further installation of necessary libraries:

\$ curl https://bootstrap.pypa.io/get-pip.py -o get-pip.py

Afterwards, the pip was installed using following command:

$\$$ python get-pip.py.

The next step included the installation of the Apples xcode tools:

$\$$ xcode-select install. Then, two crucial python packages have been installed via the console utility pip. A NumPy, a Python based fundamental package for scientific computing providing convenient and fast N-dimensional array manipulation. A SciPy package, depending on the NumPy, has been installed as well. SciPy is used for the math computations, science, and engineering. Pandas, the most popular data manipulation package in Python has been installed for processing data in tabular format.

The installation of these packages was done using pip in command line bash terminal for SciPy version 1.1.0, NumPy version 1.14.5, and Pandas version 1.11.0, stepwise:

\$ pip install scipy \$ pip install numpy \$ python3 -m pip install pandas.

Additionally, plotting packages assisting in visualizing the data: Matpotlib and Seaborn version 0.10.0, have been installed using commands:

\$ sudo python3 -m pip install matplotlib

$\$$ python3 -m pip install seaborn.

The advantages of the Matplotlib consists in its versatility and capability of creating a significant variety of scientific plots. Seaborn package is build atop of the Matplotlib. It combines the power of the Matplotlib with more intuitive approach for the scientific data visualization. After all necessary libraries have been successfully installed, the statistical analysis has been performed using available geo dataset on the sample trenches.

\subsubsection{Data preprocessing}

The QGIS part of the research produced an optimized representative sampling dataset consisting of 25 cross-section profiles having in total 12.590 bathymetric observation points. The data were read-in as a table in a .csv format and processed by algorithms in Python libraries: Pandas for reading and processing tables, NumPy for array analysis, Matplotlib for large dataset modelling, analysis and visualization. Importing data from table with variables in Comma Separated Value (.csv) file was done using Python Pandas library, installed in the previous step.

Data were converted from the attribute QGIS tables, imported and stored into .csv tables. These included vector layers, the coordinates and thematic attribute data in numerical or string format. Further data processing was implemented by Python. These include cross-section profiles having data from various vector GIS layers used to visualize several thematic maps from the project: bathymetry, geographic coordinates and depths, information on geological provinces, tectonics, geometric properties of 
the trench: steepness angles of the profiles and bathymetry, ophiolite areas, large igneous provinces and lithology, seamounts, igneous volcanic zones, sediment thickness, tectonic plates boundaries in the area.

The data.frames were created by Pandas for storing tabular 2D data. Using read_csv() function the .csv files were read into Pandas DataFrames data type. Current working folder for the Python scripting was defined as follows:

$>>>$ import os

$>>>$ os.getcwd()

$>>>$ os.chdir('/Users/pauline/Documents/Python').

Defining working folder is crucial, since it indicates the path to the data storage, manipulating and reading by Python libraries.

\subsubsection{Pandas: a Python library for creating DataFrames}

Geologic and tectonic data attributes were imported into the Python using Pandas library a csv table. Pandas, a data management library of Python enabled perform data management and manipulation, e.g. logical queries for spatial analysis. Pandas was used for various manipulations with geological data: loading from csv table, viewing, editing content, analyzing data range and structure, selecting target rows and columns, automation of the data processing, manipulation and inquiries, examining the descriptive basic statistic on data, etc.

Therefore, the start of this project initialized with the loading an existing of the GIS data set into a Pandas environment. The csv file was imported into the Pandas DataFrame using command: $\mathrm{df}=$ pd.read_csv("Tab-Bathy.csv"). The initial table for the bathymetry (a case of Mariana Trench) had 517 rows and 18 columns. At the second step, the data were analyzed by logical queries in Pandas environment for tables. Selecting necessary columns or rows and their attributes in Pandas is relatively straightforward. Thus, using iloc and loc as operations for retrieving data from Pandas data frames, necessary columns were selected for modelling by logical selections.

For example, $X=\mathrm{df} .1 \mathrm{loc}[:, 1: 13]$ was done for the case of selecting 12 first columns in the bathymetry table. Alternative syntax would be (for the case of 4 columns) $X=d f . i l o c[:,[1,2,3,4]]$ for smaller data sets where the number of columns could be defined manually. Similarly, selecting necessary row during the data analysis was done using loc[] function, e.g. $B=$ df.loc[12] returned the bathymetric observation nr. 13 (starting from 0). For instance, selecting the slope classes fir geomorphic analysis across the Mariana Trench was done using following Python snippet code:

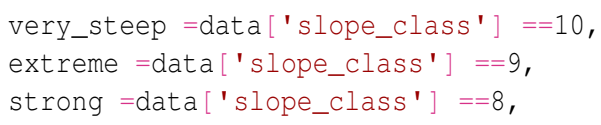

which returns a boolean expression of True/False for all 25 profiles. Selecting a particular profile and corresponding geologic columns for this profile was done using following code snippet (example of profile nr. 15):

profile_15 =data. loc [data[profile] ==15, [sedim_thick, slope_angle, igneous_volc]

Analyzing the geological data set is possible through the logical queries by Pandas, for example, to find the maximal bathymetric depth, or to find a profile that has the thickest layer of sediments. This is done by the codes:

\# What is the maximal depth? (bathymetric analysis)

data['Min'].min() 


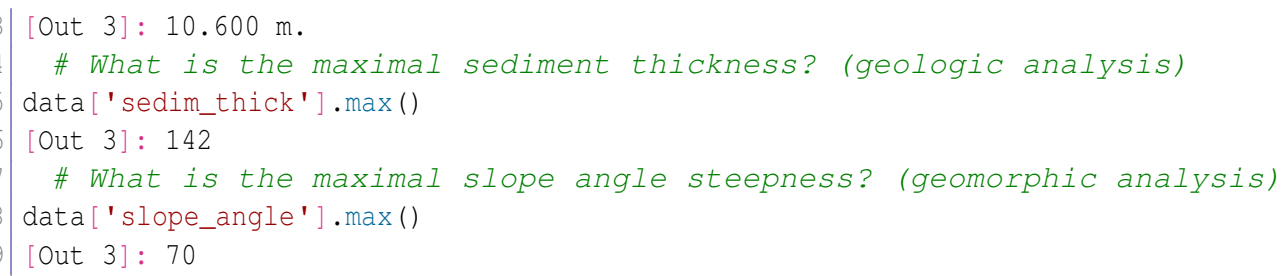

Other examples of the logical queries:

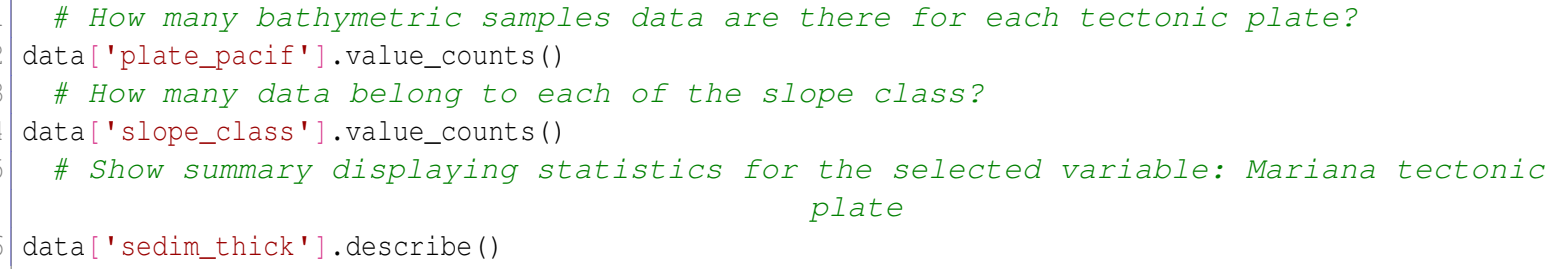

This returns a descriptive statistics on the column of sediment thickness: count 25.000000 mean 112.040000 std $27.967958 \min 46.00000025 \% 98.00000050 \% 125.000000 \quad 75 \% \quad 135.000000 \max 142.000000$ Name: sedim_thick, dtype: float64

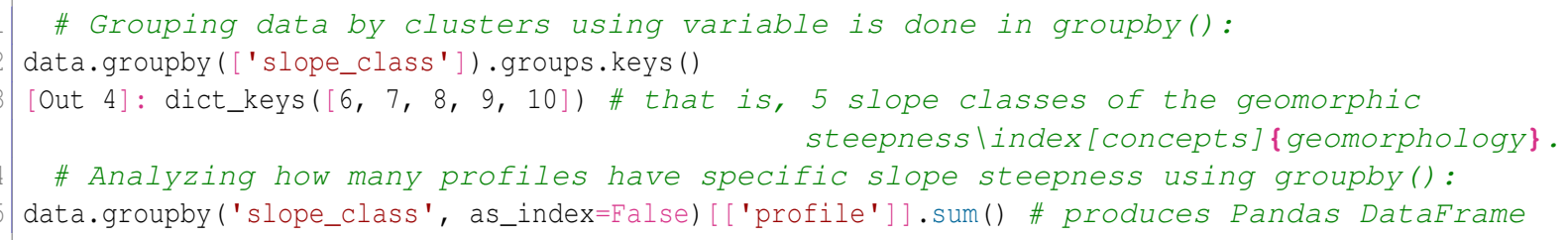

Similar logical queries are possible through Pandas environment. All manipulations with data were done using Jupyter Notebook. Data were examined and viewed to make sure that columns and rows are correctly processed. For example, a df.shape function was used to know the exact number of rows and columns., or df.ndim to check up the dimension of the array; df.head() and df.tail() for analysis of the first and last rows of the data frame. The types of each column were checked using .dtypes function.

\subsubsection{Python libraries: Matplotlib, NumPy, SciPy, Seaborn, StatsModels, Bokeh}

General functioning of Python is well described in the existing references and manuals [585]; [592]; [595]. Using Python libraries enables to process large marine geological datasets effectively, to apply advanced computation algorithms, to create namespaces while working with modules. Pythons modules contain packed classes, objects, functions and constants.

Processing geodata received from the attribute tables as vector layers was performed by Python libraries. Necessary installed libraries include Matplotlib, NumPy and SciPy. The SciPy library has many modules used for numerical computations: statistical data transformation, simulation, modeling, visualization by ML algorithms. The Matplotlib library is the main library used for statistical data processing [264], visualization and plotting. Its installation was done using command via bash terminal (example for Matplotlib): \$ python3 -m pip install matplotlib.

The next step included installing certificates to enable connections to the websites containing data frames in Python 3.7.1 on the Mac OS Mojave 10.14.3. This step was necessary, because the Python 3.x has no certificates. This action required a post-install step installing the 'certifi' package, version 
certifi-2018.11.29. To validate Secure Sockets Layer (SSL) connections the following command has been implemented in the bash terminal:

\$ sudo /Applications/Python 3.7/Install Certificates.command

Jupyter Notebook, an open-source web application for Python, was installed by command:

$\$$ sudo python3 -m pip install jupyter

It is used to store and share Python codes, equations and plot visualizations with legends. Running Jupyter Notebook was done by call:

\$ jupyter notebook. All Python scripts were processed, saved and exported via Jupyter Notebook.

Libraries and their dependancies were installed by pip: NumPy and SciPy:

\$ python3 -m pip install numpy

$\$$ python 3 -m pip install scipy

NumPy is effective tool for processing arrays, sorting and selecting of read-in data from the tables. NumPy creates a multidimensional array object from a given table.csv. Using Pythons syntax and semantics, it operates with matrices using logical, bit-wise, functional operations with elements, and performs a series of the routines for fast operations on arrays [575]. NumPy is based on the object-oriented approach, mathematical and logical manipulations with table using 'ndarray'.

Scripts, modules and codes were written using reference semantics and built-in functions of NumPy and Python. Saved scripts included written codes that parse command lines and perform graphs plotting by executing functions and modules. The namespaces of NumPy were imported from numpy.core and numpy.lib by calling:

$>>>$ import numpy as np

The depending libraries have been installed as well. These include Jinja2, NumPy, Pillow, PyYAML, Six, Tornado. Manipulating with tabular data stored in csv files was implemented in Pandas optimized for the high-level processing of tabular data. The Matplotlib library was installed and imported to customize plots.

Matplotlib library was selected as a main tool for graphical plotting by Python, as it enables operating statistical analysis and plot figures using pyplot functions: plotting and adjusting the areas, visualizing statistical outputs, selecting colors for the plots, adding labels etc. Seaborn library enables to perform refine plotting, modelling and analysis of a large set of marine geological data aimed at understanding poorly explained submarine geomorphic structure of the oceanic trenches.

StatsModels library was used for linear regression applied for data interpretation. The aim is to investigate correlation between various factors: bathymetry, geomorphology, tectonic plates and their correlation. The methodological approach include data analysis, modelling, plotting and visualizing. Statistical modelling by StatsModels include several tested algorithms:

1. weighted least square linear regression between geological variables;

2. autocorrelation;

3. design matrix;

4. Ordinary Least Square (OLS) regression;

5. quantile regression

Spatial and statistical analysis of the correlation between factors aimed at detecting of geological and geodetic factors affecting steepness and shape of the trench. Following factors were analyzed: geology (sediment thickness), geographic location of the trench, tectonic plates and depths records along the profiles: max, mean, min values, and statistical calculations of the $1^{\text {st }}$ and $3^{\text {rd }}$ quantiles. The study revealed correlations between sediment thickness, distinct variations in submarine geomorphology and sampling across the trench segments. 


\subsubsection{Data Analysis}

The profiles were analyzed by modelling in Python. A statistical modelling aimed at the analysis of the relationships between the attribute factors use main existing statistical methods. During statistical testing and experiments, numerous approaches [70]; [714]; [585]; [584] provided by Python StatsModels and Matplotlib libraries were used as the core algorithms. The statistical analysis was done using table containing attribute values of the marine geospatial parameters. Topographic values of the profiles were derived from the table with depths of samples. Min/max and quartile values were read into table. Despite variations in density of the sample data caused by geomorphic shapes (ranging from extremely steep slope to gentle slope), it was possible to merge and integrate the results of the vector overlay.

Statistical analysis was based on Python libraries that include mathematical algorithms and common approaches for data processing and analysis [123]; [65]; [99]. The KDE analysis was carried out in Seaborn library using mathematical algorithms described by [98]. Visualized results of combining five KDE plots for the bathymetric cross-section profiles are shown on (Fig. 3.9.1). It can be seen that combining five profiles enables to compare the geomorphology of the trench and significantly increases recognition of the variations, depth and heights from plotting single profiles separately. Thus, the range of the density distribution in the elevations across the archipelago and trench can be seen (Fig. 3.9.1).

\subsubsection{Letter-value plots}

The features shown on the letter-value plot (Fig. 5) are distribution of the bathymetric data samples across 25 profiles. The statistical approach is derived from the Tukey's original boxplot principle [248]. The letter-values plot shows a large number of quantiles in the bathymetric sample set, defined as 'letter values'. The layout of this plot is similar to a boxplot, modified and improved. Besides plotting a nonparametric representation of a depths distribution across the profiles, where data distribution corresponds to the observations, it plots more quantiles.

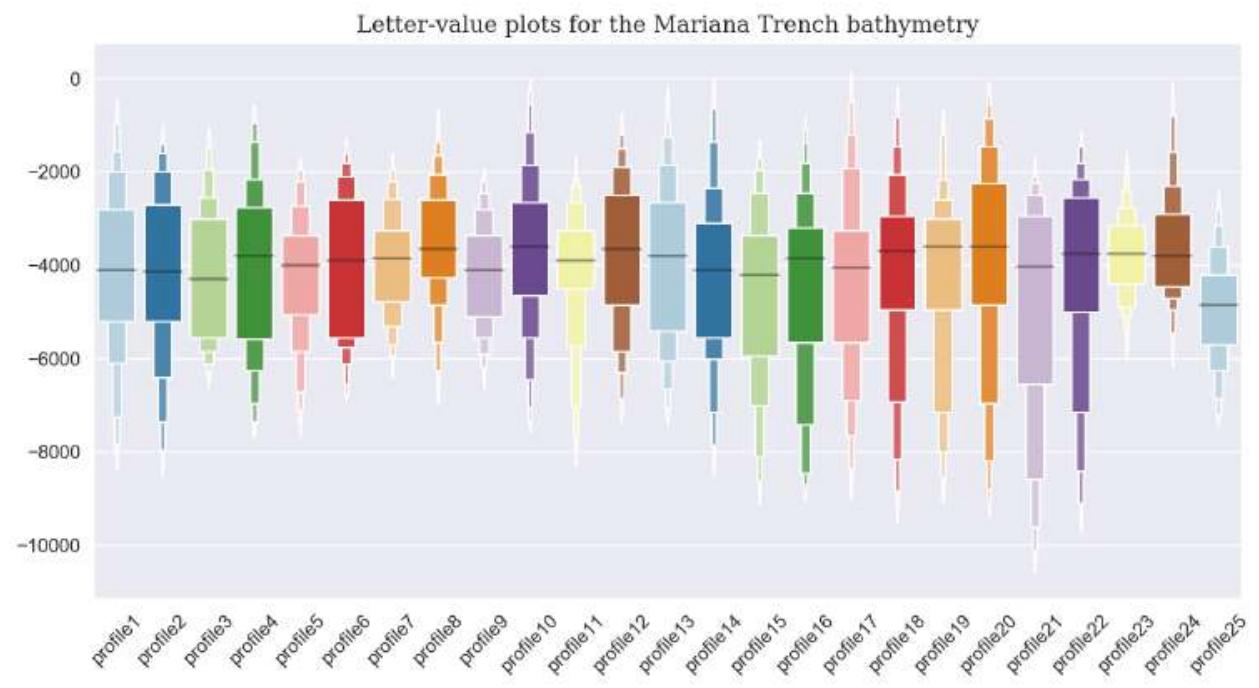

Figure 3.9.3: Mariana Trench: letter-value plot for data distribution by profiles, Python

Letter-values plot gives more deep inside into the shape of the bathymetric data distribution. Hence, it can be seen clearly that the maximal depths of the Mariana Trench are located in the south-western part of its crescent. Comparing to the boxplot, the letter-value plot provides more detailed information in the tails using letter values on the bivariate big real data sets demonstrate to be more useful due to the more detailed approach on data analysis. The letter-value plots were done using Python code A.5.8. 
Technical implementation of the letter values plots was based on the existing methods [248]; [246] embedded in Seaborn library. More sophisticated theoretical explanation on the boxplots is given [538]). Comparing box plots code with letter value plots, the letter value plots are better suited to the marine geological datasets, as they represent detailed information in the tails by letter values (Fig. 3.9.3) showing data distribution. The samples shown on the letter-value plot illustrate actual range of the samples (Y axe) by 25 profiles (X axe). The median, mean and quantiles are shown as horizontal lines on each box representing the set of the samples across each of the profile. The plots for the 25 profiles include reliable estimates of their corresponding quantiles (as Tukeys boxplot) showing outliers (profiles 2 and 3 ) labeled as observations beyond the most extreme letter values.

Calculation of the pairwise Pearson correlations and plotting correlation matrix between the geological, geomorphic and bathymetric factors was done in R. Methods to plot correlation matrix (Fig. 4.12.4) include R based data analysis that embed computing correlograms for the data arrays [201]. The methods and approaches of the Matplotlib and Seaborn libraries used for plotting figures by Python language were derived from the existing literature describing statistical algorithms [263]. Finally, the geomorphic steepness of the slopes was tested (Fig. 4.12.5) using ranking plotting algorithm available in R libraries \{ggsignif\}, \{graphics\} and $\{$ tidyverse $\}$.

\subsubsection{Violin plots}

Analysis of data distribution for depths across the 1000km hydrographic profiles using violin plot approach by script. This was done using Pythons sb.catplot() function for categorical data analysis by code A.5.1. The violin plot (Fig. 3.9.4) combines a box plot with KDE aimed to analyze the distribution of the bathymetric data.

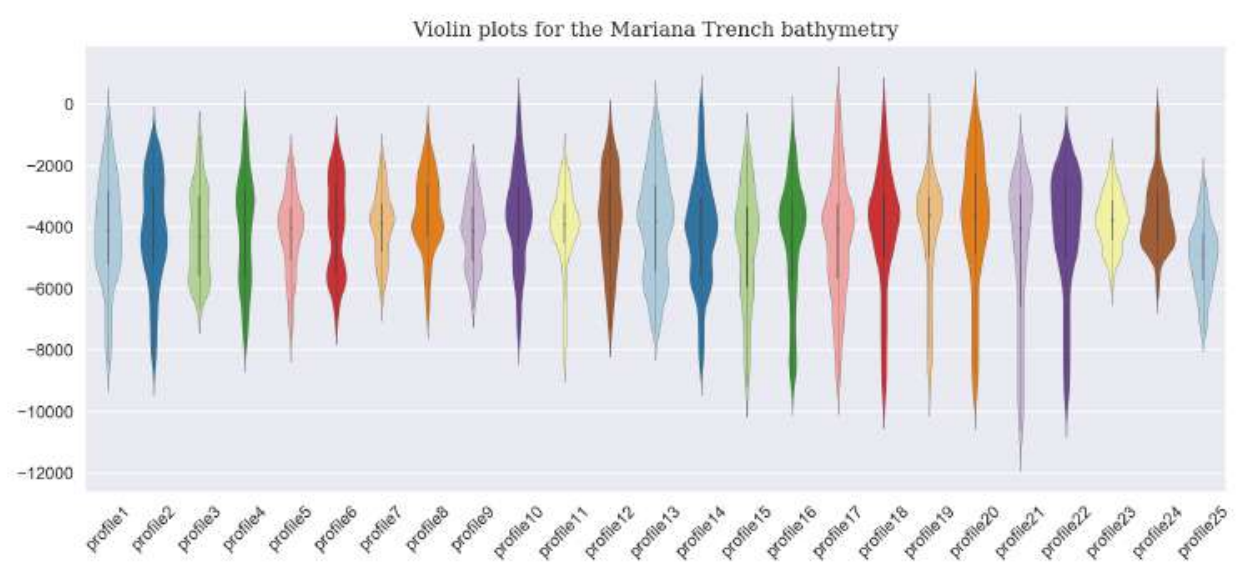

Figure 3.9.4: Mariana Trench: violin plots on depth ranges, Python, by code A.5.1 [415]

Inside the violin quartile and whiskers are shown from the boxplot. As violin plot uses the KDE, the wider portion of the violin plot shows, the higher density of the bathymetric observations. Vice versa, and narrow regions indicate very deep or very shallow values with lower density, rare across the bathymetric profile. The presented plot shows distribution of the bathymetric values: depths along the profiles.

The inter quartile ranges in the boxplot and higher density portion in KDE are placed in the same region of their categories within the violin plot. There is a notable decrease of depth in profiles 23, 24, 25 (Fig. 3), crossing Caroline Plate, which may be caused by changes in local geologic settings. Profiles 21 to 24 show the deepest depth in data range for profiles 21 and 22. Since tectonic attribute values differ significantly, a comparative analysis of the data variation across tectonic plates was undertaken. 


\subsubsection{Hierarchically-clustered heatmaps}

Cluster map was plotted by Seaborn function seaborn.clustermap() by Python code A.5.2 to group bathymetric values by ranges in 25 profiles. Cluster map is a method applied in this data analysis showing a matrix plot dataset represented as a hierarchically-clustered heat map. Core technique of the clustermap implies graphical representation of the bathymetric data ranging from 0 to $-10.000 \mathrm{~m}$, where samples are located in cells of a matrix, represented as colors (Fig. 3.9.5).

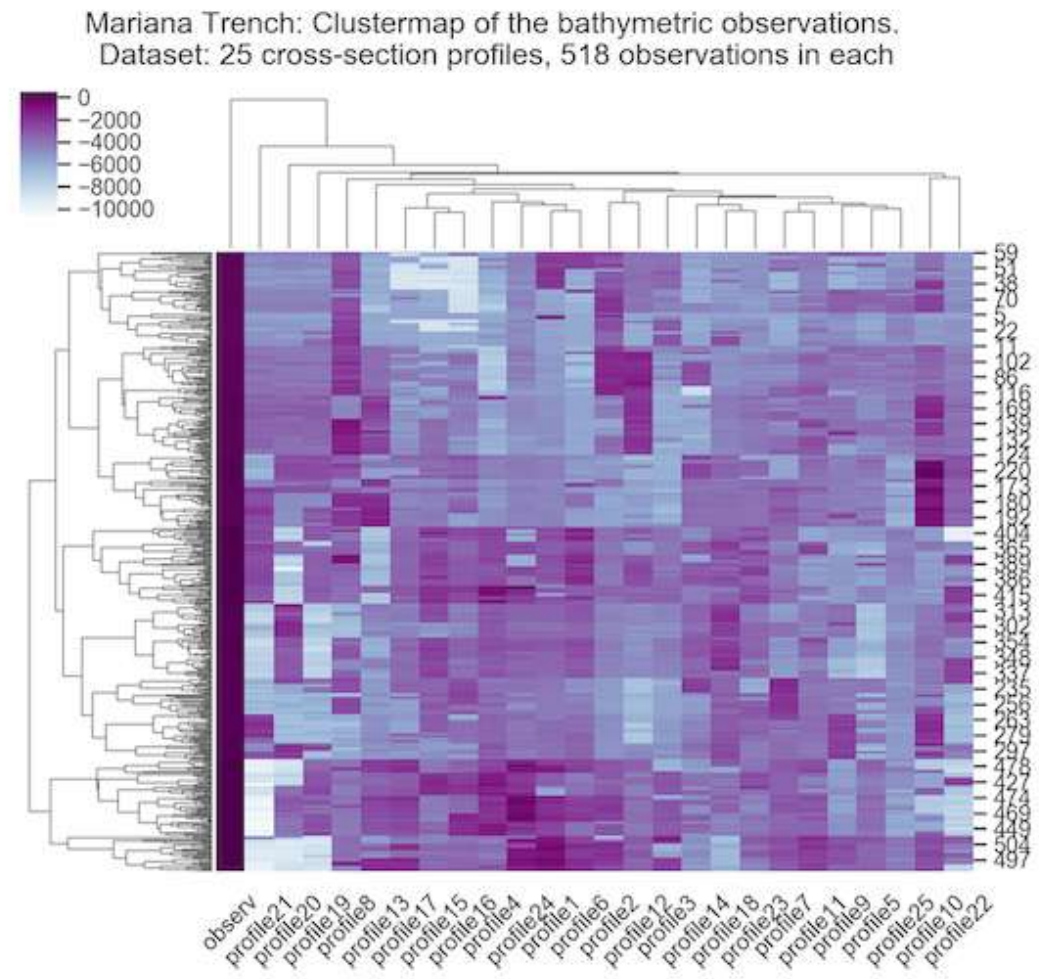

Figure 3.9.5: Mariana Trench: heatmap for the bathymetric data distribution by profiles. Python

Structured representation arranges depth values by their semantic similarity using clustering method ignoring outliers in colormap limits. To plot clustermap, Python assigns each of the 518 samples to a specific cluster of depths, divided into 6 groups with max cluster of depths $>7.500 \mathrm{~m}$. Cluster centers serve as local target points with largest node resting at the center and attracting other values of depths that belong to this cluster. Clustermap (Fig. 3.9.5) highlights groups of samples with similar depths by colors assigned as increasing darkness to the deepest values.

\subsubsection{Histograms plotted by Python}

In a general mathematical sense, a histogram is a function $m_{i}$ that counts the Nr. of samples that fall into each of the groups (bins), while graph of a histogram is a graphical way to visualize a histogram. Thus, if $n$ is the total number of samples and $k$ is the total number of bins, the histogram $m_{i}$ meets the following conditions, Formula 3.9.6.4:

$$
n=\sum_{i=1}^{k} m_{i}
$$


The data set contained environmental variables separately for tectonic plates to be analyzed. This required merging columns by category tectonic plates. Therefore, columns with the plate names were melted into one class to enable data analysis by plates. The data were processed by code A.5.4. The histograms show underlying frequency distribution of a submarine topography of the trench (Fig. 3.9.6). It allows data distribution (normal), as well as outliers, skewness. The data are distributed and colored by tectonic plates.
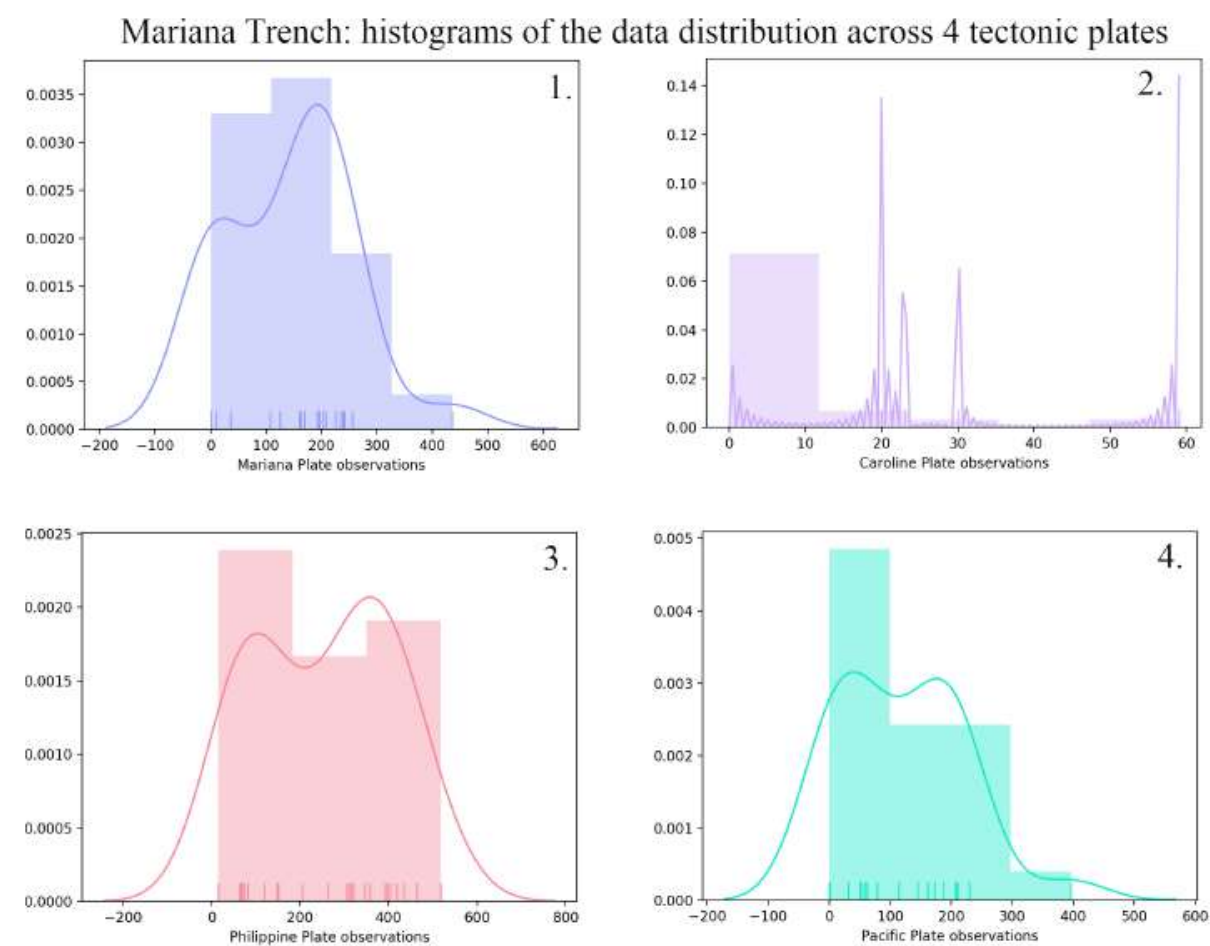

Figure 3.9.6: Mariana Trench: histograms of data distribution by tectonic plates. Python. Source: [421]

\subsubsection{Strip plots by Python}

Visualizing strip plots showing the relationship between the sediment thickness and slope angles as compared by tectonic plates was done by Python code A.5.5. The particularity of the scatter strip plots (stripplot()) lies in its nature: this is a categorical type of plot showing variable dependance (max depths by profile) upon another variable (tectonic plates). It represents depth values by 25 profiles sorted along tectonic plates. One can see the difference on data distribution. Pacific and Mariana plates are comparable, while Philippine Plate covers the majority of the data. As can be seen on Fig. 3.9.6, the majority of the observation points are located in the Pacific and Philippine plates, following by Mariana, while Caroline only covers a few points [421]. Sedimentation processes differ significantly by four tectonic plates, due to the overall complexity of the sedimentation, trigger factors and mechanisms.

\subsubsection{Euler-Venn diagrams by Python}

The Euler-Venn diagram were used for visualizing logical relations between geological variable. It shows modelling intersection and correlation of various factors for four cases where overlapping in values or concepts are visualized. Fig. 3.9.7 (A) shows cumulative total sediment thickness by tectonic plates. Fig. 3.9.7 (B) shows detected igneous volcanic spots. Fig. 3.9.7 (C) shows slope degree and Fig. 3.9.7 (D) shows methodological overlay showing the approaches of this work: GIS data mapping and 
digitizing, geological analysis and Python and R programming languages. Fig. 3.9.7 shows modelling intersection and correlation of various factors in the Mariana Trench project. In particular, it shows A): Bathymetric observations by plates, cumulative computing; B): Sediment thickness, slope degree and closeness of the volcanic spots; C): Subdivision of the slope steepness by classes; D): Methodological approaches. The Euler-Venn diagram was done by Python code A.5.26.

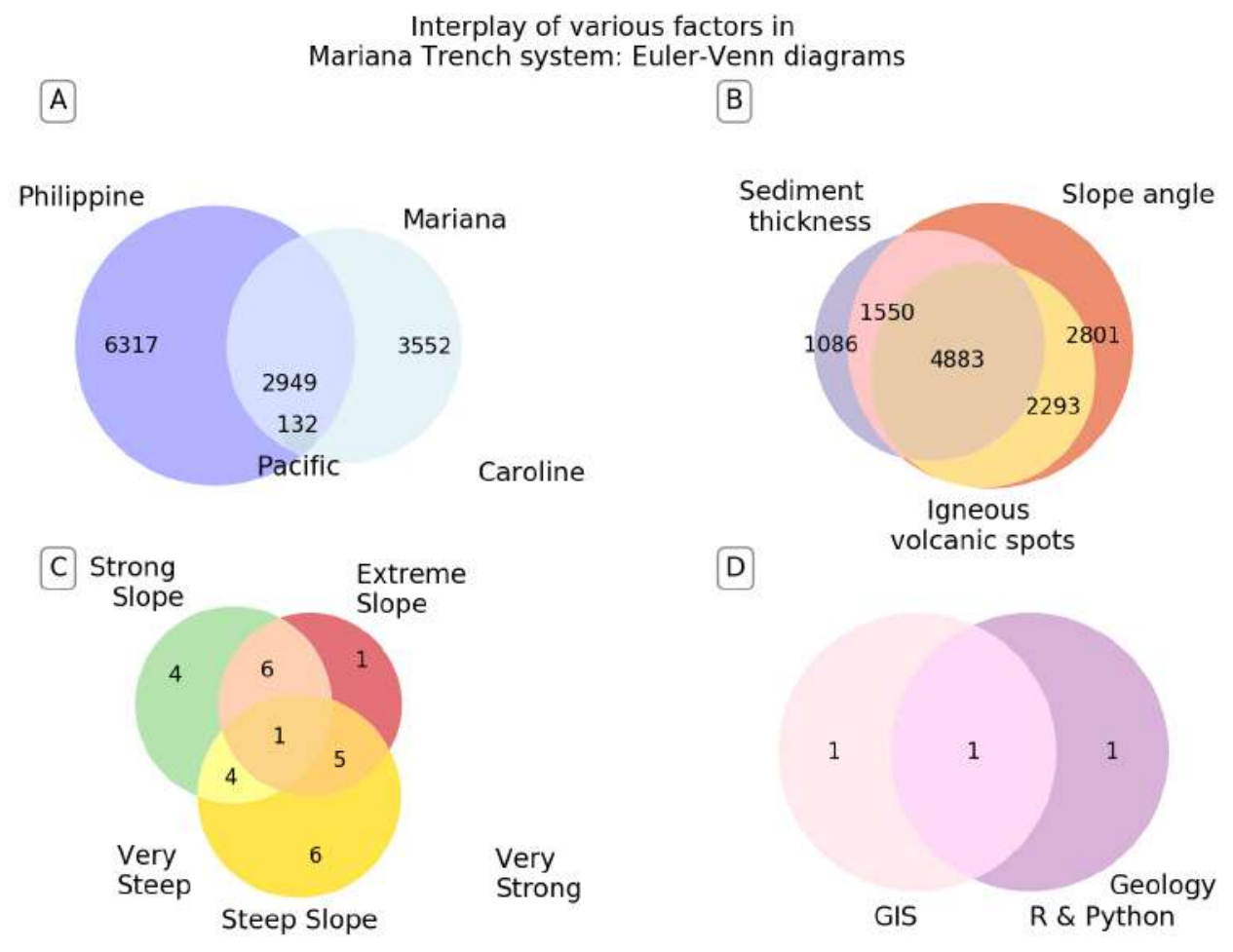

Figure 3.9.7: Mariana Trench: Euler-Venn diagrams, Python [415]

\subsubsection{Regression Analysis}

The regression models propose that $Y_{i}$ is a function of $X_{i}$ and $\beta$, with $e_{i}$ representing an additive statistical error term (residual) that stands in for umodeled determinants of $Y_{i}$ or random statistical noise, Formula 3.9.6.7:

$$
Y_{i}=f\left(X_{i}, \beta\right)+e_{i}
$$

Initially, 25 profiles were visualized by area chart and facet grid (Fig. 3.9.8). This gives an overview of the geometry (shape and steepness) and bathymetry (depths) of the profiles. 
Bathymetric cross:-5ection 25 profiles of the Mariana Trench:

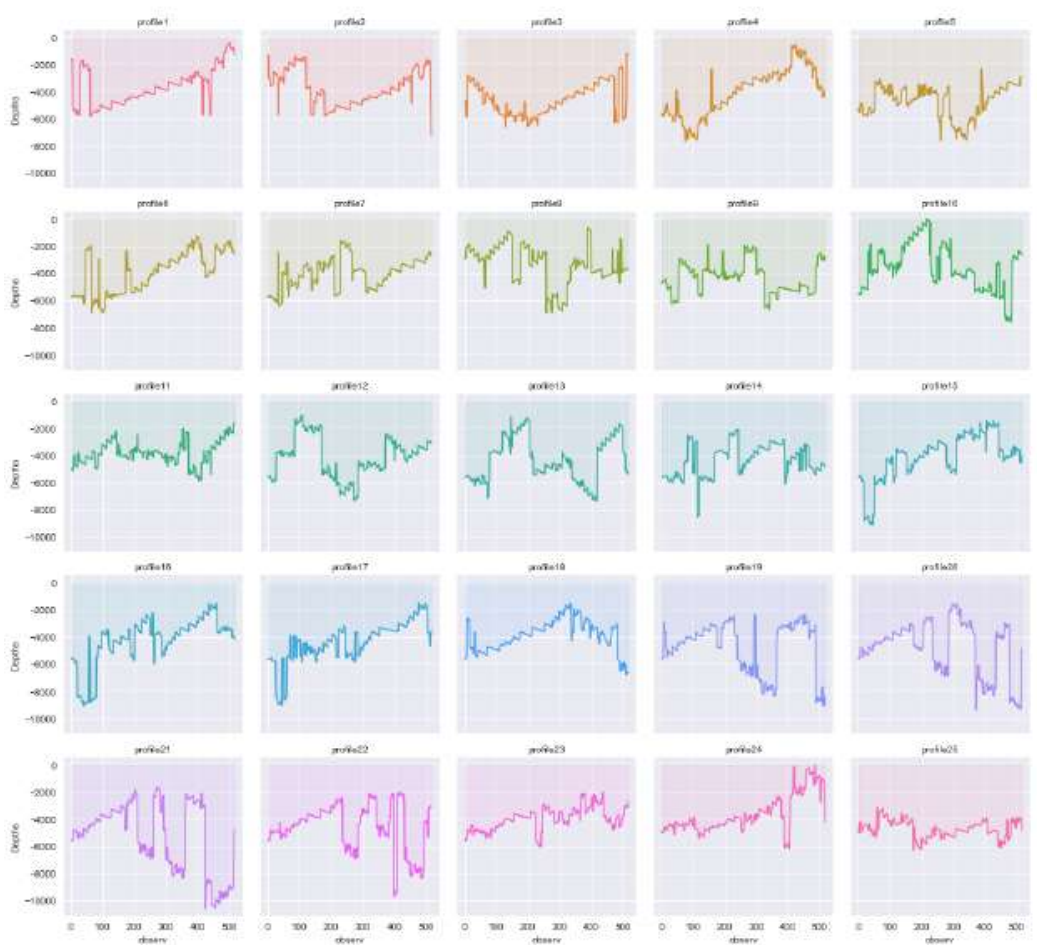

Figure 3.9.8: Mariana Trench: area chart and facet grid of the profiles, Python (Seaborn)

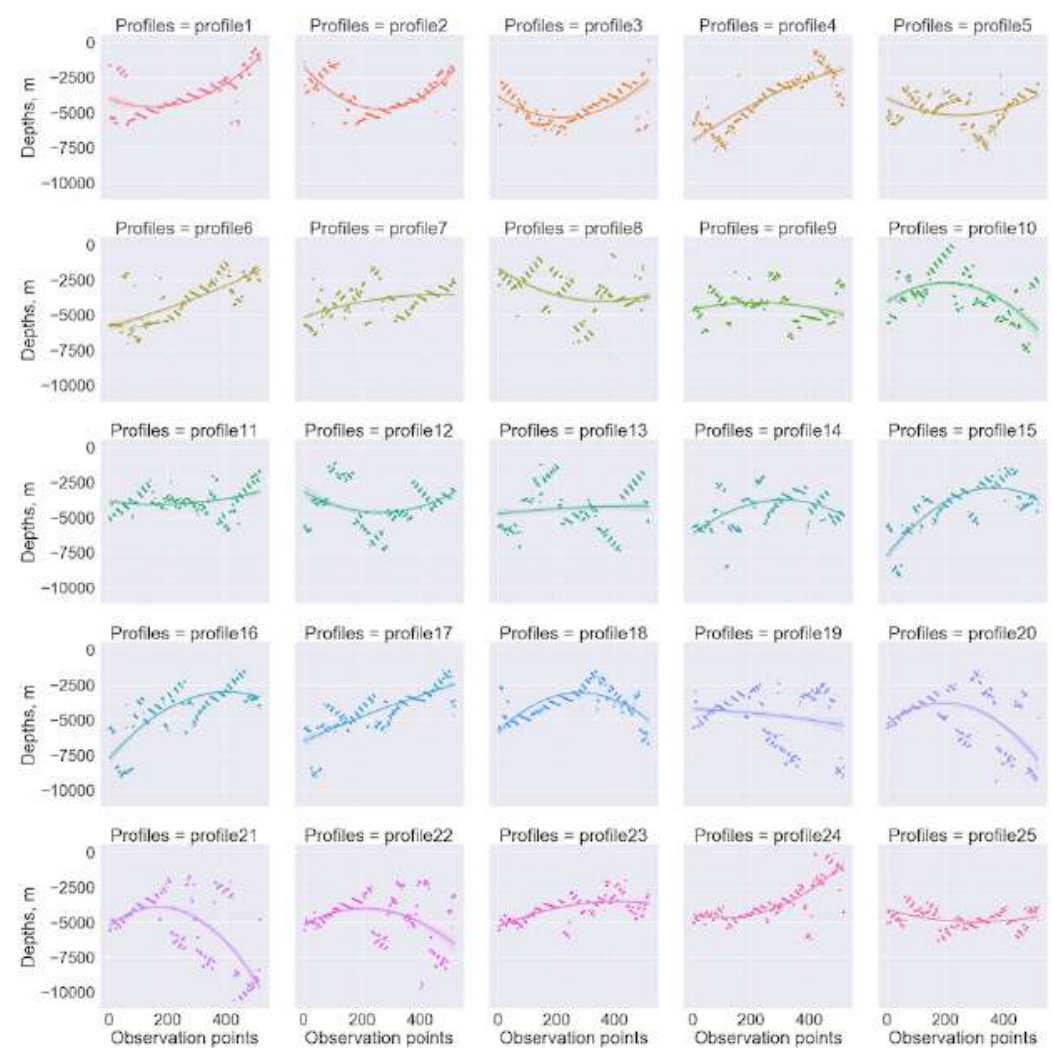

Figure 3.9.9: Mariana Trench: facet grid of the regression analysis of the profiles, Python 
Second, the regression analysis for the 25 profiles (Fig. 3.9.9) has been done using $\operatorname{lmplot}($ ) function which is a figure-level function that combines regplot() and FacetGrid() functions of the Matplotlib, Python. The regression analysis was done using Python code A.5.7.

\subsubsection{Cluster heatmap and hexagonal data distribution and Kernel Density estimation}

Hexagonal mapping is another useful approach for analysis of the big data sets when there are many observation points that may overlap. In this case, the data set comprised 12.950 points. Hexagonal binning that plots density rather than points showing concentration between data values in specific profiles (Fig. 3.9.10, right). Depth points are binned into gridded hexagons and distribution (the number of depths ranges per hexagon). As a result, it is displayed (Fig. 3.9.10, right) using the density of color within the hexagons. The KDE is a non-parametric approach that visualized the probability of the density of a depth variables by profiles (Fig. 3.9.10, left). Joint Hexagonal and KDE plots are drawn by Python code A.5.9.
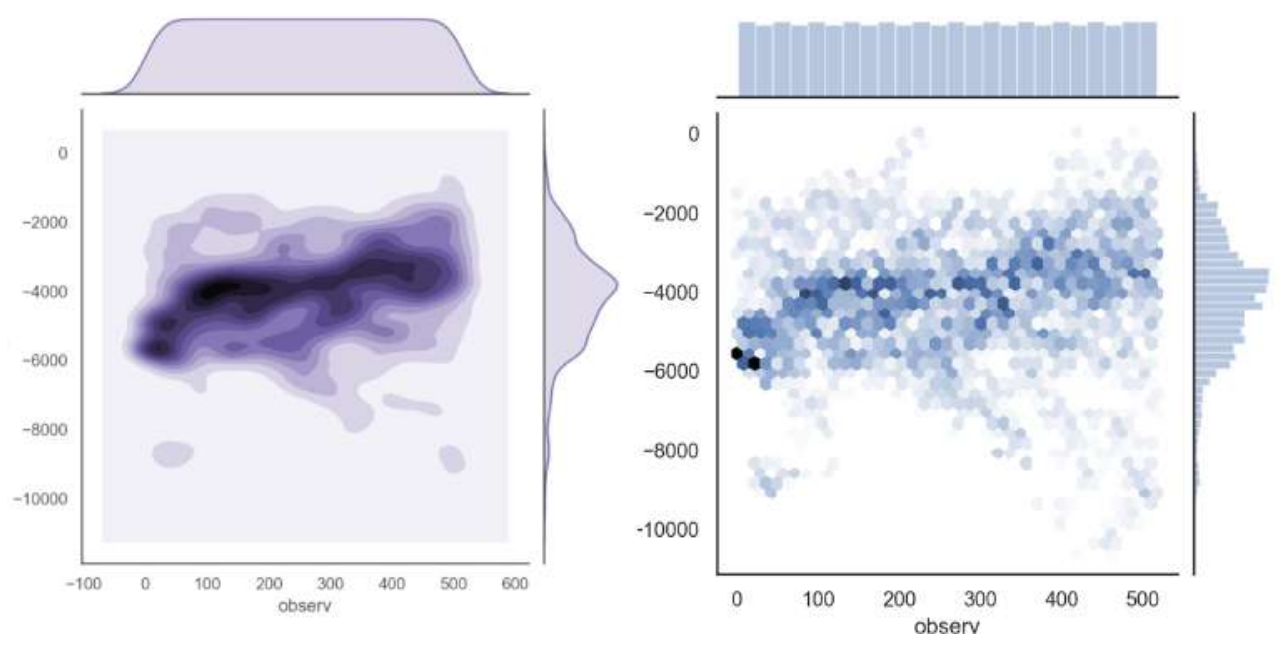

Figure 3.9.10: Mariana Trench: hexagonal and KDE plots by profiles. Python code A.5.9

The color palette was selected as reversed, i.e. the most deep values are visualized as light purple values, and vice versa. The $\mathrm{x}$ axis shows the bathymetric profiles, the $\mathrm{y}$ axis shows the observation points in each profile. The color shows the depth recorded values. The left y axis shows the sub-division of the observations into hierarchical dendrograms starting from the two groups and soon, grouped based on the similarity of the depths. The records of geologic data (sediment thickness), submarine topography (slope angle degree and steepness by profiles) and bathymetry (absolute depth values: maximal and mean) on the map was also analyzed with respect to relationship in the dependence of the parameters.

\subsubsection{Correlograms by Python}

Correlograms, or covariance matrices, give the background for all standard multivariate techniques. Correlograms allow to check randomness of data, and analyze data structure [176]. Three correlation methods research were tested (Pearson, Kendall and Spearman to visualize the relationship between the trench variables and representing a matrix of correlations schematically in forms numbers placed within the shaded squares (two of the three methods are shown on Fig. 3.9.11). 


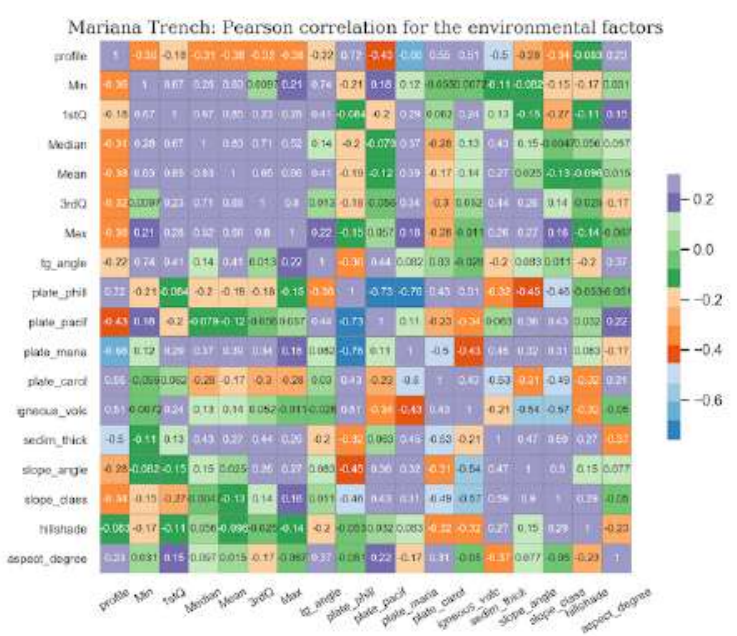

(a) Pearson's correlation (parametric approach)

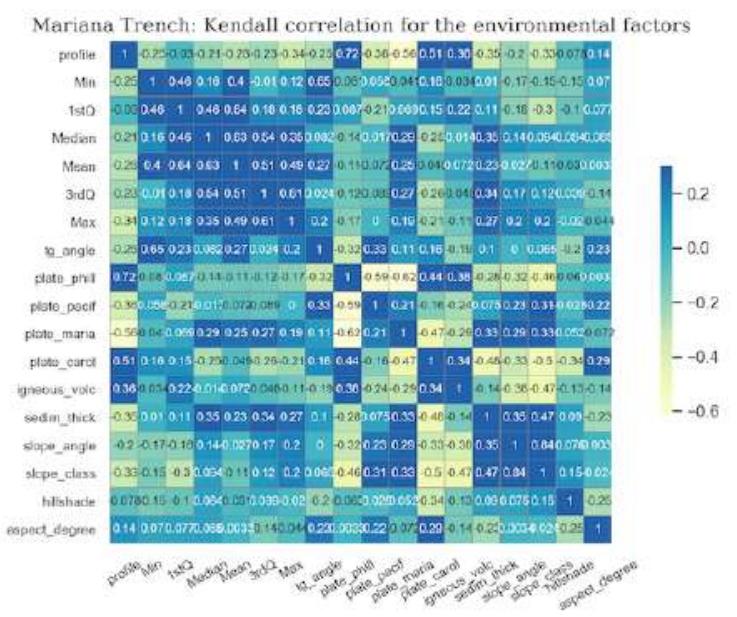

(b) Kendal rank correlation (non-parametric approach)

Figure 3.9.11: Mariana Trench: correlation matrices for bivariate analysis, Python

The Unweighted Pair Group Method with Arithmetic Mean (UPGMA) algorithm constructs a rooted tree (dendrogram) that reflects the structure present in a pairwise similarity matrix (or a dissimilarity matrix). The mean distance between elements of each cluster is computed by Formula 3.9.6.9:

$$
\frac{1}{|A| *|B|} \sum_{x \in A} \sum_{y \in B} d(x, y)
$$

The numbers give the degree of the correlation, ranging from -1.0 to 1.0. In the shaded rows, each cell is given the assigned color, explained in the legend, subdivided into four classes ranging from two to four depending on the sign of the correlation. The intensity of color is scaled in proportion to the magnitude of the correlation. Several variations have interpreted the criterion of similarity of the properties and interrelationships. A represented clustering of the matrix (a. k. a. heat map), made by Python code A.5.10, shows the variables with the displayed correlations. Plotting correlation matrix induces a partial-ordering on the geological variables as contiguous clusters. The covariance matrix $K_{x x}$ is the matrix whose $(\mathrm{i}, \mathrm{j})$ entry is the covariance estimated by Formula 3.9.6.9:

$$
K_{x_{i} x_{j}}=\operatorname{cov}\left[X_{i}, X_{j}\right]=E\left[\left(X_{i}-E\left[X_{i}\right]\right)\left(X_{j}-E\left[X_{j}\right]\right)\right]
$$

where the operator $\mathrm{E}$ denotes the expected value (mean) of its argument. The associated names of the environmental variables (slope angles, sediment thickness, $\max / \mathrm{min}$ and mean depth values) are shown on the correlogram (Fig. 3.9.11) annotated on the axes. The matrices were done by NumPy and Pandas objects read in as tables and imported by Seaborn library. The data were processed by Python code A.5.6. The correlograms show dependancies between the factors affecting trench based on the relationships of the values.

The effectiveness of the correlograms lies in its properties: the diagonal shows distribution of each of the geological variables by a representative square plot which helps to analyze the relationship between the pairs of numerical variables within a matrix. Correlation between each pair of variables is visualized through a numerical symbols and highlighted by colors. The use of both Pearson and Kendall correlation techniques (Fig. 3.9.11) is used for exploratory analysis to observe a matrix of geological variables. 


\subsubsection{Data distribution}

The box plots were made to show data distribution by 25 profiles via Python code A.5.11 based on the existing statistical methods [177]; [34]; [538]. Vertical lines extending from boxes (whiskers) indicate variability of depths outside the upper and lower quartiles.

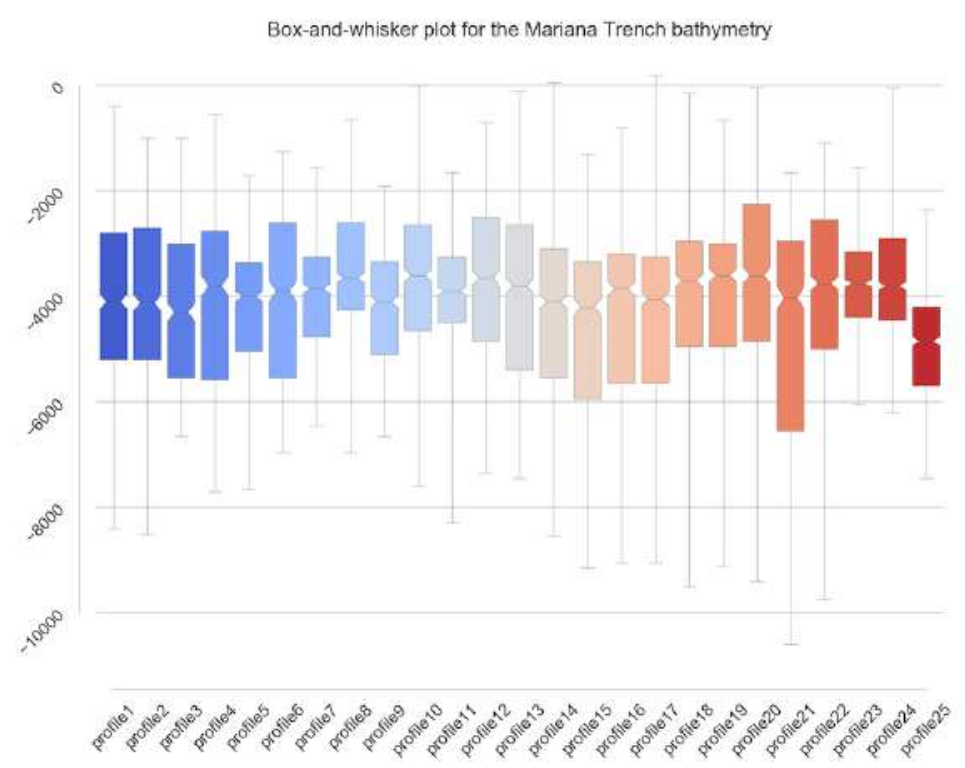

Figure 3.9.12: Mariana Trench: box-and-whisker plot for data distribution by 25 profiles. [419]

The depth ranges increases along the axis of the trench, from north to south, with a constant slope gradient, until it reaches depths $>11,000 \mathrm{~m}$ (profiles 20 and 21, Fig. 3.9.12). Correlation between the factors is higher in the SW of the trench and decreased towards SW. The statistical analysis of samples of the dataset shown correlation between depths and location of the profiles.

\subsubsection{Probability of the depths distribution by KDE plots}

An implementation of the fundamental frequency estimation is presented by KDE. The algorithm of $\mathrm{KDE}$ is based on a frequency-domain approach. It was applied to visualize probability of the depth ranges and bathymetric patters in various segments of the trench, Fig. 3.9.1 and 3.9.13.

Mathematically, KDE is a non-parametric way to estimate the probability density function of a random variable. The $\left(x_{1}, x_{2},, x_{n}\right)$ is a univariate independent, identically distributed sample drawn from distribution with a density $f$. Estimating shape of this function $f$ is based on its kernel density estimator by Formula 3.9.6.11:

$$
\hat{f}_{h}(x)=\frac{1}{n} \sum_{i=1}^{n} K_{h}\left(x-x_{i}\right)=\frac{1}{n h} \sum_{i=1}^{n} K\left(\frac{x-x_{i}}{h}\right)
$$

where $\mathrm{K}$ is the kernel, i.e. a non-negative function and $h>0$ is a smoothing parameter, the bandwidth. This method was implemented using Python code A.5.16. Python libraries Pandas, Matplotlib, Seaborn and OS were used to process data by an embedded algorithms to obtain probability frequency. 

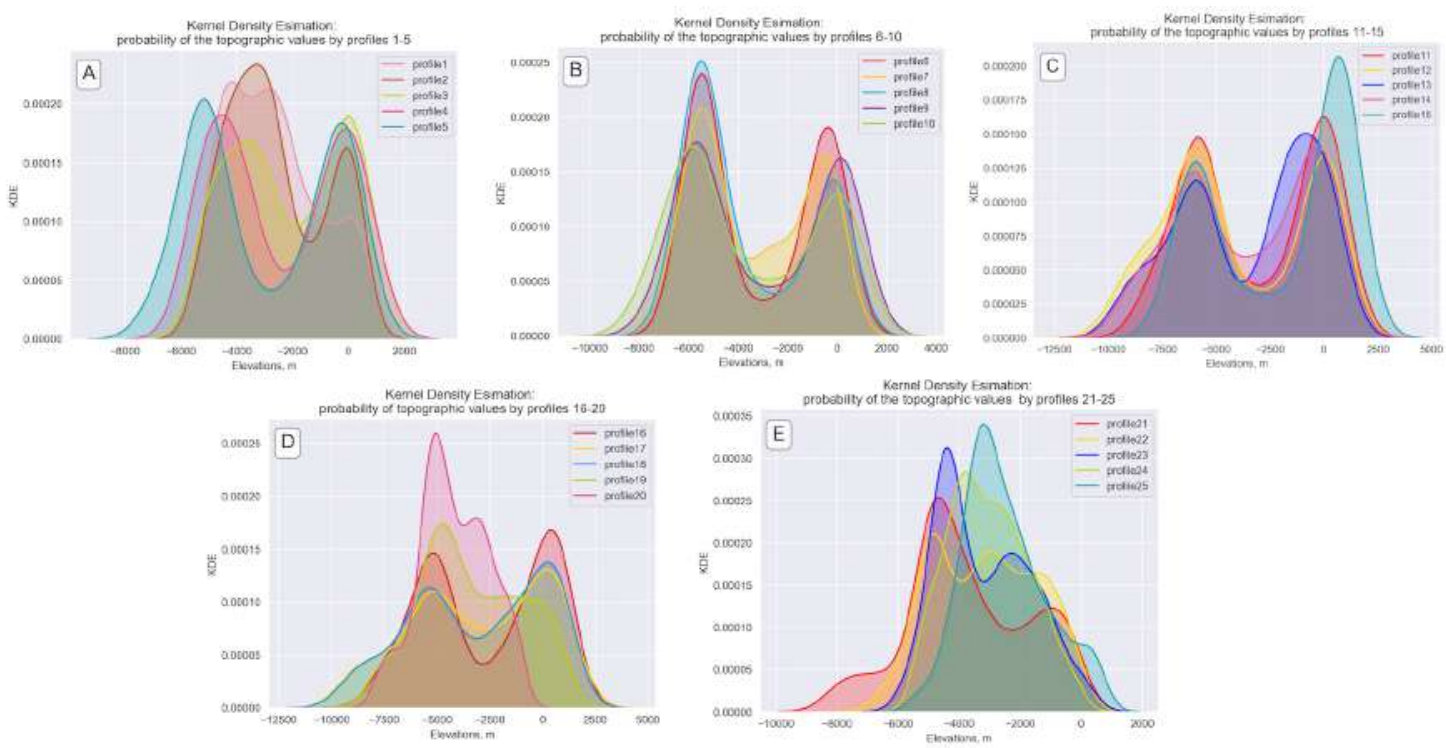

Figure 3.9.13: Philippine Trench: KDE of the bathymetric profiles, Python (Matplotlib and Seaborn)

\subsubsection{Data sorting and grouping}

A geomorphological analysis (Fig. 3.9.14), based on Python code A.5.12, uses computed values of the slope steepness ${ }^{\circ}$ by profiles in series of 25 transects assuming constant values of the slope aspect, using depths and sample points as a reference.

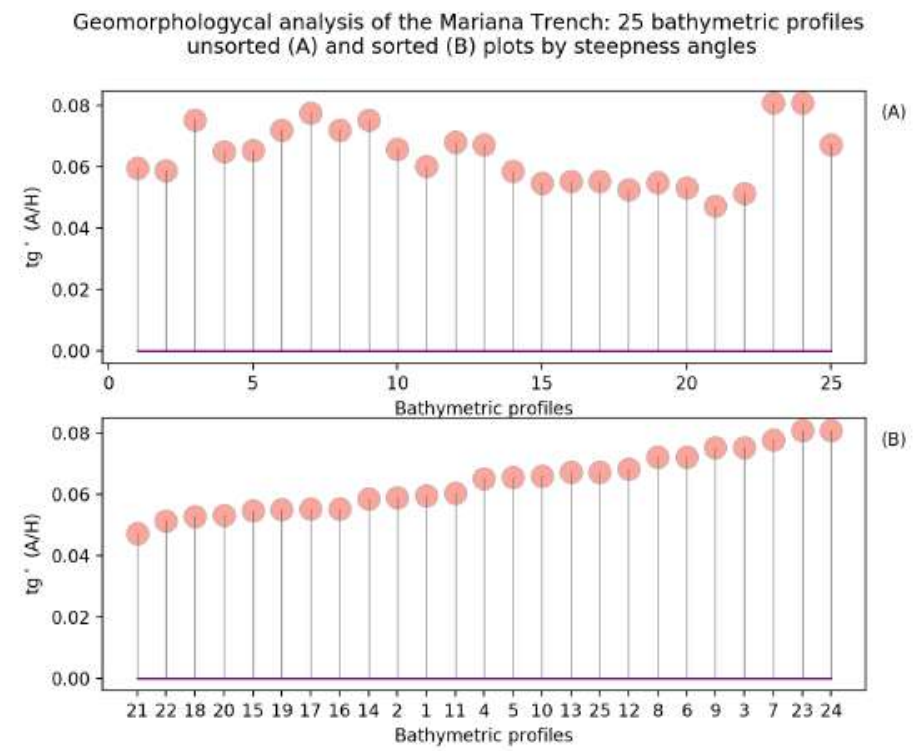

Figure 3.9.14: Mariana Trench: stem plot of the slope gradient steepness by 25 profiles.

The analysis shown that profiles 6, 9, 3, 7, 23 and 24 have similar steepness and can be grouped as the least steep, as shown by the reverse values of the angles $\operatorname{tg}^{\circ}$. Conversely, profiles $20,21,22$, and 18 have are deepest which can be explained by changes in geometry of the trench at various geospatial locations. 


\subsubsection{Hierarchical dendrogram and clustermap}

The Hierarchical Cluster Analysis (HCA) as shown on Fig. 3.9.15, was done using SciPy embedded algorithm of clustering based on the weighted average linkage clustering algorithm, Weighted Pair Group Method with Arithmetic Mean (WPGMA). Mathematical background to the data partition is as follows. The WPGMA algorithm constructs a rooted tree dendrogram that reflects the structure presented in a pairwise distance similarity matrix. At each step, the nearest two clusters, $i$ and $j$, are combined into a higher-level cluster $i \cup j$. Then, its distance to another cluster $\kappa$ is simply the arithmetic mean of the distances between $\kappa$ and members of $i \cup j$ : Formula 3.9.6.13:

$$
d_{(i \cup j, \kappa)}=\frac{d_{(i, \kappa)}+d_{(j, \kappa)}}{2}
$$

It demonstrates an approach of the method of cluster analysis used to build a hierarchy of bathymetric clusters based on the segmentation of the topographic features among 25 cross-section profiles. The dendrogram (Fig. 3.9.15) shows geomorphic similarity among profiles crossing the trench. Specifically, it illustrates the subdivision of the bathymetric values within each cluster composed by the U-shaped link between a main cluster and its branches representing bathymetric grouping. The dendrogram showing the hierarchical dendrograms clusters was plotted by Python code A.5.13 in five steps.

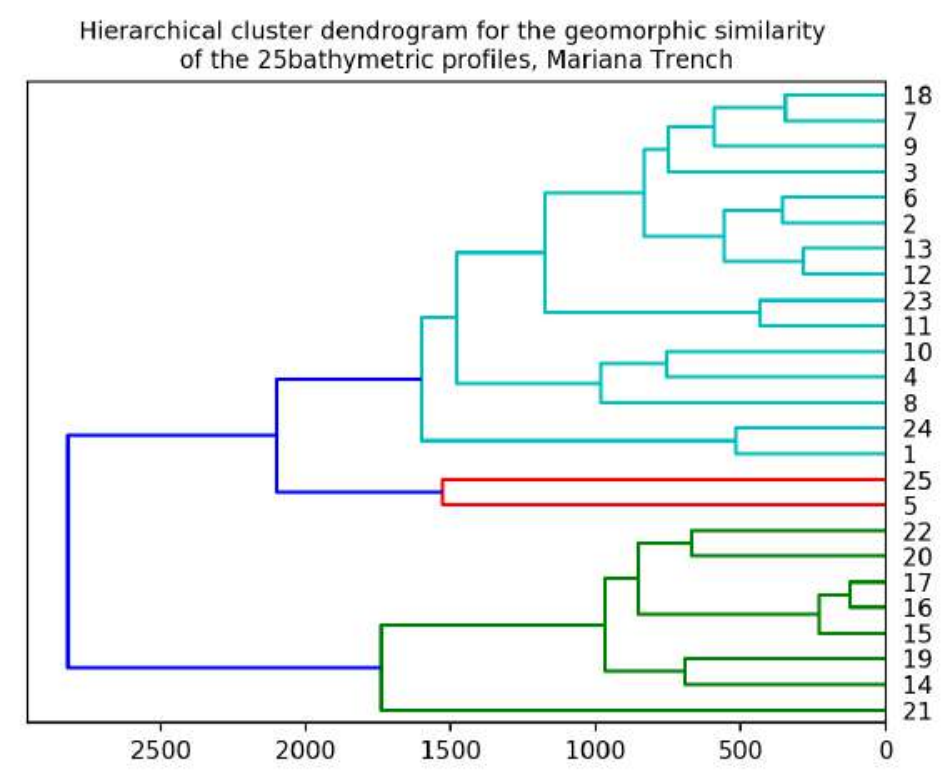

Figure 3.9.15: Mariana Trench: hierarchical cluster dendrogram of the profiles. Python

The choice of an appropriate metric influences the shape of the clusters, since elements may be close to each other according to one distance and farther away to the other. Two first forks of the of the U-link ('parents' of clusters) indicate which clusters were merged, while the length of each two corresponding branches visualize the distance between the children. Marginal dendrograms are represented on the Clustermap that shows another approach of data grouping in statistical analysis where main area of the plot show ranging data and marginal dendrograms clusters of the similarity groups. 


\subsubsection{Principal Component Analysis (PCA)}

The PCA was made by PCA function from Scikit Learn library of Python (from sklearn.decomposition import PCA). PCA) is a statistical procedure that applies orthogonal transformation to convert a dataset of probably correlated variables to a new dataset of linearly uncorrelated variables, principal components. PCA is mathematically defined as an orthogonal linear transformation that modifies the data to a new coordinate system. In this way, the greatest variance by scalar projection of the data lies on the first coordinate ( $1^{\text {st }}$ principal component), the $2^{\text {nd }}$ greatest variance on the $2^{\text {nd }}$ coordinate, etc.

Using orthogonal transformation procedure embedded in PCA to convert a set of samples on sediment thickness and possibly correlated variables into a set of values of the linearly uncorrelated variables [2]. In order to maximize variance, the first weight vector w(1) in PCA satisfies Formula 3.9.6.14:

$$
w_{1}=\operatorname{argmax}_{\|w\|=1}=\left\{\sum_{i}\left(t_{1}\right)_{i}^{2}\right\}=\operatorname{argmax}_{\|w\|=1}=\left\{\sum_{i}\left(x_{i} * w\right)^{2}\right\}
$$

The $n^{\text {th }}$ component is found by subtracting the $1^{\text {st }} k-1$ components from $X$ by Formula 3.9.6.14:

$$
\hat{X}_{k}=X-\sum_{s=1}^{k-1} X w_{s} w_{s}^{T}
$$

Using PCA is especially useful technique in case of marine geological large datasets and other implications of the big geodataset with many variables for each sample for exploratory data analysis [301]. The PCA enables to better visualize variations: sediment thickness, slope steepness and depth ranges.

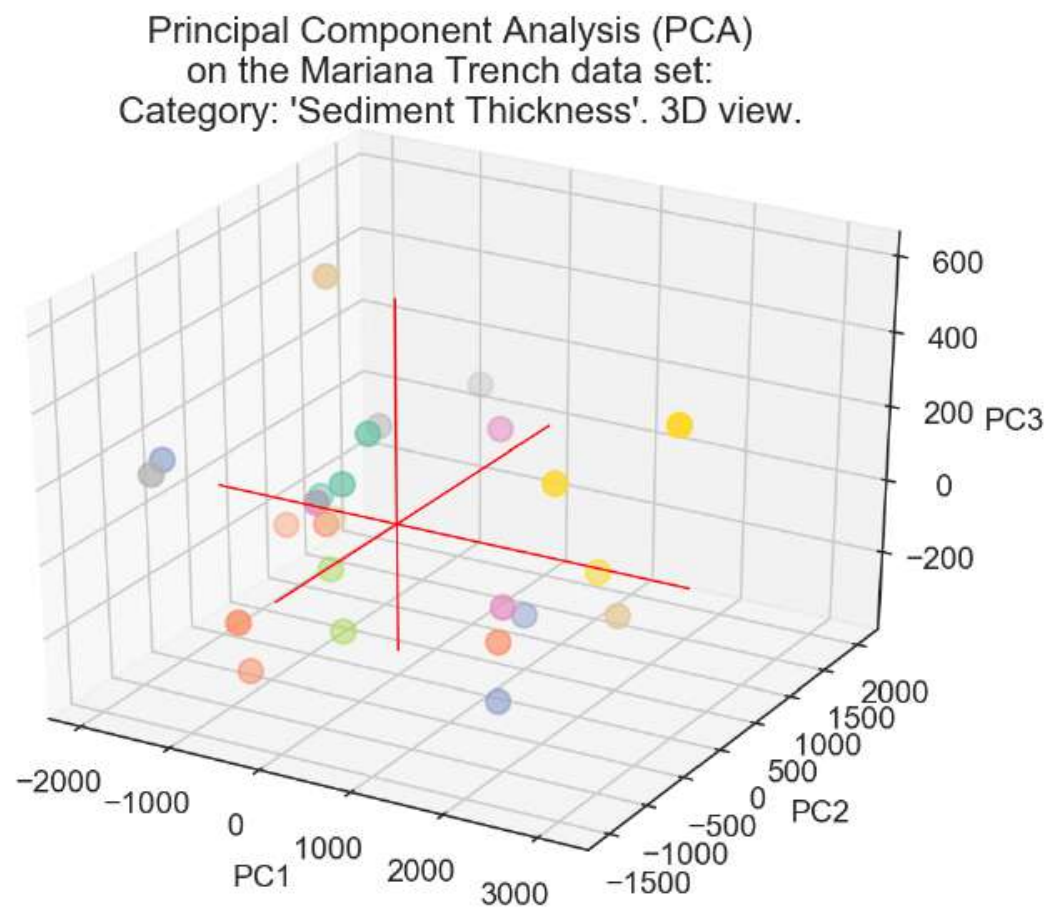

Figure 3.9.16: Mariana Trench: PCA of the sediment thickness by 25 bathymetric profiles, 3D view.

The PCA on the bathymetric spatial series was performed to assess the overall spatial geomorphic variability of the cross-section profiles and their similarities (Fig. 3.9.16). For this calculation the sediment thickness as a categorical value of the studied area was used. 


\subsubsection{3D scatterplot matrices for fata correlation}

The analysis data by correlation was performed using 3D scatterplot showing dependancies between the environmental factors, Fig.3.9.17. 3-dimensional scatterplots (3D plots) enable to discover relationships between three variables at the same time. Geometrically transformed display 3D techniques of Python aims at finding transformations of the 3-dimensional datasets.

A point affine projection of the dataset into a $3 \mathrm{D}$ space represented in classic $(\mathrm{X}, \mathrm{Y}, \mathrm{Z})$ format is a technique approach of the 3D scatterplot matrices. This is a data visualization method which links 3 factors, encouraging and imploring to access possible causal relationship between the plotted variables. The graph is made by means of the ax.scatter() function of the Matplotlib library using Python code A.5.14 in 3 steps.
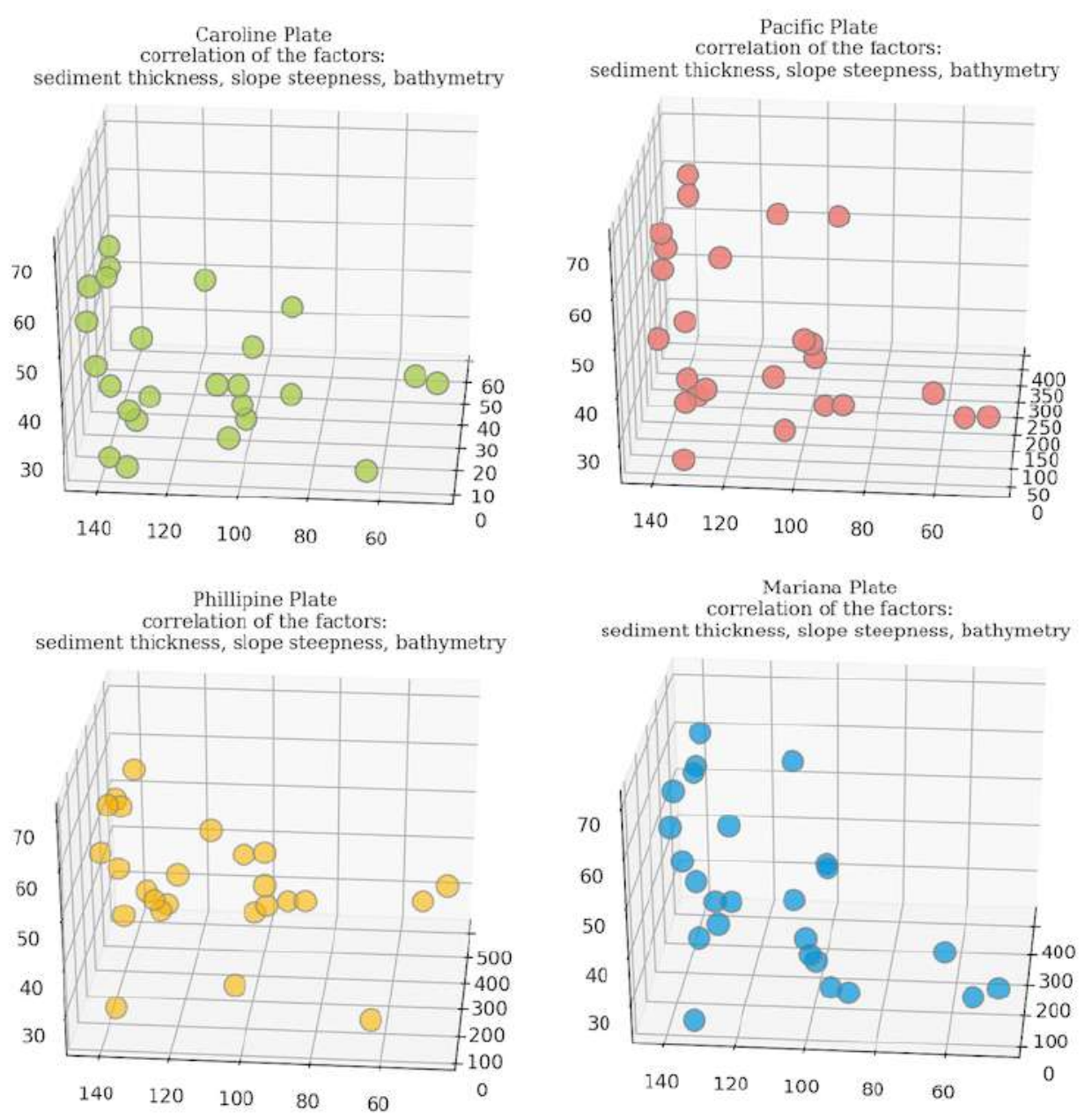

Figure 3.9.17: Mariana Trench: 3D scatterplot of the relationships between environmental factors

The 3D scatterplot matrices (Fig. 3.9.17) show variability of the geological, geometric and bathymetric factors (that is, sediment thickness, steepness of slope degrees and depth values) that is similar to the model by four tectonic plates. The sediment thickness is broadly correlated with the slope steepness degree, showing consistent geographic patterns by two pairs of plates: firstly, Mariana and Pacific, and secondly, Caroline and Philippine (Fig. 3.9.17). 


\subsubsection{ANOVA}

The purpose of the ANOVA method in Python part of this dissertation was to test significant differences between the means of the marine geological variables, that is sedimentation, tectonic and geospatial factors. The definitional equation of sample variance is as follows in Formula 3.9.6.16:

$$
s^{2}=\frac{1}{n-1} \sum\left(y_{i}-\bar{y}\right)^{2}
$$

Where the divisor is called the degrees of freedom, the sum presents the sum of squares, the result is the mean square and the squared terms are deviations from the sample mean. The fundamental technique is a partitioning of the total sum of squares into components related to the effects used in the model. Test differences in means for groups of these variables for the statistical significance was done by existing algorithms [194]; [554]; [24]. The ANOVA is accomplished by analyzing variance: partitioning total variance into the components, due to true random error (i.e., within-group) and the components that are due to differences between the means.
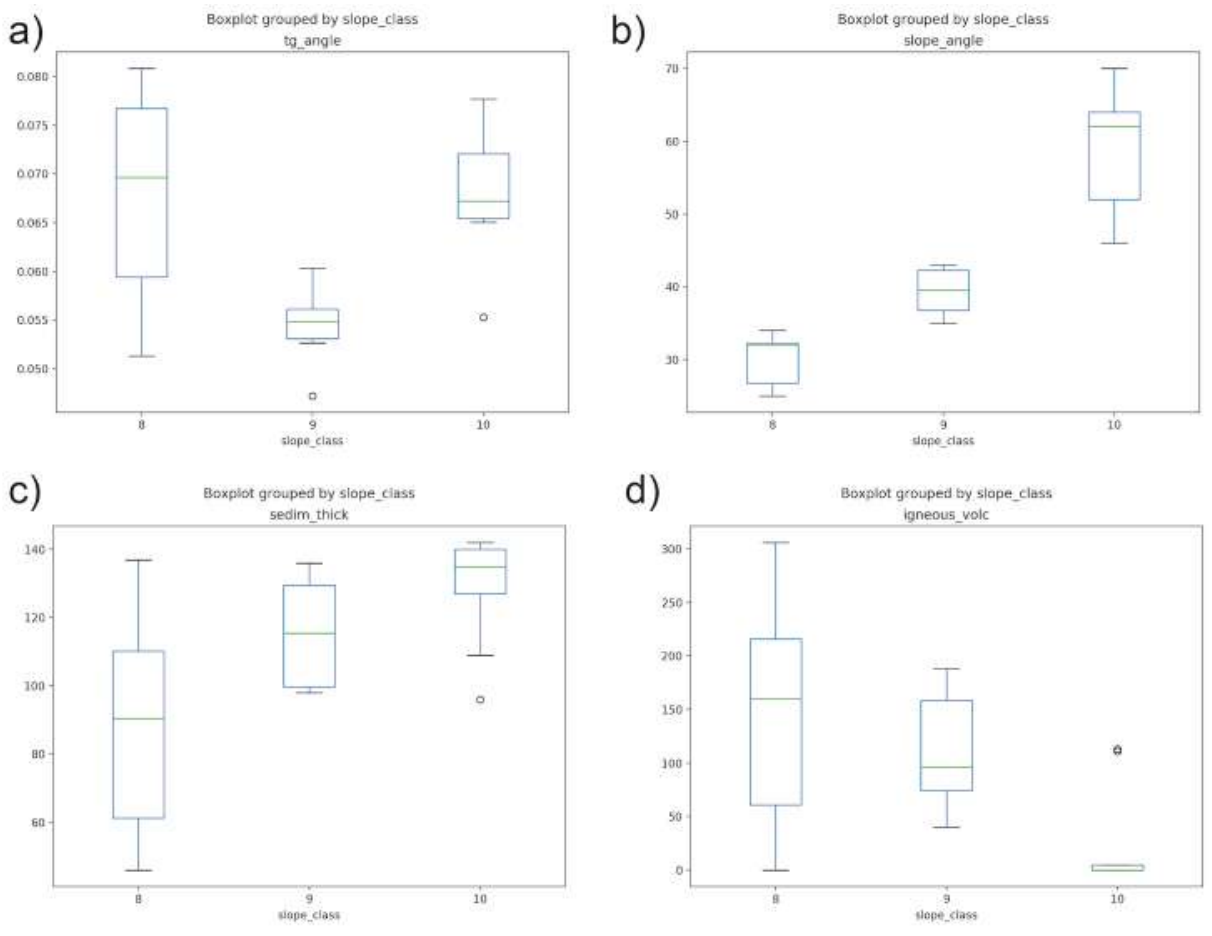

Figure 3.9.18: Mariana Trench: one-way ANOVA box plots

Computed F values (0.270259 and 0.459078) and statistical significance obtained from testing with ANOVA shows the effect of depth and model scenario on the sediment thickness estimated through the StatsModels library of Python (statsmodels.stats.anova anova_lm) by embedded function ANOVA by Python code A.5.15, and Pandas for table data processing. The correlation cluster dendrogram between a spatial series of the transects shows grouping between the profiles based on their geomorphic similarities. One-way ANOVA box plots were computed and plotted to show relationship between the selected environmental, bathymetric and geomorphological variables based on the analysis of similarities.

Deep-sea sediments have consistent correlation with the slope class of the steepness, Fig. 3.9.18 (c). Lower effect has the location of the igneous volcanic areas near the trench on the geometry of the 
profiles, as referred by the angle ${ }^{\circ}$ (Fig 3.9.18, d). While shape of the trench is less steep and absolute depths are lower in the NE part of the trench (Pacific and Mariana plates), the bathymetry is substantially deeper in its SE part (Caroline and Philippine Sea plates). These findings also support variations in the deformation of the subducting plate along the Mariana Trench [778] detected by analysis of flexural bending and normal fault features. Normal faults initiated outwards and grew toward the trench axis, and the trench relief and maximum fault throws are greater in the $\mathrm{S}(5 \mathrm{~km}$ and $320 \mathrm{~m})$ comparing to the $\mathrm{N}$ and $\mathrm{C}(2 \mathrm{~km}$ and $200 \mathrm{~m})$.

\subsubsection{Flowchart network}

Data analysis is aimed to find potential influence from various geological and tectonic factors affecting geomorphology of the trenches. Statistical analysis of the data set in marine geology requires adequate tools for big data processing. In this context, a Python-based methodology is combined with GIS geospatial data analysis. This thesis uses libraries Pandas, NumPy and SciPy. Data processing involves subsampling of the auxiliary masked data frames from the initial large dataset that only consists of target variables: sediment thickness, slope angle degrees and bathymetric samples. Flowchart includes 3 stages (Fig. 3.9.19) visualized as logical parts: QGIS data processing; statistical analysis; spatial analysis.

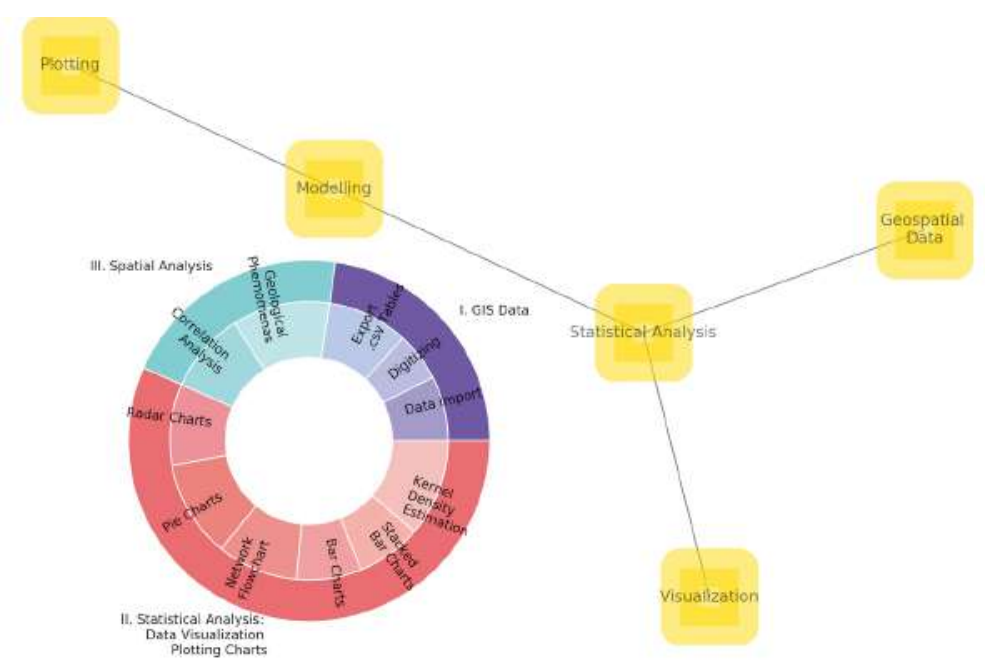

Figure 3.9.19: Methodological network, [428]

$1^{\text {st }}$ block consisted in processing marine geological data by QGIS: data import, digitizing, data export into .csv tables, processing in Python. The cross-section transects were digitized. Their attribute tables contained numerical data on geology, tectonics, volcanism and bathymetry by sample points along each profile. $2^{\text {nd }}$ block contained in data interpretation and approaches of the statistical data analysis. $3^{\text {rd }}$ block presents geospatial analysis by visualizing interplay between geological and tectonic variables. Mathematical algorithms were applied by libraries [38] SciPy, NumPy.

\subsubsection{Visualizing bathymetric pattern by stacked area charts}

Plotting stacked area charts is one of the key approaches In marine geology to visualize depths range of the aimed to analyze, to what extent depths may reach in particular trench segment. Apart from visual clearance of the plot (Fig. 3.9.20), showing maximal abrupt depth by profiles 20 and 21 (SW of the Mariana), there are other features in this approach.

Various marine geological phenomena can be investigated in the data set by adding color ranges for stepwise visualization in the plot: the shallowest parts of the seafloor with minimal depths, $3^{\text {rd }}$ quar- 
tiles, mean, median depths, $1^{\text {st }}$ quartile. This visualizes the variability of the geomorphic patters by the segments that highlight bathymetric variability across the profile.

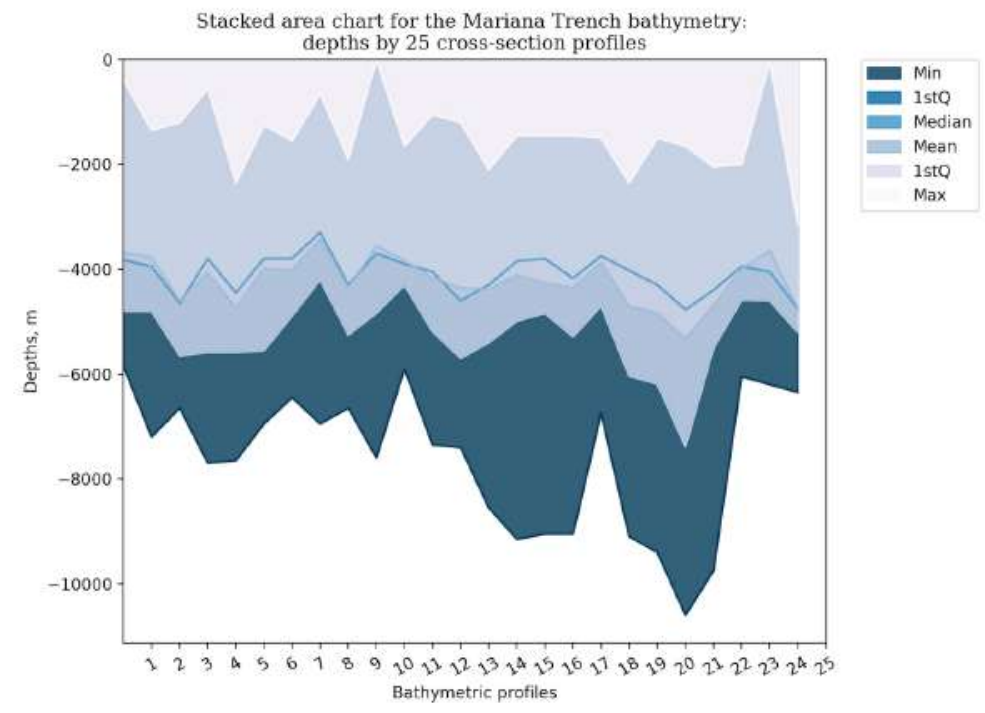

Figure 3.9.20: Mariana Trench: bathymetric patters visualized by stacked area charts.

The methodology was implemented by Python code A.5.17. Following Python libraries were used to plot stacked area charts: Pandas, NumPy, Matplotlib, Seaborn and OS.

\subsubsection{Stacked bar plots}

Variations in the distribution of the bathymetric data by stacked bar plots (charts) were made by following Python libraries: NumPy, Pandas, Matplotlib and OS (Fig. 3.9.21), using Python code A.5.19.

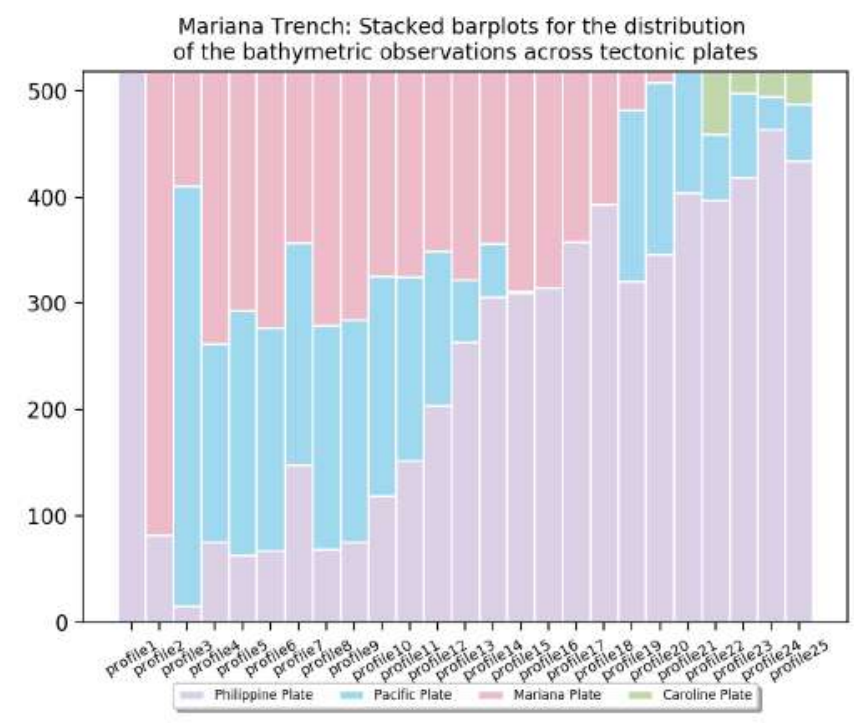

Figure 3.9.21: Mariana Trench: stacked bar plots on depths variations by profiles, Python. 


\subsubsection{Radar charts for analysis of depth distribution}

Radar chart is a special case of the statistical analysis in marine geological datasets. It is an interesting visualizing method in data analysis as graphical visualization of the multivariate data. Here they are presented in form of 2-dimensional circular chart of 6 quantitative variables with depths on axes attribute values on the circular axe: maximal, $3^{\text {rd }}$ quartile, median, mean $3^{\text {rd }}$ quartile and minimal values. Various values that can be visualized by profiles, which requires a facetted multi-plots technique possible in radar charts. Fig. 3.9.22 presents a series of the radar charts showing depth variation by selected profiles, plotted by libraries Math, Pandas, NumPy, Matplotlib, Seaborn and OS. The algorithm was based on Matplotlib library, Python code A.5.18.
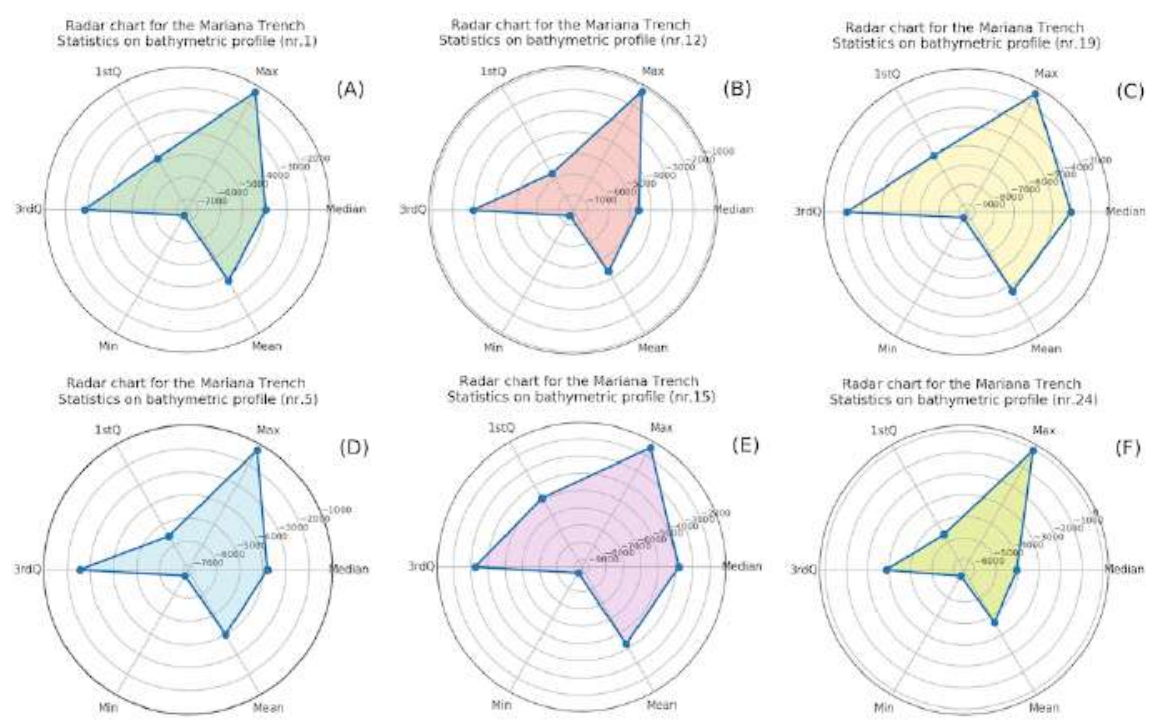

Figure 3.9.22: Mariana Trench: radar charts of the variation in bathymetric data

\subsubsection{Stacked bar charts for analysis of sediment thickness}
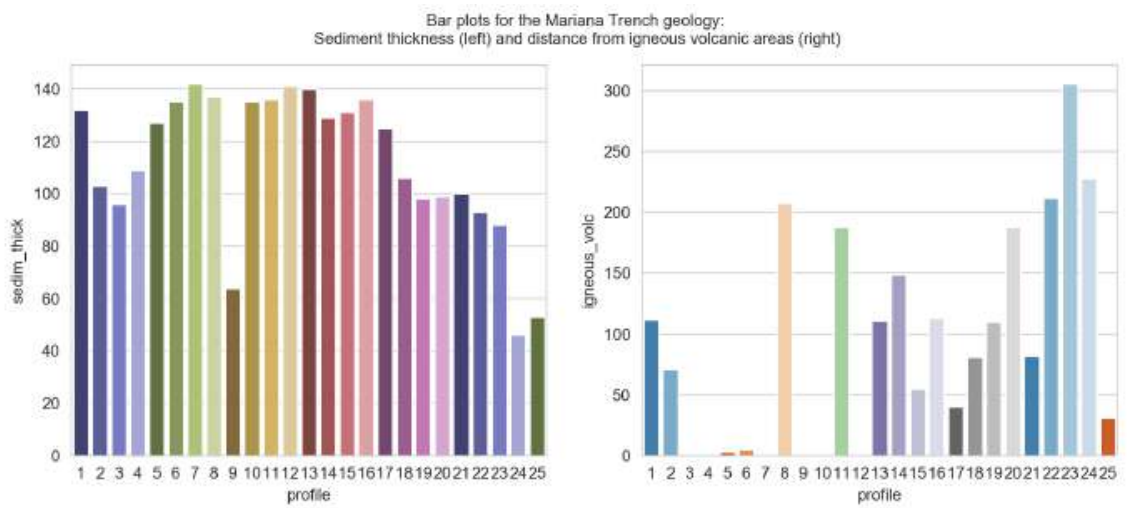

Figure 3.9.23: Mariana Trench: stacked bar charts showing geological factors. Python.

Analysis of the distribution of sediment thickness by profiles and its correlation with closeness of the igneous volcanic areas as by distance is visualized by the stacked bar charts (Fig. 3.9.23) by Python code A.5.20 using libraries NumPy, Matplotlib, Pandas and OS. 


\subsubsection{Pie charts for circular visualization of the bathymetry vs tectonic plates}

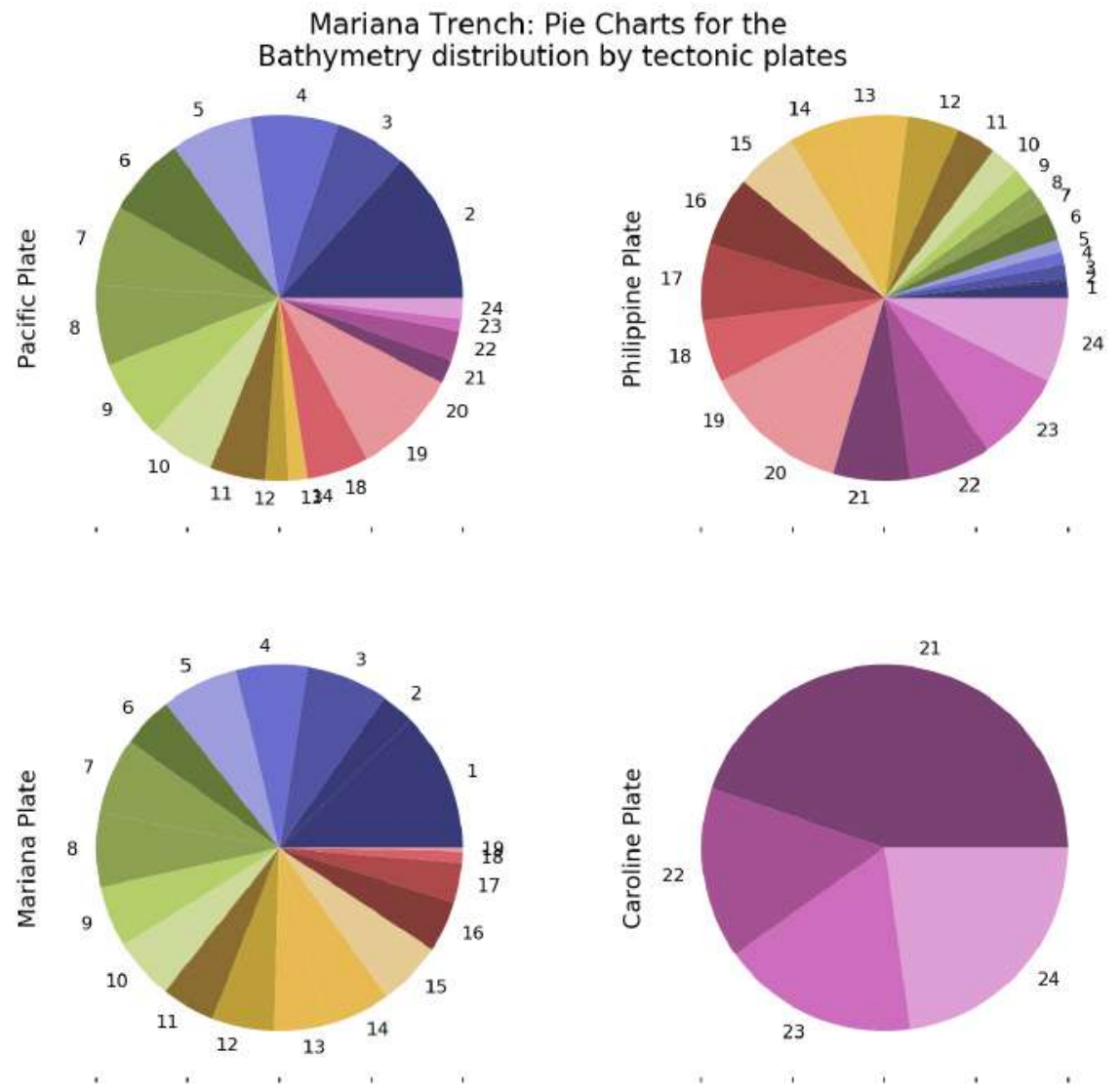

Figure 3.9.24: Mariana Trench: pie charts of the bathymetric data distribution by tectonic plates. Python.

Regarding categorial distribution methods, a pie chart plotting is based on the analysis of the distribution of the bathymetric values by tectonic plates (Fig. 3.9.24). Circular visualization of the bathymetry showing relationship between tectonic plates and distribution of the data by pie charts was performed by Python code A.5.21 in 3 steps by libraries Pandas, NumPy, Matplotlib and OS.

\subsubsection{Design matrix and model fit summary by Ordinary Least Squares}

Variables of the geologic interest were stored in a table consisting of 18 rows where numeric information describes geology, bathymetry, geodesy and tectonics of the trench. To fit most of the models covered by StatsModels Python library, the design or regressor matrix was created using existing approaches [160]; [70]; [548]. The first is a matrix of endogenous variables of sediment thickness, which show the response or geological regress and varying environmental conditions: geographic location, depth or tectonic plate. The design matrix dmatrices shows the results of the first six lines representing values of explanatory variables in a set of geological attributes, Mariana Trench. The computing of the OLS by StatsModels of Python based on Formula 3.9.6.23:

$$
b_{1}=\frac{\sum_{i=1}^{n}\left(x_{i}-\bar{x}\right)\left(y_{i}-\bar{y}\right)}{\sum_{i=1}^{n}\left(x_{i}-\bar{x}\right)}
$$


Where, $\mathrm{n}$ is the sample size; $\mathrm{x}$ is a constant and a scalar regressor; $\mathrm{y}$ is a random regressor, sampled together with $\mathrm{x} ; \mathrm{h}$ is the number of lags being tested. Each row of the calculated OLS coefficient estimates is an individual bathymetric profile with the successive columns corresponding to the geologic and oceanographic variables and their specific values across the profiles.

\subsubsection{Quantile statistics (QQ)}

Used algorithm is very straightforward with a selected function of qqplot() by StatsModels. The QQ regression is a common abbreviation for quantile by quantile statistical plot. The plot shows (Fig. 3.9.27, [424]) one quantile against another across various geological parameters: Sediment thickness; Slope angle degrees; four tectonic plates; distribution of the samples of igneous volcanic areas. Technically, the plotting was performed using Python code A.5.22 for each corresponding plot. The QQ statistics calculation has been based on the following Formula 3.9.6.24 after [513]:

$$
Q=n(n+2) \sum_{k=1}^{n} \frac{l_{k}^{2}}{n-k}
$$

Where, $\mathrm{n}$ is the sample size; rho is the sample autocorrelation at lag $\mathrm{k}$, and $\mathrm{h}$ is the number of lags being tested. The comparison of the six subplots enables to analyze the form of their shape against a straight line. The quantiles are bathymetric sample observations with geologic attribute values placed in the ascending order. The QQ statistics is used over the pool of the sampling data to study their distribution. A QQ statistic is a visual representation of the quantiles of a standard normal distribution of the geological data set across the trench, showing their variation in space.

Quantile regression estimates conditional median and other quantiles of the response geological variables. Upper two rows of the plot show (Fig. 4 in [424]) data distribution for sediment thickness (m) versus geologic parameters across tectonic plates, data distribution for the cumulative sediment thickness and slope angle degree by profiles. The quantile regressions were plotted for the following variables: A) Sediment thickness; B) Slope angle degrees; C) Pacific Plate; D); Philippine Plate E) Mariana Plate; F) Volcanic spots, Fig. ?? by Python code A.5.24 by StatsModels.
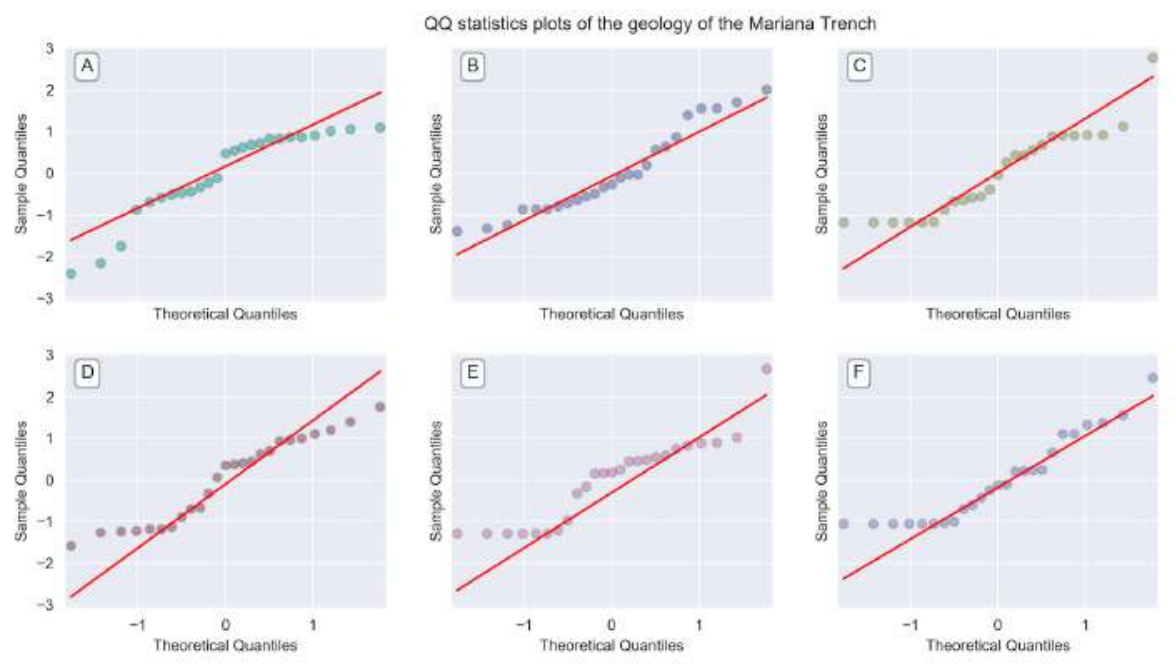

Figure 3.9.25: Plotted QQ statistics for the data distribution

Essentially, quantile regression is another approach of the linear regression used for the conditional median of the response geologic variable given changing bathymetric values southwards across the 
trench. The quantitative results of the quantile regression (Tab. 3 in [424]) show computations for quantile regression for the sediment thickness against geologic parameters and tectonic plates: A) Pacific Plate B) Philippine Plate C) Mariana Plate D) Caroline Plate E) Cumulative sediment thickness F) Slope ${ }^{\circ}$ by profiles.
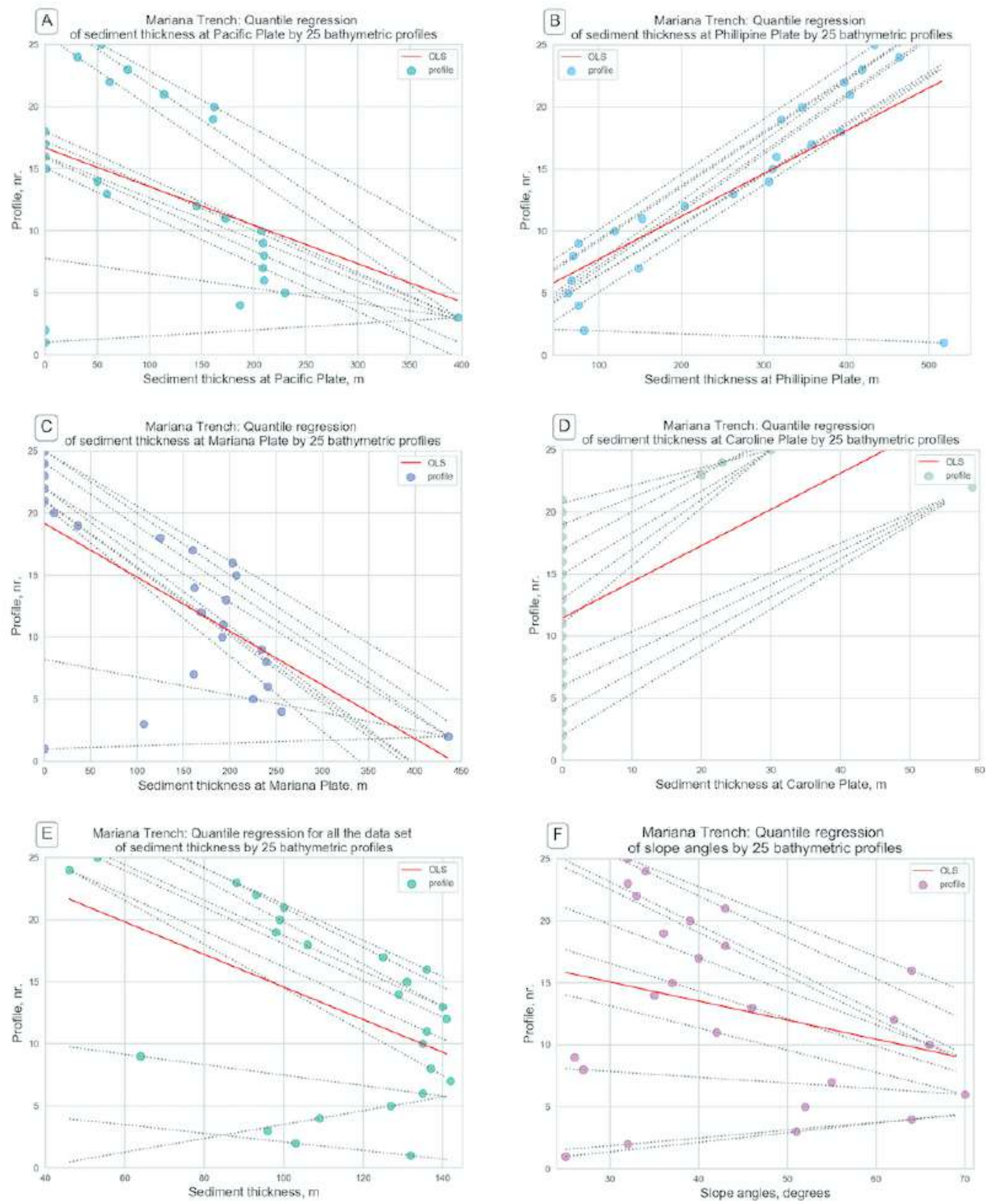

Figure 3.9.26: Quantile regression plotted for sediment thickness (m) versus geologic parameters

Each QQ profile has a given value for data distribution by quantiles across the trench profiles. The distribution of the geologic residuals show data correlation for several cases: frequency of data distribution by plates, sediment thickness, range of depths for max values and geomorphic shape as slope ${ }^{\circ}$. The results represent the computed numerical values of the quantile regression. 


\subsubsection{Weighted Least Squares}

A WLS for the geological variables analysis data distribution: by tectonic plates, sediment thickness, bathymetry and slope ${ }^{\circ}$. Following variables are visualized: A) Pacific Plate, B) Philippine Plate, C) Mariana Plate, D) Sediment thickness, E) Depths (max); F) Slope angle degree.

A WLS is a statistical approach representing a special case of the generalized least squares. WLS is a standard approach in regression analysis to approximate the solution of the overdetermined systems for complex marine geological systems. The least squares algorithms has two sub-types: linear or ordinary least squares and nonlinear least squares.
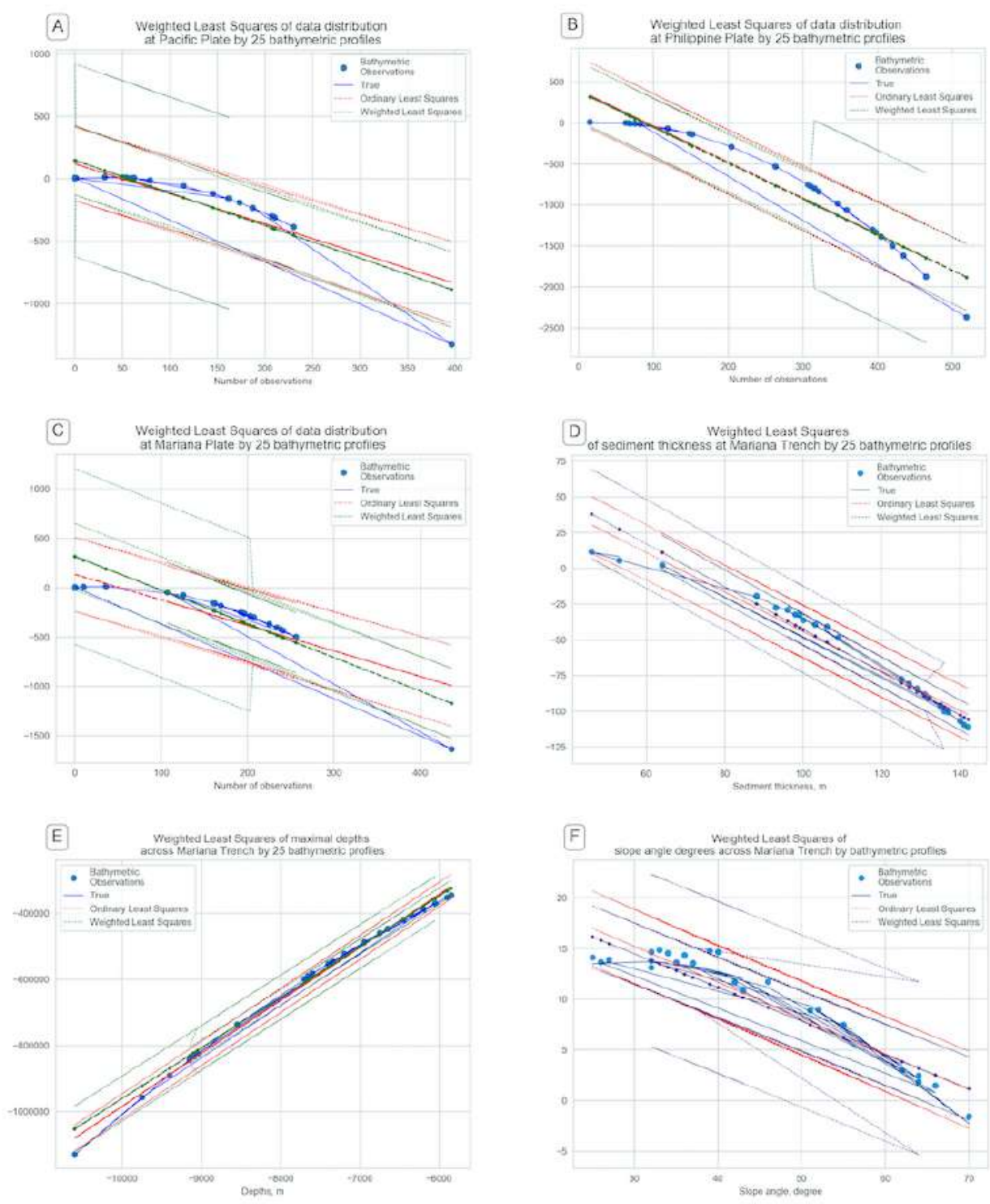

Figure 3.9.27: Weighted Least Squares plotted for data distribution.

In scope of this dissertation, only linear least squares were tested: OLS and its generalization, a WLS. The off-diagonal entries of the correlation matrix of geological residuals are null variances of the observations, yet unequal along the covariance matrix. The calculation is based on the principle of the Gauss-Newton algorithm that solves a non-linear least squares problem by modifying a Newton's method for finding a min of a function. The computation is based on general approach of the existing 
equation [59], Formula 3.9.6.25:

$$
S(\beta)=\sum_{i=1}^{m} r_{i}^{2}(\beta)
$$

Where $\mathrm{m}$ functions $r=\left(r_{1}, r_{m}\right)$ (residuals) of $\mathrm{n}$ variables $\beta=(\beta 1,, \beta n)$, with $m \geq n$

The calculations of the WLS for the data se shows computations of the WLS modelling for the data distribution by plates, [424], done according to the reported procedures [665]; [696] by the Python code snippet A.5.23.

\subsubsection{Isotonic regression}

The statistical numerical method of the isotonic regression was applied as a non-metric multidimensional scaling aimed at fitting a line to a sequence of the observations provided the line has variation in forms, that is non-decreasing and or non-increasing everywhere across the observations. Furthermore, the line lies most close to the observations pool. The concept of the isotonic regression has been introduced by [339] and further developed by [53]. The principle of the computation algorithm of the isotonic regression lies in the following Formula 3.9.6.26 of the problem of Quadratic Program (QP):

$$
\min \sum_{i=1}^{n} w_{i}\left(x_{i}-a_{i}\right)^{2}
$$

subject to $x_{i} \leq x_{j}$ for all $(\mathrm{i}, \mathrm{j}) \in E$, where $x_{i}$ and $x_{j}$ are constraints; $\mathrm{E}$ are the edges or the is the set of pairs ( $i, j$ ) for each constraint; $w$ is a weights vector; $n$ is a number of observations. The isotonic estimator, g minimizes the weighted least squares-like condition by Formula 3.9.6.26:

$$
\min _{g \in A} \sum_{i=1}^{n} w_{i}\left(g\left(x_{i}\right)-f\left(x_{i}\right)\right)^{2}
$$

Where, $\mathrm{A}$ is the set of all piecewise linear, non-decreasing continuous functions; $\mathrm{f}$ is a known function. Further references on isotonic regression and its applications are given by ??. The presented plot of the isotonic regression (Fig.3.9.28) shows a non-decreasing approximation of a function while minimizing the mean squared error on the training bathymetric data set of the 25 profiles.
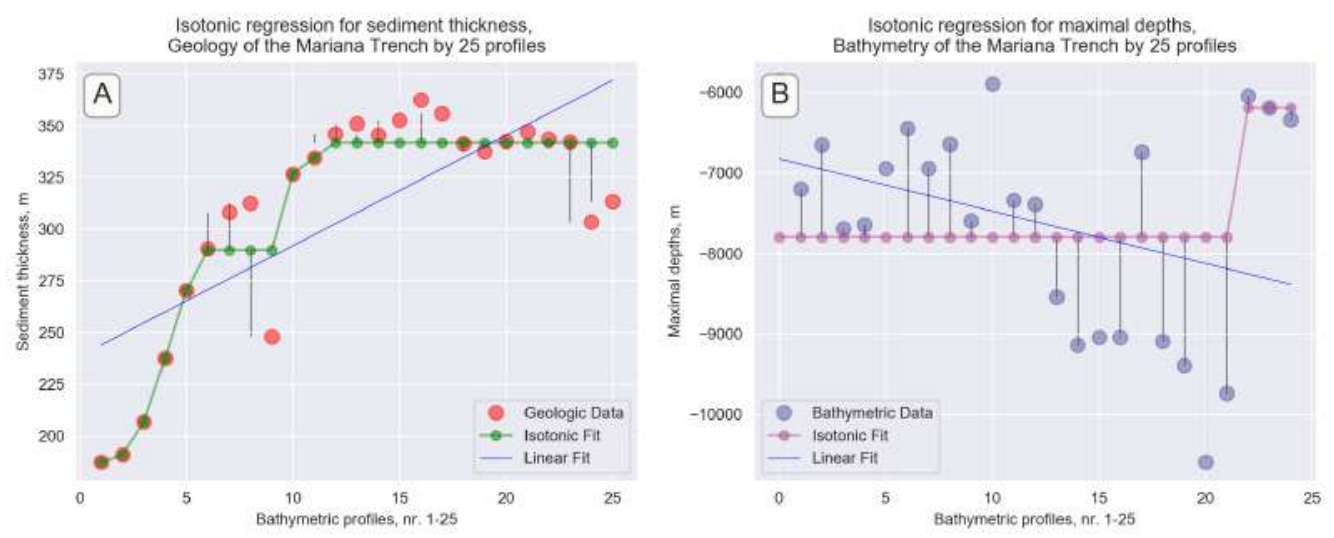

Figure 3.9.28: Mariana Trench: isotonic regression for variables, Python [415]

The benefit of this kind of a model is consists in the flexibility of the model, that is, the function does not assume any form for the target function such as linearity. Thus, the real data o the observed values 
by 25 profiles can be compared with the isotonic curves, as can be seen on the isotonic regression graph for the selected variables: geological data on sediment thickness layer (A) and maximal depths recorded by 25 profiles (B) (Fig. 3.9.28). Further references are given by [363].

\subsubsection{Dynamic regression model: SARIMA}

The methodology of the dynamic regression model is based on the StatsModels embedded algorithm [665]. The abbreviation State Autoregressive Moving Average (SARIMA) stands for the model, initially developed by [15]. The concept of the application of the SARIMA time series estimation and post estimation lies in the following. Changes in variables taken as time lags in classic dynamic regression models are applied towards profiles ( 1 to 25). Unlike in time series case when ARIMA fits the univariate models with time-dependent disturbances, this case applies space-dependent disturbances, crossing sampling (X axe), [424]. Given a time series data $X_{t}$ where $t$ is an integer index and the $X_{t}$ are real numbers, an ARMA $\left(p^{\prime}\right.$, q) model is given by Formula 3.9.6.27:

$$
\left(1-\sum_{i=1}^{p^{\prime}} \alpha_{i} L^{i}\right) X_{t}=\left(1+\sum_{i=1}^{q} \theta_{i} L^{i}\right) \varepsilon_{t}
$$

The model includes both dependent and independent variables, the selected type of SARIMA was SARIMAX (Python code A.5.25). The first group consists in changing variables: geologic settings and bathymetry (depths). The $2^{\text {nd }}$ group (independent variables) is presented by the profiles lags that cross the trench with the distance between each of $100 \mathrm{~km}$ and the length of $1000 \mathrm{~km}$. This cross-section profiles are taken as independent variables. Therefore, the dependent variables differ spatially in the segments of the trench. Python code for used SARIMAX algorithm and Statespace Model Results, [424]. Tested case is a Mariana Trench tectonics: sediment thickness across the Philippine Sea Plate. The model fits univariate model of the geomorphic structure of the trench by independent values of the distribution of the bathymetric samples by profiles with dependent disturbances of depths. Fitting the model was done using Python code A.5.25.

The conducted statistical data modelling and several types of the regression analysis were aimed to compare variance in the geological datasets of the trench explained by the complex interplay of the geomorphic, geological and oceanological attributes of the data and bathymetric factors of their location at several segments. Several linear models of correlation between factors were computed, analyzed and explained by the groups of variables. Tested environmental variables of the Mariana Trench include four main geological factors (location on the tectonic plates, slope steepness degree, sediment thickness of the layer and bathymetric depth and submarine volcanism) and attributes of the 25 cross-section bathymetric profiles (mean values, maximal depths, median values and two quartile sub-division of the data sets) and the shared variances between environment and attributes.

Shared variance arises due to correlations between the factor of sediment thickness and slope angle degree, e.g. because the attributes of the sediment accumulation are influenced by the trench shape apart from the directly or indirectly depending on the oceanological conditions of the submarine currents. The dynamic regression model is possible using Python function embedded in StatsModels library: State Autoregressive Moving Average. The model shows autocorrelation of the data by bathymetric profiles. The results demonstrated a correlation between the geological variables and geospatial location of the samplings across the trench, which proves the interplay between multiple factors affecting submarine geomorphology. 


\subsection{ITT $_{\mathrm{E}} \mathrm{X}$ for processing bathymetric data}

Bathymetric GIS data processing by QGIS and LATEX is an experimental approach of the GIS data processing after imported through QGIS digitizing, possible $\mathrm{ITT}_{\mathrm{E}} \mathrm{X}$ using available available resources [331].
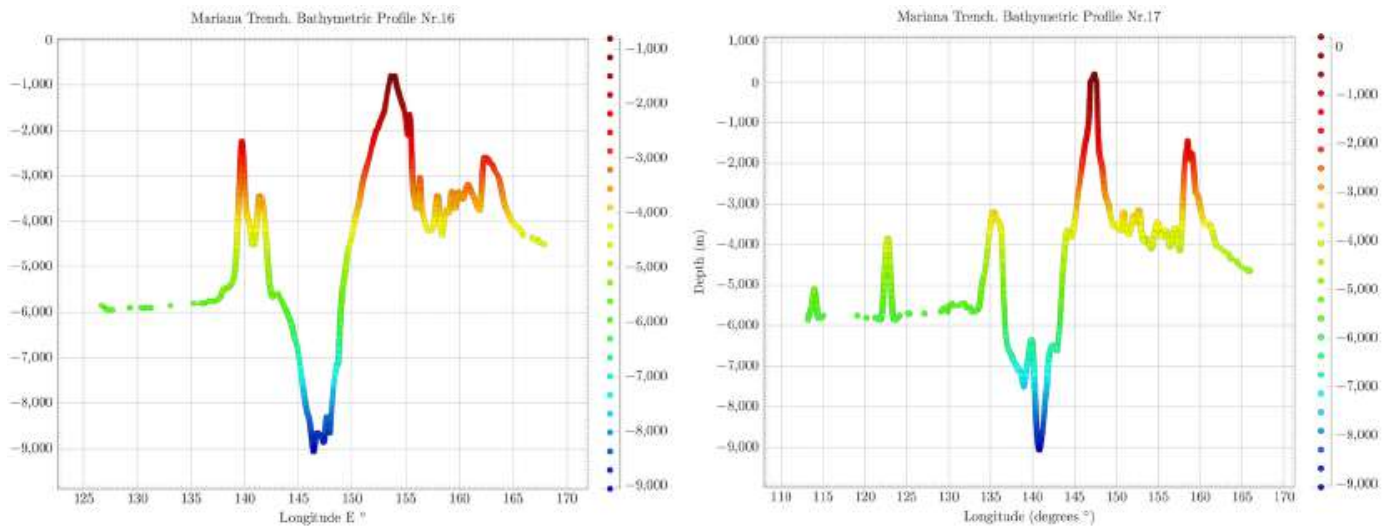

Figure 3.10.1: Mariana Trench: selected bathymetric profiles. Plotting: $\mathrm{LT}_{\mathrm{E}} \mathrm{X}$

After a square of the area was crossed by the profiles, the .csv table was imported for processing in $\mathrm{LT}_{\mathrm{E}} \mathrm{X}$. The coordinated were saved in a table with three columns: elevations, latitude and longitude. Some necessary packages have been installed from The Comprehensive TEX Archive Network (CTAN). The visualization of the profiles has been performed in $\mathrm{LT}_{\mathrm{E}} \mathrm{X}$. Technically, following $\mathrm{T}_{\mathrm{E}} \mathrm{X}$ code was used: A.2.1. QGIS processing resulted in cross-section profiles.
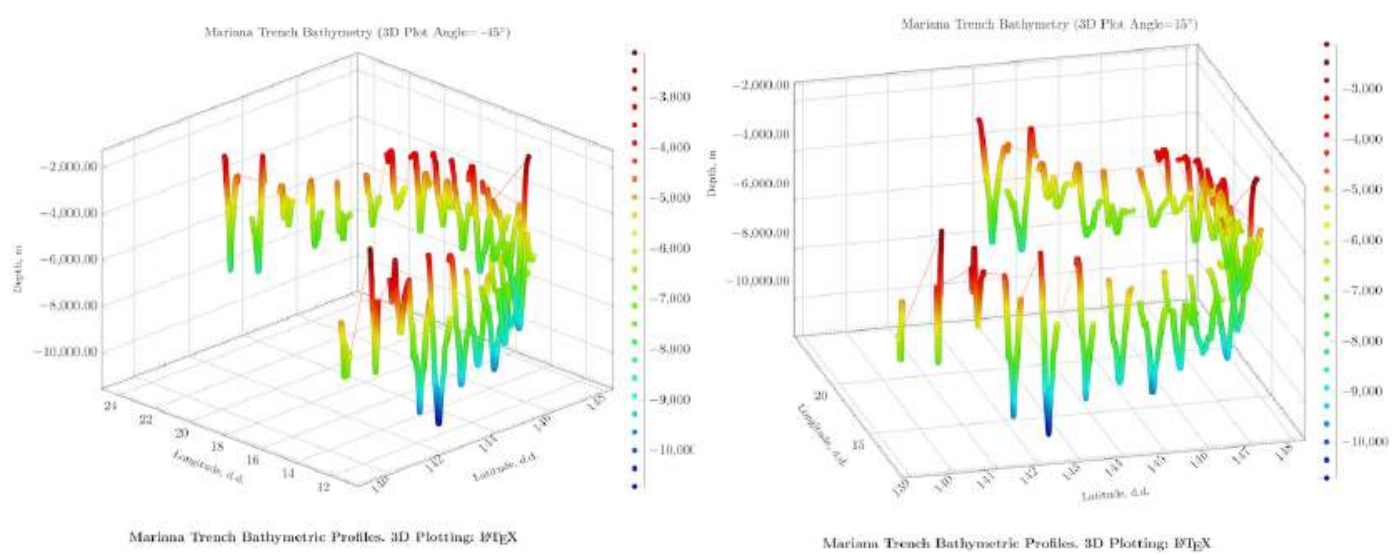

Figure 3.10.2: Mariana Trench: 3D-view of the 25 bathymetric profiles. Plotting: $\mathrm{L}_{\mathrm{TE}} \mathrm{X}$ 


\section{Chapter 4}

\section{Results}




\subsection{Classification of the submarine geomorphology}

Oceanic trenches present important part of the oceanic lithosphere. They are developed on the oceanward side of both island arcs and orogens that form above subduction zones. Deep-sea trenches are the largest linear depressed features of the Earths surface, notable for their depth and continuity. For example, the PCT is $4500 \mathrm{~km}$ long and reaches depths of 7-8km BSL. The trenches in the western Pacific Ocean are typically deeper than those of the eastern Pacific Ocean, the greatest trench depths, of $10-11 \mathrm{~km}$, detected in the Mariana and TongaKermadec trenches.

Following geomorphological profile shape types have been identifies and trenches are classified into seven types: U-formed (in plan), V-formed (in plan), asymmetric, crescent-formed, sinuous-formed, elongated, elongated to upside-down-ridge-like, cascade-formed, circular-like, arcuate, symmetric of irregular: left- or right-sided.

For each geomorphological type (U, V, asymmetric and so on) characteristic steepness sub-types are identified: strong, very strong, extreme, steep, very steep. Furthermore, valley slopes are classified as follows: very high, high, moderate, low based on the degree of curvature. Hence, size classes and valley slope classes are analyzed in the context of physical environment as well as tectonic and geological development of the area of trench formation. Flexural bending shape of a subducting lithospheric plate has effects on the tectonic loading at the trench axis, strength as well as faulting effects of the subducting tectonic plate. Necessarily, it is reflected in the variety of the trench shape forms.

Main factor controlling the max depth of a trench is tectonics: the age of the subducted oceanic lithosphere, since it determines the depth to the oceanic crust entering the trench. The remarkable contrast between trench depths in the east and west Pacific Ocean is largely explained by the systematic difference in the age of the seafloor in these regions. Generally, plate age (relatively young or old plates) is a prevailing factor in controlling trench cross-sectiongin shape, independent from the axial sediment loadings. Trench geomorphology and width of the cross-section profiles are mainly controlled by the elastic thickness reduced by tectonic faulting near the trench axis. In turn, they are affected slightly by the initial thickness of the subjecting tectonic plate. The reduction of the tectonic plate causes significant deepening and narrowing of trench valleys.

As seen intros dissertation base don the cross-sections, trenches are generally $50-100 \mathrm{~km}$ in width. In cross-section they form an asymmetric V-shape with the steepest slope, of $8-20^{\circ}$, on the side opposite the subducting ocean floor. The sediment fill of the trenches vary greatly as demonstrate din this work, from virtually nothing, as in the TT and KT, to almost complete, as in the AT. This is explained by the supply of sediment coming from the adjacent continental areas. Trench depth is also reduced by the subduction of aseismic ridges.

Bending of the lithosphere plate gives rise to the topographic bulge presented in the subducting tectonic plate on the oceanward side of the island arc. Regional rise of the seafloor bathymetry is located between 100-200km from the trench axis. It has an amplitude of several hundred $\mathrm{m}$. The presence of this bulge is a consequence of the downward deflection of the subducting plate.

In this dissertation, a systematic mapping and analysis of their geometric shape forms has been conducted abseils don the detailed analyses of 20 trenches of the Pacific Ocean with a diverse range of characteristics (geology, tectonics and geophysical settings).

PT: irregular sharp V-shaped trench (in plan) trench. The cross-sections of the selected segment have a strongly asymmetric view which is caused by the Philippine Islands (Mindanao) located on the west. Therefore, western part of the cross-sections has a smooth gradual decrease in depths in a uniform way from -75 to $40 \mathrm{~km}$ in the left flank with a slope of $31^{\circ}$. The $2^{\text {nd }}$ segment stretches from 40 until $10 \mathrm{~km}$ of the left cross-section with a gradient slope of $40,60^{\circ}$. The last and short segment on the left $(10-0 \mathrm{~km})$ has a steepness of $28^{\circ}$. The right flank of the profile has following variation in steepness. A segment of 0-20 km has a slope of $44^{\circ}$, following by the fragment of $20-35 \mathrm{~km}\left(41,70^{\circ}\right)$ and $35-50 \mathrm{~km}\left(25,0^{\circ}\right)$. 
A long segment on the right $(50-200 \mathrm{~km})$ has a very uniform geomorphology with almost no significant variations and dominating depths at around $-6,000 \mathrm{BSL}$. The deepest segment of the PT $(10-0 \mathrm{~km}$ on the profile from the center line) has more gentle slope with a steepness of $28^{\circ}$ versus $44^{\circ}$ on the right flank for the same segment. The cross-sections of the PT have asymmetric profile caused by the adjacent Mindanao Island. PT has a V-shape form in its deepest parts. Fig. 4.12.1 and 4.17.1 show vertical cross section transects perpendicular to the segment for PT. A lower placed graph shows a median stacked cross-section profile (red line) and an interval of the error bars for the measurements. Variation in the trench gradient angles, steepness and elevation variation from the western and eastern flanks are caused by tectonic settings.

KKT: cascade-shaped trench. Variations in the geomorphology fo the KKT are as follows. Southern part reaches $-8,200 \mathrm{~m}$ maximal depths while northern has $-7,800 \mathrm{~m}$. Trench morphology in the northern termination of the southern segment of the KKT, just approaching the Bussol Strait is at the U-trending seafloor rise. Wedge-shaped form of the trench is being formed in its $\mathrm{S}$ part on the $\mathrm{W}$ trench slope. Area around the northern part of the trench identified features of the trench geomorphological system (submarine canyons, trench wedge, submarine ridges, and basins) in the $\mathrm{N}$ part of the trench. Wedgelike or U-shaped morphology of the trench in two parts S- and $\mathrm{N}$ are distinct from the inner-ward slope and in longitudinal direction along the trench axis. S profiles along the trench, comparing to the $\mathrm{N}$ segment, located near the intense volcanic area demonstrate erosional moats at $-3000 \mathrm{~m}$ depths. Orthogonal bathymetric profiles across the $\mathrm{S}$ and $\mathrm{N}$ segments of the KKT identify two distinct $\mathrm{U}$ - and V-shaped morphologic features with affecting dominant processes: (1) in its $\mathrm{N}$ segment, the dominant processes along the Kamchatka Peninsula are sediment deposition; (2) S part is distinct by the processes of erosion and intense sediment transportation. $\mathrm{N}$ part of the trench show deeper values and less steep slopes comparing to the $\mathrm{S}$ segment, which refer to the erosional moats and drift of the submarine sediments. S part has deeper bathymetric ranges and steeper gradient slope. This is influenced by the intensive seismicity and volcanic activities. KKT forms more V- shaped valley in its $\mathrm{S}$ segment with about $3 \mathrm{~km}$ wide in profiles and more $\mathrm{U}$-shaped form in the $\mathrm{N}$ part.

KT: elongated to upside-down-ridge-like trench. Profiles in Fig. 4.6.1 are roughly perpendicular to the trench axis. Latitude beside each profile indicates position of the axial bottom. KT has gentle shape form of the western slope off Tonga Ridge (Fig. 4.6.1, B), abrupt shape with 2,641 depth records from $-6,600$ to $-6,800 \mathrm{~m}$ (Fig. 4.7.2). Comparing the deepest values $>9,000$ meters for the KT there are 251 samples proving that TT is deeper than KT. For seafloor depths at range from $-6,000$ to $-5,000 \mathrm{KT}$ has more values in this range: 6167 samples [420], Fig. 4.7.2. KT has gentle slope and shallow depths which can also be seen on Fig. 4.6.1. This illustrates tectonic and geological local variations, as well as different sedimentation of the KT causing variations in their geomorphic shape despite their close location.

PaT: irregular V-shaped left-sided trench. Bathymetric profiles of the axis of the PaT have very sharp yet irregular V-shape except for its northern portion. Such a form indicates bare bottom or very thin sediment cover of the axis. Northern portion about $25 \mathrm{~km}$ long north of $7^{\circ} 38^{\prime} \mathrm{N}$ has U-shaped bottom that becomes gradually wider in northward direction. Fig. 4.15.1 shows bathymetric profiles of the PT. The average dip of the landward slope is ca. $12^{\circ}$, whereas much steeper 10 to $50 \mathrm{~m}$ high scarps are occasionally take place. Barrow-like bathymetric pattern is recognized on the lower landward slope close to the trench axis. It may be a slumped block with no deep-sea terraces which have trapped sediments. If surface sediments or rocks are collapsed into the axis, the $\mathrm{V}$-shaped bottom will be buried to form flat basin, unless subduction or tectonic erosion proceeds. Such avalanche appears to occur easily and frequently, as dipping angles of the lower landward slope exceeds slope failure limit in PT.

MnT: sinuous-shaped trench. It is a relatively young, shallow and narrow subducting plate trench (ca. 15-36 Ma), small trench relief and width. Along the trench axis, the bathymetry is deeper and narrower at the $\mathrm{S}$ and $\mathrm{C}$ sections than that of the $\mathrm{N}$ area. Depth and geomorphology of the slope of the MnT vary significantly for the depths range $-3,500$ to $-4,500$ : minimal values are notable for the northern part of the 
trench where 526 observation points $(18,2 \%)$ are recorded for the depths $-4,000$ to $-4,200 \mathrm{~m}$, as shown on Fig. 4.13.2 A. S part of the trench has steeper slope gradient from the oceanward part. N part is steeper in the continental slope part (Fig. 4.13.1). Submarine terraces can be noted on the $\mathrm{N}$ segment of the trench (Fig. 4.13.1) at depths - 2,000 m. Generally, model of the N part shows more steep degree of the oceanward slope ( Fig. 4.13.1). Gradually slanting terrace on the $\mathrm{S}$ segment can be seen on the fragment 50-100 of the cross-section with depths from $-1,100$ to $-1,300 \mathrm{~m}$. Two segments of the trench located on the $\mathrm{N}$ and SE part of the trench differ: $\mathrm{N}$ segment has shallower values of depths comparing to the $\mathrm{S}$, but more steep slope on the Luzon Island side.

AT: elongated. NW part of the trench on the side of the islands chain has steeper and shorter slope with located series of marine terraces. The average slopes of its northern side range between $3^{\circ}$ and $4^{\circ}$, while those of its even shallower southern side are $1^{\circ}$ or $2^{\circ}$

MT: V-shaped (in plan). Large trench relief and width. Dominating are steep (7-9 ${ }^{\circ}$ slopes and flat bottom. Gradient slopes markedly symmetric accurate ' $V$ '-shape form in its deepest parts. Perpendicular transects cross-sections: steeper gradient slope on the N (Fig. 4.17.1, below) flank on the archipelago's side (Fig. 4.17.1).

Table 4.1.1: Mariana Trench: variations in gradient steepness of the right flank

\begin{tabular}{ll}
\hline Segment at distance $\mathbf{0 - 2 8} \mathbf{~ k m}$ & Slope steepness of $40,5^{\circ}$ from the vertical plummet. \\
\hline Segment at distance $\mathbf{2 8 - 3 7} \mathbf{~ k m}$ & Slope steepness of $43,33^{\circ}$ from the vertical plummet. \\
\hline Segment at distance $\mathbf{3 7 - 5 0 ~} \mathbf{~ k m}$ & Slope steepness of $30,43^{\circ}$ from the vertical plummet. \\
\hline Segment at distance $\mathbf{5 0 - 9 0} \mathbf{~ k m}$ & $\begin{array}{l}\text { Arc-shape gradual increase of the elevation which stabilizes after } \\
100 \mathrm{~km}<-4000 \mathrm{BSL} .\end{array}$ \\
\hline
\end{tabular}

Table 4.1.2: Mariana Trench: variations in gradient steepness of the left flank

\begin{tabular}{ll}
\hline Segment at distance $\mathbf{0 - 1 5} \mathbf{~ k m}$ & Slope steepness of $33,10^{\circ}$ from the vertical plummet. \\
\hline Segment at distance $\mathbf{1 5 - 2 5} \mathbf{~ k m}$ & Slope steepness of $45^{\circ}$ from the vertical plummet. \\
\hline Segment at distance $\mathbf{2 5 - 4 0 ~} \mathbf{~ k m}$ & Slope steepness of $30,75^{\circ}$ from the vertical plummet. \\
\hline Segment at distance $\mathbf{4 0 - 5 0 ~} \mathbf{~ k m}$ & Slope steepness of $28^{\circ}$ from the vertical plummet. \\
\hline
\end{tabular}

The relief surrounding left flank slope: uneven submarine terrain comparing to its right flank with complex submarine relief. It presents accurate and steep in its shape form. Major depth samples are between $-3000--5000 \mathrm{~m}$ (Fig. 4.17.2) AT: elongated. Geomorphology in NW part of the trench on the side of the islands chain has steeper and shorter slope with located series of marine terraces. The average slopes of its northern side range between $3^{\circ}$ and $4^{\circ}$, while those of its even shallower southern side are $1^{\circ}$ or $2^{\circ}$

MT: V-shaped (in plan). Large trench relief and width. Dominating are steep (7-9 ${ }^{\circ}$ ) slopes and flat bottom. Gradient slopes markedly symmetric accurate 'V'-shape form in its deepest parts. Perpendicular transects cross-sections: steeper gradient slope on the N (Fig. 4.17.1, below) flank on the archipelago's side (Fig. 4.17.1). Slope steepness on the left flank: $33,10^{\circ}$ at $0-15 \mathrm{~km}$ from the center of the vertical plummet. A segment $15-25 \mathrm{~km}$ has a steepness of $45^{\circ}$, segment of $25-40 \mathrm{~km}-30,75^{\circ}$, a segment of $40-50 \mathrm{~km}-28^{\circ}$. Gradient steepness of the right flank varies: the segment at distance 0-28 $\mathrm{km}$ has a steepness of $40,5^{\circ}$ from the vertical plummet, $28-37 \mathrm{~km}$ from the start point has a $43,33^{\circ}$ of steepness. It then gradually gentles to $30,43^{\circ}$ until $50^{\text {th }} \mathrm{km}$. The segment $50-90 \mathrm{~km}$ : arc-shape gradual increase of 
the elevation which stabilizes after $100 \mathrm{~km}<-4000$ BSL (Fig. 4.17.1). The relief surrounding left flank slope: uneven submarine terrain comparing to its right flank with complex submarine relief. It presents accurate and steep in its shape form. Major depth samples are between $-3000--5000 \mathrm{~m}$ (Fig. 4.17.2) .

TT: U-shaped (in plan). TT has shallower depths comparing to the KT. The deepest values of TT $>9,000$ meters cover 320 samples. Variations of the seafloor depths at range from $-6,000$ to $-5,000 \mathrm{~m}$ (Fig. 4.7.2) that TT has 4803 samples [420]. Cross-section profiles demonstrated that TT geomorphology has steeper gradient slope on the western flank (Fig. 4.6.1, A). The results show deeper bathymetry and more seafloor roughness for the TT. Hence, TT has steep gradient of the profiles.

MAT: symmetric-shaped. The submarine geomorphic structure of the trench has straight shape form of the slopes with more steep oceanward forearc. Its geometry has relatively steep and strait shape which correlates with seismicity. Major depth observation samples have values of -3000 to $-6200 \mathrm{~m}$, seafloor is 3-5 km wide. The output model of the cross-section profiles is provided at Map 4.4.1 showing the initial bathymetric map (Map 4.4.1 B) and above a plotted series of the profiles (Map 4.4.1 A), such as oceanward backers of the trench and more steeper slope on the continental side. However, other areas, particularly the terraces were less well defined, perhaps due to the local specific geomorphic features of the study object: the geomorphology of the MAT presents a very straight steep slopes without significant curvatures. Spatial analysis performed by the GMT revealed that major depth observation points of the MAT are located in between the -3000 and -6200 meters (Map 4.4.1 and Fig. 3.3.3). The deepest bathymetry data range with 1,111 records takes $25 \%$ of the total pool of the sample observation points. As can be seen on Fig. 4.4.1, right, the mean values of the observation samples have a value of $-2,200$, while LMS mode indicates $7,5 \%$ of values at $-4,000$ to $-3,500 \mathrm{~m}$, and median values have values of $-3,200$ to $-3,300 \mathrm{~m}$.

PCT: asymmetric-shaped. Geomorphology differs in two parts. Chilean segment: deeper bathymetry and steeper gradient slope on the Nazca Plate (Fig. 4.5.1, A). Peruvian segment of the trench (Fig. 4.5.1, B) demonstrates a gentler landform on the oceanward side. A comparison of the highest data frequency for both segments: Peruvian segment has the majority of data (23\%) 1,410 samples (-4,500 m to $-4,700$ $\mathrm{m}$ are the most frequent values for the Peruvian segment of the trench). It shows a peak of all data with a very steep pattern in distribution. Other data in the neighbor diapason are much lower: 559 samples $(-4,700$ to $-5,000 \mathrm{~m})$ and $807(-4,200$ to $-4,400 \mathrm{~m})$ for the Peruvian segment. Chilean segment has more even data distribution. Furthermore, data range: 205 samples for $-4,700 \mathrm{~m}$ to $-5,000 \mathrm{~m}$ (agains 559 for the Peruvian segment); 731 for $-4,200 \mathrm{~m}$ to $-4,400 \mathrm{~m}$ (against 807 for the Peruvian segment); 317 for the range of $-4,500 \mathrm{~m}$ to $-4,700 \mathrm{~m}$ (against 1,410 in the Peruvian segment). The most frequent depth for the Peruvian segment of the PCT is a range $-4,000 \mathrm{~m}$ to $-4,200 \mathrm{~m}$ ( 827 samples) against a range of $-4,500 \mathrm{~m}$ to $-4,700 \mathrm{~m}$ for the Peruvian segment (1,410 samples). Peruvian segment is generally deeper and steeper with abrupt slopes (Fig. 4.5.1).

NBT: asymmetric U-shaped. NBT: asymmetrical U-shaped cross-section dipping westwards with $35^{\circ}$ eastward slope, and $41^{\circ}$ slope (Fig. 4.11.2, A). The SCT has $33^{\circ}$ slope oceanwards while $33,69^{\circ}$ landwards increasing in relief more direct on the oceanward side. The increase in depth by NBT is more gentle: in $50 \mathrm{~km}$ segment it reaches $2000 \mathrm{~m}$ BSL $(-7,000$ to -5,000) on the Solomon Sea side. In the crosssection graph, the NBT is markedly asymmetric in the landward slope and has an arc form in the east (Fig. 4.11.2, B). NBT is shallower comparing to the SCT: it has median $<-7,000 \mathrm{~m}$. The highest sample values are recorded in range $-5,000$ to $-5,200 \mathrm{~m}$ (272) gradually followed by ranges $-5,200$ to $-5,000$, $-5,000$ to $-4,800$ and $-4,800$ to $-4,600 \mathrm{~m}$ (number of samples: $204,189,157)$. The depth to the bottom of the NBT becomes gradually deeper in a segment of -50 to $0 \mathrm{~m}$ in cross-section, decreasing from $-3,000$ to $-7,000$ in WE direction, with maximum depths reaching $-7,000 \mathrm{~m}$ and median value $-8,000 \mathrm{~m}$.

SCT: symmetric, 'V'-shaped. The SCT is symmetric with accurate ' $V$ ' form for the segment of 50 to $-50 \mathrm{~km}$ on the graph (Fig. 4.11.2, A). The increase for SCT is abrupt in profile: for the distance $0-50 \mathrm{~km}$ the depths rise from $-8,000$ to $-5,200 \mathrm{~m}$. For the transect segment of -50 to $0 \mathrm{~m}$ in a cross- 
section the depth to the bottom becomes deeper decreasing from $-3,000$ to $-8,000$ in WE direction, that is, the gradient slope is steeper. Geomorphology is explained by the context of the historic and actual geomorphic and sedimentary processes that finally affected trench formation and structure. San Cristobal is deeper comparing to the NBT with bathymetric data reaching $-9,000 \mathrm{~m}$ while NBT has only 1 sample point $<-8,000 \mathrm{~m}$. The most frequent values for the SCT lie in range $-4,600$ to $-4,800 \mathrm{~m}$ ( 217 samples), $-4,600$ to $-4,400$ (202 samples) and $-4,400$ to $-4,200$ (167 samples), Fig. 4.11.2. The majority of the observation samples for both trenches lie in range of - 4000 to $-5,000 \mathrm{~m}$.

HT: arcuate barrel-shaped, trench. HT has trough-like shape form in its cross-section. Whilst it serves as a terrain variable in this study to examine the geomorphic landform, variation of the geomorphic slopes were compared for the trenches and following findings noted: HT has a trough-like flat wide bottom, steeper gradient slope on the North Island flank (Fig. 4.21.1, A). Data distribution for the HT (Fig. 4.20.1, B) [387] demonstrates equalized patterns for depths $-600 \mathrm{~m}$ to $-2,600 \mathrm{~m}$ with samples $<60$ for each bin, most data are detected at ca. 30-40 samples for a bin, $\leq 4 \%$. Notable peak have data located on the shallow areas $(\leq-500 \mathrm{~m})$ where max values are detected for interval -400 to $-300 \mathrm{~m}$ (258 samples): a slope of the North Island (frequency from 5\%-12\%). Geomorphic curvature and distribution of the seamounts near the Puysegur, Hjort and HTes reflect the interplay between the complex tectonic processes occurring at a subducting tectonic plates and variations in the tension between the spreading ridges and the transform faults [403]. Generally, a strong correlation of the trenchs axe with borders of three lithospheric tectonic plates (Antarctic Plate, Pacific Plate and Info-Australian Plate) can be noted, which underpins strong correlation of the trench geomorphology with direction of the tectonic slab lineaments, as plate movements, geologic lineaments and extend of the fracture zones in the final end lead to the formation of the trench axis through the plates motions. Local geologic settings, linear extension of the tectonic slabs, complex tectonic processes and sedimentation of the HT might explain variations in their geomorphic structure and shape of the submarine landforms.

YT: V-shaped (in plan) trench. General pattern for YT: steep slopes and deep bathymetric records. Profiles of the axis of the YT have sharp V-shape. YT reaches $-7000 \mathrm{~m}$ in its median curve of the profiles, while the PT only $-6200 \mathrm{~m}$, that is the PT is shallower. Second, YT has distinctly more abrupt slope and steep gradient of the profiles oceanward (Fig. 4.15.1, B) comparing to the PT (Fig. 4.15.1, A). [332] earlier pointed that extensive slope failure is occurring on the landward slope of the PT from which great amount of mass is wasted to the trench axis. Hence, if surface sediments or rocks are collapsed into the trench axis, the V-shaped bottom will be gradually buried to form a flat basin, unless subduction or the tectonic erosion proceeds. Submarine sediment avalanches occur easily and frequently, when dipping angles of the lower landward slope partly exceed slope failure limit. Inner slopes on the YT are more steep and abrupt (Fig. 4.15.1, B). The average dip of the landward slope is recognized as about $29^{\circ}$ for the YT westwards $41^{\circ}$ eastwards. Data distribution for the YT (605 samples): depth range at -5000 to $-6000 \mathrm{~m}$ : YT has 53 samples. YT has steep slopes and generally deep sample records, deep values within range of $-7000 \mathrm{~m}--6000 \mathrm{~m}$ : 68 samples.

PsT: sharp irregular right-sided V-shaped trench. PsT (Fig. 4.21.1, B: middle plot) has asymmetric $\mathrm{V}$-form with steep gradient on the E slopes and more gentle slope on the $\mathrm{W}$. The results of the comparison of the median values (red line on Fig. 4.21.1 for the trenches show that selected segment of the HT has shallower depths with maximal not exceeding - 2,500 m (Fig. 4.21.1, A), while PsT is reaching up to 6,000 m (Fig. 4.21.1, B). PsT (Fig. 4.20.1, A) has a bimodal type of data distribution with two peaks. The first peak has three notable bins range $-4,200$ to $-4,400 \mathrm{~m}$ (373 samples detected, data frequency $18 \%$ ), range $-4,000$ to $-4,200$ (182 samples, data frequency 9,6\%) and $-4,400 \mathrm{~m}$ to $-4,600 \mathrm{~m}$ (216 samples, data frequency $11,5 \%$ ). The second peak covers depths from $-2,200$ to $-3,000 \mathrm{~m}$ with the data frequency below 7,5\%. The peak corresponds to the Macquarie Arc bordering the trench slope.

JT: irregular-V-shaped trench (north); elongated left-sided trench (south). Comparative analysis of the two parts of the a series of cross-section profiles (Fig. 4.19.1) revealed more steep slope on the 
northern part of the trench on the continental slope part beneath the frontal wedge of the North American tectonic plate. Southern part of the JT shows more gentle slope on the Honshu Island. The location of the swath profiles traversing the two segment of the JT South-West to North-East direction is shown in Fig. 4.19.1. 12 profiles were drawn for the southern segment and 14 profiles for the northern one. Highly rugged geomorphological structure of the median profiles, and altitude increase in the S-N direction can be seen on the northern part of the JT (Fig. 4.19.1). geological settings and seismicity of the area impact the trench roughness and general geomorphic shape when studying bathymetric patterns and variations by the cross-sectioning profiles of JT, which is shown on the geological map (Fig. 2.18.2) with high level of the seismicity, repetitive earthquakes and volcanism along the JT. W part of the trench (Honshu Island slope) has steeper slopes comparing to the oceanward slopes for both segments, which can also be seen on the 3D model shown on Fig. 2.18.5.

IBT: asymmetric trench in two different parts. Southern segment of the trench is deeper and has more accurate V-form with a steeper gradient slope on both slopes (Fig. 4.18.1, B). Northern part of the trench (Fig. 4.18.1, A) has asymmetric shape of the slope with notable submarine terrace on the western part and more straight shape on the oceanwards side (Fig. 4.18.1, A). Comparison of the oceanward flank of the both segments of the IBT show similar geomorphic shape but seamounts on the $\mathrm{N}$ segment (Fig. 4.18.1). The 3D model of the Izu-Bonin shows (Fig. 4.18.2) seamounts on the E part of the trench, [405].

VtT: trough-like W-shaped trench. Selected segment of the VtT has shallower depths with maximal $\leq-5,000 \mathrm{~m}$ while VT is depths with $\geq-6,000 \mathrm{~m}$. The deepest values $>5,000 \mathrm{~m}$ for VtT give in total 413 values $(238,130,29,14,2)$ samples. The geometric form of the two trenches varies: VtT has more flat wide bottom similar to a trough, with steeper gradient slope on the eastern flank (Fig. 4.8.1, A: upper plot). Neighboring surface is rather flat for VtT, surrounded by both North Fiji Basin (eastern flank) and its western flank (Fig. 4.9.2) [388]. A strong correlation of the VtT axes with borders of the 2 tectonics plates (Pacific Plate and Info-Austrlian Plate) takes place. Hence, geomorphology of the VtT correlates with slabs, continuation of the plate movements, lineaments and extend of fracture zones which lead to the formation of the VtT axis determined by the plate motion. Geological settings, stretch of the tectonic slabs, tectonic processes and sedimentation of the VtT explain differences in their structure and geomorphic shape form.

RT: irregular-shaped: right-sided trench with differences for two segments. Median stacked profile on the S part (Fig. 4.14.1 A) show more gentle slope shape with submarine terraces, while there are no clear on $\mathrm{N}$ part of the forearc slope (Fig. 4.14.1 B). At the same time the depth of the forearc slope increases in the northern segment of the RT (Fig. 4.14.1 B). Certain differences in the depth ranges of the RT along the Ryukyu island arc. The depth and geometry of the slope vary considerably: maximal values of $-5,500$ to $-5,700 \mathrm{~m}$ are notable for the $\mathrm{N}$ part of the RT where 334 samples are recorded, Fig. 4.14.2 (A). With a slight difference, $\mathrm{S}$ part demonstrates comparable values (329 samples) for the same depth range. More clear differences are for the depths $>6,000 \mathrm{~m}$. S part of the trench (Fig. 4.14.2 (B) has only 9 samples with depths $>6,800 \mathrm{~m}$ while $\mathrm{N}$ part shows 41,59 and 23 records, with a maximal values reaching $-7,460 \mathrm{~m}$. Moderate to shallow depths with ranges from $-3,000$ to $-5,000 \mathrm{~m}$ are comparable for both parts of the RT with values not exceeding 68 samples for the $\mathrm{N}$ part and 42 samples for the $\mathrm{S}$. The forearc basin $>2,000 \mathrm{~m}$ and $<1,000 \mathrm{~m}$ BSL shows more samples in the $\mathrm{N}$ part of the trench than in the $\mathrm{S}$. In contrast, a wide terrace with depths shallower than $25 \mathrm{~m}$ is generally larger (161 samples) in the $\mathrm{S}$ part of the RT. 2 spatially different segments of the RT show that N part of the RT has deeper values comparing to the S, Fig. 2.13.1: deepest values of the $\mathrm{C}$ part are seen in the deep area extending seaward offshore from the Miyako Fault (Fig. 2.13.2) [392].

VT: crescent-shaped circular-like (in plan) trench. Bathymetry of VT is generally deeper with depths reaching $-7,000 \mathrm{~m}$ in values in the selected segment. VT is depths with $\geq-6,000 \mathrm{~m}$. VT is surrounded by more complex submarine relief of both North Fiji Basin (eastern flank) and its western flank (Fig. 4.9.2). Generally, a strong correlation of the trench's axes with borders of the two tectonics plates 
(Pacific Plate and Info-Austrlian Plate) is evident. This implies that the geomorphology of the trenches is strongly correlated with slabs, since continuation of the plate movements, lineaments and extend of fracture zones leads to the formation of the trench axis strongly determined by plates motions. Local geological settings, stretch of the tectonic slabs, complex tectonic processes and sedimentation of the VT explain differences in their structure and geomorphic shape form. Correlation between seafloor geology with VT location can be illustrated by sediment accumulation resulted in a significant load. Thick VT fill sediments may lead to the obscured morphologic expression of the outer part of the trench or deformed front. Sediment accumulation affect the lithospheric downward deflection in the vicinity of the VT and the amount of the subducted sediments.

Deep-sea trenches are one of the most enigmatic and not enough studied geomorphic systems on the Earth. At the same time, it is in deep-sea trenches that geophysicists can observe how sections of the oceanic seafloor of the the old Earth's crust is subducting, and model processes that tee place in the mantle of the Earth, to see how it interacts with the oceanic crust. In view of this, the importance of the studies of deep-sea trenches is clear for Earth science. In total, about two dozen deep-sea trenches in the Atlantic, Pacific and Indian oceans are known. Their depth in general exceeds 6,000 m. The six deepest trenches of the Earth are located in the Pacific Ocean: MT (11 $034 \mathrm{~m})$, JT (10 $554 \mathrm{~m})$, KKT (10 $542 \mathrm{~m})$ and PT (10 $540 \mathrm{~m})$ trenches, as well as TT trenches $(10882 \mathrm{~m})$ and KT (10 047) $\mathrm{m}$. 


\subsection{Kuril-Kamchatka Trench}

Southern segment of the KKT Comparative assessment of the bathymetry of the KKT was performed for southern and northern segments separated by the Bussol Strait. The profiling was undertaken using GMT modules 'grdimage', 'grdtrack' and 'psxy'. Modelling consists of the collected data of $10706 \mathrm{ob}-$ servation samples from 52 profiles in southern part and 12726 from 62 profiles in the northern segment. The GMT modules psrose and pshistograms were used to plot histograms and rose diagrams visualizing bathymetric variables of depths. The geology was mapped using GMT modules pscoast, grdcut, grdcontour and psxy to plot lineaments and geological objects (ophiolites, faults, earthquakes, trench, magnetic anomalies, tectonic slabs, fracture zones and volcanoes).

The results show that the southern part has deeper bathymetric values, vary in geomorphic structure and has steeper gradient slopes comparing to the north, which is caused by the seismicity, volcanism, geologic and tectonic settings. The comparison of the bathymetry in KKT shown variations in the northern and southern segments: southern part reaches $-8,200 \mathrm{~m}$ maximal depths while northern has $-7,800$ $\mathrm{m}$. This is influenced by the geological settings: earthquakes magnitude and seismicity are higher in the south-west. The submarine terraces and floodplains were observed at $-4000 \mathrm{~m}$ depth forming landforms located southwards off the Bussol Strait. This geospatial analysis contributes to the development of the geological mapping with an example of the Kamchatka area, a region with high seismicity and repeated earthquakes. Technically, the comparison of the two parts of the trench was performed by means of the set of the cross-section profiles plotted by GMT in an automatic regime for northern and southern part of the trench. The morphology of both segments was then compared with aim to identify the characteristics of the trench geomorphology.
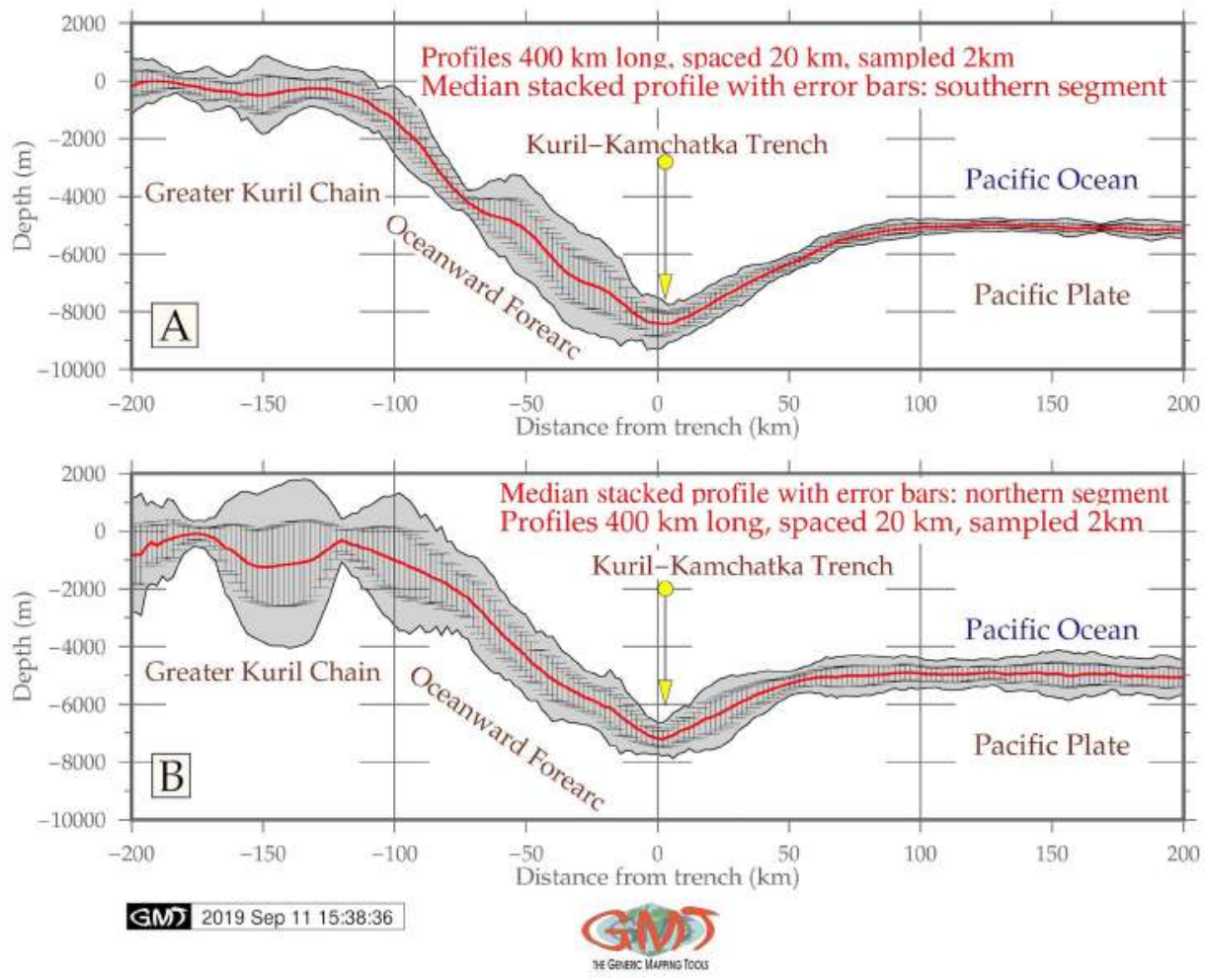

Figure 4.2.1: Kuril-Kamchatka Trench: median stacked profiles

The summary interpretation of the 52 NE-SW cross-section profiles across the KKT in the southern 
part (highlighted as green line on the Fig. 3.5.2) shows following results. At the $S$ region (in the proximity of the active volcanic spots, Fig. 3.5.2), the seafloor depths are found to decrease with increasing latitude gradually while moving northwards. Trench morphology in the northern termination of the southern segment of the KKT, just approaching the Bussol Strait is at the U-trending seafloor rise. Besides, there is indication of the slab subduction along the NW margin of the trench facing the Sea of Okhotsk.

Trench-parallel, linear system of islands stretches along the southern part of the Greater Kuril Chain: Iturup Island, Urup, Shikotan and minor chain of islands. These islands provide a natural barrier to the extensive downslope sediment transport from the southern Sea of Okhotsk to the trench. To a certain extent, they are trapped behind the chain of islands and further restrict the supply of the sediments to the central part of the trench downslope. The submarine terraces are presented along the southern part of the trench axis. A common trend is that southern part of the seafloor depths are found to vary considerably, even within neighboring selected profiles.

Wedge-shaped body of the trench is being developed in its southern part on the westwards trench slope in front of the Sea of Okhotsk inner trench wall closer to the islands Kunashir, Urup and Iturup from the Kuril Greater Chain. It shows a typical and distinct morphologic impact from the nearby subduction zone. The areas of the submarine terraces interspersed with the floodplains have been observed in the southern part of the trench at $-4000 \mathrm{~m}$ depth forming distinctive patterns on the landforms located immediately southwards the Bussol Strait. The southern part of the KKT near Kuril Basin (Fig. 3.5.2) creates conditions for the short sediment transport from the islands between the terrestrial sediments of the Sakhalin Island and the Kurils with marine sediments sinking to the trench.

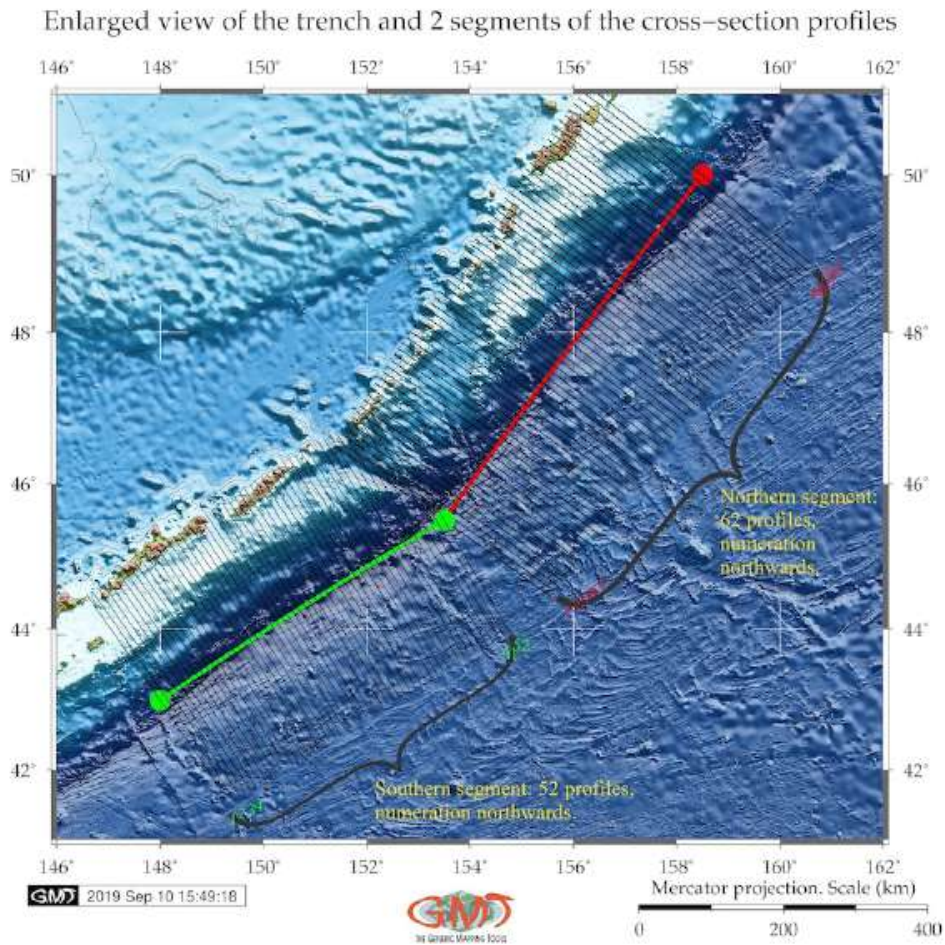

Map 4.2.1: Kuril-Kamchatka Trench: enlarged view of the profiles

In the southern segment, the sedimentation system goes in a transverse direction of the trench stretching: it brings the sediments from the islands located on the south of Sea of Okhotsk: Hokkaido, Kunashir, Iturup, Urup and minor islands of the southern part of Greater Kuril Chain [398]. Southern part of the trench serves as a sink for the sediment dispersal systems along the active margins of the Kuril Islands. It 
is longitudinally fed by the sediments derived from the southern Kurils. The location of the compressionextension tectonic slabs as demonstrated on Fig. 3.3.9 and average deformation of the trenchs axis is directly affected by the source of earthquakes located in the south of the Greater Kuril Chain.

Northern segment of the KKT Northern part of the KKT (red line segment on Fig. 3.5.1) reflects in its morphological features: combined effects of the tectonic slab subduction, collision and sedimentation processes and closeness of LIPs in northern part of the Pacific Ocean near Bering Sea. In particular they are determined by the rate of the Pacific Plate convergence, sediment supply and topography of the subducting seafloor [409]. Fracture zones oriented in NW direction from the Pacific Plate towards the trench affect sediment deposition. Sediment deposits filling the trench are controlled by the rate of the Pacific Plate convergence towards Okhotsk Plate.

The analysis and interpretation of the 62 NE-SW cross-section profiles across the KKT in the N part shows following results. The sequence of profiles crossing the northern part of the trench show truncated landforms at the canyon walls of the Greater Kuril Chain, which rise ca. $1000 \mathrm{~m}$ Above Sea Level (ASL) while southern part of the islands chain (Iturup and Urup islands) show ca. $400 \mathrm{~m}$ ASL. The area around the northern part of the trench identified features of the trench geomorphological system (submarine canyons, trench wedge, submarine ridges, and basins) in the northern part of the trench. The trench-parallel longitudinal sedimentation system carries sediments eroded from the Kamchatka orogenic system to the east, along the Kamchatka Peninsula. These deposits are then moved to the NE part of the trench, Fig. 2.1.1.

Northern part of the KKT receives the sediments transported in a southwest direction from the downslopes of the Kamchatkaand northern islands. Trench-fill sediments are derived from the volcanic arcs formed by the Kamchatka Peninsula and northern segment of the Kuril islands, and adjacent volcanic basins. Sediments are transported to the northern part of the trench From the Kurils through the set of submarine canyons directed transverse to the axis of the N KKT filling it by terrigenous sediments.

Orthogonal profiles line Nr. 1 and 7, located north of the KKT in perpendicular direction off the Academy of Sciences Rise (Fig. 2.1.1) reveal steeper shape form caused by seismic settings and sedimentary accumulation patterns of the SE parts of Sea of Okhotsk. The increased number of profiles in northwards direction show shallower depths which illustrates previous discussion on the variations in the sedimentation processes of $\mathrm{N}$ and $\mathrm{S}$ segments, and the landform of the profiles.

Farther down the trench and NE of the Shiashkotan Island from the Kurils, profile line 42 and 49 cross take the form of an irregularly shaped trough of ca. $8 \mathrm{~km}$ width. Trench floor morphology here is characterized by the gentle slope patterns and depths not exceeding 7,400 $\mathrm{m}$. On both profiles, the N wall of the trench is the island-ward sloping surface of the Kuril islands. Profile line 56 shows mainly flat and parallel form at the shallower depths that extend to about 7,200 $\mathrm{m}$ in the seafloor. Profile line 62 shows more shallower depth and gentle slope shape following the enlargement of the trench valley starting northwards from the Paramushir Island. Stacks of local small hills and bulges across the trench indicate multiple sediment deposition processes along the trench slope in its $\mathrm{N}$ part.

Comparison of the southern and northern segments Comparing northern and southern parts of the trench, the wedge-like or U-shaped morphology of the trench in two parts south- and northwards from the Bussol Strait are distinct not only from the inner-ward slope facing the Sea of Okhotsk and the Greater Kurils Chain, but also in longitudinal direction along the trench axis [409]. This particular may be explained by the response to the gradual changes in seafloor topography patterns. Another impact can be added by the oceanological factors, such as intensive bottom currents. Diverse types of the sediment deposits filling the trench in its northern and southern part differ in substrate content: more volcanic sediments are in the south comparing to the northern part, which can be influenced by the different seismic settings and sediment transport paths. Steeper landforms are in general observed in the southern 
part of the trench comparing to those in its northern segment. In both southern and northern parts of the trench, the floor deposits are influenced by the lateral and longitudinal sediment supply.

The results of the comparative analysis of the two distinct parts of the trench located north- and southwards from the Bussol Strait show that southern part is deeper reaching $-8,200 \mathrm{~m}$ depth while northern part has $-7,800$ at maximal records. The data analysis was performed to examine the spatial variation of the trench geomorphology including the interrelationships of the factors affecting its variation (geodetic, seismic, geologic and bathymetric). Variations in the earthquakes magnitude and seismisity in the study area that are higher in the south-western part of the trench, as well as to a lesser extent location in the magnetic anomalies located in the north-east, influence the bathymetric patterns that show deeper values in the southern part and geomorphic landforms distribution. The cross-section profiles across the northern part of the KKT show deeper values of the depth and less steep slopes comparing to the southern segment, which refer to the erosional moats and drift of the submarine sediments.

On the contrary, southern profiles along the trench, comparing to the northern segment, located near the intense volcanic area demonstrate erosional moats at $-3000 \mathrm{~m}$ depths adjusting the Greater Kuril Chain. This reflects a series of recent earthquakes erupted near Shikotan Island in the southern part of the KKT. Besides, the anomalous metallogeny of the southern Kuril segment is determined by the deep geodynamics, which provided the impact of fluid energy fluxes from sub-subduction and suprasubduction asthenospheric zones. The profiles in the southern segment of the trench show more complex pattern of the processes of erosion along the upper slope and sediment deposition comparing to the northern segment. Therefore, the landward oriented submarine ridges of the trench facing the Greater Kuril Chain form oblique landform shape towards the coast of the southern Kurils. Southern part of the trench follows the exposition to the erosion processes in NE to SW direction caused by the intense earthquakes located on the south of the Greater Kuril Chain.

Northern part of the trench affected by numerous earthquakes located on the Kamchatka Peninsula is influenced by the large amount of the accumulated sediments. Necessarily it forms the shallower depths and gentle flat slopes in the morphology of the northern part of the KKT. On the contrary, the southern part is presented by V-shape formed slopes and steeper morphology which is affected by the specific geophysical conditions of the southern part of the Kuril Islands characterized by the magnetized anomaly zones of the oceanic crust. The junction of two different segments of the Kuril Islands, southern and northern, corresponds to a sub-latitudinal magnetic anomaly. The north-east direction of the magnetic anomalies are recorded on the oceanic slope of the trench up to its island slope while the southern segment of the trench axis is oriented in parallel.

The orthogonal bathymetric profiles across the southern and northern segments of the KKT identify two distinct U- and V-shaped morphologic features with affecting dominant processes: (1) in its northern segment, the dominant processes along the Kamchatka Peninsula are sediment deposition; (2) southern part located near the Hokkaido, Iturup and Urup islands and minor island of the Greater Kuril Chain are distinct by the processes of erosion and intense sediment transportation. The explosive volcanism in different parts of the KKT explain a high mass of sediments formed by gradual sediment accumulation.

Comparing the resulting two graphs (Fig. 3.5.1 and 3.5.2), two parts of the trench located northand southwards from the Bussol Strait show that southern part is deeper reaching $-8,200 \mathrm{~m}$ depth while northern part has $-7,800$ at maximal records. It can be explained by the fact that northern part of the trench affected by numerous earthquakes located on the Kamchatka Peninsula is influenced by the large amount of the accumulated sediments. Necessarily, it forms the shallower depths and gentle flat slopes in the morphology of the northern part of the KKT. The results of the dataset analysis were compared and found out that profiles located in the southern and northern parts vary in depths and geomorphic steepness, due to the impact of the geological settings and seismicity.

In general, the profiles in the $\mathrm{N}$ part of the trench show deeper values and less steep slopes comparing to the $\mathrm{S}$ segment, which refer to the erosional moats and drift of the submarine sediments. On the contrary, 
$\mathrm{S}$ part of the trench has deeper bathymetric ranges and steeper trench gradient slope, comparing to the $\mathrm{N}$ part. This can be influenced by the intensive seismicity and volcanic activities in this particular area of the trench. Furthermore, the trench forms more V- shaped valley in its $\mathrm{S}$ segment with about $3 \mathrm{~km}$ wide in profiles and more $\mathrm{U}$-shaped form in the $\mathrm{N}$ part. The shape of the slopes and steeper morphology of the $\mathrm{S}$ part is affected by the specific geophysical conditions of the $\mathrm{S}$ part of the Kuril Islands characterized by the magnetized anomaly zones of the oceanic crust.

The V-shaped valley of the trench segment neighboring Iturup and Urup islands goes in east-northward direction where is faces the Bussol Strait. Afterwards, the trench continues direction in the N segment along the islands Shiashkotan, Kharimkotan, Onekotan, Paramushir and Shumshu and finally reaches Kamchatka Peninsula. Variations in S and N part of the trench reflect differences in local geological settings of the respecting segments. The trench is associated with tectonic subduction zones. Besides geological factors, trench geomorphology is affected by local tectonic settings. Collision of the tectonic plates can be the a reason that affected both the KKT motion and the morphology of the subducting Pacific Plate at depth in $\mathrm{N}$ and $\mathrm{S}$ parts of the trench that could be sliced in the two distinct morphologies in its $\mathrm{N}$ and $\mathrm{S}$ parts. Distinct changes in trench geomorphology is illustrated by [545]: changes between the horizontal slab and vertical arcs. Variations in physical slab settings can be the result of the plate distortion as its shape transforms between near horizontal to near vertical and change in the velocity of the subduction plate, or a combination of both.

Various geophysical factors affect the geomorphological structure of the trench and cause variations in its morphological structure among which tectonics plays the major role in the trench formation. For the case of the KKT, two tectonic plate have responses to its tectonic history, which could be caused by the ongoing subduction of the major Pacific Plate under the minor Okhotsk Plate [58]. The latter is a region of the active grabens located southwards of a chain of small sedimentary basins in the Cherskii Mountains, North Russia [656].

A longitudinal main channel is usually formed on the bottom of the deep-sea trench under the influence of turbidite currents [590]. It creates favorable conditions for the distinctive movements of the sand sediments that shape large elongated accumulations of the sediments [158]. For example, in case of the Mariana Trench, there are two general types of sedimentation. The $1^{\text {st }}$ one is represented by the pelagic sediments, accumulated as a result of gravitational forces moving suspended matter from the water column into the deeper parts. The $2^{\text {nd }}$ type is represented by the aleurite-clay sediments. In high latitudes they may be mixed with the iceberg sediments. The speed of such terrigenous sedimentation can reach 175-200 mm/1000 years. The sediments in the bottoms of deep ocean trenches mainly accumulate horizontally sand and silt turbidites with gradational stratification. Correct analysis of possible accumulation of the sediments within trench, its underlying tectonics and geology may visualize correlation between the deep-sea deposits and changes at the sea surface. Big data sets in geology are especially well suited to quantifying correlations between trench seafloor geomorphology and sedimentation. Deepsea trench modelling is necessary for the robust estimation of the ocean mineral resources. Estimation of the deposits in seafloor resources requires precise computation of the big geological data sets. 


\subsection{Aleutian Trench}

The GMT based modelling demonstrated following results. The topography in the study area ranges between -8200 to $2000 \mathrm{~m}$ (Map 4.3.1). The geoid gravitational model shows the majority of values lies in the interval between -10 to $20 \mathrm{mGal}$ with the lowest values along the trench. The profiles plotted in an automated regime are located with a distance of $20 \mathrm{~km}$ between each pair, spaced every $2 \mathrm{~km}$ along the profiles itself and have a total length of $400 \mathrm{~km}$, that is $200 \mathrm{~km}$ to both sides from the trench. According to the statistical histogram modelling, the most often depth value in the study area is - 4800 with frequency 1722.
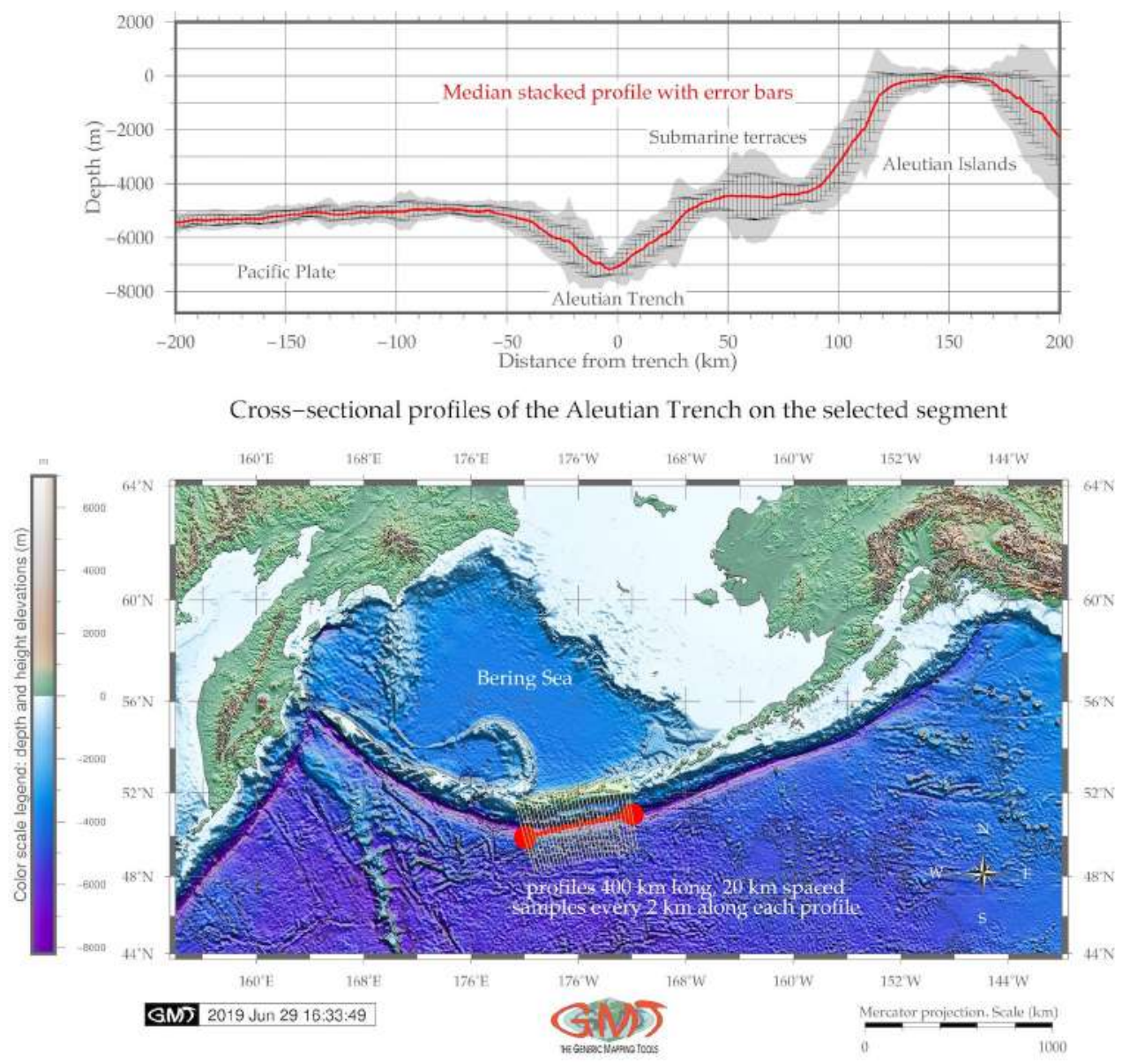

Map 4.3.1: Aleutian Trench: digitized cross-section profiles. [370]

The derived cross-section profiles on a selected segment of the trench (a map on Map 4.3.1) includes a combination of the ETOPO1 bathymetric map with a set of the automatically drawn profiles (Map 4.3.1, lower part), and a statistical visualization of the median stacked profiles with error bars (Map 4.3.1, graph on the upper part). Four approaches for the profile linear trend modelling were tested. Finally, a surface modelling was performed using xyz modelling from the ASCII data. The results of this study demonstrated (Map 3.3.16) distribution of the local occurrence of bathymetric data along the cross-section profiles. Visualizing submarine geomorphology provided context and guidance for further geological and oceanographic discussions regarding hadal trench shape, occurrence of terraces, steepness of the slopes, location of canyons, as well as their distribution. 


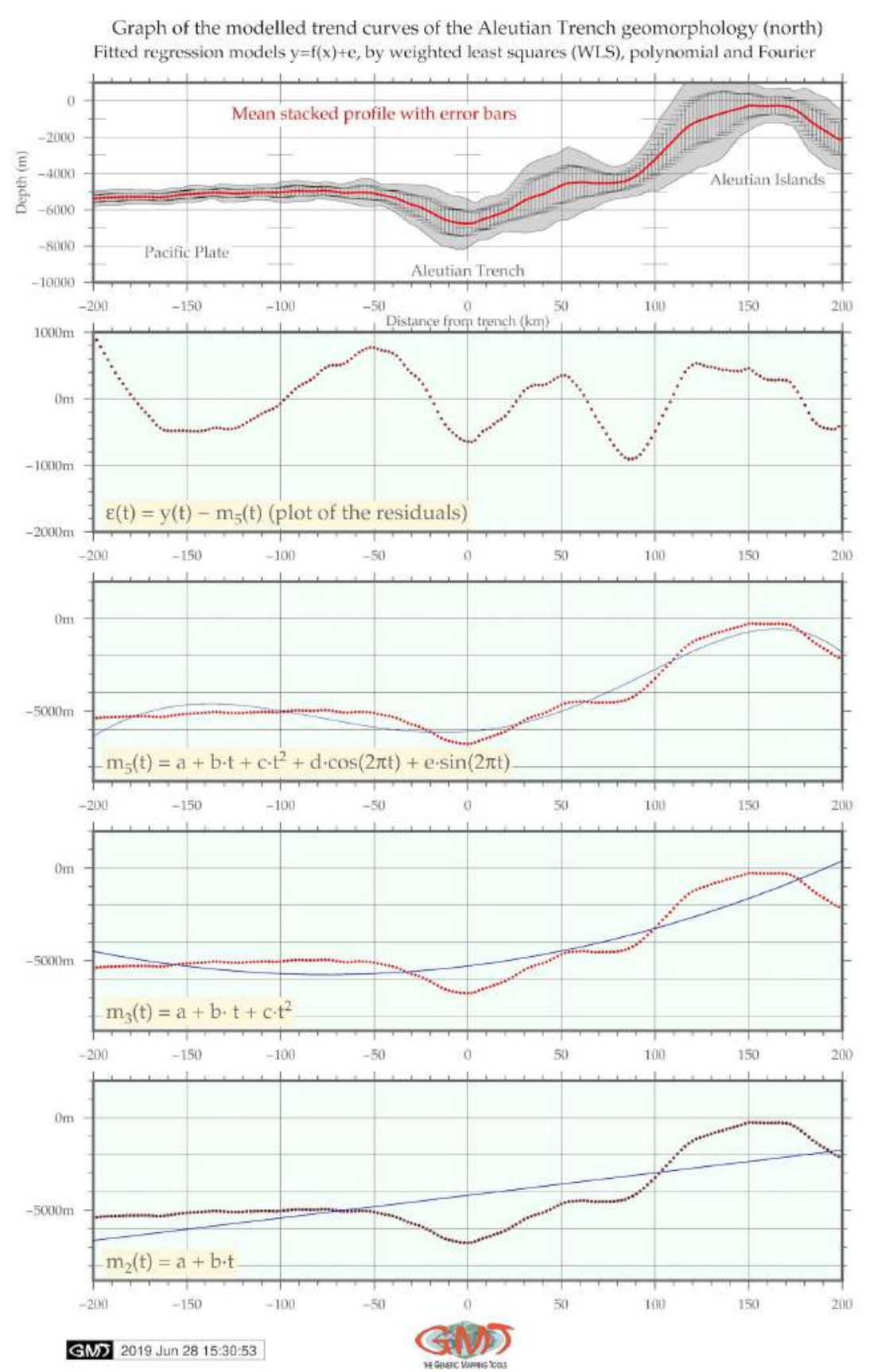

Figure 4.3.1: Aleutian Trench: modeled trend curves of the relief of the mean cross-section profile. [370]

The bathymetry was visualized using geo color palette. The original data is derived from the seasurface satellite altimetry measurements and ocean soundings provided by numerous global geospatial sources. Therefore, the ETOPO1 includes existing bathymetry data and uses interpolated gravity values elsewhere. The statistical analysis of the bathymetric data shown (Fig. 4.3.2) that depths with ranges between -5600 and $-5400 \mathrm{~m}$ have occurrence of $1106(8 \%)$; depths with ranges -5400 and $-5200 \mathrm{~m}$ have occurrence of 846 (7\%); depths with ranges -4900 and $-5200 \mathrm{~m}$ have occurrence of $1297(11 \%)$. The highest values demonstrated values of -4900 and -4700 with 1722 occurrences $(13,2 \%)$. Significantly low values demonstrated shallow areas with depth ranges between -4500 and $-3000 \mathrm{~m}$ with occurrence of below 200 (all of then less than 2,5\%). Values with ranges shallower than $-500 \mathrm{~m}$ naturally belong to 
the coastal shelf areas near the Aleutian Islands adjusting the trench.
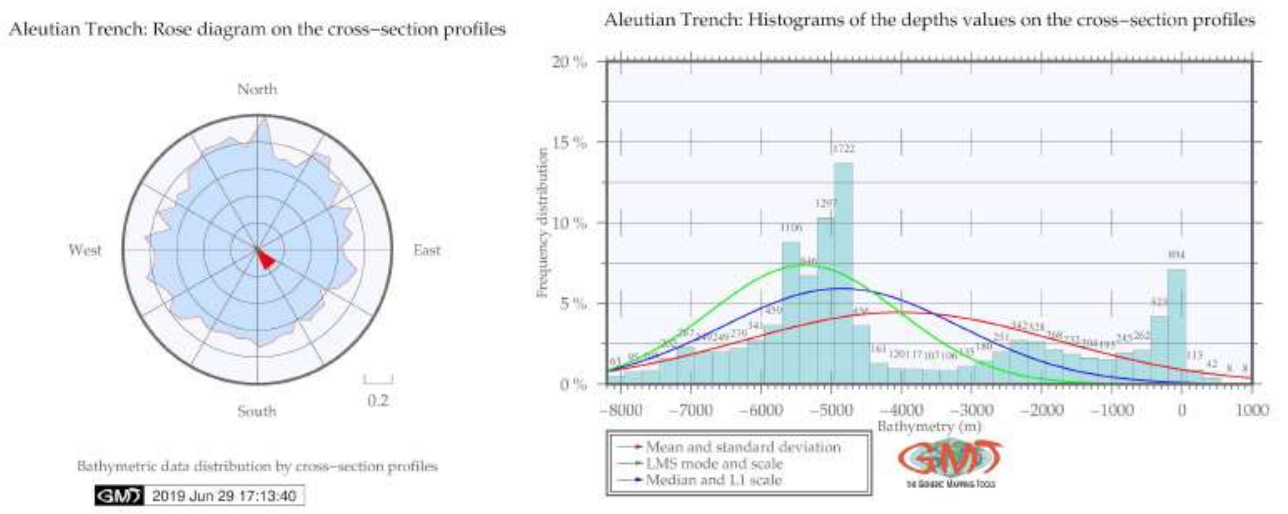

Figure 4.3.2: Aleutian Trench: histogram chart on bathymetric data distribution by profiles. [370]

Furthermore, a geomorphic analysis (Fig. 4.3.1 and 2.2.4) shown that north-western part of the trench on the side of the islands chain has steeper and shorter slope with located series of marine terraces. Several models and maps illustrate geological, geophysical and geomorphic modelling of the area including an outline of the shell scripting, the model, and visualized maps. To assist in the identification of the geomorphology of the AT, bathymetric ETOPO1 data were contoured at $500 \mathrm{~m}$ intervals using GMT module grdcontour (Fig. 2.2.2).

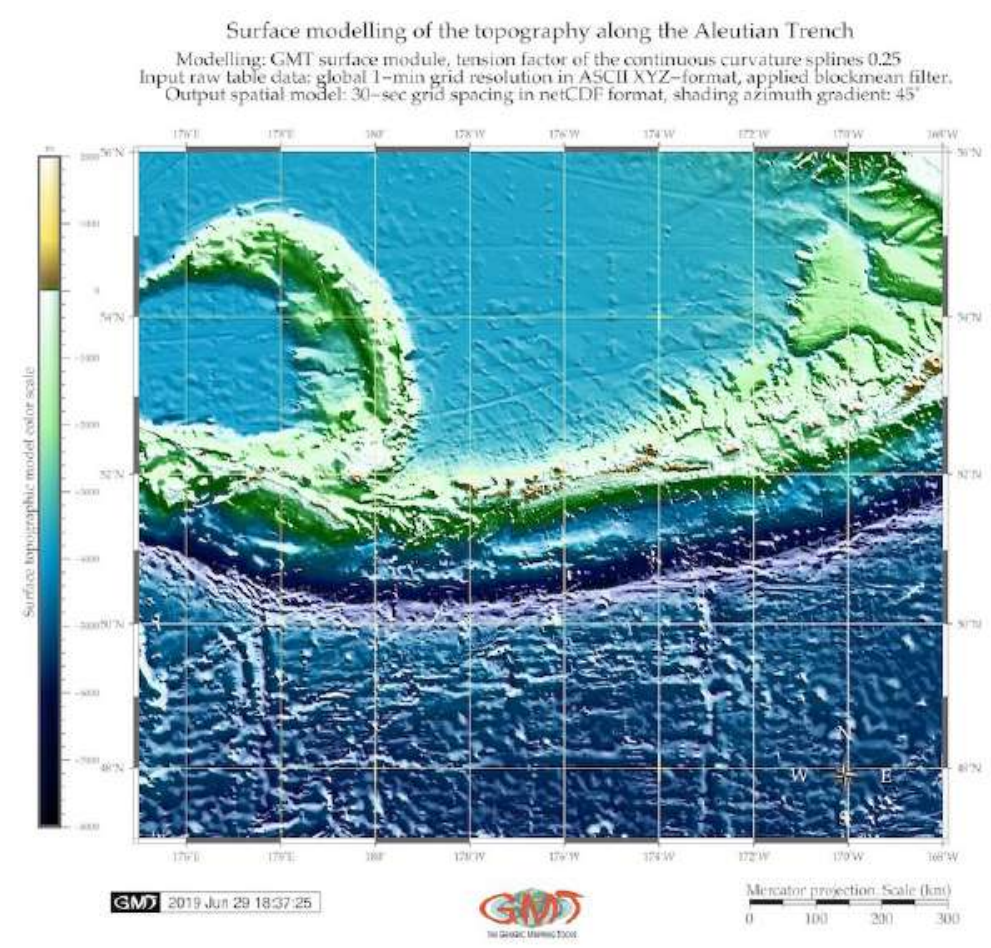

Map 4.3.2: Aleutian Trench: topographic surface modelling from the ASCII xyz data. [370]

Geomorphic analysis in GMT module trend1d was applied to build statistical trends with four functional approaches (Fig. 4.3.1) and visualization of median and mean profiles (Map 4.3.1). The results of the surface modelling (Map 4.3.2 and 3.3.16) are received by modelling xyz dataset. 


\subsection{Middle America Trench}

The results of the geospatial data modelling show geomorphic shape of the submarine landforms in the MAT and surface trends that reveal unevenness in the structure. The submarine geomorphic structure of the trench has straight shape form of the slopes with more steep oceanward forearc. Its geometry has relatively steep and strait shape which correlates with seismicity. Major depth observation samples have values of -3000 to $-6200 \mathrm{~m}$, seafloor is $3-5 \mathrm{~km}$ wide. The marine vertical gravity at the trench correlates with the tectonic slab contours. The intermediate values $(20-30 \mathrm{mGal})$ are detected on the trench slopes while the highest values on the mountainous areas. The output model of the cross-section profiles is provided at Map 4.4.1 showing the initial bathymetric map (Map 4.4.1 B) and above a plotted series of the profiles (Map 4.4.1 A), such as oceanward backers of the trench and more steeper slope on the continental side.
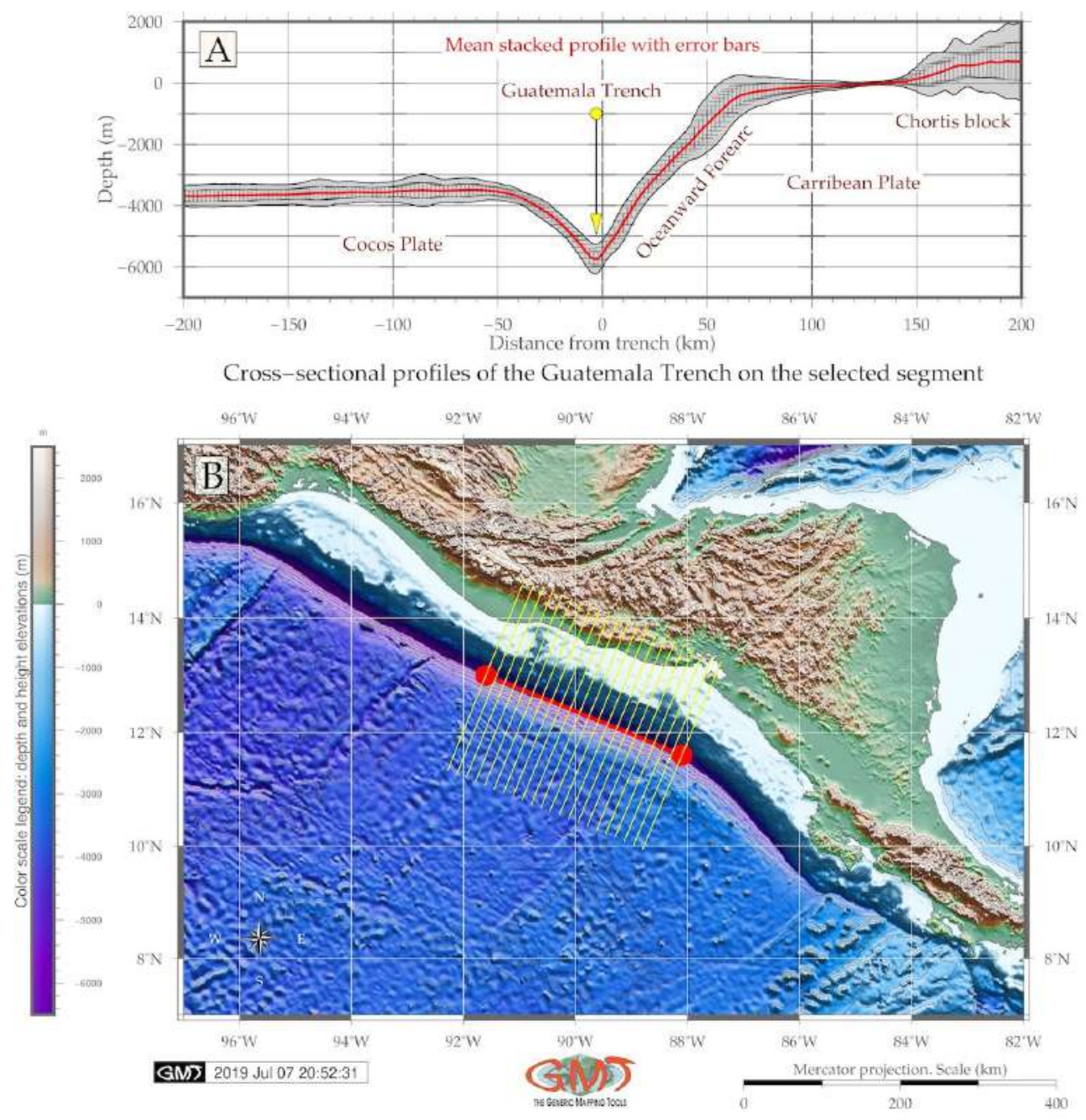

Map 4.4.1: Middle America Trench: cross-section profiles on the selected segment, [413]

However, other areas, particularly the terraces were less well defined, perhaps due to the local specific geomorphic features of the study object: the geomorphology of the MAT presents a very straight steep slopes without significant curvatures. Multiple factors affect MAT geomorphology which is formed as a results of the complex interaction between the geochemical situation, lithology, sedimentation processes, geological trigger factors and tectonic mechanisms in the study area. These factors include include 
among others tectonic history of the study area, strong influence of the volcanic active zone, geochemical content of the substrate. The position of the bathymetric observations in the trend analysis (Fig. 3.3.3, A) indicates the main common trend similarities in the sea floor characteristics between the geomorphic units. Thus, Fig. 3.3.3, A shows clear separation of the oceanward slope with steeper angle Cocos Plate basin, trench valley and rocky Charts block unit.

Modelling geospatial data highlighted the geomorphology and geometric shape of the trench. The geometry of the trench demonstrates its relatively steep and strait shape which correlate with previous seismic record results [674] showing the trench floor to be $3-5 \mathrm{~km}$ wide. The spatial analysis performed by the GMT revealed that major depth observation points of the MAT are located in between the -3000 and -6200 meters (Map 4.4.1 and Fig. 3.3.3). Frequency data distribution of the bathymetric samples shows notable changes within the MAT by the profiles. There is a certain increase of frequency in depths between -3000 and $-4000 \mathrm{~m}$ (Fig. 4.4.1) that may be caused by the specific geologic properties of the Cocos Plate.
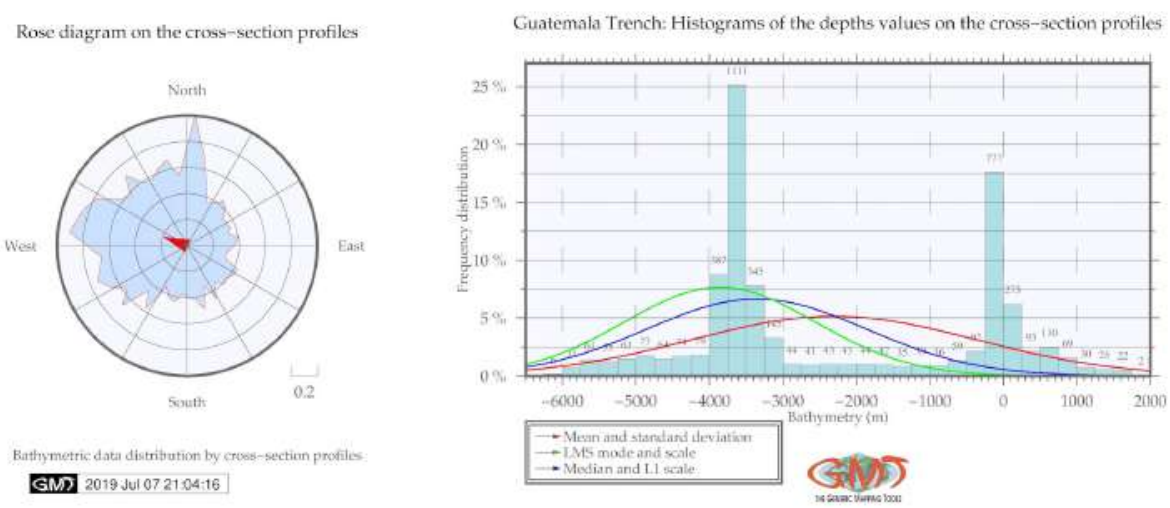

Figure 4.4.1: Middle America Trench: histograms of the samples distribution by cross-section profiles, [413]

The deepest bathymetry data range with 1,111 records takes $25 \%$ of the total pool of the sample observation points. As can be seen on Fig. 4.4.1, right, the mean values of the observation samples have a value of $-2,200$, while LMS mode indicates 7,5\% of values at $-4,000$ to $-3,500 \mathrm{~m}$, and median values have values of $-3,200$ to $-3,300 \mathrm{~m}$. The North-West distribution of the rose diagram (Fig. 4.4.1, left) shows steep slope on the oceanward forearc of the trench with relatively few observation samples due to the steepness on the continental slope with denser samples on the Cocos Plate where the geomorphology has more gentle form that can also be noted on (Map 4.4.1, A). A geoid gravitation model differs significantly by movements in a south-east direction along the study area with clearly detected stripe of the Pacific Volcanic Chain (Fig. 3.3.10, [413]).

Maximal values of the gravity above $20 \mathrm{mGal}$ are recorded in the south-eastern part of the region southwards Nicaragua: Nicoya Peninsula and Costa Rica (colored red on the modeled map) [411], [413]. The area of Nicaragua has mainly values of 5-15 mGal (orange on the modeled map). The area of Gulf of Tehuantepec has the lowest detected gravity values in the range of -15 to $-25 \mathrm{mGal}$ (Fig. 3.3.10). The results indicate that marine vertical gravity at the MAT are clearly connected with the trench tectonics correlating with contours of the major lines of tectonic slabs. The intermediate values $(20-30 \mathrm{mGal})$ are locate on the trench slopes (colored orange on the Fig. 3.3.13), while the highest values are detected mainly on the mountainous areas (colored rose on the Fig. 3.3.13). The findings suggest that submarine geomorphic structure of the MAT has straight shape form of the slopes with more steep slope on the oceanward forearc. 


\subsection{Peru-Chile Trench}

Findings in the automatic digitizing of the transect profiles, visualized as two segments (Fig. 4.5.1) are as follows: the Chilean trenchs geomorphology has deeper bathymetry and steeper gradient slope on the Nazca Plate (Fig. 4.5.1, A); on the contrary, the Peruvian segment of the trench (Fig. 4.5.1, B) demonstrates a gentler landform on the oceanward side. The comparison of the histograms on bathymetry in both segments shows that Peruvian segment has shallower depths with the maximal reaching $-6,500$ $\mathrm{m}$, while the Chilean segment reaches $-7,800 \mathrm{~m}$ in depth (Fig. 4.5.2). The frequency of the depth records in the Chilean segment has more unified data distribution for the depth range of $-6,000 \mathrm{~m}$ to $-7,000 \mathrm{~m}$ with number of sample points: $86,88,88,72$.
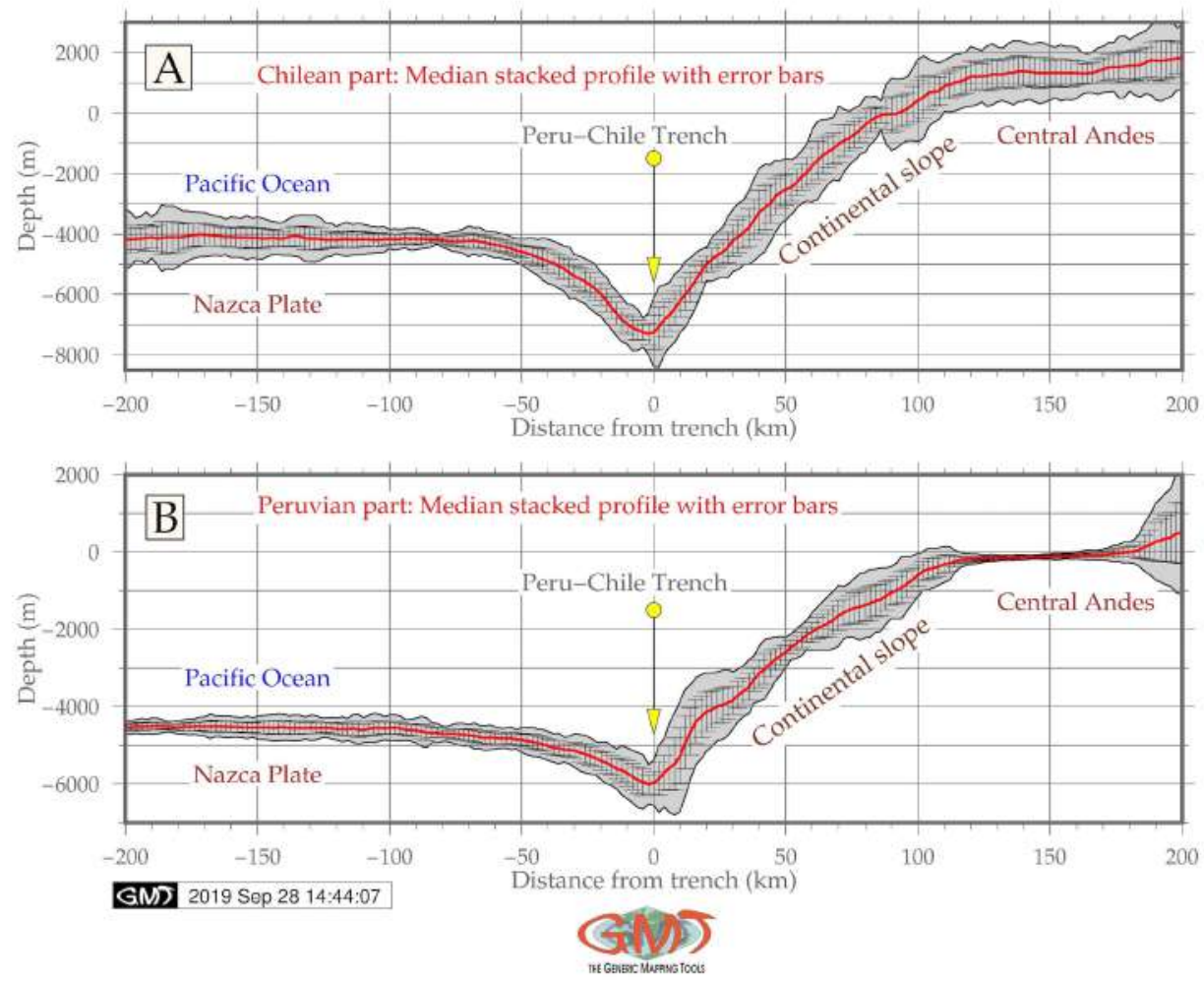

Figure 4.5.1: Peru-Chile Trench: profiles in Chilean (A) and Peruvian (B) parts [411]

For the same depth diapason, the Peruvian part has 56 and 84 samples. A comparison of the highest data frequency for both segments shows: the Peruvian segment has the majority of data (23\%) 1,410 samples $(-4,500 \mathrm{~m}$ to $-4,700 \mathrm{~m}$ are the most frequent values for the Peruvian segment of the trench). It shows a peak of all data with a very steep pattern in distribution. Other data in the neighbor diapason are much lower: 559 samples $(-4,700$ to $-5,000 \mathrm{~m})$ and $807(-4,200$ to $-4,400 \mathrm{~m})$ for the Peruvian segment. At the same time, the Chilean segment has more even data distribution. Taking a look at the same data range: 205 samples for $-4,700 \mathrm{~m}$ to $-5,000 \mathrm{~m}$ (versus 559 for the Peruvian segment); 731 for $-4,200 \mathrm{~m}$ to $-4,400 \mathrm{~m}$ (versus 807 for the Peruvian segment); 317 for the range of $-4,500 \mathrm{~m}$ to $-4,700 \mathrm{~m}$ (versus 1,410 in the Peruvian segment, which is the most frequent). On the contrary, the most frequent depth for the Peruvian segment of the PCT is a range from $-4,000 \mathrm{~m}$ to $-4,200 \mathrm{~m}$ (827 recorded samples) versus a range of $-4,500 \mathrm{~m}$ to $-4,700 \mathrm{~m}$ for the Peruvian segment (1,410 recorded samples). This demonstrates that Peruvian segment of the PCT is generally deeper and the geomorphology is steeper with abrupt slopes (Fig. 4.5.1). 
Cross-sectional profiles of the Peru-Chile Trench on two selected segments

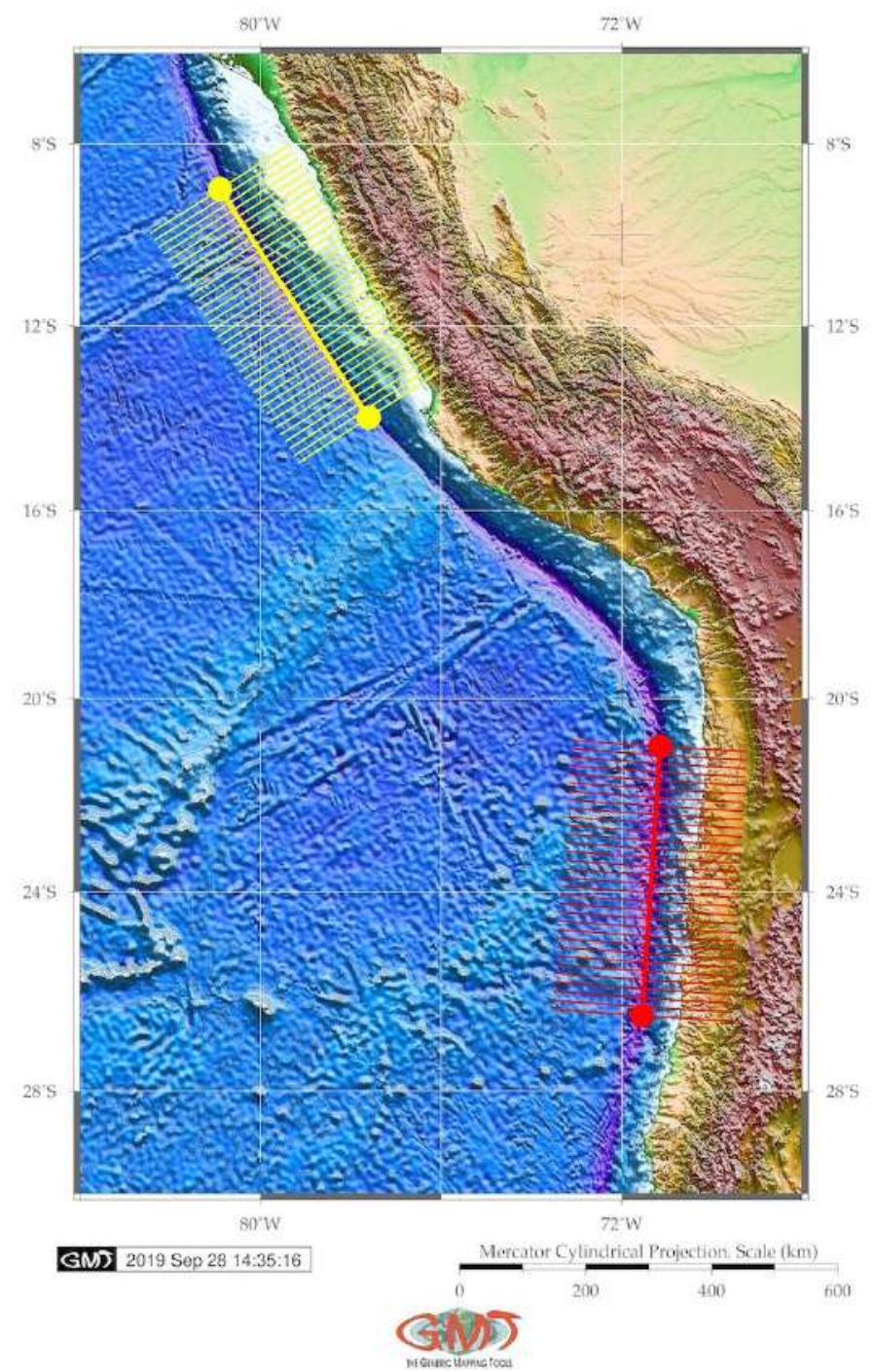

Map 4.5.1: Peru-Chile Trench: digitized profiles of Peruvian and Chilean segments [411]
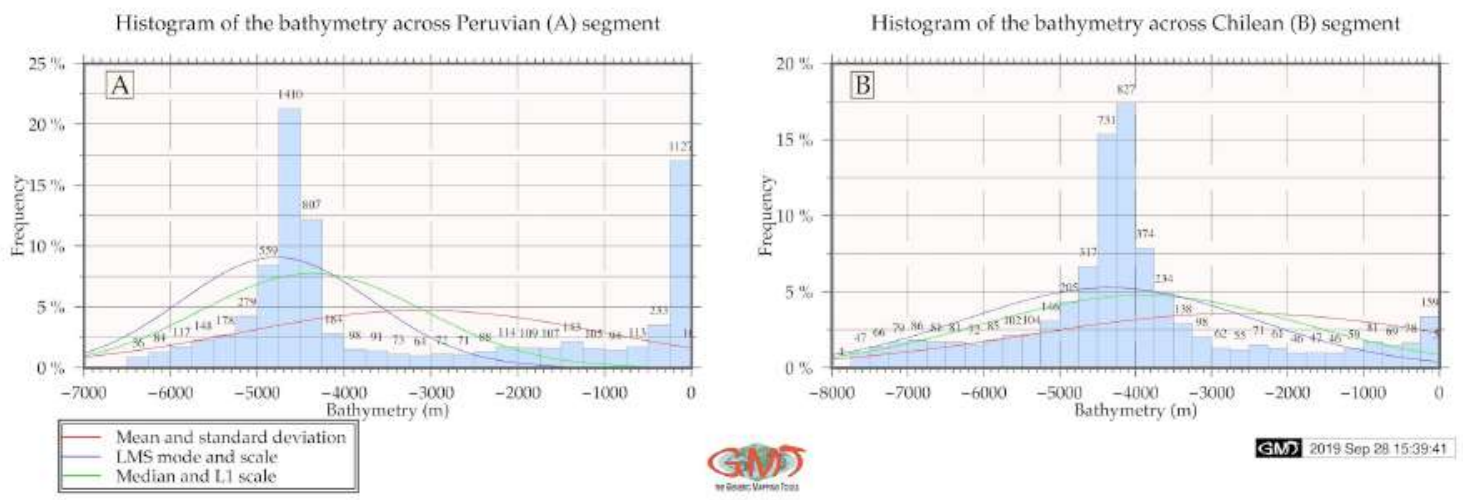

Figure 4.5.2: Peru-Chile Trench: histograms for the Peruvian and Chilean segments [411] 


\subsection{Kermadec Trench}

The resulting profiles are visualized as two segments (red and green for both trenches) on Fig. 2.6.1, left. Automatic digitizing of the cross-section profiles for KT demonstrated that KT (Fig. 4.6.1, B) has more gentle shape form of the western slope off Tonga Ridge.
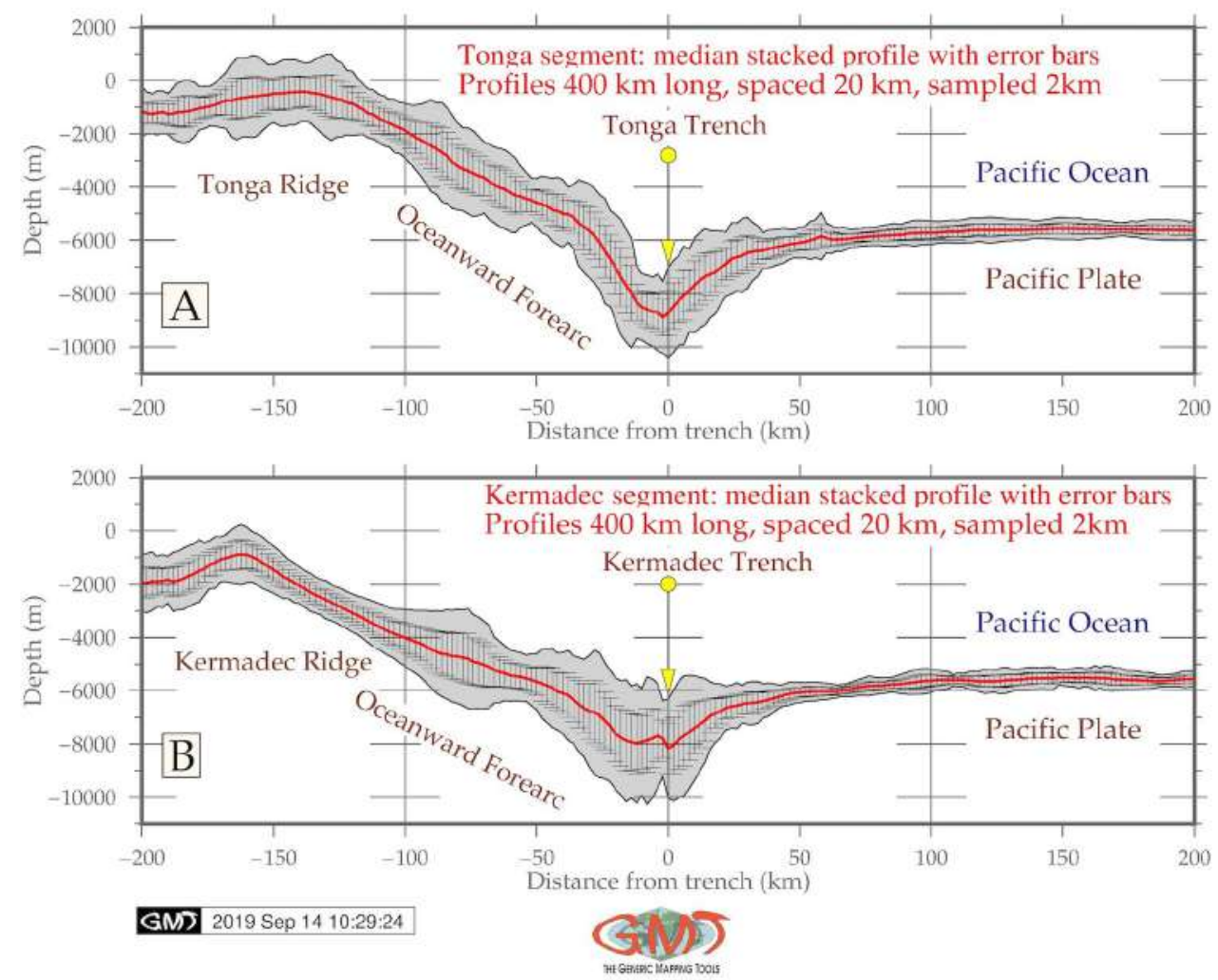

Figure 4.6.1: Kermadec and Tonga trenches: geomorphological modelling. Source: [420]

The results of the comparative analysis of the two trenches show that KT has more abrupt shape with 2,641 depth records from $-6,600$ to $-6,800$ meters (Fig. 4.7.2). Comparing the deepest values $>9,000$ meters for the KT there are 10, 18, 48, 72 and 103, which gives together 251 observation samples proving that TT is deeper than KT. If we compare the variations of the seafloor depths at range from $-6,000$ to $-5,000$, it can be sen (Fig. 4.7.2) that KT has more values in this range: 1820, 2641, 1203 and 503 giving together 6167 samples [420]. KT has more gentle slope and shallower depths which can also be seen on Fig. 4.6.1. This illustrates tectonic and geological local variations, as well as different sedimentation of the Kermadec and Tonga trenches causing variations in their geomorphic shape despite their close location.

Oceanic lithosphere has a complex structure varying in different parts of the trenches located in the areas of the subducted tectonic plates. There are reports on typology and classification of the sediments on the seafloor [138], [139]; [148]; [349]; [506]; [722]. The approaches are generalized into standard geospatial analysis aimed at the description of the location and features of the sediments in various trenches of the ocean. Correlation between the subduction, earthquakes, sediment thickness on the seafloor of the trench and upper plate strain is discussed [239]. 


\subsection{Tonga Trench}

TT has shallower depths comparing to the KT. Comparing the deepest values $>9,000$ meters for TT there are 5, 39, 72, 95, 109 observations, that sums together 320 samples. Comparing the variations of the seafloor depths at range from $-6,000$ to $-5,000$, it can be sen (Fig. 4.7.2) that TT has 4803 numbers of samples (a sum of 1221, 2089, 1019 and 544), [420]. Automatic digitizing of the cross-section profiles demonstrated that TT geomorphology has steeper gradient slope on the western flank (Fig. 4.6.1, A).

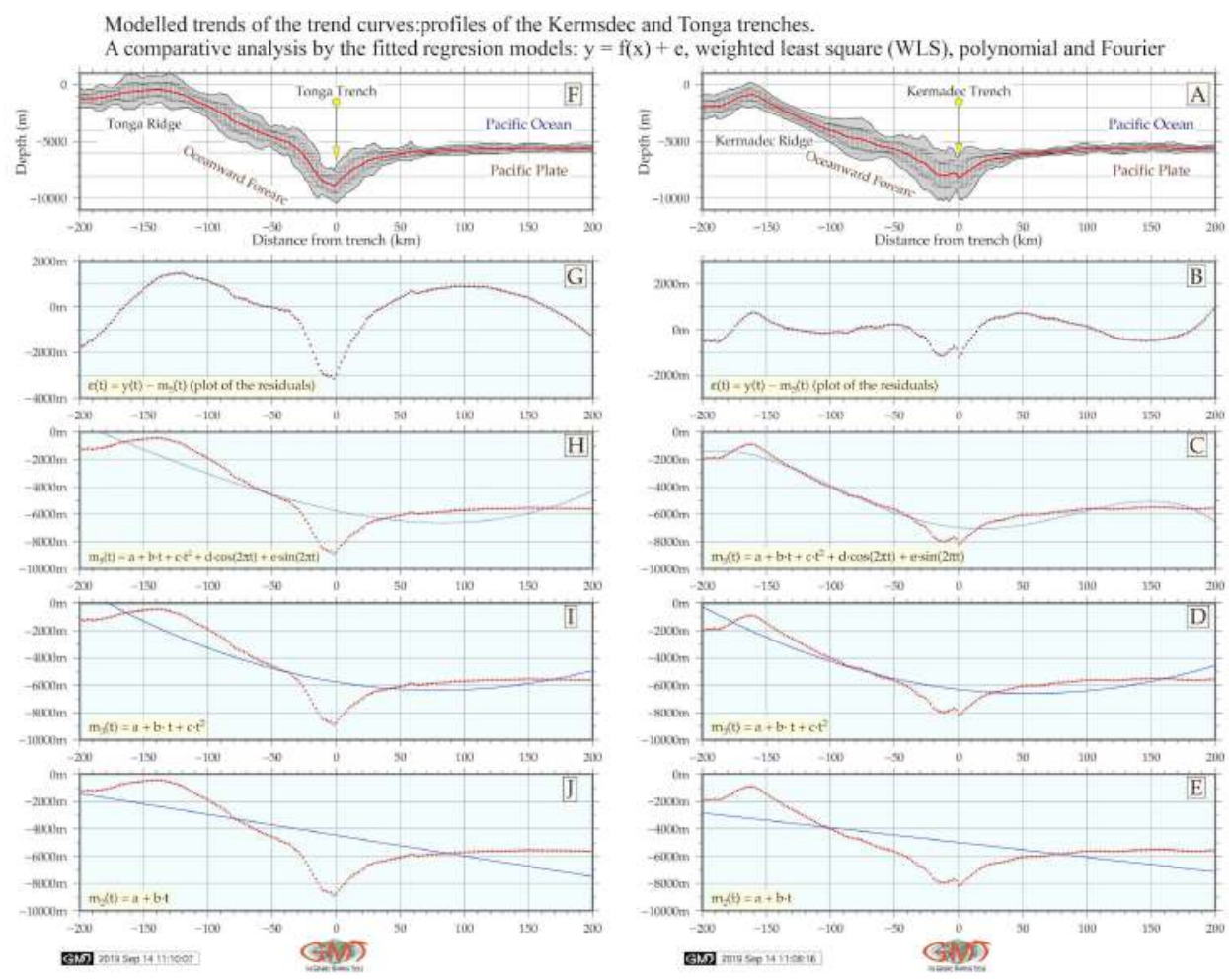

Figure 4.7.1: Kermadec and Tonga trenches: models of slope gradient trends by profiles. Source: [420]

The results show deeper bathymetry and more seafloor roughness for the TT. Hence, comparing to the KT, TT has steeper gradient of the profiles.
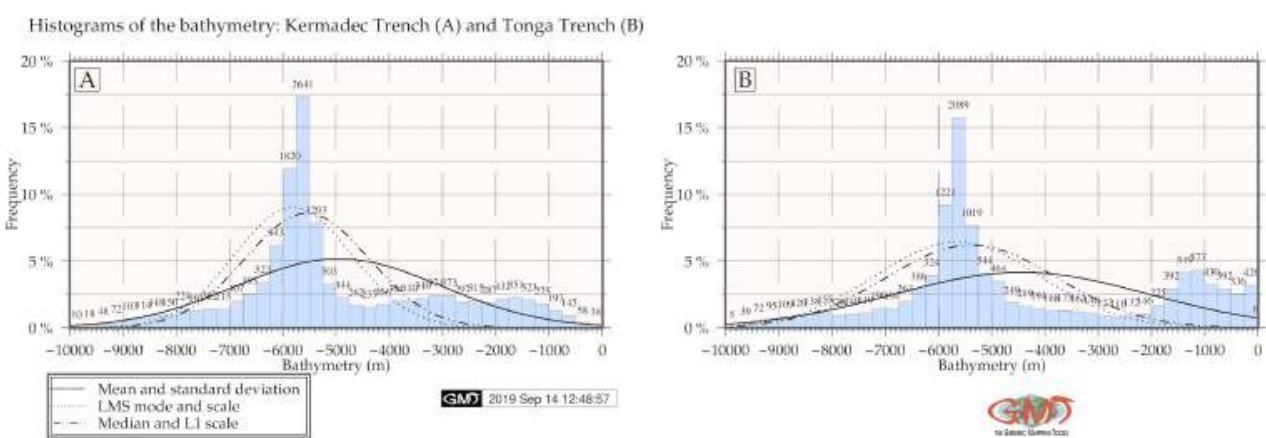

Figure 4.7.2: Kermadec and Tonga trenches: histograms of the bathymetric data distribution. [420] 


\subsection{Vanuatu (New Hebrides) Trench}

Modelling cross-section profiles for VT demonstrated (Fig. 4.8.1) that bathymetry of VtT is generally shallower with depths not exceeding $-6,100 \mathrm{~m}$, while VT reaches $-7,000 \mathrm{~m}$ in values in the selected segment [407].
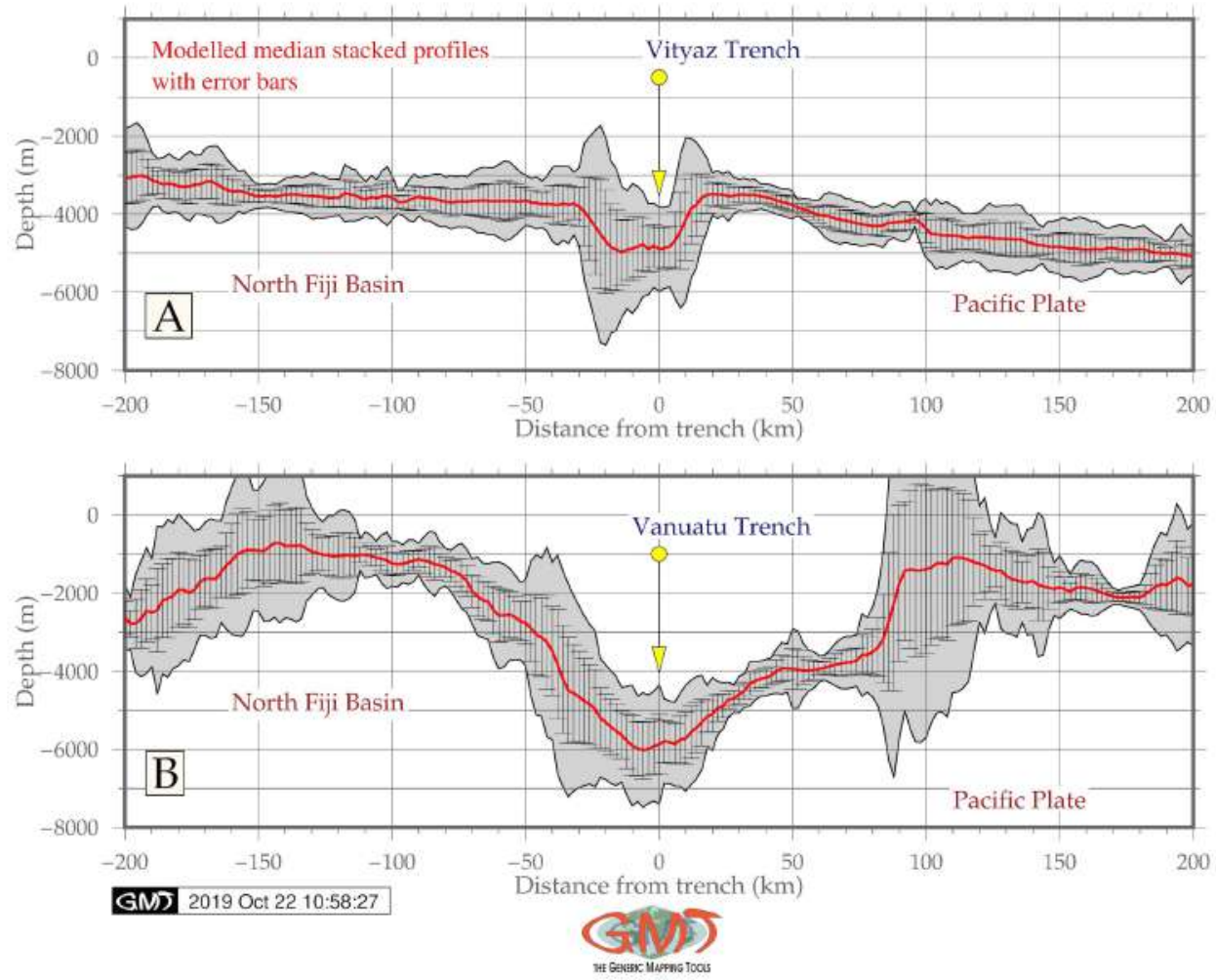

Map 4.8.1: Vanuatu and Vityaz trenches: cross-section profiles map

The histogram shape varies by two trenches: VtT has a 'bell-shape' data distribution with two peaks at range $-3,500$ to $-3,700 \mathrm{~m}$, and the second at $-4,800$ to $-5,000 \mathrm{~m}$, that is the majority of values are in general within the range of $-5,000$ to $-3,000 \mathrm{~m}$. Here there are 1605 samples $(517,653$ and 435$)$ recorded at the first peak with depth values from $-3,300$ to $-4,000$ and 839 sample observations $(238,304,297)$ at depths from $-4,500$ to $-5,200 \mathrm{~m}$ [407].
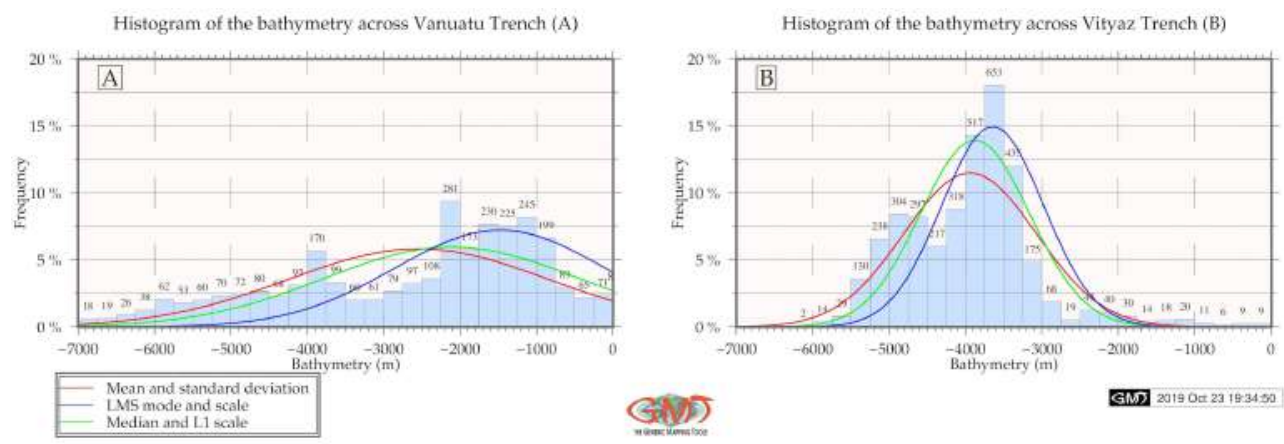

Map 4.8.2: Vanuatu and Vityaz trenches: histograms of the cross-section profiles 


\subsection{Vityaz Trench}

The comparative analysis of the geomoprhic modelling of VtT and VT shows in following findings. VT (Fig. 4.8.1, B: lower plot) has more V-form classic shape for the trench with gentle shapes on both western and eastern slopes. The comparison of the median values (Fig. 4.8.1) of two trenches shows that selected segment of the VtT has shallower depths with maximal $\leq-5,000 \mathrm{~m}$ while VT is depths with $\geq-6,000 \mathrm{~m}$. The deepest values $>5,000 \mathrm{~m}$ for $\mathrm{VtT}$ give in total 413 values $(238,130,29,14,2)$ samples [407]. The geometric form of the two trenches varies: VtT has more flat wide bottom similar to a trough, with steeper gradient slope on the eastern flank (Fig. 4.8.1, A: upper plot).

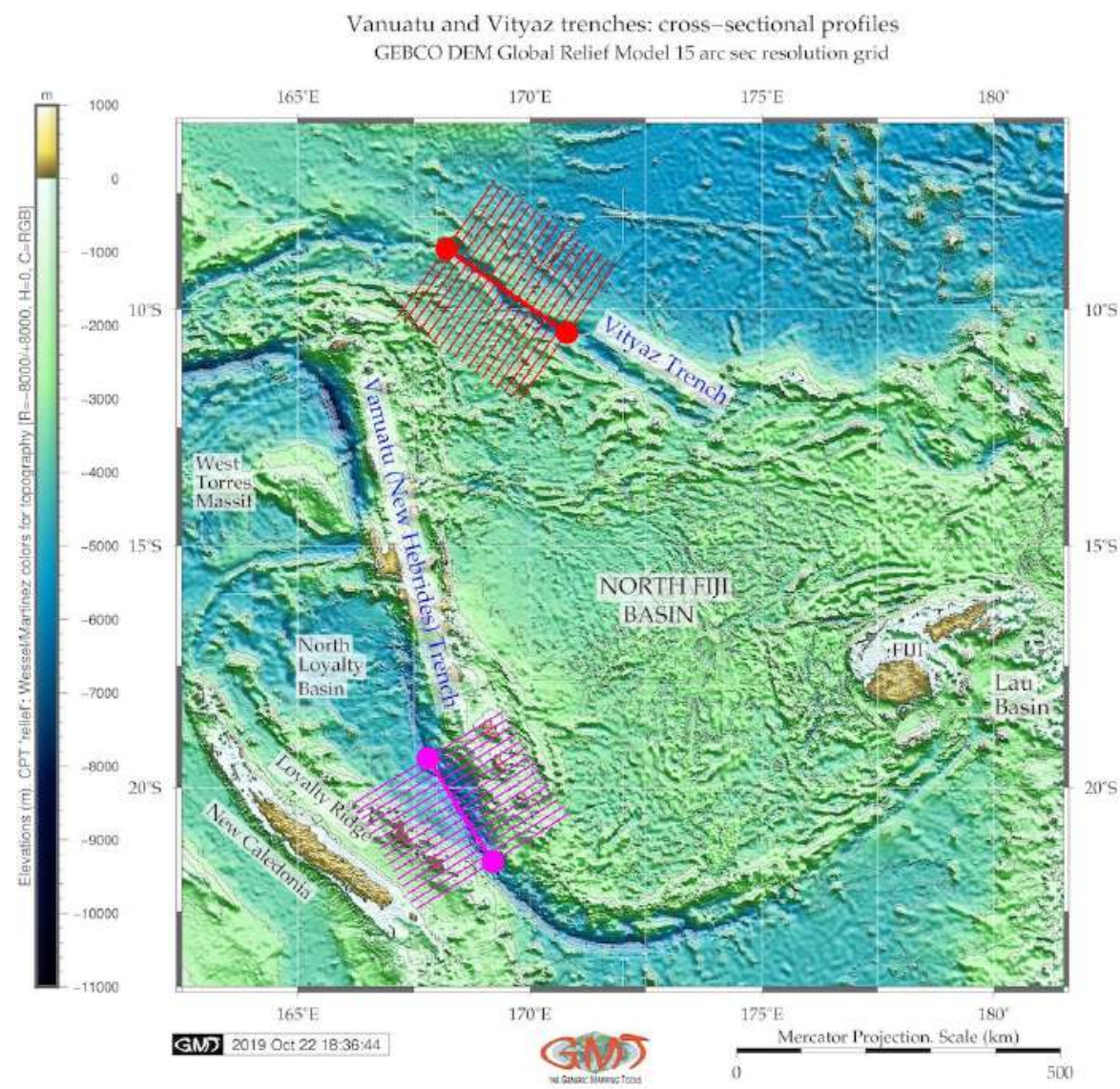

Map 4.9.1: Vanuatu and Vityaz trenches: digitizing cross-section profiles

Surrounding relief of the two trenches varies: for VtT, neighboring surface is rather flat while VT is surrounded by more complex submarine relief of both North Fiji Basin (eastern flank) and its western flank (Fig. 4.9.2). Generally, a strong correlation of the trench's axes with borders of the two tectonics plates (Pacific Plate and Info-Austrlian Plate) is evident. This implies that the geomorphology of the trenches is strongly correlated with slabs, since continuation of the plate movements, lineaments and extend of fracture zones leads to the formation of the trench axis strongly determined by plates motions. Local geological settings, stretch of the tectonic slabs, complex tectonic processes and sedimentation of the VT and VtT explain differences in their structure and geomorphic shape form [407]. 
Vanuatu Trench (left) and Vityaz Trench (right): composite overlay of the 3D topographic mesh model on top of the 2D ETOPO1 contour plot

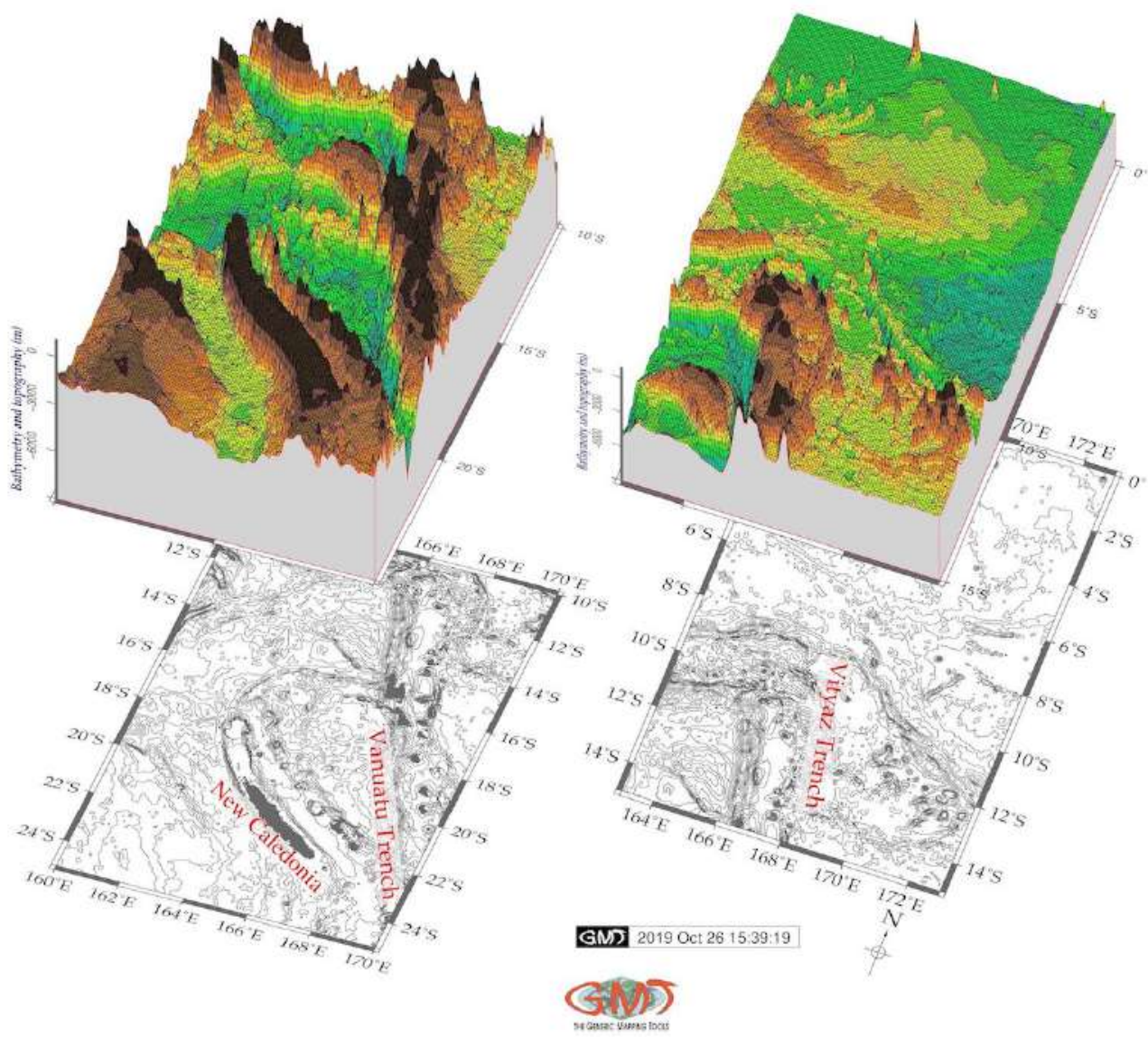

Map 4.9.2: Vanuatu and Vityaz trenches: 3D models

The comparative analysis of the geophysical grids revealed structural characteristics of the two oceanic trenches, VT and VtT and adjacent oceanic crust of the north Fiji Basin. The coherency of the grids using gravity and vertical gravity gradient data confirms that grids coincides well for $10 \mathrm{mGal}$ with the 3-10 mean gravity anomaly transition zone where the coherence increases. In the interval of 10-20 mGal the coherency declines to a very narrow interval, and correlation coincides until $100 \mathrm{mGal}$ of the tested values. Gravity gradient coherency add new information to the interpretation of the data covering active convergent margins in Pacific Ocean. Data distribution for the VT is more even with slight increase of depth in $-2,200$ to $-800 \mathrm{~m}$ with total 1,353 samples $(281,173,230,225,245,199$ for the relevant bins on the histogram left) [407]. The histograms for the transecting profiles of the VT and VtT are visualized of Fig. 4.8.2.

Correlation between seafloor geology with trench location can be illustrated by sediment accumulation resulted in a significant load. Thick trench fill sediments may lead to the obscured morphologic expression of the outer part of the trench or deformed front. Sediment accumulation affect the lithospheric downward deflection in the vicinity of the trench and the amount of the subducted sediment [109]. The effective elastic thickness at the subduction zones of the tectonic plates has important impacts on the tectonic and geodynamic processes of the trench, providing restrictions for the strength of the oceanic lithosphere [755]. 


\subsection{New Britain (Bougainville) Trench}

NBT has asymmetrical U-shaped cross-section dipping westwards with $35^{\circ}$ eastward slope, and $41^{\circ}$ westward slope (Fig. 4.11.2, A) [383]. The SCT has $33^{\circ}$ slope oceanwards while $33,69^{\circ}$ landwards increasing in relief more direct on the oceanward side.
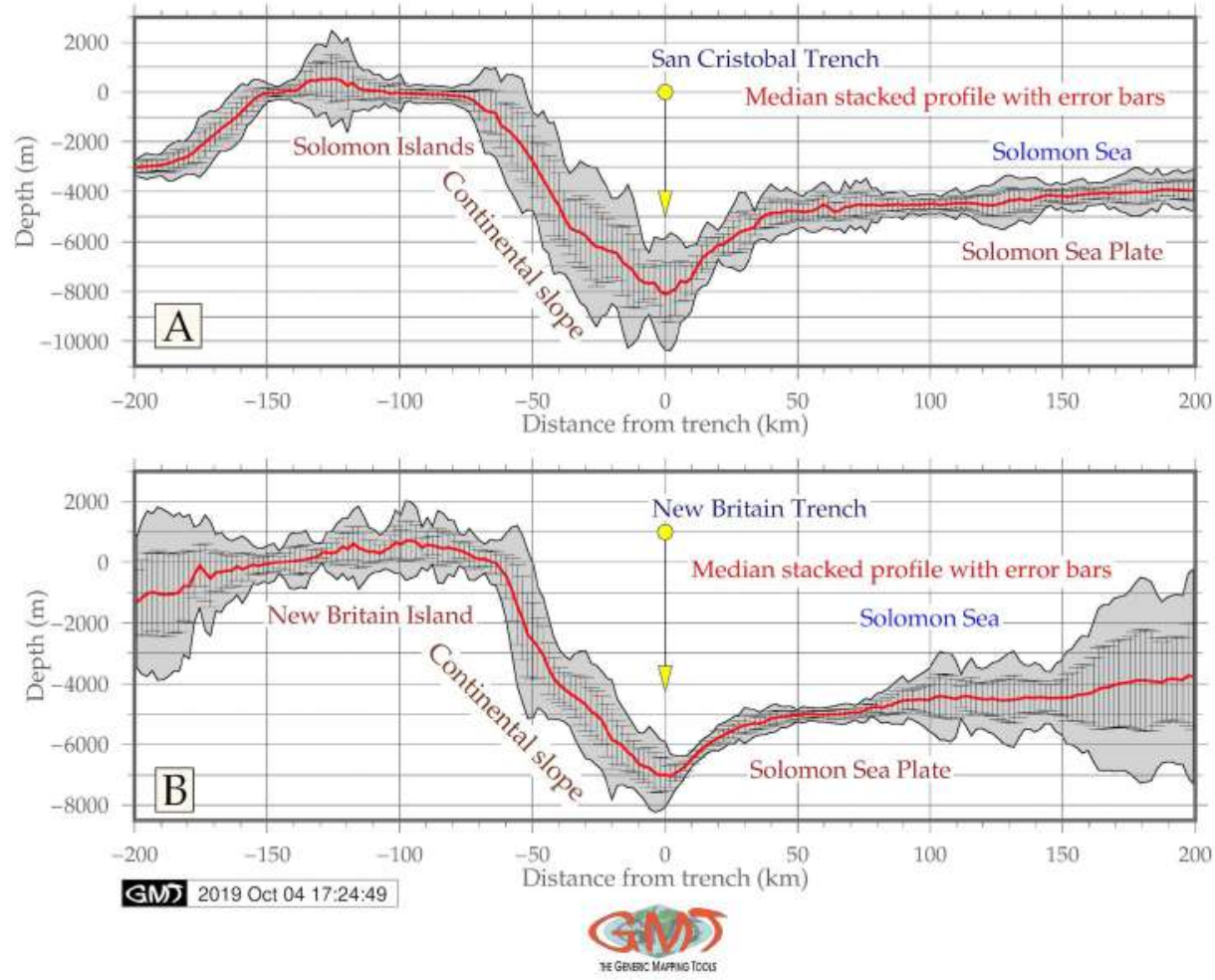

Figure 4.10.1: New Britain and San Cristobal trenches: graph model of the cross-section profiles

The increase in depth by NBT is more gentle: in $50 \mathrm{~km}$ segment it reaches $2000 \mathrm{~m}$ BSL $(-7,000$ to $-5,000)$ on the Solomon Sea side. In the cross-section graph, the NBT is markedly asymmetric in the landward slope and has an arc form in the east (Fig. 4.11.2, B). NBT is shallower comparing to the SCT: it has median $<-7,000 \mathrm{~m}$. The highest sample values are recorded in range $-5,000$ to $-5,200 \mathrm{~m}$ (272) gradually followed by ranges $-5,200$ to $-5,000,-5,000$ to $-4,800$ and $-4,800$ to $-4,600$ m (number of samples: $204,189,157)[383]$. The depth to the bottom of the NBT becomes gradually deeper in a segment of -50 to $0 \mathrm{~m}$ in cross-section, decreasing from $-3,000$ to $-7,000$ in WE direction, with maximum depths reaching $-7,000 \mathrm{~m}$ and median value $-8,000 \mathrm{~m}$. The histogram has a slightly more skewed truncated view (right-sided) with visually dominating values in shallower depths, while diminishing values below $-5,000$ $\mathrm{m}$ BSL comparing to the SCT with bell-shaped normal data distribution [383].

Mathematic approximation of the gradient slopes for the NBT and SCT applied 3 types of the Fourier functions modelling the general trend of the profile curves (median) and residuals plotted for both trenches (example for the SCT is shown on Fig. 4.11.1). Free-air gravity anomalies Fig. 2.10.3 derived from the satellite altimeter measured Sea Surface Height (SSH) have an anomaly range from -60.0 mGal and lower over the hadal trenches (deep purple color). The NBT and SCTes are distinguishable by the isolines. Lower geoid values $(42-65 \mathrm{mGal}$, lime color) are notable for the regions north-east off the Solomon Islands. The tectonic and bathymetric complexity of the area (linear features, isolated constructs on the seafloor, seamounts) explains variations in the bathymetry of the NBT [383]. 


\subsection{San Cristobal Trench}

The SCT is more symmetric having accurate ' $\mathrm{V}$ ' form for the segment of - 50 to $-50 \mathrm{~km}$ on the graph (Fig. 4.11.2, A). The increase for SCT is abrupt in profile: for the distance $0-50 \mathrm{~km}$ the depths rise from $-8,000$ to $-5,200 \mathrm{~m}$.
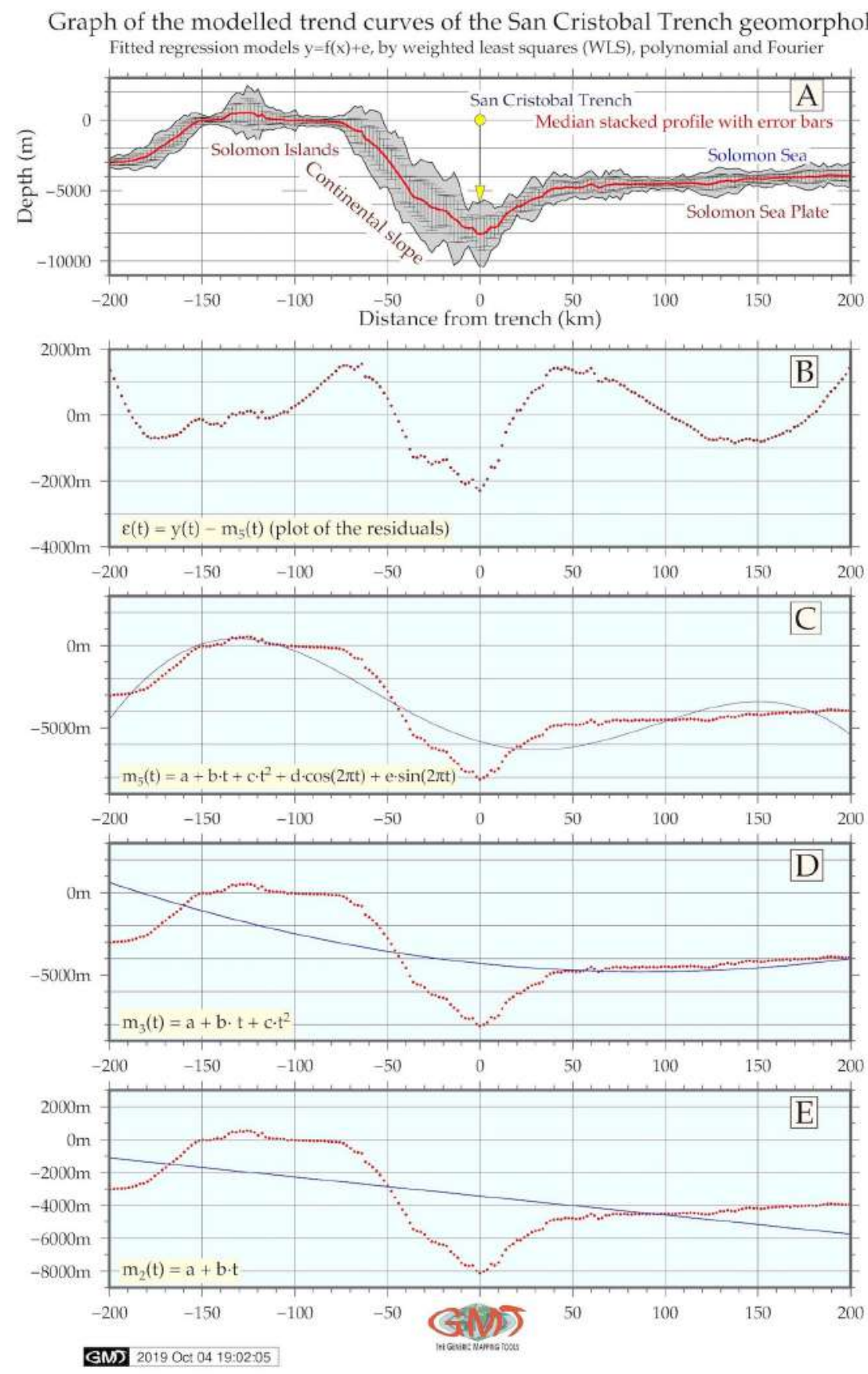

Figure 4.11.1: San Cristobal Trench: modeled trends of the slopes gradient by profiles

For the transect segment of -50 to $0 \mathrm{~m}$ in a cross-section the depth to the bottom becomes deeper decreasing from $-3,000$ to $-8,000$ in WE direction, that is, the gradient slope is steeper. Geomorphology 
is explained by the context of the historic and actual geomorphic and sedimentary processes that finally affected trench formation and structure. Associated to the oceanward side of the SCT, several separated minor canyons and furrows has been defined (Fig. 4.11.2, A).

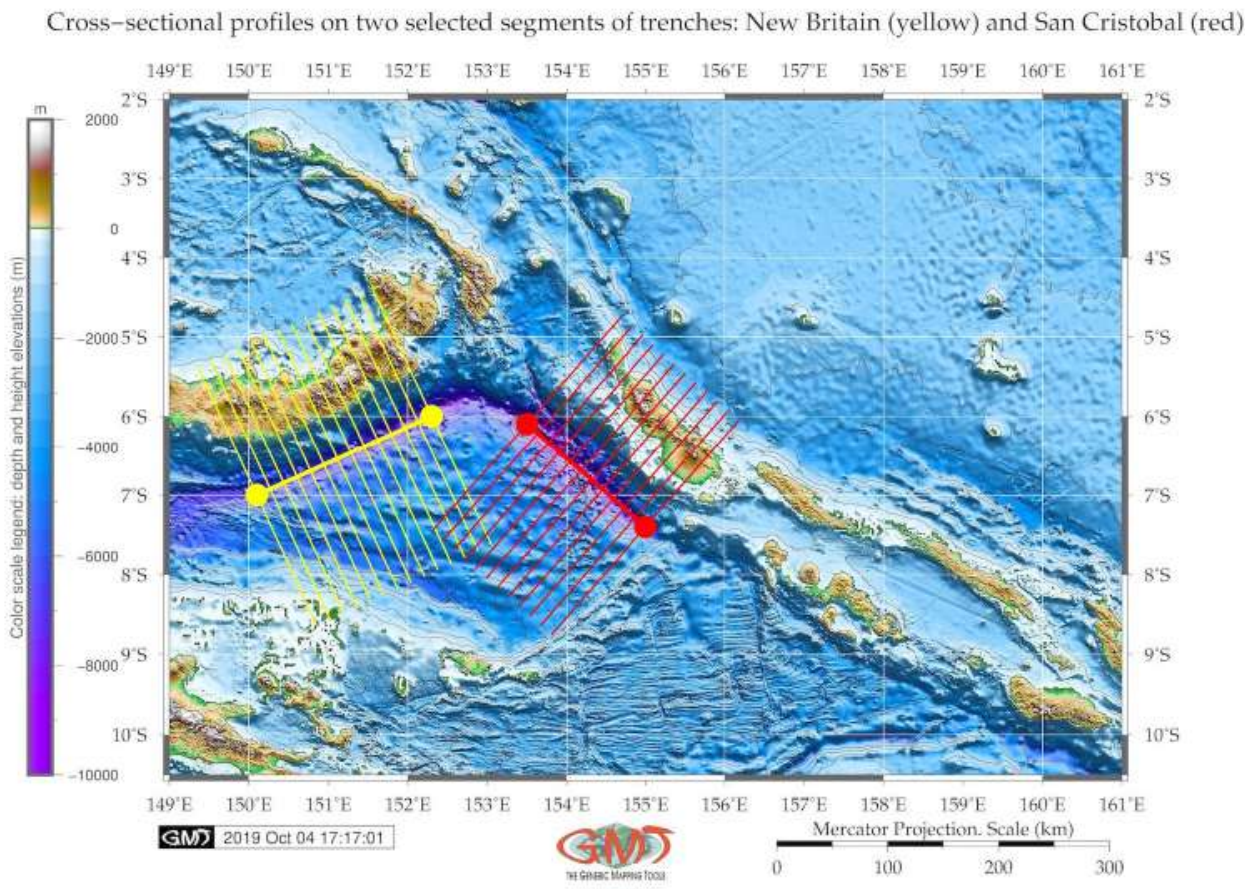

Map 4.11.1: New Britain and San Cristobal trenches: segments of the digitized profiles

The statistical comparison of the two trenches (Fig. 4.11.2) shows that the San Cristobal is generally deeper with bathymetric data reaching $-9,000 \mathrm{~m}$ while NBT has only 1 sample point $<-8,000 \mathrm{~m}$. The most frequent values for the SCT lie in range $-4,600$ to $-4,800 \mathrm{~m}$ (217 samples), $-4,600$ to $-4,400$ (202 samples) and $-4,400$ to $-4,200$ (167 samples) [383]. The majority of the observation samples for both trenches lie in range of -4000 to $-5,000 \mathrm{~m}$. The geoid shows density of the topographic structures and the upper mantle lithosphere, the geoid anomaly or height can be high irrespective of the real topography. Therefore, as can be seen (Fig. 2.10.1), the color of geoid for the Papua New Guinea Island has similar range (65-85 mGal) as Bismark Sea (orange color on the map).

Many factors affect deep-sea trench structure, dynamics and present geomorphology. The complexity of the processes happening at subduction zones in illustrated [746]: oceanic crust and sediment is recycled into the mantle, causing mantle melting and heterogeneity, arc magmatism, degassing and the creation of new continental crust. However, the trench is being formed at such areas of the tectonic plates subduction. The subduction and subduction-related volcanism are the major processes through which geochemical components are being recycled between the Earths crust, lithosphere and mantle [764]. A large proportion of the earthquakes and volcanoes are related to the subduction [319]. 
Histograms of the bathymetry, San Cristobal (A) and New Britain (B) trenches
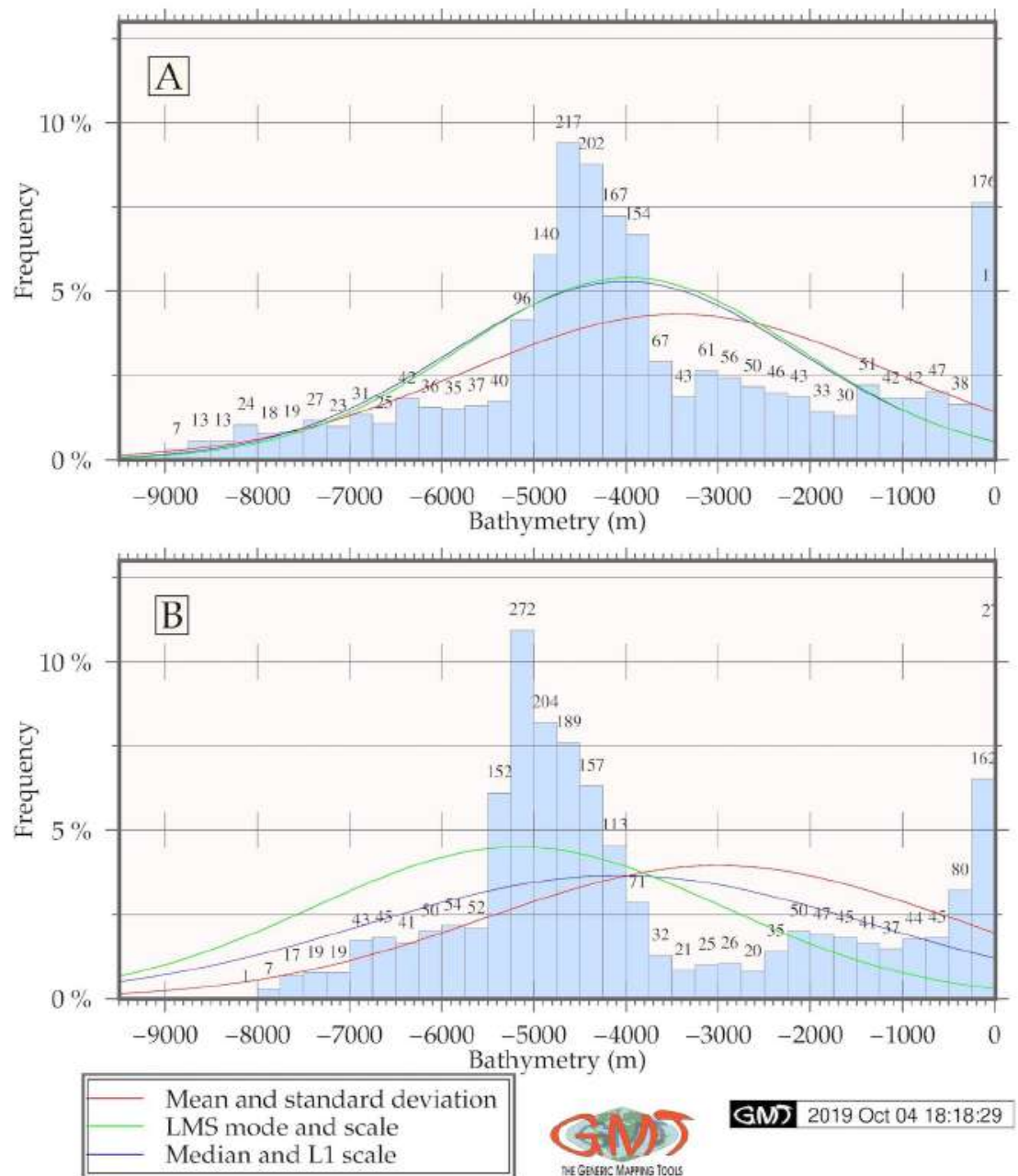

Figure 4.11.2: New Britain and San Cristobal trenches: histograms for bathymetric samples

Deep-sea volcanism results from a range of processes including dehydration, melting and melt migration. The deepest known earthquakes occur in the subducted lithosphere at depths of 660-700 km but their cause is still not explained. In addition, motion and velocities of the lithospheric plates at the Earths surface are largely controlled by the buoyancy forces that drive subduction. Because of the wide variety of processes involved, subduction zones can be regarded as natural laboratories through which dynamic behaviour in the Earths mantle can be studied. These factors explain variations in the submarine geomorphology of the trenches. 


\subsection{Philippine Trench}

PT (Fig. 4.12.1) has a classic symmetric bell-shape form of histograms showing depth distribution with a notable sharp increase in data frequency at the interval of $-5,000$ to $-6,000 \mathrm{~m}$ BSL taking together 1,117 samples ( $22 \%$ and $15 \%$ of the data pool, i.e. $37 \%$ ).

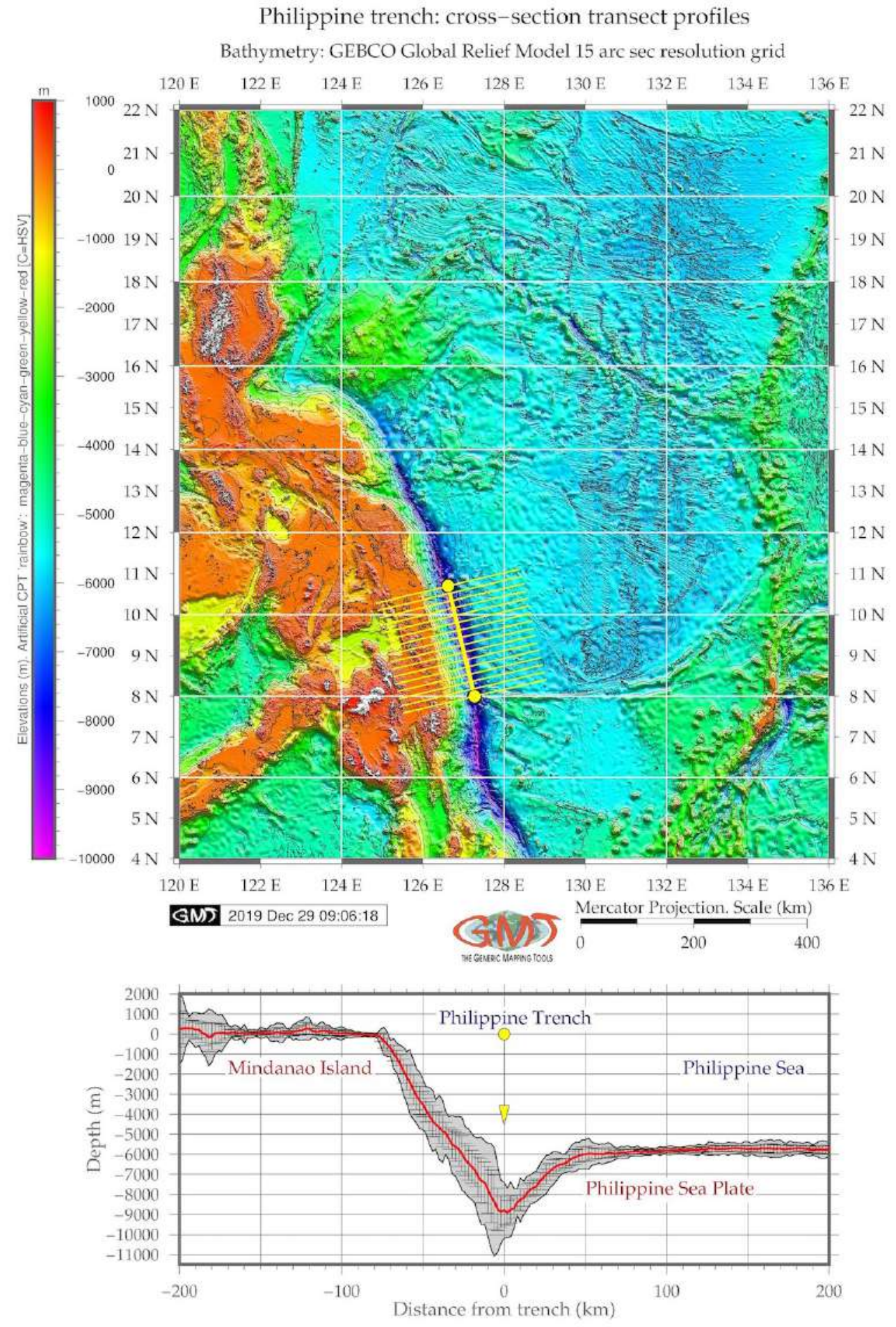

Map 4.12.1: Cross-section transect profiles: Philippine Trench 
It indicates an abrupt gradual decrease of depths which can also be seen on Fig. 4.12.1. The crosssections of the selected segment have a strongly asymmetric view which is caused by the Philippine Islands (Mindanao) located on the west. Therefore, western part of the cross-sections has a smooth gradual decrease in depths in a uniform way from -75 to $40 \mathrm{~km}$ in the left flank with a slope of $31^{\circ}$. The $2^{\text {nd }}$ segment stretches from 40 until $10 \mathrm{~km}$ of the left cross-section with a gradient slope of $40,60^{\circ}$. The last and short segment on the left $(10-0 \mathrm{~km})$ has a steepness of $28^{\circ}$. The right flank of the profile has following variation in steepness. A segment of $0-20 \mathrm{~km}$ has a slope of $44^{\circ}$, following by the fragment of $20-35 \mathrm{~km}\left(41,70^{\circ}\right)$ and $35-50 \mathrm{~km}\left(25,0^{\circ}\right)$. A long segment on the right $(50-200 \mathrm{~km})$ has a very uniform geomorphology with almost no significant variations and dominating depths at around $-6,000 \mathrm{BSL}$. The deepest segment of the PT (10-0 km on the profile from the center line) has more gentle slope with a steepness of $28^{\circ}$ versus $44^{\circ}$ on the right flank for the same segment.

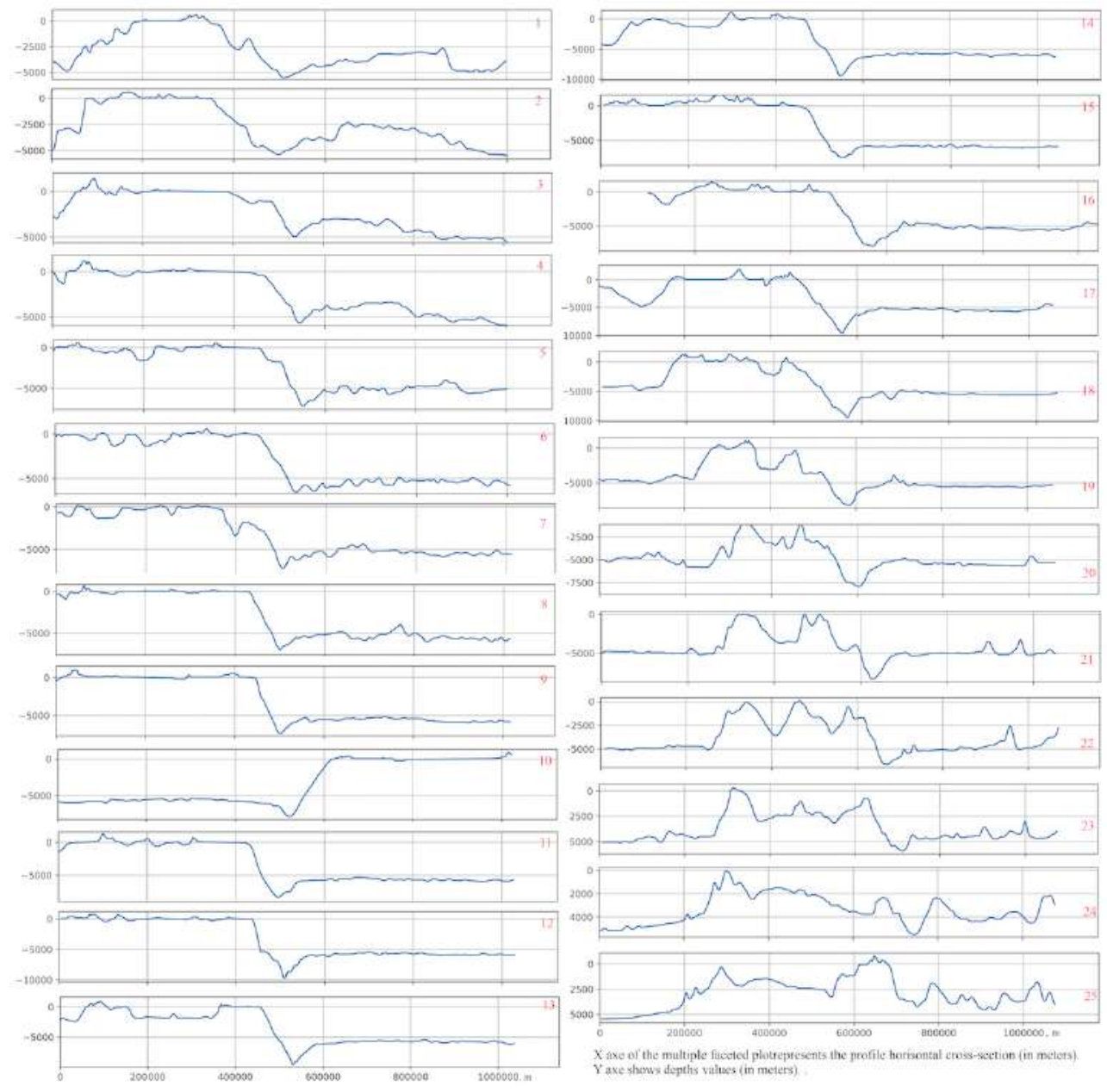

Figure 4.12.1: Philippine Trench: faceted plot of the profiles. Plotting: QGIS

Unlike MT, the cross-sections of the PT have asymmetric profile caused by the adjacent Mindanao Island. Both trenches have a V-shape form in their deepest parts. Fig. 4.12.1 and 4.17.1 show vertical cross section transects perpendicular to the segment for MT and PT. A lower placed graph shows a median stacked cross-section profile (red line) and an interval of the error bars for the measurements. Comparison of the two graphs clearly shows the variation in the trenches gradient angles, steepness and elevation variation from the western and eastern flanks of the trenches. 3D bathymetry model of the selected segment of the PT shows to the S (left) of the trench the margin is characterized by steep slope 
adjacent close to the Mindanao Island, to the $\mathrm{N}$ by sediment accretion, and to the NW by tectonic erosion. 3D relief map of the MT showing selected segment of the Challenger Deep is characterized to the NW (left on the figure) off the trench a Mariana Ridge, to the NE a chain of seamounts, and to the south by sediment accretion.

Comparing the MT and PT, seafloor bathymetry varies more notable westward of the trench axis by the MT. West Mariana Ridge (Fig. 4.17.1) is located $\mathrm{N}$ off the trench axis at distance of 0-50 km, while $\mathrm{N}$ part of Caroline Ridge is intersected by the $\mathrm{S}$ transects of the trench profiles at a distance of ca.180-200 $\mathrm{km}$. A prominent trench-parallel belt of seamounts visualized on the 3D graphindex[concepts]plot!3D (Fig. 2.16.2), appears at $148^{\circ}-149^{\circ} \mathrm{E}$. A group of seamounts eastwards off the PT (Fig. 2.11.5), stretching in a south-east direction with a narrow seamount bases and shallow apexes appears $E$ off the archipelago at the trench axis at $130^{\circ} \mathrm{E}-135^{\circ} \mathrm{E}$. However, at an area of the plate subduction $127^{\circ} \mathrm{E}-129^{\circ} \mathrm{E}$, seamounts are absent and the seafloor has more unified pattern. Starting at $16^{\circ} \mathrm{N}-126^{\circ} \mathrm{E}$, a ridge can be noted near the trench axis (Fig. 4.12.1). Marine free-air gravity anomaly in the PSB is presented on Fig. 2.11.4. Higher values $(>80 \mathrm{mGal})$ of the gravity fields structure are apparent at volcanic areas and Philippine archipelago, as seen in orange to red colored areas on Fig. 2.11.4. Anomalies $>60 \mathrm{mGal}$ are evident in the trench areas Fig. 2.11.4, which are consistent with previous results ([753]; [649]; [688]).
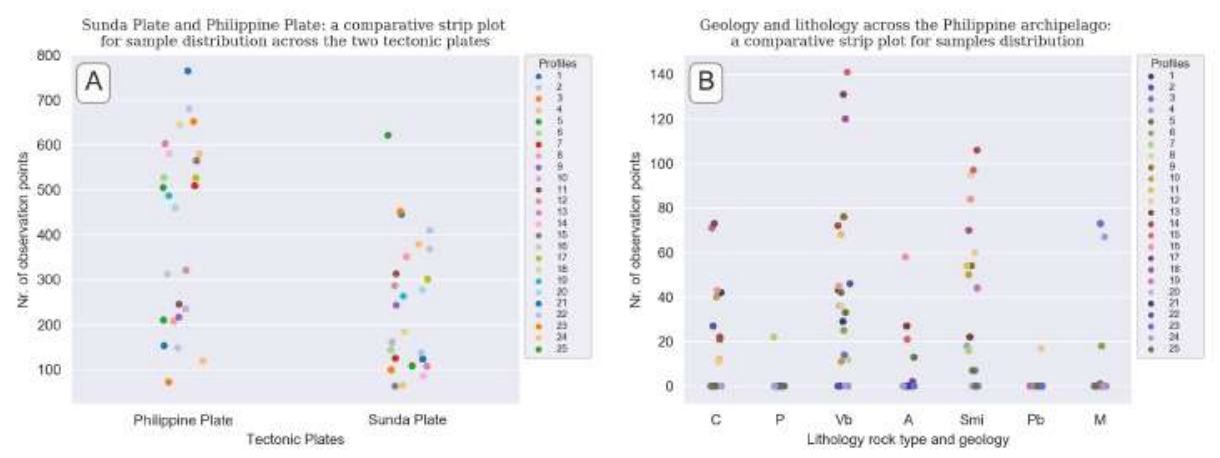

Figure 4.12.2: Philippine Trench: strip plots by tectonic plates and geology, Python code A.5.5 [414]

The results were compared with existing 2D and 3D geophysical and geological maps, visualization of the slab gaps or tears in the PSP (e.g. [622]; [311]; [588]; [582]; [266]; [280]; [127]) to highlight the geology, geophysical settings and geomorphic features of the submarine trenches in PSB area. Comparative analysis of the MT and PT located on the margins of the PSB is focused on modelling and mapping of the 2 oceanic trenches located on the margins of the basin of the PSP: MT and PT. The aim was to analyze and compare variability of their geomorphological shape forms.

Two segments in the southern parts of the trenches were transected by a series of the cross-section profiles. A segment of the PT is located south off Mindanao, a segment of MT - in the Challenger Deep area. Samples received through transecting were analyzed and compared. A statistical analysis shown variability in depths by samples in both trenches. PT has a classic symmetric bell-shape form of histograms showing depth distribution with a notable sharp increase in data frequency at the interval of $-5,000$ to $-6,000 \mathrm{~m}$ ( $37 \%$ of the data pool). The cross-sections of the segment have an asymmetric view. Western part of the cross-sections has a smooth gradual decrease in depths at $-75-40 \mathrm{~km}$ with a slope of $31^{\circ}$.

The analysis of the PT geomorphology by Python and R shown correlation between changes in the slope steepness and geological variables. Variations in the slope steepness correlate with sediment thickness across the trench. Variations in the landform are explained by a combination of factors: geology, tectonics, increasing depths in bathymetry, caused by the tectonic slab dynamics. The results obtained 
by different statistical approaches performed using $\mathrm{R}$ and Python libraries are analyzed and integrated in order to provide a more detailed understanding of the character of the geomorphic structure of the PT. The cross-sectional profiles give the insight to the variations in the geomorphological shape of the PT and archipelago (Fig. 4.12.1). The extreme depths values in the data set are notable for the following profiles: profile Nr. 12 (max depth: -9.700 meters), profile Nr. 13 (max depth: $-9.600 \mathrm{~m}$ ), profile Nr. 14 (max depth: $-9.400 \mathrm{~m}$ ), profile Nr. 18 (max depth: $-9.450 \mathrm{~m}$ ). All these profiles are cross sectioning the PT in its central part where its geomorphic pattern can be characterized from steep slope (profiles Nr. 12 and 13, see Fig. 4.12.5) to very steep slopes (profiles 14 and 18). Other profiles have depths not exceeding $9.000 \mathrm{~m}$.
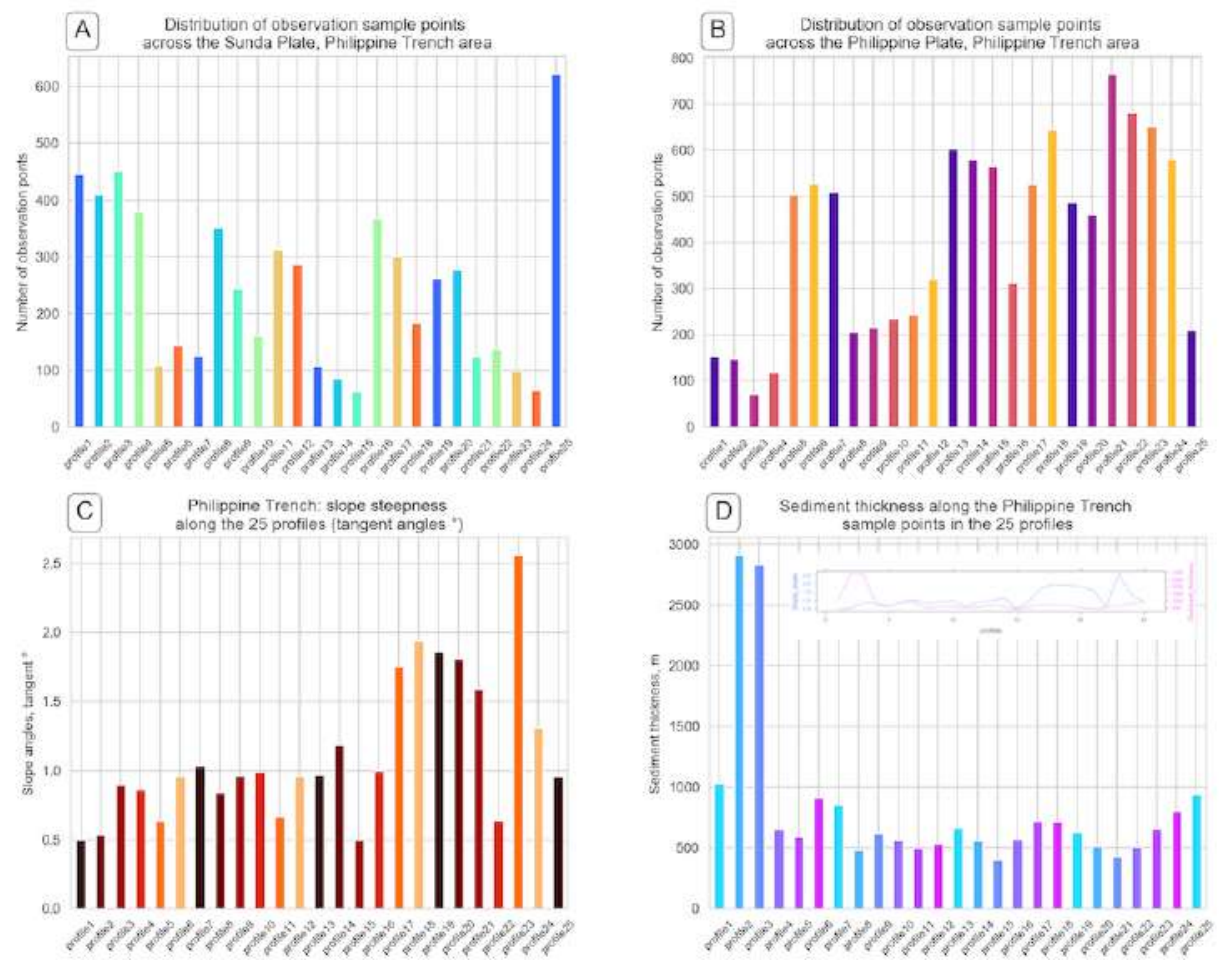

Figure 4.12.3: Philippine Trench: samples distribution by tectonic plates. Plotting: Python, and R [414]

The strip plots (Fig. 4.12.2) comprise two visualized relationship types of the data distribution, namely by seven types of the underlie geology with code given and explained in Table 1 (Fig. 4.12.2, A) and two tectonic plates: Sunda Plate and Philippine Plate (Fig. 4.12.2, B). The distribution of the samples across the two tectonic plates is uneven (Fig. 4.12.2, A). The Philippine Plate comprise more samples located in the Philippine Sea eastwards from the PT. The maximal sampling can bee seen on the profiles 21, 22 and 23 in the southern part of the cross-sectioning (as shown on Map 3.6.2) with 765, 651 and 652 taken samples, respectively. This is explained by the complex submarine landforms in the western part of the Philippine Sea (Fig. 4.12.1, the cross section profiles). Profiles 1-4 demonstrate (Fig. 4.12.2, A) significantly lower density of the observation samples not exceeding 200. This part of the section is located in the northern part of the PT and is characterized gentle landforms of the submarine geomorphology.

As can be seen from the Fig. 4.12.2 (B), the Precambrian (shield) rocks (P) are only present in profiles 5, 7, 24 and 19 and do not exist in the sample sets of other profiles. South tended data distribution is characterized for lithology types basic-ultrabasic plutonic rocks $(\mathrm{Pb})$ where data are recorded for the profiles Nr. 12, 18-19, 21, 23-25, that is on the southern part of the Philippine archipelago. The metamorphic rocks (M) are noted across the profiles 23-25, 4, 6, 15-16, that is their distribution is more evenly 
spread across the study area. In this dissertation, data with complex lithology of Mesozoic, Jurassic and Cretaceous origin (C) and Metamorphic rocks (M) have comparable spatial heterogeneity with observation records not overcoming 80 sample observation points. On the contrary, basic volcanic rocks of the Cenozoic volcanic formations $(\mathrm{Vb})$ have significantly higher values reaching maximal values at profiles 18, 17 and 15 having values of 120,131 and 141 registered samples, respectively.

Mixed sedimentary consolidated rocks of Cenozoic formation (Smi) had the highest detected values at profile 14 with 106 recorded points following by profile 8 (95 recorded samples). Finally, alluvial deposits of the Quaternary have the highest data density recorded at profiles 16 (58 samples), following below by profile 13 and 15 ( 27 and 21 samples, respectively), that is the central part of the Philippines crossing the archipelago in the shelf area (Fig. 4.12.2, B). The distribution of the sample points across the PT has four distinct groups with the increased values caused by the steep pattern in the geomorphology (Fig. 4.12.3, B): first group include profiles Nr. 5, 6, and 7 (northern part of the PT crossing further Manila Trench). Second group comprises a group of profiles Nr. 13, 14 and 15: central transect of the PT moving westwards towards the Negros Trench. Third part includes two profiles Nr. 17 and 18. Finally, fourth part includes profiles Nr. 21, 22, 23, 24, that is a southern part of the PT where the transects move further crossing Sulu Trench and Cotabato Trench on the block of Sunda tectonic plate.

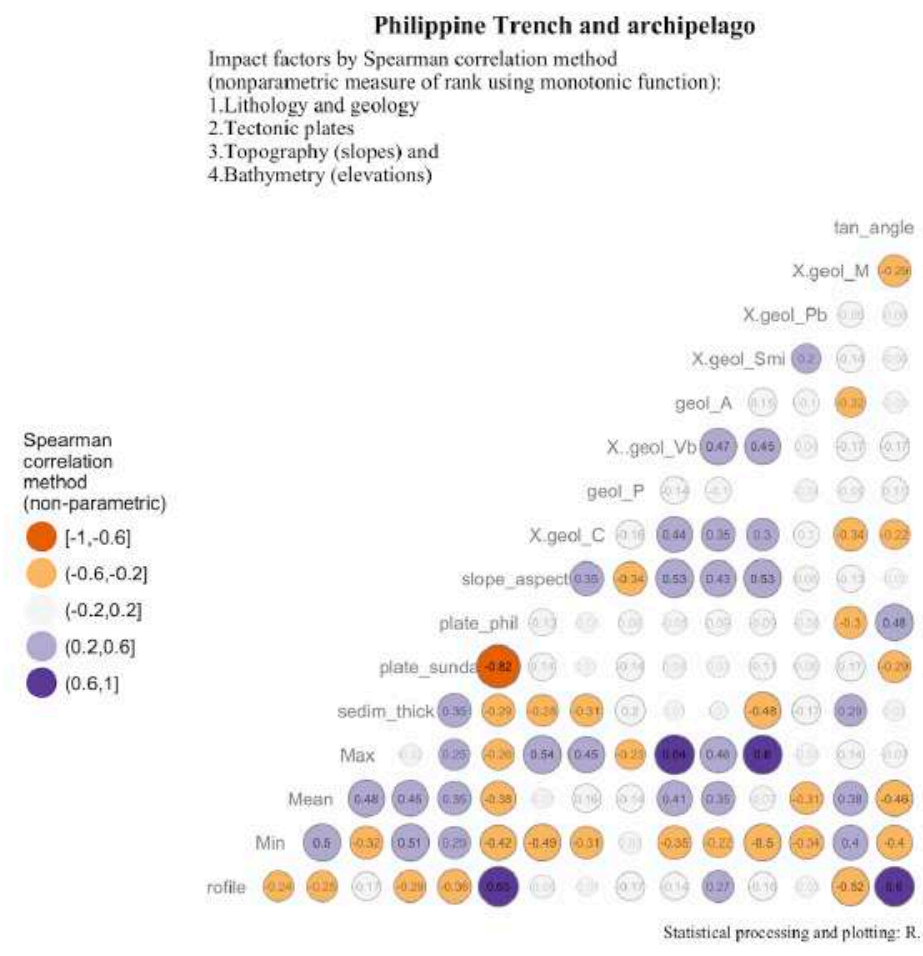

Figure 4.12.4: Philippine Trench: correlation matrix of variables (Spearman method), Plotting: R [414]

The opposite distribution is for the Sunda Plate (Fig. 4.12.3, A): profiles 1-4 (northern Sunda) have increased values, followed by the $2^{\text {nd }}$ group of profiles (8-12), then $3^{\text {rd }}$ group (profiles 16-17 and 19-20) and profile Nr. 25 with max value for the Sunda Plate. The sediment thickness has a relatively even distribution for all the profiles, which is described by [238] who pointed that the sedimentation in the PT is not significantly high to fill in the axis along the trench. However, the exception have profiles Nr. 2 and 3 with a distinct rise in the sedimentation volume caused by geologic conditions of the sedimentation in PT [355] (Fig. 4.12.3, D). SE part of the trench (profiles 17-21) has a distinct steeper geomorphic shape (Fig. 4.12.3, C) which is caused by complex relationship between tectonic slabs and geological settings. Fitted model of the matrix shows (Fig. 4.12.4) variables representing correlation between the elements 
of the trench system: elevation as topographic and bathymetric samplings (max/min, mean depth values and heights), sediment thickness, number of samples across tectonic plates (Sunda Plate and Philippine Plate), geomorphic elements of slope across the trench (tangent ${ }^{\circ}$, slope aspect), types of the geology (rock lithology). Absolute coordinates were excluded as a factor to remove the effect of the location. In total 15 variables were tested by attribute classes: geology: 7, geomorphology: 2, sedimentation: 1, tectonics: 2 and bathymetry: 3. Computed matrix visualizing impact factors is shown on Fig. 4.12.4. The effects of the variations in the slope ${ }^{\circ}$ were tested by computed tangent ${ }^{\circ}$ for the profiles (Fig. 4.12.5 plot 1) and repeated the analysis by ranking profiles according to the slope steepness (Fig. 4.12 .5 plot 2). Grouping profiles by slopes was performed by dividing the range into 5 classes: strong slope, very strong slope, steep slope, very steep slope, extreme slope.

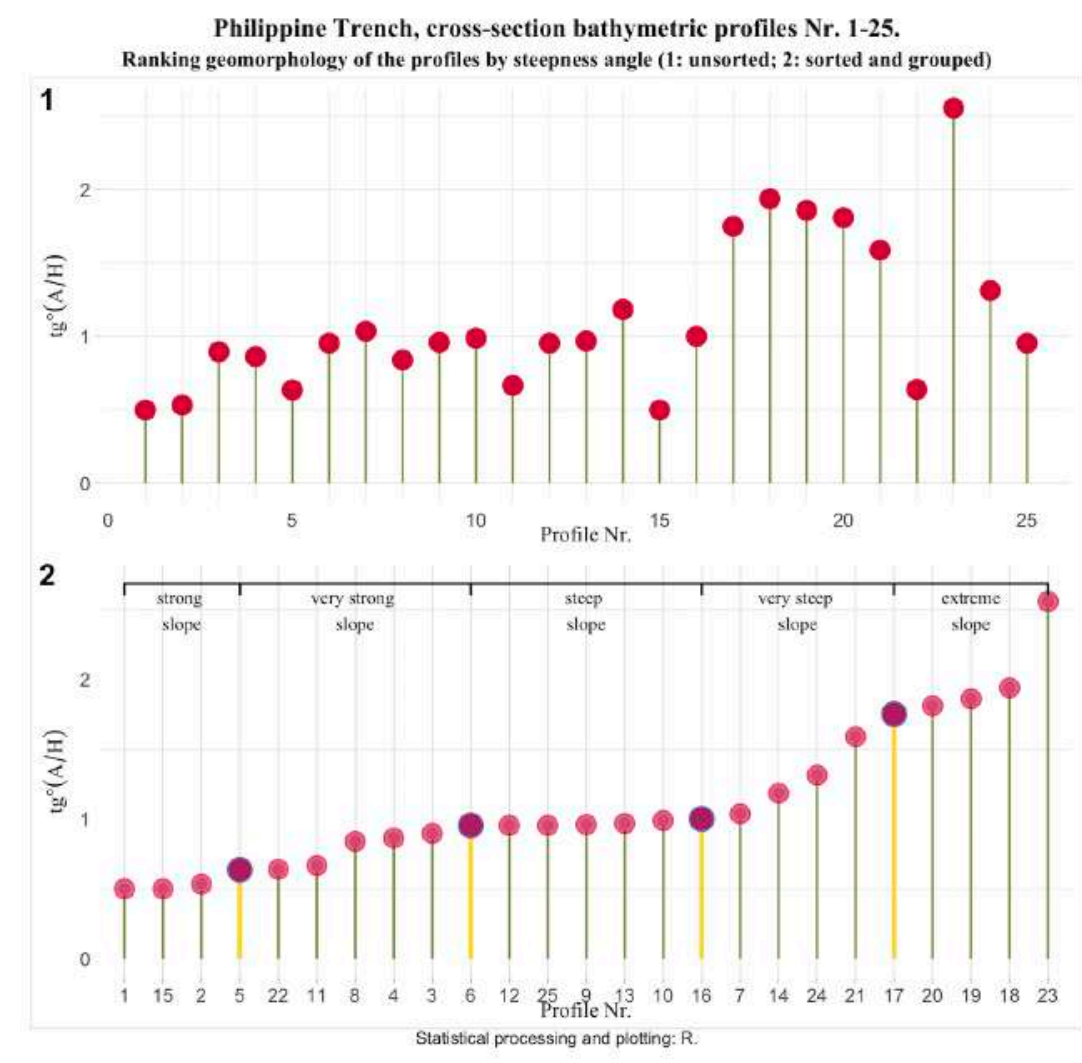

Figure 4.12.5: Philippine Trench: ranking geomorphology of the cross-section profiles. Plotting: R [414]

The results highlight geomorphic variation and complex characteristics of the impact factors of geological origin affecting the trench. Location on various tectonic plates along with geological factors (sediment thickness) and lithology contributes in geomorphic shaping of the actual form of the PT. Crosssectional transects were taken in the southern regions, through key features such as deep valley, slopes, moraines, PSB basin, and adjacent shelf area. The datasets were combined with multi-source grids explained in detailed 'Data and Materials'. 


\subsection{Manila Trench}

The results of the geomorphological modelling and mapping of the MnT (Map 4.13.1) shown spatial variation in the different parts of the trench [406]. The characterization of the seafloor geology was performed by analyzing the trench and tectonic slabs location and areas of the submarine volcanoes. The profile transects were compared and differences in the geomorphic shape in southern and northern parts of the trench were revealed: southern part has steeper slope gradient on the oceanward part; northern part is steeper on the continental slope part. The submarine terraces are located on the northern segment of the trench at depths $-2,000 \mathrm{~m}$.
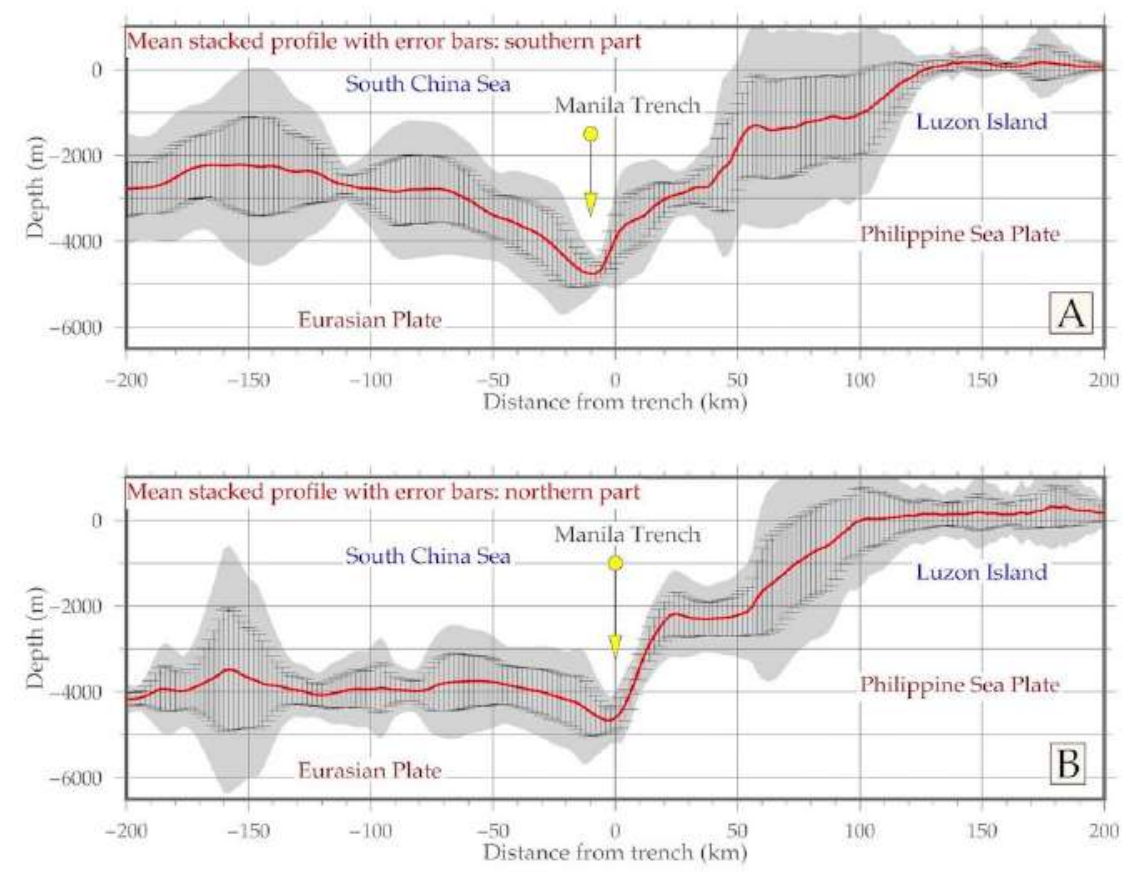

Figure 4.13.1: Manila Trench: transect of the digitized cross-section profilesh

Depth and geomorphology of the slope vary for the range $-3,500$ to $-4,500 \mathrm{~m}$ : minimals for the northern part of the trench with 526 samples $(18,2 \%)$ for the depths $-4,000$ to $-4,200 \mathrm{~m}$. The histogram for the northern part has bimodal distribution with two peaks. Southern part shows 142 values for the minimals - 3,500 to $-3400 \mathrm{~m}$ [406]. The statistical comparison of the data proved northern part of the trench to be deeper. The GMT functionality shown in this paper enabled integration and interpretation of the multi-source data and approaches: automatically digitized profiles, geological mapping, 2D and 3D bathymetric modelling, statistical analysis, mathematical approximation for the trend modelling.

Two different trench segments were analyzed aimed at detecting their spatial changes for an area covering MnT and adjusting Luzon Island (northern Philippines). The south-east directed second segment (plotted as green line on the Map 4.13.1) shown steeper slopes on the oceanward side of the trench and deeper bathymetric records. On the contrary, northern segment (plotted as almost vertical yellow-colored line on Map 4.13.1) demonstrated softer geomorphic shapes yet steeper gradient from the Luzon Island side [406]. The fine-resolution data such as SRTM grid was used to map bathymetry and topography of the study area and 1- min resolution from the gravity data (Jason-1, CryoSat).

The statistical results (Fig. 4.13.2) show differences in the depth ranges of the MnT along the Luzon island. The depth and geomorphology of the slope vary significantly for the depths range $-3,500$ to $-4,500$ : minimal values are notable for the northern part of the trench where 526 observation points $(18,2 \%)$ are 
recorded for the depths $-4,000$ to $-4,200 \mathrm{~m}$, as shown on Fig. 4.13.2 A [406].

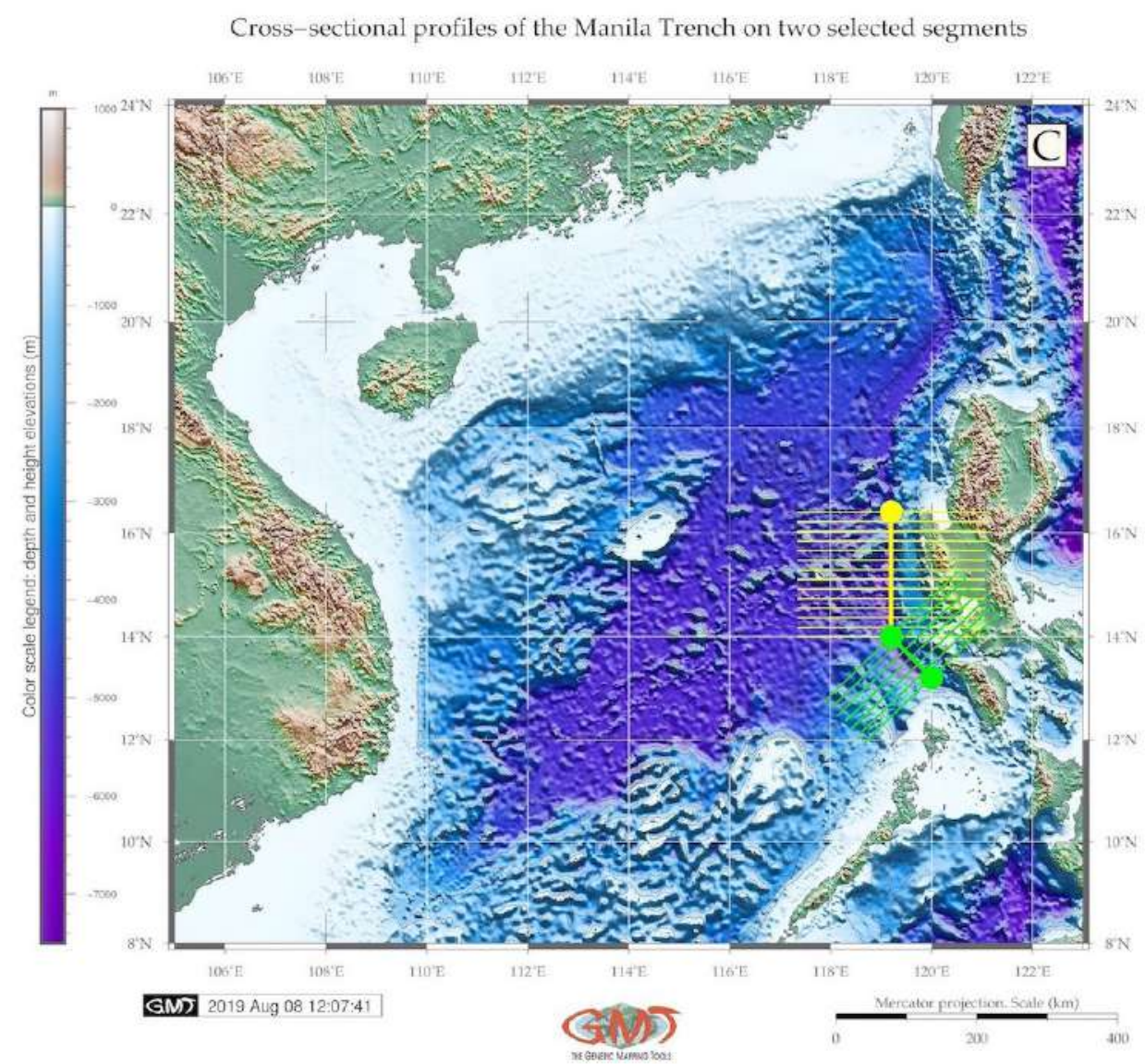

Map 4.13.1: Manila Trench: two segments of the digitized cross-section profiles

The histogram for the northern part has a clear bimodal distribution with two peaks. The second peak shows areas crossing the Luzon island. On the contrary, S part demonstrates 142 values for the minimal bathymetry with values $-3,500$ to $-3400 \mathrm{~m}$; the second peak also shows areas of the Luzon Island. The comparison of the statistical data analysis clearly shows that the $\mathrm{N}$ part of the trench is deeper.

The southern part of the trench has steeper slope gradient from the oceanward part and on the contrary, the northern part is steeper in the continental slope part (Fig. 4.13.1). Submarine terraces can be noted on the $\mathrm{N}$ segment of the trench (Fig. 4.13.1) at depths - 2,000 m. Generally, model of the N part shows more steep degree of the oceanward slope (pairwise comparing on Fig. 4.13.1). However, a gradually slanting terrace on the S part of the trench can be seen on the fragment 50-100 of the cross-section with depths from $-1,100$ to $-1,300 \mathrm{~m}$ [406]. Hence, the comparison between two segments of the trench located on the $\mathrm{N}$ and SE part of the trench show that $\mathrm{N}$ segment has shallower values of depths comparing to the $\mathrm{S}$, but more steep slope on the Luzon Island side.

As for the geophysical modelling, based on the patterns of the free-air gravity map of the MnT (Fig. 2.12.3), high density materials are distributed continuously from the $\mathrm{N}$ the $\mathrm{S}$ Taiwan vertically southwards to the Luzon Island, the Philippines from $-50 \mathrm{mGal}$ to $-200 \mathrm{mGal}$. The majority of the values in the South China Sea areas lie between the 10 to $30 \mathrm{mGal}$, while values $>60 \mathrm{mGal}$ can be noted in the island areas and southern Philippines [404]. The results of the geomorphological modelling and mapping of the MnT highlighted underlying tectonics conditions where the collision of two tectonic plates causes instability: repetitive earthquakes, submarine volcanism and seismicity. 
Histograms of the bathymetry, Manila Trench: northern (A) and southern (B) parts
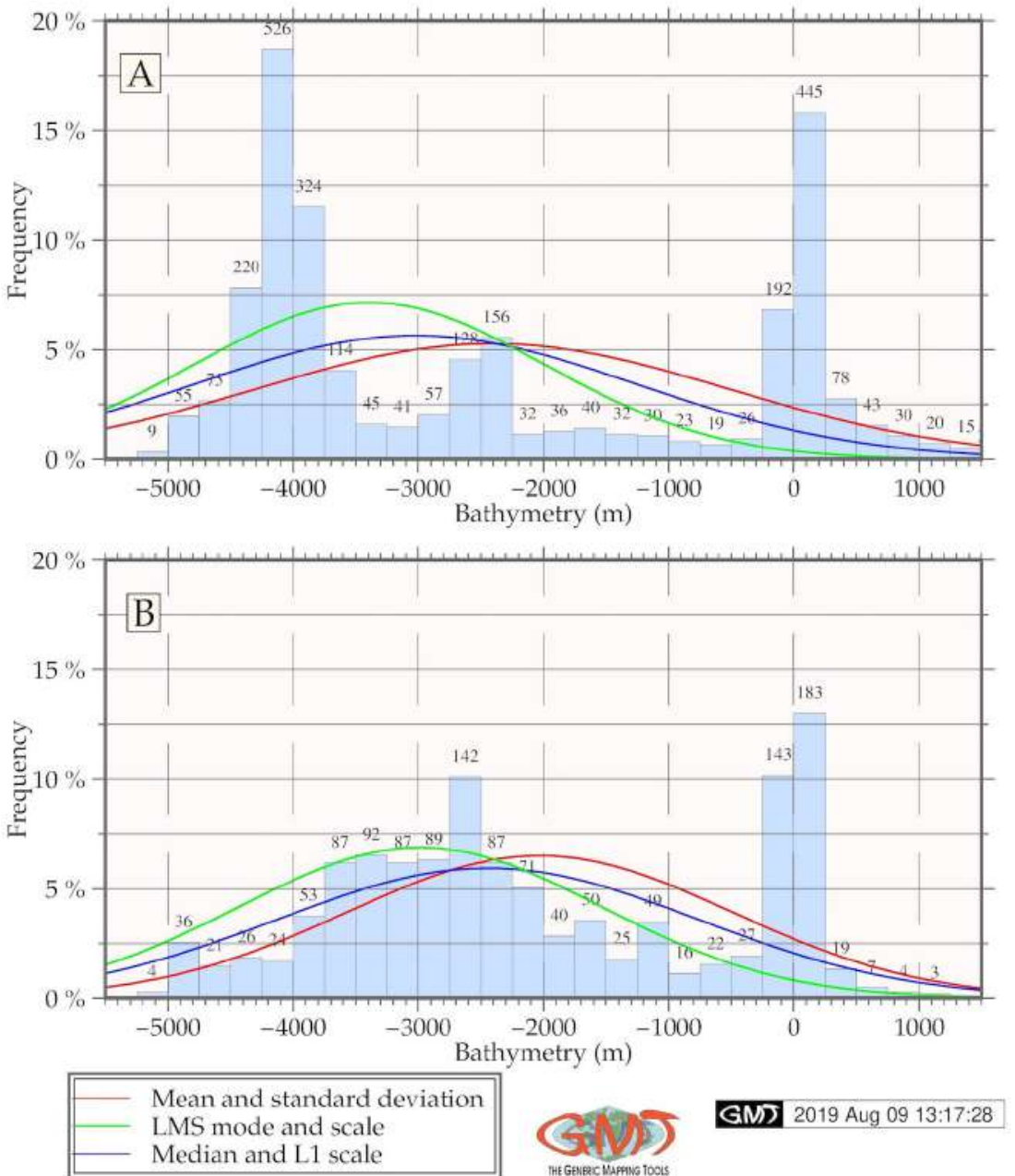

Figure 4.13.2: Manila Trench: histograms of the bathymetry

Strong topographical isolation and complex mix of water masses distinct trenches from other oceanic regions. Difficulties to study deep-sea life and habitats zone $(6000-11,000 \mathrm{~m})$ that presents the last great frontier in marine science are caused by remote location. Studies on marine biology are currently limited to the bathyal (200-3000 m) and abyssal depths (3000-6000 m), [269]. Specifics of the benthic biology consists in the geomorphic shape of the trench: despite representing 1-2\% of the global benthic area, hadal zone constitute the deepest $45 \%$ area of the vertical depth gradient [287].

Consequently, the communities of the MnT represent spatially isolated environments, highly distinct from the shallower areas. It present a cluster of deep habitats that include features of the continental slopes, abyssal plains and unique properties of the hadal geomorphology affecting biological aspects. Hadal fauna survive on the fringes of two extremes caused by the hydrostatic pressure and remoteness from the surface-derived food supply [286]. The interconnectivity of the factors affecting hadal ecosystems is described by [751], who reviewed various aspects of the hadal biogeochemistry: the effect of food supply on hadal ecosystems, hadal carbon cycle in the sub-seafloor under high hydrostatic pressure and pollution in the hadal trenches. 


\subsection{Ryukyu Trench}

The statistical results (Fig. 4.14.2) on the modelling RT show certain differences in the depth ranges of the RT along the Ryukyu island arc. The depth and geometry of the slope vary considerably: maximal values of $-5,500$ to $-5,700 \mathrm{~m}$ are notable for the northern part of the trench where 334 observation points are recorded, as shown on Fig. 4.14.2 (A) [392]. With a minor difference, southern part demonstrates comparable values ( 329 samples) for the same depth range.
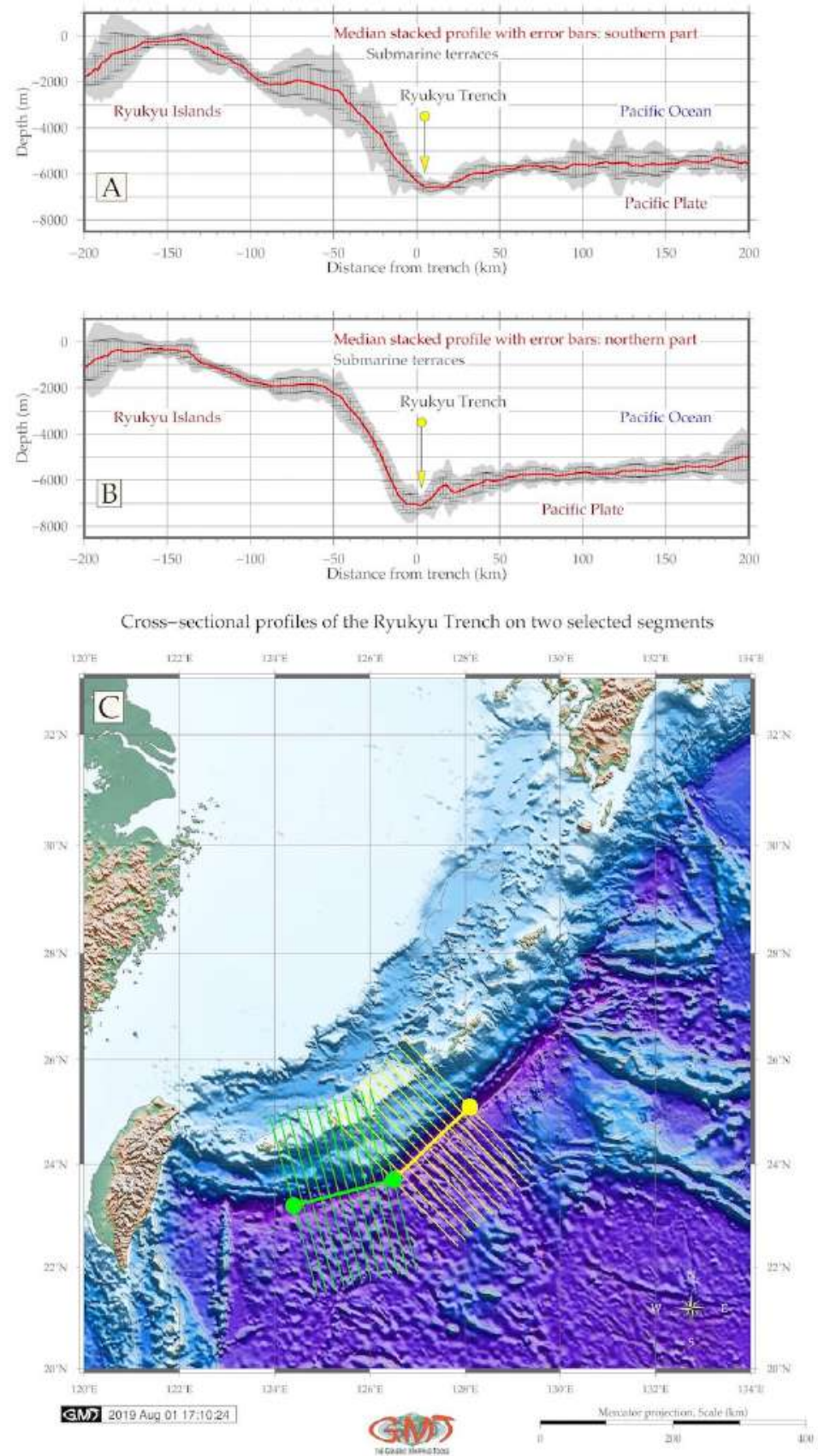

Map 4.14.1: Ryukyu trench: cross-section profiles of the southern and northern segments

However, more significant differences can be seen for the depths $>6,000 \mathrm{~m}$. Thus, the southern part 
of the trench (shown on Fig. 4.14.2 (B) has only few values (9 samples) with depths $>6,800 \mathrm{~m}$ while the northern part shows 41,59 and 23 records, with a maximal values reaching $-7,460 \mathrm{~m}$. Moderate to shallow depths with ranges from $-3,000$ to $-5,000 \mathrm{~m}$ are comparable for both parts of the trench with values not exceeding 68 samples for the northern part and 42 samples for the southern, respectively [392].

The forearc basin deeper than 2,000 $\mathrm{m}$ and shallower than 1,000 $\mathrm{m}$ BSL shows more samples data in the northern part of the trench than in the south. In contrast, a wide terrace with depths shallower than $25 \mathrm{~m}$ is generally larger (161 samples) in the southern part of the trench [392]. To conclude, the comparison between the two spatially different segments of the trench show that northern part of the trench has deeper depths comparing to the southern. This can also be noted on Fig. 2.13.1 where the deepest values of the central part are seen in the deep area extending seaward offshore from the Miyako Fault (Fig. 2.13.2).

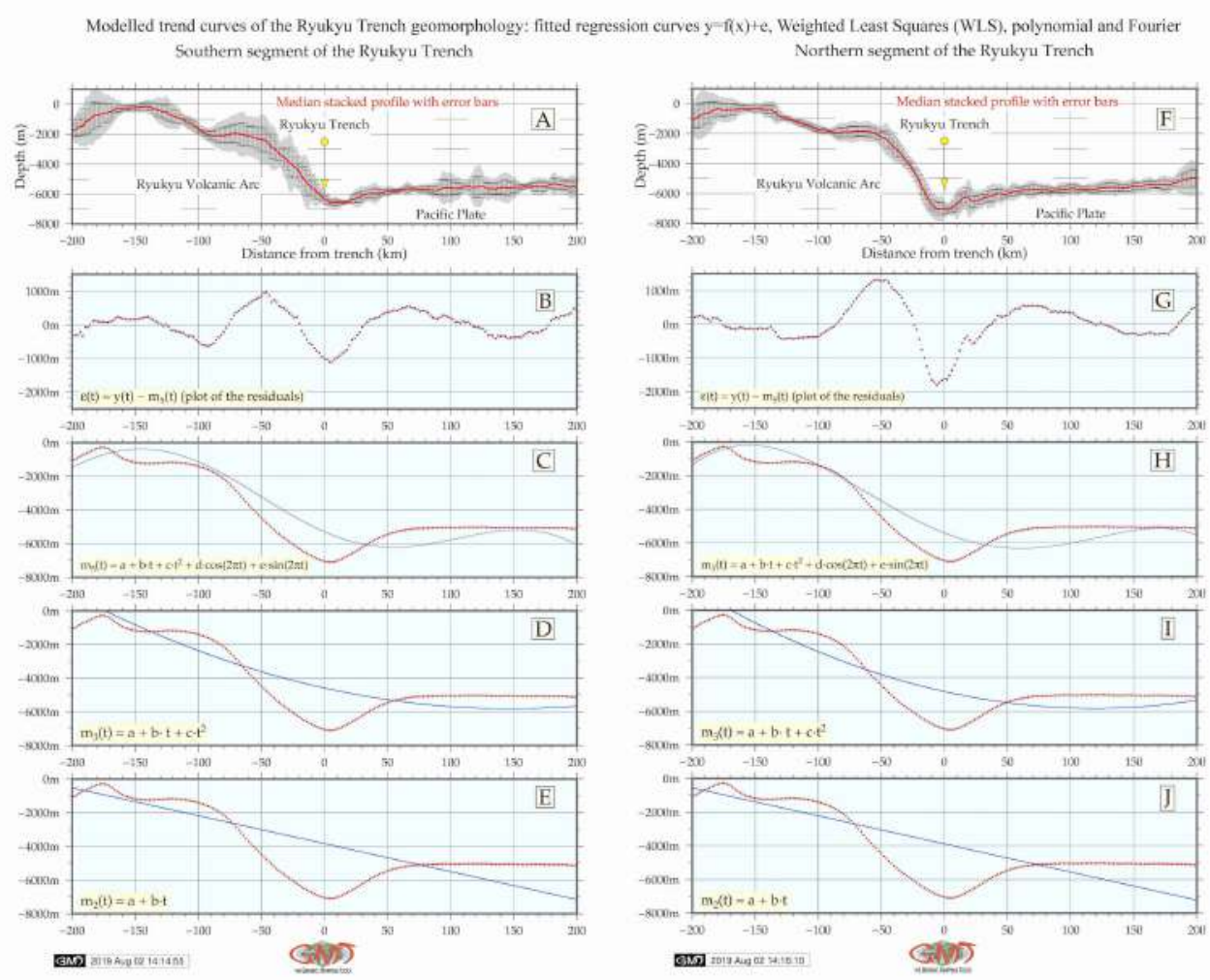

Figure 4.14.1: Ryukyu Trench: models of the slope gradient trends for the profile curves

As can be noticed on the comparison of Fig. 4.14.1 A and Fig. 4.14.1 B, the median stacked profile on the southern part (Fig. 4.14.1 A) demonstrates slightly more gentle slope shape with submarine terraces, while there are no clear on northern part of the forearc slope (Fig. 4.14.1 B). At the same time the depth of the forearc slope increases in the northern segment of the trench (Fig. 4.14.1 B). These changes of the slope geomorphology are also highlighted by the contour of the increased marine free-air gravity anomaly, as a triangle shaped island located at $126^{\circ} \mathrm{E} 24^{\circ} \mathrm{N}$ (Fig. 2.13.4) [392].

Geometric approximation of the trend curves (Fig. 4.14.1) shows similarity between the segments while applying coarse linear model (Fig. 4.14.1: E and J; Fig. 4.14.1: D and I) [392]. Specifically, its shows modelling trend curves for general geomorphological transects and slope gradients using various mathematical approximations. However, the differences in the geomorphic variations become more notable at the polynomial functions (Fig. 4.14.1: C and H; Fig. 4.14.1: B and G) [392]. 
Histograms of the bathymetry, Ryukyu Trench: northern (A) and southern (B) parts
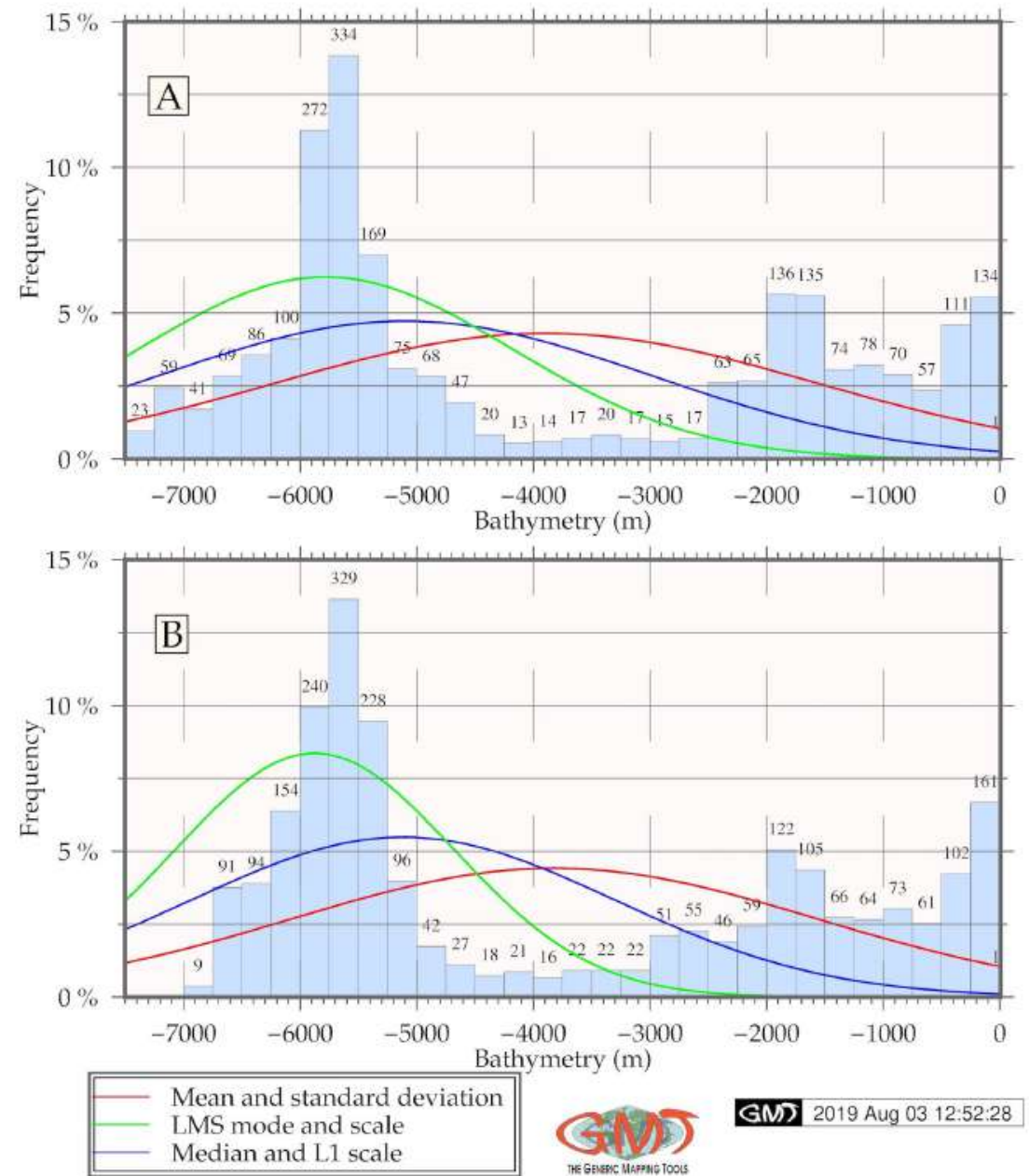

Figure 4.14.2: Ryukyu Trench: histograms of frequency of the depth distribution

The geoid model shows geoidal undulation in the south-western part of the area east off Taiwan Island (Fig. 2.13.3). Generally, the major part of the area has geoid values range of 25 to $35 \mathrm{mGal}$. The increased values ( $>35$ to $85 \mathrm{mGal}$ ) can be seen on the south-eastern part in the Philippine Sea area, while lower values (15-25 mGal) bordering continental shelf stretch along the East China Sea and the lowest $(<15 \mathrm{~m} \mathrm{Gal})$ mainly occupy land areas.

Various studies have been undertaking to analyze the complexity of the system of deep ocean trenches and reveal possible impact factors (recent studies [624], [522], [761], [175], [269], [101], [69], [225]. Current analysis of the trench geomorphology and variability of the steepness indicate the importance of geological factors. Complex tectonic and geomorphic features of the trench was reviewed using a set of cross-section profiles with local geologic settings located in four tectonic plates. The results demonstrated dependences between the geomorphic factors and geology (slope angles and sediment thickness, respectively) on the profile morphology. 


\subsection{Palau Trench}

The results of the data analysis demonstrated spatial geomorphic unevenness of the PT. The information and conceptual framework for the sediment thickness of the World Ocean published by [134] was used in this research. Ranking geologic data has a step in geomorphic analysis where the levels of the slope degree are determined by the geospatial impact. Therefore, geomorphic variations typically necessitate an additional sub-task of the geological analysis of the study area.
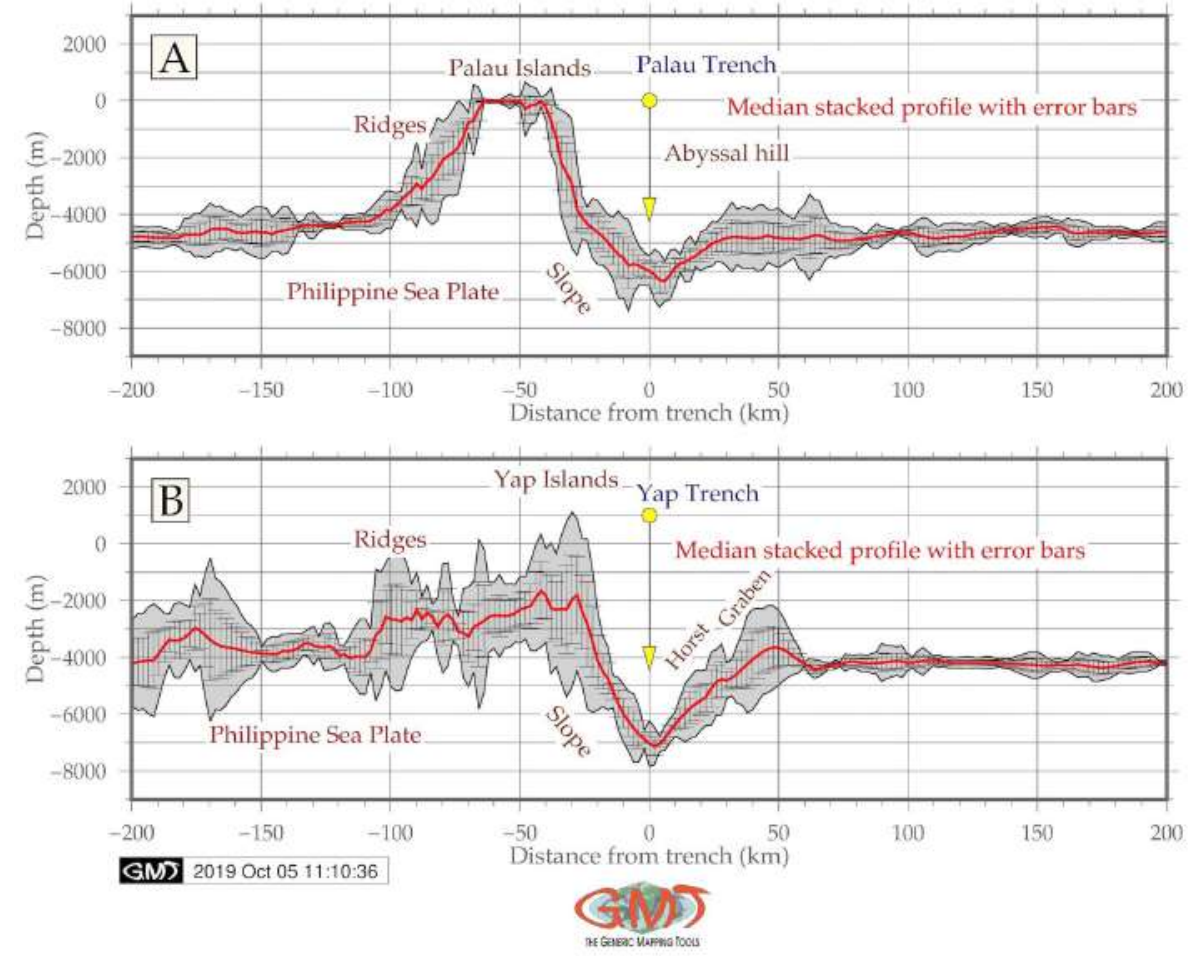

Figure 4.15.1: Yap and Palau trenches: geomorphological modelling of the profiles [412]

Data distribution for the PT has remarkable pattern: the amount of depths in range of $-5000 \mathrm{~m}$ to -4000 $\mathrm{m}$ is large (737 samples at PT). The same situation can be seen for the depth range at $-5000 \mathrm{~m}$ to $-6000 \mathrm{~m}$ : PT has 152 samples. In general, PT has more gentle slope both landwards and oceanwards. Topographic profiles of the PT axis has U-shape. PT has the majority of values higher and/or below $-6000 \mathrm{~m}$. PT has more gentle geomorphic slope land- and oceanwards. Contours of the free-air gravity anomalies (Fig. 2.14.2) in general reflect bathymetric isolines (Fig. 2.15.1). Comparing to the neighboring Mariana Trench, gravity field of the Yap and PT are narrower (purple colored strip on the map).

Free-air gravity values reach positive above 100 to $500 \mathrm{mGal}$ (red color) mostly over the area of Philippine Islands and small islands of the archipelago. Positive 70 to $100 \mathrm{mGal}$ are notable over the shelf areas (orange color on the map). Gravity over the basin of the Philippine Sea generally fluctuates between -20 to $0 \mathrm{mGal}$ range (light blue) to $020 \mathrm{mGal}$ (cyan). The characteristics of the gravity field mirrors correlation between the gravity anomaly and geoid undulation as determined by [229] for gravity anomalies from a grid of geoid undulations. The geoid model (Fig. 2.15.2) visualizes subdued isolines in the Yap and PT. 
Histograms on bathymetric data: Yap (A) and Palau (B) trenches
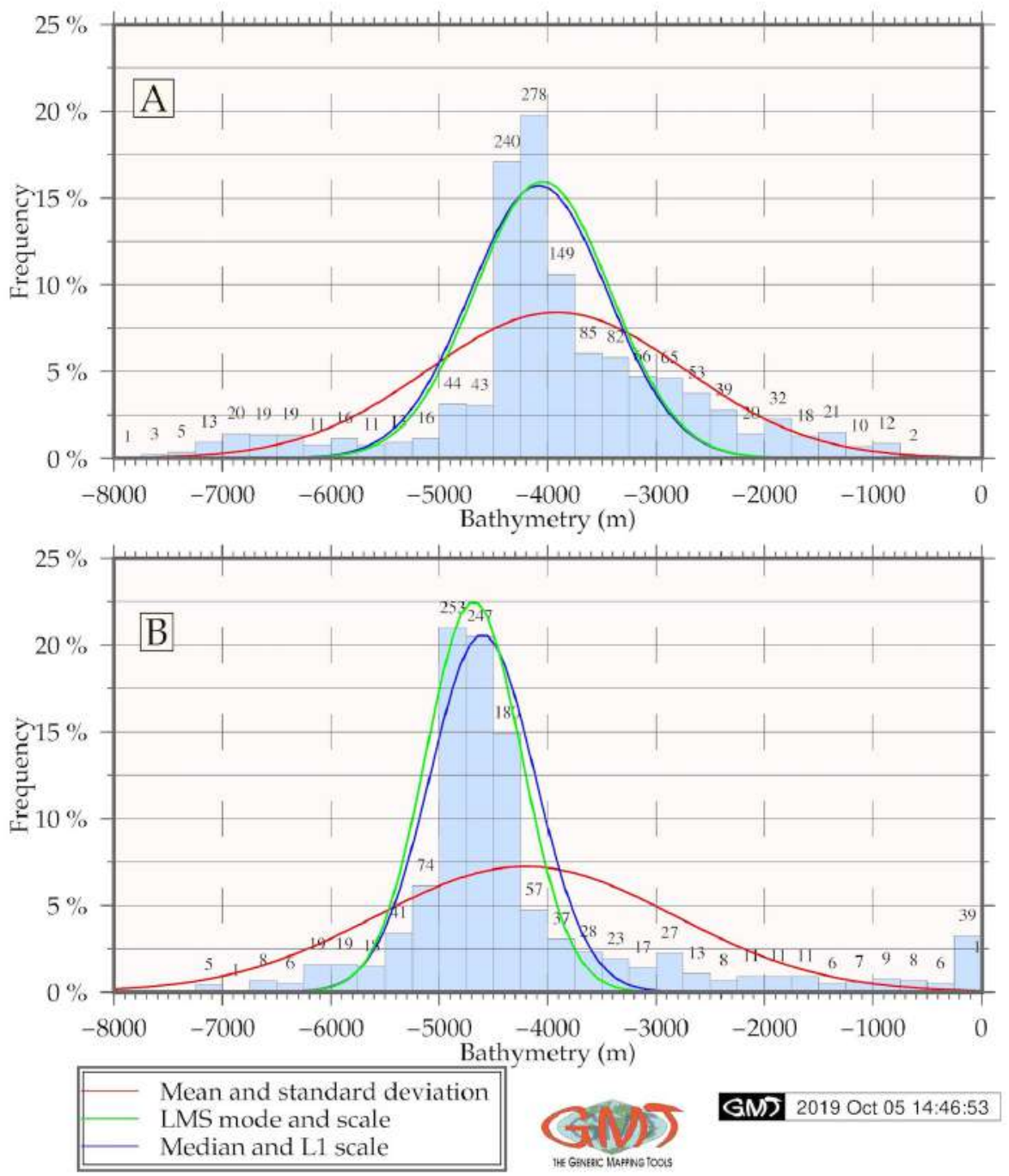

Figure 4.15.2: Yap and Palau trenches: statistical histograms on bathymetry [412]

Trench formation is a very complex process that is known to be influenced by a variety of geological and tectonic factors. These may not adequately explain the process of trench deep formation, its further development and what is the impact in a variety of factors affecting hadal structure of the ocean trenches. Studies of the oceanic trenches based on the profiles cross-section have been undertaken in the past, e.g. [562], yet based on technical methods of that time. Until now, little attempts has been available on application of shell scripting towards modelling ocean trenches in marine geology, and this research contributed to this question. 


\subsection{Yap Trench}

According to the statistical analysis (Fig. 4.15.2), the highest values for YT are from - $4000 \mathrm{~m}$ to $-4200 \mathrm{~m}$ (278 samples) with $19 \%$ and $17 \%$ of the total data pool, respectively. For the depths over -5000

$\mathrm{m}$, the model of two trenches significantly changes: decreases for the PT more clearly.
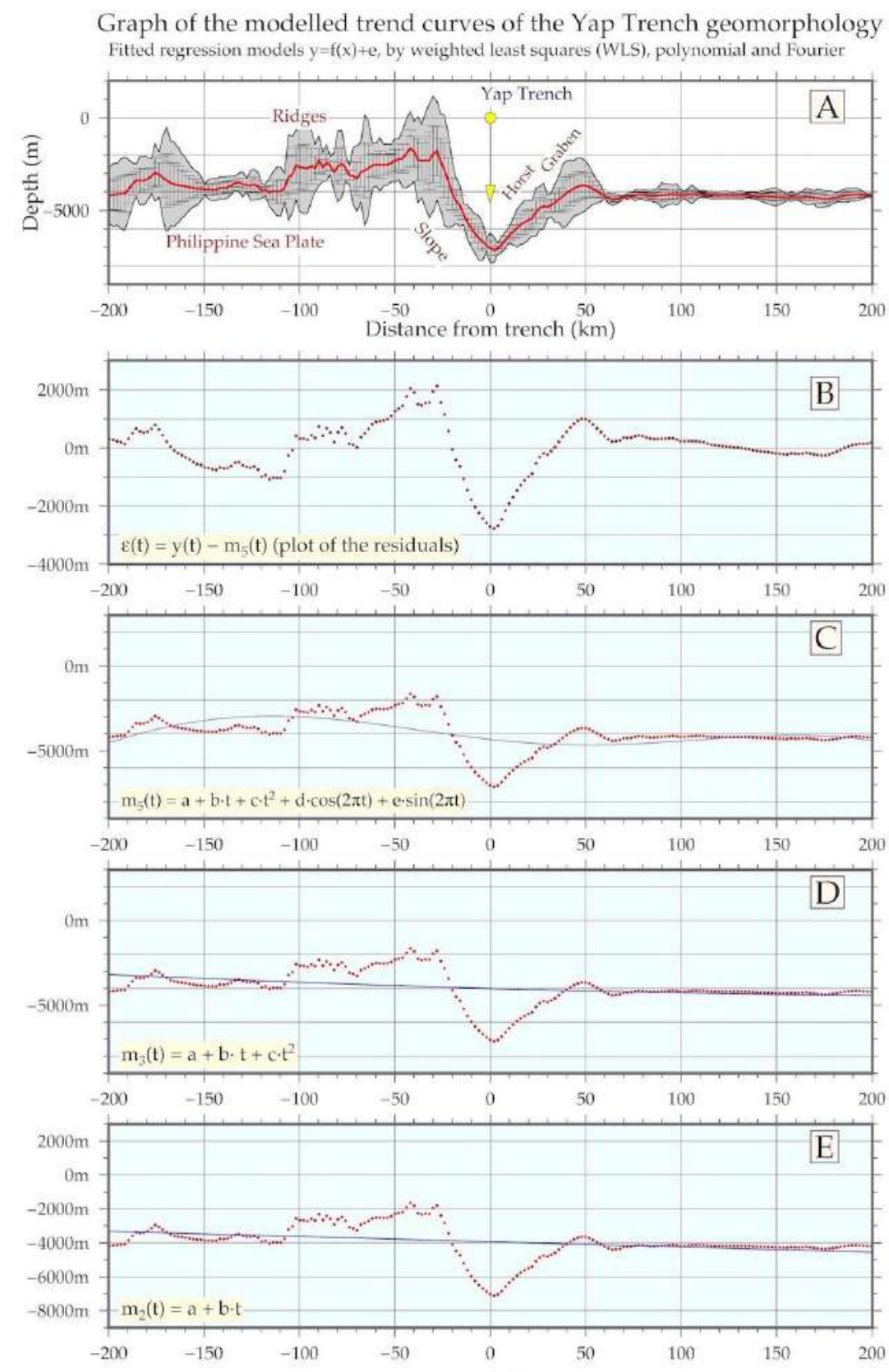

GMग 2019 Oct 05 15:03.45

Figure 4.16.1: Yap trench: trend model of the slope gradient direction [412]

Data distribution for the YT (605 samples): depth range at $-5000 \mathrm{~m}$ to $-6000 \mathrm{~m}$ : YT has in total only 53 samples. In general, YT has steeper slopes and generally deeper sample observation records. YT has more deep values within range of $-7000 \mathrm{~m}--6000 \mathrm{~m}$ : 68 samples, while PT has only 34 
samples for the same depths diapason. That means that YT has dominating depths at deeper values. In general, YT has steeper slopes and generally deeper sample observation records. Bare bottom of YT may result from the thin sediment cover of the axis which proves correlation between the factors (geology, geomorphology, geophysics, tectonics, sedimentation) affecting trench structure and dynamics [761]; [433]; [316]. Topographic profiles of the YT axis have very sharp V-shape. V-shaped trench generally indicates bare bottom of the YT with very thin sediment cover of the axis.

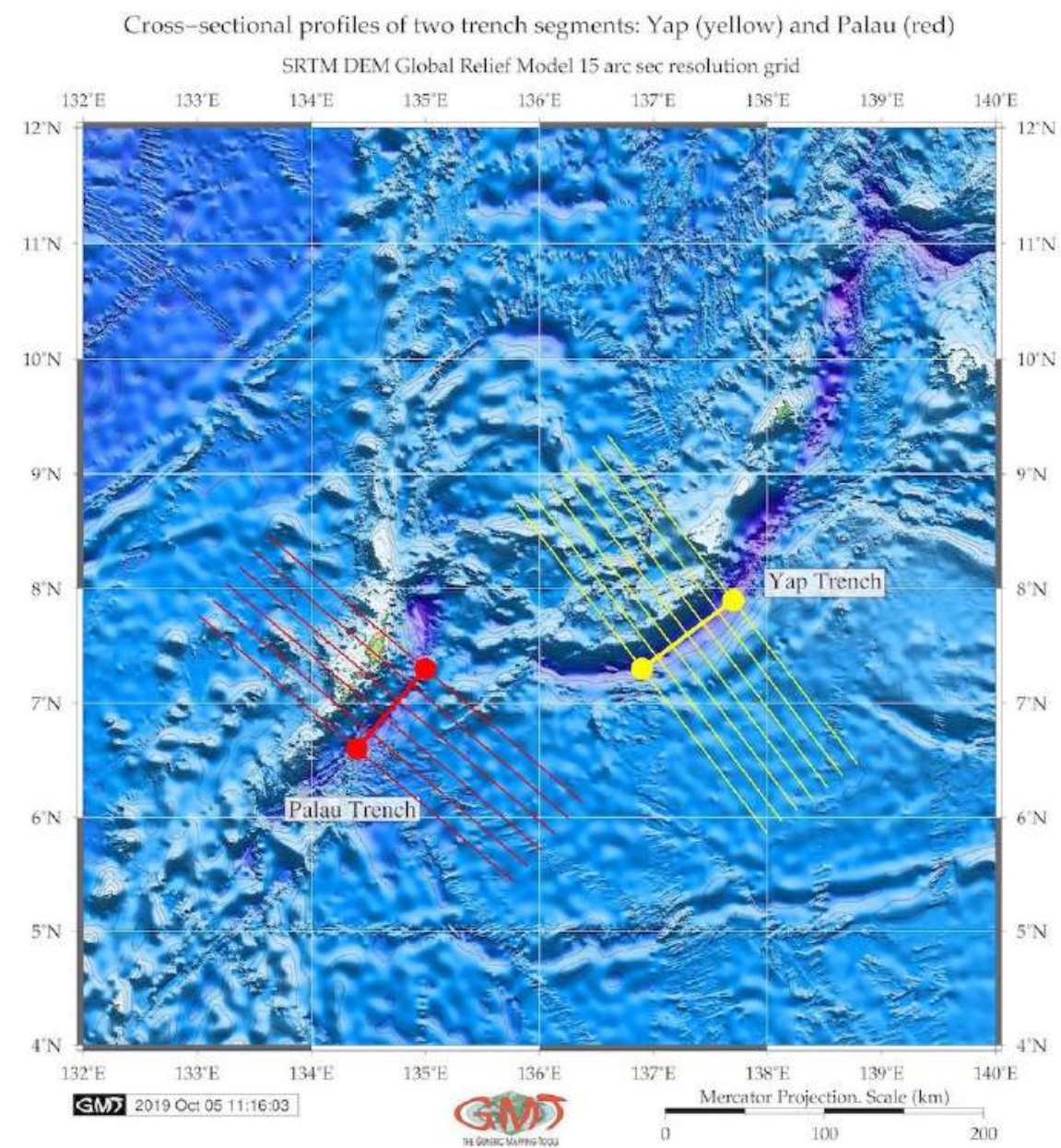

Map 4.16.1: Yap and Palau trenches: digitized cross-section profiles [412]

YT has steeper slopes and deeper records. Topographic profiles of the axis of the YT have sharp Vshape. YT reaches $-7000 \mathrm{~m}$ in its median curve of the profiles, while the PT only $-6200 \mathrm{~m}$, that is the PT is shallower. Second, YT has distinctly more abrupt slope and steep gradient of the profiles oceanward (Fig. 4.15.1, B) comparing to the PT (Fig. 4.15.1, A). [332] earlier pointed that extensive slope failure is occurring on the landward slope of the PT from which great amount of mass is wasted to the trench axis. Hence, if surface sediments or rocks are collapsed into the trench axis, the V-shaped bottom will be gradually buried to form a flat basin, unless subduction or the tectonic erosion proceeds. Submarine sediment avalanches occur easily and frequently, when dipping angles of the lower landward slope partly exceed slope failure limit. 
Composite overlay of the 3D topographic mesh model on top of the 2D geoid contour plot

Region: Yap and Palau trenches Perspective view azimuth: 165/45
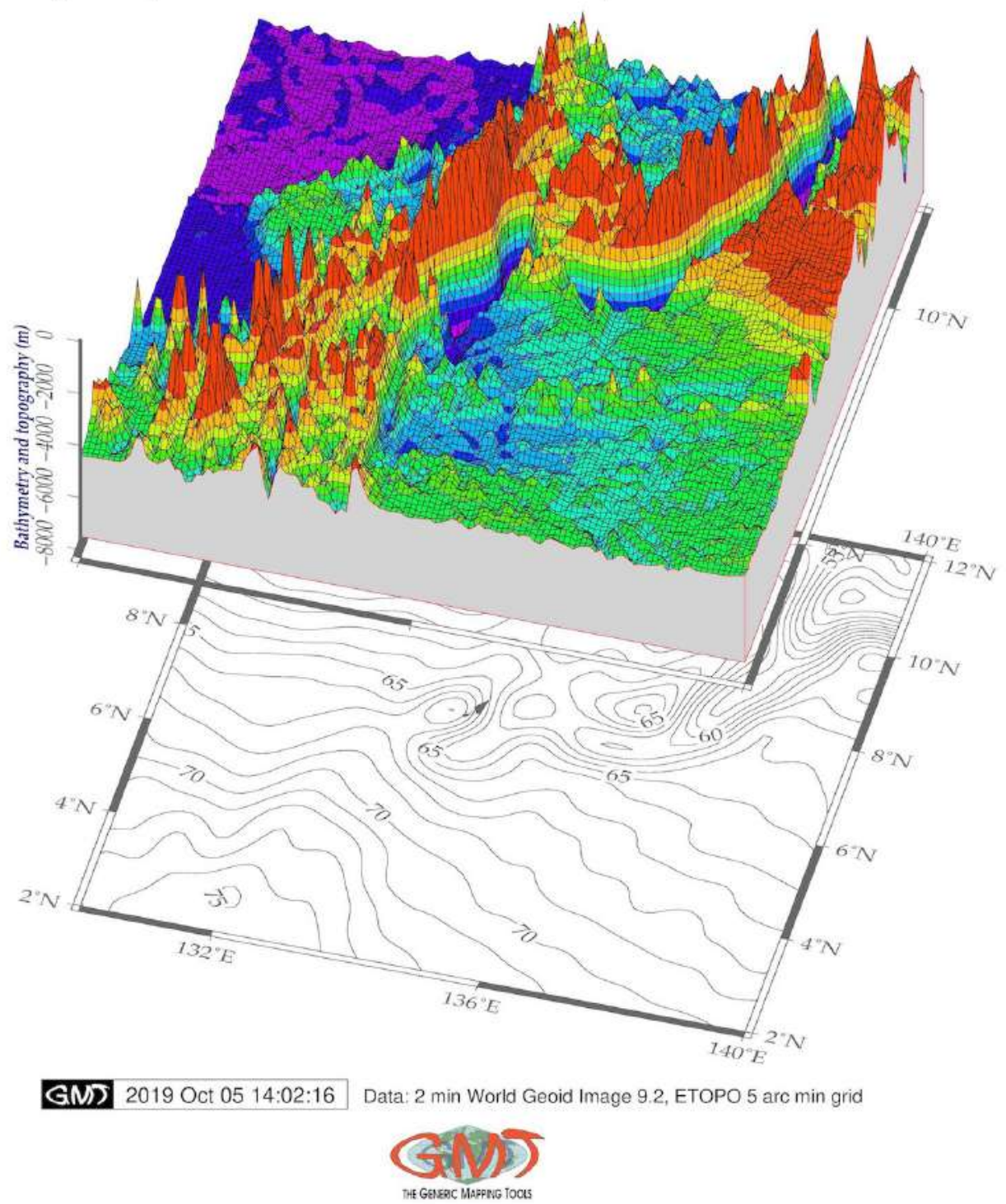

Map 4.16.2: Yap and Palau trenches: 3D mesh modelling [412]

With this in view, the comparison of the graduate slopes is important (example for YT: Fig. 4.16.1). This can contribute to the explanation of the differences between two trenches in the geomorphic shape: as we can notice, inner slopes on the YT are more steep and abrupt (Fig. 4.15.1, B) while the PT (Fig. 4.15.1, A) has more gentle slope with sediment accumulation on the inner slope side. Fig. 4.15.1 shows modelled profiles of the bathymetry of the PT (A) and YT (B) trenches. The average dip of the landward slope is recognized as about $29^{\circ}$ for the YT westwards $41^{\circ}$ eastwards and while for the PT it is $17^{\circ}$ westwards and $18^{\circ}$ eastwards, respectively. The topography of the PT is more similar to an upsidedown mound. Generally, YT has abrupt shape with no marine terraces identified. 


\subsection{Mariana Trench}

Seafloor geomorphology of the MT and of the PSB were examined using high-resolution GEBCO and ETOPO1 topographic and gravity data grids in NetCDF format, geologic vector layers and modeled profiles.

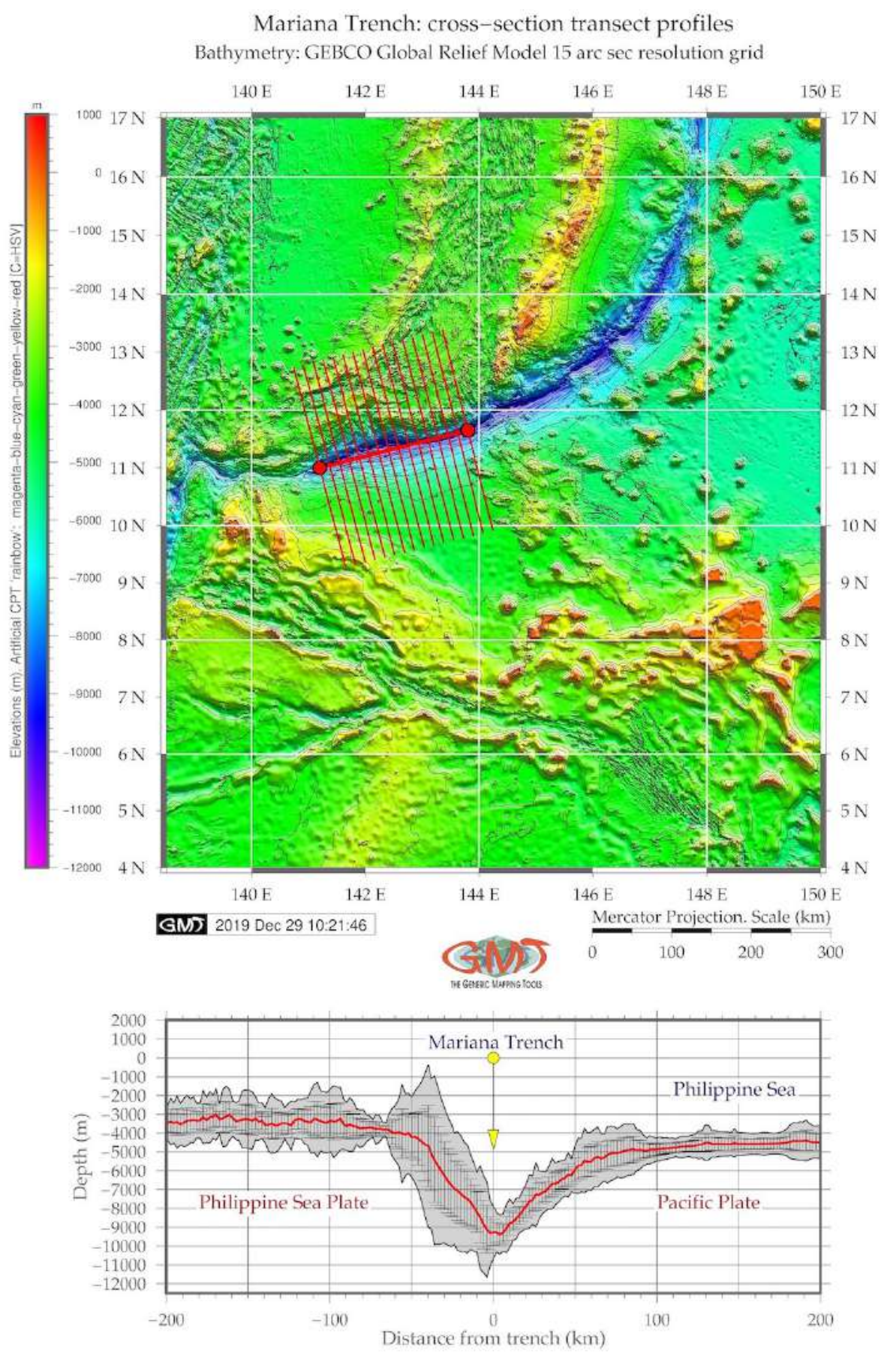

Map 4.17.1: Cross-section transect profiles of the Mariana Trench

Profiles are visualized on Fig. 4.17.1. The statistical histograms for transects bordering the PSB are visualized on Fig. 4.17.1. The shape of the histogram varies by two trenches reflecting their geomorphol- 
ogy. The statistics on topography and interpolation approaches are shown on Fig. 4.17.1. Histograms for the MT demonstrated bimodal peak for depths $-5,000--3,000 \mathrm{~m}$ with samples $<10 \%$. In this interval, the $1^{\text {st }}$ peak is covering $-4,500$ to $-5,000 \mathrm{~m} \mathrm{BSL}$ and the $2^{\text {nd }}$ one is for the $-3,800$ to $-3,000 \mathrm{~m}$. Gradual decrease in data samples $>5,000 \mathrm{~m}$ indicate a uniform way of data distribution for the depths range of $-5,000--6,500$ frequency $4-2 \%, 285$ samples. Depths at $-6,200--10,800 \mathrm{~m}$ have a frequency $<2 \%$. Shallower areas with depths $>3000 \mathrm{~m}$ and $<1,500 \mathrm{~m}$ BSL have frequency $<4 \%, 400$ samples.

Histograms of the bathymetry, Mariana (A) and Philippine (B) trenches
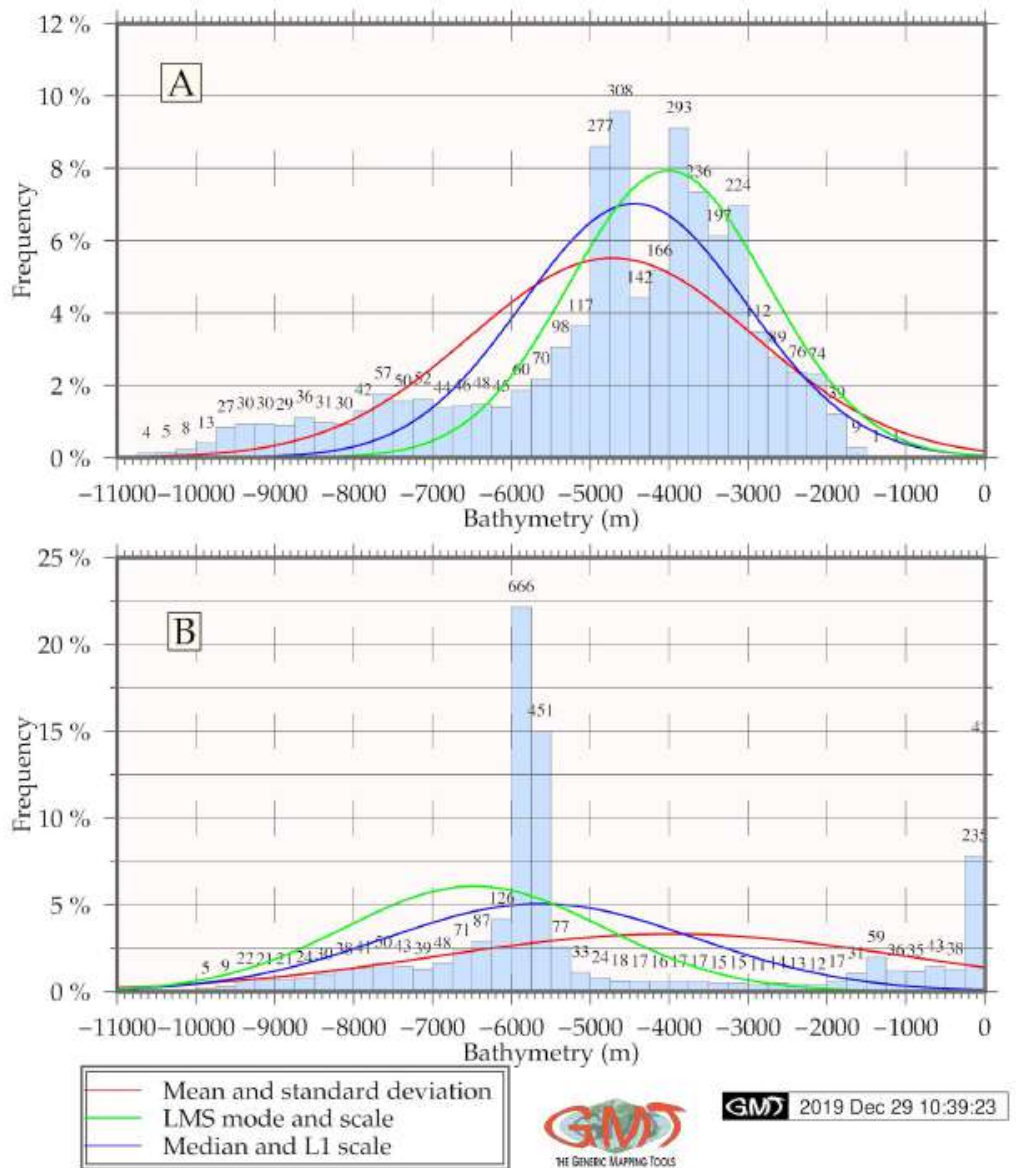

Figure 4.17.1: Histograms on depths frequency: Mariana and Philippine trenches

Gradient slopes of the trenches have markedly symmetric accurate ' $\mathrm{V}$ '-shape form in their deepest parts. Automatic digitizing of the perpendicular transects cross-sectioning MT and PT, demonstrated that MT has steeper gradient slope on the northern (Fig. 4.17.1, below) flank on the archipelago's side (Fig. 4.17.1). Slope steepness on the left flank has a $33,10^{\circ}$ at $0-15 \mathrm{~km}$ from the center from the vertical plummet. A segment on $15-25 \mathrm{~km}$ has a steepness of $45^{\circ}$, segment of $25-40 \mathrm{~km}-30,75^{\circ}$, a segment of $40-50 \mathrm{~km}-28^{\circ}$. On the right flank of the trench its gradient steepness varies as follows. The segment at distance $0-28 \mathrm{~km}$ has a steepness of $40,5^{\circ}$ from the vertical plummet, $28-37 \mathrm{~km}$ from the start point has a $43,33^{\circ}$ of steepness. It then becomes gradually becomes gentles to $30,43^{\circ}$ until $50^{\text {th }} \mathrm{km}$. The segment at $50-90 \mathrm{~km}$ consists in the arc-shape gradual increase of the elevation which stabilizes after $100 \mathrm{~km}$ $<-4000$ BSL (Fig. 4.17.1).

The relief surrounding left flank slope of the trench presents uneven submarine terrain comparing to 
its right flank with more complex submarine relief and to the PT which presents a more accurate and steep in its shape form. Results on geomorphic modelling of the MT profiles revealed that the major depth samples of the trench are between $-3000--5000 \mathrm{~m}$ (Fig. 4.17.2). Maximal depths reach up to $-10,000$ in the current dataset: profiles 20,21, 22 crossing mostly PSP (Fig. 4.17.2). Decrease of depth is in profiles 23, 24, 25, crossing Caroline Plate. Profiles Nr. 23 and 24 have the deepest depth data range, [427]. Conversely, bathymetric profiles from 1 to 16 have gradual decrease in depths, which can be noted in outliers sample location. A slight increase in depths of the profiles Nr. 4-8 was also observed of the Fig. 4.17.2.

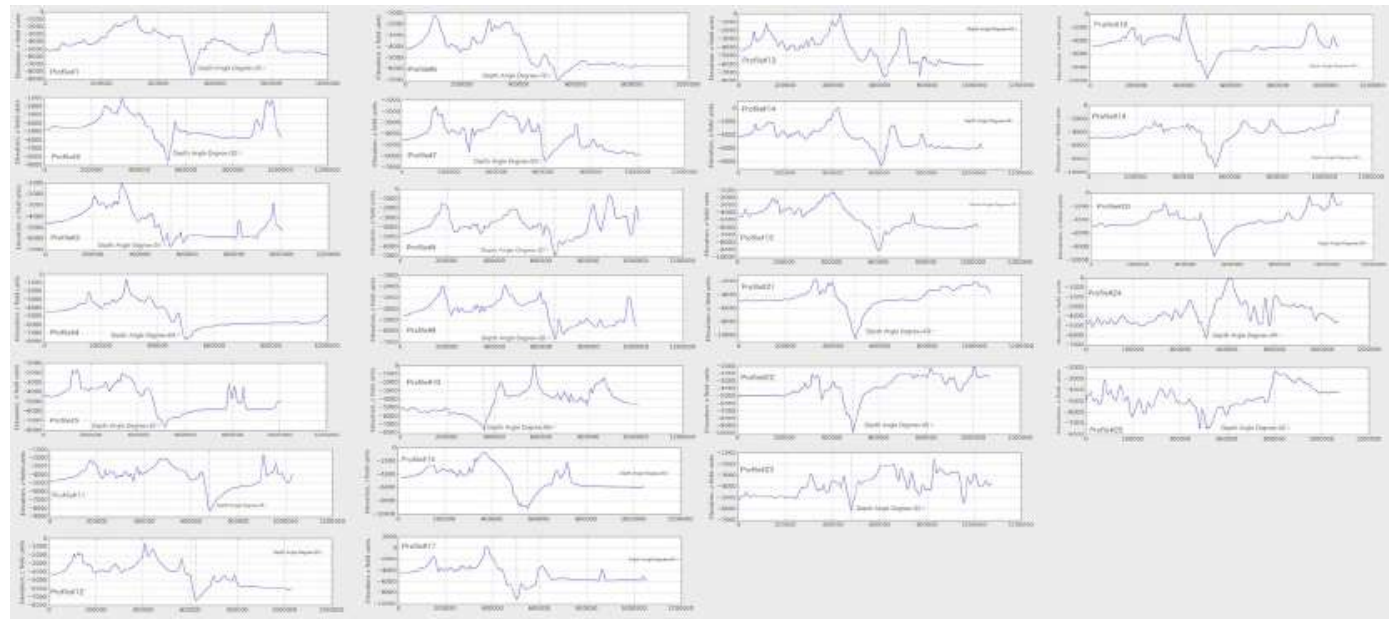

Figure 4.17.2: Mariana Trench: graph of the 25 bathymetric profiles, QGIS [415]

Changes in bathymetry may be explained by changed geological settings. Nevertheless, sediment thickness changes notably both within the trench by profiles and between tectonic plates. Since tectonic settings are not identical, the comparative analysis of data variations across tectonic plates was performed. The majority of samples of the profiles crosses Pacific Plate and Philippine Sea Plate, following my Mariana Plate, while Caroline Plate only covering a few points. Density distribution enables to compare overlapping and maximal aptitude of the density curves for the profiles and depth distribution by tectonic plates. Major trend of the trench gradient on the Pacific Plate has downward general line. The Philippine Plate, has a minimal peak by profiles \#14-21, then moving upwards. The highest values are for the Caroline Plate. Consequently, Mariana Plate has the highest density of depth distribution values, followed by the Philippine plate, then Pacific and Caroline, respectively.

From two multiple panel by groups (Fig. 3.8.7 and 3.8.8) one can compare slope angles and depth distribution by tectonic plates, and patterns of these categories by plates. Summaries of variations of the local polynomial regression of the bathymetric depths of the measured samples are presented on Fig. 4 in [415]. Upon a close examination of these summaries it can be observed that, with a mean depth value ranging from 5000 to of 3000 on the profiles, the widths of the confidence intervals are expanding more rapidly by the profiles 12 to 15 and 19 to 22 thus indicating on the large amplitude of the depths variations in this part of the MT. The profile depth is being affected by local geographic settings caused by the location on the tectonic plates with varying geological conditions. On the other hand, profiles 22 to 25 crossing Caroline Plate [415] suggests that absolute depth in this region change to become shallower than profiles crossing Philippine and Pacific Plates. This phenomenon has adverse implications for deep inter-connections between these factors.

Marine free-air gravity anomaly in the PSP area shows (Fig. 2.11.4) higher values (> $80 \mathrm{mGal}$ ) of the gravity fields structure at the volcanic areas and Philippine archipelago. Geometric differences between trench shapes are explained by the context of the historic development and actual geomorphic 
and sedimentary processes affected their formation and structure. Current study presented comparative submarine geomorphic mapping and complex analysis of the geophysical and geological settings in the Philippine Sea basin area.

Bathymetric variations Data distribution are presented on Fig. 4.17.3. By profiles they ranged from $-10.600 \mathrm{~m}$ (maximal depth in this data set) to $-3150 \mathrm{~m}$ (the shallowest point in the data set). The maximum depths in the profiles were found in profiles Nr. 20, 21, 19, 14 (Fig. 3, right, sorted bathymetry), and the minimal depths (i.e. the shallowest) consist the first group, that is profiles 24, 23, 22 and 10 (Fig. 3, right, sorted bathymetry). The deepest part of the trench is located in the SW and central segments where the trench crosses Philippine and Pacific Plates. Moderate depths correlate with Mariana Plate and the majority of the Philippine Sea Plate. The depths ranges detected across the profiles of present study are also higher in southern part of the trench than in northern segment (Fig. 4.17.3). Central part of the MT has variations in depth: the increasing depths towards $\mathrm{S}$ part were the depths are higher than in the $\mathrm{N}$ segments. By comparing the profiles Nr. 3, 4, 9, 12 from the Pandas array (Fig. 4.17.3, colored green) with profiles Nr. 18, 16, 15, 13 (orange on Fig. 4.17.3), the depths increase reaching its maximal depths in the following group (Profiles Nr. 20, 21, 19, 14, group blue, Fig. 4.17.3, right).
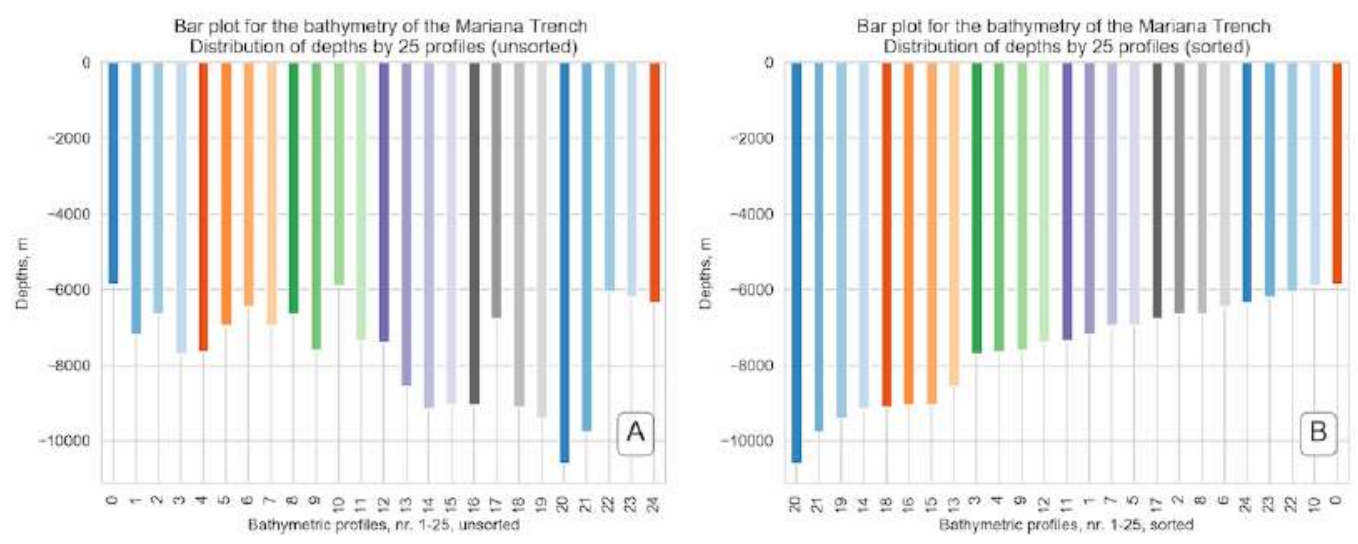

Figure 4.17.3: Mariana Trench. Data distribution analysis: maximal depths by profiles, Python [415]

This step identified variations in the steepness in various segments of the trench. Slope steepness and depths were analyzed by libraries Matplotlib, Seaborn and Bokeh. The steepest part of the trench is located in NW, C and SW segments (profiles Nr. 3, 7, 9, 23, 24) where trench crosses Philippine and Pacific plates. This segment has the largest local depths and sharp abrupt changes. The highest depth gradient is at profile Nr. 21 at the distance of $10.600 \mathrm{~m} \mathrm{BSL}$. Middle moderate slope ${ }^{\circ}$ (Profiles Nr. 1, 11, $4,5,10)$ correlate with areas where trench crosses Mariana Plate. Fig. 4.17.3 shows maximal depths by profiles, each profile has only one dot point on the plot, Fig. 4.17.2 illustrates the cross-section profiles. Profiles 19, 20, 21 and 22 had even geomorphic shape that decreased abruptly after sample 200. The unevenness of the profiles is explained by changed geologic conditions and tectonic plate (Philippine Sea to the Pacific, Mariana to the Philippine Plate). The groups of profiles 23, 24 and 25, (Fig. 9F, [415]), have similar geomorphic shapes: the first halve of the profiles is relatively even while the S part is particular for the increased depths. For better visualization, profiles are colored individually with the shared $\mathrm{X}$ axes (Fig. 9, [415]).

Geomorphic segments of the Mariana Trench have relatively balanced elevations from $-7.600 \mathrm{~m}$ (profile Nr. 11), $-7.750 \mathrm{~m}$ (profile Nr. 4), $-7.800 \mathrm{~m}$ (profile Nr. 5), $-7.750 \mathrm{~m}$ (profile Nr. 10), to $-6.200 \mathrm{~m}$ (profile Nr. 1). Depths ranges are shown on Fig. 10 [415] (jitter plot). The profiles with the least slope degree $(21,22,18,20)$ are located in the $\mathrm{S}$ segments where trench crosses Caroline Plate. The depth 
values >-9600 m BSL prevails on the bathymetric model for the deepest depth range, representing depths of the very steep slopes of the trench. Sediment sources are connected with trench tectonics where values of the sediment thickness are 140-120 decreasing to $50 \mathrm{~mm}$. Sedimentation differs significantly by plates, due to the complex of the sediment processes and mechanisms. Among other are turbidity caused by gravity sliding, biochemical deposits, closeness of seismic zones, igneous volcanic areas. Besides, due to the funnelling effect, trench sediment deposits speed is faster and thickness is greater than abyssal basins.
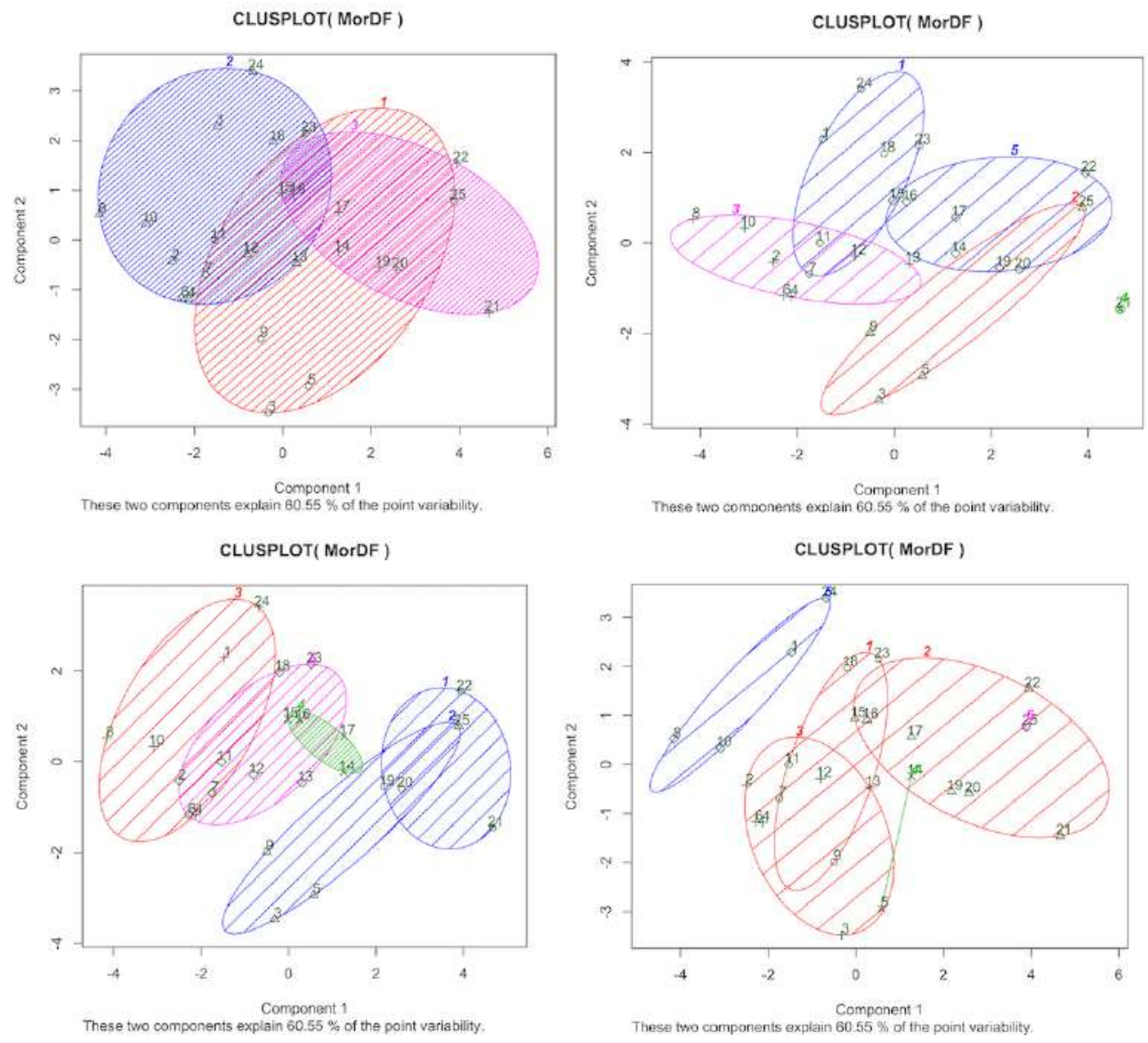

Figure 4.17.4: Mariana Trench. Correlation, k-means Clustering and Data Grouping, R [422]

Correlation and k-means clustering $k$-means algorithm shows groups across all profiles, with the number of groups represented by variable. Several clusters were tested (2 to 7 (Fig. 4.17.5), optical number is 5: cluster circle contained the number of samples and overlapping was minimal (Fig 4.17.5). Correlation matrix is presented on Fig. 16 ([422]) showing crossing in the combination of factors. Comparison of the bi-factor shows pairwise correlation (Fig. 17, [422]). Comparative analysis (Fig. 4.17.5) enabled to observe a marked influence on variables as bi-factors. In response to the decreasing sediment thickness the slope ${ }^{\circ}$ goes in parallel; location of the volcanic igneous areas cause a cyclic repetition of the curve for the slope ${ }^{\circ}$. Igneous volcanic areas have correlation with the slope ${ }^{\circ}$ and aspect ${ }^{\circ}$. Variable factors have distinct effect on the trench geomorphology: slope angle, tectonic plates, sediment thickness, aspect $^{\circ}$ and volcanic igneous areas, geographic location.

Data partition and ranking Analysis of the angle steepness of the cross-section profiles along the trench revealed (Fig. 3.8.13) that cross-section profiles form cluster groups with similar geomorphic 
properties divided into 5 groups. $1^{\text {st }}$ group: profiles $21,22,18$ and 20 , 'strong slope' $\operatorname{tg}^{\circ}$, ca. $0.05 .2^{\text {nd }}$ group: profiles: $15,19,16,17,14,2$, class 'very strong slope', $\operatorname{tg}^{\circ}$ angle of 0.057 to $0.058 .3^{\text {rd }}$ group, 'extreme slope', profiles: $1,11,4,5,10$ and 13 , the average slope $\operatorname{tg}^{\circ}, 0.060-0.070 .4^{\text {th }}$ group, 'steep slope', profiles: $25,12,6,8,3$, slope $\operatorname{tg}^{\circ}, 0.070-0.075$. $5^{\text {th }}$ group, highest steepness, profiles: 9,7 , 23,24 , with average slope $\operatorname{tg}^{\circ}$ up to 0.079 . Although steepness is related to the slab subduction in this particular area, the nature of the slope expansion may be associated with other factors, e.g. topography, volcanism and location. The data grouping has been created using libraries \{tidyverse\} and \{ggsignif\} for reordering and normalization of the steepness angle (Fig. 3.8.13). Additional Chinese fonts (Fig. 4.17.5) were activated through libraries $\{$ extrafont $\}$ and $\{$ extrafontdb $\}$

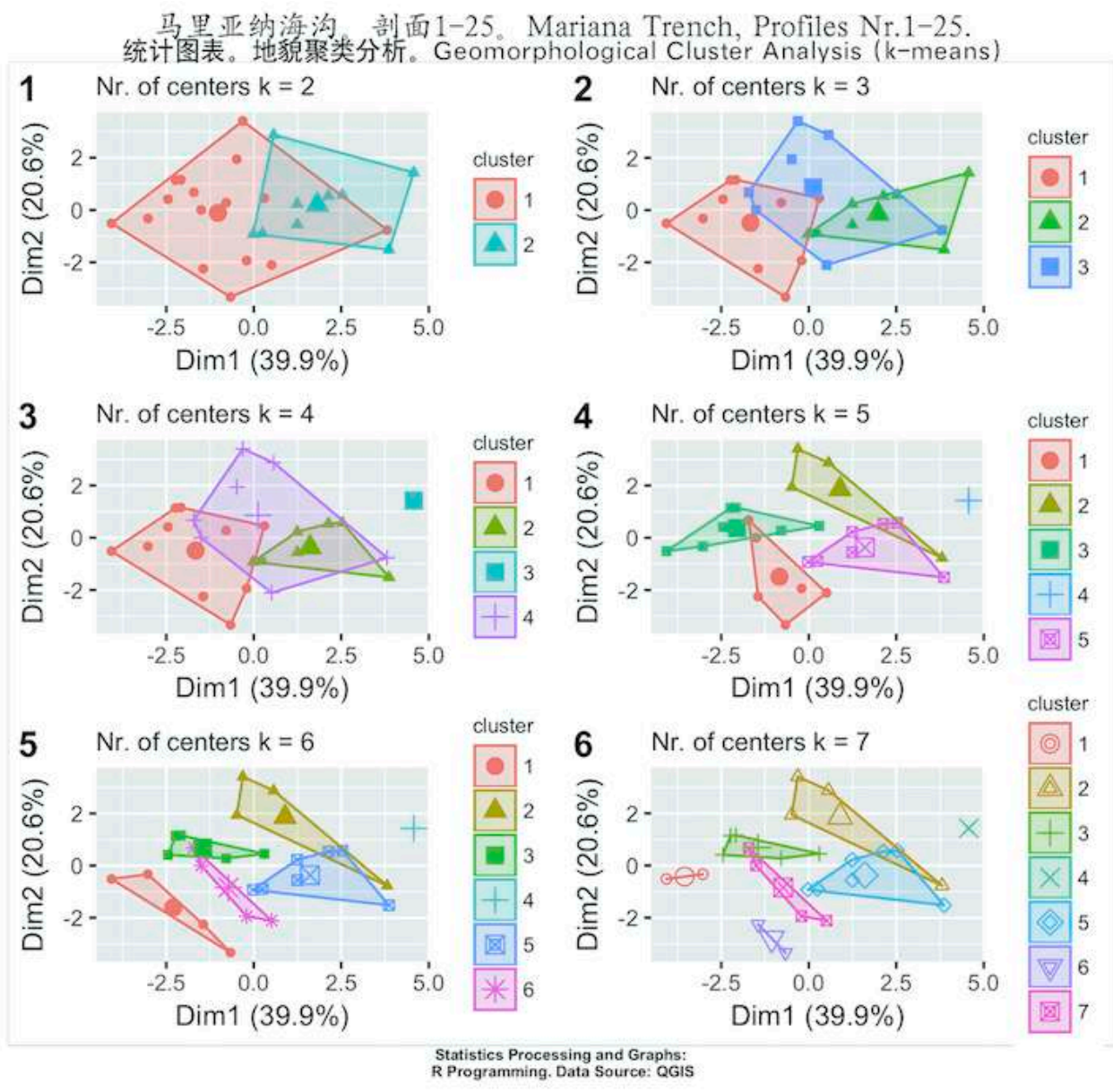

Figure 4.17.5: Results of the $k$-means clustering of the Mariana Trench with different $k$-values, R [422]

5 classes were grouped: strong slope, very strong slope, extreme slope, steep slope, very steep slope. They show trench steepness according to the results of the cluster analysis. General trend has a scope of 0.03 (ca. 0.05-0.08) of the profiles steepness. Re-classification of the slope ${ }^{\circ}$ across the trench and statistical normalization have crucial role in the analysis of the slope. Profiles nr. 23 and 24 have the highest slope steepness, located on the Philippine Plate. 2 large classes of the normalized degree angles were observed: $1^{\text {st }}$ below average ${ }^{\circ}$ (profiles nr. $\left.1,2,11,14-19,21-22\right)$ and $2^{\text {nd }}$ above average ${ }^{\circ}$ (all the rest). Steepness was shaped by the components of the igneous volcanic areas: profiles \# 20, 22, 23, 24 with notable amount of igneous volcanic observation points $(>180)$ correlate with steepness ${ }^{\circ} .5$ classes of the slope steepness are selected due to the changed geomorphic properties. Circular bar plots enabled 
to visualize depth distribution and slope angle values using R scripts, [422].

Kernel density curves Mariana Plate has the highest KDE of depth distribution values, followed by the Philippine Plate, then Pacific and Caroline, respectively. KDE shown in a combined plot enabling to compare the overlapping and maximal aptitude of the density curves for the profiles and depth distribution by tectonic plates. Major trend of the trench ${ }^{\circ}$ located on the Pacific Plate has downward general line trend. Philippine Plate has a minimal peak by profiles \#14-21 then moving upwards. The highest value for Caroline Plate has profile \#23, while maximal level for the Mariana Plate has profile \#7. Philippine Plate, has a minimal peak by profiles \#14-21 then moving upwards. The highest value for the Caroline Plate has profile \#23, while maximal level for Mariana Plate has profile \#7.

Composition charts (Fig. 3.8.7), show comparison of the slope ${ }^{\circ}$ by profiles. Basic concepts include interrelation of various factors (geological structure, bathymetric patters, tectonic plates location and subduction, spreading, transform fault, depths) affecting trench geomorphology [403]. Comparison of the properties of the oceanic crust and ophiolite sections, sediment thickness and depth across profiles enabled to make a better understanding of the ties among geospatial factors influencing trench geomorphology. Tectonic plates, geometry $\left(\operatorname{tg}^{\circ}\right)$, sediment thickness, geology (volcanic areas, earthquakes), tectonics play crucial role in the geomorphology of the trench. Other factors include slope steepness ${ }^{\circ}$, angle aspect, bathymetry (depth at basement), means, median and minimal values, geographic location. A hierarchical treemap of impact factors generated using R code: A.6.39 is presented by code [433].

Mariana Trench is important integral feature of active continental margins in west Pacific Ocean. Its mainland and oceanward slopes have complicated steps of various shapes and sizes, caused by active tectonic and sedimentation. The steepness of the trench slopes averages in $4-5^{\circ}$. Tectonic plates have more steep ${ }^{\circ}$ with average slopes of 10 to $15^{\circ}$, but their individual parts can be limited to steeper slopes as subjects to the gravitational flow system of the submarine canyons and valleys. Complex distribution of various geologic material on the adjacent abyssal plains contributes to the formation of the geomorphic features of the ocean bottom in the trench. Slope degree and amplitude contribute to sediment thickness, aspect ${ }^{\circ}$ has lesser effect.

Spatial variations in trench morphology Quantified similarities in data distribution were assessed by correlation matrices and cluster analysis. Large gradients in variability occur within and among $\mathrm{N}$ and $\mathrm{S}$ part of the trench and in the $\mathrm{E}$ curve of its shape directed towards transform lines near Magellan Seamounts and Marcus-Wake seamount. Geomorphology of the trench is dominated by following factors: closeness of the submarine volcanic areas, location of Philippine and Mariana tectonic plates, sediment thickness. Middle part of the trench (profiles: 14 up to 17), has very strong slopes, roughly equal proportions of sediment thickness. Variations in sediment thickness by profiles were defined as indirectly impacted from the changed slope ${ }^{\circ}$ that gives conditions for sediment accumulations. If a certain segment of the trench is located near the active volcanic area, sedimentation rates increase. Profiles $\mathrm{Nr}$. 1, 24, 25, 23 are notable for high sediment thickness on the Philippine Plate, profiles Nr. 2, 4, 6, 8 have the highest values for the Mariana Trench, profiles Nr. 3, 5, 8, 6 have the highest values of the sediment thickness for the Pacific Plate. Profiles located on the Caroline plate have the least values with only few samples. Five unique regions were compared, and impact factors affecting morphology analyzed by means of the statistical analysis. 


\subsection{Izu-Bonin Trench}

Cross-sectioned profiles are visualized as two segments of the IBT (Fig. 3.3.14). The results of the modelling demonstrated that southern segment of the trench is deeper and has more accurate V-form with a steeper gradient slope on both slopes (Fig. 4.18.1, B), [405]. Northern part of the trench (Fig. 4.18.1, A) has asymmetric shape of the slope with notable submarine terrace on the western part and more straight shape on the oceanward side (Fig. 4.18.1, A), [405].
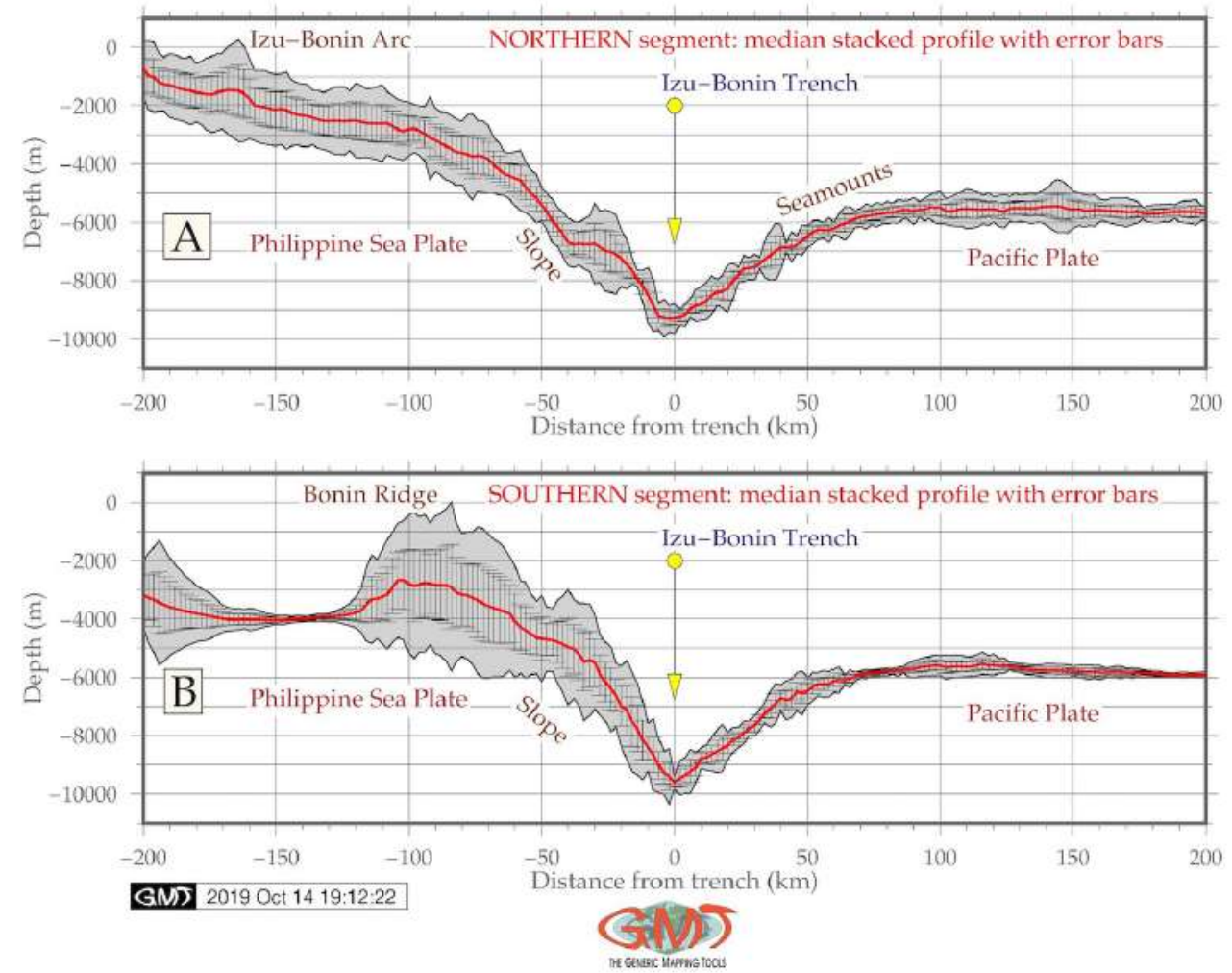

Map 4.18.1: Izu-Bonin Trench: modeled graph of the cross-section profiles in two segments

Furthermore, southern segment of the IBT has Bonin Ridge distinguishable on the graph. Comparison of the oceanward flank of the both segments of the IBT show similar geomorphic shape but seamounts on the northern part (Fig. 4.18.1). The 3D model of the Izu-Bonin shows (Fig. 4.18.2) seamounts (exaggerated for the better visual effects) on the eastern part of the model. IBT is colored as deep-purple color with a general profile view on the grey draping border.

Statistical analysis of the two segments shows (Fig. 4.18.3) following results. For the N segment (Fig. 4.18.3, A) that for the most illustrative range of depths (that is from $-5,000$ to $-6,000 \mathrm{~m}$ ), the $\mathrm{N}$ segments shows in total 1,037 recorded samples (304, 407, 248 and 78), while S segments shows (Fig. 4.18.3, B) shows in total 931 samples $(523,304,77$ and 27). Furthermore, the histogram for the S segment has clear bimodal distribution with two peaks: 523 samples taking $20 \%$ shows the most frequent depth values for the $\mathrm{S}$ segment that lie in the range of $-5,800$ to $-6,000 \mathrm{~m}$. The $2^{\text {nd }}$ peak takes almost $10 \%$ of the data pool correlating with the Bonin Ridge location, [405].

These are the data on the range from $-4,200$ to $-3,800 \mathrm{~m}$. For the $\mathrm{N}$ segment, the most repetitive samples (407 values, $13,5 \%$ ) are taken by the depths from $-5,600$ to $-5,800 \mathrm{~m}$, followed by depths in range $-5,800$ to $-6,000 \mathrm{~m}$ (304 samples with $10 \%)$. In the $\mathrm{N}$ segment, the data distribution has more samples located on the shallow areas (146 recorded observations) pointing at the Izu-Bonin Arc, while 
for the $\mathrm{S}$ segment there are no data recorded in this bathymetric range, [405]. That means that $\mathrm{S}$ segment has more V-shape trench cross-section profile which is notable on Fig. 4.18.1.

\section{Izu-Bonin Trench: 3D composite mesh model}

Overlay of the topographic 3D on top of the 2D geoid contour plot

Data: ETOPO 5 arc min grid, World Geoid Image 9.25 min grid

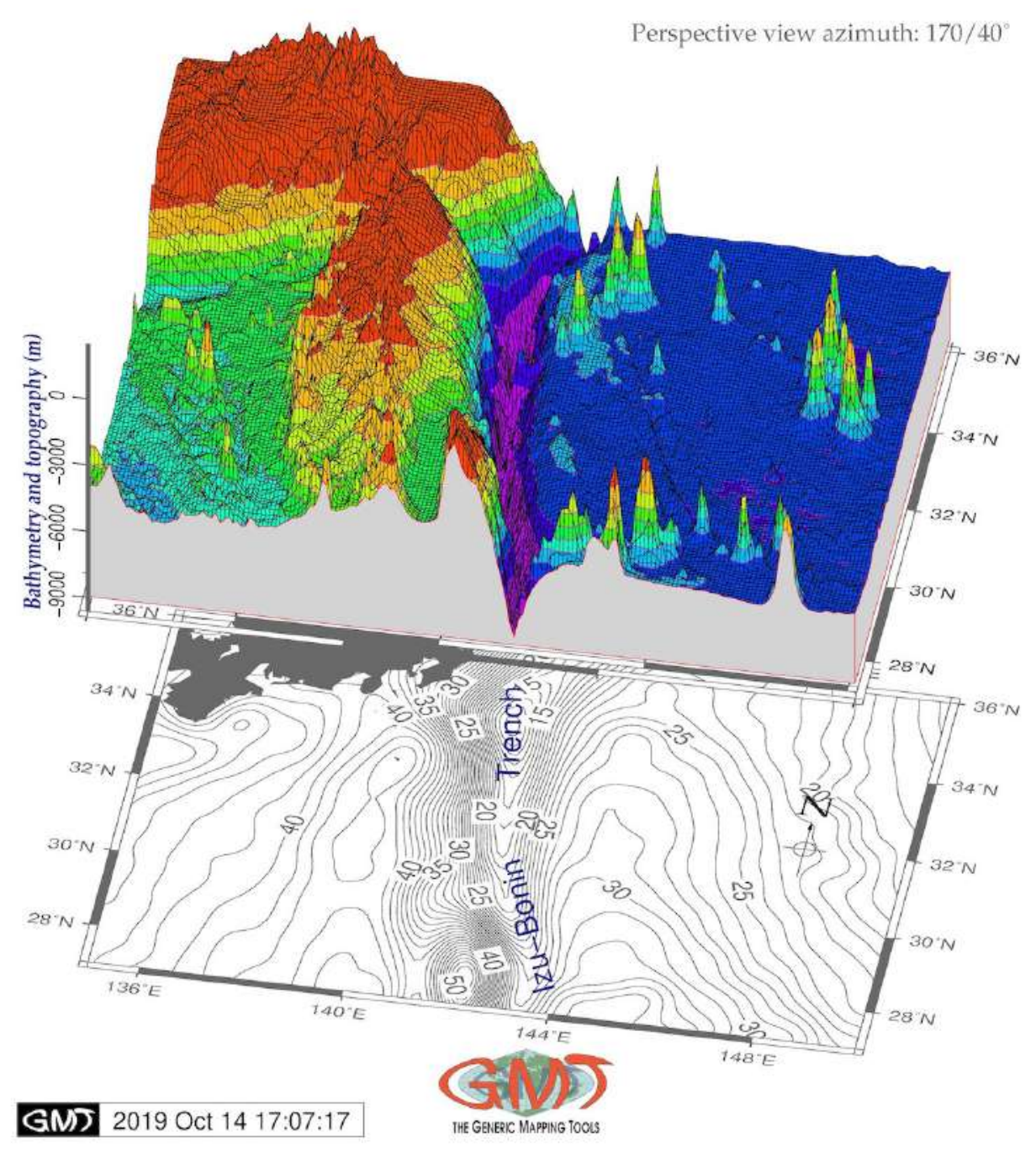

Map 4.18.2: Izu-Bonin Trench: 3D mesh model map

Before now, oceanic trenches were thought to have strongly restricted life activities, which is caused by the extreme conditions that delimit vertical constrains in distinct bathymetric strata and define distribution of organisms. High hydrostatic pressure, temperature, salinity, oxygen, scarcity of food, submarine volcanism, tectonic plate subduction, lack of UV are major factors limiting presence, functioning and location of the species in the trenches. Continued studies of the biology discovered new phenomena: the biomass and abundance of fauna increase with depth in some trenches, although their species richness decrease downward [122]. Vast microbial and faunal community structure, abundance, biodiversity, level of endemism and adaptation towards extreme condition in hadal species [504]; [505]. 


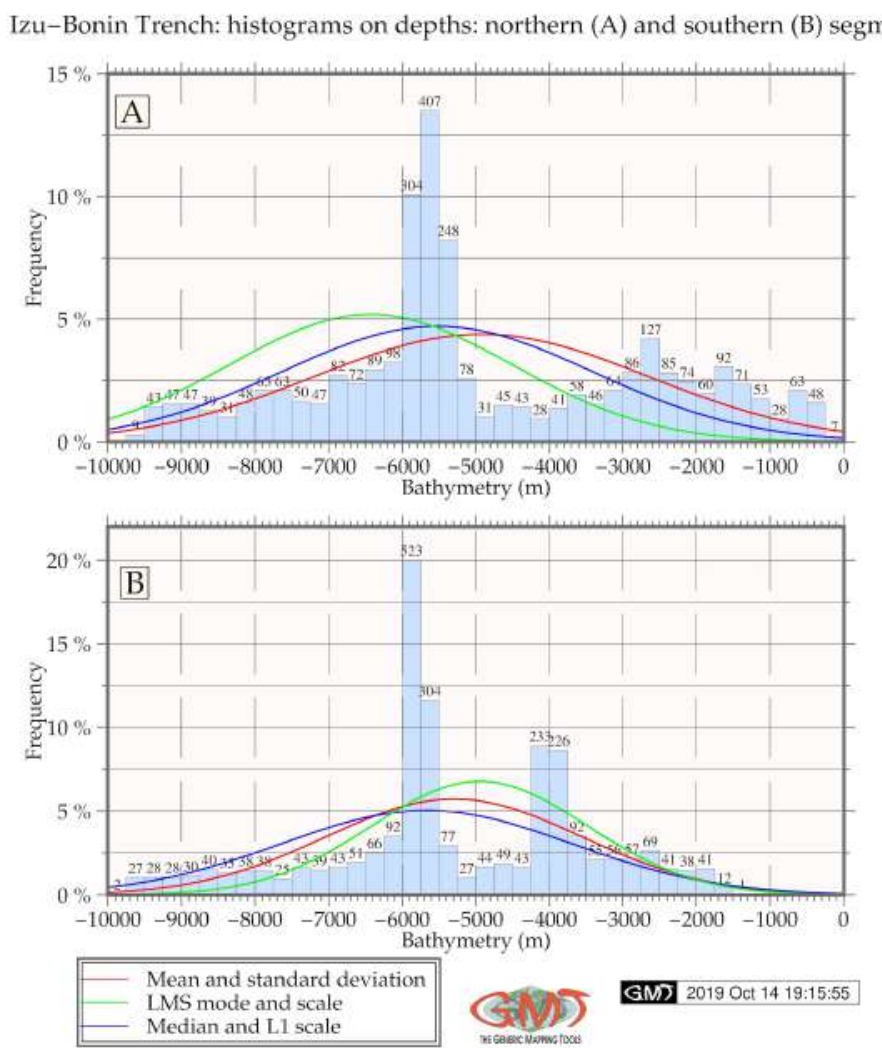

Map 4.18.3: Izu-Bonin Trench: statistical histograms of the depth frequency

Life exists in the ocean's hadal zones at extreme depths of the Pacific Ocean, [223], [227]; [238]; [284]; [336]; [694]; [736]. The existence of the organisms at such depths strongly depends on the turbulence of the streams and motion of the submarine currents. Specific processes characteristic for the deep hadal communities were reported by [353] with a case study of Dermacoccus abyssi isolated from the deepest areas of the oceans for dye decolorization. Species are strongly influenced by oceanographic properties and geomorphic structure of the trench [636]. High sedimentation rates and biomass, intense microbial activity and chemosynthetic communities play crucial role in biogeochemical cycles of the trenches. Therefore, deep-sea biosphere deserves a special attention since this is a specific area of trenches where life conditions are created [510]; [361]; [303].

Deep-sea ecosystems arises interest due to their potential to serve a various range of the industrial needs [669]. Pressure within the trench increases by $1 \mathrm{MPa}$ per $100 \mathrm{~m}$, reaching $100 \mathrm{MPa}$ in the deepest places [754]. Discovered new species of the deep-sea are Spongicoloides and Corbitella [336]. Life at such depths requires supply of nutrients in form of chemical species, transported by the bottom water through the deep currents ventilating trenches and upbringing nutrients. It was discovered [712] that microbe communities play certain role in global carbon sequestration and carbon cycle of the trench. 


\subsection{Japan Trench}

Since fundamental bathymetric variable is the depth, or elevation records BSL geomorphic analysis of the GEBCO datasets in the form of DEMs, was performed for computation, comparison and descriptive statistical analysis of the two segments of the JT [396]. Hence, the comparative analysis of the two parts of the a series of cross-section profiles (Fig. 4.19.1) revealed more steep slope on the northern part of the trench on the continental slope part beneath the frontal wedge of the North American tectonic plate.
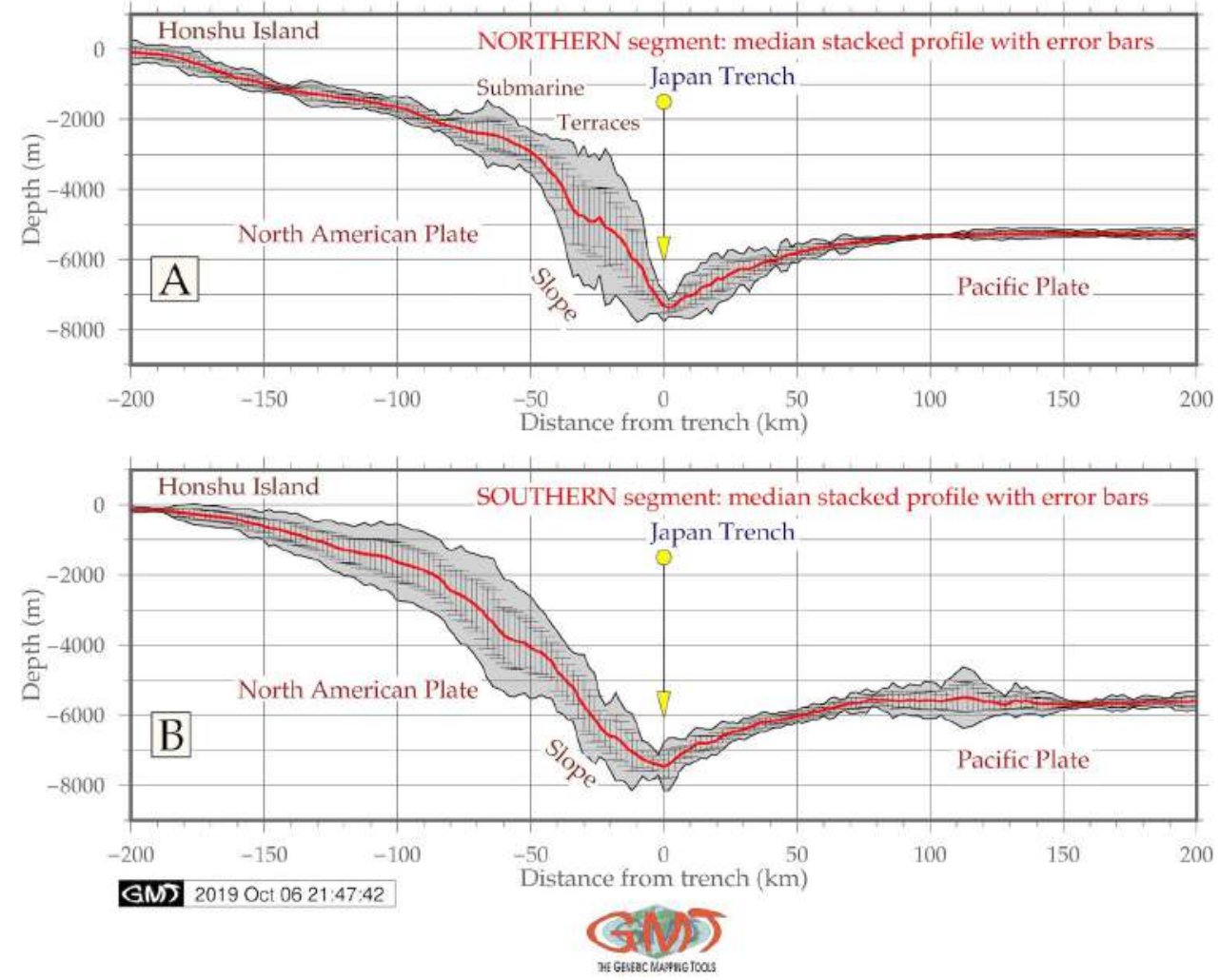

Figure 4.19.1: Japan Trench: modeling geomorphic cross-section profiles

Southern part of the JT shows more gentle slope on the Honshu Island. The location of the swath profiles traversing the two segment of the JT South-West to North-East direction is shown in Fig. 4.19.1. 12 profiles were drawn for the southern segment and 14 profiles for the northern one. Highly rugged geomorphological structure of the median profiles, and altitude increase in the S-N direction can be seen on the northern part of the JT (Fig. 4.19.1). The results were interpreted based on the hypothesis that geological settings and seismicity of the area impact the trench roughness and general geomorphic shape when studying bathymetric patterns and variations by the cross-sectioning profiles of JT, which is shown on the geological map (Fig. 2.18.2) with high level of the seismicity, repetitive earthquakes and volcanism along the path of the trench. Consequently, W part of the trench (Honshu Island slope) has steeper slopes comparing to the oceanward slopes for both segments, which can also be seen on the 3D model shown on Fig. 2.18.5 [396].

The statistical analysis of the most frequent bathymetric value for the northern part of the JT (Fig. 4.19.2, A) shows a range of -5300 - to $-5500 \mathrm{~m}$ (683 samples recorded). As for the southern part, the most frequent depths lie within interval of -5500 to -5800 meter (531 samples detected, Fig. 4.19.2, B). Furthermore, comparing the deepest values of the bathymetry, one can notice the southern part to be slightly deeper: the deepest records up to $-8000 \mathrm{~m}$ (8 samples are recorded) [396]. 


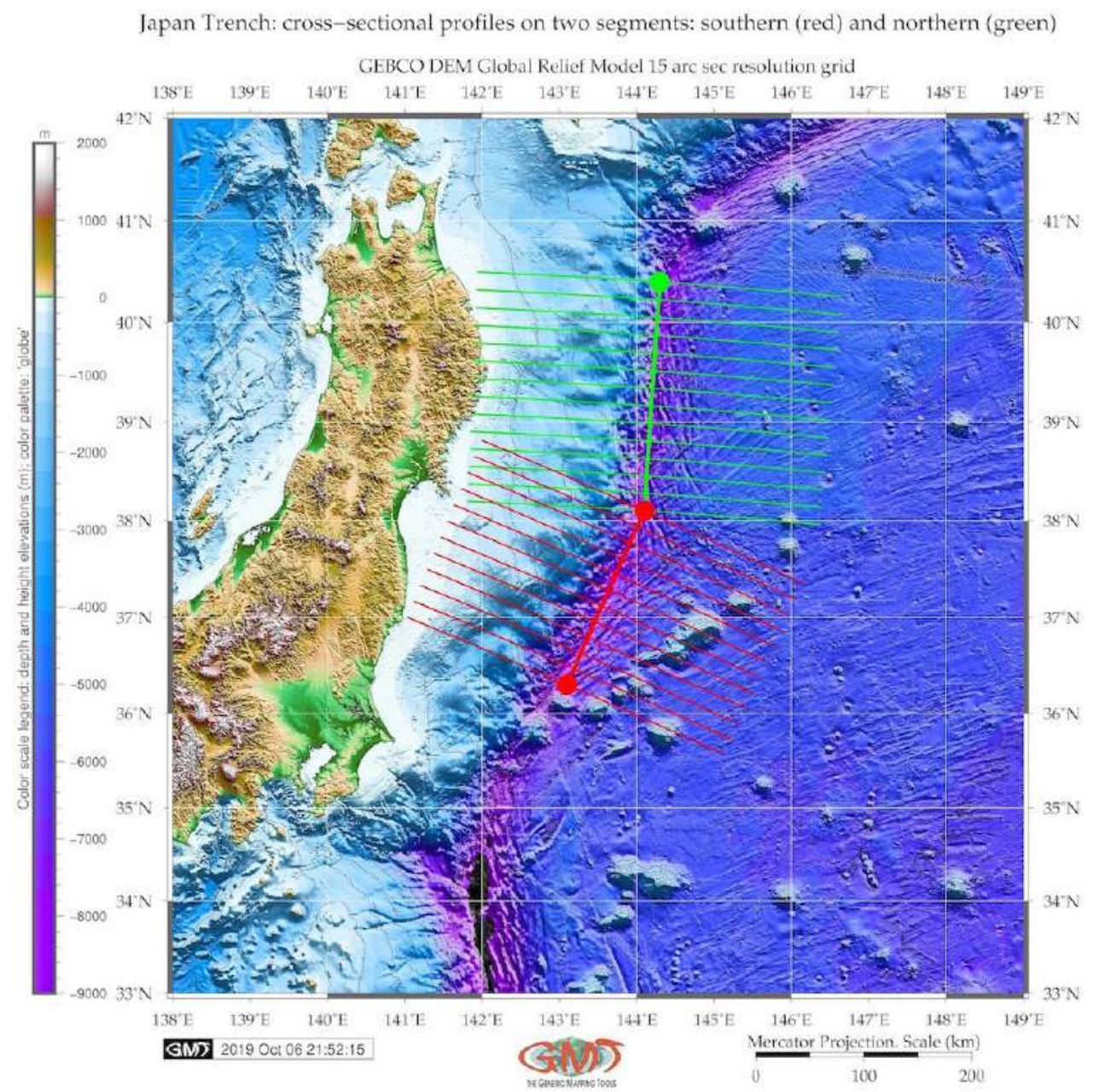

Map 4.19.1: Japan Trench: map of the cross-sectional profiles along two segments

In total, 139 samples $(8+29+42+59)$ are located on the depths from -7000 to $-8000 \mathrm{~m}$ in the $\mathrm{S}$ part of the trench (Fig. 4.19.2 B, left part of the graph). In the $\mathrm{N}$ part of the trench, the same depth range has 124 records (12, 59 and 53 in the deepest part of the profile, Fig. 4.19.2 A, left part of the graph). Furthermore, the values located on the depths from -4000 to -5000 meter are more frequent for the $\mathrm{S}$ part of the trench: 134 records in total $(35+33+37+29$ samples, Fig. $4.19 .2, \mathrm{~B})$, while $\mathrm{N}$ part of the trench do not overstep 100: 91 records $(21+23+21+26$ records, Fig. 4.19.2, A). To sum up, the S part is shallower than $\mathrm{N}$ part of the trench. It shows more deep values and the most frequent value is deeper that by the $\mathrm{N}$ segment (Fig. 4.19.2) [396]. 

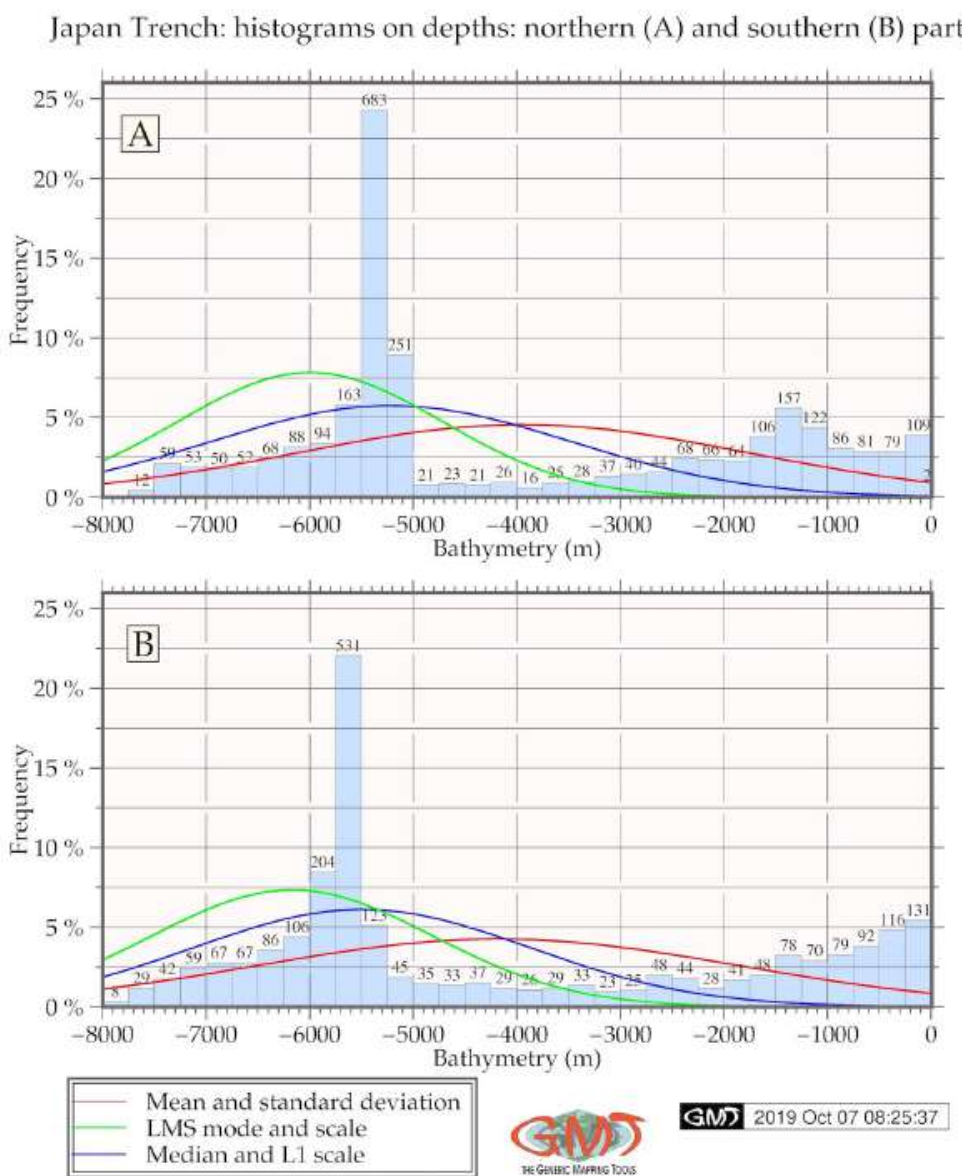

Figure 4.19.2: Japan Trench: statistical analysis of the data distribution (histograms)

Geophysical investigation of the presented modeling of geoid (a mean sea level model) and free-air gravity anomalies reflect the density variations of the Earth in the area across the JT and surroundings (Fig. 2.18.3 and 2.18.4). The recorded area of the JT has geoid values of 0-20 mGal (Fig. 2.18.3), [396] as can be clearly seen as a light green color with dense isolines. The highest values on the geoid elevations is recorded by the Honshu Island (above $40 \mathrm{mGal}$, shown as red color on the map). The rest of the area is covered by the values in the range of $20-40 \mathrm{mGal}$ [396], which shows moderate geoid undulations.

Gravity map (Fig. 2.18.4) shows density variations of the Earths interior in the study area. Free-air model shows gravity reduction from the topographic surface to the geoid in the study area. Map of freeair gravity anomalies (Fig. 2.18.4) is defined with respect to the elevation showing values below -30 $\mathrm{mGal}$ in the JT area (visualized by deep purple color on the map). The marine areas of the Sea of Japan and the Pacific Ocean have values of up to $40 \mathrm{mGal}$ of elevations. Certain areas on the Japan Islands (Honshu and Hokkaido) reach above $100 \mathrm{mGal}$ (red color on the map) [396] showing high values in concern to gravity. 


\subsection{Puysegur Trench}

PsT (Fig. 4.21.1, B: middle plot) has asymmetric V-form with steep gradient on the E slopes and more gentle slope on the W. Hjort Trench has a classic symmetric shape form with comparative gradients on both $\mathrm{W}$ and $\mathrm{E}$ slopes (Fig. 4.21.1, C, lower plot). The results of the comparison of the median values (red line on Fig. 4.21.1 for all the three sub-plots) of three trenches show that selected segment of the HT has shallower depths with maximal not exceeding - 2,500 m (Fig. 4.21.1, A), while PsT is reaching up to $-6,000$ m (Fig. 4.21.1, B).

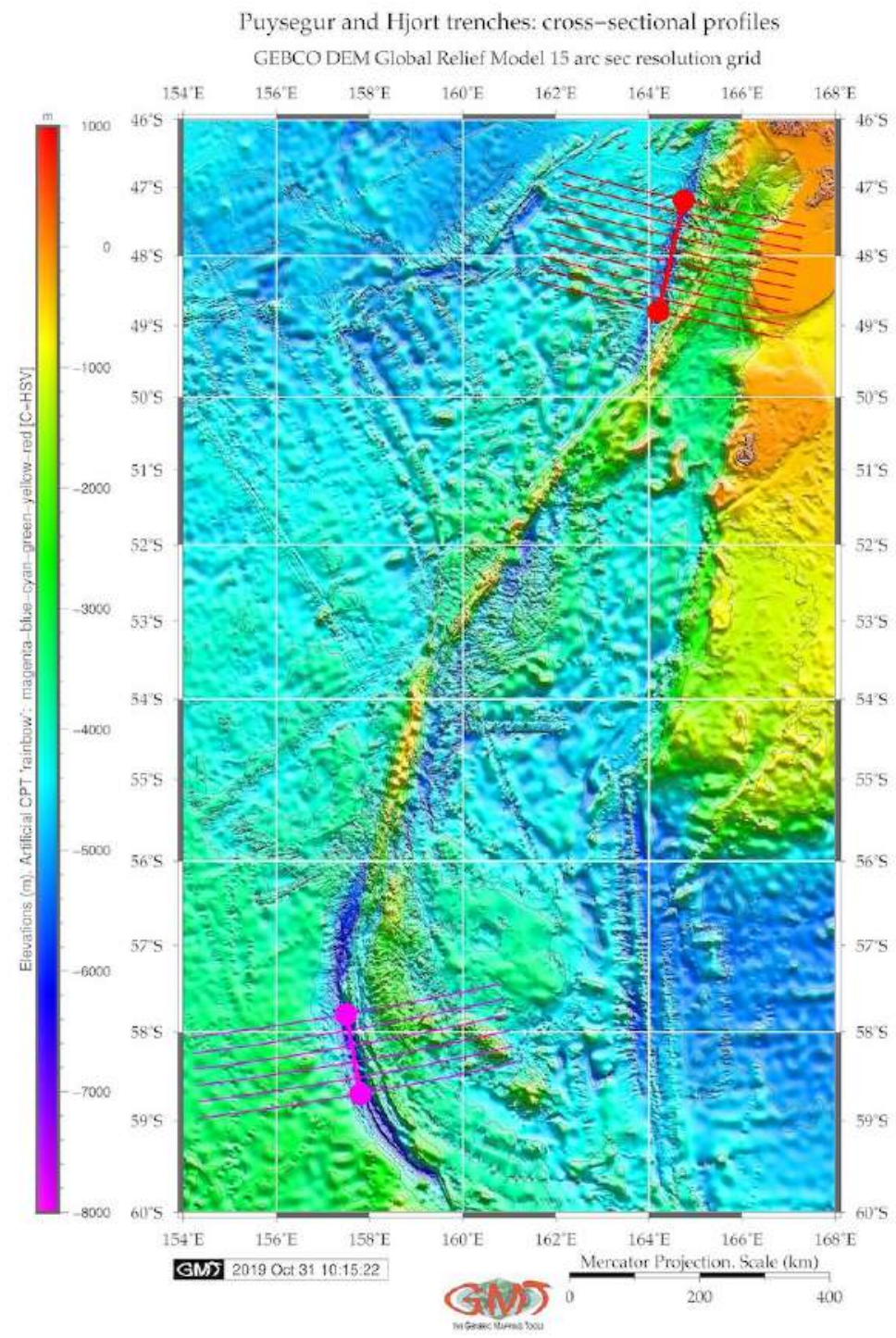

Map 4.20.1: Puysegur and Hjort trenches, Macquarie Island Arc: Digitizing cross-section profiles

The surrounding relief of the Hjort Trench presents the most uneven terrain comparing to the other trenches with the deepest values $>6,000 \mathrm{~m}$ (Fig. 4.21.1, C). The neighboring terrain has a gentle slope on the oceanward side for HT and a steep slope on the E flank for PsT, surrounded by complex submarine relief along the Macquarie Arc (Fig. 2.20.1). PsT (Fig. 4.20.1, A) has a bimodal type of data distribution with two peaks. The first peak has three notable bins range $-4,200$ to $-4,400 \mathrm{~m}$ (373 samples detected, data frequency $18 \%$ ), range $-4,000$ to $-4,200$ (182 samples, data frequency 9,6\%) and $-4,400 \mathrm{~m}$ to $-4,600$ 
$\mathrm{m}$ (216 samples, data frequency 11,5\%). The second peak covers depths from $-2,200$ to $-3,000 \mathrm{~m}$ with the data frequency below 7,5\%. The peak corresponds to the Macquarie Arc bordering the trench slope.

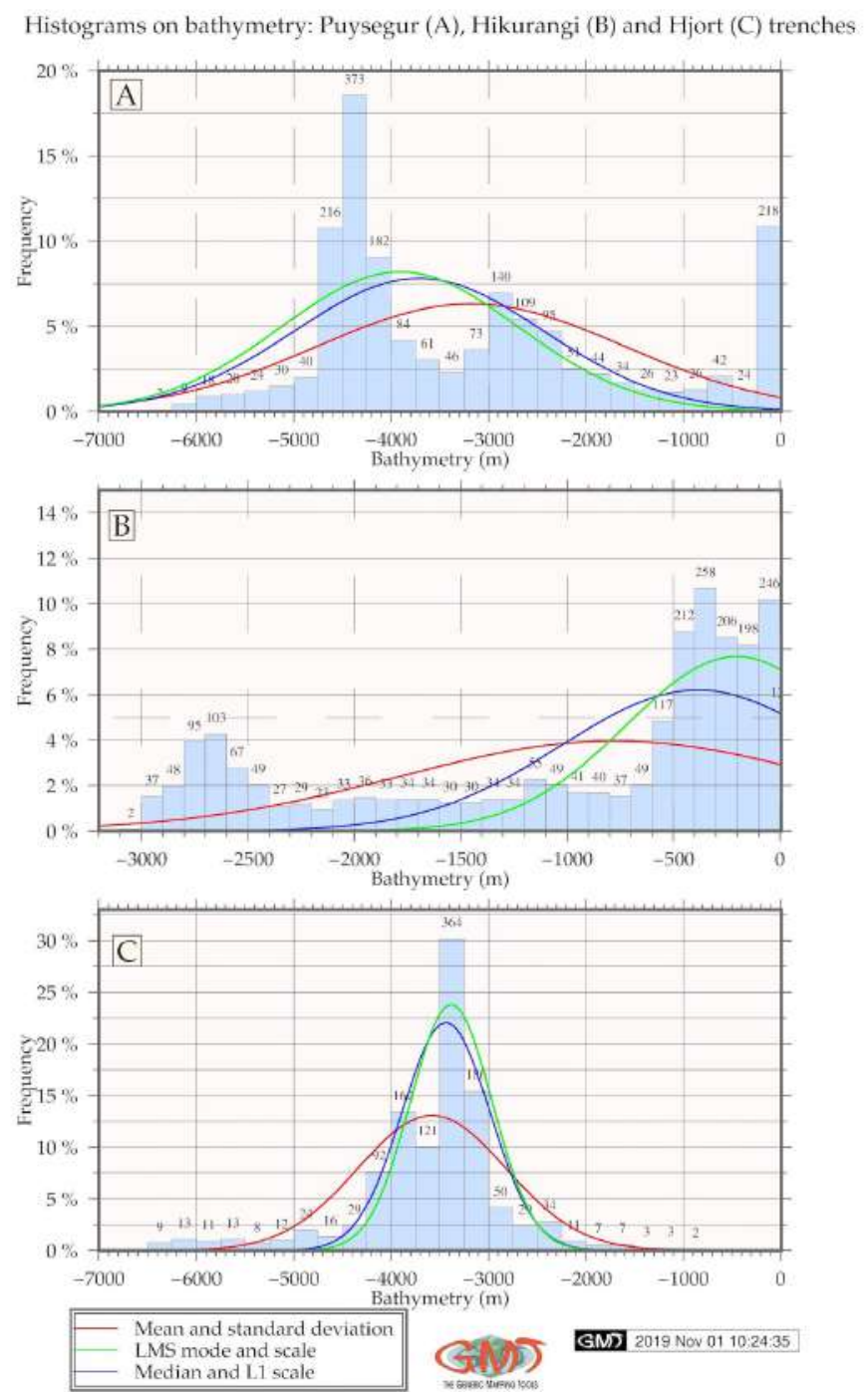

Figure 4.20.1: Comparative analysis on data distribution by Hikurangi, Puysegur and Hjort trenches

Hjort Trench (Fig. 4.20.1, C) has a classic bell-shape form with a clear peak of data at depths $-3,200$ to $-3,400 \mathrm{~m}$. (364 samples, $30 \%$ of data frequency). The abrupt decrease in sample values off both flanks corresponds to the steep slope of the trench W off Hjort Plateu. Spreading fabrics are eastwards off PsT, with minor ridges (Fig. 2.19.2). This geomorphology is particularly well expressed along Macquarie Arc, between $51,5^{\circ}$ and $54^{\circ}$ with ridges formed due to the sedimentation processes. The ridges resembling elongated seamounts are on the NW side off PsT interspersed with minor troughs (Fig. 2.19.2). The average depth of the seafloor deepens abruptly (Fig. 4.21.1, A) from -5,400 (216 samples) to the $-6,200$ m (9 samples). Data distribution has a clear bimodal way for PsT with peaks at ranges $-4,200$ to $-4,400$ (373 samples) and at $-3,200$ to $-3,000 \mathrm{~m}$ (140 samples). The histogram for Hjort Trench has a classic bell-shape form with one peak in data distribution at range $-3,300$ to $-3,500 \mathrm{~m}$ (364 samples), Fig. 4.21.1, C. 


\subsection{Hikurangi Trench}

HT proved to have more trough-like shape form in its cross-section, while PsT and Hjort trenches have classic V-form.

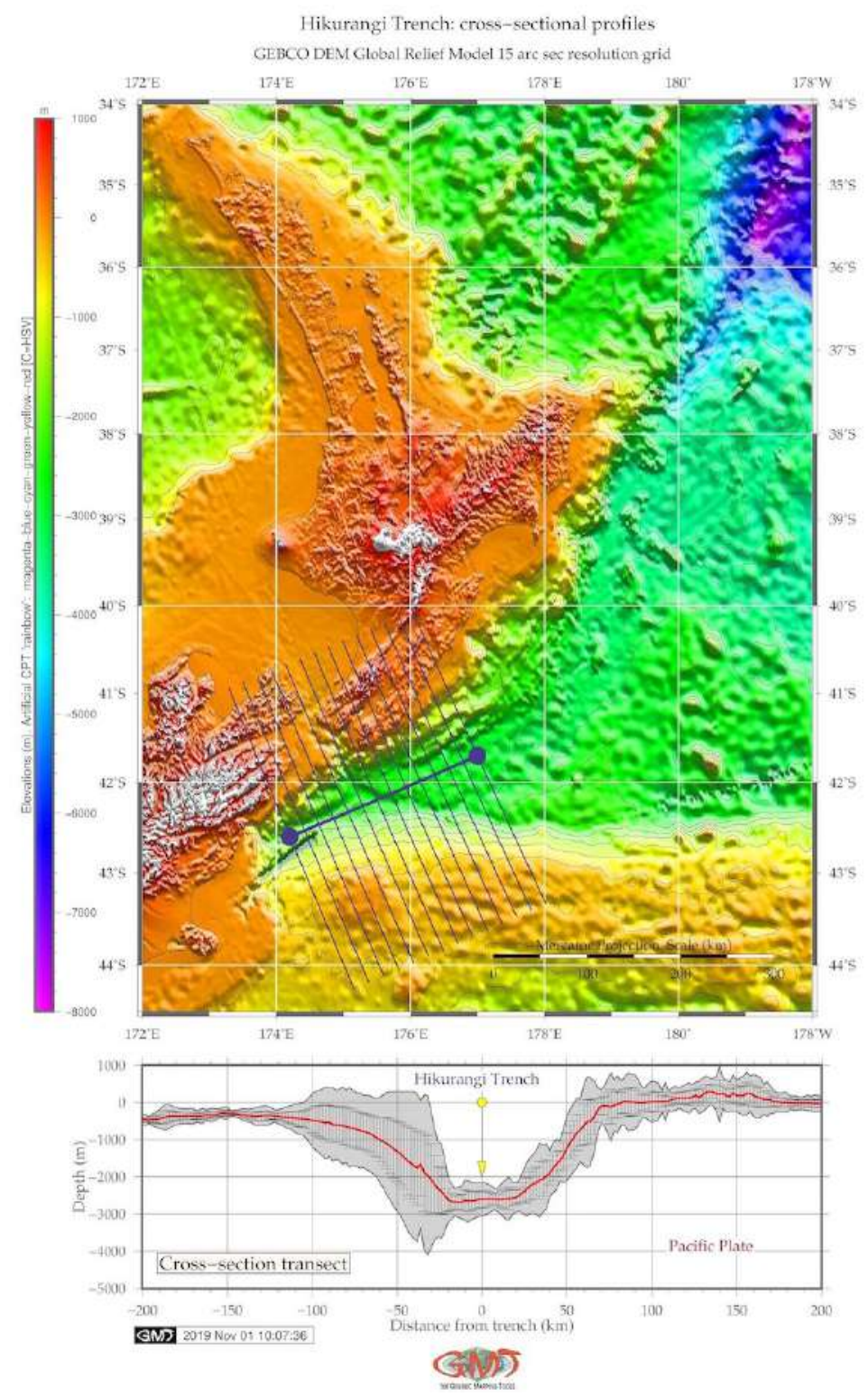

Map 4.21.1: Hikurangi Trench, North Island, New Zealand: Digitizing cross-section profiles

Whilst it serves as a terrain variable in this study to examine the geomorphic landform, variation of the geomorphic slopes were compared for the trenches and following findings noted: HT has a trough-like flat wide bottom, steeper gradient slope on the North Island flank (Fig. 4.21.1, A) [387]. The statistical histograms for the transecting profiles of the Hikurangi, Puysegur and Hjort trenches are visualized on Fig. 4.20.1. The evaluation of the descriptive statistics on bathymetry in three trenches and interpolation approaches shows following results. The shape of the histogram varies by all the three trenches reflecting their geomorphology.

Data distribution for the HT (Fig. 4.20.1, B) demonstrates almost equal pattern for depths $-600 \mathrm{~m}$ to 
$-2,600 \mathrm{~m}$ with samples $<60$ for each bin (most data are detected at ca. 30-40 samples for a bin, not exceeding 4\%). One can clearly see a rising increase of data with depths below 500, that is a slope of the North Island (frequency from 5\% to 12\%) [387]. Geomorphic curvature and distribution of the seamounts near the Puysegur, Hjort and HTes reflect the interplay between the complex tectonic processes occurring at a subducting tectonic plates and variations in the tension between the spreading ridges and the transform faults [403]. In the northwest region off PsT, GEBCO swath bathymetric data (Figures 3.3.8 and 2.19.2) enable to see rather complex submarine relief: linearly expressed ridge geomorphology, a series of small elongated seamounts, minor troughs and flat areas of the seabed.
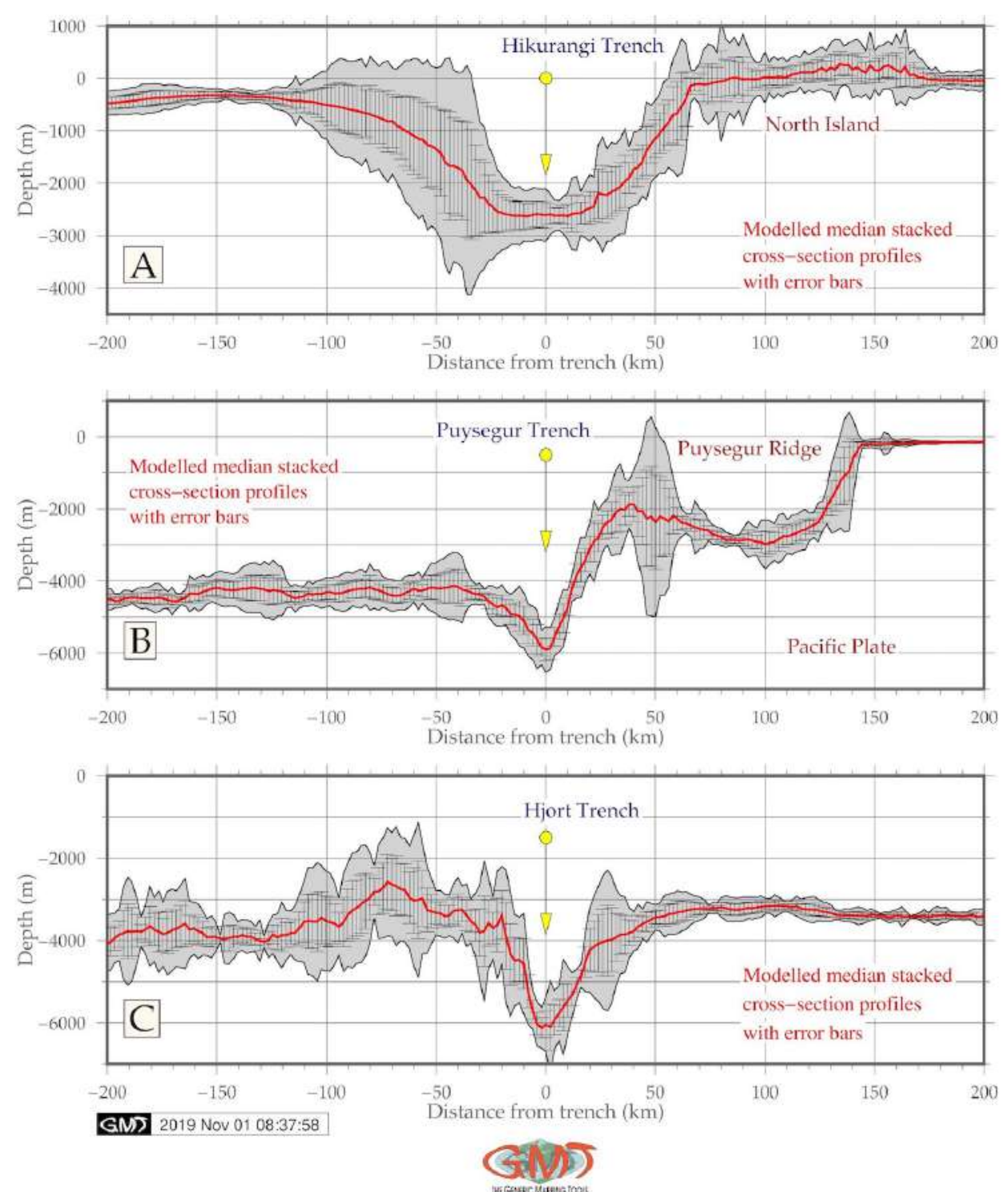

Figure 4.21.1: Geomorphic cross-sections by Hikurangi, Puysegur and Hjort trenches

Data distribution for HT (Fig. 4.21.1, B), the bathymetry has more equalized patterns at the depths $-2,500$ to $-600 \mathrm{~m}$. Notable peak have data located on the shallow areas (shallower than $-500 \mathrm{~m}$ ) where maximal values are detected for the range -400 to $-300 \mathrm{~m}$ (258 samples) [387]. Generally, a strong correlation of the trenchs axes with borders of the three lithospheric tectonic plates (Antarctic Plate, Pacific Plate and Info-Australian Plate) can be noted, which underpins strong correlation of the trench 
geomorphology with direction of the tectonic slab lineaments, as plate movements, geologic lineaments and extend of the fracture zones in the final end lead to the formation of the trench axis through the plates motions. Local geologic settings, linear extension of the tectonic slabs, complex tectonic processes and sedimentation of the HT, PsT and Hjort trenches might explain variations in their geomorphic structure and shape of the submarine landforms.

Comparative analysis of the geophysical settings among the three oceanic trenches revealed their structural characteristics and adjacent oceanic crust of the southern Antarctic region. Visualized gravity and geologic settings add new information to the interpretation of the data covering active convergent margins and in particular, a zone of Macquarie Triple Junction in Southwest Pacific Ocean, Antarctic. HT presented unique characteristics of the seafloor as trough-shaped form. By recognizing geomorphic shape and geologic settings at the seafloor, distinctly different from Puysegur and Hjort Trenches, a gradual decrease of depths along the slope of the North Island was observed. Targeted seafloor mapping in crosssections highlighted active seafloor processes that created unique geomorphic for the three trenches.

Comparative analysis of the submarine geomorphology of the HT (HkT), PsT and Hjort Trench (HT), located off New Zealand coasts, SW Pacific Ocean shows following findings. PsT stretching from the South Island to the Macquarie Triple Junction, Macquarie Fault Zone. HkT continues PsT southwards from the Macquarie Island and characterized by frontal subduction erosion, numerous seamounts, extensional upper plate. HjT is characterized by an oblique subduction zone [387]. Unique tectonic setting of this region consist in two subduction zones: northern (Hikurangi margin) and southern (Puysegur margin), connected by oblique continental collision along the Alpine Fault of South Island. This cause variations in the submarine geomorphic structure of the trenches. PsT/HjT subduction is highly oblique (dextral) and directed southwards. Hikurangi subduction is directed northwestwards. South Island is caught in between by the 'subduction scissor'.

Comparative histogram equalization of topographic grids (equalized, normalized, quadratic) was done by module grdhisteq. Automated cross-sectioning was done using grdtrack module. $\mathrm{HjT}$ has a classic symmetric shape form with comparative gradients on both $\mathrm{W}$ and $\mathrm{E}$ slopes, trough-like flat wide bottom, steeper gradient slope on the North Island flank. PsT has an asymmetric V-form with steep gradient on the eastern slopes and more gentle slope on the west. The comparison of the medians of the trenches show that selected segment of the HkT has shallower depths with maximal $<-2,500 \mathrm{~m}$, whilst PsT is reaching up to $-6,000 \mathrm{~m}$. The deepest values $>6,000 \mathrm{~m}$ for $\mathrm{HjT}$ with the steepest slope gradient comparing to Hikurangi and Puysegur trenches.

Neighboring terrain has a gentle slope on the oceanward side for HkT, and a steep slope on the eastern flank for PsT. Data distribution for the HkT demonstrates almost equal pattern for the depths from - $600 \mathrm{~m}$ to $-2,600 \mathrm{~m}$ with samples $<60$ for each sample bin. PsT has a bimodal type of data distribution with two peaks. The $1^{\text {st }}$ peak has 3 notable bins range $-4,200$ to $-4,400 \mathrm{~m}$ (373 samples, frequency $18 \%$ ), range 4,000 to $-4,200$. The $2^{\text {nd }}$ peak covers depths $-2,200$ to $-3,000 \mathrm{~m}$, frequency $<7,5 \%$. The peak corresponds to the Macquarie Arc bordering trench slope. A phenomenon of the tectonic plates subduction explains the asymmetry of the trenches. Geomorphic shape and structure of HkT, PsT and HjT are affected by geologic processes and factors and vary, as demonstrated on the presented modeled profiles.

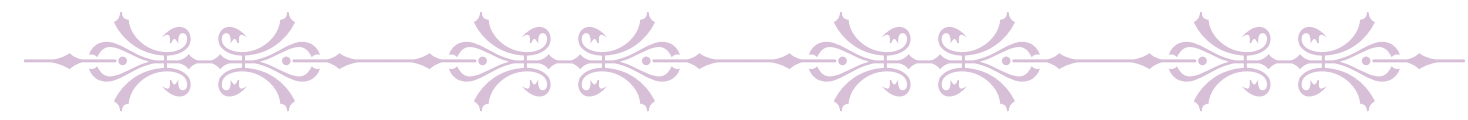




\section{Chapter 5}

\section{Discussion}

\subsection{Novelty}

$\mathrm{P}$ RECISE modelling of the deep ocean trenches has not been proposed in the existing literature. Some attempts are given [601]; [748] to aimed mostly at the environmental ocean monitoring. Modelling trenches still remains a challenging task in marine geology. In view of this, advanced methods of data analysis, modelling and precise computing by combinations of GMT, R and Python for processing geological datasets as numerical arrays are novel approaches demonstrated in this dissertation. Hence, there are both theoretical and practical innovations of the research presented in this dissertation.

- Theoretical novelty lies in the classification, systematic mapping and comparative spatial analysis, geomorphological transect modelling of the 20 deep-sea trenches of the Pacific Ocean that does not exists in the available literature. Multi-source data analysis was applied for submarine geomorphology, to study variations in the types of the submarine landforms. A combination of the geophysical visualization, geological analysis and GMT-based mapping of the 20 deep-sea trenches along the Pacific Ocean margins does not present in the existing works so far.

- Practical novelty consists in the developed and tested methodology of the cross-disciplinary approach that includes a sequence of the GMT and IT tools (programming languages Python, R, Matlab, AWK) for data processing and complex statistical analysis based on the embedded mathematical algorithms.

- Technical novelty consists in the presented novel methodology of modelling geomorphology of the trenches. Developed and presented in this dissertation, the algorithms is based on GMT. It considers three principal variables: length of the transect segment, distance between the samples and density of sampling. Variables were selected for script, shaped current cross-section shapes of the landforms and defined curvatures of the modeled transects. Visualized graphs are based on numerical model through systematic digitizing of the profiles for each trench.

It should be stressed that a GMT shell scripting based mapping was applied for geospatial modelling and cartographic mapping, instead of the traditional GIS (e.g. Idrisi GIS [435], [473]; ENVI GIS [436], [479]; ILWIS GIS [445], [474], [481], [483]; eCognition [475]; OBIA technique of image processing [446]; ArcGIS [437], [326], [438], [439]; Erdas Imagie [482]). R and Python statistical libraries were used instead of Excel software often used in marine research [440], [380]. Tested, presented and explained functionality of a variety of GMT modules enabled to perform automated digitizing of the orthogonal profiles crossing 20 trenches in the perpendicular direction. Through modelling, landform shapes and steepness were visualized, compared and statistically analyzed as a basis for classification. 


\subsection{Actuality}

$\mathrm{M}$

ODELLING deep-sea trench is one of the most complicated issues in the marine geology: in contrast with the terrestrial ones, submarine regions still remain the least accessible areas on the Earth. Hence, oceanic trenches can only be studied by computer based modelling, RS methods, advanced mapping and sophisticated algorithms of data analysis. Therefore, using special tools of advanced spatial analysis, processing and modeling using advanced cartographic solutions enables to get closer insight into the deepest regions of the ocean visualizing areas with the most difficult access [78].

Understanding geomorphology, structure and shape of the submarine landforms in deep-sea trenches is crucial to modelling their geophysical and geological phenomena as the deepest places on the Earth. Numerical analysis of such complex structures based on the advanced data analysis and shell scripting significantly increases the precision and speed of data processing, as well as results reliability. It helps to improve investigations of the marine geology and submarine geomorphology of the oceans, as current understanding of tectonic, geological and oceanographic patterns and processes is largely based on the correct modelling. ML algorithms and automatization improves the precision and quality of mapping. GMT, largely used in this thesis, provides advanced cartographic solutions enabling to model, analyze, map, visualize and calculate the phenomena of the submarine geology.

Therefore, the actuality of the presented dissertation consist in the classification of the 20 deep-sea trenches, systematic mapping and geomorphological transect modelling. General conceptual idea of the presented dissertation can be extrapolated to other objects of ocean topography. Current dissertation contributed both towards marine geological studies and towards technical demonstration of the advanced data analysis by GMT shell scripting and programming languages Python and R.

Big data taken from the cruise observations and measurements in in-situ conditions are common in marine geology. Datasets derived from the R/V cruises have specifically large volumes of sampling. Together with their variety and different types (lithology and rocks of the seafloor, geological structure, tectonics, etc.) it arises a question of their effective processing. Algorithms of data processing by GMT, reshaping tables in AWK, and statistical analysis supported by R and Python enable to operate with big data volumes, generate data frames for the reprocessing and modelling. Without ML algorithms, geospatial analysis cannot be accurate and may lead to shortcomings and cause errors. ML is therefore indispensable for such remotely located areas as modelling abyssal depths.

The speed of data processing is another point of concern in marine geology that can be managed effectively by the advanced solutions of data analysis. Sophisticated algorithms of the data analysis and specialized techniques embedded in libraries of Python and $\mathrm{R}$ enable to extract the insights in the complexity of the marine geological factors affecting the structure of the submarine seafloor. Given these reasons, the advantages of using programming in the marine geological research opens clear and distinct perspectives.

High precision cartography, machine learning techniques, flexibility of shell scripting and compatibility with Unix programs ensure high standards of GMT and its suitability for geospatial modelling. Main tasks demonstrated in this dissertation include developed methodology base don technical GMT scripting for data analysis. These included ML, digitizing cross-section profiles, visualizing and analysis of the datasets, 3D-mesh modelling, contour plotting, statistical analysis. Modelling geomorphological slope of the deep-sea trenches is important in relation to several reasons:

1. Slope gradient is relevant as a geomorphological concept, since it impacts the stability of the geologic sediments and grain size.

2. Geomorphic slopes accelerate ocean deep currents related to the food supply chain and exposure for the deep-sea fauna species. 
3. Slopes and specific landforms of the trench geomorphology induce erosion, movement, fall and replacements of sediments depending on their size.

4. Geomorphic characteristics of slopes influence submarine landforms of the trenches.

5. Geomorphology of the trench presents crucial characteristics for benthic habitat: stability of sediments depends on the slope steepness affects the ability of the deep-sea fauna species to dwell.

Specific focus of this dissertation is laid on its multi-disciplinary scope that performs systematic mapping, modelling and classification of 20 trenches base don the combines cartographic methods of geospatial and statistical data modelling. Methodologically, the steps included data visualization, modelling cross-section profiles, geospatial analysis, mapping, statistical analysis of the submarine landforms of the 20 trenches. The initial datasets were extracted from the USGS public sources and embedded layers in the GMT (e.g. coastlines). Particular aim was to classify and analyze variations in submarine geomorphology in 20 trenches. A variety of the GMT modules [743] adjusted for modelling grids, plotting vector layers, computing statistical graphs and perform aesthetically fine cartographic solutions proved to be a perfect tool. The importance of the developing and technical improving of the innovative methods in cartographic data processing is indisputable since visualization and precise modelling are key approaches in geological data analysis. Automatization has been significantly increased over the past years. However, using programming and scripting in cartography still remains lower comparing to the use of the traditional GIS.

Current techniques for GIS modelling of the marine geology of trenches mostly identify and handle relations and processes among tectonic slabs, depths and seismicity [612] or tectonic slub subduction and migration. Existing studies do not detail much variations among geomorphological classes of the trenches, but focus on geological modelling. From this perspective, such insufficiency is the result of limited access to the trenches, systematic limits to the techniques and constraint in usage of the advanced GIS. GMT based marine geological modelling and visualization of the big datasets increases significantly, broadens the perspectives of the marine research to the multi-disciplinary level.

Technical scripts used for advanced statistical analysis are presented in full in the Appendix A for future replication and reproducible analysis in other trenches of the World Ocean: e.g. Makran Trench [397], Puerto Rico Trench and Cayman Trough [391], Cascadia Trench [389], and other oceans: Sunda Trench [385], Bay of Bengal and Andaman Sea of the northern Indian Ocean [386], Java and Sumatra segments [379] of the Indonesian Archipelago in the Indian Ocean [382], South Sandwich Trench, Atlantic Ocean [403], Antarctic and the Southern Ocean, e.g. Ross Sea [378], Weddell Sea [375] or Scotia Sea [377].

Technical application of GMT demonstrated effectiveness and functionality for data analysis, precise and accurate high-quality cartographic mapping, shell scripting workflow for geodata processing. Proposed techniques and methodology of the GMT shell scripting presented in a stepwise workflow provided effective framework for further geological mapping and can be applied for similar research. The GMT proved to be is a powerful scripting cartographic toolset for geological, geophysical and topographic mapping, geomorphic modelling and descriptive statistical analysis of the data retrieved from the automatic digitizing. Methodology of the presented dissertation laid a strong focus on the technical routines of the cartographic workflow, mapping and modelling based on the GMT shell scripting that enabled to identify bathymetric cross section profiles of the hadal trenches that show similarity by their complex parameters, so that they could be grouped into patters. Visualized maps demonstrated excellent possibilities of the GMT for geological mapping, geodetic and geophysical modelling.

In view of the above said, the actuality of the presented dissertation fully based on the sequential combination of the advanced data analysis (R, Python, AWK and Octave/Matlab programming, GMT and ${ }_{\mathrm{IT}_{\mathrm{E}} \mathrm{X}} \mathrm{X}$ visualization, QGIS data processing) is clear. Classification, comparative analysis, systematic 
mapping and geomorphic modelling of the oceanic trenches of the Pacific Ocean has a great scientific and practical interest. The $1^{\text {st }}$ relates to the testing theory of plate tectonics related to the actual geomorphological forms of the trenches. The $2^{\text {nd }}$ is caused by the estimation of the time and place of where earthquakes may arise. A correlation with distribution of the volcanic igneous areas, and economic needs for mineral resources are other goals for studies deep trenches. 


\subsection{Reflections on submarine geomorphology}

7 HE asymmetry of the deep-sea trenches is explained by the phenomenon of the tectonic plates subduction. Subduction of one lithospheric plate to the Earths mantle while another plate is being deformed induces a formation of the oceanic trench which eventually forms through filling the space in between the plates. Necessarily, the complexity and variety of the bathymetric shapes in various trenches arises. The geomorphology of the oceanic trenches is influenced by a set of geologic processes and factors affecting their shape form, gradient steepness depths, and structure. Of these, tectonic plates movements and slab geometry are crucial controlling factors. This can be seen by comparison of the visualized geophysical setting and geomorphology of the trench seafloor. Other factors affecting trench structure and playing essential role in their morphology include age and convergence rate of the plates, intermediate slab dip, width of the sinking plate, sediment thickness of the basement, bathymetric factors, such as depth at basement, means, median and minimal values, closeness of the igneous volcanic areas causing possible earthquakes, and geographic location across the tectonic continental plates.

As a result, the bathymetry of the trench seafloor reflects processes of the plate tectonics: movement, deformation and bending which is associated with mantle convection at the global scale. Complex distribution of various geological factors on the adjacent abyssal plains of the ocean contributes to the formation of the geomorphic features of the ocean bottom in the trenches. Therefore, studying combination of these factors is a prerequisite for the correct understanding of the complex processes that take place in the abyssal environment of the hadal trench.

Variations in the seafloor geomorphology are caused by the uneven distribution of the elevations on the Earth with distinctly irregular hypsography. The majority of the depths is occupied by the deep basins (ca. 4-6.5 km) while relatively few areas are covered by shallow zones. Tectonic plate boundaries are the hotspot areas where the most of the largest earthquakes take place and oceanic slabs descend beneath the continental lithosphere causing trench migration [775]. The largest earthquakes sometimes accompanied by strong tsunami waves mostly occur in the shallow part of the subduction zones [769].

The geomorphology of the oceanic trenches in general reflects fluvial riverine geometry, albeit a general approximation. Setting aside the complexity of the river structure that includes the mainstreams, branches and other features [637]; [695]; [710], the overall approach of the riverine geomorphology may be adopted to the studies of the deep-sea trenches to a certain extent, in scope of the computer modeling and numerical analysis. The submarine trenches are important spaces within the ocean seafloor [126]. They may be approximated to the tributary river flows as channels for the flow of turbidity currents across the seafloor. Fine-grained sediments, e.g. clay and silt, are deposited from the turbidity currents channeled from the continental margins along submarine canyons down into deep ocean trenches.

Seafloor is constantly experiencing deformations under the effects of plate tectonic processes. Various factors affect formation, functioning and sustainability of the deep-sea trenches as one of the unique places of the oceans [601], [593]. Among them, tectonics plates movement, subduction of the underlying slab into the deep mantle, seismic activities in the study area, e.g. submarine earthquakes [673]. Other factors include geological phenomena identifying characteristics of the submarine geomorphology of the trench, previously [713], [759], [560].

There is a broad interest to the geologic structure and tectonic evolution of oceanic trenches supported by numerous studies ([578], [355]; [581], [244]), however those studies are mostly focused on the geophysical settings of the trenches. 20 deep-sea trenches dissecting the margins of the Pacific Ocean have been the target of the presented dissertation which investigated spatial variability of their submarine geomorphology aimed at classification. Effective data processing helped to gain more insights into the seafloor geomorphology. The sketch on the impacts of the trench geomorphology was analyzed, summarizing various factors: tectonics, geological structure, sediments, bathymetry, lithology, etc. Dissertation classifies variations in trench geomorphology. 


\subsection{Perspectives of the IT tools for geology}

$\mathrm{P}$

RESENTED dissertation demonstrated a multi-disciplinary approach combining effective processing of the complex data sets by programming, shell scripting and statistical algorithms. Sequential use of Python, AWK, R and Octave/Matlab is effective for geological data processing. Study of the seafloor is possible not only by QGIS, but using R: network analysis, factors analysis, plotting, diagrams, cluster analysis by various methods (k-means, dendrograms, silhouettes), triple correlation by ternaries [416]. IT based methodology is focused on technical approaches in the analysis of trench geomorphology used as a background for classification. Classification received by application of the technical methods with geomorphic analysis are presented.

Tested functionality of GMT modules proved it to be a highly effective cartographic toolset for geological data analysis enabling precise mapping, automated sampling of the orthogonal transects. GMT based modelling helped to visualize and compare shape of the submarine landforms, steepness gradient of the trenches which were used as a basis for classification. Presented GMT based approach provided a cost-effective solution to the seafloor mapping of the deep-sea trenches. Benefits of the GMT based seafloor mapping to a broad spectrum of visualization of seafloor, and convergence toward a standard suite of high quality raster/vector datasets (e.g. GEBCO, SRTM15), maps and plots were demonstrated in this thesis. GMT aimed to advance cartographic visualization and modelling at high standards, perform quality mapping. This can be effectively used for analysis of submarine landforms, providing knowledge base to detail bathymetry. Besides geological applications, GMT can be successfully used in agricultural mapping [369], geomorphological mapping [371], climate and environmental studies [372].

Comparing $\mathrm{R}$ and Python, both languages have significant functionality for marine geological data analysis. However, Python, being a high-level language, demonstrated more straightforward approach for the statistical analysis. Python is an interpreted language that enables programs to be written compactly and readably splitting them into reusable modules [640] that process and model big datasets. Encapsulation, inheritance and polymorphism of Python are the main advantages while working with big data in marine geology and processing large tables. Simple and vectorized syntax structures and semantics of Python enable to write code concisely and effectively resulting in fewer hard-to-find bugs comparing to the codes written on $\mathrm{C}++$, which minimizes the chance of conflicts in a code. Using NumPy for processing tables in .csv format and arrays facilitate advanced mathematical operations on large numbers of data. $\mathrm{R}$ implies more power in data visualization.

Programming scripts are presented in this dissertation. Effective data visualization provided by libraries enabled better targeting of the distinct areas in the trench that include specific geomorphic features. Functionality of R and Python and their statistical libraries is highly effective for the statistical analysis in marine geology. Data analysis demonstrated effectiveness of the selected methods. Advanced data processing enabled to analyze variations in geomorphology in the trenches, visualize correlation with geological settings. Combined effects of geological and lithological factors that affect geomorphology of the trenches were visualized by statistical methods.

Using advanced IT tools, such as $\mathrm{LTT}_{\mathrm{E}} \mathrm{X}$ and GitHub as repository for projects and scripts is highly useful for geodata processing [468] and can be used to perform information analysis, organizing and structuring data, standardization and classification for data analysis in large volumes [447], [469], [439], [441]. Technical shell GMT scripts, full codes of R, Octave, LTEXand Python and statistical workflow outlined in this thesis are presented in the Appendix for replication, to enable their repeatability and reuse in further works. The dissertation contributed towards development of quantitative and statistical methods in marine geology, in particular aimed at the objective analysis of the ocean trench geomorphology, systematic mapping and classification of the submarine landforms. 


\section{Chapter 6}

\section{Conclusion}

$\mathrm{T}$

HIS dissertation offers an overview of geomorphological classification performed using advanced data analysis, GMT based modelling and mapping. The research aimed at analyzing variations in 20 deep-sea trenches of the Pacific Ocean. It presents a multidisciplinary approach combining cartographic modelling and statistical data analysis. The results enabled to present classification of the trenches based on their geomorphic properties, variations in slopes, analysis of steepness gradients and bathymetry.

Data analysis in geosciences supported by advanced methods is important novel method aimed to increase precision of the computations and operating with big data in marine geology. However, performing data analysis of the marine geological datasets raises a challenge. Existing solutions mostly apply tradition methods of the GIS. In contrast, this dissertation demonstrated a programming languages used in marine geology. Combination of the advanced methods with spatial analysis by GIS plugins and GMT scripting enables to process marine geological datasets in a quick and easy way.

GMT based data analysis enabled to map remotely located areas such as deep-sea trench, to visualize and analyze geophysical and geological settings. Other approaches to perform spatial data analysis in marine geology include pure statistical data modelling using programming languages, such as Python and R, and statistical analysis. However, the advantages of the GMT consists in the possibility to perform both cartographic mapping and statistical analysis using the same program. Various types of data processing can be performed in GMT environment: data analysis, modelling, mapping and statistical analysis and visualization. Besides, the GMT ML approach enables repeatability of the techniques for each of the studied 20 trenches of the Pacific Ocean. Therefore, the GMT scripting toolset was selected as a main tool for data modelling and cartographic mapping by GMT documentation [739], [742].

Methodology is supported by GMT for cartographic visualization, plotting and modelling. Mapping includes visualized local settings of the trenches for spatial analysis, based on a sequential use of GMT modules. The GMT approach represents a cost-effective approach to visualize seafloor. This approach delivers a knowledge base upon which more detailed studies on links between geology, tectonics, geophysics and bathymetry can be identifies. Overlapping in GMT enables to map various layers (tectonic plates, earthquakes, faults) and depth sample points. QGIS plugins facilitate reading coordinates, reprojecting coordinates, layouts visualization, attribute data conversion into csv tables.

Technically, experimental approach of the cartographic modelling with numerical statistical analysis by GMT modules was used to analyze geological and geophysical data sets. Visualization of the series of thematic maps (geology, bathymetry, geoid, gravimetry, 3D modelling, 2D profiles trends modelling, digitized cross-section profiles) demonstrated powerful functionality of the GMT and proved to be effective cartographic instrument for data analysis. Increasing diversity of the spatially distributed data on Earth observation together with application of the advanced cartographic methods and shell scripting greatly enhance the potential of the geospatial modeling. 
Application of the cartographic modelling towards marine geological data enables to perform classification based on the detected spatial differences in the submarine geomorphology. Modelling spatial variations in trench geomorphology facilitates studies of the plate tectonics. Modelling seafloor shape is one of the fundamental issues in modern marine geology. Proper techniques of mapping and modelling trenches advance seafloor studies but they are still developing [729], [741]. Mapping submarine landforms has certain limitations in progress due to the remote location of the trenches. Therefore, modelling seafloor by means of ML algorithms and shell scripting is an effective tool for such a task.

High-resolution data sets were visualized for bathymetric, geological and geophysical mapping of the 20 trenches. Orthogonal cross-sections of the profiles were automatically digitized and processed by GMT in the selected segments of the trenches. Geomorphological classification was based on modelling. Descriptive statistical data analysis was performed for quantitative comparative analysis of the geomorphic forms of 20 trenches. Trenches were modeled in an automated regime by GMT using highresolution bathymetric datasets (GEBCO, ETOPO1 and SRTM). Using developed methodology of the advanced data analysis, geomorphological modelling, mapping and classification are performed for 20 trenches.

From this point of view, this work presented a GMT based methodology for visualization, modelling, interpretation and classification of the submarine geomorphology of the trenches demonstrating new approaches to the mapping. In contrast to the classic cartographic approaches with GUI, e.g. ArcGIS ESRI based [324], [325]; [698], [489], [484], in geodata visualization and mapping [190]; [660]; [485]; [342]; [699]; [324], [327], [447] or other examples of the geospatial modelling applied for geodetic approximations, 3D modelling [715], [27], [291], GMT is notable for shell scripting algorithms as a core concept. Traditional handmade digitizing is a tedious routine prone to errors. On the contrary, GMT based automatization of the cartographic techniques significantly improves modelling quality and precision. Technically, the results show the effectiveness of scripting in modelling submarine geomorphology. The results of the data analysis show distinct unevenness in the geomorphic structure of the trenches.

Although existing maps enable to visualize seafloor with certain resolution and accuracy, there is still a lack of detailed maps of deep-sea trenches, their models and visualization focused on geomorphic form and shape. Integrating GMT based mapping with geological, gravity and bathymetric datasets presented accurate, high-resolution geomorphic maps and cross-section bathymetric models. Approaches to the geological data analysis are diverse: techniques of ternary diagrams visualizing correlation between variables [619], [422], geophysical methods, e.g. DC-resistivity and SASW [120], civil engineering [365], measurements of soil and lime properties, e.g. compression soil tests, indirect tensile tests, triaxial tests [501], various approaches to the data analysis, plotting and visualization, e.g. factor analysis [95], [432], correlograms [433], scatterplot matrices [430], regression analysis [424], data processing by TeX [366]. In contrast with existing works, current thesis present statistical analysis made by Python and R.

High-resolution datasets and raster grids were used for classification of the submarine geomorphology, performed using detailed information on bathymetry and topography of the 20 deep-sea trenches of the Pacific Ocean [367]. The dissertation focused on the geomorphic assessment of variations in their shapes. The research contributes to the improvement of the technical methods of the geomorphic modelling. The review of the statistical methods presented in current thesis can be applied methodologically for comparing and benchmarking different research schemes on other trenches. Furthermore it can be used for analysis of the submarine earthquake connections with ocean trench formation and tectonic slab movement or controlling impact factors during geospatial analysis.

To conclude, methodology of the presented dissertation includes programing languages, statistical analysis, mathematical algorithms for data processing and visualizing, GMT for geomorphic modelling, GIS for digitizing bathymetric profiles and spatial analysis. 


\subsection{Global Summary}

$\mathrm{T}$

HIS thesis presented application of the advanced scripting and programming application to classification, modelling and mapping variations in the submarine geomorphology of the 20 oceanic trenches of the Pacific Ocean. It described methodology for using selected statistical libraries aimed at geomorphic visualization and analysis of the ocean seafloor. The innovative idea of this thesis consisted in integrated use of GMT, Octave, QGIS R and Python programming languages and statistical analysis towards marine geological studies. Technically, the thesis was performed using advanced methods of data analysis: R, Python, GMT, Octave and AWK. Statistical analysis includes a range of the described algorithms through numerous statistical libraries used for data analysis. Nowadays, ocean modelling and conservation becomes one of the most vibrant, paramount endeavors of the marine geology. Application of advanced data modelling towards geomorphic studies revealed variations in their geomorphic forms and structure, and highlighted factors affecting abyssal morphology.

Methodologically, the dissertation contributed towards technical application of the GMT based methods for bathymetric modelling and mapping for deeper understanding of the differences in geomorphology and geophysical settings of the oceanic trenches located along the margins of the Pacific Ocean. It is aimed to produce a set of the cross-section profiles for 20 deep-sea trenches varying in geomorphology. The developed techniques can be utilized at similar works for detailed seafloor mapping. The classification and comparison of the submarine geomorphology and differences among trenches are presented. The thesis elaborated and answered question of how the structure of trench can be classified, measured, compared and analyzed by means of advanced data analysis.

Main objective of the presented dissertation was to perform geomorphological classification based on comparative analysis and map variations in the submarine landform structure of the 20 deep-sea trenches of the Pacific Ocean [368]. To this aim, an objective method combining various approaches was performed including GMT shell script based mapping, statistical analysis, GIS visualization and graphical plotting. Profile transect modelling was exemplified using sampling on the segments of the AOI in topography of the trenches. Mapping deep-sea trenches needs support of reliable, detailed and accurate seafloor maps.

Functional GMT-based framework for cartographic mapping and modelling of the ASCII datasets enabled to quantify variability in the bathymetry of spatially distributed transects of the trenches. The results revealed unevenness in the geomorphology among 20 trenches. Factors affecting their structure are discussed and reviewed. These include local settings, sediment thickness, slope steepness, depths, location. Distinct correlation between the geological factors affect geomorphology of the trenches. Full scripts of GMT, AWK, R, Python and GNU Octave programming languages are presented for repeatability in the Appendix section.

The dissertation presented successful application of the variety of scripting libraries of GMT in marine geology which resulted in high-quality precise mapping, fine cartographic instruments, flexibility of scripting and coding, compatibility with UNIX utilities. Using such advantages of the GMT for geological data modelling and mapping definitely facilitates data processing, enables high-precision analysis and mapping data frames. Application of the GMT towards geological data analysis and visualization is highly effective and promising comparing to the traditionally used GIS. Classifying and modelling submarine geomorphology revealed a consistent pattern of their structural and morphological features. These include deep abyssal valleys, steep slopes, bounded by a submarine deep basin moraines at the outer limits of the trenches. Submarine ridges are explained as a series of small moraines, stacked behind a larger moraines.

Supported by sound literature review, this dissertation identified and classified variabilities among the geomorphology of major 20 trenches of the Pacific Ocean. High accuracy of the performed statistical data analysis and cartography has been supported by chosen advanced algorithms of the ML data processing 
and high-resolution data: raster grids, ASCII, vector QGIS layers and attribute tables. 


\subsection{Recommendations}

$\mathrm{A}$

$S$ a recommendation for further research focused on ocean trenches, traditional methods of seafloor studies should include a combination of both GIS and statistical analysis such as R and Python, or Octave. Studies of spacial data series should be accompanied by graphics, facetted plots to facilitate comparison of the data by groups. This is especially useful while processing multi-dimensional geological data. Since there are variations in trench geomorphology, as well as correlations among factors affecting their formation and geomorphology, mathematical algorithms and objective analyses based approaches of data analysis should be explicitly used. A contemporary perspective of GMT, R and Python based methods of geological data for modelling trench geomorphology is demonstrated in this thesis.

Programming scripts provided in the Appendix are recommended as a template for similar studies. Application of the statistical tools provided by functionality of $\mathrm{R}$ and Python offer optimal prospects for understanding bathymetry and geomorphology of the oceanic trenches. Differences in variation of geomorphological forms can be detected by application of various methods and algorithms, as different approaches can highlight correlations. It is recommended to apply and test various statistical algorithms of data analysis.

Cross-disciplinary quantitative approach for geomorphological analysis is recommended for future studies. Using $\mathrm{R}$ and Python for marine geoscience research does not only make geological modelling simpler and less error-prone. It also facilitates complex simulations involving multi-dimensional modelling with varying parameters. It is also recommended to apply developed and presented methods for other deep-sea trenches. Processing multi-source data by the ML methods enables to speed up our understanding of the submarine geomorphology of the ocean seafloor. A combination of the advanced tools for spatial data processing, such as R, Python, AWK and Octave/MATLAB programming, GMT enables to perform integration of such complex heterogeneous data from a variety of sources for the in-depth analysis.

Application of the programming languages ( $R$, Python, Octave and AWK) is strongly recommended in geoscience research as an addition to the traditional GIS methods. From all available statistical methods it is necessary to select the most suitable to the modelling type: data ranking, data distribution (e.g. box plots or violin plots, linear regression or isotonic regression), correlation matrix or correlogram ellipses, etc. Correct chosen algorithms of the statistical modelling helps to best visualize and analyze the data set. Visualizing the full range of the geomorphology across the trench should be done using various methods: by the deepest values (i.e. each profiles can have only one dot point), or by showing the full line of profile (i.e. the profile shows the cross section in its length), in circular or bar plot or dot plot types, as presented in this dissertation

Finally, as a last recommendation, more detailed marine geological datasets could be included for data analysis. These include data from the cruises: currents, sediment texture, water circulation at various depths. Geological interpretations can be used to extrapolate geomorphic type of the transects along the trench. Using GMT shell scripting for cartographic modelling increases automatization of the mapping routine. Therefore, GMT is strongly recommended for geological data analysis and classification. Presented techniques and methodology of GMT shown effective framework for geological mapping. Environmental factors may be studied additionally by existing methods of the environmental management, ecological monitoring and data analysis [476], [448], [449], [450], [451], [452], [453]. Thorough multidimensional data processing in marine geology should include following data: tectonic (continental margin plates), geological (geologic structure), lithological (sedimentation) and oceanological (direction of the deep currents). 


\subsection{Outlook and future developments}

$\mathrm{A}$

$\mathrm{S}$ demonstrated in this thesis, active use of the programming languages in geoscience research is effective to advance studies of the bathymetry. Development in statistical methods such as $\mathrm{R}$ and Python enables to treat multi-source types of the marine geological data. Studies of such complex objects as oceanic trenches, have specific points that distinguish them from the terrestrial areas. $1^{\text {st }}$, seafloor rocks are studied mainly by RS methods. Samples include cores obtained from drilling or platforms, collected by dredging. $2^{\text {nd }}$, thorough understanding of the basics of geophysics, geography, geomorphology, oceanography, cartography, informatics and principles of data interpretation are prerequisites for marine geology [374]. Hence, a variety of methods of the advanced data analysis is necessary to study deep-sea trenches.

Rigorous and quantitative quantitative data analysis performed by $\mathrm{R}$ and Python and supported by GIS is effective for investigation of such large-scale geologic structures as trenches. If surface of the whole trench is modeled, the extra- or interpolation of the depths by profiles increase random errors due to the complex nature of the real situation of physical environment. It can be either the effects of the external factors on the geomorphic structure (tectonic slab movement that affects the shape of the trench segment) or mathematical approaches of the algorithm of approximation. In the most difficult segments (e.g., areas of triple junctions), it is possible to take more dense profiles digitizing. However, in this case it would be reasonable to large scale this particular area as enlarged fragment.

Nowadays, ocean modelling and conservation become one of the most vibrant, paramount endeavors in marine geology [623]. Understanding structure of the trenches helps to improve investigation of the marine geology. Particular problem in the analysis of the ocean seafloor lies in the complexity of the processes involved in trench formation. Therefore, submarine geomorphic modelling should encompass not only submarine landforms, but its links with tectonics, seismicity, earthquakes repeatability and magnitude, oceanological parameters (current direction and strength), lithology (origin and properties of the underlying rocks).

Future work should consider applying other GMT modules and their combination to develop complex approaches of the cartographic-geophysical investigations: earthquake intensity modelling, mapping volcanic arcs. Application of GRASS GIS is recommended for GIS data processing [393], [388], [398], [381]. Combination and overlapping of various geospatial data aimed to examine and quantify landforms in connection with local settings by existing methods of spatial analysis enables to get information on geological, tectonic and environmental thematic mapping apply spatial analysis at various scales. Other recommendation could include integration of GMT with programming and advanced statistical packages.

Future works may include satellite image processing for coastal and shelf areas by available methods of image analysis: Google Earth [472], Landsat TM/ETM+ and MSS imagery [480], [477], [454], [466], [478], [455], [456], [457], [458], [395], , [394]. Applying various software, e.g. ILWIS GIS [471], [459], [464], eCognition for OBIA [460], [467], Quantum GIS [399], [461], [462], [465], ENVI GIS, ArcGIS [487]; [463], [486], Erdas Imagine, SAGA GIS [395], [384], [390] are useful for spatial analysis.

Future applications should include analysis of the interplay between the elements of the submarine ecosystem, predicting changes in its structure, reconstruct origin and evolution of the trench dynamics, interpret slab motions [664]; [588]; [564]; [242], tectonic and sedimentary processes in the marginal seas [198], [199], [200]. Given non available tools of the ML and operating with big data in marine geology, studies should apply more complicated numerical data analysis and visualization. Maps produced and demonstrated in this thesis can be used as a template for seafloor mapping and modelling at regional and local scales.

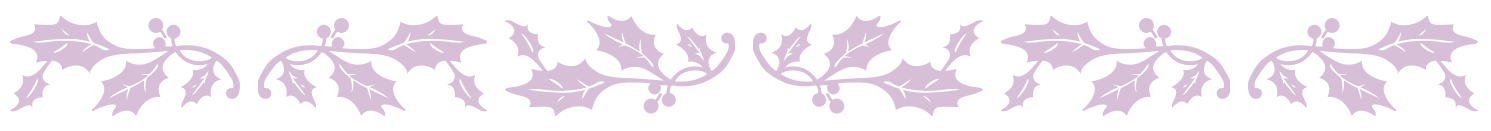




\section{Author's Publications}

${ }^{1}$ P. Lemenkova, "SAGA GIS for Computing Multispectral Vegetation Indices by Landsat TM for Mapping Vegetation Greenness", Contemporary Agriculture 70, 67-75 (2021), URL: https: / / sciendo. com/article/10. 2478/contagri-2021-0011.

${ }^{2}$ P. Lemenkova, "Topography of the Aleutian Trench south-east off Bowers Ridge, Bering Sea, in the context of the geological development of North Pacific Ocean”, Baltica 34, 27-46 (2021), URL: https : / gamtostyrimai . lt/en/publications/listingCategory/category.1020.

${ }^{3}$ P. Lemenkova, "Scripting Languages for Geomorphological Modelling and Topographic Visualization of Serbia”, Zbornik Matice srpske za prirodne nauke 140, 113-125 (2021), URL: http : / / doiserbia . nb. rs / journal. aspx?issn=0352-4906.

${ }^{4}$ P. Lemenkova, "Mapping environmental and climate variations by GMT: a case of Zambia, Central Africa", Zemljite i biljka 70, 117-136 (2021), URL: http: //www.sdpz.rs/index.php/sr-yu/casopis-zemljistei-biljka.

${ }^{5}$ P. Lemenkova, “Accurate and rapid big spatial data processing by scripting cartographic algorithms: advanced seafloor mapping of the deep-sea trenches along the margins of the Pacific Ocean”, in Bringing Land, Ocean, Atmosphere and Ionosphere Data to the Community for Hazard Alerts (May 24, 2021), URL: https : / / agu . confex.com/agu/21workshop2/meetingapp.cgi/Home/0, SLIDESHARE.

${ }^{6} \mathrm{P}$. Lemenkova, "Morphostructure features of the deep-sea trenches in the Pacific Ocean: the problem of their origin", Russian, in Seminar of the laboratory of regional geophysics and natural disasters, in Russian (May 24, 2021), SLIDESHARE.

${ }^{7}$ P. Lemenkova, "The visualization of geophysical and geomorphologic data from the area of Weddell Sea by the Generic Mapping Tools”, Studia Quaternaria 38, 19-32 (2021), URL: https : / /www.czasopisma.pan.pl/sq.

${ }^{8}$ P. Lemenkova, "Cartographic Processing of the Multi-Source Geospatial Datasets by GMT for Mapping Variability in Geologic Setting and Bathymetry of the Pacific Ocean", Mercator 20, 1-18 (2021), URL: http: / / www.mercator.ufc.br/mercator/article/view/e20013.

${ }^{9}$ P. Lemenkova, "Exploring structured scripting cartographic technique of GMT for ocean seafloor modeling: A case of the East Indian Ocean", Maritime Technology and Research 3, 162-184 (2021), URL: https : // so 04. tci-thaijo.org/index.php/MTR/article/view/248158.

${ }^{10}$ P. Lemenkova, "Geodynamic setting of Scotia Sea and its effects on geomorphology of South Sandwich Trench, Southern Ocean”, Polish Polar Research 42, 1-23 (2021), URL: https : / journals .pan.pl/ppr/136510.

${ }^{11} \mathrm{P}$. Lemenkova, "Data-driven insights into correlation among geophysical setting, topography and seafloor sediments in the Ross Sea, Antarctic", Caderno de Geografia 31, 1-20 (2021).

${ }^{12}$ P. Lemenkova, "Java and Sumatra Segments of the Sunda Trench: Geomorphology and Geophysical Settings Analysed and Visualized by GMT”, Glasnik Srpskog Geografskog Drustva 100, 1-23 (2020).

${ }^{13}$ P. Lemenkova, “Using R packages 'tmap', 'raster' and 'ggmap' for cartographic visualization: An example of dem-based terrain modelling of Italy, Apennine Peninsula", Zbornik radova - Geografski fakultet Univerziteta u Beogradu 68, 99-116 (2020).

${ }^{14}$ P. Lemenkova, "GRASS GIS for classification of Landsat TM images by maximum likelihood discriminant analysis: Tokyo area, Japan”, Geodetski glasnik 51, 5-25 (2020). 
${ }^{15}$ P. Lemenkova, "Insights on the Indian Ocean tectonics and geophysics supported by GMT", Risks and Catastrophes Journal 27, 67-83 (2020).

${ }^{16} \mathrm{P}$. Lemenkova, "Sediment thickness in the Bay of Bengal and Andaman Sea compared with topography and geophysical settings by GMT”, Ovidius University Annals Series: Civil Engineering 22, 13-22 (2020).

${ }^{17}$ P. Lemenkova, "Scripting cartographic methods of GMT for mapping the New Britain and San Cristobal trenches, Solomon Sea, Papua New Guinea”, Revista da Casa da Geografia de Sobral 22, 122-142 (2020).

${ }^{18} \mathrm{P}$. Lemenkova, "Analysis of the difference in depths and variation in slope steepness of the Sunda Trench, Indonesia, east Indian Ocean”, Revista de Geomorfologie 22, 21-41 (2020).

${ }^{19}$ P. Lemenkova, "Sentinel-2 for High Resolution Mapping of Slope-Based Vegetation Indices Using Machine Learning by SAGA GIS", Transylvanian Review of Systematical and Ecological Research 22, 17-34 (2020).

${ }^{20}$ P. Lemenkova, "GRASS GIS for topographic and geophysical mapping of the Peru-Chile Trench", Forum geografic 19, 143-157 (2020), URL: http: / / forumgeografic.ro/2021/2704/.

${ }^{21}$ P. Lemenkova, "GEBCO and ETOPO1 gridded datasets for GMT based cartographic mapping of Hikurangi, Puysegur and Hjort Trenches, New Zealand”, Acta Universitatis Lodziensis. Folia Geographica Physica 19, 7 18 (2020).

${ }^{22}$ P. Lemenkova, "GRASS GIS Modules for Topographic and Geophysical Analysis of the ETOPO1 DEM and Raster Data: North Fiji Basin, Pacific Ocean”, Geographia Napocensis 14, 27-38 (2020).

${ }^{23}$ P. Lemenkova, “Applying Automatic Mapping Processing by GMT to Bathymetric and Geophysical Data: Cascadia Subduction Zone, Pacific Ocean”, Journal of Environmental Geography 13, 15-26 (2020).

${ }^{24}$ P. Lemenkova, "Object Based Image Segmentation Algorithm of SAGA GIS for Detecting Urban Spaces in Yaoundé, Cameroon”, Central European Journal of Geography and Sustainable Development 2, 38-51 (2020).

${ }^{25}$ P. Lemenkova, "Geomorphology of the Puerto Rico Trench and Cayman Trough in the Context of the Geological Evolution of the Caribbean Sea", Annales Universitatis Mariae Curie-Sklodowska, sectio B Geographia, Geologia, Mineralogia et Petrographia 75, 115-141 (2020).

${ }^{26}$ P. Lemenkova, "Using GMT for 2D and 3D Modeling of the Ryukyu Trench Topography, Pacific Ocean", Miscellanea Geographica 25, 1-13 (2020).

${ }^{27}$ P. Lemenkova, "NOAA Marine Geophysical Data and a GEBCO Grid for the Topographical Analysis of Japanese Archipelago by Means of GRASS GIS and GDAL Library", Geomatics and Environmental Engineering 14, 25-45 (2020).

${ }^{28}$ P. Lemenkova, "Hyperspectral Vegetation Indices Calculated by Qgis Using Landsat Tm Image: a Case Study of Northern Iceland”, Advanced Research in Life Sciences 4, 70-78 (2020).

${ }^{29}$ P. Lemenkova, "SAGA GIS for information extraction on presence and conditions of vegetation of northern coast of Iceland based on the Landsat TM", Acta Biologica Marisiensis 3, 10-21 (2020).

${ }^{30} \mathrm{P}$. Lemenkova, "The geomorphology of the Makran Trench in the context of the geological and geophysical settings of the Arabian Sea”, Geology, Geophysics and Environment 46, 205-222 (2020).

${ }^{31}$ P. Lemenkova, "GEBCO Gridded Bathymetric Datasets for Mapping Japan Trench Geomorphology by Means of GMT Scripting Toolset”, Geodesy and Cartography 46, 98-112 (2020).

${ }^{32}$ P. Lemenkova, "Fractal surfaces of synthetical DEM generated by GRASS GIS module r.surf.fractal from ETOPO1 raster grid", Journal of Geodesy and Geoinformation 7, 86-102 (2020).

${ }^{33}$ P. Lemenkova, "Python libraries matplotlib, seaborn and pandas for visualization geospatial datasets generated by QGIS", Analele tiinifice ale Universitii "Alexandru Ioan Cuza" din Iai - seria Geografie 64, 13-32 (2020).

${ }^{34}$ P. Lemenkova, "Integration of geospatial data for mapping variation of sediment thickness in the North Sea", Scientific Annals of the Danube Delta Institute 25, 129-138 (2020).

${ }^{35}$ P. Lemenkova, "Mapping Beaufort Sea Topography and Geophysical Settings Using High-Resolution Geospatial Data and GMT”, Geografické informácie 24, 4-18 (2020).

${ }^{36}$ P. Lemenkova, "R Libraries \{dendextend $\}$ and $\{$ magrittr $\}$ and Clustering Package scipy.cluster of Python For Modelling Diagrams of Dendrogram Trees", Carpathian Journal of Electronic and Computer Engineering 13, 5-12 (2020). 
${ }^{37}$ P. Lemenkova, "Seafloor Mapping of the Atlantic Ocean by GMT: Visualizing Mid-Atlantic Ridge Spreading, Sediment Distribution and Tectonic Development”, Acta Geobalcanica 6, 145-157 (2020).

${ }^{38}$ P. Lemenkova, "Mapping South China Sea Region by GMT for Marine Geological Analysis and Visualization", Analele Universitii din Oradea, Seria Geografie 30, 107-121 (2020).

${ }^{39}$ P. Lemenkova, "Variations in the bathymetry and bottom morphology of the Izu-Bonin Trench modelled by GMT”, Bulletin of Geography. Physical Geography Series 18, 41-60 (2020).

${ }^{40}$ P. Lemenkova, "Cartographic Interpretation of the Seafloor Geomorphology Using GMT: a Case Study of the Manila Trench, South China Sea", Aksaray University Journal of Science and Engineering 4, 1-18 (2020).

${ }^{41}$ P. Lemenkova, "GMT Based Comparative Geomorphological Analysis of the Vityaz and Vanuatu Trenches, Fiji Basin”, Geodetski List 74, 19-39 (2020).

${ }^{42} \mathrm{P}$. Lemenkova, "Visualization of the geophysical settings in the Philippine Sea margins by means of GMT and ISC data", Central European Journal of Geography and Sustainable Development 2, 5-15 (2020).

${ }^{43}$ P. Lemenkova, "GMT-based geological mapping and assessment of the bathymetric variations of the KurilKamchatka Trench, Pacific Ocean”, Natural and Engineering Sciences 5, 1-17 (2020).

${ }^{44}$ P. Lemenkova, "AWK and GNU Octave Programming Languages Integrated with Generic Mapping Tools for Geomorphological Analysis”, GeoScience Engineering 65, 1-22 (2019).

${ }^{45}$ P. Lemenkova, "Geomorphological modelling and mapping of the Peru-Chile Trench by GMT", Polish Cartographical Review 51, 181-194 (2019).

${ }^{46}$ P. Lemenkova, “Automatic Data Processing for Visualising Yap and Palau Trenches by Generic Mapping Tools”, Cartographic Letters 27, 72-89 (2019).

${ }^{47}$ P. Lemenkova, "Geophysical Modelling of the Middle America Trench using GMT", Annals of Valahia University of Targoviste. Geographical Series 19, 73-94 (2019).

${ }^{48}$ P. Lemenkova, "Geospatial Analysis by Python and R: Geomorphology of the Philippine Trench, Pacific Ocean", Electronic Letters on Science and Engineering 15, 81-94 (2019).

${ }^{49}$ P. Lemenkova, "Calculating slope gradient variations in the submarine landforms by R and Python statistical libraries”, MANAS Journal of Engineering 7, 99-113 (2019).

${ }^{50}$ P. Lemenkova, "Plotting Ternary Diagrams by R Library ggtern for Geological Modelling”, Eastern Anatolian Journal of Science 5, 16-25 (2019).

${ }^{51}$ P. Lemenkova, "Deep-Sea Trenches of the Pacific Ocean: a Comparative Analysis of the Submarine Geomorphology by Data Modeling Using GMT, QGIS, Python and R. Mid-Term PhD Thesis Presentation: Current Research Progress", in Seminar Mid-Term PhD Thesis Presentation (Nov. 2019).

${ }^{52}$ P. Lemenkova, "Topographic surface modelling using raster grid datasets by GMT: example of the KurilKamchatka Trench, Pacific Ocean", Reports on Geodesy and Geoinformatics 108, 9-22 (2019).

${ }^{53}$ P. Lemenkova, "Generic Mapping Tools and Matplotlib Package of Python for Geospatial Data Analysis in Marine Geology”, International Journal of Environment and Geoinformatics 6, 225-237 (2019).

${ }^{54}$ P. Lemenkova, "GMT Based Comparative Analysis and Geomorphological Mapping of the Kermadec and Tonga Trenches, Southwest Pacific Ocean”, Geographia Technica 14, 39-48 (2019).

${ }^{55}$ P. Lemenkova, "Computing and Plotting Correlograms by Python and R Libraries for Correlation Analysis of the Environmental Data in Marine Geomorphology”, Jeomorfolojik Aratrmalar Dergisi / Journal of Geomorphological Researches 3, 1-16 (2019).

${ }^{56}$ P. Lemenkova, "Statistical Analysis of the Mariana Trench Geomorphology Using R Programming Language", Geodesy and Cartography 45, 57-84 (2019).

${ }^{57}$ P. Lemenkova, "K-means Clustering in R Libraries \{cluster\} and \{factoextra\} for Grouping Oceanographic Data”, International Journal of Informatics and Applied Mathematics 2, 1-26 (2019).

${ }^{58}$ P. Lemenkova, "Testing Linear Regressions by StatsModel Library of Python for Oceanological Data Interpretation”, Aquatic Sciences and Engineering 34, 51-60 (2019). 
${ }^{59}$ P. Lemenkova, "Numerical Data Modelling and Classification in Marine Geology by the SPSS Statistics", International Journal of Engineering Technologies 5, 90-99 (2019).

${ }^{60}$ P. Lemenkova, "Regression Models by Gretl and R Statistical Packages for Data Analysis in Marine Geology", International Journal of Environmental Trends 3, 39-59 (2019).

${ }^{61}$ P. Lemenkova, "Geostatistical Analysis of the Data Sets on the Mariana Trench, Pacific Ocean", in Seminar presentation (Apr. 2019).

${ }^{62}$ P. Lemenkova, "Processing oceanographic data by Python libraries NumPy, SciPy and Pandas", Aquatic Research 2, 73-91 (2019).

${ }^{63}$ P. Lemenkova, “An Empirical Study of R Applications for Data Analysis in Marine Geology”, Marine Science and Technology Bulletin 8, 1-9 (2019).

${ }^{64}$ P. Lemenkova, "Scatterplot Matrices of the Geomorphic Structure of the Mariana Trench at Four Tectonic Plates (Pacific, Philippine, Mariana and Caroline): a Geostatistical Analysis by R", in Problems of tectonics of continents and oceans, Proceedings of the $51^{\text {st }}$ Tectonics Meeting, Vol. 1, edited by K. E. Degtyarev (Institute of Geology RAS, Jan. 2019), pp. 347-352.

${ }^{65}$ P. Lemenkova, "Factor Analysis by R Programming to Assess Variability Among Environmental Determinants of the Mariana Trench", Turkish Journal of Maritime and Marine Sciences 4, 146-155 (2018).

${ }^{66} \mathrm{P}$. Lemenkova, " $\mathrm{R}$ scripting libraries for comparative analysis of the correlation methods to identify factors affecting Mariana Trench formation", Journal of Marine Technology and Environment 2, 35-42 (2018).

${ }^{67}$ P. Lemenkova, "Hierarchical Cluster Analysis by R language for Pattern Recognition in the Bathymetric Data Frame: a Case Study of the Mariana Trench, Pacific Ocean", in Virtual simulation, prototyping and industrial design, Proceedings $5^{\text {th }}$ Int'l Conference Issue 5, Vol. 2, edited by M. N. Krasnyansky (Nov. 2018), pp. 147-152, ISBN: 978-5-8265-1997-4.

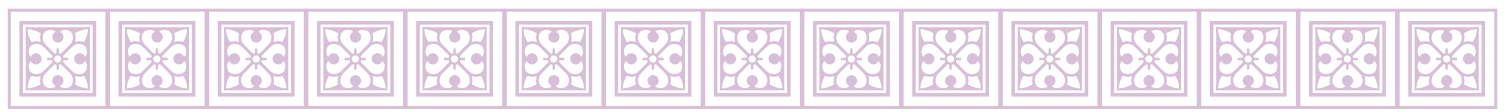




\section{Appendices}




\section{Appendix A}

\section{Programming codes}

\section{A.1 Octave/Matlab language}

\section{A.1.1 Octave/Matlab script for cartographic visualization of the bathymetric profiles}

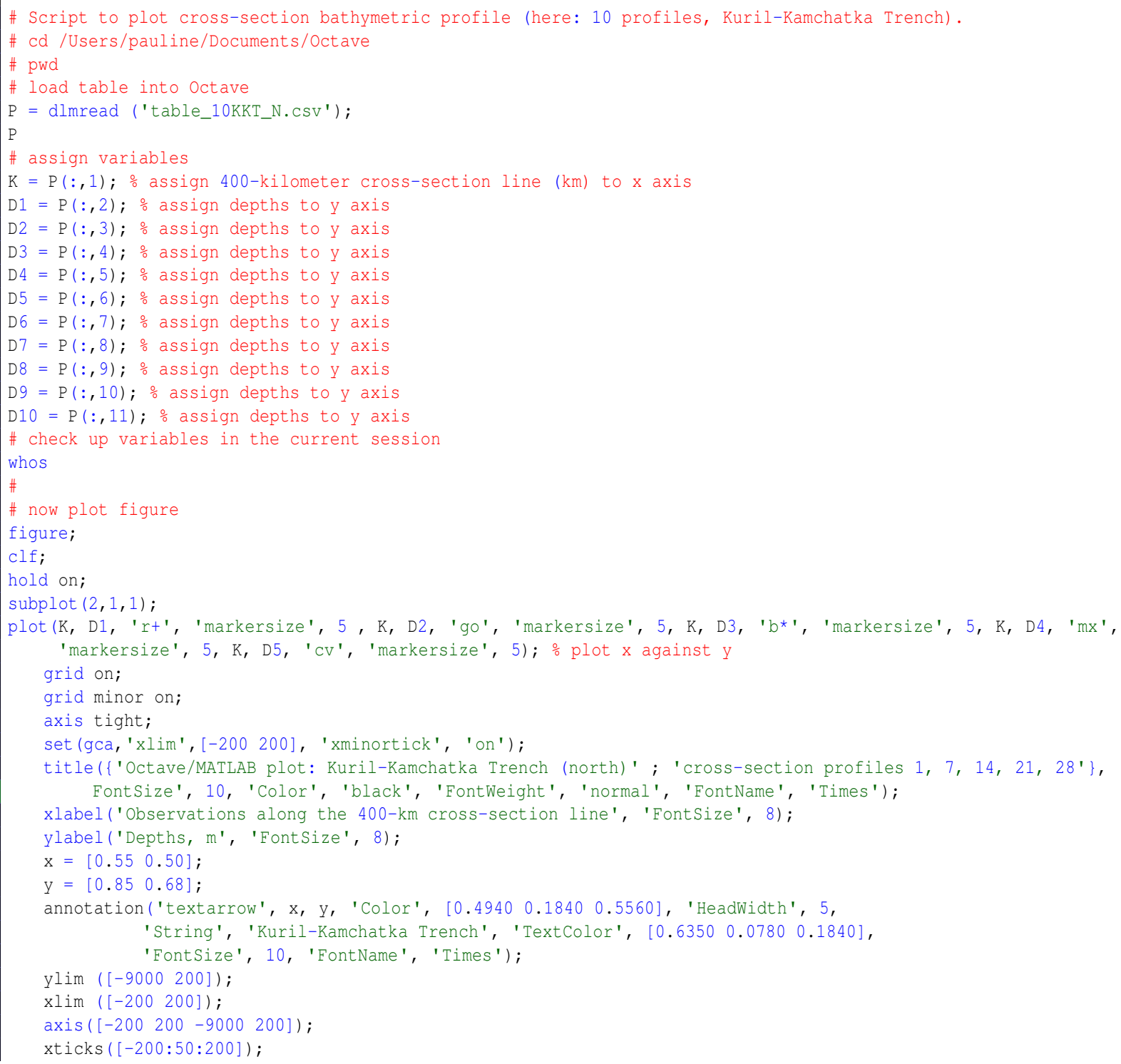




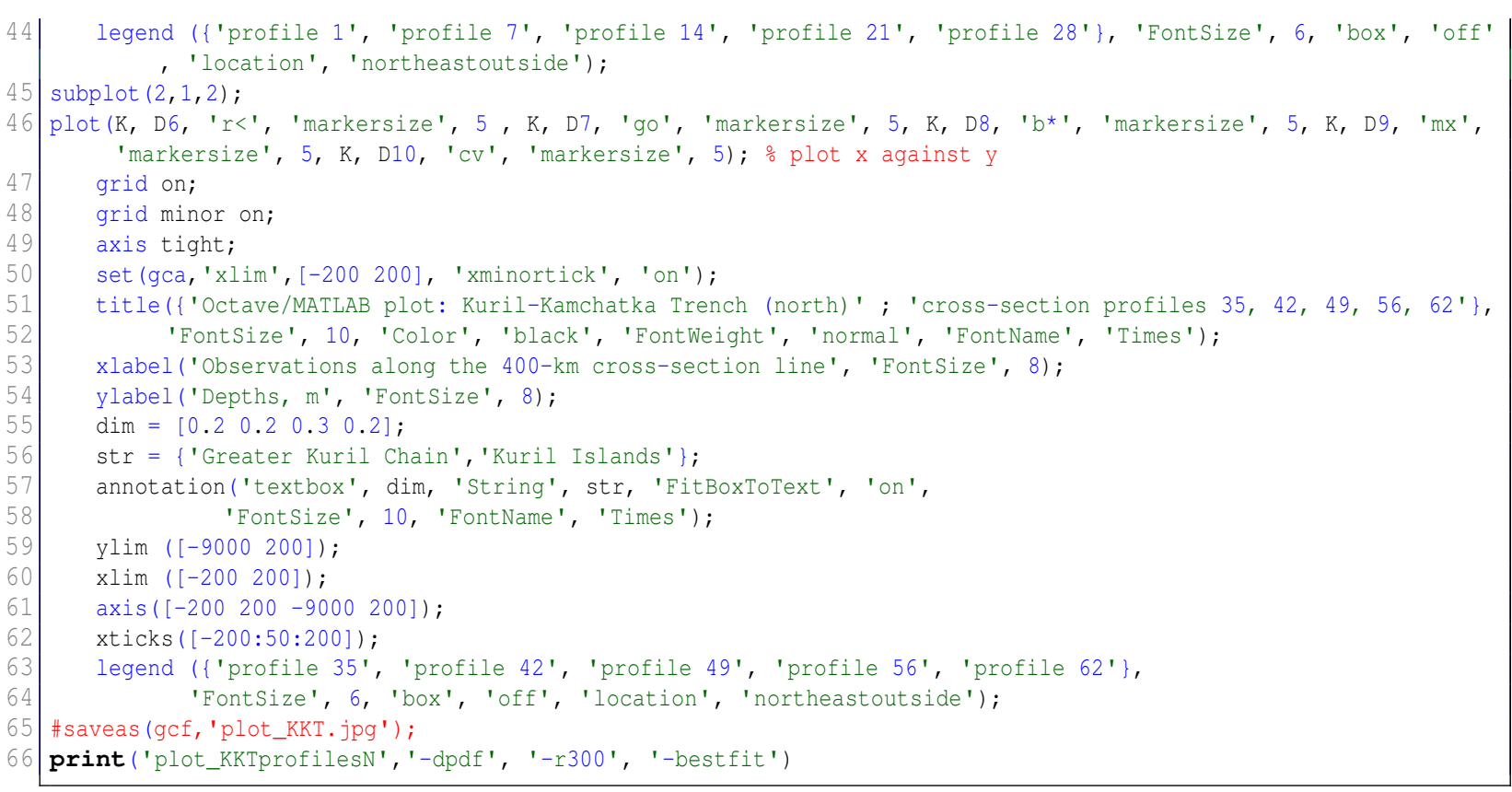

codes/Octave.m

\section{A.2 $\quad \mathbf{T}_{\mathbf{E}} \mathrm{X}$ macro language}

\section{A.2.1 IAT $_{\mathrm{E}} \mathrm{X}$ code to plot bathymetric profiles}

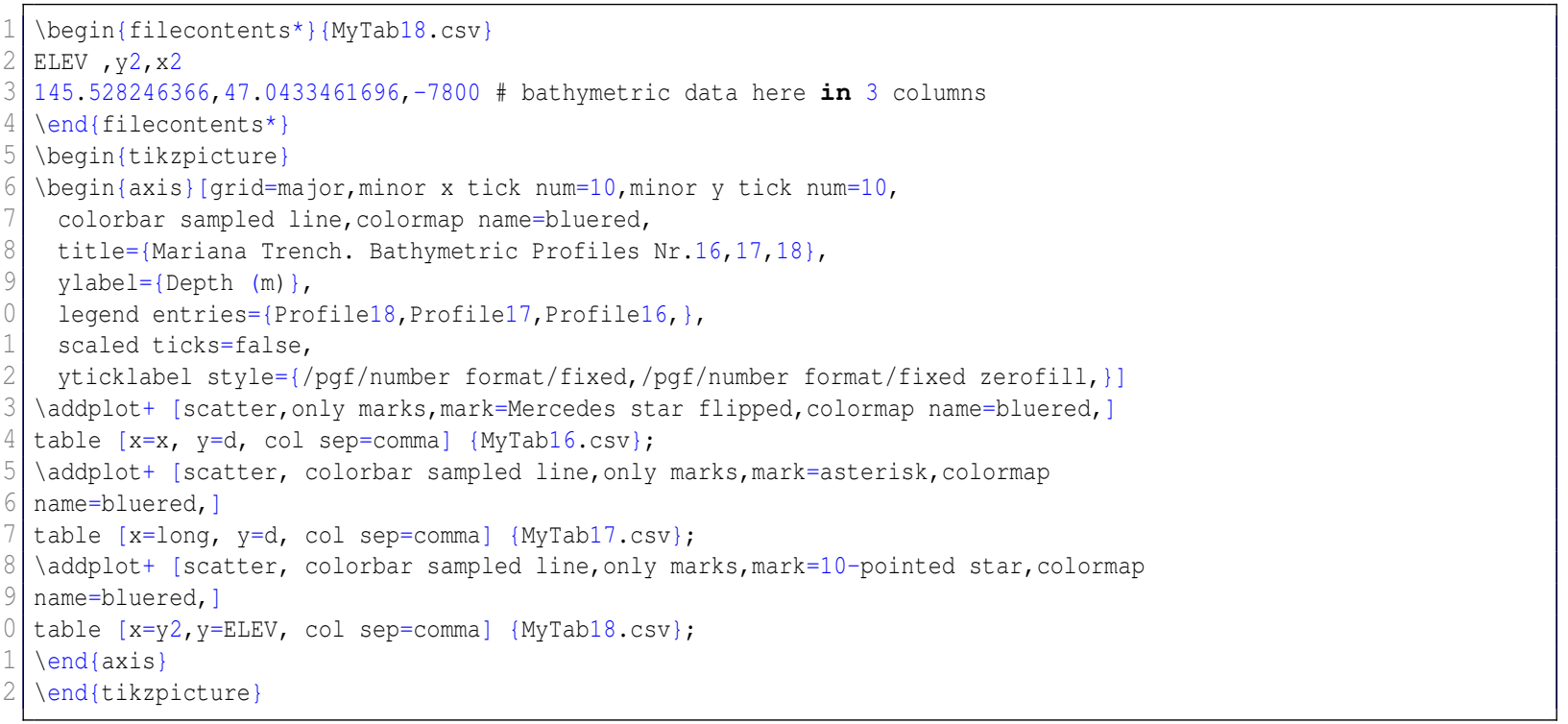

codes/Latex-bathymetry.tex 


\section{A.3 AWK language}

\section{A.3.1 AWK shell script for table reshaping}

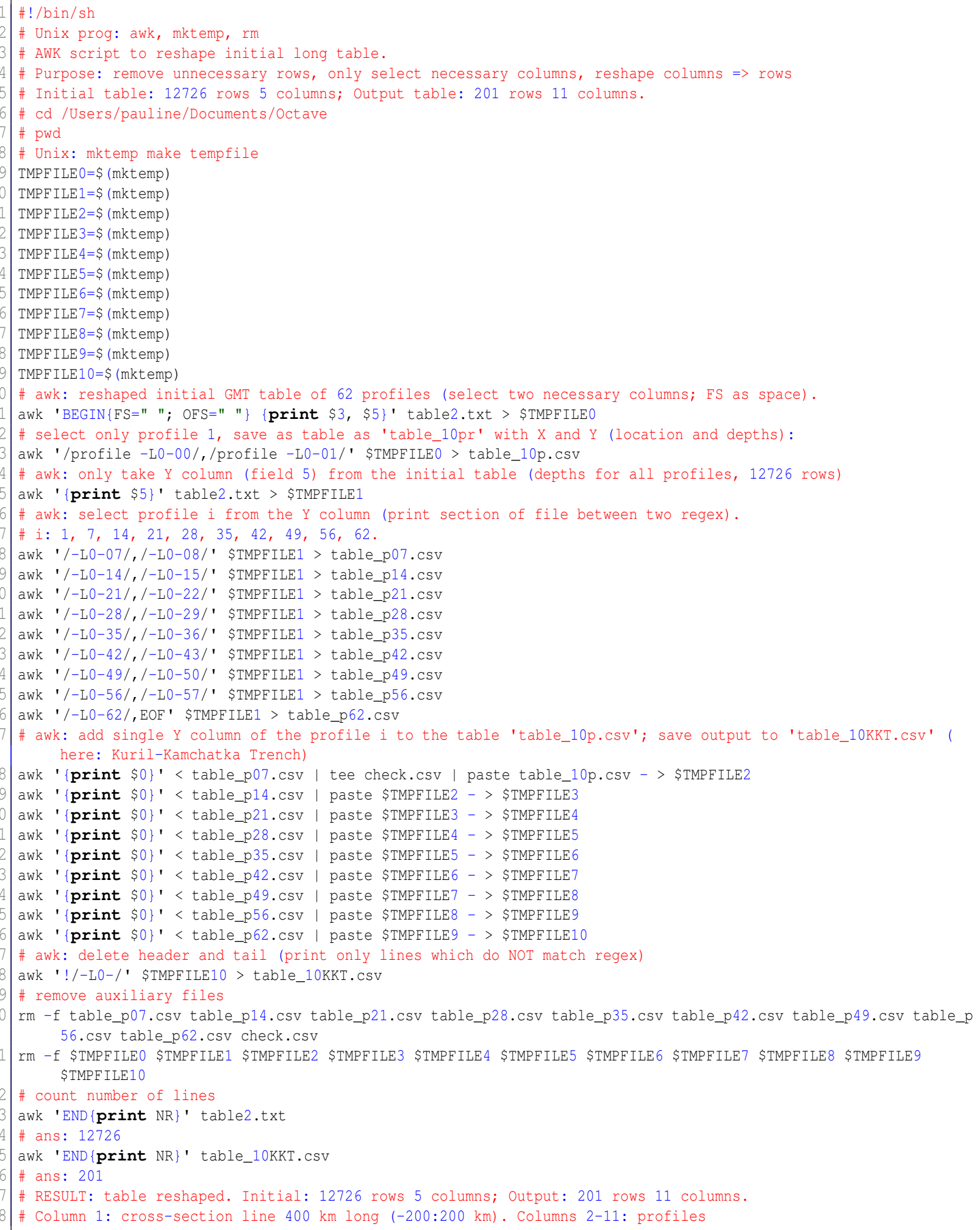

codes/AWK.sh 


\section{A.4 GMT shell/bash scripts}

\section{A.4.1 GMT script for bathymetric mapping, ETOPO1 (here: KKT)}

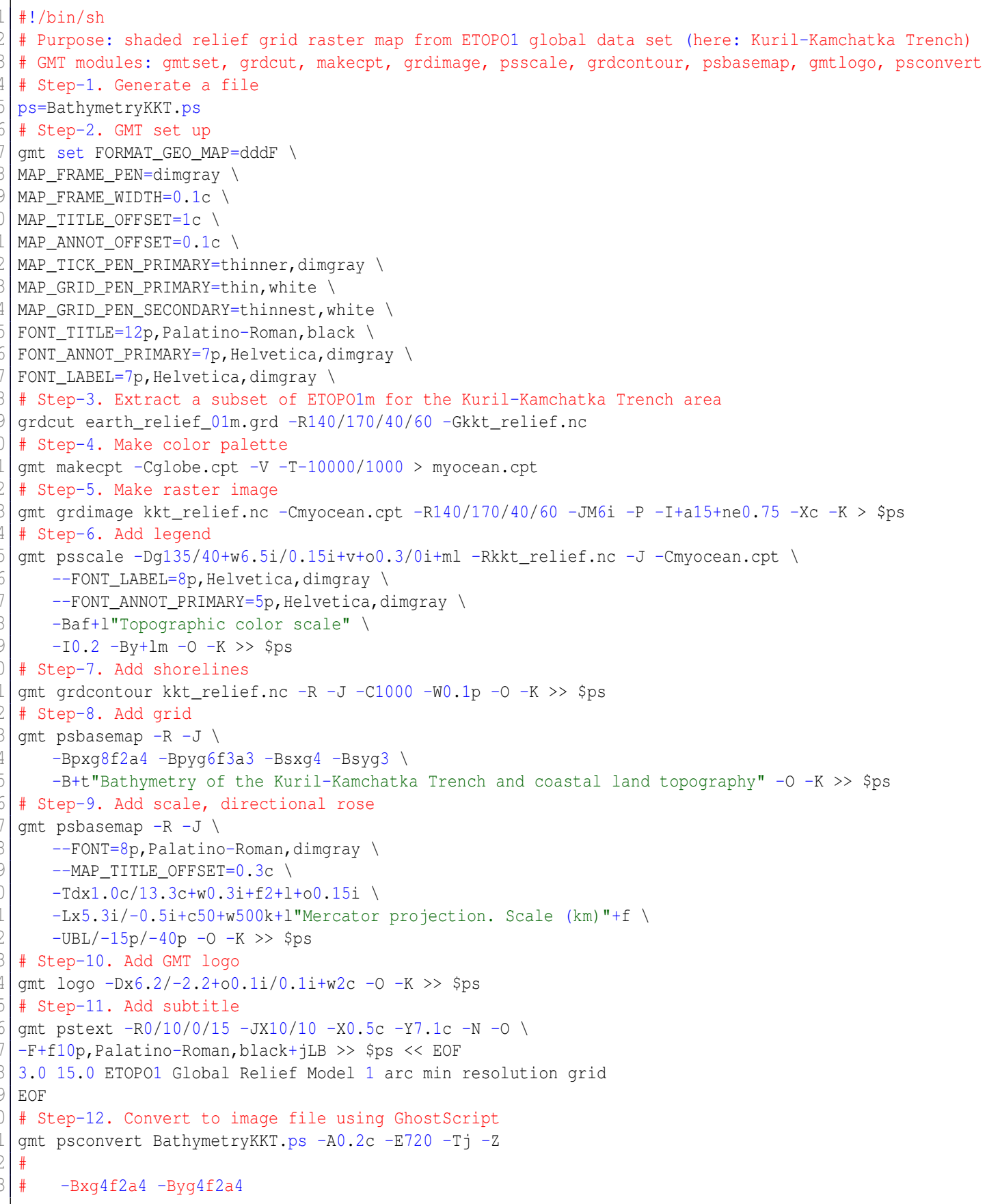

codes/GMT-01.sh 


\section{A.4.2 GMT script for 3D mesh grid modelling, DEM based (here: AT)}

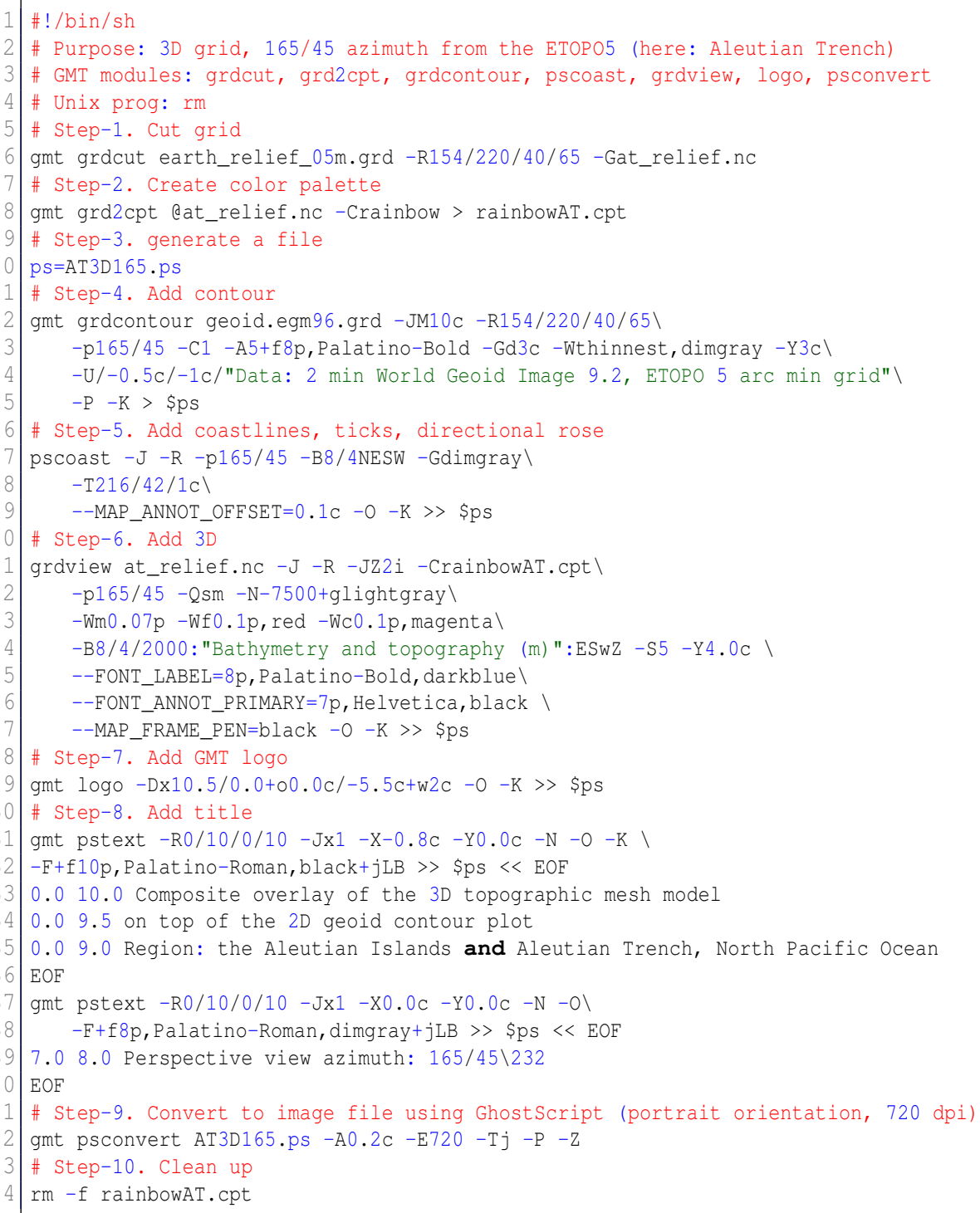

codes/GMT-02.sh 


\section{A.4.3 GMT script for bathymetry contour mapping (here: KKT)}

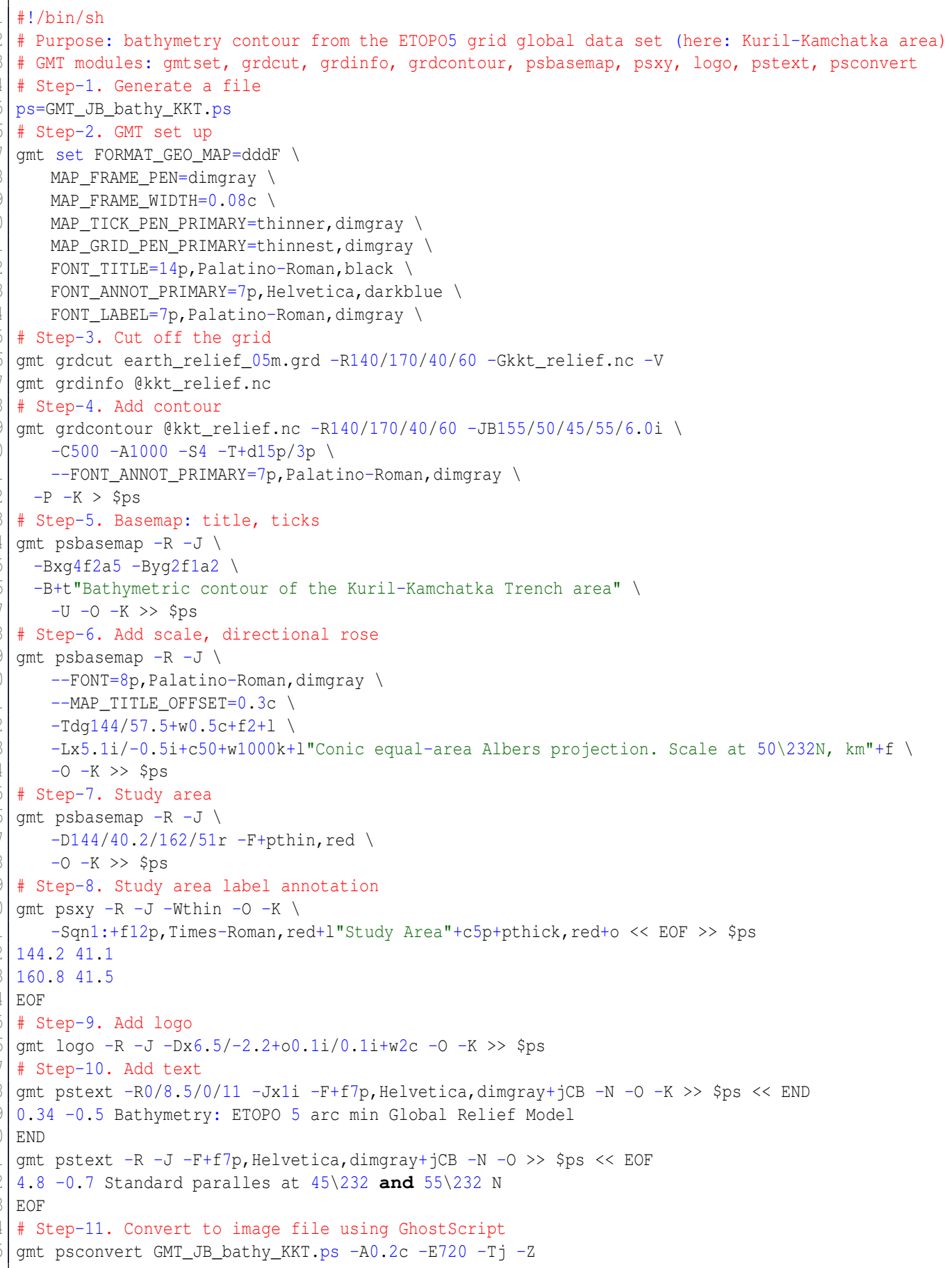

codes/GMT-03.sh 


\section{A.4.4 GMT script for geoid modelling (here: KKT)}

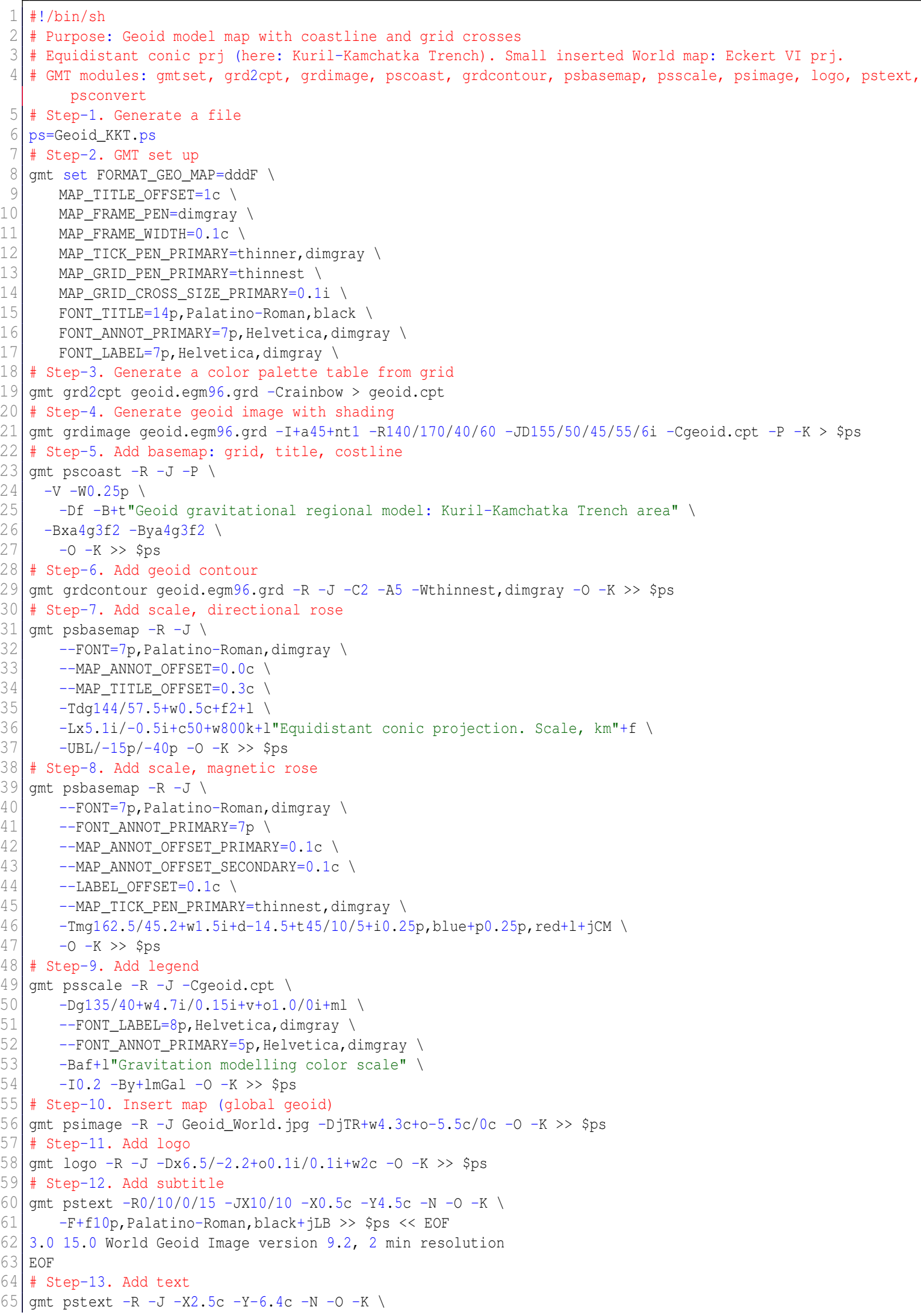




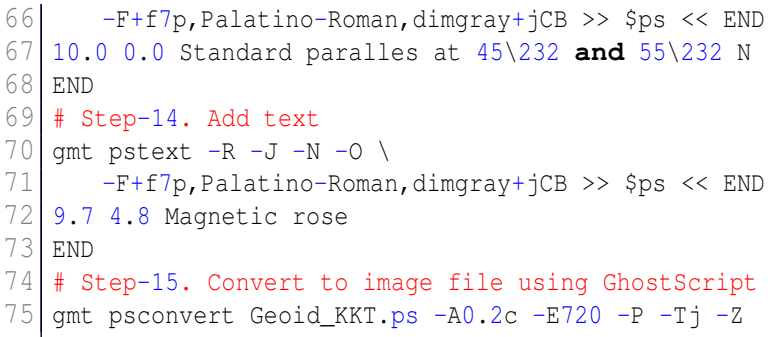

codes/GMT-04.sh

\section{A.4.5 GMT script for geological World map}

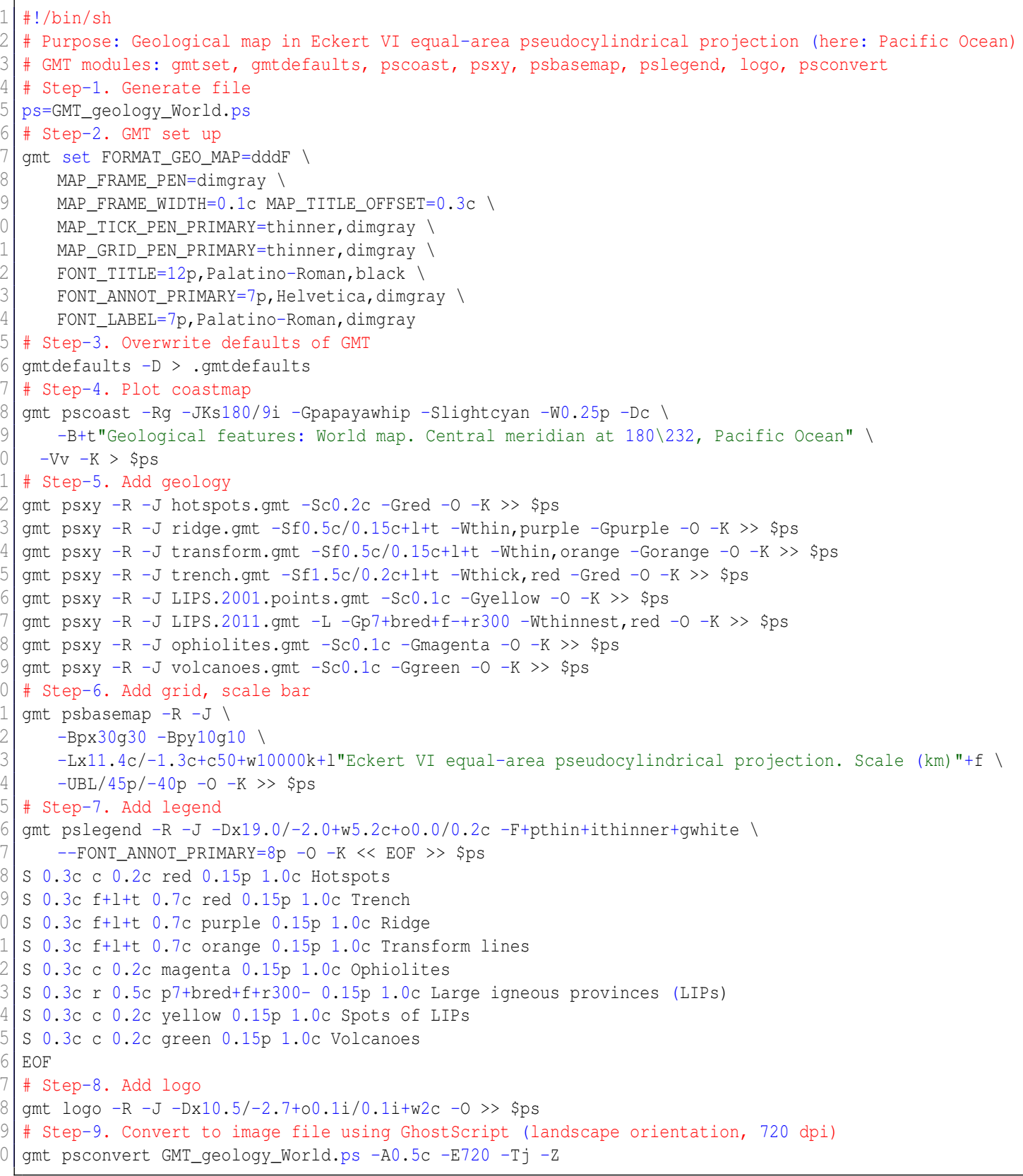

codes/GMT-05.sh 


\section{A.4.6 GMT script for regional geological map (here: MAT)}

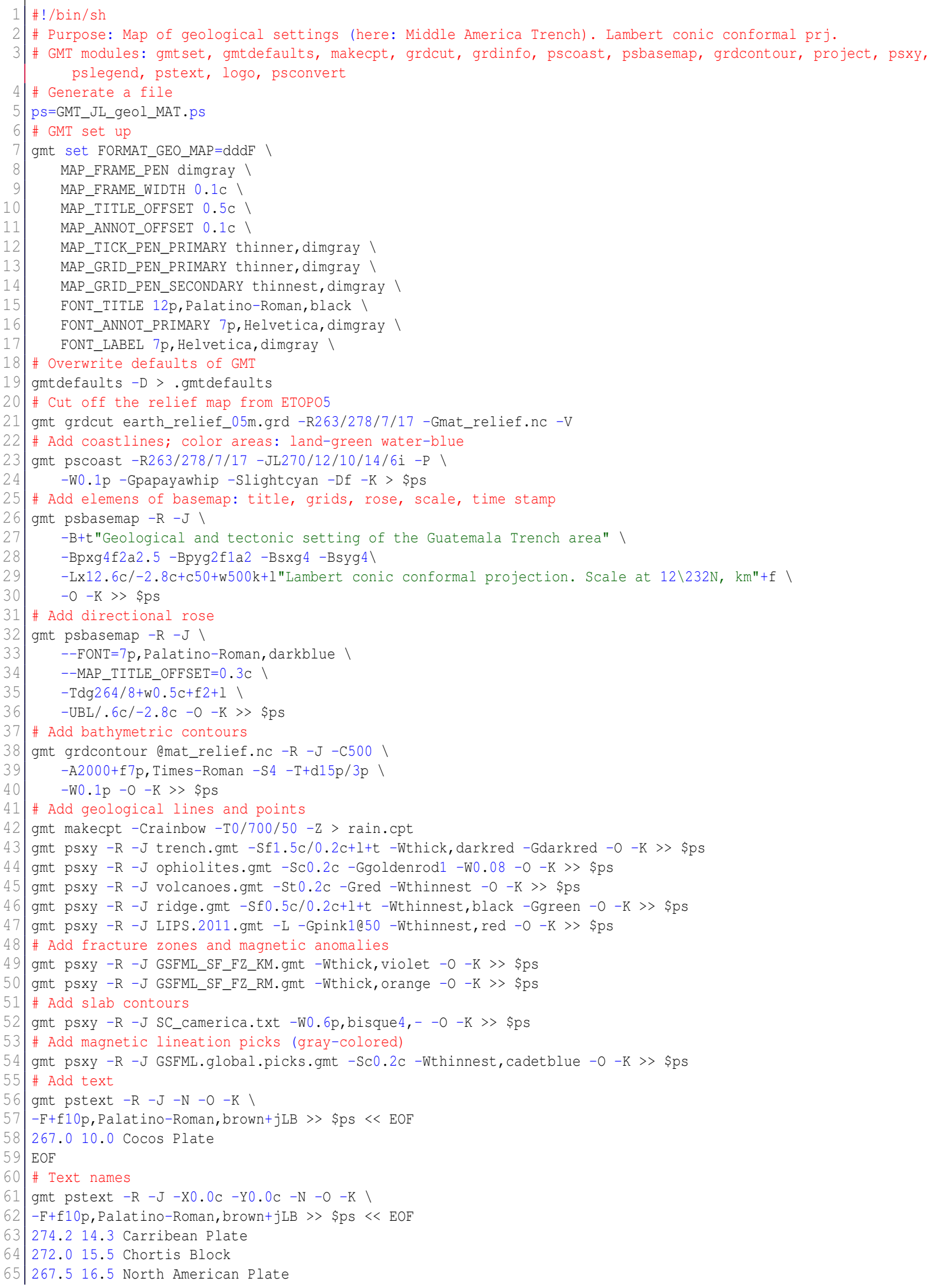




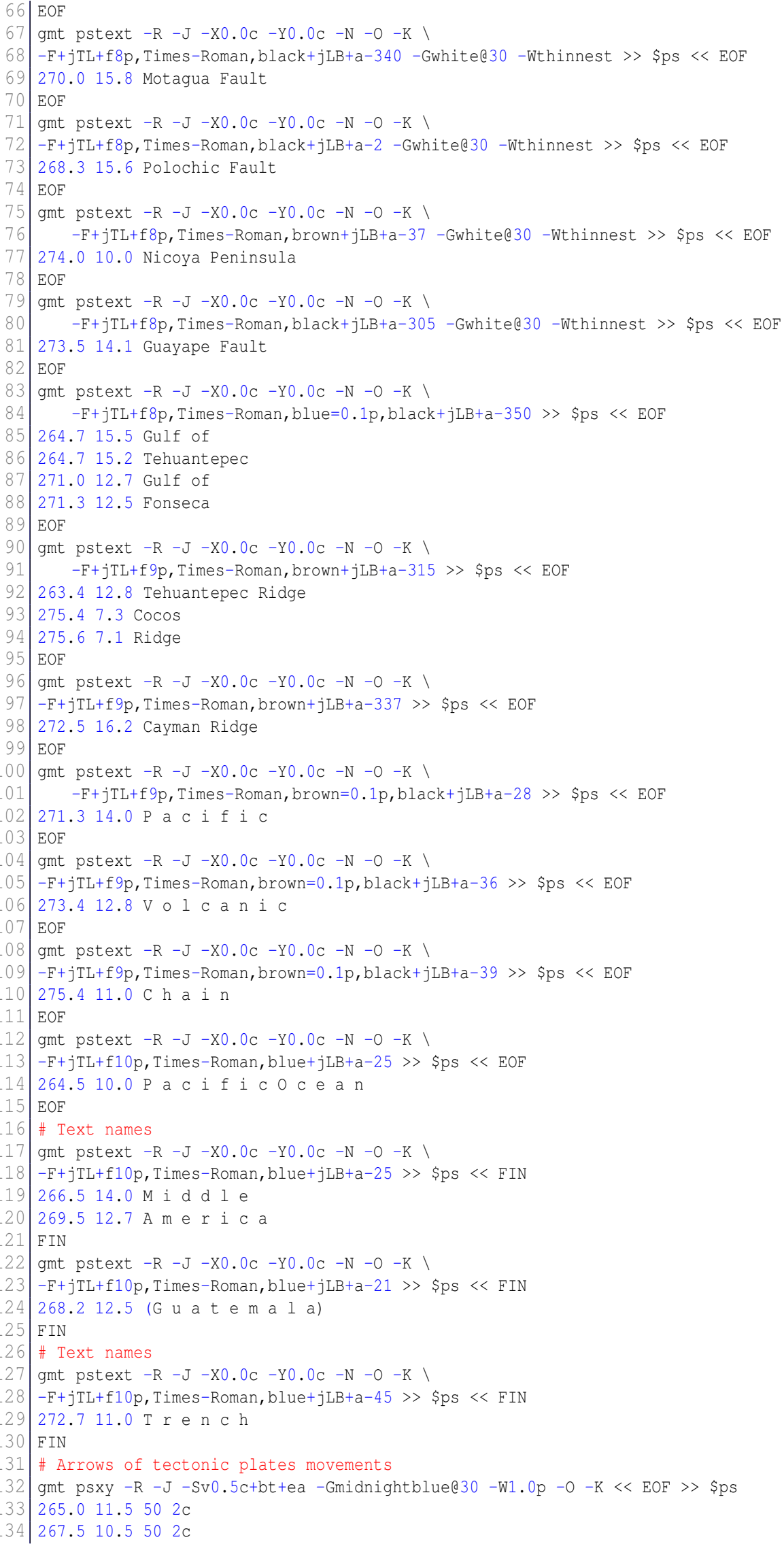




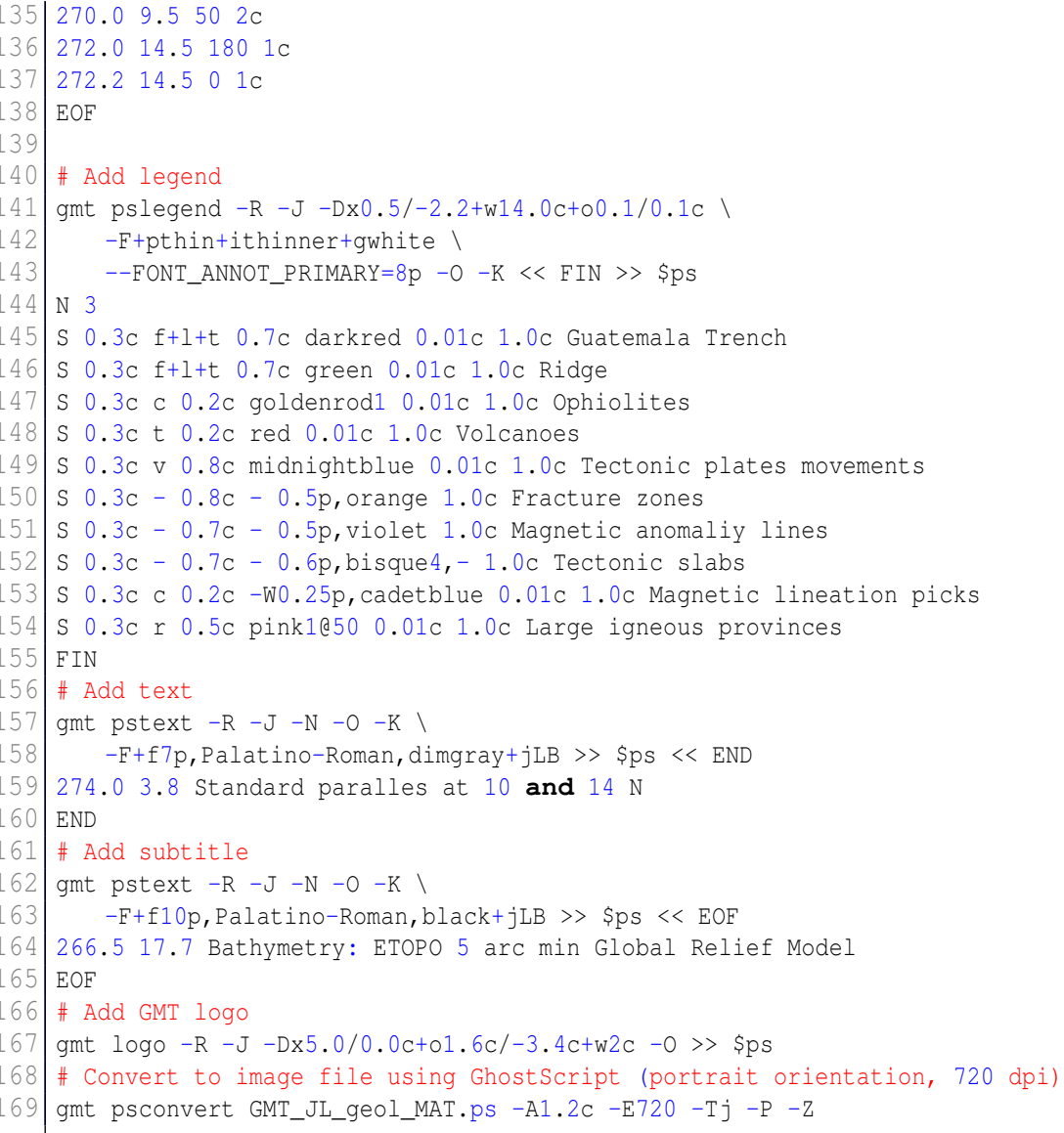

codes/GMT-06.sh 


\section{A.4.7 GMT script for free-air gravity modelling (here: KKT)}

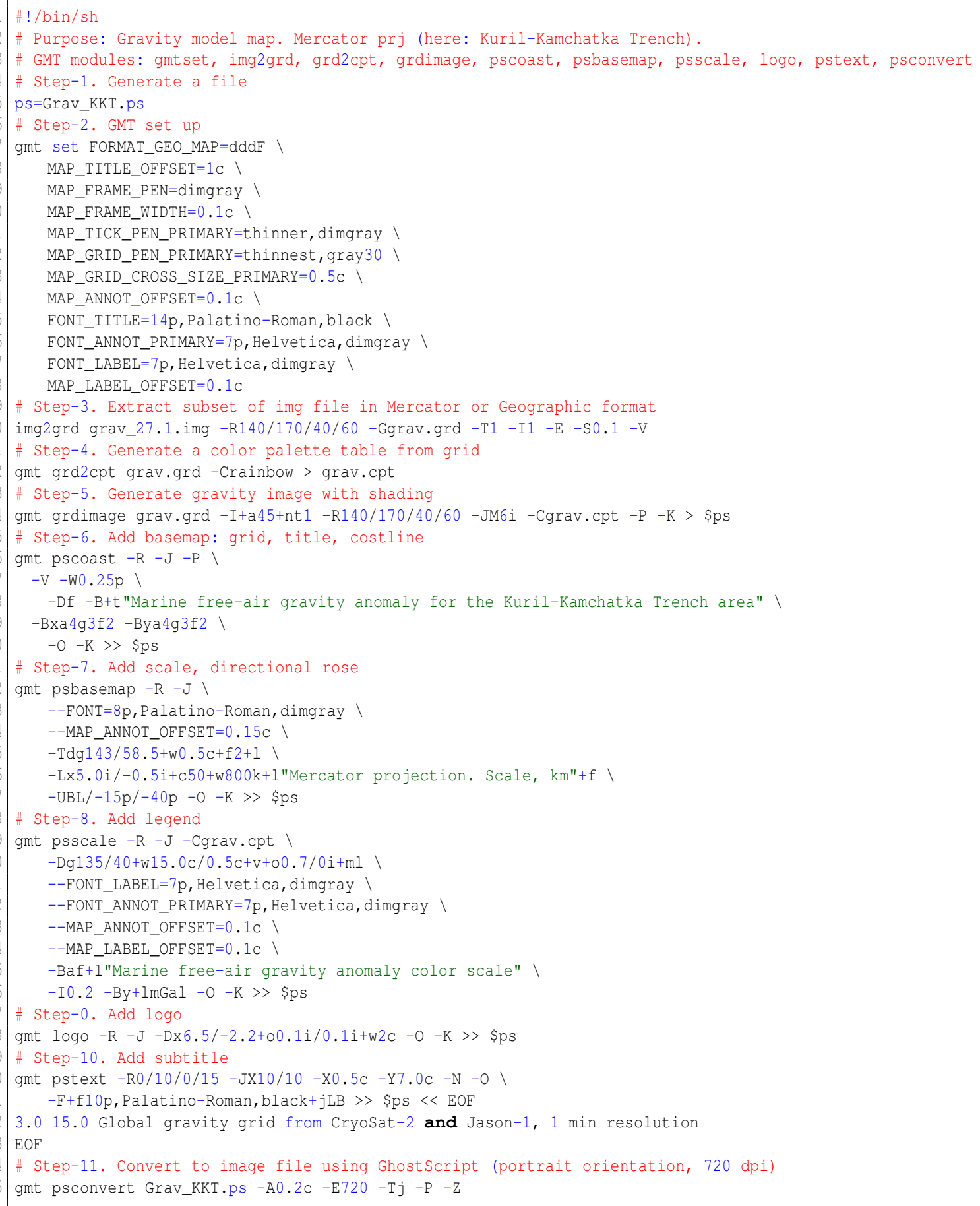

codes/GMT-07.sh 


\section{A.4.8 GMT script for generating and plotting stacked cross-sectioning bathymetric pro- files (here: MAT). Profiles info: $400 \mathrm{~km}$ long, spaced $20 \mathrm{~km}$, sampled every $2 \mathrm{~km}$}

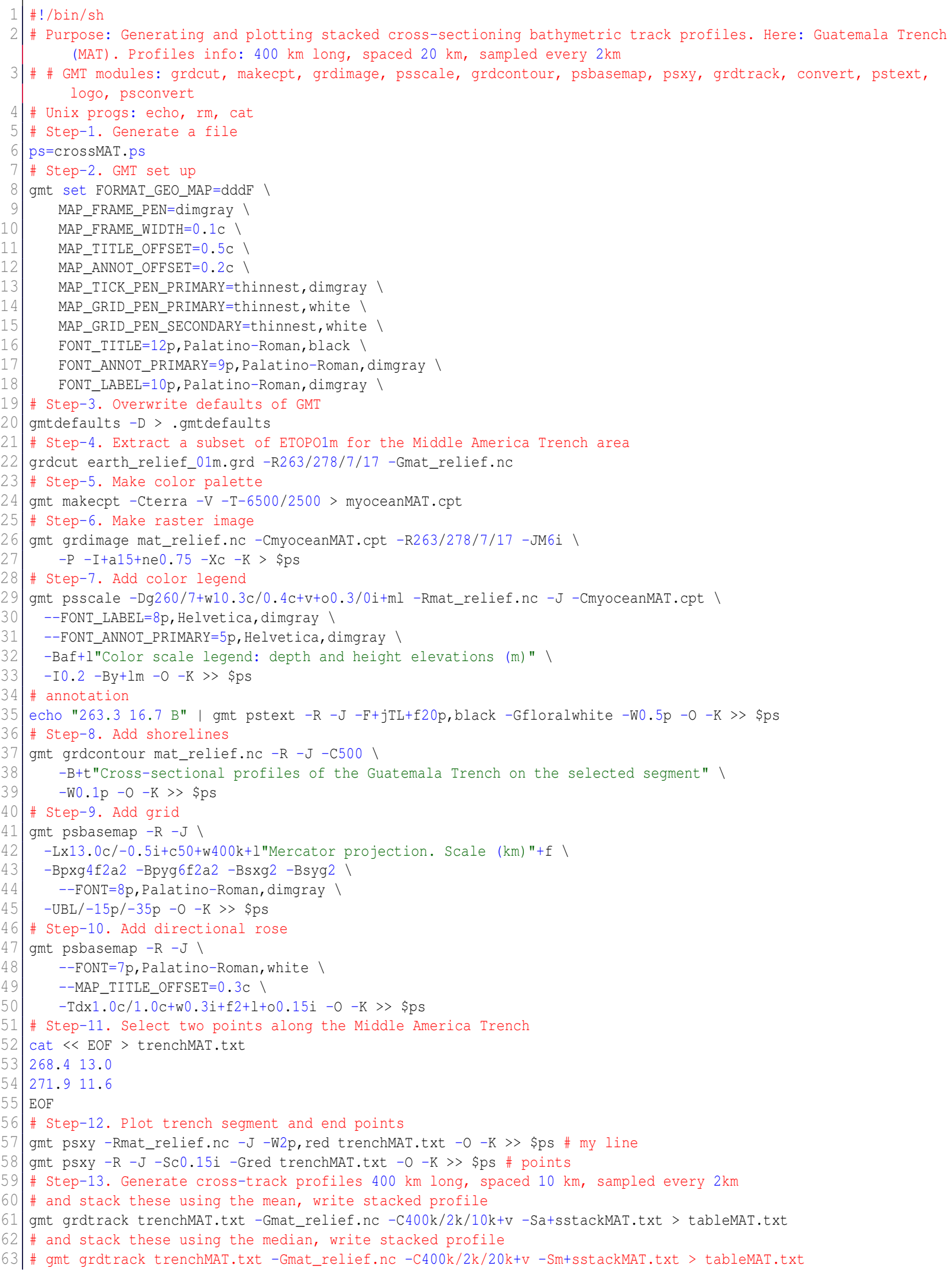


64 gmt psxy -R -J -W0.5p, yellow tableMAT.txt $-0-\mathrm{K}>\$ p s$

65 \# Step-14. Add text annotation

66 gmt pstext $-\mathrm{R}-\mathrm{J}-\mathrm{F}+\mathrm{f} 10$, Palatino-Roman, white $-0-\mathrm{K} \gg$ \$ps $<<$ END

6719247.5 profiles $400 \mathrm{~km}$ long, $20 \mathrm{~km}$ spaced

6819246.5 samples every $2 \mathrm{~km}$ along each profile

6918057 Pacific Ocean

70 END

71 \# Step-15. Show upper/lower values encountered as an envelope

72 gmt convert stackMAT.txt -00,5 > envMAT.txt

73 gmt convert stackMAT.txt -00,6 -I -T > envMAT.txt

74 \# Step-16. Plot graph (statistical mean for the profiles)

75 gmt psxy -R-200/200/-7000/2000 -JX15.2c/5c -Y13.0c envMAT.txt -W0.5p ।

-Bpxag100f10+1"Distance from trench $(\mathrm{km}) ">$

-Bpya2000gf+l"Depth (m) " ।

-Bsxg50 -Bsyg1000)

--FONT_ANNOT_PRIMARY=9p, Palatino-Roman, dimgray ।

- MAP_LABEL_OFFSET $=0.1 \mathrm{C} \backslash$

--MAP_GRID_PEN_PRIMARY=thinner, dimgray \

--MAP GRID PEN SECONDARY=thinnest, dimgray ।

--FONT_LABEL=10p, Palatino-Roman, dimgray -BWeSn ।

-Glightgray $-0-\mathrm{K}>$ \$ps

gmt psxy $-\mathrm{R}-\mathrm{J}-\mathrm{W} 1.0 \mathrm{p}-\mathrm{Ey}+\mathrm{p} 0.2 \mathrm{p}$ stackMAT.txt $-0-\mathrm{K} \gg \$ \mathrm{ps}$

gmt psxy $-\mathrm{R}-\mathrm{J}-\mathrm{W} 1.0 \mathrm{p}$, red stackMAT.txt $-0-\mathrm{K}>\$ \mathrm{ps}$

\# Step-17. Add test annotations

8 echo "0 1500 Mean stacked profile with error bars" | gmt pstext -R -J -Gwhite -F+jTC+f10p, red -0 -K >> \$ps

9 echo "120 -3000 Carribean Plate " | gmt pstext -R -J -F+jTC+f10p,orangered4 -Gwhite -0 -K >> \$ps

90 echo "-10 0 Guatemala Trench" | gmt pstext -R -J -F+f10p, orangered4+jTC -Gwhite $-0-\mathrm{K}>$ \$ps

1 echo "-100 -5000 Cocos Plate" | gmt pstext -R -J -F+jTC+f10p, orangered4 -Gwhite $-0-K>\$ p s$

92 echo "140 -1000 Chortis block" | gmt pstext -R -J - F+jTL+f10p, darkbrown -Gwhite -0 -K >> \$ps

93 echo "15 -5500 Oceanward Forearc" | gmt pstext -R -J -F+jTL+f10p, darkbrown+a-310 -Gwhite -0 -K >> \$ps

94 echo "-190 1500 A" | gmt pstext -R -J -F+jTL+f18p,black -Gfloralwhite -W0.5p -0 -K > \$ps

95 \# Arrow

96 gmt psxy -R -J -Sv0.15i+bctea -Gyellow -W0.5p -0 -K $<$ EOF $>$ \$ps

$97-3-1000 \quad 270 \quad 2.2 \mathrm{C}$

$98 \mathrm{EOF}$

99 \# Step-18. Add GMT logo

100 gmt logo $-\mathrm{Dx} 6.2 /-14.7+0.25 \mathrm{c} / 1.5 \mathrm{c}+\mathrm{w} 2 \mathrm{c}-0>$ ps

101 \# Step-19. Clean up

102 \#rm -f z.cpt trenchA2.txt tableA2.txt envA2.txt stackA2.txt

103 \# Step-20. Convert to image file using GhostScript (portrait orientation, 720 dpi)

104 gmt psconvert crossMAT.ps -A0.2C -E720 - Tj -P - Z

codes/GMT-08.sh 


\section{A.4.9 GMT script for topographic surface modelling from the xyz ASCII data (here: MT)}

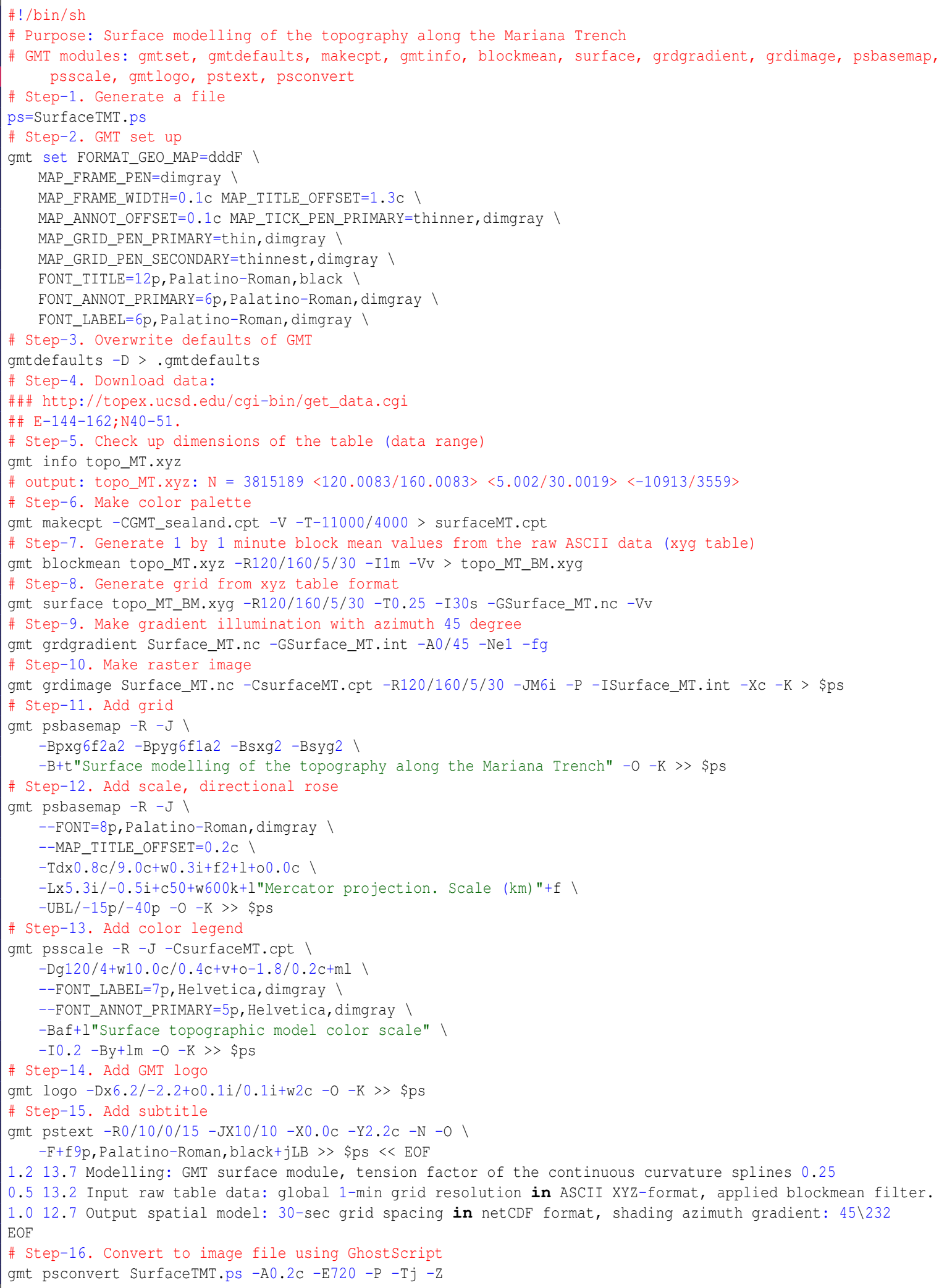

codes/GMT-09.sh 


\section{A.4.10 GMT script for gridding xyz data by Nearest Neighbor algorithm (here: KKT)}

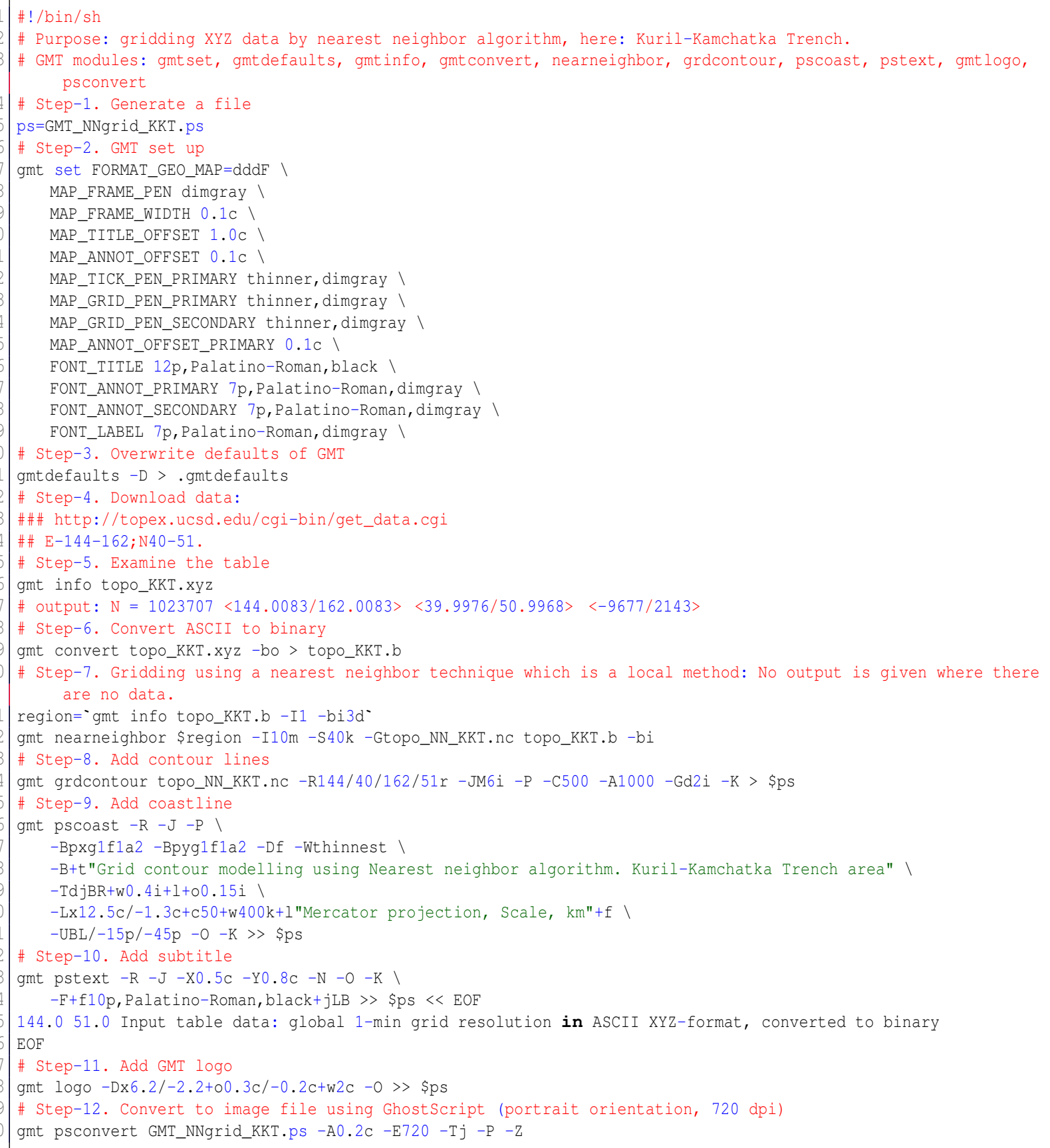

codes/GMT-10.sh 


\section{A.4.11 GMT script for regression trend1d mixed models (here: AT)}

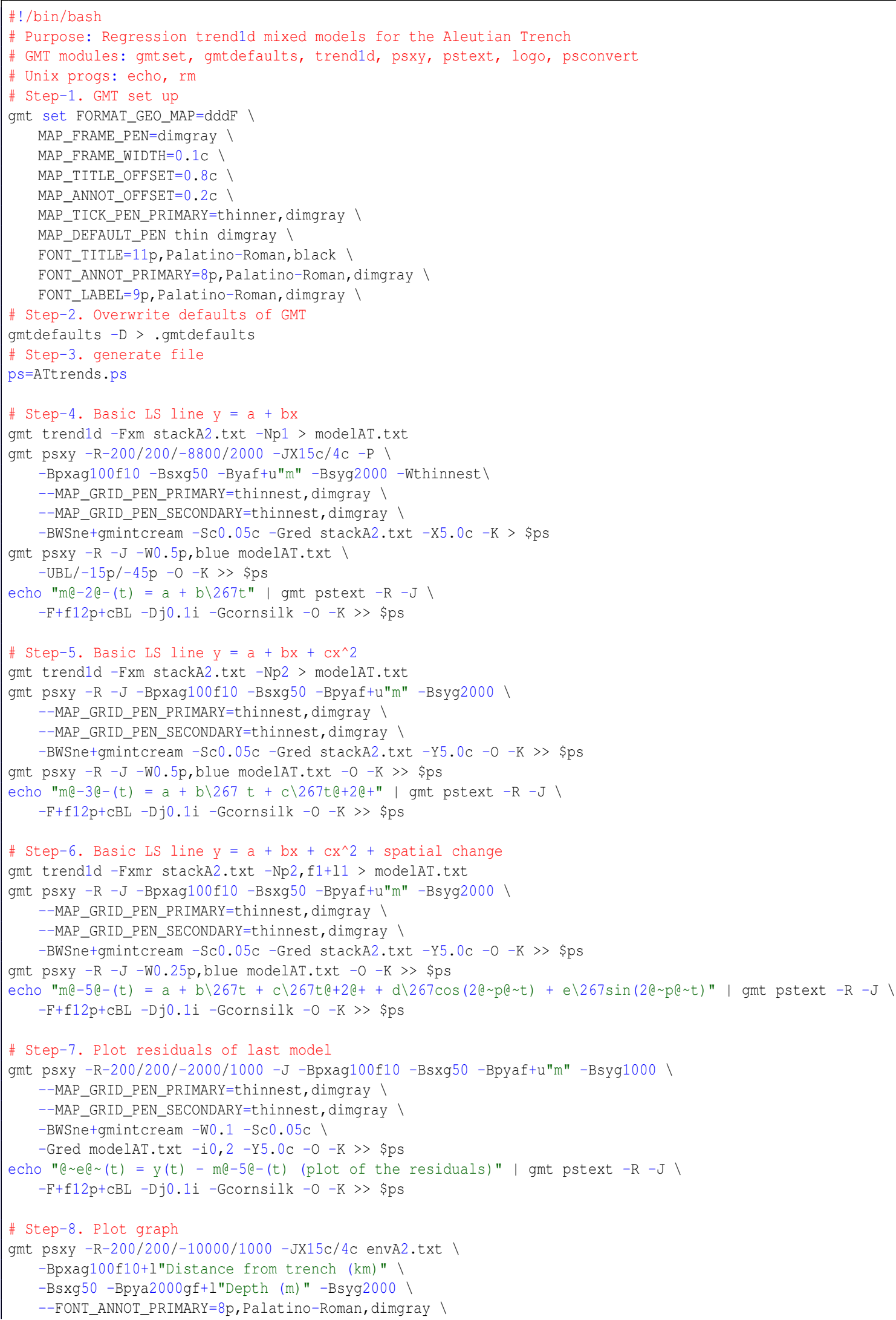




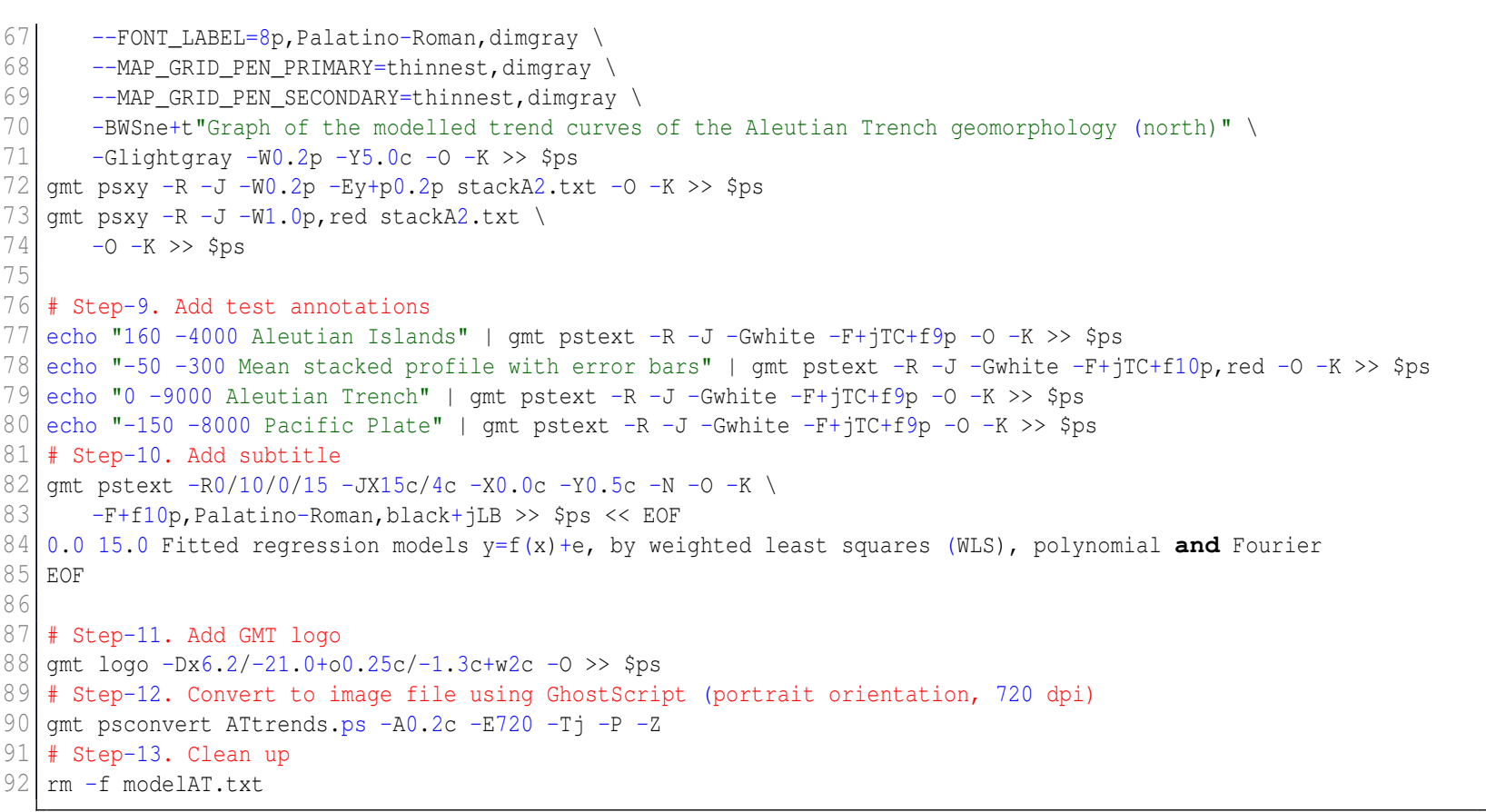

codes/GMT-11.sh 


\section{A.4.12 GMT script for 2D bar histogram and rose diagram (here: MAT)}

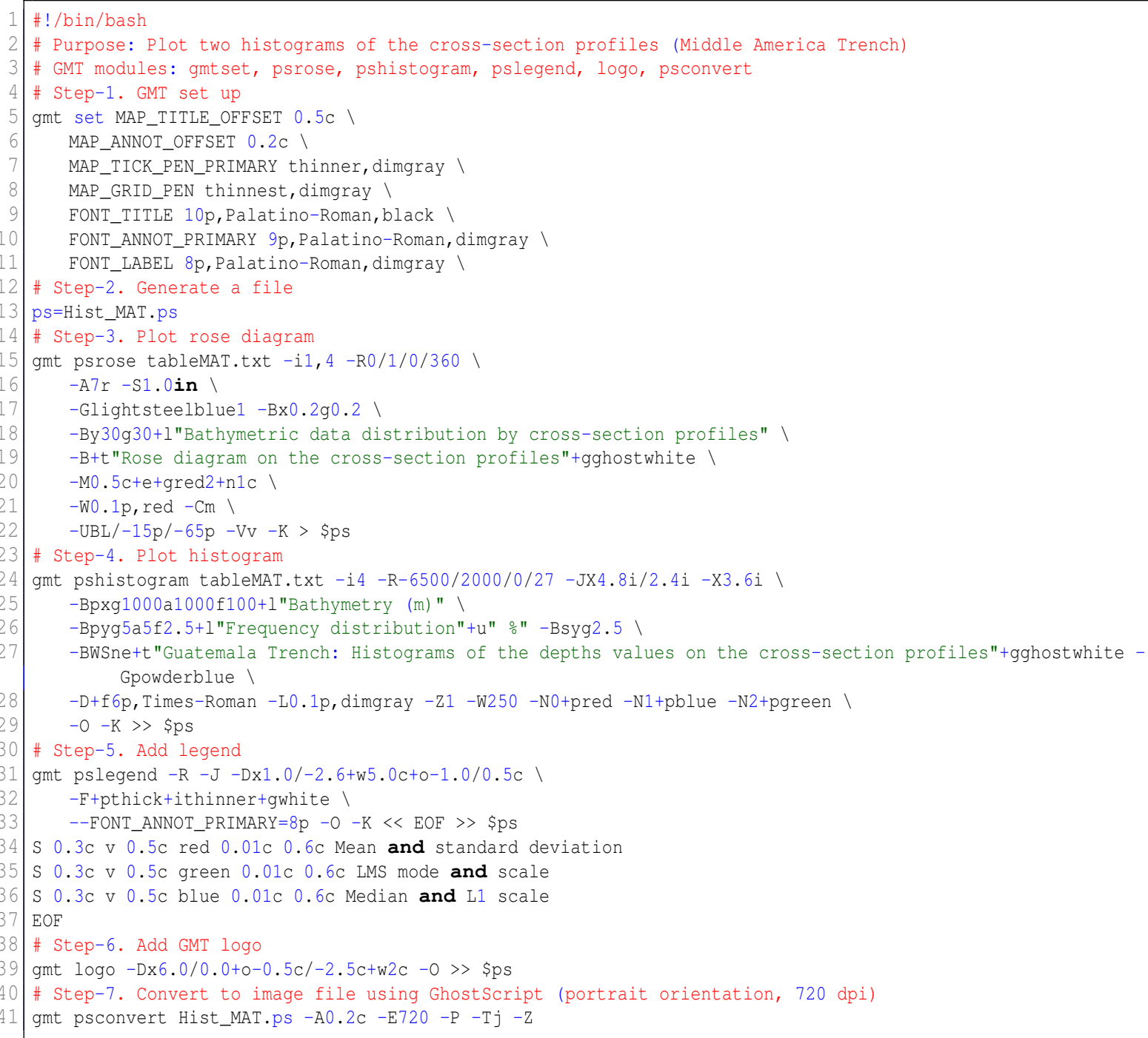

codes/GMT-12.sh 


\section{A.4.13 GMT script for 3D bar histogram plot (here: KKT)}

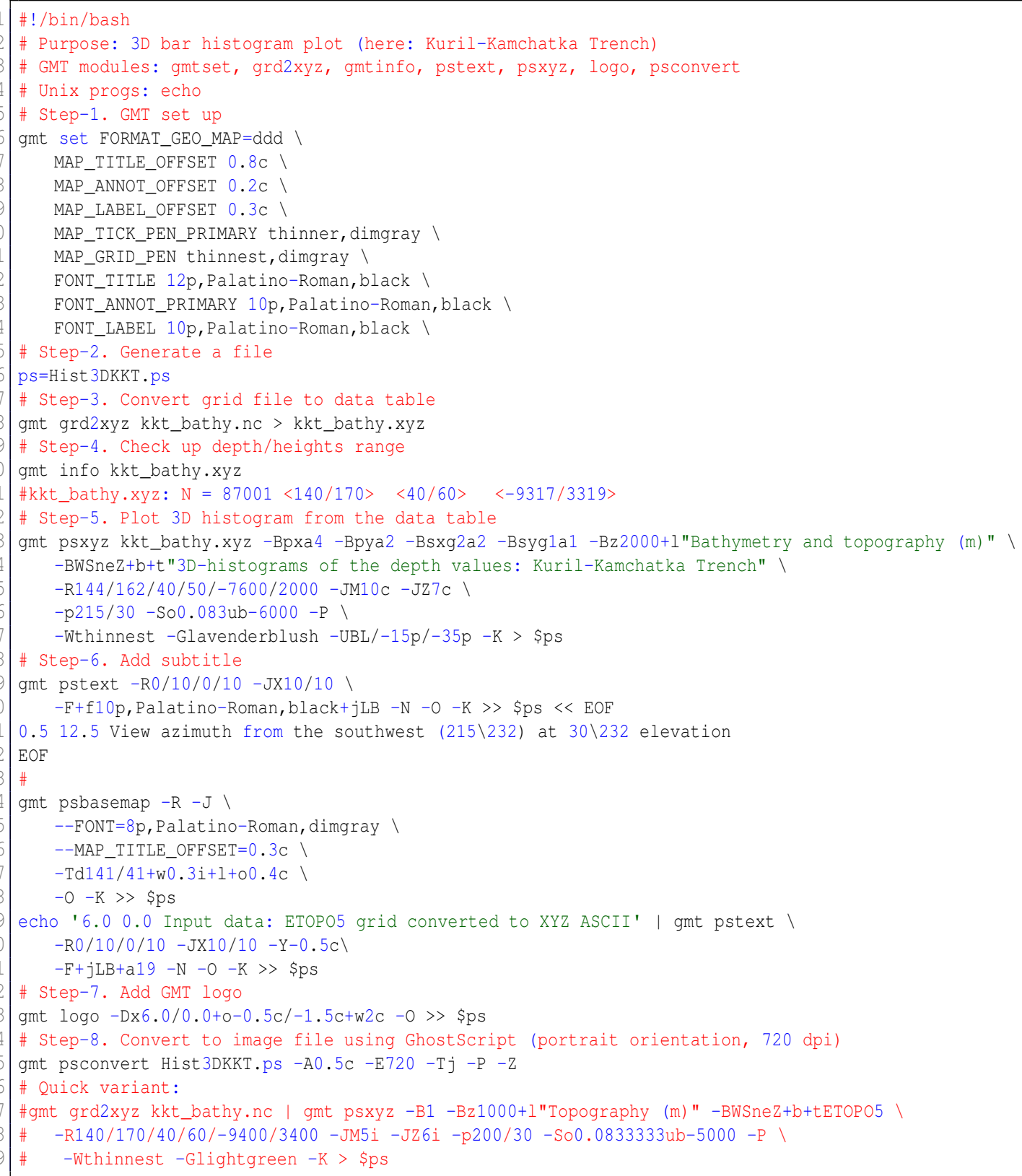

codes/GMT-13.sh 


\section{A.5 Python language scripts}

\section{A.5.1 Python code for statistical data analysis by violin plots}

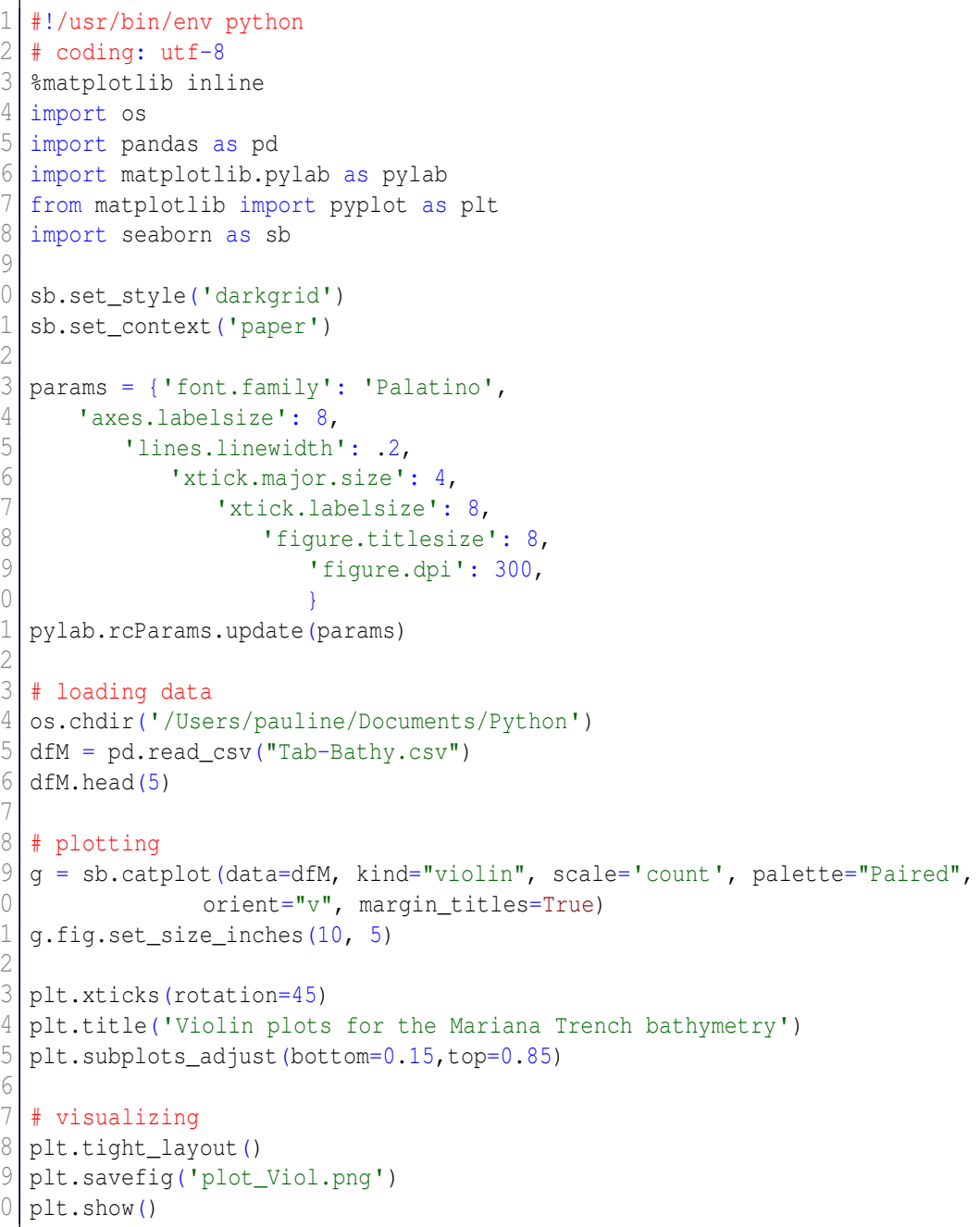

codes/Python-01.py

\section{A.5.2 Python code for clustermap: bathymetric data distribution by profiles}

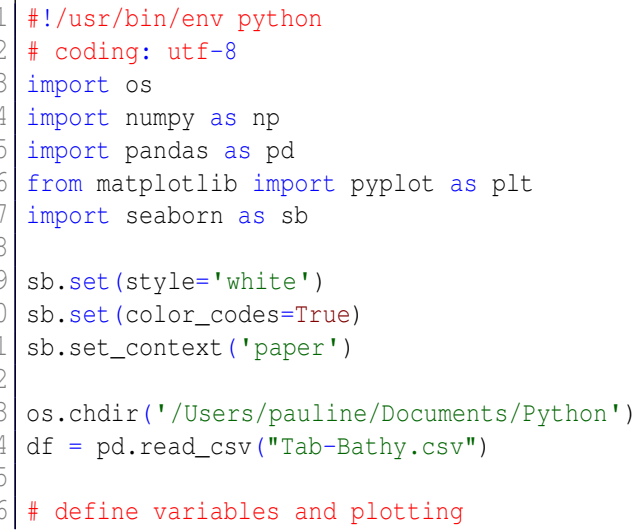




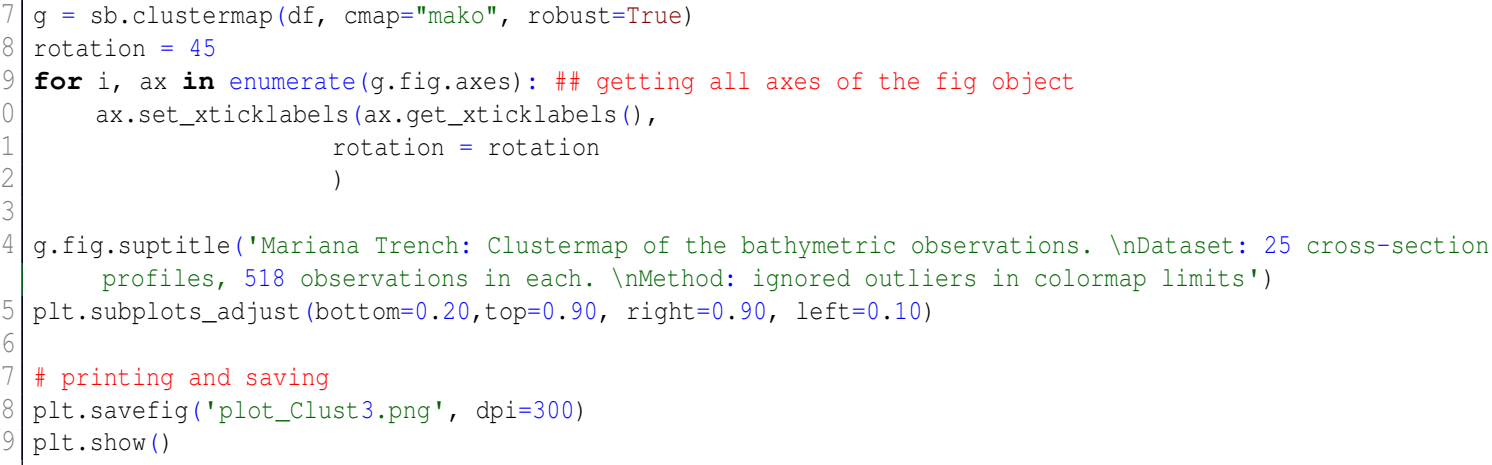

codes/Python-02.py

\section{A.5.3 Python code for histograms: distribution of the observation samples}

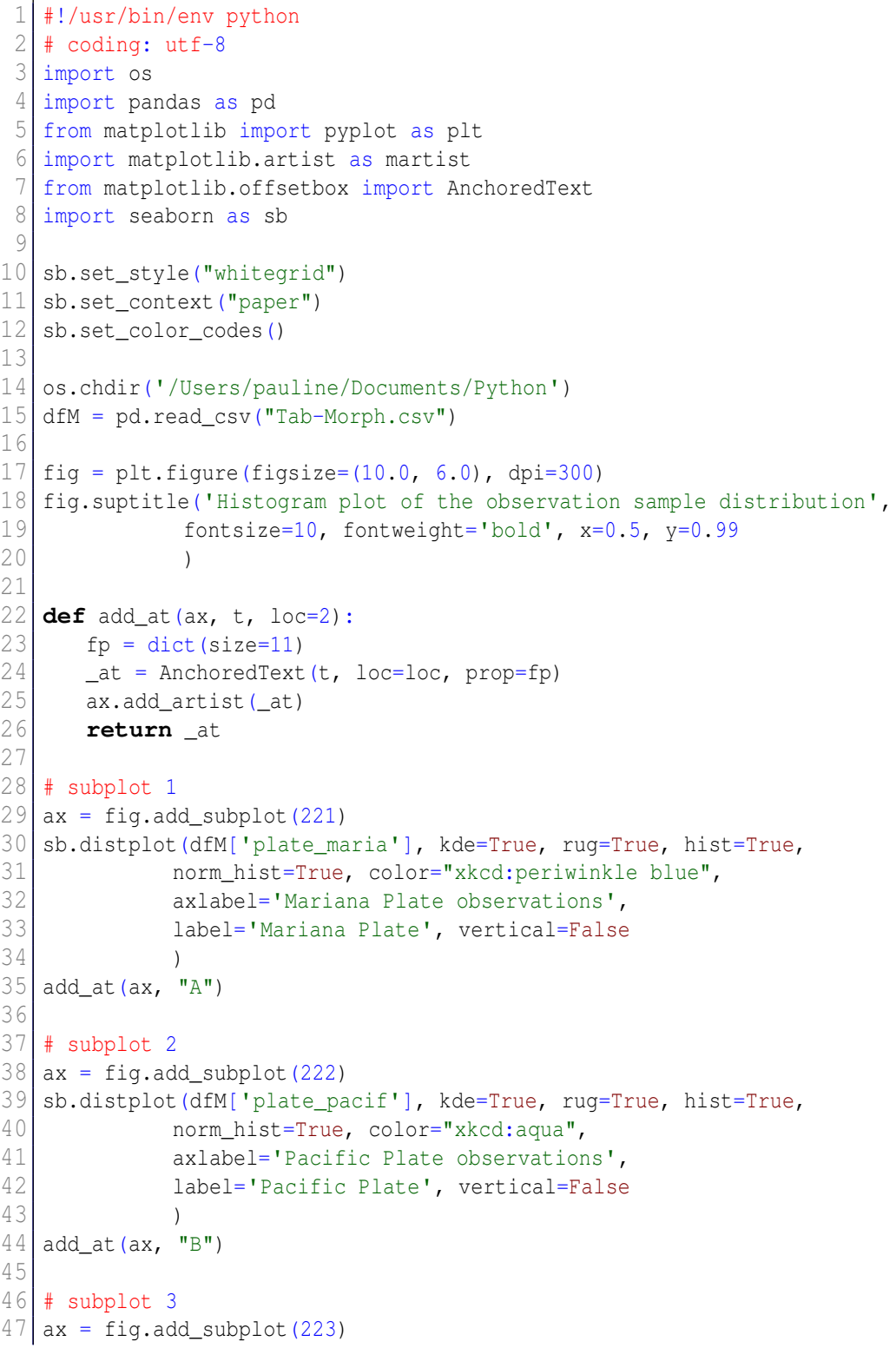




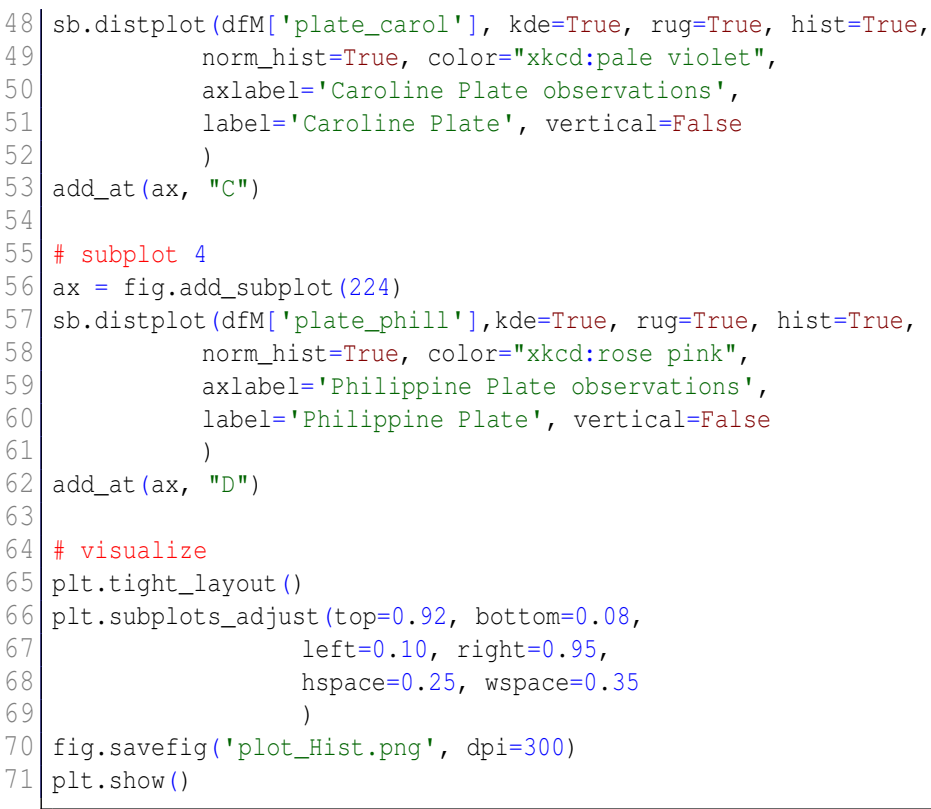

codes/Python-03.py

\section{A.5.4 Letter-value plots for the Mariana Trench bathymetry}

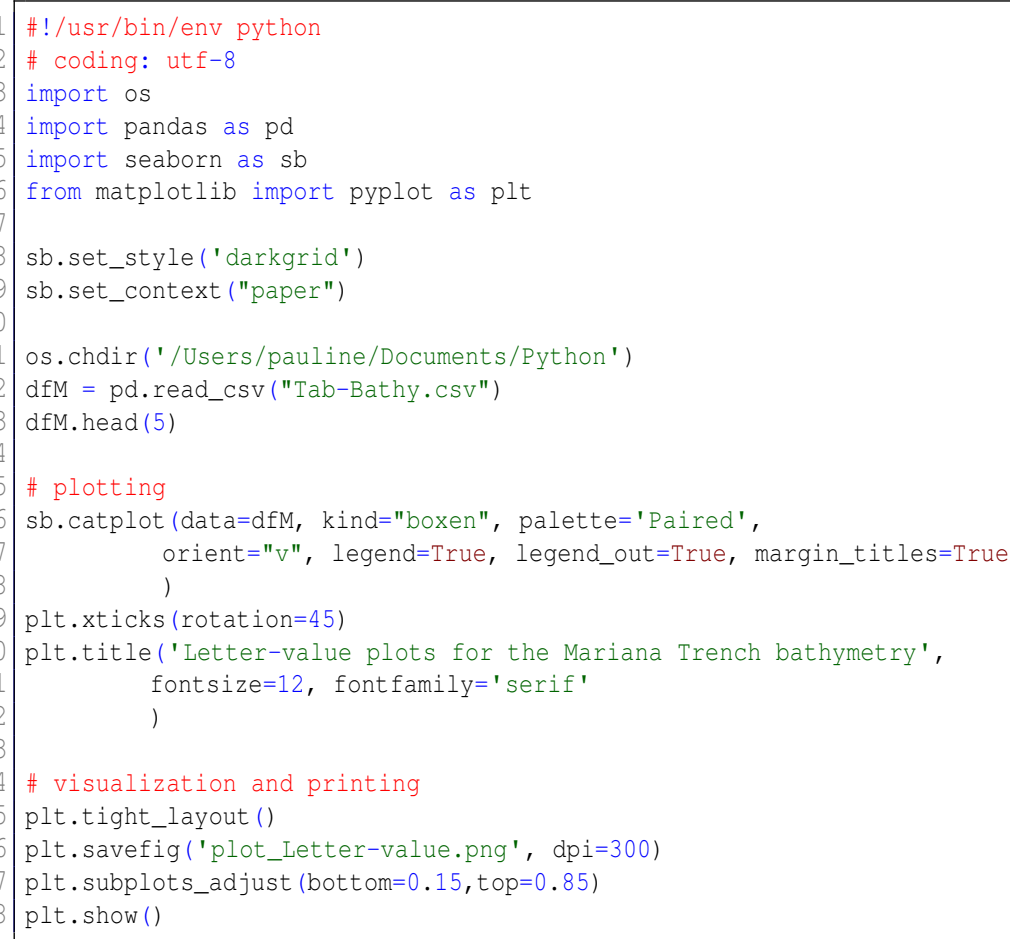

codes/Python-04.py 


\section{A.5.5 Python code for the strip plots (here: Philippine Trench)}

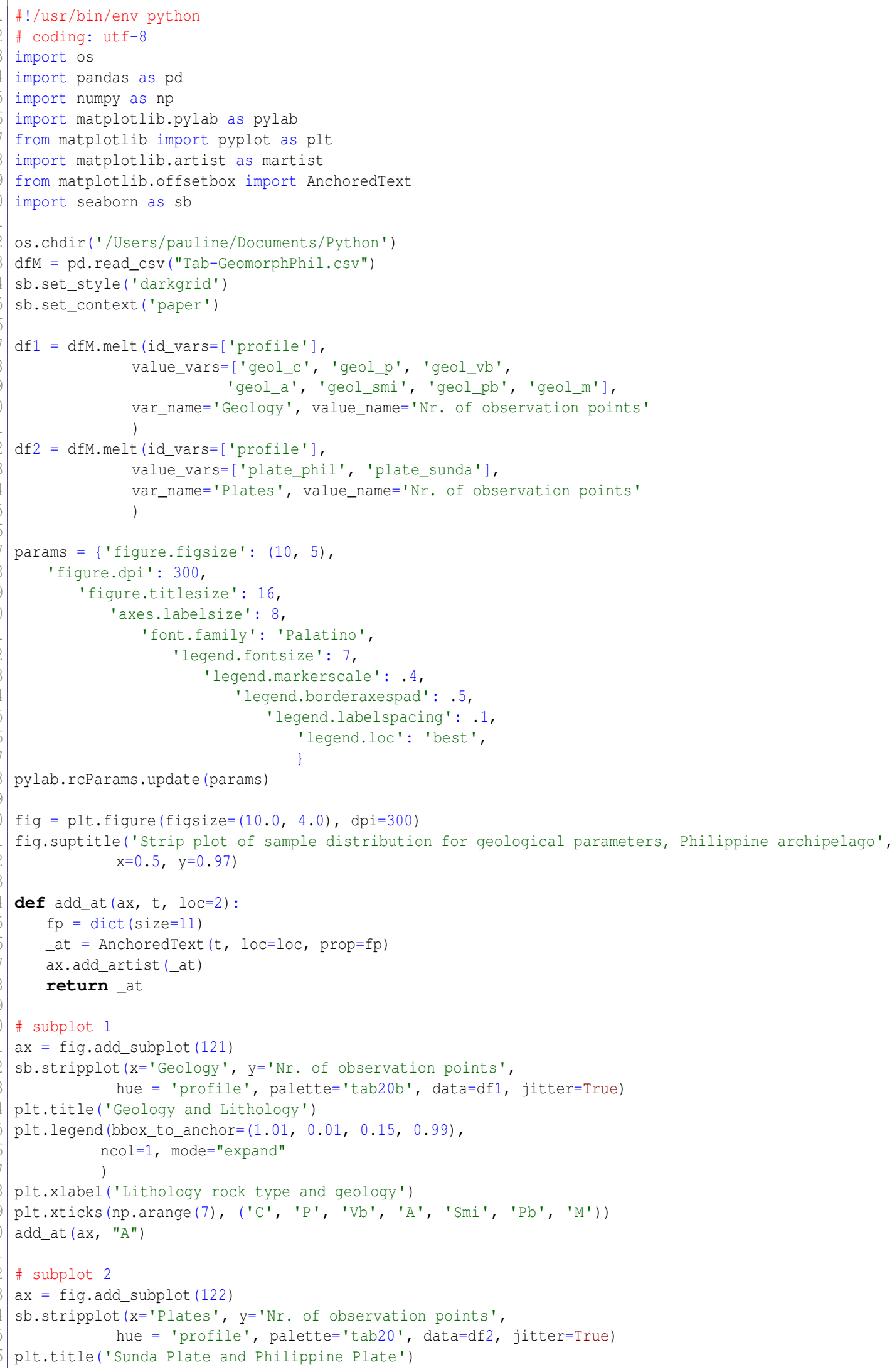




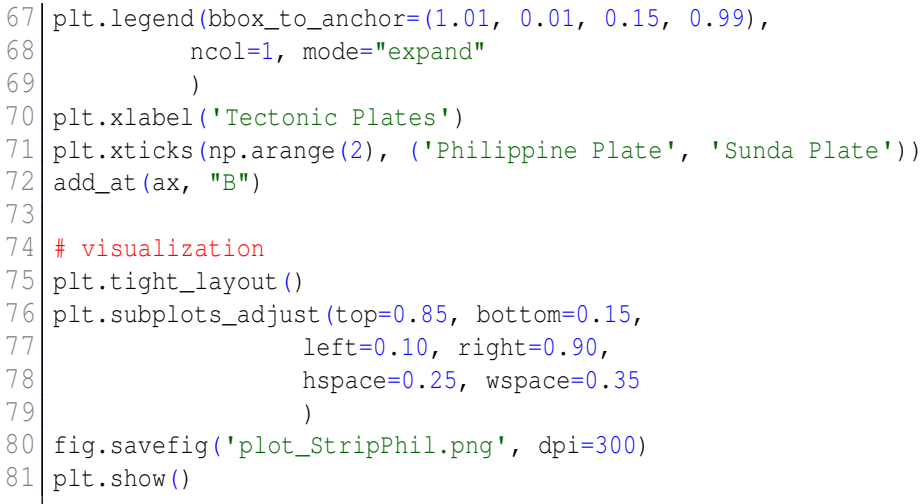

codes/Python-05.py

\section{A.5.6 Python code for the correlogram matrices by Seaborn library}

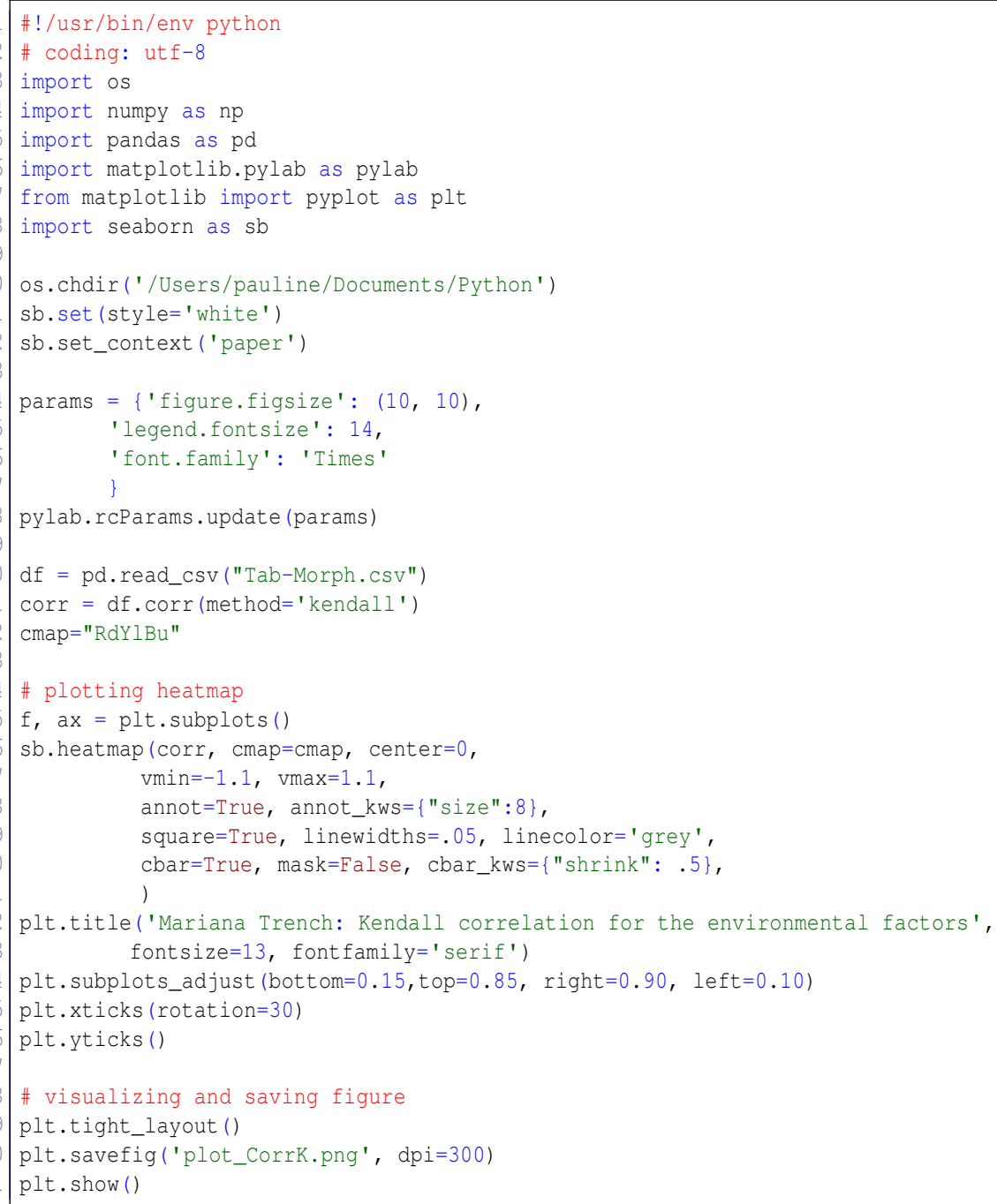

codes/Python-06.py 


\section{A.5.7 Python code for the regression analysis}

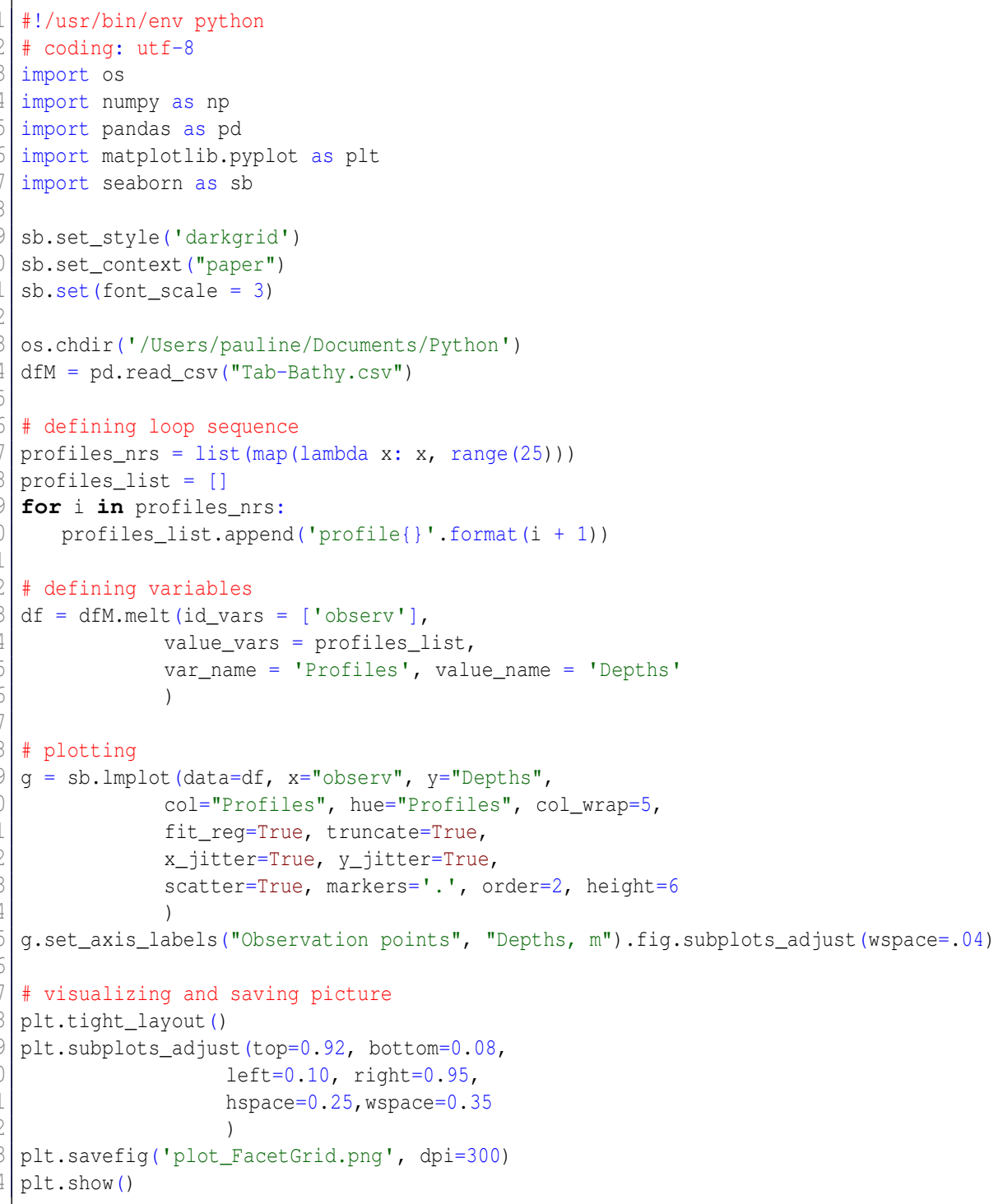

codes/Python-07.py

\section{A.5.8 Python code for Letter-value plots for the Mariana Trench bathymetry}

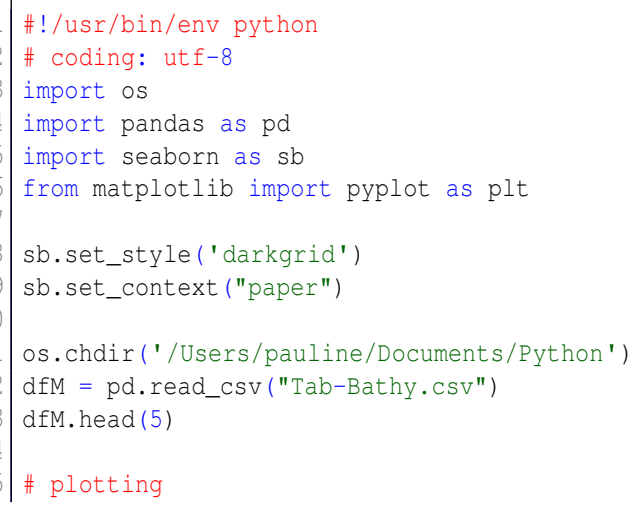




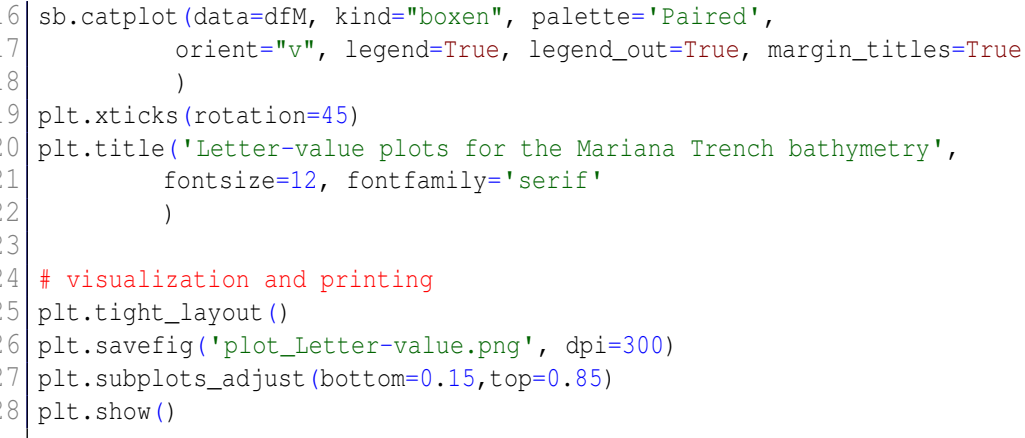

codes/Python-04.py

\section{A.5.9 Python code for joint Hexagonal and KDE plots}

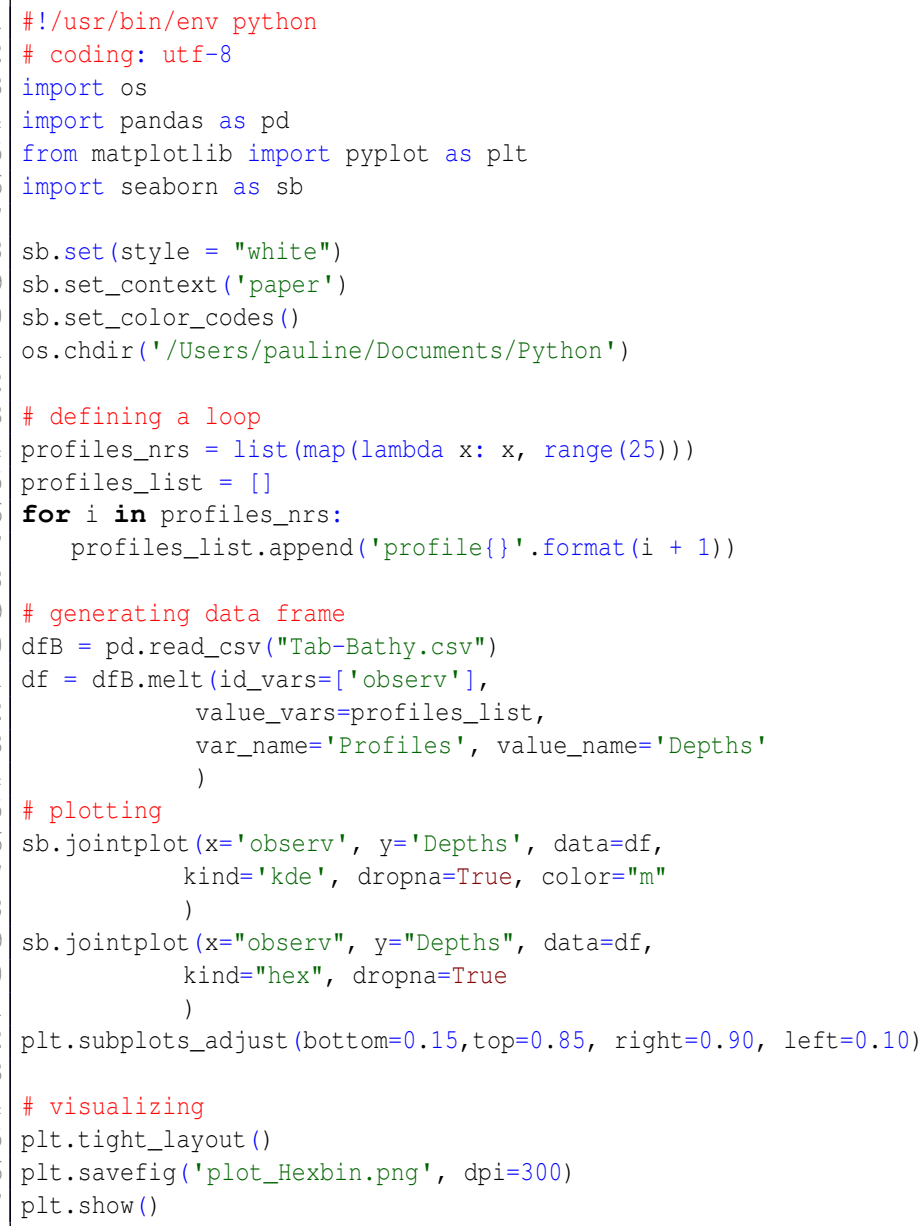

codes/Python-09.py

\section{A.5.10 Python code for the correlogram plot (here: Pearson's method)}

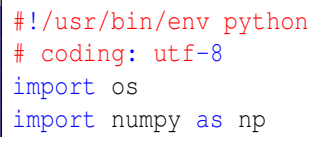




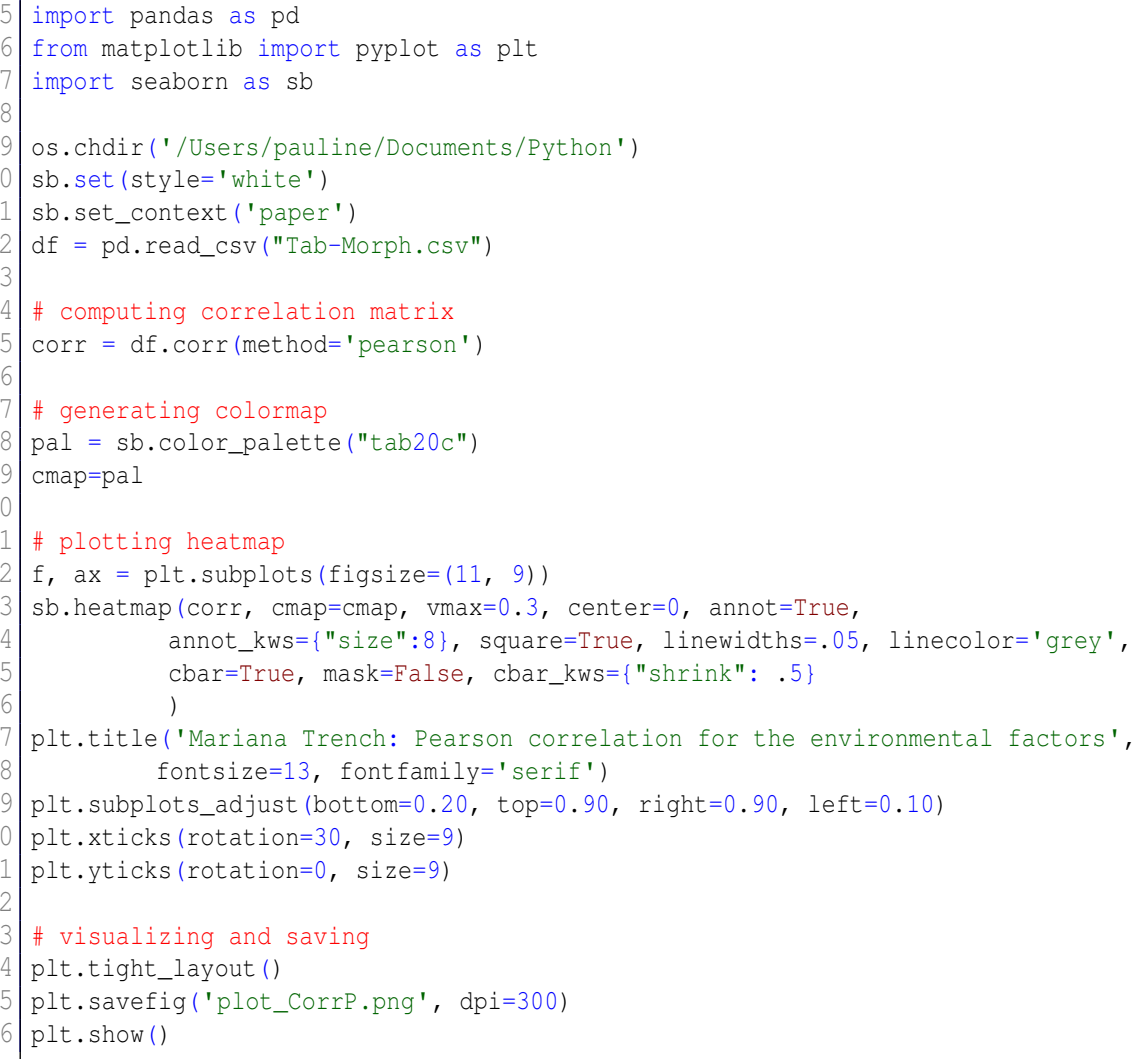

codes/Python-10.py

\section{A.5.11 Python code for a box-and-whisker plot for the Mariana Trench bathymetry}

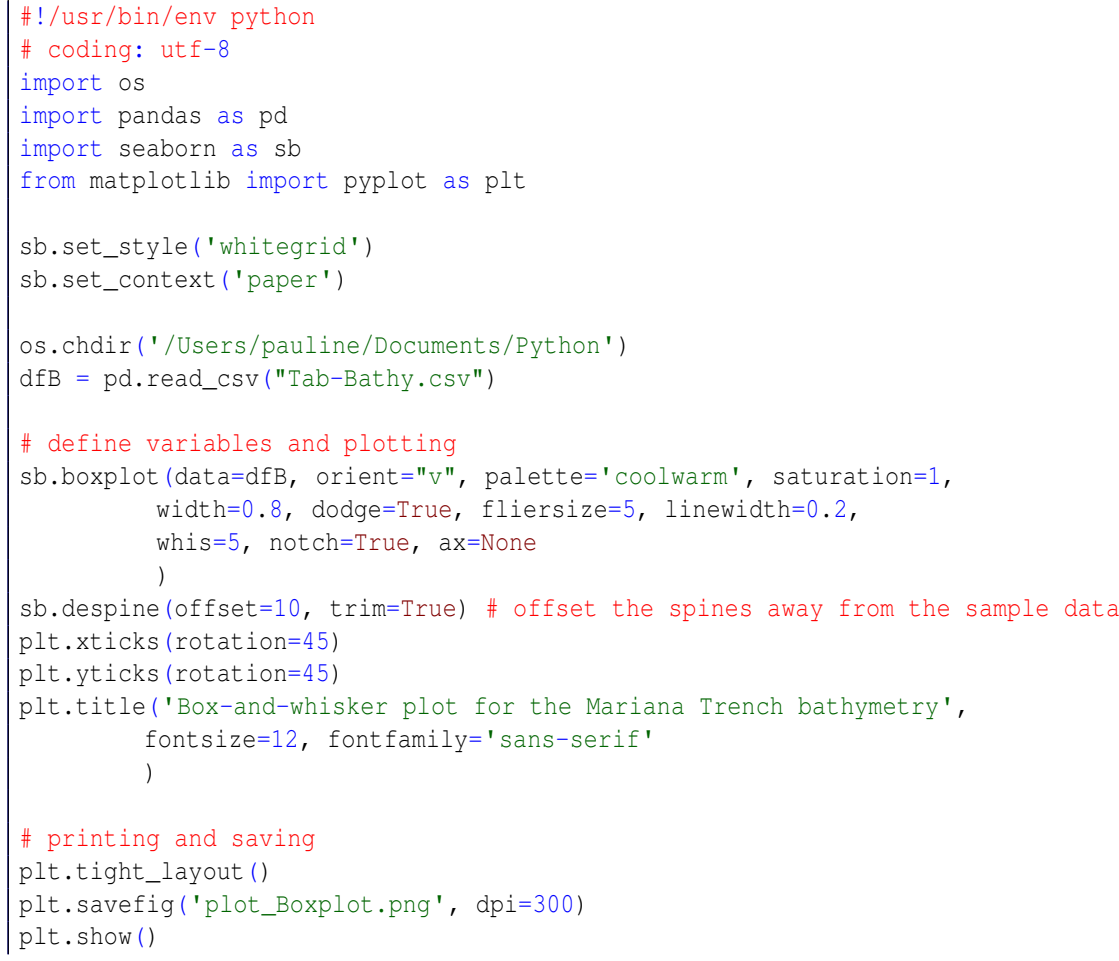


codes/Python-11.py

\section{A.5.12 Python code for sorting data in stem plots: analysis of the angle steepness}

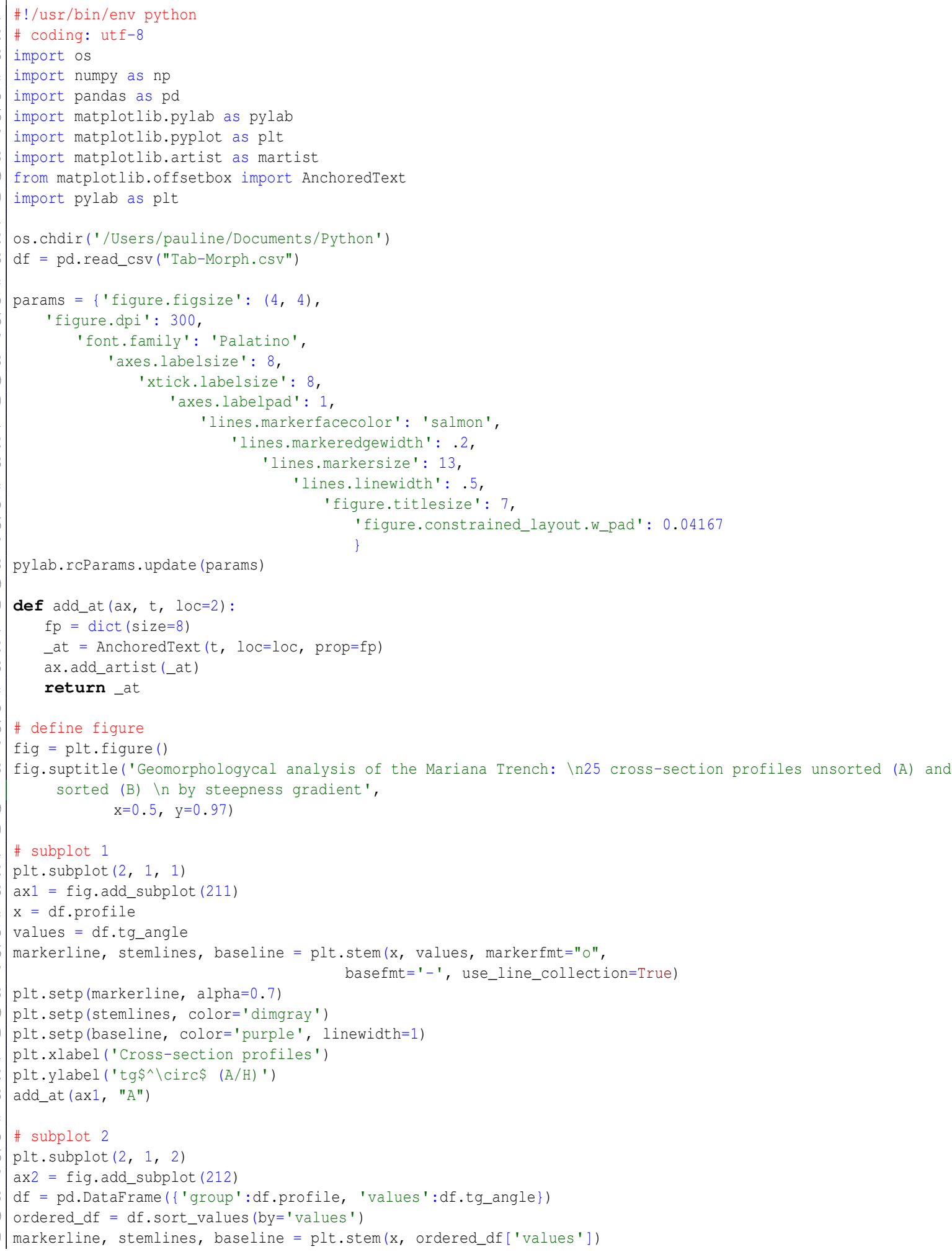


61 plt.setp (markerline, alpha=0.7)

62 plt.xticks (x, ordered_df ['group'])

3 plt.xlabel ('Cross-section profiles')

4 plt.ylabel ('tg\$^\Circ\$ (A/H) ')

5 add_at (ax2, "B")

7 \# visualizing

plt.tight_layout ()

plt.subplots_adjust $($ top $=0.85$, bott $o m=0.15$,

left $=0.20$, right $=0.95$,

hspace $=0.25$, wspace $=2.8$

plt.savefig('plot_Stems.png')

plt.show ()

codes/Python-12.py

\section{A.5.13 Python code for plotting dendrograms}

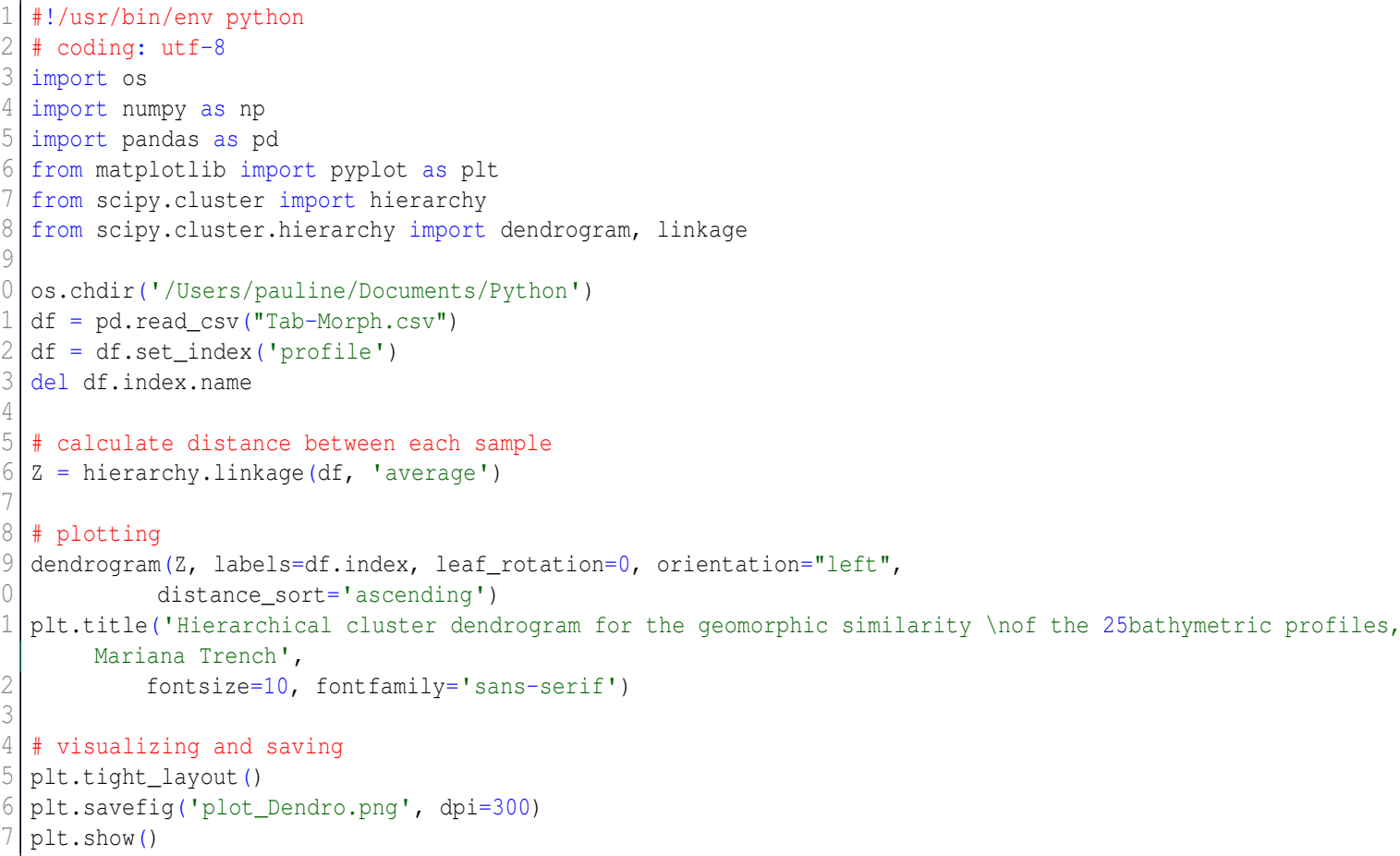

codes/Python-13.py

\section{A.5.14 Python code for 3D scatter plots: correlation of the factors (sediment thickness, slope steepness, bathymetry)}

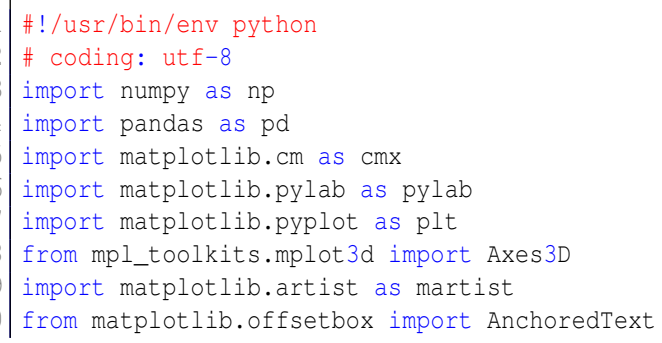




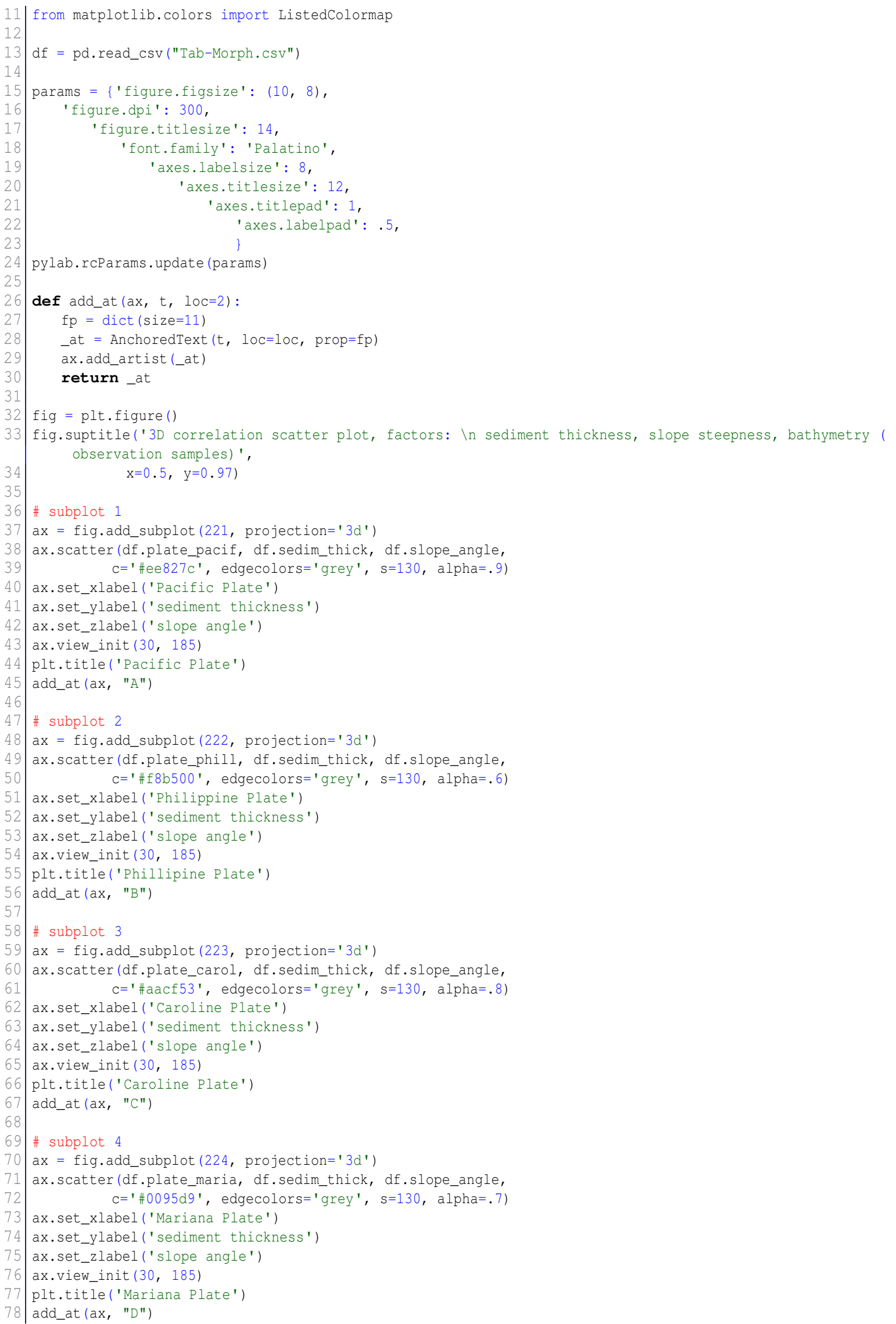




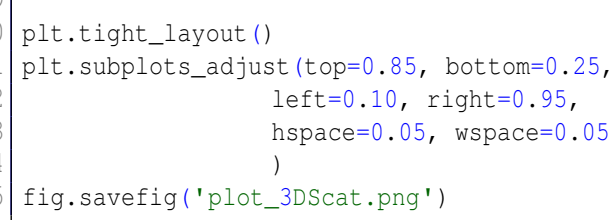

codes/Python-14.py

\section{A.5.15 Python code for ANOVA}

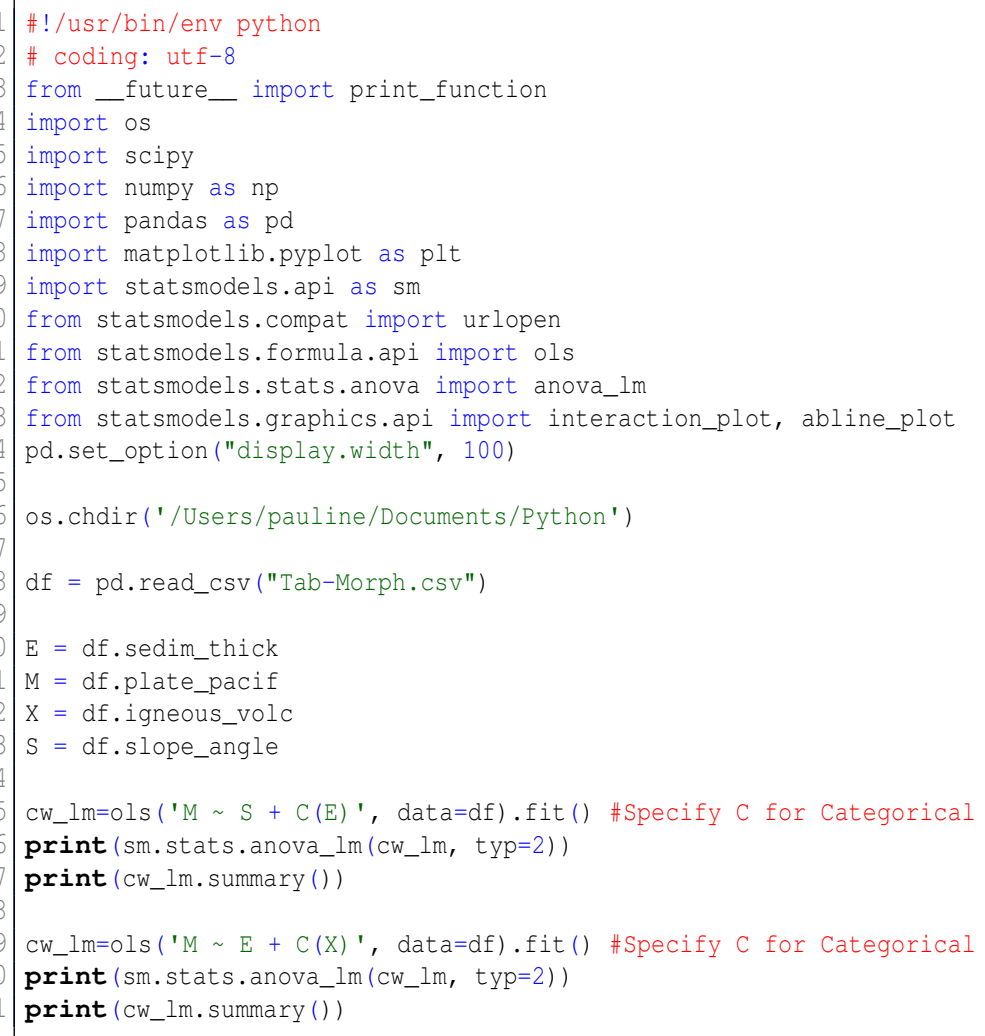

codes/Python-15.py

\section{A.5.16 Python code for KDE, example for the subplot (F)}

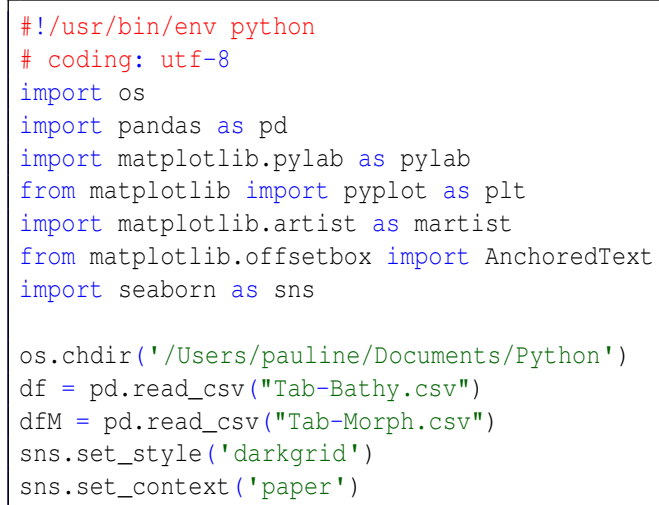




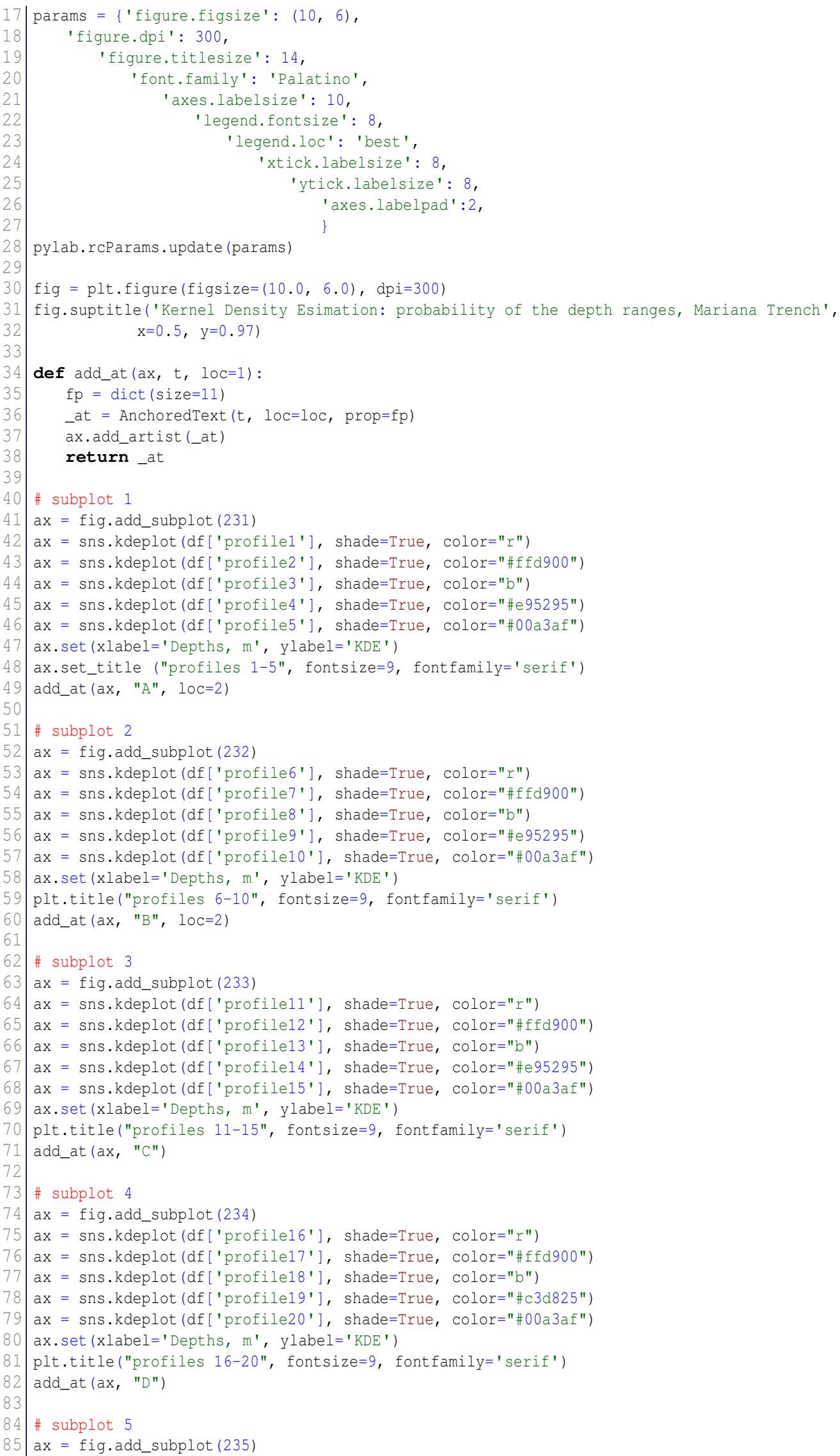


B 6 ax = sns.kdeplot (df['profile21'], shade=True, color="r")

$7 \mathrm{ax}=$ sns.kdeplot (df ['profile22'], shade=True, color="\#ffd900")

$8 \mathrm{ax}=$ sns.kdeplot (df ['profile23'], shade=True, color="b")

$a x=$ sns.kdeplot (df ['profile24'], shade=True, color="\#c3d825")

ax = sns.kdeplot (df ['profile25'], shade=True, color="\#00a3af")

ax.set (xlabel='Depths, m', ylabel='KDE')

plt.title ("profiles 21-25")

add_at (ax, "E")

\# subplot 6

ax = fig.add_subplot (236)

$\mathrm{ax}=$ sns.kdeplot (dfM['Min'], shade=True, color="r")

$\mathrm{ax}=$ sns.kdeplot (dfM['Mean'], shade=True, color="\#ffd900")

$\mathrm{ax}=$ sns.kdeplot (dfM['Max'], shade=True, color="b")

$\mathrm{ax}=$ sns.kdeplot (dfM['1stQ'], shade=True, color="\#65318e")

$\mathrm{ax}=$ sns.kdeplot (dfM['3rdQ'], shade=True, color="\#00a3af")

ax.set (xlabel='Depths, $\mathrm{m}$ ', ylabel='KDE')

plt.title("bathymetric depth ranges, profiles 1-25")

add_at (ax, "F")

\# visualizing and saving

plt.tight_layout ()

plt.subplots_adjust ( $\mathrm{top}=0.90$, bottom $=0.08$,

left $=0.10$, right $=0.95$,

hspace $=0.3$, wspace $=0.3$ )

plt.savefig('plot_KDE.png', dpi=300)

plt.show ()

codes/Python-16.py

\section{A.5.17 Python code for stacked area charts on the bathymetry}

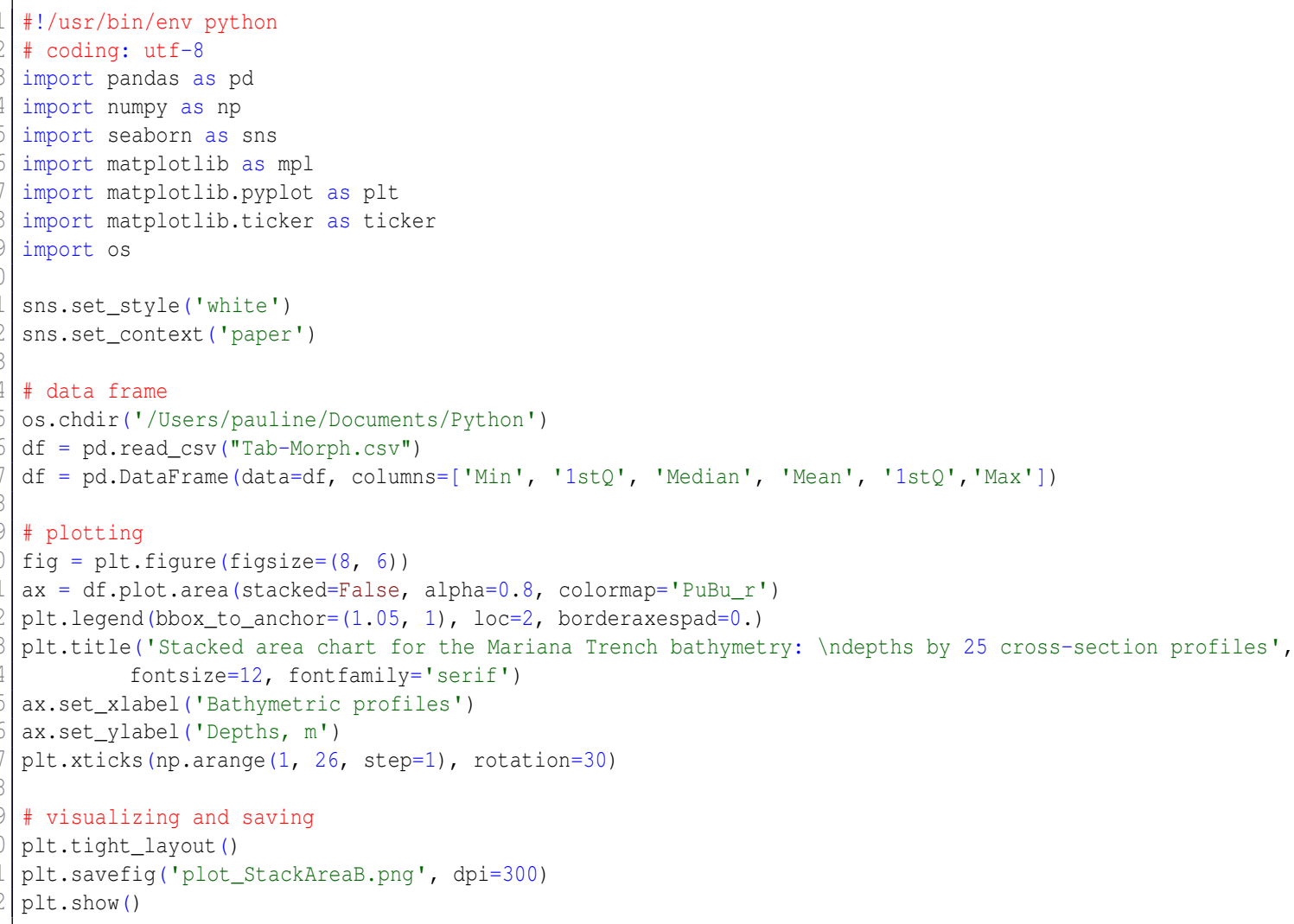

codes/Python-17.py 


\section{A.5.18 Python code for the facetted plot of the radar charts}

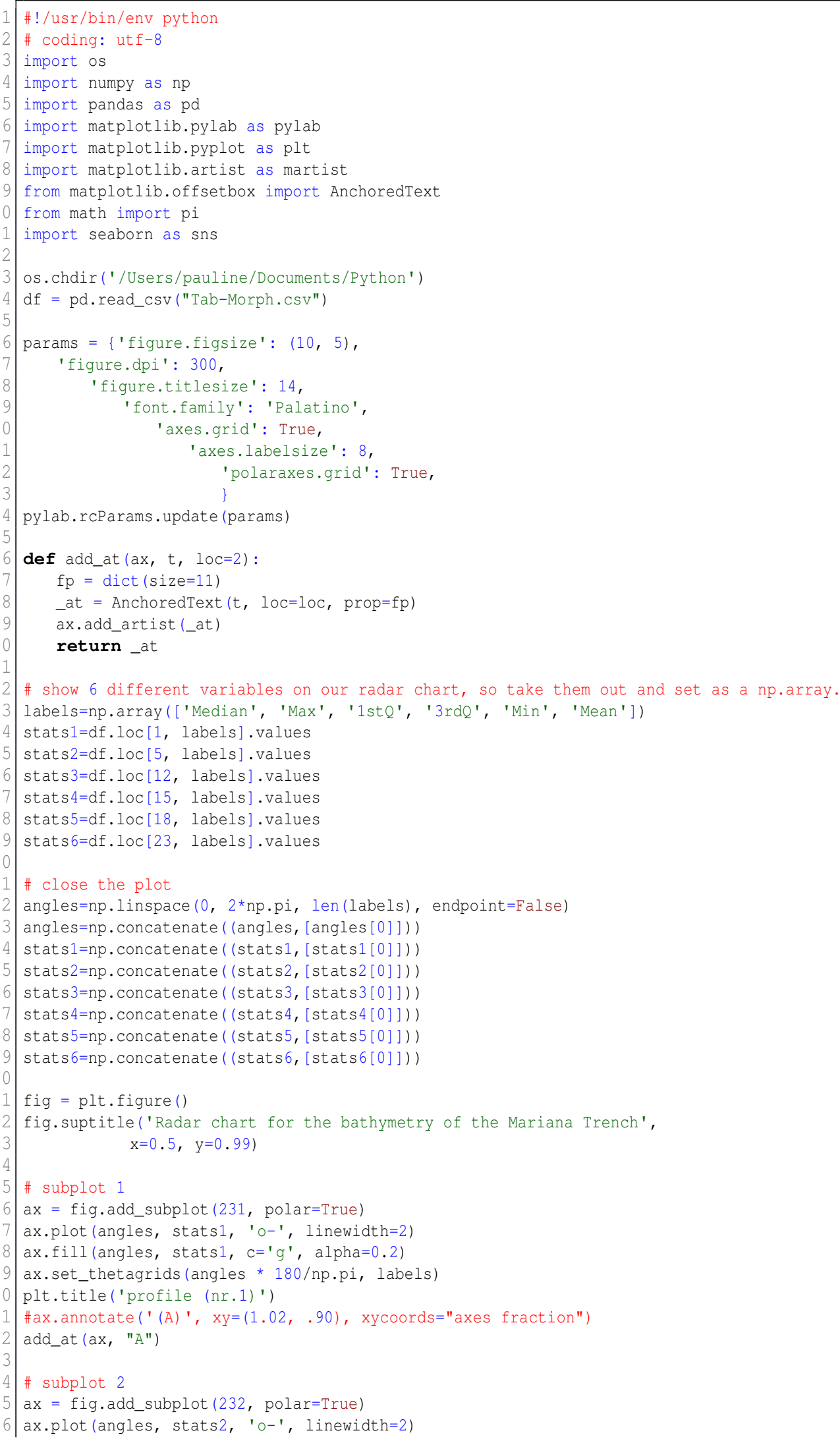


67 ax.fill(angles, stats2, c='\#a0d8ef', alpha=0.4)

68 ax.set_thetagrids (angles * 180/np.pi, labels)

69 plt.title('profile (nr.5)')

70 add_at (ax, "B")

72 \# subplot 3

ax = fig.add_subplot (233, polar=True)

4 ax.plot (angles, stats3, 'o-', linewidth=2)

5 ax.fill (angles, stats3, c='\#ee827c', alpha=0.4)

6 ax.set_thetagrids(angles * 180/np.pi, labels)

plt.title ('profile (nr.12)')

add_at (ax, "C")

80 \# subplot 4

ax = fig.add_subplot (234, polar=True)

ax.plot (angles, stats4, 'o-', linewidth=2)

ax.fill (angles, stats4, c='plum', alpha=0.4)

ax.set_thetagrids (angles * 180/np.pi, labels)

plt.title('profile (nr.15)')

add_at (ax, "D")

\# subplot 5

ax = fig.add_subplot (235, polar=True)

ax.plot (angles, stats5, 'o-', linewidth=2)

ax.fill (angles, stats5, c='\#ffd900', alpha=0.2)

ax.set_thetagrids (angles * 180/np.pi, labels)

plt.title('profile (nr.19)')

add_at (ax, "E")

\# subplot 6

ax = fig.add_subplot (236, polar=True)

ax.plot (angles, stats6, 'o-', linewidth=2)

ax.fill (angles, stats6, $c=$ '\#c3d825', alpha=0.4)

ax.set_thetagrids (angles * 180/np.pi, labels)

plt.title ('profile 24')

add_at (ax, "F")

plt.tight_layout ()

plt.subplots_adjust (top $=0.85$, bottom $=0.08$,

left $=0.10$, right $=0.95$,

hspace $=0.25$, wspace $=0.35$

fig.savefig('plot_RadarChart.png', dpi=300)

plt.show ()

codes/Python-18.py

\section{A.5.19 Python code for the distribution of the bathymetric data by stacked bar plots}

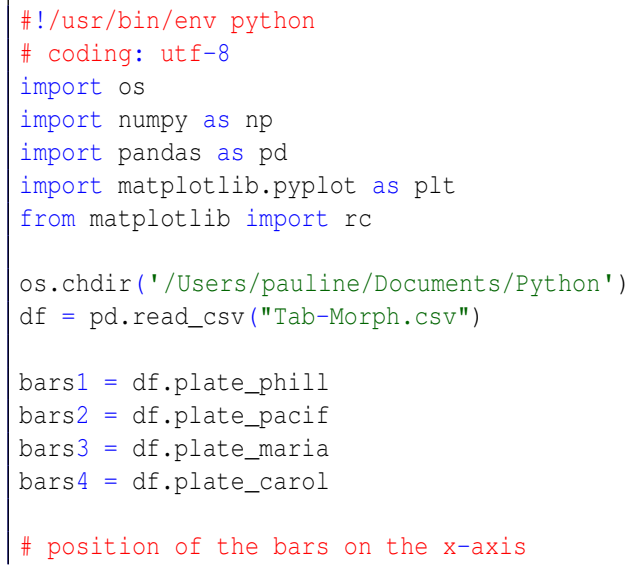




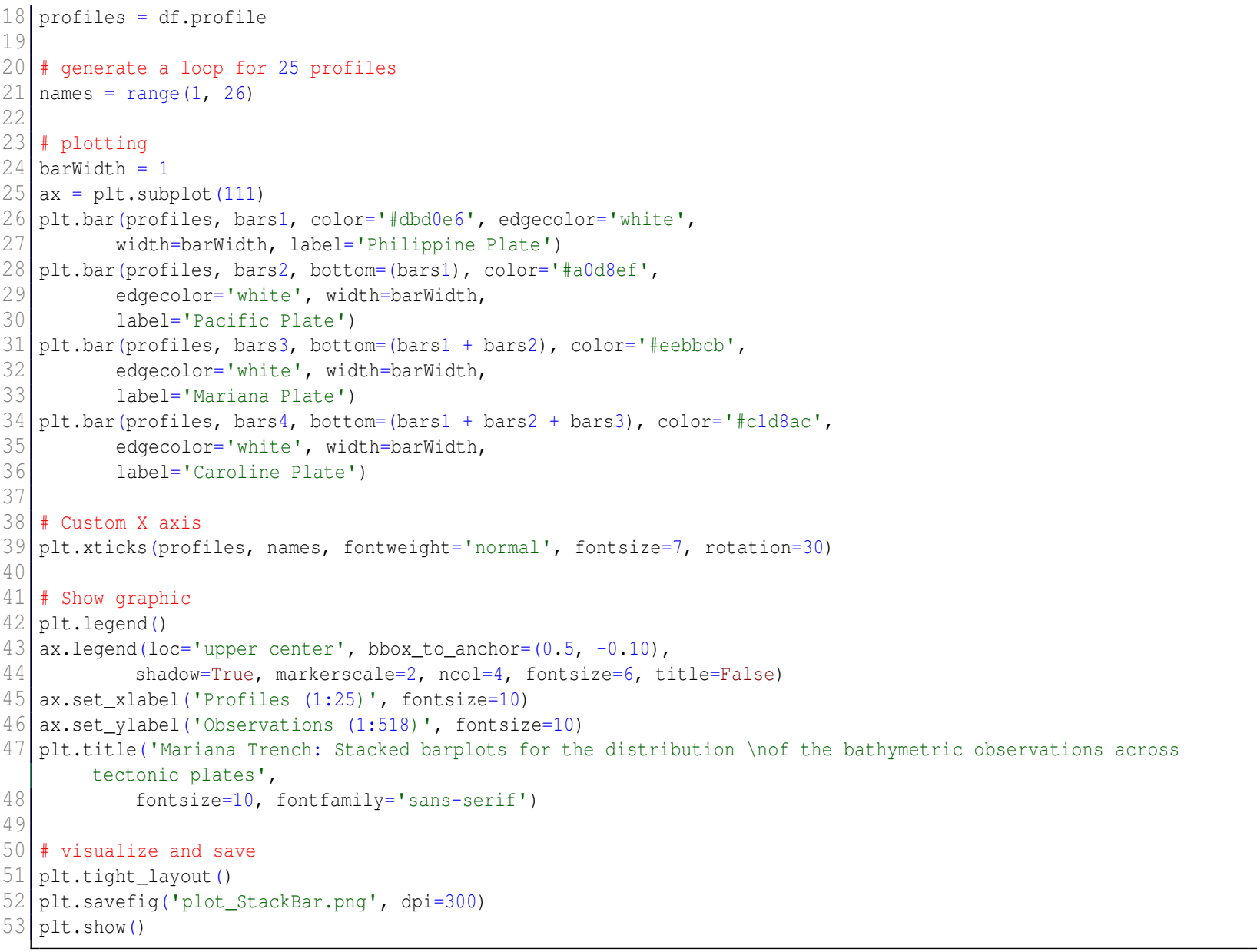

codes/Python-19.py

\section{A.5.20 Python code for analysis of the distribution of sediment thickness, stacked bar charts}

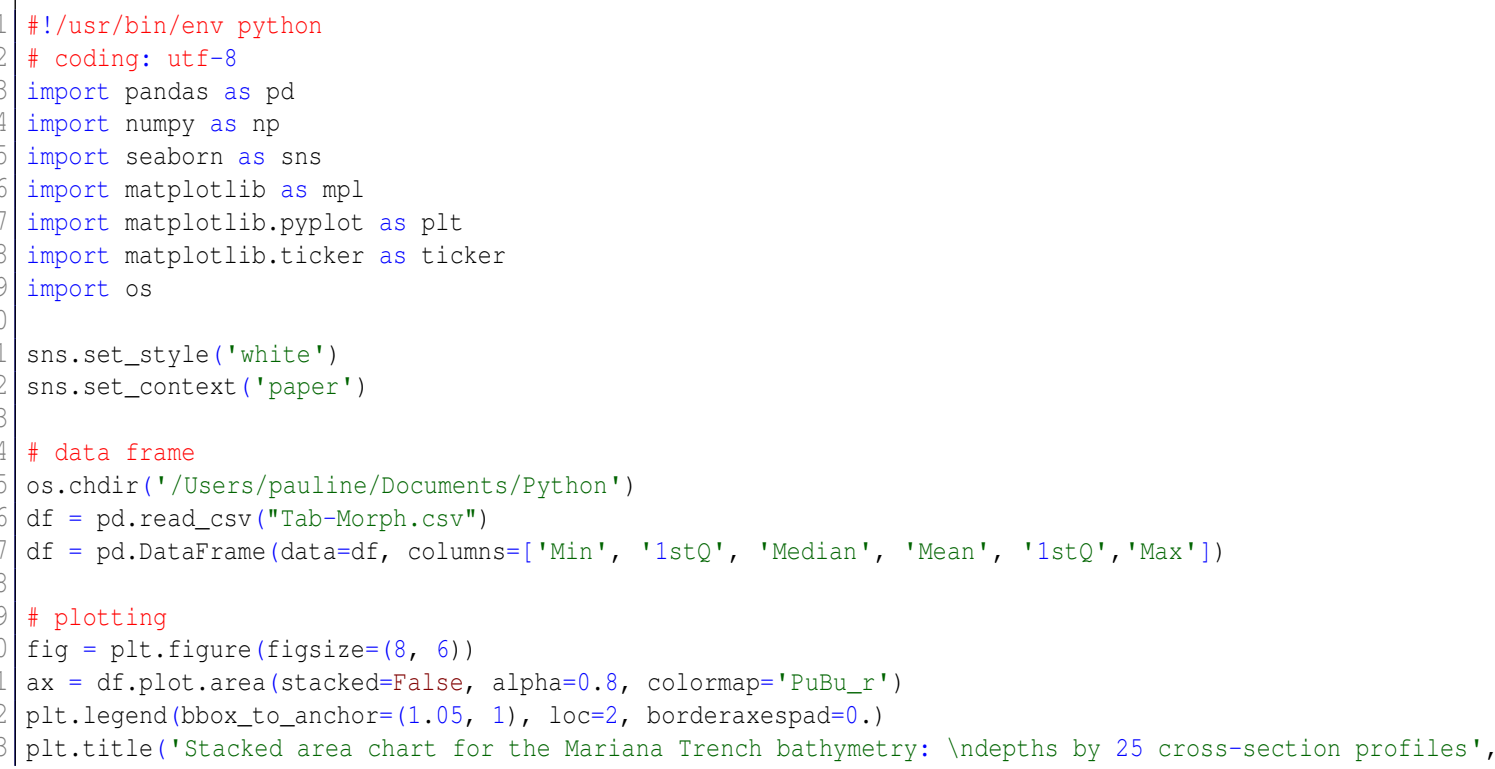




\section{A.5.21 Python code for pie charts visualizing bathymetry vs tectonic plates}

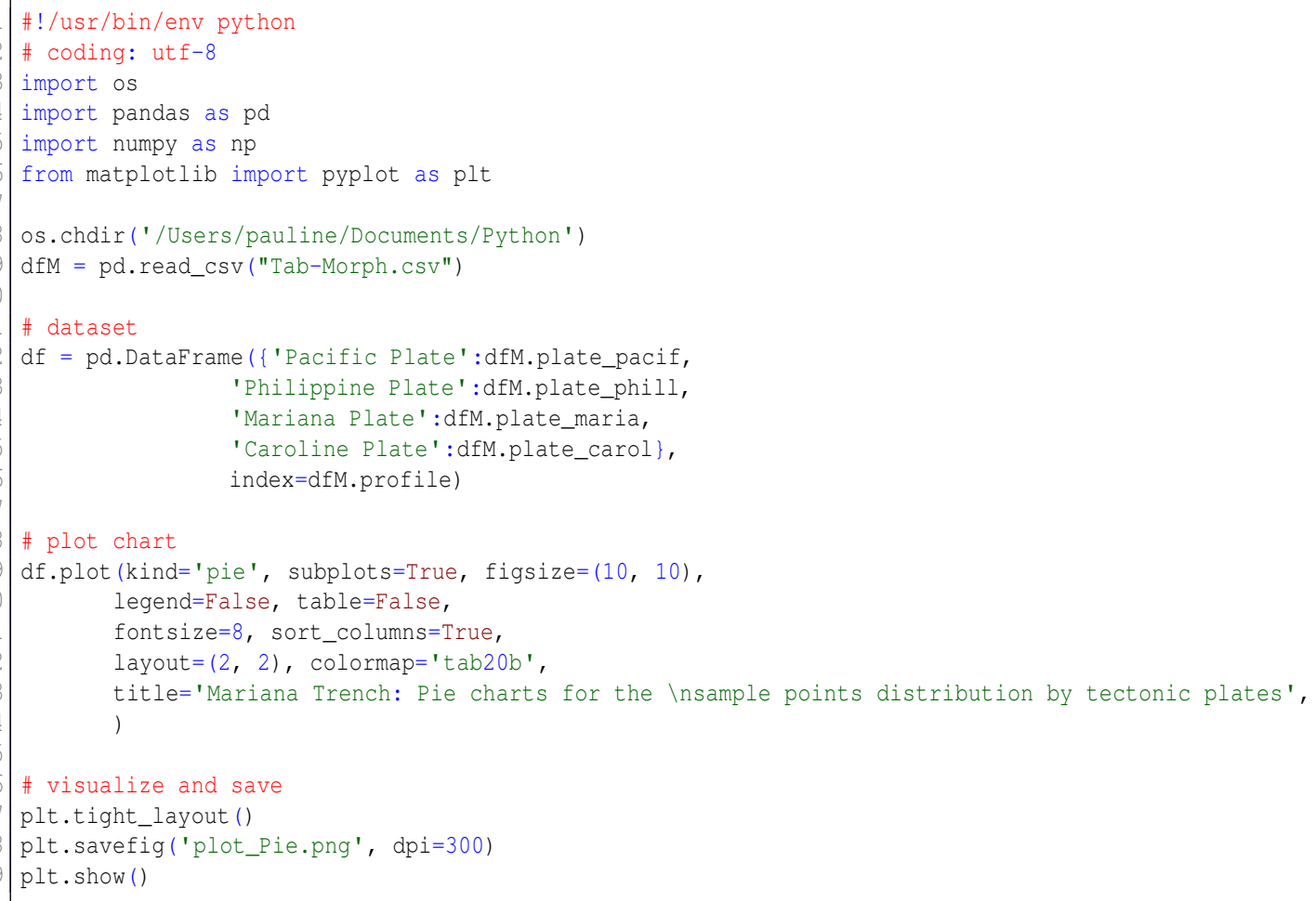

codes/Python-21.py

\section{A.5.22 Python code for QQ plots visualizing descriptive statistics for the bathymetry}

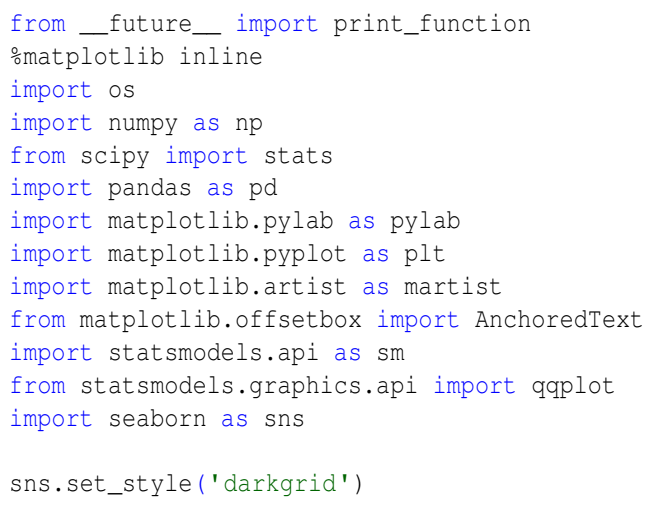




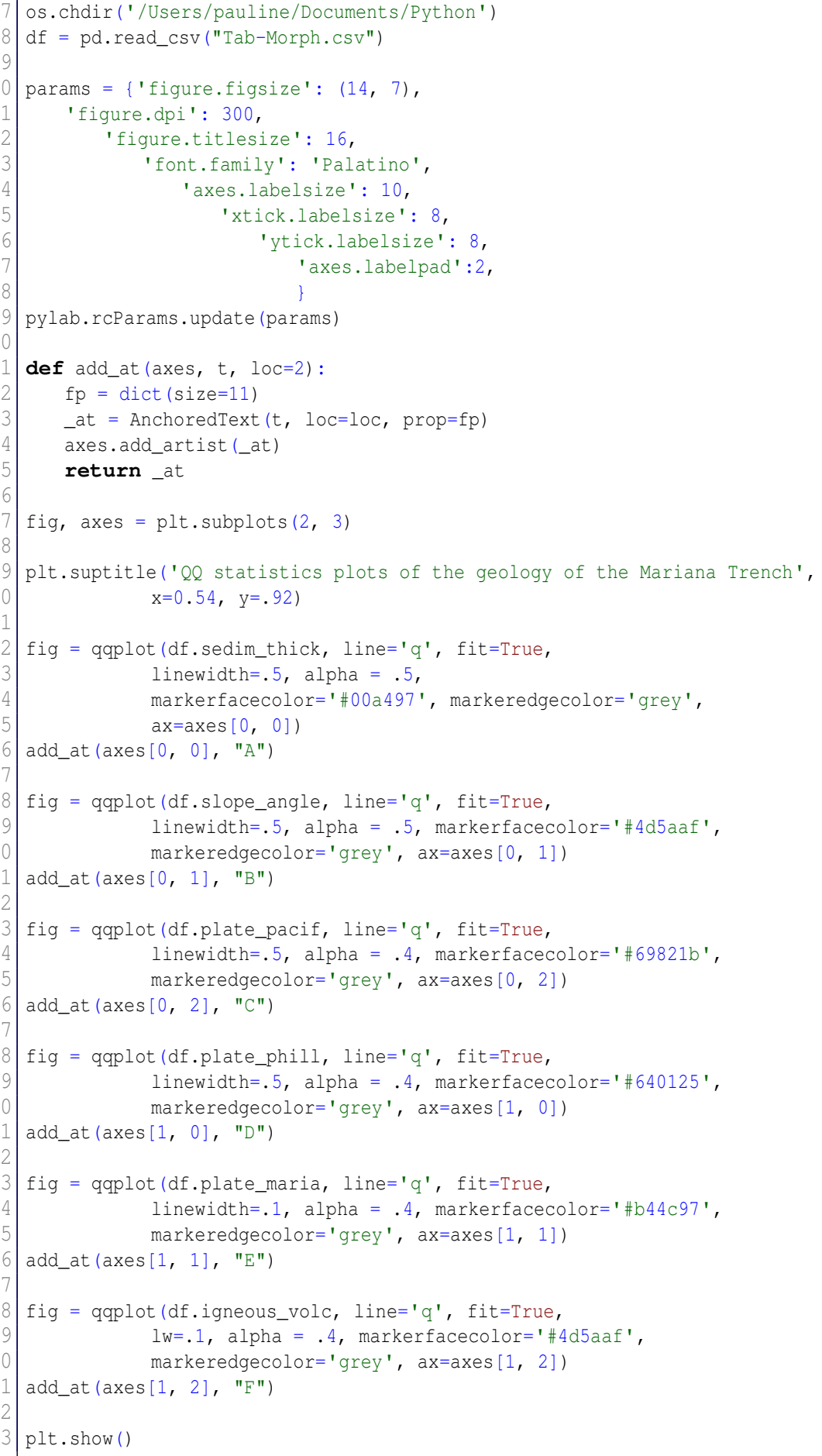

codes/Python-22.py

\section{A.5.23 Python code for WLS calculations}

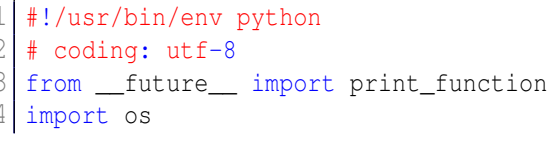




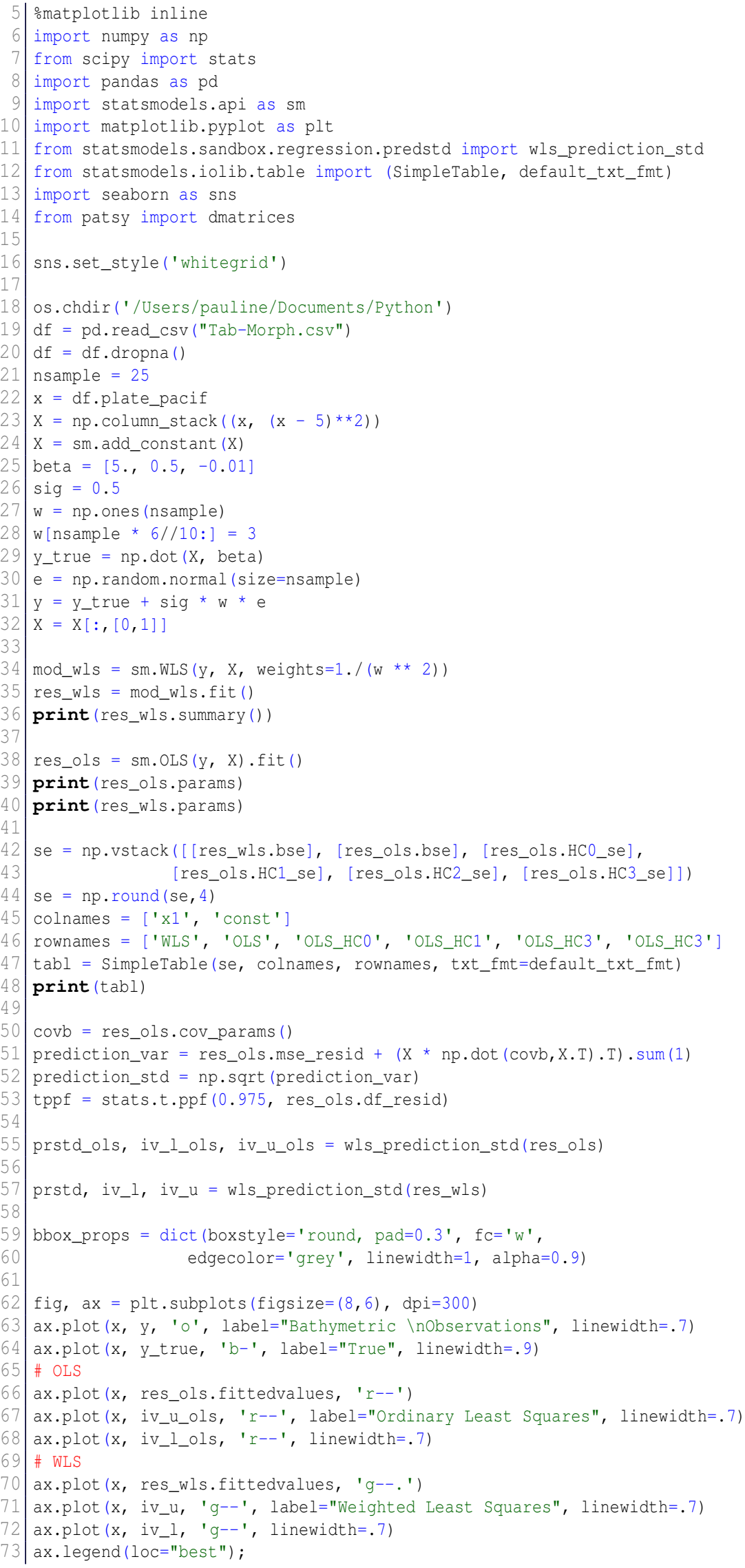




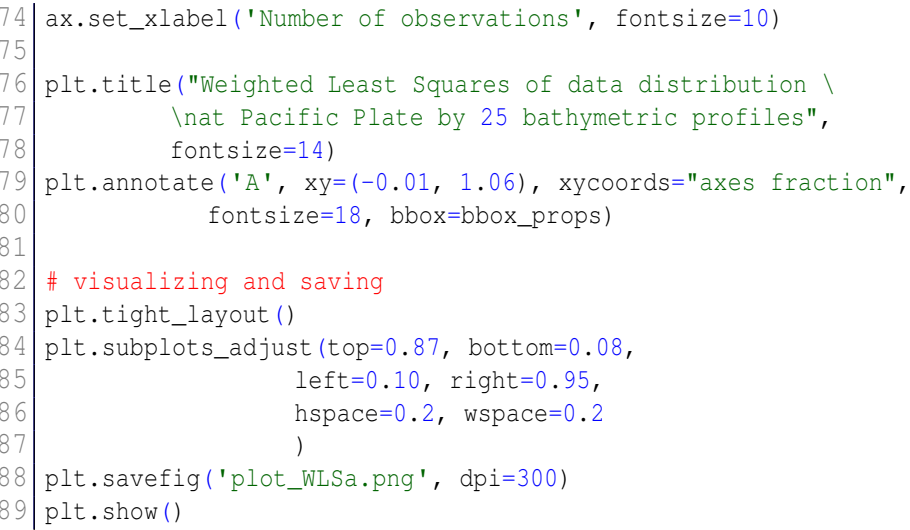

codes/Python-23.py

\section{A.5.24 Python code for quantile (QQ) regression}

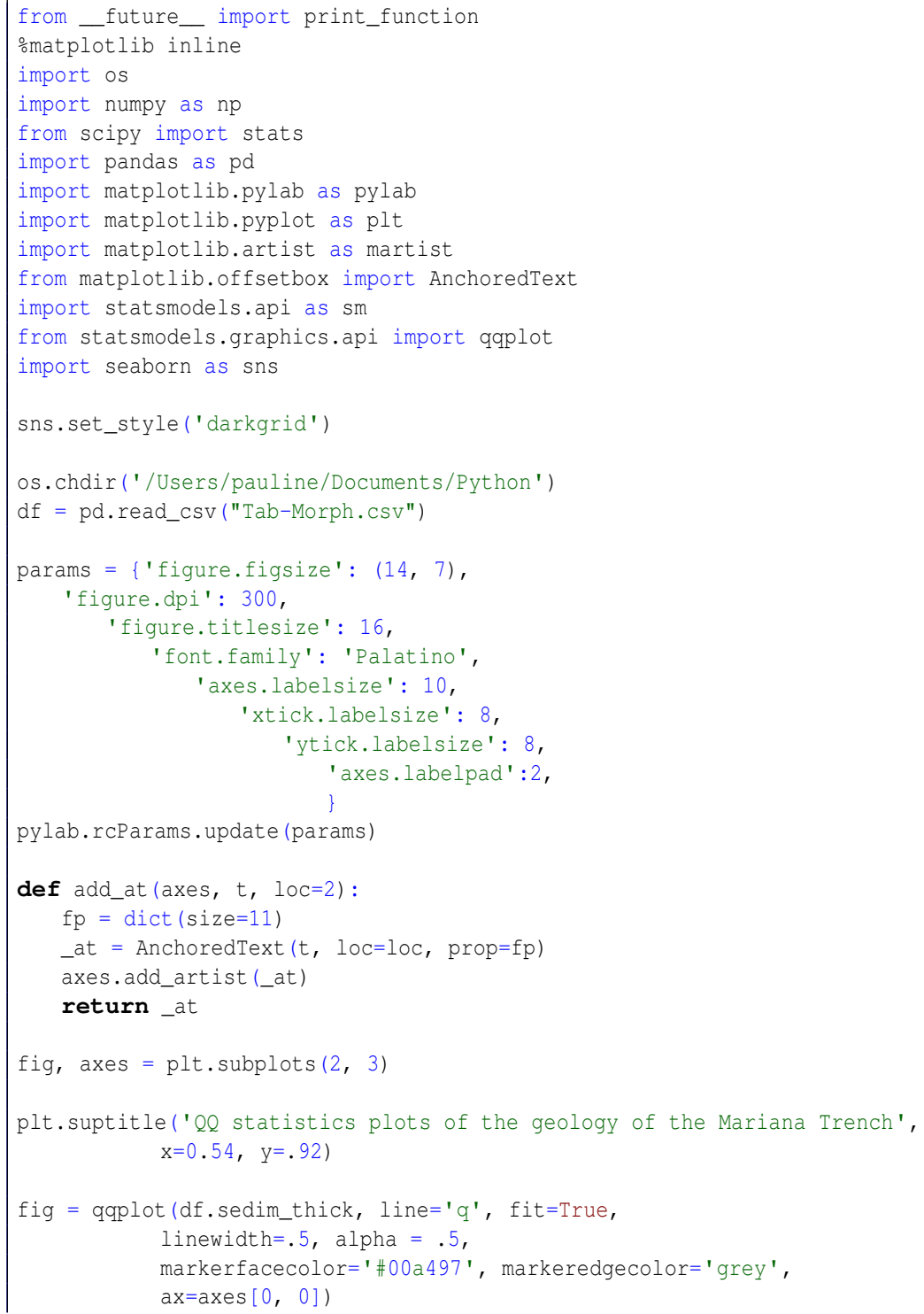




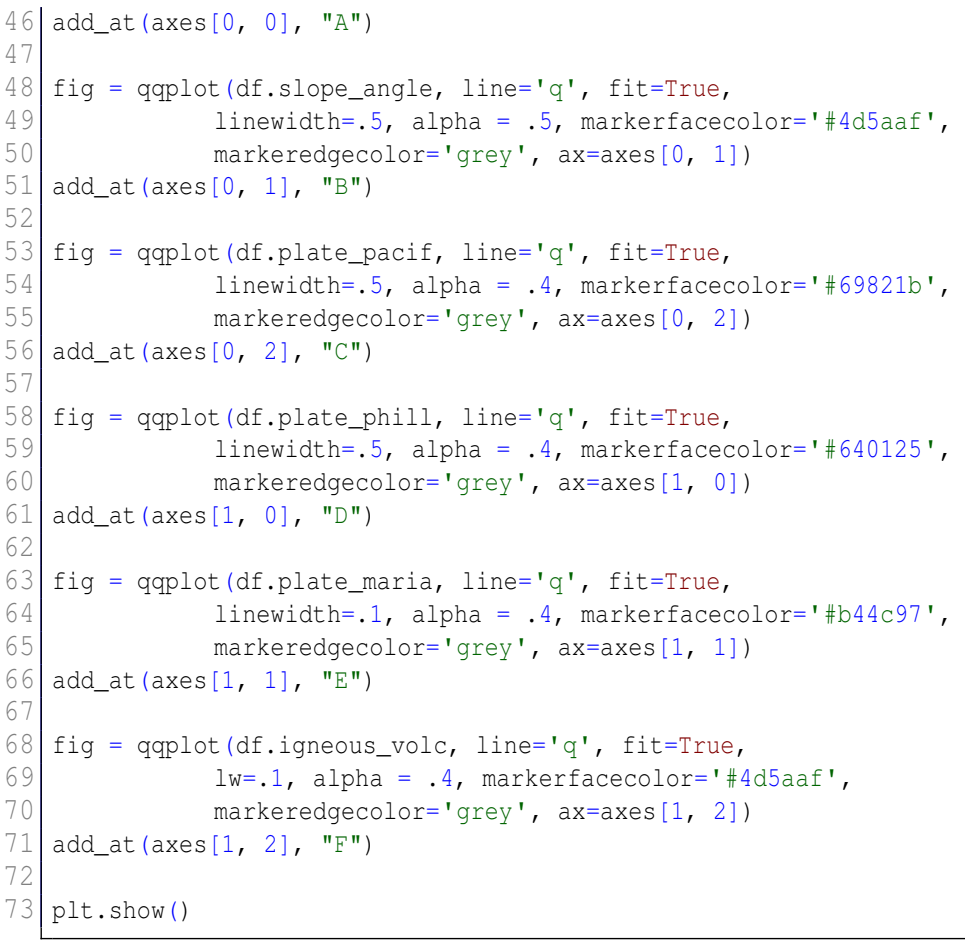

codes/Python-24.py

\section{A.5.25 Python code for SARIMA model}

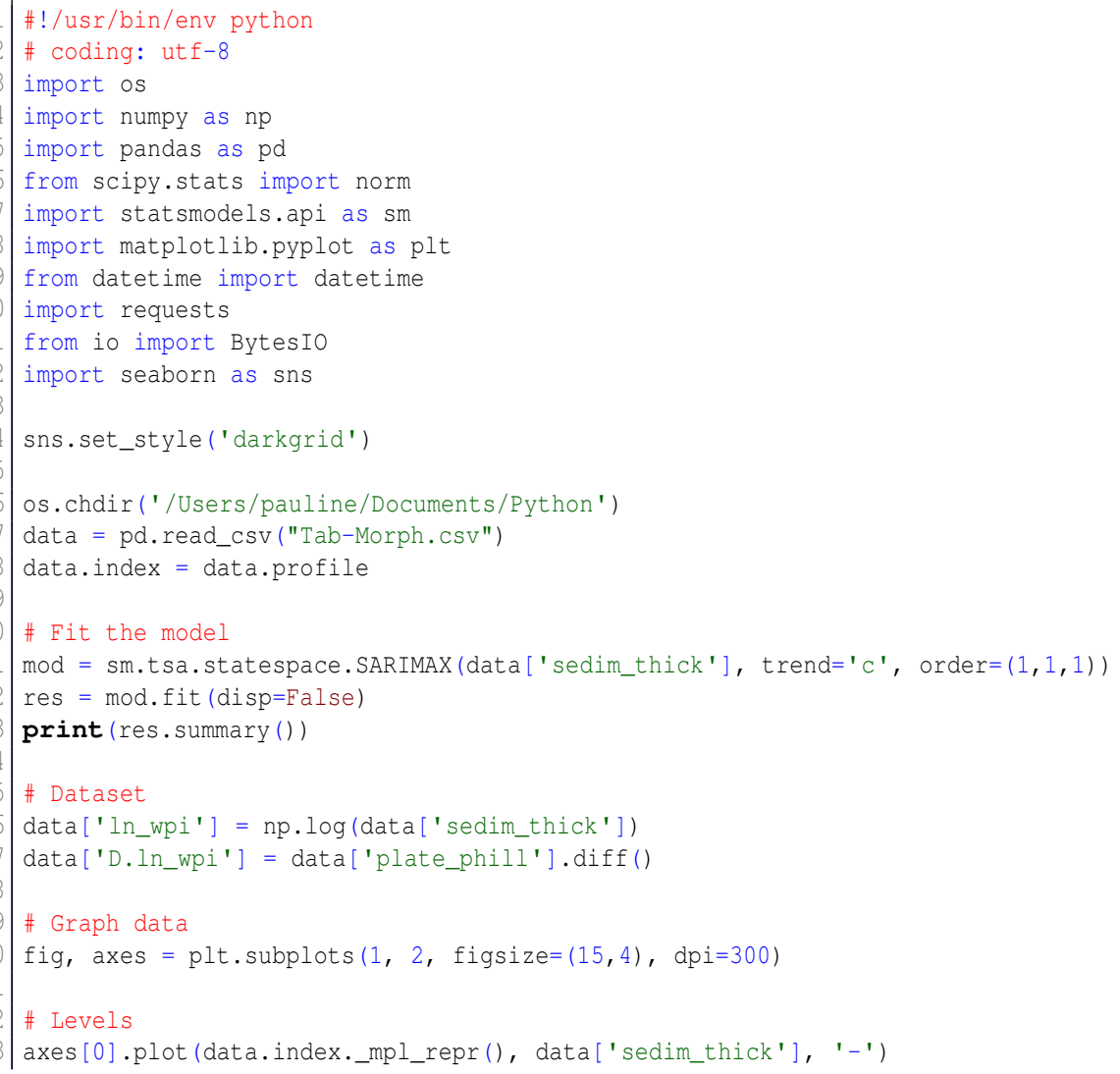




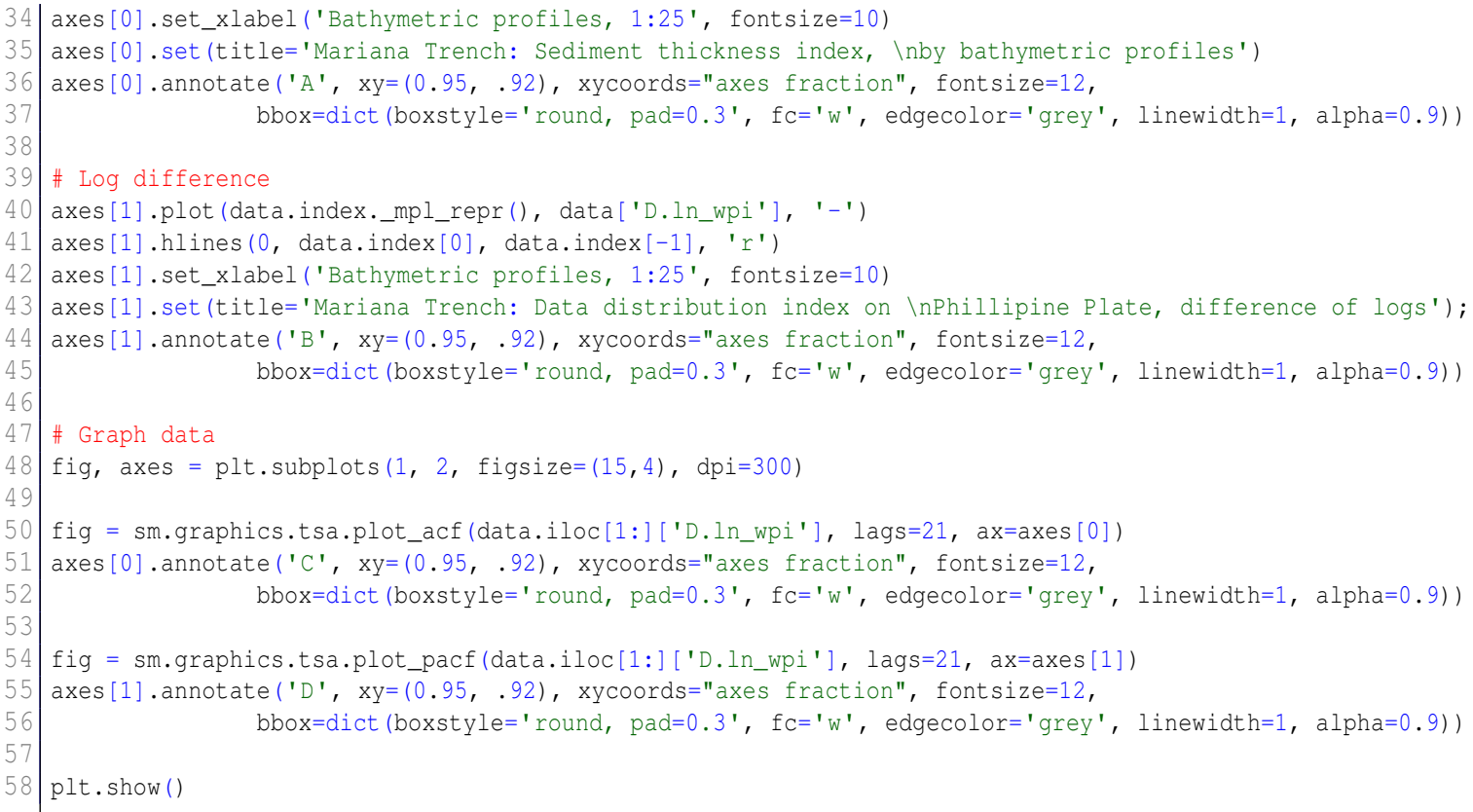

codes/Python-25.py

\section{A.5.26 Python code for Euler-Venn diagrams}

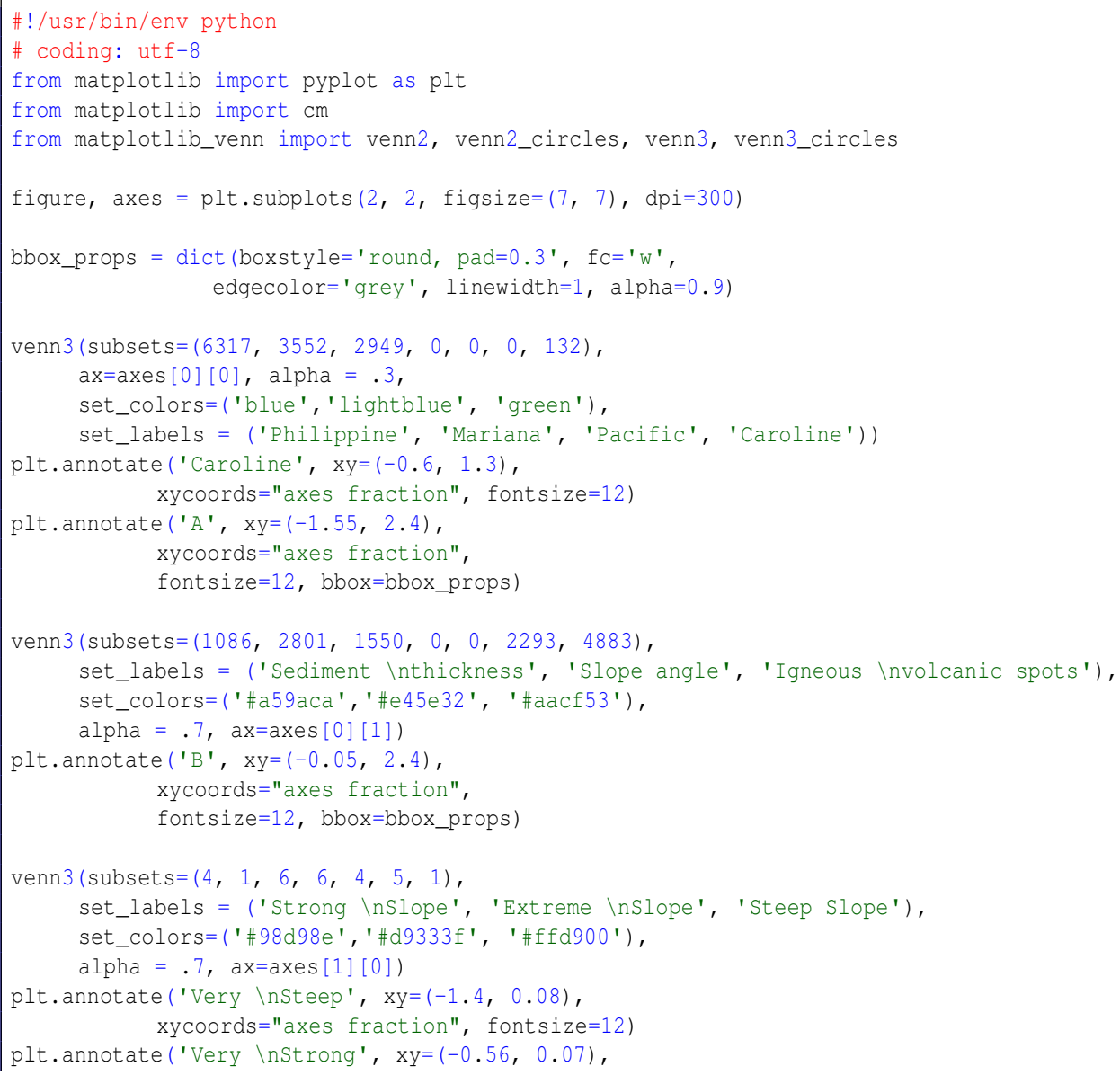




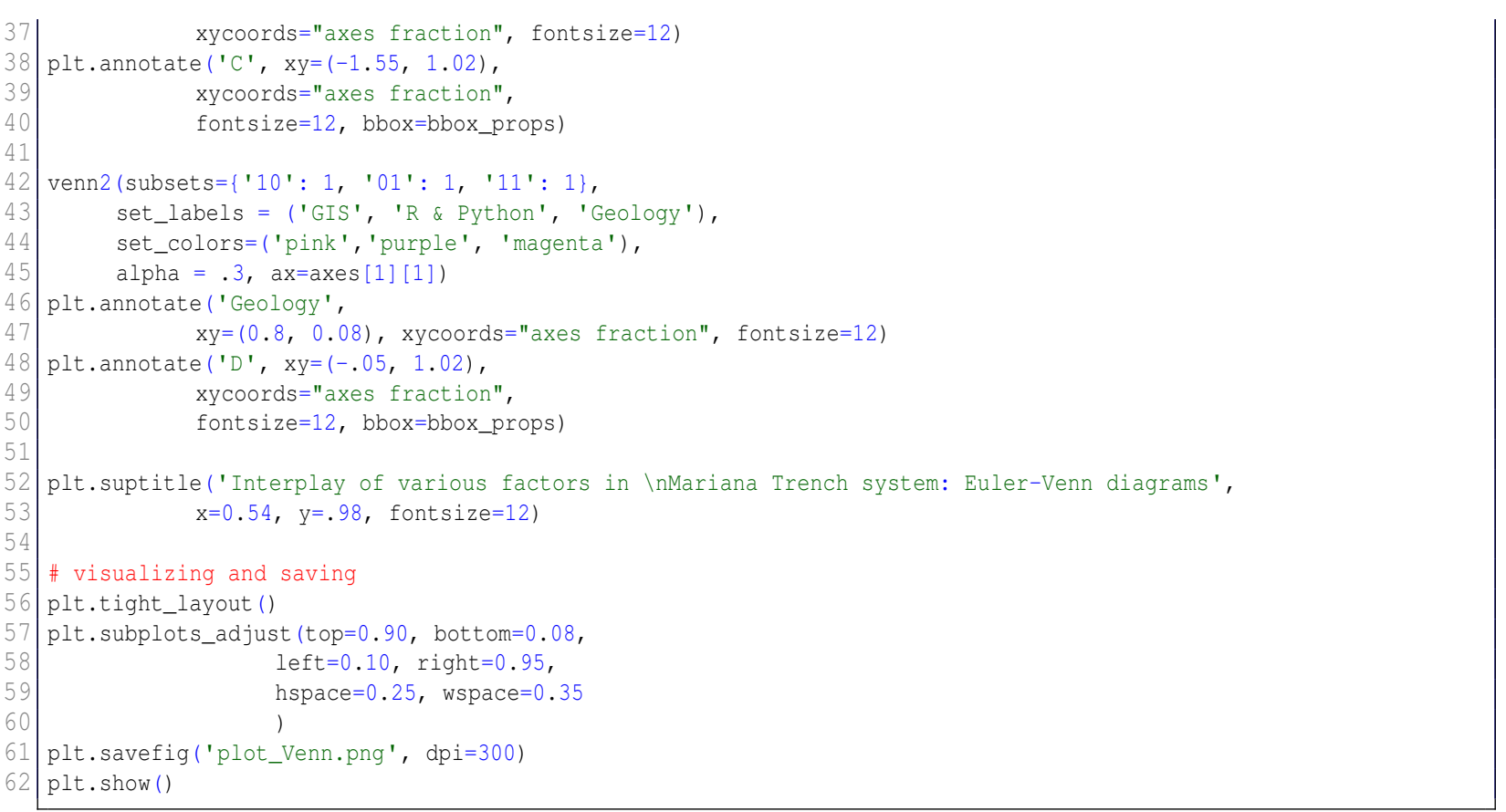

codes/Python-26.py 


\section{A.6 R language scripts}

\section{A.6.1 R code to create histograms using (ggplot) library}

Source data available on my GitHub.

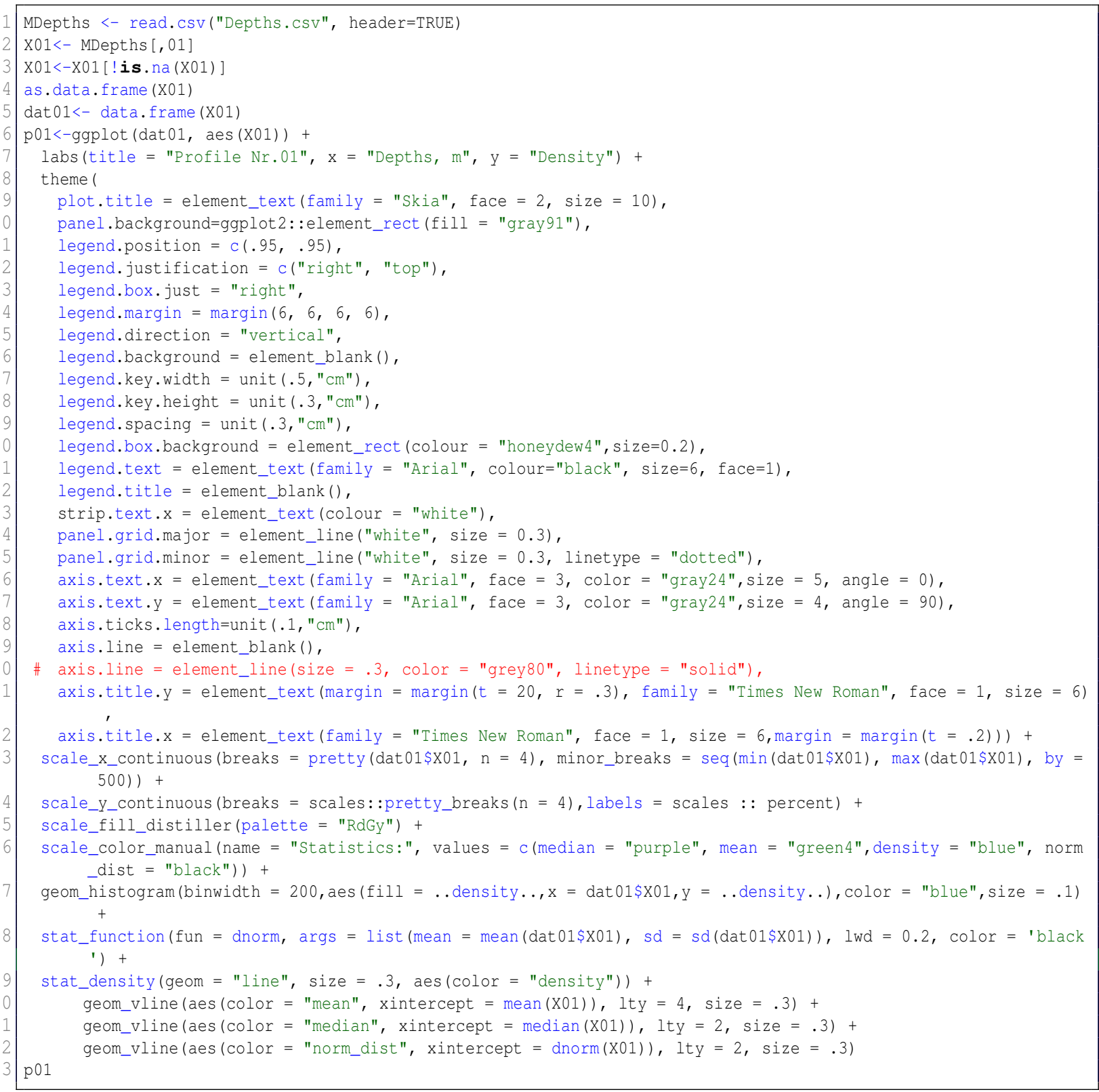

$\operatorname{codes} / \mathrm{R}-01 . \mathrm{r}$

xlvi 


\section{A.6.2 $R$ code to generate boxplots 'whiskerplots' using default boxplot function}

Source data available on my GitHub.

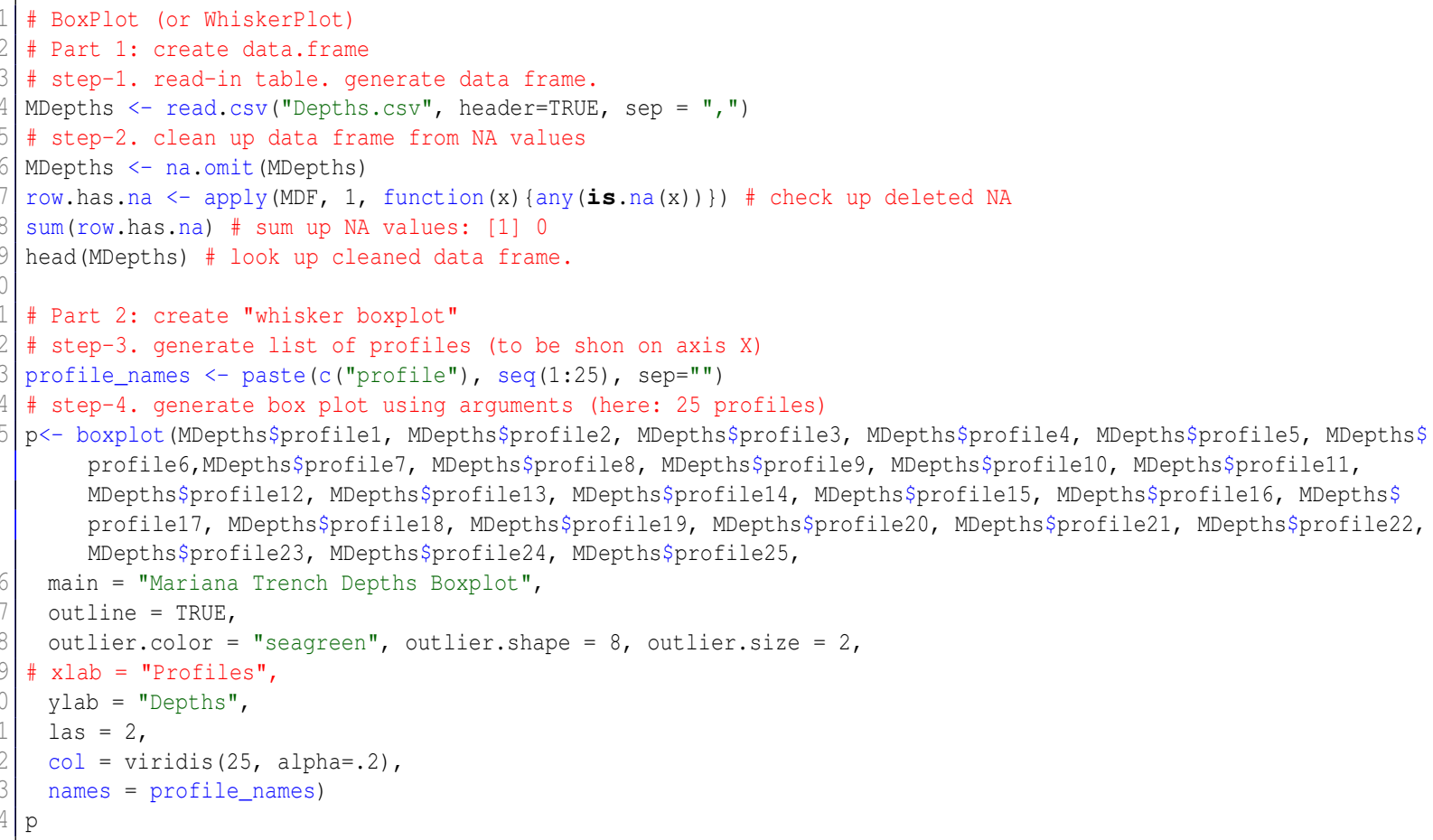

codes/R-02.r 


\section{A.6.3 R code for notched boxplot using (ggboxplot)}

\section{Source data available on my GitHub.}

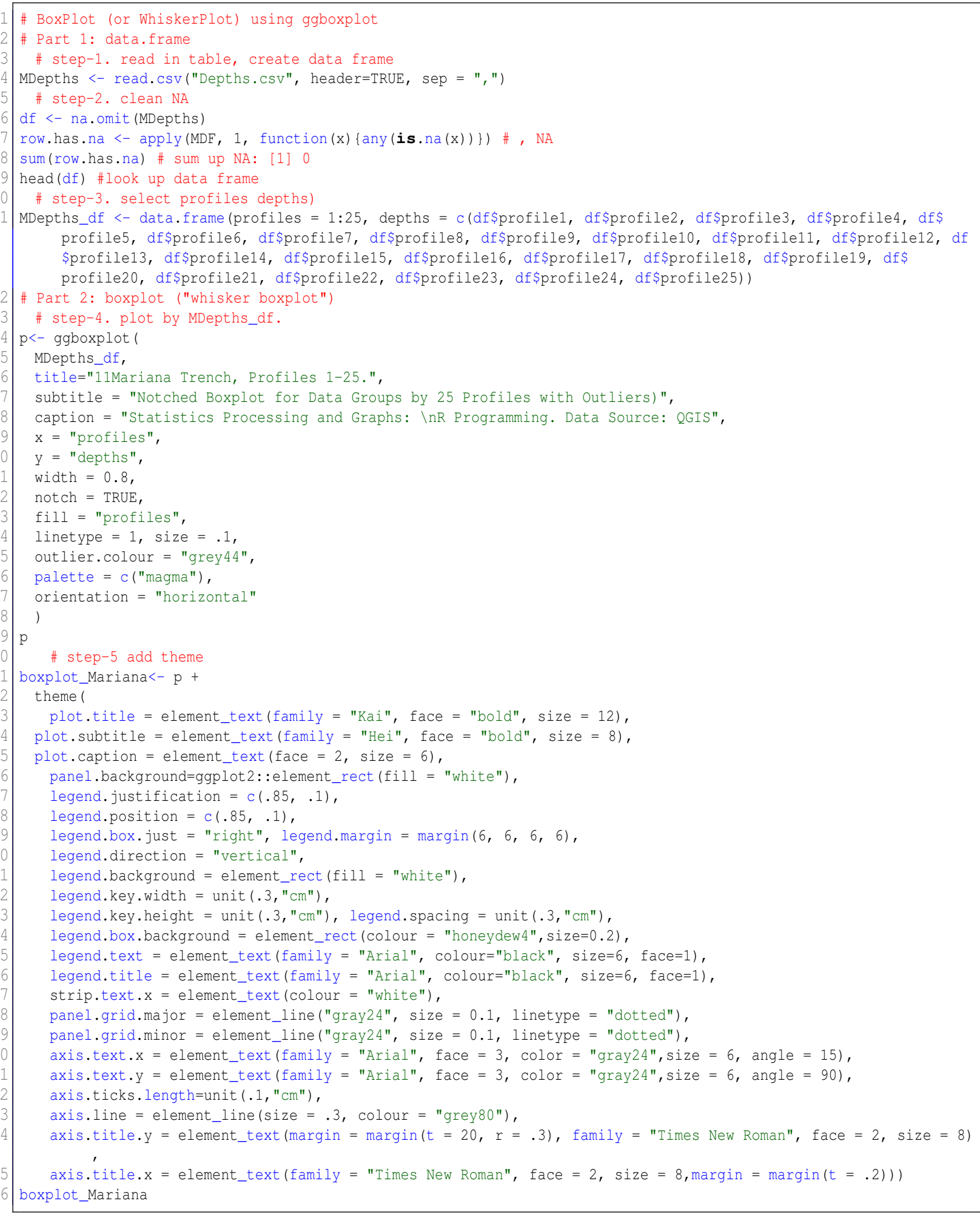

$\operatorname{codes} / \mathrm{R}-03 . \mathrm{r}$

xlviii 


\section{A.6.4 R code to generate QQ quantile statistics for facetted wrapped plot}

\section{Source data available on my GitHub.}

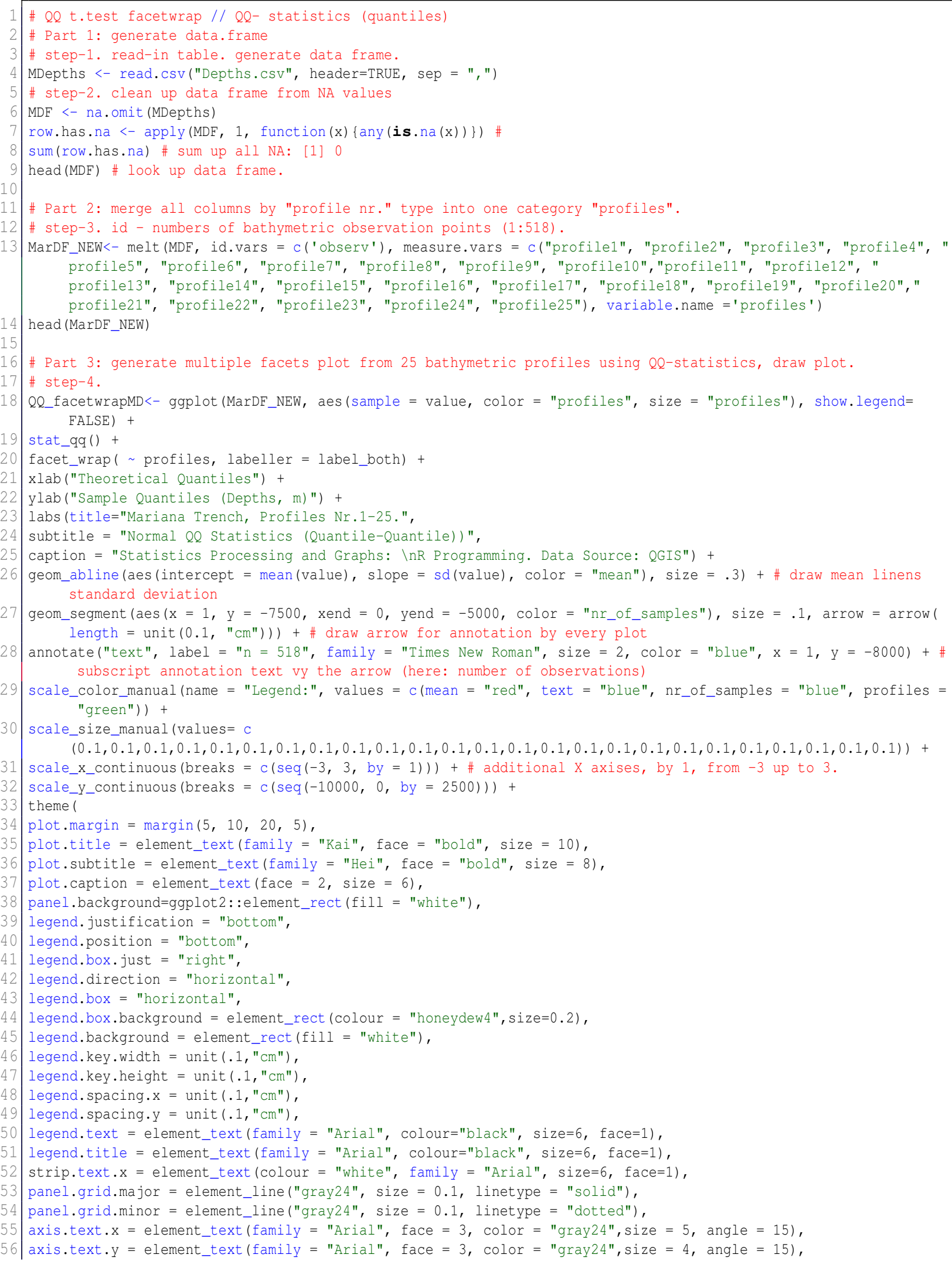


57 axis.ticks. length=unit $(.1, " \mathrm{~cm} ")$,

58 axis.line = element_line ( $\operatorname{size}=.3$, colour = "grey80"),

59 axis.title.y = element_text (margin $=\operatorname{margin}(t=20, r=.3)$, family $=$ "Times New Roman", face $=2$, size $=8)$,

60 axis.title. $x=$ element_text (family = "Times New Roman", face $=2$, size $=8, \operatorname{margin}=\operatorname{margin}(t=.2))$ )

61 guides $(\mathrm{col}=$ guide_legend $($ nrow $=2, \operatorname{ncol}=3$, byrow $=$ TRUE $)$ ) \# extend legend vertically.

62 QQ_facetwrapMD

codes/R-04.r

\section{A.6.5 $R$ code for regression analysis for the bathymetric profiles}

\section{Source data available on my GitHub.}

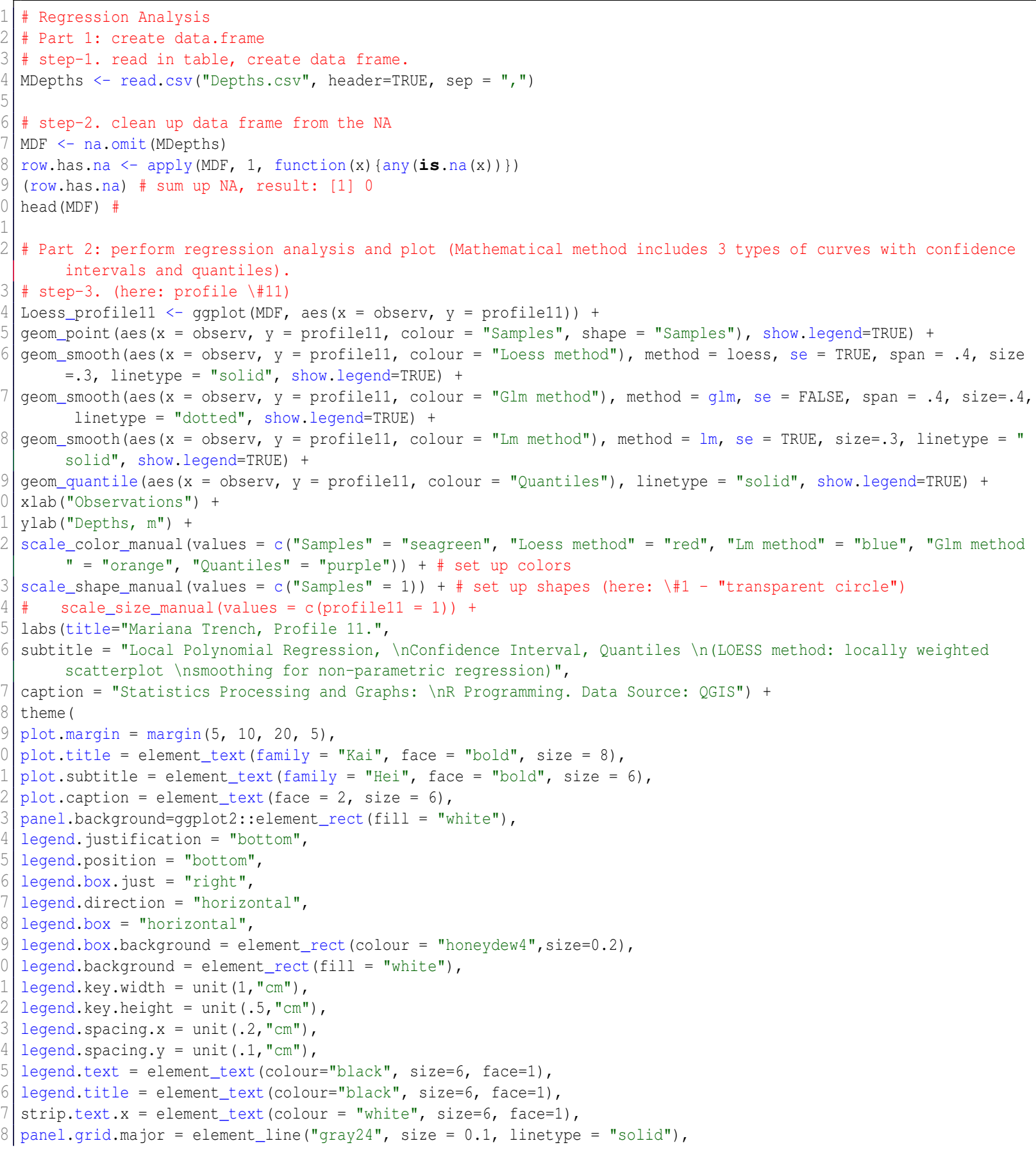




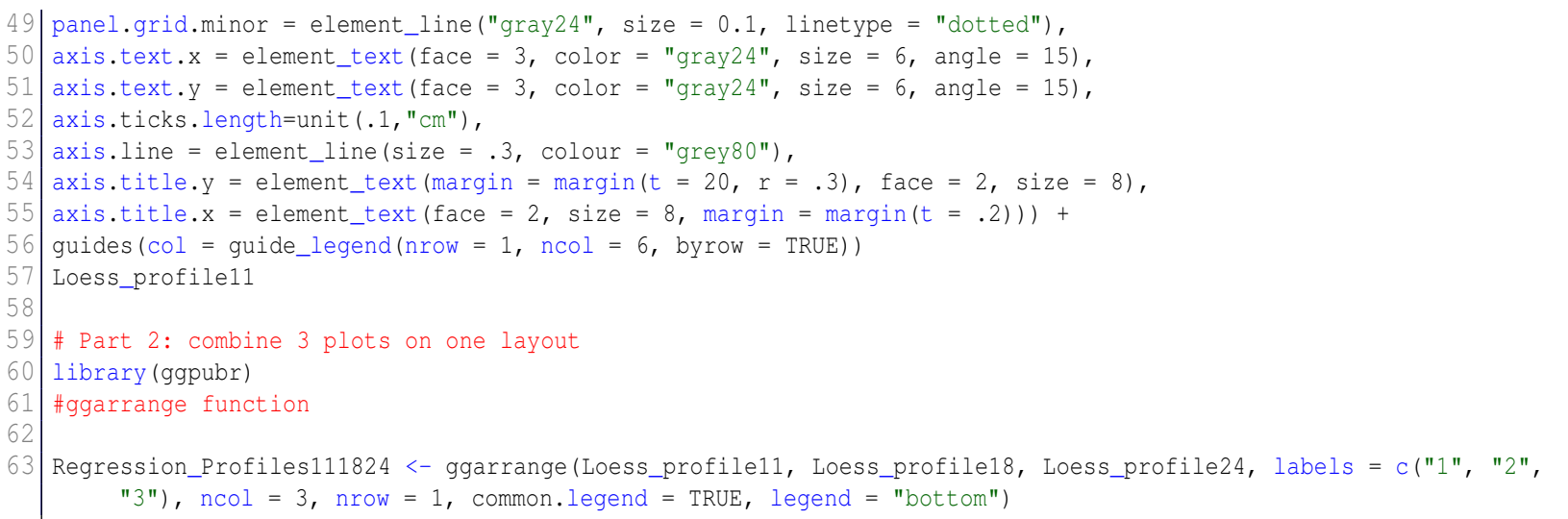

codes/R-05.r

\section{A.6.6 R code for cluster analysis, dendrograms}

\section{Source data available on my GitHub.}

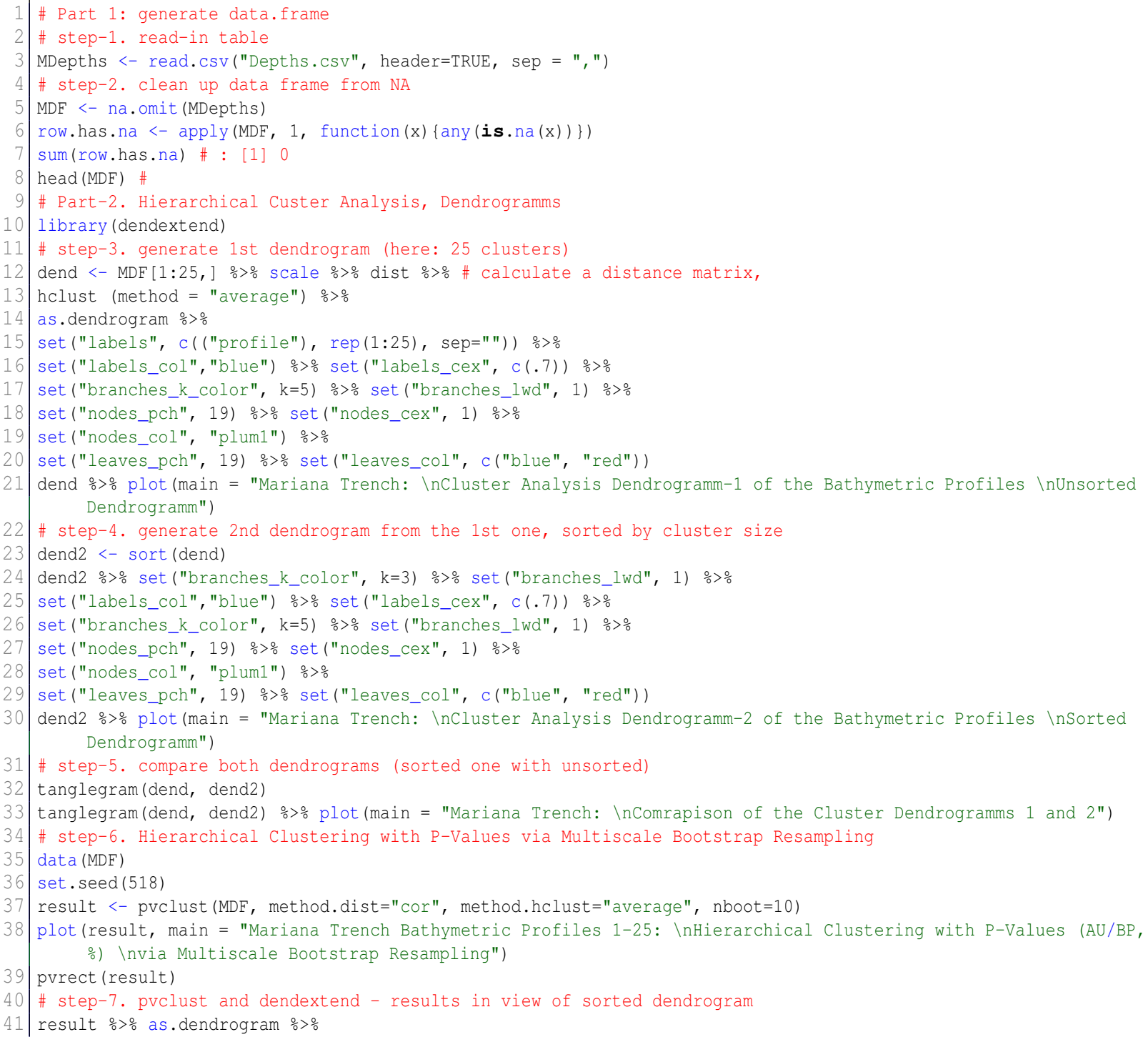


42 set ("branches_k_color", $k=5$, value = c("purple", "orange", "cyan1", "firebrick1", "springgreen")) 응

43 plot (main = "Mariana Trench Bathymetric Profiles 1-25: Cluster Dendrogram\nwith AU/BP Values (\%). nAU: Approximately Unbiased p-Value \n and BP: Bootstrap Probability")

44 result $\%>$ text

45 result $\%>$ pvrect

46 \# the end. results can be saved as a pdf via "Save As" (here: 5 figures for every step from 3- to 7)

codes/R-06.r

\section{A.6.7 R code for correlogram by (ggplot) library}

\section{Source data available on my GitHub.}

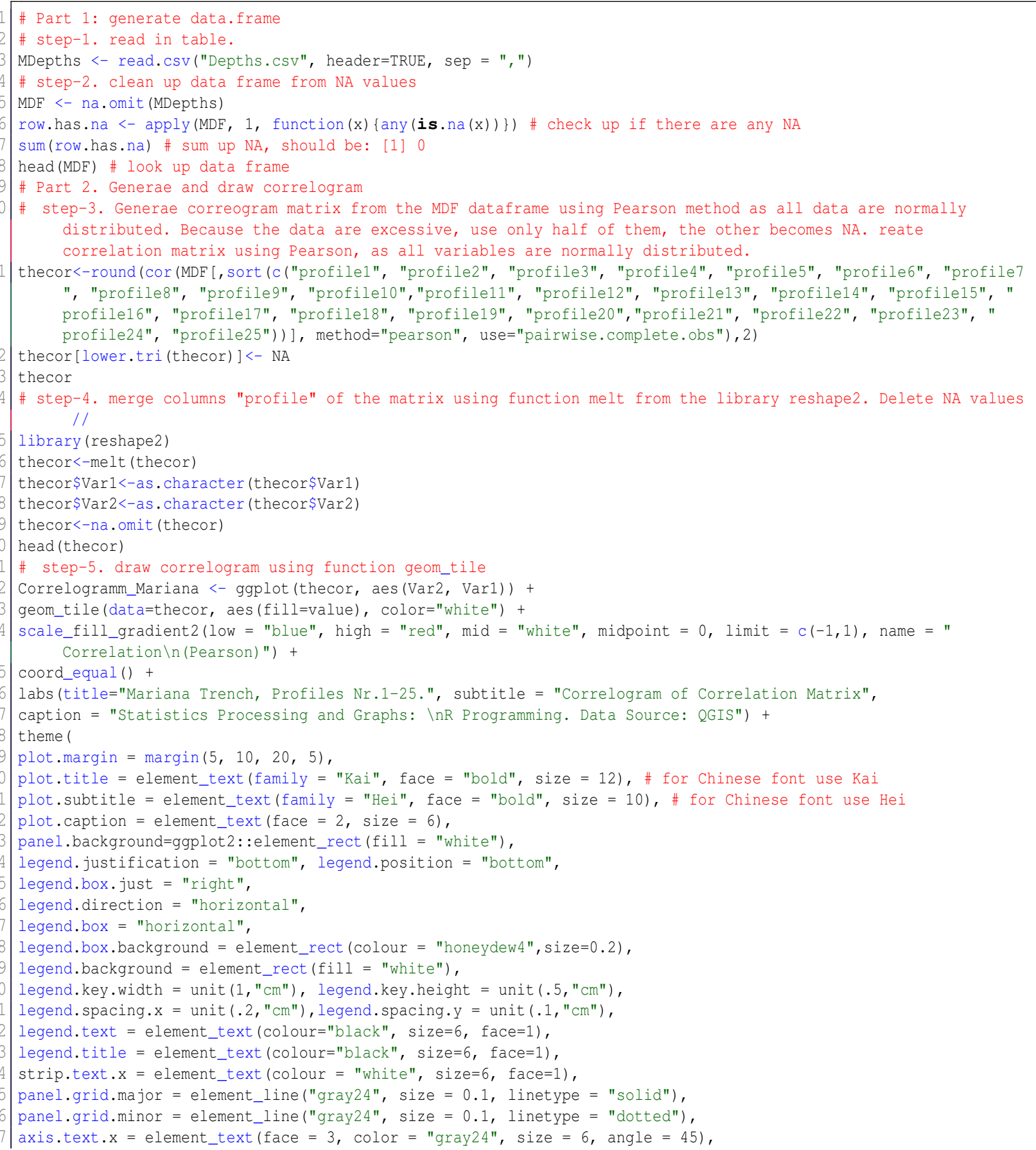


48 axis.text.y $=$ element_text $($ face $=3$, color $=$ "gray $24 "$, size $=6$, angle $=15$ )

49 axis.ticks.length=unit $(.1, " \mathrm{~cm} ")$,

50 axis.line = element_line (size $=.3$, colour = "grey80"),

51 axis.title.y $=$ element_text (margin $=\operatorname{margin}(t=20, r=.3)$, face $=2$, size $=8)$,

52 axis.title.x $=$ element_text $($ face $=2$, size $=8, \operatorname{margin}=\operatorname{margin}(t=.2)))+$

53 guides $(\mathrm{col}=$ guide_legend $(\mathrm{nrow}=1$, ncol $=6$, byrow $=$ TRUE) $)$ \# improve design of the legend.

54 Correlogramm_Mariana

55 ggsave("Correlogramm_Mariana.pdf", device = cairo_pdf, fallback_resolution = 300)

codes/R-07.r

\section{A.6.8 R code for Principal Component Analysis (PCA)}

\section{Source data available on my GitHub.}

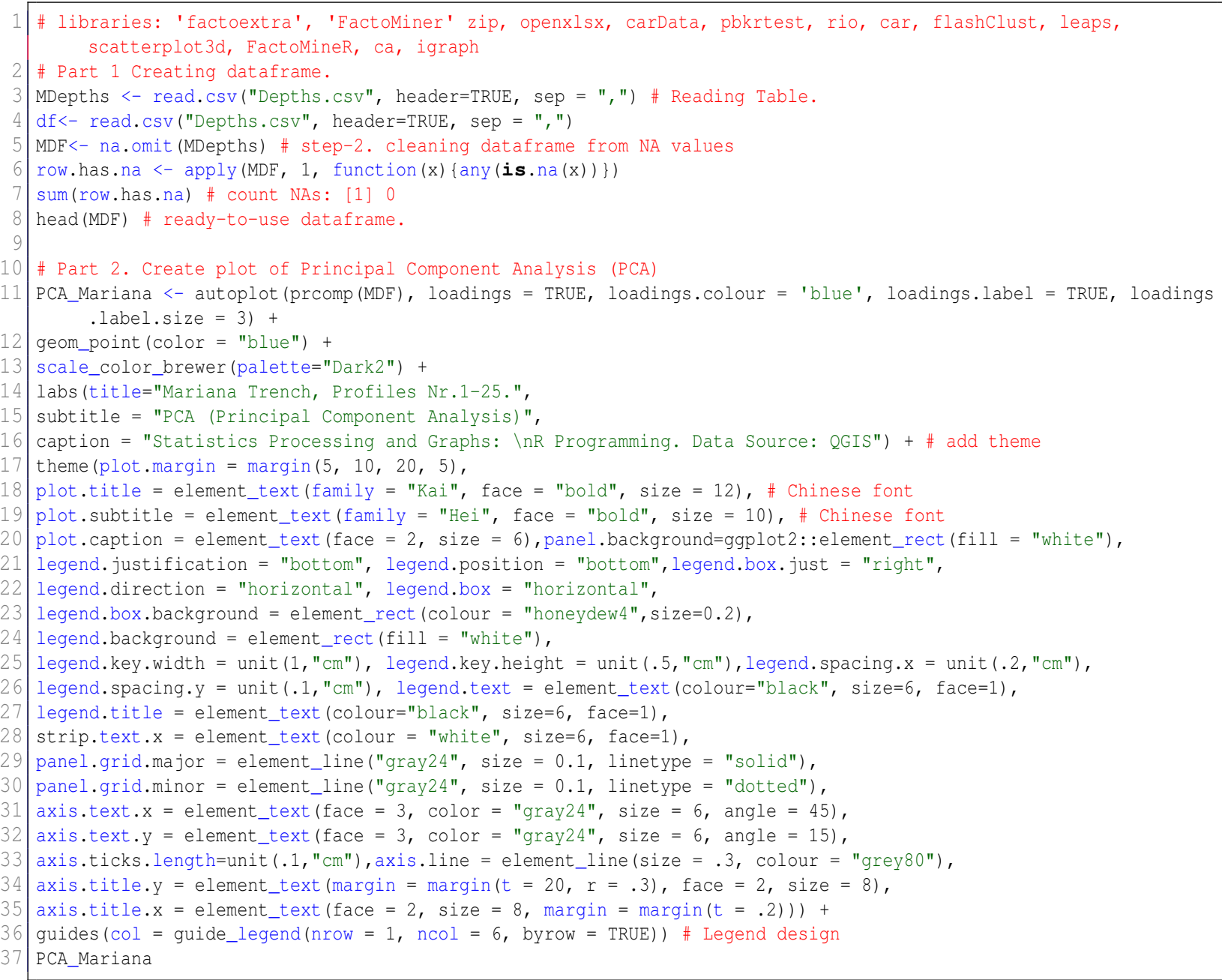

codes/R-08.r 


\section{A.6.9 $R$ code for $k$-means clustering}

\section{Source data available on my GitHub.}

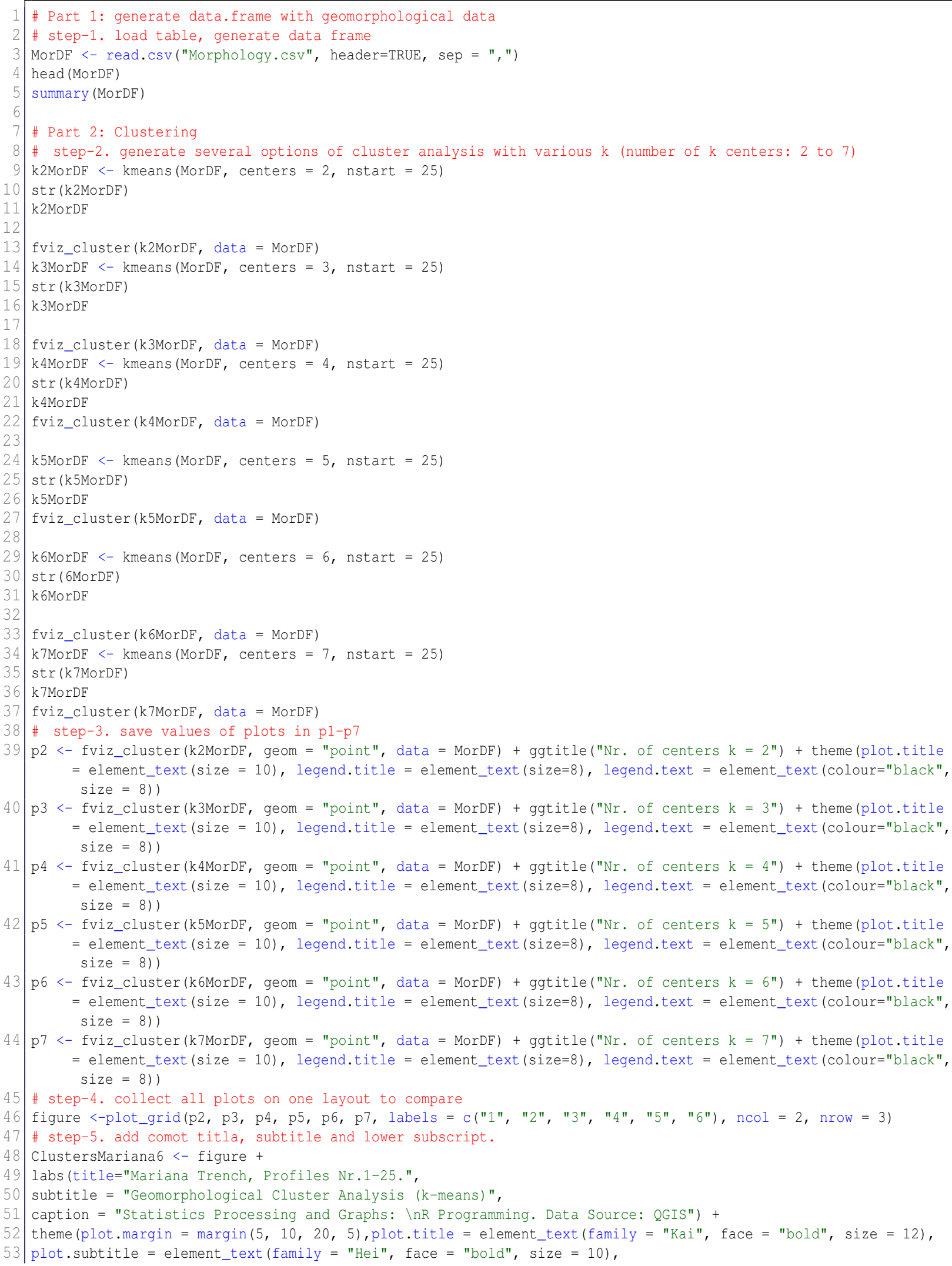


54 plot.caption $=$ element_text (face $=2$, size $=6)$, panel.background=ggplot2: :element_rect (fill = "white"),

55 legend.justification = "bottom", legend.position = "bottom", legend.box.just = "right", legend.direction = " horizontal",

56 legend.box = "horizontal", legend.box.background = element_rect (colour = "honeydew4",size=0.2),

57 legend.background = element_rect (fill = "white"),

58 legend.key.width $=$ unit $(1, " \mathrm{~cm} ")$, legend.key.height $=$ unit $(.5, " \mathrm{~cm} ")$,

59 legend.spacing. $\mathrm{x}=\operatorname{unit}(.2, \mathrm{~cm})$, legend. spacing.y $=$ unit $(.1, " \mathrm{~cm} ")$,

60 legend.text = element_text (colour="black", size=6, face=1),

61 legend.title = element_text (colour="black", size=6, face=1))

62 ClustersMariana6

codes/R-09.r

\section{A.6.10 R code for Pairwise Standard Scatter Plots of k-means Cluster Correlation (com- paring 4 tectonic plates)}

Source data available on my GitHub.

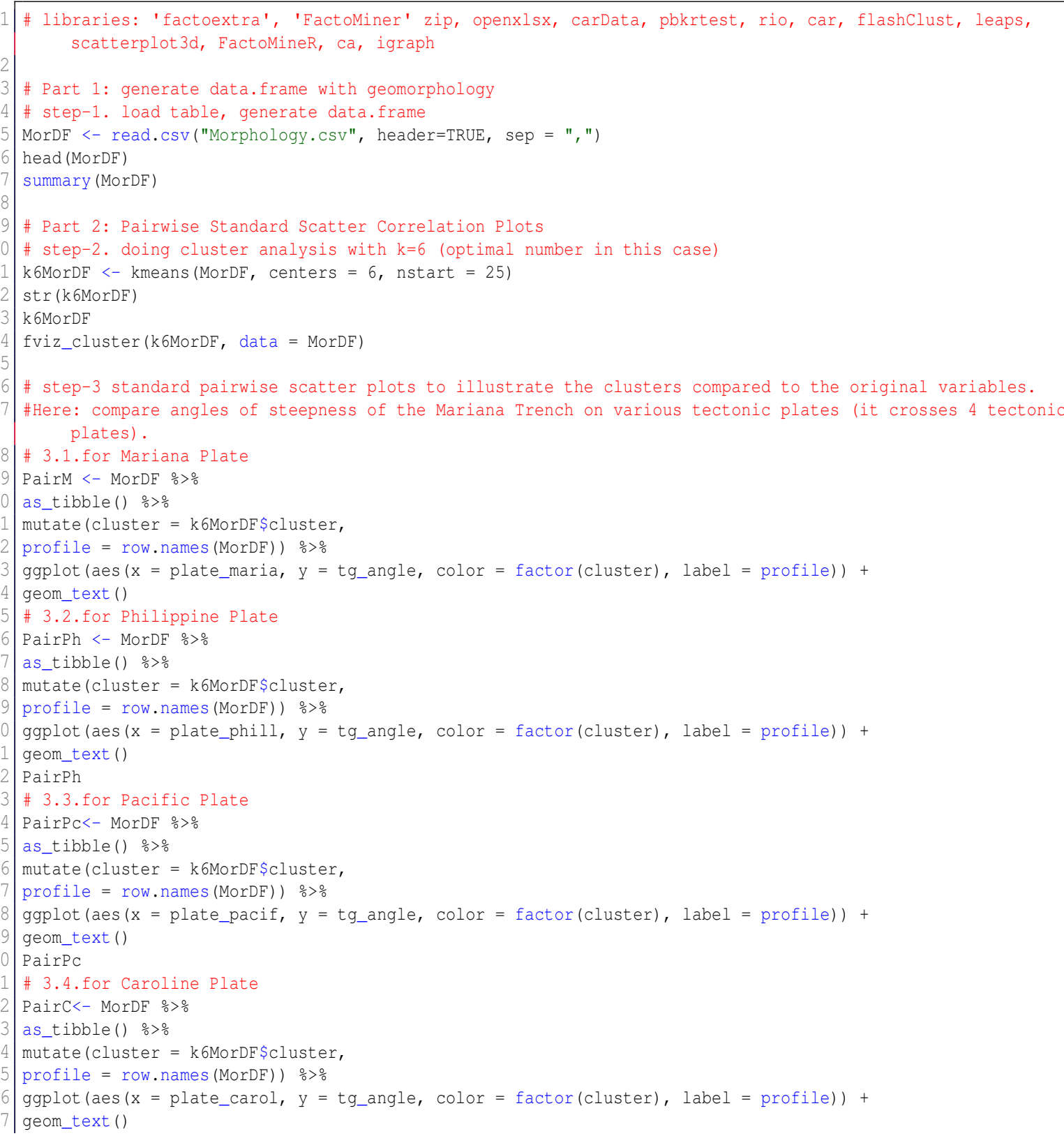




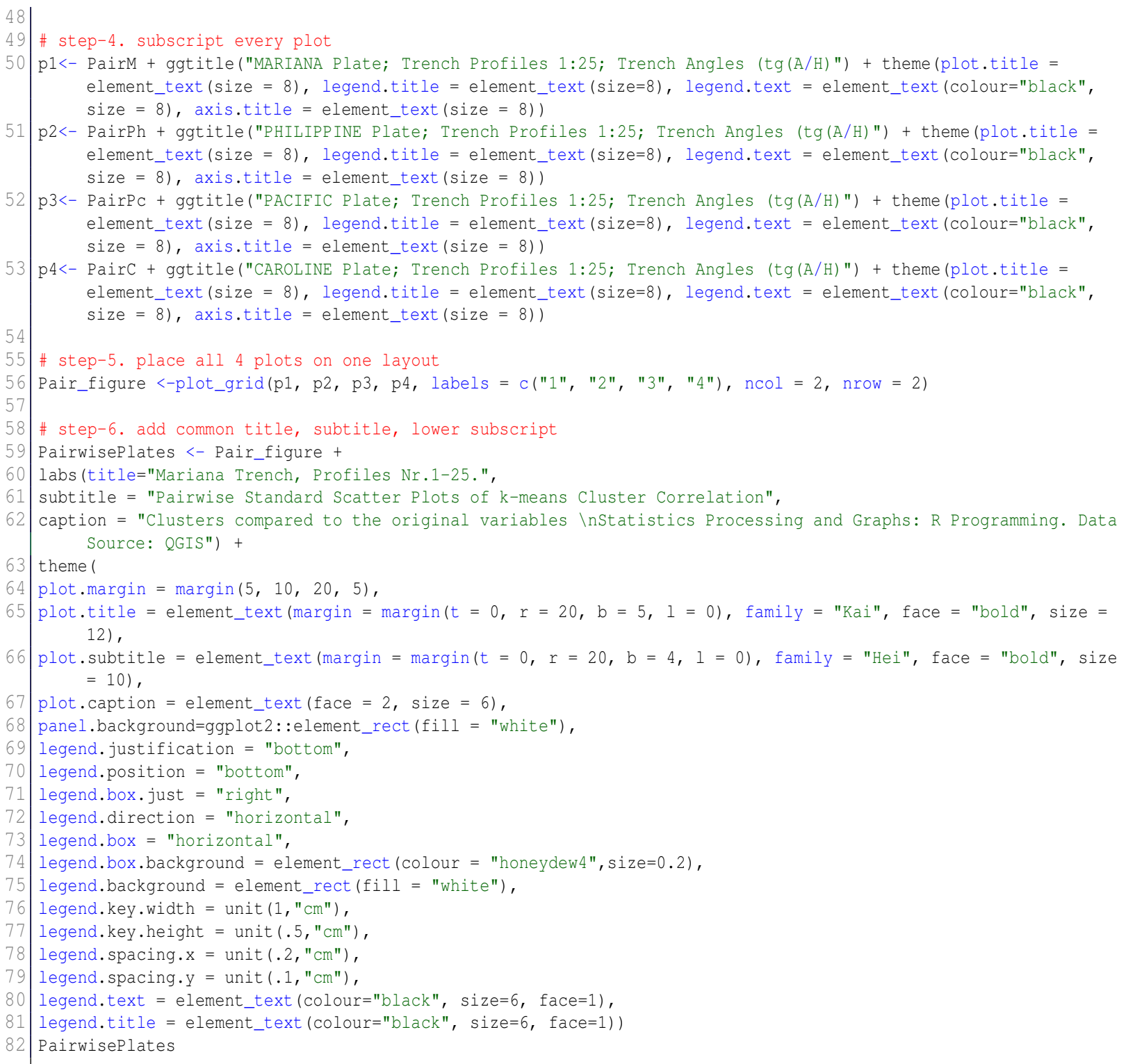

codes/R-10.r 


\section{A.6.11 R code for 'lollipop' charts and diverging bars by (ggplot) library}

\section{Source data available on my GitHub.}

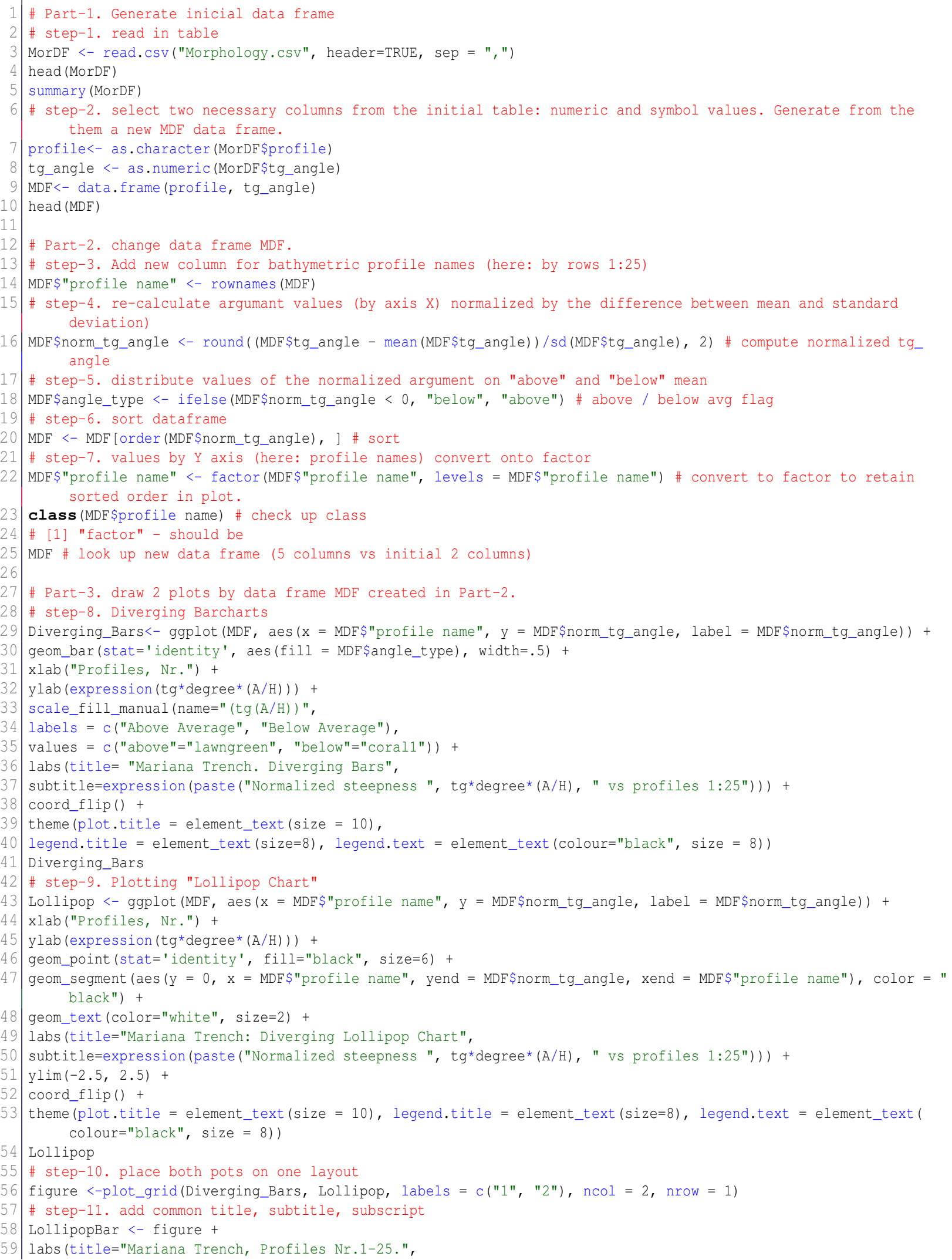




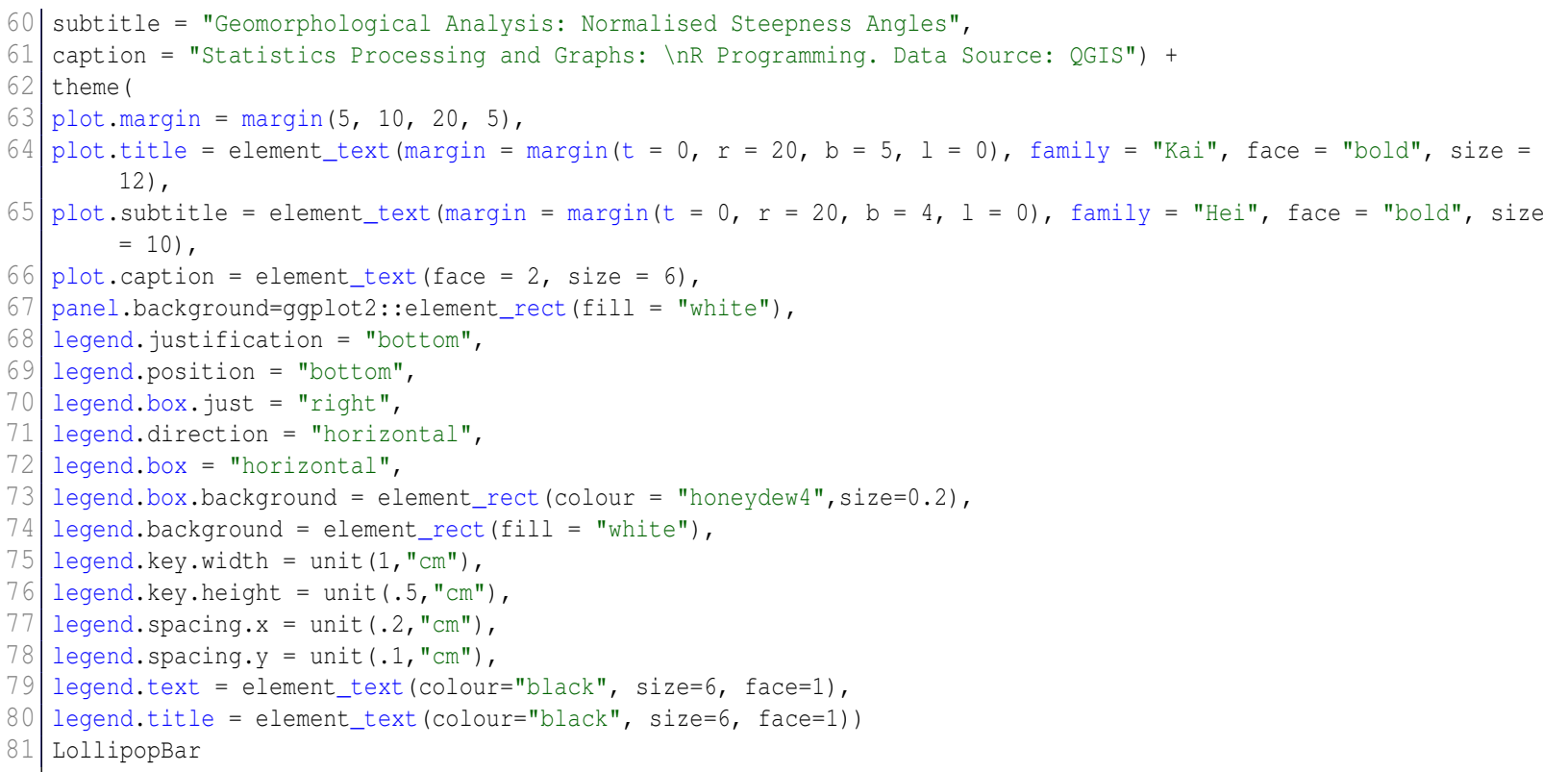

codes/R-11.r 


\section{A.6.12 R code for Dumbbell chart by (ggalt) and (ggplot2) libraries}

\section{Source data available on my GitHub.}

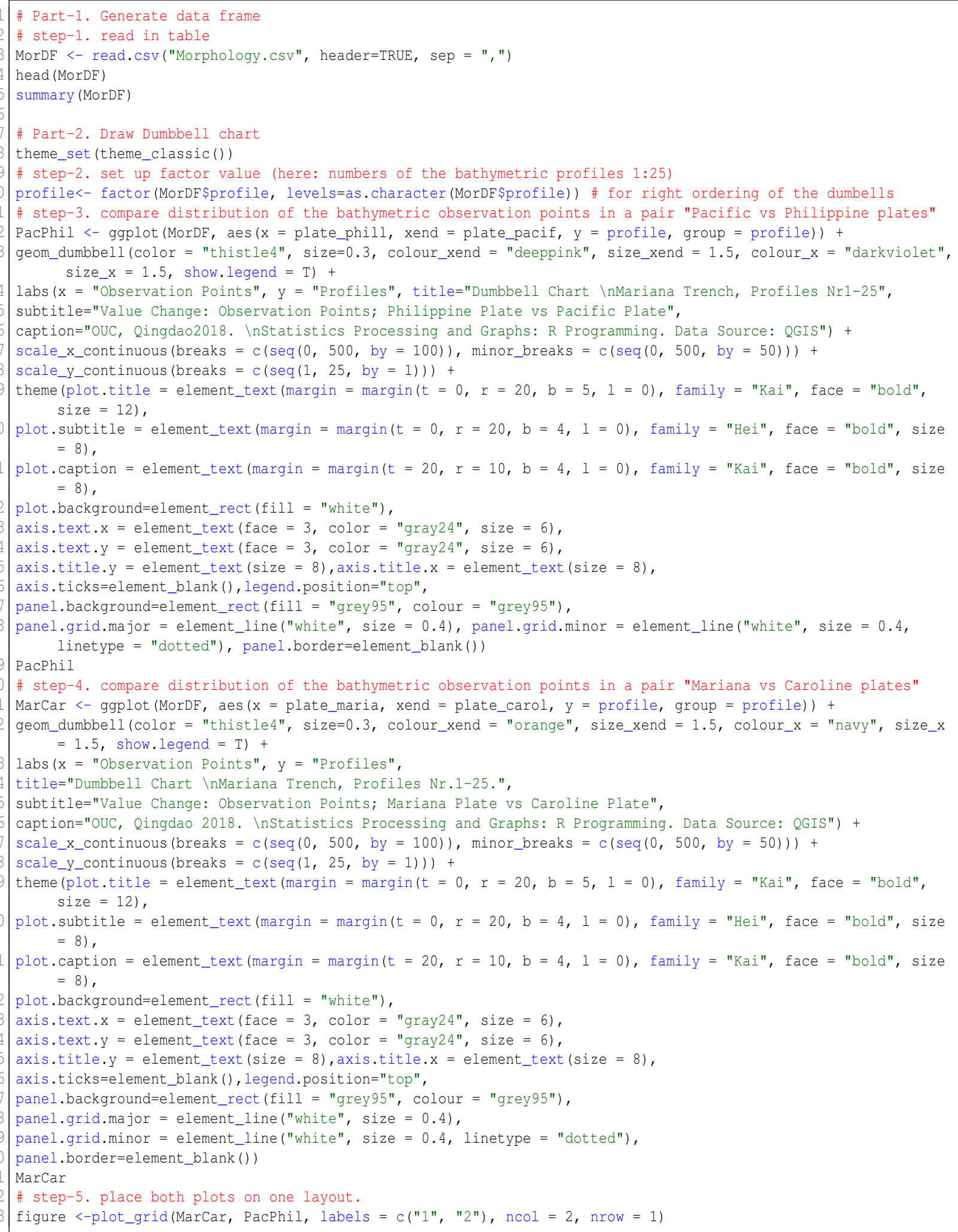

codes/R-12.r 


\section{A.6.13 $R$ code for categorywise bar charts}

\section{Source data available on my GitHub.}

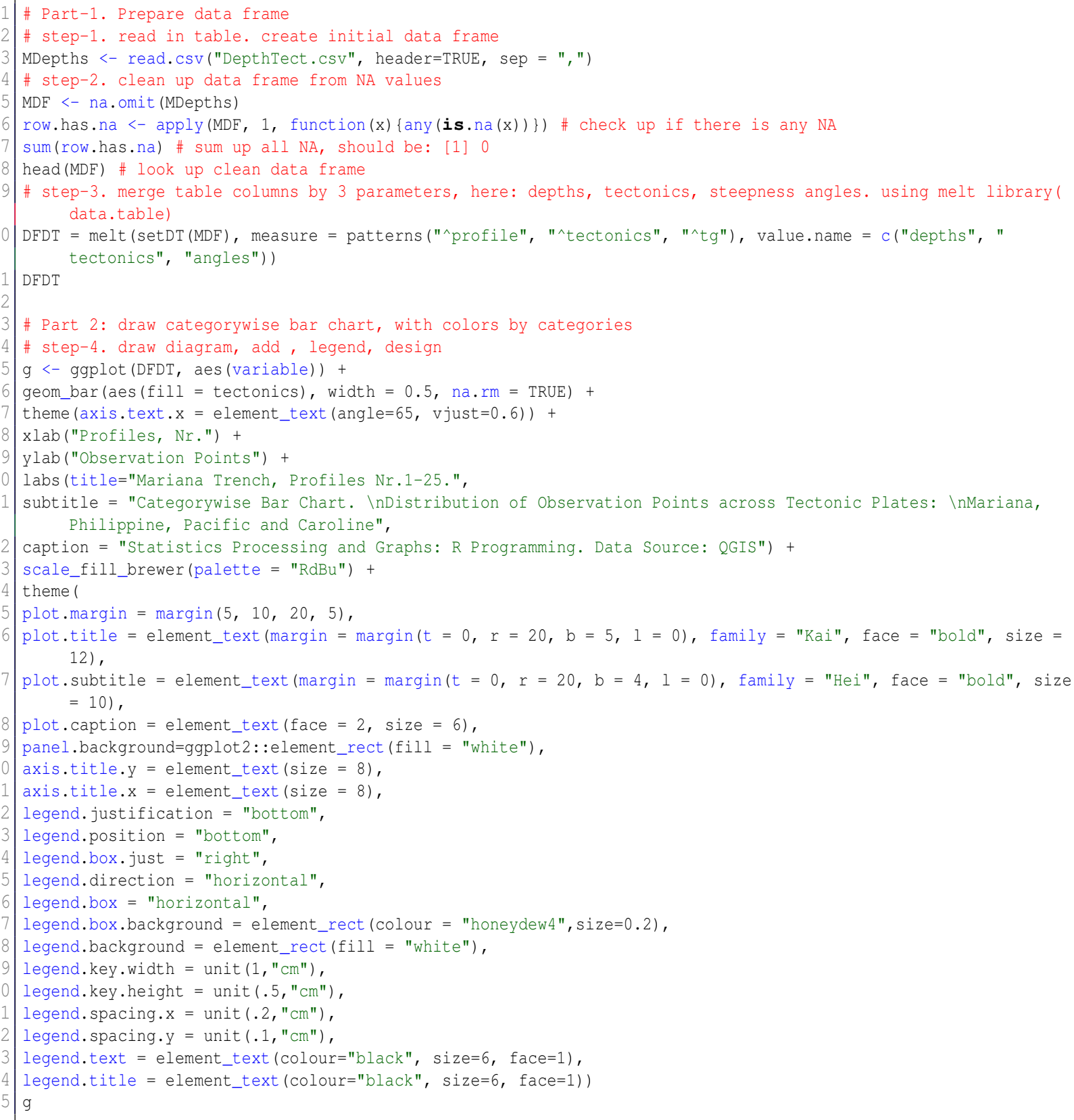

codes/R-13.r 


\section{A.6.14 R code for dot plot with encircling by (ggalt) library}

\section{Source data available on my GitHub.}

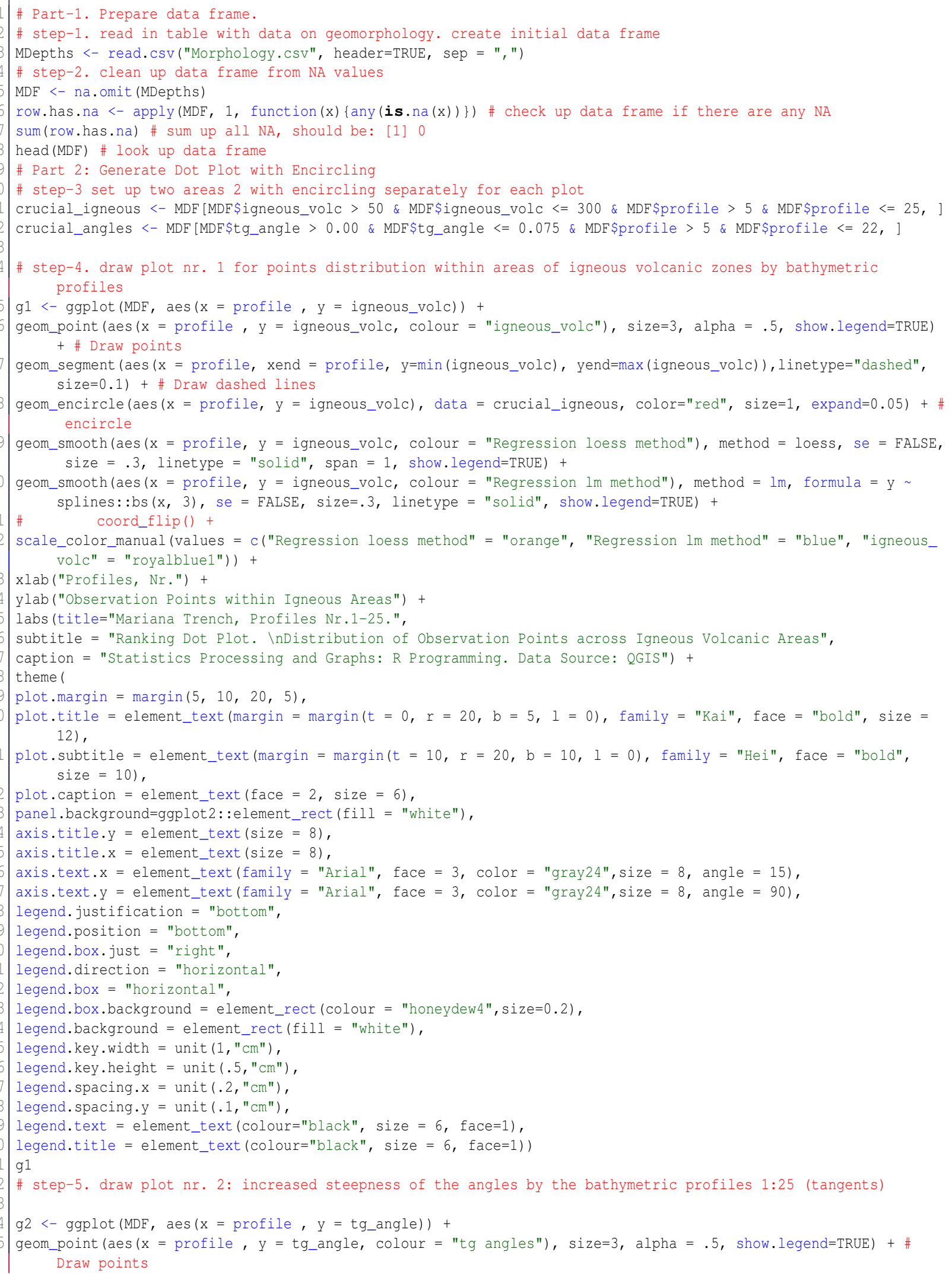




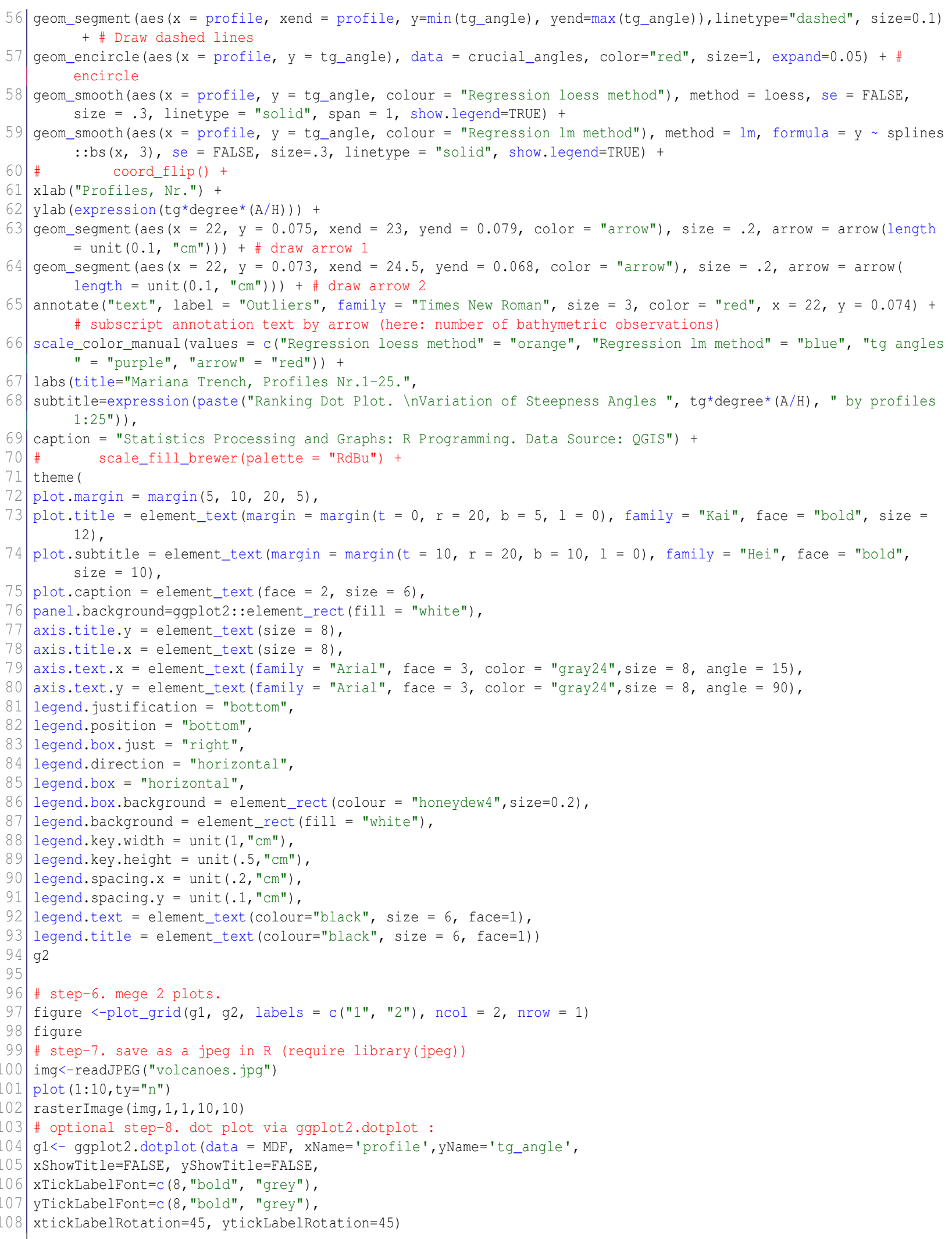

codes/R-14.r 


\section{A.6.15 $R$ code for double-Y axis using (LatticeExtra) library to perform comparative analysis of categories}

Source data available on my GitHub.

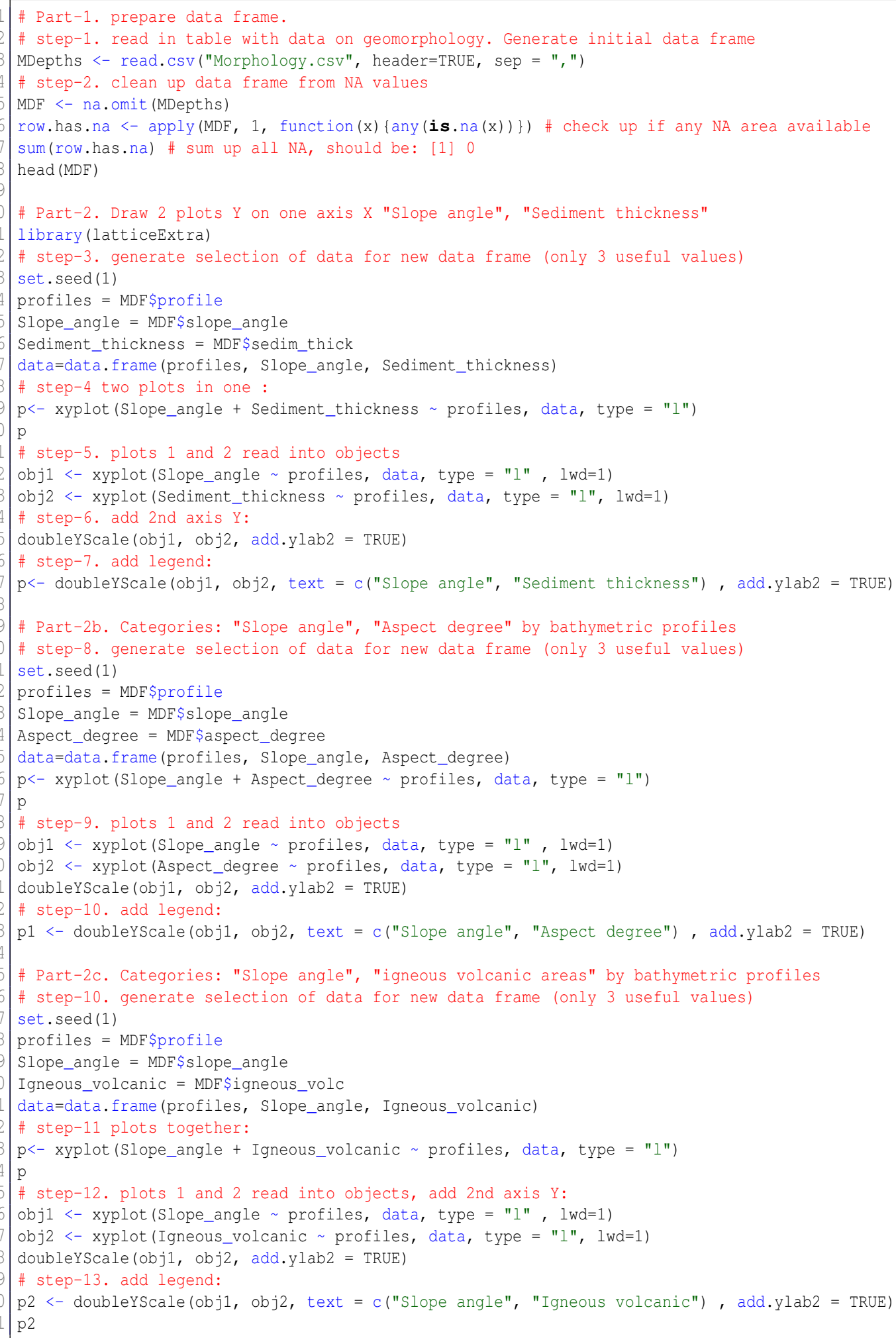

codes/R-15.r 


\section{A.6.16 R code for circular barplot by library tidyverse}

\section{Source data available on my GitHub.}

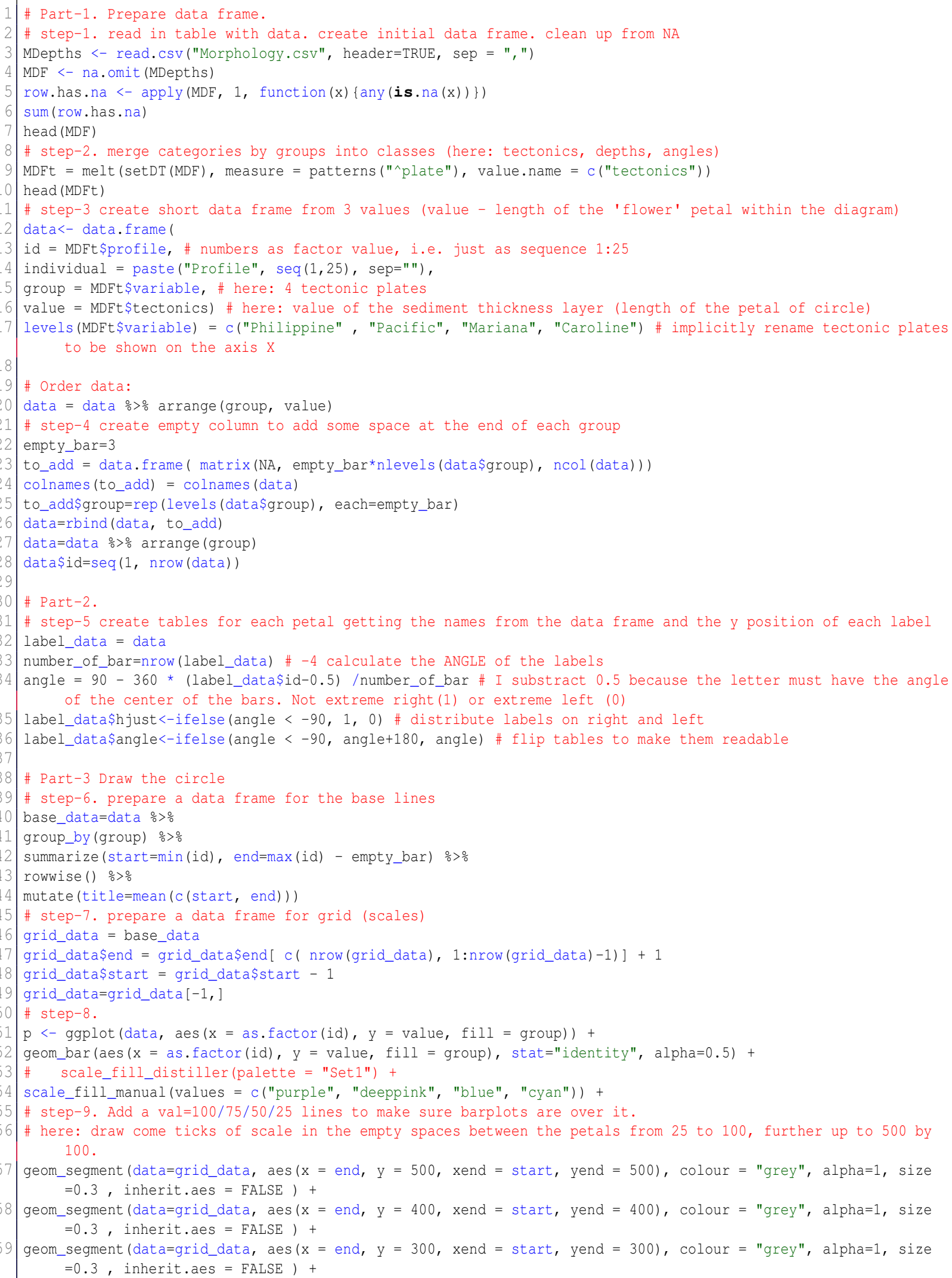




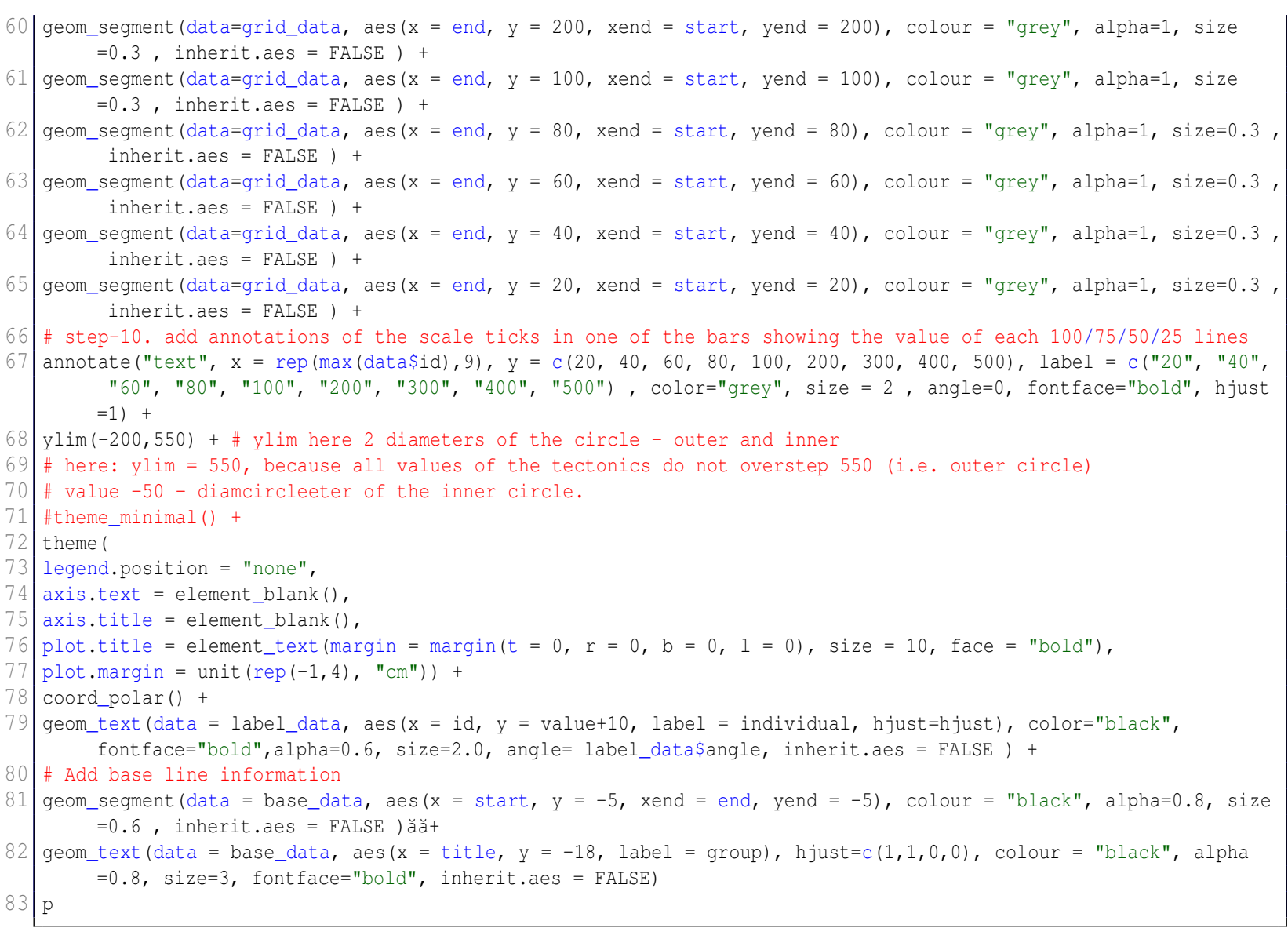

codes/R-16.r 


\section{A.6.17 R code for multiple strip plots divided groups, by LatticeExtra library}

\section{Source data available on my GitHub.}

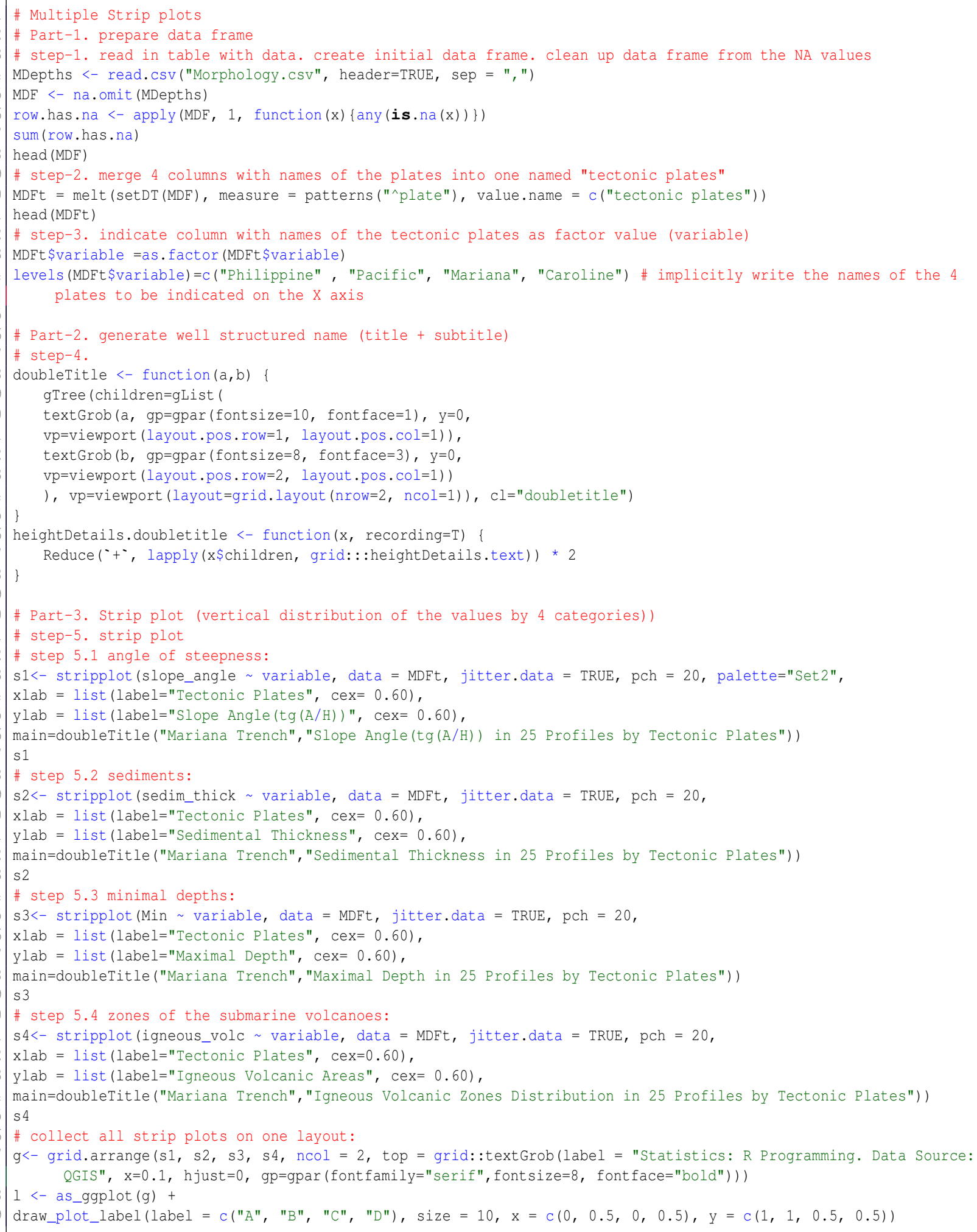

codes/R-17.r 


\section{A.6.18 $R$ code for multiple panels by groups (tectonic plates, depths, slope angles)}

Source data available on my GitHub.

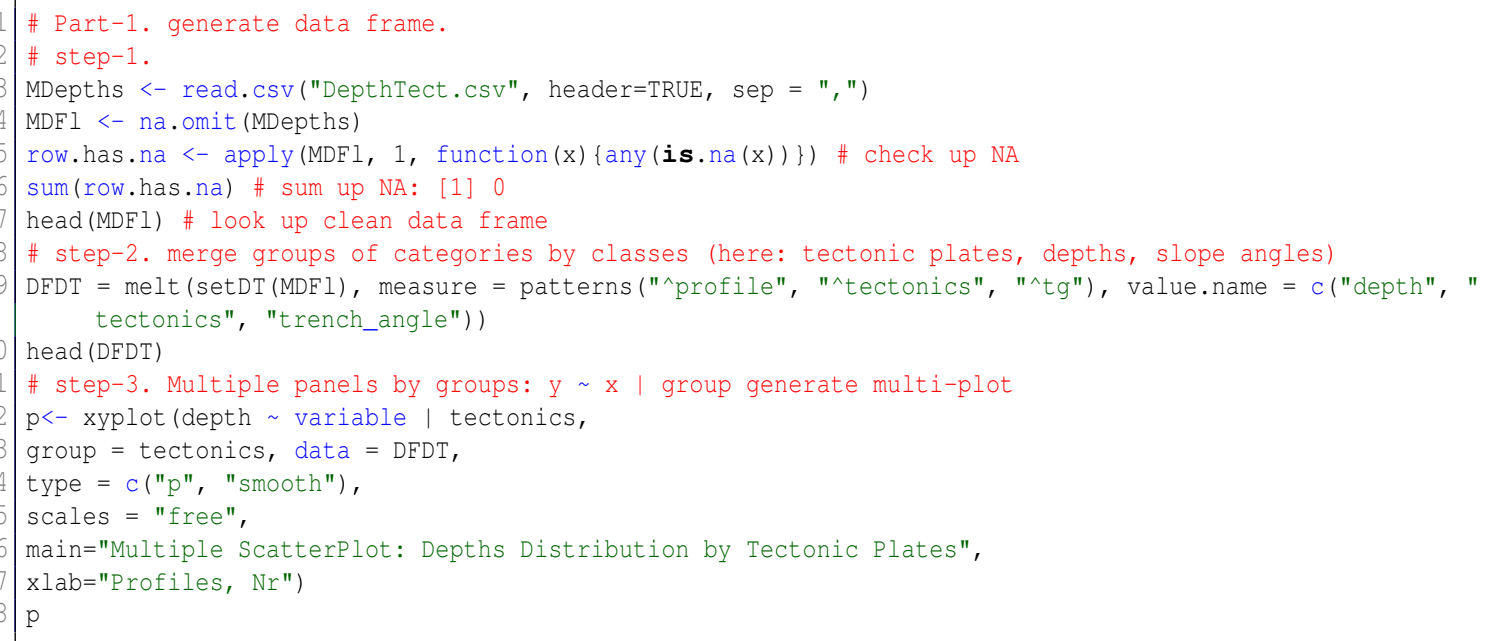

codes/R-18.r

\section{A.6.19 $R$ code for density curves: data distribution}

Source data available on my GitHub.

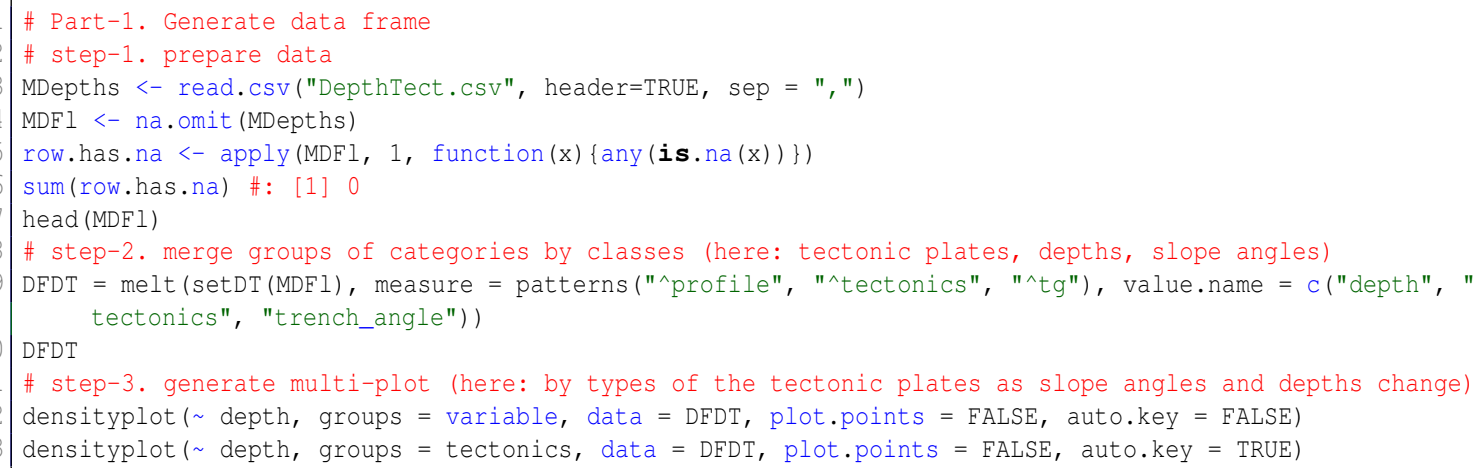

codes/R-19.r 


\section{A.6.20 $R$ code to generate brackets for the specific regions along the Mariana Trench using library (pBrackets)}

Source data available on my GitHub.

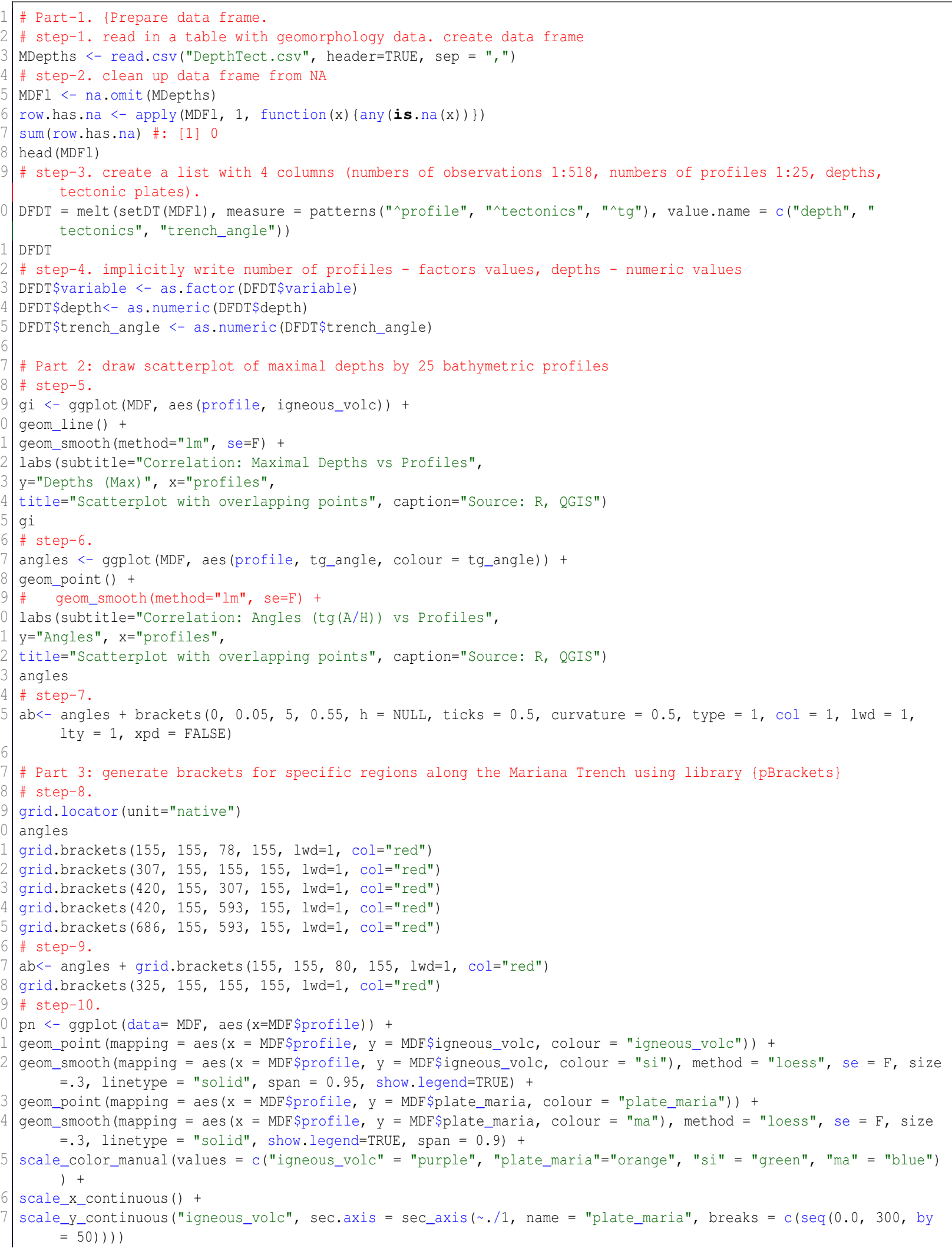




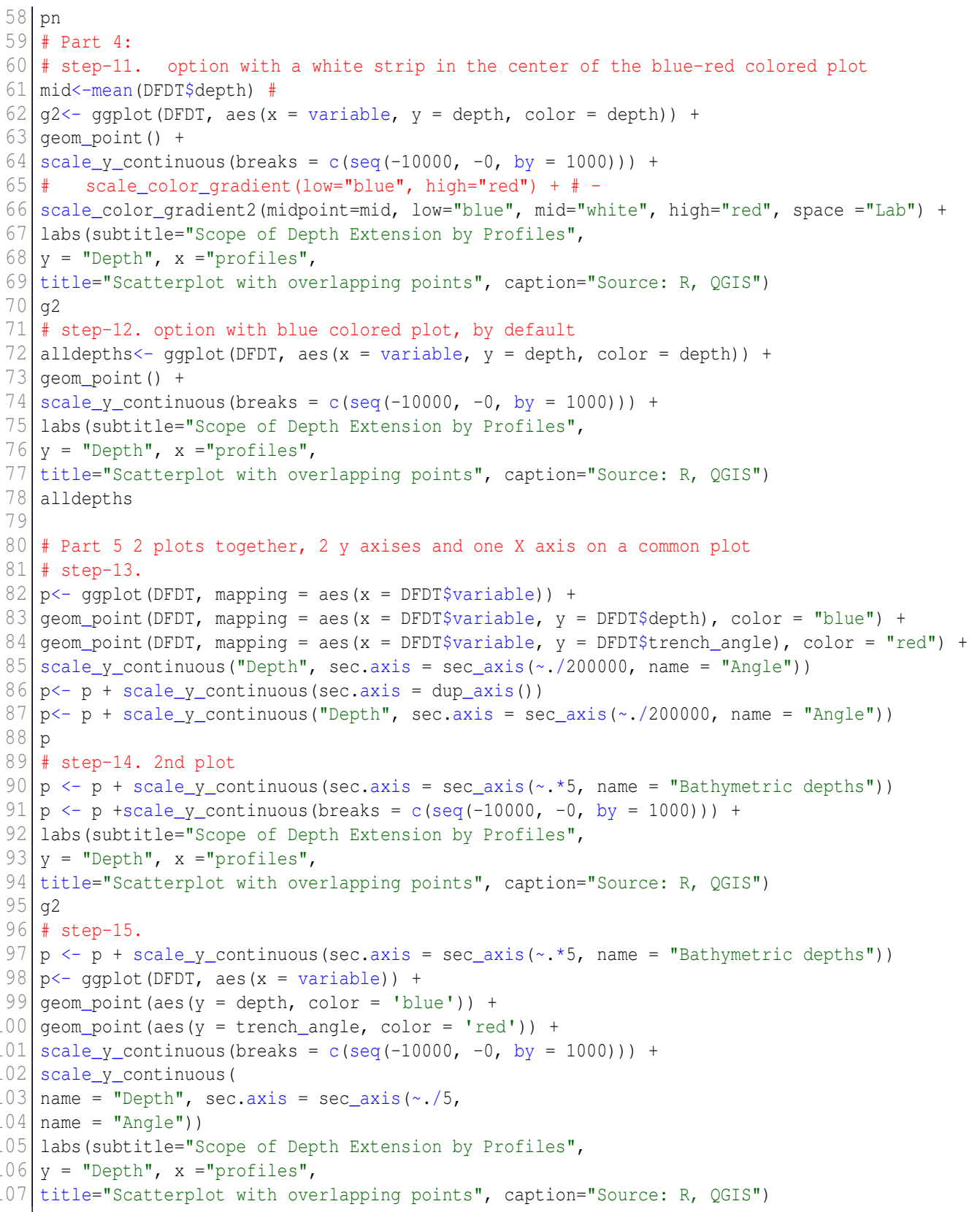

codes/R-20.r

lxix

Polina Lemenkova:

Deep-Sea Trenches of the Pacific Ocean: ...Data Modeling by GMT, Python and R 


\section{A.6.21 $R$ code for radar chart using (fmsb) library}

Source data available on my GitHub.

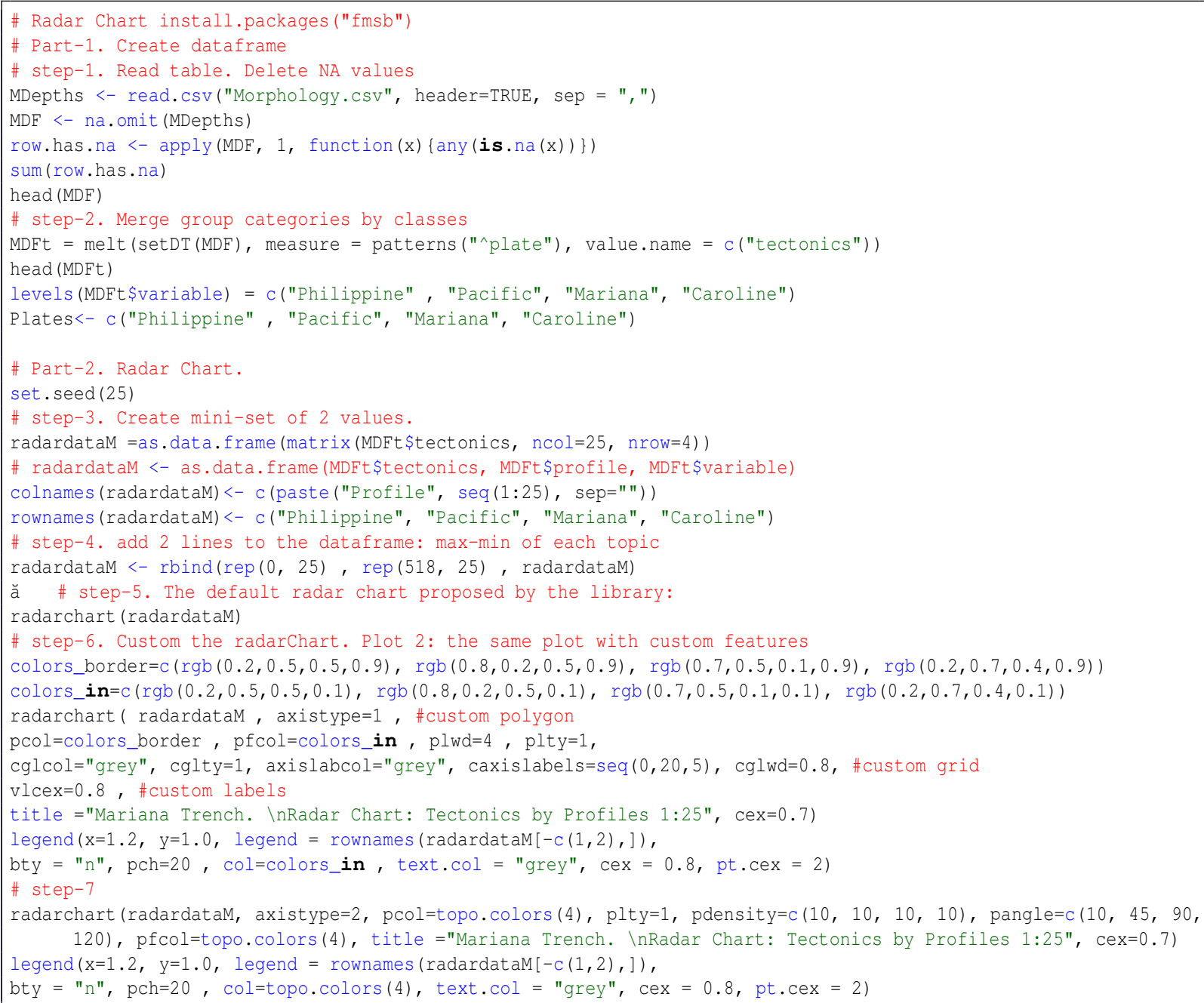

codes/R-21.r

\section{A.6.22 $R$ code for highlighted group in lollipop chart by libraries (ggsignif) and (tidy- verse)}

Source data available on my GitHub.

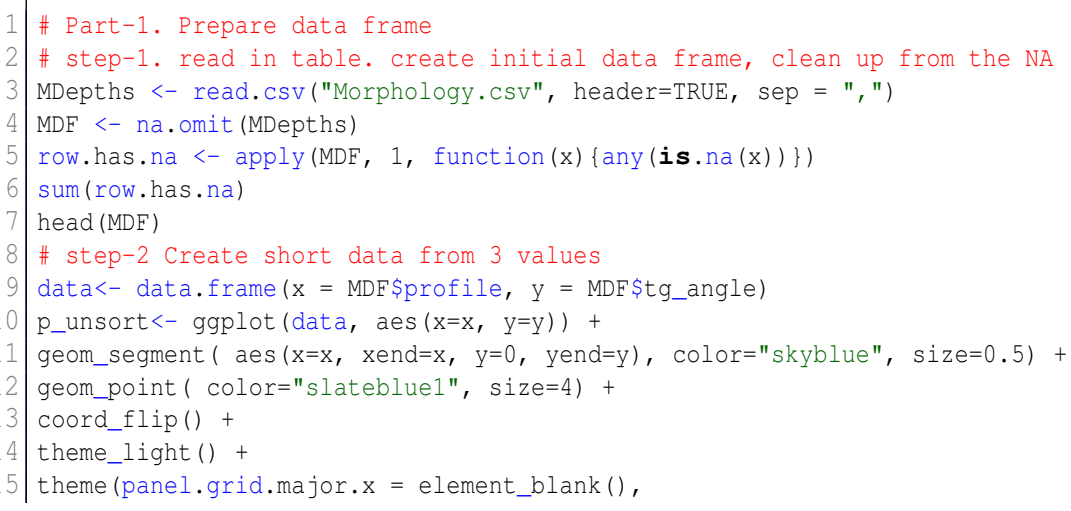




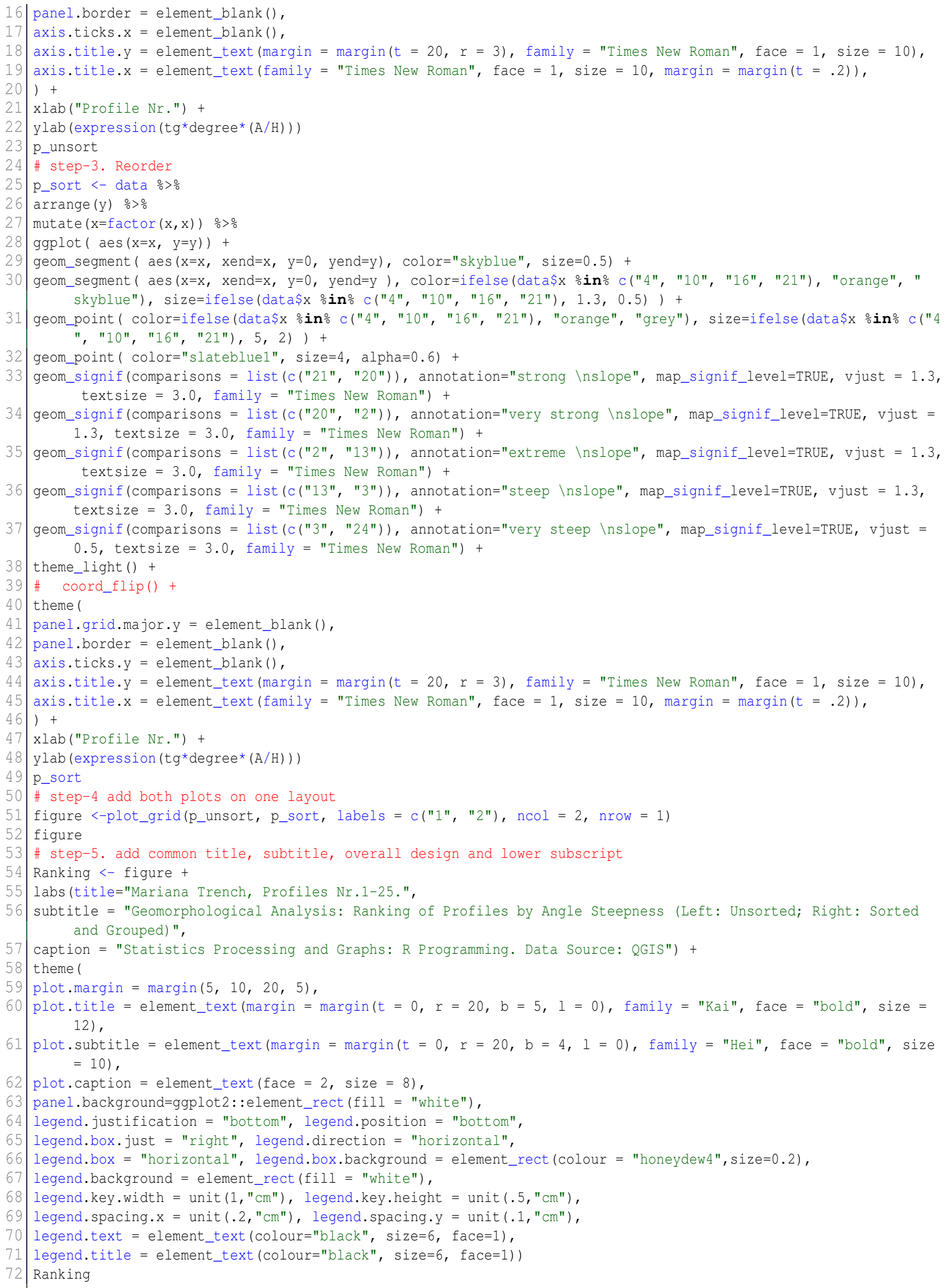

codes/R-22.r 


\section{A.6.23 $R$ code for Euler-Venn Diagram (logical correlation of objects) using (venn) li- brary}

Source data available on my GitHub.

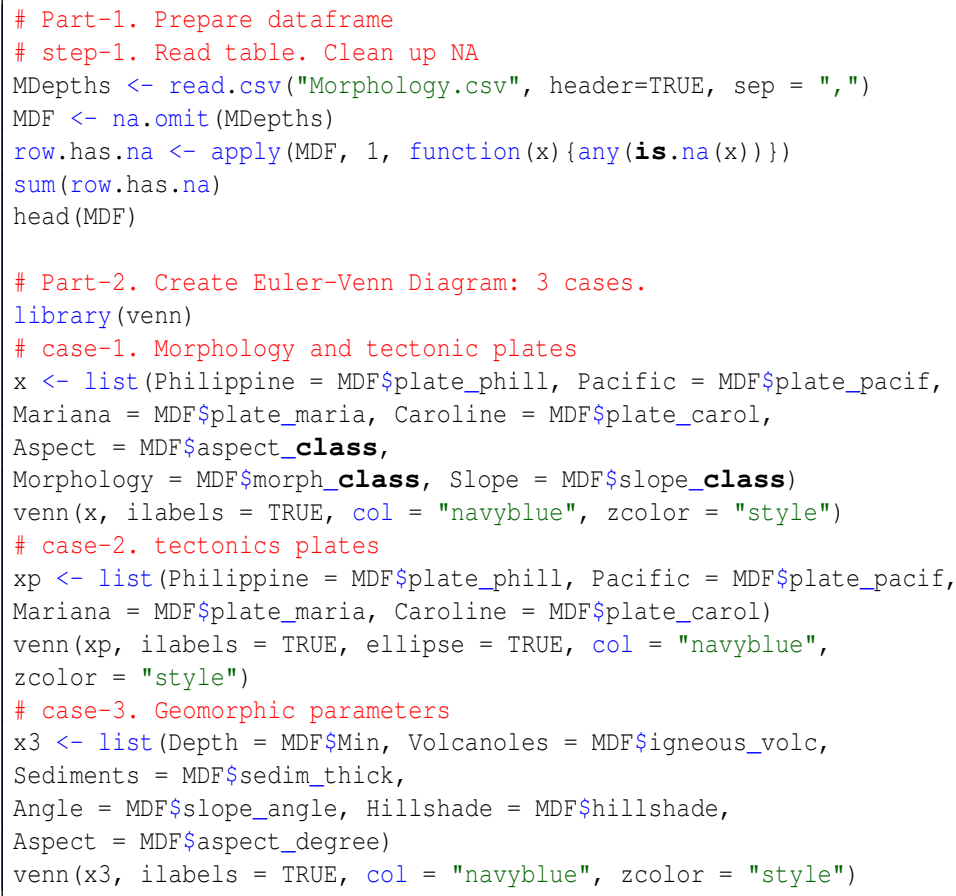

codes/R-23.r 


\section{A.6.24 $R$ code for animation using (gganimate), (gapminder) and (ggplot2) libraries: re- gression analysis plots for 25 bathymetric profiles}

Source data available on my GitHub.

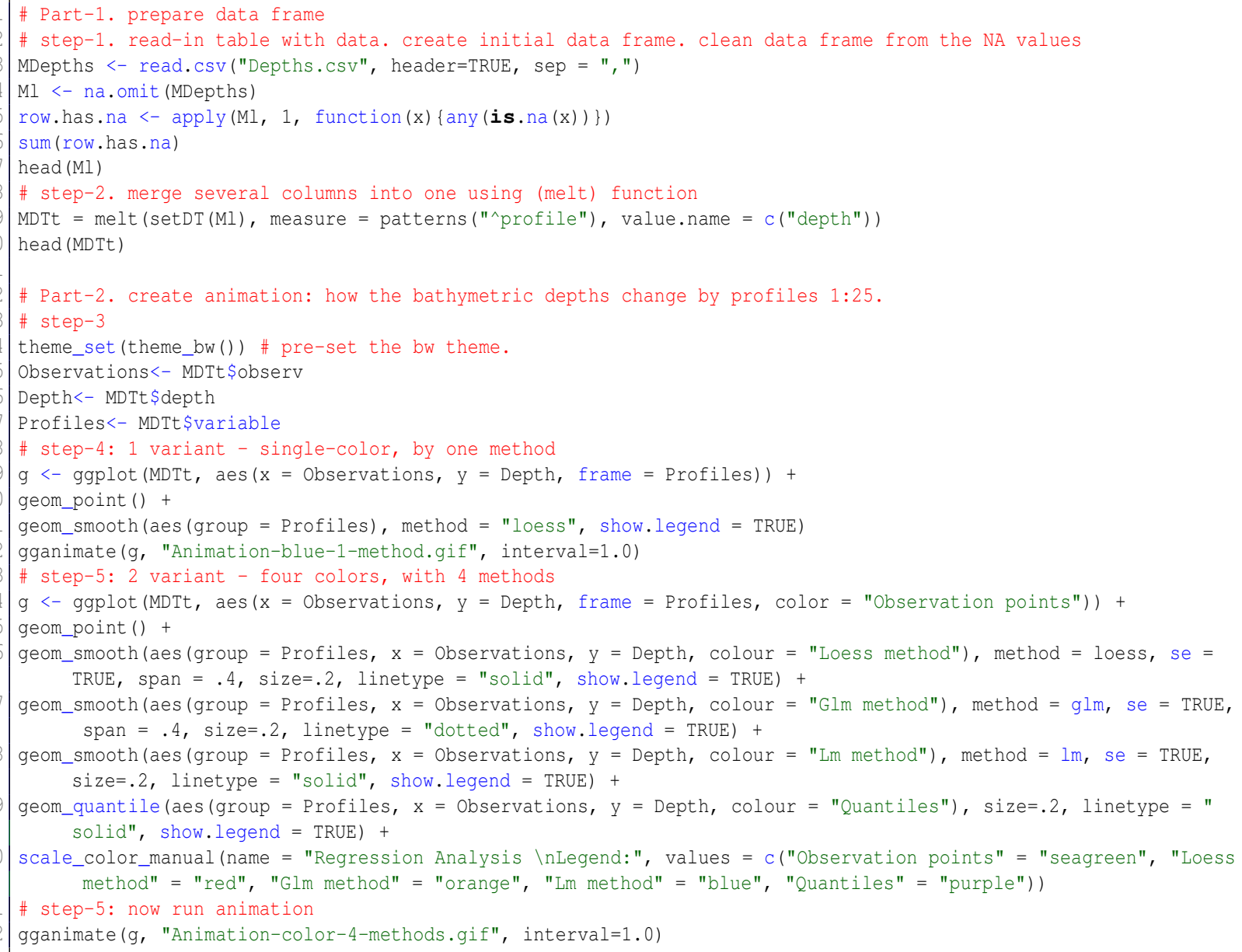

codes/R-24.r 


\section{A.6.25 $R$ code for 'violin' plots using (violinmplot) library: statistical analysis of bathy- metric data distribution}

Source data available on my GitHub.

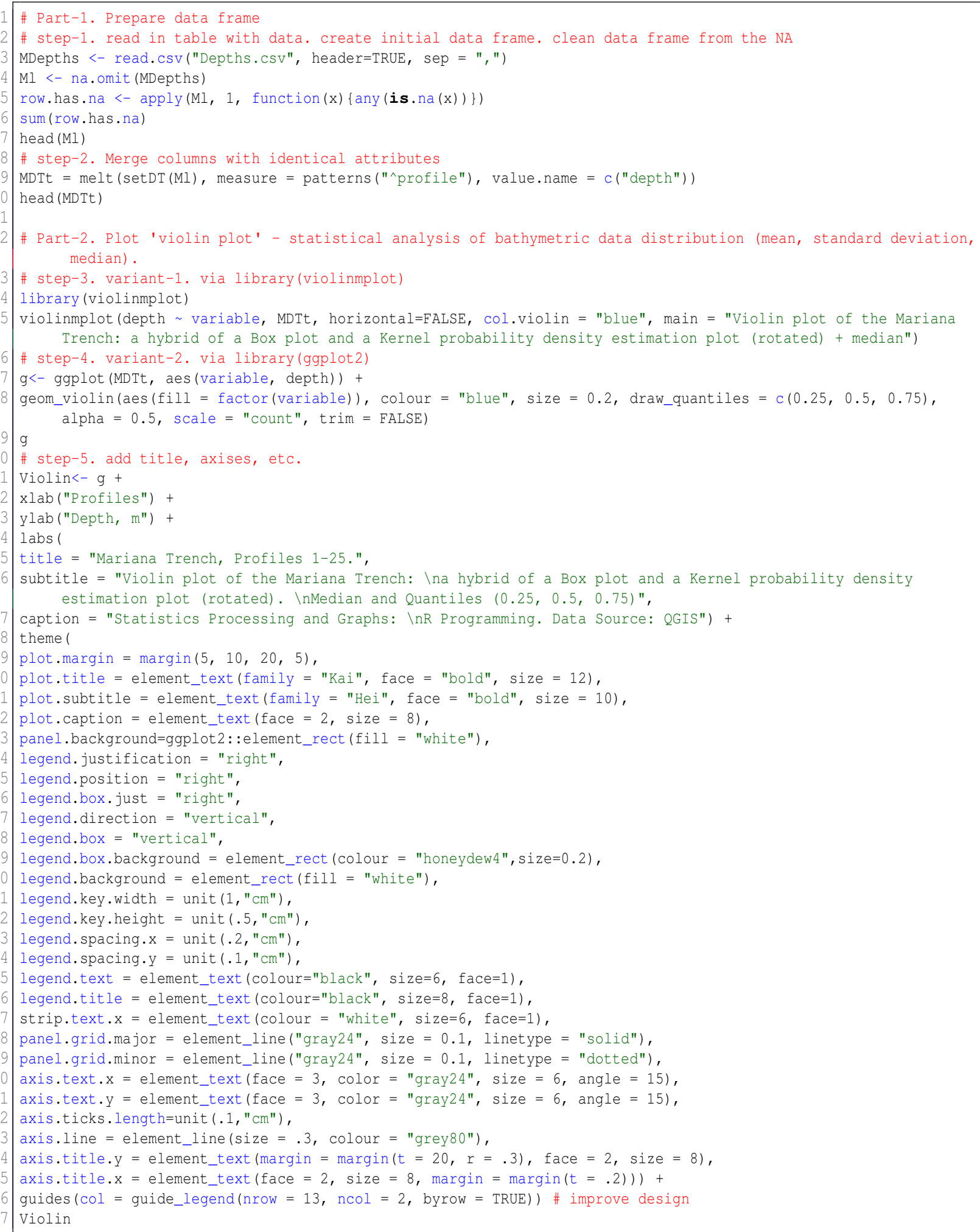

$\operatorname{codes} / \mathrm{R}-25 . \mathrm{r}$

lxxiv 


\section{A.6.26 R code for Exploratory Factor Analysis (EFA) using (FactoMiner), (factoextra) and (psych) libraries}

Source data available on my GitHub.

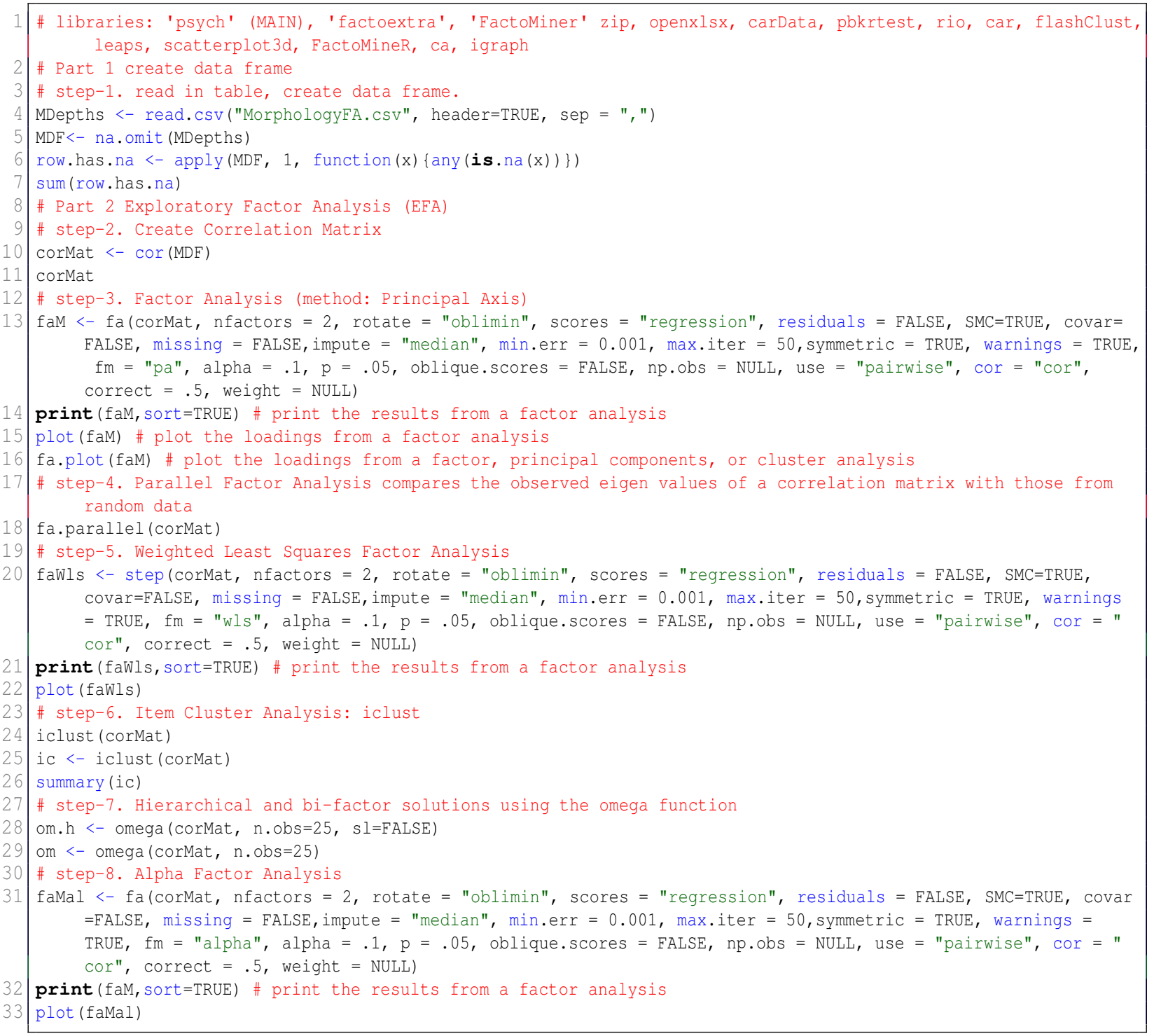

$\operatorname{codes} / \mathrm{R}-26 . \mathrm{r}$ 


\section{A.6.27 $R$ code for hexagonal plot by library(hexbin): bathymetric data distribution, Mariana Trench}

Source data available on my GitHub.

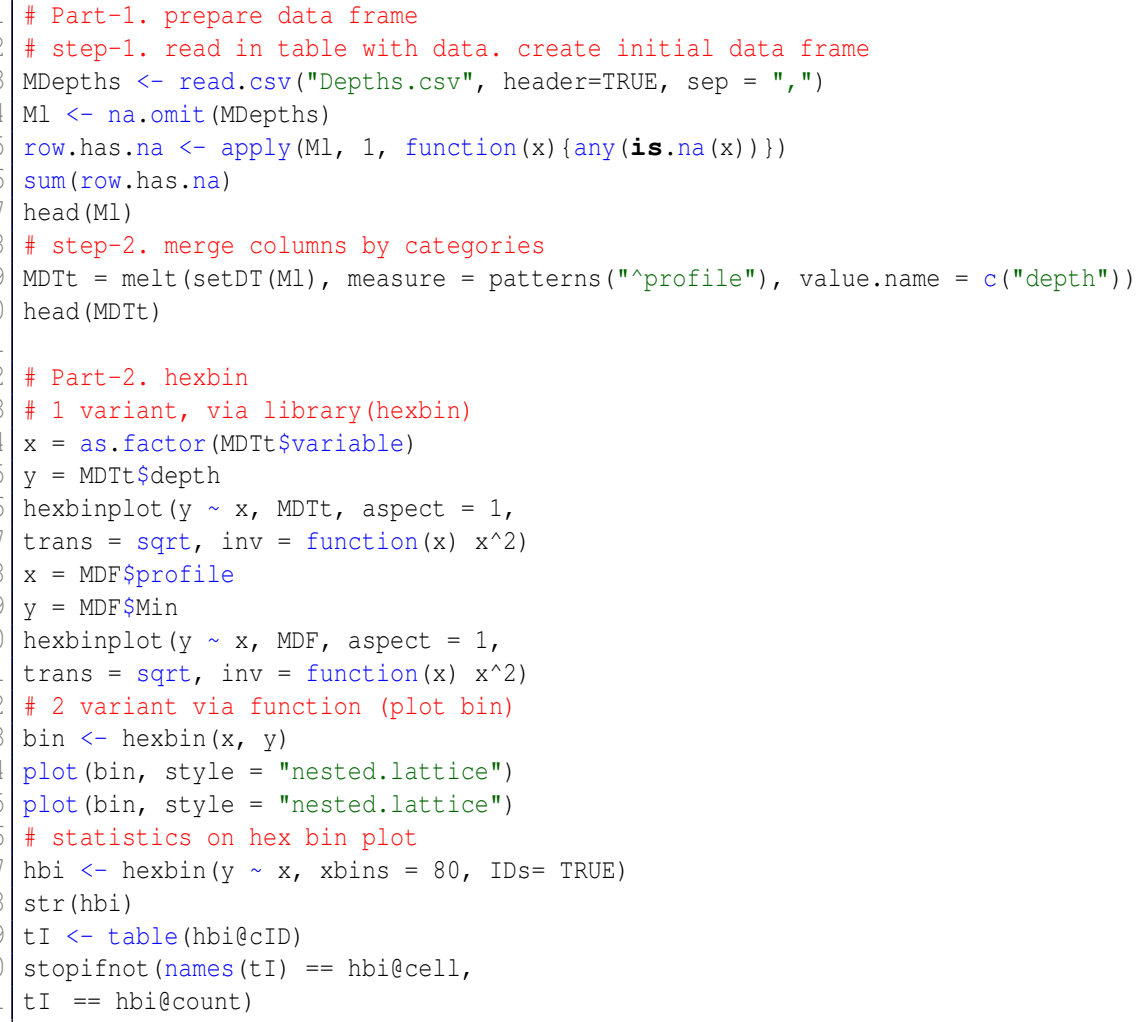

codes/R-27.r 


\section{A.6.28 R code for ANOVA for Mariana Trench}

\section{Source data available on my GitHub.}

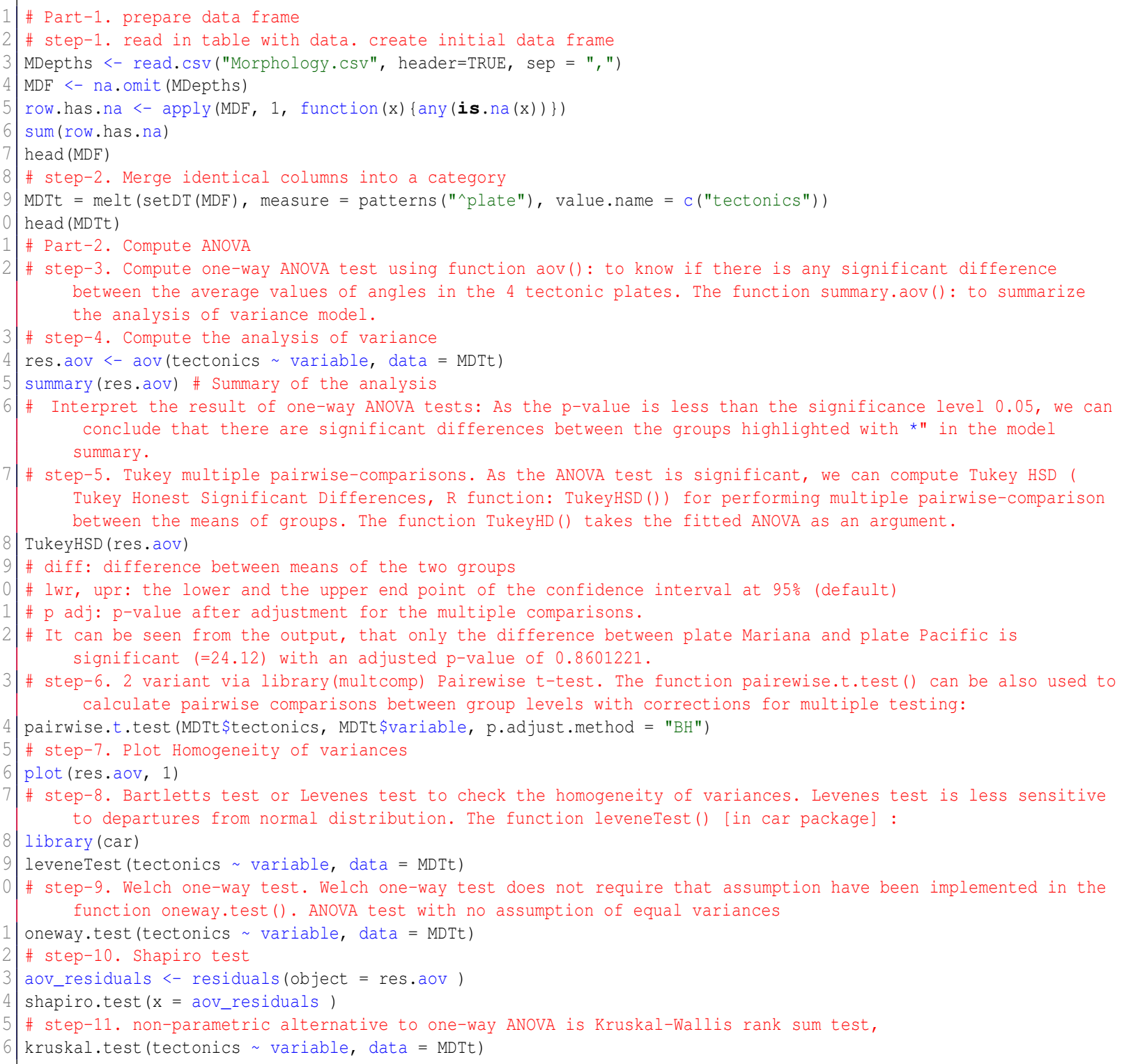

codes/R-28.r 


\section{A.6.29 $R$ code for Ternary Diagram by (ggtern) library}

\section{Source data available on my GitHub.}

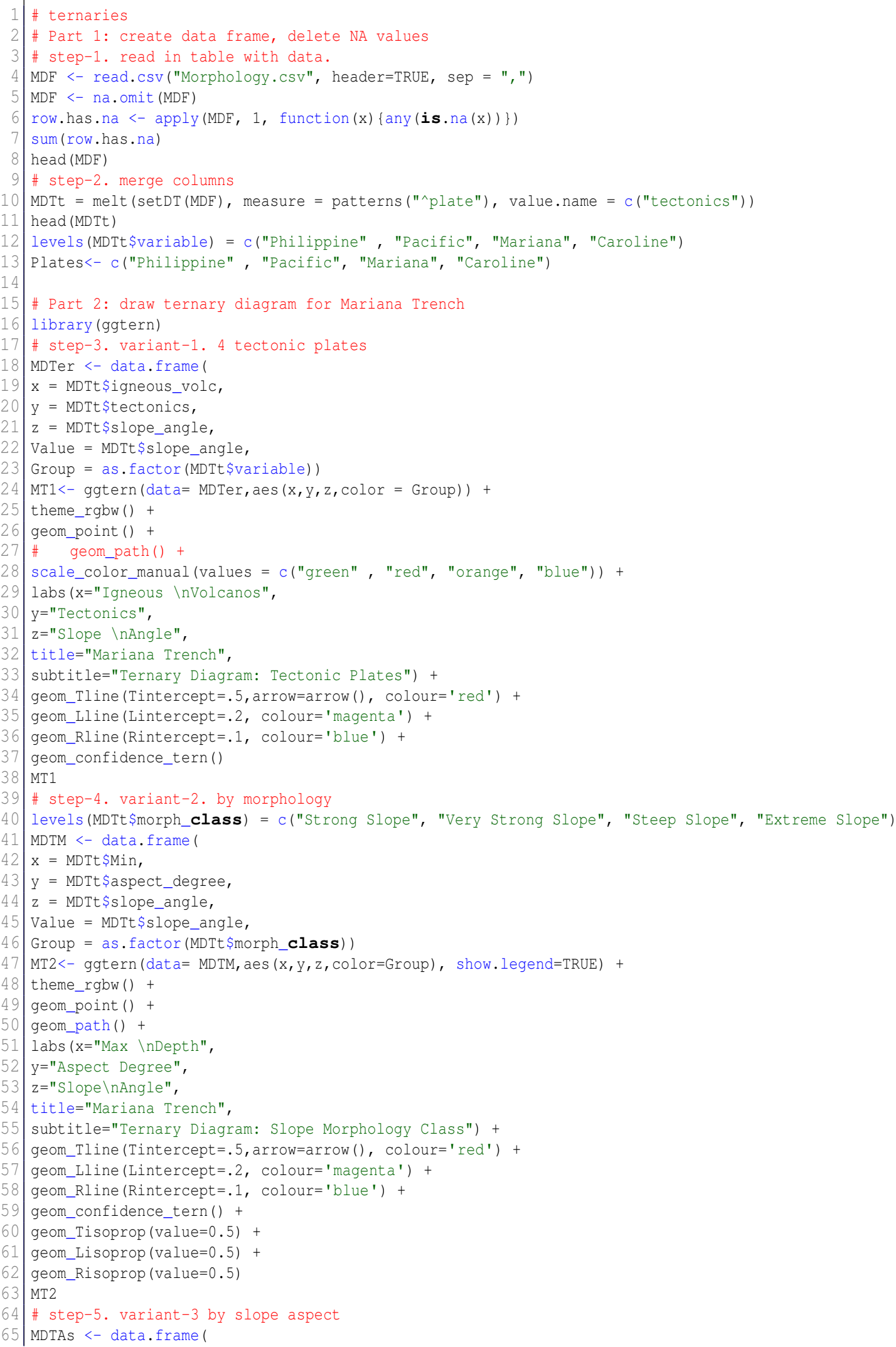




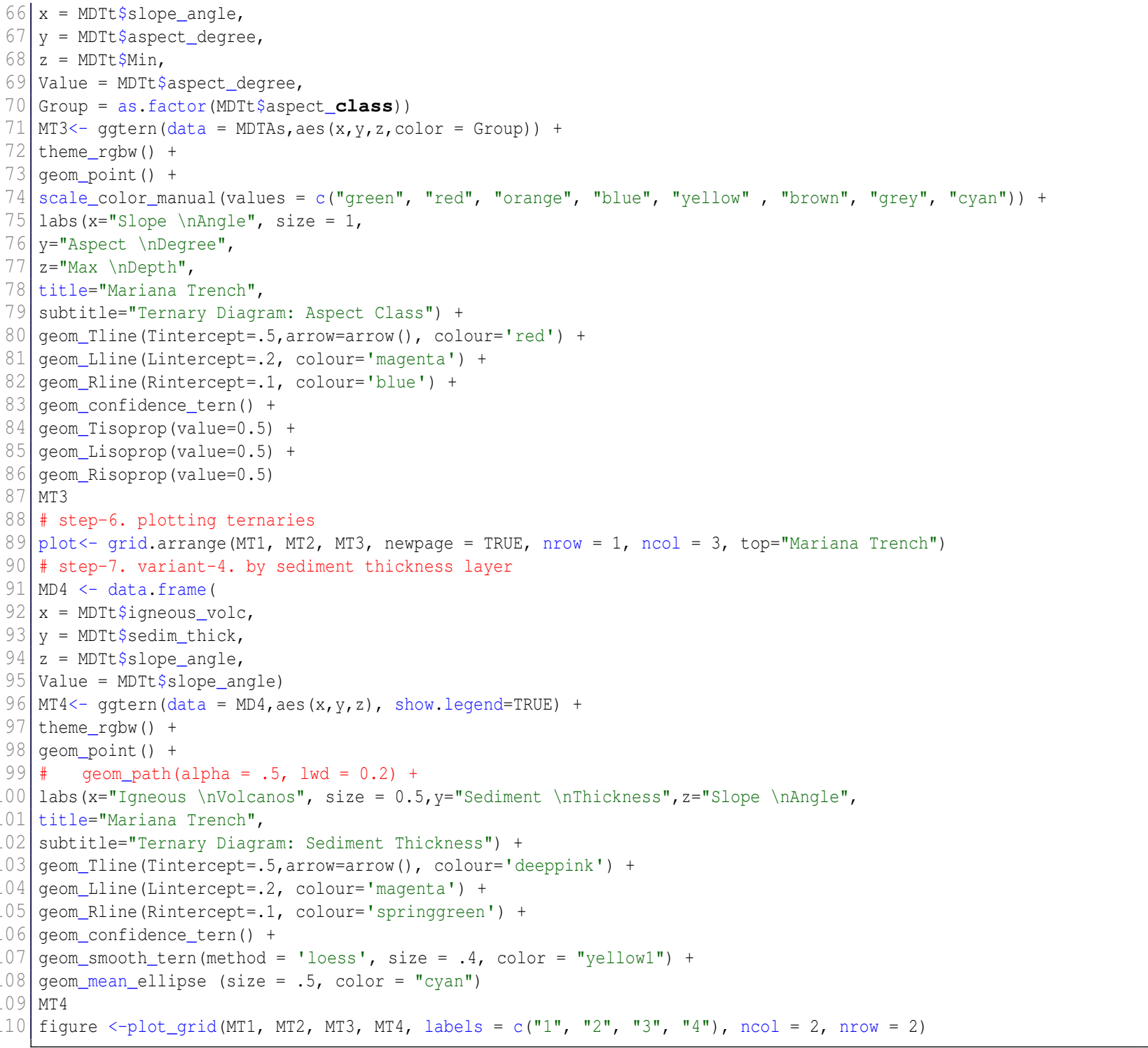

codes/R-29.r 


\section{A.6.30 $R$ code for silhouette plot by (cluster) library}

Source data available on my GitHub.

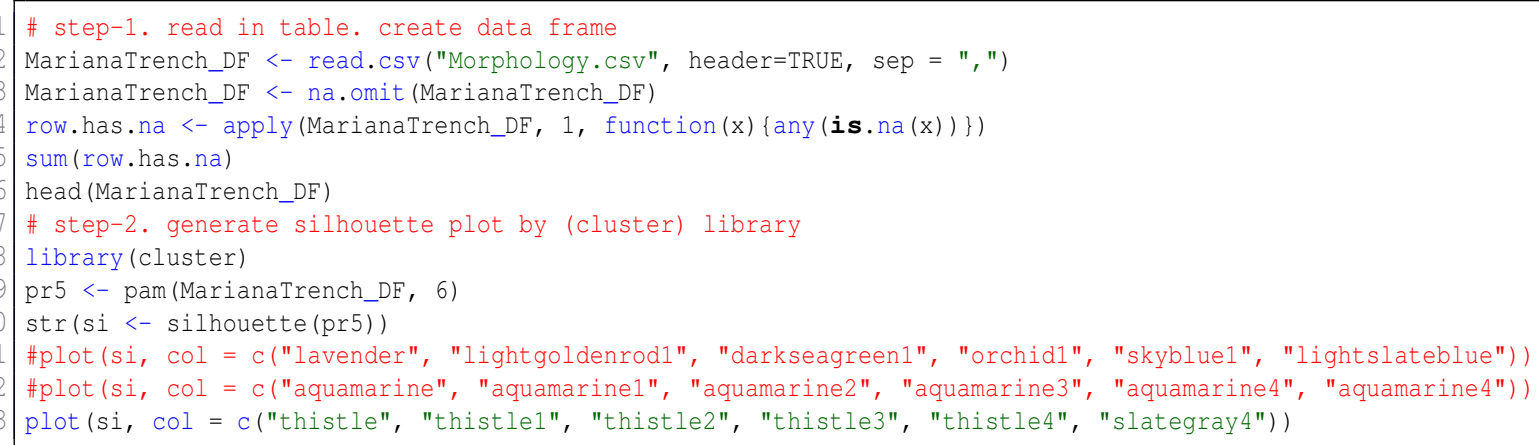

codes/R-30.r

\section{A.6.31 $R$ code for mosaic and association plots}

Source data available on my GitHub.

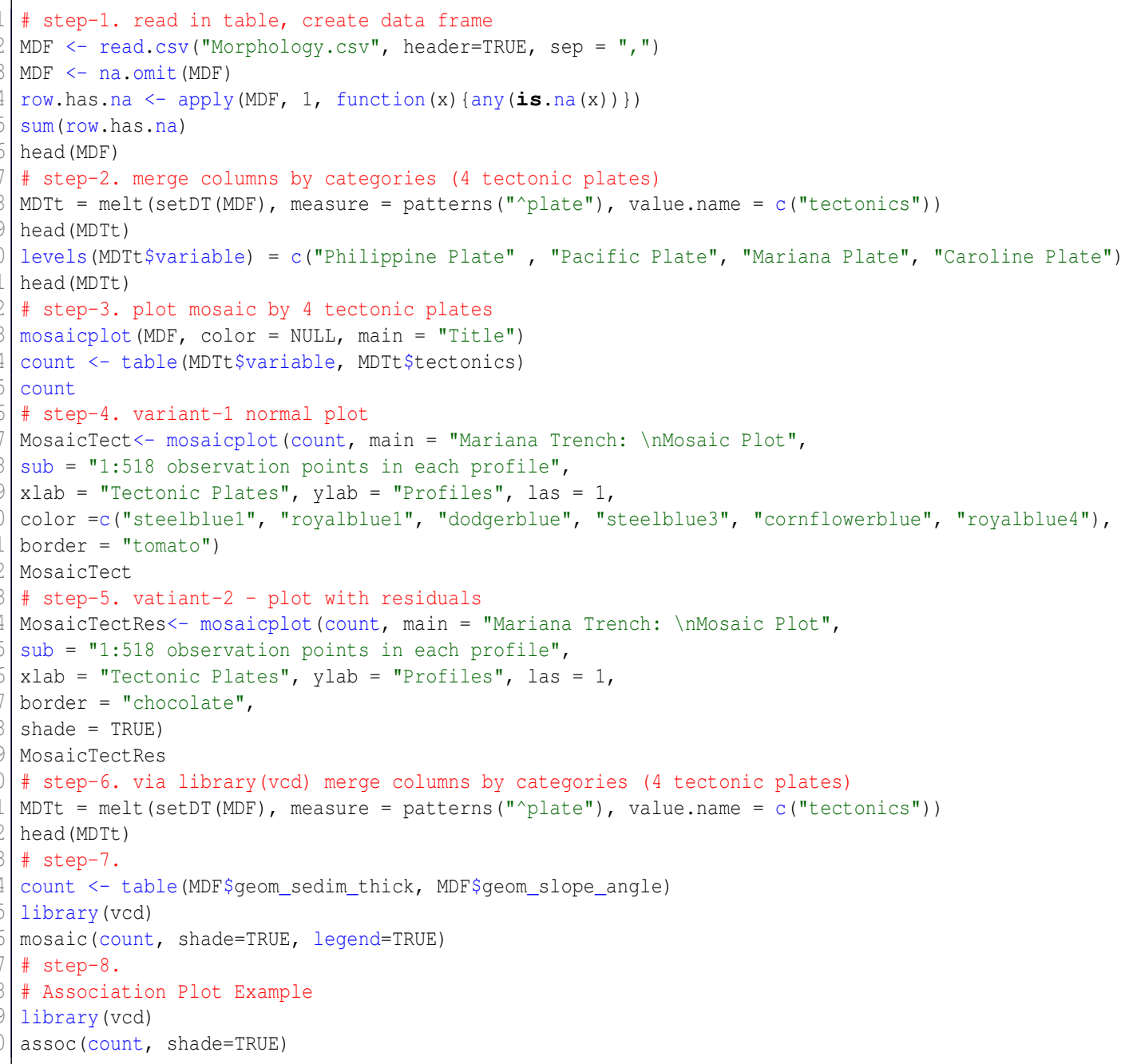

codes/R-31.r 


\section{A.6.32 $R$ code plot correlation ellipses using library(ellipse)}

Source data available on my GitHub.

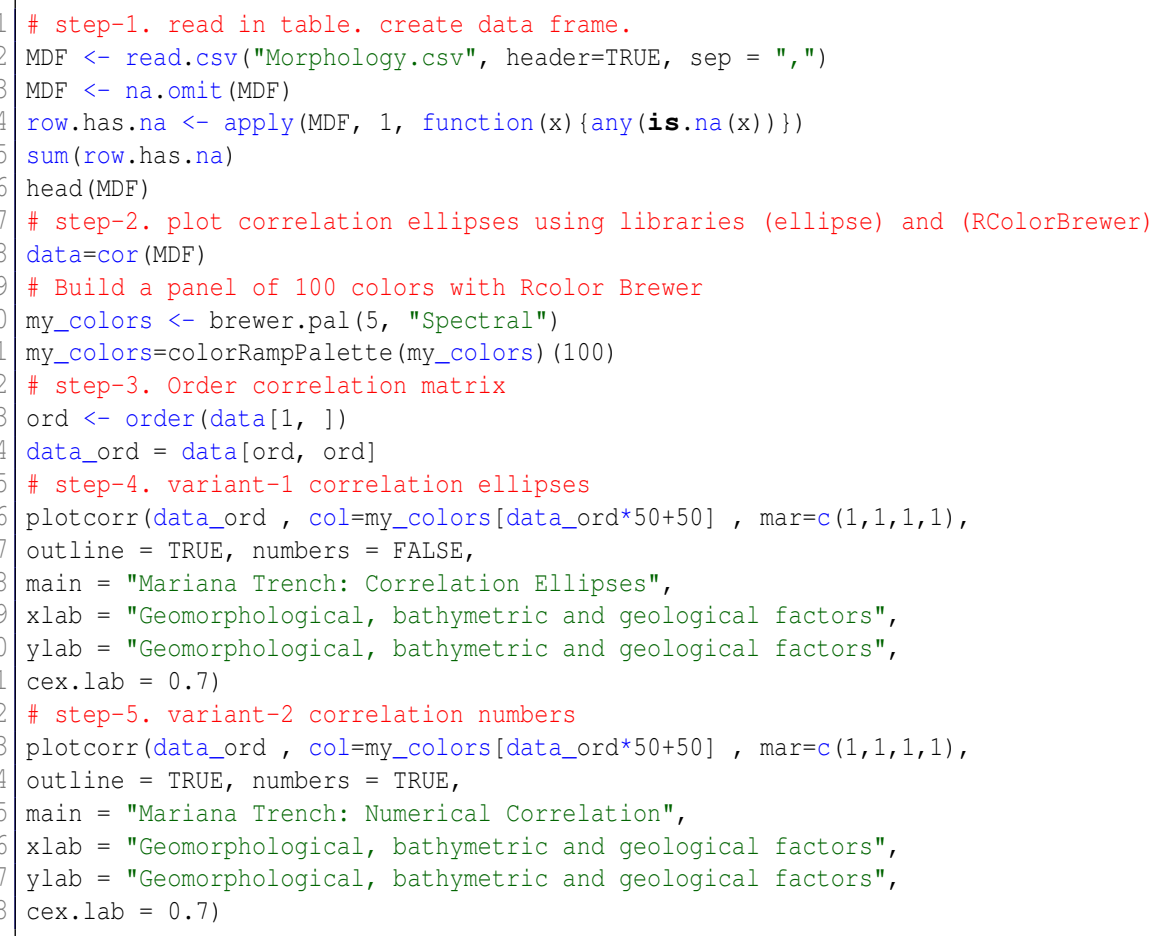

codes/R-32.r

\section{A.6.33 $R$ code for level plot using (ggplot2) library: sediment thickness}

Source data available on my GitHub.

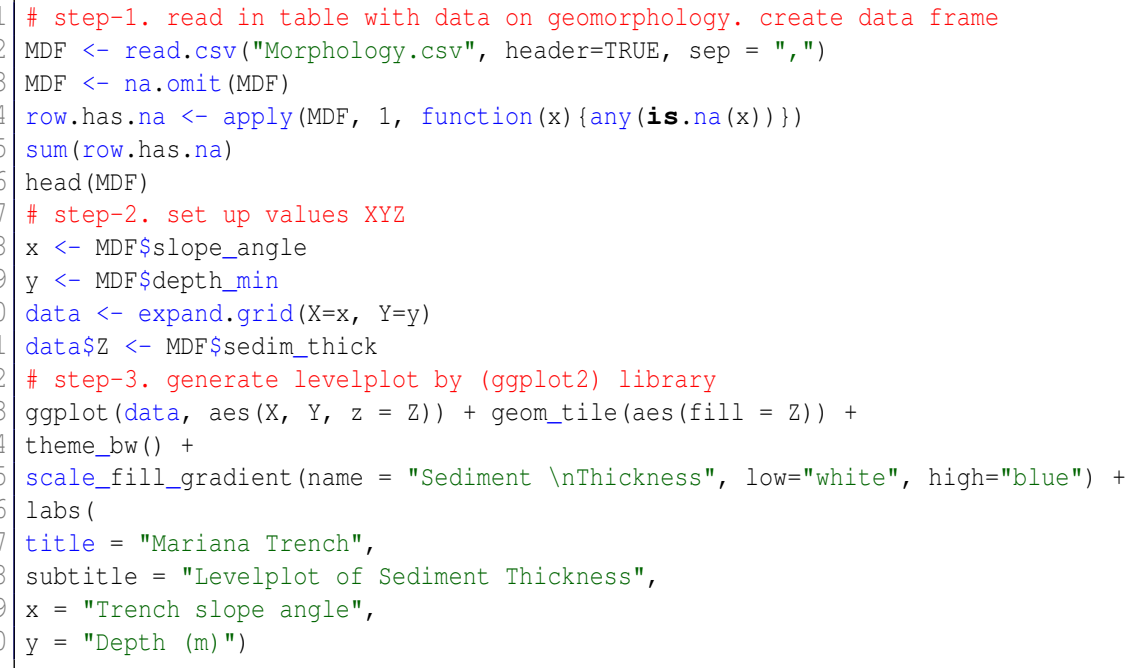

codes/R-33.r 


\section{A.6.34 $R$ code for hierarchical edge funding by (ggraph), (igraph), (tidyverse), (RColor- Brewer) libraries: Mariana Trench project}

Source data available on my GitHub.

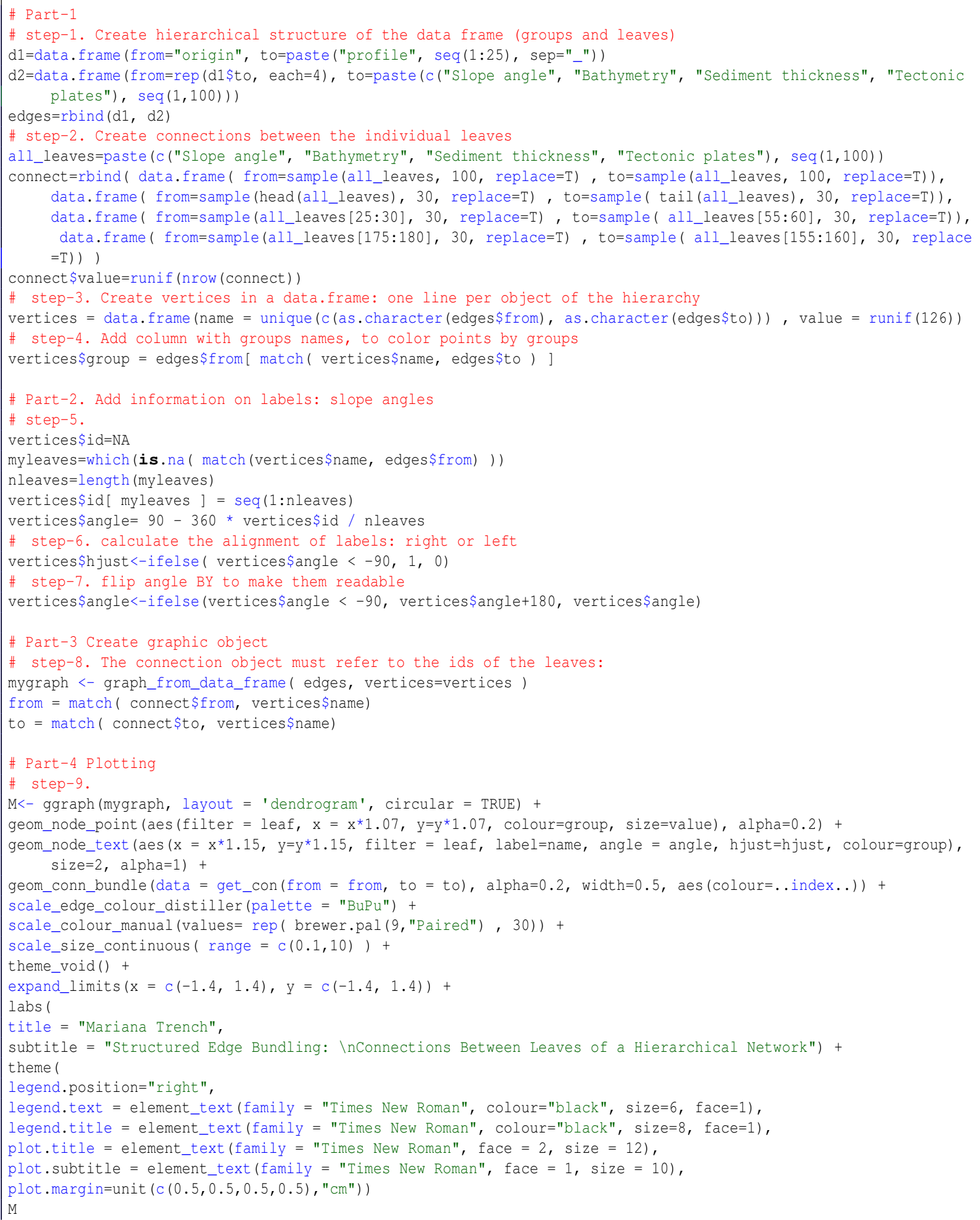

codes/R-34.r 


\section{A.6.35 R code for ridgeline plots by (ggridges) and (ggplot2) libraries}

\section{Source data available on my GitHub.}

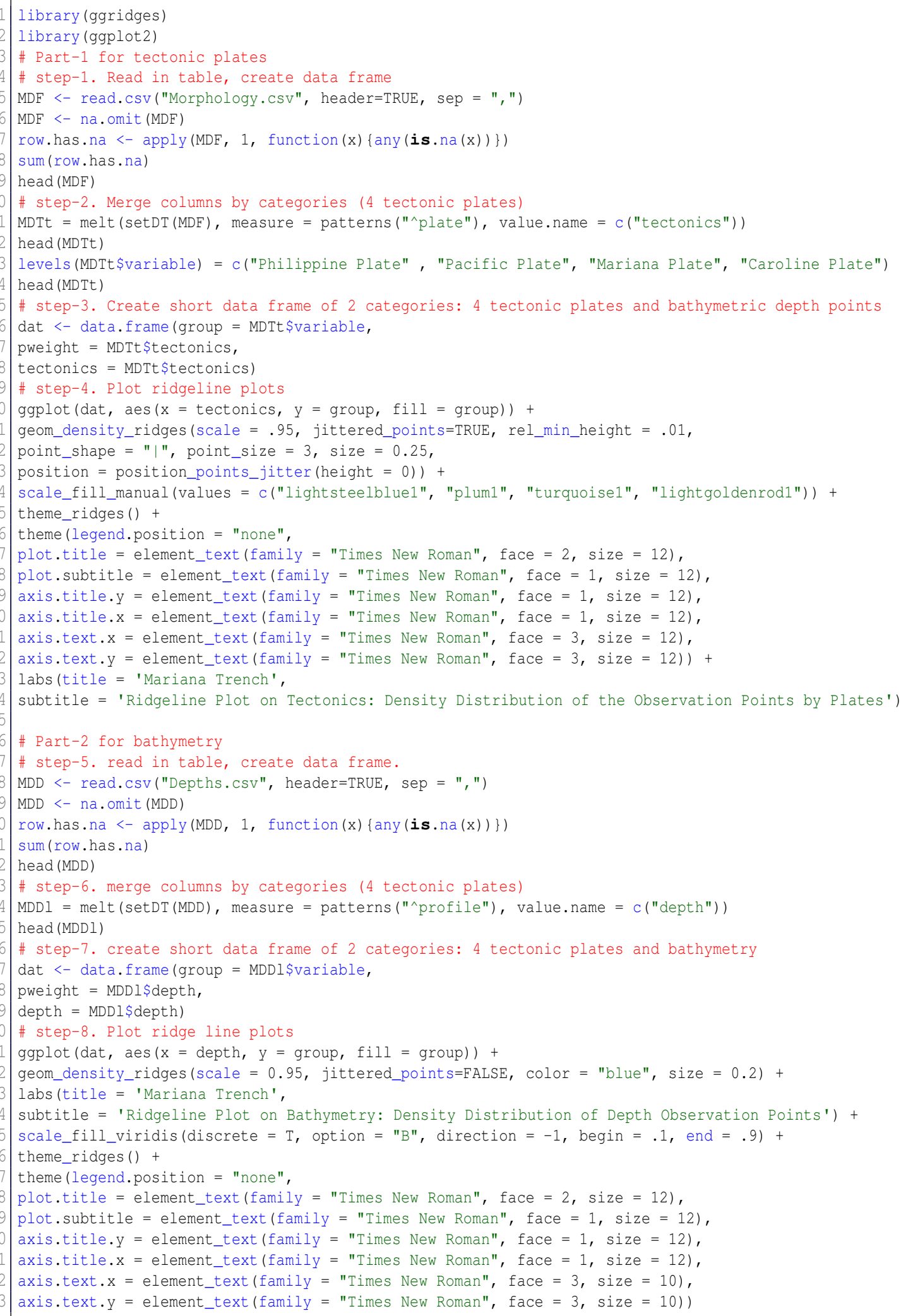

codes/R-35.r 


\section{A.6.36 R code for word could by libraries (wordcloud), (tm), (RXKCD): Mariana Trench project}

Source data available on my GitHub.

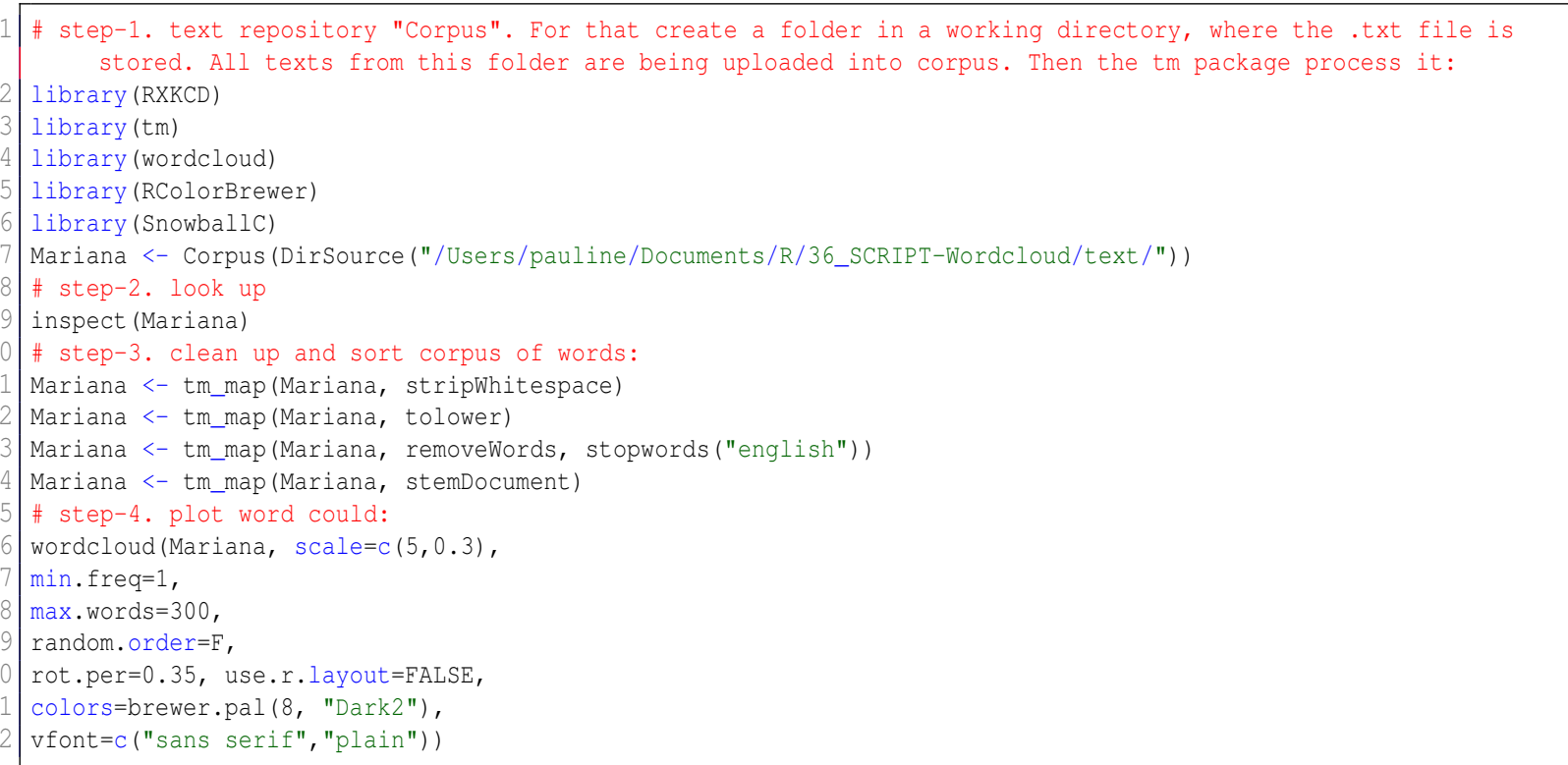

codes/R-36.r

\section{A.6.37 R code for 'waffle' plot by library (ggplot2): bathymetric data distribution}

Source data available on my GitHub.

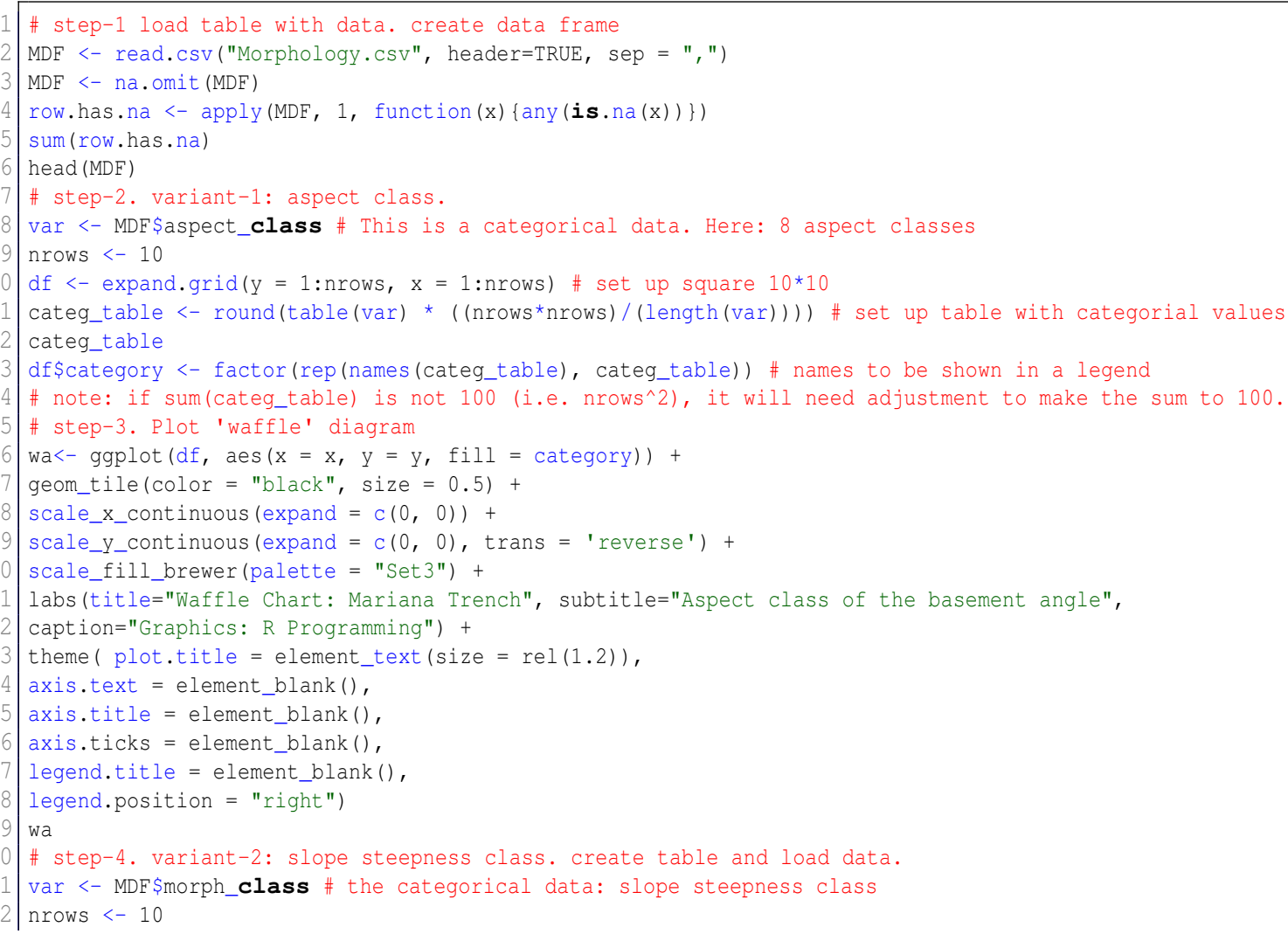




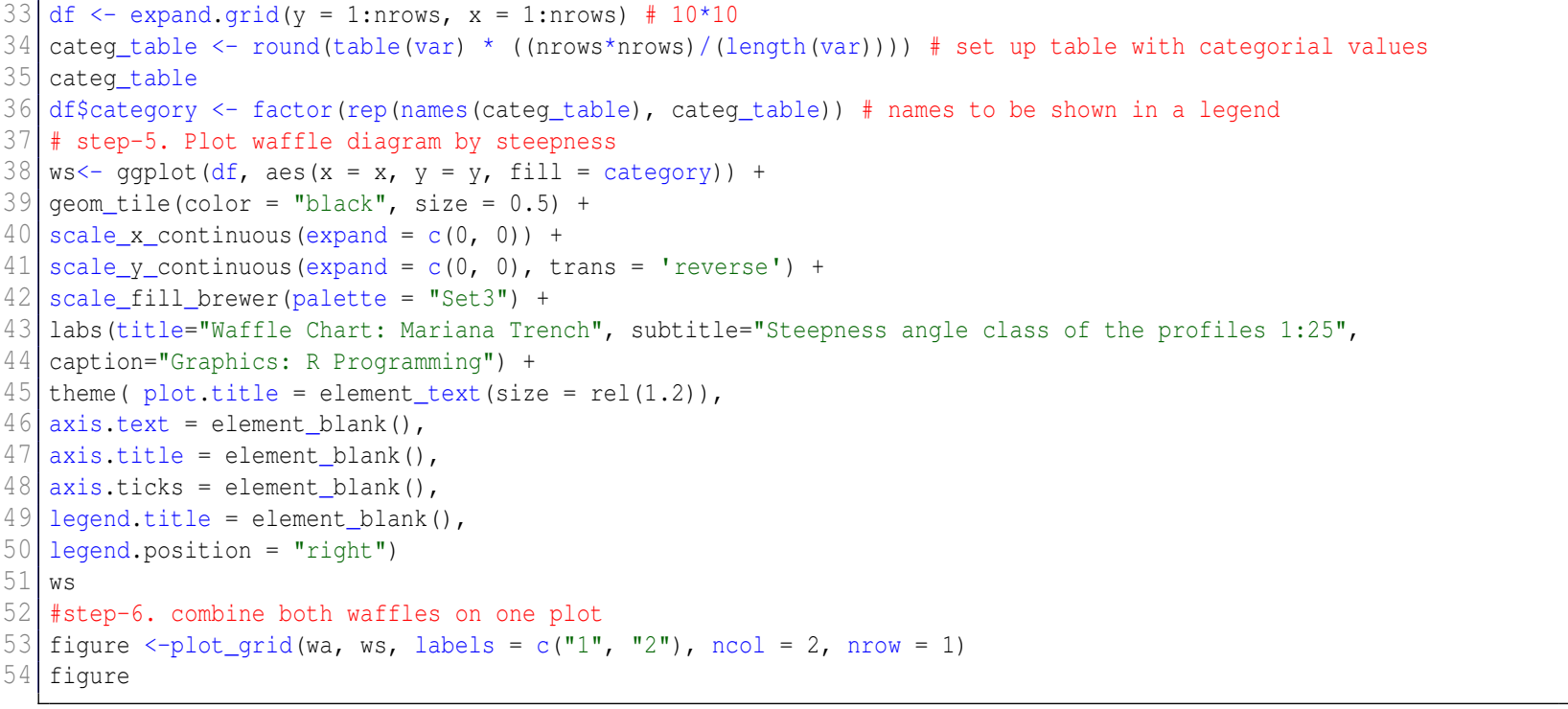

codes/R-37.r

\section{A.6.38 R code for 'waffle' plot by library (waffle): bathymetric data distribution}

Source data available on my GitHub.

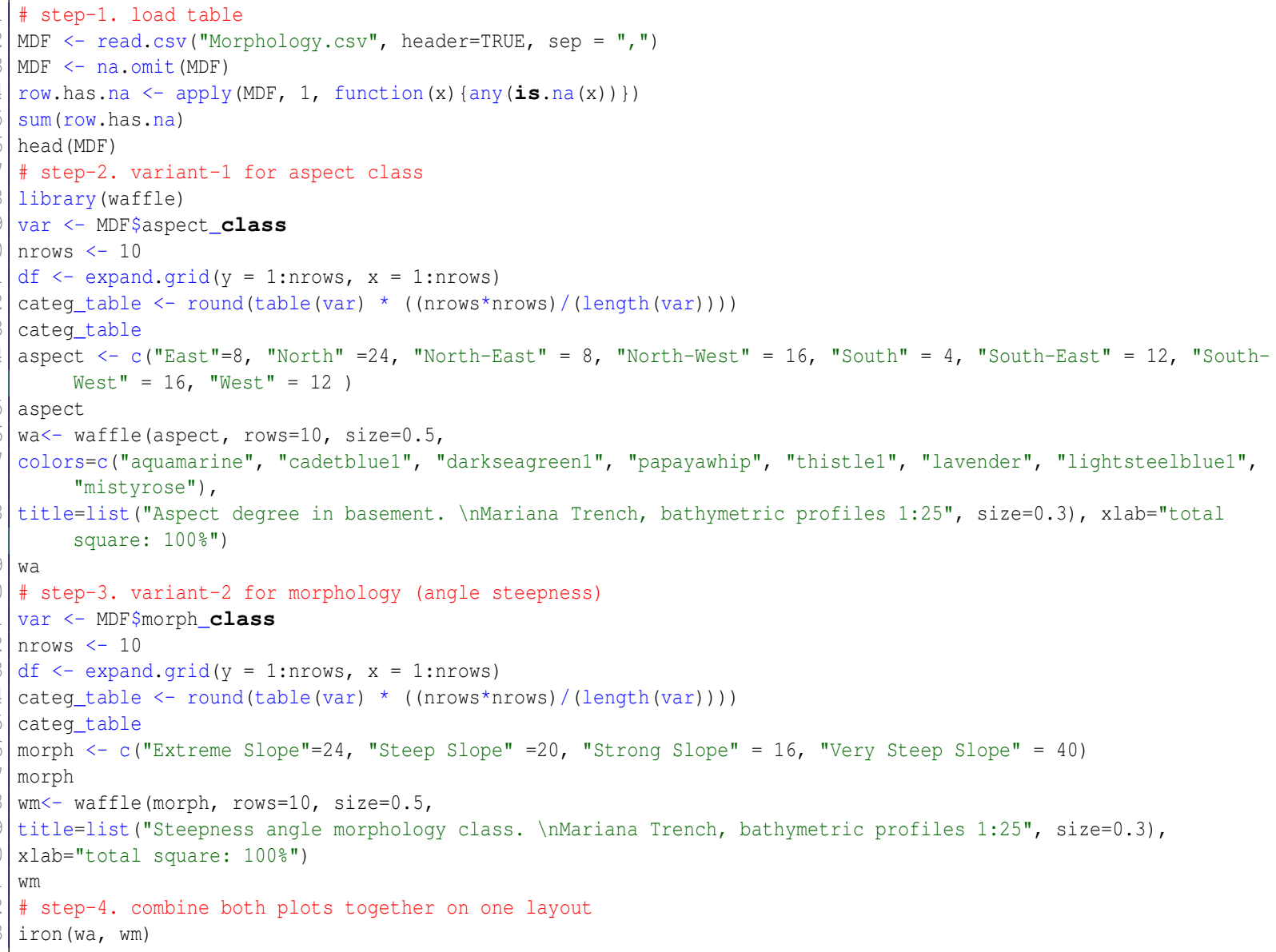

codes/R-38.r 


\section{A.6.39 $R$ code for treemap by library (treemap)}

Source data available on my GitHub.

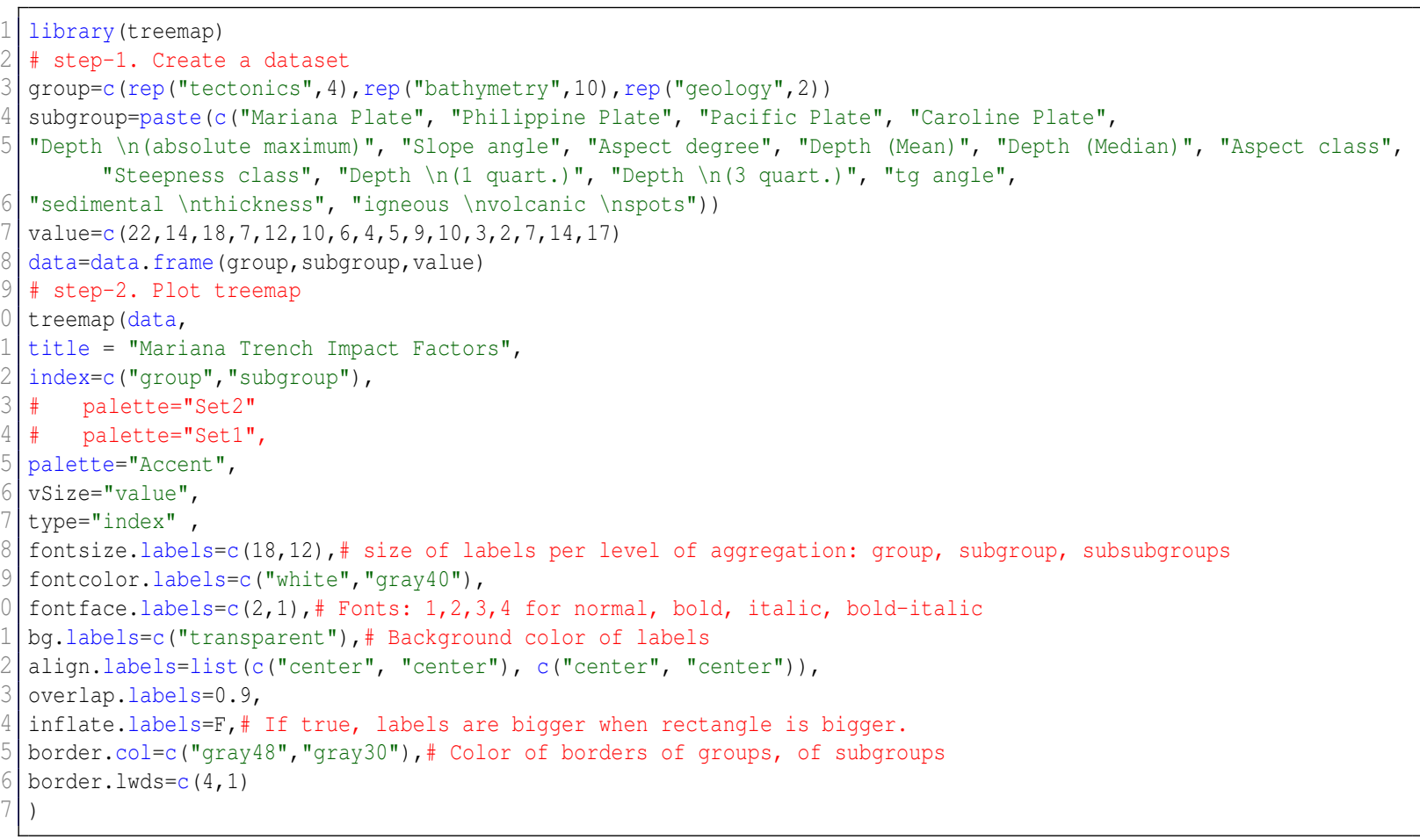

codes/R-39.r

\section{A.6.40 R code for network by (igraph) library: Mariana Trench project}

Source data available on my GitHub.

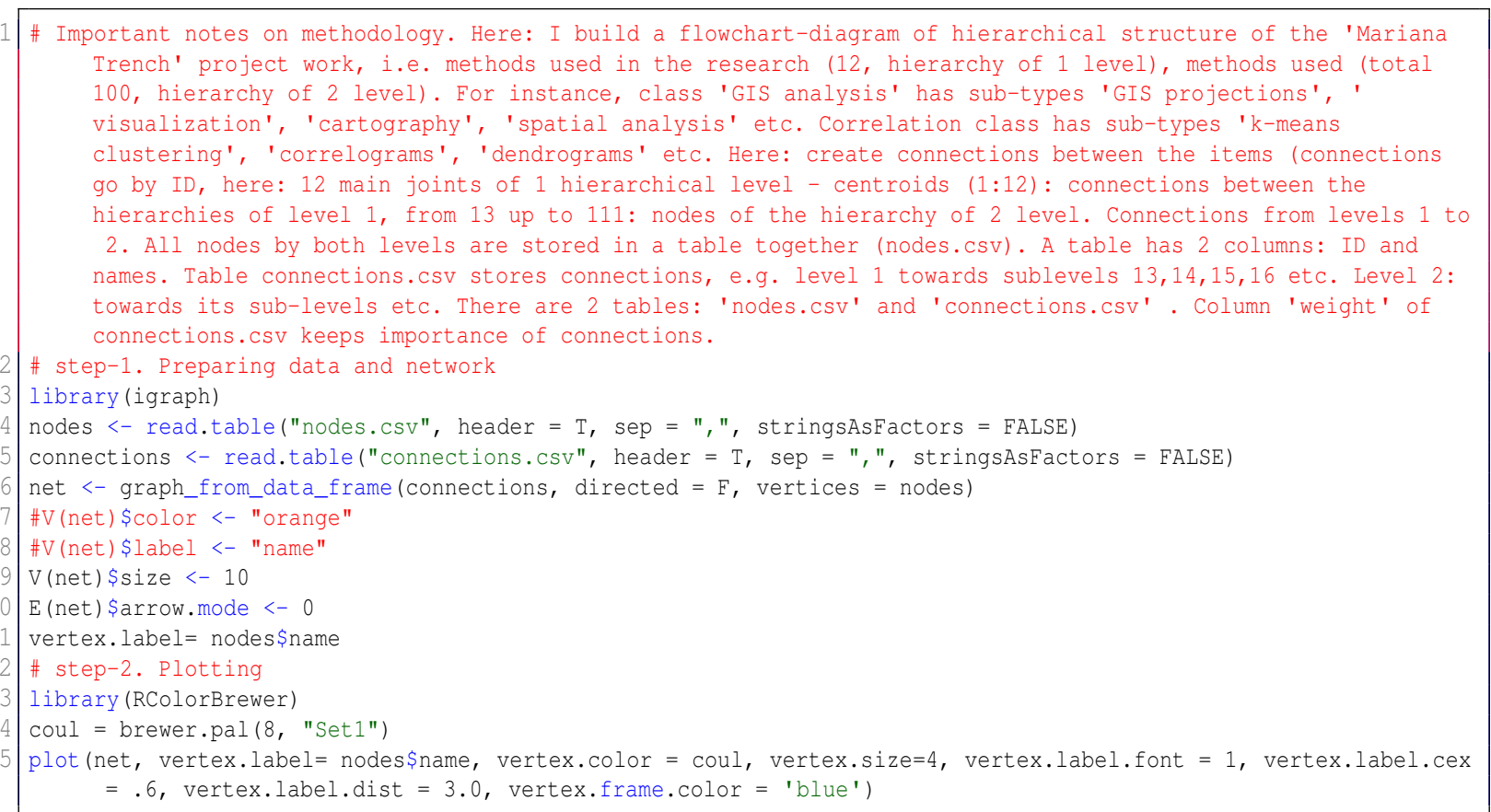

codes/R-40.r 


\section{A.6.41 $R$ code for scatterplot matrices by (GGally) library to assess data distribution, Mariana Trench}

Source data available on my GitHub.

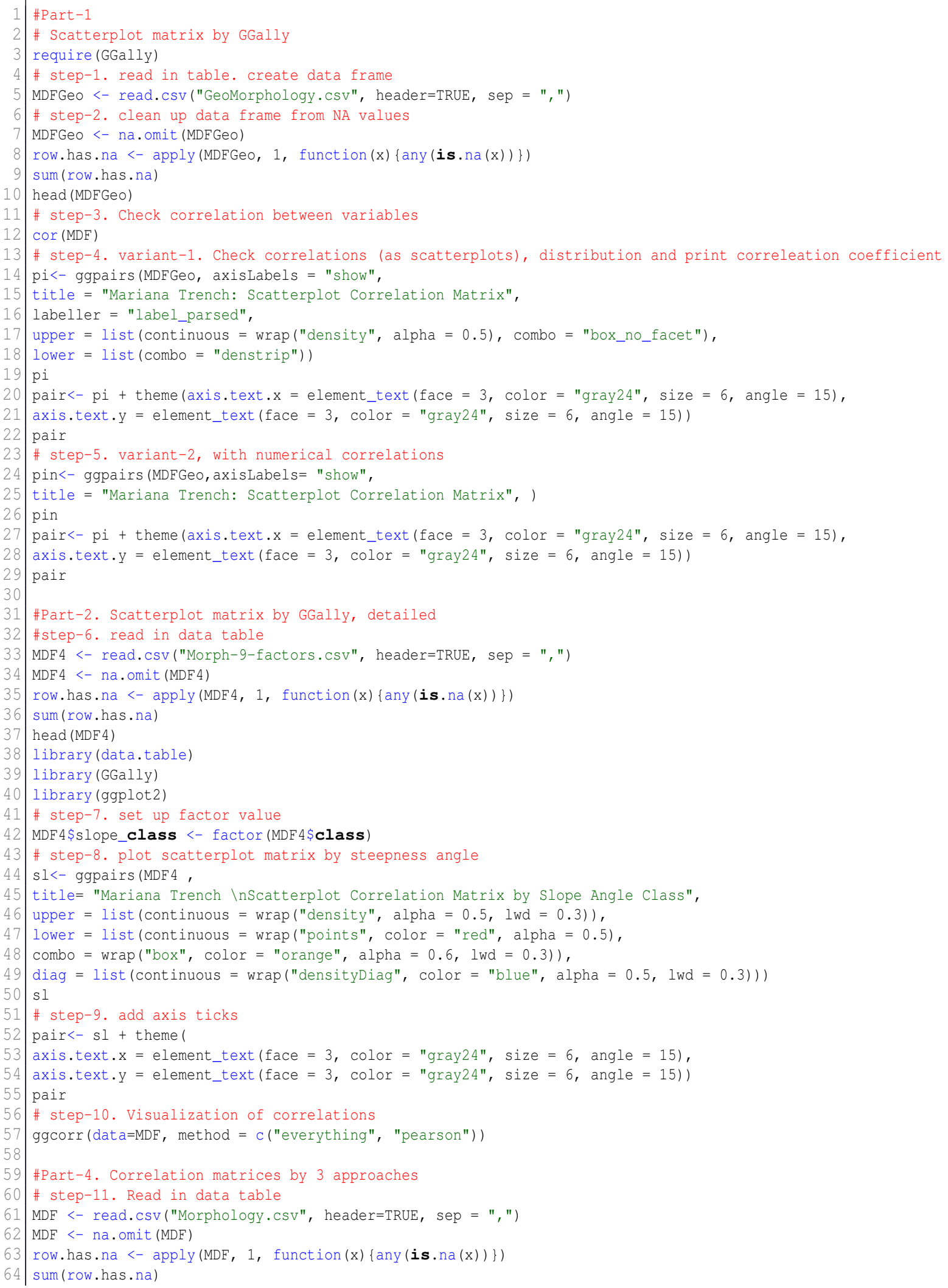




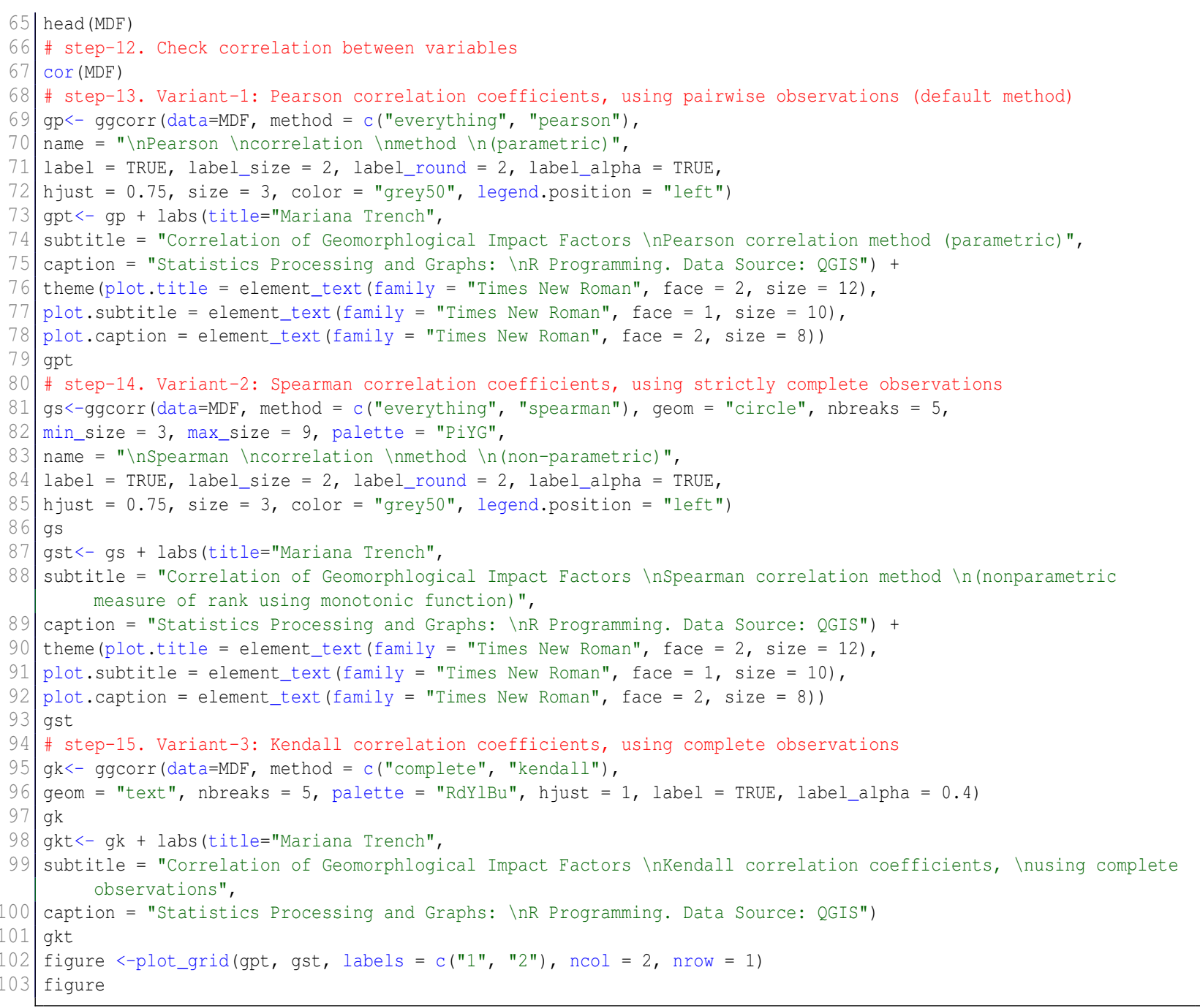

codes/R-41.r

lxxxviii

Deep-Sea Trenches of the Pacific Ocean: ...Data Modeling by GMT, Python and R 


\section{A.6.42 $R$ code for diagonal scatterplot matrices by (car) library}

\section{Source data available on my GitHub.}

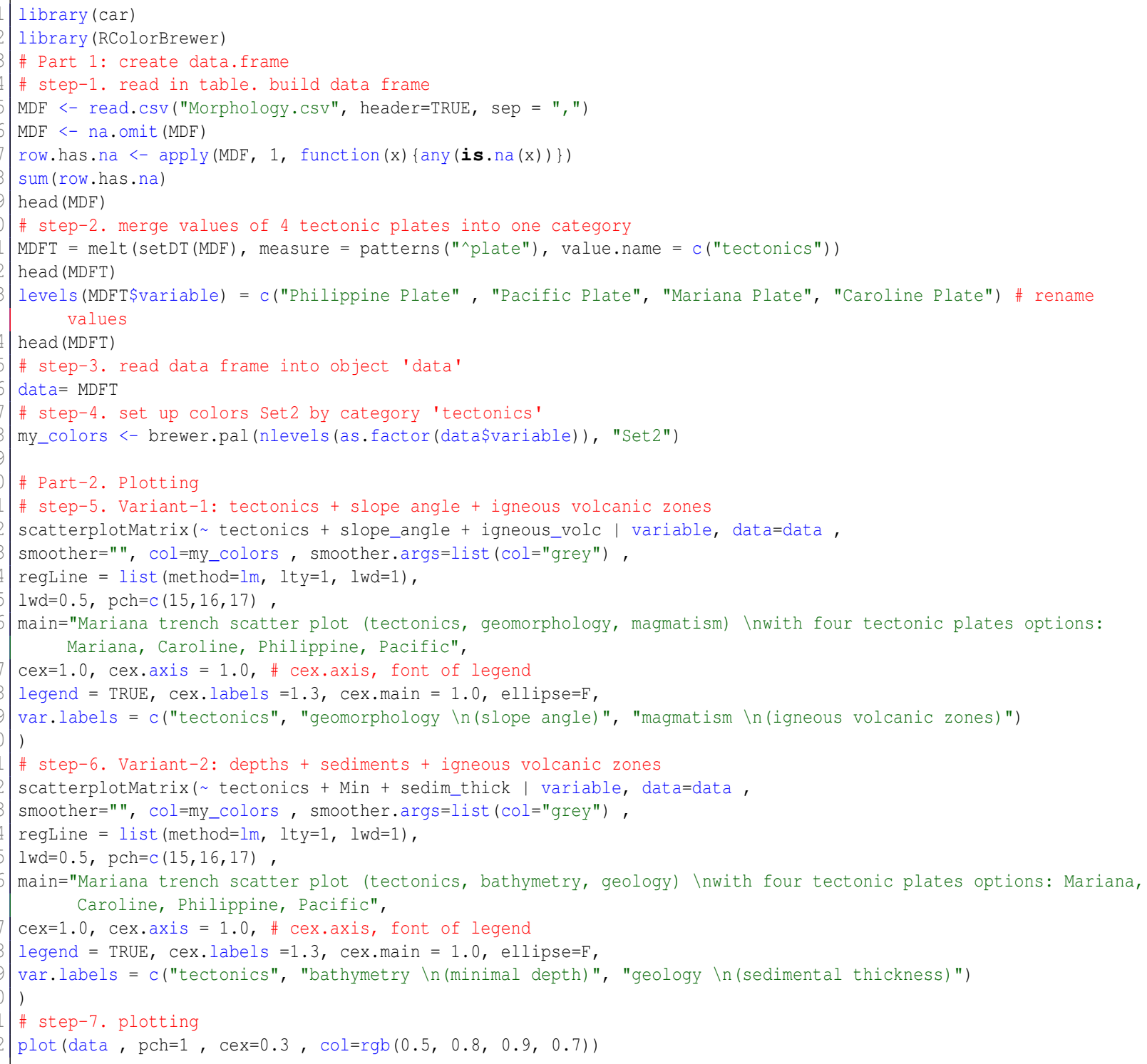

codes/R-42.r 


\section{Appendix G}

\section{Indices}




\section{G.1 Index of Places}

This index lists the geographic places and locations mentioned in this dissertation

A

Academy of Sciences Rise 188

Acapulco Trench .......22

Agrigan, Island .......63

Aleutian Arc ...... 15, 18

Aleutian Islands .........18

Aleutian Trench ..... 18, 20

Aleutian-Komandorsky chain ..........18

Alpine Fault .... 72-74, 76

Amami Sankaku Basin . . 66

Andean Cordillera .......28

Andes ...............28 28

Andes, Central .........28

Antarctic .......202, 241

Antarctic Plate ..26-28, 183, 240

Antarctica ............ 31

Arica bend ...........28 28

Atacama Desert ........29 29

Atacama Trench ....... 26

Atlantic Ocean ......... 57

Australia ...... 30, 31, 35

Australian Plate .... 35, 72

Ayu Trough ............53

\section{B}

Bering Sea .......... 188

Biobío Canyon .........27

Bismarck Sea fault ...... 35

Bismark Sea .......... 35

Bismark Sea back-arc basin 35

Bonin Islands $\ldots \ldots .64,65$

Boso triple junction . . . . 65

Bougainville Island ......37

Bougainville Trench .....35

Bounty Trough ....... 77

Bussol Strait ...17, 186-189

C

Calle-Calle Canyon ..... 27

Caribbean Plate .... 22, 24
Carnegie Ridge ........ 28

Caroline Plate ....53, 55, 57

Caroline Ridge ........ 55

Central Depression ......28

Central valley ..........28

Challenger Deep .....57, 63

Chatham Rise ...... 30, 77

Cherskii Mountains ..... 14

Chile ..........15, 26, 28

Chile Ridge .......... 28

Chile Tripe Junction . . ...28

Chiloé segment ........27 27

China ...............5 57

Choiseul Island ......... 37

Chortis Block ..........24

Coastal Cordillera .......28

Cocos Plate ..........21

Cocos Ridge ...... 21, 23

Cook Strait ........... 30

Copiapó Ridge .........28

Cordillera, Andean . . ... 29

Cordillera, Coastal ...... 29

Costa Rica .......23, 195

Cotabato Trench .......211

E

East Luzon Trough ...... 44

East Mariana Basin .....63

East Pacific Rise .... 22, 28

Easter microplate ......28

Easter Seamount Chain . . 28

Ecuador .............26

Eurasian Plate ... 15, 45, 48

$\mathbf{F}$

Fiji ...............6 63

Fiji, North ............34

Fiordland Massif . ...... 72

Franciscan subduction zone 22

Futuna Island ......... 34

G

Greater Kuril Chain . 14, 17 , 187-189
Guam ...............64

Guatemala Trench ......21

\section{H}

Hikurangi Margin 73, 75, 77

Hikurangi Plateau ...... 77

Hikurangi Trench 72, 75-77, $183,239,241$

Hikurangi Trough .......30

Hjort Plateau ......... 73

Hjort Ridge ...........73

Hjort Trench 72, 74-76, 239, 241

Hokkaido Island 13, 17, 189

Honduras Platform ..... 22

Honshu Island ......... 68

Honshu island arc .....665

Huon Gulf .............35

I

Imperial Canyon .......27

Indian Ocean .......... 57

Indo-Australian Plate 31, 35, $72,74,75,183,240$

Iquique Ridge $\ldots \ldots \ldots .28$

Iturup Island ... 14, 17, 187, 189

Izu Islands $\ldots \ldots \ldots \ldots 64$

Izu-Bonin Collision Zone 65

Izu-Bonin Trench . . . 64-66

Izu-Bonin-Mariana Arc . .63, 66

Izu-Ogasawara Trench . . 64

J

Jalisco .............. 22

Japan ...........48, 67

Japan Plate . . ......... 67

Japan Trench ... 25, 64, 67

Japan trench-arc system ..67

Juan Fernández microplate 28

Juan Fernández Ridge . . 28 
$\mathbf{K}$

Kamchatka Peninsula 15, 16, $18,188,189$

Kamchatka-Aleutian triple junction .......18

Kerama Fault ..........49

Kermadec Ridge ........ 31

Kermadec Trench ....72, 77

Kronotskiy arc ......... 18

Krusenstern strait ...... 14

Kunashir Island .... 14, 187

Kuril Island Chain . . ... 17

Kuril-Kamchatka Arc . . 15

Kuril-Kamchatka subduction zone .........15

Kuril-Kamchatka Trench 13, 186

Kuroshio .14

Kyushu Island ........ 48

Kyushu-Palau Ridge .....53

\section{$\mathbf{L}$}

Louisville Seamount Chain 31

Lua .................. 34

Luzon Arc ...........47

Luzon Island . . 45, 213, 214

\section{M}

Macquarie Arc . ..... 237

Macquarie Fault Zone . . . 72, 241

Macquarie Island . . . . . 72

Macquarie Ridge Complex 72

Macquarie Triple Junction 72,241

Magellan Seamounts ...230

Malaita Island .......... 37

Manila Trench ......45, 47

Marcus-Wake Seamounts 230

Mariana Islands .... 34, 57

Mariana Plate .......... 57

Mariana Trench ..... 57, 63

Maule .................27

Meiji Guyot seamount ... 15

Mexico ............222

Middle America ....... 21
Middle America Transverse Zone .........22 22

Middle America Trench . 21

Mindoro Island ........ 45

Miyako Fault .... 184, 217

Miyako-jima (Island) ....52

Mocha ..............27 27

Mocha Fracture Zone 27, 28

Motagua Fault ......... 24

Motagua-Polochic system 24

\section{N}

Nankai subduction zone .70

Nazca Plate ..... 22, 26-28

Nazca Ridge . . . ........28

Negros Trench ........211

New Britain arc ........35

New Britain Island ...... 35

New Britain Trench .. 35, 37

New Hebrides Trench . . . 32

New Zealand .31, 63, 72-74, 76,77

Nicaragua ....... 24, 195

Nicoya Peninsula ... 24, 195

North America ..........22

North American Plate 14, 22 , 67

North Bismarck Plate ....35

North Island 31, 75, 77, 183, 240

Northern Chile 29

0

O'Higgins Guyot ...... 28

Ogasawara Plateau ...64, 65

Okhotsk Plate ........ 188

Okinawa Trough ....... 48

Okinawa-jima (Island) . . .52

Ontong Java Plateau . 35, 77

Oyashio ............... 14

\section{$\mathbf{P}$}

Pacific Ocean 17, 30, 31, 34, $35,57,77,188$

Pacific Ocean, south ....26

Pacific Ocean, southwest 241

Pacific Plate .. 15, 17, 22, 35, $37,57,69,72,74$, $75,183,188,240$
Pacific Volcanic Chain ...24

Palau Islands ......... 53

Palau Trench .......... 53

Panama, Isthmus of . . . . 22

Papua New Guinea .. 35, 53, 55

Paramushir Island . . . . . 188

Parece Vela Basin ...... 56

Peru ...............28

Peru-Chile Trench 20, 26, 29

Chilean ...........29 29

Chiloé .............29 29

Maule ...........29 29

Peruvian ..........29 29

Philippine Archipelago .. 43, 57

Philippine Fault ........44

Philippine Sea .. 53, 65, 210

Philippine Sea Plate . 45, 53, $55,57,65,210$

Philippine Trench ...... 39

Philippines ..... 213, 214

Polochic Fault .........24

Puysegur Bank .........72

Puysegur Margin .......73

Puysegur Trench .72, 74-76, 239, 241

\section{$\mathbf{R}$}

Ramu-Markham Fault ... 35

Ring of Fire ....... 15, 67

Ryukyu island arc . . 48, 184, 216

Ryukyu Trench ....48, 216

\section{$\mathbf{S}$}

Sakhalin Island ....... 187

Samoan Passage .......6 60

San Antonio Canyon .... 27

San Cristobal Island ..... 37

San Cristobal Trench .... 37

Sanriku-Haruka-Oki . . . . 69

Santa Isabel Island . . . . . 37

Sea of Japan ..........67 67

Sea of Okhotsk .. 14, 15, 17, 187, 188

Shiashkotan Island .... 188

Shikoku Basin ......64, 65

Shikotan Island ... 187, 189 
Solomon island arc . . 35, 37

Solomon Sea ....... 35, 37

Solomon Sea Plate ... 35, 37

Sorol Trough ......... 55

South America .........28

South American Plate ... 26

South Bismarck Plate ....35

South China Sea ....... 45

South Island ... . 72-74, 241

South Kuril ............ 16

Southern Ocean .........20

Sulu Trench

.. 211

Sunda Plate 45,210

\section{$\mathbf{T}$}

Taitao Triple Junction 28, 29

Taiwan Island . . 45, 48, 218

Taltal Ridge .......... 28

Tanega-shima ...........49
Tasman Sea ........... .74

Tehuantepec Ridge ...... 21

Tohoku ...........68, 70

Tohoku-Oki ..........6 68

Tokachi-Oki ..........69

Tokara Channel .........49

Tokyo ................64 64

Tolten Canyon ......... 27

Tonga Platform ........ 31

Tonga Ridge . . ... 180, 198

Tonga Trench ...31, 182, 199

Tonga-Kermadec Arc . . . . 30

Tonga-Kermadec Ridge . . 31

Tonga-Kermadec-Hikurangi subduction system 77

\section{U}

Urup Island $\ldots .14,187,189$

\section{V}

Valdivia ..............27

Valdivia Fracture Zone . . 27

Vanuatu Trench ........ 32

Vityaz Trench ..........33

W

West Bismarck arc ..... 35

Woodlark Basin .... 35, 37

World Ocean ......... 57

Y

Yaku-shima ...........449

Yap Islands ...........55

Yap Trench ............55

Yap-Palau subduction zone 55 


\section{G.2 Index of Concepts}

This index lists the most essential concepts and definitions used in this dissertation, including both geological and technical terminology (programming, statistics, mathematics)

A

abyssal

plain, 58

zone, 61

accretionary wedge, 77

aeolian processes, 18

algorithm

ANOVA, 167

Levene's test, 145

Pairewise t-test, 145

Shapiro-Wilk test of normality, 146

Tukeys honest significance test, 145

approach, 12

autocorrelation, 172

EFA, 142

Euclidean distance metric, 132

Gauss-Newton, 174

KDE, 119, 122, 139, $154,155,160,162$, 164,230

least squares, 174

nonlinear, 174

ordinary, 174

weighted, 174

LOESS

method, 125

Savitzky-Golay smoothing filter, 125

Principal Component Analysis, 138, 165

QQ, 172, 173

regression

isotonic, 175

quantile, 153, 172

regression analysis, 125, 158

non-parametric, 125

SARIMA, 176 ternary diagrams, 129

Artificial Intelligence, 85

Machine Learning, x, 7 , $9,12,78,84,85$, 103, 119, 120, 139, 140, 152, 243, 248-250, 252, 253

axial rift, 6

\section{B}

back arcs, 71

bathymetry, 61

biological communities, 61

buoyancy, 34, 206

\section{C}

canyons

underwater, 61

steps, 61

cartography, 243

data

CMT, 80, 88-90, 92

CryoSat-2, 78

DEM, 80

EGM96, 80, 90, 98, 99, 102

ENVISAT, 81

ETOPO1, 3, 78, 80, $85,86,90,94,95$, 100, 101, 110, 111, 191-193, 224, 249

ETOPO5, 80

GEBCO, $x, 3,12$, 78-81, 85, 86, 90, 92, 94, 95, 224, 234, 240, 247

Google Earth, 80

GSHHGD, 78, 80, 90

GVP database, 80

ISC database, 80

Jason-1, 78

KMZ, 90

raster, 84
SPOT3, 81

SPOT4, 81

SRTM, x, 12, 37, 78, $80,213,247,249$

vector, 84

grid, 83

map element, 83

annotation, 83

coastline, 83

color scale, 83,86

directional rose, 83 , 86, 101, 108

embellishment, 86

grid, 83

grid ticks, 86, 108

labels, 83

legend, 83, 86, 101, 108,111

logo, 86

north direction, 83

scale bar, 83, 86, 108

vector lines, 83,86

map projection, 83,86 ,

101,111

azimuthal, 86

cylindrical, 86

Cylindrical

Equal-Area

Gall-Peters, 86

Eckert IV equal-area pseudo-cylindrical, 86

Gall-Peters, 102

Lambert Azimuthal Equal-Area, 86

Mercator, 86, 95

Mollweide pseudo-cylindrical homolographic equal-area, 86

Oblique Mercator, 86

Orthographic azimuthal, 86 
Polyconic, 86

Transverse Mercator, 86

cliffs, 62

cluster analysis, 138

cluster, 133

clustering

k-means, 133, 134

dendrogram, 164

segmentation, 164

continental

collision, 34, 74

crust, 74

margins, 60

shelf, 61

slab age-buoyancy, 61

slope, 20

convergent, 73

correlation

coefficient, 135

correlogram, 160

correlogram ellipse, 134

covariance matrices, 160

Kendall, 137, 160

Pearson, 136, 160

Spearman, 136, 160

D

décollement, 70

data

analysis, 243

ASCII, 78, 83, 88, 95, 108, 109, 191, 250, 251

distribution, 125, 227

frame, 82

grouping, 138

modeling, 8

multidimensional, 126

ranking, 131

set, 243

skewness, 125

sorting, 138

variables, 123

visualizing, 243

deep-sea

basins, 34, 58

depressions, 58

ridges, 61 deformation

coseismic, 77

rheology, 34

dehydration, 206

dislocations

lateral, 63

vertical, 63

$\mathbf{E}$

Earth

crust, 49,58

lower, 69

oceanic, 60, 77

evolution, 34

lithosphere, 16, 34, 42, $51,55,58,60,63$, 66

magma

magma chamber, 16

magmatism, 23, 116

mantle, 60

deep, 77

island-arc, 69

mantle plume, 17

pillow lava, 60

Mohorovičić (Moho) boundary, 58

earthquake, ix, x, 4-8, 12, 14-16, 18, 24, 26, $28,29,34,63,88$, 184, 230, 234, 245, $246,248,253$

centroid moment tensor, 88

deep, 34

focal

mechanism, 17, 33, $41,42,74,88$

zone, 16

hypocenter, 45, 88, 90

magnitude, 186

submarine, 246, 249

erosion, 18

F

fault, 6, 59

graben, 14, 25, 54, 61, 190

horst, 25, 54, 61 stretching, sub-parallel, 77

transform

dextral, 76

near-vertical, 73

fluid thermal fluxes, 16

forearc, 77

fracture, 15, 63

G

gas hydrates, 77

GDAL, 83

geochemical recycling, 34

geochemistry, 74

geodesy, 11, 92, 117, 153, 171, 189, 244, 249

GPS, 77, 93

geoid, 37, 74, 78, 84-86, 98, 101, 191, 195, 203, 205, 218, 236

undulation, 219

Geologic time period

Cenozoic, 211

Cretaceous, 49, 211

Early, 60

Late, 22, 60

Eocene, 44, 74

Late, 18

Jurassic, 49, 58, 211

Mesozoic, 18, 23, 24, 44, 49, 60, 63, 211

Miocene, 25, 39, 74

Middle, 25

Neogene, 67

Oligocene, 27, 39, 74

Paleocene, 25

Paleogene, 22, 24

Pliocene, 22

Early, 25

Precambrian, 210

Quaternary, 25, 44, 60, $67,74,211$

Tertiary, 18

geomorphology, 61, 66, 67, 69, 73, 74, 76-78, 80, 81, 83-86, 91, 100, 101, 103, 104, $111,113-118,120$, 124-126, 130-135, 
137-144, 147, 149 .

$151,153,155,163$,

$165,167,168,173$,

176, 179-181, 185,

186, 188-191, 193

GIS, 1, 3, 7-12, 78, 81-83, $91,97,114,117$, 147, 149, 150, 168, 177, 242, 244, 248-250, 252, 253

ArcGIS, 114

GRASS GIS, 253

MapInfo, 114

QGIS, 97, 150

GMT, 83

module

blockmean, 95

blockmedian, 95

blockmode, 95

gmt.conf, 84

gmtdefaults, 84

gmtinfo, 84

gmtlogo, 84, 104

gmtset, 84, 98, 105

gmtwhich, 84

grd2cpt, 98, 101

grdcontour, 83, 84, 98, 101

grdcut, 83, 84, 101

grdgradient, 108

grdhisteq, 84, 95

grdimage, 83, 84, 98, 186

grdtrack, 83, 105, 186

grdview, 101

img2grd, 101

logo, 98, 101, 105

makecpt, 84, 95

nearneighbor, 84

psbasemap, 83, 84, 98

pscoast, 84, 98, 101

psconvert, 84, 98, 101, 104,105

pshistogram, 84, 105

psimage, 98

pslegend, 105

psmeca, 88,89

psrose, 105 psscale, 84, 98, 101

pstext, 84, 98, 101

psvelo, 92

psvelomeca, 89

psxy, 83, 104, 186

trend $1 \mathrm{~d}, 83$

Google Earth, 90

gravitation, 62

flow system, 58

instability, 62

gravity

anomaly

marine free-air, 10 , 85, 98, 101, 203, 209, 214, 217, 219, 226, 236

pull, 62

\section{H}

hills, 6

hydrosphere, 66

\section{I}

interseismic coupling, 77

L

landslide, 61

submarine, 62

lateral

displacement, 62

geologic shifts, 61

ledges, 61

\section{M}

magnetic anomaly lineations, 63

mainland bank, 62

marginal seas, 62

melting, 206

mid-ocean ridge, 58, 60 basalts, 63

mineral physics, 74

$\mathbf{N}$

normalized steepness, 137

O

ocean bedrock, 61

ores, multi-metal, 16
$\mathbf{P}$

passive margins, 61

petrology, 74

plate

boundary, 74

deformation, 62 transpression, 73, 74

lithospheric, 58

motion, right-lateral, 72

ophiolites, 58

upper, 77

plateau, 61

marginal, 61

oceanic, 77

plot

2D, 3, 101, 105, 151, 209, 213, 248

3D, 3, 50, 83, 99-101, 119, 166, 184, 208, 209, 213, 231, 234, 243, 248, 249

scatterplot matrix, 166

area chart, 158

boxplot, 119, 120, 122, $142,154,155$

categorywise, 127

clustermap, 156

Euler-Venn diagram, 147, 157, 158

facet grid, 158

facetted, 125

flowchart network, 168

hexagonal, 135

mapping, 160

letter-value, 119, 154, 155

pie chart, 171

projection

affine, 166

scalar, 165

radar charts, 129, 170

ridgeline, 127

stacked

area, 168

bar, 169

strip plot, 157

subplot, 172 
violinplot, 155

programming language

AWK, 115, 250

$\mathrm{C}++, 247$

MATLAB, ix, 114, 252

Octave, ix, 115, 247, 250

Python, ix, 153, 247, 250

Jupyter Notebook, 153

Math, 170

Matplotlib, 8, 148, 149, 152-155, 162, 170

Matpotlib, 150

NumPy, 8, 148-150, $152,153,168,170$

OS, 162,170

Pandas, 149, 150, 162, 170

Scikit Learn, 165

SciPy, 8, 148-150, 152, 153, 164, 168

Seaborn, 150, 153, $155,162,170$

StatsModels, 8, 149, $153,172,176$

R, ix, 247, 248, 250

bkde, 123

car, 11

correlplot, 137

data.table, 136

dendextend, 138

extrafont, 229

extrafontdb, 229

fmsb, 129

ggalt, 129

ggimage, 137

ggplot2, 120, 121, $125,127,128,131$, 138

ggridges, 127

ggsignif, 155, 229

graphics, 155

gridExtra, 138

gridGraphics, 138

hclust, 138
kde.R, 123

KernSmooth, 123

LatticeExtra, 130

LatticeExtra2, 126

magrittr, 138

Matrix, 137

mclust, 137

methods, 138

tidyverse, 127, 155, 229

vcd, 120, 132

violinmplot, 122

violinplot, 121

waffle, 131

\section{$\mathbf{R}$}

ridge, 6,61

longitudinal, 61

rift, 60

rock

igneous

basalt, 23, 25, 34, 53, 58,60

basalt, tholeiitic, 23

basalts, phyric, 23

basalts, plagioclase

phyric

high-alumina, 23

clinopyroxene, 23

diabase, 60

gabbro, 58, 60

microlites, 23

olivine, 23, 63

olivine-plagioclase, 23

quartz, 60

quartz-trachyte, 60

tholeiites magma

series, 23

tholeiites, island-arc, 23

tholeiites, oceanic, 23

trachyte, 60

ultrabasic, 210

ultrabasic complex, 60

ultrabasites, 60

mechanics, 74

metamorphic, 211 sedimentary

clastic, 60

turbidite, 20

\section{$\mathbf{S}$}

seafloor, ix, x, 3-8, 12-14, 25, 34, 35, 40, 43, 44, 46, 47, 54, 56, $58,60-62,84,85$

bathymetry, 61

spreading, 6, 60 spreading fabric, 63

seamounts, 5, 14, 27, 28, 47, 49, 58, 69, 76, 77, 151, 183, 184, 209, 230, 231, 238, 240, 241

sedimentation, 58

abyssal, 62

accumulation, 60

active, 60

areal, 60

avalanche, 19

terrigenous, 18,60

sediments, 20

aleurite-clay, 190

ash, sand-size, 20

clay, 20

pelagic, 190

precipitation, 59

ringwoodite, 63

terrigenous material, 18

thickness, 60, 172

trap, 60

wadsleyite, 63

seismicity, 14, 17, 18, 28, 32-34, 39, 41, 44, 45, 47, 50, 63, 67, 68, 70, 74, 116, 186

adiabatic shear instabilities, 39

seismology, 74

shelf, 62

continental, 77

slab, 63

cold, 70

dehydration, 71

mineralogy, 70

morphology, 39 
subduction, 39, 70

advance, 39

buoyancy, 39

dynamics, 39

rate, 39

retreat, 39

stagnation, 41

stress field, 39

warm, 70

slope, 57, 61

inclination, 63

instability

tension cracks, 33, 62,

63,68

stability, 63

statistics

argument, 161

descriptive, 125

median, 172

noise, 158

quantiles, 172

significance, 167

SPSS, 105

variable, 161

dependent, 125

independent, 125

variance, 167

structural geology, 74

subduction

deep, 74

dip, 15

dipping, 77

dynamics, 74

frontal erosion, 77

margins, 75

oblique, 76

process, 74

scissors, 73, 76

sediment, 60

slab, 59

speed, 77

zone, $71,73,74$

submarine

canyons, 20, 58

margins of continents, 62

valleys, 58 volcanoes, 66

suspension flows, 62

$\mathbf{T}$

tectonic

block rotations, 77

plate, 60, 61

boundary, 6

collision, 77

movements, 63

subduction, 34, 74

velocity, 61

tension fractures, 62

terrace, 61

marine, 15

submarine, 20

submerged, 77

thermochronology, 77

thresholds, 59

transform

fault, right-lateral, 72

transformation

kinetics, 34

phase, 34

trench, 76

curvature, 76

dynamics, 60

kinematics, 77

profile

arcuate barrel-shaped, 183

asymmetric, 57, 182, 184

cascade-shaped, 180

crescent-shaped circular-like, 184

elongated, 180, 181, 183

irregular, 179

irregular right-sided, 184

irregular V-shaped, 179, 183

irregular V-shaped

left-sided, 180

irregular V-shaped

right-sided, 183 sinuous-shaped, 180

symmetric, 182

transverse, 57

trough-like W-shaped, 184

U-shaped, 182

V-shaped, 181, 183

triple junction, 72

trough, 59, 76

tsunami, 77

U

UNIX

bash, 104

shell script, 83

utility

cat, 104

cut, 83

echo, 83, 95, 101, 104

rm, 83, 101, 104

V

velocity, horizontal fields, 77

volcanic

activities, 15

island arc, 15, 58, 62, 74

volcanism, $\mathrm{x}, 4,11,16,25$,

27, 34, 40, 42, 44, $50,60,66,67,116$, 142, 147, 168, 176, 184, 186, 189, 205, 206, 214, 229, 232, 234

W

Wadati-Benioff zone, 63, 77 wave

body

magnitude, 89

ocean, 60, 61

oceanic (T-waves), 63

period, 89

primary (P-waves), 90

seismic, 39, 58, 74, 89

surface (L-waves)

magnitude, 89

tsunami, 246

velocity, 12,71 


\section{G.3 Index of Authors}

This index lists authors of the cited literature sources used in this dissertation

A

Abbott (L. D.) .......... 35

Abdi (H.) ............ 165

Adamic (J.) ............ 18

Adler (P. M.)....... 33, 81

Adrianov (A. V.) ........ 14

Agapova (G. V.) ........6 6

Agarwal (B. N. P.) ..... 116

Aho (A. V.) .......... 110

Airey (D.) ............

Aiuppa (A.) .......... 32

Aivazis (M.) ......... 171

Akiyoshi (H.) . . . . . . . 65

Aksentov (K. I.) . . . . . . . 29

Alalykina (I.)........... 14

Albarau (J. F.) . . . . . . . 233

Alden (A.) .............. 39

Alexeiev (D. V.) . . . . . . 18

Alexeiev (D.)...........18

Algeo (T. J.) . . . . . . . . . 6

Ali (J. R.) ..... . 4, 7, 42, 44

Ali (M.) ............. 154

Ali (S. M.) ........... 233

Allard (P.) . ........... 32

Allen (G.) . . . . . . . . 79, 80

Alsdorf (D.) . . . . . . . . . . 8 80

Alvarez-Gómez (J. A.) . 7, 25

Amante (C.) ....... . 78, 80

Ammon (C. J.) . . . . . . . 68

Anderson (C. A.) ........ 58

Anderson (C. D.) 4, 7, 42, 44

Anderson (M. E.) ........ 30

Anderson (M. O.) ... 44, 57

Anderson (R. N.) . . . . . . 93

Ando (K.)............. 29

Ando (M.) ........ . 44, 48

Andrade (J. F.) . . . . . . . . 81

Angel (M. V.) . . . . . . . 26

Angulo Ibanez (J. M.) . . 105, 154

Aniel-Quiroga (Í.) . . . . . 25

Ansley (C. F.) . . . . . . . 176

Appelgate (B.) . ........ 58

Arai (K.) ......... 52, 67
Arai (S.) ............66 66

Arakawa (Y.) . .........666

Araki (E.) ........ 35, 37

Arcay (D.) ........... 218

$\operatorname{Arcos}$ (M. E.) .......... 15

Arculus (R. J.) ..... 20, 66

Argus (D. F.) . 15, 63, 92, 93

Arisa (D.) ............66 66

Armstrong (A. A.) ... 57-59

Arndt (J. E.). . . . . . . . . 79

Arpa (C. B.) ........... 4

Arriagada (C.) $\ldots \ldots \ldots 8,28$

Arróspide (F.) . . . . . . . 8 81

Arzu (I.) . . . . . . . . . . . . 24

Asada (M.).............34

Asano (S.) . . . . . . . . . . 67

Asanuma (T.). . .........67 67

Asao (K.).........44, 66

Ashi (J.)..........67, 70

Ashraf (M.) ........... 233

Ashworth (P. J.) ....... 246

Atwater (B. F.) . . . . . . . 15

Aubouin (J.) . . . . . . . 22-24

Augustin (J.-M.) . . . . . . 233

Auzende (J. M.) . ....... 32

Avendonk (H. J. A.) van . . 47

Awcock (G.) .......... 246

Azéma (J.)......... 22-25

\section{B}

Babonneau (N.) ........ 29

Bacolcol (T.)....... 44, 83

Bagas (L.) . ........... 116

Bai (Y.)....... 18, 55, 198

Bailey (R. A.) . . . . . . 167

Baker (E. K.) .... 14, 43, 218

Baker (E. T.) ........44, 57

Baker (S. J.) ...... 4, 42, 44

Baldwin (S. L.) . . . . . . . 35

Ballance (P. F.) . . . . . . . 77

Banasik (P.) . . . . . . . . . 249

Bani (P.) .............. 32

Bannister (S.) ...... 76, 77
Baranov (B. V.) .. 14, 15, 18, 190

Barazangi (M.) ........6 63

Barker (D. H. N.) . . . . . . 77

Barnes (J. D.) . . . . . . . 64

Barnes (P. M.) . . . 72, 76, 77

Barnett (H. F. J.) . . . . . . . 18

Barr (I. D.) ............ 14

Barrier (E.) ........... 24

Bartlett (D. H.) . . 57, 61, 233

Bas (T. P. L.) . . . . . . . 81

Bateman (D.) ........ 114

Bates (D. M.) ........ 162

Bathe (F.) . . . . . . . . 81

Baumann (K.)......... 81

Baumberger (T.) .... 44, 57

Bautista (C. B.) ..... 44, 45

Bautista (M. L. P.) ... 44, 45

Bazanova (L. I.) . . . . . . 15

Beaudoin (J.) . . . . . . 57-59

Beaumais (A.) .......... 32

Beavan (J.) . ....... . 72, 77

Beazley (D. M.) ....... 168

Beccaluva (L.) ..... 56, 58

Bechter (T.) . . . . . . . . . 81

Beck (S. L.) . . . . . . . . 16

Becker (J. J.) . . . . . . . . . 6

Becker (N.) . ......... 58

Becker (T. W.) . . 6, 7, 44, 49, $57,58,77$

Beek (P.) van der ....... 37

Behn (M. D.) . ... 34, 58, 59

Behrmann (J. H.) . . . . . . 29

Behrmann (J. S.) . ... 28, 29

Beier (C.) ........ 33, 205

Belkin (I. M.) . . . . . . . 14

Bell (R. E.) ........... . 77

Bello-González (J. P.) . . 8, 28

Belyaev (G. M.) ........ 31

Berger (J.-F.) . . . . . . . . 81

Berghe (E.) van den . . 8, 233

Bermas (P. P. J.) ........ 44

Bernardel (G.) . . . . . . . . 73

Berndt (C.) ...... . 61, 233 
Berryman (K. R.) . . . 76, 77

Berthet (T.)......42, 50, 51

Bertoldi (W.) ......... 81

Bertrand (H.) . . . . . . . . 32

Besana (G. M.) . . . . . . . 44

Best (B. D.) . . . . . . . . . 119

Best (M. J.) . . . . . . . . 175

Bevis (M.)......... 30, 33

Bialas (J.) ....... 76, 77

Bilina (R.) . . . . . . . . . 105

Billington (S.) . . . . . . . 18

Bina (C. R.) . . 39, 41, 43, 63, $65,74,218$

Bindeman (I. N.) . . . . . 15

Binder (B.) . . . . . . . . . . 6

Bird (P.) . . . . . . 7, 13, 190

Birk (S.) . . . . . . . . 81

Björck (A.) . . . . . . . . . 175

Blankenship (L. E.) ..... . 31

Blondel (M.) . . . . . . . . . 152

Bloomer (S. H.) . . . . . . . 31

Blusztajn (J.) . . . . . . . 50

Blöschl (G.) . . . . . . . . . 9

Bobbitt (A. M.) .... . 44, 57

Bodine (J. H.) . . . . . . . 7, 58

Bogdanic (T.) . . . . . . . 28

Bogdanov (I.) ....... 33, 81

Bogdanov (J. A.) ....... 61

Bogdanov (J. L.)........ . 57

Bogolepov (K. V.) ...... . 34

Bohlmann (H.) . . . . . . 253

Bohrmann (G.) . . . . . . . 6

Bolik (F.) . . . . . . . . . 81

Bonali (F. L.) . . . . . . . 246

Boriskina (N. G.). . . . 14, 16

Borradaile (G. J.) . . 120, 154

Bose (S.) . . . . . . . . . . 70

Boston (B.) ........ 8, 67

Bougault (H.) . ........ 23

Bourgeois (J.)...... 15, 17

Bourrouilh-Le Jan (F. G.). 33

Boutelier (D.)......61, 218

Bovolo (C. I.) . . . . . . . . 116

Bowden (D. A.) . 76, 77, 246

Bowin (C.) . . . . . . . . . 7

Box (G. E. P.) . 154, 171, 172

Brandl (P. A.) . . . 20, 33, 66

Brandt (A.) .......... . 14
Braud (J.) . . . . . . . . 6

Braz (C.) . . . . . . . . . 28

Bretz (F.) . . . . . . . . 126

Brown (D.) . . . . . . . . 47

Brown (S. T.) ......... 246

Brucher (M.) . . . . . . . . 152

Brune (S.) . . . ....... 34

Bruns (T. R.) . . . . . . . 36

Budanova (L. Y.) ........ 6

Bui (Q. C.)............45

Bujakowski (K.). . . . . . . 249

Buland (R.) ......... . . 80

Burbank (D.) . . . . . . . . . 80

Burlini (L.). . . . . . . . . . 7

Burnett (B.) ... . 44, 211, 233

Burnley (P. C.) . ........ 63

Bursa (M.) . . . . . . . . . . 98

Butterfield (D. A.) . . . 44, 57

Butuzova (G. O.) . . . . . . 60

Byrne (T. B.) . . . . . 67, 70

\section{C}

Cadien (D. B.) . . . . . . . 31

Calabrese (S.) . . . . . . . . 32

Calder (B. R.) . . . 57-59, 243

Calmant (S.) .... 30 30, 33, 34

Cameron (A. C.) . . . . . 125

Cameron (J.) ..........61 61

Campbell (K. A.) . . . . . . 77

Campos (J.) ............ 5

Cande (S. C.) ....... 28, 29

Cannata (A.) .......... 33

Cao (L.) .........41, 43

Cao (W.)............56

Capote (R.) ........ 7, 25

Carfantan (J. C.) . . . . 22-24

Carlson (P. R.) ....... 7, 58

Carney (J. N.) ........... 33

Caro (E.) ............. 80

Carrizo (D.) ........ 28, 34

Carron (M. J.) . . . . . . . . . 7

Cartapanis (O.) ......... 29

Castillo (P. R.) . ....... 31

Cazenave (A.) . . . . . . . . 74

Cecioni (A.) ........ 28, 29

Chadwick (W. W. J.). . 44, 57

Chakravarti (N.) . . . . . . 175

Chandler (M.) ......... . 56

Chang (C.) .......667, 70
Chang (C.-P.) . . ..... 83

Chang (H. K.) . ........51

Chang (W. Y.) . . . . 4, 42, 44

Chang (W.-Y.) ......43, 53

Charvis (P.) .......... 33

Chase (C. G.) . . . . . 61, 116

Chayes (D.) . . . . . . . . . . 79

Chazot (G.) ........... 32

Chen (C. H.) . . . . . . . . 15

Chen (C.-H.).......43, 53

Chen (D.) ...... 6, 61, 218

Chen (H.) ....... . 57, 233

Chen (J.).............6 6

Chen (L.) ..... . 6, 61, 218

Chen (M.) . . . . . . . . . . 209

Chen (P.-C.). . . . . . . . .51

Chen (S.) . . . . . . . . . . 50

Chen (W.) ........... 17

Chen (Y.)..........29, 56

Chen (Y.-F.). . . . . . . . 44 43

Cheng (Z.) . . . . . . . . . 47

Chester (F. M.) . . . . . . . . 70

Cheung (K. F.) ..... 18, 68

Chiang (G.-T.) ....... 116

Chiba (H.) . . . . . . . . . 57

Chikov (B. M.)......... 34

Chilés (J.-P.) . . . . . . . . 249

Chin (S.-J.) . . . . . . . . 45

Chiquin (L.)........... 24

Chiquin (M.) .......... 24

Chiu (J.-K.) . . . . . . . 4, 42

Chiu (S.-D.) .......... 101

Chiyonobu (S.) . . 43, 65, 209

Chou (T.-A.) . . . . . . . . 80

Christensen (U. R.) . . 40, 74

Christenson (B. W.) . 76, 249

Churikova (T.) ....... 246

Ciaccio (A. D.) . . . 105, 154

Cielen (D.). . . . . . . . . . . 154

Cifuentes (I. L.) . . . . . . . 28

Cirano (M.) . . . . . . . . . 148

Clark (K.) . . . . . . . 76, 77

Clark (M. R.) . . 8, 29-32, 61, $215,218,232,233$, 246

Clarke (S.) ........... 5

Cloetingh (S.) ........ 28

Cobas (M.) .......... 148 
Cochran (U.) . ..... . 76, 77

Cochrane (G. R.) ....... 36

Coffin (M. F.) . . . . . . . . 73

Coffin (R. B.) .......... 77

Coli (M.)........105, 154

Collerson (K. D.).... . 30, 31

Collot (J.-Y.) . . . . . . . . 74

Comiti (F.) ........... 81

Conin (M.) ....... 6 67, 70

Conrad (C. P.) . . . . . 6, 6, 198

Consalvey (M.) . . . . . . . . . 8

Contreras-Reyes (E.). .... 8, 27-29, 34, 202

Cooper (A. K.) . . . . . . . 36

Corbi (F.) ............ 218

Coren (F.)............. . 74

Cornillon (P. C.) ........ 14

Costello (M. J.) . . . . . . . . . 8

Cotten (J.) . ............ 33

Coulbourn (W. T.) . . . . . 25

Cournapeau (D.) ...... 152

Covault (J. A.) . . . . . . . 43

Cowan (D. S.) . . . . . . . 25

Crameri (F.)........... 149

Crawford (B. R.) . . 242, 246

Cressie (N. A. C.) . . . . 105

Crippen (R.) .......... . 80

Crosato (A.). . . . . . . . . . 81

Cruden (A. R.) . . . . .61, 218

Crutchley (G. J.) . . . . 76, 77

Cui (W.) ............. 4

Cui (X.) ............ 7

Cui (Z.) .......... 29, 56

Cull (J. P.) . . . . . . . . . . 37

Culotta (R.) ............6 67

Cuomo (N. J.) . . . . . . . . 12

Curtis (A. C.) ...... 20, 57

Cízková (H.). . 41, 43, 63, 65, 218

\section{D}

D'Arrigo (R.) . ......... 16

Dada (O. A.)........29, 56

Dahlin (T.)............ 249

Dai (L.) .............. 5

Dale (D.) ............. 155

Daly (R. A.) ...........6 6

Danovaro (R.) ... 26, 29, 232

Dantas (E.)........... 81
Davey (F. J.) . . . . . . . . . 74

David (H. A.) ........ . 154

Davies (H. L.) .......... 37

Davis (G. P.). . . . 101, 108

Davis (J. C.) ...... 105, 125

Davis (J. R.) . . 105, 116, 150

De Batist (M.) ..... 76, 77

De Leo (F. C.) . . . . . . . . 246

DeBari (S. M.) ..... 65, 209

Deen (T.) . . . . . . . . . . . 253

Delfiner (P.) . . . . . . . . . 249

Della Croce (N.). . . . . . 232

Delteil (J.) . . . . . . . . . . . 74

Demant (A.) ........ 22-24

DeMets (C.) . . 15, 63, 92, 93

Den (N.) . . . . . . . . . . 67

Deng (H.) . . . . . . . . 6

Depner (J.) . . . . . . . . . 6

Deschamps (A.).....44, 59

Dezileau (L.). ..........29

Di Giacomo (D.) . . . . . . 80

Di Giuseppe (E.) ........6

Dic (R.) ............6 61

Dierssen (H. M.) . . . . . 4, 12

Dimalanta (C. B.).......44

Ding (H.) . . . . . . . . 47

Ding (W.) ...........47

Divins (D.) . ......42, 219

Dixon (T. H.) . . . . . . . 93

Dmitriev (Y. I.) . . . . . . 23

Doglioni (C.) . . . . . . . . 5

Dokht (R. M. H.) . . . . . . . 5

Dolotov (Y. S.). . . . 43, 198

Dong (D.) ........ 55, 198

Doo (W.-B.) .. 45, 47, 48, 51, 101

Dorschel (B.) . . . . . 79, 80

Dosso (L.) . . . . . . . . . 32

Dostal (J.).......34, 56, 58

Dougherty (D.) . . . . . 112

Dove (M. T.) . . . . . . . . 116

Dowling (L.).......76, 77

Downes (G.) . . . . . . . . . 77

Draut (A. E.) . . . . . . . . 18

Drazen (J. C.)30-32, 61, 215, 218, 232, 233

Dresen (G.) . . . . . . . 68

Drewes (H.) . . . . . . . . 18
Droettboom (M.) ....... 155

Dubinin (E. P.) . . . . . . 60

Dubourg (V.) .......... 152

Duchesnay (E.)........152

Duncan (R. A.) ..... 30, 77

Dunn (D. C.) . . . . . . . . 119

Dupuy (C.)............. 34

Duquesnoy (T.)........24

Duren (R.) . . . . . . . . . 80

Durham (W. B.) . . . . . . 63

Dutkiewicz (A.) ....... 198

Dziewonski (A. M.) . . 80, 88

\section{E}

Eagles (G.) . ......... 253

Eakins (B. W.) . . . . . 78, 80

Eaton (J. W.) . ......... 114

Eberhart-Phillips (D.) . 76, 77

Ebina (N.) . . . . . . . . . 57

Edwards (M.) ......... 58

Egloff (F.) . . . . . . . . . 48

Eissen (J.-P.) . . . . . . 32, 33

Ekman (M.) . ..........98

Ekstróm (G.) . . . . 18, 80, 88

Elek (I.) . ........... . 133

Elliott (T.) ... . 60, 63, 218

Ellis (S. M.) . ..... 73, 77

Endo (D.) . . . . . . . . . 66

Engdahl (E. R.) ..... 18, 80

Ernst (W. G.) . . . . . . . 190

Escauriaza (C.) ........ 81

Eustace (R. M.) . . . . . . 60

Everitt (B.) . ......... 171

Ewart (A.) .........30, 31

Ewen (J.) . . . . . . . . . . 116

Ewing (J. I.). . . . . . . . . 667

Ewing (M.) . . . . . . . . . 67

\section{F}

Faas (R. W.). . . . . . . . . 25

Fabre (D.)...........6 6

Faccenda (M.) . . . . . . 7, 47

Faccenna (C.)6, 7, 42, 44, 49, $57,58,61,63,66$, 77,116

Factor (J.) ............6 6

Fagereng (A.) .......... 77

Fahl (A.) ............. 253

Falahat (S.) .......... 29 
Falconer (R.) . . . . . . 79, 80

Falvey (D. A.) .......... 30

Fan (J.).....44, 45, 55, 198

Fan (L.) ......... . 57, 233

Fang (J.) ... 31, 56, 215, 233

Fang (P.) ............47

Farr (T. G.) . . . . . . . 80

Faure (K.) .... . 76, 77, 249

Faustino-Eslava (D. V.) . . 44

Feigl (T.) . ...... 249, 253

Fernandez (M. O.) ....... 5

Ferrari (L.) . . . . . . . . . 28

Ferrini (V.) . ...... 79, 80

Filizola (N.) . . . . . . . . 81

Fink (H.) .......... 68

Finlayson (D. M.) . . . . . 37

Firing (E.) .......... 155

Fischer (R. L.) . ....... 26

Fisher (E. H.) ........ 81

Fitzgerald (P. G.) . . . . . . 35

Flament (N.) . . . . . . . . . 28

Fletcher (M.) . . . . . . . . . 5

Fliedner (M.).......... 18

Flores (O.) ........... 24

Flueh (E. R.) .......27, 29

Fodrie (F. J.) . . . . . . . 18

Fohrmann (M.) . . . . . . . 77

Forsyth (D. W.) ..... 34, 40

Forwick (M.)......... 249

Fourré (E.) . . . . . . . . . . . 32

Francis (R.) ... 98, 101, 209

Franco (A.) ............ 24

Fraser (G. D.) . . . . . . . 18

Freitag (R.) . . . . . 15, 18

Freymuth (H.) . . 60, 63, 218

Friedman (J. R.) . . . . . . 30

Friendly (M.) . . . . . . 160

Frigge (M.) . ......... 162

Fryer (G.) ....... 18, 58

Fryer (P.) ....... 8, 58, 61

Fu (Y.) . ........... 202

Fujie (G.)........12, 65

Fujii (T.) 30-32, 64, 215, 232

Fujikura (K.) ......... 60

Fujio (S.) ............ 29

Fujioka (K.) ... 4, 6, 42, 53, 55-57, 63, 65, 68, $183,209,222,246$
Fujiwara (T.) . 44, 53, 55, 70, 183,222

Fukao (Y.).......5, 15, 17

Fukumori (H.)......... 14

Fuller (I.) . . . . . . . . . 8 81

Fuller (M.) ...... 4, 7, 44

Funiciello (F.)... 6, 7, 42, 61, 63, 66, 116, 198, 218

Furukawa (R.)......... 15

Furuya (H.)........44, 66

\section{G}

Gaedicke (C.)..... 15, 18

Gaillot (A.) .......... 233

Gaina (C.) ........... 56

Galbraith (E.) ......... 29

Galewsky (J.) ......... 35

Galicia (O.) ........... 24

Gallagher (S.) . . . . . . . 5

Galli (C.) ............. 24

Gallo (N. D.) . . . . . . . . 61

Gambi (C.).....26, 29, 232

Gamble (J. A.) . . . . . . . 30

Gamo (T.) ............ 57

Ganzey (L. A.) ........ 17

Gao (R.) .............. 34

Gao (X.) ......... 41, 43

Garaebiti (E.) ....... 32, 33

Garcia (E.) . 80, 98, 101, 209

Gardner (J. V.) ..... . 57-59

Garfunkel (Z.)..........58

Garzanti (E.) .......... 150

Gauger (S.)...... 249, 253

Gauthier (P. J.) ......... 32

Ge (H.) ....... 31, 56, 215

GEBCO Committee..... .79

Geersen (J.) . . . . . . . 27, 29

Gelman (A.) . . . . . . . 167

Gerringer (M. E.)31, 32, 232, 233

Gerya (T. V.) . . . . . . . . . 7

Giacobbe (S.) . ....... 233

Gieskes (J.) . . 6, 18, 61, 218

Giletycz (S. J.) . . . . . . . 83

Gill (J.).............. 105

Gille (S. T.) .......... 43

Giuseppe (E. D.) . . 42, 63, 66

Glade (T.) . . . . . . . . . 249
Glud (R. N.) ... 29, 30, 233

Go (C. N. A.) ......... 45

Gohl (K.) . ...... 249, 253

Goldfinger (C.) ......... 7

Golovand (O.).......... 14

Golub (G. H.) . . . . . . 155

Gong (L.)...........233

Gong (W.) .......... 4, 66

Gong (Z.) ....... 57, 233

González (M.). ......... . 25

Goodlife (A. M.) . . . . . . 31

Gorbatov (A.).. .5, 15, 17, 34, 190

Gordeev (E.) . ... . 5, 15, 17

Gordon (R. G.) 15, 63, 92, 93

Gorini (M. A. V.) ..... 6, 9

Gorman (A. R.) . ... . 73, 77

Gorospe (M. L.) . . . 242, 246

Gorshkov (G. S.) . . . . . 15

Gouretski (V.) ......... 80

Graf (W.) ............ 81

Gramfort (A.) ........ 152

Grand (S. P.) ......... 8

Granger (B. E.) . . . . . . 152

Grebennikova (T. A.) . . 17

Green II (H. W.) . . . . . . . 63

Gregorova (B.) ........ 249

Gregorová (B.) . . . 242, 249

Greinert (J.) . ...... 76, 77

Gretskaya (E. V.) . . . . . 17

Grevemeyer (I.) . . . . 27, 29

Griffiths (J. S.) . . . . . 28, 29

Griffiths (R. W.) ........ 63

Grisel (O.) ........... 152

Grobys (J.)........... 253

Gross (M.) . ......... 135

$\mathrm{Gu}$ (Y. J.) ............ 5

Gualtieri (C.) ........ 81

Gubbins (D.) ..........6 63

Guo (L.) ............. 5

Guo (W.).............. 4

Guo (Y.)..........4, 66

Guotana (J. M. R.) . . . . . . 44

Gupta (A.) ............ 70

Gurnell (A. M.) . . . . . . 81 81

Gurnis (M.) ........... 56

Gurvich (E. G.) . . 57, 58, 61

Gusiakov (V. K.) ...... 17 
Gutiérrez Gutiérrez (O. Q.) 25

Gutscher (M.-A.) . . . . 42, 50

Guzmán-Speziale (M.) . . 22

Géli (L.) ............. 5

Gómez-González (J. M.) . 22

\section{H}

Haase (K. M.) ..... . 33, 205

Hackney (R.).........663

Haddock (S. H. D.) . . . . 8

Haines (J.) . . . . . . . . . 72

Hall (R.)...... 4, 7, 42, 44

Halpin (P. N.) . . . . . . . 119

Halterman (R. L.) . . . . . 150

Hamada (C.) . . . . . . . . . 253

Hang (T. T.) . . . . . . . . 56

Hao (K.-C.) . . . . . . . 45, 47

Haraguchi (S.) ...... 4, 42

Hardy (K.) . . . . . . . . . . 61

Haren (H.) van. . . . . 61, 233

Harrington (A. N.) . . . . 150

Harris (J.) . . . . . . . . . . . 80

Harris (P. T.) . 14, 43, 58, 218

Hartley (A. J.) . . . . . . 28, 29

Hartwell (A. M.) ...... 233

Hashima (A.) ...... 44, 66

Hashimoto (J.) ........ 58

Hashimoto (K.) . . . . . . . 37

Hass (C.) . . . . . . . . . . 249

Hauberg (S.) . . . . . . . . 114

Hauton (C.) . . . . . . . 81

Hawkins (J. W.) . . . . . . 31

Haxby (F.) ........... 219

Hayakawa (M.) . . . . . . . 67

Hayakawa (T.) . . . . . . . 69

Hayes (D. E.) ........... 29

He (C.) . . . . . . . . . . 246

He (E.) . . . . . . . . . . . 47

He (R.-W.) . . . . . . . . . . 34

Heesemann (M.). . . . . . . . 29

Heezen (B. C.) . . . . . . 6, 32

Heiskanen (W.) . . . . . . . 98

Heki (K.) . . . . . . . . . 66

Helffrich (G. R.) . . . 60, 66

Helu (S.). ............. 30

Henrys (S. A.) . . . . . . . . 77

Henrys (S.) . . . . . . . 76, 77

Hensley (S.)..........880
Hergt (J. M.) . . . . . . . . 31

Herman (F.).......... 76

Hessler (R. R.) . 44, 211, 233

Heubeck (C.) ...... . 27, 29

Heuret (A.) . . 6-8, 42, 54, 61, $62,116,198,218$

Heyman (W. D.) ........ 81

Hickey-Vargas (R.) . . . 20, 66

Hilde (T. W. C.) .... . 44, 253

Hillenbrand (C. D.) . . . . 253

Hillenbrand (C.-D.) . . . . 249

Hilst (R. D.) van der . . 8, 48, $58,63,80$

Hino (R.) . . . . 35, 37, 65, 69 Hirano (N.) . . . . . . 60, 246

Hirano (S.) ........ 43, 44 Hoaglin (D. C.) 125, 155, 162 Hoernle (K.) . . . . . . . . 246 Hofmann H. Kafadar (K.) 154, 155

Hokanishi (N.) ........ 66

Holbroock (W. S.) ....... 18

Hollister (C. D.) . . . . . . 32

Holm (R. J.) . . . . . . . . . . 35

Holt (A. F.) 44, 49, 57, 58, 77

Honda (M. C.) ........ 50

Honza (E.) ............ 37

Horiuchi (D.) ..... . 49, 209

Horleston (A. C.)... . 60, 66

Hornik (K.) . . . . . . . 176

Horton (T.)............ 30

Hothorn (T.) . . . . . . . 126

Hotta (H.) . . . 4, 63, 67, 68

Howard (F.).......... 5

Howarth (J.) ...... . 76, 77

Howell (A.) . . . . . . . 76, 77

Hsieh (H.-S.) . . . . . . . . 43

Hsu (S.-K.)29, 42, 43, 45, 47, 48, 51

Hsu (Y.-J.). ....... 44, 83

Hsua (S.-K.) . . . . . . . 101

$\mathrm{Hu}$ (D.) . . . . . . . . . . . 47

$\mathrm{Hu}(\mathrm{Y}.) \ldots \ldots \ldots \ldots \ldots .4$

Huaman (D.) ...... 33, 81

Huang (H. L.) . . . . . . . . 7

Huang (H.-C.) . . . . . . . 45

Huang (Y.-S.) . . 47, 48, 101

Hubble (T.) .......... 5
Hudson (P. F.) . . . . . . . 81

Huene (R.) ... 18, 25, 34, 67, 104

Huijbregts (C.) ........ 9

Hull (A.) . . . . . . . . . . . 77

Hunen (J.) van . . . 42, 63, 66

Hunter (J. D.) . . . . . . . . 152

Hunter (J.) . . . . . . . 155

Husker (A.) . . . . . . . . 28

Husson (L.) . . . . . . . . . 58

Hussong (D. M.) . . . 66, 209

Huvenne (V. A. I.) . . . . . 81

Hwang (R.-D.). . . . 4, 42, 44

Hühnerbach (V.) .......81

\section{I}

Ianniruberto (M.) . . . . . 8 81

Ichikawa (K.) . . . . . . 67

Ichino (M. C.) . 61, 215, 218

Ichiyama (Y.) . ......66 66

Iglewicz (B.) . . . . . . . 162

IHO ....... 3, 7, 80

Iidaka (T.) .......... 43

Ikari (M. J.) . . . . . . . . . . 5

Ikehara (K.) . . . . 6 67, 68

Ikuta (R.) . . . . . . . . . 48

Iliev (A. Y.) . . . . . . 17

Imai (T.) . . . . . . . . . 48

Imaoka (T.) . . . . . . . 50

Ingalls (S.) . . . . . . . . 6

Ingram (C. L.). . 44, 211, 233

Inoue (T.) . . . . . 52, 67

International Seismological

Centre.......8 80

Irino (T.) . . . . . . . . 68

Iryu (Y.) . . . . 43, 52, 65, 209

Isacks (B. L.) . . . . 30, 63, 70

Ishibashi (J.-i.) . . . . . . 57

Ishibashi (K.) . . . . . . 77

Ishida (K.) . . . . . . . . . 44

Ishii (T.) 4, 8, 42, 56, 58, 246

Ishizuka (H.) . . . . . . . 50

Ishizuka (O.). . .4, 20, 42, 56, $63,64,66,209,246$

Iso (N.) . . . . . . . . . . 77

Isse (T.) . . . . . . . . 43

Ito (A.) . . . . . . . 12, 43

Ito $(\mathrm{H}.) \ldots \ldots \ldots \ldots \ldots 6$

Ito (T.) . . . . .44, 66, 68 
Itoh (M.) . . . . . . . 51, 233

Iton (T.) . . . . . . 6 67, 70

Iwabuchi (Y.) . . 53, 55, 183, 222

Iwasaki (L. T.) . ....... 48

Izbekov (P. E.) ........ 15

\section{J}

Jaccard (S. L.) . . . . . . . . . 29

Jackson (R. J.) . . . . . . . . 37

Jakobsson (M.)...... .79, 80

Jamieson (A. J.) 8, 12, 29-32, $60,61,215,218$, 232,233

Janeka (K.) . . . . . . . . 249

Jang (J.-P.) . . . . . . . . . . 51

Janssen (C.) . . . . . . . . . . 68

Jara (J.) . ..... . 27, 29, 202

Jarrard (R.) . . . . . . . . 61

Jean-Baptiste (P.) . . . . . . 32

Jelsma (H. A.) . . . . . . . . . 35

Jenkins (R. G.) . . . . . . . 60

Jensen (A.) . . . . . . . . . . . 28

Jiang (X.)..........4, 66

Jiao (R.) .......... . 76, 77

Jicha (B. R.) ..... 15, 246

Jimenez-Diaz (A.) . . . . . 7

Johnson (R. W.) . ...... 37

Jones (D. O. B.) 61, 215, 218

Jones (E.)............ 105

Jordan (T. H.) . . . . . 43, 209

Joron (J.-L.) . . . . . . . . . . 23

Joshima (M.) ... 37, 63, 209

Journel (A. G.) . . 9, 123, 125, 165

Joydas (T. V.) . . . . . . . 233

Judge (A. V.) . . . . . . . . 7

Jung (W.-Y.) . . . . . . . . . 7

Just (J.) . . . . . . . . . . . . 253

Jónasson (H.) . . . . . . . 198

\section{$\mathbf{K}$}

Kaiho (Y.) ............ 70

Kaistrenko (V. M.) . . . . . 17

Kalnins (L. M.) . . . . . . . . . 7

Kameda (J.)......... 5, 70

Kameo (K.)........ .44, 66

Kamimura (A.) ..... 65, 69

Kanagawa (K.)......67, 70
Kanamatsu (T.). . 4, 6, 42, 57, $67,68,70$

Kanamori (H.) 16, 58, 61, 68

Kanazawa (T.) 43, 48, 65, 69

Kaneda (H.) ........ 44, 66

Kaneda (K.)............64

Kaneda (Y.) . . . . . 12, 69, 70

Kao (H.) ....... 17, 43, 53

Karato (S.) ..... . 58, 70, 74

Karig (D. E.) . ..... . 43, 44

Karner (G. D.) . . . . . . . . 219

Kasahara (A.) .........6 68

Kasahara (J.) .... . 55, 65, 69

Kasatkin (S. A.) ..... 14, 16

Katagiri (H.).......51, 233

Katao (H.) ............ 55

Kato (M.) ........ 43, 209

Kawabata (H.)..........50

Kawabe (M.)..........58

Kawamura (K.) .... 51, 233

Kay (R. W.) ........... 18

Kazakova (V.) .......... 25

Keene (J. B.) . . . . . . . . . . 37

Kelemen (P. B.) ....... 246

Kendrick (E.) .......... 30

Kennett (B. L. N.)34, 63, 190

Kennett (J.) ...........6 6

Kernigan (B. W.) ..... 110

Kharlamov (A. A.) . . . . . 17

Khomarudin (M. R.) . . . 103

Khomich (V. G.) . . . . 14, 16

Kido (Y.) . . . . . . . . . . . 69

Kilgallen (N. M.) . 29, 30, 60, 61

Kilner (J.) . . . . . . . . . . . 77

$\operatorname{Kim}($ S. H.) ......... 6

$\operatorname{Kim}(Y$. M.). . . . . . . . 222

Kiminami (K.) ......... 50

Kimura (A.) ...... 61, 233

Kimura (G.) . ...... 67, 70

Kinoshita (M.) ..... 67, 70

Kirby (J. F.) . .......... 7

Kirby (S. H.) . . . 18, 63, 205

Kirkpatrick (J. D.) . ..... 70

Kitagawa (S.) ....... 8, 59

Kitahashi (T.) . . 51, 60, 233

Kitamura (A.) ......... .48

Kitazato (H.) . 29, 30, 53, 56,
$183,222,233$

Kitazawa (K.) .......... 30

Kiyokawa (S.).........664

Kizaki (K.). ...........49

Klaucke (I.) . . . 61, 77, 233

Klauco (M.) . . . . . 242, 249

Klauer (B.). . . . . . . . . . .81

Klauo (M.). . . . . . . . . . 249

Kleiber (C.) . . . . . . . . . 127

Klemperer (S. L.) ....... 18

Klingelhoefer (F.) . 42, 50, 51

Kluesner (J. W.) . . . . . . 18

Kniesz (K.) ........... 14

Knuth (D. E.) . . . . . . . 177

Kobayashi (K.) . 4, 53, 55, 63, $68,183,222$

Kober (M.) .......... 249

Kobrick (M.) . ......... 80

Kodaira (S.) 8, 12, 48, 64, 67, 69, 70

Kohn (B. P.) . ...... 76, 77

Kohn (R. J.)........... 176

Koizumi (K.)..........44 44

Kojima (S.) .... 51, 60, 233

Koleda (P.) . . . . . . . . . 249

Kong (X.) ............ 5

Kono (T.) . ............. 69

Kopf (A. J.) ........... 5

Koresawa (S.) ......... 55

Kostoglodov (V.) . . . . 17, 28

Kotowicz (D.) ......... 253

Kou (Q.)............2233

Kozyreva (N. P.) . . . . . . . 17

Krabbenhoeft (A.) ...... 77

Kravchunovskaya (E. A.) 15, 17

Krbetschek (M.) ........ 15

Krishnakumar (P. K.) . . 233

Kroenke (L. W.) . . . . . . . 77

Kruger (S.) . . . . . . . 249

Kruskal (J. B.) . . ...... 175

$\mathrm{Ku}$ (C.-Y.) ........... 47

Kuhlman (D.) ......... 150

Kuhn (G.) . . . . . . . 249, 253

Kukowski (N.) . . . ..... 77

Kulm (L. D.) . . . . 27, 29, 42

Kumar (M.) ........... 80

Kuo (B.-Y.) ........... 51 
Kurnosov (V. B.) . . . . 23, 25

Kusano (Y.)........20, 66

\section{$\mathbf{L}$}

Laaha (G.) ........... 9

LaBrecque (J. L.) . . . . . 219

Lacey (N. C.) . ...29-31, 61

Lacharité (M.) ........ 198

Ladd (J.)............... . 25

Ladner (R.) . . . . . . . . . 6

Laing (A.) . .......... 37

Lallemand (S.) . . 6-8, 29, 42, 44, 49, 51, 54, $57-59,61-63,66$, $67,77,116,218$

Lamarche (G.) 74, 76, 77, 79, 80

Lamba (T. S.) . ....... 116

Lambeck (K.) . . . . . . . 37

Lander (A. V.) . . . . . . . 15

Lang (W.) ....... 61, 233

Lanier (A.) . . . . . . . . . . 7

Larina (N. I.) . . . . . . . . 6

Larsen (B.) . . . . . . 211, 246

Larsen (W. A.) . . . . 155, 162

Larter (R. D.) . . . . . . . . 253

Lasserre (C.) .......... 24

Lavier (L.) . . . . . . . . . 47

Lavrenteva (A.)......... 14

Lawford (S.) . . . . . . . . 105

Lay (T.) . .......... 68

Le (T. B.) ........... 81

Lebellegard (P.) . . . . . 33

Lebrun (J.-F.) . . . . . . . . 74

Leduc (D.) ..... 30, 31, 233

Lee (C.-S.) . . 42-44, 50, 51, 253

Lee (S.-M.) . . . 4 44, 55, 222

Lees (J. M.) . . . . . . . . . 17

Leeuw (J. d.) .......... 176

Lehu (R.) ............. 29

Leinweber (V.) . . . . . . . 253

Lemenkov (V.) ........ 249

Lemenkova (P.) ix, xvi-xviii, $\mathrm{xx}$-xxii, 4, 6, 9-16, 18-28, 32-35, 37, 44-46, 48-51, 53-56, 61, 63-65, $67,70,72-78,81$,
$84,85,87,94,97$,

98, 100, 101, 103-106, 109, 111, 114-116, 120-122, 125-130, 133-135, 137-144, 147-149, $155,157,158,162$, $168,172,173,175$, 176, 180, 182-184, 187, 188, 191-203, 205, 209-214, 216, 217, 219-223, 226-232, 234-236, 239-242, 244, 247, $249,250,252,253$

Lemoine (A.) ............5

Lensch (N.) . . . . . . . . . 253

Leonov (V. L.) ........ 15

Leslie (R. B.). . . . . . . . 28

Leslie (S. D.) . ..... 28, 29

Lester (R.) . . . . . . . . . . 47

Levin (L. A.) . . . . 18, 31, 61

Levy (L. S.) . . . . . . . 116

Lewin (J.) .......... 246

Lewis (J. C.) .......67, 70

Lewis (K. B.) ...... . 76, 77

$\mathrm{Li}(\mathrm{C}.) \ldots \ldots \ldots \ldots$, 66

$\mathrm{Li}(\mathrm{F}.) \ldots \ldots \ldots \ldots \ldots 47$

Li (J.) . ............ 47

Li (Q.-S.) . . . . . . . . 34

$\mathrm{Li}(\mathrm{S}.) \ldots \ldots \ldots \ldots \ldots 5$

Li (T.-D.) . . . . . . . . . 34

Li (X.) ............ 233

Li (Y.) ......... 57, 233

Liang (C.-W.) 42, 43, 45, 101

Lieberman (J. E.) . . . . . 110

Lima (S. M.) . . . . . . . 33

Lin (A. T. S.) . . . . . . . 83

Lin (A. T.) .......... 29

Lin (C.-R.) . . . . . . . . 51

Lin (J. W. B.) . . . . . . 148

Lin (J.) . . 34, 58-61, 63, 168, 246

Lin (J.-Y.) . . 4, 42, 43, 45, 48

Lin (S.-C.) . . . . . . . . . 51

Lin (W.) ........67, 70

$\operatorname{Lin}(\mathrm{X}.) \ldots \ldots \ldots \ldots 47$

Lin (Y.-C.) . . . . . . . . 43
Lin (Z.) ......... 29, 56

Lindh (P.)............ 249

Lindley (I. D.) . . . . . 35, 37

Linke (P.). ....... .76, 77

Linley (T. D.) 29-32, 61, 232

Lisicyn (A. P.) . . . . 61, 198

Listanco (E. L.) . . . . . . . 4

Lister (G. S.) . . . . 28, 34, 63

Litchfield (N.) . .... 76, 77

Little (R. P.) . . . . . . . . . 37

Little (T. A.) . . . . . . 76, 77

Litvin (V. M.) . . . . . . 4, 6

Liu (C.-S.). .......47, 51

Liu (F.) . . . . . . . . . . 7

Liu (H.) ..... . 45, 57, 233

Liu (J.)......... 57, 233

Liu (M.) . . . . . . . . . . 7

Liu (R.) ........... 233

Liu (X.) ............ 56

Liu (Y.) ...... . 45, 56, 246

Lizarraide (D.) . . . . . . 18

Ljung (G. M.) . . . . . . 172

Lo (C.-L.) . . 4, 42, 45, 47, 48, 101

Loan (C. F.) van ........ 155

Lodolo (E.) . . . . . . . . . 74

Loher (M.) . . . . . . . . . 6

Long (M. D.) ..........48

Long (P. J. G.) ....... 115

Lonsdale (P. F.) . . . . 31, 104

Lopes (R. M. C.) ....... 33

Lorenz (R. D.). . . . . . . . . 33

Louat (R.) ........ 33, 246

$\mathrm{Lu}$ (B.) ............. 56

$\mathrm{Lu}(\mathrm{J}.) \ldots \ldots \ldots \ldots . \ldots 56$

Luchinina (A. A.) .......17

Ludwig (T.) ........... 190

Ludwig (W. J.) . ....... 67

Luis (J. F.) . . 48, 80, 83, 244, 248

Luna (J.).............24

Luo (M.)....... 6, 61, 218

$\operatorname{Lv}(\mathrm{X}.) \ldots \ldots \ldots \ldots \ldots 56$

Lyon-Caen (H.) . ....... 24

Lörz (A.-N.)..... 14, 30, 31

\section{M}

Ma (L.) ............47

Ma (Y.-F.) . . . . . . . . 101 
Macdonald (K. C.) ...... 42

MacFarlane (A.) ......... 33

Machiyama (H.) ........ 52

MacInnes (B. T.) .... 15, 17

MacLeod (C. J.) ........ 31

Macmillan-Lawler (M.) . . 14, 43,218

Madariaga (R.) ......... 5

Madin (L. P.) . . . . . . . . 8

Mahoney (J. J.) . . . . . . . . 77

Maillet (P.)............ 33

Maiorova (A. S.) ....... 14

Mair (P.)............ 176

Makris (J.) ............ 48

Maksymowicz (A.)...27, 29, 202

Malys (S.) ........... 98

Malyutina (M.) ......... 14

Mammerickx (J.) ........ 35

Manea (M.) ........... 28

Manea (V. C.). ...... 15, 28

Manikandan (K. P.) . . . . 233

Mann (P.) ............. 73

Mao (A.) ............. 93

Mao (L.).............. 81

$\operatorname{Mao}($ X.)............6 6

Marcelot (G.) .......... 34

Marchese (E.) .........81

Marcon (Y.) ...... 6, 233

Mark (D. F.) . . . . . . . . . . 35

Markovic (V.) . ........ 249

Markovic (V.) . . . . 242, 249

Markovi (V.) . . . . . . . . . 249

Marks (K. M.) ...... 6, 79

Marova (N. A.) .........6 6

Marques (A. C.) ........ 5

Marta-Almeida (M.) . . . 148

Martin (A. P.) . 61, 215, 218

Martin (J. B.).......... 18

Martin (R. A.) . . . . . . . . 77

Martin (T.) ............ 5

Martinez (F.) ..... . 58, 209

Martins (L. O.) .... 61, 233

Marton (F. C.) ...... 39, 74

Martínez-Díaz (J. J.) . . . . 25

Maruyama (S.) ....... 9, 44

Masson (D. G.) ..... 6, 81

Masuda (H.) .......... 57
Mather (A. E.) ..... . 28, 29

Matsuda (H.) .......... 52

Matsuzaki (H.) ......... 56

Maulana (T.) ......... 103

Maury (R. C.) .........23

Maus (S.) ........... 56

Mayer (L. A.) . . 79, 80, 243

Mayor (D. J.) 29, 30, 61, 215

Mayr (C.)........... 253

McCaffrey (R.) . . . . . . . 77

McCarthy (A.) ...... 20, 66

McClusky (S. C.) ....... 37

McColl (S.) ........... 81

McGeary (S.) ......... 18

McGill (R.) ...... 155, 162

McIntosh (K.) ..... 47, 51

Mckenzie (D.) .......... 7

McMillan (P. A.) ....... 18

McMillan (P. J.) . 31, 32, 232

McNeill (L. C.) . . . . . 67, 70

McNutt (M. K.) ......... 7

McQueen (H.) . . . . . . . . . 37

Meckel (T. A.) . . . . . . . 73

Meijer (P. T.) . . . . . . . 25

Melanholina (E. N.) . . . . .61

Melhuish (A.) . ......... 74

Menard (H. W.) ..... 4, 42

Mendoza (G.) ......... 18

Mercier de Lepinay (B.). . 77

Merle (S. G.) . . . . . . 44, 57

Metaxas (A.) ......... 198

Metrich (N.) .......... 33

Metzger (E. J.) ......... 43

Meysman (A. D. B.) . . . 154

Micallef (A.) ...........6 6

Michel (V.) ......... 152

Michibayashi (K.) ... . 8, 58

Middelboe (M.) . ...... . 29

Middelkoop (H.)....... 81

Mikhina (V.) . ......... 25

Miller (M. S.) . . 34, 63, 190

Milliman (J. D.) ......... 9

Millman (K. J.) . .......171

Minami (H.) .......... 50

Mitchell (D.) . .......... . 5

Mitchell (N. C.) . ....... 6

Miura (S.)...... 67, 69, 70

Miyairi (Y.) . ......... 48

cvi

Polina Lemenkova:

Deep-Sea Trenches of the Pacific Ocean: ...Data Modeling by GMT, Python and R
Miyauchi (T.) . . . 44, 66, 77

Mochizuki (K.) . . 35, 37, 55

Molina (E.) ........... 24

Molnar (P.) . . . . . . 63, 70

Monahan (D.).......79, 80

Montagner (J.-P.) . . . . . . 43

Montgomery (D. C.) . . 167

Monzier (M.)...........33

Moore (G. F.) . . . 8, 67, 104

Moore (J. C.) ..... . 67, 70

Morales (L.) . . . . . . . 68

Moran (C. L.) .......... 31

Morgan (P. J.).......37, 244

Morgan (W. J.) ... 23, 58, 61

Mori (H.) ....... . 61, 233

Mori (J. J.) . . . . . . . . . . . 70

Mori (Y.) ......... 50, 66

Moritz (H.) .......... 98

Mosher (S.) . . . . . . . . . 73

Mosteller (F.) . . . . . . . . 125

Mountjoy (J. J.) . .... 76, 77

Moyer (C. L.) . . . . . 20, 57

Murauchi (S.) ..........6 67

Murdmaa (I.)..........25

Murphy (B.) .......... 37

Murray (H. W.) .... 18, 220

Myers (J. L.) . .... . 105, 136

Müller (D.) . . . . . . . 89, 90

Müller (R. D.) 28, 39, 56, 98, 101, 198, 209, 253

Münker (C.) . . . . . . . . 246

\section{$\mathbf{N}$}

Nagahashi (Y.) . . . . . . 68

Nagaraja (H. N.) . ..... 154

Naka (J.) ......... 63, 209

Nakakuki (T.) ......... 253

Nakamura (M.).........48

Nakamura (T.). .........56

Nakamura (Y.) . 8, 44, 67, 70

Nakanishi (A.) . . . . . 64, 69

Nakanishi (M.)......58, 63

Nakao (A.) . . . . . . . . . . 68

Nakata (T.) ........ 43, 44

Nakazawa (T.) . . 43, 65, 209

Nanayama (F.) . ........ 15

Naumann (R.) . . . . . . . . 68

Neal (C. R.) . . . . . . . . . 77

Negishi (H.). .......... .44 
Neira (C.) . . . . . . . . . 18

Nelson (C. H.) . . . . . . . 42

Nelson (S.) . . . . . . . . . 6

Neprochnov (J. P.) . . . . . 57

Nesbitt (E. A.) ......... 77

Nettles (M.) ...... . 80, 88

Netzeband (G. L.) 76, 77, 253

Netzeband (G.) . . . . . . . 253

Ngiwsara (L.). .....661, 233

Nguyen (P. H.) . . . . . . . 45

Nicol (A.) . . . . . . . 75, 77

Nielsen (S. G.) . . . . . . . 50

Ning (J.)............ 246

Nishimura (A.) . . 43, 65, 209

Nishino (M.) . . . . . . . . . 69

Nishizawa (A.) . . 49, 55, 64, 209

Niu (Y.) . . . . . . . . . 31

No (T.) . ........... 70

Noguchi (I.)...........667

Nolasco (R.) . . . . . . . . . 148

Nomaki (H.) .......... 60

Normark (W. R.) . . . . 7, 58

Norton (I.) . . . . . . . . . . 25

NumPy Community 150, 153

Nunnally (C. C.)......... 30

\section{$\mathbf{O}$}

O'Callaghan (S.) . . . . . 198

O’Dor (R.)............233

Oakley (A. J.) .........8

Oda (H.) ........ 56, 246

Oda (M.) . . . 43, 50, 65, 209

Ogawa (Y.). 4, 60, 63, 65, 68, 246

Ogura (K.)..........50

Oguri (K.) . . . . . . 29, 56

Ohara (Y.) 4, 6, 8, 42, 44, 50, $56-58,80,209,246$

Ohashi (Y.) .......... 48

Oikawa (M.)....... 49, 209

Oike (K.) ........ . 44, 45

Okal (E. A.) ....... 63, 205

Okamoto (A.) ....... 8, 58

Okamura (Y.) ...... 49, 209

Okino (K.) . . 4, 6, 34, 42, 44, 57,222

Okuyama (M.).....61, 233
Oliphant (T. E.) . . . 105, 119, 152,154

Oliver (J.)..........663

Olu (K.) ............ 233

Oncken (O.) ......661, 218

Ondréas (H.) . ........ 233

Ooka (T.) .... . 43, 65, 209

Orozco-Esquivel (T.). ...28

Osborn (K. J.) ......... 8

Oshika (J.) ..........66 66

Oskin (M.) . . . . . . . . . . 80

Osses (A.) . . . . . . . . . . . 29

Ota (Y.)............ 77

Otero (P.) ........... 148

Otsuji (N.) ............ 56

Otsuki (K.) .......209, 253

Owens (W. B.) ......... 20

Ozawa (A.) ...........4

\section{$\mathbf{P}$}

Pabst (S.) . . . . . . . . . . 190

Paller (M.)........... . 80

Pan (B.) .............. . 4

Papadopoulos (V. P.) ... . 233

Pape (T.)............6

Papenberg (C.) ........ 77

Parajka (J.)........... 9

Parello (F.)........... 32

Park (J.-O.) . . . . . . . . . 69

Parsiegla (N.) ......... 253

Passos (A.) .......... 152

Pathom-aree (W.) .. 61, 233

Payot (B. D.)..........44

Pebesma (E.).......... 9

Pecher (I. A.) . . . . . . 76, 77

Pedley (K.) ....... 76, 77

Pedoja (K.) ........... 15

Pedregosa (F.)......... 152

Pelc-Mieczkowska (R.) . 249

Peliz (A.) . . . . . . . . . . 148

Pelletier (B.) ... . 32-34, 246

Pereira (J.)........... 148

Perepelov (A. B.) ....... 15

Peresypkin (V. I.) ...... 233

Perez (F.) ........... 152

Perez (J. S.) . ..... . 43, 44

Perktold (J.) ..... . 175, 176

Perlin (N.) . . . . . . . . . 119

Perrot (M.)............ 152

cvii

Deep-Sea Trenches of the Pacific Ocean: ...Data Modeling by GMT, Python and R
Petersen (C. J.) . . . . . . 77

Peterson (P.) ......... 105

Petitat (M.) .......... 249

Petterson (M. G.) ....... 77

Peyret (M.) .......... 218

Peña (R. E.) ..........44

Pflanz (D.) ............ 15

Pham (T. T.) . . . . . . . 45

Pharaoh (A.) ..........6 6

Philipps-Bussau (K.) . . . . 14

Phillips (D. A.) . . . . . . 33

Pierre (G.) ........ 33, 81

Piertney (S. B.) ... 30, 31, 60

Pillet (R.) . . . . . 33, 34, 56

Pineda (V.) ........ 28, 29

Pinegina (T. K.) . . . . 15, 17

Pinheiro (A.) . . . . . . . 81

Plank (T.) . . . . . . . . . 70

Pleijel (F.) .......... 8

Pletterbauer (F.) ...... . 81

Polissar (P. J.) . . . . . . . . 70

Pollnac (R. B.).... 242, 246

Ponomareva (V. V.) ..... 15

Porras (O.)............ 24

Portnyagin (M. V.) . . 15, 246

Power (W.)............ 77

Praeg (D.)............6 6

Prasad (K. V. K. K.) . . 116

Prettenhofer (P.) . . . . . . 152

Price (R. C.) . . . . . . . 30

Priede (I. G.) . . . . . 30 30, 215

Prince (R. A.) . . . . . . . . 29

Promper (C.) . . . . . . . . 249

Pronin (A. A.) .......... 28

Puga-Bernabeu (A.).......5 5

Punongbayan (R. S.). .44, 45

Pushharovskij (J. M.) . 57, 61

Pysklywec (R. N.) ...... 73

Python Development Team 148,247

Pérez (M. E.). . . . . . . . . 18

Pérez-Gussinyé (M.) . . . . . 7

\section{Q}

Qin (Q.).........57, 233

Qiu (X.) ............. 47

Queaño (K. L.) ......... 44

Qurban (M. A.) ....... 233 


\section{$\mathbf{R}$}

R Development Core Team $119,127,131,142$

Rabaoui (L.) ......... 233

Rabinowitz (H. S.) ...... 70

Rackebrandt (N.) ...... 253

Raitt (R. W.) . . . . . . . . 26

Ramos (N. T.) . . . . . . . . 44

Ranero (C. R.) . . . . . . . . 244

Rangin (C.) . . . . . . . 22-24

Rapinski (J.) . . . . . . . . . 249

Rapp (R. H.) . . . . . . . . 99

Rathburn (A. E.) ........ 18

Ratzov (G.) ........... 29

Razjigaeva (N. G.) . . . . . 17

Recy (J.).............. 30

Regalla (C.) ....... 67, 70

Regelous (M.) ... 30, 31, 205

Reichel (T.) ........27, 29

Reichert (C.) . . . . . . . . 27

Reid (W. D. K.) . . . . . . 12

Remitti (F.) . . . . . . . . . 70

Renkin (M. L.) . . . . . . . 15

Requena (J.) .......... 24

Resentini (A.) ........ 150

Resing (J. A.) . ..... 44, 57

Reutter (K.-J.).........28

Rew (R. K.) ...... 101, 108

Reyes (A. G.) . .... . 76, 249

Reyners (M.) ...... . 76, 77

Rhede (D.) . . . . . . . . . 68

Ribeiro (J. M.) . . . . . . . . 209

Richard (C.)............ 30

Richmond (L.) . . . . . . 253

Riedel (M. R.)... 58, 70, 205

Rijsingen (E.) van . .... 218

Ripper (I. D.). . . . . . . . 37

Ritchie (H.) ........30, 60

Robbins (A. D.) . . 110, 112

Roberts (J. J.) . . . . . . . 119

Roberts (N. M.) . . 105, 116, 150

Robin (C.) .........32, 33

Robinson (R.) . . . . . . . . 77

Robison (B. H.) . . . . . . 8

Robles (V.)............24

Rodriguez (E.) . . . . . . . 80

Roest (W. R.)....28, 39, 253
Romankevich (E. A.) . . 233

Romer (R. H. W.)...... . 205

Romero (J.) . . . . . . . . . . 24

Romsos (C.).......... 7

Rosen (P. A.) . . . . . . . 80

Rosenbaum (G.) ......... 35

Rosgen (D. L.) ........ 246

Ross (D. A.) ....... 25, 104

Rossum (G.) van . . 148, 247

Rost (D.) . . . . . . . . . 190

Roth (L.) ........... 80

Rothery (D. A.) . . . . . . 242

Rouland (D.) . . . . . . . 56

Roult (G.). . . . . . . . . .56

Rouse (G. W.) . . . . . . . . 8

Rovere (M.) . . . . . . . . . . 79

Rowden (A. A.) 8, 29-31, 61, $76,77,215,218$, 233, 246

Rowe (C. D.) . . . . . . . . 70

Rowe (C.) ........... . 70

Royden (L. H.)44, 49, 57, 58, 77

Ruangrassamee (A.) . . . 45

Rubie (D. C.) ...663, 74, 205

Rudenko (M. V.) . .......6 6

Ruff (L. J.) . .... . 16, 61, 74

Ruhl (H. A.) .. 61, 215, 218

Ruiz (J.) ............ 7

Ruiz-Villarreal (M.) . . . 148

Rupp (J.) ...... 14, 43, 218

Ruppert (N. A.) ........ 17

Ryan (H. F.).......... 18

Römer (M.) . . . . . . . . . 6

\section{S}

Sacchi (M. D.)......... .5

Saelem (N.) . . . . . . . . . . 45

Saffer (D. M.) . . . . 5, 67, 70

Saha (P.) ............ 70

Sahling (H.) . . . . . . . . 6

Saito (K.) ....... 60, 246

Saito (S.) ..........67, 70

Sakairi (N.).......61, 233

Salah (M. K.) .......... 43

Samowitz (I. R.) .... 34, 40

Sandilands (M.) ..... 9, 120

Sandwell (D. T.). 6-8, 78, 80, 83, 86, 98, 101,
102,209

Sangawa (A.) ...... . 43, 44

Sano (T.) ............. 64

Sano (Y.) ............. 57

Santos (A.) ........ 45, 81

Santos Ferreira (C.) dos . . 6

Sarmiento-Rojas (L. F.) . . 28

Sasaki (K.)...........52

Sasaki (T.) ...........6 67

Satake (K.)............ 15

Sato (H.) ......... 44, 66

Sato (T.) . . 43, 44, 52, 55, 65, 66, 69, 209

Sattarova (V. V.) . ....... 29

Savage (H. M.) . . . . . . . 70

Savostin (L. A.) ..... 14, 190

Savov (I. P.) .... 20, 66, 190

Scharroo (R.) 48, 80, 83, 244, 248

Schellart (W. P.) . . 12, 28, 63

Schenke (H. W.). 80, 85, 103, 249,253

Scherwath (M.)......... 29

Scheuber (E.) ......... 28

Schiano (P.)............ 33

Schiller (J.) .......... 81

Schlacher (R.) . . . . . . . . 8

Schloter (P.). . . . . . . . 253

Schlueter (P.) . . . . . . 253

Schluter (P.)..........253

Schmidt-Effing (R.)..... 24

Schmitt (A. K.) ......... 15

Schmitt (T.) . . . . . . . . . . 79

Schnurle (P.) .......... 51

Scholl (D. W.) . .... . 18, 34

Schubert (G.) ...... 22, 58

Schutz (B. E.) . ......... 30

Sclater (J. G.) . . . . . . . 15

Scorpio (V.) ..........81

Sdroliasa (M.) . . 28, 39, 253

Seabold (S.) . . . . . 175, 176

Seal (D.) . . . . . . . . . . 80

Seekings (L. C.) ...... . 4, 9

Seliverstov (N. I.) . . . 17, 18

Sella (G. F.) . . . . . . . . . 93

Sen (A.) ............. 233

Senda (R.) ............66 66

Senger (K.) .......... 77 
Senna (H.) ....... 56, 246

Seno (T.)9, 43, 44, 58, 63, 65

Serri (G.) .........56, 58

Seton (M.)........28, 56

Seward (D.) ....... 76, 77

Shaffer (S.) . . . . . . . . 80

Shank (T. M.) . . 61, 215, 218

Shen (C.) ............. . . 37

Shepard (F. P.) . . . . . 6, 246

Shephard (G.) ......... 56

Sherman (K.)........... 14

Shevchenko (A. Y.). . 23, 25

Shi (X.).......6, 61, 218

Shi (Y.) ......... 34, 45

Shigeno (K.) . . . . . . . 15

Shimada (J.) ......... 80

Shimamura (H.) . . . . . . 48

Shimanaga (M.) . 51, 60, 233

Shimizu (K.) ..........66 66

Shimokawa (K.) . ....... 15

Shinjo (R.)............ 50

Shinmura (T.) . ........ 66

Shinohara (M.) 35, 37, 65, 69

Shiobara (H.) ...... . 43, 65

Shipboard Scientific Party 24, 25,195

Shipley (N.)........... 15

Shiraiwa (T.) . . . . . . 16

Shirao (M.) ........... 64

Shishikura (M.) ....... 48

Shito (A.) ............ 43

Shor (G. G.) . . . . . . . . . 104

Shu (Y.) . ............. 50

Shukuno (H.) ..... . 63, 209

Shyu (J. B. H.) . . . . . . 83

Sibuet (J.-C.). . 42, 43, 47, 51

Silver (E. A.) ........... 35

Sims (K. W. W.) .......246

Singer (B. S.) . ....... 15

Singh (R.) ........... 30

Sirisansaneeyakul (S.) ... 61, 233

Skyllingstad (E. D.) . . . 119

Skøien (J. O.) .......... 9

Smirnov (Y. B.) . . . . . . 17

Smith (C. R.) . ........ 246

Smith (I. E. M.) . . . . . . 30

Smith (W. H. F.) . 6-8, 48, 78,
$80,83,86,98$,

101-104, 209, 244, 248, 249

Snaith (H.) ....... 79, 80

Snieder (R. K.) . . . . . . . 63

Snyder (G. L.) . . . . . . . . 18

Solan (M.) . . . . . . . . . 215

Solidum (R.) . . . . . . . . 44

Solomina (O.) . . . . . . . . 16

Soloviev (S. L.) . . . . . . 45

Song (A. T. R.) . . . . . . 83

Soofi (K.) ........ 80, 101

Sorbadere (F.) . . . . . . . . 33

Sosson (M.) . ........... 74

Spagnolo (M.). ......... 14

Spakman (W.) ...... 42, 50

Spencer (K.)...... 65, 209

Spina (L.).............33

Srivastava (S.). .......116

Stagpoole (V.) . . . . . . . 8 80

Stankov (U.).......242, 249

Stehlikova (J.) . . . . . . . . 29

Stein (S.) . 15, 39, 63, 74, 93, 205

Stephan (J.-F.)..........23

Stern (L. A.) . . . . . . . . 63

Stern (R. J.) . ..... 63, 209

Stern (T.) . ............ 77

Stetson-Lee (T.) . . . 105, 116, 150

Stewart (A. L.) .. 31, 32, 232

Stewart (H. A.) . ....... 233

Stewart (R. B.) ......... 30

Stolz (A.) . ............ 37

Storchack (D. A.) . . . . . . 80

Stouthamer (E.) ....... 81

Stowell (J.) ........... 30

Stransky (B.) .......... 14

Strasser (M.) . . . . . . . . 68

Straub (S. M.) . . . . . . . . 64

Strick (R. J. P.) . . . . . . 246

Strutz (T.) . .......... 175

Stuart (J. E.) . . . . . . . . . 37

Stutz (M.) ........... 110

Suarez (G.) . . . . . . . . 17

Suckro (S.) .......... 253

Sudo (M.) ....... 4, 20, 66

Suetova (I. A.) . . . . . . . 249
Sugioka (H.) .......... 43

Sugrobov (V. M.) . . . . . . 17

Sun (C.) ............. 56

Sun (Y.) .......... 4, 66

Sun (Z.) ...... 47, 57, 233

Suo (Y.) .............. 5

Sutherland (R.) . . 72, 74, 77

Suwarsono............. 103

Suyehiro (K.) ...... 35, 37

Suzuki (K.) . ......... 66

Suzuki (S.). ...........44

Svensson (M.). . . . . . . . 249

Swan (A. R. H.) ..... 9, 120

Symonds (P.) .......... 73

Syvitski (J. P. M.) . . . . . . . 9

Sá (J. P. M.) de ........ 105

\section{T}

Tackley (P.) ........... 34

Taddeucci (J.) . . . . . . . . 33

Tagami (T.) ........... 4

Tagawa (M.) ......... 253

Taira (A.) ............ 70

Taira (K.) ......... 8, 59

Takahashi (M.) . . 43, 65, 209

Takahashi (N.) 12, 64, 67, 69, 70

Takayanagi (H.) .. 43, 52, 65, 209

Tal (M.) ............ 81

Talandier (J.) . . . . . . . . . 33

Talsma (A.) ........... 56

Tam (T. A. I.) . ........ 44

Tamaki (K.) ..........663

Tamura (A.)..........66

Tamura (C.) ........... 55

Tamura (Y.)....... 63, 209

Tan (H.) .............. 37

Tang (X.) ........29, 56

Tani (K.) . . . . . . . . . . . 64

Tani (S.) .............. 79

Taniguchi (H.). .........665

Tappin (D. R.) . ..... 30, 31

Tapster (S.) ........... 35

Tardy (M.) . ........22-24

Tasaka (M.) ........ 8, 58

Taylor (B.) . 8, 30, 31, 35, 64, 65, 209

Taylor (F. W.) . . . . . 30, 33 
Taylor (R. N.) . . . . . 63, 209

Taylor (R.) .... . 60, 63, 218

Tejero (R.) ............. 7

Teng (T.-L.) . .......4, 9

Tharp (M.) . . . . . . . . . . 6

Theberge (A. E. J.) . 4, 12, 57

Theiling (C.) ......... 246

Theunissen (T.) . . 42, 50, 51

Thirion (B.) .......... 152

Thornburg (T. M.) . . . . . 27

Thovert (J.-F.) . . . . . 33, 81

Tian (J.)......... 57, 233

Tiao (G. C.) . . . . . 154, 171

Tibaldi (A.) ........... 246

Tiffin (D. L.) . . . . . . . . 37

Tikhonchuk (E. A.) .... . 17

Tikoff (B.) . . . 105, 116, 150

Timm (N. H.) . . . . . . . 154

Tobino (H. J.) . . . . . . 67, 70

Toki (T.) ............. 57

Tokmakian (R.).........43

Tokuyama (H.) . . . . . . . 65

Tomaszewski (D.) . . . . . 249

Tomiyama (N.) . ........ 55

Tonarini (S.) . . . . . . . 190

Tong (H.) ........... 6

Torii (Y.) ............ 205

Torres (M.)...........6 6

Torsvik (T.) . ......... 56

Tournon (J.) . . . . . . . 22-25

Townend (J.) . . . . . . . . 77

Toy (V. G.) ....... 28, 70

Tregoning (P.) ......... 37

Treml (E. A.).......... 119

Trevethan (M.) ........ 81

Trimmer (R.) . . . . . . . . 6

Trivedi (P. K.) . . . . . . 125

Tryon (M.) ........... 18

Tsai (C.-H.) . ..... 51, 101

Tsai (M.-T.) ....... 42, 44

Tsai (Y.-C.) . .......... 44

Tsuboi (T.) ............56

Tsuji (T.) . ....... 67, 70

Tsukanov (N. V.) .... 15, 18

Tsumura (N.) ...... 44, 66

Tsunogai (U.) . . . . . . . . 57

Tsuru (T.) .............. 69

Tsutsumi (H.) . . . . . 43, 44
Tsutsumi (Y.) . . . . . . . . 64

$\mathrm{Tu}(\mathrm{Y}.) \ldots \ldots \ldots \ldots \ldots 48$

Tukey (J. W.) . 125, 155, 162

Turcotte (D. L.). . . . . . . 22

Turko (N. N.) . . . . . . . . 6

Turnbull (J.) . ..... . 76, 77

Turner (M.) ........... 56

Turnewitsch (R.).......29

Turtle (E. P.) . . . . . . . . . 33

Tyler (P. A.) . . . . . . . . 81

\section{$\mathbf{U}$}

Udintsev (G. B.) . . 198, 253

Uenzelmann-Neben (G.) 253

Uijttewaal (W. S. J.) . . . 81

Ujiie (K.) . . . . . . . . . . 70

Ujiié (Y.) ............ 50

Umland (J.) . ......... 80

Underwood (M. B.) . 6 67, 70

Urabe (T.) ........... 48

Uruski (C.) . . . . . . . . . 72

Us (M.)............. 44

Usami (K.)............668

Ushakov (S. A.) . . . . . . 60

Ushakova (L. A.) . . . . . . 249

Uto (K.) . ............ 64

Uyeda (S.) . . . . 58, 66, 209

\section{V}

V. (L.) ..............253

Valenzuela (R. W.) . .....28

Vallier (T. L.)............ 30

Van Ark (E. M.) ..... 39, 74

Van Wess (J. D.) . . . . . . . 28

Vanderplas (J.) . . . . . . 152

Vanreusel (A.) ...... 26, 29

Varoquaux (G.) . . . . . . 152

Vermeesch (P.) . . . . . . . 150

Vervoort (J. D.) . . . . . . . 246

Vetrov (A. A.) ......... 233

Vicenzi (E. P.) . . . . . . . 190

Viglione (A.) . . . . . . . . . 9

Vigneresse (J. L.) . . . . . . 116

Villaseor (A.) . . . . . . . . 244

Vils (F.).......60, 63, 218

Vita-Finzi (C.) . ........28

Voelker (D.) ....... 5, 29

Vogt (P. R.)............ 7

Voight (J. R.). . . . . . 233
Von Rosenberg (J.).......6

$\mathrm{Vu}$ (P. H.) . . . . . . . . . . . 45

Völker (D.) ........ 27, 29

\section{W}

Wada (H.). . . . . . . . . . 56

Wadge (G.) . . . . . . . . . 249

Wakita (K.) . . . . . . . . . 67

Walker (S. L.) . . . . . .44, 57

Wallace (G.) ...........6 6

Wallace (L. M.) . . . . 75, 77

Wang (C.).............56

Wang (C.-C.) .......... 51

Wang (F.) ............ 4

Wang (H.) ........... 77

Wang (H.-F.) ..... 48, 101

Wang (J.)..........37, 47

Wang (L.)............233

Wang (M.)........57, 233

Wang (P.) ............. 5

Wang (S. M.) . . . . . . . . 45

Wang (T. K.) .... 42, 47, 50

Wang (X.) ..... 50, 57, 233

Wang (Y.) . ............. 5

Wang (Z.) ...... 4 41, 43, 47

Warner (J. C.) . . . . . . . . 119

Warren (B. A.) ......... 20

Watts (A. B.) .... . 7, 58, 78

Watts (D. G.) .......... 162

Watts (K. E.) ........... 15

Wdinrebe (W.) ....... 244

Weatherall (P.) . . . 6, 79, 80

Webb (L. E.) ........... . 35

Webb (T. J.) ...........233

Webster (J.) ........... 5

Wefer (G.) . . . . . . . . 68

Wehbring (R.) . ........ 114

Wei (Y.) ............. 233

Weibenga (W. A.)........36

Weinberger (P. J.) . . . . . 110

Weinrebe (W.)27, 29, 77, 202

Weinstock (C. L.)...... 232

Weiss (R.) ........... 152

Weissel (J. K.) . . . . 9 93, 219

Welber (M.) . . . . . . . . . .81

Well (A. D.) . .... . 105, 136

Wells (R. E.) .......... . 18

Wen (S.)......... .43, 53

Wendt (J. I.) . . . . . . 30 30, 31 
Wenzhöfer (F.) .. 29, 30, 233

Werner (M.) . . . . . . . . . . 80

Werner (R.) . . . . . . . . . 246

Wessel (P.) 48, 78, 80, 83, 86, 101, 103, 104, 244, 248, 249

Westfall (P.) .......... 126

Weston (J.) . . . . . . . . . . . 80

Wheat (C. G.) . . . . . . . 233

White (T.) ......... 116

Whiteway (T.) ..... 43, 58

Wickham (H.) . . . . 154, 155

Widiyantoro (S.) . 5, 8, 15, 17

Wiedicke (M.) ..... . 27, 29

Wiens (D. A.) .......... 56

Wigley (R.) ........... 79

Wiles (G.) . . . . . . . . 16

Willbold (M.) .. 60, 63, 218

Williams (A.) . . . . . . . 8

Williams (L. J.) . . . . . . . 165

Wilson (K.) ............ 77

Wintersteller (P.) . . . . . . . 6

Wirth (R.) . . . . . . . . . . 68

Wobbe (F.) . . 48, 80, 83, 244, 248

Woelki (D.) ........... 205

Wolf (F.) ......... 76, 77

Wolf (R.) ............ 24

Wolff (G. A.) . . . . . . . . . 81

Wolfson-Schwehr (M.) . . 70

Wood (R. A.) ........... . 74

Wood (W. T.) . . . . . . . . . 77

Woodhead (J. D.) . . 31, 209

Woodhouse (J. H.) . . . . . . 80

Worthington (T. J.) . . . . . 30

Wright (D. J.) ....... 31, 81

Wright (J.).......... 242

$\mathrm{Wu}$ (F. T.) ........ 44, 45

$\mathrm{Wu}(\mathrm{G}.) \ldots \ldots \ldots \ldots . . \ldots 37$

$\mathrm{Wu}(\mathrm{S}.) \ldots \ldots \ldots .41,43,44$

$\mathrm{Wu}(\mathrm{T} .-\mathrm{R}.) \ldots \ldots \ldots \ldots . . .45$

$\mathrm{Wu}(\mathrm{W} .-\mathrm{N}.) \ldots \ldots \ldots \ldots .48$

$\mathrm{Wu}(\mathrm{X}.) \ldots \ldots \ldots \ldots \ldots, 4$
Wue (H.-Y.)

Wörner (G.)

.246

\section{$\mathbf{X}$}

Xing (J.)...........4, 66

$\mathrm{Xu}(\mathrm{H}$.$) ......... 57, 233$

$\mathrm{Xu}(\mathrm{X}.) \ldots \ldots \ldots \ldots . . .50$

$\mathrm{Xu}(\mathrm{Y}.) \ldots \ldots 29,31,56,215$

Xuan (S.) .............. 37

\section{Y}

Yagi (Y.) . . . . . . . . . 68

Yale (M. M.) . . . . . . 80, 101

Yamada (Y.) ....... 67, 70

Yamaguchi (T.) . ........ 52

Yamaki (S.) ............ 15

Yamamoto (S.) ...... 44, 66

Yamamoto (Y.) ......667, 70

Yamasaki (M.) ........ 50

Yamashiro (T.) ........ 59

Yamazaki (T.) . . 43, 65, 209

Yamazaki (Y.)....... 18, 68

Yanagimoto (D.) . . 8, 29, 59

Yancey (P. H.)..61, 215, 218, 232, 233

Yang (A.) ........... 202

Yang (C.-C.) . . . . . . . . 44

Yang (G.) . ............ 37

Yang (H.) . .......... 246

Yang (J.) ......... 29, 56

Yang (P.-H.). . . . . . . . 116

Yang (Y.) .........29, 56

Yanovskiy (F. A.) . . . . . . 17

Yayanos (A. A.) . 31, 44, 211, 233

Yeh (Y.-C.) . . . . . . 45, 51

Yeh (Y.-L.) . . . . . . 43, 53

Yogodzinski (G. M.). .20, 66, 246

Yokoyama (Y.) ........ 48

Yoneshima (S.) . . . . . 35, 37

Yoshida (M.). .15, 18, 39, 42, $77,218,222$

Yoshii (T.)
Yoshikawa (S.) ........ . 34

Yoshioka (S.)......... 205

Yoshizawa (K.) ........ 43

Yu (G.-K.)....... .4, 42-44

Yu (H.) ..........29, 56

Yu (H.-S.) . ....... 47, 246

$\mathrm{Yu}(\mathrm{P}.) \ldots \ldots \ldots \ldots \ldots \ldots$

Yu (Q.-Y.) …...... 116

$\mathrm{Yu}$ (S.-B.) .........44, 83

Yuasa (M.) .... . 63, 64, 209

Yuen (D. A.) .... 4 45, 58, 70

Yulianto (F.) . . . . . . . 103

Yumul (G. P. J.) . ....... 44

\section{$\mathbf{Z}$}

Zack (T.) ........... 190

Zahirovic (S.) ......... 56

Zayakin (Y. A.) ........ 17

Zeileis (A.) .......... 127

Zeng (Z.) .............. 50

Zenkevich (N. L.) . .......6 6

Zhan (W.) ...... 60, 61, 63

Zhang (B.) ...........6 6

Zhang (C. L.) ...... . 57, 233

Zhang (D.)............116

Zhang (F.)......60, 61, 63

Zhang (G.) ....... 55, 198

Zhang (J.)............47

Zhang (L.) ............ 246

Zhang (X.-H.) ..... 57, 233

Zhang (Y.) ........... 5

Zhang (Y.-Z.) ......57, 233

Zhang (Z.) ....... 55, 198

Zhao (D. P.) ........... 7

Zhao (D.)..........44, 45

Zhao (M.)............47

Zheng (H.-W.).........34

Zhou (Z.)....34, 58, 59, 168

Zhu (G.) ............. 34

Ziebis (W.)...........18

Zimmermann (K.) ..... 253

Zonenshain (L.) ..... 14, 190

Zou (L.)..........57, 233

Zou (Y.) ...........6 6

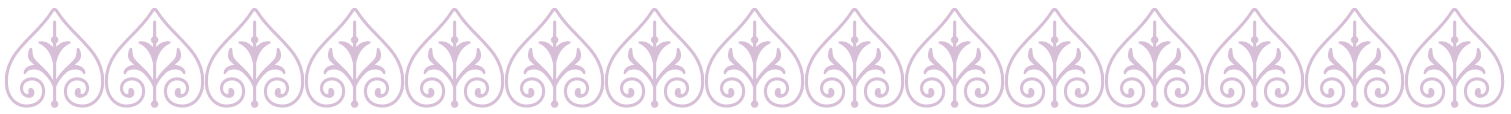

cxi

Polina Lemenkova:

Deep-Sea Trenches of the Pacific Ocean: ...Data Modeling by GMT, Python and R 


\section{Bibliography}

${ }^{1}$ L. D. Abbott, E. A. Silver, and J. Galewsky, "Structural evolution of a modern arc-continent collision in Papua New Guinea", Tectonics 13, 1007-1034 (1994).

${ }^{2}$ H. Abdi and L. J. Williams, "Principal component analysis", Wiley Interdisciplinary Reviews: Computational Statistics 2, 433-459 (2010).

${ }^{3}$ G. V. Agapova, L. Y. Budanova, N. L. Zenkevich, N. I. Larina, V. M. Litvin, N. A. Marova, M. V. Rudenko, and N. N. Turko, "Geofizika okeana. Geofizika okeanskogo dna”, in, edited by Neprochnov (Nauka, Moscow, USSR, 1979) Chap. Geomorphology of the Ocean Floor, pp. 150-205.

${ }^{4}$ B. N. P. Agarwal and S. Srivastava, "FORTRAN codes to implement enhanced local wave number technique to determine the depth and location and shape of the causative source using magnetic anomaly. ", Computers \& Geosciences 34, 1843-1849 (2008).

${ }^{5}$ A. V. Aho, B. W. Kernigan, and P. J. Weinberger, The AWK Programming Language (New York, NY: AddisonWesley, 1988), ISBN: 0-201-07981-X.

${ }^{6}$ A. V. Aho, B. W. Kernigan, and P. J. Weinberger, “AWK-A Pattern Scanning and Processing Language”, Software Practice and Experience 9, 267-279 (1979).

${ }^{7}$ A. Alden, Here are the Sizes of Tectonic or Lithospheric Plates, Retrieved from https://www.thoughtco.com/sizesof-tectonic-or-lithospheric-plates-4090143, 2019, November 4, 2019.

${ }^{8}$ D. V. Alexeiev, C. Gaedicke, N. V. Tsukanov, and R. Freitag, "Collision of the Kronotskiy arc at the NE Eurasia margin and structural evolution of the Kamchatka-Aleutian junction", International Journal of Earth Sciences (Geologische Rundschau) 95, 977-993 (2006).

${ }^{9}$ J. A. Alvarez-Gómez, O. Q. Gutiérrez Gutiérrez, Í. Aniel-Quiroga, and M. González, "Tsunamigenic potential of outer-rise normal faults at the Middle America trench in Central America", Tectonophysics 574-575, 133143 (2012).

${ }^{10}$ J. A. Alvarez-Gómez, P. T. Meijer, J. J. Martínez-Díaz, and R. Capote, “Constraints from finite element modeling on the active tectonics of northern Central America and the Middle America Trench", Tectonics 27, 1-12 (2008).

${ }^{11}$ C. Amante and B. W. Eakins, ETOPO1 1 Arc-Minute Global Relief Model: Procedures, Data Sources and Analysis (NOAA Technical Memorandum, 2009), p. 19.

${ }^{12}$ M. E. Anderson, "Studies on the Zoarcidae (Teleostei: perciformes) of the Southern Hemisphere. XI. A new species of Pyrolycus from the Kermadec Ridge", Journal of the Royal Society of New Zealand 36, 63-68 (2006).

${ }^{13}$ M. Ando, A. Kitamura, Y. Tu, Y. Ohashi, T. Imai, M. Nakamura, R. Ikuta, Y. Miyairi, Y. Yokoyama, and M. Shishikura, "Source of high tsunamis along the southernmost Ryukyu trench inferred from tsunami stratigraphy”, Tectonophysics 722, 265-276 (2018).

${ }^{14}$ M. V. Angel, “Ocean trench conservation”, Environmentalist 2, 1-17 (1982).

${ }^{15}$ C. F. Ansley and R. J. Kohn, "Estimation, filtering, and smoothing in state space models with incompletely specified initial conditions", Annals of Statistics 13, 1286-1316 (1985).

${ }^{16}$ K. Arai, H. Matsuda, K. Sasaki, H. Machiyama, T. Yamaguchi, T. Inoue, T. Sato, H. Takayanagi, and Y. Iryu, "A newly discovered submerged reef on the Miyako-Sone platform, Ryukyu Island Arc, Northwestern Pacific", Marine Geology 373, 49-54 (2016). 
${ }^{17}$ K. Arai, T. Inoue, K. Ikehara, and T. Sasaki, "Episodic subsidence and active deformation of the forearc slope along the Japan Trench near the epicenter of the 2011 Tohoku Earthquake", Earth and Planetary Science Letters 408, 9-15 (2014).

${ }^{18}$ D. Arisa and K. Heki, “Transient crustal movement in the northern Izu-Bonin arc starting in 2004: A large slow slip event or a slow back-arc rifting event?”, Tectonophysics 682, 206-213 (2016).

${ }^{19}$ F. Arróspide, L. Mao, and C. Escauriaza, "Morphological evolution of the Maipo River in central Chile: Influence of instream gravel mining”, Geomorphology 306, 182-197 (2018).

${ }^{20}$ J. Aubouin, J. Azéma, J. C. Carfantan, A. Demant, C. Rangin, M. Tardy, and J. Tournon, “The Middle America Trench in the Geological Framework of Central America", Deep Sea Drilling Project Reports and Publications 67, 747-755 (1982).

${ }^{21}$ J. M. Auzende, B. Pelletier, and J.-P. Eissen, "Back-arc Basin: Tectonics and Magmatism", in, edited by B. Taylor (New York, New York, 1995) Chap. The North Fiji Basin: geology, structure and geodynamic evolution, pp. 139-175.

${ }^{22}$ J. Azéma and J. Tournon, "The Guatemalan Margin, the Nicoya Complex, and the Origin of the Caribbean Plate”, Deep Sea Drilling Project Reports and Publications 40, 739-745 (1982).

${ }^{23}$ Y. Bai, Y. Yamazaki, and K. F. Cheung, “Amplification of drawdown and runup over Hawaii's insular shelves by tsunami N-waves from mega Aleutian earthquakes", Ocean Modelling 124, 61-74 (2018).

${ }^{24}$ R. A. Bailey, Design of Comparative Experiments (Cambridge University Press, 2008), ISBN: 978-0-521-683579.

${ }^{25}$ S. L. Baldwin, P. G. Fitzgerald, and L. E. Webb, "Tectonics of the New Guinea Region”, Annual Review of Earth and Planetary Sciences 40, 495-520 (2012).

${ }^{26}$ P. F. Ballance, "Evolution of the upper Cenozoic magmatic arc and plate boundary in northern New Zealand", Earth and Planetary Science Letters 28, 356-370 (1976).

${ }^{27}$ P. Banasik and K. Bujakowski, “The Use of Quasigeoid in Leveling Through Terrain Obstacles”, Reports on Geodesy and Geoinformatics 104, 57-64 (2017).

${ }^{28}$ M. Barazangi, B. L. Isacks, and J. Oliver, "Propagation of seismic waves through and beneath the lithosphere that descends under the Tonga island arc", Journal of Geophysical Research 77, 952-958 (1972).

${ }^{29}$ D. H. N. Barker, R. Sutherland, S. Henrys, and S. Bannister, "Geometry of the Hikurangi subduction thrust and upper plate, North Island, New Zealand”, Geochemistry Geophysics Geosystems 10, 1-23 (2009).

${ }^{30}$ J. D. Barnes and S. M. Straub, "Chorine stable isotope variations in Izu Bonin tephra: Implications for serpentinite subduction", Chemical Geology 272, 62-74 (2010).

${ }^{31}$ P. M. Barnes, G. Lamarche, J. Bialas, S. Henrys, I. A. Pecher, G. L. Netzeband, J. Greinert, J. J. Mountjoy, K. Pedley, and G. J. Crutchley, "Tectonic and geological framework for gas hydrates and cold seeps on the Hikurangi subduction margin, New Zealand”, Marine Geology 272, $26-48$ (2010).

${ }^{32}$ P. M. Barnes and B. Mercier de Lepinay, "Rates and mechanics of rapid frontal accretion along the very obliquely convergent southern Hikurangi margin, New Zealand", Journal of Geophysical Research 102, 2493124952 (1997).

${ }^{33}$ I. D. Barr and M. Spagnolo, "Understanding controls on cirque floor altitudes: Insights from Kamchatka", Geomorphology 248, 1-13 (2015).

${ }^{34}$ D. M. Bates and D. G. Watts, Nonlinear Regression Analysis and Its Applications, 2nd ed. (John Wiley \& Sons, Inc. A Wiley-Interscience Publication, New York, 1988), 102 pp., ISBN: 0470139005.

${ }^{35}$ C. B. Bautista, M. L. P. Bautista, K. Oike, F. T. Wu, and R. S. Punongbayan, “A new insight on the geometry of subducting slabs in northern Luzon, Philippines", Tectonophysics 339, 279-310 (2001).

${ }^{36}$ A. Beaumais, H. Bertrand, G. Chazot, L. Dosso, and C. Robin, "Temporal magma source changes at Gaua volcano, Vanuatu island arc", Journal of Volcanology and Geothermal Research 322, 30-47 (2016).

${ }^{37}$ J. Beavan and J. Haines, "Contemporary horizontal velocity and strain rate fields of the PacificAustralian plate boundary zone through New Zealand”, Journal of Geophysical Research: Solid Earth 106, 741-770 (2001). 
${ }^{38}$ D. M. Beazley, Python essential reference (Addison-Wesley Professional, 2009).

${ }^{39}$ L. Beccaluva, G. Serri, and J. Dostal, "Geochemistry of Volcanic Rocks From the Mariana, Yap and Palau Trenches Bearing on the Tectono-Magmatic Evolution of the Mariana Trench-Arc-Backarc System”, Developments in Geotectonics 21, 481-508 (1986).

${ }^{40}$ T. Bechter, K. Baumann, S. Birk, F. Bolik, W. Graf, and F. Pletterbauer, "LaRiMo - A simple and efficient GIS-based approach for large-scale morphological assessment of large European rivers", Science of the Total Environment 628-629, 1191-1199 (2018).

${ }^{41}$ S. L. Beck and L. J. Ruff, "Rupture process of the great 1963 Kurile Islands earthquake sequence: asperity interaction and multiple event rupture”, Journal of Geophysical Research 92, 123-138 (1987).

${ }^{42}$ J. J. Becker, D. T. Sandwell, W. H. F. Smith, J. Braud, B. Binder, J. Depner, D. Fabre, J. Factor, S. Ingalls, S. H. Kim, R. Ladner, K. M. Marks, S. Nelson, A. Pharaoh, R. Trimmer, J. Von Rosenberg, G. Wallace, and P. Weatherall, "Global bathymetry and elevation data at 30 arc seconds resolution: SRTM30_PLUS", Marine Geodesy 32, 355-371 (2009).

${ }^{43}$ J. S. Behrmann, S. D. Leslie, and S. C. Cande, "Tectonics and geology of spreading ridge subduction at the Chile Triple Junction: A synthesis of results from Leg 141 of the Ocean Drilling Program”, Geologische Rundschau 83, 832-852 (1994).

${ }^{44}$ C. Beier, P. A. Brandl, S. M. Lima, and K. M. Haase, "Tectonic control on the genesis of magmas in the New Hebrides arc (Vanuatu)", Lithos 312-313, 290-307 (2018).

${ }^{45}$ I. M. Belkin, P. C. Cornillon, and K. Sherman, "Fronts in large marine ecosystems", Progress in Oceanography 81, 223-236 (2009).

${ }^{46}$ J. P. Bello-González, E. Contreras-Reyes, and C. Arriagada, "Predicted path for hotspot tracks off South America since Paleocene times: Tectonic implications of ridge-trench collision along the Andean margin", Gondwana Research 64, 216-234 (2018).

${ }^{47}$ G. M. Belyaev, Deep-Sea Ocean Trenches and Their Fauna (Nauka Publishing House, 1989).

${ }^{48}$ J.-F. Berger, "Hydrological and post-depositional impacts on the distribution of Holocene archaeological sites: The case of the Holocene middle Rhône River basin, France", Geomorphology 129, 167-182 (2011).

${ }^{49}$ K. R. Berryman, "Distribution, age, and deformation of Late Pleistocene marine terraces at Mahia peninsula, Hikurangi subduction margin, New Zealand”, Tectonics 12, 1365-1379 (1993).

${ }^{50}$ K. R. Berryman, Y. Ota, T. Miyauchi, A. Hull, K. Clark, K. Ishibashi, N. Iso, and N. Litchfield, "Holocene paleoseismic history of upper-plate faults in the Southern Hikurangi subduction margin, New Zealand, deduced from marine terrace records", Bulletin of the Seismological Society of America 101, 2064-2087 (2011).

${ }^{51}$ W. Bertoldi, M. Welber, A. M. Gurnell, L. Mao, F. Comiti, and M. Tal, "Physical modelling of the combined effect of vegetation and wood on river morphology", Geomorphology 246, 178-187 (2015).

${ }^{52}$ G. M. Besana, H. Negishi, and M. Ando, "The three-dimensional attenuation structures beneath the Philippine archipelago based on seismic intensity data inversion", Earth and Planetary Science Letters 15, 1-11 (1997).

${ }^{53}$ M. J. Best and N. Chakravarti, “Active set algorithms for isotonic regression; a unifying framework”, Mathematical Programming 47, 425-439 (1990).

${ }^{54}$ M. Bevis, F. W. Taylor, B. E. Schutz, J. Recy, B. L. Isacks, S. Helu, R. Singh, E. Kendrick, J. Stowell, B. Taylor, and S. Calmant, "Geodetic observations of very rapid convergence and back-arc extension at the Tonga arc", Nature 347, 249-251 (1995).

${ }^{55}$ R. Bilina and S. Lawford, Python for Unified Research in Econometrics and Statistics (2009).

${ }^{56}$ C. R. Bina, S. Stein, F. C. Marton, and E. M. Van Ark, "Implications of slab mineralogy for subduction dynamics", Physics of the Earth and Planetary Interiors 127, 51-66 (2001).

${ }^{57}$ I. N. Bindeman, V. L. Leonov, P. E. Izbekov, V. V. Ponomareva, K. E. Watts, N. Shipley, A. B. Perepelov, L. I. Bazanova, B. R. Jicha, B. S. Singer, A. K. Schmitt, M. V. Portnyagin, and C. H. Chen, "Large-volume silicic volcanism in Kamchatka: ArAr and UPb ages, isotopic, and geochemical characteristics of major pre-Holocene caldera-forming eruptions”, Journal of Volcanology and Geothermal Research 189, 57-80 (2010). 
${ }^{58}$ P. Bird, “An updated digital model of plate boundaries”, Geochemistry Geophysics Geosystems 4, 1027-1027 (2003).

${ }^{59}$ A. Björck, Numerical methods for least squares problems (SIAM, Philadelphia, US, 1996), ISBN: 0-89871-3609.

${ }^{60}$ L. E. Blankenship, A. A. Yayanos, D. B. Cadien, and L. A. Levin, "Vertical zonation patterns of scavenging amphipods from the Hadal zone of the Tonga and Kermadec Trenches", Deep-Sea Research I 53, 48-61 (2006).

${ }^{61}$ J. H. Bodine and A. B. Watts, "On the lithospheric flexure seaward of the Bonin and Mariana trenches", Earth and Planetary Science Letters 43, 132-148 (1979).

${ }^{62}$ I. Bogdanov, D. Huaman, J.-F. Thovert, G. Pierre, and P. M. Adler, "Tectonic stresses seaward of an aseismic ridge - Trench collision zone. A remote sensing approach on the Loyalty Islands, SW Pacific", Tectonophysics 499, 77-91 (2011).

${ }^{63}$ J. L. Bogdanov, Gidrotermal'nye rudoprojavlenija riftov Sredinno-Atlanticheskogo hrebta (Hydrothermal deposits of rift in the Mid-Atlantic ridge), Russian, edited by Bogdanov (Nauchnyi mir, Moscow, 1997), 167 pp.

${ }^{64}$ K. V. Bogolepov and B. M. Chikov, Geologiya dna okeanov (Geology of the ocean floor), Russian, edited by V. N. Saks and E. E. Fotiadi (Nauka, Moscow, 1976), 246 pp.

${ }^{65}$ G. J. Borradaile, Statistics of Earth Science Data (Springer, 2003), 79 pp.

${ }^{66}$ S. Bose, P. Saha, J. J. Mori, C. Rowe, K. Ujiie, F. M. Chester, M. Conin, C. Regalla, J. Kameda, V. G. Toy, J. D. Kirkpatrick, F. Remitti, J. C. Moore, M. Wolfson-Schwehr, Y. Nakamura, and A. Gupta, "Deformation structures in the frontal prism near the Japan Trench: Insights from sandbox models", Journal of Geodynamics 89, 29-38 (2015).

${ }^{67}$ B. Boston, G. F. Moore, Y. Nakamura, and S. Kodaira, "Forearc slope deformation above the Japan Trench megathrust: Implications for subduction erosion”, Earth and Planetary Science Letters 462, 26-34 (2017).

${ }^{68}$ F. G. Bourrouilh-Le Jan and J. Talandier, "Sédimentation et fracturation de haute énergie en milieu récifal: tsunamis, ouragans et cyclones et leur effets sur la sédimentologie et la géomorphologie d'un atoll: motu et hoa, à Rangiroa, Tuamotu, Pacifique SE”, Marine Geology 67, 263-333 (1985).

${ }^{69}$ D. Boutelier, O. Oncken, and A. R. Cruden, "Trench-parallel shortening in the forearc caused by subduction along a seaward-concave plate boundary: Insights from analogue modelling experiments", Tectonophysics 611, 192-203 (2014).

${ }^{70}$ G. E. P. Box and G. C. Tiao, Bayesian Inference in Statistical Analysis, Section 8.1.1 (New York: John Wiley and Sons, 1992), ISBN: 0-471-57428-7.

${ }^{71}$ A. Brandt, I. Alalykina, H. Fukumori, O. Golovand, K. Kniesz, A. Lavrenteva, A.-N. Lörz, M. Malyutina, K. Philipps-Bussau, and B. Stransky, "First insights into macrofaunal composition from the SokhoBio expedition T (Sea of Okhotsk, Bussol Strait and northern slope of the Kuril-Kamchatka Trench)", Deep-Sea Research Part II 154, 106-120 (2018).

${ }^{72}$ C. Braz, M. Seton, N. Flament, and R. D. Müller, "Geodynamic reconstruction of an accreted Cretaceous backarc basin in the T Northern Andes”, Journal of Geodynamics 121, 115-132 (2018).

${ }^{73}$ F. Bretz, T. Hothorn, and P. Westfall, Multiple Comparisons Using R (CRC Press, Taylor and Francis Group, LLC, Boca Raton, FL, U.S., 2011), 193 pp., ISBN: 978-1-58488-574-0.

${ }^{74}$ S. Brune, "Plate Boundaries and Natural Hazards. AGU Geophysical Monograph 219", in, edited by J. C. Duarte and W. P. Schellart (AGU, Sydney, Australia, 2016) Chap. Rifts and rifted margins: A review of geodynamic processes and natural hazards, pp. 1-21.

${ }^{75} \mathrm{P}$. C. Burnley and H. W. Green II, "Faulting associated with the olivine to spinel transformation in $\mathrm{Mg} 2 \mathrm{GeO} 4$ and its implications for deep-focus earthquakes", Journal of Geophysical Research 96, 425-443 (1991).

${ }^{76}$ M. Bursa, "Primary and Derived Parameters of Common Relevance of Astronomy, Geodesy, and Geodynamics", Earth, Moon, and Planets 69, 51-63 (1995).

${ }^{77} \mathrm{G}$. O. Butuzova, Hydrothermal-sedimentary ore formation in the world the ocean, Russian (GEOS, Moscow, 2003), 136 pp. 
${ }^{78}$ B. R. Calder and L. A. Mayer, "Automatic processing of high-rate, high-density multibeam echosounder data”, Geochemistry Geophysics Geosystems 4, 1-24 (2003).

${ }^{79}$ S. Calmant, B. Pelletier, P. Lebellegard, M. Bevis, F. W. Taylor, and D. A. Phillips, "New insights on the tectonics along the New Hebrides subduction zone based on GPS results", Journal of Geophysical Research 108, 22 (2003).

${ }^{80}$ A. C. Cameron and P. K. Trivedi, Regression Analysis of Count Data (Cambridge University Press, Cambridge, UK, 2013).

${ }^{81}$ S. C. Cande and R. B. Leslie, "Late Cenozoic tectonics of the southern Chile Trench", Journal of Geophysical Research 91, 471-496 (1986).

${ }^{82}$ L. Cao, Z. Wang, S. Wu, and X. Gao, “A new model of slab tear of the subducting Philippine Sea Plate associated with Kyushu-Palau Ridge subduction”, Tectonophysics 636, 158-169 (2014).

${ }^{83}$ J. N. Carney and A. MacFarlane, "Geological evidence bearing on the Miocene to Recent structural evolution of the New Hebrides arc”, Tectonophysics 87, 147-175 (1982).

${ }^{84}$ M. J. Carron, P. R. Vogt, and W.-Y. Jung, GOMaP (Global Ocean Mapping Program): A Proposed International Long-Term Project to Systematically Map the Worlds Ocean Floors From Beach to Trench (2013).

${ }^{85}$ O. Cartapanis, S. L. Jaccard, and E. Galbraith, "Carbon burial in deep-sea sediment and implications for oceanic inventories of carbon and alkalinity over the last glacial cycle", Climate of the Past Discussions, 10.5194/cp2018-49 (2018).

${ }^{86}$ P. R. Castillo, P. F. Lonsdale, C. L. Moran, and J. W. Hawkins, "Geochemistry of mid-Cretaceous Pacific crust being subducted along the TongaKermadec Trench: Implications for the generation of arc lavas", Lithos 112, 87-102 (2009).

${ }^{87}$ A. Cazenave and L. J. Ruff, Seasat geoid anomalies and the macquarie ridge complex. food and agriculture organization of the united nations, 1985.

${ }^{88}$ A. Cecioni and V. Pineda, "Geology and Geomorphology of Natural Hazards and Human-Induced Disasters in Chile”, Developments in Earth Surface Processes 13, 379-413 (2010).

${ }^{89}$ W. W. J. Chadwick, S. G. Merle, E. T. Baker, S. L. Walker, J. A. Resing, D. A. Butterfield, M. O. Anderson, T. Baumberger, and A. M. Bobbitt, “A Recent Volcanic Eruption Discovered on the Central Mariana Back-Arc Spreading Center”, Frontiers in Earth Science 6, 1-16 (2018).

${ }^{90}$ W. Y. Chang, G.-K. Yu, R.-D. Hwang, and J.-K. Chiu, "Lateral Variations of Rayleigh-wave Dispersions in the Philippine Sea region”, Terrestrial, Atmospheric and Oceanic Sciences 18, 859-878 (2007).

${ }^{91}$ P. Charvis and B. Pelletier, "The northern New Hebrides back-arc troughs: history and relation with the North Fiji basin”, Tectonophysics 170, 259-277 (1989).

${ }^{92}$ C. G. Chase, "Extension behind island arcs and motions relative to hot spots", Journal of Geophysical Research 83, 5385-5388 (1978).

${ }^{93}$ Z. Cheng, W. Ding, M. Faccenda, J. Li, X. Lin, L. Ma, P. Fang, and H. Ding, "Geodynamic effects of subducted seamount at the Manila Trench: Insights from numerical modeling”, Tectonophysics 764, 46-61 (2019).

${ }^{94}$ G.-T. Chiang, T. White, M. T. Dove, C. I. Bovolo, and J. Ewen, "Geo-visualization Fortran library", Computers \& Geosciences 37, 65-74 (2011).

${ }^{95}$ J.-P. Chilés and P. Delfiner, Geostatistics. Modelling Spatial Uncertainty (Wiley, New York, U.S., 1999), 805 pp.

${ }^{96}$ S.-J. Chin, J.-Y. Lin, Y.-C. Yeh, K.-C. Hao, and C.-W. Liang, "Seismotectonic characteristics of the Taiwan collision-Manila subduction T transition: The effect of pre- existing structures", Journal of Asian Earth Sciences 173, 113-120 (2019).

${ }^{97}$ U. R. Christensen, "The influence of trench migration on slab penetration into the lower mantle", Earth and Planetary Science Letters 140, 27-39 (1996).

${ }^{98}$ A. D. Ciaccio, M. Coli, and J. M. Angulo Ibanez, "Studies in theoretical and applied statistics selected papers of the statistical societies", in (Springer, 2012) Chap. Advanced Statistical Methods for the Analysis of Large Data Sets, p. 464, ISBN: 978-3-642-21036-5. 
${ }^{99}$ D. Cielen, A. D. B. Meysman, and M. Ali, Introducing Data Science. Big Data, Machine Learning and More, Using Python Tools (Manning, Shelter Island, U.S., 2016), 322 pp.

${ }^{100}$ I. L. Cifuentes, “The 1960 Chilean earthquakes”, Journal of Geophysical Research 94, 665-680 (1989).

${ }^{101}$ H. Cízková and C. R. Bina, "Geodynamics of trench advance: Insights from a Philippine-Sea-style geometry”, Earth and Planetary Science Letters 430, 408-415 (2015).

${ }^{102}$ K. Clark, J. Howarth, N. Litchfield, U. Cochran, J. Turnbull, L. Dowling, A. Howell, K. R. Berryman, and F. Wolf, "Geological evidence for past large earthquakes and tsunamis along the Hikurangi subduction margin, New Zealand", Marine Geology 412, 139-172 (2019).

${ }^{103}$ M. R. Clark, A. A. Rowden, R. Schlacher, A. Williams, and M. Consalvey, "The ecology of seamounts: structure, function, and human impacts”, Annual Review of Marine Science 2, 253-278 (2010).

${ }^{104}$ E. Contreras-Reyes, E. R. Flueh, and I. Grevemeyer, "Tectonic control on sediment accretion and subduction off south-central Chile: implications for coseismic rupture processes of the 1960 and 2010 megathrust earthquakes", Tectonics 29, 1-27 (2010).

${ }^{105}$ E. Contreras-Reyes, I. Grevemeyer, E. R. Flueh, and C. Reichert, "Upper lithospheric structure of the subduction zone offshore southern Arauco Peninsula, Chile at 38' ', Journal of Geophysical Research 113, 1-10 (2008).

${ }^{106}$ E. Contreras-Reyes, I. Grevemeyer, E. R. Flueh, M. Scherwath, and M. Heesemann, "Alteration of the subducting oceanic lithosphere at the southern central Chile trench-outer rise", Geochemistry Geophysics Geosystems 8, 1-10 (2007).

${ }^{107}$ E. Contreras-Reyes and A. Osses, "Lithospheric flexure modeling seaward of the Chile trench: implications for oceanic plate weakening in the Trench Outer Rise region", Geophysical Journal International 182, 97-112 (2010).

${ }^{108}$ E. Contreras-Reyes and D. Carrizo, "Control of high oceanic features and subduction channel on earthquake ruptures along the Chile-Peru subduction zone”, Physics of the Earth and Planetary Interiors 186, 49-58 (2011).

${ }^{109}$ E. Contreras-Reyes, J. Jara, A. Maksymowicz, and W. Weinrebe, "Sediment loading at the southern Chilean Trench and its tectonic implications”, Journal of Geodynamics 66, 134-145 (2013).

${ }^{110}$ A. K. Cooper, G. R. Cochrane, and T. R. Bruns, "Velocity structure of the upper crust beneath the Solomon IslandsBougainville Island arc. Circum-Pacific council for energy and mineral resources”, Earth Science Series 7, 23-46 (1989).

${ }^{111}$ M. J. Costello and E. van den Berghe, "Ocean biodiversity informatics: a new era in marine biology research and management”, Marine Ecology Progress Series 316, 203-214 (2006).

${ }^{112}$ W. T. Coulbourn, "Stratigraphy and Structures of the Middle America Trench", Deep Sea Drilling Project Reports and Publications 67, 691-706 (1982), URL: https: / / doi.org/.

${ }^{113}$ J. A. Covault, "Submarine fans and canyonchannel systems: a review of processes, products, and models", Nature Education Knowledge 3, 1-4 (2011).

${ }^{114}$ D. S. Cowan, "Origin of "Vein Structure" in Slope Sediments on the Inner Slope of the Middle America Trench off Guatemala", Deep Sea Drilling Project Reports and Publications 32, 645-650 (1982).

${ }^{115}$ F. Crameri, "Geodynamic diagnostics, scientific visualisation and StagLab 3.0”, Geoscientific Model Development 11, 2541-2562 (2018).

${ }^{116}$ N. A. C. Cressie, Statistics for Spatial Data (Wiley-Interscience, New York, U. S., 1991), 928 pp.

${ }^{117}$ W. Cui, Y. Hu, W. Guo, B. Pan, and F. Wang, "Reprint of A preliminary design of a movable laboratory for hadal trenches", Methods in Oceanography 10, 178-193 (2014).

${ }^{118}$ W. Cui and X. Wu, "A Chinese strategy to construct a comprehensive investigation system for hadal trenches", Deep-Sea Research Part II 155, 27-33 (2018).

${ }^{119}$ A. C. Curtis and C. L. Moyer, "Mariana forearc serpentinte mud volcanoes harbor novel communities of extremophilic ArchaeaJ", Geomicrobiology Journal 30, 430-441 (2005).

${ }^{120}$ T. Dahlin, M. Svensson, and P. Lindh, "DC Resistivity and SASW for Validation of Efficiency in Soil Stabilisation Prior to Road Construction”, Procs. EEGS99, Budapest, Hungary, 6-9 September 1999, Ls5, 1-3 (1999). 
${ }^{121}$ R. A. Daly, "Origin of submarine 'canyons"”, American Journal of Science 31, 401-420 (1936).

${ }^{122}$ R. Danovaro, C. Gambi, and N. Della Croce, "Meiofauna hotspot in the Atacama Trench, eastern South Pacific Ocean”, Deep-Sea Research Part I 49, 843-857 (2002).

${ }^{123}$ H. A. David and H. N. Nagaraja, Order Statistics (Wiley Series in Probability and Statistics, New York, U. S., 2003).

${ }^{124}$ H. L. Davies, J. B. Keene, K. Hashimoto, M. Joshima, J. E. Stuart, and D. L. Tiffin, "Bathymetry and canyons of the western Solomon Sea", Geo-Marine Letters 6, 181-191 (1987).

${ }^{125}$ J. C. Davis, Statistics and Data Analysis in Geology (Wiley, 2002).

${ }^{126}$ F. C. De Leo, C. R. Smith, A. A. Rowden, D. A. Bowden, and M. R. Clark, "Submarine canyons: hotspots of benthic biomass and productivity in the deep sea", Proceedings of the Royal Society B: Biological Sciences 277, 2783-2792 (2010).

${ }^{127}$ S. M. DeBari, B. Taylor, K. Spencer, and K. Fujioka, “A trapped Philippine Sea plate origin for MORB from the inner slope of the Izu-Bonin trench", Earth and Planetary Science Letters 174, 183-197 (1999).

${ }^{128}$ C. DeMets, R. G. Gordon, and D. F. Argus, "Geologically current plate motions”, Geophysical Journal International 181, 1-80 (2010).

${ }^{129}$ C. DeMets, R. G. Gordon, D. F. Argus, and S. Stein, “Current plate motions”, Geophysical Journal International 101, 425-478 (1990).

${ }^{130}$ A. Deschamps and S. Lallemand, "Intra-Oceanic Subduction Systems: Tectonic and Magmatic Processes", in , Vol. 219, edited by R. D. Larter and P. T. Leat (2003) Chap. Geodynamic setting of Izu-Bonin-Mariana boninites, pp. 163-185, URL: https://sp. lyellcollection.org/content/219/1/1.

${ }^{131}$ R. Dic, “Novaja global'naja tektonika (New global tectonics)”, Russian, in (Mir, Moscow, 1974) Chap. Jevoljucija kontinentov i okeanicheskih basseinov kak rezul'tat spredinga okeanicheskogo dna (the Evolution of continents and ocean basins as a result of the spreading ocean floor), pp. 26-32.

${ }^{132}$ H. M. Dierssen and A. E. J. Theberge, "Encyclopedia of Natural Resources", in (Taylor \& Francis, 2014) Chap. Bathymetry: Features and Hypsography, pp. 1-7.

${ }^{133}$ H. M. Dierssen and A. E. J. Theberge, "Encyclopedia of Natural Resources", in (Taylor \& Francis, 2014) Chap. Bathymetry: History of Seafloor Mapping, pp. 1-5.

${ }^{134}$ D. Divins, Total sediment thickness of the worlds oceans and marginal seas (NOAA National Geophysical Data Center, Boulder, CO, 2003).

${ }^{135}$ Y. I. Dmitriev, "Basalts of the Middle America Trench (Guatemala Transect) and Their Correlation With Oceanic and Island-Arc Tholeiites”, Deep Sea Drilling Project Reports and Publications 67, 577-584 (1982).

${ }^{136}$ C. Doglioni, "Comment on 'The potential influence of subduction zone polarity on overriding plate deformation, trench migration and slab dip angle' by W. P. Schellart”, Tectonophysics 463, 208-213 (2009).

${ }^{137}$ R. M. H. Dokht, Y. J. Gu, and M. D. Sacchi, "Waveform inversion of SS precursors: An investigation of the northwestern Pacific subduction zones and intraplate volcanoes in China", Gondwana Research 40, 77-90 (2016).

${ }^{138}$ Y. S. Dolotov, Processes of Relief Formation and Sedimentation on the Tidal Coasts of the World Ocean, Russian, edited by G. A. Safyanov (Scientific World, Moscow, 2010), 180 pp., ISBN: 978-5-91522-235-8.

${ }^{139}$ D. Dong, Z. Zhang, Y. Bai, J. Fan, and G. Zhang, "Topographic and sedimentary features in the Yap subduction zone and their implications for the Caroline Ridge subduction”, Tectonophysics 722, 410-421 (2018).

${ }^{140}$ W.-B. Doo, K.-C. Hao, D. Brown, C.-L. Lo, S.-K. Hsu, and Y.-S. Huang, "Serpentinization of the fore-arc mantle along the Taiwan arc-continent collision of the northern Manila subduction zone inferred from gravity modeling", Tectonophysics 691, 282-289 (2016).

${ }^{141}$ W.-B. Doo, C.-L. Lo, S.-K. Hsua, C.-H. Tsai, Y.-S. Huang, H.-F. Wang, S.-D. Chiu, Y.-F. Ma, and C.-W. Liang, "New gravity anomaly map of Taiwan and its surrounding regions with some tectonic interpretations", Journal of Asian Earth Sciences 154, 93-100 (2018).

${ }^{142}$ W.-B. Doo, C.-L. Lo, W.-N. Wu, J.-Y. Lin, S.-K. Hsu, Y.-S. Huang, and H.-F. Wang, "Strength of plate coupling in the southern Ryukyu subduction zone", Tectonophysics 723, 223-228 (2018). 
${ }^{143}$ D. Dougherty and A. D. Robbins, sed \& $a w k$, 2nd ed. (Sebastopol, CA: O'Reilly Media, 1997), ISBN: 1-56592225-5.

${ }^{144}$ H. Drewes, G. D. Fraser, G. L. Snyder, and H. F. J. Barnett, "Geology of Unalaska Island and adjacent insular shelf, Aleutian Islands, Alaska”, U.S. Geological Survey Bulletin 1028, 583-676 (1961), URL: https: //pubs . usgs.gov/bul/1028s/report.pdf.

${ }^{145}$ E. P. Dubinin and S. A. Ushakov, Oceanic rift genesis (GEOS, Moscow, 2001), 293 pp.

${ }^{146}$ R. A. Duncan, T. L. Vallier, and D. A. Falvey, "Geology and offshore resources of pacific island arcs; tonga region", in , edited by D. W. Scholl and T. L. Vallier (Circum-Pac. Counc. Energy and Miner. Resour., Houston, TX, United States, 1985) Chap. Volcanic episodes at Eua, Tonga Islands, pp. 281-290, URL: https : / / www . osti.gov/biblio/7230072.

${ }^{147}$ C. Dupuy, J. Dostal, and G. Marcelot, "Geochemistry of basalts from central and southern New Hebrides arc: implication for their source rock composition”, Earth and Planetary Science Letters 60, 207-225 (1982).

${ }^{148}$ A. Dutkiewicz, R. D. Müller, S. O’Callaghan, and H. Jónasson, "Census of seafloor sediments in the worlds ocean", Geology 43, 795-798 (2015).

${ }^{149}$ A. M. Dziewonski, T.-A. Chou, and J. H. Woodhouse, "Determination of earthquake source parameters from waveform data for studies of global and regional seismicity", Journal of Geophysical Research 86, 2825-2852 (1981).

${ }^{150}$ J. W. Eaton, D. Bateman, S. Hauberg, and R. Wehbring, GNU Octave. A high-level interactive language for numerical computations. Free Your Numbers, 5th ed., Octave version 5.1.0 (Online, 2019), URL: https : / / octave.org/octave.pdf.

${ }^{151}$ M. Ekman, "What Is the Geoid? Coordinate Systems, GPS, and the Geoid", Reports of the Finnish Geodetic Institute 95, Ed. M. Vermeer, 49-51 (1995).

${ }^{152}$ M. Ekman, "Impacts of geodynamic phenomena on systems for height and gravity”, Bulletin Géodésique 63, 281-296 (1989).

${ }^{153}$ G. Ekstróm and E. R. Engdahl, "Earthquake source parameters and stress distribution in the Adak Island region of the central Aleutian Islands, Alaska", Journal of Geophysical Research 84, 15499-15519 (1989), URL: https://doi.org/10.1029/JB094iB11p15499.

${ }^{154}$ G. Ekstróm and M. Nettles, "Calibration of the HGLP seismograph network and centroid-moment tensor analysis of significant earthquakes of 1976," Physics of the Earth and Planetary Interiors 101, 219-243 (1997).

${ }^{155}$ G. Ekstróm, M. Nettles, and A. M. Dziewonski, “The global CMT project 2004-2010: Centroid-moment tensors for 13,017 earthquakes", Physics of the Earth and Planetary Interiors 200-201, 1-9 (2012).

${ }^{156}$ E. R. Engdahl and S. Billington, "Focal depth determination of central Aleutian earthquakes", Bulletin of the Seismological Society of America 76, 77-93 (1986), URL: https : / / pubs . geoscienceworld.org/ssa/ bssa/article-abstract/76/1/77/118783/focal-depth-determination-of-central-aleutian.

${ }^{157}$ E. R. Engdahl, R. D. van der Hilst, and R. Buland, "Global teleseismic earthquake relocation with improved travel times and procedures for depth determination", Bulletin of the Seismological Society of America 88, $722-743$ (1998).

${ }^{158}$ W. G. Ernst, "Subduction, ultrahigh-pressure metamorphism, and regurgitation of buoyant crustal slices implications for arcs and continental growth", Physics of the Earth and Planetary Interiors 127(1-4, 253-275 (2001).

${ }^{159}$ R. M. Eustace, H. Ritchie, N. M. Kilgallen, S. B. Piertney, and A. J. Jamieson, "Morphological and ontogenetic stratification of abyssal and hadal Eurythenes gryllus sensu lato (Amphipoda: Lysianassoidea) from the PeruChile Trench”, Deep-Sea Research Part I 109, 91-98 (2016).

${ }^{160}$ B. Everitt, The Cambridge Dictionary of Statistics, 2nd ed. (Cambridge University Press, Cambridge, UK, 2002), $293 \mathrm{pp}$.

${ }^{161}$ A. Ewart, K. D. Collerson, M. Regelous, J. I. Wendt, and Y. Niu, "Geochemical evolution within the TongaKermadec Lau arc back-arc systems: the role of varying mantle wedge composition in space and time", Journal of Petrology 39, 331-368 (1998). 
${ }^{162}$ R. W. Faas, "Gravitational Compaction Patterns Determined from Sediment Cores Recovered during the Deep Sea Drilling Project Leg 67 Guatemalan Transect: Continental Slope, Middle America Trench, and Cocos Plate”, Deep Sea Drilling Project Reports and Publications 30, 617-638 (1982).

${ }^{163}$ M. Faccenda, T. V. Gerya, and L. Burlini, "Deep slab hydration induced by bending-related variations in tectonic pressure", Nature Geosciences 2, 790-793 (2009).

${ }^{164}$ C. Faccenna, A. Heuret, F. Funiciello, S. Lallemand, and T. W. Becker, "Predicting trench and plate motion from the dynamics of a strong slab", Earth and Planetary Science Letters 257, 29-36 (2007).

${ }^{165}$ C. Faccenna, E. D. Giuseppe, F. Funiciello, S. Lallemand, and J. van Hunen, "Control of seafloor aging on the migration of the Izu-Bonin-Mariana Trench”, Earth and Planetary Science Letters 288, 386-398 (2009).

${ }^{166}$ C. Faccenna, A. F. Holt, T. W. Becker, S. Lallemand, and L. H. Royden, "Dynamics of the Ryukyu Izu-BoninMarianas double subduction system”, Tectonophysics 746, 229-238 (2018).

${ }^{167}$ J. Fan and D. Zhao, "P-wave anisotropic tomography of the central and southern Philippines", Physics of the Earth and Planetary Interiors 286, 154-164 (2019).

${ }^{168}$ T. G. Farr, P. A. Rosen, E. Caro, R. Crippen, R. Duren, S. Hensley, M. Kobrick, M. Paller, E. Rodriguez, L. Roth, D. Seal, S. Shaffer, J. Shimada, J. Umland, M. Werner, M. Oskin, D. Burbank, and D. Alsdorf, "The Shuttle Radar Topography Mission”, AGU Review of Geophysics 45, 1-30 (2007).

${ }^{169}$ M. O. Fernandez and A. C. Marques, "Combining bathymetry, latitude, and phylogeny to understand the distribution of deep Atlantic hydroids (Cnidaria)", Deep-Sea Research Part I 133, 39-48 (2018).

${ }^{170}$ V. Ferrini, "Briefing on the work of GEBCO (General Bathymetric Chart of the Oceans)", in $19^{\text {th }}$ meeting of the meso american - caribbean sea hydrographic commission (machc), Cartagena de Indias, Colombia, 28 November - 1 December (2018).

${ }^{171}$ D. M. Finlayson and J. P. Cull, “Structural profiles in New Britain-New Ireland region”, Journal of the Geological Society of Australia 20,37-47 (1973), URL: https:// doi .org/10.1080/14400957308527893.

${ }^{172}$ R. L. Fischer and R. W. Raitt, "Topography and structure of the Peru-Chile Trench”, Deep-Sea Research 9, 424-443 (1962), URL: https://doi.org/10.1016/0011-7471 (62) 90094-3.

${ }^{173}$ M. Fliedner and S. L. Klemperer, "Crustal structure transition form oceanic arc to continental arc, eastern Aleutian Islands and Alaska Peninsula", Earth and Planetary Science Letters 179, 567-579 (2000), URL: https : / / crustal. stanford. edu/sites/g/files/sbiybj12201/f / publications / fliednerklemperer. alaskapeninsula.epsl_.2000.pdf.

${ }^{174}$ R. Freitag, C. Gaedicke, B. V. Baranov, and N. V. Tsukanov, "Collisional processes at the junction of the Aleutian-Kamchatka arcs: new evidence from fission track analysis and field observation”, Terra Nova 13, 433442 (2001).

${ }^{175}$ H. Freymuth, F. Vils, M. Willbold, R. Taylor, and T. Elliott, "Molybdenum mobility and isotopic fractionation during subduction at the Mariana arc", Earth and Planetary Science Letters 432, 176-186 (2015).

${ }^{176}$ M. Friendly, "Corrgrams: Exploratory displays for correlation matrices", The American Statistician 19, 1-16 (2002).

${ }^{177}$ M. Frigge, D. C. Hoaglin, and B. Iglewicz, "Some Implementations of the Boxplot", The American Statistician 43, 50-54 (1989).

${ }^{178}$ P. Fryer, N. Becker, B. Appelgate, F. Martinez, M. Edwards, and G. Fryer, "Why is the Challenger Deep so deep?", Earth and Planetary Science Letters 211, 259-269 (2003).

${ }^{179}$ G. Fujie, A. Ito, S. Kodaira, N. Takahashi, and Y. Kaneda, "Confirming sharp bending of the Pacific plate in the northern Japan Trench subduction zone by applying a traveltime mapping method", Physics of the Earth and Planetary Interiors 157, 72-85 (2006).

${ }^{180}$ K. Fujioka, K. Okino, T. Kanamatsu, and Y. Ohara, "Morphology and origin of the Challenger Deep in the Southern Mariana Trench”, Geophysical Research Letters 29, 1372 (2002).

${ }^{181}$ K. Fujioka, K. Okino, T. Kanamatsu, Y. Ohara, O. Ishizuka, S. Haraguchi, and T. Ishii, "Enigmatic extinct spreading center in the West Philippine backarc basin unveiled”, Geology 27, 1135-1138 (1999). 
${ }^{182}$ T. Fujiwara, C. Tamura, A. Nishizawa, K. Fujioka, K. Kobayashi, and Y. Iwabuchi, "Morphology and tectonics of the Yap Trench", Marine Geophysical Research 21, 69-86 (2000).

${ }^{183}$ F. Funiciello, C. Faccenna, A. Heuret, S. Lallemand, E. Di Giuseppe, and T. W. Becker, "Trench migration, net rotation and slab-mantle coupling”, Earth and Planetary Science Letters 271, 233-240 (2008).

${ }^{184}$ C. Gaedicke, B. V. Baranov, N. I. Seliverstov, D. Alexeiev, N. V. Tsukanov, and R. Freitag, "Structure of an active arc-continent collision area: the Aleutian-Kamchatka junction", Tectonophysics 325, 63-85 (2000).

${ }^{185}$ C. Galli, "Ophiolite and island-arc volcanism in Costa Rica”, Geol. Soc. Am. Bull. 90, 444-452 (1979).

${ }^{186}$ N. D. Gallo, J. Cameron, K. Hardy, P. Fryer, D. H. Bartlett, and L. A. Levin, "Submersible- and lander-observed community patterns in the Mariana and New Britain Trenches: Influence of productivity and depth on epibenthic and scavenging communities”, Deep-Sea Research Part I 99, 119-133 (2015).

${ }^{187}$ C. Gambi, A. Vanreusel, and R. Danovaro, "Biodiversity of nematode assemblages from deep-sea sediments of the Atacama Slope and Trench (South Pacific Ocean)”, Deep-Sea Research I 50, 103-117 (2003).

${ }^{188}$ J. V. Gardner, A. A. Armstrong, B. R. Calder, and J. Beaudoin, “So, How Deep Is the Mariana Trench?”, Marine Geodesy 37, 1-13 (2014).

${ }^{189}$ Z. Garfunkel, C. A. Anderson, and G. Schubert, "Mantle circulation and the lateral migration of subducted slabs", Journal of Geophysical Research 91, 7205-7223 (1986).

${ }^{190}$ S. Gauger, G. Kuhn, K. Gohl, T. Feigl, P. Lemenkova, and C.-D. Hillenbrand, "Swath-bathymetric mapping", The expedition ANT-XXIII/4 of the R/V Polarstern in 2006. Reports on Polar and Marine Research 557, 38-45 (2007).

${ }^{191}$ GEBCO Committee, General Bathymetric Chart of the Oceans (GEBCO) - from the coast to the deepest trench, https://www.hydro-international.com/content/article/from-the-coast-to-the-deepest-trench, 2016.

${ }^{192}$ J. Geersen, "Sediment-starved trenches and rough subducting plates are conducive to T tsunami earthquakes", Tectonophysics 762, 28-44 (2019).

${ }^{193}$ J. Geersen, D. Voelker, and J. H. Behrmann, "Submarine geomorphology”, in, edited by J. Geersen (Springer, 2018) Chap. Oceanic Trenches, pp. 409-424.

${ }^{194}$ A. Gelman, “Analysis of variance? Why it is more important than ever.”, Annals of Statistics 33, 1-53 (2005).

${ }^{195}$ S. J. Giletycz, A. T. S. Lin, C.-P. Chang, and J. B. H. Shyu, "Relicts of mud diapirism of the emerged wedge-top as an indicator of gas hydrates destabilization in the Manila accretionary prism in southern Taiwan (Hengchun Peninsula)", Geomorphology 336, 1-17 (2019).

${ }^{196}$ J. Gill, Generalized Linear Models: A Unified Approach (Sage Publications, 2001).

${ }^{197}$ S. T. Gille, E. J. Metzger, and R. Tokmakian, "Seafloor topography and ocean circulation”, Oceanography 17, 47-54 (2004).

${ }^{198}$ K. Gohl, G. Eagles, G. B. Udintsev, R. D. Larter, G. Uenzelmann-Neben, H. W. Schenke, P. Lemenkova, J. Grobys, N. Parsiegla, P. Schlueter, T. Deen, G. Kuhn, and C. D. Hillenbrand, "Tectonic and Sedimentary Processes of the West Antarctic Margin of the Amundsen Sea Embayment and Pine Island Bay", in $2^{\text {nd }}$ scar open science meeting (2006).

${ }^{199}$ K. Gohl, G. Uenzelmann-Neben, G. Eagles, A. Fahl, T. Feigl, J. Grobys, J. Just, L. V., N. Lensch, C. Mayr, N. Parsiegla, N. Rackebrandt, P. Schluter, S. Suckro, K. Zimmermann, S. Gauger, H. Bohlmann, G. Netzeband, and P. Lemenkova, Deep crustal refraction and reflection seismics; crustal and sedimentary structures and geodynamic evolution of the West Antarctic continental margin and Pine Island (2006), pp. 20-30.

${ }^{200}$ K. Gohl, G. Uenzelmann-Neben, G. Eagles, A. Fahl, T. Feigl, J. Grobys, J. Just, V. Leinweber, N. Lensch, C. Mayr, N. Parsiegla, N. Rackebrandt, P. Schloter, S. Suckro, K. Zimmermann, S. Gauger, H. Bohlmann, G. L. Netzeband, and P. Lemenkova, Crustal and Sedimentary Structures and Geodynamic Evolution of the West Antarctic Continental Margin and Pine Island Bay (Alfred Wegener Institute Helmholtz Centre for Polar and Marine Research, 2006), pp. 11-12.

${ }^{201}$ G. H. Golub and C. F. van Loan, Matrix Computations, 3rd ed. (The John Hopkins University Press, Baltimore and London, 1996). 
${ }^{202}$ W. Gong, X. Jiang, Y. Guo, J. Xing, C. Li, and Y. Sun, “Strike-slip tectonics within the northernmost Philippine Sea plate in an arc continent collisional setting”, Journal of Asian Earth Sciences 146, 265-278 (2017).

${ }^{203}$ A. Gorbatov, Y. Fukao, S. Widiyantoro, and E. Gordeev, "Seismic evidence for a mantle plume oceanwards of the Kamchatka-Aleutian trench junction”, Geophysical Journal International 146, 282-288 (2001).

${ }^{204}$ A. Gorbatov, V. Kostoglodov, G. Suarez, and E. Gordeev, "Seismicity and structure of the Kamchatka subduction zone", Geophysical Journal International, 102, 883-898 (1997), URL: https : / agupubs . onlinelibrary . wiley.com/doi/pdf/10.1029/96JB03491.

${ }^{205}$ M. A. V. Gorini, “Proceedings geomorphometry 2009”, in, edited by R. Purves, S. Gruber, R. Straumann, and T. Hengl (University of Zurich, Zurich, Switzerland, 2009) Chap. Physiographic classification of the ocean floor: a multi-scale geomorphometric approach, pp. 98-105.

${ }^{206}$ G. S. Gorshkov, Catalog of the Active Volcanoes of the World Including Solfatara Fields. P. VII. Kurile Islands (Napoli: International Volcanological Association Press, 1958).

${ }^{207}$ V. Gouretski, “Using GEBCO digital bathymetry to infer depth biases in the XBT data”, Deep-Sea Research Part I 62, 40-52 (2012).

${ }^{208}$ S. P. Grand, R. D. van der Hilst, and S. Widiyantoro, "Global Seismic Tomography: A Snapshot of Convection in the Earth", GSA Today 7, 2-7 (1997).

${ }^{209}$ H. W. Green II and P. C. Burnley, “A new self- organizing mechanism for deep-focus earthquakes”, Nature 341, 733-737 (1989).

${ }^{210}$ J. Greinert, K. B. Lewis, J. Bialas, I. A. Pecher, A. A. Rowden, D. A. Bowden, M. De Batist, and P. Linke, "Methane seepage along the Hikurangi Margin, New Zealand: Overview of studies in 2006 and 2007 and new evidence from visual, bathymetric and hydroacoustic investigations”, Marine Geology 272, 6-25 (2010).

${ }^{211}$ R. W. Griffiths, R. Hackney, and R. D. van der Hilst, “A laboratory investigation of effects of trench migration on the descent of subducted slabs", Earth and Planetary Science Letters 133, 1-17 (1995).

${ }^{212}$ M. Gross, "How deep are the oceans?", Current Biology 26, 445-460 (2016).

${ }^{213}$ D. Gubbins and R. K. Snieder, "Dispersion of P waves in subducted lithosphere: evidence for an eclogite layer", Journal of Geophysical Research 96, 6321-6333 (1991).

${ }^{214}$ J. M. R. Guotana, B. D. Payot, C. B. Dimalanta, N. T. Ramos, D. V. Faustino-Eslava, K. L. Queaño, and G. P. J. Yumul, “Arc and backarc geochemical signatures of the proto-Philippine Sea Plate: Insights from the petrography and geochemistry of the Samar Ophiolite volcanic section”, Journal of Asian Earth Sciences 142, 77-92 (2017).

${ }^{215}$ E. G. Gurvich, Metallonosnye osadki Mirovogo okeana (Metalliferous sediments of the World Ocean), Russian (Nauchnyi Mir, Moscow, 1998), 340 pp.

${ }^{216}$ V. K. Gusiakov, "Tsunamis on the Russian Pacific coast: history and current situation", Russian Geology and Geophysics 57, 1259-1268 (2016).

${ }^{217}$ M.-A. Gutscher, F. Klingelhoefer, T. Theunissen, W. Spakman, T. Berthet, T. K. Wang, and C.-S. Lee, "Thermal modeling of the SW Ryukyu forearc (Taiwan): Implications for the seismogenic zone and the age of the subducting Philippine Sea Plate (Huatung Basin)”, Tectonophysics 692, 131-142 (2016).

${ }^{218}$ M. Guzmán-Speziale and J. M. Gómez-González, "Seismic strain rate along the Middle America Trench reveals significant differences between Cocos-North America and Cocos-Caribbean convergence", Geophysical Journal International 166, 179-185 (2006).

${ }^{219}$ R. Hall, "Cenozoic geological and plate tectonic evolution of SE Asia and the SW Pacific: computer-based reconstructions, model and animations", Journal of Asian Earth Sciences 20, 353-431 (2002).

${ }^{220}$ R. Hall, J. R. Ali, C. D. Anderson, and S. J. Baker, "Origin and motion history of the Philippine Sea Plate", Tectonophysics 251, 229-250 (1995).

${ }^{221}$ R. Hall, M. Fuller, J. R. Ali, and C. D. Anderson, "Active margins and marginal basins of the western pacific", in, Vol. 88, edited by B. Taylor and J. Netland (Geophysical Monograph Series AGU, Washington, D. C., 1995) Chap. The Philippine Sea Plate: magnetism and reconstructions, pp. 371-404.

${ }^{222}$ R. L. Halterman, Learning to program with Python (Python Software Foundation, 2011), 283 pp. 
${ }^{223}$ H. van Haren, C. Berndt, and I. Klaucke, "Ocean mixing in deep-sea trenches: New insights from the Challenger Deep, Mariana Trench”, Deep-Sea Research Part I 129, 1-9 (2017).

${ }^{224}$ A. N. Harrington, Hands-on Python Tutorial Release 1.0 for Python Version 3.1+ (Loyola University Chicago, US, 2015), $191 \mathrm{pp}$.

${ }^{225}$ P. T. Harris, M. Macmillan-Lawler, J. Rupp, and E. K. Baker, “Geomorphology of the oceans”, Marine Geology 352, 4-24 (2014).

${ }^{226} \mathrm{P}$. T. Harris and T. Whiteway, "Global distribution of large submarine canyons: geomorphic differences between active and passive continental margins", Marine Geology 285, 69-86 (2011).

${ }^{227}$ A. M. Hartwell, J. R. Voight, and C. G. Wheat, "Clusters of deep-sea egg-brooding octopods associated with warm fluid discharge: An ill-fated fragment of a larger, discrete population?”, Deep-Sea Research Part I 135, 1-8 (2018).

${ }^{228}$ A. Hashima, T. Sato, H. Sato, K. Asao, H. Furuya, S. Yamamoto, K. Kameo, T. Miyauchi, T. Ito, N. Tsumura, and H. Kaneda, "Simulation of tectonic evolution of the Kanto Basin of Japan since 1 Ma due to subduction of the Pacific and Philippine Sea plates and the collision of the Izu-Bonin arc", Tectonophysics 679, 1-14 (2016).

${ }^{229}$ F. Haxby, G. D. Karner, J. L. LaBrecque, and J. K. Weissel, "Digital images of combined oceanic and continental data sets and their uses in tectonic studies", EOS Transactions, American Geophysical Union 64, 995-1004 (1983).

${ }^{230}$ T. Hayakawa, J. Kasahara, R. Hino, T. Sato, M. Shinohara, A. Kamimura, M. Nishino, T. Sato, and T. Kanazawa, "Heterogeneous structure across the source regions of the 1968 Tokachi-Oki and the 1994 Sanriku-Haruka-Oki earthquakes at the Japan Trench revealed by an ocean bottom seismic survey", Physics of the Earth and Planetary Interiors 132, 89-104 (2002).

${ }^{231}$ D. E. Hayes, “A geophysical investigation of the Peru-Chile Trench”, Marine Geology 4, 309-351 (1966).

${ }^{232}$ E. He, M. Zhao, X. Qiu, J.-C. Sibuet, J. Wang, and J. Zhang, "Crustal structure across the post-spreading magmatic ridge of the East Sub-basin in the South China Sea: Tectonic significance", Journal of Asian Earth Sciences 121, 139-152 (2016).

${ }^{233}$ B. C. Heezen, “The floors of the oceans. I. The North Atlantic”, Geological Society of America Special Paper 65, 1-122 (1959).

${ }^{234}$ B. C. Heezen and C. D. Hollister, The face of the deep (Oxford University Press, 1971), pp. 1-659.

${ }^{235}$ B. C. Heezen and M. Tharp, World Ocean Floor Panorama, Map in full color, painted by H. Berann, Mercator Projection, scale 1:23,230,300, 1168E1930 mm (New York, U. S., 1977).

${ }^{236}$ W. Heiskanen and H. Moritz, Physical Geodesy (W. H. Freeman and Co, San Francisco., 1967).

${ }^{237}$ J. M. Hergt and J. D. Woodhead, "A critical evaluation of recent models for Lau-Tonga arc-backarc basin magmatic evolution”, Chemical Geology 245, 9-44 (2007).

${ }^{238}$ R. R. Hessler, C. L. Ingram, A. A. Yayanos, and B. Burnett, "Scavenging amphipods from the floor of the Philippine Trench", Deep-Sea Research Part I 25, 1029-1047 (1978).

${ }^{239}$ A. Heuret, C. P. Conrad, and F. Funiciello, "Relation between subduction megathrust earthquakes, trench sediment thickness and upper plate strain”, Geophysical Research Letters 39(5), 131-138 (2012).

${ }^{240}$ A. Heuret and S. Lallemand, "Plate motions, slab dynamics and back-arc deformation", Physics of the Earth and Planetary Interiors 149, 31-51 (2005).

${ }^{241}$ W. D. Heyman and D. J. Wright, "Marine Geomorphology in the Design of Marine Reserve Networks", The Professional Geographer 63, 429-442 (2011).

${ }^{242}$ T. W. C. Hilde and C.-S. Lee, “Origin and evolution of the West Philippine Basin: a new interpretation”, Tectonophysics 102, 85-104 (1984).

${ }^{243}$ R. D. van der Hilst and T. Seno, "Effects of relative plate motion on the deep structure and penetration depth of slabs below the Izu-Bonin and Mariana island arcs", Earth and Planetary Science Letters 120, 395-407 (1993).

${ }^{244}$ N. Hirano, Y. Ogawa, and K. Saito, "Long-lived early Cretaceous seamount volcanism in the Mariana Trench, Western Pacific Ocean”, Marine Geology 189, 371-379 (2002). 
${ }^{245}$ S. Hirano, T. Nakata, and A. Sangawa, "Fault topography and quaternary faulting along the Philippine Fault zone, Central Luzon, the Philippines", Journal of Geography 95, 1-23 (1986).

${ }^{246}$ D. C. Hoaglin, "Understanding robust and exploratory data analysis", in, Vol. 2 (Wiley, New York, U.S., 1983) Chap. Letter values: A set of selected order statistics, pp. 33-57.

${ }^{247}$ D. C. Hoaglin, F. Mosteller, and J. W. Tukey, Understanding Robust and Exploratory Data Analysis (Wiley, New York, U.S., 1983).

${ }^{248}$ K. Hofmann H. Kafadar and H. Wickham, "Letter-value plots: Boxplots for large data", The American Statistician 489, 72-83 (2011).

${ }^{249}$ W. S. Holbroock, D. Lizarraide, and S. McGeary, "Structure and composition of the Aleutian island arc and implications for continental crustal growth", Geology 27, 31-34 (1999).

${ }^{250}$ R. J. Holm, S. Tapster, H. A. Jelsma, G. Rosenbaum, and D. F. Mark, "Tectonic evolution and copper-gold metallogenesis of the Papua New Guinea and Solomon Islands region”, Ore Geology Reviews 104, 208-226 (2019).

${ }^{251}$ A. F. Holt, L. H. Royden, T. W. Becker, and C. Faccenna, "Slab interactions in 3-D subduction settings: The Philippine Sea Plate region”, Earth and Planetary Science Letters 489, 72-83 (2018).

${ }^{252}$ E. Honza, H. L. Davies, J. B. Keene, and D. L. Tiffin, "Plate boundaries and evolution of the Solomon Sea region", Geo-Marine Letters 7, 161-168 (1987).

${ }^{253}$ A. C. Horleston and G. R. Helffrich, "Constraining sediment subduction: A converted phase study of the Aleutians and Marianas", Earth and Planetary Science Letters 359-360, 141-151 (2012).

${ }^{254}$ S.-K. Hsu, Y.-C. Yeh, J.-C. Sibuet, W.-B. Doo, and C.-H. Tsai, “A mega-splay fault system and tsunami hazard in the southern Ryukyu subduction zone”, Earth and Planetary Science Letters 362, 99-107 (2013).

${ }^{255}$ Y.-J. Hsu, S.-B. Yu, A. T. R. Song, and T. Bacolcol, "Plate coupling along the Manila subduction zone between Taiwan and northern Luzon", Journal of Asian Earth Sciences 51, 98-108 (2012).

${ }^{256}$ H. L. Huang and D. P. Zhao, "High-resolution mantle tomography of China and surrounding regions", Journal of Geophysical Research 11, 10.1029 /2005JB004066 (2006).

${ }^{257}$ T. Hubble, J. Webster, P. Yu, M. Fletcher, D. Airey, S. Clarke, D. Mitchell, D. Voelker, A. Puga-Bernabeu, F. Howard, S. Gallagher, and T. Martin, "Submarine Mass Movements and their Consequences. Advances in Natural and Technological Hazards Research", in , edited by G. Lamarche (Springer International Publishing, Switzerland, 2016) Chap. chapter 12. Submarine Landslides and Incised Canyons of the Southeast Queensland Continental Margin, pp. 125-134.

${ }^{258}$ P. F. Hudson, H. Middelkoop, and E. Stouthamer, "Flood management along the Lower Mississippi and Rhine Rivers (The Netherlands) and the continuum of geomorphic adjustment", Geomorphology 101, 209-236 (2008).

${ }^{259}$ R. Huene and R. Culotta, "Tectonic erosion at the front of the Japan Trench convergent margin”, Tectonophysics 160, 75-90 (1989).

${ }^{260}$ R. Huene, J. Ladd, and I. Norton, "Geophysical Observations of Slope Deposits, Middle America Trench off Guatemala”, Deep Sea Drilling Project Reports and Publications 38, 719-732 (1982).

${ }^{261}$ R. Huene and S. Lallemand, "Tectonic erosion along the Japan and Peru convergent margins", Geological Society of America Bulletin 102, 704-720 (1990).

${ }^{262}$ R. Huene and D. W. Scholl, "Observations at Convergent Margins Concerning Sediment Subduction, Subduction Erosion, and the Growth of Continental Crust", Review of Geophysics 29, 279-316 (1991).

${ }^{263}$ J. Hunter, D. Dale, E. Firing, and M. Droettboom, Matplotlib Release 2.2.2. (2018).

${ }^{264}$ J. D. Hunter, "Matplotlib: A 2D graphics environment”, Computing in Science \& Engineering 9, 90-95 (2007).

${ }^{265}$ L. Husson, "Trench migration and upper plate strain over a convecting mantle", Physics of the Earth and Planetary Interiors 212-213, 32-43 (2012).

${ }^{266}$ D. M. Hussong and S. Uyeda, "Tectonic process and the history of the Mariana Arc: A synthesis of the results of deep sea drilling project leg 60", Initial Reports of the Deep Sea Drilling Project 60, 909-929 (1982). 
${ }^{267}$ V. A. I. Huvenne, P. A. Tyler, D. G. Masson, E. H. Fisher, C. Hauton, V. Hühnerbach, T. P. L. Bas, and G. A. Wolff, “A Picture on the Wall: Innovative Mapping Reveals Cold-Water Coral Refuge in Submarine Canyon", PlosOne 6, 1-9 (2011).

${ }^{268}$ M. Ianniruberto, M. Trevethan, A. Pinheiro, J. F. Andrade, E. Dantas, N. Filizola, A. Santos, and C. Gualtieri, "A field study of the confluence between Negro and Solimoes Rivers. Part 2: Bed morphology and stratigraphy", Comptes Rendus Geoscience 350, 43-54 (2018).

${ }^{269}$ M. C. Ichino, M. R. Clark, J. C. Drazen, A. J. Jamieson, D. O. B. Jones, A. P. Martin, A. A. Rowden, T. M. Shank, P. H. Yancey, and H. A. Ruhl, "The distribution of benthic biomass in hadal trenches: A modelling approach to investigate the effect of vertical and lateral organic matter transport to the seafloor", Deep-Sea Research Part I 100, 21-33 (2015).

${ }^{270}$ Y. Ichiyama, H. Ito, N. Hokanishi, A. Tamura, and S. Arai, "Plutonic rocks in the MineokaSetogawa ophiolitic mélange, central Japan: Fragments of middle to lower crust of the IzuBoninMariana Arc?”, Lithos 282-283, 420-430 (2017).

${ }^{271}$ IHO, GEBCO Gazetteer of Undersea Feature Names (IHO-IOC, Oct. 2012).

${ }^{272}$ IHO, Standardization of Undersea Feature Names: Guidelines Proposal form Terminology, 4th ed. (International Hydrographic Organization and Intergovernmental Oceanographic Commission, Monaco, 2008).

${ }^{273}$ M. J. Ikari, J. Kameda, D. M. Saffer, and A. J. Kopf, “Strength characteristics of Japan Trench borehole samples in the high-slip region of the 2011 Tohoku-Oki earthquake", Earth and Planetary Science Letters 412, 35-41 (2015).

${ }^{274}$ K. Ikehara, T. Kanamatsu, Y. Nagahashi, M. Strasser, H. Fink, K. Usami, T. Irino, and G. Wefer, "Documenting large earthquakes similar to the 2011 Tohoku-oki earthquake from sediments deposited in the Japan Trench over the past 1500 years", Earth and Planetary Science Letters 445, 48-56 (2016).

${ }^{275}$ A. Y. Iliev, V. M. Kaistrenko, E. V. Gretskaya, E. A. Tikhonchuk, N. G. Razjigaeva, T. A. Grebennikova, L. A. Ganzey, and A. A. Kharlamov, "Tsunamis: case studies and recent developments. advances in natural and technological hazards research”, in, edited by K. Satake (Springer, Netherlands, 2005) Chap. Holocene tsunami traces on Kunashir Island, Kurile subduction zone, pp. 171-192.

${ }^{276}$ International Seismological Centre, ISC-EHB dataset, 2019.

${ }^{277}$ B. L. Isacks and P. Molnar, "Distribution of stresses in the descending lithosphere from a global survey of focal mechanism solutions of mantle earthquakes", Reviews of Geophysics and Space Physics 9, 103-173 (1971).

${ }^{278}$ J.-i. Ishibashi, U. Tsunogai, T. Toki, N. Ebina, T. Gamo, Y. Sano, H. Masuda, and H. Chiba, "Chemical composition of hydrothermal fluids in the central and southern Mariana Trough backarc basin", Deep-Sea Research Part II 121, 126-136 (2015).

${ }^{279}$ O. Ishizuka, K. Uto, and M. Yuasa, "Intra-Oceanic Subduction Systems: Tectonic and Magmatic Processes”, in, edited by R. D. Larter and P. T. Leat (Geological Society London Special Publications, London, U. K., 2003) Chap. Volcanic history of the back-arc of the Izu-Bonin (Ogasawara) arc, pp. 187-205.

${ }^{280}$ O. Ishizuka, M. Yuasa, Y. Tamura, H. Shukuno, R. J. Stern, J. Naka, M. Joshima, and R. N. Taylor, "Migrating shoshonitic magmatism tracks Izu-Bonin-Mariana intra-oceanic arc rift propagation", Earth and Planetary Science Letters 294, 111-122 (2010).

${ }^{281}$ O. Ishizuka, R. Hickey-Vargas, R. J. Arculus, G. M. Yogodzinski, I. P. Savov, Y. Kusano, A. McCarthy, P. A. Brandl, and M. Sudo, “Age of Izu-Bonin-Mariana arc basement”, Earth and Planetary Science Letters 481, 8090 (2018).

${ }^{282}$ T. Isse, H. Shiobara, J.-P. Montagner, H. Sugioka, A. Ito, A. Shito, T. Kanazawa, and K. Yoshizawa, “Anisotropic structures of the upper mantle beneath the northern Philippine Sea region from Rayleigh and Love wave tomography", Physics of the Earth and Planetary Interiors 183, 33-43 (2010).

${ }^{283}$ T. Ito and Y. Ogawa, "Origin of ferro-manganese nodules from the Japan Trench oceanward slope", The Geographical Journal, Tokyo Geographical Society 103, in Japanese with English abstract, 684-695 (1994).

${ }^{284}$ M. Itoh, K. Kawamura, T. Kitahashi, S. Kojima, H. Katagiri, and M. Shimanaga, "Bathymetric patterns of meiofaunal abundance and biomass associated with the Kuril and Ryukyu trenches, western North Pacific Ocean", Deep-Sea Research Part I 58, 86-97 (2011). 
${ }^{285}$ A. J. Jamieson, The hadal zone: life in the deepest oceans (Cambridge University Press, 2015).

${ }^{286}$ A. J. Jamieson and T. Fujii, “Trench Connection”, Biology Letters 7, 641-643 (2011).

${ }^{287}$ A. J. Jamieson, T. Fujii, D. J. Mayor, M. Solan, and I. G. Priede, "Hadal trenches: the ecology of the deepest places on Earth", Trends in Ecology and Evolution 25, 190-197 (2009).

${ }^{288}$ A. J. Jamieson, N. M. Kilgallen, A. A. Rowden, T. Fujii, T. Horton, A.-N. Lörz, K. Kitazawa, and I. G. Priede, "Bait-attending fauna of the Kermadec Trench, SW Pacific Ocean: Evidence for an ecotone across the abyssalhadal transition zone", Deep-Sea Research I, 58, 49-62 (2011).

${ }^{289}$ A. J. Jamieson, N. C. Lacey, A.-N. Lörz, A. A. Rowden, and S. B. Piertney, “The supergiant amphipod Alicella gigantea (Crustacea: Alicellidae) from hadal depths in the Kermadec Trench, SW Pacific Ocean”, Deep-Sea Research Part II Topical Studies in Oceanography 92, 107-113 (2013).

${ }^{290}$ A. J. Jamieson, “A contemporary perspective on hadal science”, Deep-Sea Research Part II 155, 4-10 (2018).

${ }^{291}$ K. Janeka, "Transformation of 3D geospatial data into CityGML - a case of Prague", Reports on Geodesy and Geoinformatics 107, 41-48 (2019).

${ }^{292}$ C. Janssen, R. Naumann, L. Morales, R. Wirth, D. Rhede, and G. Dresen, "Co-seismic and/or a-seismic microstructures of JFAST 343 core samples from the Japan Trench”, Marine Geology 362, 33-42 (2015).

${ }^{293}$ R. Jarrard, "Relations among subduction parameters", Reviews of Geophysics 24, 217-284 (1986).

${ }^{294}$ P. Jean-Baptiste, P. Allard, E. Fourré, P. Bani, S. Calabrese, A. Aiuppa, P. J. Gauthier, F. Parello, B. Pelletier, and E. Garaebiti, "Spatial distribution of helium isotopes in volcanic gases and thermal waters along the Vanuatu (New Hebrides) volcanic arc", Journal of Volcanology and Geothermal Research 322, 20-29 (2016).

${ }^{295}$ R. Jiao, F. Herman, and D. Seward, “Late Cenozoic exhumation model of New Zealand: Impacts from tectonics and climate", Earth-Science Reviews 166, 286-298 (2017).

${ }^{296}$ R. Jiao, D. Seward, T. A. Little, and B. P. Kohn, "Unroofing of fore-arc ranges along the Hikurangi Margin, New Zealand: Constraints from low-temperature thermochronology.", Tectonophysics 656, 39-51 (2015).

${ }^{297}$ A. Jimenez-Diaz, J. Ruiz, M. Pérez-Gussinyé, J. F. Kirby, J. A. Alvarez-Gómez, R. Tejero, and R. Capote, "Spatial variations of effective elastic thickness of the lithosphere in Central America and surrounding regions", Earth and Planetary Science Lettres 391, 55-66 (2014).

${ }^{298}$ R. W. Johnson, "Volcanism in Australasia: A collection papers in honour of the late G. A. M. Taylor, G. C.", in, edited by R. W. Johnson (Elsevier, Amsterdam, 1976) Chap. Late Cainozoic volcanism and plate tectonics at the southern margin of the Bismarck Sea, Papua New Guinea, pp. 101-116.

${ }^{299}$ E. Jones, T. E. Oliphant, and P. Peterson, SciPy: open source scientific tools for Python (2014), URL: http: //www.scipy.org.

${ }^{300}$ J.-L. Joron, H. Bougault, R. C. Maury, and J.-F. Stephan, "Basalt from the Cocos Plate, Site 487, Leg 66: Petrology and Geochemistry”, Deep Sea Drilling Project Reports and Publications 66, 731-734 (1982).

${ }^{301}$ A. G. Journel, Fundamental of Geostatistics in Five Lessons. Short Course in Geology: Volume 8, $28^{\text {th }}$ International Geological Congress (American Geophysical Union, Washington D.C., 2000), 57 pp.

${ }^{302}$ A. G. Journel and C. Huijbregts, Mining Geostatistics, Chapter 5 (Academic Press, 1978), 600 pp.

${ }^{303}$ T. V. Joydas, M. A. Qurban, S. M. Ali, J. F. Albarau, L. Rabaoui, K. P. Manikandan, M. Ashraf, V. P. Papadopoulos, S. Giacobbe, and P. K. Krishnakumar, "Macrobenthic community structure in the deep waters of the Red Sea”, Deep-Sea Research Part I 137, 38-56 (2018).

${ }^{304}$ A. V. Judge and M. K. McNutt, "The relationship between plate curvature and elastic plate thickness: a study of the Peru-Chile trench", Journal of Geophysical Research 96, 16625-16639 (1991), URL: https : / doi . org/ 10.1029/90JB01772.

${ }^{305}$ L. M. Kalnins and A. B. Watts, "Spatial variations in effective elastic thickness in the Western Pacific Ocean and their implications for Mesozoic volcanism”, Earth and Planetary Science Letters 286, 89-100 (2009).

${ }^{306}$ A. Kamimura, J. Kasahara, M. Shinohara, R. Hino, H. Shiobara, G. Fujie, and T. Kanazawa, "Crustal structure study at the Izu-Bonin subduction zone around $31^{\circ} \mathrm{N}$ : implications of serpentinized materials along the subduction plate boundary", Physics of the Earth and Planetary Interiors 132, 105-129 (2002). 
${ }^{307}$ H. Kao and W. Chen, "The double seismic zone in Kuril-Kamchatka: the tale of two overlapping single zones", Geophysical Journal International 99, 6913-6930 (1994), URL: https : / doi .org/10.1029/93JB03409.

${ }^{308}$ S. Karato, M. R. Riedel, and D. A. Yuen, "Rheological structure and deformation of subducted slabs in the mantle transition zone: implications for mantle circulation and deep earthquakes", Physics of the Earth and Planetary Interiors 127, 1-7 (2001).

${ }^{309}$ S. Karato and D. C. Rubie, “Towards an experimental study of deep mantle rheology: a new multi-anvil sample assembly for deformation studies under high pressures and temperatures”, Journal of Geophysical Research 102, 20111-20122 (1997).

${ }^{310}$ D. E. Karig, “Accreted terranes in the northern part of the Philippine archipelago", Tectonics 2, 211-236 (1983).

${ }^{311}$ M. Kato and T. H. Jordan, "Seismic structure of the upper mantle beneath the western Philippine Sea", Physics of the Earth and Planetary Interiors 110, 263-283 (1999).

${ }^{312}$ M. Kawabe, "Deep Ocean Circulation: Physical and Chemical Aspects”, in, edited by T. Teramoto (1993) Chap. Deep water properties and circulation in the western North Pacific, pp. 17-37.

${ }^{313}$ R. W. Kay, “Aleutian magnesian andesites: melts from subducted Pacific ocean crust”, Journal of Volcanology and Geothermal Research 4, 117-132 (1978).

${ }^{314}$ J. Kennett, Marine Geology (Prentice-Hall, Englewood Cliffs, N.J., 1982).

${ }^{315}$ V. G. Khomich, N. G. Boriskina, and S. A. Kasatkin, "Geology, magmatism, metallogeny, and geodynamics of the South Kuril Islands”, Ore Geology Reviews 105, 151-162 (2019).

${ }^{316}$ Y. M. Kim, S.-M. Lee, and K. Okino, "Comparison of gravity anomaly between mature and immature intraoceanic subduction zones in the western Pacific", Tectonophysics 474, 657-673 (2009).

${ }^{317}$ K. Kiminami, T. Imaoka, K. Ogura, H. Kawabata, H. Ishizuka, and Y. Mori, “Tectonic implications of Early Miocene OIB magmatism in a near-trench setting: The Outer Zone of SW Japan and the northernmost Ryukyu Islands", Journal of Asian Earth Sciences 135, 291-302 (2017).

${ }^{318}$ S. H. Kirby, W. B. Durham, and L. A. Stern, "Mantle phase changes and deep-earthquake faulting in subducted lithosphere”, Science 252, 216-225 (1991).

${ }^{319}$ S. H. Kirby, S. Stein, E. A. Okal, and D. C. Rubie, "Deep earthquakes and metastable phase transformations in subducting oceanic lithosphere", Review of Geophysics 34, 261-306 (1996).

${ }^{320}$ T. Kitahashi, K. Kawamura, S. Kojima, and M. Shimanaga, "Bathymetric patterns of a and b diversity of harpacticoid copepods at the genus level around the Ryukyu Trench, and turnover diversity between trenches around Japan", Progress in Oceanography 123, 54-63 (2014).

${ }^{321}$ T. Kitahashi, R. G. Jenkins, H. Nomaki, M. Shimanaga, K. Fujikura, and S. Kojima, "Effect of the 2011 Tohoku Earthquake on deep-sea meiofaunal assemblages inhabiting the landward slope of the Japan Trench", Marine Geology 358, 128-137 (2014).

${ }^{322}$ K. Kizaki, “Geology and tectonics of the Ryukyu Island”, Tectonophysics 125, 193-207 (1986).

${ }^{323}$ I. Klaucke, W. Weinrebe, C. J. Petersen, and D. A. Bowden, “Temporal variability of gas seeps offshore New Zealand: Multi-frequency geoacoustic imaging of the Wairarapa area, Hikurangi margin”, Marine Geology 272, 49-58 (2010).

${ }^{324}$ M. Klauco, B. Gregorova, U. Stankov, V. Markovic, and P. Lemenkova, "Determination of ecological significance based on geostatistical assessment: a case study from the Slovak Natura 2000 protected area", Central European Journal of Geosciences 5, 28-42 (2013).

${ }^{325}$ M. Klauco, B. Gregorová, P. Koleda, U. Stankov, V. Markovic, and P. Lemenkova, "Land Planning as a Support for Sustainable Development Based on Tourism: A Case Study of Slovak Rural Region”, Environmental Engineering and Management Journal 16, 449-458 (2017).

${ }^{326}$ M. Klauco, B. Gregorová, U. Stankov, V. Markovic, and P. Lemenkova, "Interpretation of Landscape Values, Typology and Quality Using Methods of Spatial Metrics for Ecological Planning”, in Environmental \& climate technologies. proceedings of the $54^{\text {th }}$ conference (2013), pp. 1-1. 
${ }^{327}$ M. Klauo, B. Gregorová, U. Stankov, V. Markovi, and P. Lemenkova, "Landscape metrics as indicator for ecological significance: assessment of Sitno Natura 2000 sites, Slovakia”, in Ecology and environmental protection, Conference Proceedings (2014), pp. 85-90.

${ }^{328}$ B. Klauer, J. Schiller, and F. Bathe, Cost-effective improvement of river morphology, Document in EconStor (Leibniz-Informationszentrum Wirtschaft Leibniz Information Centre for Economics in Cooperation with: Helmholtz Centre for Environmental Research (UFZ), 2014).

${ }^{329}$ C. Kleiber and A. Zeileis, Applied Econometrics with R (Springer, 2008).

${ }^{330}$ F. Klingelhoefer, T. Berthet, S. Lallemand, P. Schnurle, C.-S. Lee, C.-S. Liu, K. McIntosh, and T. Theunissen, "P-wave velocity structure of the southern Ryukyu margin east of Taiwan: Results from the ACTS wide-angle seismic experiment", Tectonophysics 578, 50-62 (2012).

${ }^{331}$ D. E. Knuth, The $T_{E} X B o o k$, Addison-Wesley (Addison-Wesley Publishing Company, Reading, Massachusetts, 1984), 483 pp., ISBN: 0-201-13448-9.

${ }^{332}$ K. Kobayashi, K. Fujioka, T. Fujiwara, Y. Iwabuchi, and H. Kitazato, "Why is the Palau Trench so Deep? DeepSea Trench without Plate Convergence", Proc. Japan Acad. 73, Ser. B, 89-94 (1997), URL: https : / / www . jstage.jst.go.jp/article/pjab1977/73/6/73_6_89/_pdf.

${ }^{333}$ S. Kodaira, L. T. Iwasaki, T. Urabe, T. Kanazawa, F. Egloff, J. Makris, and H. Shimamura, "Crustal structure across the middle Ryukyu trench obtained from ocean bottom seismographic data", Tectonophysics 263, 39-60 (1996).

${ }^{334}$ S. Kodaira, T. No, Y. Nakamura, T. Fujiwara, Y. Kaiho, S. Miura, N. Takahashi, Y. Kaneda, and A. Taira, "Coseismic fault rupture at the trench axis during the 2011 Tohoku-Oki earthquake", Nature Geoscience 5, 646650 (2012).

${ }^{335}$ X. Kong, S. Li, Y. Wang, Y. Suo, L. Dai, L. Géli, Y. Zhang, L. Guo, and P. Wang, "Causes of earthquake spatial distribution beneath the Izu-Bonin-Mariana Arc", Journal of Asian Earth Sciences, 10.1016/ j. jseaes.2017. 10.015 (2017).

${ }^{336}$ Q. Kou, L. Gong, and X. Li, “A new species of the deep-sea spongicolid genus Spongicoloides (Crustacea, Decapoda, Stenopodidea) and a new species of the glass sponge genus Corbitella (Hexactinellida, Lyssacinosida, Euplectellidae) from a seamount near the Mariana Trench, with a novel commensal relationship between the two genera", Deep-Sea Research Part I 135, 88-107 (2018).

${ }^{337}$ A. Krabbenhoeft, J. Bialas, I. Klaucke, G. J. Crutchley, C. Papenberg, and G. L. Netzeband, "Patterns of subsurface fluid-flow at cold seeps: The Hikurangi Margin, offshore New Zealand", Marine and Petroleum Geology 39, 59-73 (2013).

${ }^{338}$ A. Krabbenhoeft, G. L. Netzeband, J. Bialas, and C. Papenberg, "Episodic methane concentrations at seep sites on the upper slope Opouawe Bank, southern Hikurangi Margin, New Zealand", Marine Geology 272, 71-78 (2010).

${ }^{339}$ J. B. Kruskal, “Nonmetric Multidimensional Scaling: A numerical method”, Psychometrika 29, 115-129 (1964).

${ }^{340}$ C.-Y. Ku and S.-K. Hsu, "Crustal structure and deformation at the northern Manila Trench between Taiwan and Luzon islands", Tectonophysics 466, 229-240 (2009).

${ }^{341}$ D. Kuhlman, A Python Book: Beginning Python, Advanced Python, and Python Exercises, edited by O. Tutorial (Moscow, 2013), 278 pp., URL: https ://www.davekuhlman.org/python_book_01.pdf.

${ }^{342}$ G. Kuhn, C. Hass, M. Kober, M. Petitat, T. Feigl, C.-D. Hillenbrand, S. Kruger, M. Forwick, S. Gauger, and P. Lemenkova, The response of quaternary climatic cycles in the south-east pacific: development of the opal belt and dynamics behavior of the west antarctic ice sheet, Expeditionsprogramm Nr. 75 ANT XXIII/4, AWI, Bremerhaven, Germany, 2006.

${ }^{343}$ M. Kumar, "Free 'Cook Book' for gridding bathymetric data", EOS Transactions American Geophysical Union 94, News, Washington, D.C., USA, 88-88 (2013).

${ }^{344}$ B.-Y. Kuo, C.-C. Wang, S.-C. Lin, C.-R. Lin, P.-C. Chen, J.-P. Jang, and H. K. Chang, "Shear-wave splitting at the edge of the Ryukyu subduction zone", Earth and Planetary Science Letters 355-356, 262-270 (2012). 
${ }^{345}$ V. B. Kurnosov, I. Murdmaa, V. Kazakova, V. Mikhina, and A. Y. Shevchenko, "Mineralogy of Sediments from the Middle America Trench (Guatemala Transect)", Deep Sea Drilling Project Reports and Publications 67, 515-528 (1982).

${ }^{346}$ V. B. Kurnosov and A. Y. Shevchenko, "Secondary Minerals in Basalts from the Middle America Trench, Leg 67”, Deep Sea Drilling Project Reports and Publications 22, 551-555 (1982).

${ }^{347}$ N. C. Lacey, D. J. Mayor, T. D. Linley, and A. J. Jamieson, "Population structure of the hadal amphipod Bathycallisoma (Scopelocheirus) schellenbergi in the Kermadec Trench and New Hebrides Trench, SW Pacific", Deep-Sea Research Part II 155, 50-60 (2018).

${ }^{348}$ N. C. Lacey, A. A. Rowden, M. R. Clark, N. M. Kilgallen, T. D. Linley, D. J. Mayor, and A. J. Jamieson, "Community structure and diversity of scavenging amphipods from bathyal to hadal depths in three South Pacific Trenches", Deep-Sea Research Part I 111, 121-137 (2016).

${ }^{349}$ M. Lacharité and A. Metaxas, "Hard substrate in the deep ocean: How sediment features influence epibenthic megafauna on the eastern Canadian margin”, Deep-Sea Research Part I 126, 50-61 (2017).

${ }^{350}$ S. Lallemand, A. Heuret, C. Faccenna, and F. Funiciello, "Subduction dynamics as revealed by trench migration", Tectonics 27, 3014 (2008).

${ }^{351}$ G. Lamarche, J.-Y. Collot, R. A. Wood, M. Sosson, R. Sutherland, and J. Delteil, "The Oligocene-Miocene Pacific-Australia plate boundary, south of New Zealand: Evolution from oceanic spreadingto strike-slip faulting”, Earth and Planetary Science Letters 148, 129-139 (1997).

${ }^{352}$ G. Lamarche and J.-F. Lebrun, "Transition from strike-slip faulting to oblique subduction: active tectonics at the Puysegur Margin, South New Zealand”, Tectonophysics 316, 67-89 (2000).

${ }^{353}$ W. Lang, S. Sirisansaneeyakul, L. O. Martins, L. Ngiwsara, N. Sakairi, W. Pathom-aree, M. Okuyama, H. Mori, and A. Kimura, "Biodecolorization of a food azo dye by the deep sea Dermacoccus abyssi MT1.1T strain from the Mariana Trench", Journal of Environmental Management 132, 155-164 (2014).

${ }^{354}$ A. Lanier, C. Romsos, and C. Goldfinger, "Seafloor habitat mapping on the Oregon continental margin: A spatially nested GIS approach to mapping scale, mapping methods, and accuracy quantification", Marine Geodesy 30, 51-76 (2007).

${ }^{355}$ B. Larsen, "Sediments from the Philippine Trench", Galathea Report 9, 7-21 (1968).

${ }^{356}$ T. Lay, Y. Yamazaki, C. J. Ammon, K. F. Cheung, and H. Kanamori, "The 2011 MW 9.0 off the Pacific coast of Tohoku earthquake: comparison of deep-water tsunami signals with finite-fault rupture model predictions", Earth Planets Space 63, 797-801 (2011).

${ }^{357}$ T. B. Le, A. Crosato, and W. S. J. Uijttewaal, "Long-term morphological developments of river channels separated by a longitudinal training wall”, Advances in Water Resources 113, 73-85 (2018).

${ }^{358}$ D. Leduc, "New species of Thelonema, Metasphaerolaimus, and Monhystrella (Nematoda, Monhysterida) from Kermadec Trench, Southwest Pacific”, European Journal of Taxonomy 158, 1-19 (2015).

${ }^{359}$ D. Leduc and A. A. Rowden, "Nematode communities in sediments of the Kermadec Trench, Southwest Pacific Ocean”, Deep-Sea Research Part I 134, 23-31 (2018).

${ }^{360}$ D. Leduc, A. A. Rowden, R. N. Glud, F. Wenzhöfer, H. Kitazato, and M. R. Clark, "Comparison between infaunal communities of the deep floor and edge of the Tonga Trench: possible effects of differences in organic matter supply”, Deep-Sea Research Part I Oceanographic Research Papers 116, 264-275 (2016).

${ }^{361}$ D. Leduc, A. A. Rowden, R. N. Glud, F. Wenzhöfer, H. Kitazato, and M. R. Clark, "Comparison between in faunal communities of the deep floor and edge of the Tonga Trench: Possible effects of differences in organic matter supply", Deep-Sea Research Part I 116, 264-275 (2016).

${ }^{362}$ S.-M. Lee, "Deformation from the convergence of oceanic lithosphere into Yap trench and its implications for early-stage subduction", Journal of Geodynamics 37, 83-102 (2004).

${ }^{363}$ J. d. Leeuw, K. Hornik, and P. Mair, "Isotone Optimization in R: Pool-Adjacent-Violators Algorithm (PAVA) and Active Set Methods", Journal of Statistical Software 32, 1-24 (2009).

${ }^{364}$ R. Lehu, S. Lallemand, S.-K. Hsu, N. Babonneau, G. Ratzov, A. T. Lin, and L. Dezileau, "Deep-sea sedimentation offshore eastern Taiwan: Facies and processes characterization”, Marine Geology 369, 1-18 (2015). 
${ }^{365}$ V. Lemenkov and P. Lemenkova, "Measuring Equivalent Cohesion Ceq of the Frozen Soils by Compression Strength Using Kriolab Equipment", Civil and Environmental Engineering Reports 31, 63-84 (2021), URL: https://ceer.com.pl/resources/html/article/details?id=215589.

${ }^{366}$ V. Lemenkov and P. Lemenkova, "Using TeX Markup Language for 3D and 2D Geological Plotting”, Foundations of Computing and Decision Sciences 46, 43-69 (2021), URL: https : / content. sciendo. com/view/ journals/fcds/46/1/article-p43.xml.

${ }^{367}$ P. Lemenkova, Morphostructural features of deep-sea trenches of the Pacific Ocean, the problem of their origin (Report), Russian (Moscow, Russia, 2021), pp. 1-268.

${ }^{368} \mathrm{P}$. Lemenkova, Morphostructural features of deep-sea trenches of the Pacific Ocean, the problem of their origin (Synopsis), Russian (Moscow, Russia, 2021), pp. 1-46, URL: https : / / www . researchgate . net / publication/351979556_Morphostructural_features_of_deep-sea_trenches_of_the_Pacific_ Ocean_the_problem_of_their_origin.

${ }^{369}$ P. Lemenkova, "SAGA GIS for Computing Multispectral Vegetation Indices by Landsat TM for Mapping Vegetation Greenness”, Contemporary Agriculture 70, 67-75 (2021), URL: https: / / sciendo.com/article/10. 2478/contagri-2021-0011.

${ }^{370}$ P. Lemenkova, "Topography of the Aleutian Trench south-east off Bowers Ridge, Bering Sea, in the context of the geological development of North Pacific Ocean”, Baltica 34, 27-46 (2021), URL: https: / / gamtostyrimai. lt/en/publications/listingCategory/category.1020.

${ }^{371}$ P. Lemenkova, "Scripting Languages for Geomorphological Modelling and Topographic Visualization of Serbia”, Zbornik Matice srpske za prirodne nauke 140, 113-125 (2021), URL: http : / / doiserbia . nb. rs / journal. aspx?issn=0352-4906.

${ }^{372}$ P. Lemenkova, "Mapping environmental and climate variations by GMT: a case of Zambia, Central Africa", Zemljite i biljka 70, 117-136 (2021), URL: http://www.sdpz.rs/index.php/sr-yu/casopis-zemljistei-biljka.

${ }^{373}$ P. Lemenkova, “Accurate and rapid big spatial data processing by scripting cartographic algorithms: advanced seafloor mapping of the deep-sea trenches along the margins of the Pacific Ocean", in Bringing Land, Ocean, Atmosphere and Ionosphere Data to the Community for Hazard Alerts (May 24, 2021), URL: https: / / agu . confex.com/agu/21workshop2/meetingapp.cgi/Home/0, SLIDESHARE.

${ }^{374}$ P. Lemenkova, "Morphostructure features of the deep-sea trenches in the Pacific Ocean: the problem of their origin", Russian, in Seminar of the laboratory of regional geophysics and natural disasters, in Russian (May 24, 2021), SLIDESHARE.

${ }^{375} \mathrm{P}$. Lemenkova, "The visualization of geophysical and geomorphologic data from the area of Weddell Sea by the Generic Mapping Tools", Studia Quaternaria 38, 19-32 (2021), URL: https: / /www . czasopisma.pan.pl/sq.

${ }^{376}$ P. Lemenkova, "Cartographic Processing of the Multi-Source Geospatial Datasets by GMT for Mapping Variability in Geologic Setting and Bathymetry of the Pacific Ocean”, Mercator 20, 1-18 (2021), URL: http: / / www. mercator.ufc.br/mercator/article/view/e20013.

${ }^{377}$ P. Lemenkova, "Geodynamic setting of Scotia Sea and its effects on geomorphology of South Sandwich Trench, Southern Ocean”, Polish Polar Research 42, 1-23 (2021), URL: https : / journals.pan.pl/ppr/136510.

${ }^{378}$ P. Lemenkova, "Data-driven insights into correlation among geophysical setting, topography and seafloor sediments in the Ross Sea, Antarctic", Caderno de Geografia 31, 1-20 (2021).

${ }^{379}$ P. Lemenkova, "Java and Sumatra Segments of the Sunda Trench: Geomorphology and Geophysical Settings Analysed and Visualized by GMT”, Glasnik Srpskog Geografskog Drustva 100, 1-23 (2020).

${ }^{380}$ P. Lemenkova, 'Using R packages 'tmap', 'raster' and 'ggmap' for cartographic visualization: An example of dem-based terrain modelling of Italy, Apennine Peninsula", Zbornik radova - Geografski fakultet Univerziteta u Beogradu 68, 99-116 (2020).

${ }^{381}$ P. Lemenkova, "GRASS GIS for classification of Landsat TM images by maximum likelihood discriminant analysis: Tokyo area, Japan”, Geodetski glasnik 51, 5-25 (2020).

${ }^{382}$ P. Lemenkova, “Insights on the Indian Ocean tectonics and geophysics supported by GMT”, Risks and Catastrophes Journal 27, 67-83 (2020). 
${ }^{383}$ P. Lemenkova, "Scripting cartographic methods of GMT for mapping the New Britain and San Cristobal trenches, Solomon Sea, Papua New Guinea”, Revista da Casa da Geografia de Sobral 22, 122-142 (2020).

${ }^{384}$ P. Lemenkova, "Sentinel-2 for High Resolution Mapping of Slope-Based Vegetation Indices Using Machine Learning by SAGA GIS”, Transylvanian Review of Systematical and Ecological Research 22, 17-34 (2020).

${ }^{385}$ P. Lemenkova, "Analysis of the difference in depths and variation in slope steepness of the Sunda Trench, Indonesia, east Indian Ocean”, Revista de Geomorfologie 22, 21-41 (2020).

${ }^{386} \mathrm{P}$. Lemenkova, "Sediment thickness in the Bay of Bengal and Andaman Sea compared with topography and geophysical settings by GMT", Ovidius University Annals Series: Civil Engineering 22, 13-22 (2020).

${ }^{387}$ P. Lemenkova, "GEBCO and ETOPO1 gridded datasets for GMT based cartographic mapping of Hikurangi, Puysegur and Hjort Trenches, New Zealand”, Acta Universitatis Lodziensis. Folia Geographica Physica 19, 7 18 (2020).

${ }^{388}$ P. Lemenkova, “GRASS GIS Modules for Topographic and Geophysical Analysis of the ETOPO1 DEM and Raster Data: North Fiji Basin, Pacific Ocean”, Geographia Napocensis 14, 27-38 (2020).

${ }^{389}$ P. Lemenkova, “Applying Automatic Mapping Processing by GMT to Bathymetric and Geophysical Data: Cascadia Subduction Zone, Pacific Ocean”, Journal of Environmental Geography 13, 15-26 (2020).

${ }^{390}$ P. Lemenkova, “Object Based Image Segmentation Algorithm of SAGA GIS for Detecting Urban Spaces in Yaoundé, Cameroon”, Central European Journal of Geography and Sustainable Development 2, 38-51 (2020).

${ }^{391}$ P. Lemenkova, "Geomorphology of the Puerto Rico Trench and Cayman Trough in the Context of the Geological Evolution of the Caribbean Sea", Annales Universitatis Mariae Curie-Sklodowska, sectio B Geographia, Geologia, Mineralogia et Petrographia 75, 115-141 (2020).

${ }^{392}$ P. Lemenkova, "Using GMT for 2D and 3D Modeling of the Ryukyu Trench Topography, Pacific Ocean", Miscellanea Geographica 25, 1-13 (2020).

${ }^{393}$ P. Lemenkova, "NOAA Marine Geophysical Data and a GEBCO Grid for the Topographical Analysis of Japanese Archipelago by Means of GRASS GIS and GDAL Library", Geomatics and Environmental Engineering 14, 25-45 (2020).

${ }^{394}$ P. Lemenkova, "Hyperspectral Vegetation Indices Calculated by Qgis Using Landsat Tm Image: a Case Study of Northern Iceland”, Advanced Research in Life Sciences 4, 70-78 (2020).

${ }^{395}$ P. Lemenkova, "SAGA GIS for information extraction on presence and conditions of vegetation of northern coast of Iceland based on the Landsat TM", Acta Biologica Marisiensis 3, 10-21 (2020).

${ }^{396}$ P. Lemenkova, “GEBCO Gridded Bathymetric Datasets for Mapping Japan Trench Geomorphology by Means of GMT Scripting Toolset”, Geodesy and Cartography 46, 98-112 (2020).

${ }^{397}$ P. Lemenkova, "The geomorphology of the Makran Trench in the context of the geological and geophysical settings of the Arabian Sea”, Geology, Geophysics and Environment 46, 205-222 (2020).

${ }^{398}$ P. Lemenkova, "Fractal surfaces of synthetical DEM generated by GRASS GIS module r.surf.fractal from ETOPO1 raster grid”, Journal of Geodesy and Geoinformation 7, 86-102 (2020).

${ }^{399}$ P. Lemenkova, "Python libraries matplotlib, seaborn and pandas for visualization geospatial datasets generated by QGIS”, Analele tiinifice ale Universitii "Alexandru Ioan Cuza" din Iai - seria Geografie 64, 13-32 (2020).

${ }^{400}$ P. Lemenkova, "Integration of geospatial data for mapping variation of sediment thickness in the North Sea", Scientific Annals of the Danube Delta Institute 25, 129-138 (2020).

${ }^{401}$ P. Lemenkova, "Mapping Beaufort Sea Topography and Geophysical Settings Using High-Resolution Geospatial Data and GMT”, Geografické informácie 24, 4-18 (2020).

${ }^{402}$ P. Lemenkova, "R Libraries \{dendextend\} and \{magrittr $\}$ and Clustering Package scipy.cluster of Python For Modelling Diagrams of Dendrogram Trees", Carpathian Journal of Electronic and Computer Engineering 13, 5-12 (2020).

${ }^{403}$ P. Lemenkova, "Seafloor Mapping of the Atlantic Ocean by GMT: Visualizing Mid-Atlantic Ridge Spreading, Sediment Distribution and Tectonic Development”, Acta Geobalcanica 6, 145-157 (2020).

${ }^{404}$ P. Lemenkova, "Mapping South China Sea Region by GMT for Marine Geological Analysis and Visualization", Analele Universitii din Oradea, Seria Geografie 30, 107-121 (2020). 
${ }^{405} \mathrm{P}$. Lemenkova, "Variations in the bathymetry and bottom morphology of the Izu-Bonin Trench modelled by GMT”, Bulletin of Geography. Physical Geography Series 18, 41-60 (2020).

${ }^{406}$ P. Lemenkova, "Cartographic Interpretation of the Seafloor Geomorphology Using GMT: a Case Study of the Manila Trench, South China Sea”, Aksaray University Journal of Science and Engineering 4, 1-18 (2020).

${ }^{407}$ P. Lemenkova, "GMT Based Comparative Geomorphological Analysis of the Vityaz and Vanuatu Trenches, Fiji Basin”, Geodetski List 74, 19-39 (2020).

${ }^{408}$ P. Lemenkova, "Visualization of the geophysical settings in the Philippine Sea margins by means of GMT and ISC data", Central European Journal of Geography and Sustainable Development 2, 5-15 (2020).

${ }^{409}$ P. Lemenkova, "GMT-based geological mapping and assessment of the bathymetric variations of the KurilKamchatka Trench, Pacific Ocean”, Natural and Engineering Sciences 5, 1-17 (2020).

${ }^{410}$ P. Lemenkova, "AWK and GNU Octave Programming Languages Integrated with Generic Mapping Tools for Geomorphological Analysis”, GeoScience Engineering 65, 1-22 (2019).

${ }^{411}$ P. Lemenkova, "Geomorphological modelling and mapping of the Peru-Chile Trench by GMT", Polish Cartographical Review 51, 181-194 (2019).

${ }^{412}$ P. Lemenkova, “Automatic Data Processing for Visualising Yap and Palau Trenches by Generic Mapping Tools”, Cartographic Letters 27, 72-89 (2019).

${ }^{413}$ P. Lemenkova, "Geophysical Modelling of the Middle America Trench using GMT", Annals of Valahia University of Targoviste. Geographical Series 19, 73-94 (2019).

${ }^{414}$ P. Lemenkova, "Geospatial Analysis by Python and R: Geomorphology of the Philippine Trench, Pacific Ocean", Electronic Letters on Science and Engineering 15, 81-94 (2019).

${ }^{415} \mathrm{P}$. Lemenkova, "Calculating slope gradient variations in the submarine landforms by $\mathrm{R}$ and Python statistical libraries”, MANAS Journal of Engineering 7, 99-113 (2019).

${ }^{416}$ P. Lemenkova, "Plotting Ternary Diagrams by R Library ggtern for Geological Modelling”, Eastern Anatolian Journal of Science 5, 16-25 (2019).

${ }^{417}$ P. Lemenkova, "Deep-Sea Trenches of the Pacific Ocean: a Comparative Analysis of the Submarine Geomorphology by Data Modeling Using GMT, QGIS, Python and R. Mid-Term PhD Thesis Presentation: Current Research Progress", in Seminar Mid-Term PhD Thesis Presentation (Nov. 2019).

${ }^{418}$ P. Lemenkova, "Topographic surface modelling using raster grid datasets by GMT: example of the KurilKamchatka Trench, Pacific Ocean”, Reports on Geodesy and Geoinformatics 108, 9-22 (2019).

${ }^{419}$ P. Lemenkova, "Generic Mapping Tools and Matplotlib Package of Python for Geospatial Data Analysis in Marine Geology”, International Journal of Environment and Geoinformatics 6, 225-237 (2019).

${ }^{420}$ P. Lemenkova, "GMT Based Comparative Analysis and Geomorphological Mapping of the Kermadec and Tonga Trenches, Southwest Pacific Ocean”, Geographia Technica 14, 39-48 (2019).

${ }^{421}$ P. Lemenkova, "Computing and Plotting Correlograms by Python and R Libraries for Correlation Analysis of the Environmental Data in Marine Geomorphology", Jeomorfolojik Aratrmalar Dergisi / Journal of Geomorphological Researches 3, 1-16 (2019).

${ }^{422}$ P. Lemenkova, "Statistical Analysis of the Mariana Trench Geomorphology Using R Programming Language", Geodesy and Cartography 45, 57-84 (2019).

${ }^{423}$ P. Lemenkova, "K-means Clustering in R Libraries \{cluster\} and ffactoextra\} for Grouping Oceanographic Data”, International Journal of Informatics and Applied Mathematics 2, 1-26 (2019).

${ }^{424}$ P. Lemenkova, “Testing Linear Regressions by StatsModel Library of Python for Oceanological Data Interpretation”, Aquatic Sciences and Engineering 34, 51-60 (2019).

${ }^{425}$ P. Lemenkova, "Numerical Data Modelling and Classification in Marine Geology by the SPSS Statistics", International Journal of Engineering Technologies 5, 90-99 (2019).

${ }^{426}$ P. Lemenkova, "Regression Models by Gretl and R Statistical Packages for Data Analysis in Marine Geology", International Journal of Environmental Trends 3, 39-59 (2019). 
${ }^{427}$ P. Lemenkova, "Geostatistical Analysis of the Data Sets on the Mariana Trench, Pacific Ocean", in Seminar presentation (Apr. 2019).

${ }^{428}$ P. Lemenkova, "Processing oceanographic data by Python libraries NumPy, SciPy and Pandas", Aquatic Research 2, 73-91 (2019).

${ }^{429}$ P. Lemenkova, “An Empirical Study of R Applications for Data Analysis in Marine Geology”, Marine Science and Technology Bulletin 8, 1-9 (2019).

${ }^{430}$ P. Lemenkova, "Scatterplot Matrices of the Geomorphic Structure of the Mariana Trench at Four Tectonic Plates (Pacific, Philippine, Mariana and Caroline): a Geostatistical Analysis by R", in Problems of tectonics of continents and oceans, Proceedings of the $51^{\text {st }}$ Tectonics Meeting, Vol. 1, edited by K. E. Degtyarev (Institute of Geology RAS, Jan. 2019), pp. 347-352.

${ }^{431} \mathrm{P}$. Lemenkova, Replication data for: factor analysis by r programming to assess variability among environmental determinants of the mariana trench, Dec. 2018, Publisher: Harvard Dataverse.

${ }^{432}$ P. Lemenkova, "Factor Analysis by R Programming to Assess Variability Among Environmental Determinants of the Mariana Trench", Turkish Journal of Maritime and Marine Sciences 4, 146-155 (2018).

${ }^{433} \mathrm{P}$. Lemenkova, "R scripting libraries for comparative analysis of the correlation methods to identify factors affecting Mariana Trench formation”, Journal of Marine Technology and Environment 2, 35-42 (2018).

${ }^{434}$ P. Lemenkova, "Hierarchical Cluster Analysis by R language for Pattern Recognition in the Bathymetric Data Frame: a Case Study of the Mariana Trench, Pacific Ocean", in Virtual simulation, prototyping and industrial design, Proceedings $5^{\text {th }}$ Int'1 Conference Issue 5, Vol. 2, edited by M. N. Krasnyansky (Nov. 2018), pp. 147-152, ISBN: 978-5-8265-1997-4.

${ }^{435}$ P. Lemenkova, "Using GIS for Monitoring Lacustrine Ecosystem: a Case Study of Laguna de Gallocanta, Spain", in Problems of the environmental landscape planning, Conference Proceedings, edited by A. I. Klimenko (2016), pp. 237-240.

${ }^{436}$ P. Lemenkova, "Urban-Rural Environmental Gradient in a Developing City: Testing ENVI GIS Functionality”, in Abishevskie readings, Innovation in the complex processing of mineral raw materials (2016).

${ }^{437}$ P. Lemenkova, "Geodata Management for the Environmental Assessment: a Case Study of Central Finland", in Problems of ecology and safety. dalnevostochnaja vesna - 2016, Proceeding of the $14^{\text {th }}$ International Conference, edited by I. P. Stepanova and G. E. Nikiforova (2016), pp. 29-31.

${ }^{438}$ P. Lemenkova, "Flow Direction and Length Determined by ArcGIS Spatial Analyst and Terrain Elevation Data Sets", in Priority directions of the development of young research farmers in modern science, International Conference Proceedings in Honor of the $25^{\text {th }}$ Anniversary of Caspian Research Institute of Arid Agriculture (PNIIAZ RAAS), edited by N. A. Shcherbakova and A. N. Bondarenko (2016), pp. 579-583.

${ }^{439}$ P. Lemenkova, "Linking Data Between the Worksheets and GIS Databases for Effective Management of the Environmental Projects", in Green bridge through generations, $3^{\text {rd }}$ international farabi readings, Materials of the $5^{\text {th }}$ International Student Forum (2016), pp. 349-353.

${ }^{440}$ P. Lemenkova, "Chemical Pollution of Coastal Waters in the Izmir Bay, Aegean Sea”, in Biodiversity and evolution, Proceedings of the International Conference in Honor of Academics O.G. Kusakin (2016), pp. 121126.

${ }^{441}$ P. Lemenkova, "Bibliographic Resources and Data for Ecology Seminars", in Ecological and biological issues of use of natural resources in agriculture (2016), pp. 3-8.

${ }^{442}$ P. Lemenkova, "Experience of Converting Raster Images into Vector Format using AutoTrace Software", in Reality - the sum of the information technologies (2015), pp. 105-108.

${ }^{443}$ P. Lemenkova, "Data Capture for Seafloor Bathymetric Mapping Using Software Caris Hips, GMT and ArcGIS", in Actual problems of the modern machinery, Proceedings International Conference, edited by D. A. Chinakhov (2015), pp. 111-117.

${ }^{444}$ P. Lemenkova, “A Technical Approach of Image Segmentation in ENVI GIS to Identify Thematic Clusters for Visualization of Urban Transformations", in Reality - the sum of information technologies (2015), pp. 100-104. 
${ }^{445}$ P. Lemenkova, "Mapping agricultural lands by means of GIS for monitoring use of natural resources", in Actual problems of the conservation and development of biological resources, Proceedings of the International Conference (2015), pp. 226-229.

${ }^{446}$ P. Lemenkova, "Topology, Homogeneity and Scale Factors for Object Detection: Application of eCognition Software for Urban Mapping using Multispectral Satellite Image", in Internet and society. modeling (2015), pp. 80-85.

${ }^{447}$ P. Lemenkova, "Environmental Hazard Prevention: Monitoring and Control of Landslide Risks in Mountainous Forests", in Actual problems in the development of forestry (2015), pp. 20-21.

${ }^{448}$ P. Lemenkova, "Environmental Modelling of Coastal Cities: Urban Landscapes as Complex, Vulnerable and Dynamically Developing Structures", in Natural resource management and environmental protection, Theory and practice of the economic regulation, Proceedings of the $13^{\text {th }}$ International Conference (2015), pp. 636-642.

${ }^{449}$ P. Lemenkova, “The New Image of the Suburban Estonia: Evolution of the Environmental Neighborhood under Architectural Reorganization", in Modern trends and perspectives in the development of tourism and hospitality, Proceedings of the $2^{\text {nd }}$ Conference in Honor of the $100^{\text {th }}$ Anniversary of the Ryazan State University (2015), pp. 42-46.

${ }^{450}$ P. Lemenkova, "Environmental Modelling of Urban Landscapes as Complex, Vulnerable and Dynamically Developing Structures", in Biodiversity. bioconservation. biomonitoring, Proceedings of the $2^{\text {nd }}$ International Conference in Honor of the $75^{\text {th }}$ Anniversary of the Adygea State University (2015), pp. 170-173.

${ }^{451}$ P. Lemenkova, "Calculating Areas of the Land Cover Types Using Multi-Temporal Images to Visualize Environmental Dynamics", in Education, science and industry: development and prospects of cooperation within the framework of regional technology platforms, Materials of the Online Conference (2015), pp. 6-11.

${ }^{452}$ P. Lemenkova, "Types of the Human Impacts on the Ecosystems for the GIS Based Environmental Monitoring”, in Biological and ecological regional studies: global, russian and regional problems (2015), pp. 215-218.

${ }^{453}$ P. Lemenkova, “The Distribution of Insecticides, Pesticides and Polychlorinated Biphenyls in the Sediments of the Barents Sea”, in Innovations in chemistry, petrochemical industry and biotechnology (2015), pp. 224-227.

${ }^{454}$ P. Lemenkova, "Satellite Image Based Mapping of Wetland Tundra Landscapes Using ILWIS GIS”, in Actual problems of the state and management of water resources (2015), pp. 110-113.

${ }^{455}$ P. Lemenkova, “Analysis of Landsat NDVI time series for detecting degradation of vegetation”, in Geoecology and sustainable use of mineral resources, From science to practice, Proceedings of the $3^{\text {rd }}$ International Conference of Young Scientists (2015), pp. 11-13.

${ }^{456}$ P. Lemenkova, "Importance of the Remote Sensing Image Analysis for Mapping Forest Land Cover in umava National Park", in Forestry: bridge to the future, 90 years higher forestry education in bulgaria, Book of Abstracts of the International Conference (2015), pp. 70-71.

${ }^{457} \mathrm{P}$. Lemenkova, "To the question of the environmental education: how Landsat TM, ETM+ and MSS images can be processed by GIS-techniques for geospatial research", in Trends and perspectives in creating regional systems of the additional education of adults, Proceedings of the International Conference (2015), pp. 108-111.

${ }^{458}$ P. Lemenkova, "Linking GIS and Remote Sensing Data to Study Vegetation Patterns", in New approaches of the high-technologies engineering: priorities in the development and human resources, Proceedings of the $3^{\text {rd }}$ International Conference (2015), pp. 174-178.

${ }^{459}$ P. Lemenkova, "Innovations in the Geoscience Research: Classification of the Landsat TM Image Using ILWIS GIS for Geographic Studies", in Prospects for the higher school development, Proceedings of the $8^{\text {th }}$ International Conference (2015), pp. 60-63.

${ }^{460}$ P. Lemenkova, "Geo-Information Technologies of Object Based Image Analysis (OBIA) for Urban Mapping", in Questions of cybersecurity, modeling and information processing in the modern socio-technical systems, Proceedings of the International Conference (2015), pp. 110-112.

${ }^{461}$ P. Lemenkova, "Sustainable Forest and Wildlife Resources in Czech Republic", in Fundamental and applied questions of the forest soil science, Proceedings of the $6^{\text {th }}$ Conference (2015), pp. 103-105. 
${ }^{462}$ P. Lemenkova, “Upholding Open Source Principles for Education: Use of Quantum GIS for Teaching Geoinformatics", in Actual problems of the earth sciences, Geological and geographic studies of the cross-border regions, Proceedings of the International Seminar (2015), pp. 130-133.

${ }^{463}$ P. Lemenkova, "Making Geodata Repository Using Arc Editor", in Real estate cadastre and monitoring natural resources session 7: using it tools (2015).

${ }^{464}$ P. Lemenkova, "Forest Monitoring Using Remote Sensing Data and ILWIS GIS”, in Recent research directions in the xxi century: theory and practice, Vol. 3.2, 9 (2015), pp. 346-350.

${ }^{465}$ P. Lemenkova, "Effectiveness of the Geospatial Data Processing and Use of Statistical Information for Proper Environmental Planning and Zoning: Example of the umava National Park, Czech Republic", in Innovative development of agricultural science and education, World experience and current priorities, Materials of the International Conference, Vol. 3 (2015), pp. 303-306.

${ }^{466}$ P. Lemenkova, “Assessing and Monitoring Geoecological Status of West Turkish Landscapes for Sustainable Development: Processes, Activities and Problems", in Geographic aspects of the sustainable development of regions, Vol. 2 (2015), pp. 78-81.

${ }^{467}$ P. Lemenkova, “Object Based Image Analysis for Urban Mapping and City Planning in Belgium”, in Virtual simulation, prototyping and industrial design, Proceedings of the $2^{\text {nd }}$ International Conference, Vol. 2.2 (2015), pp. 44-48.

${ }^{468}$ P. Lemenkova, "Data Sharing, Distribution and Updating Using Social Coding Community Github and LTEX Packages in Graduate Research", in Integration of the education and science, Challenges of the modern world, Proceedings of the International Conference, Vol. 1 (2015), pp. 3-7.

${ }^{469}$ P. Lemenkova, "Requirements for the Database Structuring for the Agricultural Monitoring in ArcGIS", in Actual problems of the it, electronics and radiotechnics, Vol. 1 (2015), pp. 79-81.

${ }^{470}$ P. Lemenkova, "Smart Seafloor Mapping in Real Time Regime Using Deep-Sea Multibeam Echosounder Hydrosweep DS', Izvestiya MGTU 'MAMI' 5 Economics and management, Social and human sciences, 23-27 (2015).

${ }^{471}$ P. Lemenkova, "Modelling Landscape Changes and Detecting Land Cover Types by Means of Remote Sensing Data and ILWIS GIS”, Bulletin of the Ufa State Petroleum Technological University 1 Information technologies, Problems and solutions, 265-271 (2015).

${ }^{472}$ P. Lemenkova, "Google Earth web service as a support for GIS mapping in geospatial research at universities", in Web-technologies in the educational space, Problems, approaches, perspectives (Mar. 2015), pp. 460-464.

${ }^{473}$ P. Lemenkova, "Cost-Effective Raster Image Processing for Geoecological Analysis using ISOCLUST Classifier: a Case Study of Estonian Landscapes”, in Modern problems of geoecology and landscapes studies (2014), pp. 74-76.

${ }^{474}$ P. Lemenkova, "Risks of Cryogenic Landslide Hazards and Their Impact on Ecosystems in Cold Environments", in The effects of irrigation and drainage on rural and urban landscapes (2014), p. 27.

${ }^{475}$ P. Lemenkova, "Detection of Vegetation Coverage in Urban Agglomeration of Brussels by NDVI Indicator Using eCognition Software and Remote Sensing Measurements", in Gis and remote sensing, Gis day, Proceedings of the $3^{\text {rd }}$ International Conference (2014), pp. 112-119.

${ }^{476}$ P. Lemenkova, "Rural Sustainability and Management of Natural Resources in Tian Shan Region, Central Asia", in Celebrating pastoral life, Heritage and economic development, Proceedings of the International Conference (2014), pp. 81-89.

${ }^{477}$ P. Lemenkova, "Opportunities for Classes of Geography in the High School: the Use of CORINE Project Data, Satellite Images and IDRISI GIS for Geovisualization”, in Perspectives for the development of higher education, Proceedings of the $7^{\text {th }}$ International Conference (2014), pp. 284-286.

${ }^{478}$ P. Lemenkova, "Bringing Geospatial Analysis to the Social studies: an Assessment of the City Sprawl in China", in $10^{\text {th }}$ international congress of the hellenic geographical society (2014).

${ }^{479}$ P. Lemenkova, "Understanding Spatiotemporal Forms, Triggers and Consequences of Urban Dynamics in Taipei: 1990-2005", in Socio-economic transition of china: opportunities and threats (Apr. 3, 2014). 
${ }^{480}$ P. Lemenkova, "Spatial Analysis for the Assessment of the Environmental Changes in the Landscapes of Izmir Surroundings", in $10^{\text {th }}$ international conference on environmental, cultural, economic and social sustainability (Jan. 22, 2014).

${ }^{481}$ P. Lemenkova, "Monitoring changes in agricultural landscapes of Central Europe, Hungary: application of ILWIS GIS for image processing”, in Geoinformatics: theoretical and applied aspects (2013).

${ }^{482}$ P. Lemenkova, "Geospatial Technology for Land Cover Analysis, Middle east and africa (mea) geospatial digest”, in (Nov. 2013).

${ }^{483}$ P. Lemenkova, "Impacts of Climate Change on Landscapes in Central Europe, Hungary", in Current Problems of Ecology, Ecological monitoring and management of nature protection, Proceedings of the $8^{\text {th }}$ International Conference, Vol. 2 (2012), pp. 134-136.

${ }^{484} \mathrm{P}$. Lemenkova, Seagrass mapping and monitoring along the coasts of crete, greece, M.Sc. Thesis, University of Twente, Faculty of Earth Observation and Geoinformation (ITC), 2011.

${ }^{485}$ P. Lemenkova, "Using ArcGIS in Teaching Geosciences”, B.Sc. Thesis (Lomonosov Moscow State University, Faculty of Educational Studies, Moscow, Russia, 2007), 58 pp.

${ }^{486}$ P. Lemenkova, "Geoecological Mapping of the Barents Sea Using GIS”, in International cartographic conference (icc) (July 12, 2005).

${ }^{487}$ P. Lemenkova, "Geoecological Mapping of the Barents and Pechora Seas" (Lomonosov Moscow State University, Faculty of Geography, Department of Cartography and Geoinformatics, Moscow, Russia, May 18, 2004), $78 \mathrm{pp}$.

${ }^{488}$ P. Lemenkova and I. Elek, "Clustering Algorithm in ILWIS GIS for Classification of Landsat TM Scenes (Mecsek Hills Region, Hungary)", in Geosciences and environment. near-surface geophysics (2012).

${ }^{489}$ P. Lemenkova, C. Promper, and T. Glade, "Economic Assessment of Landslide Risk for the Waidhofen a.d. Ybbs Region, Alpine Foreland, Lower Austria", in Protecting society through improved understanding, $11^{\text {th }}$ International Symposium on Landslides and the $2^{\text {nd }}$ North American Symposium on Landslides \& Engineered Slopes, edited by E. Eberhardt, C. Froese, A. K. Turner, and S. Leroueil (June 2012), pp. 279-285.

${ }^{490}$ A. Lemoine, R. Madariaga, and J. Campos, "Slab-pull and slab-push earthquakes in the Mexican, Chilean and Peruvian subduction zones", Physics of the Earth and Planetary Interiors 132, 157-175 (2002).

${ }^{491}$ R. Lester, K. McIntosh, H. J. A. van Avendonk, L. Lavier, C.-S. Liu, and T. K. Wang, "Crustal accretion in the Manila trench accretionary wedge at the transition from subduction to mountain-building in Taiwan", Earth and Planetary Science Letters 375, 430-440 (2013).

${ }^{492}$ L. S. Levy, “Taming the tiger”, in , edited by L. S. Levy (Springer Books on Professional Computing, New York, NY, 1987) Chap. AWK A Prototyping Language.

${ }^{493} \mathrm{~F}$. Li, Z. Sun, D. Hu, and Z. Wang, "Crustal structure and deformation associated with seamount subduction at the north Manila Trench represented by analog and gravity modeling”, Marine Geophysical Research 34, 13-27 (2013).

${ }^{494}$ J. E. Lieberman, “GRef2End: a GeoRefő to EndNoteő bibliography translator written in awk”, Computers \& Geosciences 18, 1271-1275 (1992).

${ }^{495}$ J. W. B. Lin, “qtem 0.1.2: a Python implementation of the Neelin-Zeng quasi-equilibrium tropical circulation model", Geoscientific Model Development 1, 315-344 (2008).

${ }^{496}$ J.-Y. Lin, Y.-F. Chen, C.-S. Lee, S.-K. Hsu, C.-W. Liang, Y.-C. Lin, and H.-S. Hsieh, "Strike-slip intraplate earthquakes in the Western Philippine Sea Plate", Tectonophysics 608, 499-504 (2013).

${ }^{497}$ J.-Y. Lin, S.-K. Hsu, J.-C. Sibuet, C.-S. Lee, and C.-W. Liang, "Plate tearing in the northwestern corner of the subducting Philippine Sea Plate", Journal of Asian Earth Sciences 70-71, 1-7 (2013).

${ }^{498}$ J.-Y. Lin and C.-L. Lo, "Earthquake-induced crustal gravitational potential energy change in the Philippine area", Journal of Asian Earth Sciences 66, 215-223 (2013).

${ }^{499}$ J.-Y. Lin and C.-L. Lo, "Earthquake-induced crustal gravitational potential energy change in the Philippine area”, Journal of Asian Earth Sciences 66, 215-223 (2013). 
${ }^{500}$ W. Lin, T. B. Byrne, M. Kinoshita, L. C. McNeill, C. Chang, J. C. Lewis, Y. Yamamoto, D. M. Saffer, J. C. Moore, H.-Y. Wue, T. Tsuji, Y. Yamada, M. Conin, S. Saito, T. Iton, H. J. Tobino, G. Kimura, K. Kanagawa, J. Ashi, M. B. Underwood, and T. Kanamatsu, "Distribution of stress state in the Nankai subduction zone, southwest Japan and a comparison with Japan Trench”, Tectonophysics 692, 120-130 (2016).

${ }^{501} \mathrm{P}$. Lindh, "Compaction- and strength properties of stabilised and unstabilised fine-grained tills", Lund University, PhD Thesis. ISRN: LUTVDG/TVGT-1013-SE, 10.13140/RG.2.1.1313.6481 (2004).

${ }^{502}$ I. D. Lindley, "New Britain Trench, Papua New Guinea: An extensional element in a regional sinistral strike-slip system”, New Concepts in Global Tectonics Newsletter 41, 15-27 (2006).

${ }^{503}$ I. D. Lindley, "Early Cainozoic stratigraphy and structure of the Gazelle Peninsula, east New Britain: An example of extensional tectonics in the New Britain arc-trench complex", Australian Journal of Earth Sciences 35, 231-244 (1988).

${ }^{504}$ T. D. Linley, M. E. Gerringer, P. H. Yancey, J. C. Drazen, C. L. Weinstock, and A. J. Jamieson, "Fishes of the hadal zone including new species, in situ observations and depth records of Liparidae", Deep-Sea Research Part I.

${ }^{505}$ T. D. Linley, A. L. Stewart, P. J. McMillan, M. R. Clark, M. E. Gerringer, J. C. Drazen, T. Fujii, and A. J. Jamieson, "Bait attending fishes of the abyssal zone and hadal boundary: Community structure, functional groups and species distribution in the Kermadec, New Hebrides and Mariana trenches", Deep-Sea Research Part I 121, 38-53 (2017).

${ }^{506}$ A. P. Lisicyn, Osadkoobrasovanie v okeanah (Sedimentation in the oceans), Russian, edited by P. L. Bezrukov (Nauka, Moscow, 1974), 545 pp.

${ }^{507}$ A. P. Lisicyn, J. A. Bogdanov, and E. G. Gurvich, Gidrotermal'nye obrazovanija riftovyh zon okeana (Hydrothermal formation of rift zones of the ocean), Russian, edited by V. M. Kupcov (Nauka, Moscow, Institute of Oceanology. n.a. P. P. Shirshov, 1990), 341 pp.

${ }^{508}$ V. M. Litvin, Morfostruktura dna okeanov (Morphostructure of the ocean floor), Russian, edited by A. N. Lastochkin (Nedra, Leningrad, 1987), $275 \mathrm{pp}$.

${ }^{509}$ M. Liu, X. Cui, and F. Liu, "Cenozoic rifting and volcanism in eastern China: A mantle dynamic link to the Indo-Asian collision?”, Tectonophysics 393, 29-42 (2004).

${ }^{510}$ R. Liu, L. Wang, Y. Wei, and J. Fang, “The hadal biosphere: Recent insights and new directions”, Deep-Sea Research Part II 155, 11-18 (2018).

${ }^{511}$ Y. Liu, A. Santos, S. M. Wang, Y. Shi, H. Liu, and D. A. Yuen, “Tsunami hazards along Chinese coast from potential earthquakes in South China Sea", Physics of the Earth and Planetary Interiors 163, 233-244 (2007).

${ }^{512}$ Y. Liu, X. Liu, X. Lv, W. Cao, C. Sun, J. Lu, C. Wang, B. Lu, and J. Yang, "Watermass properties and deep currents in the northern Yap Trench observed by the Submersible Jiaolong system", Deep-Sea Research Part I 139, 27-42 (2018).

${ }^{513}$ G. M. Ljung and G. E. P. Box, “On a Measure of a Lack of Fit in Time Series Models”, Biometrika 65, 297-303 (1978).

${ }^{514}$ C.-L. Lo, W.-B. Doo, K.-C. Hao, and S.-K. Hsu, "Plate coupling across the northern Manila subduction zone deduced from mantle lithosphere buoyancy", Physics of the Earth and Planetary Interiors 273, 50-54 (2017).

${ }^{515}$ E. Lodolo and F. Coren, "The Westernmost Pacific Antarctic plate boundary in the vicinity of the Macquarie triple junction”, Terra Antarctica 1, edited by C. A. Ricci, 158-161 (1994).

${ }^{516}$ M. Loher, Y. Marcon, T. Pape, M. Römer, P. Wintersteller, C. dos Santos Ferreira, D. Praeg, M. Torres, H. Sahling, and G. Bohrmann, "Seafloor sealing, doming, and collapse associated with gas seeps and authigenic carbonate structures at Venere mud volcano, Central Mediterranean", Deep-Sea Research Part I 137, 76-96 (2018).

${ }^{517}$ M. D. Long and R. D. van der Hilst, "Shear wave splitting from local events beneath the Ryukyu arc: Trenchparallel anisotropy in the mantle wedge", Physics of the Earth and Planetary Interiors 155, 300-312 (2006).

${ }^{518}$ P. J. G. Long, Introduction to Octave. Based on: P. Smith Tutorial Guide to Matlab (Department of Engineering University of Cambridge, Sept. 2005). 
${ }^{519}$ R. Louat and B. Pelletier, "Seismotectonics and present-day relative plate motions in the New Hebrides,-North Fiji Basin region”, Tectonophysics 167, 41-55 (1989), URL: https : / / doi .org/10 .1016/0040-1951 (89) 90293-X.

${ }^{520}$ W. J. Ludwig, J. I. Ewing, M. Ewing, S. Murauchi, N. Den, S. Asano, H. Hotta, M. Hayakawa, T. Asanuma, K. Ichikawa, and I. Noguchi, "Sediments and structure of Japan Trench", Journal of Geophysical Research 71, 2121-2137 (1966).

${ }^{521}$ M. Luo, T. J. Algeo, H. Tong, J. Gieskes, L. Chen, X. Shi, and D. Chen, "More reducing bottom-water redox conditions during the Last Glacial Maximum in the southern Challenger Deep (Mariana Trench, western Pacific) driven by enhanced productivity”, Deep-Sea Research Part II 155, 70-82 (2018).

${ }^{522}$ M. Luo, J. Gieskes, L. Chen, X. Shi, and D. Chen, "Provenances, distribution, and accumulation of organic matter in the southern Mariana Trench rim and slope: Implication for carbon cycle and burial in hadal trenches", Marine Geology 386, 98-106 (2017).

${ }^{523}$ H. Lyon-Caen, E. Barrier, C. Lasserre, A. Franco, I. Arzu, L. Chiquin, M. Chiquin, T. Duquesnoy, O. Flores, O. Galicia, J. Luna, E. Molina, O. Porras, J. Requena, V. Robles, J. Romero, and R. Wolf, "Kinematics of the North American-Caribbean-Cocos plates in Central America from new GPS measurements across the PolochicMotagua fault system", Geophysical Research Letters 33, 1-5 (2006).

${ }^{524}$ K. C. Macdonald, "Encyclopedia of ocean sciences”, in (Elsevier, 2001) Chap. Mid-ocean ridge tectonics, volcanism and geomorphology, pp. 1798-1813.

${ }^{525}$ B. T. MacInnes, E. A. Kravchunovskaya, T. K. Pinegina, and J. Bourgeois, "Paleotsunamis from the central Kuril Islands segment of the Japan-Kuril-Kamchatka subduction zone”, Quaternary Research 86, 54-66 (2016).

${ }^{526}$ P. Maillet, M. Monzier, J.-P. Eissen, and R. Louat, "Geodynamics of an arc-ridge junction: the case of the New Hebrides Arc/North Fiji Basin”, Tectonophysics 165, 251-258 (1989).

${ }^{527}$ A. S. Maiorova and A. V. Adrianov, "Deep-sea spoon worms (Echiura) from the Sea of Okhotsk and the adjacent T slope of the Kuril-Kamchatka Trench”, Deep-Sea Research Part II 154, 177-186 (2018).

${ }^{528}$ S. Malys, The wgs 84 reference frame, National Imagery and Mapping Agency, 1996.

${ }^{529}$ J. Mammerickx, Bathymetry of the South Pacific, Chart 11 (Scripps Institute of Oceanography and Institute of Marine Science, La Jolla, U. S., 1971).

${ }^{530}$ V. C. Manea, M. Manea, L. Ferrari, T. Orozco-Esquivel, R. W. Valenzuela, A. Husker, and V. Kostoglodov, “A review of the geodynamic evolution of flat slab subduction in Mexico, Peru, and Chile", Tectonophysics 695 , 27-52 (2017).

${ }^{531}$ X. Mao, B. Zhang, H. Deng, Y. Zou, and J. Chen, “Three-dimensional morphological analysis method for geologic bodies and its parallel implementation”, Computers \& Geosciences 96, 11-22 (2016).

${ }^{532}$ E. Marchese, V. Scorpio, I. Fuller, S. McColl, and F. Comiti, "Morphological changes in Alpine rivers following the end of the Little Ice Age", Geomorphology 295, 811-826 (2017).

${ }^{533}$ M. Marta-Almeida, M. Ruiz-Villarreal, P. Otero, M. Cobas, A. Peliz, R. Nolasco, M. Cirano, and J. Pereira, "OOF3: A Python engine for automating regional and coastal ocean forecasts", Environmental Modelling \& Software 26, 680-682 (2011).

${ }^{534}$ R. A. Martin, E. A. Nesbitt, and K. A. Campbell, "The effects of anaerobic methane oxidation on benthic foraminiferal assemblages and stable isotopes on the Hikurangi Margin of eastern New Zealand", Marine Geology 272, 270-284 (2010).

${ }^{535}$ D. G. Masson, "Fault Patterns at Outer Trench Walls”, Marine Geophysical Researches 13, 209-225 (1991).

${ }^{536}$ A. E. Mather, A. J. Hartley, and J. S. Griffiths, "The giant coastal landslides of Northern Chile: Tectonic and climate interactions on a classic convergent plate margin", Earth and Planetary Science Letters 388, 249-256 (2014).

${ }^{537}$ L. A. Mayer, M. Jakobsson, G. Allen, B. Dorschel, R. Falconer, V. Ferrini, G. Lamarche, H. Snaith, and P. Weatherall, "The Nippon Foundation - GEBCO Seabed 2030 Project: The Quest to See the Worlds Oceans Completely Mapped by 2030”, Geosciences 8, 63 (2018). 
${ }^{538}$ R. McGill, J. W. Tukey, and W. A. Larsen, "Variations of Box Plots", The American Statistician 32, 12-16 (1978).

${ }^{539}$ D. Mckenzie and C. Bowin, "Relationship between bathymetry and gravity in Atlantic Ocean", Journal of Geophysical Research 81, 1903-1915 (1976).

${ }^{540}$ T. A. Meckel, M. F. Coffin, S. Mosher, P. Symonds, G. Bernardel, and P. Mann, “Underthrusting at the Hjort Trench, AustralianPacific plate boundary: Incipient subduction?”, Geochemistry, Geophysics, Geosystems 4, 1099 (2003).

${ }^{541}$ A. Melhuish, R. Sutherland, F. J. Davey, and G. Lamarche, "Crustal structure and neotectonics of the Puysegur oblique subduction zone, New Zealand”, Tectonophysics 313, 335-362 (1999).

${ }^{542}$ H. W. Menard, "Deep-sea channels, topography, and sedimentation”, American Association of Petroleum Geologists Bulletin 39, 236-255 (1955).

${ }^{543}$ A. Micallef, "Marine geomorphology: geomorphological mapping and the study of submarine landslides", in , edited by Micallef, 15 (NA, 2011) Chap. 13: Developments in Earth Surface Processes. Developments in Earth Surface Processes, pp. 377-395.

${ }^{544}$ K. Michibayashi, M. Tasaka, Y. Ohara, T. Ishii, A. Okamoto, and P. Fryer, "Variable microstructure of peridotite samples from the southern Mariana Trench: Evidence of a complex tectonic evolution”, Tectonophysics 444, 111-118 (2007).

${ }^{545}$ M. S. Miller, A. Gorbatov, and B. L. N. Kennett, "Heterogeneity within the subducting Pacific slab beneath the Izu-Bonin-Mariana arc: Evidence from tomography using 3D ray tracing inversion techniques", Earth and Planetary Science Letters 235, 331-342 (2005).

${ }^{546}$ M. S. Miller, B. L. N. Kennett, and G. S. Lister, "Imaging changes in morphology, geometry, and physical properties of the subducting Pacific plate along the Izu-Bonin-Mariana arc", Earth and Planetary Science Letters 224, 363-370 (2004).

${ }^{547}$ J. D. Milliman and J. P. M. Syvitski, "Geomorphic/tectonic control of sediment discharge to the ocean: The importance of small mountainous rivers", The Journal of Geology 100, 525-544 (1992).

${ }^{548}$ K. J. Millman and M. Aivazis, "Python for Scientists and Engineers", Computing in Science \& Engineering 13, 9-12 (2011), URL: https : / / www . computer . org/csdl / magazine / cs / 2011 / 02 / mcs2011020009/ $13 \mathrm{rRUx} 0 \mathrm{xPMx}$.

${ }^{549}$ H. Minami and Y. Ohara, "Detailed volcanic morphology of Daisan-Miyako Knoll in the southern T Ryukyu Arc”, Marine Geology 404, 97-110 (2018).

${ }^{550}$ H. Minami and Y. Ohara, "Detailed morphology and bubble plumes of Daiichi-Amami Knoll in the central Ryukyu Arc”, Marine Geology 373, 55-63 (2016).

${ }^{551}$ N. C. Mitchell, Submarine Geomorphology. Reference Module in Earth Systems and Environmental Sciences (NA, 2015).

${ }^{552}$ S. Miura, N. Takahashi, A. Nakanishi, T. Tsuru, S. Kodaira, and Y. Kaneda, "Structural characteristics off Miyagi forearc region, the Japan Trench seismogenic zone, deduced from a wide-angle reflection and refraction study", Tectonophysics 407, 165-188 (2005).

${ }^{553}$ D. Monahan, "GEBCO: the Second Century", Hydro International 8, University of New Hampshire, 1-10 (2004).

${ }^{554}$ D. C. Montgomery, Design and Analysis of Experiments, 5th ed. (New York: Wiley, 2001), ISBN: 978-0-47131649-7.

${ }^{555}$ M. Monzier, C. Robin, J.-P. Eissen, and J. Cotten, "Geochemistry vs. seismo-tectonics along the volcanic New Hebrides Central Chain (Southwest Pacific)", Journal of Volcanology and Geothermal Research 78, 129 (1997).

${ }^{556}$ G. F. Moore, P. F. Lonsdale, and R. Huene, "Near-Bottom Observations of the Middle America Trench off Guatemala”, Deep Sea Drilling Project Reports and Publications 67, 707-718 (1982).

${ }^{557}$ W. J. Morgan, “The latest global tectonics”, Russian, in, edited by I. V. Luchickij (Mir, Moscow, 1974) Chap. Oceanic, deep-sea trenches, large faults and crustal blocks, p. 448. 
${ }^{558}$ W. J. Morgan, "Rises, trenches, great faults, and crustal blocks", Journal of Geophysical Research Atmospheres 73, 1959-1982 (1968).

${ }^{559}$ D. Müller, Deep Earth Structure and Global Tectonics, GEOL 2001 Geological Hazards and Solutions (University of Sydney, School of Geosciences, Division of Geology and Geophysics, 2002), p. 117.

${ }^{560}$ C. Münker, G. Wörner, G. M. Yogodzinski, and T. Churikova, "Behaviour of high field strength elements in subduction zones: constraints from Kamchatka-Aleutian arc lavas", Earth and Planetary Science Letters 224, 275-293 (2004).

${ }^{561}$ H. W. Murray, "Profiles of the Aleutian Trench", Geological Society of America Bulletin 56, 757-782 (1945).

${ }^{562}$ H. W. Murray, "Profiles of the Aleutian Trench", Bulletin of the Geological Society of America 56, 757-782 (1945).

${ }^{563}$ J. L. Myers and A. D. Well, Research Design and Statistical Analysis, 2nd ed. (Lawrence Erlbaum, 2003), 508 pp.

${ }^{564}$ T. Nakakuki, C. Hamada, and M. Tagawa, "Generation and driving forces of plate-like motion and asymmetric subduction in dynamical models of an integrated mantlelithosphere system”, Physics of the Earth and Planetary Interiors 166, 128-146 (2008).

${ }^{565}$ Y. Nakamura, S. Kodaira, S. Miura, C. Regalla, and N. Takahashi, "High resolution seismic imaging in the Japan Trench axis area of Miyagi. Northeast. Jpn”, Geophysical Research Letters 40, 1713-1718 (2013).

${ }^{566}$ M. Nakanishi, K. Tamaki, and K. Kobayashi, "Magnetic anomaly lineations from Late Jurassic to Early Cretaceous in the west-central Pacific Ocean”, Geophysical Journal International 109, 701-719 (1992).

${ }^{567}$ M. Nakanishi and J. Hashimoto, “A precise bathymetric map of the worlds deepest seafloor, Challenger Deep in the Mariana Trench”, Marine Geophysical Research 32, 455-463 (2011).

${ }^{568}$ F. Nanayama, K. Satake, R. Furukawa, K. Shimokawa, B. F. Atwater, K. Shigeno, and S. Yamaki, "Unusually large earthquakes inferred from tsunami deposits along the Kuril trench”, Nature 424, 660-663 (2003).

${ }^{569}$ C. R. Neal, J. J. Mahoney, L. W. Kroenke, R. A. Duncan, and M. G. Petterson, "The Ontong Java Plateau”, Geophysical Monograph Series 100, 183-216 (1997).

${ }^{570}$ C. H. Nelson and L. D. Kulm, “Turbidites and deep water sedimentation”, in, edited by G. V. Middleton and A. H. Bouma (Society of Economic Paleontologists and Mineralogists, Tulsa, OK, U.S.A., 1973) Chap. Submarine fans and channels, pp. 39-70.

${ }^{571}$ P. H. Nguyen, Q. C. Bui, P. H. Vu, and T. T. Pham, "Scenario-based tsunami hazard assessment for the coast of Vietnam from the Manila Trench source", Physics of the Earth and Planetary Interiors 236, 95-108 (2014).

${ }^{572}$ A. Nicol and L. M. Wallace, "Temporal stability of deformation rates: Comparison of geological and geodetic observations, Hikurangi subduction margin, New Zealand”, Earth and Planetary Science Letters 258, 397-413 (2007).

${ }^{573}$ A. Nishizawa, K. Kaneda, A. Nakanishi, N. Takahashi, and S. Kodaira, "Crustal structure of the ocean-island arc transition at the mid Izu-Ogasawara (Bonin) arc margin”, Earth Planets Space 58, e33-e36 (2006).

${ }^{574}$ W. R. Normark and P. R. Carlson, "Giant submarine canyons: Is size any clue to their importance in the rock record?”, Geological Society of America Special Paper 370, 175-190 (2003).

${ }^{575}$ NumPy Community, NumPy User Guide. Release 1.16.1 (User Guide, 2019), 148 pp.

${ }^{576}$ C. C. Nunnally, J. R. Friedman, and J. C. Drazen, "In situ respiration measurements of megafauna in the Kermadec trench", DeepSea Research Part I, 118, 30-36 (2016).

${ }^{577}$ A. J. Oakley, B. Taylor, and G. F. Moore, "Pacific plate subduction beneath the central Mariana and Izu-Bonin fore-arcs: new insights from an old margin”, Geochemistry Geophysics Geosystems 9, 1230-1236 (2008).

${ }^{578}$ H. Oda and H. Senna, "Regional variation in surface wave group velocities in the Philippine Sea", Tectonophysics 233, 265-277 (1994).

${ }^{579}$ Y. Ogawa, T. Seno, H. Tokuyama, H. Akiyoshi, K. Fujioka, and H. Taniguchi, "Structure and development of the Sagami trough and the Boso triple junction", Tectonophysics 160, 135-150 (1989). 
${ }^{580}$ Y. Ogawa, K. Kobayashi, H. Hotta, and K. Fujioka, "Tension cracks on the oceanward slopes of the northern Japan and Mariana Trenches”, Marine Geology 141, 111-123 (1997), URL: https : / / doi . org / 10 . 1016 / S0025-3227(97) 00059-5.

${ }^{581}$ Y. Ohara, K. Fujioka, O. Ishizuka, and T. Ishii, "Peridotites and volcanics from the Yap arc system: implications for tectonics of the southern Philippine Sea Plate", Chemical Geology 189, 35-53 (2002), URL: https: // doi . org/10.1016/S0009-2541(02)00062-1.

${ }^{582}$ Y. Okamura, A. Nishizawa, M. Oikawa, and D. Horiuchi, "Differential subsidence of the forearc wedge of the Ryukyu (Nansei-Shoto) Arc caused by subduction of ridges on the Philippine Sea Plate", Tectonophysics 717, 399-412 (2017).

${ }^{583}$ K. Okino, Y. Ohara, T. Fujiwara, S.-M. Lee, K. Koizumi, Y. Nakamura, and S. Wu, "Tectonics of the southern tip of the Parece Vela Basin, Philippine Sea Plate”, Tectonophysics 466, 213-228 (2009).

${ }^{584}$ T. E. Oliphant, Guide to NumPy, 2nd ed. (CreateSpace, 2015), 148 pp., ISBN: 978-1517300074.

${ }^{585}$ T. E. Oliphant, "Python for scientific computing”, Computing in Science \& Engineering 9, 10-20 (2007), URL: https://ieeexplore.ieee.org/document/4160250.

${ }^{586}$ K. J. Osborn, S. H. D. Haddock, F. Pleijel, L. P. Madin, and G. W. Rouse, "Deep-sea, swimming worms with luminescent bombs", Science 325, 964 (2009).

${ }^{587}$ J. Oshika, Y. Arakawa, D. Endo, T. Shinmura, and Y. Mori, “A rare basanite distribution in the northern part of the Izu-Bonin volcanic arc, Japan: Petrological and geochemical constraints", Journal of Volcanology and Geothermal Research 270, 76-89 (2014).

${ }^{588}$ K. Otsuki, "Westward migration of the Izu-Bonin Trench, northward motion of the Philippine Sea Plate, and their relationships to the Cenozoic tectonics of Japanese island arcs", Tectonophysics 180, 351-367 (1990).

${ }^{589}$ A. Ozawa, T. Tagami, E. L. Listanco, C. B. Arpa, and M. Sudo, "Initiation and propagation of subduction along the Philippine Trench: evidence from the temporal and spatial distribution of volcanoes", Journal of Asian Earth Sciences 23, 105-111 (2004).

${ }^{590}$ S. Pabst, T. Zack, I. P. Savov, T. Ludwig, D. Rost, S. Tonarini, and E. P. Vicenzi, "The fate of subducted oceanic slabs in the shallow mantle: Insights from boron isotopes and light element composition of metasomatized blueschists from the Mariana forearc", Lithos 132-133, 162-179 (2012).

${ }^{591}$ I. A. Pecher, S. A. Henrys, W. T. Wood, N. Kukowski, G. J. Crutchley, M. Fohrmann, J. Kilner, K. Senger, A. R. Gorman, R. B. Coffin, J. Greinert, and K. Faure, "Focussed fluid flow on the Hikurangi Margin, New Zealand - Evidence from possible local upwarping of the base of gas hydrate stability", Marine Geology 272, 99-113 (2010).

${ }^{592}$ F. Pedregosa, G. Varoquaux, A. Gramfort, V. Michel, B. Thirion, O. Grisel, M. Blondel, P. Prettenhofer, R. Weiss, V. Dubourg, J. Vanderplas, A. Passos, D. Cournapeau, M. Brucher, M. Perrot, and E. Duchesnay, "ScikitLearn: machine learning in Python", The Journal of Machine Learning Research 12, 2825-2830 (2011), URL: https://scikit-learn.org/stable/.

${ }^{593}$ B. Pelletier and R. Louat, "Seismotectonics and present-day relative plate motions in the Tonga-Lau and KermadecHavre region”, Tectonophysics 165, 237-250 (1989).

${ }^{594}$ B. Pelletier, S. Calmant, and R. Pillet, “Current tectonics of the Tonga-New Hebrides region”, Earth and Planetary Science Letters 164, 263-276 (1998).

${ }^{595}$ F. Perez and B. E. Granger, "IPython: a system for interactive scientific computing”, Computing in Science \& Engineering 9, 21-29 (2007), URL: https: / / ieeexplore. ieee.org/document / 4160251.

${ }^{596}$ J. S. Perez and H. Tsutsumi, "Tectonic geomorphology and paleoseismology of the Surigao segment of the Philippine fault in northeastern Mindanao Island, Philippines”, Tectonophysics 699, 244-257 (2017).

${ }^{597}$ D. Pflanz, C. Gaedicke, R. Freitag, M. Krbetschek, N. V. Tsukanov, and B. V. Baranov, "Neotectonics and recent uplift at Kamchatka and Aleutian arc junction, Kamchatka Cape area, NE Russia", International Journal of Earth Sciences 102, 903-916 (2013).

${ }^{598}$ R. Pillet and B. Pelletier, "Tectonique active, tsunamis et sismicité en Nouvelle Calédonie", Notes Techniques, Sciences de la Terre, Géologie-Géophysique, IRD Noumea 28, 1-19 (2005). 
${ }^{599}$ R. Pillet, D. Rouland, G. Roult, and D. A. Wiens, "Crust and upper mantle heterogeneities in the Southwest Pacific from surface wave phase velocity analysis", Physics of the Earth and Planetary Interiors 110, 211-234 (1999).

${ }^{600}$ T. K. Pinegina, J. Bourgeois, E. A. Kravchunovskaya, A. V. Lander, M. E. Arcos, K. Pedoja, and B. T. MacInnes, "A nexus of plate interaction: vertical deformation of Holocene wave-built terraces on the Kamchatsky Peninsula (Kamchatka, Russia)", Geological Society of America Bulletin 125, 1554-1568 (2013).

${ }^{601}$ R. B. Pollnac, B. R. Crawford, and M. L. Gorospe, "Discovering factors that influence the success of communitybased marine protected areas in the Visayas, Philippines", Ocean and Coastal Management 44, 683-710 (2001).

${ }^{602}$ M. V. Portnyagin and V. C. Manea, "Mantle temperature control on composition of arc magmas along the Central Kamchatka Depression”, Geology 36, 519-522 (2008).

${ }^{603}$ K. V. K. K. Prasad and T. S. Lamba, "Natural language interface based on keyword extraction using AWK", Microprocessors and Microsystems 11, 157-160 (1987).

${ }^{604}$ R. A. Prince and L. D. Kulm, "Crustal rupture and the initiation of imbricate thrusting in the Peru-Chile Trench", GSA Bull. 86, 1639-1653 (1975), URL: https : / / doi .org/10.1130/0016- 7606 (1975) 86<1639: CRATIO> $2.0 . \mathrm{CO} ; 2$.

${ }^{605}$ A. A. Pronin, "Morphology and tectonics of oceanic deepwater trenches and the problem of 'Benioff zones'”, International Geology Review 23, 249-256 (1981).

${ }^{606}$ J. M. Pushharovskij and E. N. Melanholina, Tektonicheskoe razvitie Zemli. Tihij okean i ego obramlenie (Tectonical development of the Earth. Pacific Ocean and its marginal areas), Russian (Nauka, Moscow, 1992), 263 pp.

${ }^{607}$ J. M. Pushharovskij and J. P. Neprochnov, Stroenie dna severo-zapada Tihogo okeana: (Geofizika, magmatizm, tektonika) (Structure of the North-West Pacific ocean floor: (Geophysics, magmatism, tectonics)), Russian, edited by J. P. Neprochnov (Nauka, Moscow, 1984), 226 pp.

${ }^{608}$ R. N. Pysklywec, S. M. Ellis, and A. R. Gorman, "Three-dimensional mantle lithosphere deformation at collisional plate boundaries: A subduction scissor across the South Island of New Zealand", Earth and Planetary Science Letters 289, 334-346 (2010).

${ }^{609} \mathrm{R}$ Development Core Team, R: a Language and Environment for Statistical Computing (R Foundation for Statistical Computing, Vienna, Austria, 2014), URL: https://www.r-project.org/.

${ }^{610}$ H. S. Rabinowitz, H. M. Savage, T. Plank, P. J. Polissar, J. D. Kirkpatrick, and C. D. Rowe, "Multiple major faults at the Japan Trench: Chemostratigraphy of the plate boundary at IODP Exp. 343: JFAST", Earth and Planetary Science Letters 423, 57-66 (2015).

${ }^{611}$ N. T. Ramos, H. Tsutsumi, J. S. Perez, and P. P. J. Bermas, “Uplifted marine terraces in Davao Oriental Province, Mindanao Island, Philippines and their implications for large prehistoric offshore earthquakes along the Philippine trench", Journal of Asian Earth Sciences 45, 114-125 (2012).

${ }^{612}$ C. R. Ranero, A. Villaseor, P. J. Morgan, and W. Wdinrebe, "Relationship between bending-faulting at trenches and intermediate-depth seismicity", Geochemistry Geophysics Geosystems 6, 1-25 (2005).

${ }^{613}$ R. H. Rapp, Geoid and Its Geophysical Interpretation. Global Geoid Determination, Ed. by Vanicek and Christou (CRC Press, Boca Raton, FL, U. S., 1994).

${ }^{614}$ A. E. Rathburn, L. A. Levin, M. Tryon, J. Gieskes, J. B. Martin, M. E. Pérez, F. J. Fodrie, C. Neira, G. Fryer, G. Mendoza, P. A. McMillan, J. W. Kluesner, J. Adamic, and W. Ziebis, "Geological and biological heterogeneity of the Aleutian margin (1965-4822m)", Progress In Oceanography 80, 22-50 (2009).

${ }^{615}$ M. Regelous, K. D. Collerson, A. Ewart, and J. I. Wendt, “Trace element transport rates in subduction zones: evidence from $\mathrm{Th}, \mathrm{Sr}$ and $\mathrm{Pb}$ isotope data for TongaKermadec arc lavas", Earth and Planetary Science Letters 150, 291-302 (1997).

${ }^{616}$ W. D. K. Reid, N. J. Cuomo, and A. J. Jamieson, "Geographic and bathymetric comparisons of trace metal concentrations $(\mathrm{Cd}, \mathrm{Cu}, \mathrm{Fe}, \mathrm{Mn}$, and $\mathrm{Zn})$ in deep-sea lysianassoid amphipods from abyssal and hadal depths across the Pacific Ocean", Deep-Sea Research Part I 138, 11-21 (2018).

${ }^{617}$ M. L. Renkin and J. G. Sclater, "Depth and age in the North Pacific", Journal of Geophysical Research 93, 2919-2935 (1988). 
${ }^{618}$ R. K. Rew and G. P. Davis, "NetCDF: an interface for scientific data access", IEEE Computer Graphics and Applications 10, 76-82 (1990).

${ }^{619}$ A. G. Reyes, B. W. Christenson, and K. Faure, "Sources of solutes and heat in low-enthalpy mineral waters and their relation to tectonic setting, New Zealand", Journal of Volcanology and Geothermal Research 192, 117-141 (2010).

${ }^{620} \mathrm{M}$. Reyners, "The central role of the Hikurangi Plateau in the Cenozoic tectonics of New Zealand and the Southwest Pacific”, Earth and Planetary Science Letters 361, 460-468 (2013).

${ }^{621}$ M. Reyners, D. Eberhart-Phillips, and S. Bannister, "Tracking repeated subduction of the Hikurangi Plateau beneath New Zealand", Earth and Planetary Science Letters 311, 165-171 (2011).

${ }^{622}$ J. M. Ribeiro, R. J. Stern, F. Martinez, J. D. Woodhead, M. Chen, and Y. Ohara, “Asthenospheric outflow from the shrinking Philippine Sea Plate: Evidence from Hf-Nd isotopes of southern Mariana lavas", Earth and Planetary Science Letters 478, 258-271 (2017).

${ }^{623}$ L. Richmond and D. Kotowicz, "Equity and access in marine protected areas: The history and future of traditional indigenous fishing in the Marianas Trench Marine National Monument", Applied Geography 59, 117124 (2015).

${ }^{624}$ E. van Rijsingen, S. Lallemand, M. Peyret, D. Arcay, A. Heuret, F. Funiciello, and F. Corbi, "How Subduction Interface Roughness Influences the Occurrence of Large Interplate Earthquakes", Geochemistry Geophysics Geosystems 19, 1-29 (2018).

${ }^{625}$ I. D. Ripper, “Global tectonics and the New Guinea-Solomon Islands region”, Search 1, 226-232 (1970).

${ }^{626}$ H. Ritchie, A. J. Jamieson, and S. B. Piertney, "Population genetic structure of two congeneric deep-sea amphipod species from geographically isolated hadal trenches in the Pacific Ocean”, Deep-Sea Research Part I 119, 50-57 (2017).

${ }^{627}$ A. D. Robbins, GAWK: Effective AWK Programming: A Users Guide for GNU Awk, for the 5.0.0 (or later) version of the GNU implementation of $A W K$, 5th ed. (Boston, USA, 2019), ISBN: 1-882114-28-0.

${ }^{628}$ A. D. Robbins, Awk by example, Part 2: Records, loops, and arrays. Common threads. (IBM DeveloperWorks, 2001).

${ }^{629}$ A. D. Robbins, Awk by example, Part 3: String functions and checkbooks? Common threads. (IBM DeveloperWorks, 2001).

${ }^{630}$ A. D. Robbins, Effective Awk Programming: A User's Guide for Gnu Awk (1.0.3 ed.) (Bloomington, IN: iUniverse, 2000), ISBN: 0-595-10034-1.

${ }^{631}$ A. D. Robbins, Awk by example, Part 1: An intro to the great language with the strange name. Common threads, online (IBM DeveloperWorks, 2000).

${ }^{632}$ J. J. Roberts, B. D. Best, D. C. Dunn, E. A. Treml, and P. N. Halpin, "Marine geo-spatial ecology tools: an integrated framework for ecological geoprocessing with ArcGIS, Python, R, MATLAB, and C++", Environmental Modelling \& Software 25, 1197-1207 (2010).

${ }^{633}$ N. M. Roberts, B. Tikoff, J. R. Davis, and T. Stetson-Lee, "The utility of statistical analysis in structural geology", Journal of Structural Geology 125, 64-73 (2018).

${ }^{634}$ B. H. Robison, “Conservation of deep pelagic biodiversity”, Conservation Biology 23, 847-858 (2009).

${ }^{635}$ B. H. Robison, "Deep pelagic biology", Journal of Experimental Marine Biology and Ecology 300, 253-272 (2004).

${ }^{636}$ E. A. Romankevich, A. A. Vetrov, and V. I. Peresypkin, “Organic matter of the World Ocean”, Russian Geology and Geophysics 50, 299-307 (2008).

${ }^{637}$ D. L. Rosgen, “A classification of natural river”, Catena 22, SSD10341-8162(94)E0046-3, 169-199 (1994).

${ }^{638}$ D. A. Ross, "Sediments of the northern Middle America Trench", Geological Society of America Bulletin 82, 303-322 (1971).

${ }^{639}$ D. A. Ross and G. G. Shor, "Reflection profiles across the Middle America Trench", Journal of Geophysical Research Atmospheres 70, 5551-5572 (1965). 
${ }^{640}$ G. van Rossum and Python Development Team, Python Tutorial Release 3.6.4. (Python Software Foundation, 2018), 446 pp., URL: https://www.academia.edu/39043140/Python_Tutorial_Release_3_6_4_Guido_ van_Rossum_and_the_Python_development_team.

${ }^{641}$ A. Ruangrassamee and N. Saelem, "Effect of Tsunamis generated in the Manila Trench on the Gulf of Thailand", Journal of Asian Earth Sciences 36, 56-66 (2009).

${ }^{642}$ L. J. Ruff and H. Kanamori, "Seismicity and the subduction process", Physics of the Earth and Planetary Interiors 23, 240-252 (1980).

${ }^{643}$ N. A. Ruppert, J. M. Lees, and N. P. Kozyreva, "Seismicity, earthquakes and structure along the Alaska-Aleutian and Kamchatka-Kurile Subduction Zones: a review”, Geophysical Monograph Series 172, 10.1029/172GM12 (2007).

${ }^{644}$ H. F. Ryan, R. Huene, R. E. Wells, D. W. Scholl, S. H. Kirby, and A. E. Draut, "History of earthquakes and tsunamis along the eastern Aleutian-Alaska megathrust, with implications for tsunami hazards in the California Continental Borderland", in Studies by the u.s. geological survey in alaska, edited by J. A. Dumoulin and C. Dusel-Bacon, U.S. Geological Survey Professional Paper 1795A (2011).

${ }^{645}$ J. P. M. de Sá, Applied Statistics Using SPSS, Statistics, Matlab and R, 2nd ed., Library of Congress Control Number: 2007926024 (Springer, Porto, Portugal, 2007), 520 pp., ISBN: 978-3-540-71971-7.

${ }^{646}$ M. K. Salah, T. Seno, and T. Iidaka, "Seismic anisotropy in the wedge above the Philippine Sea slab beneath Kanto and southwest Japan derived from shear wave splitting", Journal of Asian Earth Sciences 34, 61-75 (2009).

${ }^{647}$ I. R. Samowitz and D. W. Forsyth, "Double seismic zone beneath the Mariana Island arc", Journal of Geophysical Research 86, 7013-7021 (1981).

${ }^{648}$ D. T. Sandwell, E. Garcia, K. Soofi, P. Wessel, and W. H. F. Smith, "Towards 1 mGal Global Marine Gravity from CryoSat-2, Envisat, and Jason-1”, The Leading Edge 32, 892-899 (2013).

${ }^{649}$ D. T. Sandwell, R. D. Müller, W. H. F. Smith, E. Garcia, and R. Francis, "New global marine gravity model from CryoSat-2 and Jason-1 reveals buried tectonic structure", Science 346, 65-67 (2014).

${ }^{650}$ D. T. Sandwell and W. H. F. Smith, "Global marine gravity from retracked Geosat and ERS -1 altimetry: ridge segmentation versus spreading rate”, Journal of Geophysical Research 114, B01411, 1-18 (2009).

${ }^{651}$ D. T. Sandwell, M. M. Yale, and W. H. F. Smith, "Marine gravity anomalies from GEOSAT and ERS-1 satellite altimetry", Journal of Geophysical Research Atmospheres 102, 10039-10054 (1997).

${ }^{652}$ T. Sano, M. Shirao, K. Tani, Y. Tsutsumi, S. Kiyokawa, and T. Fujii, "Progressive enrichment of arc magmas caused by the subduction of seamounts under Nishinoshima volcano, Izu-Bonin Arc, Japan", Journal of Volcanology and Geothermal Research 319, 52-65 (2016).

${ }^{653}$ L. F. Sarmiento-Rojas, J. D. Van Wess, and S. Cloetingh, "Mesozoic transtensional basin history of the Eastern Cordillera, Colombian Andes: inferences from tectonic models", Journal of South America Earth Science 21, 383-411 (2006).

${ }^{654}$ T. Sato, J. Kasahara, H. Katao, N. Tomiyama, K. Mochizuki, and S. Koresawa, "Seismic observations at the Yap Islands and the northern Yap Trench”, Tectonophysics 271, 285-294 (1997).

${ }^{655}$ V. V. Sattarova and K. I. Aksentov, "Geochemistry of mercury in surface sediments of the Kuril Basin of the Sea of Okhotsk, Kuril-Kamchatka Trench and adjacent abyssal plain and northwest part of the Bering Sea", Deep-Sea Research Part II 154, 24-31 (2018).

${ }^{656}$ L. A. Savostin, L. Zonenshain, and B. V. Baranov, "Geology and plate tectonics of the Sea of Okhotsk, Geodynamics of the Western Pacific-Indonesian Region”, Geodynamics Series 11, AGU, Washington, D. C., 189-221 (1983).

${ }^{657}$ W. P. Schellart, "Subduction zone trench migration: Slab driven or overriding-plate-driven?", Physics of the Earth and Planetary Interiors 170, 73-88 (2008).

${ }^{658}$ W. P. Schellart, "The potential influence of subduction zone polarity on overriding plate deformation, trench migration and slab dip angle", Tectonophysics 445, 363-372 (2007). 
${ }^{659}$ W. P. Schellart, G. S. Lister, and V. G. Toy, "A Late Cretaceous and Cenozoic re-construction of the Southwest Pacific region: tectonics controlled by subduction and slab rollback processes”, Earth. Rev. 76, 191-233 (2006).

${ }^{660}$ H. W. Schenke, S. Gauger, and P. Lemenkova, Swath sonar bathymetry during Polarstern cruise ANT-XXIII/4 (PS 69) with links to multibeam raw data files, Dataset, 2008, Alfred Wegener Institute, Bremerhaven, PANGAEA.

${ }^{661}$ H. W. Schenke and P. Lemenkova, "Zur Frage der Meeresboden-Kartographie: Die Nutzung von AutoTrace Digitizer für die Vektorisierung der Bathymetrischen Daten in der Petschora-See”, German, Hydrographische Nachrichten 81, 16-21 (2008).

${ }^{662}$ E. Scheuber, T. Bogdanic, A. Jensen, and K.-J. Reutter, "Tectonics of the southern central andes", in ().

${ }^{663}$ R. Schmidt-Effing, “Alter und Genese des Nicoya-Komplexes, einer ozeanischen Pàlaokruste (Oberjura bis Eozàn) im sudlichen Zentralamerika”, Geologische Rundschau 68, 457-494 (1979).

${ }^{664}$ M. Sdroliasa, W. R. Roest, and R. D. Müller, “An expression of Philippine Sea plate rotation: the Parece Vela and Shikoku Basins", Tectonophysics 394, 69-86 (2004).

${ }^{665}$ S. Seabold and J. Perktold, "Statsmodels: Econometric and statistical modeling with python", in Proceedings of the $9^{\text {th }}$ python in science conference (2010), pp. 1-6.

${ }^{666}$ L. C. Seekings and T.-L. Teng, "Lateral variations in the structure of the Philippine Sea Plate", Journal of Geophysical Research 82, 317-324 (1977).

${ }^{667}$ N. I. Seliverstov, Structure of the oceanic floor near Kamchatka and the geodynamics of the zone of KurilKamchatka and Aleutians trenches Joint, in Russian (Moscow: Nauchni Mir, 1998), URL: http : / / repo . kscnet.ru/403/2/Seliverstov.pdf.

${ }^{668}$ G. F. Sella, T. H. Dixon, and A. Mao, "REVEL: a model for recent plate velocities from space geodesy”, Journal of Geophysical Research 107, 11-30 (2002).

${ }^{669}$ A. Sen, H. Ondréas, A. Gaillot, Y. Marcon, J.-M. Augustin, and K. Olu, "The use of multibeam backscatter and bathymetry as a means of identifying faunal assemblages in a deep-sea cold seep", Deep-Sea Research Part I 110, 33-49 (2016).

${ }^{670}$ R. Senda, K. Shimizu, and K. Suzuki, "Ancient depleted mantle as a source of boninites in the Izu-BoninMariana arc: Evidence from Os isotopes in Cr-spinel and magnetite”, Chemical Geology 439, 110-119 (2016).

${ }^{671}$ T. Seno and S. Maruyama, "Paleogeographic reconstruction and origin of the Philippine Sea”, Tectonophysics 102, 53-84 (1984).

${ }^{672}$ M. Seton, R. D. Müller, S. Zahirovic, C. Gaina, T. Torsvik, G. Shephard, A. Talsma, M. Gurnis, M. Turner, S. Maus, and M. Chandler, "Global continental and ocean basin reconstructions since 200Ma", Earth-Science Review 113, 212-270 (2012).

${ }^{673}$ F. P. Shepard, Submarine Geology (Harper \& Row, New York, U.S., 1963).

${ }^{674}$ Shipboard Scientific Party, "Site 500: Middle America Trench Axis”, Deep Sea Drilling Project Reports and Publications 8, 315-347 (1982).

${ }^{675}$ Shipboard Scientific Party, "Site 499: Middle America Trench Axis”, Deep Sea Drilling Project Reports and Publications 7, 267-314 (1982).

${ }^{676}$ Shipboard Scientific Party, “6. Site 498: Middle America Trench Lower Slope”, Deep Sea Drilling Project Reports and Publications 6, 245-266 (1982).

${ }^{677}$ Shipboard Scientific Party, “Site 496: Middle America Trench Upper Slope”, Deep Sea Drilling Project Reports and Publications 4, 143-192 (1982).

${ }^{678}$ Shipboard Scientific Party, "Site 495: Cocos Plate - Middle America Trench Outer Slope”, Deep Sea Drilling Project Reports and Publications 1, 79-141 (1982).

${ }^{679}$ Y. Shu, S. G. Nielsen, Z. Zeng, R. Shinjo, J. Blusztajn, X. Wang, and S. Chen, "Tracing subducted sediment inputs to the Ryukyu arc- Okinawa Trough system: Evidence from thallium isotopes", Geochimica et Cosmochimica Acta 217, 462-491 (2017). 
${ }^{680}$ J. O. Skøien, G. Blöschl, G. Laaha, E. Pebesma, J. Parajka, and A. Viglione, “rtop: An R package for interpolation of data with a variable spatial support, with an example from river networks", Computers \& Geosciences 67, 180-190 (2014).

${ }^{681}$ Y. B. Smirnov and V. M. Sugrobov, "Terrestrial heat flow in the Kurile-Kamchatka and Aleutian provinces-III, Assessment of temperature at depth and thickness of the lithosphere", Journal of Volcanology and Seismology 2, in Russian, 3-18 (1980).

${ }^{682}$ Y. B. Smirnov and V. M. Sugrobov, "Terrestrial heat flow in the Kurile-Kamchatka and Aleutian provinces - II, The map of measured and background heat flow", Journal of Volcanology and Seismology 1, in Russian, 16-31 (1980).

${ }^{683}$ Y. B. Smirnov, V. M. Sugrobov, and F. A. Yanovskiy, "The terrestrial heat flow of Kamchatka”, Journal of Volcanology and Seismology 13, 181-210 (1992).

${ }^{684}$ I. E. M. Smith and R. C. Price, "The TongaKermadec arc and HavreLau back-arc system: their role in the development of tectonic and magmatic models for the western Pacific", Journal of Volcanology and Geothermal Research 156, 315-331 (2006).

${ }^{685}$ I. E. M. Smith, T. J. Worthington, R. B. Stewart, R. C. Price, C. Richard, and J. A. Gamble, "Felsic volcanism in the Kermadec Arc, SW Pacific; crustal recycling in an oceanic setting", Geological Society Special Publications 219, 99-118 (2003), URL: https://sp. Iyellcollection.org/content/219/1/99.

${ }^{686}$ W. H. F. Smith, “On the accuracy of digital bathymetric data”, Journal of Geophysical Research 98, 9591-9603 (1993).

${ }^{687}$ W. H. F. Smith and D. T. Sandwell, "Marine gravity field from declassified Geosat and ERS-1 altimetry”, Journal of Geophysical Research Atmospheres 102, 10039-10054 (1997).

${ }^{688}$ W. H. F. Smith and D. T. Sandwell, "Global Sea Floor Topography from Satellite Altimetry and Ship Depth Soundings", Science 277, 1956-1962 (1997).

${ }^{689}$ O. Solomina, G. Wiles, T. Shiraiwa, and R. D’Arrigo, “Multiproxy records of climate variability for Kamchatka for the past 400 years", Climate of the Past 3, 119-128 (2007).

${ }^{690}$ S. L. Soloviev and C. N. A. Go, Catalogue of Tsunamis on the Western Shore of the Pacific Ocean. in Russian (Academy of Sciences of the USSR. Nauka Publishing House, Moscow, 1974), p. 439.

${ }^{691}$ F. Sorbadere, P. Schiano, N. Metrich, and E. Garaebiti, "Insights into the origin of primitive silica-undersaturated arc magmas of Aoba volcano (Vanuatu arc)”, Contributions to Mineralogy and Petrology 162, 995-1009 (2011).

${ }^{692}$ L. Spina, J. Taddeucci, and A. Cannata, "Explosive volcanic activity at Mt. Yasur: A characterization of the acoustic events (9-12th July 2011)", Journal of Volcanology and Geothermal Research 322, 175-183 (2016).

${ }^{693}$ V. Stagpoole, H. W. Schenke, and Y. Ohara, “A name directory for the ocean floor", Eos 97, 1-2 (2016).

${ }^{694}$ H. A. Stewart and A. J. Jamieson, "Habitat heterogeneity of hadal trenches: Considerations and implications for future studies", Progress in Oceanography 161, 47-65 (2018).

${ }^{695}$ R. J. P. Strick, P. J. Ashworth, G. Awcock, and J. Lewin, "Morphology and spacing of river meander scrolls", Geomorphology 310, 57-68 (2018).

${ }^{696}$ T. Strutz, Data Fitting and Uncertainty (A practical introduction to weighted least squares and beyond) (Springer Vieweg, 2016), ISBN: 978-3-658-11455-8.

${ }^{697}$ M. Stutz, Get started with GAWK: AWK language fundamentals, online (IBM Developer Works, 2006).

${ }^{698}$ I. A. Suetova, L. A. Ushakova, and P. Lemenkova, "Geoecological Mapping of the Barents Sea Using GIS", in Proceedings of the International Cartographic Conference (ICC) (International Cartographic Association, 2005).

${ }^{699}$ I. A. Suetova, L. A. Ushakova, and P. Lemenkova, "Geoinformation mapping of the Barents and Pechora Seas", Geography and Natural Resources 4, edited by V. A. Snytko, 138-142 (2005).

${ }^{700}$ R. Sutherland, P. M. Barnes, and C. Uruski, "Miocene-recent deformation, surface elevation, and volcanic intrusion of the overriding plate during subduction initiation, offshore southern Fiordland, Puysegur Margin, southwest New Zealand", New Zealand Journal of Geology and Geophysics 49, 131-149 (2006). 
${ }^{701}$ S. Suzuki, R. E. Peña, T. A. I. Tam, G. P. J. Yumul, C. B. Dimalanta, M. Us, and K. Ishida, “Development of the Philippine Mobile Belt in northern Luzon from Eocene to Pliocene”, Journal of Asian Earth Sciences 142 , 32-44 (2017).

${ }^{702}$ A. R. H. Swan and M. Sandilands, Introduction to Geological Data Analysis, Library of Congress: QE33.2.S82S931995; Dewey Decimal Classification (UDC): 550/.72 (Blackwell Science, Cambridge, Mass., USA, 1995), 446 pp.

${ }^{703}$ K. Taira, S. Kitagawa, T. Yamashiro, and D. Yanagimoto, "Deep and Bottom Currents in the Challenger Deep, Mariana Trench, Measured with Super-Deep Current Meters”, Journal of Oceanography 60, 919-926 (2004).

${ }^{704}$ K. Taira, D. Yanagimoto, and S. Kitagawa, “Deep CTD Casts in the Challenger Deep, Mariana Trench”, Journal of Oceanography 61, 447-454 (2005).

${ }^{705}$ S. Tani, Understanding oceans, The UNESCO Courier, 65-69, 2017.

${ }^{706}$ D. R. Tappin, "Sedimentary basins of the world: south pacific sedimentary basins", in, edited by P. F. Ballance (Elsevier, Amsterdam, 1993) Chap. 2. The Tonga frontal arc basin, pp. 12-22.

${ }^{707}$ B. Taylor, "Proc. odp, sci. results, 126. ocean drilling program", in, edited by B. Taylor and K. Fujioka (College Station, TX, 1992) Chap. Rifting and the volcanictectonic evolution of the IzuBoninMariana arc, pp. 627-651.

${ }^{708}$ B. Taylor, “Bismarck Sea: evolution of a back-arc basin”, Geology 7, 171-174 (1979).

${ }^{709}$ A. E. J. Theberge, “Thirty years of discovering the Mariana Trench”, Hydro International 12, 38-39 (2008), URL: https: / / www . hydro-international.com/content/article/thirty-years-of-discoveringthe-mariana-trench.

${ }^{710}$ C. Theiling, "4-2 Ecological Status and Trends of the UMRS 1998. River Geomorphology”, in (1998) Chap. 4. River Geomorphology and Floodplain Habitats, pp. 1-21.

${ }^{711}$ T. M. Thornburg and L. D. Kulm, "Submarine-fan development in the southern Chile Trench: a dynamic interplay of tectonics and sedimentation", Geol. Soc. Amer. Bull 102 (1990).

${ }^{712}$ J. Tian, L. Fan, H. Liu, J. Liu, Y. Li, Q. Qin, Z. Gong, H. Chen, Z. Sun, L. Zou, X. Wang, H. Xu, D. H. Bartlett, M. Wang, Y.-Z. Zhang, X.-H. Zhang, and C. L. Zhang, "A nearly uniform distributional pattern of heterotrophic bacteria in the Mariana Trench interior", Deep-Sea Research Part I 0, 00-00 (2018).

${ }^{713}$ A. Tibaldi and F. L. Bonali, "Intra-arc and back-arc volcano-tectonics: Magma pathways at Holocene AlaskaAleutian volcanoes”, Earth-Science Reviews 167, 1-26 (2017).

${ }^{714}$ N. H. Timm, Applied Multivariate Analysis (Springer Science \& Business Media, 2007), 695 pp., ISBN: 978-0387-95347-2.

${ }^{715}$ D. Tomaszewski, J. Rapinski, and R. Pelc-Mieczkowska, "Concept of AHRS Algorithm Designed for Platform Independent IMU Attitude Alignment”, Reports on Geodesy and Geoinformatics 104, 33-47 (2017).

${ }^{716}$ P. Tregoning, K. Lambeck, A. Stolz, P. J. Morgan, S. C. McClusky, P. van der Beek, H. McQueen, R. J. Jackson, R. P. Little, A. Laing, and B. Murphy, "Estimation of current plate motions in Papua New Guinea from Global Positioning System observations", Journal of Geophysical Research 103, 12181-12203 (1998).

${ }^{717}$ T. Tsuboi, H. Wada, T. Nakamura, T. T. Hang, H. Matsuzaki, N. Otsuji, K. Fujioka, K. Oguri, and H. Kitazato, "Deep-sea limestone block as a source of 14C-depleted dissolved inorganic carbon at the Palau Trench", Chemical Geology 364, 1-8 (2014).

${ }^{718}$ T. Tsuru, J.-O. Park, N. Takahashi, S. Kodaira, Y. Kido, Y. Kaneda, and T. Kono, "Tectonic features of the Japan Trench convergent margin off Sanriku, northeastern Japan, revealed by multichannel seismic reflection data", Journal of Geophysical Research 105, 16403-16413 (2000), URL: https : / a gupubs . onlinelibrary . wiley . com/doi/pdfdirect/10.1029/2000JB900132.

${ }^{719}$ D. L. Turcotte and G. Schubert, Geodynamics, 2nd ed. (Cambridge University Press, U.K., 2013), 472 pp., ISBN: 1429238607.

${ }^{720}$ R. Turnewitsch, S. Falahat, J. Stehlikova, K. Oguri, R. N. Glud, M. Middelboe, H. Kitazato, F. Wenzhöfer, K. Ando, S. Fujio, and D. Yanagimoto, "Recent sediment dynamics in hadal trenches: Evidence for the influence of higher-frequency (tidal, near-inertial) fluid dynamics”, Deep-Sea Research Part I 90, 125-138 (2014). 
${ }^{721}$ E. P. Turtle, R. M. C. Lopes, and R. D. Lorenz, “Temporal behavior and temperatures of Yasur volcano, Vanuatu from field remote sensing observations, May 2014”, Journal of Volcanology and Geothermal Research 322, 158167 (2016).

${ }^{722}$ G. B. Udintsev, Relief $i$ stroenie dna okeanov (Relief and the structure of the ocean floor), Russian, edited by A. V. Il'yin (Nedra, Moscow, 1987), 239 pp.

${ }^{723}$ Y. Ujiié, "Mud diapirs observed in two piston cores from the landward slope of the northern Ryukyu Trench, northwestern Pacific Ocean”, Marine Geology 163, 149-167 (2000).

${ }^{724}$ S. Uyeda and H. Kanamori, "Back-arc opening and the mode of subduction", Journal of Geophysical Research 84, 1049-1061 (1979).

${ }^{725}$ P. Vermeesch, A. Resentini, and E. Garzanti, “An R package for statistical provenance analysis”, Sedimentary Geology 336, 14-25 (2016).

${ }^{726}$ J. L. Vigneresse, "Which language should be used to sort multifield records?”, Computers \& Geosciences 21, 1131-1137 (1995).

${ }^{727}$ C. Vita-Finzi, “Serial deformation”, Proceedings of the Geologists’ Association 116, 293-300 (2005).

${ }^{728}$ D. Völker, T. Reichel, M. Wiedicke, and C. Heubeck, “Turbidites deposited on Southern Central Chilean seamounts: Evidence for energetic turbidity currents", Marine Geology 251, 15-31 (2008).

${ }^{729} \mathrm{G}$. Wadge, GIS for geology, 3(1): 93-98 (Terra Nova, 1992).

${ }^{730} \mathrm{~K}$. Wakita, "Geology and tectonics of Japanese islands: a review the key to understanding the geology of Asia", Journal of Air Transport Management 31, 75-87 (2013).

${ }^{731}$ L. M. Wallace, M. Reyners, U. Cochran, S. Bannister, P. M. Barnes, K. R. Berryman, G. Downes, D. EberhartPhillips, A. Fagereng, S. M. Ellis, A. Nicol, R. McCaffrey, J. Beavan, S. Henrys, R. Sutherland, D. H. N. Barker, N. Litchfield, J. Townend, R. Robinson, R. E. Bell, K. Wilson, and W. Power, "Characterizing the seismogenic zone of a major plate boundary subduction thrust: the Hikurangi Margin”, Geochemistry. Geophysics. Geosystems 10, 10.1029/2009GC002610 (2009).

${ }^{732}$ H. Wang, G. J. Crutchley, and T. Stern, "Gas hydrate formation in compressional, extensional and un-faulted structural settings e Examples from New Zealand's Hikurangi margin”, Marine and Petroleum Geology 88, 6980 (2017).

${ }^{733}$ J. C. Warner, N. Perlin, and E. D. Skyllingstad, "Using the model coupling toolkit to couple earth system models", Environmental Modelling \& Software 23, 1240-1249 (2008).

${ }^{734}$ B. A. Warren and W. B. Owens, "Deep currents in the central subarctic Pacific Ocean", Journal of Physical Oceanography 18, 529-551 (1988).

${ }^{735}$ P. Weatherall, K. M. Marks, M. Jakobsson, T. Schmitt, S. Tani, J. E. Arndt, M. Rovere, D. Chayes, V. Ferrini, and R. Wigley, "A new digital bathymetric model of the world's oceans", Earth and Space Science 2, 331-345 (2015).

${ }^{736}$ T. J. Webb, E. van den Berghe, and R. O’Dor, “Biodiversity’s Big Wet Secret: The Global Distribution of Marine Biological Records Reveals Chronic Under-Exploration of the Deep Pelagic Ocean”, PlosOne 5, 1-6 (2010).

${ }^{737}$ W. A. Weibenga, “The Western Pacific: Island arcs, marginal seas, geochemistry”, in, edited by P. J. Coleman (University of Western Australia Press, Nedlands, AU, 1973) Chap. Crustal Structure of the New Britain-New Ireland Region, pp. 163-177.

${ }^{738}$ J. K. Weissel and R. N. Anderson, “Is there a Caroline plate?”, Earth Planetary Science Letters 41, 143-158 (1978).

${ }^{739}$ P. Wessel and W. H. F. Smith, The Generic Mapping Tools. Version 4.5.18 Technical Reference and Cookbook (Computer software manual. U.S.A., 2018).

${ }^{740}$ P. Wessel and W. H. F. Smith, "A Global Self-consistent, Hierarchical, High-resolution Shoreline Database”, Journal of Geophysical Research 101, 8741-8743 (1996).

${ }^{741}$ P. Wessel and W. H. F. Smith, "Free software helps map and display data", EOS Transactions of the American Geophysical Union 72, 441 (1991). 
${ }^{742}$ P. Wessel, W. H. F. Smith, R. Scharroo, J. F. Luis, and F. Wobbe, The Generic Mapping Tools. GMT Man Pages. Release 5.4.5 (Computer software manual. U.S.A., 2019).

${ }^{743}$ P. Wessel, W. H. F. Smith, R. Scharroo, J. F. Luis, and F. Wobbe, "Generic mapping tools: Improved version released”, EOS Transactions of the American Geophysical Union 94, 409-410 (2013).

${ }^{744}$ P. Wessel and A. B. Watts, “On the accuracy of marine gravity measurements”, Journal of Geophysical Research 93, 393-413 (1988).

${ }^{745}$ J. Weston, E. R. Engdahl, J. Harris, D. Di Giacomo, and D. A. Storchack, "ISC-EHB: Reconstruction of a robust earthquake dataset”, Geophysical Journal International 214, 474-484 (2018).

${ }^{746}$ D. Woelki, M. Regelous, K. M. Haase, R. H. W. Romer, and C. Beier, "Petrogenesis of boninitic lavas from the Troodos Ophiolite, and comparison with IzuBoninMariana fore-arc crust", Earth and Planetary Science Letters 498, 203-214 (2018).

${ }^{747}$ D. J. Wright, S. H. Bloomer, C. J. MacLeod, B. Taylor, and A. M. Goodlife, "Bathymetry of the Tonga Trench and Forearc: a map series”, Marine Geophysical Researches 21, 489-511 (2000), URL: https: //doi .org/10. 1023/A: 1026514914220 .

${ }^{748}$ J. Wright and D. A. Rothery, The Ocean Basins: Their Structure and Evolution, 2nd ed. (Elsevier, 1998).

${ }^{749}$ T.-R. Wu and H.-C. Huang, "Modeling tsunami hazards from Manila trench to Taiwan", Journal of Asian Earth Sciences 36, 21-28 (2009).

${ }^{750}$ X. Xu, M. Yamasaki, M. Oda, and M. C. Honda, "Comparison of seasonal flux variations of planktonic foraminifera in sediment traps on both sides of the Ryukyu Islands, Japan”, Marine Micropaleontology 58, 45-55 (2005).

${ }^{751}$ Y. Xu, H. Ge, and J. Fang, "Biogeochemistry of hadal trenches: Recent developments and future perspectives", Deep-Sea Research Part II 155, 19-26 (2018).

${ }^{752}$ Y. Yagi, A. Nakao, and A. Kasahara, "Smooth and rapid slip near the Japan Trench during the 2011 Tohoku-oki earthquake revealed by a hybrid back-projection method", Earth and Planetary Science Letters 355-356, 94-101 (2012).

${ }^{753}$ T. Yamazaki, M. Takahashi, Y. Iryu, T. Sato, M. Oda, H. Takayanagi, S. Chiyonobu, A. Nishimura, T. Nakazawa, and T. Ooka, "Philippine Sea Plate motion since the Eocene estimated from paleomagnetism of seafloor drill cores and gravity cores", Earth Planets Space 62, 495-502 (2010).

${ }^{754}$ P. H. Yancey, M. E. Gerringer, J. C. Drazen, A. A. Rowden, and A. J. Jamieson, "Marine fish may be biochemically constrained from inhabiting the deepest ocean depths", PNAS (Proceedings of the National Academy of Sciences of the United States of America) 111, 4461-4465 (2014).

${ }^{755}$ A. Yang and Y. Fu, "Estimates of effective elastic thickness at subduction zones", Journal of Geodynamics 117, 75-87 (2018).

${ }^{756}$ G. Yang, C. Shen, J. Wang, S. Xuan, G. Wu, and H. Tan, "Isostatic anomaly characteristics and tectonism of the New Britain Trench and neighboring Papua New Guinea”, Geodesy and Geodynamics 9, 404-410 (2018).

${ }^{757}$ J. Yang, Z. Cui, O. A. Dada, Y. Yang, H. Yu, Y. Xu, Z. Lin, Y. Chen, and X. Tang, "Distribution and enrichment of trace metals in surface marine sediments collected by the manned submersible Jiaolong in the Yap Trench, northwest Pacific Ocean”, Marine Pollution Bulletin 135, 1035-1041 (2018).

${ }^{758}$ Y.-L. Yeh, H. Kao, S. Wen, W.-Y. Chang, and C.-H. Chen, "Surface wave tomography and azimuthal anisotropy of the Philippine Sea Plate", Tectonophysics 592, 94-112 (2013).

${ }^{759}$ G. M. Yogodzinski, S. T. Brown, P. B. Kelemen, J. D. Vervoort, M. V. Portnyagin, K. W. W. Sims, K. Hoernle, B. R. Jicha, and R. Werner, "The role of subducted Basalt in the Source of Island Arc Magmas: evidence from seafloor Lavas of the Western Aleutians”, Journal of Petrology 56, 441-492 (2015).

${ }^{760}$ S. Yoneshima, K. Mochizuki, E. Araki, R. Hino, M. Shinohara, and K. Suyehiro, "Subduction of the Woodlark Basin at New Britain Trench, Solomon Islands region”, Tectonophysics 397, 225-239 (2005).

${ }^{761}$ M. Yoshida, "Trench dynamics: Effects of dynamically migrating trench on subducting slab morphology and characteristics of subduction zones systems", Physics of the Earth and Planetary Interiors 268, 35-53 (2017).

${ }^{762}$ T. Yoshii, "Detailed cross-section of the deep seismic zone beneath northeastern Honshu, Japan", Tectonophysics 55, 349-360 (1979). 
${ }^{763}$ S. Yoshikawa, K. Okino, and M. Asada, "Geomorphological variations at hydrothermal sites in the southern Mariana Trough: Relationship between hydrothermal activity and topographic characteristics", Marine Geology 303-306, 172-182 (2012).

${ }^{764}$ S. Yoshioka, Y. Torii, and M. R. Riedel, "Impact of phase change kinetics on the Mariana slab within the framework of 2-D mantle convection", Physics of the Earth and Planetary Interiors 240, 70-81 (2015).

${ }^{765}$ G.-K. Yu, "Surface wave study of the Philippine Sea Plate", Proceedings of the National Science Council Part A 6, 281-296 (1982).

${ }^{766}$ G.-K. Yu and W. Y. Chang, "Lateral variations in the upper mantle structure of the Philippine Sea basin", Terrestrial, Atmospheric and Oceanic Sciences 2, 281-296 (1991).

${ }^{767}$ G.-K. Yu, M.-T. Tsai, and R.-D. Hwang, "Velocity dispersion and amplitude attenuation of Rayleigh waves across the Philippine Sea", Terrestrial, Atmospheric and Oceanic Sciences 11, 515-524 (2000).

${ }^{768}$ H.-S. Yu, "Nature and distribution of the deformation front in the Luzon Arc-Chinese continental margin collision zone at Taiwan", Marine Geophysical Researches 25, 109-122 (2004).

${ }^{769}$ H.-S. Yu, Y. Liu, H. Yang, and J. Ning, "Modeling earthquake sequences along the Manila subduction zone: Effects of three-dimensional fault geometry", Tectonophysics 733, 73-84 (2018).

${ }^{770}$ Q.-Y. Yu, L. Bagas, P.-H. Yang, and D. Zhang, "GeoPyTool: A cross-platform software solution for common geological calculations and plots", Geoscience Frontiers 10, 1437-1447 (2019).

${ }^{771}$ S.-B. Yu, Y.-J. Hsu, T. Bacolcol, C.-C. Yang, Y.-C. Tsai, and R. Solidum, "Present-day crustal deformation along the Philippine Fault in Luzon, Philippines", Journal of Asian Earth Sciences 65, 64-74 (2013).

${ }^{772}$ F. Yulianto, Suwarsono, T. Maulana, and M. R. Khomarudin, "Analysis of the dynamics of coastal landform change based on the integration of remote sensing and GIS techniques: Implications for tidal flooding impact in Pekalongan, Central Java, Indonesia”, Quaestiones Geographicae 38, 17-29 (2019).

${ }^{773}$ Y. A. Zayakin and A. A. Luchinina, Catalogue of Tsunamis on Kamchatka, in Russian (Obninsk: VNIIGMIMtsd, 1987).

${ }^{774}$ F. Zhang, J. Lin, and W. Zhan, "Variations in oceanic plate bending along the Mariana trench", Earth and Planetary Science Letters 401, 206-214 (2014).

${ }^{775}$ L. Zhang, C. He, Y. Liu, and J. Lin, "Frictional properties of the South China Sea oceanic basalt and implications for strength of the Manila subduction seismogenic zone”, Marine Geology 394, 16-29 (2017).

${ }^{776}$ H.-W. Zheng, R. Gao, T.-D. Li, Q.-S. Li, and R.-W. He, “Collisional tectonics between the Eurasian and Philippine Sea plates from tomography evidences in Southeast China”, Tectonophysics 606, 14-23 (2013).

${ }^{777}$ Z. Zhou, J. Lin, and M. D. Behn, "Mechanism for normal faulting in the subducting plate at the Mariana Trench", Geophysical Research Letters 42, 4309-4317 (2015).

${ }^{778} \mathrm{Z}$. Zhou and J. Lin, "Elasto-plastic deformation and plate weakening due to normal faulting in the subducting plate along the Mariana Trench”, Tectonophysics 734-735, 59-68 (2018).

${ }^{779}$ G. Zhu, Y. Shi, and P. Tackley, "Subduction of the Western Pacific Plate underneath Northeast China: Implications of numerical studies", Physics of the Earth and Planetary Interiors 178, 92-99 (2009).

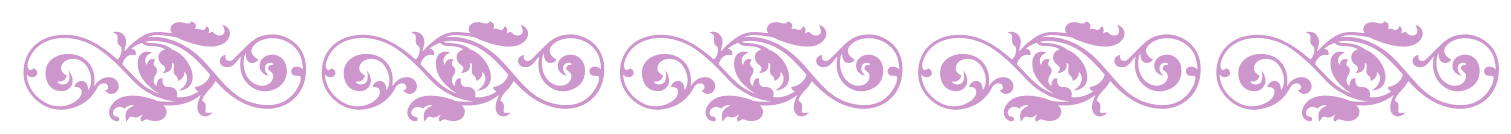

